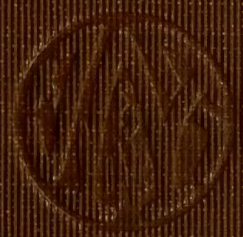

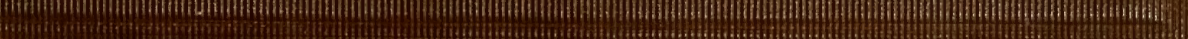




$$
\text { 。 }
$$








\section{INSECT PESTS}

OF

\section{FARM, GARDEN AND ORCHARD}

BY

\section{E. DWIGH'T SANDERSON}

Formerly Entomologist of the Delaware, Texas and New Hampshire Agricultural Experiment Stations and Director of the New Hampshire and West Virginia Agricultural Experiment Stations.

SECOND EDITION

REVISED AND ENLARGED

BY

LEONARD MARION PEAIRS

Professor of Entomology West Virginia University

NEW YORK

JOHN WILEY AND SONS, INC.

LONDON : CHAPMAN \& HALL, LIMITED. 


\section{SB 931 518}

COPYRIGHT, 1912

BY

E. DWIGHT SANDERSON

COPYRIGHT, 1921

E. DWIGHT SANDERSON

AND

LEONARD M. PEAIRS

Printed in the U. S. A.

APR 271921

(a) $\mathrm{Cl} .4611805$ 


\section{PREFACE}

The edition of the writer's "Insects Injurious to Staple Crops," first published ten years ago, having been exhausted, the publishers requested a revision. It was found, however, that the advances in economic entomology during the past decade were such that it was necessary practically to rewrite the book. At the time it was first published two other books were projected; one to deal with the insects affecting garden crops, and the other to discuss those affecting fruits. Pressure of regular work prevented the author from completing the manuscript for these works and in 1907 Dr. Chittenden issued his excellent book on "Insects Injurious to Vegetables," so that there seemed to be no immediate demand for another volume on that subject. At the same time two other well-known entomologists were working upon books which would cover fruit insects, so that the writer abandoned the field to them. Subsequently, the work of one of these friends was cut short by his sudden death, and the other abandoned the task, at least for the present.

Under these circumstances, it seemed that there was a distinct place for a book to cover all the insects affecting the crops of farm, garden and orchard, and having leisure to devote to it, the author developed the work in its present form.

It has been the author's effort to discuss all of the more important insects of farm, and garden and orchard at sufficient length to give a clear idea of their life histories and habits, and also the best means of control, so that the book may be used as a reference work both by the student of economic entomology and by the practical farmer, gardener, or fruit-grower. Insects of minor or local importance have been purposely omitted. The insects of practically all of the leading crops are considered, except the citrus fruits. With these the author is unfamiliar, but it is hoped to add a chapter upon them by a competent authority in a subsequent edition. In general, the discussion of insects 
and their control as given is based upon conditions east of the Rockies, and practically no consideration has been given to the conditions of the Pacific Coast or of the irrigated country of the far West.

The author is well aware that there are doubtless many errors of fact or of wrong emphasis in these pages. Such must necessarily be the case in a work the greater part of which must be compiled. All of the leading authorities on the subject discussed have been consulted and the writer has endeavored to present their evidence fairly, with such interpretation as his personal knowledge made possible. He will be greatly indebted to those who will aid him in securing the accuracy of the work by reporting any errors or by suggesting improvements in it, as it is hoped to revise the pages from time to time so that they may serve as a reliable reference work upon our insect pests of the farm, the garden, and the orchard.

On the following pages are given the sources from which the illustrations have been secured, but the author wishes to express his special appreciation of the very large number of figures which were furnished him by Dr. L. O. Howard, Chief of the Bureau of Entomology, and Mr. J. A. Arnold, Chief of the Division of Publications, of the United States Department of Agriculture, either as electrotypes or original drawings or photographs, and to Ginn \& Company of Boston, for the loan of numerous electrotypes made for an Elementary Entomology by Prof. C. F. Jackson and the writer, now being published by them.

West Virginia Univergity,

E. Dwight Sanderson.

Morgantown. 


\section{PREFACE TO THE SECOND EDITION.}

No better indication of the activity of the students of American economic entomology could be cited than the fact that a text book dealing with injurious insects requires revision at rather frequent intervals. The present revision is issued in the hope that it may record in some measure the progress which investigators have made since the book was first prepared.

Since the publication of the first edition the senior author has left active work in economic entomology, but he has been fortunate in securing the collaboration of his former colleague, who has made a thorough revision of the original text. He has added several new articles and three new chapters dealing with the insect pests directly affecting man and the domestic animals and with the insects affecting citrus fruits.

Other changes in the text will be found to be minor ones, with the exception of the additions mentioned, and are mainly for the purpose of bringing up to date the recommendations for control.

No attempt to conform to the latest usage in naming of families has been made for the reason that most students using this text will be more familiar with the names as used in Comstock's Manual than with the modern usage.

May, 1920.

E. DWight SANDERSON. 


\section{ACKNOWLEDGEMENTS}

The authors wish to express their sincere appreciation of the courtesy extended by those friends mentioned below who have assisted in this work by furnishing electrotypes, photographs and drawings, thus making possible the illustration of the volume.

The United States Department of Agriculture, through Dr. L. O. Howard, Chief of the Bureau of Entomology, and Mr. J. A. A. Arnold, Chief of the Division of Publications, furnished a large number of electrotypes and plates. The illustrations eredited to Dr. C. V. Riley have been secured from various sources.

Dr. S. A. Forbes, State Entomologist of Illinois, Prof. Glen W. Herrick of Cornell University, Prof. F. L. Washburn of Minnesota, Prof. H. A. Gossard of the Ohio Station, Prof. R. H. Petit of Michigan Agr. College, Prof. P. J. Parrott of the New York Station at Geneva, and the late Dr. John B. Smith of New Jersey, all furnished several illustrations. Prof. W. E. Rumsey of West Virginia made his excellent collection of photographs available.

Prof. H. Garman of Kentucky, Director R. W. Thatcher of the Washington Expt. Station, Prof. S. J. Hunter of the University of Kansas, Prof. T. B. Symons of Maryland, Prof. H. E. Summers of Iowa, Director P. H. Rolfs of the Florida Station, Dr. T. C. Johnson of the Virginia Truck Station, Director J. C. Kendall of the New Hampshire Station, Director S. W. Fletcher of the Virginia Station, Dr. W. E. Britton of Connecticut, Prof. R. I. Smith of North Carolina, Dr. A. L. Quaintance of the Bureau of Entomology, Director F. B. Mumford of the Missouri Station, and Prof. C. S. Crandall of the Illinois Station, all furnished several valuable illustrations

Dr. E. W. Berger kindly read over the copy for the chapter on Citrus Fruit Insects and assisted by correcting mistaken statements and offering many helpful suggestions for the improvement of the chapter. 
The Friend Mfg. Co., The Deming Co., F. E. Myers and Bro., The Spraymotor Co., E. C. Brown and Co., The Goulds Mfg. Co., and the Bean Spray Pump Co., all makers of spraying appliances, furnished many of the illustrations of such apparatus, while the Corona Chemical Co. and the Niagara Sprayer Co. furnished some of the illustrations of dusters.

The Orange Judd Publishing Co. furnished some of the Riley figures.

Many others helped by allowing their illustrations to be used.

All illustrations have been properly credited in the text. Credit for much of the direct and indirect assistance freely given by many persons can not be extended to individuals but is none the less appreciated.

The publishers of this volume, John Wiley and Sons, Inc., have done all in their power to cooperate with the authors and make the task of preparing the manuscript as light as possible, and to them and their organization we wish to extend our thanks. 


\section{CONTENTS}

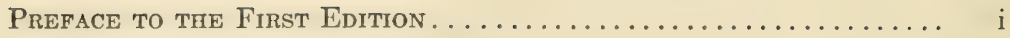

Preface to the Revised Edition...................... iii

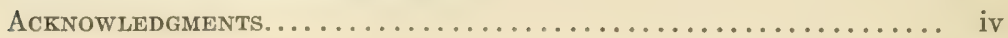

Chapter

PAGE

I. Injury to Crops by Insect Pests................ 1

II. Beneficial Insects, Predaceods and Parasitic........ 8

III. Structure and Development of Insects, .......... 20

IV. Farm Methods for the Control of Insects . ......... 29

V. Insecticides............................ 39

VI. Spraying and Dusting Apparatus. ................ 59

VII. Insects Affecting Grains, Grasses and Miscellaneous Crops........................... 78

VIII. Insects Injurious to Small Grains.............. 117

IX. Insects Injurious to Corn................... 143

X. Insects Injoriods to Stored Grains............... 176

XI. Insects Injurious to Clover and Alfalfa. . . . . . . . . . 189

XII. Insects Injurious to Tobacco.................. 212

XIII. Insects Injurious to Cotton................... 226

XIV. Insects Injurious to Potatoes and Tomatoes......... 256

XV. Insects Injuriods to Beans and Peas............. 278

XVI. Insects Injurious to Beets and Spinach............ 299

XVII. Insects Injurious to Cabbage and Related Crops...... 314

XVIII. Insects Injurious to Melons, Cucumbers, Squash, Etc . 340

XiX. Insects Injurious to Miscellaneods Garden Crops...... 361

XX. Insects Injurious to the Strawberry............. 389

XXI. Insects Injurious to the Raspberry and Blackberry ... 403

XXII. Insects Injurious to the Currant and Gooseberry . . . . 418

XXIII. Insects Injuriods to the Grape................ 432

XXIV. Insects Injurious to Orchard Fruits............ 470

XXV. Insects Injurious to the Apple and Pear.......... 514

XXVi. Insects Injurious to the Peach, Plum and Cherry . . . . . 575

XXVII. Insects Injurious to Cimrus Frutts.............. 599

XXVili. Insects Injuriods to Man and in the Household . . . . . 635

XXIX. Insects Injurious to Domestic Animals and Poultry . . . 657

BibliographY................................6 689

IndEx. . . . . . . . . . . . . . . . . . . . . . . . . 692 


\title{
INSECT PESTS
}

\section{OF \\ FARM, GARDEN AND ORCHARD}

\author{
CHAPTER I \\ THE INJURY TO CROPS BY INSECT PESTS
}

Ever since the locust plagues in the time of the Pharaohs history is replete with accounts of insect scourges and the enormous losses they have caused the agriculturists of all ages. However, instead of diminishing with the advancement of agricultural methods, injurious insects have undoubtedly become both more numerous and more destructive in modern times. "In no country in the world do insects impose a heavier tax on farm products than in the United States. The losses resulting from the depredations of insects on all the plant products of the soil, both in their growing and in their stored state, together with those on live stock, exceed the entire expenditures of the National Government, including the pension roll and the maintenance of the Army and the Navy."* "Very careful estimates, based on crop reports and actual insect damage over a series of years, show that the loss due to insect pests of farm products, including fruits and live stock, now reaches the almost inconceivable total of $\$ 1,000,000,000$, annually." $\dagger$ The above quotations from Mr. C. L. Marlatt, Assistant Chief of the Bureau of Entomology, United States Department of Agriculture, may appear to the reader either ludicrous or startling, according to the extent of his information concerning the role which insects play in our Agricultural

* C. L. Marlatt, Yearbook U. S. Department of Agriculture, 1904, p. 461.

$\dagger$ C. L. Marlatt, Journal of Economic Entomology, IV, 109. 
economy, which forms the warp of American prosperity. It should be borne in mind that these figures are based on pre-war estimates and that they now need considerable revision upward but that the totals will not reach the amounts expended by the nation during a state of war.

A brief resume of the damage done by insect pests, of the costs of fighting them and of the estimates which form the basis for the above statements will make them more convincing.

Growing Cereals.-Probably no insect does as widespread damage as the Hessian-fly, attacking our chief staple, wheat, as well as rye and barley. One-tenth of the whole crop, valued at $\$ 150,000,000$ to $\$ 175,000,000$ is generally conceded to be destroyed by this pest every year. In some sections the loss is frequently as great as 30 to 50 per cent, and it undoubtedly was responsible in a great measure for the necessity for governmental regulations of the use of wheat flour during the great war. The southern grain-louse or "green-bug" caused a loss estimated at from $\$ 5,000,000$ to $\$ 10,000,000$ in Texas, Oklahoma and Kansas in 1907 , and every year there is a considerable shrinkage in the wheat crop as a result of the presence of this and other species of plantlice. This injury will doubtless amount, on the average, to as much as 2 or 3 per cent of the entire crop, worth from $\$ 30,000,000$ to $\$ 50,000,000$.

The corn crop of 1919 was worth at least three and one-half billions of dollars. The total was reduced at least two to three per cent by the chinch-bug and not less than 5 per cent by the corn-earworm while other insects accounted for several per cent more or less. Estimating the total insect depreciation of this erop at only ten per cent gives a total of $\$ 350,000,000$ for the one year.

The total value of cereal crops in 1919 was over $\$ 7,000,000,000$, which was undoubtedly at least ten per cent less than it would have been could the insect injury have been totally eliminated.

Hay and Forage Crops.-A host of small insects attack our grasses and forage crops, many of them being so small that they are unnoticed, though their aggregate injury is sometimes enormous. Of the larger pests of grasses and forage plants the army worns are among the best known and have often caused a loss of over half a million dollars to a single state in one season. 
Grasshoppers of various species are also always more or less injurious and of ten become a serious menace. Probalbly the most serious injury, however, is done by subterranean larve such as the cut-worms, wireworms, white grubs, and webworms, which breed in sod land, and by the hordes of little leaf-hoppers which are always prevalent, but whose injury often passes unnoticed. Ten per cent of the hay crop was worth $\$ 150,000,000$ in 1919 and this is a fair estimate of the damage done to hay and forage crops by their insect enemies.

Cotton.-The cotton plant has a number of injurious insect enemies, of which the boll weevil, bollworm, and leafworm are the most injurious. In 1904 the writer made a statistical study of the decrease in the cotton crop of Texas due to the boll weevil, and showed that it was then costing that state $\$ 25,000,000$ per annum.* This estimate has been confirmed by independent investigations made by Mr. W. D. Hunter of the U. S. Bureau of Entomology, and although the loss in Texas is not so serious at present, the weevil has spread eastward as far as Georgia, so that its total injury remains practically the same, and has undoubtedly been a large factor in the higher price of cotton in recent years. The bollworm is most injurious in the southwestern cotton-producing States, where it causes a loss from 5 to 60 per cent of the crop. The total damage to cotton by the bollworm is approximately $\$ 100,000,000$ per annum and not infrequently exceeds that amount. In 1880 the United States Entomological Commission made an investigation of the cotton worm and valued its ravages at $\$ 30,000,000$, but with the extensive use of Paris green and arsenical poisons its injury has been greatly reduced and now amounts to from $\$ 5,000,000$ to $\$ 20,000,000$ annually. Various minor pests of the cotton plant inflict a considerable amount of local injury and with the above pests damage the crop at least 10 per cent, worth $\$ 160,000,000$ in 1919 .

Tobacco.-Tobaceo is attacked by insects, which form one of the chief "bugbears" of tobacco growing, at all stages of its existence. Ten per cent of the crop, worth $\$ 35,000,000$, is certainly destroyed by them every year.

* E. D. Sanderson, The Boll Weevil and the Cotton Crop of Texas. (Bulletin Dept. of Agriculture, Insurance, Statistics and History, Austin, Texas, 1905, p. 28, 7 maps.) 
Truck Crops.--Truck crops are peculiarly susceptible to insect attacks, and their control forms one of the chief items in the cost of production. It is safe to say that truck crops suffer from insect ravages fully twice as much as do the staples, or 20 per cent of their total value. Statisties are not available for the present value of truck crops, but they were probably worth $\$ 1,500,000,000$ in 1919 , making the insect tax for the trucker fully $\$ 300,000,000$.

Fruits.-Fruit trees are also much more seriously injured by insects than are the staple crops, and their control involves a large expense to the fruit-grower. Where it is not combated, the codling moth, or apple worm, causes a loss of from 30 to 50 per cent of the crop, and where it is controlled by spraying a considerable expense is involved. The loss and cost of treatment for this pest alone amount, to $\$ 35,000,000$ for the United States, and were it not for the fact that it is now largely controlled in the principal fruit-growing sections, the loss would be double or treble this sum. The loss due to the San Jose scale is difficult to estimate, but it is well known that it has destroyed millions of trees and that in the principal fruit regions where this pest is prevalent it is necessary to treat the trees annually at a cost of from 10 to 25 cents per tree, so that $\$ 10,000,000$ a year would be a very conservative estimate of its annual cost. Both deciduous and citrus fruits have a host of insect pests, always present and doing more or less damage and occasionally becoming so abundant as to threaten the life of the trees or their crops. Fifteen per cent of the value of our fruit products, worth at least $\$ 75,000,000$, is certainly destroyed by insect pests every year.

Forest Insects.-Only those who have had opportunity to observe the ravages of insects in timber and in timber products can appreciate the enormous losses which they occasion. Probably no one is better informed upon this matter than Dr. A. D. Hopkins, in charge of the Forest Insect Investigations of the U. S. Bureau of Entomology, who has made a life study of these pests in all parts of the country. In a recent circular* he states that " the amount of insect-killed and damaged timber left in the woods, plus the reduction in value of that utilized, to be charged

*A. D. Hopkins, Circular 129, Bureau of Entomology, U. S. Dept. Agr. 
to insects is not far from an equivalent of 10 per cent of the value of the annual output of forest products of all kinds, in the rough. The total value of the forest products of the United States in 1907 is given as $\$ 1,280,000,000$; the losses from insect depredations would therefore represent an annual loss in cash value of more than $\$ 100,000,000 . "$ To this should be added a similar loss to farm woodlots, which may be estimated at an additional $\$ 10,000,000$. The insect injury to the shade trees of city streets, parks, and estates should also be mentioned, for such pests as the gypsy moth, the elm leaf-beetle, tussock moths, etc., are not only causing enormous losses and large expense for their control, but they are often reducing the values of real estate and through killing the trees are destroying the scenic value of property and changing the esthetic environment in a manner which it will require many decades to remedy, if the previous conditions can ever be even partially reproduced. The State Forester of Massachusetts has recently shown that the New England States and the Federal Government have spent fully $\$ 7,000,000$ in fighting the gypsy and brown-tail moths in New England, and at the present time the New England States, the Federal Government, municipalities and private individuals are spending over $\$ 1,000,000$ per annum in this warfare for the preservation of their shade and forest trees.

Live Stock.-Insect pests, including the ticks and mites, are almost as important as enemies of live stock as of crops. The principal drawback to cattle raising in the South is the Texas fever, transmitted by the cattle tick, which has been charged by the officials of the bureau of Animal Industry with a loss of $\$ 100,000,000$ annually. The ox-warble, which causes the "grubby" hides of cattle, causes a loss estimated at from $\$ 30,000,000$ to $\$ 50,000,000$ per year due to the depreciated value of the hides and the lessened quantity and poorer quality of the beef of affected animals. The serew-worm fly is a constan ${ }^{1}$ annoyance to cattle and source of loss on the range, and numerous biting and parasitic flies cause a considerable loss to the grower of live stock, both through astual damage and through the annoyance preventing growth and production. The sheep scab, sheep tick, the sheep bot - causing "staggers" or "grub-in-the-head"- horn-fiy, buffalo-fly, blackfly, and numerous species of lice which affect all of the domestic animals, are among the pests which must be combated by the 
stockman. In 1919 the live stock products were worth $\$ 8,000,000,000$, and it is estimated that fully 10 per cent of this amount was lost through injury from insects.

Stored Products. - Even after the crops have been gathered and garnered, and indeed after they and animal products have been manufactured, they are constantly subject to the attacks of numerous "weevils," "moths," and other insect pests of stored products. Every housewife and every merchant knows that only through constant surveillance these ravages can be prevented. Mills, tobacco warehouses, storage houses, and vessels, must be frequently cleaned and often must be fumigated to prevent the increase of insect pests peculiar to them. It is estimated that at least 3 per cent of the cereal crops are destroyed by insects while in storage, which would mean a loss of $\$ 200,000,000$, and in many cases the loss to corn, particularly in the South, is much greater. The total loss due to insects in stored goods of all kinds is impossible to estimate, but would fall not far short of $\$ 300,000,000$.

With this brief statement of the losses due to insect pests we may summarize them in a table which will show that the total is based upon conservative estimates.

Annual Values of Farm Crops and losses Crargeable to Insect Pests*.

\begin{tabular}{|c|c|c|c|}
\hline PRODUCT & VALUE & $\begin{array}{l}\text { PERCENTAGE } \\
\text { OF LOSS }\end{array}$ & $\begin{array}{c}\text { AMOUNT OF } \\
\text { LOSS }\end{array}$ \\
\hline 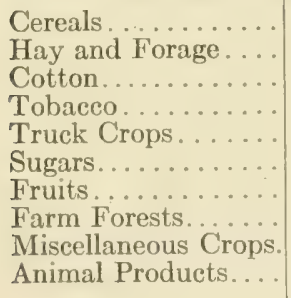 & $\begin{array}{r}\$ 7,000,000,000 \\
1,500,000,000 \\
1,600,000,000 \\
375,000,000 \\
1,500,000,000 \\
200,000,000 \\
500,000,000 \\
110,000,000 \\
250,000,000 \\
8,000,000,000\end{array}$ & $\begin{array}{r}10 \\
10 \\
10 \\
10 \\
20 \\
10 \\
15 \\
10 \\
5 \\
5\end{array}$ & $\begin{array}{r}\$ 700,000,000 \\
150,000,000 \\
160,000,000 \\
37,500,000 \\
300,000,000 \\
20,000,000 \\
75,000,000 \\
11,000,000 \\
12,500,000 \\
400,000,000\end{array}$ \\
\hline \multicolumn{3}{|c|}{$\$ 21,035,000,000$} & $\$ 1,866,000,000$ \\
\hline \multicolumn{3}{|c|}{ 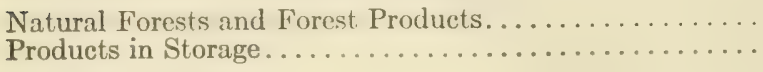 } & $\begin{array}{l}100,000,000 \\
300,000,000\end{array}$ \\
\hline \multicolumn{3}{|c|}{ Grand Total . . . . . . . . . . . . . . . . . } & $\$ 2,266,000,000$ \\
\hline
\end{tabular}

* Based on estimates from the U.S. Bureau of Entomology with modifications by the writers. Crop values based on estimates from the U. S. Department of Agriculture Yearbook for 1918 and various estimates for the year 1919 . 
This table will indicate that two billions of dollars is a conservative estimate of the damage done by insects annually to the agricultural interests of the country.

The old saying, "One man's loss is another man's gain " will not apply to this damage. While the fluctuation in the amount of crops does influence prices received by the farmers it does not obviate the loss, even though the farmer receives as much money for the reduced crop as he would have for a full crop. The effect is merely to shift the burden of the loss from the farmer to the consumer. The damage done by the insects remains as a definite destruction of wealth of the community just as truly as loss from fire and storm, even though such loss is borne not by the owner of the property destroyed but by an insurance company.

A real benefit to the community at large from these insects is coming to be recognized more and more. That is, that to succeed against the handicaps of insect injury as well as the other hazards incident to modern agriculture, the farmer must become a student of the factors insuring success. He must, as he usually can, learn the methods of agriculture best suited to prevent the loss from insects. This will tend to broaden his education, to make him more observant of conditions affecting successful farming and indirectly is bound to make him a more intelligent and efficient farmer and a better citizen. Who can say that such benefit does not largely overbalance the tremendous loss due to the presence of the insects. 


\section{CHAPTER II}

\section{BENEFICIAL INSECTS, PREDACEOUS AND PARASITIC}

\section{Ladybird-beetles}

After his strawberries have been ruined by the strawberry weevil, the garden truck by cutworms, the wheat despoiled by the Hessian fly, the melon-patch fallen a prey to plant-lice, and the fruit crop has been a failure on account of the codling moth, plum curculio, and San Jose scale, it is scarcely surprising that the farmer does as one of my acquaintances did and " orders the hands to kill everything that crawls."

But such would be entirely too heroic a measure, and if strictly adhered to the remedy would be as bad as the disease, for it would mean not only useless labor, but the destruction of the most effective means whereby insect pests are held in check. We pride ourselves - and justly — that with our spray pumps and deadly sprays many crops can be effectually protected; but were it not for those other insects which feed upon these injurious forms, what an enormous, and, in some instances, futile task it would be!

Among these beneficial insects the little ladybird-beetles of the family Coccinellidce are entitled to be in the first rank. Almost all these beetles and larvæ feed upon plant-lice and scale insects. Of such value are those feeding upon scale insects that not many years ago several Australian species were imported into California that they might prey upon the San Jose and other scales. One of these was eminently successful and almost completely destroyed the cottony cushion-scale.

Of those feeding upon plant-lice, one of the most common is the Nine-spotted Ladybird (Coccinella novemnotata). This beetle is about one-fourth of an inch long, with black head and body. The wing-covers are orange-yellow marked with nine black spots - four on each side and one on the central suture. The larva has been fancied to resemble a miniature alligator; it is nearly twice as long as wide, almost black, marked with bluish and orange spots, and has long legs, which carry it around quite rapidly. The beetles hibernate during the winter and 
come forth in the spring and lay their eggs wherever the young will be able to find food when they hatch. When the larva has satisfied its ravenous appetite and become full grown it fastens itself to a leaf or twig, - seemingly by its tail, if such
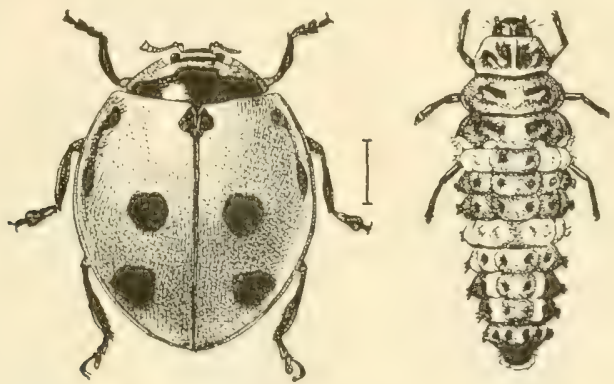

FIg. 1.-The nine-spotted ladybird (Coccinella noremnotata), and its larva; enlarged. (After Chittenden, U. S. Dept. Agr.)

a term might be allowed, - transforms to the pupa, and in a week or ten days the adult beetle emerges from the pupal skin. This life-cycle is repeated several times during the summer season, before the fall brood enters winter quarters.

Another very common form among plant-lice on garden truck is the little Adalia bipunctata, or Two-spotted Ladybird. It is
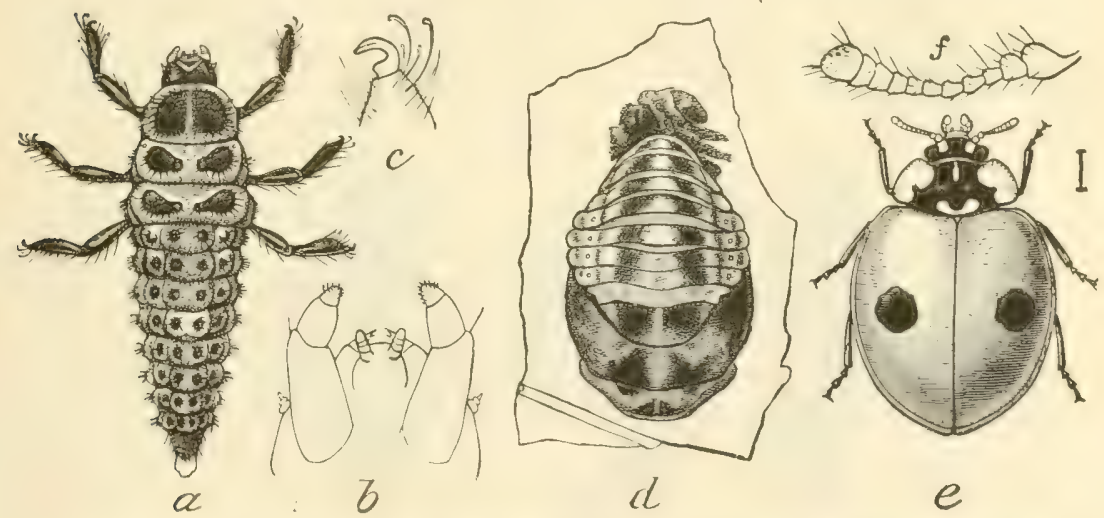

FIg. 2.-The two-spotted ladybird (Adalia bipunctata): $a$, larva; $b$, mouthparts of same; $c$, claw of same; $d$, pupa; $e$, adult; $f$, antenna of same; all enlarged. (After Marlatt, U. S. Dept. Agr.)

slightly smaller than the preceding, and with only one black spot on each wing-cover (Fig. 2). 
Several other species, in the genus Hippodamia, are very useful, and among them the Convergent Ladybird (Hippodamia convergens) is one of the best known. Its name is received from two white dashes on the black thorax, which converge posteriorly. The thorax has also a white margin, and there are thirteen black dots on its orange wing-covers. These larvæ

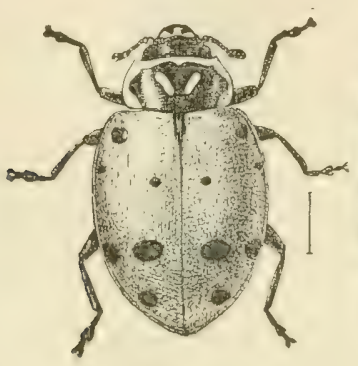

a

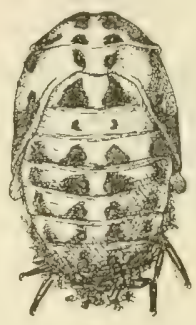

b

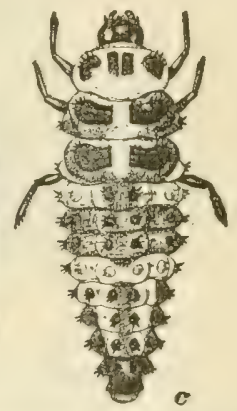

FIG. 3.-The convergent ladybird (Hippodamia convergens): $a$, adult; $b$, pupa; $c$, larva; enlarged. (After Chittenden, U. S. Dept. Agr.)

and beetles are very common among the plant-lice on melonvines, and are an important factor in their extermination. They have also been noted for eating the black peach aphis and many other plant-lice.

A form which is often very abundant among plant-lice on corn is the Spotted Ladybird (Megilla maculata). The head, thorax,
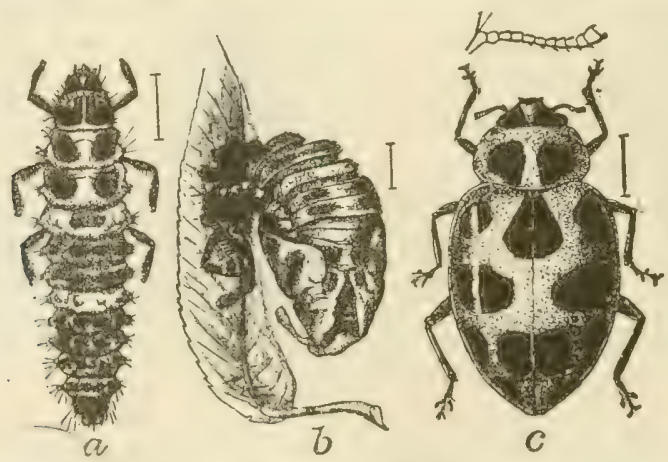

FIG. 4. - The spotted ladybird (Megilla maculata): $a$, larva; $b$, pupa; $c$, adult; enlarged. (After Chittenden, U. S. Dept. Agr.)

and wing-covers are a dark pink, with two black spots on the thorax and ten on the wing-covers. Such numbers of these 
little fellows have frequently been found huddled together under the rubbish at the base of some tree in a last year's cornfield that they might be taken up by the handful without difficulty. Many other species feed upon plant-lice, but the above are the most common, and all bear a resemblance to one another, being generally orange or red with black spots, and of a characteristic

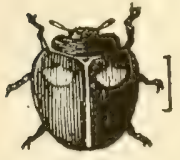

$a$.

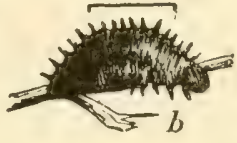

Fig. 5.-The twice-stabbed ladybird (Chilocorus bivulnerus). $a$, adult; $b$, larva; enlarged. (After Riley.) round or oval form, flattened below, so that the legs may be drawn in under the wing-covers.

Those ladybirds which feed upon scales are much smaller and are black, though sometimes spotterl with red or orange.

As far as known, there is no way in which these useful allies may be encouraged or increased in numbers, but it is trusted that the above may give such a brief view of their habits that fewer may be killed through ignorance concerning their true worth.

\section{Syrphus-flies}

Besides the little beetles described above there is a family of flies, the Syrphide, many of whose larvæ feed upon plantlice. This family is a very large one, and thus the habits of its different members vary considerably. One of them, the dronefly, so closely resembles a honeybee as to be almost indistinguishable from it. The larva of this fly (Eristalis tenax) is one of the common rat-tailed maggots which are found in putrid matter. It is thought that the old "bugonia" superstition of the ancients that bees came from

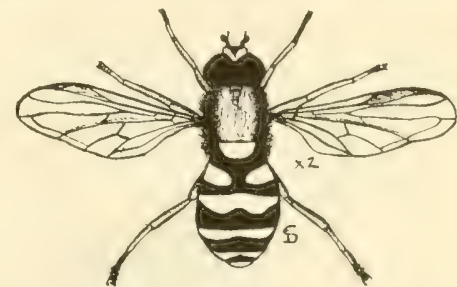

Fig. 6. - Syrphus ribesii; enlarged. maggots in dead animals, etc., was due to the confusion of this fly with honey-bee.

In another group of the family, the adult flies of which also quite closely resembles bees, the larva are parasitic in the nests of honey-and bumble-bees, feeding upon their larvæ. 
But the larva of possibly the typical portion of the family, embracing the genus Syrphus and its near allies, are entirely predaceous upon plant-lice. Rarely can a colony of plantlice be found without some of these little enemies hard after them.

The adult syrphus-fly is a very striking insect, with its dark green metallic thorax, and abdomen variously banded with yellow and black. The female fly lays her eggs upon some plant bearing plant-lice. The larvæ which hatch from these are elongate, flattened maggots, about one-half an inch long, with hardly a trace of a head, but with four small hooks, which serve as jaws, projecting from the more pointed end of the body. These maggots are often of a light-green color, and so like the color of the plants as to render them most difficult to recognize. The young larvæ at once commence crawling over the plant in search of aphids, and as soon as they come in contact with one it is firmly clasped by the small hooklets until the juices are sucked from its body. In this manner very large numbers are destroyed, a single maggot of the American Syrphus-fly (Syrphus americanus) having been observed to eat twenty-five apple plant-lice (Aphis pomi) in as many minutes. When the larva is ready to pupate it attaches itself tc a leaf, and the larval skin dries up and forms a case or puparium inside of which the pupa remains until it transforms to the adult fly.

Though most of these larvæ feed upon plant-lice upon the leaves, one of them, the Root-louse syrphus-fly (Pipiza radicans),
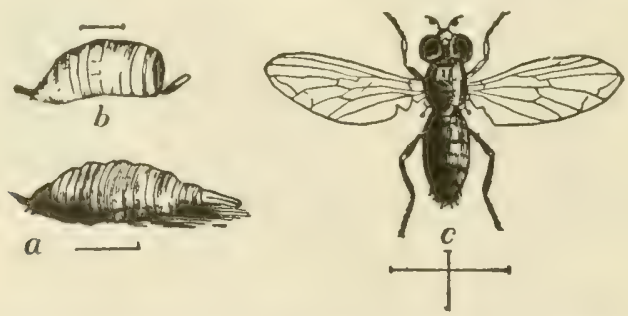

Fig. 7.-The root-louse syrphus-fly (Pipiza radicans). a. maggot; $b$, puparium; $c$, fly. (After Riley.)

lives entirely underground during that stage, and feeds upon the root-lice of the apple and the grape. None of this family is injurious, and as a large portion of them are so beneficial 
as frequently to destroy whole broods of plant-lice, they should not be disturbed in their good work if possible to avoid it.

\section{The Ground-beetles}

If, as you scrape away the loose chips at the base of a tree in your door-yard, turn over an old log in the woodland, or pick up a fallen fence-rail, you will scrutinize the inhabitants under these shelters, a number of shining black beetles varying in length from one fourth to $1 \frac{1}{2}$ inches will usually be noticed. If the city reader be not so fortunate as to be familiar with or have access to these hiding-places, he may find large numbers of the beetles
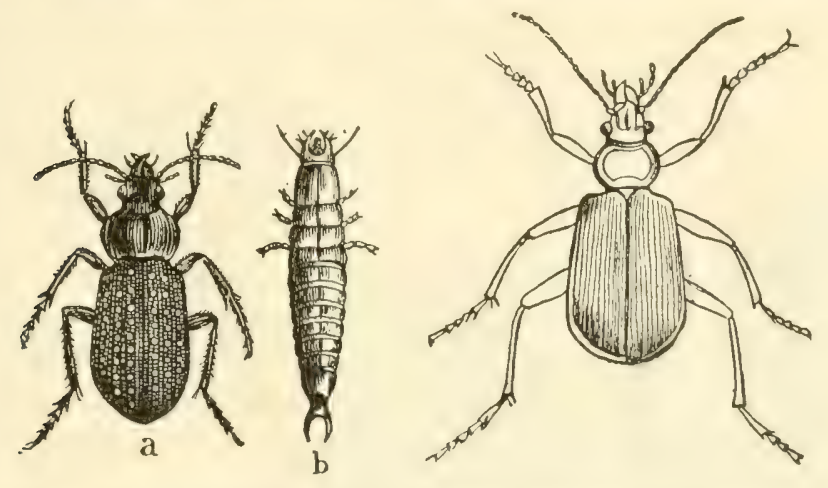

Fig. 8.-The fiery ground-beetle (Calosoma calidum). a, beetle; $b$, larva; $c$, "the searcher" (Calosoma scrutator). (After Riley.)

under any electric are light during the warm summer evenings; for there they are having a sumptuous banquet upon the small flies and moths attracted by the glare. They are rarely seen at large during the day, as they are almost exclusively nocturnal insects, and from their habit of remaining almost entirely in or on the ground they are usually known as "Ground-beetles." As might therefore be inferred, they are exceedingly valuahle to the farmer by destroying large numbers of noxious insects which pass a part or all of their existence in the soil. Besides the glossy black forms which are most commonly seen, many are brilliantly marked with gold, green, purple, and iridescent tints.

The Fiery Ground-beetle (Calosoma calidum), so called on account of the wing-covers being dotted with bright gold, has 
many times been of great assistance in helping to rid a corn-field of cutworms. The larva of this insect are about one inch in length, of a dark brown color, with the skin of a hard, horny texture like that of the beetle. They have strong, prominent jaws, and at the posterior end of the body is a forked appendage looking much like another pair of jaws. It is not only surprising that these larvæ will eat so large a number of cutworms as they have frequently been known to do, but that they will dare to attack such a formidable creature fully three or four times as large as themselves, but their assault is sharp and vigorous, and a single larva has often been seen to kill and eat several full-grown cutworms in a short time. Many instances of the good work of this beetle are on record, among which one by the late Professor J. A. Lintner may be cited, where he found

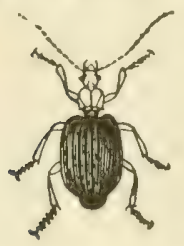

FIG. 9.-Lebiagrandis. (After Riley.)

them eating large numbers of the corncrambus-sometimes locally known as the corn bud-worm. Another somewhat larger beetle, called by Professor J. H. Comstock " the Searcher" (Calosoma scrutator), and in fact one of the largest of the family, is a brilliant metallic green, bordered with a dark purplishblue, and has the good quality of having a very particular appetite, causing it to kill large numbers of caterpillars, but to eat only part of each.

While in the earth as puper large numbers of the Colorado potato-beetles are destroyed by members of this family, and
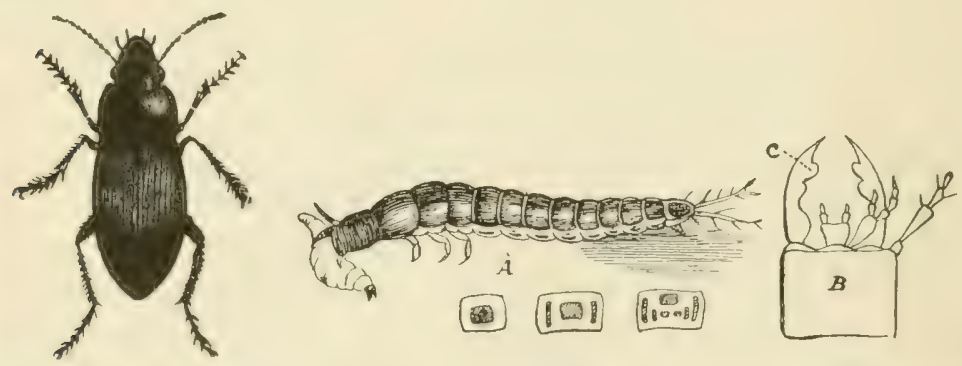

Fig. 10.-The murky ground-beetle (IIarpalus caliginosus): adult at left; $a$, larva; $b$, head of same; $c$, mandible. (After Riley.)

one species, Lebia grandis which is peculiar in that the wingcovers are somewhat abbreviated, thus leaving the tip of the 
abdomen exposed, has been notieed on the plants cating the eggs and young larvæ of this old potato pest.

Another valuable species is one called by Dr. Riley the Murkey Ground-beetle (Harpalus caliginosus). Its larva is of considerable assistance to fruit-growers by eating large numbers of curculio larvæ which it secures from the plums after they have fallen to the earth. From a glance at its formidable jaws, Fig. $10 b-c$, it is easy to conjecture the fate of many a curculio grub.

Thus here again are found some "bugs" that are friends and not foes, worthy of all the protection that can be afforded them, and well repaying such careful observation of their habits as may be bestowed upon them.

\section{Insect Parasites}

Though large numbers of injurious insects are annually destroyed by those which are purcly predaceous upon them, many more succumb to those minute forms which live parasitically within them. A few of these parasites belong to the order Diptera, or true flies, but most of them are classed in the order Hymenoptera, in which order are also included the sawflies, ants, wasps, and bees.

Of the half-dozen families of hymenopterous parasites one of the largest and most beneficial is that of the

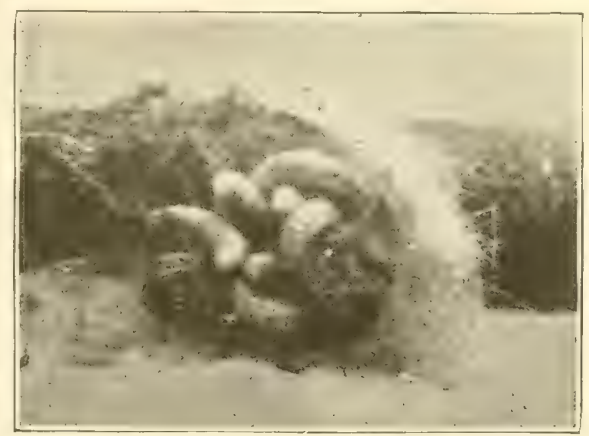

FIG. 11.-Maggots of Pimpla inquisitor, a parasitic Ichneumon-fly, feeding on a caterpillar which had spun its cocoon and was ready to pupate.

Ichneumon-flies. The illustrations will best show the form and structure of these insects, which the casual observer will hardly be able to distinguish from other families of the group. But it will be noticed that the fine veins of the wings vary considerably in the different parasites figured and it is by these that the entomologist is enabled to separate the different groups and often to identify the species at a glance. Both this and the follow- 
ing family are peculiar in having an exceedingly long ovipositor or egg-tube, of which they make a very good use. It is with this extensile tube that the female deftly punctures the skin of some unsuspecting caterpillar, and under it inserts her eggs. In a few days there hatch from these a host of young maggots which feed upon the juices and tissues of the caterpillar, but are seemingly careful to avoid injuring any of its vital organs, for as soon as the caterpillar reaches its full growth it changes to a pupa, apparently unaffected. When the maggots have reached their full size each spins up a small silken cocoon inside the pupa, entirely filling up its now dead shell, and instead of a beautiful moth appearing in the spring, a horde of small flies are seen to emerge from round holes in the side of the pupa, or cocoon.

Thus large numbers of such pests as the apple-tree tent-caterpillar (Malacosoma americana), bagworms, (Thyridopteryx ephemeroformis); caterpillars of the swallow-tailed butterflies

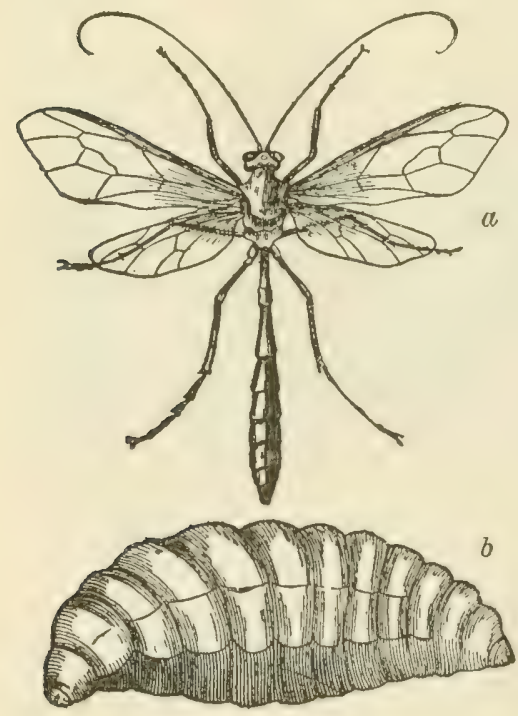
which feed upon parsley, carrots, etc., and a host of others, are consumed by members of this family.

Those belonging to the genus Ophion are partial to the large American silkworms which produce some of our largest and most beautiful moths, and difficulty is frequently experienced in rearing a desired number of moths on account of the large percent of cocoons parasitized.

The species of the family Braconidoe are very similar to those of the preceding one, and contain some equally benFIg. 12.-The long-tailed Ophion (Ophion eficial insects, feeding as they macrurum). a, adult; $b$, maggot; do upon such pests as the cod-
enlarged. (After Riley.)

ling moth, webworms, plumcurculio grubs, plant-lice, etc. Some of the more common forms of this family belong to the genus . Kicrogaster, and their small 
white cocoons may frequently be seen almost covering one of our large tomato- or tobacco-worms (see page 220 ), the pupæ of which are often known as "horn-blowers." Many mistake these cocoons for the eggs of the worms, and therefore destroy some of their best friends. Though some thus spin their cocoons on the outside of the host, others remain inside of the parasitized insect until the adult fly emerges. Thus dead plant-lice may often be found with a large round hole in the abdomen - the only evidence of where one of these parasites has emerged. The Chalcis-flies, Chalcidido, which comprise another closely related family, are often exceedingly minute insects, sometimes not over one one-hundredth of an inch long. They are generally of a metallic black color, and the usual veins of the wings are almost entirely absent. Many of these flies are parasitic upon plant-lice, while a large number of their larva live and mature in the eggs of other insects.

Very similar to the chalcis-flies in the habits of infesting plant-lice and insect eggs are some even smaller insects-in fact the smallest known, the largest being rarely over one-twenty-fifth and the smallest only six-orseven one-thousandths of an inch in length - with a correspondingly tremendous and unpronounceable name, known to science as the Proctotrypidœ. During the last half century the American farmer has been compelled to contend with an increasing number of insect pests, which now and then have become veritable scourges.

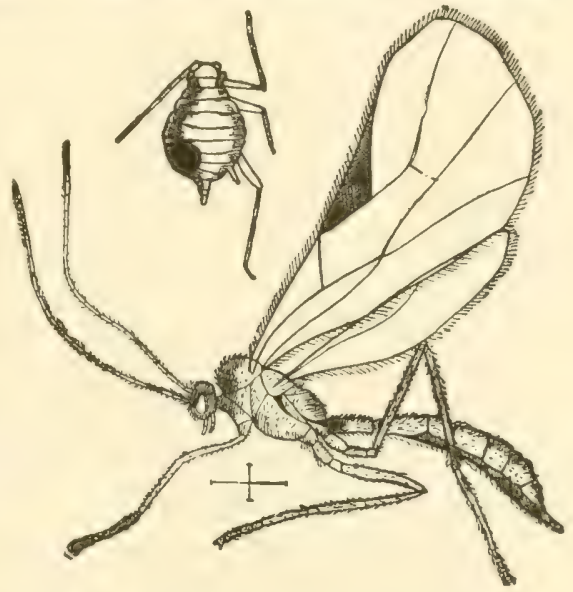

FIG. 13.-A plant-louse parasite. (Aphidius avenaphis), showing above the parasitized louse from which it has issued. (Copied from J. B. Smith.)

Every now and then we hear of communities assembling for prayer and fasting to appease the Alnighty, whose wrath has hurled a new insect plague against them, but such a procedure is by no means as 
common as formerly, and little reflection will show that these scourges are entirely due to natural causes. In fact they are very largely brought about by man himself. Some of these pests are due to the fact that in trying to subdue nature by clearing and cultivating the land, man has deprived the insects of their naturai food plants. They must, therefore, needs feed upon that which is substituted by him, and as it is less abundant than the former wild vegetation, the number of insects and the injury they inflict are more apparent.

By far the larger number of our worst pests, however, are those which come to us from foreign shores. Foreign insects are constantly being imported in one way or another, sometimes being already established pests in other lands and sometimes only becoming so under their new surroundings. These are even more injurious than those native, for whereas many of our native birds, insects, and diseases constantly prey upon native insects and thus keep their numbers in clieck, the enemies of imported pests rarely accompany them, and they thus increase at an alarming rate and do enormous damage before they are attacked by the natural enemies of similar native pests. It is in the case of these imported pests that the value of parasitic and predaceous insects is most apparent. In an effort to make use of them to fight the gypsy and brown-tail moths in New England, the U. S. Bureau of Entomology has for several years been importing large numbers of the parasites and predaceous enemies of these pests and liberating them in affected regions, thus carrying on a practical experiment on a large scale which may show the importance of these parasites in combating imported pests.

Even with our native pests, however, we have frequent examples of the value of parasitic and predaceous enemies. Thus the southern grain louse, or "green bug," was soon brought under control by the myriads of little parasites which preyed upon it (see page 140), and these were artificially transported for some distance and liberated in large numbers. Though these efforts at the distribution of this parasite may be open to some question as to their effectiveness, other parasites have been successfully 
distributed, and there can be no question that before long we shall come better to understand how we may make use of these valuable allies, and some day we may be able to duplicate the apparent miracle by which Dame Nature sweeps away an insect plague in a few days with the aid of these apparently insignificant parasites. 


\section{CHAPTER III}

\section{STRUCTURE AND DEVELOPMENT OF INSECTS}

THE more experience the farmer has with insect pests, the more he comes to realize that if he would successfully combat them he must have a certain amount of knowledge concerning their structure and growth.

In general, the artificial means which may be effectually used to combat an insect pest will depend more or less upon the anatomical structure of the insect, while control by general methods of culture will depend upon a knowledge of the peculiarities of its life-history. The value of a proper understanding of these important factors in insect control is therefore apparent.

\section{General Structure of an Insect}

The body of an insect is composed of three separate parts the head, thorax, and abdomen (Fig. 14), each of which is com-

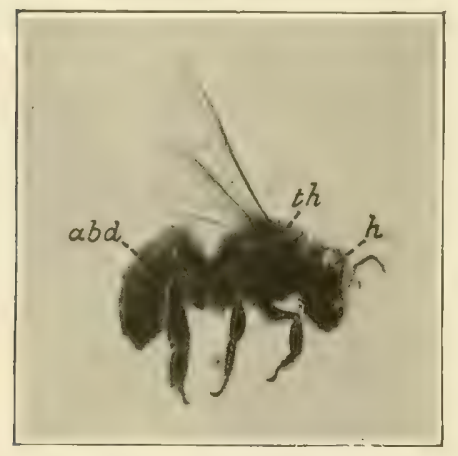

Fic. 14.-Honey-bee, showing the three principal regions of the body of an insect:- $h$, head; th, thorax; $a b d$, abdomen. posed of several rings or segments. To the head are attached the jointed antennæ, or feelers, the compound eyes, and the mouthparts, which are described below. Each of the three segments of the thorax bears a pair of legs, and adult insects usually possess one or two pairs of wings upon the last two segments of the thorax. The abdomen is composed of nine or ten segments, but bears no appendages save the ovipositor of the females of certain orders.

Harvest-mites, or "daddy-long-legs," sow-bugs, thousandlegged worms, and related forms are often popularly called 
insects, but all of them can readily be distinguished from true insects by their possessing more than six legs, the harvest-mites and spiders having eight and the others ten or more.

\section{How Insects Grow}

With rare exceptions insects hatch from eggs laid by the adult females. Upon hatching they are but little larger than the egge, and often bear but little resemblance to their parents. Thus the young caterpillar would never be recognized as the immature stage of the butterfly by one unfamiliar with its trans-

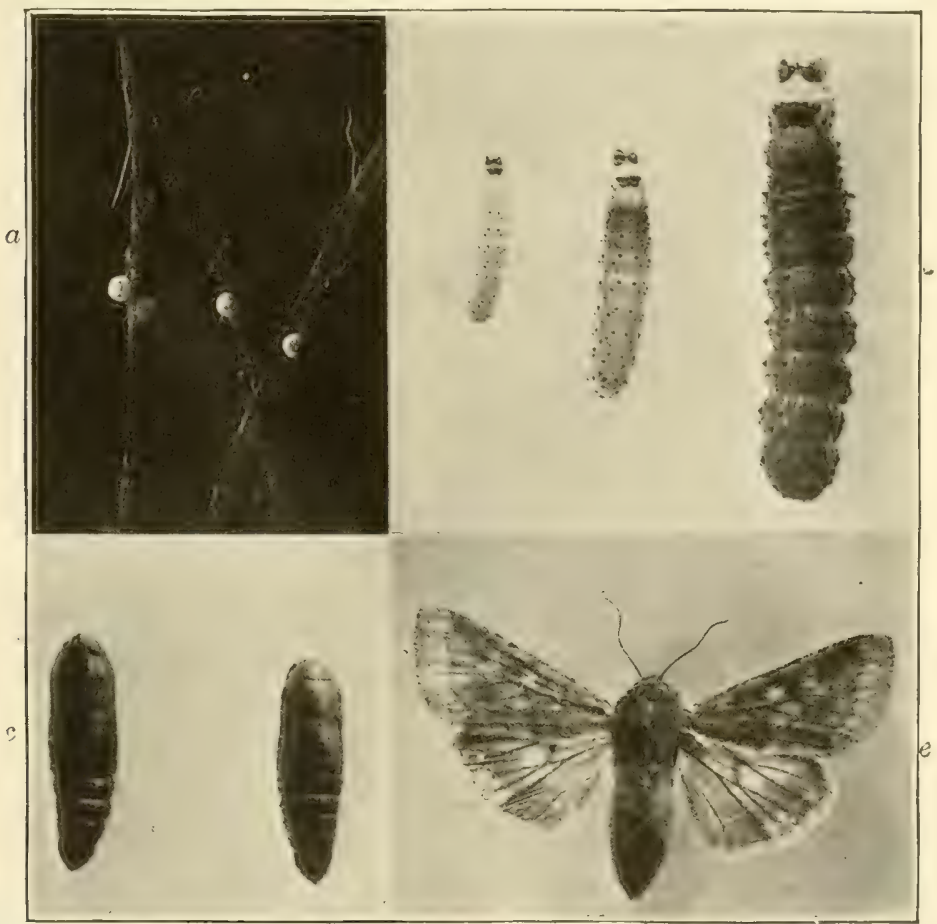

FIG. 15.-Complete metamorphosis. The different stages of the corn earworm (Chloridea obsoleta Fab.): $a$, eggs on corn-silk; $b$, the first three larval stages; $c$, pupa from below; $d$, same from above; $e$, adult mothall enlarged; $b$, about twice natural size.

formations. Grasshoppers and some other insects, however, upon hatching from the egg bear a marked resemblance to the adult form, except that they lack wings. 
Complete Metamorphosis. - When the caterpillar hatches from the egg it at once commences to feed and grows very rapidly, but before long an obstacle to further growth arises. Unlike higher animals, insects possess no internal skeleton or framework for the organs of the body, but the outer skin becomes hardened and to it the muscles and ligaments are attached. This hardening of the skin is best seen in the horny wing-covers of the beetles, and is due to the secretion of a hard substance called chitin. This chitin is secreted by all parts of the szin in greater or less degree, and thus forms a sort of shell for the whole body. Though this hardening is not so apparent in larvæ as in adult insects, it always occurs and it is for this reason that when the young caterpillar has made a certain growth it is forced to shed its skin, which refuses to expand further, in order to develop more fully. Thus the skins of insects are shed several times (see Fig. $15, b)$,- -usually five or six, but sometimes as many as twenty, this process being known as molting. During its life as a caterpillar, which is called the larval stage, and during which it is called a larva, it is an elongate, worm-like creature, with six short, jointed legs on the three thoracic segments, a pair of fleshy false legs or pro-legs on the last abdominal segment, and probably several pairs of pro-legs between these and the true legs. No traces of wings can be seen, but the body is often covered with hairs, spines, or warty tubercles.

With the next molt the insect changes in appearance most radically, becoming a pupa, or chrysalis, as this stage is termed for butterflies. During the pupal stage the insect remains dormant either in a small cell slightly under the surface of the earth, or in a silken cocoon spun by the caterpillar, or merely attached to the food-plant by a strand of silk or the cast larval skin. In many of the Diptera,-the order including flies, mosquitoes, gnats, etc.,--however, the last larval skin is not shed, but hardens and forms a case-called a puparium-within which the pupal stage is passed.

The typical pupa (Fig. 15, c, d) of a butterfly or moth resembles neither the adult insect nor the larva, is of a more or less oral shape, with the wings and antennx tightly folded at the sides, the legs drawn up snugly together under them, and the head and mouth-parts bent upon the breast, or sternum, though 
not all of these parts are always recognizable, the legs and mouthparts being sometimes lacking. Gradually the adult insect develops, and at last the pupal skin is broken open and the airy

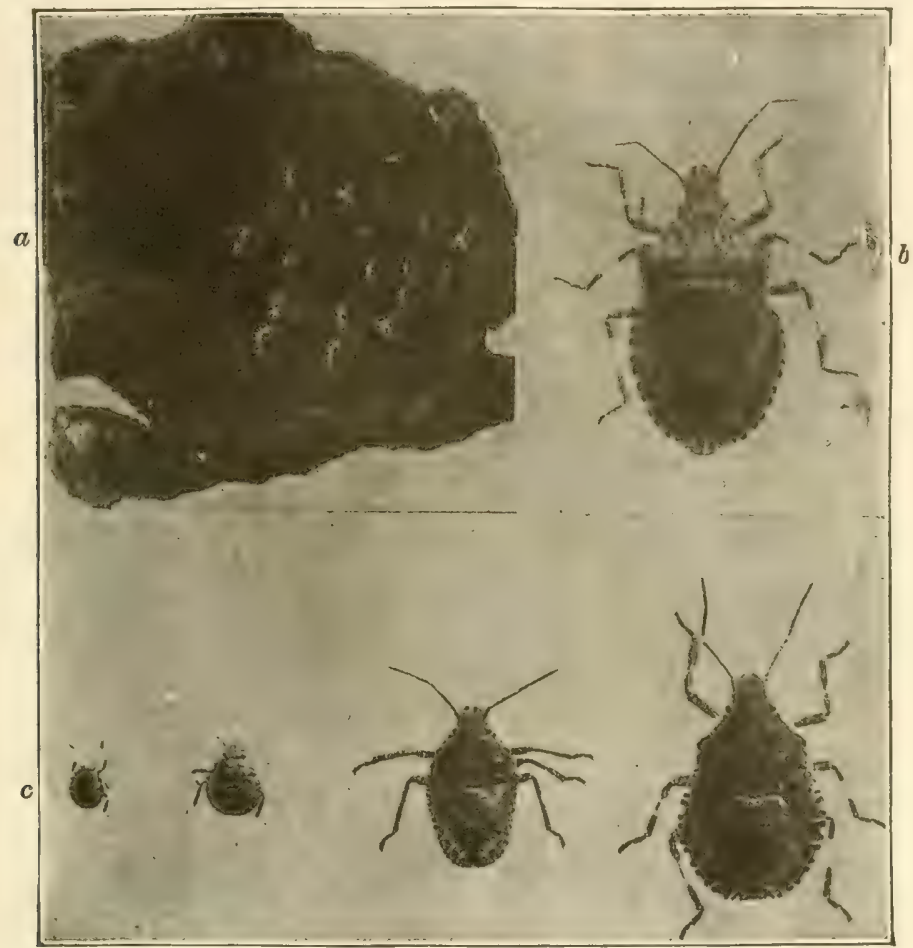

FIG. 16.-Incomplete metamorphosis of a bug (Brachymena 4-pustulata): $a$, eggs; $b$, adult bug; $c$, different stages of young bugs or nymphs.

butterfly emerges to enjoy a short life and perpetuate the species. Such a series of transformations is that commonly found among butterflies and moths (Lepidoptera), beetles (Coleoptera), flies (Diptera), and bees (Hymenoptera), and is known as a complete metamorphosis. All of these insects normally pass through four stages, egg, larva, pupa, and adult.

Incomplete Metamorphosis.-In contrast to this mode of development is that of the grasshoppers (Orthoptera), bugs (Hemiptera), and some other insects. As already stated, these are much like the adult upon emerging from the egg. With 
each molt they become larger and small wing-like pads gradually appear on the sides of the thorax. There is no dormant or pupal stage, the adult insect differing from the previous stages in having fully developed wings, being larger, and often by an accompanying change of markings. The immature stages of such insects are called nymphs, and this development an incomplete metamorphosis, having but three stages, egg, nymph, and adult (Fig.16).

The time occupied by the complete life-cycle of an insect varies from a week or ten days for the plant-lice to thirteen or səventeen vears for some cicadas, and is entirely dependent upon the habit of the species and the climate. A correct knowledge of the exact time and conditions under which the transformations occur for each individual insect pest is therefore often most essential when seeking means for its control.

\section{How Insects Feed}

The material to be used in combating a given insect is largely

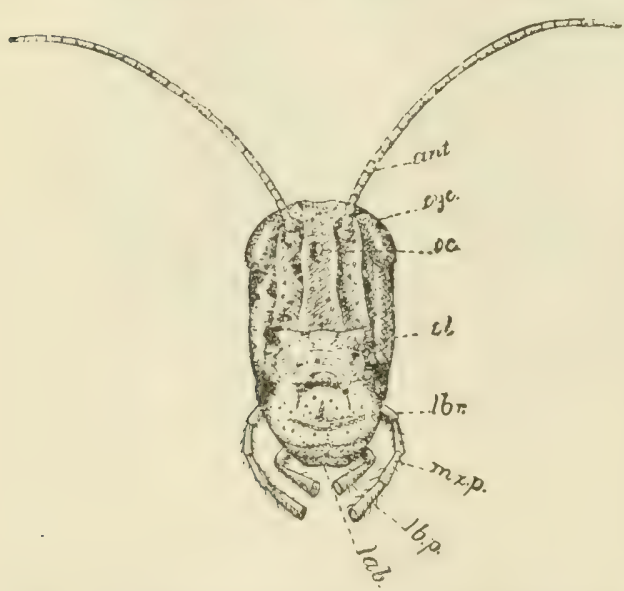
dependent upon the structure of its mouthparts. Much Paris green is wasted upon insects unable to eat it and which it will, therefore, never kill.

Insects may be roughly divided into two classes, those which bite and those which suck their food. Among the former are the beetles, grasshoppers, the larvæ of butterflies

YIg.17.-Front-view face of grasshopper (Schizto- and moths, and the cerca americana): ant., antenna; oc., ocellus; larva of saw-flies; and lip; mx.p., maxillary palpus; lab.p., labial pal- among the latter are pus; gal., galea, lobe of maxilla; lab., labium, or butterflies, flies, bees,
under lip.

and bugs, while the

larva of most flies and bees do not possess mouth-parts homoIogous with those of the above. 
Biting Mouth-parts.-Mouth-parts typical of those of biting insects are easily seen in the grasshopper (Figs. 17 and 18). In brief, they consist of an upper and a lower lip, between which are two pairs of jaws which work transversely. The upper pair of jaws, or mandibles, are stout, short, and horny, usually sharpened at the tip, slightly serrated at the margins, and flattened at the base. The lower pair of jaws, or maxilla are longer, not so strong, and to each of them is attached an accessory lobe, and a jointed style called a palpus or feeler. At each side of the lower lip) is another palpus, these palpi bearing sensory organs.

Sucling Mouth-parts.-In the sucking insects these mouthparts are prolonged into a tube through which the juices of the food plant-or animal-are sucked. In the plant-lice and other

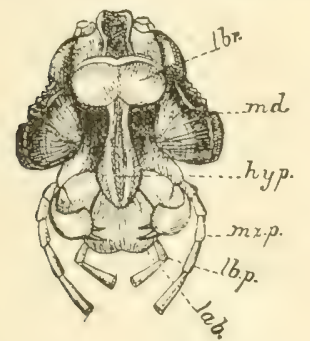

Fig. 18.- $A$, mouth-parts of grasshopper separated to show position and relation; $B$, mouth-parts dissected; $l b r .$, labrum; md., mandible; hyp., hypopharynx or tongue; $m x . p$., maxillary palpus; $l b . p$, labial palpus; lab., labium; $\max .$, maxillæ.
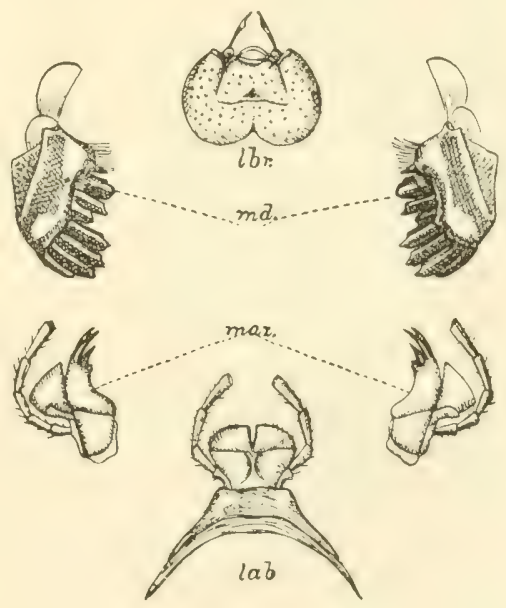

bugs the lower lip is elongated so that it forms a tube, and the maxillæ and mandibles consist of long har-like bristles, or setee, enclosed within this tube (Fig. 20). The tip of this beak is rested upon the surface of a leaf into which the setæ are thrust, lacerating the tissue, and by a pumping process of the mouth the juices are sucked up through the beak. The structure of the mouth-parts of the various orders of sucking insects varies considerably, but all agree in that they suck up the food in a liquid state. Any application of a porsonous spray to the surface of tolıge will be of no avail against them, ${ }^{*}$ though sure death to

- Liquid poisoned baits, used for house-flies, adults of omon-maggots, etc., form an exception to this rule. 
most biting insects which chew the leaves. Sucking insects must therefore be killed by other means.

\section{How Insects Breathe}

Along the side of a caterpillar or larva, on one thoracic seg-

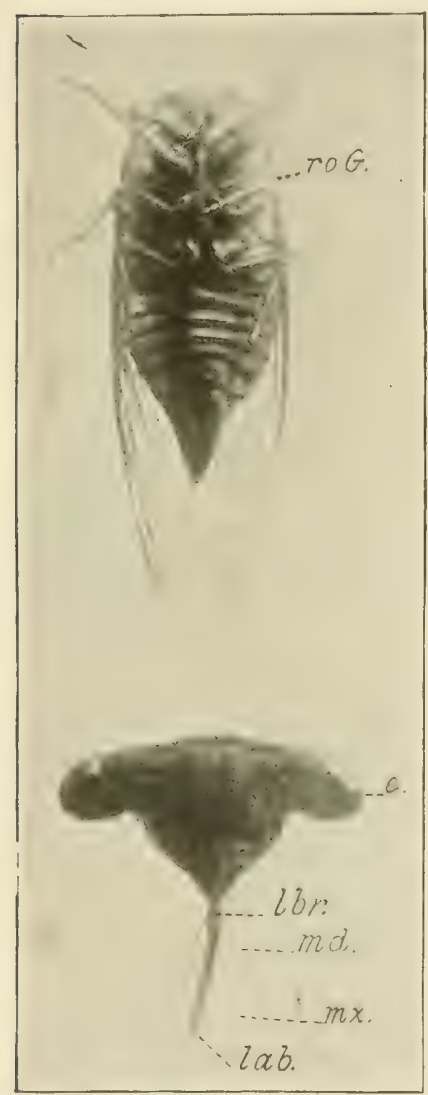

Fig. 19.-Cicada, showing mouthparts of a bug, a sucking insect; the body-cavity. The blood coming a, seen from below, beak or into the heart from the body-cavity
rostrum (ro. G.) reposing between forelegs; $b$, head removed: is propelled forward toward the $e$, eye; lbr., labrum; md., man- head, where it again flows into the
dible-seta; mx., maxillary set $x$; lab., labium. of blood are maintained throughout the body, but other than the heart there is nosystem of blood-vessels, the blood merely filling the body-cavity around and through the various organs and 
tissues. Constantly flowing around tne respiratory tubes or trachere, the blood is quickly and thoroughly purified, though the

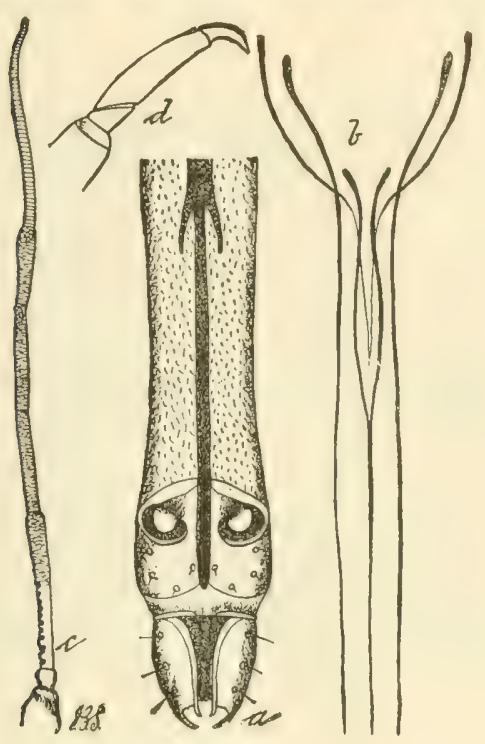

FIG. 20.-Mouth-parts of a plantlouse: $a$, the jointed beak; $b$, the lancets, much enlarged; $c$, antenna; d, foot. (After J. B. Smith.)

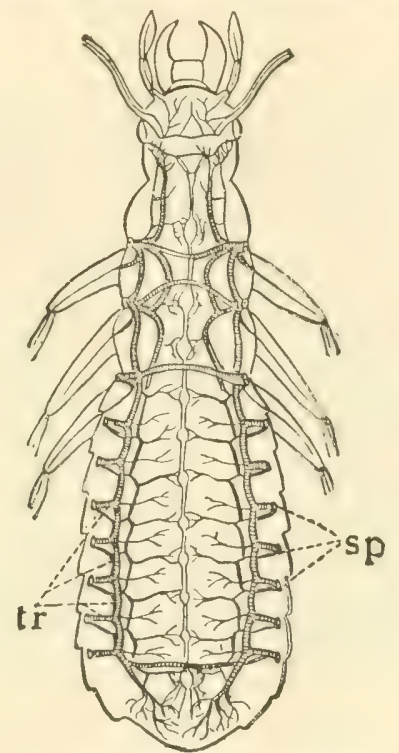

Fig. 21.-Diagram of tracheal or breathing system of an insect: $s p$., spiracles; $t r$., trachea. (After Kolbe.)

exact manner in which this is done is not definitely known. The respiratory system has absolutely no connection with the mouth or pharynx (Fig. 23, ph), as have the lungs of the higher animals,

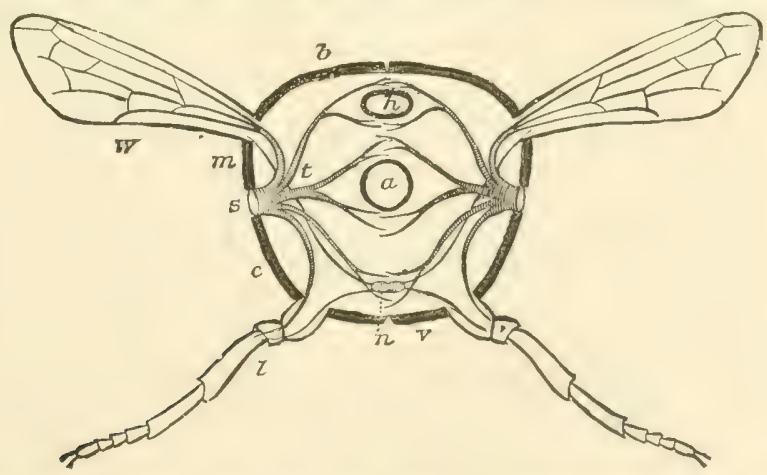

FIG. 22.-Ideal section through an insect: $a$, alimentary canal; $h$, heart; $n$, nerve cord; $s$, spiracle; $t$, tracheal tubes; $l$, legs; $w$, wings. (From Riverside Natural History.) 
and if an insect is to be suffocated, it must be done by closing the spiracles. It is in this way that tobacco-dust, lime, pyrethrum, and similar insecticides kill sucking insects, by penetrating the spiracles and choking the tracheal system. Whale-oil soap,

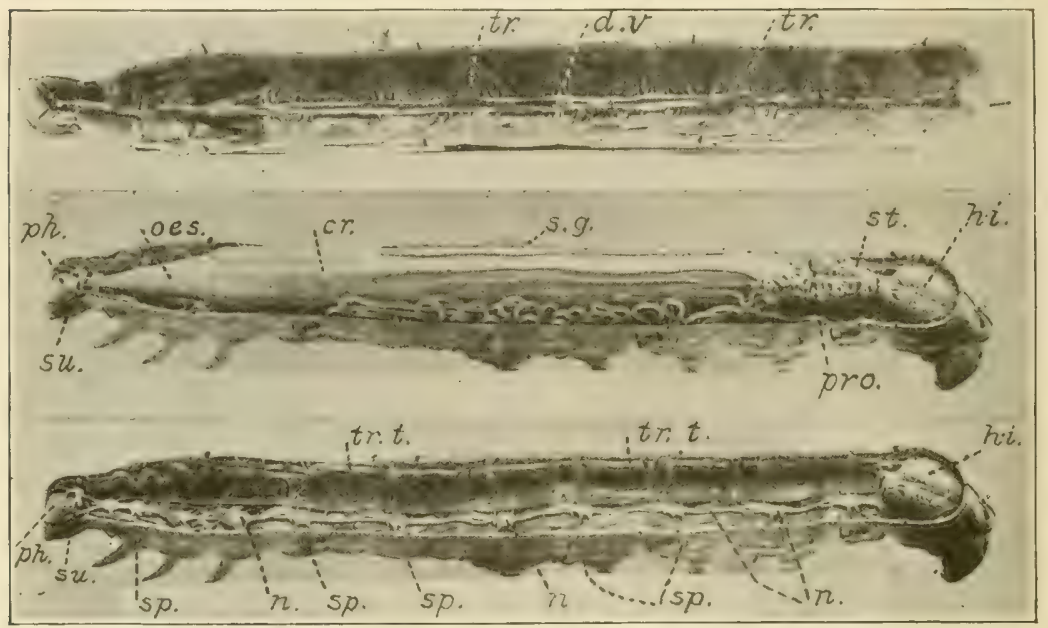

FIG. 23.-Internal anatomy of silk-worm, from photo of Azoux Model: $A$, upper or dorsal bodywall seen from within; $B$, the back of the silkworm removed, showing alimentary canal; $C$, alimentary canal removed, showing nervous system and tracheal trunks; tr., trachea; d.v., dorsal vessel or heart; ph., pharynx or mouth; su., supra-oesophageal ganglion; sp.sp., spiracles or breathing pores; n., nerve eord; tr.t., tracheal trunk; oes., oesophagus or throat; $c r$. , crop); s.g., silk gland; pro., proventriculus; st., stomach; $h . i .$, hind intestine.

kerosene emulsion, and the other "contact" insecticides, or "irritants," also stop up the spiracles and thus cause death, but they may act as "irritants," penetrating the skin and thus killing the insect. When insects are killed by means of a gas such as carbon bisulfide or hydrocyanic acid gas, they are asphyxiated by a substitution of these gases for air, the same as are the higheranimals.

Though arsenical poisons are generally used as sprays for biting insects, soft-bodied caterpillars and similar larva are often killed by the use of contact insecticides, which affect them the same as sucking insects.

The reader will observe that, almost without exception, the remedies advised for different insect pests in the following pages are determined by some peculiarity, either of structure or development, of the insect to be combated. 


\section{CHAPTER IV}

\section{FARM METHODS FOR THE CONTROL OF INSECTS}

THE old adage "an ounce of prevention is worth a pound of cure," is never more true than in the control of insect pests, for in almost all cases their successful control is by prevention before the injury has become acute, rather than by destruction after the injury is noticeable. Even insecticides must be applied so that they will kill the insect before it has done serious damage, for after damage is apparent it is too late to prevent the injury, so that the use of insecticides for the protection of crops must be of a preventive nature. In the control of insects affecting the staple crops which are grown over immense areas with a small profit per acre, it is evidently impracticable to use insecticides and mechanical methods which are used in the orchard and garden. For the control of staple crop insects we are compelled to rely largely on general methods of farm management, which may be carried out in connection with the farm operations at small cost, and which will fatally interfere with the development of the insect to be controlled. To do this intelligently involves an understanding of the life-history of the insect, revealing the time at which it is most vulnerable and the reason for the method of control advised. The importance of such a knowledge of the life-histories and habits of insects to be controlled by farm methods will become apparent in the following chapters.

Though the insects affecting staple crops are more largely controlled by farm methods, those of the garden and orchard may be much reduced by the intelligent application of the same principles, and he who adapts his methods so as to prevent insect attack will be much more successful than one who depends upon artificial means for their destruction.

Looking Ahead.-In planning the management of their land and crops for the coming season, few farmers consider the effect 
which any given procedure will have upon the injurious insects with which they may have to contend. A field which has for several years been in wheat, corn, or tobacco, may be sown with some other crop for the sake of soil improvement, but how often is it considered necessary to rotate crops to avoid insect pests? In most cases they are left out of consideration until a crop has been seriously injured and the necessity for a change of methods thus impressed on the owner.

Particularly while crops are young they should be frequently inspected and examined for any evidence of the pests which commonly affect them. Be prepared to attack any pests which may be found upon their first appearance, for many of the most destructive insects increase with amazing rapidity, and when they have become abundant it is too late to prevent the damage.

Crop Rotation.--One of the most important factors in insect control is the rotation of crops in such a manner that the same crop shall not be grown continuously on the land. In many cases a yearly rotation will be advantageous, while a frequent rotation will always be found beneficial. Many insects feed on one crop only. It is evident, therefore, that if they hibernate in or near the field which it occupied and it is then planted to the same crop the next year, they will be furnished food for their increase, while if the field be planted in a crop not attacked by the insects peculiar to the previous crop they will have to migrate from it, with probably a very considerable mortality as a consequence, for they will radiate in all directions and many will die before finding food, while many more will have been destroyed in the preparation of the old field for the new crop.

The western corn root-worm may be entirely controlled by a rotation so that corn is never grown two successive years on the same land, for the larvie feed only on the roots of corn, and when it is followed by a small grain, grass, or clover, they are starved out. Injury by the Iessian fly to wheat is also very materially reduced where a frequent rotation is practised, as is that of the chinch-bug on corn.

Care should be exercised to arrange a rotation in which erops nearly related botanieally (lo not follow each other, for usually the same insects attack them. Thus white grubs, cutworms, 
and wireworms live normally in grass land, and where it has not been plowed for several years they often become exceedingly abundant. If the sod be then turned under and the land planted to corn these insects will attack the corn, and as there are relatively few plants to the number of insects which were feeding upon the grass, the injury will usually be serious. To avoid this, sod land should be planted in a small grain, buckwheat, potatoes, or some crop not affected by these pests. Similarly, the insects which affect cabbage usually feel on all the cole crops, and turnips, radishes, ete., following cabbage will be liable to injury by the same pests. Clovers, cowpeas, and other leguminous crops become of importance in rotation in this connection, as they are not usually attacked by the insects affecting other crops, and of course are widely used in every good rotation for the purpose of storing nitrogen in the soil through their root tubercles.

Time of Planting.-Planting crops so that they may avoid the greatest abundance of their worst insect enemies is often the best method for their protection. Late-sown wheat is usually exempt from the attack of the Hessian-fly (see page 119) and late-planted corn is much less affected by the stalk-borer (see page 82) than that planted earlier. On the other hand early planting of early-maturing varieties often enables the crop to mature before its pests become most abundant. Thus early planting and early varieties are of the greatest importance in preventing injury by the cotton boll weevil, the cotton bollworm and corn ear-worm, and early varicties of peas escape the injury of the pea aphis.

IVeeds.-Many insects feed upon some common weed in one stage while in another stage they are injurious to a cultivated crop. Thus the flea-beetles feed upon the roots of solanaceous weeds during the larval stage, while the ardults attack all sorts of garden crops. In many cases caterpillars, such as the salt marsh caterpillar, army worms, the white-lined sphinx moth, and grasshoppers multiply upon weeds growing in neglected fields until they overfiow and destroy crops. Many insects feed on weeds during the early part of the season or after the crop which they injure is harvested, so that the destruction of these weeds may often considerably shorten their breeding season or increase their mortality. Thus the corn root-aphis lives on the roots 

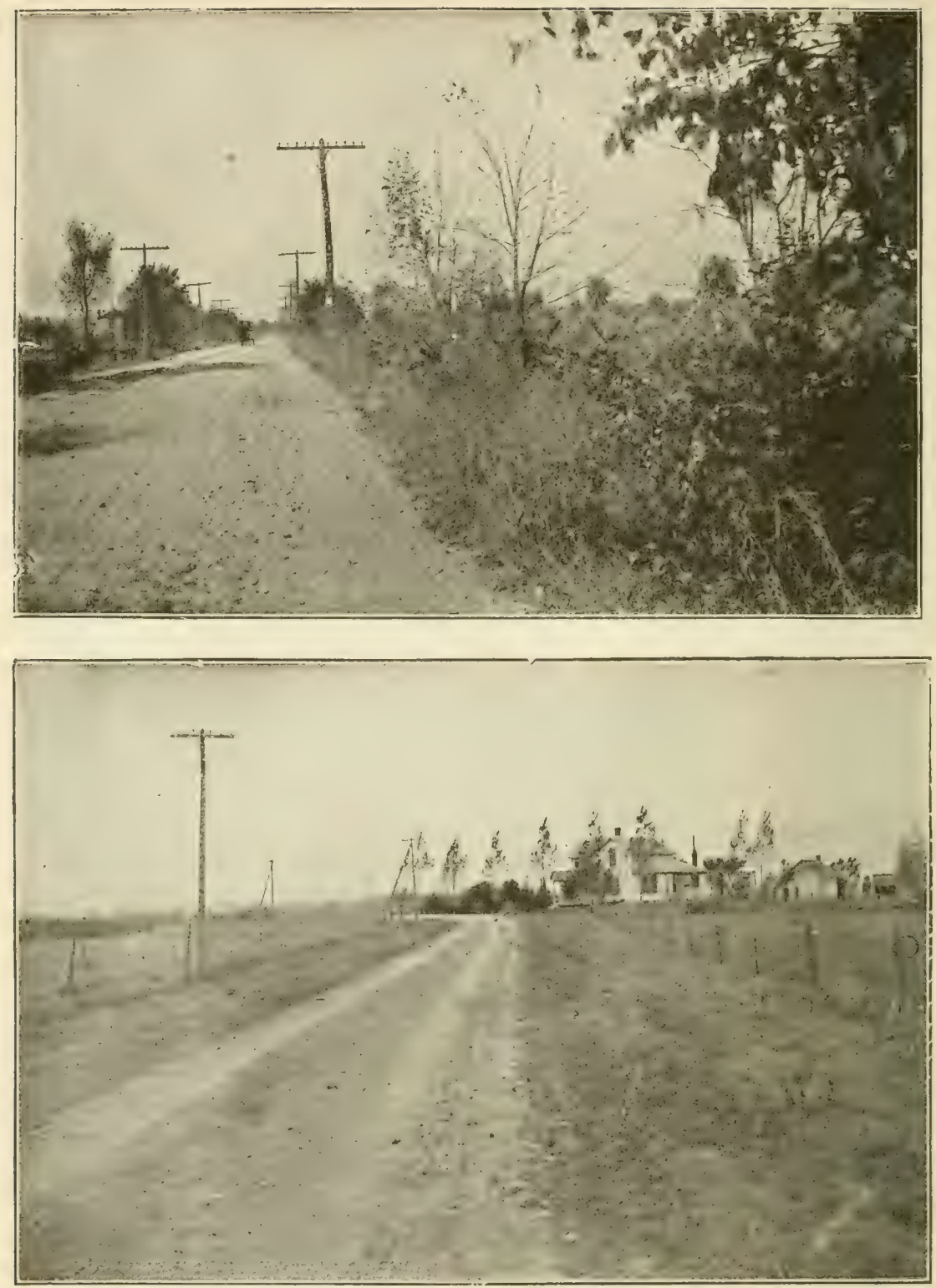

Fig. 24.- Above, a poorly kept roadside with rail fence overgrown with brambles, thus affording protection for large numbers of destructive insects during winter. Below, a well kept roadside, offering the least protection possible for destructive insects. (After Webster, U. S. Dept. Agr.). 
of smartweed and other weeds and grasses until corn is available, and cutworms feed on whatever vegetation is found before a crop is planted. In this connection "volunteer" plants should be classed as weeds, as they frequent!y furnish food for insects in the same way. Thus the cotton boll weevil feeds on volunteer cotton in early spring and the Hessian-fly on volunteer wheat in late summer and early fall. Such useless trees as wild cherry and seedling apple trees might also be considered as weeds, as they harbor many of the insect pests of our orchards and should be destroyed as far as possible.

Fertilization and Culture.-Although there is evidence that under some conditions, kainit, lime and nitrate of soda may have some direct effect on insects, it is probable that their chief importance is so to stimulate the plant that it will not be subject to insect attack or will grow in spite of some injury. It is well known that plants which have been weakened from any cause whatsoever are much more subject to the attacks of insects and diseases, and it is therefore obvious that plants which have had a vigorous growth and which will mature rapidly will much better withstand insect attack. Thorough preparation of the soil before planting, liberal fertilization, and thorough culture are most important in growing a crop in spite of its insect enemies. In many cases liberal fertilization and culture will mature a good crop where under poorer care it would have succumbed to insect injury. In general, land covered with barnyard manure presents more favorable conditions for the hibernation of insects than that fertilized with mineral fertilizers, but unless this is very appreciably the case, the manure will usually be preferred when it is available.

Clean Farming.-After a crop has been harvested there is usually some portion of the plant which is allowed to remain on the land. In this refuse the insects peculiar to the crop often feed and multiply until killing frost and then hibernate over winter, ensuring injury to similar crops on the same land the next year. The wheat jointworm and the corn stalk-borer both winter in the stubble of those crops, and the chinch-bug commonly hibernates in the butts of corn stalks. All of these may be largely controlled by buming the stubble. Possibly the most important means of control of the cotton boll weevil is the destruction of the stalks in the fall as soon as the cotton 
can be picked, thus preventing the weevils feeding and starving them out before they are ready to hibernate, and removing the shelter for hibernation. For this reason all the remnants of a crop such as stubhle, vines, leaves, or stumps, as may be, should be removed from the field as soon after it is harvested as possible. Many insects hibernate in such rubbish and this fact may sometimes be utilized by thoroughly cleaning a ficld and leaving one or two piles of rubbish in which many of the insects will assemble

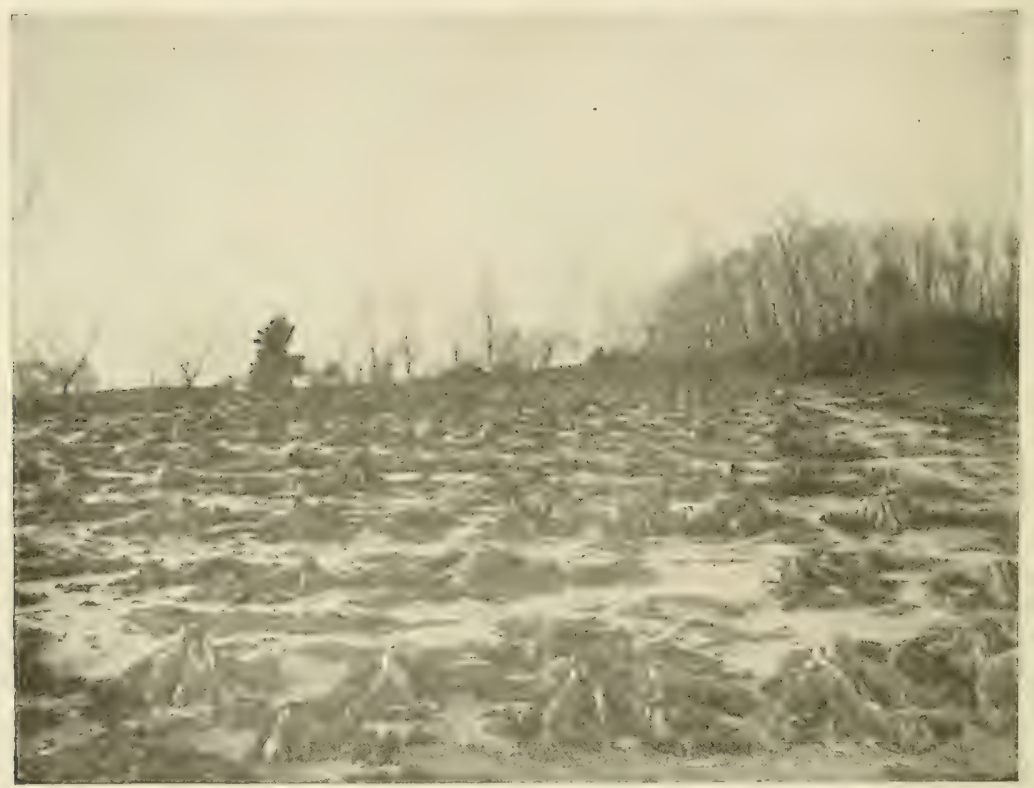

FIG. 25.-A field of cabbage stumps in midwinter, affording ideal conditions for the hibernation of cabbage pests.

for hibernation, and which may then be burned or otherwise destroyed. Many cabbage insects hibernate under the old stumps and leaves and will congregate in piles of them. Premises upon which the fence rows are kept free from weeds and grass and the fields are cleaned up and plowed as soon as possible after a crop is removed, usually suffer much less from insect pests than those of more easy-going neighbors.

Burming.-Cleaning up of stubble and of wild vegetation which furnishes food and shelter for insects may often be accom- 
plished by burning. The burning over of grass land aids greatly in the control of army worms, chinch-bugs, grasshoppers and plant-lice, while the burning of the stubble will largely control the wheat jointworm. Strawberry beds are sometimes burned over in early spring to destroy the eggs of the root-louse, and aphids on small grains may sometimes be killed out on small areas by covering with straw and burning while the plants are small.

Plowing.-Deep plowing and thorough harrowing are the most effective means of ridding the soil of many pests of staple crops.

Late Fall Plowing.-Where the succession of crops permits, plowing in the late fall is most advantageous, as it destroys the insects while hibernating, although for some insects early fall plowing and thorough harrowing during the fall are preferable. Where plowing is not possible, thorough disking is often used for the same purpose, as on alfalfa. As different insects pass the winter in different stages this method does not affect all alike. Some will be destroyed by having the cells into which they have gone to pass the winter broken up, and being unable to construct new cells they will be subjected to undue freezing and thawing and excessive moisture, and will thus be killed by the weather. Cutworms and the corn stalk-borer pass the winter in the soil as larvæ; the cotton bollworm or corn ear-worm hibernates in the pupal stage; while May beetles and click beetles hibernate as newly transformed beetles; hut all of them will be similarly affected by the breaking up of their winter cells, which is the most effective manner of combating them.

Other insects lay their eggs in the ground in the fall and these may be buried too deep for the young to emerge, or larvæ or pupæ which normally remain near the surface may be turned under so decply as to destroy them. Thus grasshopper egges are laid in the fall just beneath the surface, and by plowing in late fall or early spring they may be turned under so that but few are able to emerge, which is the best means of combating them. The apple maggot hibernates in the pupal stage just beneath the surface of the soil, and by deep plowing in early spring the puparia may be buried too deeply for the flies to emerge.

Young grasshoppers are often destroyed after they hatch by plowing deep furrows, starting at the outside of the field and plow- 
ing in a square, thus forcing them to the centre and catching large numbers of them in the furrows.

Early plowing and thorough harrowing in the spring are of value against cutworms by keeping the ground fallow and thus starving them out before a crop is planter. The same method may be used against other pests with similar habits.

Thorough cultivation in the summer has been found to be of value against many insects, affecting them differently according to their habits. Many which pupate in the soil during the summer are destroyed while making their pupal cells, or these cells are broken and they are subjected to abnormal moisture and temperature conditions and are thus killed. This has been shown to be the case with the cotton bollworm or corn ear-worm, and is true of the plum curculio, against which thorough cultivation has proved to be one of the most effective means of control in apple orchards. Thorough cultivation is also of importance in breaking up the nests of ants which care for such aphids as the corn rootaphis. Summer fallowing is used to starve out some pests; for example, the clover root-borer may be eradicated by plowing up infested clover immediately after it is cut and exposing the roots to the sun and wind which will soon dry them out and thus destroy the food of the larvæ.

Trap Crops.--Trap crops are those which are planted as a bait or lure to attract the early insects so that they may be destroyed upon them before the crop to be protected is available. Doubtless the reason that trap crops are not more frequently used by the farmer is because their successful use requires more or less of a knowledge of the life history and habits of the pest to be fought. But that is easily acquired and will make the fight against them more interesting and successful.

South of Mason and Dixon's line the harlequin cabbage bug frequently becomes the most serious pest of cabbage and related plants. When a cabbage patch has become well infested it is an exceedingly difficult matter to prevent injury, for the adult bugs cannot be killed by insecticides which will not injure the plant. If, however, a crop of kale be planted the previous fall the bugs which hibernate over winter will attack it in the spring, and may then be killed by spraying them with pure kerosene, and the danger to the cabbage crop be thus largely averted. 
A few rows of wheat are often planted early in the fall as a trap for the Hessian-fly, and as soon as the engs are deposited they are piowed under deeply and the later planting thus at least partly protected.

One of the most successful examples of averting injury by a trap crop is the use of corn to lure the cotton bollworm and thus prevent its injury to cotton. Corn is the favorite food plant of this pest, which prefers to deposit its eggs on the silk and tassels. By planting a few strips of late-maturing corn through the cotton field, they will come into silk about the time the brood of moths which normally deposit their eggs on cotton are flying and they will lay them on the com in preferenee, which should then be cut and fed to stock. In this way by planting strips composed of several rows planted at sucecssive dates, the cotton may be almost entirely protected. Possibly a morlification of this method may be applied for the protection of tomatoes or tobacco, though these crops have never been thus protected from this insect to our knowledge.

Radishes are sometimes used as a trap crop for the root-maggots which affect the ronts of eabbages and onions. The same principle is sometimes used in combating forest insects by girdling a tree upon which certain kinds of forest pests will concentrate, and then burning the tree.

These examples will suffice to show that very many of the most important insect pests may be largely controlled by simply adapting the general methods of farm management so as to avoid or prevent iniury by them. They indicate the importance of a knowledge of the life history of any inseet which is to be combated, knowing which, some of the above or similar methods will often suggest themselves as applicable. Such a control of insect life through the practical use of natural agencies epitomizes the scientific method in the art of agriculture; i. c., the most practical and effective and yet simple methods based upon exact knowledge.*

The Use of Light-Traps.-The destruction of insects by attracting them to lights at night has always attracted attention. Many such devices have been tried and several are now on the

* See F. M. Webster, Farm Practice in the Control of Field Crop Insects, Yearbook U. S. Dept. Agr., 1905, p. 465, and Some Things that the Grower of Cereal and Forage Crops Should Know about Insects, Yearbook U. S. Dept. Agr., 1908, page 367. 
market. Unfortunately, many of the most destructive insects are not attracted to lights. The codling moth and corn earworm, for instance, are rarely seen at the lights. In some cases where injurious forms are flying to the lights freely, for instance, when June-beetles are particularly abundant, they may be trapped by this method with some resulting benefit. As a rule, however, not enough individuals will be killed to make any noticeable difference in the injury to the crops attacked and while some injurious forms are being killed many beneficial ones will also be destroyed. The method is not, therefore, commonly recommended as a practical means for insect control.

Mechanical Means for the Collection of Insects. - Some benefit is realized from the collection of insects by mechanical means. Of these the most simple is hand-picking. This is practical on a small scale and is used for the control of tomato and tobaceo horn-worms and many other insects, being used even for the control of the Colorado potato beetle in small fields. Grasshoppers are collected by the use of hopperdozers as described in the discussion of those insects. Leafhoppers are collected sometimes with machines of similar construction but adapted for use with row crops. Leafhoppers and flea-beetles are collected with some success by the use of shields covered with sticky material and carried along the rows of plants attached in such position that insects disturbed will be caught on the sticky material when they hop or fly from the plants. Flies are trapped in large numbers and trapping is one of the best means of control for these insects. Mechanical means of collecting and killing insects are generally less satisfactory than the use of sprays when the latter are available for the control of the insects but serve a useful purpose for some forms which can not readily be controlled by spraying. 


\section{CHAPTER V}

\section{INSECTICIDES}

MAterials used for the destruction of insects are commonly called insecticides, and are roughly divisible into four classes:

1. Poisons, which kill by being eaten and are usually composed of various forms of arsenic and are therefore often called arsenicals. They are frequently called the stomach poisons.

2. Contact insecticides, which kill by either clogging up the spiracles, the openings of the respiratory system, or by entering the trachea, and thus causing suffocation, or by their corrosive action on the skin.

3. Repellants, which deter the insect from attacking the plant or animal to which they are applied.

4. Gases, which are used for fumigating buildings, stored products and greenhouses where other means are not practicable.

\section{Poisons}

Poisons are applied to the food of the insect and must be eaten by it to be effective. It is evident, therefore, that they are only effective against biting (mandibulate) insects, or for those which lap up their food from the surface, and that they are of no avail against the true sucking insects, such as the true bugs, which suck the juices from beneath tise surface of the plant. Poisons are not always, however, the most effective means of combating biting insects, which are sometimes more effectively controlled by contact insecticides or other means.

Nearly all of the stomach poisons are derivatives of arsenic and are therefore termed arsenicals. As they are dangerous to human life they should be kept well labeled, locked up when not in use, and vessels in which they have been used should be carefully cleaned.

1. Paris green is a green crystalline powder composed of the aceto-arsenite of copper. When properly made it should contain 
at least 50 per cent arsenic oxid $\left(\mathrm{As}_{2} \mathrm{O}_{3}\right)$, and there should be as little water-soluble arsenic as possible, for the water-soluble arsenic is the cause of the burning of foliage which often results from the use of Paris green. Various state laws require that there be not over $3 \frac{1}{2}$ per cent soluble arsenic, but even this amount is often injurious to tender foliage. Paris green is a rather coarse powder and settles readily in water, and is readily washed off by drenching rains. It costs from 35 to 50 cents per pound. It is usually used at a rate of from 3 to 8 ounces to a 50 -gallon barrel of water; 5 ounces per barrel is satisfactory for most purposes. In mixing, first stir up in a small vessel with a little water into a paste, which will mix more readily. Add an equal weight of quicklime, or slightly more will do no harm, which will take up any soluble arsenic.

2. London purple is a waste product in the manufacture of aniline dyes, and is principally arsenic and lime. It is quite variable in composition and usually contains a much higher, and quite variable, amount of soluble arsenic, so that it is apt to scald the foliage unless thoroughly mixed with fresh stone lime. For this reason it is now used only for rough work, such as poisoning grasshoppers, making poisoned bran mash, etc., and is not to be recommended for general use on fruit trees and garden crops. It usually costs 10 or 12 cents a pound, and is used in the same proportions and in the same way as Paris green.

3. Arsenate of lead is sold in the form of a white paste containing about 50 per cent water and also as a dry white powder. Standards of purity for this material require that the paste contain not more than 50 per cent water and not more than $\frac{3}{4}$ per cent water-soluble arsenic oxide, while there must be not less than $12_{2}^{1}$ per cent total arsenic oxide. The dry powder will lack the water and contain a correspondingly larger percentage of other ingredients. Since this material contains a relatively small amount of soluble arsenic it may he used at a greater strength than the other arsenicals without injuring foliage of plants which are susceptible to injury from the other arsenicals. From one to eight pounds, paste form, are used to the 50 gallon barrel of water, 2 or 3 pounds being most commonly recommended for the majority of the pests of orchard and garden. Arsenate of lead remains in suspension well, much better than Paris green, and is very ad- 
hesive, remaining on foliage for several weeks. It is made from arsenate of soda and acetate of lead and may readily be prepared by the user. This is not recommended on account of the variability in the purity of the constituent chemicals and the inconsiderable saving effected by the home preparation.

Commercial arsenate of lead may be purchased at prices ranging from 10 to 30 cents per pound for the paste and from 25 to 50 cents for the powder.

Powdered arsenate of lead was prepared first rather for use as a dust than for spraying purposes. Perfection of the process of manufacture of the dust has given a product that is as cheap and in every way as satisfactory as the paste. For this reason users are more and more coming to prefer the powder. It mixes more readily with water, remains in suspension just as well and, being of only one-half the weight of the paste, effects a considerable saving in transportation.

The powder also eliminates one source of loss to which the paste is liable, that is, drying out. Paste arsenate of lead that has dried is practically wasted as it is almost impossible to get it thoroughly mixed with water. The dust will keep indefinitely if it is stored in a dry place. Arsenate of lead in the dry form is the only arsenical used to any extent in orchard dusting.

It is well for the student to remember that spraying formulas calling for arsenate of lead usually mean the arsenate in paste form if the powder is not definitely specified. This is because the paste was first used and formulas were established on that basis.

Arsenate of lead is the most valuable and widely used of all the insecticides used as stomach poisons, having long since displaced Paris green which was formerly the leading arsenical.

4. Arsenite of lead is a compound very similar to the arsenate but less effective and contains more soluble arsenic and so is more likely to burn foliage. It is made from sodium arsenite and a lead compound but is rarely used and not to be recommended.

5. A rsenite of lime is a home-made arsenical, very much cheaper than those previously mentioned, which gives very satisfactory results for certain purposes. It is not as adhesive as arienate of lead, and as it sometimes burns foliage has been largely discarded for orchard spraying. It is, however, very satisfactory for potatoes and other low-growing crops, especially when added 
to bordeaux mixture, which sticks it to the foliage, and it may be used to good advantage for fighting grasshoppers and leaf-eating caterpillars when it is desired to poison considerable areas of weeds or waste grass. The so-called Kedzie formula (See Sodium arsenite below) is the most satisfactory, as the soda hastens the complete combination of the arsenic, and the resulting solution is in a clear liquid form which can be readily measured.*

6. Arsenate of calcium, sometimes called arsenate of lime, is an insecticide of more recent application and is perhaps the best substitute for arsenate of learl. It has several points in its favor over the lead compound, being cheaper under normal conditions, and possessing greater killing power, pound for pound, since a pound of the calcium arsenate has a greater percentage of arsenic than toes a pound of lead arsenate. It is somewhat more liable to scorch foliage than is the lead arsenate and it is recommended that it be always used with some stone lime added. It is not a safe material, according to latest reports, to use on peach foliage. Calcium arsenate is marketed as a paste and also in the dust form. It has been used as a substitute for lead arsenate in dusting work It may be prepared at home but the same objections are to be raised as against the home manufacture of lead arsenate. The formula and directions follow:

Stone lime, best grade................ 2 lbs.

Sodium arsenate, fused $\left(65 \% \mathrm{As}_{2} \mathrm{O}_{5}\right) \ldots \ldots \ldots 4 \mathrm{lbs}$.

Water........................ 1 gallon.

Dissolve the sodium arsenate in a little hot water. Place the stone lime in a wooden tub or bucket and add just enough water to start slaking. Then add the dissolved sorlium arsenate. Stir constantly and add small amounts of water from time to time until the slaking has ceased. Allow the solids to settle and pour off the clear licyuid above. The resulting paste is calcium arsenate and may be used at from one to three pounds per barrel of water. Impurities in the materials used may reduce the killing power of

* Arsenite of lime is often made by boiling 1 pound of lime with 2 pounds of white arsenic in 1 gallon of water for thirty to forty-five minutes. This results in a paste of arsenite of lime, which settles in the solution. One quart of this mixture is used per barrel of water or Bordeaux mixture, but unless the stock solution is always stirred equally well, the amount of poison in a quart will be quite variable, with varying effectiveness; hence the clear solution of arsenite of soda as in the Kedzie formula is preferable. 
the material or increase the danger of burning foliage so that it is generally wiser to use the commercial product.

7. Arsenite of zinc is another material which is occasionally used as a substitute for lead arsenate. It comes in the commercial form as a rather light powder. It has a tendency to burn foliage but has good killing qualities. It may be used, if conditions demand, with a fair degree of safety by combining it with bordeaux mixture or with lime. It should not be used at more than half the strength recommended for arsenate of lead.

8. White arsenic is the basis for all the stomach poisons, at least indirectly. It is cheap and a violent poison to insects but on account of its complete solubility is not available as a spray material. It is of value for use in poisoned baits and as a basis for the preparation of other materials.

9. Sodium arsenite is a cheap and effective insecticide, available for some uses. It is generally prepared by the user, the common Kedzie formula following:

White arsenic...................... $1 \mathrm{lb}$.

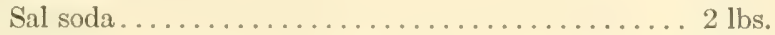

Water............................... 1 gal.

Mix the arsenic into a paste with a little water and dissolve the sal soda in the remaining water. Add the arsenic paste to the soda solution and boil until the arsenic is completely dissolved. Add water to make a full gallon and use at the rate of one quart to fifty gallons of bordeaux mixture, being careful to see that the bordeaux has an excess of lime. This material is not widely used although in some regions it is the favorite spray for potatoes.

10. Hellebore.-The powdered roots of the white hellebore are often used as an insecticicle in place of arsenicals, especially for currant worms, rose slugs, and similar saw-fly larva and for insects affecting crops soon to be eaten, as the hellebore is much less poisonous to man and animals than arsenicals. It may be applied dry, diluted with from 5 to 10 parts of flour, or as a spray, 1 ounce to a gallon of water. It is too expensive to use except for a few plants in the yard or garden, and like pyrethrum, deteriorates with age and if exposed to the air.

Harmlessness of Arsenicals when Properly Applied.-The question is frequently asked whether it is safe to apply arsenicals to vegetables and fruits to be used as food. Where sprayed or dusted 
as directed the amount of arsenic which would be deposited on the plant would not be sufficient to cause any injury, and Professor C. P. Gillette has shown that twenty-eight cabbages dusted in the ordinary way would have to be eaten at one meal in order to produce poisonous effects. Occasionally growers dust cabbage with an unreasonable amount of poison, and very rarely instances of poisoning are recorded, but there is no value in applying any more poison than is necessary to make a thin film over the surface, and more than that is wasted. Because a certain amount of poison will kill an insect does not indicate that a larger amount can kill it any "deader." Experiments have also shown that tobacco sprayed as recommended cannot possibly bear enough arsenic to he injurious, and that cattle or horses may be pastured under trees sprayed with arsenicals with impunity.*

\section{Contact Insecticides}

Contact insecticides are used against insects with sucking mouth-parts and soft-bodied biting insects which may be more readily clestroyed by this means than by arsenicals. These substances are fatal to the insect either by clogging the spiracles or trachea, and thus causing suffocation, or by corroding the skin. It should be remembered that the chitinous skin of most insects is not casily corroded, and that in most cases a material strong enough to penetrate the skin will also injure foliage, so that only soft-bodied insects can be combated with corrosive substances upon foliage.

In the application of contact insecticicles it is absolutely essential that the spray come into contact with the insect, as a mere spraying of the foliage is of no value whatever.

1. Kerosene emulsion is one of the oldest remedies for plantlice and other sucking and soft-bodied insects, and is often resorted to because it is readily made and the materials are always at hand.

Dissolve $\frac{1}{2}$ pound of hard or whale-oil soap (or 1 quart soft soap) in 1 gallon of boiling water. Add 2 gallons of kerosene and

* This is not true of grass beneath trees which have been sprayed with a straight-jet fire-hose, as is commonly done in Massachusetts in the extensive operations against the gypsy moth, but refers to spraying which has been done with an ordinary spray nozzle, which applies the material as a fine spray. 
churn with a force pump by pumping back and forth for five to ten minutes until the oil is thoroughly emulsified, forming a creamy mass with no drops of free oil visible. This stock solution is now diluted so that the resulting mixture will contain the desired per cent of kerosene. Thus for aphicls one part of the stock solution should be diluted with from 10 to 15 parts of water, giving from 4 to 6 per cent of kerosene in the spray, while for a winter wash for San José scale, it should be diluted only three or four times, giving from 16 to 22 per cent kerosene. The emulsion must be thoroughly churned and should he applied with a nozzle throwing a fine spray. Apply only enough to wet the insects. Equally effective emulsions may be made from crude petroleum, the proportion of the soap and crude oil in the stock emulsion varying with the quality of the oil. Emulsions made with some of the crude oils seem to be much less injurious to foliage of some plants than when made with kerosene. Such an emulsion is made in California from distillate oils and is known as distillate emulsion. We have used crude Texas oils with equal success.

2. Kerosene.-Pure kerosene should never be used on foliage, for though occasionally someone will report using it successfully without injury, in practically all cases serious burning of the foliage results. It was formerly recommended against the San José scale on fruit trees, but such serious injury resulted that it has been almost entirely discarded, though it may be used on apple and pear trees if applied with a nozzle which throws a fine spray, on a bright sunny day, and only a very thin film applied to the tree while it is dormant, but even these trees are often injured if the application is not made with the greatest care.

3. Crude Petroleum.-Crude petroleum is used in the same manner as kerosene against scale insects, but seems to be less injurious to the tree, and has been extensively used in New Jersey against the seale on peaches, where but little injury has resulted where it has been carefully applied. It contains more heary oils and consequently does not penetrate the bark so readily, and the light oils evaporating leave the heavy oils on the bark for some months, which aids in preventing young seales from getting a foothold. Crude oil for use as an insecticide should have a specific gravity of from $43^{\circ}$ to $45^{\circ}$ Beaumé seale, and is sold by certain Eastern conpanies as "insecticide oil." 
4. Miscible Oils.-During the last few years several manufacturers have placed on the market under various trade names what are now called miscible oils. These are petroleum rendered soluble by the addition of vegetable oils, eut or saponified with an alkali, and are really a sort of liquid petroleum soap which will combine readily with water. They have been used principally as winter washes against the San José scale, for which they are most effective when diluted 10 or 12 times. For a summer wash they have been used effectively against plant-lice and other insects for which kerosene emulsion would be used, diluted 25 to 30 times. In barrel lots the miscible oils sell at 40 to 50 cents per gallon, thus making the cost of a gallon of mixture for a winter application at 10 per cent, 4 or 5 cents per gallon.

5. Whale-oil and Other Soaps.-Any good soap is an effective insecticide for destroying aphides and young or soft-bodied larvæ. Any good laundry soap made into a thick solution one-half pound per gallon is an excellent remedy for such insects on houseplants. Whale-oil or fish-oil soap has been extensively used against scale insects and plant-lice. The best brands are made from caustic potash rather than caustic soda, and should contain not over 30 per cent of water, there being wide variation in the water content. For the pea aphis and other aphids 1 pound to 6 gallons of water has been found very effective. For a winter wash for the San José scale 2 pounds per gallon of water are applied while hot, the soap being dissolved in hot water. The soap can be hought for $3 \frac{1}{2}$ to 4 cents a pound in large quantities, thus making the treatment for scale cost from 7 to 8 cents a gallon.

6. Lime-sulfur Wash.-The lime-sulfur wash has long been the standard remedy for the San José scale on the Pacific Coast, and during the last 15 years his come into wide use in the East for the same pest. It has also been found to be an efficient remedy for the pear leaf blister-mite and the oyster-shell barklouse. In addition to its insecticidal properties it is an excellent. fungicide, and the spring applications just before the buds start are very effective in killing out the wintering spores of various fungous discases, while the diluted wash is being used as a summer spray for fungous diseases in place of bordeaux mixture. 
The usual formula is, unslaked stone lime, 20 pounds; flowers (or flour) of sulfur, 15 pounds, water to make 50 gallons. Stir up enough water with the sulfur to make a thick paste. Slake the lime in the vessel in which it is to be cooked with a small quantity of hot water. Then add the sulfur paste to the slaking lime. Add 10 or 15 gallons of water and boil for forty-five minutes. The mixture may then be diluted to make a barrel of 45 or 50 gallons, straining it carefully into the spray barrel or tank. A large iron kettle or hog-sealder may be used for boiling the wash, or where stean can be made available a steam pipe may be run into several barrels and the wash boiled in them. Such barrels may well be placed upon a platform so that the wash may be drawn from them directly into the spray-tank. The materials for making the wash will cost $1 \frac{1}{3}$ to $1_{2}^{1}$ cents per gallon and the labor practically as much more. The learling manufacturers and dealers in insecticides are now selling concentrated lime-sulfur solution which is all ready for use by merely diluting to the desired strength, at a rate which will make the solution to be used cost from $2 \frac{1}{2}$ to 3 cents per gallon, nearly as cheap as it can be made at home and ${ }^{*}$ with the saving of time and a disagreeable job. In some communities a central plant makes the wash and can sell it with a fair profit at a low rate.

7. Home-made Concentrated Lime-sulfur.-During the last few seasons many large growers have been making their own concentrated lime-sulfur solution, and where the quantity to be used warrants, a considerable saving may be effected. The New York Agricultural Experiment Station has made very careful studies* of the best methods of making and diluting the mixture from which the following is quoted:

Geneva Station Formula for Concentrated Lime-sulfur Solution.

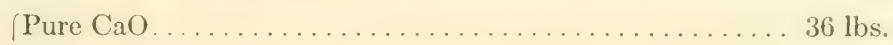

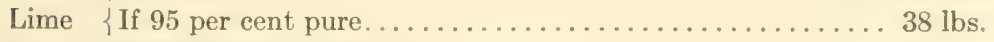

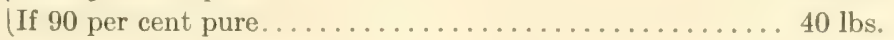

Sulfur, high grade, finely divided................. $80 \mathrm{lbs}$.

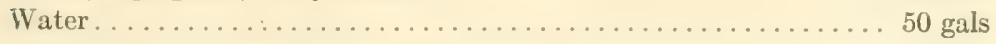

*Bulletins 329 and 330 N. Y. (Geneva) Agricultural Experiment Station 
Dilutions for Dormant and Summer Spraying with Lime-sulphor Mixtures.

\begin{tabular}{|c|c|c|c|}
\hline \multirow{2}{*}{$\begin{array}{l}\text { Reading on } \\
\text { hydrometer. }\end{array}$} & \multicolumn{3}{|c|}{$\begin{array}{l}\text { Amount of Dilution. Number of Gallons of Water to One } \\
\text { Gallon of Lime-sulfur Solution. }\end{array}$} \\
\hline & For San Jose Scale. & For Blister-mite. & $\begin{array}{l}\text { For Summer Spray- } \\
\text { ing of Apples. }\end{array}$ \\
\hline 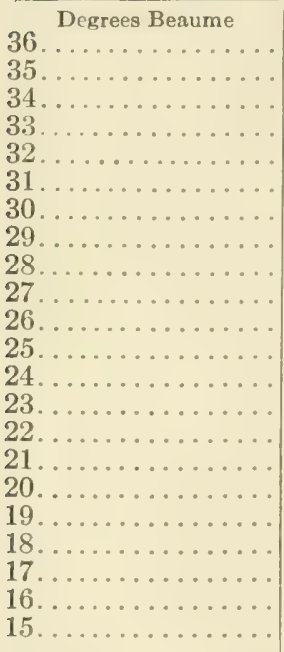 & $\begin{array}{l}9 \\
83 / 4 \\
81 / 4 \\
8 \\
71 / 2 \\
71 / 4 \\
63 / 4 \\
61 / 2 \\
6 \\
53 / 4 \\
51 / 4 \\
5 \\
41 / 2 \\
41 / 4 \\
33 / 4 \\
31 / 2 \\
31 / 4 \\
3 \\
23 / 4 \\
21 / 2 \\
21 / 4 \\
2\end{array}$ & $\begin{array}{l}121 / 2 \\
12 \\
11 \frac{1}{2} \\
11 \\
101 / 2 \\
10 \\
91 / 2 \\
9 \\
81 / 2 \\
8 \\
71 / 2 \\
7 \\
61 / 2 \\
6 \\
51 / 2 \\
5 \\
43 / 4 \\
41 / 4 \\
4 \\
33 / 4 \\
31 / 2 \\
3\end{array}$ & $\begin{array}{l}45 \\
431 / 4 \\
411 / 2 \\
40 \\
373 / 4 \\
361 / 4 \\
341 / 4 \\
323 / 4 \\
31 \\
291 / 2 \\
273 / 4 \\
26 \\
241 / 4 \\
223 / 4 \\
211 / 4 \\
193 / 4 \\
181 / 4 \\
17 \\
16 \\
15 \\
14 \\
123 / 4\end{array}$ \\
\hline
\end{tabular}

"In making, slake the lime in about 10 gallons of hot water, adding the lumps of lime gradually to avoid too violent boiling and spilling over. . . . The sulfur must be thoroughly moistened and made into an even, fluid paste without lumps (before adding to the lime). . . . Pour in the sulfur paste grcdually during the slaking, stirring constantly to prevent the formation of lumps, and when the slaking has finished add the full amount of water and boil gently for one hour. If kettles and fire are used, more than the required amount of water may be used at first, to compensate for evaporation, or the volume may be kept constant by adding successive small quantities to hold the mixture at the original level, as shown by a notch on a stick resting on the bottom of the kettle, and marked when the mixture first begins to boil. When boiling with live steam the mixture will be more likely to increase in volume than to decrease, so that no water need be added. 
"This concentrate will keep with little change, unless the weather is below $5^{\circ} \mathrm{F}$., if stored in filled, stoppered barrels. Even in open receptacles there will be no loss if the surface be covered by a layer of oil to prevent access of air. Each boiling should be tested with a Beaumé hydrometer* and its density marked on the barrels or other containers."

The dilution is based upon the specific gravity as shown by the hydrometer and may be safely made according to the outline in the above table.

In making this mixture it is important that only high-grade, pure lime should be used, and lime with less than 90 per cent calcium oxid $(\mathrm{CaO})$ should be discarded.

8. Self-boiled Lime-sulfur.--Self-boiled lime-sulfur has proven to be the only safe fungicide for the foliage diseases of the peach and stone fruits, and is used extensively as a summer spray on pome fruits. As a winter wash for San José scale it has not proven effective, but when used as a summer spray for fungous diseases it has some considerable insecticidal value. This mixture has been developed chiefly by the work of Mr. W. M. Scott formerly of the United States Department of Agriculture, from whose latest bulletin $t$ the following is quoted:

"In order to secure the best action from the lime, the mixture should be prepared in rather large quantities, at least enough for 200 gallons of spray, using 32 pounds of lime and 32 pounds of sulfur. The lime should be placed in a barrel and enough water (ahout 6 gallons) poured on to almost cover it. As soon as the lime begins to slake the sulfur should be added, after first running it through a sieve to break up the lumps, if any are present. The mixture should be constantly stirred and more water (3 or 4 gallons) added as needed to form at first a thick paste and then gradually a thin paste. The lime will supply enough heat to boil the mixture several minutes. As soon as it is well slaked water should be added to cool the mixture and prevent further cooking. It is then ready to be strained into the spray tank, diluted, and applied.

"The stage at which cold water should be poured on to stop

* These hydrometers, made specially for testing lime-sulfur mixture, may be obtained from the Bausch \& Lomb Optical Co., Rochester, N. Y., and other dealers in laboratory glassware.

† Farmers' Bulletin, 440, U. S. Dept. of Agr., p. 34. 
the cooking varies with different limes. Some limes are so sluggish in slaking that it is difficult to obtain enough heat from them to cook the mixture at all, while other limes become intensely hot on slaking, and care must be taken not to allow the boiling to proceed too far. If the mixture is allowed to remain hot for fifteen or twenty minutes after the slaking is completed, the sulfur gradually goes into solution, combining with the lime to form sulficles, which are injurious to peach foliage. It is therefore very important, especially with hot lime, to cool the mixture quickly by adding a few buckets of water as soon as the lumps of lime have slaked down. The intense heat, violent boiling, and constant stirring result in a uniform mixture of finely divided sulfur and lime, with only a very small percentage of the sulfur in solution. It should be strained to take out the coarse particles of lime, but the sulfur should be carefully worked through the strainer."

Its most important use is as a carrier for the arsenical, usually arsenate of lead, used in spraying peach trees and other plants with tender foliage.

9. Sulfur--Pure sulfur is one of the best remedies for red spider, on whatever plants it may occur, and for other mites which infest citrus fruits. It may be dusted on the infested plants or trees or applied with any other insecticide, using 1 or 2 pounds to 50 gallons. For citrus-mites the lye-sulfur wash and sulficle of line are extensively used. Sulfur is frequently dusted in poultry houses to rid them of lice, and may be mixed with lard and rubbed on the skin of domestic animals affected with lice.

10. Pyrethrum, buhach, or Persian insect powder, is made by pulverizing the petals of the pyrethrum blossom, and kills insects by clogging their lreathing pores. It is not poisonous to man or domestic animals and may therefore be used where other insecticides would be objectionable. It is chiefly used for household pests, and in greenhouses and small gardens. It deteriorates rapidly with age and should be kept in tight eans. An objection to much commonly bought is that it has been kept in stock too long by the retailer, thus losing its strength. Large users buy direct from the only American manufacturers, the Buhach Producing Co., Stockton, Cal. It may be used as a dry powder, pure or diluted with flour, or in water at the rate of 1 ounce to 2 
gallons, which should stand a day before using. For immediate use it should be boiled in water for five or ten minutes. It is frequently burnt in rooms to destroy mosquitoes and flies, for which it is effective, without leaving any odor after the room is aired.*

11. Tobacco.-A tobacco decoction may be made by boiling or steeping tobacco leaves, stems, and refuse in water at the rate of 1 pound to 1 or 2 gallons. This may be diluted slightly according to the strength of the tobaceo and the insect to be combated. Such a decoction is an excellent remedy for dipping plants affected with aphids, and may be used as a spray for plant--lice and similar soft-bodied insects. Various extracts and solutions of tobacco are now sold by manufacturers which are extensively used in spraying against plant-lice, and which are proving more satisfactory on account of their uniform strength. Tobacco dust has been used successfully against root-infesting aphids by removing the surface soil and applying a liberal dressing of the dust and then covering. The rains leaching through the tobacco carry the tobacco water to the affected roots and destroy or repel the aphids.

12. Commercial Tobacco Products are much more widely used than home-made forms for the reason that they are uniform in their strength and therefore more dependable in their action. Practically all the commercial tobacco extracts are produced by one company, the Kentucky Tobacco Products Co., of Louisville, $\mathrm{Ky}$. The most widely used of their products is called "BlackLeaf 40 " and is generally recommended as the most satisfactory remedy for soft-bodied sucking insects which require treatment during the growing season of the plant. "Nicofume," another of their products, differs from the "Black-Leaf 40 " in that it contains nicotine in volatile form and is therefore useful as a fumigant as well as for spraying. Its greatest value is in the greenhouse. It will be found satisfactory usually to use these materials a little stronger than is recommended by the company, otherwise the directions accompanying the material will apply.

13. Soaps of many kinds are efficient insecticides. They are used as a substitute for lierosene cmulsion and tobacco extracts to combat aphids and other insects, especially on house plants and in greenhouses. Various soaps are especially prepared to be used

* See Farmers' Bulletin, 444, U. S. Dept. Agr., p. 7. 
as insecticides and many of these have value. Whale-oil or fishoil soap is more widely used as an insecticide than other kinds. It may be prepared at home, using about twenty pounds of the oil, which should be saponified by stirring into it a solution of 5 to 6 pounds caustic soda in a half-gallon of water. These soaps may be found on the market, ready for use and in normal times are fairly cheap. They are widely used in nurseries to keep young trees free from scale and aphids.

14. Carbolic acid emulsion is used for various purposes. It is valuable to kill aphids and soft-bodied scale-insects and is used also for insects which attack the roots of some garden crops. It is made from whale-oil soap, $40 \mathrm{lbs}$., dissolved in 40 gallons of water and boiled for twenty minutes with 5 gallons crude carbolic acid. This product is diluted at the rate of one gallon to 15 or 20 gallons of water for use.

\section{Repellants}

Repellants include any substance which may be applied to a plant or animal to prevent insect attack. A popular notion that any vile-smelling substance will repel insect attack seems to have very little evidence in its support. Tobacco dust, air-slaked lime, or even fine road dust, thoroughly covering a plant will prevent the attack of various flea-beetles and leaf-eating beetles, but to be successful the plants must be frequently dusted and kept well covered. Bordeaux mixture, our most widely used fungicide, when liberally sprayed on potatoes and tomatoes, acts as a repellant to the little black flea-beetles which often seriously damage the young plants.

The various fly-sprays which are used for spraying cattle to prevent the annoyance of flies act merely as repellants.

Fruit-trees are often painted with a thick soap solution containing 1 pint of crude carbolic acid to 10 gallons as a repellant for the adult borers which lay their eggs on the bark.

A substance which has come into prominence in the fight against the gypsy moth in New England is tree tanglefoot, a sticky substance the same as is used to coat fly-papers. This comes in the form of a very sticky paste, a band of which is placed around the trunk of the tree and which prevents the ascent of caterpillars, as 
it will remain sticky for some weeks. It may be used in the same way to prevent the wingless female canker worms and other wingless insects from ascending trees, or to prevent the ascent of caterpillars on unaffected trees.

Various proprietary insecticides are frequently offered for sale with wonderful claims for their effect as repellants, but only in rare cases are they of any value except for use as a dust as already suggested. One of the most common fakes of this sort is that of the itinerant tree-doctor who offers to bore a hole in a tree and plug it with sulfur or other offensive compounds, which will effectively prevent any insect or fungous depredations. A generous price per tree is charged, which is the only " effect" of the treatment.

Bordeaux mixture is not, generally speaking, an insecticide but it does have a repelling aetion on some insects, notably the flea-beetles which attack potatoes and tomatoes. It is the most widely used fungicide and it or lime sulfur " summer strength" will practically always be included in the spray applied for insects, so it is well for all interested in spraying to be familiar with bordeaux. It is prepared by mixing a solution containing three to five pounds copper sulphate (bluestone), with a mixture of four to six pounds lime. These may be in from 5 to 25 gallons of water and should be mixed by pouring both at the same time into a third container, usually the spray tank or barrel. The total liquid from the above amounts should be 50 gallons.

Asphalt paint and even asphaltum are applied to trunks and branches of trees to keep out borers. Heating is generally required and the application is somewhat difficult but good results have been obtained.

\section{Gases}

Carbon Bisulfid (or disulfid) is extensively used against insects affecting stored goods and grains, and for root-feeding insects. It is a clear, volatile liquid giving off fumes heavier than air. It may be thrown directly onto grain without injury to it or placed in shallow dishes. For grain in store in fairly tight rooms apply one pound to every 100 bushels, distributing the bisulfid over the surface or in pans containing not over one-half to 1 pound each. Make the enclosure as tight as possible, covering the grain with blankets or other tight cover, if necessary, and leave for twenty- 
four hours. Recent experiments have shown that the vapor is much less effective at low temperatures and that the dosage must be greatly increased at temperatures below $60^{\circ} \mathrm{F}$. For fumigating buildings "there should be about 1 square foot of evaporating surface to every 25 square feet of floor area, and each square foot of evaporating surface should receive from one-half to 1 pound of liquid." For fumigating clothing or household goods, place them in a tight trunk and place an ounce of liquid in a saucer just under the cover. The gas is exceedingly explosive; allow no fire or light of any kind around the building or enclosure until it has been well aired. The fumes should not be inhaled, for though not seriously poisonous, they have a suffocating effect and will soon produce dizziness and a consequent headache. The treatment for root-maggots and root-feeding aphides is discussed in connection with those insects (pages 317 and 435).*

Hydrocyanic Acid Gas is extensively used for the fumigation of nursery trees and plants, certain greenhouse insects, pests of dwelling houses, storehouses, mills, etc. It is made by combining cyanide of potassium or sodium, sulphuric acid and water. The gas is slightly lighter than air and is one of the most deadly poisons known. It should be used only under competent direction and by persons thoroughly capable of understanding the directions and carrying them out. Under such circumstances the danger is negligible. Brief directions follow but these should be supplemented by first-hand advice which considers the local factors.

Take for each 100 cubic feet of space one ounce of the cyanide, one ounce of the acid and three ounces of water. Provide stone jars which will not be filled more than one-third full by the quantity of materials to be used. Use one or more for each room, according to the size of the room. Weigh out the cyanide and place the amount for each jar in a paper bag beside the jar. Pour the water into the jar and then add the acid, stirring gently at the time. Arrange the material in this manner for all the rooms. The building should previously have been made as nearly airtight as possible. An exit on the ground floor should have been provided and arranged so that it can be quickly closed and pro-

* For a complete discussion of the use of this gas, see Farmers' Bulletin, 145, U. S. Dept. Agri., and see page 184 below.

Carbon tetrachloride is now used for some purposes in much the same manner as carbon bisulphide, and is not so explosive. 
vision for opening some doors or windows on each floor from the outside should have been made.

Needless to say, the building can not be entered during the fumigation. When all is in readiness the operator or operators should start on the upper floor, in the rooms farthest removed from the stairway and drop the hags of cyanide quickly into the jars of liquid, go quickly to the next floor below and repeat the operation and so on to the ground floor and from there outside, closing and locking the last door. The building should be locked and placarded and it is well to have a watchman to warn people from the vicinity. After 12 to 24 hours the windows and doors should be opened from the outside and the building allowed to air for one to three hours when it will be safe to enter. Inside doors should be left open. A thick newspaper should be placed under each jar to protect the floor from splashing of the liquid which may occur during the generation of the gas, which may be violent. The cyanide used must be 98 to 99 per cent pure and the acid of specific gravity 1.83, commercial. This treatment will kill all stages of insects, also rats and mice but will not injure the contents of the house in any way excepting that moist fools should not be exposed to the gas. Let us repeat, however, that the gas is ONE OF THE MOST VIOLENT POISONS KNOWN.

Cyanide funigation is extensively used on the Pacific Coast for the control of insects on fruit trees, these being fumigated under specially constructed tents. Dosage tables and other information concerning this practice should be secured through the California Experiment Station at Berkeley where Dr. C. IV. Woodworth has largely perfected the methods used.

Sulfur Dioxid.-The fumes of burning sulfur, mostly sulfur dioxid, have long been recognized as a standard remedy for the fumigation of dwellings and barracks for insect pests. Suceessful fumigation for the bedbug has been reported when stick sulfur has been burned at the rate of 2 pounds per 1000 cubic feet of space. The chief oljection is the strong bleaching effect of the fumes in presence of moisture and their destructive action on vegetation. Recently this gas has been extensively used under the name of "Clayton gas," for the fumigation of ships and ships' cargoes, particularly grain. It is forced into the tight hold of a ship by special apparatus and is exceedingly penetrating and effective. The 
germinating power of seeds is quickly destroyed, but they are not injured for food. 1 to 5 per cent of the gas, with an exposure of twenty-four hours, is effective for most seed and grain pests. It cannot be used on vegetation or for moist fruits.

Tobacco Fumes.-Tobacco is extensively used as a fumigant for aphids in greenhouses and for certain plants, such as melons, by using it under covers. Several forms are now commonly used. Tobacco or nicotine extracts are sold under various trade names, and are volatilized by heating either with a small lamp or by dropping hot irons into the dishes containing the fluid. The same material may be purchased in the form of paper which has been saturated with the extract and which is burned according to directions, a certain amount being sufficient for so many cubic feet of space, which forms a more convenient method of application. Certain finely ground tobacco powders, called "fumigating-kind" tobacco powder, are used in the same way and are much the cheapest form of tobacco for fumigation, though requiring slightly more work in preparing for fumigation. These tobacco preparations are excellent for the fumigation of household plants, which may be placed in a closet and then fumigated according to the directions of the particular brand employed. Melon vines, young apple trees, bush fruits, and similar outdoor crops may be effectively rid of plant-lice by fumigating with tobacco-paper under a frame covered with canvas or muslin sized with glue or linseed oil.*

\section{Application of Insecticides}

Insecticides, especially stomach poisons and contact poisons, are usually applied in the form of a spray delivered under pressure by a force pump, the liquid being broken up into a fine mist by some kind of nozzle constructed for that purpose. As sprays they are, of course, always mixed with water according to proportions which will be mentioned at the proper places. In place of pure water, bordeaux mixture or dilute lime-sulphur is sometimes used and the spray then serves the double purpose of controlling insects and plant diseases. In some cases the fungicide,

*For further discussion of Insecticides see Farmers' Bulletin 127, U. S. Department of Agriculture. 
a stomach poison and a contact poison are all mixed together forming what might be called a " complete spray."

Arsenical poisons, and in a very few instances contact insecticides, are sometimes applied in the dry form as dusts, the process being called dusting or, less properly, dust-spraying. Truck crops may be dusted on a small scale without special machinery and the method is therefore often more convenient for the small gardener than spraying. Recent experiments have shown that dusts are as effective as sprays in controlling the insects which affect most orchard fruits and foliage. The method has not been generally adopted as yet for the reason that it is still doubtful whether dusts as at present used will entirely control the fungous diseases of the orchard. This in spite of the fact that dusting was first extensively used to control a fungus disease, the mildew of grapes. Dusting has many advantages over spraying, notably, its greater rapidity, it being possible for one outfit to dust as much in a day as several spray outfits can cover, and the elimination of the necessity to provide a water supply for the sprayers, also the consequent lightening of the outfits due to the elimination of the water. It is therefore to be hoped that the method will be developed so that it is applicable for all the pests of the orchard.

Stomach poisons are frequently used in the form of baits rather than applied directly to the plants to be protected. In such cases substances attractive to the insects are poisoned and placed where they can get them easily, usually near the plants. The most commonly used bait is poisoned bran-mash prepared according to a formula based on old usage but perfected at the Kansas Experiment Station. It is made as follows:

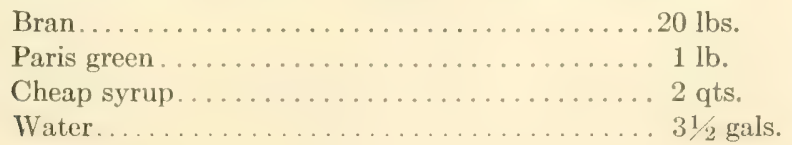

Place the Paris green and the bran in a tub and mix thoroughly while dry. Dissolve the syrup in the water and mix this with the poisoned bran, stirring thoroughly. To make the mixture more attractive to many insects, especially grasshoppers, it is flavored with oranges or lemons. This requires three oranges or lemons. They are chopped into fine bits and the chopped fruits, juice and all, are added to the mash above and stirred in thoroughly. 
This may be applied broadcast, preferably late in the evening or very early in the morning or it may be placed in small quantities near the plants liable to attack. Chickens should be kept away from the mash.

Poisoned syrups are at times sprayed on plants so that the adult insects, generally forms with sucking mouth parts, may be killed before they lay their eggs. This method has been used to some extent to control onion maggots by killing the flies which produce them.

\section{Stickers or Adhesives}

It is sometimes necessary to use some material with the insecticide in order to make the spray stick to the leaves of plants like cabbage. For this purpose a cheap form of syrup or molasses is sometimes used. This is used also, at times, to make the spray attractive to the insects so that they will eat larger quantities of it and be more quickly killed. Syrup is not generally as good a spreader or adhesive as some other materials. A soap containing resin is as effective as any material in use. This material may be made at home but the process is tedious and somewhat messy and it will be more simple in most cases to purchase it. A simple preparation of resin, used for the most part with bordeaux mixture, is made by boiling 2 pounds resin, one pound sal soda and 1 gallon of water together in an iron kettle for one to two hours. This amount is needed for each fifty gallons of spray.

Cactus solution, compounds of casein from milk and many other substances have been used as adhesives and spreaders but their use is not yet firmly established as successful. 


\section{CHAPTER VI \\ SPRAYING AND DUSTING APPARATUS}

Atomizers.-Hand atomizers of the general style shown in Fig. 26 may be purchased at any hardware store, and are useful for applying soap or oil solutions to a few house or garden plants. They are not adapted for more extensive use and to try to spray many plants, or a tree, with them, is a waste of time.

Bucket Pumps.-The simplest trpe of spray pump is that made to use in a bucket. The better types usually cost $\$ 5$ to

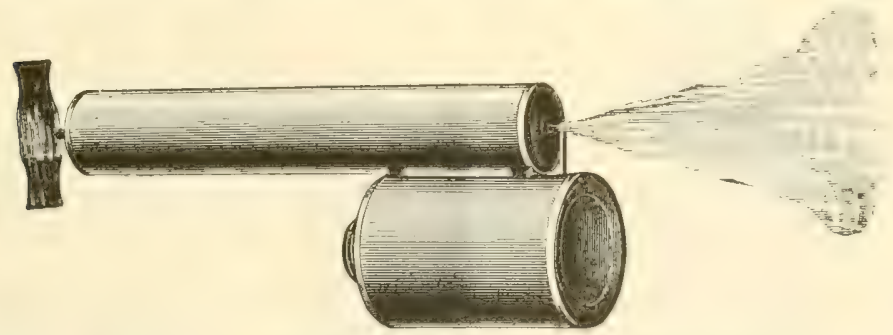

Fig. 26.-An atomizer handy for spraying a few plants.

$\$ 15$, the cheaper styles, selling for $\$ 2$ or $\$ 3$, being inferior and unsatisfactory.

There is as much difference in the structure of bucket pumps as in those of the barrel type, and many of the statements made below concerning the latter will apply also to bucket pumps. The bucket pump should have an air chamber, so that a steady pressure may be maintained. Some firms are making bucket pumps, of the same general type as the barrel pump shown in Fig. 34 , which are very satisfactory in this regard. A foot-rest attached to the pump and a clamp to attach the pump to the bucket are useful accessories.

Many firms are now selling these pumps mounted in large galvanized-iron covered buckets, and furnished with a mechanical agitator. This is a desirable arrangement, for the buckets are 
much larger than those ordinarily used, thus saving frequent filling, while the cover prevents slopping, and the pump is always ready for use without the necessity of hunting up a bucket and

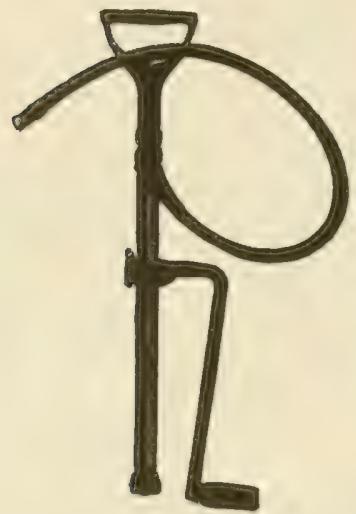

a

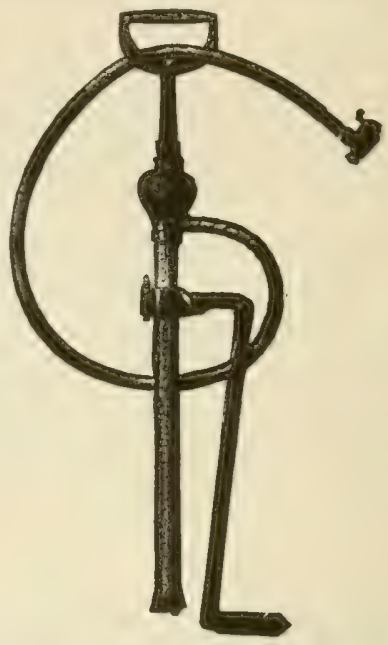

$b$

FIG. 27.- $-a$, a cheap type of bucket pump with no air-chamber, which will not maintain satisfactory pressure; $b$, a better type of busket pump with small air-chamber. (Courtesy Deming Co.)

then cleaning it, which is necessary after using a bucket which is used for other purposes.

Bucket pumps are useful for small gardens or for a few small trees or bushes.

Knapsack Pumps.-The knapsack pump consists of a copper or galvanized-iron tank, carried on the back like a knapsack, in which is mounted a bucket pump with a lever handle for pumping. In the better makes this handle is detachable and a plain handle may be attached so that the tank may be used as a simple bucket pump, for which a foot-rest is attached to the tank. The pump should have a good mechanical agitator. The copper tanks are preferable, for bordeaux mixture will soon eat through galvanized iron. Knapsack pumps are useful for spraving such crops as tomatoes, melons, etc., which cover the ground so that it is difficult to drive through them without injuring the vines, crops growing on steep hillsides, or for a small acreage of any garden crops, small fruits, or small trees. The main objections 
to them are that they are heavy to carry, thus limiting their use to a small area; they frequently slop over, and wet the carrier's back and the pumps do not develop sufficient pressure for some kinds of work. Consequently they are not as much used as formerly, but are useful for the purposes indicated, and inasmuch as they may also be used as a simple bucket pump, they are to be preferred to them. The cost varies from $\$ 8$ to $\$ 12$ or $\$ 15$.

Compressed-air Sprayers.-In recent years the compressed air sprayer has come into favor for use in small gardens. It consists of a brass tank

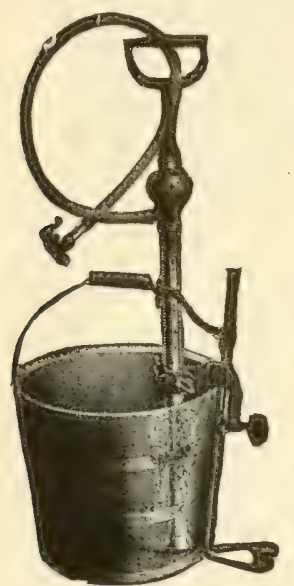

FIG. 28.-Bucket pump mounted in bucket, and mounted in tank with agitator. (Courtesy Deming Co.)

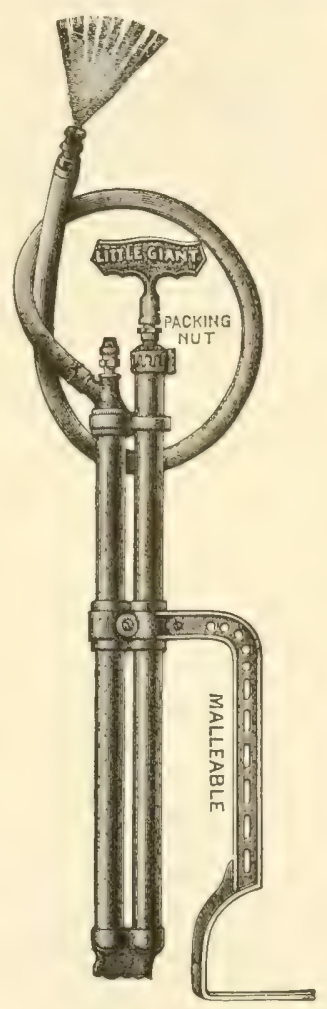

FIG. 29.-Bucket pump with large air-chamber, which will maintain a good pressure.

(Courtesy F. E. Myers\& Bro.)

which is filled with the liquid; the air is compressed by an air-pump, and spraying continues until the pressure runs down, when a stopeock is turned and the pressure is again raised by pumping. The tank holds from 3 to 5 gallons, and is carried beneath one arm, slung by a strap over the other shoulder. The chief objections to this type are that it is not very convenient to fill, though the newer models are much improved, is not 
readily repaired, has no agitator, and requires frequent pumping. On the other hand, they are easily carried, do not leak, and leave both hands free, so that one might be used for spraying a small tree from a step-ladder. These compressed-air sprayers cost from $\$ 8$ to $\$ 20$.

Barrel Pumps.-The most serviceable spray pump for the average farm is the barrel pump. With a good barrel pump 100 to 150 full-grown apple trees may be sprayed in a day, so that it will be found sufficient for an orchard of 500 trees or less. By using a row-spraying attachment, a few acres of potatoes or other row crops may be sprayed with a barrel pump much more quickly than by hand. In buying a row attachment, be sure that it is adjustable for rows of different

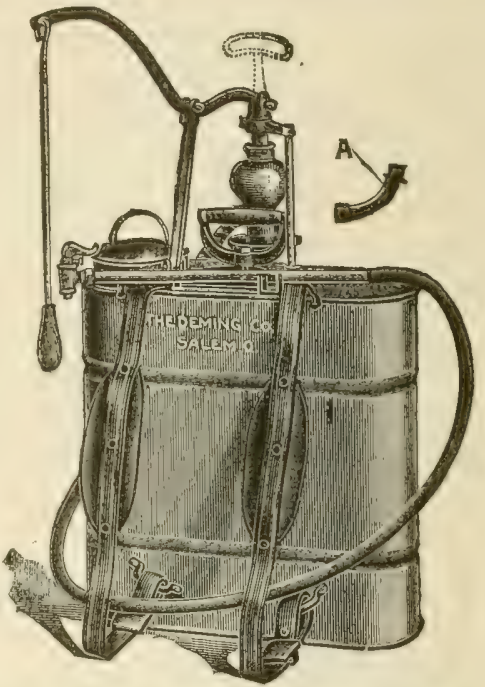

Fig. 30.-One of the best types of knapsack sprayers. Note footrest, agitator, handle, and wide straps. (Deming Co.)

widths. A good barrel pump costs from $\$ 25$ to $\$ 50$. Most of the pumps sold for less are too light to do effective work or

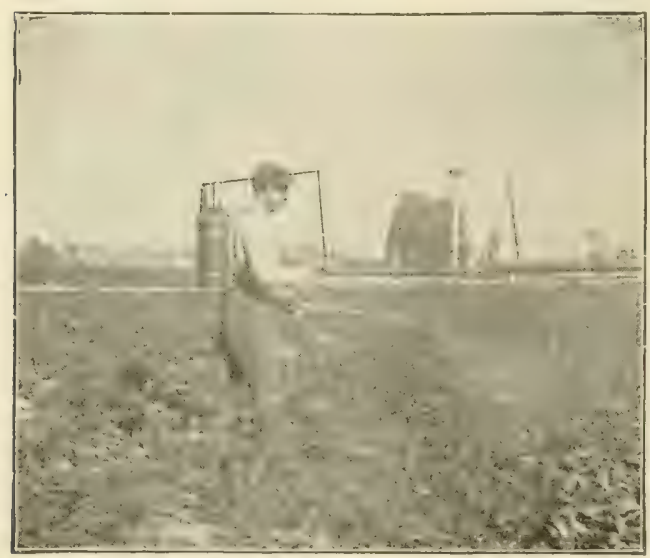

FIG. 31.-The knapsack sprayer in use. (Spramotor Co.) are not well constructed, Numerous pump companies advertise in the agricultural papers and after considering the following points one may select a suitable pump from their catalogs:

1. The pump should be guaranteed to furnish two nozzles at 80 to 100 pounds' pressure with ordinary pumping. 


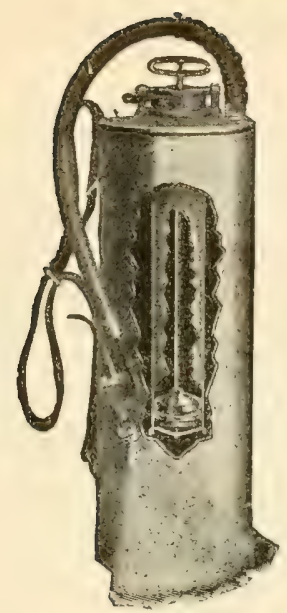

Fig. 32.-Compressed-air sprayer with section of tank removed to show air pump within.

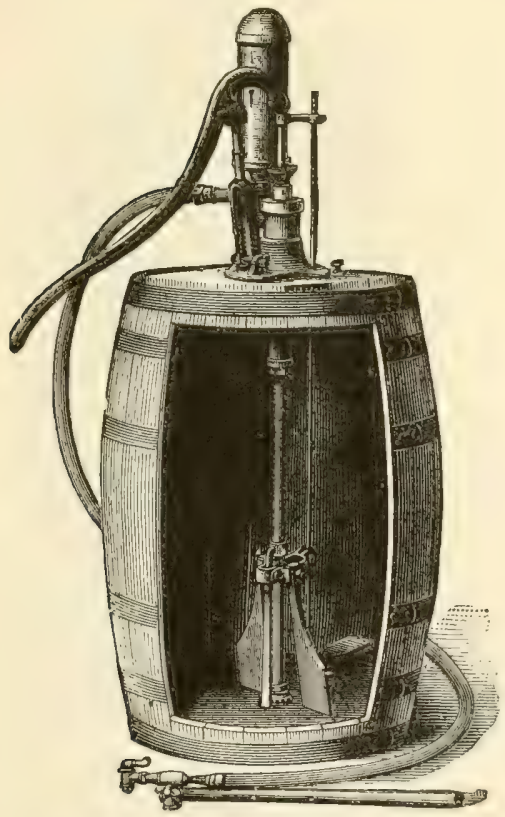

FIG. 33.-An undesirable type of barrel sprayer - now off the market; the air-chamber and other parts above the barrel render it top-heavy, and may be easily broken.

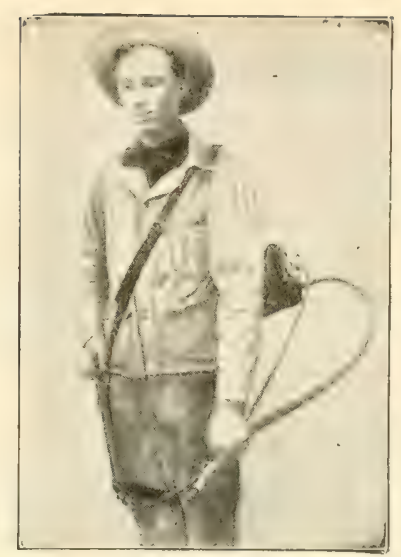

Compressed-air sprayer in position to use.

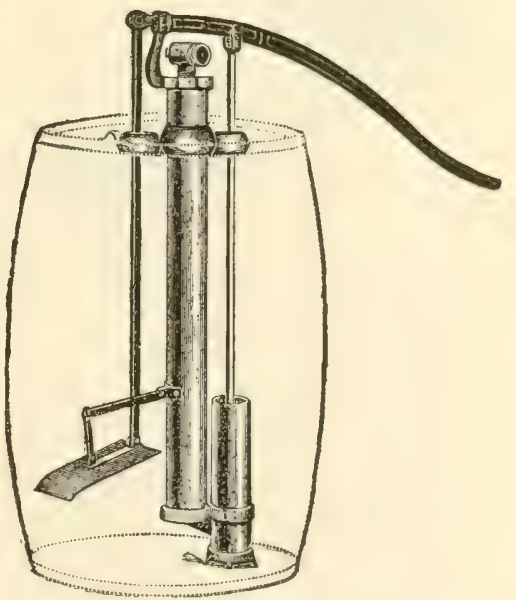

Fig. 34.-A desirable type of barrel pump embodying most of the features described. (Morrill \& Morley.) 
2. It should have a large air chamber within the barrel, and not projecting above it

3. As few of the working parts of the pump as possible should be above the hearl of the barrel, as exposed parts are easily broken.

4. The cylinder, plunger, valves and working parts should be of brass. The handles and other parts commonly made of cast iron are much more durable when made of malleable or galvanized iron.

5. There should be a good mechanical agitator of the parldle type, preferably arranged so that it can be worked with the
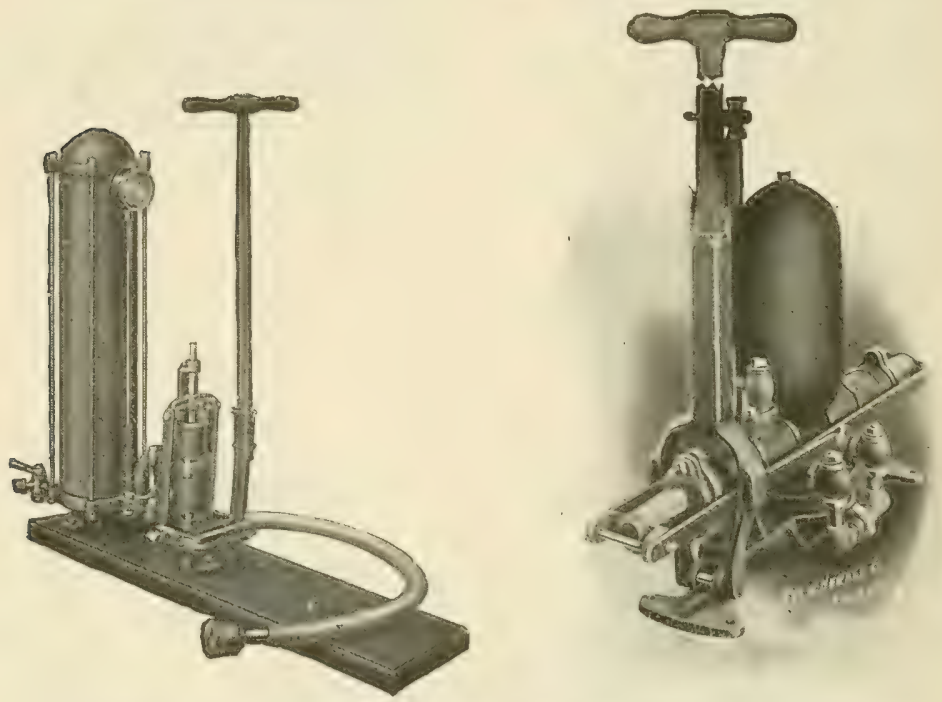

Frg. 35.-Two types of double-acting lever pumps, to he mounted on truck and connected with tank.

pump handle without operating the pump. An agitator is essential to keeping the mixture in suspension. Agitators of the so-called "jet-type," in which a stream from the bottom of the cylinder is supposed to agitate the liquid, are unsatisfactory and allow a loss of pressure without sufficiently agitating the liquid.

6. The pump should be so attached to the barrel that it can be quickly removed for repairs. Those pumps which have lugs for attaching the pump plate to the barrel are much better than those with screws. 


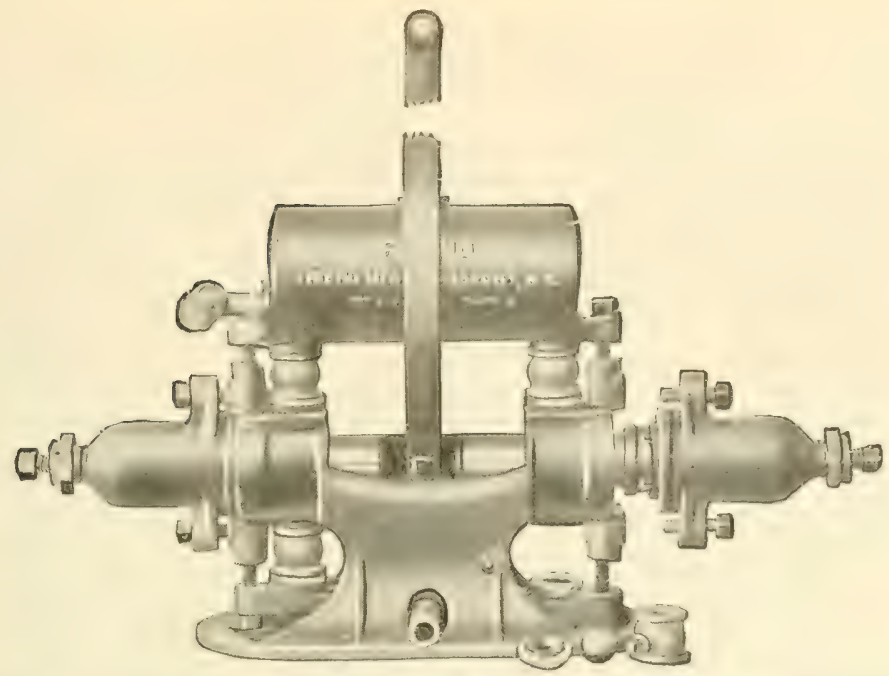

FIg. 36.-A two-cylinder pump for use with tank. Good capacity and easy operation feature this type. (Courtesy the Friend Mfg. Co , Gasport, N. Y.)

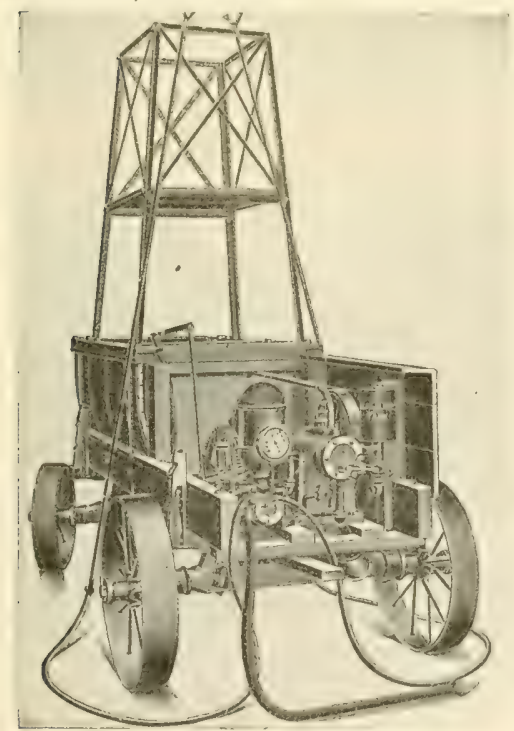

FIG. 37.-Gasoline power sprayer, complete. Note widetread steel wheels, steel tower on tank, and intake hose for filling tank where running water is not available; $31 / 2$ h.p., 4-cycle gasoline engine, will maintain 10 nozzles at $200 \mathrm{lbs}$. pressure.
7. The valves, with their seats or cages, should be readily removable for cleaning, and should be so constructed that they remain evenly ground.

All of these points may not be embodied in any one pump, but most of the better pump manufacturers are embodying these features in their newer models, a good example of which is shown in Fig. 34 .

Barrel, knapsack, and bucket pumps are manufactured which have separate tanks for oil and water which are mixed in a desired proportion and sprayed as a mechanical mixture. They have been found unreliable in controlling the amount of oil, and are not now in general use 
Horizontal Pumps.-For larger orchards and shade trees, the double-acting horizontal pumps which are operated with a lever,

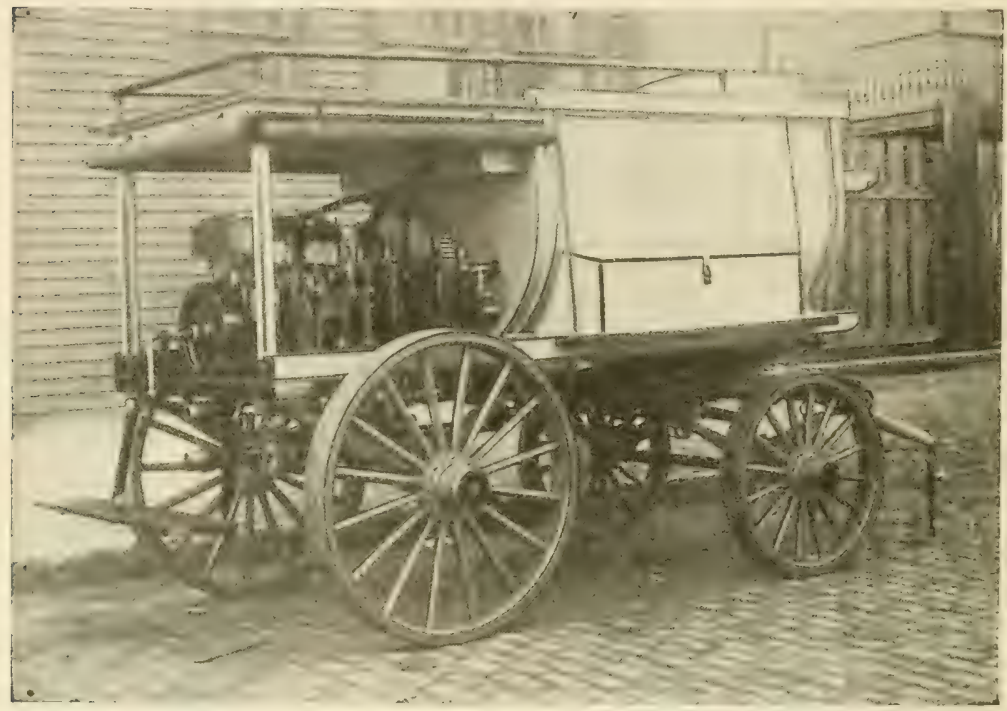

Fia. 38.-One of the latest three-cylinder power pumps. designed for spraying shade-trees and woodlands.

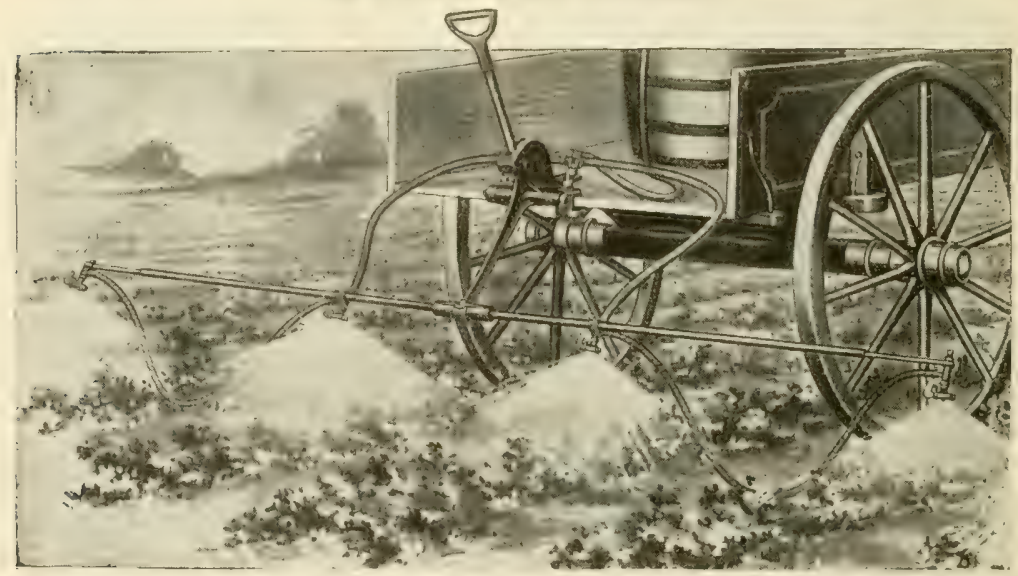

FIG. 39. - Row-spraying attachment for use with barrel pump, adjustable for various width of rows. (Deming Co.)

as shown in Figs. 35 and 36, furnish more power and consequently make more rapid work possible. They are mounted on 100 or 
150-gallon tanks and may be arranged for filling the tank where running water is not available. These pumps cost from $\$ 30$ to $\$ 50$ and will maintain 100 to 125 pounds pressure with four to eight nozzles. They are usually used with two men spraying and another driving and pumping, or a fourth man pumps and changes places now and then with the driver, as the operation of this type is rather too heavy for one man constantly.

Poucer Outfits.-For orchards of much over 500 trees or for extensive shade tree work a gasoline power outfit is more economical and enables a large area to be covered more quickly, which is often a most important consideration. Most of the pump manufacturers and many gas engine companies are selling such outfits mounted upon a truck, with spray tank, and tower complete for from $\$ 250$ to $\$ 1000$.

Traction Sprayers.-For a small acreage of potatoes or other row crops, a barrel pump with row attachment is very satisfactory, but for any considerable acreage, a two-wheeled traction sprayer is much more economical of labor and time which are the two chicf items in the cost of spraying. Such traction sprayers are made of widely different types, the power in all cases being furnished by a gear or chain which operates the pump from the wheels. The mechanical construction of the traction sprayers should be carefully studied, and if possible tested, before purchasing, as they differ greatly in efficiency. The better types cost from $\$ 100$ to $\$ 200$ and usually have attachments adapting them for all sorts of row crops, such as potatoes, strawberries, bush fruits, grapes, etc., which require different styles of piping to direct the nozzles properly.

Several traction sprayers are sold for orchard work but, though they are fairly satisfactory for small trees, they do not develop enough power for spraying large trees, and have a heavy draft.

Various other types of spraying machines have been tested and some of them put on the market. Among these may be mentioned gas-sprayers, where the gas in cylinders under pressure is used to fumish the pressure; and compressed air sprayers, where air compressed at a central station in large cylinders takes the place of gas. These have some great advantages but difficulties which arise in practical operations have kept them from being widely used. 
Nozzles.-A good nozzle is as essential as a good pump for successful spraying. The best nozzles now in common use are of three types.

The Vermorel type consists of a small chamber into which the liquid is admitted at a tangent and leaves through a small hole in a removable cap, thus making a fine, cone-shaped spray. A small

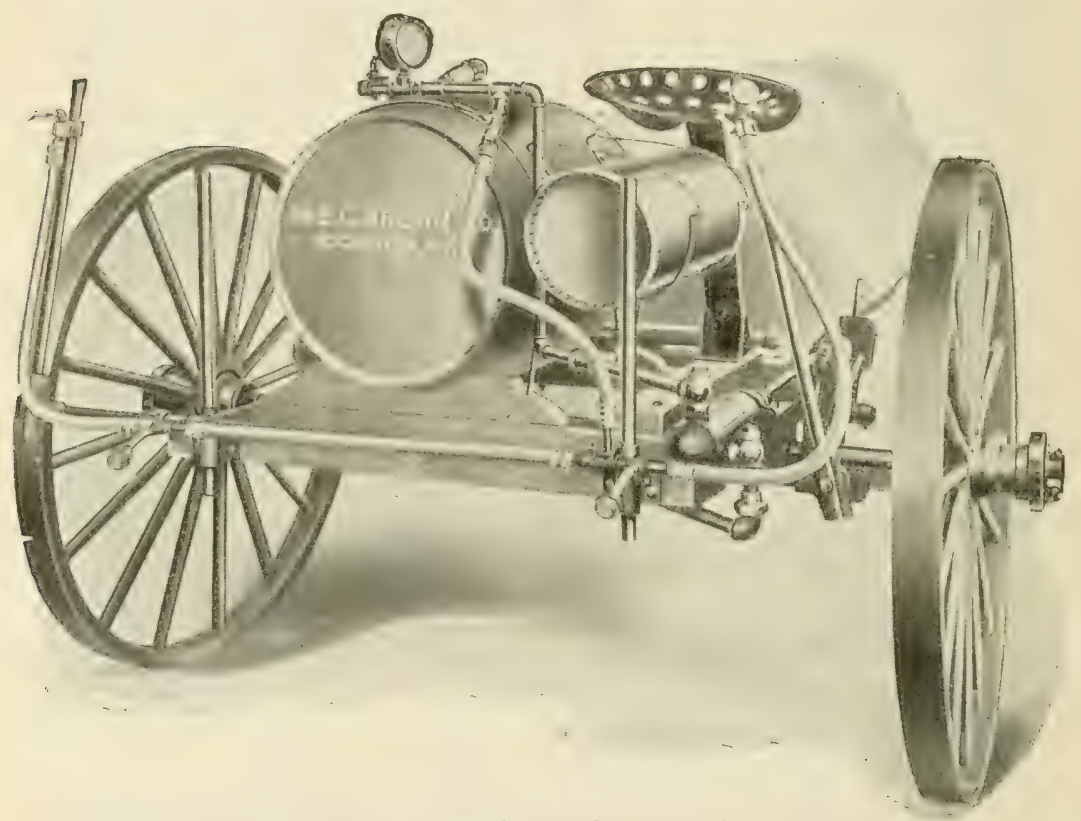

FIG. 40.-A good type of geared sprayer for row crops.

pin, with a spring to hold it back when not in use, serves as a disgorger to remove any sediment which may clog the outlet. This type of nozzle is made in many slightly different styles and often sold under trade names, such as the Demorel, Mistry and others. A slightly modificd form has no spring attached to the disgorger, but has a loose cap which is held away from the pin by the force of the liquid, and the outlet is disgorged by simply pressing the cap down on the pin. Such are the Spramotor (Spramotor Mfg. Co.) and Vapor-Mist Nozzles (Field Force Pump Co.) and are disgorged rather more easily than those with springs.

Disc type.-An evolution from the older type of nozzles now in almost universal use is the disc nozzle. This has a broader and 
flatter chamber and is variously adapted to give to the liquid a strong rotary motion which helps to break up the liquid into a

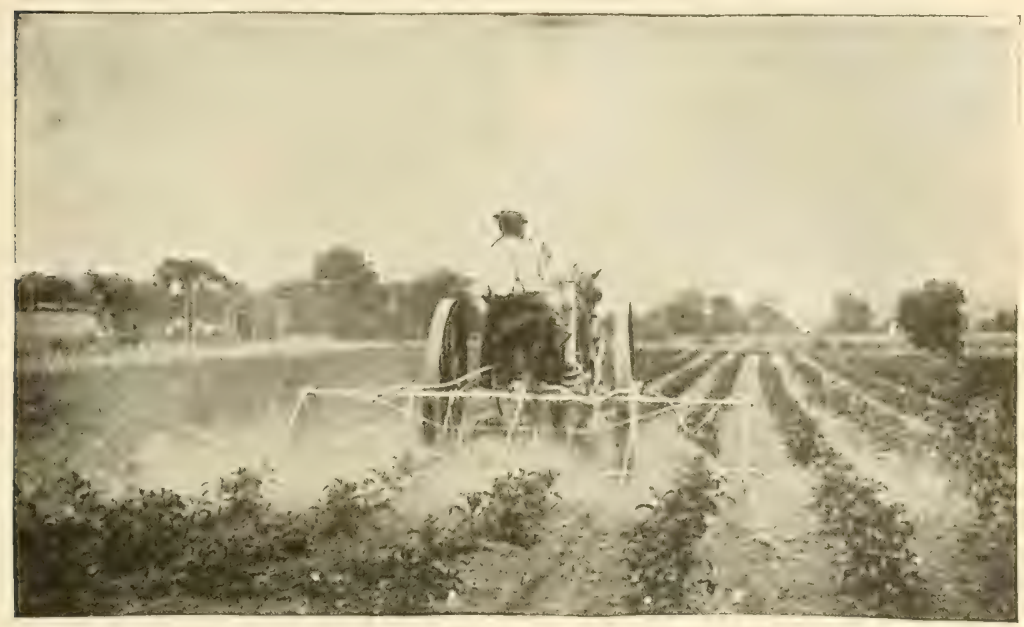

Fig. 41.-Row sprayer applying arsenate of lead to potatoes, showing arrangement of nozzles to cover vines. (After Britton.)

fine spray. There are usually interchangeable dises with apertures of varying sizes adapted for all degrees of fineness of spray and for varying the quantity of liquid delivered. Under ordi-
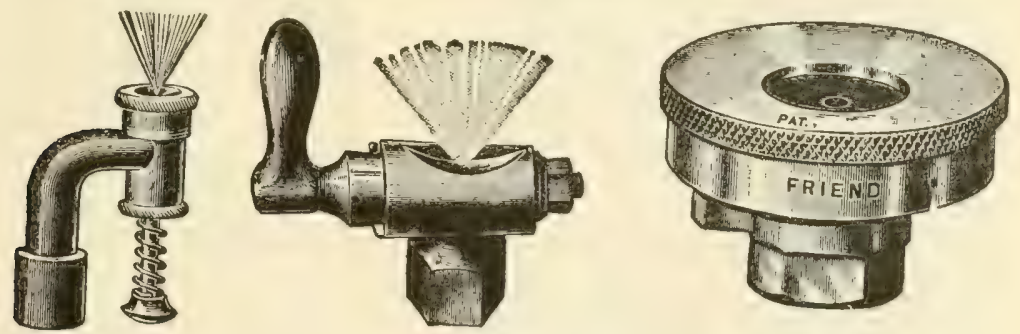

FiG. 42-Vermorel, bordeaux, and disk type of nozzles.

nary conditions only one of these is needed on a rod to deliver all the liquid that the operator can handle properly. This does away with the neeessity for "Y's" and lightens the rod. The illustration (Fig. 44) shows many of the modern types. 
The Bordeaux nozzle is of entirely different structure, the spray being formed by a straight stream hitting a lip which

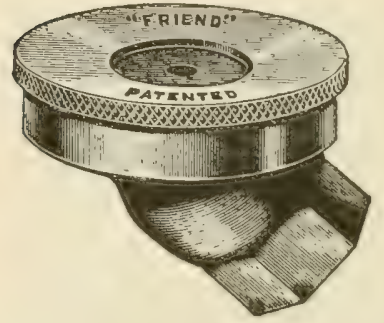

Fia. 43.-Angle form of disk type nozzle, particularly useful for orchard spraying. (Friend MIfg. Co.)

breaks it into a fan-shaped spray, the fineness of the spray being governed by the width of the aperture. To unclog the nozzle the core through which the stream emerges is reversed, thus giving a straight stream and clearing the nozzle immediately. For this reason the bordeaux nozzle is particularly adapted to traction sprayers where several nozzles are used and it is necessary to unclog them quickly. It is usually preferred for garden and row crops, and some prefer it for tree work, though it is not as widely used for that purpose as the previous types.

The bordeatux nozzle is of great value for applying whitewash, a purpose for which the spray outfit may well be used

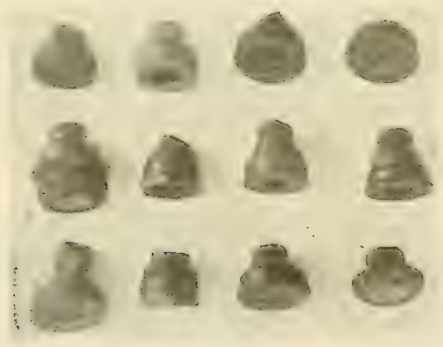

Fig. 44.-Disk Nozzles. Top row (left to right): Atomic, New Eclipse, Whirlpool, Excelall. Middle row: Tiger Strainer, Fog, Bean Mist, Nonclog Atomic. Lower row:Friend Regular, Friend Angle, Scientific, Mistry Jr. (From H. L. Crane, W. Va: Agr. Expt. Sta.)

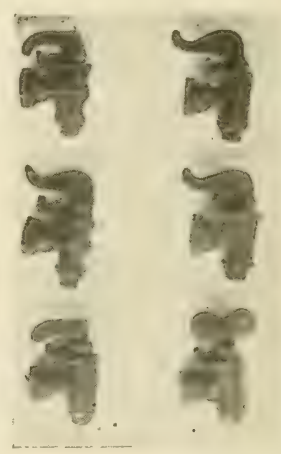

FiG. 45.-Types of bordeaux nozzles. (From H. L. Crane, W. Va. Agr. Expt. Station.)

during the off season. It, with the disk type, will be found to fill most of the needs of today for nozzles.

Solid strem nozzles.-For special purposes, such as spraying woodlands or spraying larese trees in parks or on city streets or 


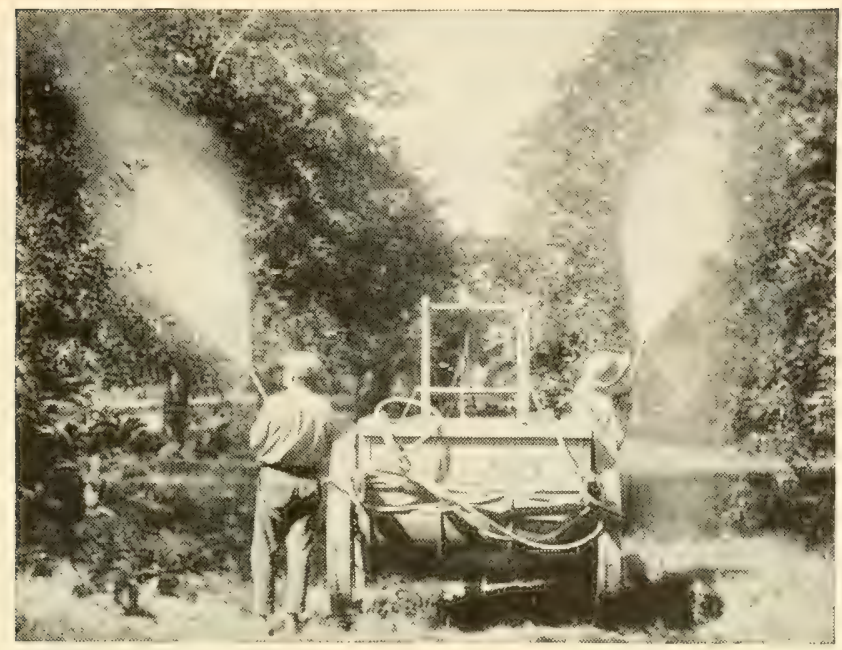

Fig. 46.-Spray-guns in operation. (Friend Mfg. Co.)

even for spraying old and very tall apple trees, a type of nozzle which delivers a solid stream of small diameter through a nozzle ending in a tube of about oneeighth inch diameter for two to five or sixinches, is used. This requires a high pressure and forces the liquid high in the air where the pressure against the air tends to break it up into a mist. For ordinary work in the orchard this type is not available.

Spray-guns.-A recent development of the spray nozzle of the ordinary type and the solid stream nozzle is the spray gun. This is a nozzle which can be made to deliver a mist like the ordinary nozzle or a solid stream or

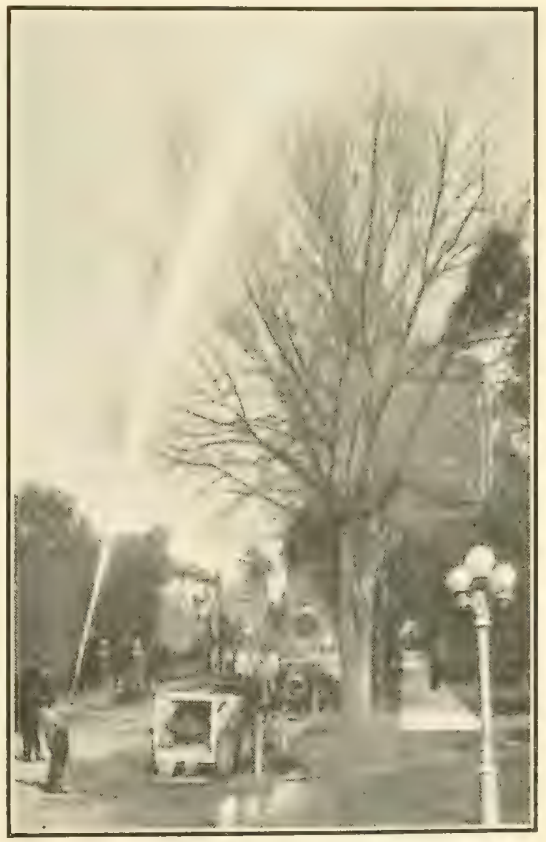

FIG. 47.-Solid stream nozzle in operation. (Courtesy the Bean Spray Pump Co.) 
almost any gradation between the two. It delivers a large amount of liquid and will greatly reduce the time required to spray an orchard, especially where the trees are large. Like the solid stream nozzle it requires a high pressure, at least 250 to 300 pounds being desirable

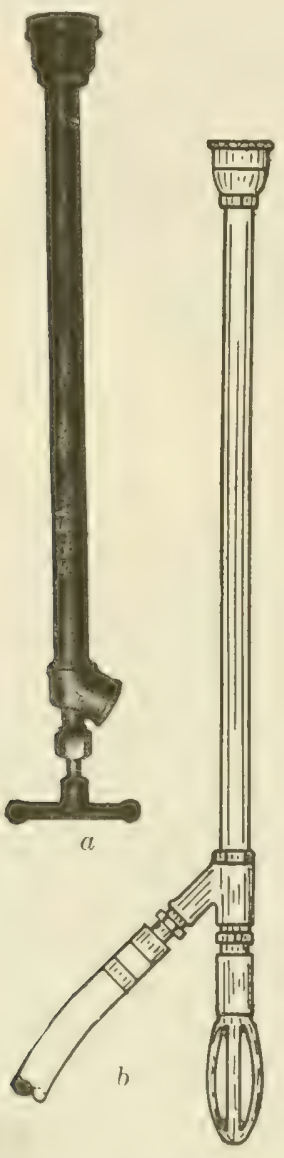

Frg. 48.-Spray-guns: a. Friend type. (Friend Mfg. Co.) b. Bean type. (Bean Spray Pump Co.)

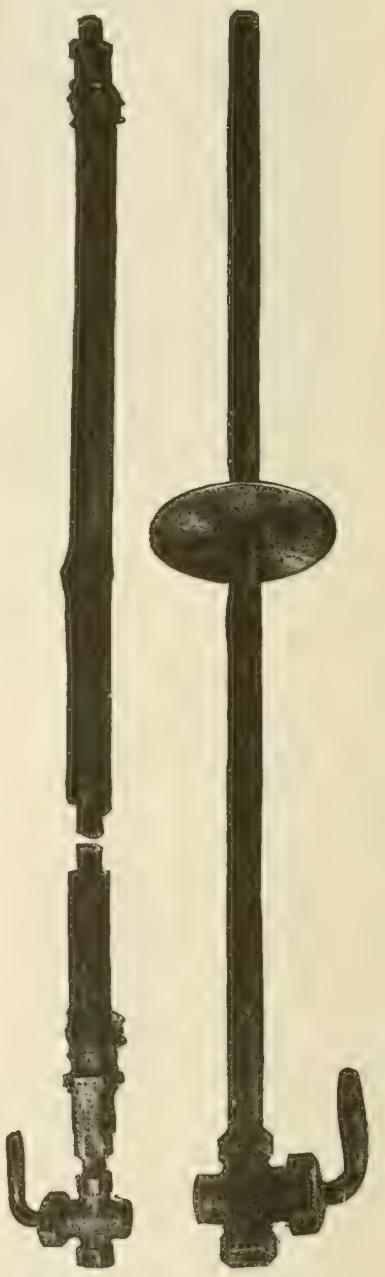

Fig. 49.-Bamboo extension rod at left, and iron rod with drip-guard at right.

for good work. Several types are on the market and while they are new to the industry they have already shown that effective 
insect and disease control can be secured with them. The spray gun is used without a rod, it being long enough to be handled without the rod.

Extension rods.-In orchard spraying where the spray gun is not used an extension rod is a necessity. This may be a bamboo rod with a brass or aluminum pipe inside, or it may be merely an iron pipe, one-fourth inch size. Lengths used vary with the size of the trees, ranging from eight feet to twelve feet. It is well to insist on a rod of sturdy construction when purchasing as one which is likely to pull apart at the connections and leak is a nuisance.

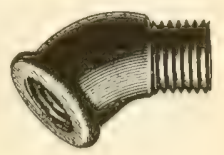

FIG. 50.-45-degree elbow for attaching nozzles to end of rod for orchard spraying.

Where the angle type of nozzle is not used it is a good plan to connect the nozzle with a 45 -degree elbow in order that the spray

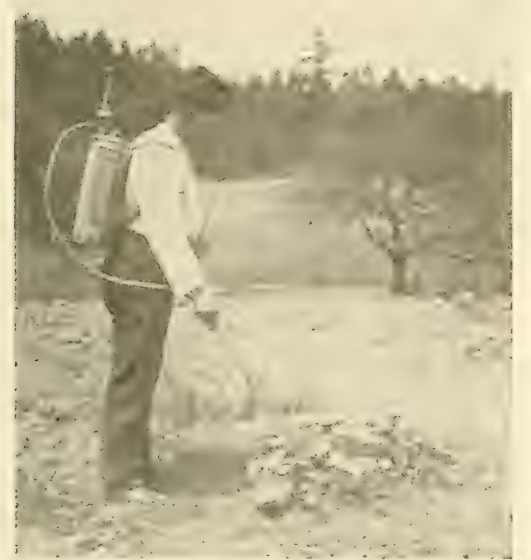

FIG. 51.-Spraying squash with underspray nozzle at right angle to rod. may be more easily directed toward the tree.

For low-growing bushes and truck crops a short rod with the nozzle attached at right angles will be found useful as it will enable one to spray the under side of these plants.

Spray hose.-Use only the best spray hose obtainable. The one-half inch size is most commonly used for orchard spraying. This should be guaranteed against a working pressure of 300 pounds. Where a spray gun is used it is necessary to have threequarter inch hose of still higher capacity. Quarter or threeeighths inch sizes are used for bucket pumps.

A common mistake is using hose leads which are too short. Twenty-five feet should be the minimum and fifty feet is better. This enables the operator to get around the tree and to keep far enough away from the outfit so that the spray will not blow over the driver, sprayer and team. 
Connections and Cut-offs.-Hose connections are important. Nothing is more aggravating than to have the hose pull loose from its connections while operations are in progress. To prevent
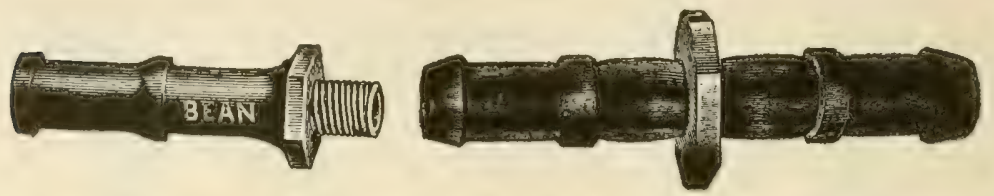

Fig. 52.-Spray hose connection, long shank type and spray hose mender. (The Bean Co.)

this, use only connections with long shanks which may be fastened with two hose-clamps over each shank. Fig. 52 shows this type of connection and an adaptation of it used for mending breaks in hose or in splicing permanently two lengths of hose. A cut-off

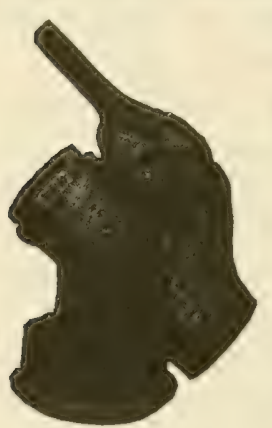

FIG. 53.-A good shut-off which allows the hose lead to hang without bending. Is also very convenient. (Friend Mfg.Co.) at each rod is necessary and this should be of a leak-proof type. A three-way cut-off at the pump is also necessary where there are two lines of hose operating With these there is complete control of the spray and one line can stop for repairs while the other continues to work.

Towers.-Many operators like to use a tower for spraying large trees and many of the power sprayers are equipped with towers. Their value is questionable, however, and many laborers refuse to work in them. It is quite probable that just as good work can be done, in most cases, by using longer rods and reaching the top of the tree from the spot nearest it at the base of the trunk. In most cases the operator will be just as near the top in this position as he is when on the tower. The spray-gun does away with the need for the tower where it is used as it will reach the top of the tallest tree.

Strainers.-To obviate the delay caused by nozzles clogging with dirt and secliment, strain all mixtures through a fine copper strainer when filling the spray tank. Have the tank tight and see that it is clean before filling. 
Dusting Apparatus.-The simplest method of applying dusts is by means of a perforated can or a cheese-cloth or muslin bag and much dust is still applied to garden crops in this way Dust bellows to foree dust into cracks for household pests, or to distribute it more economically and evenly on plants, represent the next step. Various small dusters, but with larger capacity than the bellows, are used for small plantings. These are usually of the plunger type and the dust is puffed out rather than delivered continuously. Dusters with a rotary fan or blower, delivering the dust in a continuous stream are made in many sizes. Some are operated by hand, others are geared to the truck upon which they are hauled so they operate only when the truck is in motion and some, the more modern orchard outfits, are supplied with power from a gasoline engine. All types have their uses but we are more concerned with the commercial forms than with the more primitive apparatus. Orchard dusters operated by

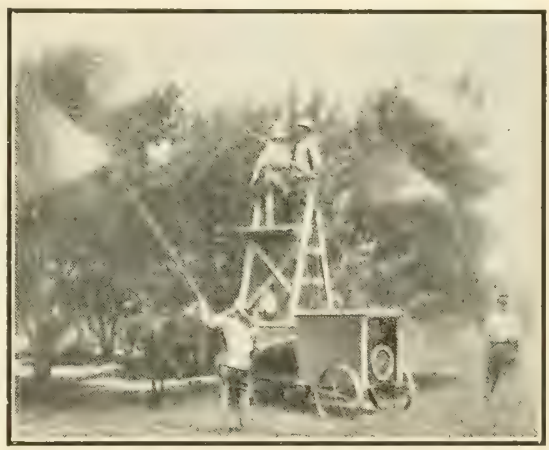

Fic. 54.-Spraying with power outfit from a tower. (Bean Spray Pump Co.)

hand are not satisfactory for use on any large scale. The power dusters on the market are quite efficient and will deliver large quantities of dust in dense clouds which have considerable carrying power. Dusting machines, owing to their more limited use, have not been mechanically perfected to the same degree as the sprayers but they undoubtedly will keep pace with the requirements as they come into general use.

Dusting mixtures are composed of arsenate of lead or of calcium mixed with some other substance which acts as a carrier. The carrier is often the fungicide or is a mixture of the fungicide with some inert material such as land-plaster or gypsum. The common formulas call for from 10 to 15 pounds arsenate with 85 to 90 pounds fincly ground sulfur, a special grade being produced for this purpose. An inert material may displace any part of the sulfur but it is not the common practice to dilute 
76 INSECT PESTS OF FARM, GARDEN AND ORCHARD
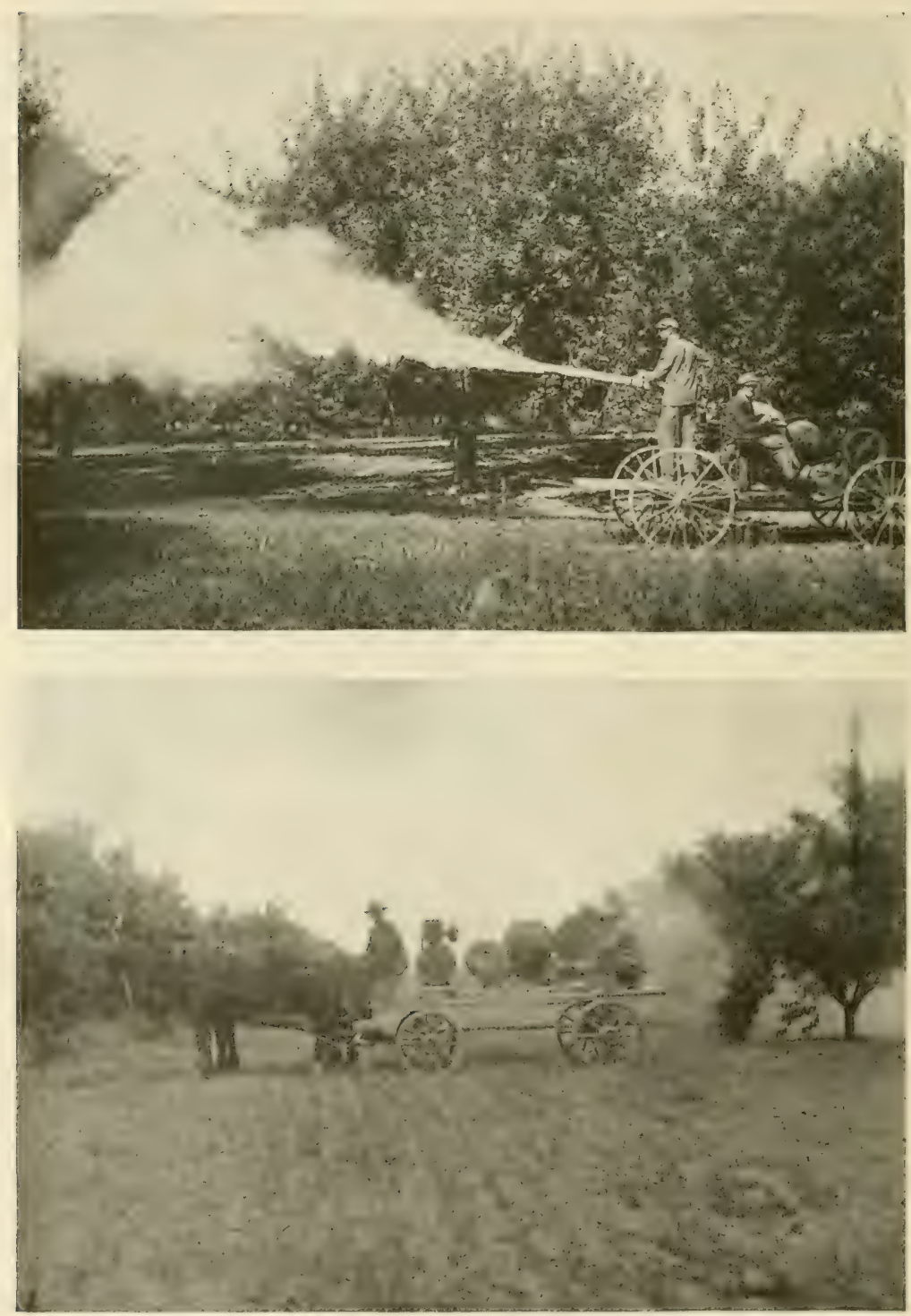

FIG. 55.-Orchard duster in operation. Courtesy the Niagara Sprayer Co., Middleport, N. Y. 
the mixture. Mixing is hest acemplished by machinery construeted for the purpose. The best means is to grind the ingredients together. Until methods of mixing are better standardized it will be wise for the user to get his materials ready-mixed.

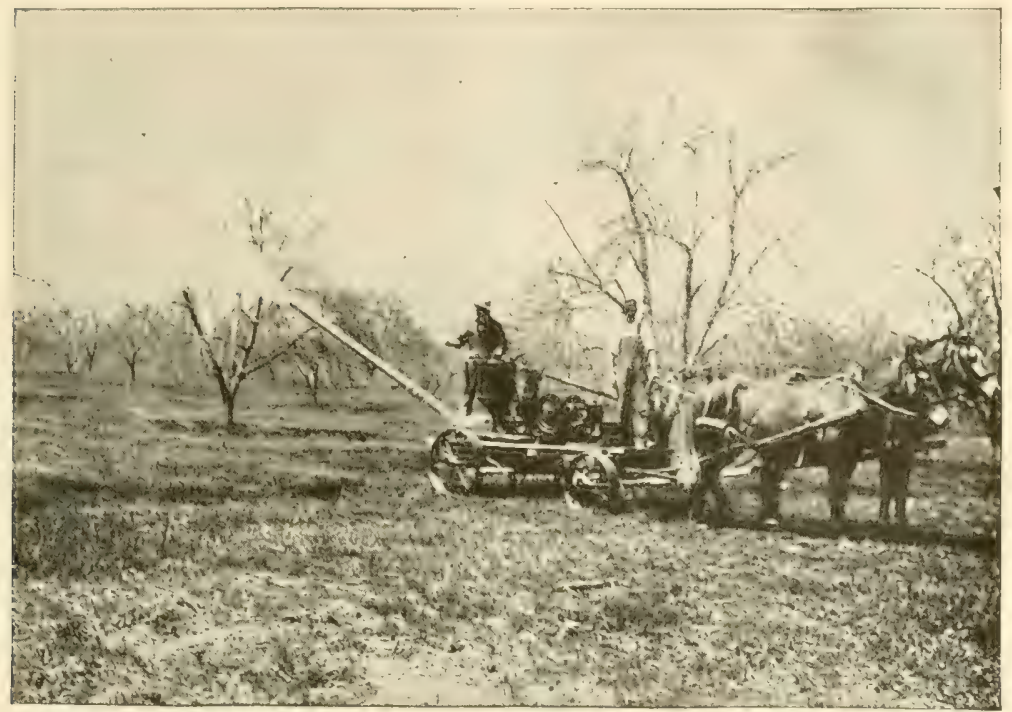

Fig. 56.-Another make of duster. (The Dust Sprayer Mfg. Co., Kansas City, Mo.)

Dry powdered bordeaux mixture is being used to some extent as the fungicide in dusting formulas but is still in the experimental stage.

Other mechanical devices for applying poisons and controlling insects will be discusser in connection with the group of insects for which they are most used.*

* For further information concerning the application of insecticides see the following: Farmers Bulletin 908 (U. S. Dept. Agr.) "Information for Fruit Growers About Insectieides, Spraying Apparatus and Important Insect Pests," A. L. Quaintance and E. H. Siegler. 


\section{CHAPTER VII}

\section{Insects Affecting Grains, Grasses, Forage and Miscellaneous Crops}

Several of our worst insect pests live normally in grass land but when they become numerous feed upon grains and various forage and garden crops, so that they are not readily classed as enemies of any one crop, and will therefore be discussed together.

\section{White Grubs *}

Among the most common pests of corn, strawberry beds, and garden crops are the large white grubs which feed upon the roots and often kill the plants. Their habit of lying curled up in a semicircle, and the large brown head, white body, and enlarged abdomen, at once distinguish them from other forms of grubs. Although they are very similar in color and form, there are numerous species, all of which are the young of different species of the large brown May-beetles or June-bugs, as they are commonly called, which frequently fly into lights in late spring.

Life History.-The eggs are laid mostly in June, preferably in grass land, but also in corn fields and gardens. The egg is of a broad oval shape, pure white, about one-tenth inch long, and is laid in a small ball of earth a half inch in cliameter, from 1 to 5 inches below the surface. The eggs hatch in about two weeks, most of them hatching by the middle of July. The young grubs feed upon plant roots, and grow slowly, as it requires two years or more for them to become full-grown. In the fall they burrow down in the soil, gradually going deeper as frost approaches until by the first freeze most of them are from 7 to 14 inches deep. The next year they do much more

* Lachnosterna spp. Family-Scarabaida. See S. A. Forbes, Bulletin 116, Illinois Agricultural Experiment Station, and J. J. Davis, Farmers' Bulletin 940, U. S. Dept. of Agr. 
serious damage, and land which has been in sod and then planted in corn, strawberries, or other crops of which they are fond, is often so full of the grubs that the crops are ruined. In 1895 an Illinois field of 250 acres which had been in grass for twenty years was so injured that the sod rould be rolled up like a carpet over the entire field. It is not surprising, therefore, that Professor Forbes records finding as many as thirty-four grubs to the hill of corn in another Illinois field which had previously been in sod. Where sod is taken into greenhouses the grubs
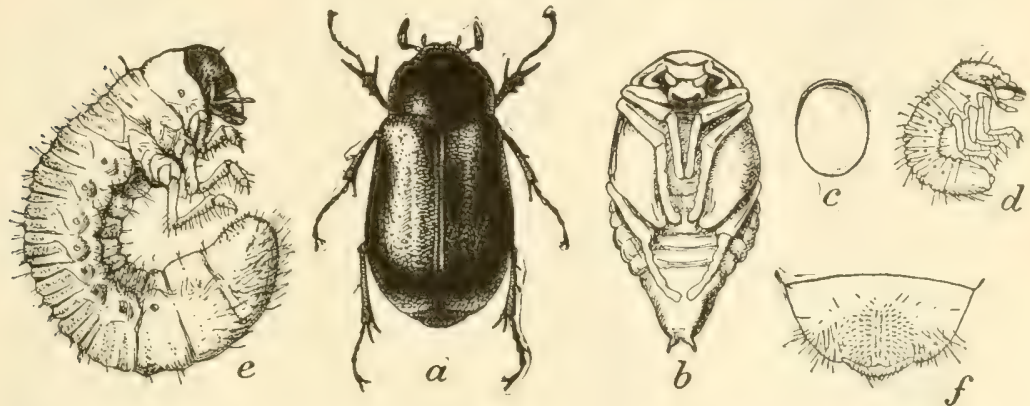

FIG. 57.-Lachnosterna arcuata: $a$, beetle; $b$, pupa; $c$, egg; $d$, newly-hatched larva; $e$, mature larva; $f$, anal segment of same from below. $a, b$, $e$, enlarged one-fourth; $c, d, f$, more enlarged. (After Chittenden, U. S. Dept. Agr.)

often become serious pests. When the grub is two, or possibly sometimes three years old, it forms a small oval cell from 3 to 10 inches below the surface and there changes to a soft, white pupa, sometime in June or July. The pupal stage lasts slightly more than three weeks, and in August or September the adult beetle wriggles out of the pupal skin, but remains in the pupal cell until the following spring, when it comes forth fully hardened. Thus three full years are occupied by the life-cycle of each brood, though grubs in all stages of development may be found in the soil every year.

The adult beetles feed at night upon the foliage of various trees. They hide in the soil during the day, migrate to the trees at dusk, and return to the fields just before daybreak. The different species have favorite food plants, but all of our common deciduous shade and forest trees are more or less eaten, poplar', 
willow, and maple being particularly relished. On a warm evening the beetles may often be heard feeding and their work may be identified by the ragging of the foliage, as if it had been torn.

Control.-As allowing land to remain in grass for several years is conducive to the increase of the grubs, a frequent rotation will prevent their multiplication, the grass being followed by potatoes, buckwheat, small grains, or some crop not seriously injured by them.

As the beetles remain in the pupal cells over winter and are tender and not fully hardened, deep plowing and thorough harrowing in fall or early spring will kill large numbers of them by breaking open the cells and exposing them to the weather and by burying and crushing them.

Swine will gorge themselves on grubs in badly infested land, and if confined so that they will thoroughly root it over, will very effectually rid it of them. Flocks of chickens or turkeys following the plow will catch a considerable number of grubs, as do the crows and blackbirds, which pay for the corn they eat by the war they wage on grubs.

The beetles may be jarred from the trees upon which they are feeding in the cooler part of the night and collected, as is extensively done in Europe. Lanterns hung over pans or tubs containing water with a surface film of kerosene placed near the trees on which they feed, will catch large numbers on warm nights when they are flying.

\section{Wireworms *}

Wireworms are hard, shining, slender, cylindrical, brown larvæ about three-quarters to 1 inch long, which bore into the seed of corn, wheat and other grains, often necessitating replanting, and also feed on their roots. as well as on potatoes, turnips, and many garden crops. They are the young stage of brownish beetles of the family Elateride, which from their habit of snapping their bodies up in the air are known as "click beetles." The beetles are one-half to three-quarters inch long, decidedly flattened, dark brown, often with darker markings, with short heads, and shield-shaped thoraxes, as shown in Fig. 58. Although the common wireworms look much alike, examination

* Family Elateridae. 
usually reveals that they belong to several species which are distinguished by a comparison of the caudal segments, as shown in Fig. 59 .

Life History. - The life history is very similar to that of the white grubs, except that from three to five years are required for the complete life cycle. The eggs are deposited in old sod land, which is the favorite breeding
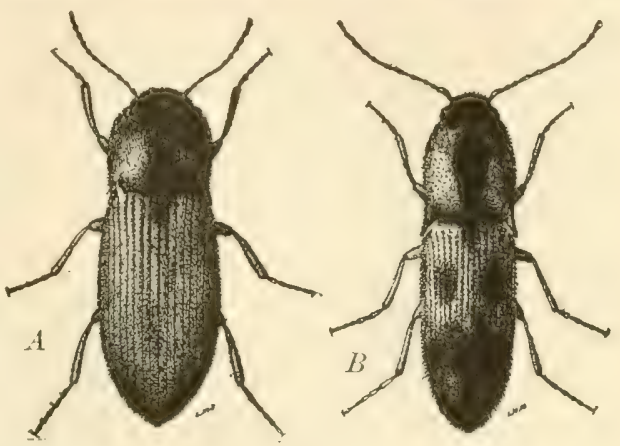
ground. The detailed life histories have not been carefully studied, but the second year after grass land has been planted in grain is that in which the worst injury occurs, particularly with corn, upon which the attack is more concentrated than with small grains. The larvæ become full grown in midsummer, form small cells in the soil and in them transform to pupæ. Three or four weeks later the adult beetles shed the pupal skins, but few of them make their way to the surface during the fall, most of them remaining in the pupal cells until the following spring.

Control.-As they resemble the white grubs in life-cycle, so the means of control are similar. By plowing in late summer or early fall and thoroughly harrowing for a month or so, large numbers of the pupa and newly transformed
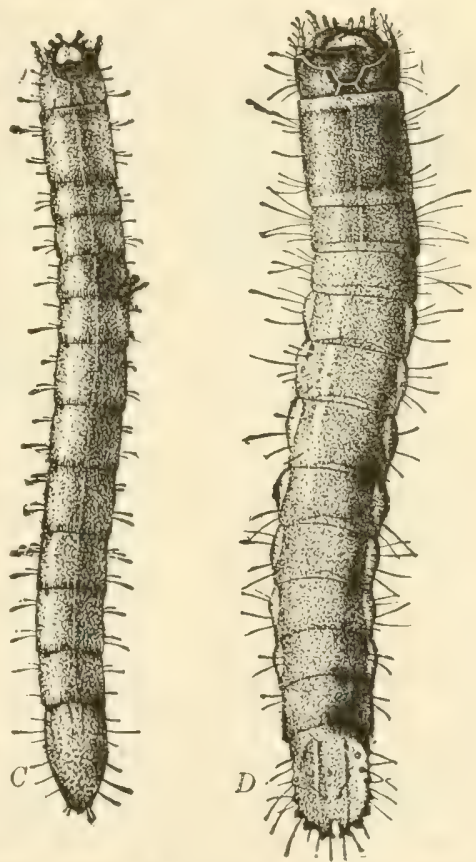

FIG. 58.-A, beetle of wheat wireworm (Agriotes mancus) $\mathrm{X} 4 ; B, D$, beetle $(X 4)$ and wireworm $(\mathrm{X})$ of Drasterius elegans; $C$, the corn wireworm (Melanotus cribulosus) X41/2. (After Forbes.) 
beetles will be destroyed. When the wireworms are numerous in restricted areas, as they often are on spots of low moist land, they may be effectually trapped with but little labor by placing under boards bunches of clover poisoned with Paris green. A short rotation of crops in which land is not allowed to remain in grass for any length of time will prevent their increase. Many remedies have been suggested for these pests but few of them have proved to have much merit in careful tests. Coating the seed with gas tar, as is done to protect it from crows, has been very widely practiced, and though previous experiments indicated that it could not be relied upon, Dr. H. T. Fernald conducted tests in Massachusetts in 1908 and 1909 in which seed coated with gas-tar and then dusted in a bucket of fine dust and Paris green suffi-
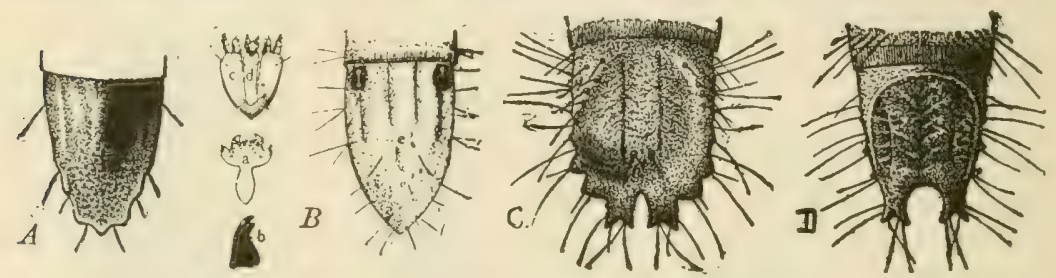

FIG. 59.-A, last segment of Melanotus communis, dorsal view (After Forbes); $B$, the wheat wireworm, Agrioles mancus - $a, b, c, d$, details of mouthparts, enlarged; $C$, caudal segment of the wireworm of Drasteterius elegans; $D$, caudal segment of the wireworm of Asaphes decoloratus, much enlarged. ( $A, C, D$, after Forbes; $B$, after Slingerland.)

cient to give the corn a greenish color, was effectively protected, the treatment seeming to act as a repellant, and not affecting the germination of the seed.

\section{The Stalk-borer *}

This species may well be called the stalk-borer, for it not only tunnels the stalks of potatoes-being often called the potato stalkborer-and tomatoes, but frequently infests corn, cotton and a long list of garden crops, grains, grasses, flowering plants, and various common weeds. Apparently the latter, such as ragweed, cocklebur and the like, are its normal food plants, and when they are destroyed or where more tender cultivated plants are near by, it attacks whatever is available. Two or three nearly related species have very similar habits.

* Papaipema nitela Gn. Family Noctuidœ. 
The adult moth (Fig. 60) is a fawn-gray or mouse color, with the outer third of the fore-wings paler and bordered within by a whitish cross-line.

Life History.-The eggs are laid in the fall on the stems of weeds and grasses, in masses of fifty or sixty, near the ground. They are about one-fiftieth inch in diameter, circular, grayish in color, with radiating ridges. They hatch in late May in

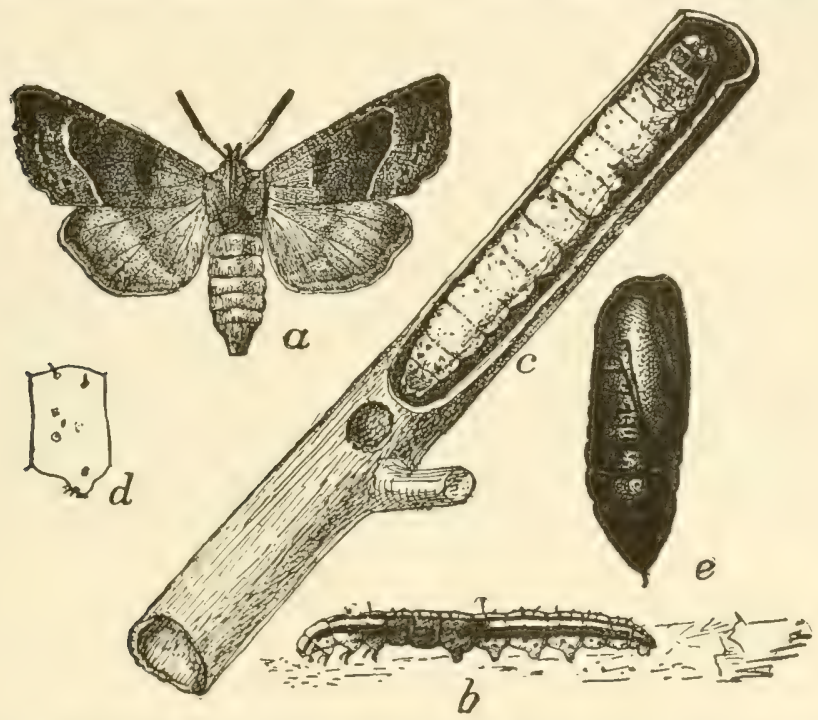

FIG. 60.-.The stalk-borer (Papaipema nitella Gn.): $a$, adult; $b$, half-grown larva; $c$, mature larva in burrow; $d$, side of one of its segments; $e_{\text {, }}$ pupa - all slightly enlarged. (From Chittenden, U. S. Dept. Agr.)

southern Minnesota and the young caterpillars at once commence to mine small galleries in the leaves of the food plants, soon riddling the leaves. In a few days they work down to the bases of the leaves and enter the stalks, which they tunnel out and not infrequently leave one plant and migrate some little distance before entering another. Infested plants are readily recognized by the wilting of the parts above the larva, the work in corn being particularly noticeable and having given the local name of "heart-worm." The larve become full grown about the first of August. They are readily recognized by the peculiar markings of the body (Fig. 60, b). The larva is al rout an inch long and varies from purplish to whitish brown, and is marked 
with five white stripes, one along the middle of the back, and two on each side. These side stripes are absent on the first four segments of the abdomen, giving the larva an appearance as if it had been pinched or injured there. As the larva matures the stripes become fainter. When ready to pupate the larva cuts a hole through the side of the stalk, and then transforms to the brown pupa in the lower part of the stalk. The pupal stage lasts about two or three weeks, and the moths emerge in late August, there being but one generation a year.

Usually the injury to crops is only in the outer rows, to which the larvie have migrated from weeds growing along the edges, or in fielc's which have been weedy in early spring, or where the rveeds have been allowed to get a start before being cultivated out.

Control.-From the life history and habits it is obvious that clean farming is the only method of effectual control. The destruction of weeds and fall plowing should prevent any general injury. Usually the injury is but local, and fortunately the caterpillars are attacked by numerous parasites which aid in their control, sometimes to the extent of killing 70 per cent of them. In small gardens the prompt destruction of infested plants will prevent the caterpillars from migrating to others. Where weeds are infested in or near a crop they should be destroyed as soon as cut, for if left on the ground the larve will promptly migrate to the nearest plants. Where fields are kept clean of weeds there will be little trouble.*

\section{Cutworms $\dagger$}

Under the general term cutworms we commonly designate any of the larvæ of several species of moths which are more or less similar in general appearance and habits, and which have the habit of feeding on low-growing vegetation, and cutting off the stem just at the surface of the ground. They should be carefully distinguished from white grubs, which are sometimes wrongly called cutworms on account of their similar habits. Some

* See Forbes, 23d Report State Entomologist of Illinois, p. 44; Washburn, 12th Report State Entomologist of Minnesota, p. 151; Journal Economic Entomology, III, p. 165; Smith, Report N. J. Agr. Exp. Sta. for 1905, pp. 584-587.

$\dagger$ Various species of the family Noctuida. 
of the species attack certain crops more commonly than others, but most of them are quite omnivorous in their feeding. When

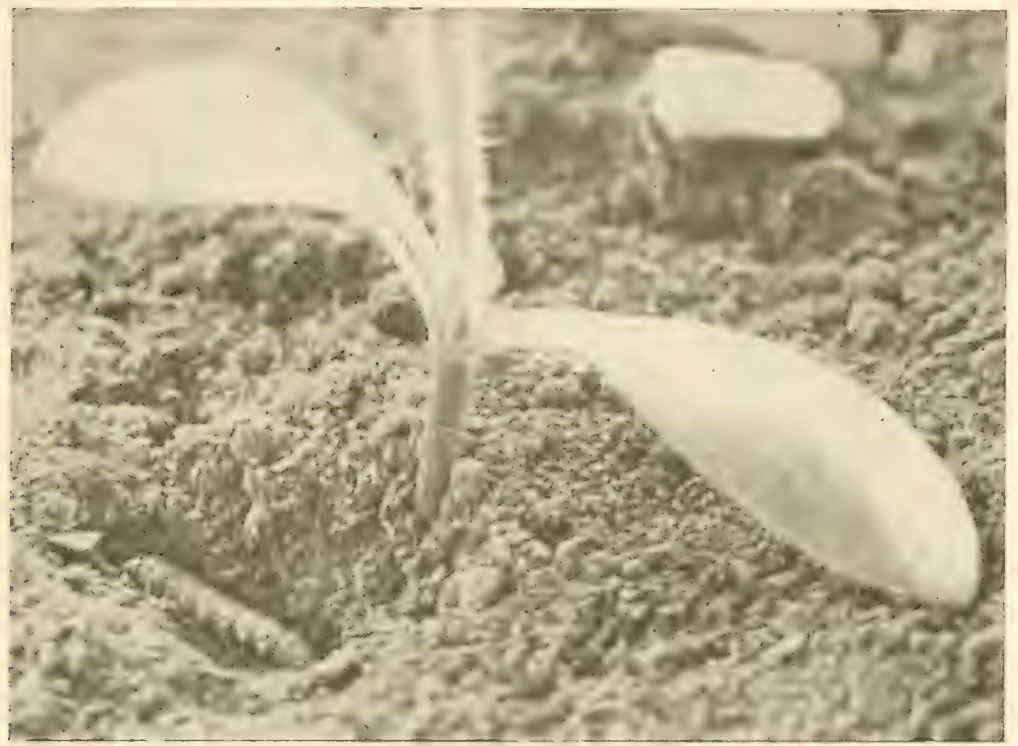

FIG. 61. - Earth removed from base of seedling to show eutworm in hidingnatural size.

they become overabundant they will eat anything green and succulent-foliage, flowers, buds, fruit, stalks, or roots, and sometimes
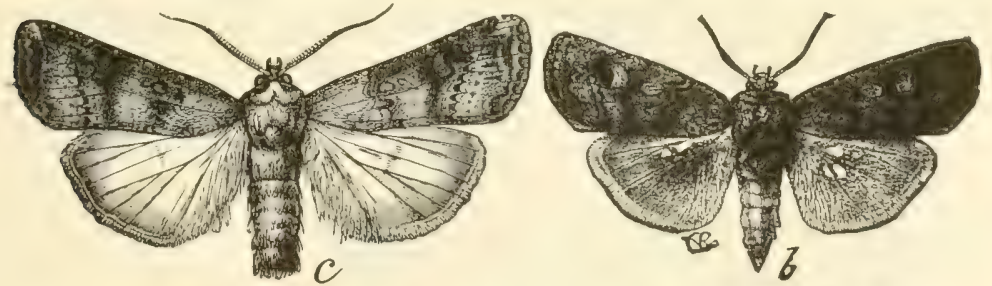

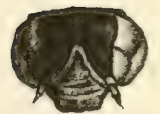

6

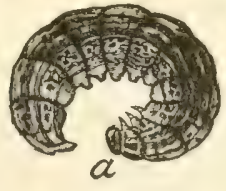

Fig. 62.-Greasy cutworm (Agrotis ypsiton); $a$, larva; $b$, head of same; $c$, adult-natural size. (After Howard, U. S. Dept. Agr.)

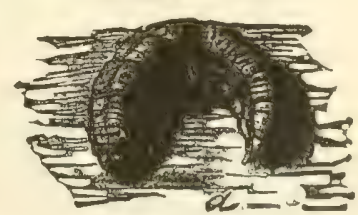

FtG. 63.-The dark-sided cutworm (Agrotis messoria). (After Riley.) 
migrate to other fields in armies like the army worms. Some species commonly climb young fruit trees which have been planted

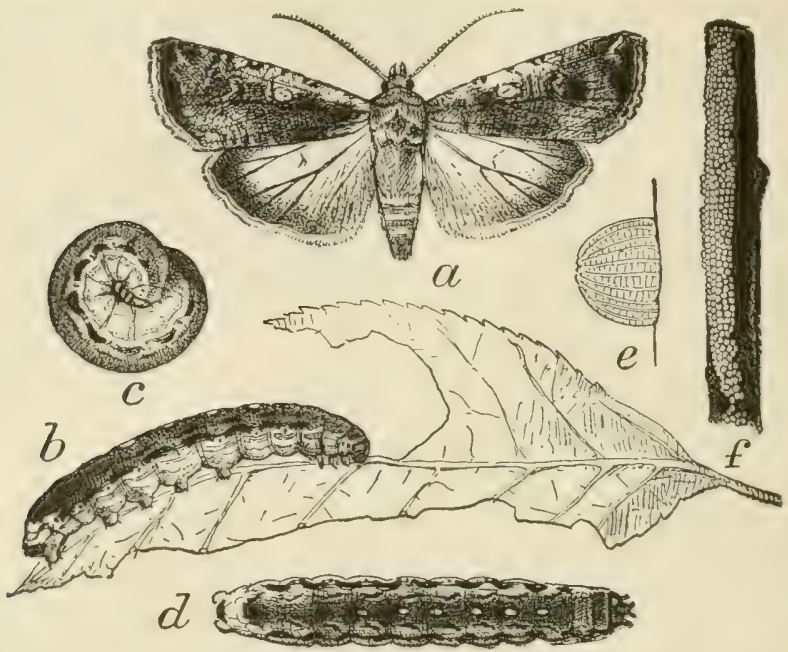

Fig. 64.-Peridromia sancia: $a$, adult, $b, c, d$, full-grown larvæ, $e, f$, eggs; all natural size except $e$, which is greatly' enlarged. (After Howard U. S. Dept. Agr )

on grassy land or which are allowed to grow in grass or weeds

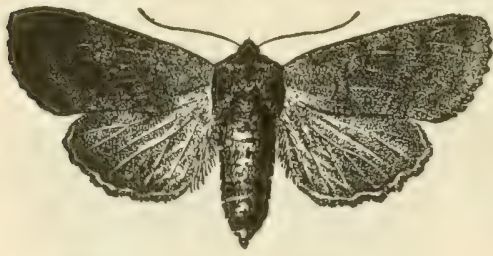
and are known as climbing cutworms. Our common species are most injurious to garden cropsand to corn, cotton, tobacco and similar crops grown in hills or rows, small grains and forage crops be-

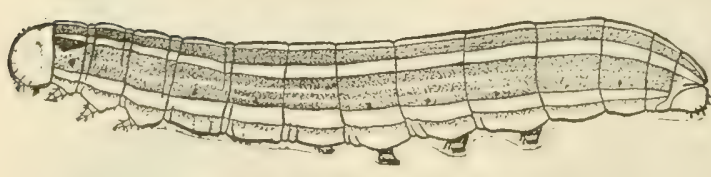

being injured but rarely.

Though over a score of species are common, it is not

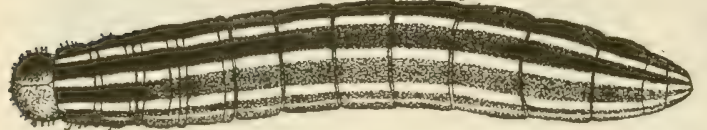
practicable to distinguish them in this discussion, and though their life

FIG. 65.-The bronzed cutworm (Vephelorles minians Guen.): back and side, views of larva-enlarged, and moth-natural size. (After Forbes.) 
histories are somewhat different, they may be considered as a class.

The adults are moths with dark fore wings, variously marked with darker or lighter spots and narrow bands as shown in Figs. 61-68, and with lighter hind-wings, which are folded over the back when at rest. Like the cutworms, they feed at night,
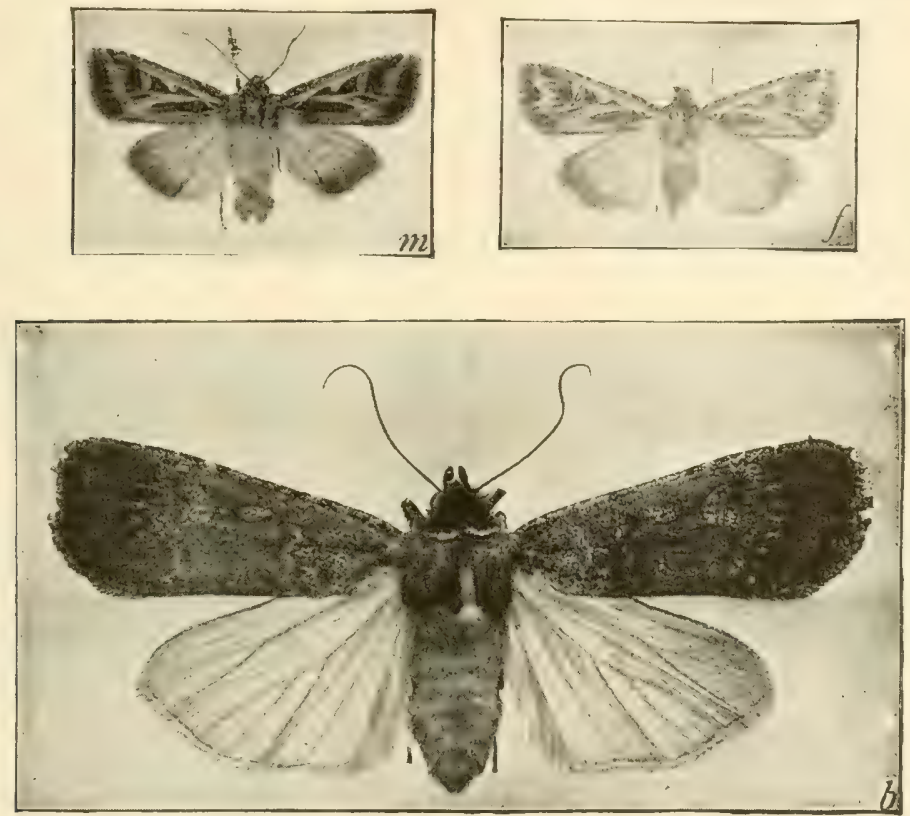

Fig. 66.-Cutworm moths: $b$, the well-marked cutworm-moth (Noctua clandestina Harris); the dingy cutworm (Feltia subgothica Haworth); male $(m)$ and female $(f)$ moths. (After Slingerland.)

sipping the nectar from flowers, and are known as owlet moths. The females deposit their eggs in grass land or where a crop has been allowed to grow up in grass and weeds in late summer, laying them in patches on the stems or leaves of grasses or weeds, or on stones or twigs in such places.

The little caterpillars which hatch from these eggs in August and September feed on the roots of whatever vegetation is available until frost, going deeper as it approaches, and finally hollow out small cells, in which they curl up and hibernate until the next 
spring. The next spring they are exceedingly hungry after their long fast, and attack any vegetation at hand with surprising voracity. If the land is in grass or weeds they have plenty of food, and if it is then plowed and planted in some crop, this will certainly be injured.

The cutworms usually become full grown during late spring or early summer, and are then about $1_{2}^{1}$ to 2 inches long, of a dull brown, gray or blackish color, often tinged with greenish, and more or less marked with longitudinal stripes, oblique dots and dashes, the markings usually being of a subdued tone, so that the cutworm harmonizes in color with the soil. They are cylindrical, with the head and prothoracic plate horny and reddish brown, and bear three pairs of jointed legs

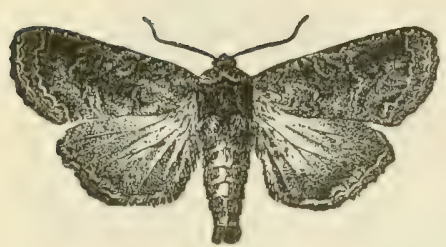

Fig. 67.- Moth of the glassy cutworm (Hadena devastatrix Brace). (After Forbes.)

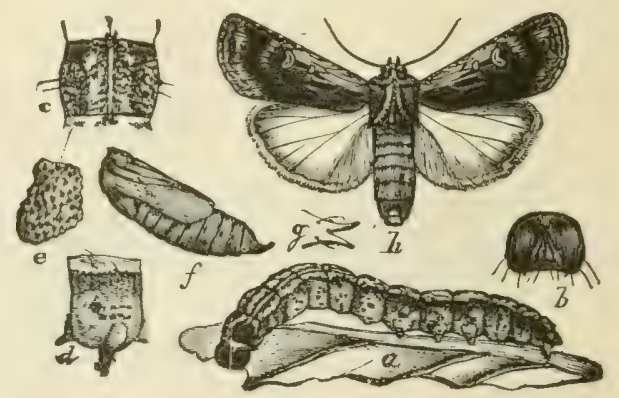

Fig. 68. - Granulated cut-worm (Agrotis ' annexa): $a$, larva; $f$, pupa; $h$, adultnatural size. (After Howard, U. S. Dept. Agr.)

on the thorax and five pairs of prolegs on the abdomen. The mature caterpillars pupate in cells a few inches below the surface and in three or four weeks the adult moths emerge, usually in July and early August in the Central and Northern States and earlier farther south.

Thus there is usually but one generation a year in the North while in the South there are commonly two generations and in some cases three. Though other stages than the larva of various species are known to hibernate sometimes, nevertheless the worst injury is usually done in the spring, when young plants have just been set or are just appearing. 
Control.-It is evident from their life history that like the white grubs and wireworms, cutworms may be most effectually combated by plowing in late fall and again plowing and harrowing thoroughly in early spring, so as to keep the land fallow and thus starve them out. Land which is to be planted in corn or crops subject to cutworm injury should be plowed as early as possible in late summer of the preceding year and kept fallow so that the moths will not deposit their eggs upon it, as they will if it is left in grass or weeds.

Poisoned bran mash (see p. 57) is probably the best thing for destroying eutworms, and if well applied a few days before plants are set or a few days after seed is planted, will often protect crops on infested land. On corn land it may be applied with a seed drill, and in gardens an onion drill is sometimes used in the same way, placing the mash on the surface near the plants; or it may be applied by hand, placing a tablespoonful near each plant or every 2 or 3 feet in the row. Distribute the mash late in the afternoon, so that it will still be moist when the worms feed at dusk. Keep poultry away from fields so treated. Clover which has been thoroughly sprayed or dipped in water containing one-third pound Paris green per barrel may be used in the same way, particularly along the outside of fields to be protected from invasion or along borders of fields next to grass.

Market gardeners frequently protect cabbage, tomato and similar plants by knocking the bottoms out of tin cans or making cylinders of building paper and placing these around the stems, sinking them into the soil. Where cutworms assume the climbing habit and attack fruit trees, distribute the bran mash or poisoned clover liberally around the bases of the trees and put a band of tanglefoot around the trunk of each tree, which will prevent their ascent. Thorough cultivation of the orchard and neighboring land will also reduce their numbers. When they assume the migratory habits of army worms, they may be controlled by the same methods as described for them. Garden plants may sometimes be protected from cutworms, as well as flea beetles, by dipping them in arsenate of lead, 3 pounds per barrel, when planting. 


\section{The Chinch-bug *}

The adult Chinch-bug is about onc-fifth inch long, with a black body. Its white wings lie folded over each other on the abdomen, and are marked by a small black triangle on their outer margins, while the bases of the antennæ and the legs are red. The young bugs are yellowish or bright red marked with brownish-black, becoming darker as they grow older. Along the Atantic coast and along the southern shores of the Great

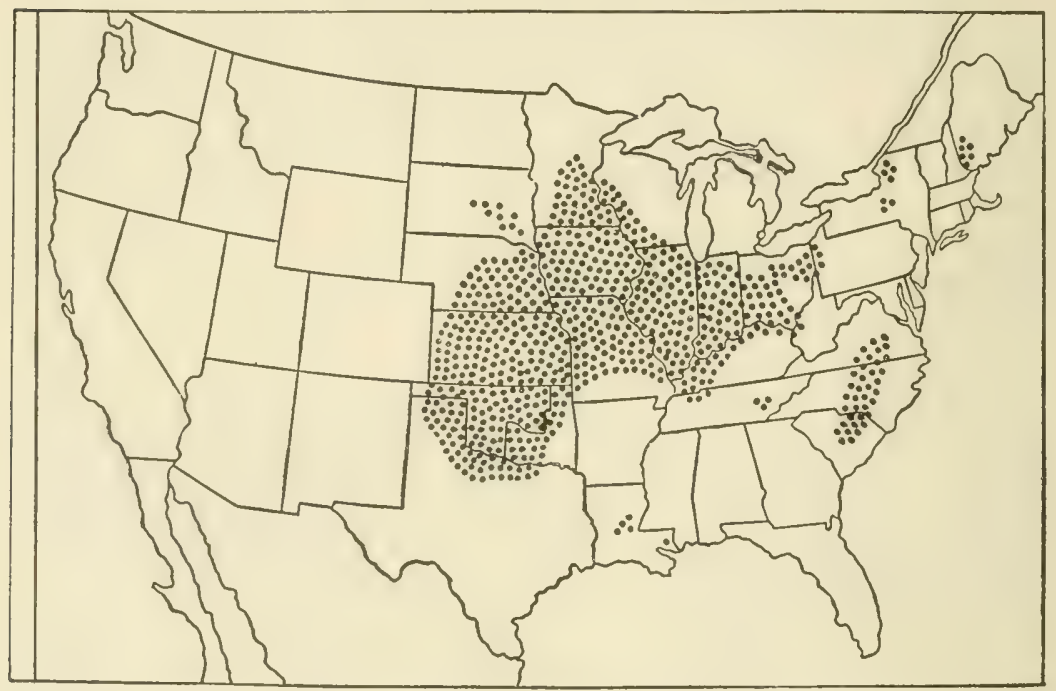

FIG. 69.-Areas in the United States over which the chinch-bug occurs in most destructive numbers. (After Webster, Dept. Agr., Farmer's Bulletin 657.)

Lakes north of a line from Pittsburg, Pa., to Toledo, Ohio, the majority of the adults have short wings reaching but half over the abdomen and are incapable of flight; but between the Alleghany and Rocky Mountains the long-winged form greatly predominates. It occurs also in restricted localities in Central America and along the Pacific coast. The worst injury is to small grains and corn in the Central and North Central States, but frequently injury is done, in the Eastern States especially, to timothy meadows which have stood for several years. Though individually insig-

* Blissus leucopterus Say. Family Lygøido. 
nificant, when assembled in countless myriads chinch-bugs have doubtless been of greater injury to the farmers of the Mississippi Valley than almost any other insect at tacking grain crops, the total damage from 1850 to 1909 being estimated at $\$ 350,000,000 *{ }^{*}$

Life History.-During the winter the bugs hibernate in clumps of grass, in corn butts, and in old shocks of corn, or under whatever rubbish is available. In early spring they assemble in fields of grass and small grains. Soon they pair and the females commence to lay their small yellowish-white eggs upon the roots or bases of the stalks, each laying some 150 to 200 eggs.
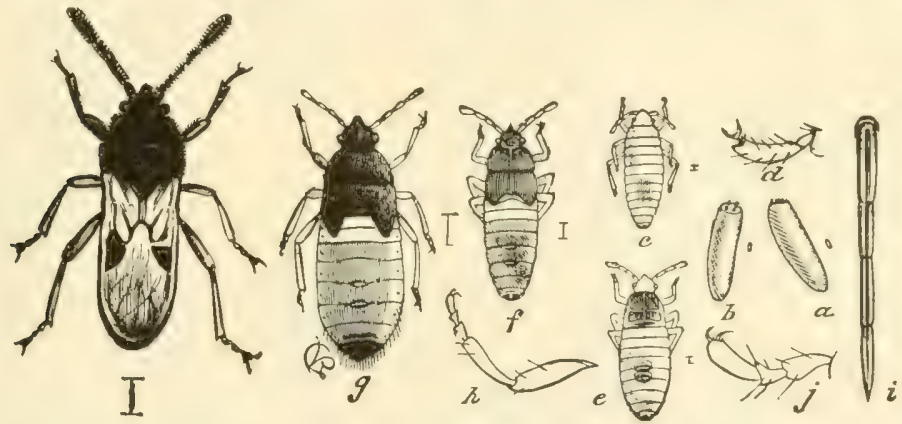

FIg. 70.-The chinch-bug (Blissus leucopterus Say): adult at left; $a, b$, eggs magnified and natural size; $c$, young nymph; $e$, second stage of nymph; $f$, third stage; $g$, full-grown nymph or pupa; $d, h, j$, legs; $i$, beak through which the bug sucks its food. (After Riley.)

The eggs are laid from the middle of April until the first of June, depending upon the latitude and weather, and hatch in two or three weeks. As the nymphs grow they often do serious injury to small grains and grass, upon which they become full grown about the time of harvest. When wheat is harvested they spread to oats and soon to corn, but, curiously enough, though the adults have wings they travel from field to field on foot, were it not for which fact we should be at a loss to cope with their migration. Eggs are now laid upon the unfolding leaves of the corn, from which the nymphs commence to emerge in about ten days. This second brood matures on corn in August and September and is the one which later hibernates over winter, though where corn is not available the whole season may be passed on grass.

* See Circular 113, Bureau Entomology, U. S. Dept. Agr., F. M. Webster, and Headlee and McColloch, Kansas Expt. Sta. Bulletin No. 191. 
Control.- The burning over of grass land, and the grass along fences, hedges, and roads, as soon as it becomes dry enough in late fall and early winter, is of prime importance to destroy the bugs after they have gone into hibernation. The removal of all corn stalks from the fields and plowing the butts under

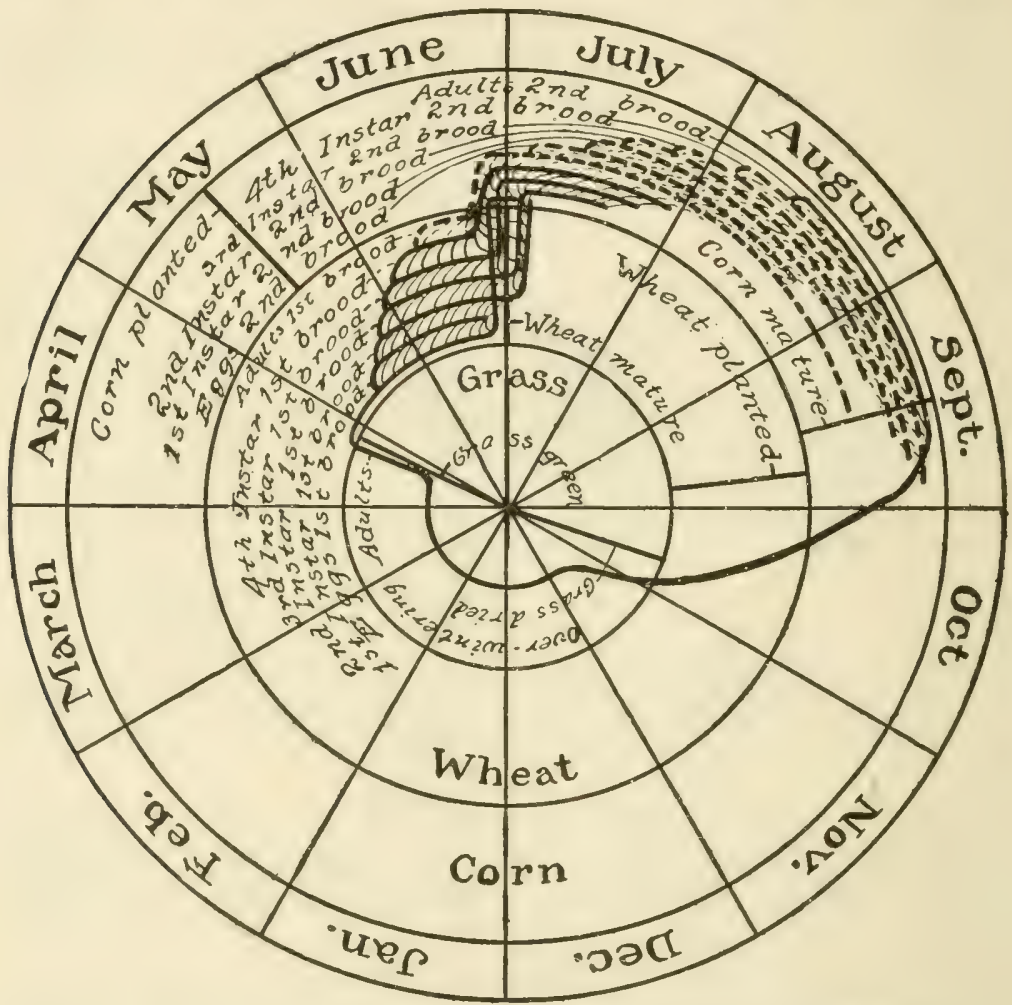

FIG. 71.-Seasonal eycle of the chinch-bug. (From Headlee and McColloch.) deeply, or where the bugs are very abundant, raking out the butts and burning them, will help rid the fields of the pest.

It is practically impossible to combat the pest in the summer on grass or small grains, but its migration to corn or from field to field may be effectually checked. In dry weather a dust furrow may be used as a barrier to good advantage. Just before harvest plow a deep furrow around the field to be protected, or on the threatened sides, and thoroughly pulverize the soil by 

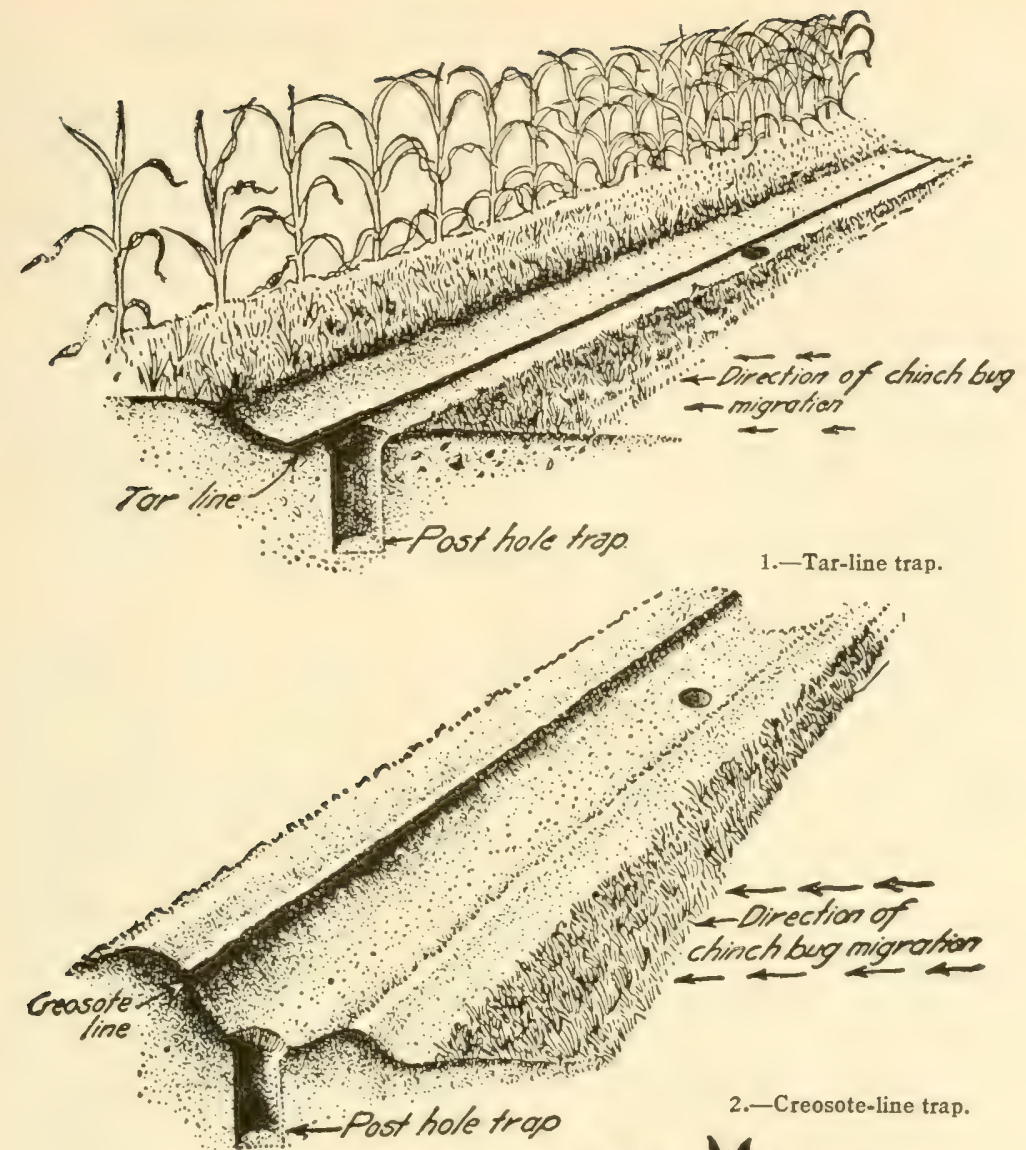

2.-Creosote-line trap.

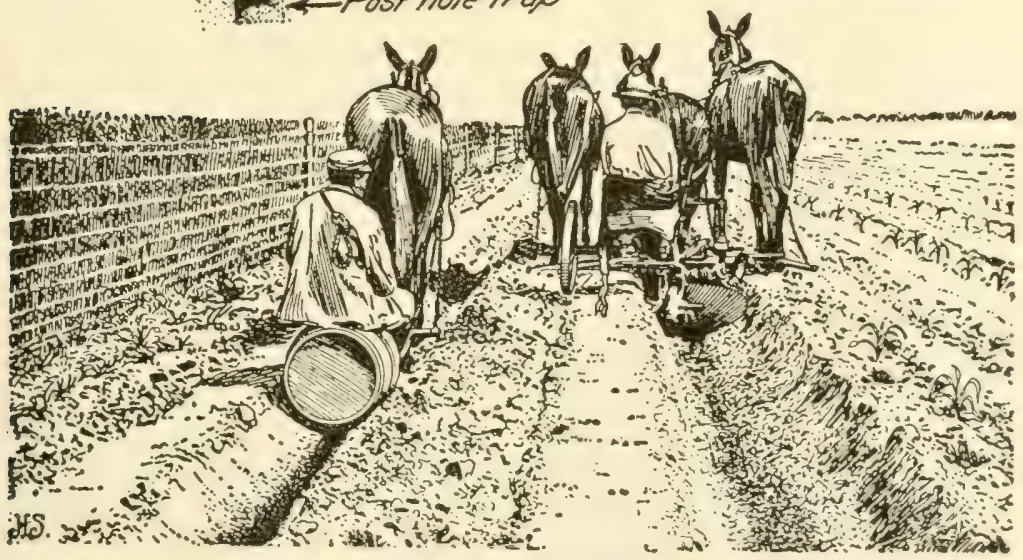

3.-Dusty-furrow. trap.

FIG. 72.-Barriers for chinch-bugs, showing methods of construction. (U. S. D. A. Bureau of Entomology.) 
dragging a heavy log back and forth in the furrow, making the side next the corn as steep as possible.* In attempting to climb this barrior, the dust will slicle from under the bugs and large numbers will accumulate in the bottom of the furrow, where they will be killed by the heat of the soil if it has a temperature from $110^{\circ}$ to $120^{\circ}$ (air temperature of over $90^{\circ}$ ). Feep the furrow clean by dragging a log through it now and then. Sink post-holes a foot deep every few feet in the bottom of the furrow and the bugs will collect in them and may be crushed or killed with kerosene. Such a dust furrow will be of no value in showery weather, and is most effective in hot dry weather on light soil; it may often be used to advantage in combination with the following methods.

In place of the dust furrow or in combination with it, a strip of coal tar is often rur around the field. The strip, which should be about the size of one's finger, can be made by pouring from a watering can with the mouth stopped down, and should be run inside the dust furrow and with post-holes sunk along its outer edge. Sometimes it is run in a zig-zag line with the holes at the immer angles so that the bugs will be concentrated at the holes. These tar strips must be freshened whenever dust or rubbish covers them. The soil may be prepared for the tar strip by plowing a back furrow and packing the top with a roller or beating it hard with spades; or a strip of sod may be prepared by scraping away the grass with a farm scraper and then smoothing carefully with shovels or hoes; or a dead furrow may be run and the tar strip run on the smooth bottom. To maintain such a tar strip for four weeks costs about $\$ 2$ a mile and has proven itself entirely practical and effective.

- if the bugs have already become numerous in the outer rows of corn, most of them may be destroyed by spraying with kerosene emulsion (see p. 44) made to contain four per cent kerosene, applying it in the early morning or towards night. It costs 65 cents a barrel diluted, and a man will spray five acres per day, using a

* Such a furrow ${ }^{\top}$ may possibly be made more readily by plowing several surrows and harrowing the ground thoroughly until reduced to a fine mulch and then plowing a dead furrow through the middle, and then dragging this with a log, making the sides as steep as possible. With such construction the furrow will cost about five cents per linear rod. 
barrel per acre. Whale-oil soap, one-half pound to the gallon of water, has proven equally effective and cost $\$ 2.00$ per barrel.

A blast torch, for which an attachment is furnished with many of the compressed-air sprayers, may be used to advantage for destroying the bugs in a dust furrow or along the tar line, or a spray of pure kerosene or crude petroleum may be used for the same purpose.

Extensive experiments have been made in Illinois and Kansas with the use of the muscardine fungus ${ }^{*}$ against the chinch-bug. Though occasionally the results seem to be profitable, and though it is undoubtedly effective in wet seasons and it may be well to distribute the fungus to places where it does not occur so that it may reduce the numbers of the bugs in wet seasons, it seems to be of very little value in dry seasons, when the injury is worst, and cannot be relied upon to check the increase of the pest when used according to the methods so far devised.

When chinch-bugs become abundant and their migration to corn seems imminent, the farmer should prepare to devote himself and as many hands as necessary to fighting them until their advance is checked, for delay will mean ruin, while the prompt use of the above methods will save the corn crop.

\section{Grasshoppers or Locusts $\dagger$}

Plagues of destructive locusts - or what we Americans call grasshoppers - have been recorded since the dawn of history. In America the worst devastation was done by the flights of the Rocky Mountain or Migratory Locust (Melanoplus spretus Thos.), which swooped down upon the States of the western part of the Mississippi Valley in the years 1873 to 1876 in destructive clouds.

\section{The Rocky Mountain Locust}

Let us first consider the species which has been the most injurious, as the other locusts differ from it in but few essential points other than in being non-migratory.

To understand correctly its habits the reader should first divide the area which this species affected into three parts. Of

*Sporotrichum globuliferum.

$\dagger$ Various species of the family Acrididoc. See W. R. Walton, Farmers' Bulletin 747, U. S. Dept. Agr. 
these (1) the Permanent Region, which included the highlands of Montana, Wyoming, and Colorado, formed the native breedinggrounds, where the species was always found in greater or less abundance;* (2) the Subpermanent Region, which included Manitoba, the Dakotas, and western Kansas, was frequently invaded; here the species might perpetuate itself for several years, but disappeared from it in time; (3) the Temporary Region, which included the States bordering the Mississippi River on the west, was that only periodically visited and from which the species generally disappeared within a year.

Spread-When for various reasons the locusts became excessively abundant in the Permanent Region they spread to the Subpermanent Region, and from there migrated to the Temporary feeding-grounds. It was the latter area which suffered most severely from their attacks, but, fortunately, they did not do serious injury the next year after a general migration. In the Subpermanent Region their injuries were more frequent than in the Temporary, but were hardly as severe or sudden as farther east. Migrating from their native haunts, flights of the grasshoppers usually reached southern Dakota in early summer, Colorado, Nebraska, Minnesota, Iowa, and western Kansas during midsummer, and southeastern Kansas and Missouri
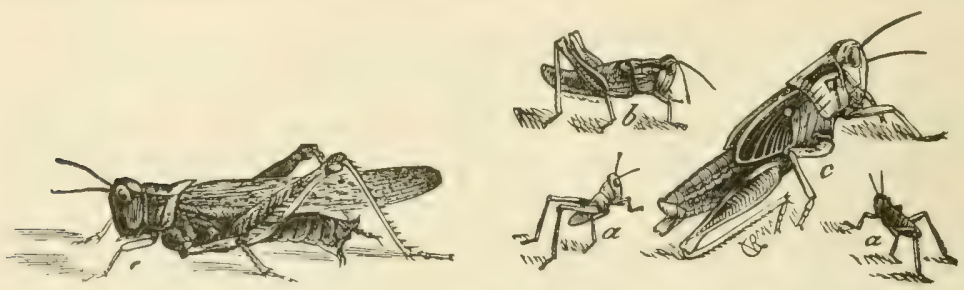

FIg. 73.-Rocky Mountain lneust; adult and different stages of growth of young. (After Riley.)

during late summer, appearing at Dallas, Texas, in 187.1, and aboist the middle of October, and even later in 1876. As thus indicated, the flights were in a general south to southeasterly direction, while west of the Rockies they descended to the more fertile valleys and plains, but without any such regularity as eastward. While the rate of these flights was variable and entirely dependent upon local weather conditions, twenty miles per day was con* Bull. 25, U. S. Dept. Agr., Div. Entomology. C. V. Riley. 
sidered a fair average. The flights were more rapid and more distance was covered in the early part of the season, when, while crossing the dry prairies, a good wind often enabled them to cover 200 to 300 miles in a day. As they first commenced to alight in their new feeding-grounds their stay was limited to but two or three days, but later in the season it was considerably lengthened, and, after a section was once infested, swarms were seen to be constantly rising and dropping during the midclle of the day.

Life History.-Over all the infested area, and while still sweeping it bare of crops and vegetation, the females commence to lay their eggs, and continue to deposit them from the middle of August until frost. For this purpose "bare sandy places, especially on

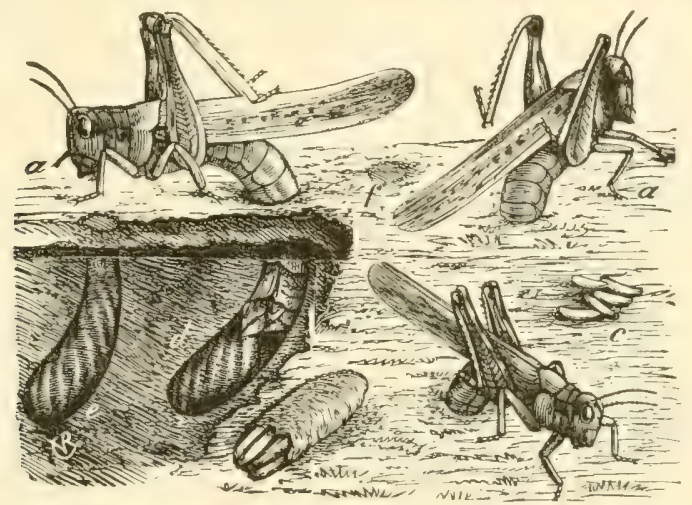

FIG. 74.-Rocky Mountain locusts: $a, a, a$, females in different positions, ovipositing; $b$, egg-pod extracted from ground, with end broken open; $c$, a few eggs lying loose on ground; $d, e$, showed the earth partially removed, to illustrate an egg-mass already in place and one being placed; $f$, shows where such an egg-mass has been covered up. (After Riley.)

high, dry ground, which is tolerahly compact and not loose," are preferred. "Meadows and pastures where the grass is closely grazed are much used, while moist or wet ground is generally avoided."

In such places the female deposits her eggs in masses of about thirty. These are placed about an inch below the surface in a pod-like cavity, which is lined and the eggs are covered by a mucous fluid excreted during oviposition. From two to five hours are required for this operation, and an average of three of these masses is deposited during a period of from six to eight weeks. 
As the time of ovipositing varies with the latitude, so the hatching of the eggs occurs from the middle or last of March in Texas till the midclle of May or first of June in Minnesota and Manitoba. Until after the molt of the first skin, and often till after the second or third molt, the young nymphs are content to feed in the immediate vicinity of their birth. When the foor becomes scarce they congregate together and in solid bodies, sometimes as much as a mile wide, march across the country, devouring every green crop and weed as they go. During cold or damp weather and at night they collect under rubbish, in stools of grass, etc., and at such times almost seem to have disappeared; but a few hours of sunshine brings them forth, as voracious as ever. When, on account of the immense numbers assembled together; it becomes impossible for all to obtain green food, the unfortunate ones first clean out the underbrush and then feed upon the dead leaves and bark of timberlands, and have often been known to gnaw fences and frame buildings. Stories of their incredible appetites are legion; a friend informs me that he still possesses a rawhide whip which they had quite noticeably gnawed in a single night!

As the nymphs become full grown they are increasingly subject to the attacks of predaceous birds and insects, insect parasites, fungous and bacterial diseases, and are also largely reduced by the cannibalistic appetites of their own numbers. When the mature nymphs transform to adult grasshoppers and thus become winged, large swarms are seen rising from the fields and flying toward their native home in the Northwest. This usually takes place during June and early July in the North, and as early as April in Texas, so that it is frequently impossible to distinguish the broods of the temporary region from the incoming brood which has migrated from the permanent region. Although the eggs for a second brood are sometimes laid, these seldom come to maturity, and the species is essentially singlebrooded.

\section{The Lesser Migratory Locust}

Besides the Rocky Mountain locust there is only one other species that truly possesses the habit of migrating, though to a far lesser extent, and which is therefore known as the Lesser Migratory Locust (Melanoplus atlantis Riley). It is considerably 
smaller than its western relative and somewhat resembles the red-legged locust both in size and appearance. The species is very widely distributed, occurring from Florida to the Arctic Circle east of the Mississippi, and on the Pacific slope north of the fortieth parallel to the Yukon. The habits and life history of the species are in all essentials practically the same as the former species, except that they have no particular breedinggrounds. Injuries by this grasshopper were first noticed in 1743, almost seventy-five years before the first record of the Rocky Mountain locust, and since then it has done more or less serious damage in some part of the territory inhabited every few years.

\section{Non-Migratory Locusts}

There are several species of locusts which, though lacking the migratory habit, and thus being more easily controlled, often become so numerous as to do serious damage over limited areas. Both as regards the regions inhabited, and its habits, life history, the common Red-legged Locust (1/alanoplus femur-rubrum Har.) hardly dif-

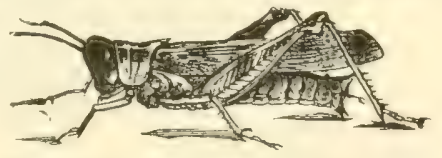

Fig. 75. - Red-legged locust (.Mclanoplus femur-rubrum Harr.). (After Riley.) fers from the last species, and is often found in company with it. It is non-migratory, however, and though the damage it does is thus entirely local, it is often of considerable importance.

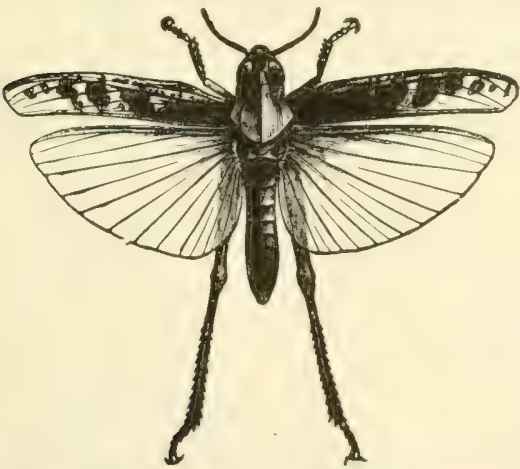

Fig. 76.-The pellucid locust (C'ammula pellucida Scud.). (After Emerton.)

Records of locust plagues in California date back as far as 1722. Many of them were doubtless due to the California Devastating Locust (Melanoplus devastator Scud.), and in the last invasion of 1885 this species outnumbered all other's seven to one. Resembling the last two species in size and markings, the habits and life history of this species are also supposed to be similar to them, though they have not as yet been thoroughly studied.

Together with the last species the Pellucid Locust (Cammula pellucida Scud.) has been largely responsible for the losses ocea- 
sioned by locusts in Califomia, and has also been found in New England, but is not noted there as especially destructive.

Our largest winged American Locust, the American Acridium (Schistocerca americana Scud.), is practically confined to the Southern States from the District of Columbia to Texas, and thence south through Mexico and Central America, being rarely found in the North. This species is essentially a tropical one, and has often been exceedingly destructive, being especially so in 1876 in Missouri, Tennessee North Carolina, Georgia, and southern Ohio.

Considerably larger than the preceding species are the Differential Locust (Melanoplus differentialis Thos.) and the Two-

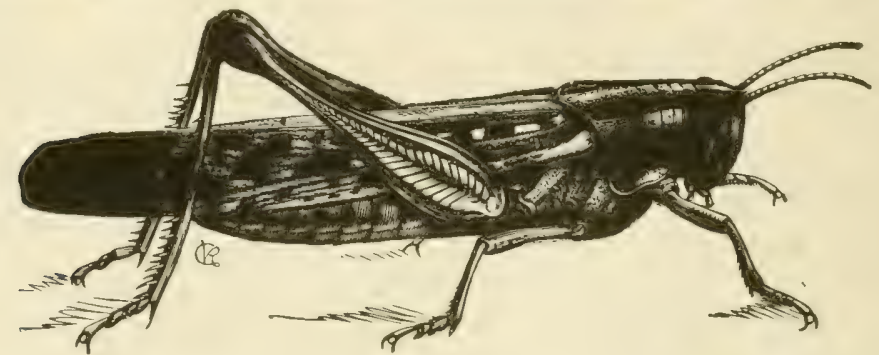

FIG. 77.-The American acridium (Schistocerca americana Scud.). (After Riley.)

striped Locust (Melanoplus bivittatus Seud.), of which the former is peculiar to the central states of the Mississippi Valley, Texas, New Mexico, and California, while the latter has a more extended range from Maine to Utah and as far south as Carolina and Texas. These two differ from the smaller species in laying

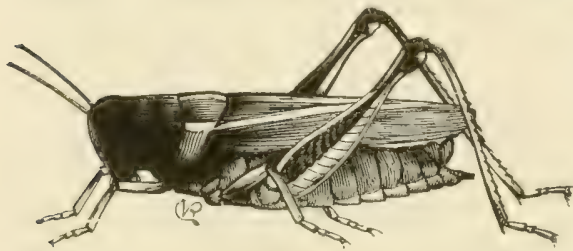

FIG. 78.-The Two-striped locust (1/4clanoplus bivittatus Scud.). (After Riley. only one or two masses of eggs, and the eggs of differentialis have often been found placed under the bark of $\operatorname{logs}$, but otherwise their habits are very similar. The two-striped locust is characterized by two yellowish stripes extending from the eyes along the sides of the head and thorax to the extremities of the wing-covers, and is ${ }^{\circ}$ probably the species most commonly observed by the farmer. 


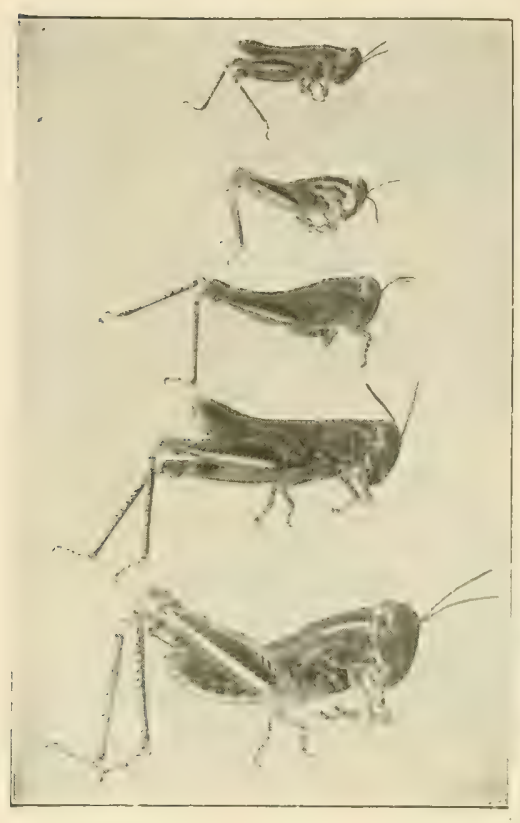

The hoppers become full grown bout the first of July. The adult is about $1 \frac{1}{2}$ inches long, its wings expand $2 \frac{1}{2}$ inches, and it is of a bright yellowish-green color. The head and thorax are olive-brown, and the front wings are of much the same color, without other markings, but with a brownish shade at the base; the hind-wings are tinged with green; the hind-thighs are bright yellow, especially below, with four black marks; the hindshanks are yellow with black spines and a ring of the same color near the base. The adults at once attack whatever crops are available, often finishing the destruction of those injured by them as nymphs, but

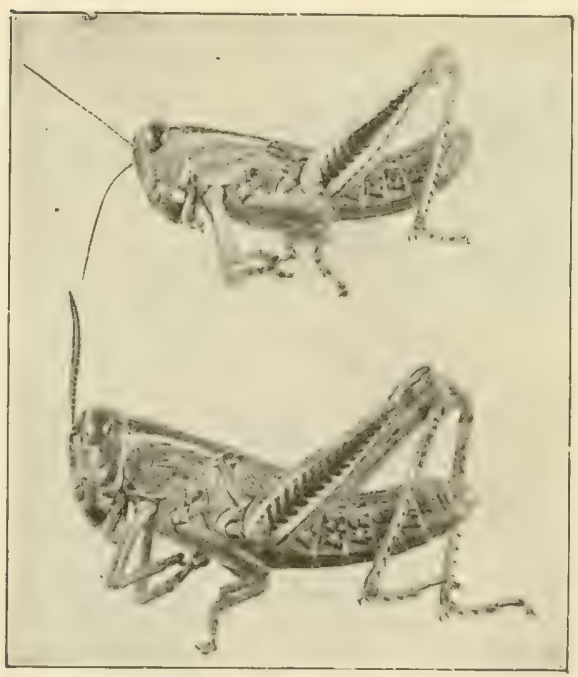

Fin. 82.-Nymphs of the differential locust in different stages ( 1 to 5 ) of growthall enlarged. in a few days their appetites seem to become somewhat appeased and they commence to mate and wander in search of suitable places for laying the eggs. Relatively few eggs are laid in cultivated ground, the favorite places being neglected fields grown up in grass and weeds, the edges of cultivated fields, private roadways, banks of ditches and small streams, and pasture lands. Alfalfa land is a favorite place for oviposition, and alfalfa is frequently seriously injured by this species. It is doubtless due 
to these egg-laying habits and the abundance of food on uncultivated land that this species always increases enormously on land which has been flooded and then lies idle for a year or two.

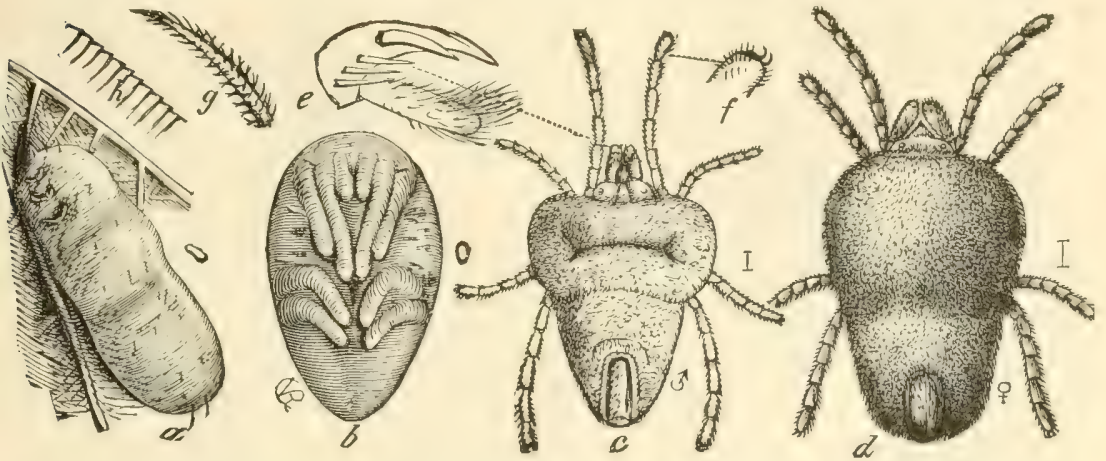

Fig. 83.-A Locust-mite (Trombidium locustarum): $a$, the larva as seen on locust's wing; $c$, male mite; $d$, female, the two latter appearing as when egg-destroyers-all greatly enlarged. (After Riley.)

Most of the eggs are laid in August and early September. Each female deposits a single egg mass of about 100 eggs just beneath the surface of the soil. During this season the females may frequently be found with the abdomens thrust deep in the soil, as the process of egg-laying requires some time. The eggs are yellow and arranged irregularly in a mass which is coated with a gluey substance to which the earth a d heres, which protects them from variable conditions of mois-

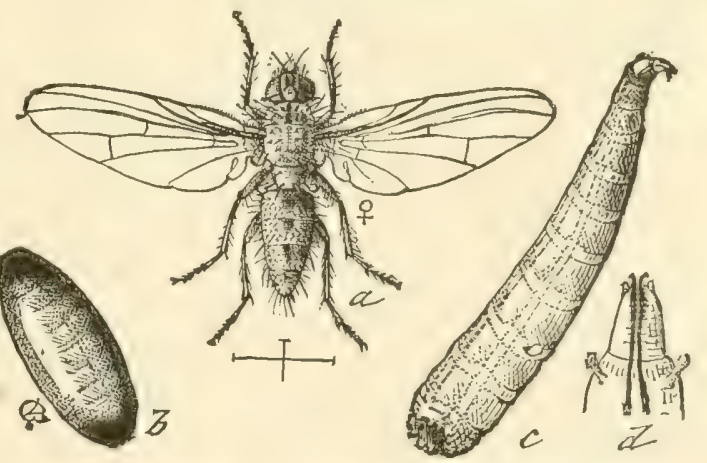

Fig. 84.-Anthomyia egg-parasite. $a$, fly, $b$, puparium; $c$, larva; $d$, head of larva. (After Riley.) ture and temperature.

Enemies.-As before mentioned, large numbers of the nymphs are destroyed before reaching maturity by their natural enemies. Among these a minute fungus undoubtedly lills many of those already somewhat exhausted, especially during damp weather. 
Almost all of our common birds, as well as many of the smaller mammals, are known to feed quite largely upon them.

A small red mite (Trombidium locustarum Riley), somewhat
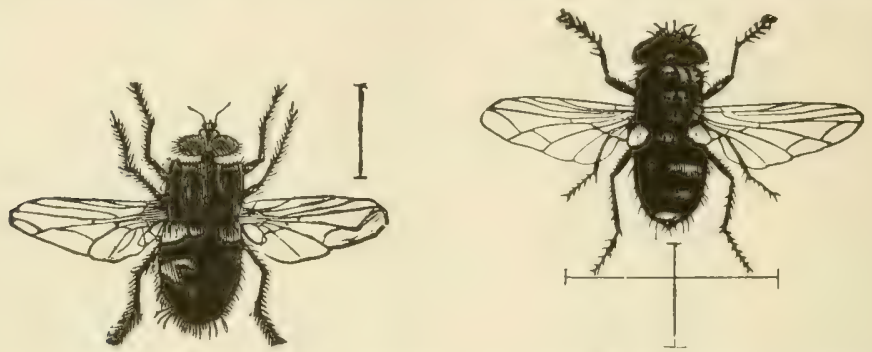

FIG. 85.-Two tachina-flies. (Exorista lcucaniœ Kirk. and E. flavicauda Riley.) (After Riley.)

resembling the common red spider infesting greenhouses, is often of great value not only in killing the nymphs by great numbers of them sucking out the life-juices of the young hopper, but also in greedily feeding upon the eggs.

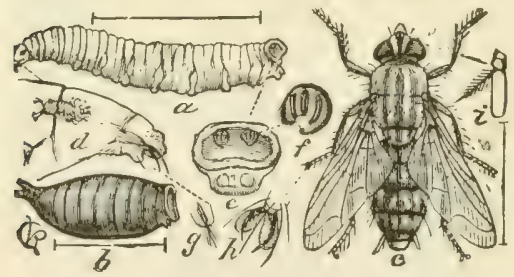

Fig. 86.-Common flesh-fly (Sarcophaga carnaria Linn.): $a$, larva; $b$, pupa; $c$, fly. Hair-lines show natural size. (After Riley.)

descend into the earth, and there transform to pupæ inside of their cast skins, and from the pupre the adult flies emerge in due time.

The maggots of one of the Bee-flies (Systcrchus oreas) feed upon grasshopper eggs, but their life history is not fully known.

The common Flesh-fly (Sarcophaga carnaria Linn.), Fig. 86, is also very destructive, though largely a scavenger.

But of all the insects attacking locusts, the Blister-beetles, which, unfortunately, are often known to us as very injurious to various garden crops, are probably of the most value. The female beetle deposits from four to five hundred of her yellowish eggs in irregular masses in loose ground, and in about ten days 
there hatch from these eggs some "very active, long-legged larvæ, with huge heads and strong jaws, which run about everywhere seeking the eggs of locusts." Each of these larvæ will consume one of the masses or about thirty eggs. The subsequent life history of these insects is very complicated on account of their peculiar habits, but the various stages are shown in Fig. 87.

Control.-As the eggs are usually laid in the ground in the fall, deep plowing in late fall or early spring effectually buries
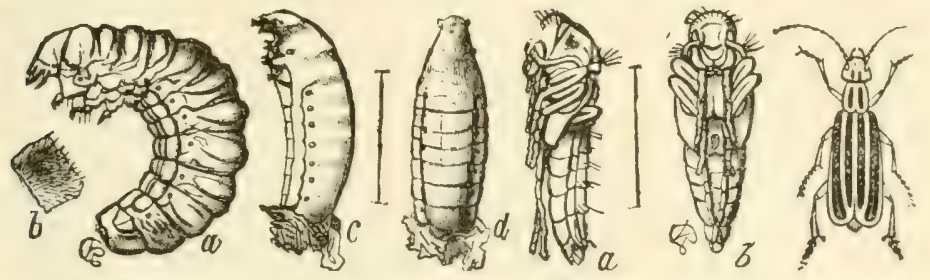

Fia. 87.-Various stages of a blister-beetle (Epicauta vittata). (After Riley.) them too deep for the young nymphs to emerge. On alfalfa land thorough disking is often used for the same purpose. Thorough harrowing in the fall so as to pulverize the soil for the depth of an inch will break up many of the egg masses, though it is not as sure a control as plowing them under.

When the young emerge, they may sometimes be destroyed by burning over stubble, grass and rubbish where it is present in sufficient quantities, or by augmenting it with straw, which may be done to advantage on cold days when the nymphs are congregated in such shelter. If the surface of the ground is smooth and hard many may be killed by the use of a heavy roller, particularly in the morning and evening, when they are sluggish in their movements. Plowing a badly infested field in a square, working toward the centre so as to drive the young nymphs inward, will result in burying many of them in the furrows, and the last may be burned or trapped in holes as described below. Simple ditches 2 feet wide and 2 feet deep form effectual barriers for the young hoppers. The sides next to the crop to be protected should be kept finely pulverized by hauling a $\log$ or a brush of dead branches through the ditch. The ditch may be made as described for chinch-bugs and is handled in the same manner, the little hoppers drifting to the bottom of the ditch, where they are killed by the heat on a hot day or 


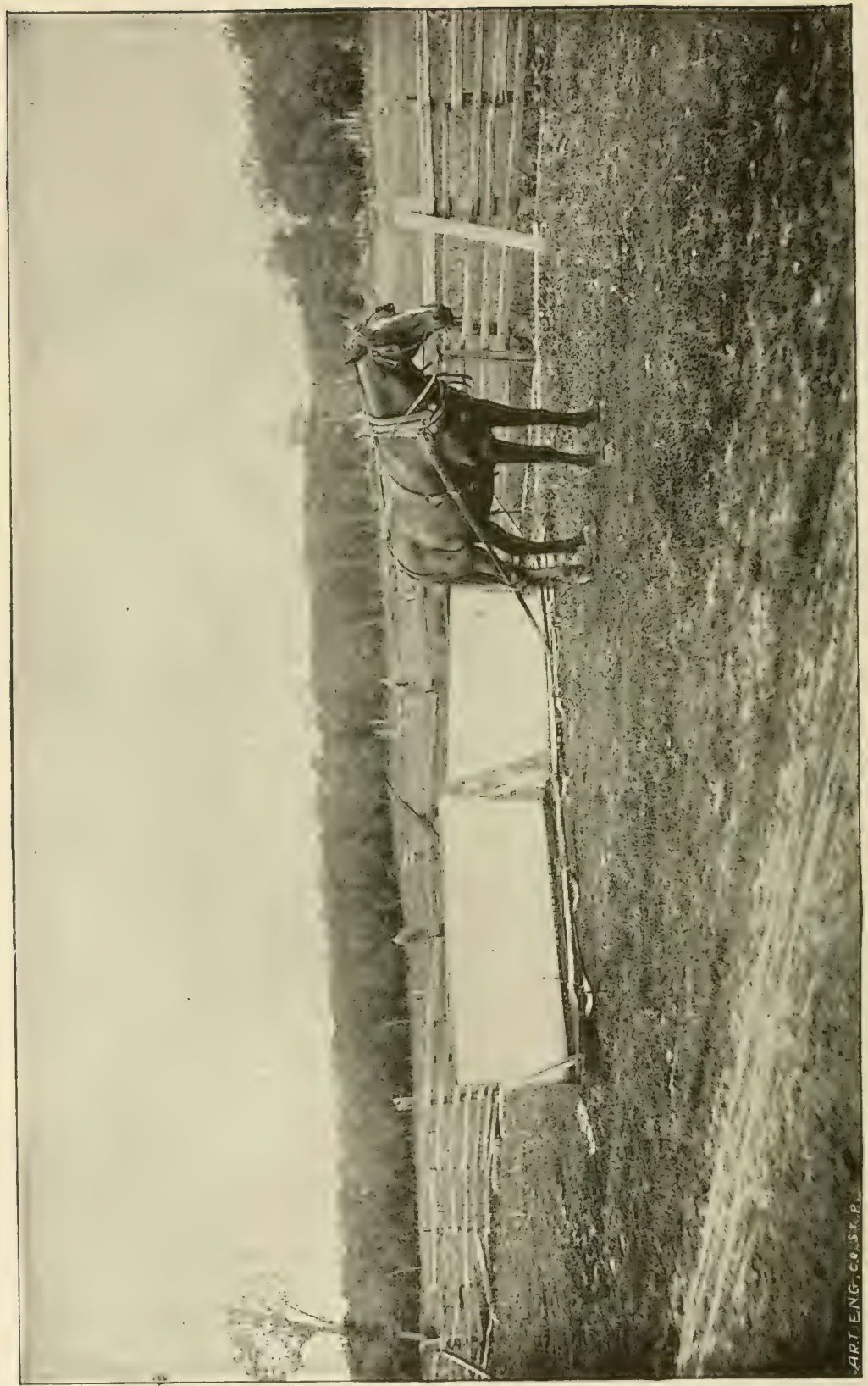

Fig. 88.-Two hopperdozers, tied together, at work. (After Lugger, Bull. 43, (Minn. Agr. Exp. Sta.) 
where they are caught in post-holes sunk every few feet in the bottom of the ditch. This method may be used to advantage in plots of corn, cotton, or garden truck which has already become infested, by running furrows around the field and occasionally through it, and then driving the young hoppers toward them, which may be readily done by a number of children armed with branches. Where ditches containing water are available the young hoppers may be very effectively destroyed by oiling the surface of the water with kerosene emulsion and then driving

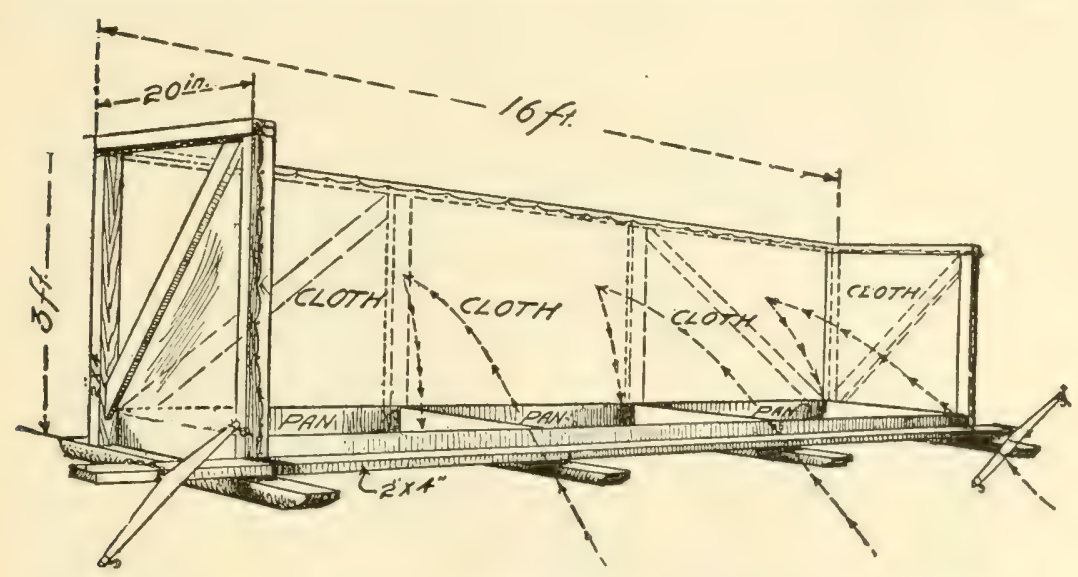

FIg. 89.-Hopperdozer with cloth back, showing construction. (After W. R. Walton, Farmers' Bulletin 747, U. S. Dept. of Agriculture.)

them into the ditches, for even if they succeed in crawling out they will succumb to the oil.

In pastures, small grains or any crops permitting their use, immense numbers of the nymphs may be caught by the use of hopperdozers, which may be utilized where the use of poisoned bran would not be possible. The hopperdozer consists of a shallow pan containing water with a surface of kerosene, crude petroleum, or coal tar, which is sometimes used without water. The pan is mounted on runners or wheels and if larger than about 3 feet square is usually provided with partitions to prevent slopping. The back and sides are high and sometimes are made of canvas. "A good cheap pan is made of ordinary sheet iron, 8 feet long, 11 inches wide at the bottom, and turned up a foot 
high at the back and an inch high in front. A runner at each end, extending some distance behind, and a cord attached to each front corner, complete the pan. We have known of from seven to ten bushels of young locusts caught with one such pan in an afternoon. It is easily pulled by two boys, and by running several together in a row, one boy to each rope, and one to each contiguous pair, the best work is performed with the least labor." Larger pans are drawn or pushed by horses. The oil is best used on the surface of water, from which the insects are removed with a strainer, and any which hop out will die after having come in contact with the oil.

Destroying the Adults. - The destruction of the winged insects is an entirely hopeless task, for, though even large numbers

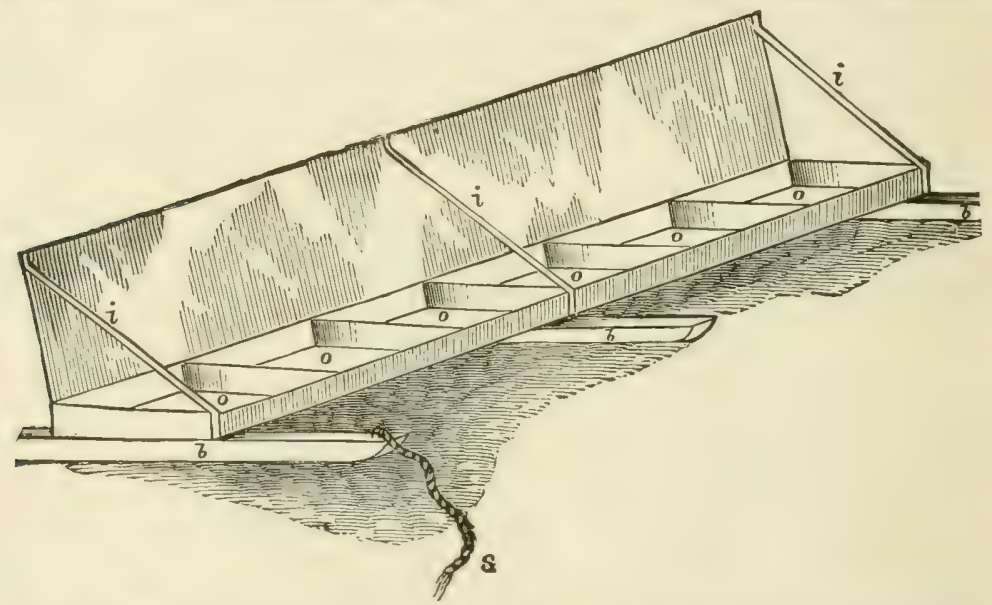

Fig. 90.-The Price oil-pan or hopperdozer, with partitions to prevent slopping. (After Riley.)

are caught, so many will remain that the damage done the crops would be but very slightly diminished. One of the most promising means for preventing the swarms of winged migratory locusts from alighting in the fields is by a dense smudge, in which some foul-smelling substances are placed. Where strictly attended, and with favorable winds, this has often proved highly successful. To accomplish the best results farmers over an extensive area should combine in its use. 
The South African Fungus.--In 1900 Professor Morgan made a test of a fungous disease which had been found to destroy large numbers of grasshoppers in South Africa, to determine whether, after starting it by artificial propagation, it would spread sufficiently to destroy any considerable number of locusts The weather was favorable, rains being frequent. Early in August it was found that " over the areas where the liquid infection

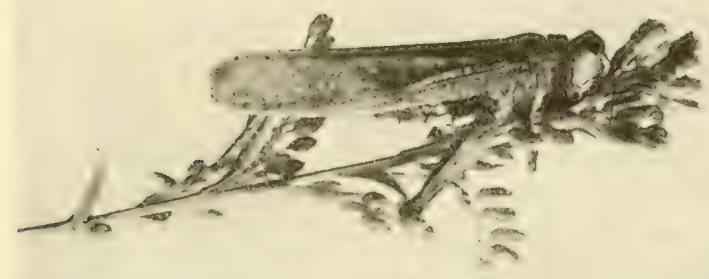

F'IG. 91.-Carolina locust killed by fungous disease. (Photo by Weed.)

was spread diseased hoppers were abundant." "As many as a dozen dead grasshoppers could be found upon a single plant, and some upon nearly every weed on ditch-banks where grasshoppers were numerous. From the centres of infection great areas had become inoculated, spreading even beyond the plantations first infected." The property upon which it was placed became thoroughly infected with the fungus. Strangely, though many other species of grasshoppers were abundant, only the differential locust was killed by it. Dr. Howard states that this disease has also spread and done effective work in Colorado. However, more recent experiments made by the writer in Texas gave only negative results, and it is doubtful if any reliance can be placed upon the artificial use of such fungous diseases for locust control.

Poisoning.-A mash composed of bran, molasses, water, and some form of arsenic, flavored with fruit juice according to formula given on page 57, has been extensively used for grasshoppers 
especially during the outbreaks of more recent years in Kansas and neighboring states. Preparation of the poison is frequently under the direction of the county agent and the Experiment Station representatives and the distribution is a community or even a county problem, in some cases poisoning being required by local ruling. Tons of paris green have been used in a single county in one year during a serious outbreak and the result has well repaid the expense and labor. A substitute which has been used considerably is the Criddle mixture, prepared by poisoning about 100 pounds of fresh horse manure with one pound paris green and using it in the same manner as the bran mash. The poisoned bran mash is now regarded as the most effective means for the control of all grasshoppers which are commonly injurious.

\section{The Army Worm*}

Almost every year some locality reports serious injury to crops by armies of caterpillars, which have not been previously known for many years. This being the case the farmers are

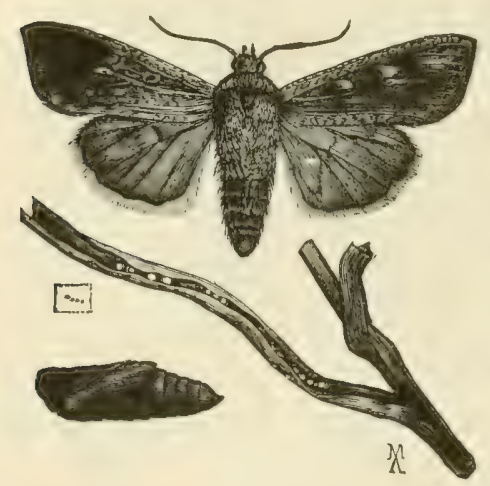

FIG. 92.-Army-worm moth (Cirphus unipuncta), pupa, and eggs in natural position in a grass-leaf. Natural size. (After Comstock.) at a loss for means to combat them, and by the time the information has been secured the pests have completed the damage. The Army Worm occurs throughout the United States east of the Rocky Mountains and lives in low, rank growths of grass, which form thenormal breeding-grounds. When from an abundance of such food, or through failure of the parasitesto prevent their increase, the caterpillars become overabundant, they assume the army habit and march en masse, consuming all in their path.

The next year their natural enemies will usually have them under control again and there will be but little damage, and then they will not be observed as injurious for a series of years, though the moths are always fairly common.

* Cirphus unipuncta Haworth. Family Noctuida. 


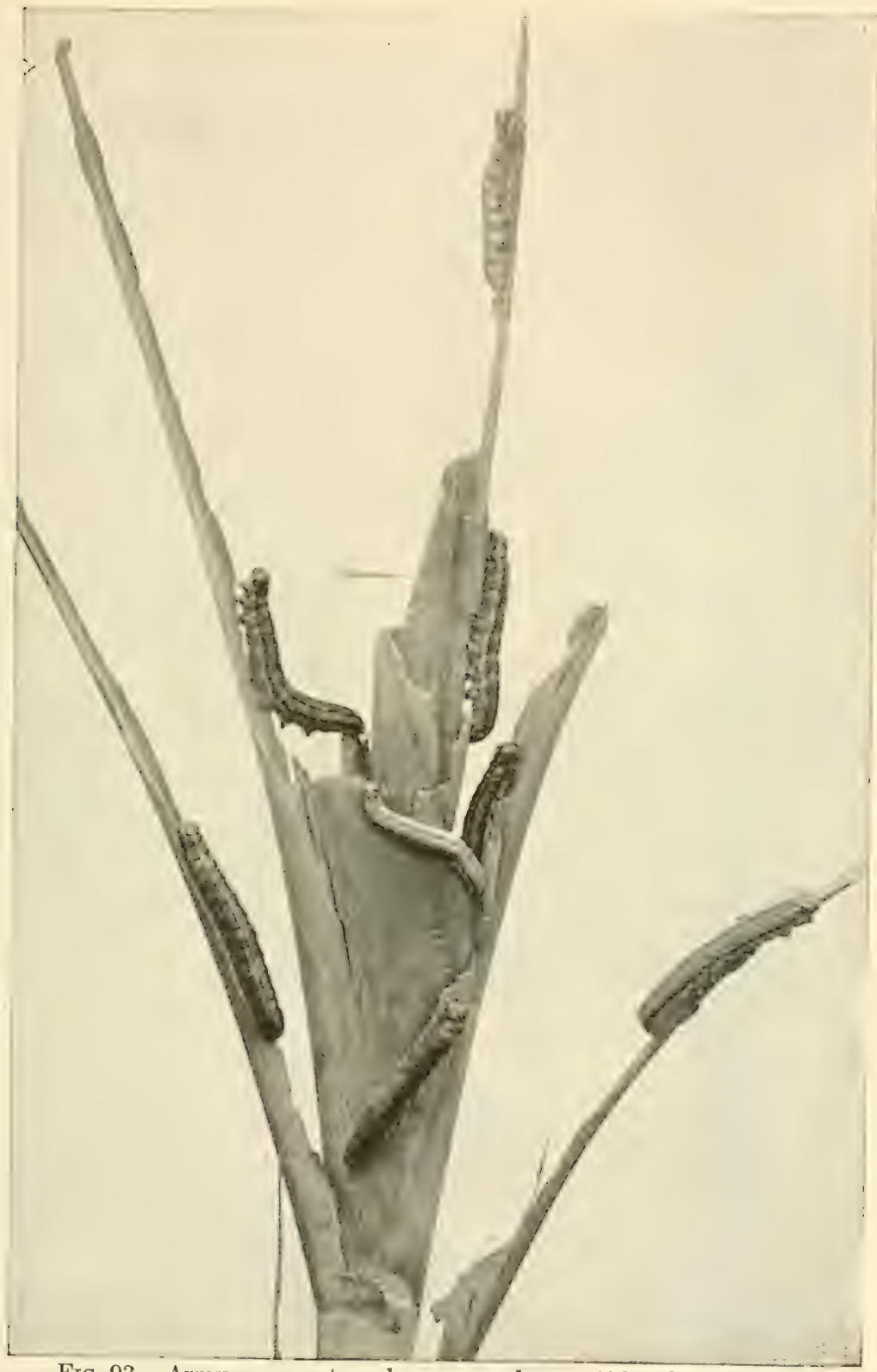

Fig. 93.-Army-worms at, work on corn-plant. (After Slingerland.) 
Life History.-In the North the moths appear early in June and the females lay the small yellowish eggs in rows of from ten to fifty in the unfolded bases of the grass leaves, covering them with a thin layer of glue. Over seven hundred may be deposited by one female, so that when the young caterpillars hatch, in about ten days, the progeny of a few moths might form a quite destructive army. The worms usually feed entirely at night, and thus whole fields will sometimes be ruined before they are discovered, though a few generally feed by day, as they all do in cloudy weather. The leaves and stalks of grains and grasses form their favorite food, the heads usually being cut off, but various garden crops are often seriously injured if they happen in their path. Though usually untouched, even clover is not exempt. In from three to four weeks the worms have become full grown and are then about $1 \frac{1}{2}$ to 2 inches long, of a dark gray or dingy black color, with three narrow, yellowish stripes above, and a slightly broader and darker one on each side, quite resembling cutworms, to which they are nearly related. They now enter the earth and transform to pupæ, from which the adult moths emerge in about

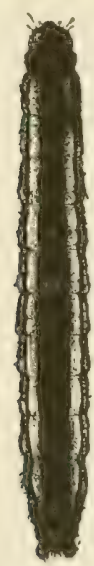

FIG. 94.-An army wor $m-a$ b out on e-t hird enlarged. (A f te r Chittenden. U.S. Dept. Agr.)

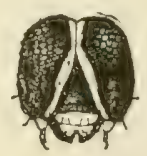

a

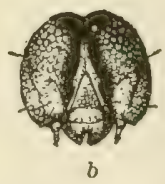

Fig. 95. - $a$, head of $\mathrm{fall}$ a r m y worm; $b$, head of a rm y worm enlarged. (After Chittenden, U.S. Dept. Agr.) two weeks. These lay eggs for another brood of worms which appear in September, but are very rarely injurious. The moths which develop from this last brood either hibernate over winter or deposit eggs, the larvæ from which become partially grown before cold weather and then hibernate. In either case the young larva feed in the spring, not usually doing much damage, pupate in May, and the moths of the first generation appear in June as already described. Thus in the North there are three 
broods a year, the young larvæ usually hibernating, while in the South there may be as many as six generations, and the moths usually hibernate over winter and lay their eggs in the spring.

The moths very often fly into lights and are among the commonest of our plain "millers." The front wings are a clay or fawn color, specked with black scales, marked with a darker shade or stripe at the tips, and with a distinct spot at the centre, which gives the specific name unipuncta. The hind-wings are somewhat lighter with blackish veins and darker margins.

Enemies.-Were it not for other insects which pray upon the army-worm, the army habit would doubtless be more often assumed and we should have to deal with them more frequently. Ordinarily, however, the parasitic and predaceous insects hold

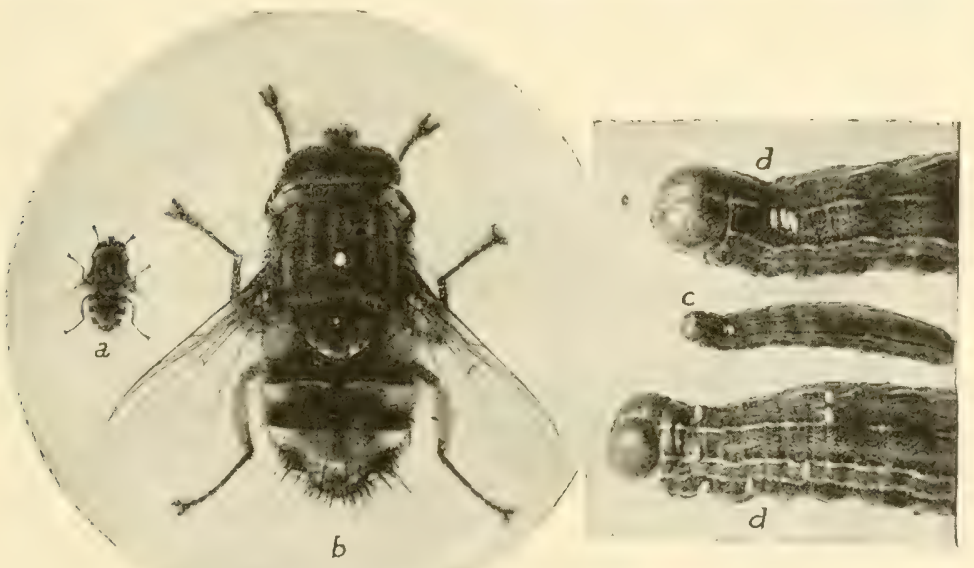

FIG. 96.-The farmer's friend, the red-tailed tachina-fly (Winthemia 4-pustu. lata): $a$, natural size; $b$, much enlarged; $c$, army worm, on which fly has laid eggs, natural size; $d$, same, much enlarged. (After Slingerland.)

them in check very efficiently and when an outbreak does occur, the later broods of the same season are often entirely destroyed by their insect enemies. Large numbers are always destroyed by the predaceous ground-beetles and their larvæ (p. 13), but their most deadly enemies are the tachina-flies (p. 104) These lay from a dozen to fifty eggs on a caterpillar, and the maggots from them enter the body and absorb the juices and tissues of the host, thus soon killing it. When feeding at night the worms 
are ordinarily free from these parasites, but when the marching habit is assumed the flies swarm around them on cloudy days and before the next year they again have the remnants of the voracious army under subjection. Therefore, worms with the tachina-fly eggs on them (Fig. 95) should never be destroyed where avoidable.

Control.-When detected, all efforts should be centred on keeping the worms out of crops not yet attacked and confining their injury to as small an area as possible. As a barrier to their progress, there is nothing better than a dust furrow made as already described for chinch-bugs (p.92), two or three of which may be found necessary in cool weather or where a fine dust cannot be maintained

Deep fall plowing and thorough harrowing will be effective against the hibernating larve, as will the burning of all grass along ditches, fences, and spots where the larvæ normally live.

By thorough spraying, or perhaps better by dusting, a strip of the crop with Paris green or some arsenical, and liberally distributing poisoned bran mash (see p. 57), large numbers may be destroyed. Where they are massed in furrows they may be destroyed by spraying them with pure kerosene or crude petroleum.

As in fighting chinch-bugs the army worm must be given immediate and conclusive combat if the loss of crops is to be prevented, for they move rapidly and destroy all in their path.

\section{The Fall Army Worm or Grass Worm *}

Though somewhat the same in its habits as the true armyworm, the Fall Army Worm is so called because it appears later in the season, the former species being rarely injurious after August 1st. It is also more omnivorous, for while the armyworm prefers grasses, and grains, the fall army-worm feeds upon a large variety of crops, inclucling sugar-beets, cow-peas, millet, sweet potatoes, and many other forage and truck crops. In Nebraska and the Central West it is a serious pest of alfalfa and is called the Alfalfa Worm. It is also sometimes very de-

* Laphygma frugiperda S. and A. Family Noctuides. See Farmers' Bulletin 752, U. S. Dept. of Agriculture. Walton and Luginbill. 
structive to lawns, as was the case in Chicago in 1899. The fali army-worm is more of a native of the Southern States, but occurs from Canada to the Gulf and west to the Rockies.

At first glance the caterpillars have much the same general appearance as the army worm, but closer examination reveals marked differences. Along each side of the borly is a longitudinal pitch-colored stripe, and along the midclle is a yellowish-gray stripe about twice as wide, which includes four black dots on each segment. The catcrpillars assume the habit of working in armies, but usually do not feed in such large numbers as the true army worms and thus are more difficult to combat.

Life History.-The winter is passed in the pupal state, the pupæ being about one-half inch long and being found in cells one-quarter to onehalf an inch below the surface. The moths emerge in the spring and the females lay their eggs on grass in clusters of fifty or more, each mass being covered with the mouse-colored hairs from the body of the female. The eggs hatch in about ten days and the caterpillars are found during May and June. The complete life history of the insect has not been carefully followed, but it seems probable that there are but two complete generations in

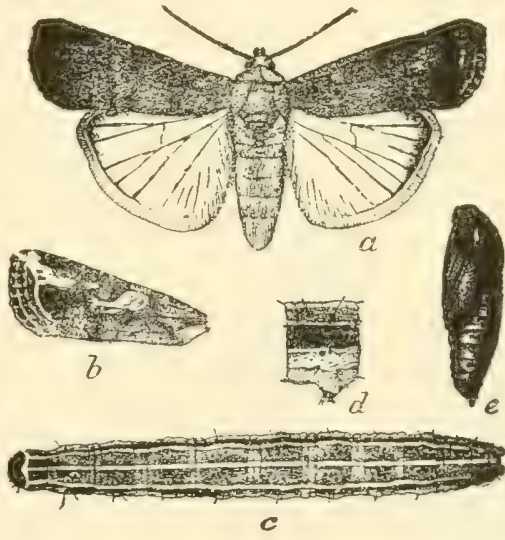

Fic. 97.-The fall army-worm: $a$, moth, plain gray form; $b$, fore wing of Prodenia-like form; $c$, larva extended; $d$, abdominal segment of larva, side view; $e$, pupa; $d$, twice natural size, others enlarged one-fourth. (After Chittenden, U. S. Dept. Agr.)

the North, three generations in the latitude of central and southern Illinois and the District of Columbia, and four in the extreme South. In any event, the destructive brood of caterpillars appears in August and early September.

The parent moth is of a "general yellowish, ash-gray color, with the second pair of wings almost transparent, but with a purplish reflection. In extent of wings it measures about $1 \frac{1}{4}$ inches, and when closed the length of the insect is about three- 
quarters of an inch. The front wings are mottled or marbled, especially near the central area, and usually there is visible a fine white line a short distance from the edge and parallel to it. The hind-wings have a fringe of darker hair as well as veins that contrast somewhat with the lighter portion" (Fig. 97).

Control.-Deep fall plowing and thorough harrowing will break up the pupal cells and thus largely prevent the development of the spring brood of moths. In perennial crops like alfalfa thorough disking may be used and on lawns deep raking with a long-toothed steel rake will kill many of the pupæ. In fields of young grain and on lawns many of the caterpillars may be killed by a heavy roller. When not present in too large numbers, the worms may be destroyed by spraying the food plants with Paris green, arsenate of lead or other arsenicals, or by the use of poisoned bran mash. When present in large numbers and the army habit is assumed they should be combated the same as the army-worm. 


\section{CHAPTER VIII}

\section{INSECTS INJURIOUS TO SMALL GRAINS *}

\section{The Hessian Fly $\dagger$}

The Hessian fly is much the most destructive of the insects attacking wheat, to which its injury is practically confined; for though it occasionally injures barley and rye, it has never

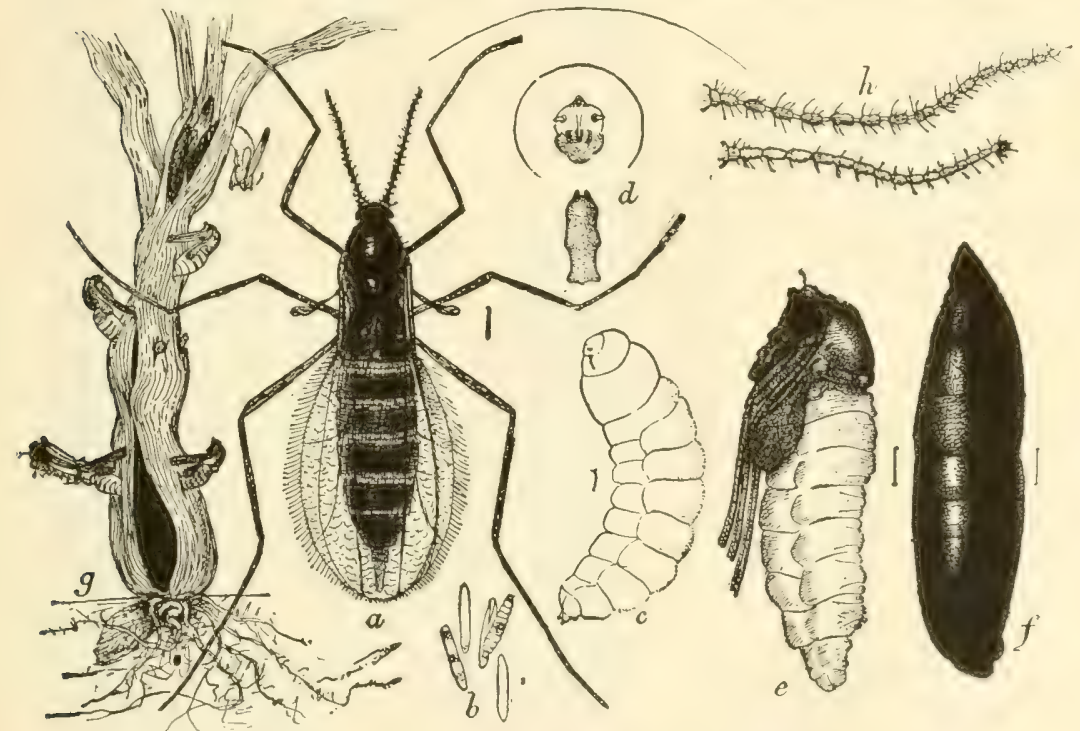

Fra. 98.-The Hessian fly (Mayetiola destructor): $a$, female fly; $b$, flaxseed stage or pupa; $c$, larva; $d$, head and breast-bone of same; $e$, pupa; $f$, puparium; $g$, infested wheat-stem showing emergence of pupæ and adults. (After Marlatt, U. S. Dept. Agr.)

been reared on other grains or grasses. Its name was received from the fact that it was first noticed on Long Island in

* Mayetiola destructor Say. Family Cecidomyiida.

† See "The Principal Insect Enemies of Growing Wheat," C. L. Marlatt, Farmers' Bulletin No. 132, U. S. Department of Agriculture. 
1779, near where the Hessian troops had landed three years before. It now occurs over the main wheat-growing area of the eastern United States between parallels $35^{\circ}$ and $45^{\circ}$ westward to the 100th meridian, on the Pacific coast, in Canada, and in many other parts of the world where wheat is grown. Not infrequently it destroys 25 to 50 per cent of the whole crop in some localities, and it has been estimated that 10 per cent of the crop of the whole country is lost from its ravages.

Life History.-The adult flies are little dark-colored gnats about one-tenth inch long, so small as to escape common observation. Each female lays 100 to 150 minute reddish eggs, one-fifteenth

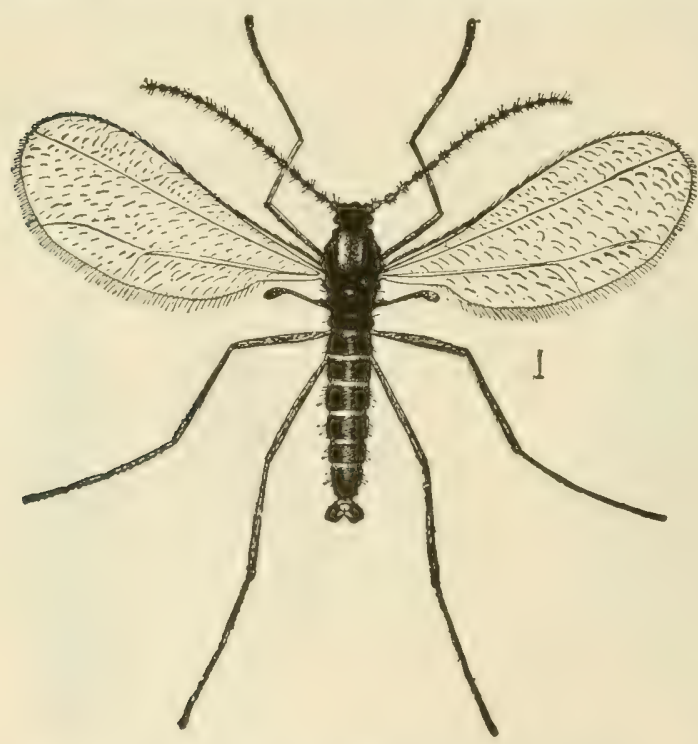

FIG. 99.-The Hessian fly, ,adult male-greatly enlarged. (After Marlatt, U. S.Dept. Agr.) inch long, "placing them in irregular rows of from three to five or more; usually up on the upper surface of the leaves. In a few days these hatch into small, reddish maggots, which soon turn white, are cylindrical, a b o u t twice as long as broad and have no true head or legs. Thefall brood maggots burrow beneath the sheath of the leaf and its base, causing a slight enlargement at the point of attack, but in the spring they usually stop at one of the lower joints, in both instances becoming fixed in the plant, absorbing its sap and destroying the tissues. The first indications of the work of the maggots on winter wheat in the fall are the tendency of the plants to stool out, the dark color of the leaves and the absence of the central stems. Later many of the plants yellow and die. The spring maggots attack the laterals, or tillers, which have escaped the previous brood, 
so weakening them that the stems break and fall before ripening and cannot be readily harvested.

About four weeks after hatching the maggots are full grown, and are greenish-white and about three-sixteenths inch long. The

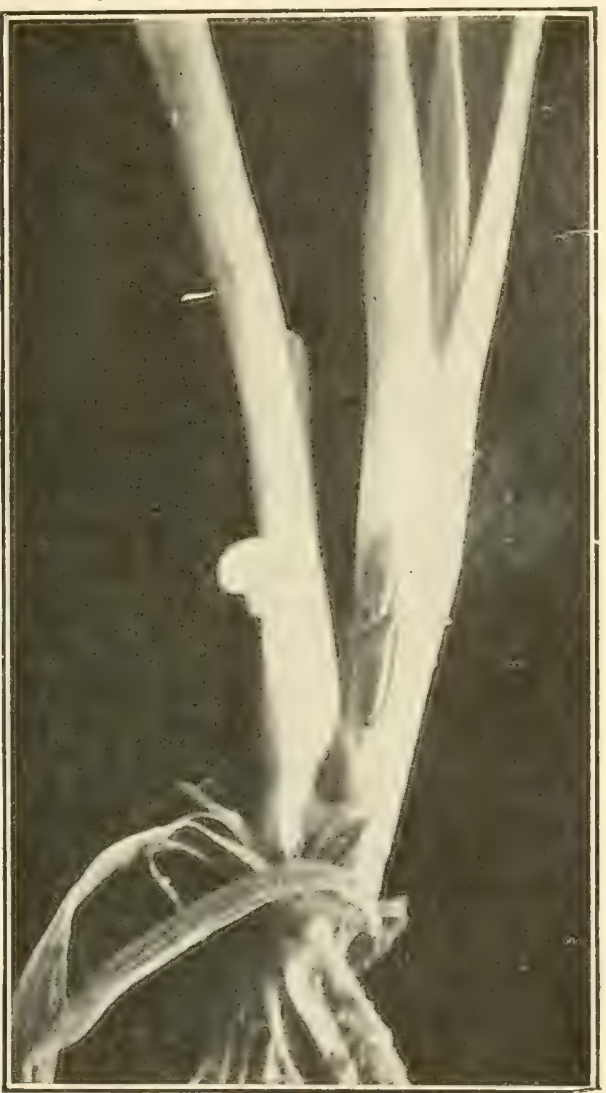

FIG. 100._"Flax-seeds" or puparia of the Hessian fly on young wheat-enlarged. (After Pettit.) skin then turns brown, shrivels slightly, and inside it is formed the pupa. This outside case, composed of the cast larval skin, is known as the "puparium," and this stage is commonly called the "flaxseed" from the resemblance to that seed. In this stage most of the fall brood passes the winter, the flies emerging in April or May, while the summer brood remains in the "flaxseed" stage in the stubble during the late summer and emerges when the first wheat is planted in the fall, emerging later farther south.

Several species of small chalcis flies (page 19) parasitize the larvæ and pupse and were it not for their assistance it would doubtless be difficult to raise wheat. As yet no practical method of increasing their abundance has been devised, though colonies have been carried to regions where they were scarce.

Control.-The principal means of avoiding injury by the Hessian fly in the winter wheat regions is late planting in the fall. Inasmuch as the flies appear within about a week and then dis- 
appear, if planting be delayed until after that time, but little of the wheat will be injured. Dry weather in late summer and early fall will delay the appearance of the flies, even with normal temperature conditions, and the further south, the later they appear. From experiments being conducted by the U. S. Bureau of Entomology, Professor F. M. Webster states that the following dates will probal)ly be found safe for sowing wheat in average seasons: in northern Michigan soon after the 1st of September; in southern Michigan and northern Ohio, about September 20th; in southern Ohio after the first week in October; in Kentucky and Tennessee, October 10th to 20th; in Georgia and South Carolina, October 25 th to November 15 th. The exact time will also depend upon altitude as well as latitude.

A rotation of the wheat crop compels the flies when they emerge from the stubble to travel in search of the young wheat plants. Should storms or heavy winds occur, the frail little flies will be destroyed in large numbers, whereas if they found wheat immediately available the mortality would be small.
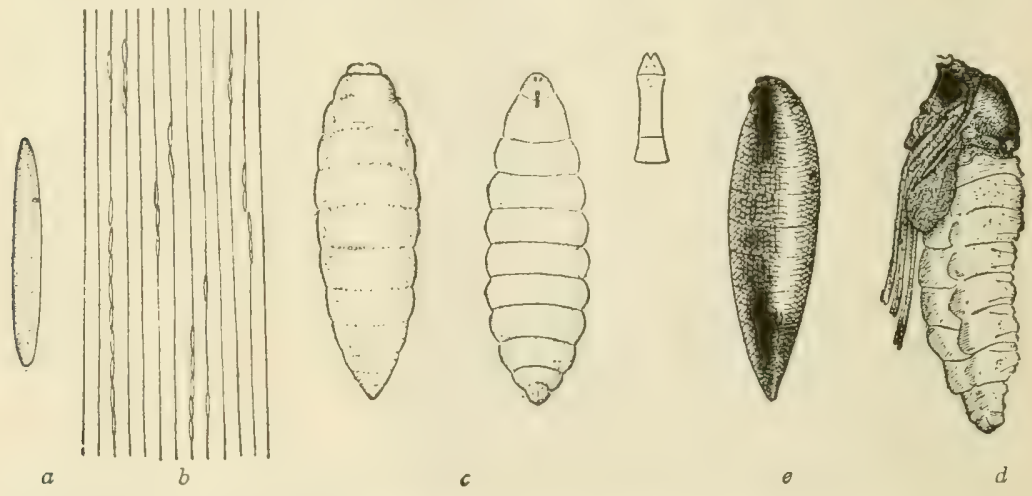

FIG. 101.-Hessian fly: $a$, egs, greatly enlarged; $b$, section of wheat-leaf showing eggs as usually deposited - less enlarged; $c$, larva; $d$, pupa taken from puparium or "flaxseed" $-e, c, d, e$, much enlarged. (After Webster and Marlatt, U. S. Dept. Agr.)

Inasmuch as most of the spring brood remain in the stubble in the flaxseed stage after harvest, if the fields be then burned over, large numbers will be destroyed. This may be done by cutting the grain rather high at harvest, and then mowing the weeds and grass and allowing them to dry a few days before burning. 
Unfortunately this practice is often impossible, owing to the practice of seeding wheat land to grass and clover.

As early volunteer plants always become badly infested and the pupæ wintering on them give rise to a spring brood which attacks the main crop, all volunteer plants should be destroyed by plowing or disking before the larvæ have matured. This principle has sometimes been utilized in the form of a trap crop, strips of wheat being sown early so as to attract the flies and then being plowed under after the bulk of the eggs had been laid upon them, thus protecting the main crop, planted later.

The enrichment of the soil, the preparation of a good seed bed, and the use of good seed, so as to secure a vigorous growing crop, are all of the greatest importance in overcoining injury by the Hessian fly. After the crop is once attacked, no truly remedial measures are known except to apply liberally some quick-acting fertilizer which will cause the plants to tiller freely and give them sufficient vigor to withstand the winter and thus increase the healthy stems the next spring.

Of late years the practice in some of the principal wheat growing states, notably in Kiansas, has been to plow the wheat stubble under deeply, destroy all volunteer plants and to roll or pack in some manner the soil in the plowed fields so that the adult flies will be unable to make their escape from the buried pupre. This is recommended as the best means of control but may well be practiced along with sowing after the "fly-free" date as determined for the region in question.

Some work with immune or partially immune varieties is in progress but no results of a definite nature have been announced.

Keeping the soil in first class condition and practicing rotation and other matters of the best farming practice will help to keep the damage from the fly from being so serious during any season as it might otherwise have been.

\section{The Wheat Joint-worm*}

For the last sixty years the joint-worm has been known as a serious pest of wheat throughout the wheat-growing region east of the Mississippi River, the damage varying from a

* Harmolita tritici Fitch. Family Chalcidide.

See W. J. Phillips, U. S. Dept. Agr. Bulletin 808, and Farmers' Bulletin 1006.」 
slight injury which is hardly noticeable, and which may escape olservation for several years, to an almost total infestation of the crop.

The adults appaar in April, May, or early June, according to the latitude, and are small black, four-winged flies about one-eighth inch long, with the joints of the legs and feet yellow. They look something like small, winged black ants (Fig. 102) and curiously enough belong to a family whose members are almost all parasitic on other insects, so that before they had been thoroughly studied they were thought to be parasites of the Hessian fly. The females lay their eggs in the stems, generally selecting the uppermost

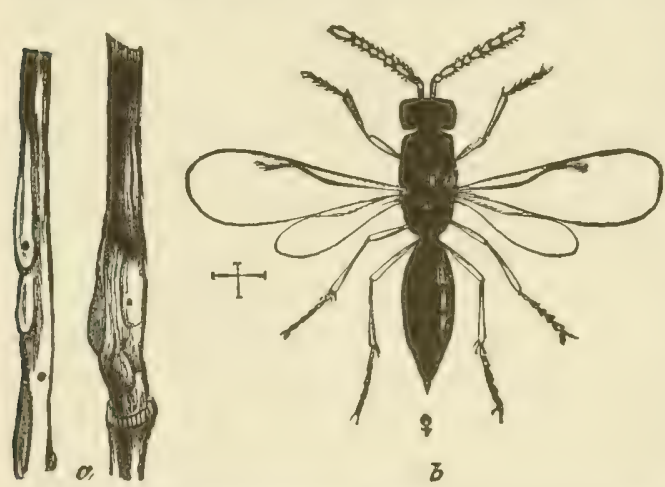

Fig. 102.-a, wheat-straw affected by joint-worm; $b$, adult as seen from above. (After Riley.) joints that have appeared at that time. "The young worms develop rapidly, each in a little cavity within the straw. Often knots, swellings, and twistings occur in the straw at the point of inf estation; again there is little sign of the insect's presence except a slight discoloration or a little deviation of the fibres and grooves of the straw from their natural course. When the infested section is split with a knife it is found to be brittle and woody in character, and contains from 3 or 4 to 20 or more yellowish larvæ, about one-eighth inch long when full-grown. These larve remain in the straw until the following spring, when they issue as adults and commence again the life cycle in the new crop. The damage is done by the worms cutting off the sap supply from the head, causing it to become shortened, containing comparatively few kernels, and such kernels as develop are apt to be small and shriveled from lack of nourishment. Also because of the brittleness of the straw high winds are apt to break much of it down."-Gossard.

The presence of the pest is always indicated at threshing by short, hard bits of straw, containing the larva, which are carried 
rake and burn. Prepare the seed bed thoroughly and fertilize well, when injury is expected, so as to ensure a strong growth and early ripening. Green manure containing infested straw should not be scattered on land to be used for wheat, and all infested straw which has not been userl up by April should be burned.

\section{The Wheat Straw-worm *}

"The Wheat Straw-worm," says Professor F. MI. IVebster, "sustains the same relation to winter-wheat culture west of the Mississippi River that the joint-worm does to the cultivation of this cereal east of this river. Both, when excessively abundant, occasion losses from slight to total. A wheat stem attacked by the joint-worm may produce grain of a more or less inferior quality and less of it; but the spring attack of the wheat strawworm is fatal to the plant affected, as no grain at all is produced, and while the second generation of the same has a less disastrous effect in the field, it nevertheless reduces the grade and weight

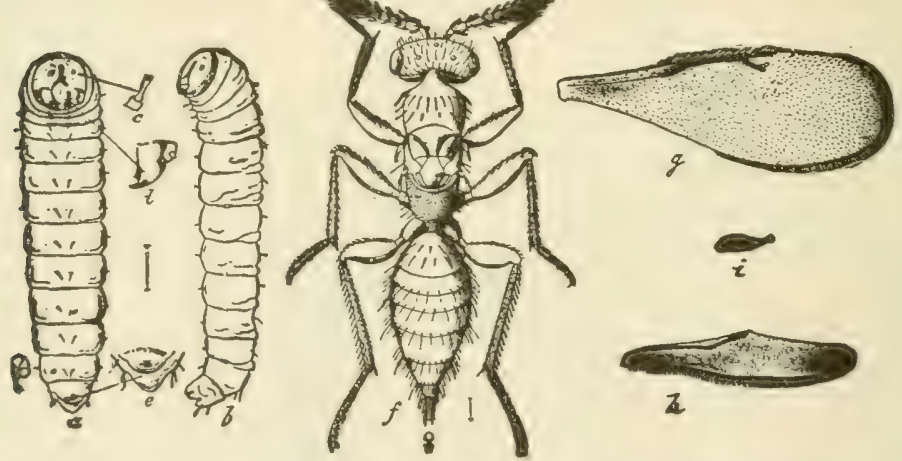

Fig. 105. - Wheat straw-worm $a$, ventral vew; $b$, side view of larva; $c$, antenne; $d$, mandible; $e$, anal segment, ventral view; $f$, adult female; $g$, fore-wing; $h$, hind-wing; $i$, aborted wing. (After Riley.)

of the grain." Though the straw-worm occurs over much of the same territory in the East as the joint-worm, it is rarely so injurious.

Life II istory and Description.†-"There are two generations

* Harmolita grandis Riley. Family Chalcidida.

See W. J. Phillips, U. S. Dept. Agr. Bulletin 808.

$\dagger$ From Circular 106, Bureau of Entomology, U. S. Dept. Agr., by F. M. Webster and Geo. I. Reeves. 
of the insect annually, the adults of the first generation difiering considerably in appearance from those of the second. To the farmer they will all look like minute or large, shining black ants, with or without wings, their legs more or less banded with yellow, and having red eyes. Individuals of the first generation emerge in April from the outstanding straws and stubble. They are very small, most of them are females, and many are wingless. The females deposit their eggs in the young wheat plants, the stems of which at this time extend but little ahove the surface of the ground. The egg is placed in or just below the embryonic wheat head and the larva or worm works within the stem, usually causing a slight enlargement. When the worm is full grown it will be found in the crown of the plant, having eaten out and totally destroyed the embryonic head, its body occupying the cavity thus formed.

"The females which deposit these eggs, being small and frequently wingless, are in no way fitted for traveling long distances, The larva or worm is of a very light straw color, indeed almost white, with brown jaws. These worms develop very rapidly and, as they feed on the most nutritious part of the plant, they become robust and larger than those found in the mature straw in late summer. In May the larvæ become full grown and pass at once through a short pupal stage. The pupæ are at first the same color as the larvæ, but later change to

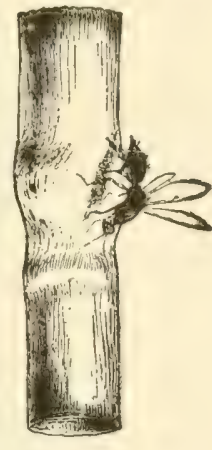

a

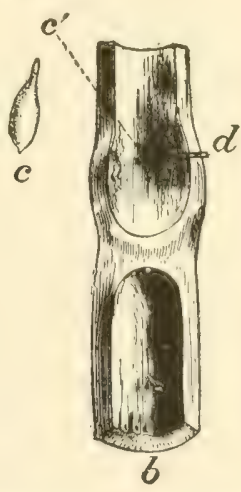

Fig. 106. -The wheat straw-iworm: method of oviposition of female of summer form: $a$, female inserting her eggs; $h$, section of wheat stem, showing egg; $c$, and ovipositor, $d ; c$, egg, greatly magnified. (After Riley and Webster, U. S. Dept. Agr.) the stem and make their way out. These adults are much larger and more robust than the individuals of the first generation and are provided with fully developed, serviceable wings. That they make good use of 
their wings, and scatter themselves about over fields adjacent to their place of development, is shown by their occurrence in fields of grasses (in the stems of which they do not breed) situated considerable distances from wheat fields. In ovipositing, the females of this generation select the largest and most vigorousgrowing stems in which to place their eggs.

"The adults of the second generation deposit their eggs from early May, in Texas, up to the middle of June, in northern Indiana, or about the time the wheat is heading. Their aim at this time is to place the eggs singly in the growing stem, just above the youngest and most succulent joints, which are not so covered by the enfolding leaf sheaths as to be inaccessible to them. Thus it is that the stage of advancement in the growth of the wheat stem at the time of oviposition of the summer generation of females determines whether the larvæ will be well upward in the straw, and therefore removed after harvest, or lower down and consequently left in the field in the stubble.

"The method of oviposition and the point where the egg is usually formed is shown in Fig. 10:3. The Jarva forms no gall, nor does it harden the stem within which it develops. There is nor-

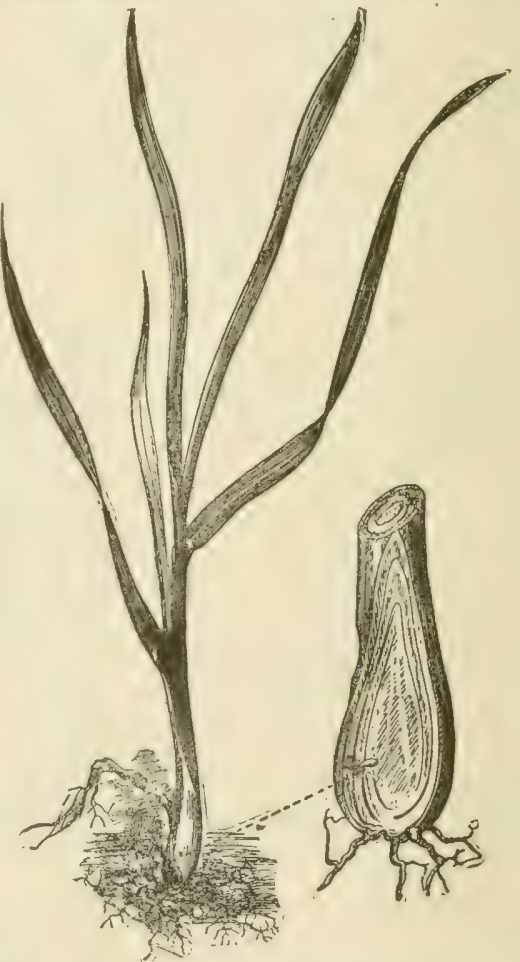

Fig. 107.-Wheat straw-worm, showing point where female of the spring form deposits the egg in young wheat in early spring. Enlarged showing position of egg at right. (After Webster, U.S. Dept. Agr.) mally but one larva in each joint; but if several eggs have been placed between joints and produce larvæ there will be one in the centre of the stem just above the joint and others in the walls just 
under the internal wall-covering or inner epidermis. These larva in the walls of the straw do not, as a rule, kill the stem, but their effect is to curtail the yickl by reducing the weight. The larva develop rapidly and reach their full growth before the straw has hardened. By Octoher, in the Middle West, though carlier in the South, they pass into the pupal stage, in which, as a rule, they remain until early spring, whereupon they develop to adults and gnaw their way out." In the Northwest, where both winter and spring wheat are grown, the injury is particularly severe to spring wheat, as the adults of the second generation from winter wheat oviposit upon it while it is still young and ruin it in much the same way as the first generation does on the winter wheat in spring. Volunteer plants which carry the pest over winter have the same effect in increasing the injury to spring wheat.

Control. - A rotation of crops which will eliminate the growing of wheat two years in succession on the same land is by all means the most successful and practicable means of control. The adults of the first generation are very small and largely

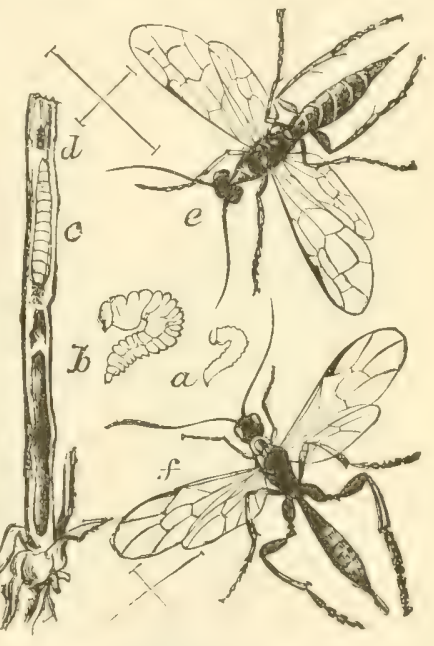
wingless; they are unable to migrate Fia. 10s. - The wheat saw-fly borer far, so that rotation is exceedingly efficacious, though it should be planned so that wheat is not planted next to stubble land, for the edge will become infested by the first gencration, and the second generation (Cephus pygmerus Linn) :i a, outline of larva, natural size; $b$, larva, enlarged; $c$, larva in wheatstalk, natural size; $d$, frass; $e$, adult female: $f$, Pachyoneruscalcitrutor, female, a parasite-enlarged. (After Curits, from "Insect Life.")

will then become distributed throughout the field. The burning of stubble and outstanding struw will be advantageous wherever practicable. Clean fallowing in early summer and the abandonment of spring-wheat culture will reduce injury in the Northwest. 


\section{Saw-Flies Attacking Wheat*}

Several members of the Hymenopterous family commonly called saw-flies, are occasionally found feeding on wheat but scarcely deserve to be ranked as pests. One of these is the Wheat Saw-fly Borer, $\dagger$ and another is called the Western Grass-stem Saw-fly.‡

The former is an importation from Europe while the latter is a native insect and is more common in the Northwest than in the Eastern States.

Both species bore in the stems of wheat and some other grass

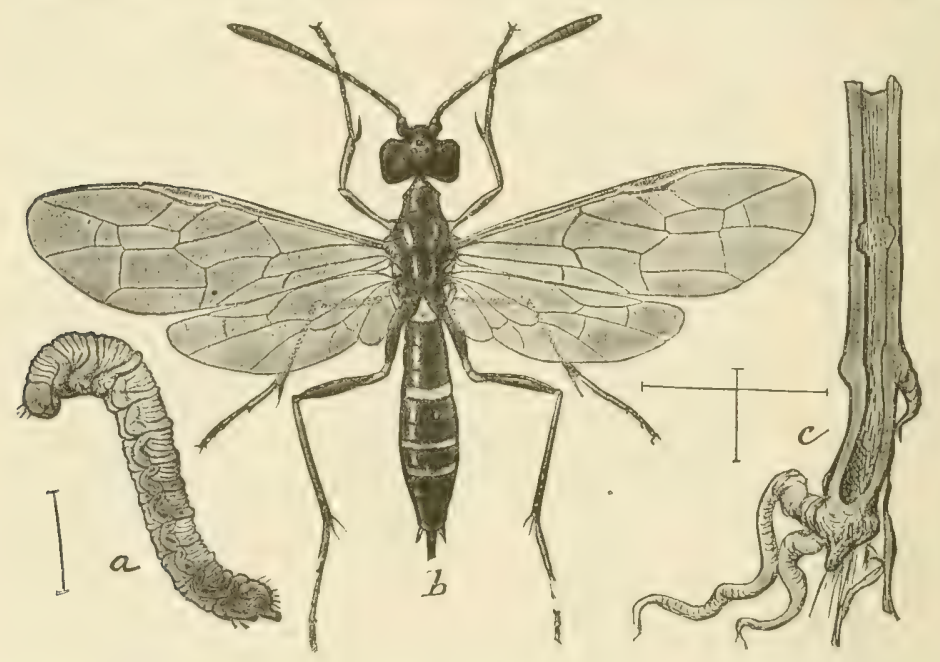

FIg." 109.-The western grass-stem saw-fly (Cephus occidentalis): a, larva; $b$, female saw-fly; $c$, grass-stem showing work; c, enlarged, a, b, more enlarged. (After Marlatt, U. S. Dept. Agr.)

plants. Eggs are laid in the stem and a single larvæ develops and feeds within the stem until full grown when it pupates within the part of the stem which is underground and there spends the winter. The adults appear about May.

Remedics.-Rotation of crops, burning of stubble and plowing the stubble under decply are the remedies suggested, should any be needed on account of the serious increase of the pests.

* Family Tenthredinidex.

† Cephus pygmaxus Linn.

$\ddagger$ Cephus occidentalis, Riley and Marlatt. 
Other species of saw-flies feed on the leaves and even on the heads of wheat. They, like the stem-borers, are rarely abundant

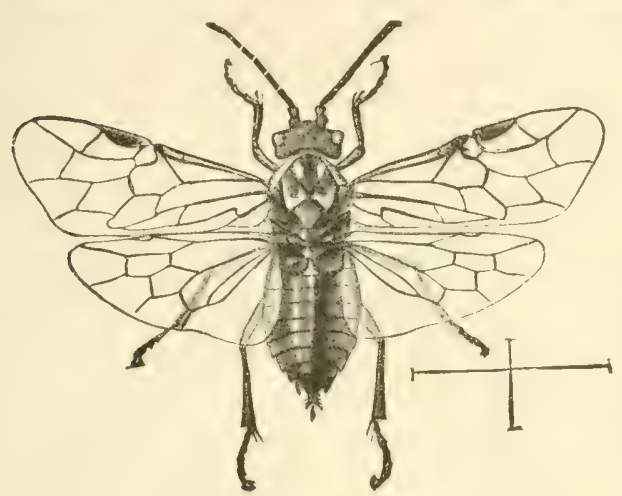

Fig. 110.-A wheat saw-fly (Dolerus ariensis Say): female-much enlarged. (After Riley and Marlatt, U. S. Dept. Agr.) enough to be troublesome. Among these are two species called merely wheat saw-flies (Dolerus arvensis Say and Dolerus collaris Say). These species occur throughout the United States and southern Canada, east of the Rockies. These sawflies are fairly large, compared with the ones previously discussed. The adults appear as dull black or bluish four-minged flies, marked inconspicuously with
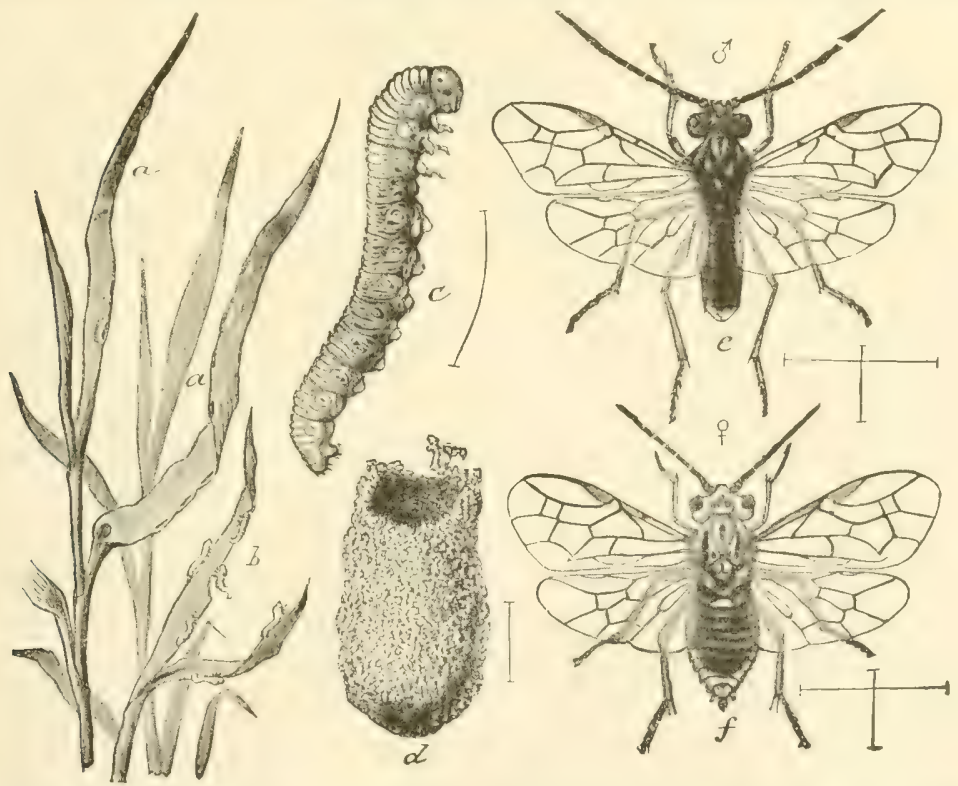

FIG. 111.-The grass saw-fly (Pachynematus extensicornis Norton): $a, a$, eggs on wheat-blade; $b$, young larva; $c$, full-grown larva; $d$, cocoon from which adult has emerged; $e, f$, adult insects-e, male; $f$, female. $a$ and $b$, natural size; $c-f$, enlarged. (After Riley and Marlatt, U. S. Dept. Agr.) 
reddish or yellow. The larvæ are grayish above and lighter beneath and reach a length of about a half-inch. They appear like any common small caterpillar but on examination will be found to have eleven pairs of legs in place of the eight pairs found on the caterpillars.

A third species, more common than any of the others is the Grass Saw-fly, (Pachynematus extensicornis Norton). The adults of this species do not differ markedly from the others but the larva became larger and are green or yellowish-green in color and have only ten mirs of legs in place of the eleven pairs found in the former species.

Adults of all these forms appear rather early in the spring and larvæ feed on the wheat, then in mid-summer go into the ground and remain there as larve until early the next spring. They may possibly be destroyed in this situation by deep plowing, which would prevent the escape of the adults. So far, injury has not been extensive enough to call for treatment.

\section{Some Wheat-maggots}

Very similar to the Hessian fly in its mode of injuring the wheat-stalk is the Wheat-stem Maggot (Meromyza americanu Fitch). The adult flies were first described by Dr. Fitch in 1856 , though the work of the maggots had probably been noticed as early as 1821 by James Worth of Bucks County, Pa., and by the Michigan Farmer in Michigan about 1845.

Extending from Dakota and Manitoba to Texas, the range of this insect practically covers all the eastern United States and southern Canada.

Unlike the Hessian fly it feeds and breeds upon wild grasses and is thus much more difficult to control. Prof. A. J. Cook found the larvæ in both barley and oats in Michigan, Prof. F. M. Webster reared an adult from blue grass (Poa pratensis), and Dr. Jas. Fletcher records it as breeding in Agropyrum, Deschampsis, Elymus, $P o a$, and Setaria viridis in Canada.

Life History.-Like the Hessian fly the adult flies lay their eggs on fall wheat in September and October, and the young maggots when hatched work their way down into the stem, either cutting it off or causing it to discolor or die. The eggs are about one-fortieth of an inch long and of a glistening white color. The 
larvæ are a light greenish color, aloout onc-fourth of an inch long tapering toward the terminal end while subeylindrieal posteriorly, being quite elongate. The pupe are the same color as the larvie, but more rounded, being only one-sixth of an inch long, and reveal the legs and wing-cases of the imago forming within them. The external case of the pupa, called the puparium, is merely the shrunken and hardened cast skin of the last larval stage, within which the insect transforms to the pupa. The fly is about one-fifth of an inch long. It is of a vellowish-white color with a black spot on the top of the head, three broad black stripes on the thorax, and three on the abdomen, which are often interrupted at the sutures, so that they form distinct spots. The eyes are a bright green.

The winter is passed by the larva in the young plants and in spring they trans form to pupæ and adult flies. These in turn deposit eggs in such a position that

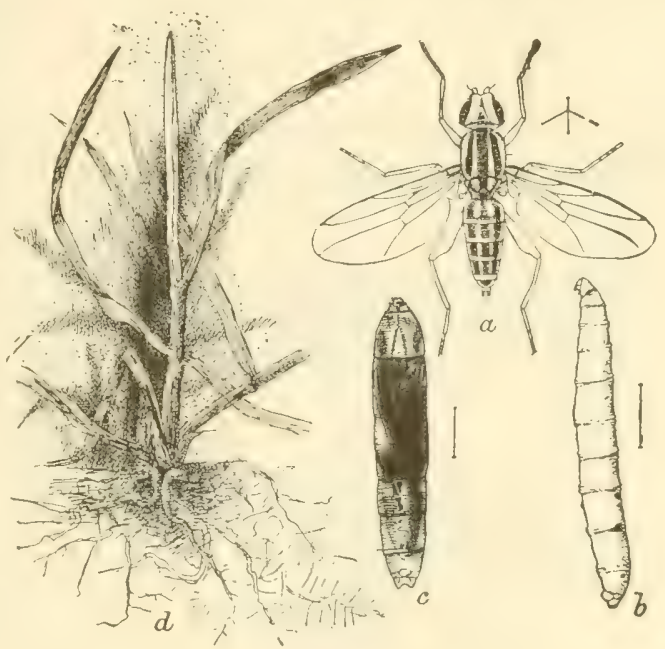

FIG. 112.- Wheat bulb-worm (Meromyza ameri(aula): a, mature fly; b, larva; c, puparium; d. infested wheat-stem-all enlarged except $d$. (After Marlatt, U. S. Dept. Agr.)

the maggots issuing from them may readily feed upon the succulent portions of the growing stalk. Numerous larve thus sapping the life of the plant soon kill it outright or cause the top and head to wither and die. The adults of this brood emerge in July and lay eggs on volunteer wheat and grasses, the maggots working in the same manner as in the fall and coming to maturity so that another brood of flies lays eggs for the fall brood on the newly planted wheat.

Owing to the fact that this insect breeds also in grasses during late summer it is much more difficult to combat than were it confined to wheat as its foortplant, as is the Hessian fly. 
Remedies.- "If the grain is stacked or thresher and the straw stacked or burned," says Professor Welster," it is clear that the number escaping would be greatly reduced," for, as the adults emerge soon after harvest, they would escape to deposit their eggs were the straw left in the fields, but " it is not likely that those in the centre of the stacks would be able to make their way out, and the threshing-machine would destroy many more. How much could be accomplished by late sowing of grain is uncertain, as the females are known to occur abundantly up to Octoher. If plots of grain were sowed immediately after harvest in the vicinity of the stacks, many of the females could, no doubt,

$a$

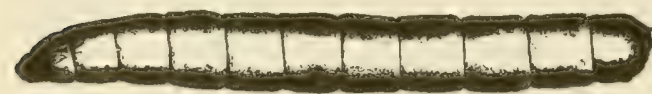

$b$
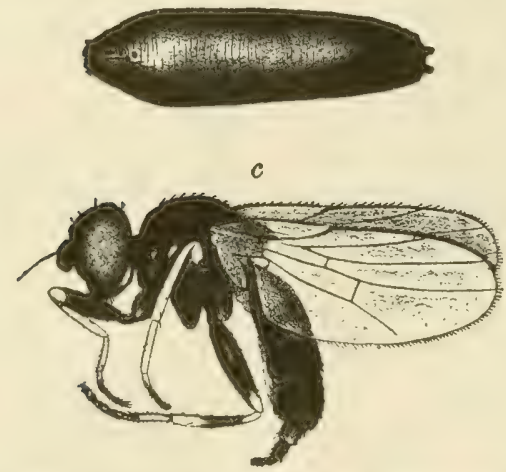

FIg. 113.-The American frit-fly (Oscinis variabilis

Loew): $a$, larva or maggot; $b$, puparium; $c$, adult fly. (After Garman.) be induced to deposit their eggs therein, and these could be destroyed by plowing under." Burning of the stubble will also aid in keeping this pest under control.

There are several undetermined species of flies belonging to $t \mathrm{he}$ genus $O s c i n i s$, which have practically the same life history as the wheat stem-maggot and injure the wheat in the same manner. They very closely resemble the common house-fly in miniature, being about one-fourth as large. They will not need consideration by the practical farmer other than in applying methods of control as already given. One species of this genus, determined by Professor H. Garman as Oscinis variabilis Loew and christened the American Frit-fly, has been found common in Kentucky and Canada, but in the larval stage is so nearly identical in appearance and habit with the stem-maggot that it can with difficulty be distinguished from it.

That these pests do not do more injury is probably due, to a 
considerable extent, to the fact that large numbers of them are destroyed by a small hymenopterous parasite, known as Calinus meromyzœ Forbes, which very commonly infests the larvæ, and by other parasites and predaceous insects.

Rarely will these pests do serious damage, but very often it is sufficient to merit consideration, and only a knowledge of their life history can give a key to their successful control.

\section{The Wheat-midge *}

History.-While the Hessian fly attacks the stalk of the wheat-plant, another species of the same family, known as the

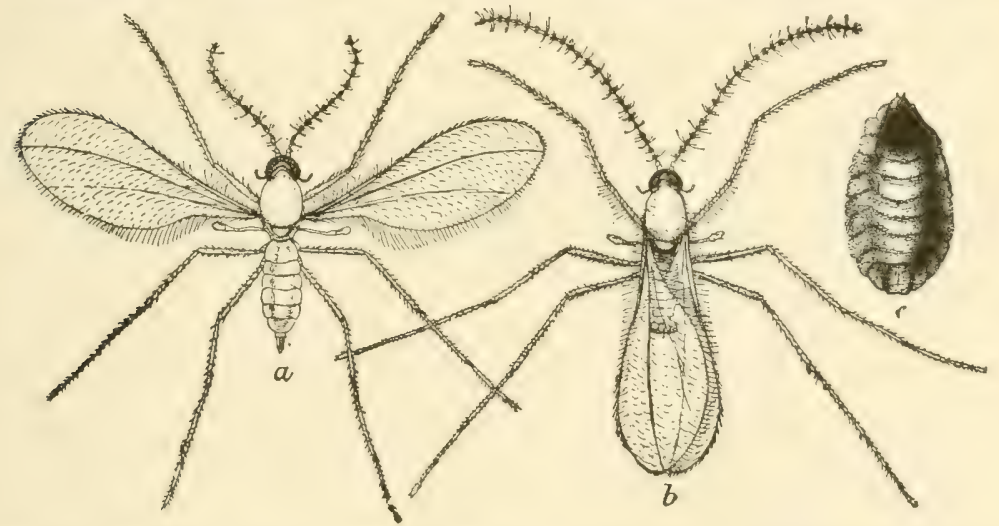

FIG 114.-Wheat-midge (Diplosis tritici): $a$, female fly; $b$, male fly; $c$, larva from below. (After Marlatt, U. S. Dept. Agr.)

Wheat-midge, or "Red Weevil," often does very serious damage to the maturing head. It, too, is a foreigner, having first been noticed as injurious in Suffolk, England, in 1795, though probable references to its depredations date back as carly as $17 \pm 1$. "In 'Ellis's Modern Husbandman' for 1745 the attacks of the vast numbers of black flies (the ichneumon parasites) are noticed in the following quaint terms: 'After this we have a melancholy sight, for, as soon as the wheat had done blooming, vast numbers of black flies attacked the wheat-ears and blowed a little yellow maggot which ate up some of the kemels in other parts of them, and which caused multitudes of ears to miss of their fulness, acting

* Diplosis tritici. Family Cecirlomyizde. See Bulletin No. 5, Vol. I, 2d Ser., Ohio Agr. Exp. Sta., F. M. Webster. 
in some measure like a sort of locust, till rain fell and washed them off; and though this evil has happened in other summers to the wheat in some degree, yet if the good providence of God had not hindered it they might have ruined all the crops of wheat in the nation.' (Hind's 'Essay on Insects and Diseases Injurious to Wheat Crops,' page 76)". It seems probable that it was first introduced into America near Quebec, where it "appears to have occurred" in 1819, and was first observed in the United States in northwestern Vermont in 1820. It did not become very destructive, however, until 1828, from which time until 1835 it kept increasing in such numbers as to cause the abandonment of the wheat crops in scme localities throughout northern New England. Serious damage was reported as due to this pest every few year's until about 1860, being most severe in 1854, in which year Dr. Fitch estimated the loss in New York alone at $\$ 15,000,000$, and in 1857 , and 1858. Since then no widespread injury has occurred, though local outbreaks are frequent, and it has spread south to the Gulf States and westward to Iowa, Minnesota, and Arkansas.

Life History.-The adult flies are small, two-winged insects, about an eighth of an inch long, of a yellow or orange color. They appear about the middle of June and lay the eggs "in a small cavity at the summit of, and formed by a groove in, the outmost chaff covering the incipient kernel." They hatch in about a week, according to Dr. Fitch, and the maggots burrow into the forming kernels. The maggots are of a reddish color, and when an ear is badly infested give it a reddish tinge, on account of which the insect is often called the "red weevil."

When full grown the larva enter the ground and usually form cocoons, in which they pass the winter in the pupal stage, though they often hibernate without such protection. Though doubtless there is usually but one brood in a season, observations by Professor F. M. Webster and others seem to point to the fact that there sometimes are two broods, as adults have been observed from August into November.

Besides wheat, the wheat-midge also sometimes injures rye, barley, and oats.

Remedics.-Plowing infested fields in the fall so deeply that the midges will be unable to reach the surface upon developing 
in the spring is by far the best means of controlling this pest, while burning the stubble previous to plowing, and a rotation of the crop, will also be of considerable aid.

\section{The English Grain-louse *}

The most common plant-louse affecting wheat and other small grains is a large green species which is always to be found on wheat plants, but which occasionally increases very rapidly, and clustering on the ripening heads sucks the juices so as seriously to injure the quality and weight of the wheat.

In the North the first individuals are found on young wheat in April, though during open winters they may be found on the plants, and in the South they continue to reproduce during most of the winter in open seasons. The aphids feed upon the leaves until the grain commences to head, when they assem-

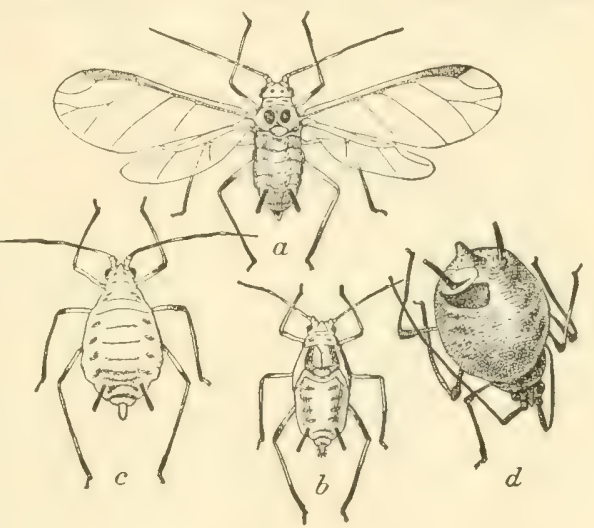

FIG. 115.-The German grain aphis(Macrosiphum cercalis IValt): $a$, winged migrant $b$, nymph of same; $c$, wingless parthenogenetic female; $d$, same showing exit hole of parasite-enlarged. (After Riley, U. S. Dept. Agr.)

ble on the heads among the ripening kernels. The females give birth to live young, bearing from 40 to 50 each, which become full grown in ten days to two weeks, and then reproduce, as is the usual method of reproduction with plant-lice (see page 390 ), so that they multiply with great rapidity, and where so few were present as to be hardly noticeable, in a few weeks they will be swarming over the heads in myriads. As the small grains ripen they migrate to various grasses and are not much in evidence during midsummer,

* Macrosiphum granaria Buckton. Family Aphidide. A nearly related species, Macrosiphum cercalis Kaltenbach, has very similar habits, is commonly associated with the species, and has not been distinguished from it by most writers. It may be recognized by lacking the blackish markings on the abdominal segments. See Pergande, Bulletin 44, Bureau of Entomology, U. S. Dept. Agr. 
but later migrate to volunteer oats and wheat, upon which they subsist until fall wheat is available. Owing to the cool weather of fall and the fact that but few individuals survive the attacks of their parasites during the summer, they rarely become abundant enough to do any damage to grains in the fall. So far as known, they hibernate over winter among the leaves of the growing plants, enough surviving both snow and cold to

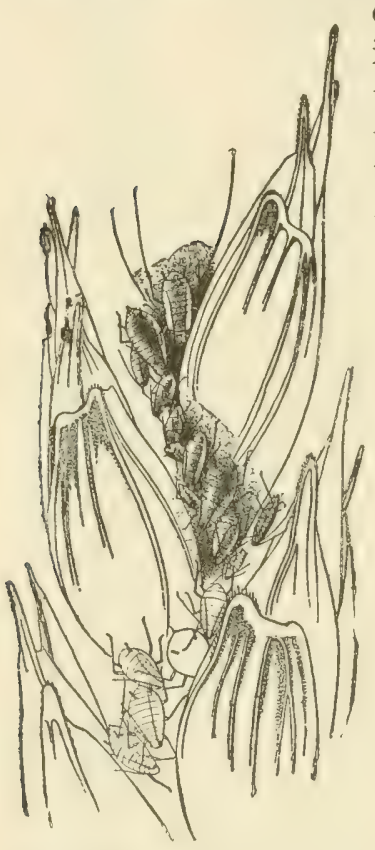

FIg. 116.-Grain a phids clustered on wheat head, greatly enlarged. (After Weed.) infest the crop the next spring. Whether true males and females produce eggs on the grain is unknown, for though they have b e e n r e are d under artificial conditions, they have never been observed in the field.

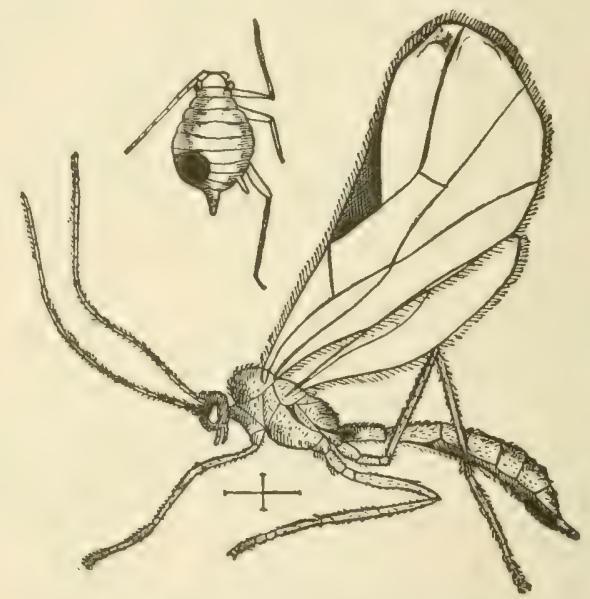

FIg. 117.-Wheat-louse parasite (Aphidius arenaphis Fitch), and parasitized louse from which it has issued. (Copied from J. B. Smith.)

Professor F. L. Washburn observed at least fourteen generations up to November 8,1907 , in southern Minnesota.

As with other aphids, both winged and wingless individuals occur throughout the season. The wingless individuals are about one-tenth inch long, with black antennæe as long as, or longer than the body, are of a yellowish-green color, often slightly pruinose, and long black nectaries extend from either side of the abdomen. The winged individuals are about the same length, with a wing expanse of about three-eighths inch, with antennæ 
a third longer than the body, and are of the same general coloration except that lobes of the thorax are brown or blackish, and the abdomen is marked with four or five transverse blackish spots in front of the nectaries.

Like the other aphids affecting small grains, this species is held in check by parasitic insects, aided by predaceous insects and fungous diseases. Injury by the aphids is usually due to the parasites having been killed off, thus giving the aphids opportunity to multiply unchecked. Among the most abundant parasites are species of the genus $A$ phidius (family Braconido), one of which is shown in Fig. 117, greatly enlarged. Cold, wet weather in spring greatly retards the development of these parasites, so that the aphids are always more numerous in such seasons. It has also been observed that an outbreak is often preceded by several dry seasons, which may be due to the fact that such dry seasons check the development of fungous diseases which kill off large numbers of the aphids and which do not propagate in hot dry weather. Thus weather conditions are very intimately associated with the abundance of the pest. When the parasites become abundant they will often completely rid a field of the aphids within a few days. All of the common ladybird-beetles (Coccinellidx), Syrphus-fly larvæ, and lace-winged fly larva (Chrysopido) are commonly found feeding upon the aphids.

Control.-No practical remedy for this speries is known nor are means of control easily suggested. The suppression of volunteer wheat and oats in early fall will prevent the multiplication of the pest before fall-sown wheat is available, and the late sowing of wheat in the fall will reduce the numbers entering hibernation. A wise rotation and the thorough preparation of the seed-bed and liberal fertilization will be of value in avoiding injury in the same way as has been described for other pests of small grains. Fortunately this species rarely does very widespread injury and its parasites usually soon bring it under control.

\section{The Spring Grain-aphis or Green Bug *}

Though long known as a serious pest of small grains in Europe, this aphis has done widespread injury in this country only during the past ten years. Though it occurs throughout the territory

\footnotetext{
* Toxoptera graminum Rond. Family Aphidido.
} 
north of latitude $41^{\circ}$, with the exception of the North Atlantic States, as far west as longitude $105^{\circ}$, the worst injury has been done in northern Texas, Oklahoma, and Kansas, though it has also been injurious in the Carolinas and Tennessee.

The habits of the insect during the winter have not been sufficiently studied to speak authoritatively, but it seems probable that it normally passes the winter in the egg stage, the small shining black eggs, one-fortieth inch long, being laid on the leaves in the late fall. In the South, however, it often continues to reproduce throughout the winter, and with a mild winter the numbers so multiply that unless checked by parasites serious injury is done by late winter or early spring. Both wingless and winged forms occur throughout the year. The wingless female

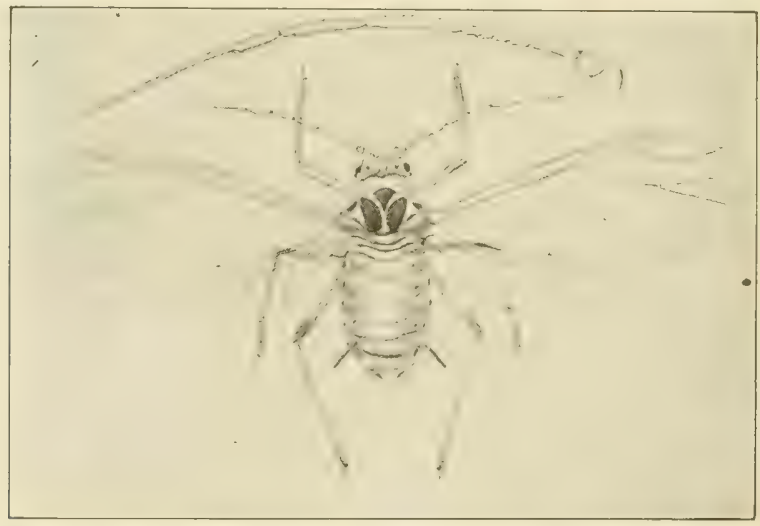

FIG. 118.-The spring grain-aphis or "green bug" (Toxoptera gramınum): $a$, winged migrant; $b$, antenna of same. $a$, much enlarged; $b$, highly magnified. (From Pergande, U. S. Dept. Agr.)

is from one-twenty-fifth to one-fourteenth inch long, yellowishgreen, with a median line slightly darker, eyes and most of the antennx black, of the shape shown in Fig. 119. The winged female is slightly larger, with a wing expanse of about onequarter inch, and of the same general coloration, except that the head is brownish-yellow and the lobes of the thorax are blackish. The aphids hatching from the eggs are all females, which give birth to live young, no male forms occurring during the summer. During her life of slightly over a month a female will give birth to 50 or 60 young, which commence to reproduce in the same manner 
when about seven days old, so the numbers of the pest obviously increase with enormous rapidity, and with thousands of tiny beaks pumping out the sap the young grain plants soon suceumb. The rate of reproduction and growth is, of course, much slower in colder weather, the above being the average for the growing season. Thus in an open winter the aphids will continue tomultiply, and by February, in northern Texas, small spots of wheat and oats will show the effect of their work, by March the injury may become widespread and serious, and by the middle of April the crops may be ruined. As the aphids become excessively abundant and the

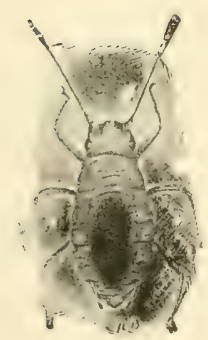

$a$

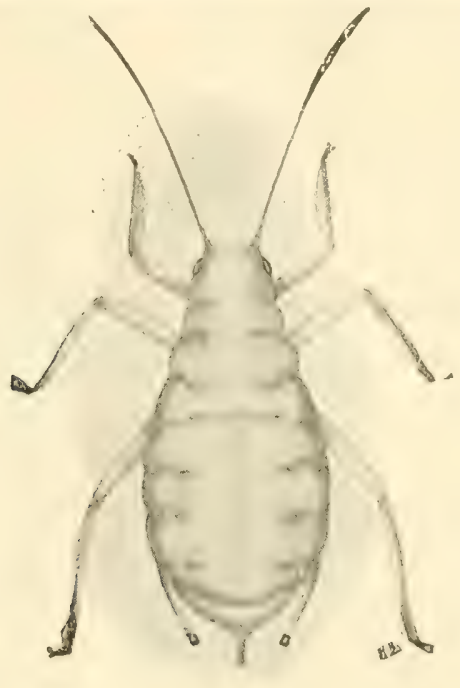

$b$

Fig. 119.-Toxoptera graminum: $a$, newly born, and $b$, adult wingless green bug, greatly enlarged. (After S. J. Hunter.)

food supply disappears, almost all develop wings, and immense clouds of the winged females are earried northward by the winds, so that an outbreak in early spring in the South leads to an infestation farther north, and excessive multiplication will again carry the pest still northward, progressing in that direction as it inereases during the season, rather than being spread at one time. Thus in 1907 it became abundant in Oklahoma in April, in Kansas in May, and by July it was found in Minnesota, where it rarely occurs and does no damage. With the maturing of wheat and oats 
the aphids migrate to various grasses, being particularly fond of Kentucky blue-grass, and may subsist on corn, on which they may feed until oats and wheat are available in the fall. Oats is the favorite food, and outbreaks of the pest have always been worst where volunteer oats is generally grown, the aphids increasing on it in the early fall and winter and later spreading to wheat. By October 15th in Minnesota and by early November in Kansas the true winged males and wingless egg-laying females have been observed, but strangely enough they have only been secured in small numbers by being reared in the laboratory, and have not been observed in the field, so that although these females laid eggs

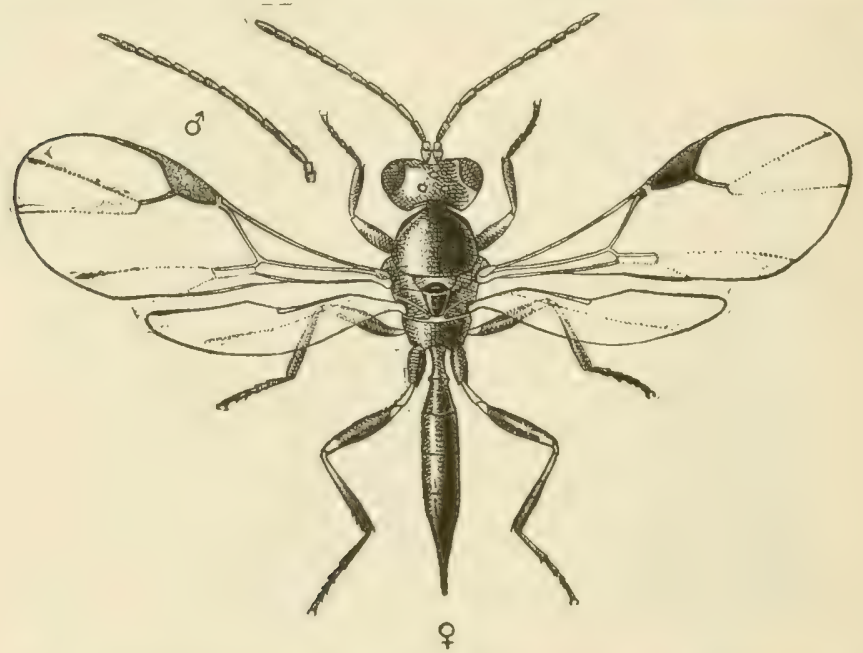

Fig. 120.-Lysiphlebus testaceipes (ress, adult female and antenna of malegreatly enlarged. (After Webster, U. S. Dept. Agr.)

freely on the leaves of grain, we do not know whether they are essential or not to the life history of the insect in the field, for while the eggs are being produced other females continue to give birth to live young until the cold of winter, and they have been observed to reproduce with a daily mean temperature barely above freezing.

Natural Control.-The natural control of this most destructive pest involves a most interesting relationship between temperature and development of the parasites which check its development. "The 'green bug' in normal years - that is, when its breeding 
begins in spring - is effectively held in check by its natural enemies, and notably by a minute, black wasp-like insect, Lysiphlebus. testaceipes Cress. (Fig. 120), that deposits eggs singly in the 'green bugs,' the grubs hatching from the eggs feeding internally on the bug and destroying it (Figs.122-123). Other natural enemies are the larvæ of certain

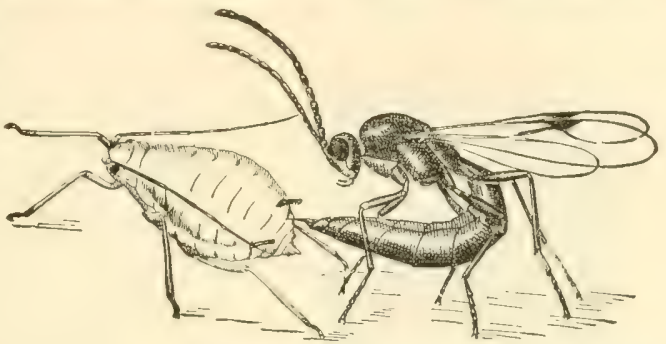

Fig. 121.-Lysiphlebus parasite in act of depositing eggs in the body of a grain-aphis-much enlarged. (After Webster, U. S. Dept. Agr.) predaceous flies, and the larva and adults of lady-beetles. The

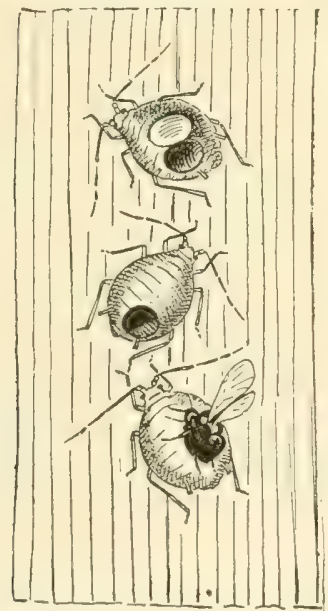

Fia. 122.--Dead "green bugs," showing hole from which the matured parasite of Lysiphlebus emerges. The top figure shows the lid still attached, but pushed back; the bottom figure shows the parasite e $\mathrm{m}$ e r $\mathrm{g}$ in $\mathrm{g}$. Enlarged. ( A f t e r Webster, U. S. Dept. Agr.) little wasp-like parasite first mentioned, however, is the one that keeps the 'green bug' in control in normal years, and in years when the latter is most abundant finally over-comes it, as was the case in 1907 in Kansas, North Carolina, and other States in the more northern part of the range of the pest."

"Unfortunately this parasitic "wasp" as with other beneficial insects - is active only while the temperature is above $56^{\circ} \mathrm{F}$., or at least $10^{\circ}$ above that at which the 'green bug' breeds freely; and herein is the wholesecret of the irregulardisastrous outbreaks of the 'green bug' in grain fields. As accounting for the outbreak in the year 1907, the 'green bug' had had a whole winter and the following late spring in which to breed and multiply unmolested, and it accomplished its principal damage, as in Texas and southern Oklahoma,before the weather was warm enough for the parasite to increase sufficiently to overcome it."

"As further illustrative of the important bearing of weather conditions, it is found that in the case of the three important outbreaks of this insect, namely, for the years 
1890, 1901, and 1907, the temperature for the first five months of each of these years, including the latter part of the winter and spring, was above the normal for the winter months and below the

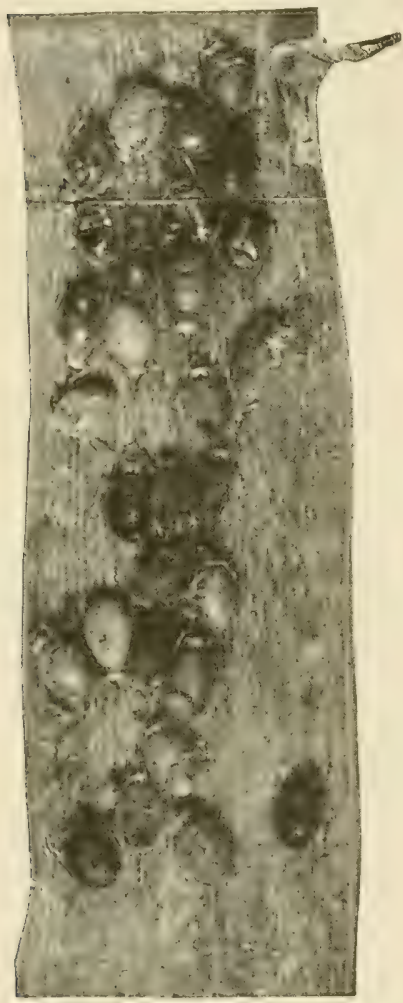

Fig. 123.-Parasitized green bugs-enlarged. (From photograph, after S. J. Hunter.) normal for the spring months; in other words, warm winters and cold, late springs."

"The little parasitic wasp which is so useful in the control of this pest is native to this country, widely distributed, and every year does its work with the 'green bug' and with other aphids. It is always present in grain fields, as show $\mathrm{n}$ by its appearance every year, tc war on these pests whenever the weather conditions make its breeding and multiplication possible, and its rate of breeding is so rapid (there being a generation about every ten days) that with a week or two of favorable weather it gains control over its host insects and destroys them.*

Control. - Most important of all methods of control is the abandonment of the growing of volunteer oats and the destruction of all volunteer oats and wheat in the early fall. Universal experience throughout the injured area shows that relatively little injury oecurs where volunteer oats is not grown.

Where small spots of grain have been injured by the pest in late winter, which is the way an outbreak usually begins in southern localities, the aphids on these small spots may be killed by spraying with 10 per cent kerosene emulsion, or whale-oil soap, 5 pounds to a barrel of water, by covering the spots with straw and burning or by plowing under the infested spots. Were this generally done before the aphids commence to multiply rapidly, it is entirely possible that widespread injury might be averted.

* From F. M. Webster, Circular 93, Bureau of Entomology, U. S. Dept. Agr. 


\section{CHAPTER IX. \\ INSECTS INJURIOUS TO CORN}

\section{The Western Corn Root-worm *}

Throughout the corn States of the northern Mississippi Valley, wherever corn is grown upon the same land it is subject to serious injury by the Western Corn Root-worm, so called because it first became injurious in Missouri and Kansas and gradually spread eastward to Ohio, though not injurious south of the Ohio River. Though the life history of the insect has not been entirely determined, the following summarizes it as observed by Professors

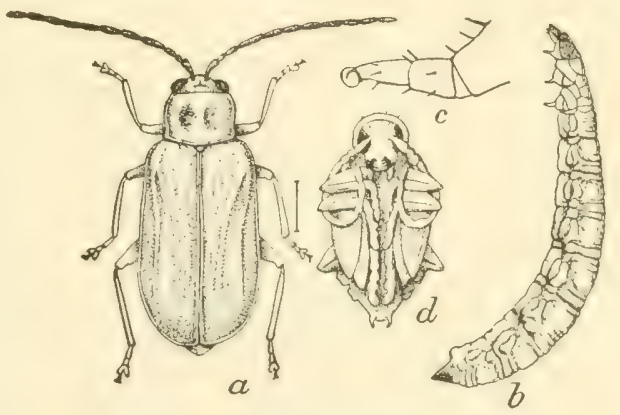
S. A. Forbes and F. M. Fig. 124.-The western corn root-iworm: a, Webster in Illinois and beetle; $b$, larva; $c$, enlarged leg of same; $d$, Indiana. The eggs are Dept. Agr.)

laid in the early fall, within a few inches of the base of the stalk, and just beneath the surface of the soil. The egg is a dirty white color, oval in shape, and about one-fiftieth inch long. The winter is passed in the egg stage, differing from most nearly related beetles in this, and the eggs hatch in the spring or early summer. At first the larvæ eat the small roots entire, but later burrow under the outer layers of the larger roots, causing the stalks on rich loam to be easily blown over, or dwarfing the plant on poorer land so that it produces but small ears. The full-grown larva is nearly white with a brown head, a little less than one-half inch long by about one-tenth inch in diameter. Three pairs of short legs are found

* Diabrotica longicornis Say. Family Chrysomelide. (See F. M. Webster, U. S. Dept. Agr. Bulletin No. 8.) 
on the thorax, but otherwise the body appears perfectly smooth to the eye, though finely wrinkled. Before pupation the color becomes slightly darker and the body shortens. Leaving the roots, the larvæ then form small oval cells in the soil and in them transform to pupæ, from which the adult beetles emerge in a short time. The beetles appear from the middle of July on through August, about two months being required for development after hatching from the egg. The beetles are of a greenish or greenish-yellow color, about one-quarter inch long, and resemble the common striped cucumber-beetle (page 340) in form. They are to be found in the corn-fields feeding upon pollen and silk until the latter becomes dry, and lay their eggs during August and September. The beetles are often found feeding upon various weeds, clover, beans, cucumber and squash vines, and the blossoms of thistle, sunflower and golden rod.

Control-As the larvæ feed only on corn, if the corn-field be planted to some other crop, starvation results, and a simple rotation in which corn is not allowed on the same land for over two years in succession usually prevents injury, though a field in which injury has occurred should be planted to some other crop at once. It is imprudent to plant corn on fields in which the beetle has been observed feeding in large numbers on clover and weeds during the late fall of the previous year. The liberal use of manure and fertilizers, and thorough cultivation will, of course, be of service in enabling the plants to withstand attack.

\section{The Southern Corn Root-worm *}

Closely related to the last species, but with somewhat different habits, the Southern Corn Root-worm is fiequently injurious to corn from Maryland and southern Ohio southward.

The adult beetle is of a bright green marked with twelve black spots, which have given it the name of 12-spotted Cucumberbeetle to distinguish it from the Striped Cucumber-beetle (parge 340), with which it is often associated feeding on cucurbs. It is somewhat larger and more robust than $D$. longicornis, and is almost omnivorous in its food habits, feeding upon the foliage and flowers of a long list of forage and garden crops, to which it often does considerable damage. Beans are frequently injured in much the

* Diabrotica 12-punctata Oliv. Family Chrysomelido. 
same way as corn and the roots of melons and other cucurbs are often so riddled by the larva as to kill the plants.

Injury to corn is done by the larvan in the spring, when they feed upon the roots while the corn is but a few inches high, bore into the crown, and boring into the base of the stalk through the young leaves eat out the "bud." The latter injury often seems to be more serious to corn than the injury to the roots, and has given the insect the common local name of "budworm," which is unfortunately applied to several other insects which do similar injury. Larvæ have been found attacking wheat, rye, millet and Johnson grass in a similar way, the beetles seeming to be attracted to fields containing Johnson grass before the corn appears, thus

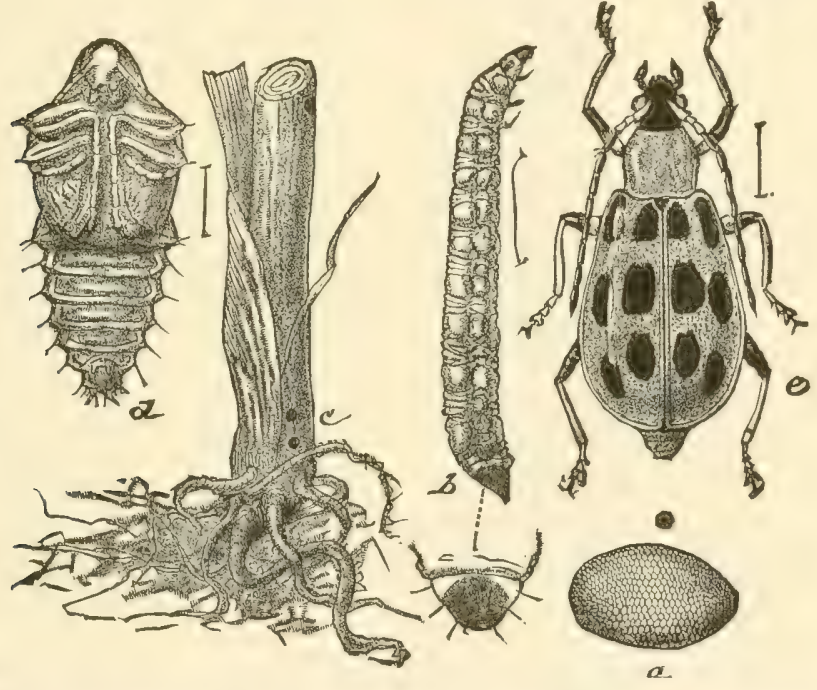

Fig. 125.-The southern corn root-worm: $a$, egg; $b$, larva; $c$, work of larva at base of cornstalk; $d$, pupa; $e$, beetle-all much enlarged except $c$. (After Riley.)

injuring such grassy fields more severely. Injury to corn seems to be worse on low, damp spots.

Life History.-The beetles hibernate over winter and are among the first insects to appear in early spring, appearing by the middle of March in the Southern States. Eggs are laid during April in the Gulf States and from late April to early June in Kentucky and the District of Columbia. The egg is dull yellow, oval, and 
about one-fortieth inch long. The eggs are laid singly just beneath the surface of the soil and hatch in from seven to ten days, those laid early in the season requiring considerably longer. The larvæ become full grown and pupate about a month later, the adult beetles of the first generation appearing during May and early June in the Gulf States and in late June and early July in the District of Columbia and Kentucky. Thus the complete life cycle recuires from six to nine weeks in the spring. Eggs are laid by the first generation of beetles, the larvæ being found on the roots of corn from midsummer until fall, when the second generation of beetles is found in October and November in Kentucky. In the Gulf States there are undoubtedly three complete generations, though they have not been carefully followed.* The beetles assemble in the late fall on clover and alfalfa upon which they feed until winter sets in, and often come out and feed during warm spelis in January and February in the Southern States.

Control.-Although rotation of crops will not be as effective in the control of this species as in the case of $D$. longicornis, it will undoubtedly be found of value to avoid planting corn in succession where injury is probable. By planting late, after the beetles have laid their eggs, injury has been avoided in Georgia. Liberal seeding, using ten grains of seed per hill, will give a sufficient stand free from attack, so that by thinning a good stand may be secured. Fields which are well infested with Johnson grass, or other thickstemmed grasses, should be avoided, for as already indicated the beetles will be attracted to them before the corn is up. Both on account of the feeding habits of the larva and the migratory habits of the beetles no insecticide treatment commends itself as practicable.

\section{The Corn-root Webworm $\uparrow$}

Injury.-When young corn-plants are seen to stop growing, become deformed, and to die off in such numbers as to frequently necessitate replanting, upon examination of the roots the injury will sometimes be found to be due to the work of a small caterpillar. Two or three, very often five or six, and sometimes as many as

* In the Northern States, where this species is not a pest of corn, but is common on cucurbs and garden plants, there is probably but a single generation with a life history very similar to that of the striped cucumber-beetle, which see.

$\dagger$ Crambus caliginosellus Clem. Family Crambido. 
eight or nine, will be found at the base of a plant about an inch below the surface of the soil, and not over 4 to 6 inches from the stalk, usually being in close proximity to it. If each larva is covered with a fine, loose web, to which cling particles of earth forming a sort of case, it is probably a corn-root webworm.

Where the webworms are present in any number they will often necessitate a second, third, or sometimes a fourth planting, making the corn very late and involving considerable expense. The worms bore into the young stalks just above the ground, frequently cutting them off entirely. Later on the larger stalks are gouged out at or slightly above the surface of the ground, and the larvæ burrow into the folded leaves,

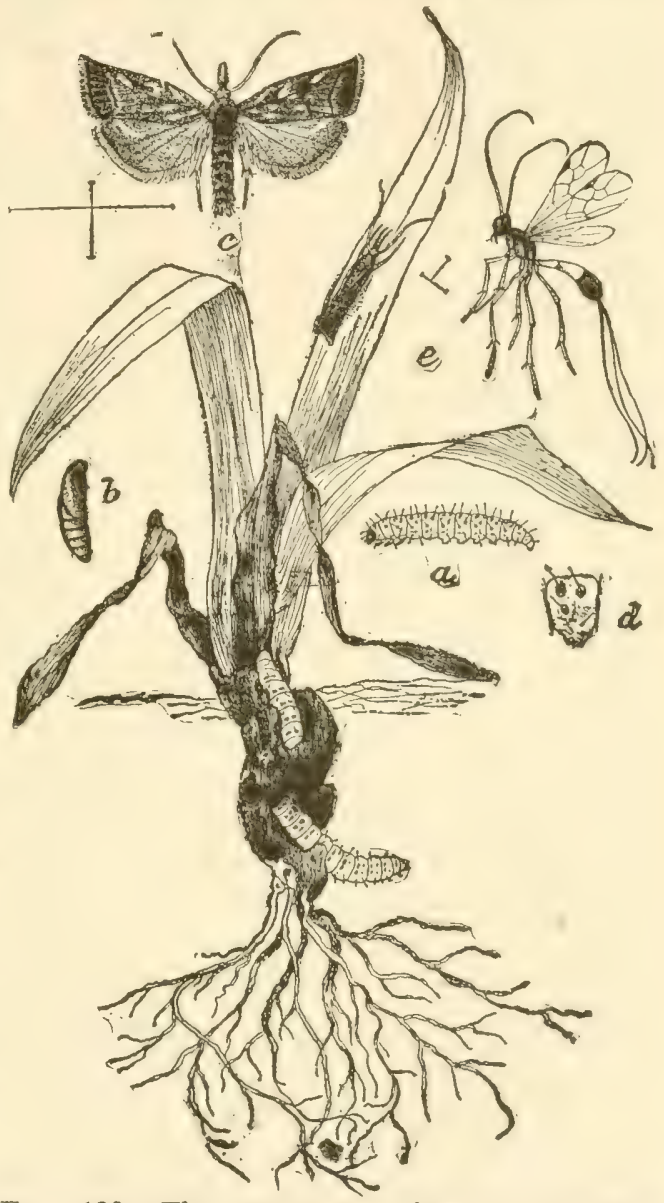

FIG. 126.-The corn-root web-worm (Crambus caliginosellus): $a$, larva; $b$, pupa; $c$, moth; $d$, segment of larva; $e$, parasite. (After Johnson.)

which when they unfold have several transverse rows of three to five holes. On account of this habit these insects are sometimes known as "budworms." Strong plants will often make a new start and survive the injury, but remain much behind those not attacked, while most of the weaker plants will decay and rot off. 
The Moth.-As one walks through pasture or grass land, many little white and yellowish moths are seen flying about on all sides, but quickly disappear as they alight on the grass. If a single individual be watched more closely, it will be noticed that in alighting upon a blade of grass it quickly rolls its wings very tightly around its body, and hugs up close to the grass so that it is hardly distinguishable from it. Projecting from the head in front is what appears to be a long beak or snout, on account of which these moths are often known as "snout moths," but which really consists of the palpi or feelers. The "grassmoths," as they are sometimes called, belong to the genus Crambus and include several common species, which are marked with silver stripes and bands, as well as golden lines and markings, so that they often present a very handsome appearance.

Life History. - These are the parents of the web-worms which do so much injury to the young corn-roots, the principal depredators upon corn belonging to the species Crambus caliginosellus. They lay their eggs in grass land in May or early June, dropping them on the surface among the rubbish or vegetation, or attaching them to the grass. They are oval in form and of a yellowish color, each being marked with regularly placed ridges. About two hundred eggs are laid by each female. In from six to ten days the eggs hatch. The young larvæ soon form their loose silken webs or tubes at or a little below the surface of the soil, burrowing among the roots, and feeding upon the stalk and outer leaves, or killing the plant by attacking the crown. The larvæ vary considerably in color, from a yellowish white, through pink, to a reddish or brownish shade, and are studded with small tubercles, each bearing a tuft of bristly hairs. The larvæ become full grown in from five to seven weeks and are then from onehalf to three-fourths of an inch long. During the latter part of July they form cocoons, sometimes in the larval tubes, in which they pass the pupal stage and from which the moths emerge some twelve to fifteen days later. Eggs are laid for another brood in grass lands during August and September, the larvæ hatching in September and October and becoming partly grown before winter. They hibernate in their webs over winter, and as soon as the grass commences its growth in the spring they are to be found feeding upon it, becoming full grown early in May. 
Preventive.-As the natural food of these insects is grass, it is not surprising that corn planted on sod land should be worst injured; and though the injury done the grass may not have been noticeable, when the available food is so greatly diminished by substituting for grass the comparatively few hills of corn the injury becomes much more serious and apparent. Though the planting of corn on sod land is a most common practice, injury by this and many other insect pests of corn-most of whose native food is grass - might be avoided by planting any other crop than a grain, such as potatoes. Otherwise plowing late in the fall and harrowing so as to expose the larvæ to the weather, or plowing so deeply that they will be buried so that they cannot regain the surface, will do much to prevent injury the next season. Inasmuch as the moth will not lay her eggs upon plowed land if the land be plowed early she will be driven to other fields; but the exact time of oviposition varies for different latitudes.

Generous fertilization will aid the plants in overcoming injury very considerably. Dr. J. B. Smith advises "the application of all the necessary potash in the form of kainit, put on as a top-dressing after the field is prepared for planting," and says: "Fall plowing and kainit as a top-dressing in spring will, I feel convinced, destroy by all odds the greater proportion of the webworms that infest the sod, and would also destroy or lessen many other pests which trouble corn during the early part of its life."

\section{The Corn-root Aphis *}

Where patches of corn become dwarfed, the leaves becoming yellow and red, with a general lack of vigor, the grower may well be suspicious of the presence of the Corn-root aphis. These little aphids, which cluster on the roots of corn, are a bluishgreen color, with a white waxy bloom, and of the form shown in Fig. 127. Two short, slender tubes project from the posterior part of the abdomen which are commonly called honey-tubes, because they were formerly supposed to give out the honey-dew, which is so relished by the ants which tend the aphids to secure it. The winged female has a black head and brownish-black thorax, with pale green abdomen bearing three or four blackish

* Aphis maidi-radicis Forbes. Family Aphidido. 
marginal spots and small dark specks over the surface. The antennæ are dark and the legs blackish.

The corn-root aphis occurs throughout the principal corngrowing States, but has been most destructive where corn is most extensively grown and is often planted year after year on the same land. Dr. Forbes, to whom we are indebted for most of our knowledge of this pest, ${ }^{*}$ has observed fields of corn in Illinois planted in corn for the second scason totally ruined by the root-aphis. Broom-corn and sorghum are the only other cultivated crops which have been injured, but the list of food
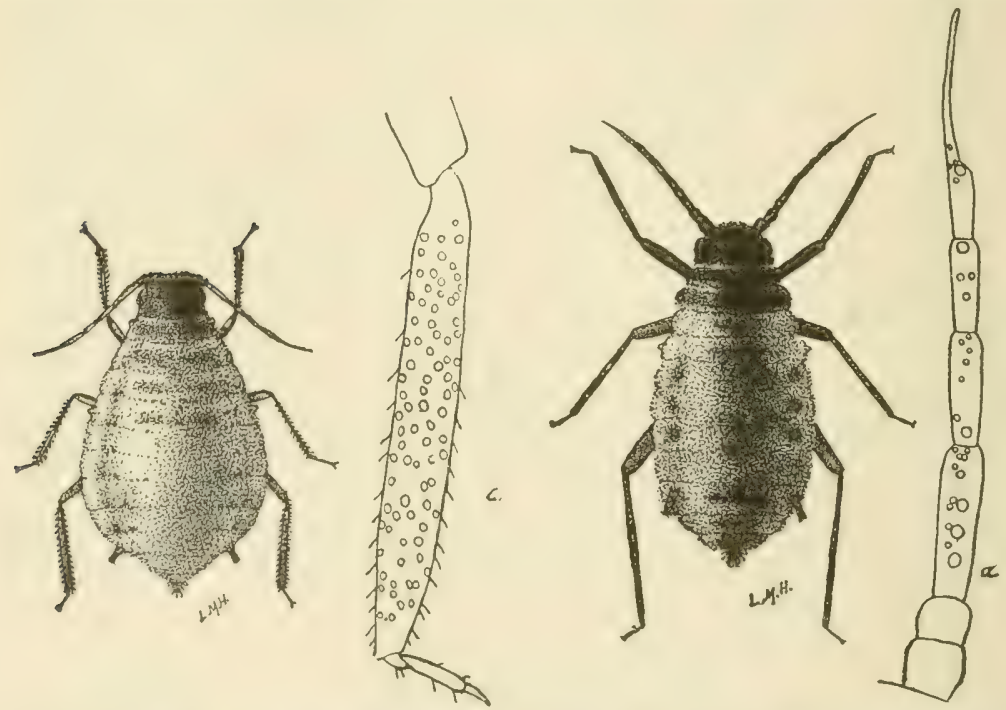

Fig. 127.-The corn root-aphis (A phis maili-radicis Forbes): at left, oviparous female; $a$, hind tibia, showing sensoria; at right, male; $a$, antenna -much enlarged. (After Forbes.)

plants includes smartweed, pusslane, ragiveed, foxtail, and crab. grasses, and many other weeds and grasses which spring up in the corn-field. In South Carolina Professor A. F. Conradi has found it injuring cotton.

* S. A. Forbes, 17th, 18th, and 25th Reports of the State Entomologist of Illinois; Bulletin 60, Bureau of Entomology, U. S. Dept. Agr., p. 29; Bulletins 104, 130, and 17S, Illinois Agr. Exp. Sta. [See also J. J. Davis, Bulletin 12, Part VIII, Technical Series, and U. S. Dept. Bulletin 891, Bureau of Entomology, U. S. Dept. Agr., and F. M. Webster, Circular 86, Bureau of Entomology, U. S. Dept. Agr. 

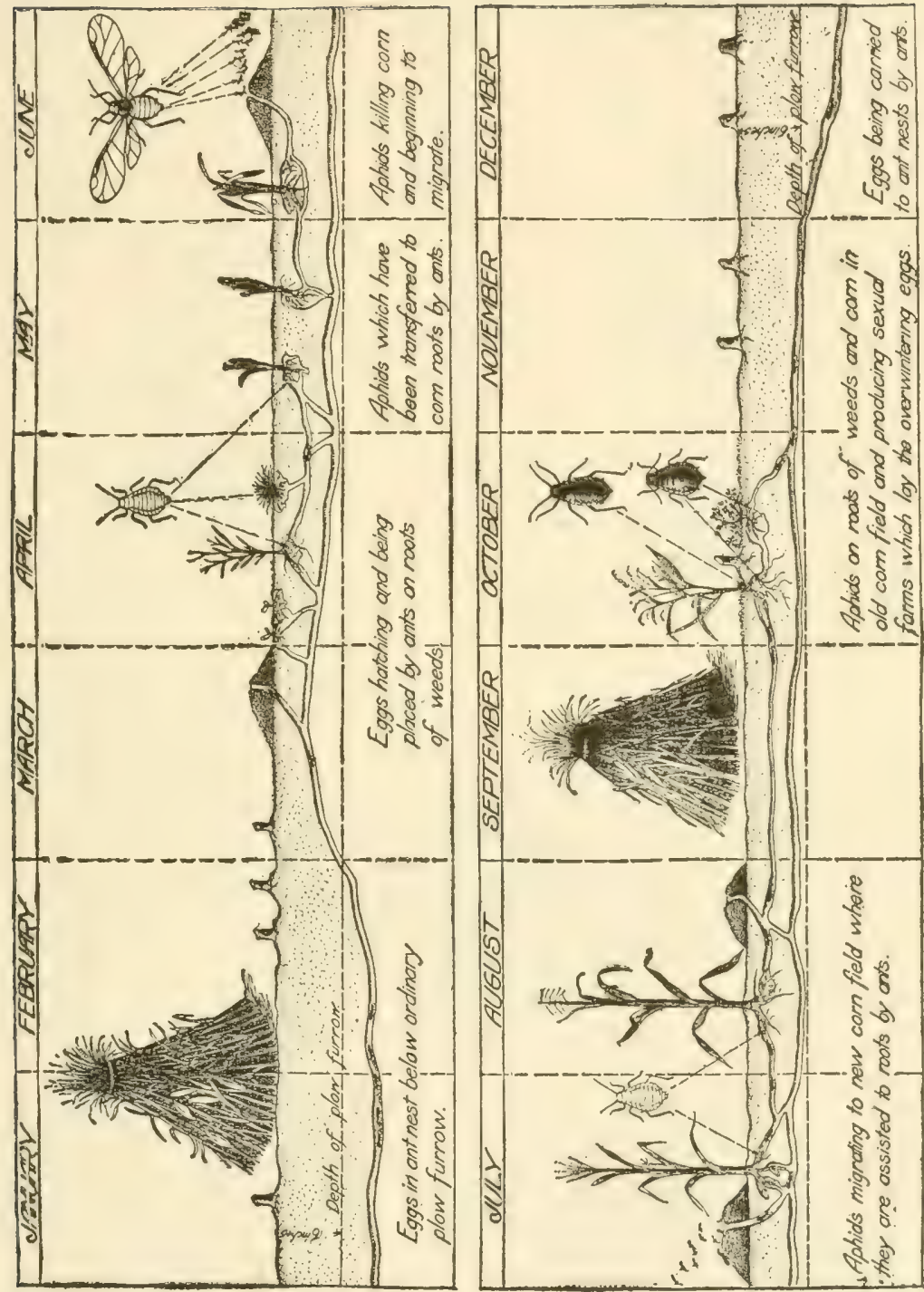

FIG. 128.-Diagram showing history of the corn root-aphid and its relations with the cornfield ant. Note that during the winter the aphids are carried by the ants below the frost line, where the plow cannot reach them. (After J. J. Davis, U. S. Dept. Agr. Bulletin 891.) 
If the nests of the small brown ant* so common in corn-fields infested with the root-aphis, be broken open during the winter,
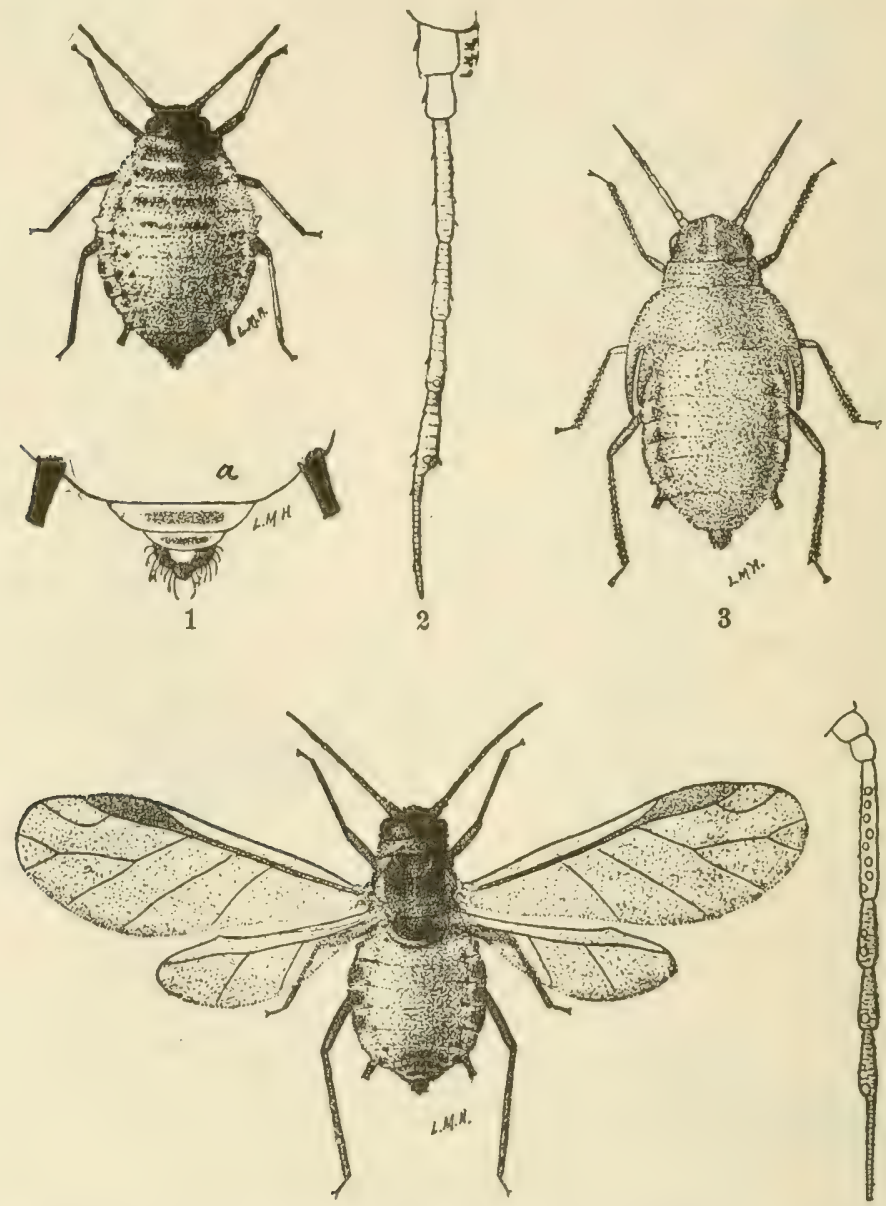

Frg. 129.-The corn-root aphis (Aphis madidi-radicis Forbes): 1, wingless vivaparous female; $a$, apex of abdomen; 2 , antenna of same; 3 , pupa; 4 , winged vivaparous female; 5 , antenna of same. (After Forbes.)

many of the little black aphis eggs, which have been carefully stored by the ants, will be found. They are a glossy black color, oval in shape, and will sometimes be found in small piles in the

* Lasius niger Linn. var. americanus Emery. See Forbes, Bulletin 131, Illinois Agr. Exp. Sta. 
chambers of the ants' nests. On warm days the ants bring them up to the warmer surface soil and in cold weather carry them far down into the unfrozen earth. With the appearance of young smartweed and foxtail-grass in April and May the eggs commence to hatch. The ants at once lay bare the roots of these plants and carry their young wards to them, where large colonies soon become established. If the field is not planted in corn, the lice will feed later upon the roots of pigeon-grass or purslane. In early May lice, the second generation, commence to appear, among them being both wingless and winged forms. This brood and all of these during the summer are produced by females known as agamic females, which give birth to live young without mating with a male. As soon as corn plants are available the ants again transfer the aphids to their roots, and carry any winged aphids which may have spread over the field down on to the roots of the corn. All through the summer the ants attend the lice, burrowing around the roots of the corn, and carrying them from plant to plant, in return for which the aphids give off the sweet honey-dew, when stroked by the ants' antennæ, upon which the ants feed. During the summer the aphids continue to reproduce with extreme rapidity, an aphid maturing and giving birth to young about eight days after it is born, each generation taking about sixteen days and there being about twelve generations during the season. Both winged and wingless agamic females occur throughout the summer, but late in September and in October wingless forms which develop into true males and females are produced. These mate and the females lay eggs during October, most of them being carried by the ants to their nests, where the eggs are laid.

Control.-Owing to the fact that the aphids do not migrate until the second generation, a rotation of crops will be of great service in checking their injuries, as corn planted on uninfested land will not be attacked until it has been able to secure a good start, and if well fertilized will be able to withstand successfully whatever injury may occur. Rarely is corn on land not in corn the previous year seriously injured, and where infestation has not been serious throughout a community, it may usually be grown two years in succession with safety. 

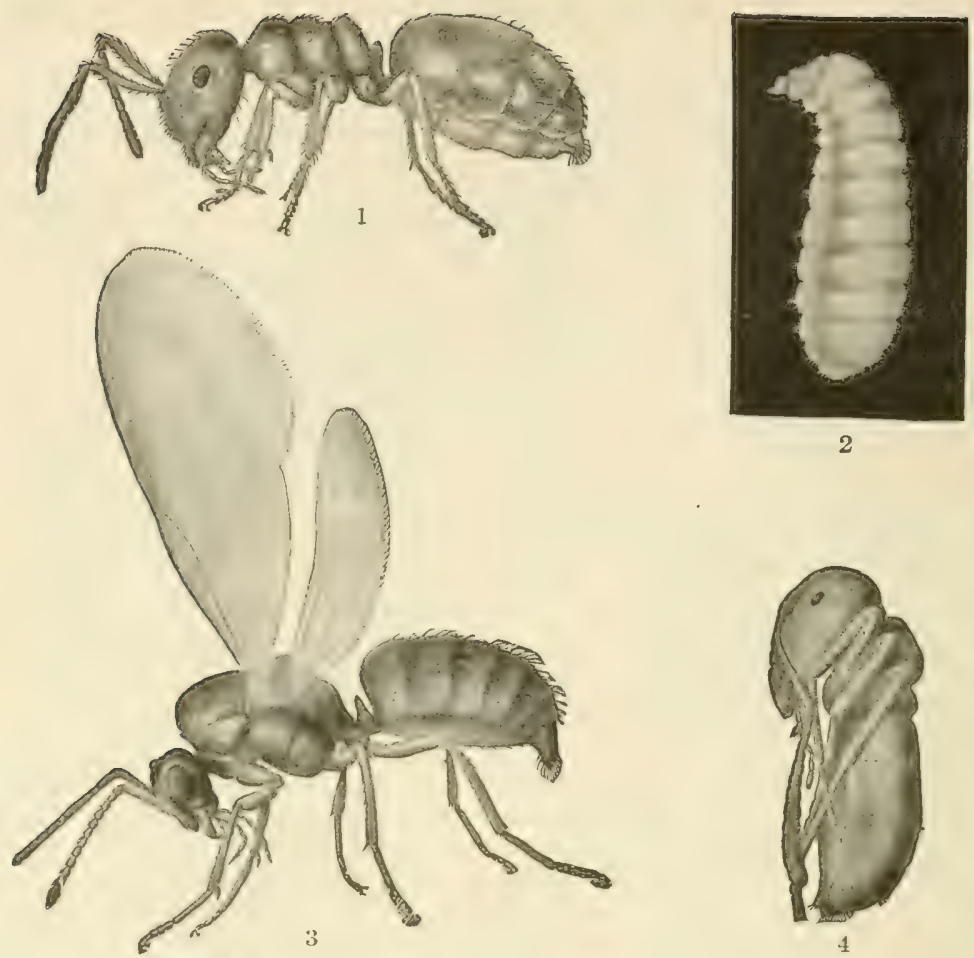

2

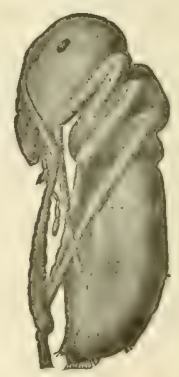

4
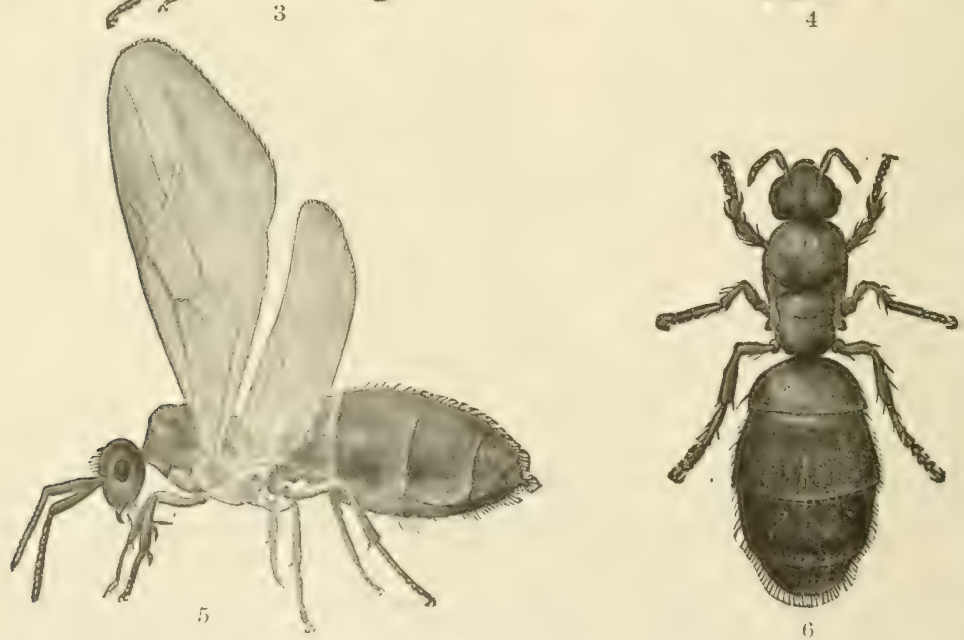

FIG. 130.-The corn-field ant (Lasius niger americanus): '1, worker; 2, larva; 3 , winged male; 4, pupa; 5, winged female; 6 , female with wings removed. (After Forbes.) 
The proper fertilization of plants affected with root insects is always of great importance, enabling the plant to make a crop in spite of them if the attack is not too severe. Professor F. M. Webster observes that land which has been fertilized with barnyard manure is much less injured by this insect than that where commercial fertilizers are used.

As the ants not only sprear the pest during spring and summer, but house the eggs in their nests over winter, any means for destroying their nests will be of importance in controlling the aphids. Where it is practicable, deep plowing in late fall and winter, with thorough harrowing, will break up the nests, and land so treated has shown decidedly less injury the next season. Similarly plowing deeply and harrowing several times in spring not only breaks up the ants' nests, but destroys the weeds and grasses upon which the aphids feed before corn is up, and also furnishes the best possible seed-bed and soil conditions. This should be particularly thorough in low spots where weeds are thickest and where the aphids appear first. Such spring cultivation has been demonstrated as very effective in the control of the pest. In recent years Professor S. A. Forbes has conducted experiments in Illinois which seem to show that dipping the seed in a repellant such as a lemon oil will render it obnoxious to the ants, and thus protect the hill. This has not proven successful, however, when heavy rains followed planting and washed off the repellant. Lemon oil was used by adding 1 gallon of wood alcohol to 1 pint of oil of lemon, of which 3 fluid ounces (6 tablespoonfuls) were stirred into each gallon of seed used, being sure that all the seeds were well coated. Such a treatment cost about ten cents per acre and resulted in reducing the number of aphids 89 per cent and the number of ants 79 per cent, so that it may well be given a trial, but the chief reliance should be placed upon rotation and early cultivation.

\section{The Corn Leaf-aphis *}

Although the corn leaf-aphis is not often very seriously injurious to corn, in Texas and other Southern States it frequently becomes so abundant on sorghum and com, and in winter on 1. c.

* A phis maidis Fitch. Family Aphidido. See Webster and Davis, 
barley, as to do considerable injury. This species is also of interest in that it appears on corn foliage in midsummer at the time when the numbers of the root-aphis commence to decrease on the roots, and it was for many years thought to be the same species. Careful rearing experiments made under the direction of Dr. S. A. Forbes have failed to show any connection between the rootaphis and leaf-aphis, the aphids from the roots being unable to establish themselves on the leaves and those on the leaves never migrating to the roots.*

Dr. Forbes describes the species in his twenty-third report as follows: "In the latter part of the summer this bluish-green

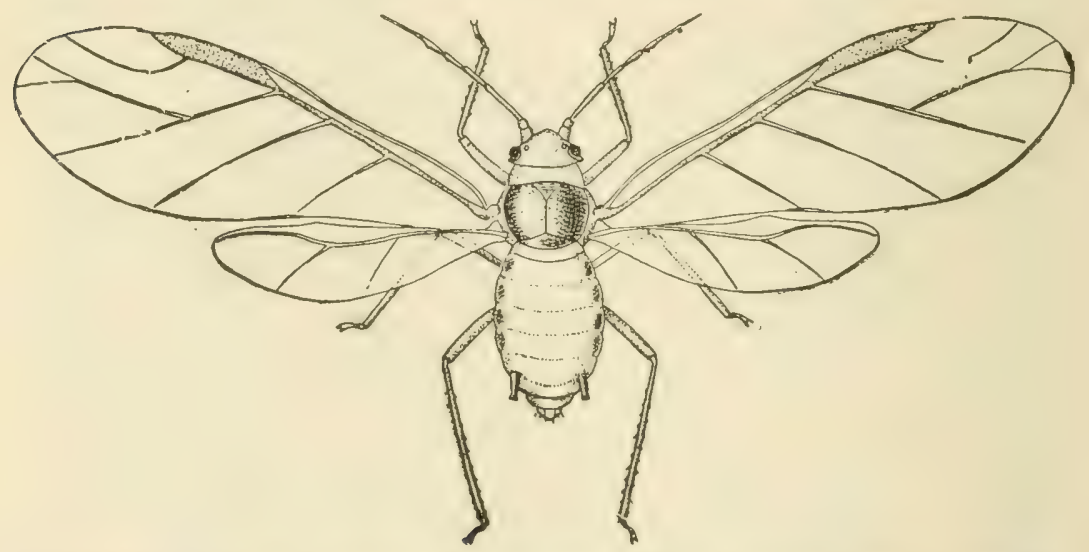

Fig. 131.-The corn leaf-aphis (Aphis maidis Fitch): winged female - much enlarged. (After Webster, U. S. Dept. Agr.)

plant-louse may occasionally be found on the younger leaves, the tassel, and the upper part of stalks of corn, and more abundantly and frequently on broom-corn and sorghum. Multiplying in place by the birth of living young, which do not wander from their place of origin, these leaf-lice may become abundant enough to kill the leaves and to some extent to affect the health of the plant. The insect is, however, rarely seriously injurious to corn, but there is some evidence, . . . that it may prevent the fertilization of the kernel by sucking the sap from the silk and killing it before it has performed its function. Heavily infested

* S. A. Forbes, 13th, 16th, 18th, and 23d Reports of the State Entomologist of Illinois. 
corn leaves turn yellow or red, and may shrivel and die, particularly if the weather be dry at the time. Broom-corn is considerably damaged by a reddened discoloration of the brush, due to a bacterial affection following upon the plant-louse punctures.

"The wingless form of this aphis about $2 \mathrm{~mm}$. (one-twelfth inch) long and half as wide at the widest part, the body being somewhat ovate in outline. The general color is pale green, with the cauda, cornicles and the greater part of the rostrum, antennæ and legs black. The head is marked with two longitudinal dark bands, and the abdomen with a row of black spots on each side and a black patch about the base of the cornicles. The latter are swollen in the middle, making the outlines convex.

The winged form is somewhat different in color, the head being black and the thorax chiefly black above. The abdomen is pale green, bluish at the sides, with two transverse black bands preceding the cauda, and the segments behind it edged with dark." These differences between this and the root aphis are shown in the accompanying figures. "Aphis maidis has been reported at various times as a corn insect from New York to Texas, Minnesota and California. The species makes its

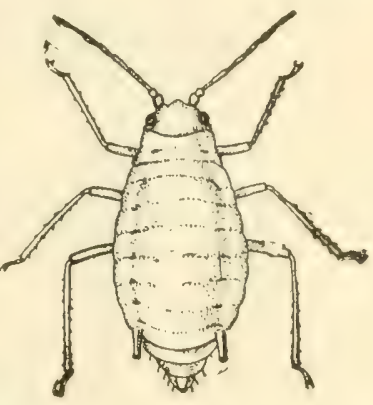
appearance in midsummer, our earliest Fig. 132.-The wingles s date (Illinois) being July 9, when specimens were found on young leaves of corn. We have no record whatever to show female of the corn leafaphis-much eniarged. (After Webster, U. S. Dept. Agr.)

whence it comes or where it lives preceding this time. Having once commenced to breed on the food-plants mentioned, it continues there until freezing weather overtakes it, when, with the death of its food plants, it gradually disappears, leaving neither eggs nor hibernating adults on or about these plants, and passing the winter we do not know how or where." Its occurrence on barley in Texas in January may throw some light upon its wintering habits in the South. "The latest to develop in the field largely acquire wings, and as the sap supply in the plant diminishes they fly away. Wingless females, on the other hand, perish on the 
spot. Indications are thus very strong that this is a migrating species whose second food plant is thus far unknown."

No experiments in the practical treatment of this pest seem to have been recorded.

\section{The Larger Corn Stalk-borer *}

Throughout the South from Maryland to Louisiana and west-

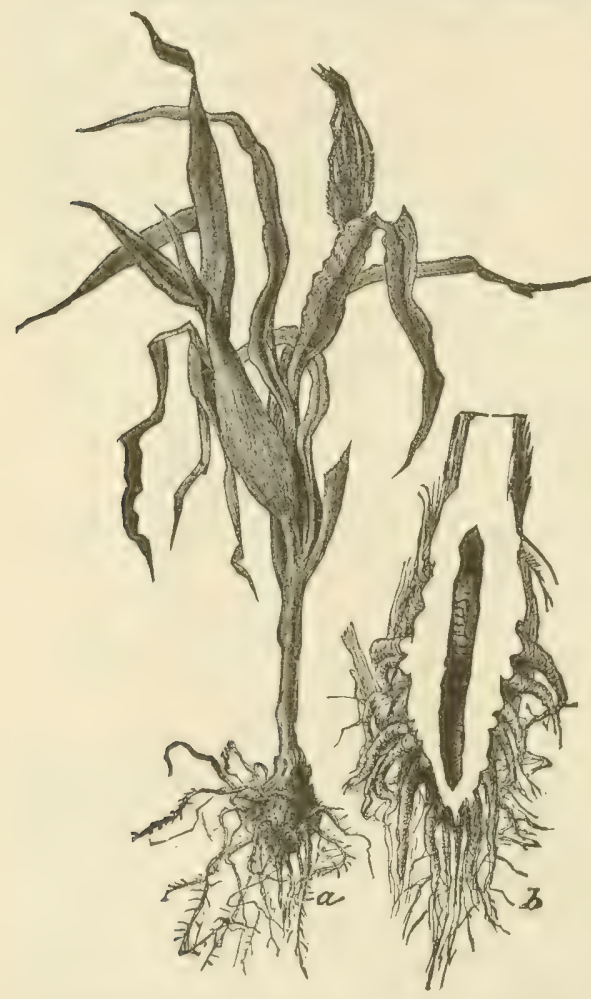
ward to Kansas more or less serious injury is done by large white, brown-spotted caterpillars which bore into the stalks. In spring the young caterpillars bore into the heart of the young plant and like other insects with similar habits (see page 146) are known as "budworms." Later the hollowing out of the. stalk so weakens the plant that it is readily broken over by the wind. Consequently a loss of from 25 to 50 per cent of the crop not infrequently results where the pest is abundant.

Life History.-When the caterpillars become full grown in the fall they burrow down into the tap-root and there pass the winter

Fig. 133. - Work of the larger corn stalk- in a small cavity at or near borer: $a$, general appearance of stalk in- the surface of the ground. $b$, same cut open to show pupa and larval About the time the land is burrow. (After Howard, U. S. Dept. Agr.) being prepared for corn, from March 15 to April 30, depending on the locality, the larva changes into a reddish-brown pupa, from which the moth emerges in ten days or more. The moth is brownish-yellow in color with

* Diatraca zeseolella Dyar. Family Crambida. See Farmers' Bulletin 1025, U. S. Dept. of Agr. 
wings expanding $\mathbf{1}_{4}^{1}$ inches, the hind-wings being darker and bearing faint markings (Fig. 135). The eggs are laid at dusk upon the under surface of the leaves of the young corn, and hatch in from seven to ten days. The eggs are flat, scale-like, and placed in rows of from two to twenty-five, slightly overlapping each other. They are 3-100 inch long, by two thirds as wide, at first a creany-white, but gradually becoming a reddish brown. The young larva bores into the stalk, often destroying the "bud," and then at or near the ground, where it burrows upward in the pith, seldom damaging:

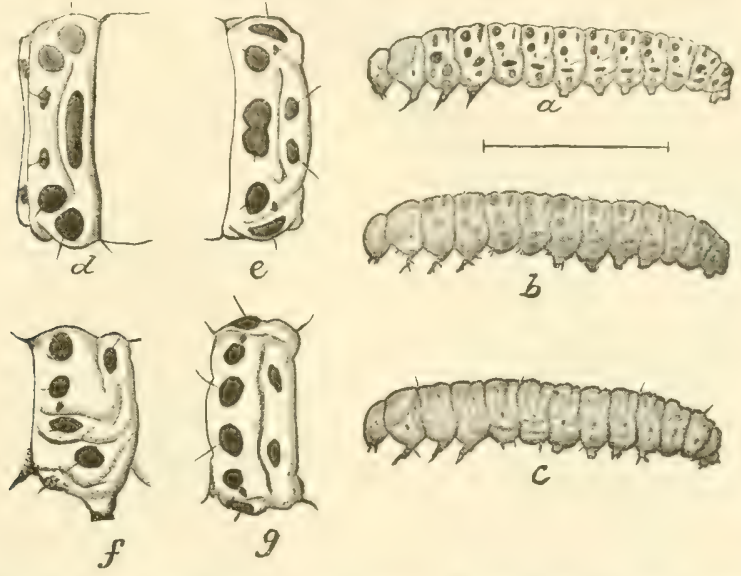

FIg. 134.- $a, b, c$, varieties of the larva of the larger corn stalk-borer; $d$, third thoracic segment; $e$, eighth abdominal segment; $f$, abdominal segment from side; $g$, same from above - enlarged. (After Howard, U. S. Dept. Agr.)

the stalk above the third joint. As the borers grow they become quite active and frequently leave and re-enter the stalk, thus making several holes. The caterpillars become full grown in twenty to thirty days, and are about one inch long, dirty-white, thickly covered with dark spots, each of which bears a short, dark bristle. The mature caterpillar bores outward to the surface of the stalk, making a hole for the escape of the adult moth, which it covers with silk, and then transforms to a pupa in its buriow. This occurs during July, and the moths of the second generation emerge in seven to ten days. The second brood larve feed on the old stalks, tunneling them between the second joint and the ground, and become full grown about harvest time when they go into winter quarters in the root as above described. 
Control.-It has been observed that late planted corn is much less injured than that planted early, but as it is more seriously injured by some other pests, late planting may not be advisable.

Where corn has been seriously injured, the old stalks or butts

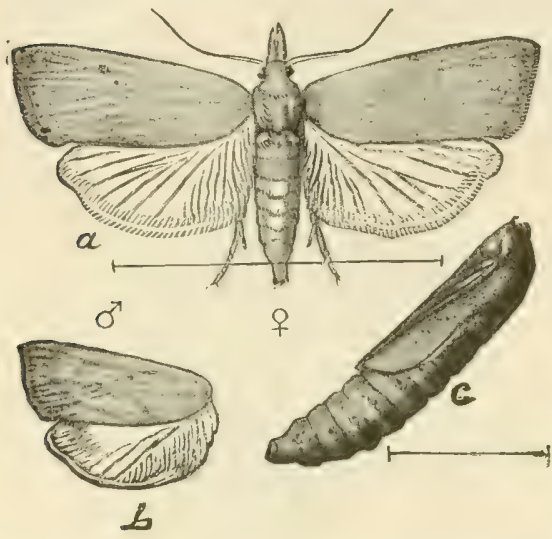

FIG. 135.-The larger corn stalk-borer, $a$, female; $b$, wings of male; $c$, pupai - all somewhat enlarged. (After Howard, U. S. Dept. Agr.) should be dragged off the field and burned late in the fall, thus destroying the over-wintering borers. When corn is stripped for fodder, the stalks left standing and the land sown in small grain, the most favorable conditions are allowed the borers for safely passing the winter and developing into moths which will fly to new fields in the spring.

A simple rotation of crops will also lessen injury considerably, as Dr. L. O. Howard has observed that where fields which had been in corn the previous year were damaged 25 per cent, those planted on sod land were damaged but 10 per cent, though reasonably close to land which had been in corn.

\section{Bill-bugs *}

Throughout the South and often in the more Northern States, Canada, and the West the bill-bugs sometimes become serious enemies of young corn-plants. They are called "bill-bugs" on account of the prolongation of the head, termed a bill or snout, peculiar to all the weevils or "snout-beetles," by means of which they are enabled to drill holes in the corn-stalks. Several species belonging to the genus Sphenophorus are commonly injurious to corn. One of these, S. parvulus Gyll., also attacks small grains and timothy, and is therefore known as the Grain Sphenophorus. Another species, S. obscurus Boisd., does considerable injury to sugar-cane in Hawaii. The adult beetles are from one-fourth to

* Species of Sphenophorus. Family Calandrida. See S. A. Forbes, 23d Report of the State Entomologist of Illinois. Also Farmers' Bulletin 1003, U. S. Dept. Agr., and Z. P. Metcalf, N. C. Expt. Sta. Bull., 13 Tech. 
three-fourths of an inch long, of the form shown in the illustration, and are of a brown or black color, marked with darker longitudinal ridges on the wing-covers. The larva is a thick fleshy white grub, from one-fourth to five-eight hs of an inch long, with a brown head and cervical shield on the first segment, and footless.

Life History.-The life histories of the different species are but partially known.

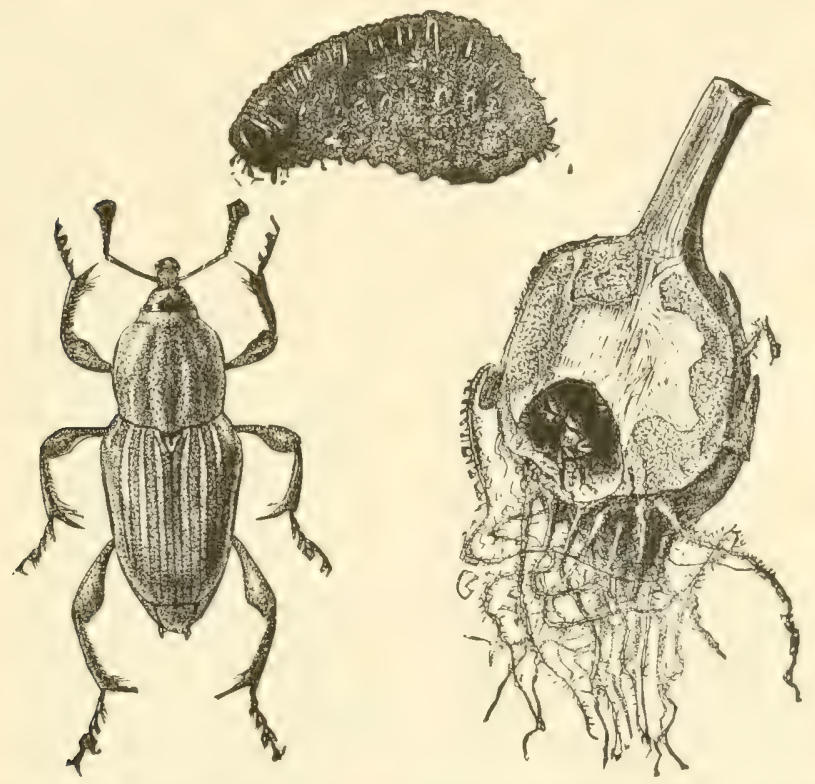

FIG. 136.-Sphenophorus ochreus, larva, adult, and work in roots of Scirpus. (After F. M. Webster, "Insect Life.")

S. parvulus hibernates over winter as a beetle, appearing in March and April. The female punctures the stalk of wheat or timothy-oats and barley are also sometimes attacked-a little above the roots, and deposits her egg in the cavity. This is done in May or June or even up to July 1st. The larvæ are to be found during July, becoming full grown and pupating during the latter part of that month. The larve will eat out quite a cavity in the interior of the stalk or bulb, and then attack the roots, thus often killing a whole clump or stool of small grain or timothy. The pupal stage is passed in a small cell in the earth and lasts from two to three weeks, adult beetles emerging from the middle of August to the first of October. 
One of the species most injurious to corn is S. ochreus Lec. The life history is much the same as that of $S$. parvulus, though eggs have been found as late as July 30th. The natural food-plant of this species, however, is the common club-rush (Scirpus fiuviatitis), the roots of which consist of bulbs connected by smaller slender roots. The eggs are deposited in or about the roots of this rush, never having been found on corn. The bulbs of the rush are very hard and oftentimes as large as hens' eggs. In them the larvæ burrow, becoming full grown and transforming to pupæ, from which the adult beetles appear in August and September. When the rush becomes too hard for the beetles they citen attack a common reed (Phragmites communis), piercing and splitting lengthwise the unfolded terminal leares, and eating out the succulent portions within. The injury to corn is done by the beetles while the corn is still young, feeding upon it in the same manner as do the other species. "Stancling with the head downward and the feet embracing the lower part of the stalk," says Dr. Forbes, "they slowly sink the beak into the plant, using the jaws to make the necessury perforation. By moving forward and backward and twisting to the right and left, the beetle will often hollow out a cavity beneath the surface much larger than the superficial injury will indicate." As the lower part of the stalk becomes hardened, they leave it for the terminal portion, and when the ears commence to form they often penetrate the husk and gouge out the soft cob. Sometimes the injury thus inflicted is but slight, merely resulting in a puncturing of the leaves when they unfold, these holes being in a series across the leaf resulting from a single puncture when the leaf was folled, and looking much like the work of the corn-root webworm; but when several beetles attack a young plant, they will either kill it outright or so deform the foliage and stalk that no ear will mature.

Several other species have also been known to do more or less injury to corn, viz., S. scoparius, placichus, cariosus, sculptilis, and pertinax, but so far as known their habits and injuries are much the same as of those already described.

Means of Control.- The control of these pests is rather a difficult task. s'. ochreus, as in fact are all of the species, is most injurious on recently cleared swamp-lands, and usually disappears as fast as these lands are drained and cultivated. Planting flax, potatoes, or some crop not attacked by these insects for the first 
crop will largely prevent so serious injury to a subsequent corn crop. The burning over of gratsis-and swamp-lands infested with the beetles will also be of considerable value.

\section{The Maize Bill-bug *}

Throughout the Southern States and northward to Kansas there has been more or less serious injury hy a bill-buy which has
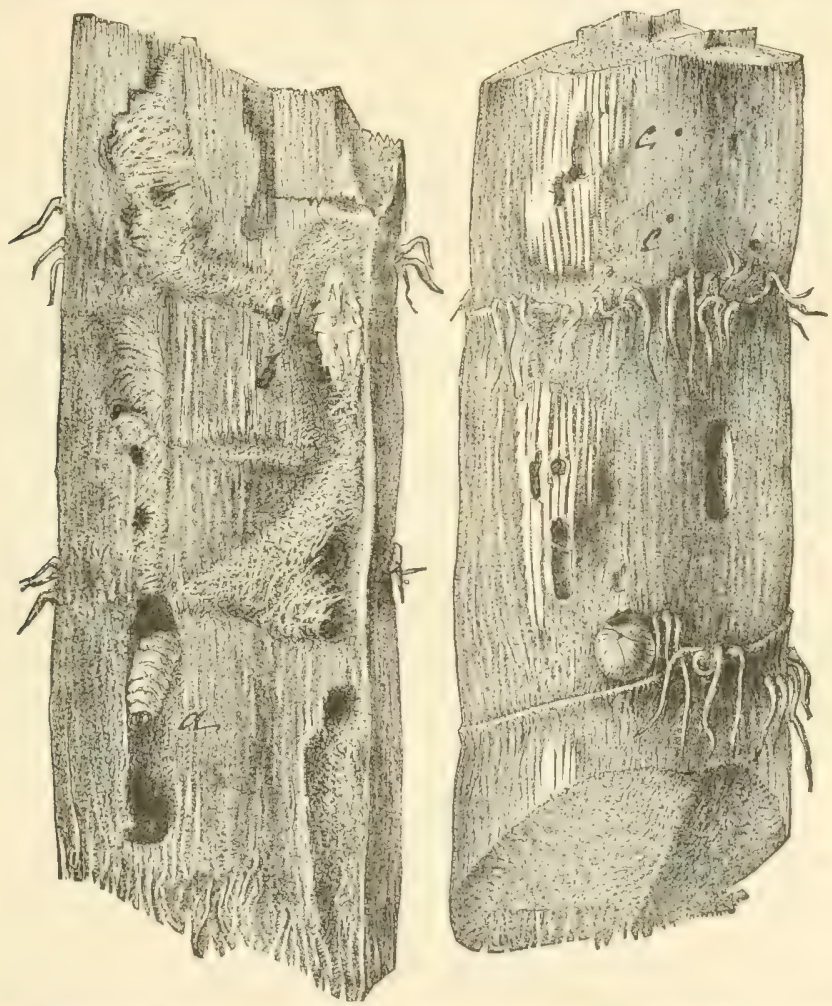

Fig. 137.- Sections of sugar-cane showing work of sphenophorus obscurus: $a$, larva; $b$, pupa; $c$, probable points of oviposition. (After Riley and Howard, "Insect Life.")

been recognized for many years as Sphenophorus robustus Horn. Recently Dr. F. H. Chittenden has recognized this insect as a new

* Sphenophorus maidis Chittn., see E. O. G. Kelly, Bulletin 95, Part II, Bureau of Entomology, U. S. Dept. Agr See also W. P. Hayes, Tech. Bulletin 6, Kansas Expt. Station, and Farmers' Bulletin 1003, U. ... Dept. Agr. 
species and Mr. E. O. G. Kelly has published a complete account of its life history, from which the following is taken.

As will be seen below this species is known to pass its entire life history upon the corn-plant so that the common name given it appropriately distinguishes it from other bill-bugs previously mentioned. It has, however, been found feeding and probably

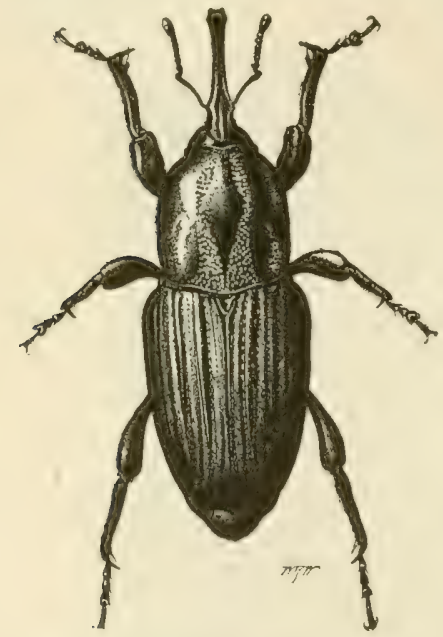

FIg. 138. - The maize bill-bug

(Sphenophorus mendis Chitn.) - four times natural size. (After Kelly, U.S. Dept. Agr.) breeding in swamp-grass (Tripsacum dactyloides), which may be its native food plant.

Life History. - The eggs were found in southern Kansas during June, laid in punctures made by the female in young corn-plants. These egg punctures are mere slits and do not seem materially to injure the plant. The eggs hatch in from seven to twelve days, and from them emerge small footless, dingy white grubs, with chestnut-brown heads, of the appearance shown in Fig. 140. "They at once begin feeding on the tissues of the young corn at the bottom of the egg puncture, directing their burrow inward and downward into the taproot. When they finish eating the tender parts of the taproot they direct their feeding upward, continuing until full grown, allowing the lower portion of the burrow to catch the frass and excrement. This burrowing of the taproot of the young growing corn-plant is disastrous to the root system; . . allowing it to die or become more or less dwarfed." Often the young larva burrow into the heart of the plant and cut off the growing bud, thus killing the top. The larvæ become full grown early in August, when they are about four-fifths of an inch long. "The larvw, on finishing their growth, descend to the lower part of the burrow, to the crown of the taproot, cutting the pith of the cornstalk into fine shreds, with which they construct a cell where they inclose themselves for pupation." The pupre are to be found in these cells in late August and early September, the pupal stage lasting ten to twelve days. The adults 
commence to emerge by the middle of August and continue to do so until the middle of September. "Some of them leave the pupal cells, but most of them remain there for hibernation." Those which emerged disappeared and probably hibernated in some dense, coarse grass nearby. Those which hibernated in the pupal cells

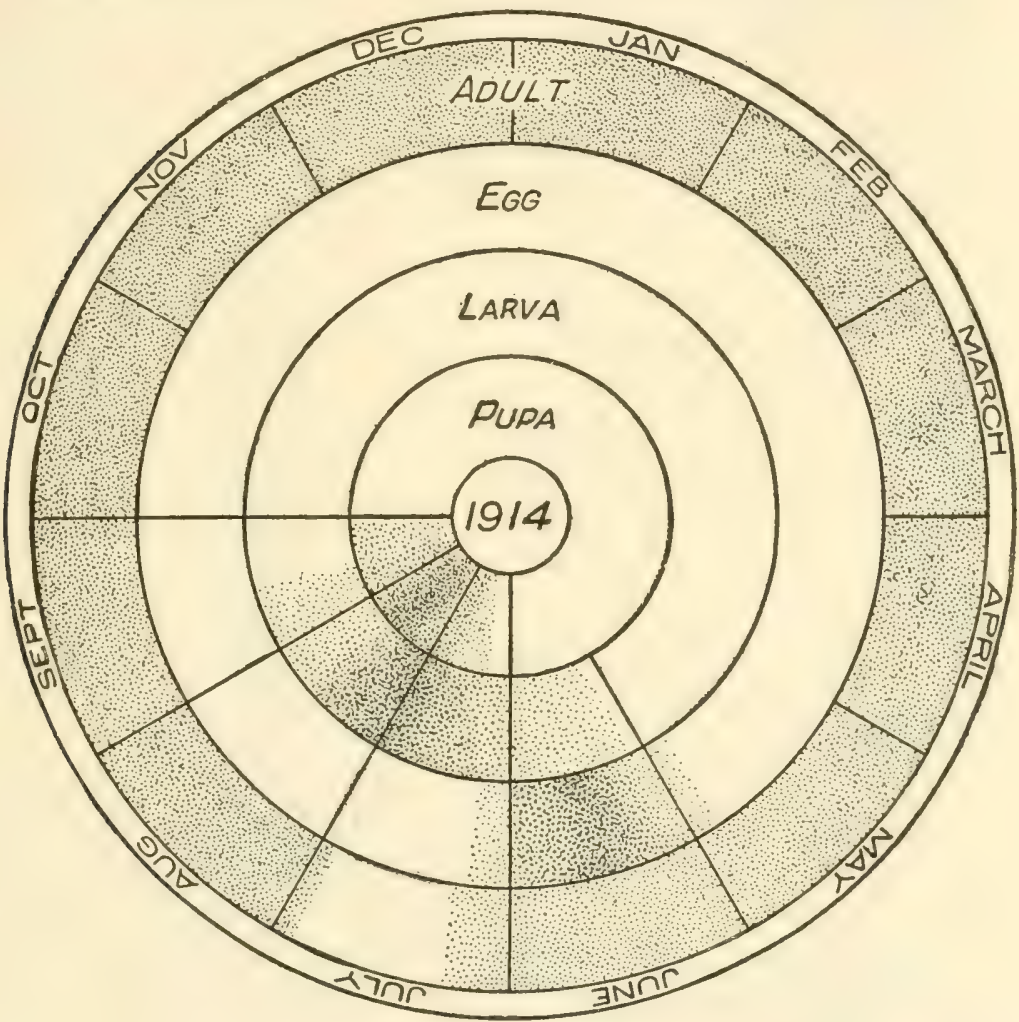

FIG. 139.-Diagram representing the seasonal appearance of the maize billbug in 1914 in Kiansas. (After W. P. Hayes, Technical Bulletin 6, Kansas Agr. Expt. Station.)

emerged the next spring about the time that young corn was sprouting. The beetles are from two-fifths to three-fifths of an inch long, of a dull shining black color, and sculptured as shown in Fig. 138. "The beetles are rarely observed on account of their quiet habits and because they are covered with mud-a condition which is more or less common among several species of this genus 
and which is caused by a waxy exudation of the elytra to which the

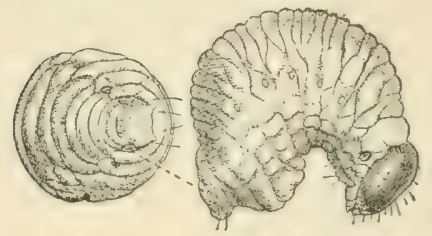

Fig. 140.-Larva of the maize hillbug-twice natural size. (After Kelly, U. S. Dept. Agr.) soil adheres. The presence of the adults of this species in a cornfield is made evident by the withering of the top leaves of very young corn-plants, the plants having been severely gouged. After the plants grow 10 to 15 inches tall they do not kill them, but gouge out such large cavities in the stalks that they become twisted into all sorts of shapes. The attacked plants sucker profusely, affording the young, tender growth for the beetles to feed upon, even for many days after the non-infested plants have become hard." Injury seems to be most serious on low land. Injury by this species somewhat resembles that done by the larger corn stalk-borer (Diatraea zeacolella), but is easily distinguished from the work of the other billbugs, as the punctures of the latter, which usually form a row or rows of holes in the leaves when they unfold, are not always fatal to the plants.

Control.-Inasmuch as most of the beetles hibernate in the corn stubble, they may be readily destroyed by pulling out and burning the stubble. Care must be taken, however, to pull out the taproot, as the stalk will be liable to break above the beetle and leave it in the ground. As the infested stallis have a poor root system, they are easily

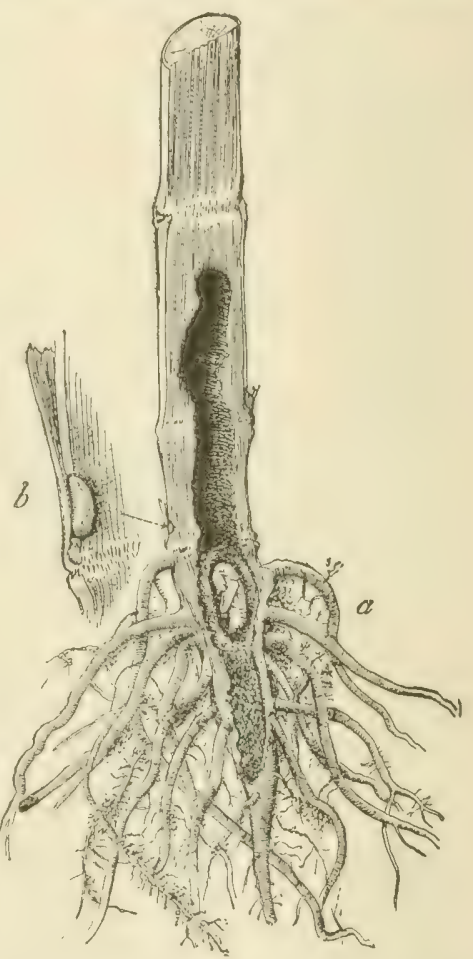

FIG, 141.-Corn plant showing the result of attack of the maize billbug: a, larval hurrow containing pupa in natural position-reduced two-thirks; h, egg-puncture containing egrg-enlarged (After Fielly, U. S. Dept. Agr.)

pulled. Crop rotation and fall plowing are also of great value. 


\section{The Lesser Corn Stalk-borer *}

This small moth has been sporadically injurious for many years and seems to be on the increase in the Southern States where it is at times injurious to corn, sorghums, wheat, cowpeas and crabgrass, as well as other plants in considerable numbers.

Description. - The
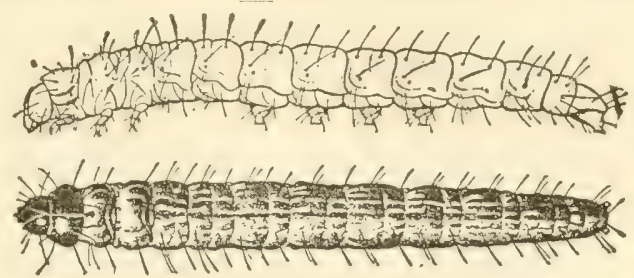
moth is a small, Fig. 142. - The lesser cornstalk borer: larra, greatly brownish gray form enlarged. (After Luginbill and Ainslie, L. C.) with a wing expanse of less than one inch. The fore wings of the female are darker than those of the male. The larve are slender caterpillars, three quarters of an inch in length. Their prevailing color is a light green with darker markings, prominent among which are brownish transverse bands.

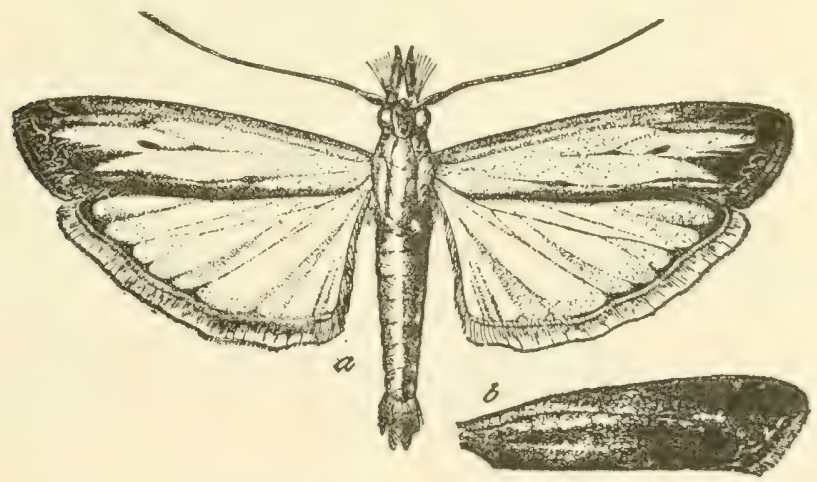

FIG. 143.-The lesser corn stalk-borer: $a$, male moth; $b$, fore-wing of female moth. Greatly enlarged. (After Luginbill and Ainslie, L. C.)

Lije history.-Eggs are produced throughout the summer and fall and the winter is passed in the larval or pupal stage. There are probably as many as four generations in the southern range of the insect and fewer in the North.

* Elasmopalpus lignosellus Zeller. Family Pyalididre.

See U. S. Dept. Agr. Bulletin 539, Luginbill and Ainslie. 
Injury.-Injury from these insects is, as the name indicates, due to their boring in the stalks of the food plant. It may be anywhere from slight to total. They seem to prefer crops grown on sandy soil.

Control.-Absolutely clean cultivation, including cleaning up of fence rows and waste places, along with late fall plowing, are recommended as the best methods of control.

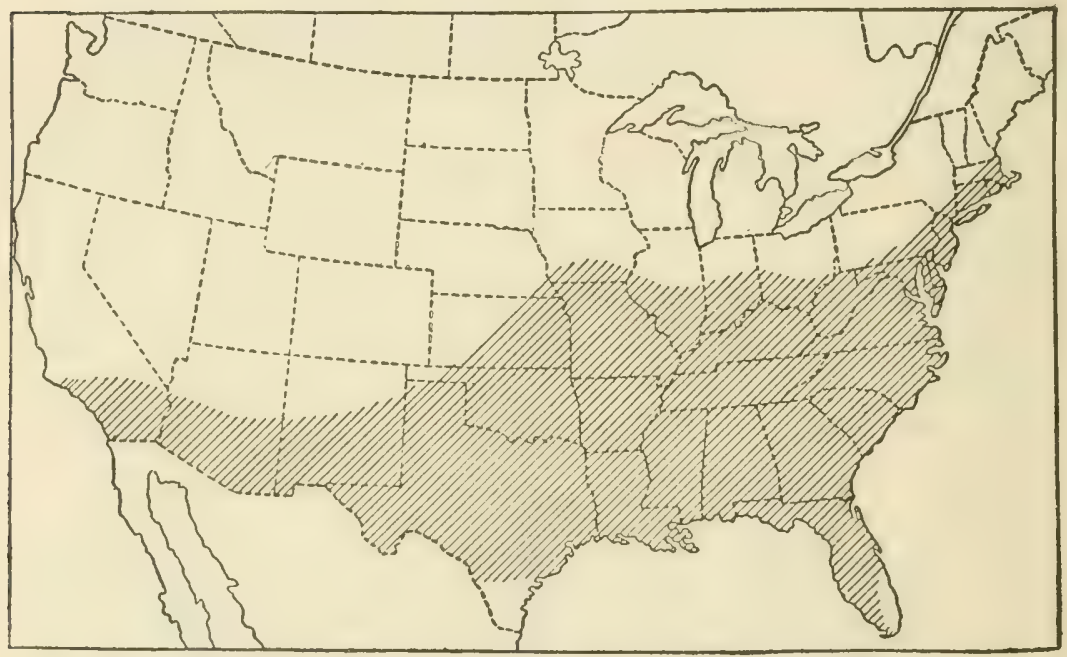

FIG. 144.-MIap showing present known distribution of the lesser corn stalkborer (Elasmopalpus lignosellus) in the United States. (After Luginbill and Ainslie, L. C.)

\section{The Corn Ear-worm *}

Practically the only insect injuring the ears of field-corn and the worst insect pest of sugar-corn, is the ear-worm. In the extreme South it is almost impossible to grow sugar-corn successfully on account of its injury, while farther north it largely reduces the profits of corn grown for the cannery, and destroys a considerable percentage of the kernels of field-corn. It is a most cosmopolitan insect, being found throughout the United States and in many parts of the world, and has a long list of food plants, being known as the tomato fruit-worm, tobacco bud-worm, and cotton boll-

* Chloridea obsoleta Fab. Family Noctuidæe.

See H. Garman, Bulletin 187, Tentucky Agr. Expt. Station and Farmers' Bulletin 872, U. S. Dept. Agr.) 
worm when attacking these plants, besides which it feeds on beans, peas, and many garden crops and forage plants, such as cowpeas and alfalfa.

Life History.-Along the Gulf Coast the first moths appear in April, in the latitude of $33^{\circ}$ about the middle of May, and in the latitude of Delaware and Kansas, early in June.

The moth is about three-quarters of an inch long with a wing expanse of about $1 \frac{1}{2}$ inches and is extremely variable in color and markings. Some are dull olive green while others are yellowish

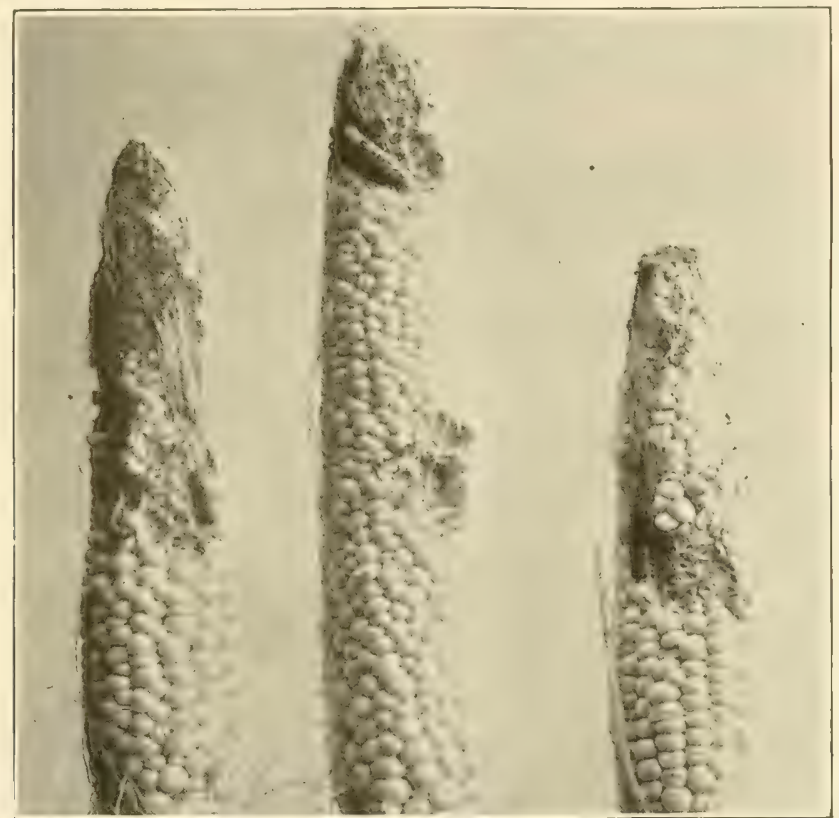

FIG, 145.-Corn ear-worms at work. The central cob has been attacked by a nearly full-grown worm, which has bored through the husk near the middle.

or nearly white and with almost no markings. In the most typical moths the wings are bordered with dark bands, the wing veins are black and the fore-wings are spotted with black.

The eggs are hemispherieal in shape, about one-fifteenth inch in diameter, light yellowish, and prettily corrugated with ridges as shown in Fig. 201. Those of the first brood are laid on corn, peas, 
beans, or whatever food-plants are available, and hatch in three to five days, depending upon the temperature.

The caterpillars of the first generation often attack corn when about knee-high, feeding in the axils of the tender leaves, so that
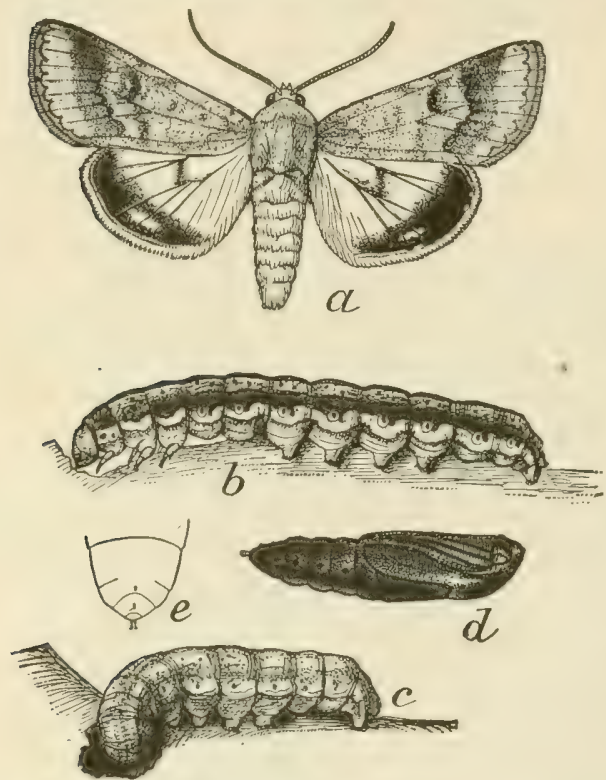

Fig. 146.-Corn ear-worm or cotton bollworm (Chlorilea obsoleta): $a$, adult moth; $b$, dark full-grown larva; $c$, light-colored full-grown larva; $d$, pupa-natural size. (After Howard, U. S. Dept. Agr.) when the leaves unroll they bear horizontal rows of holes. The caterpillars are exceedingly variable in color, being from a light green through rose color and brown to almost black, and either striped, spotted or perfectly plain. They become full grown in about $2 \frac{1}{2}$ weeks and are then about $1 \frac{1}{4}$ to $1 \frac{1}{2}$ inches long. When done feeding the caterpillar burrows 2 to 5 inches into the soil near the base of the plant. A cell is then constructed which runs back to within a half inch of the surface of the soil, so that the moth may readily push off this surface soil and escape. The burrow finished, the larva retires to the bottom of the cell and there molts and enters the pupal.

The pupa is four-fifths inch long, shining reddish-brown. During the summer the moths emerge about two weeks later, but the last generation in the fall passes the winter in the pupal stage. Thus the complete life cycle from egg to adult moth requires slightly over a month in midsummer, and from six to eight weeks for the spring and fall broods.

The second generation of moths appears about the middle of July in the latitude of Delaware and Kansas. In the far South the second generation of moths appears when corn is com- 
ing into silk and tassel, upon which the moths always prefer to lay their eggs. As a result, the caterpillars of the second generation of the South, and the third farther North, do serious injury to field-corn, gnawing out the kernels at the tips of the ears, and furnishing favorable conditions for molds to propagate, which

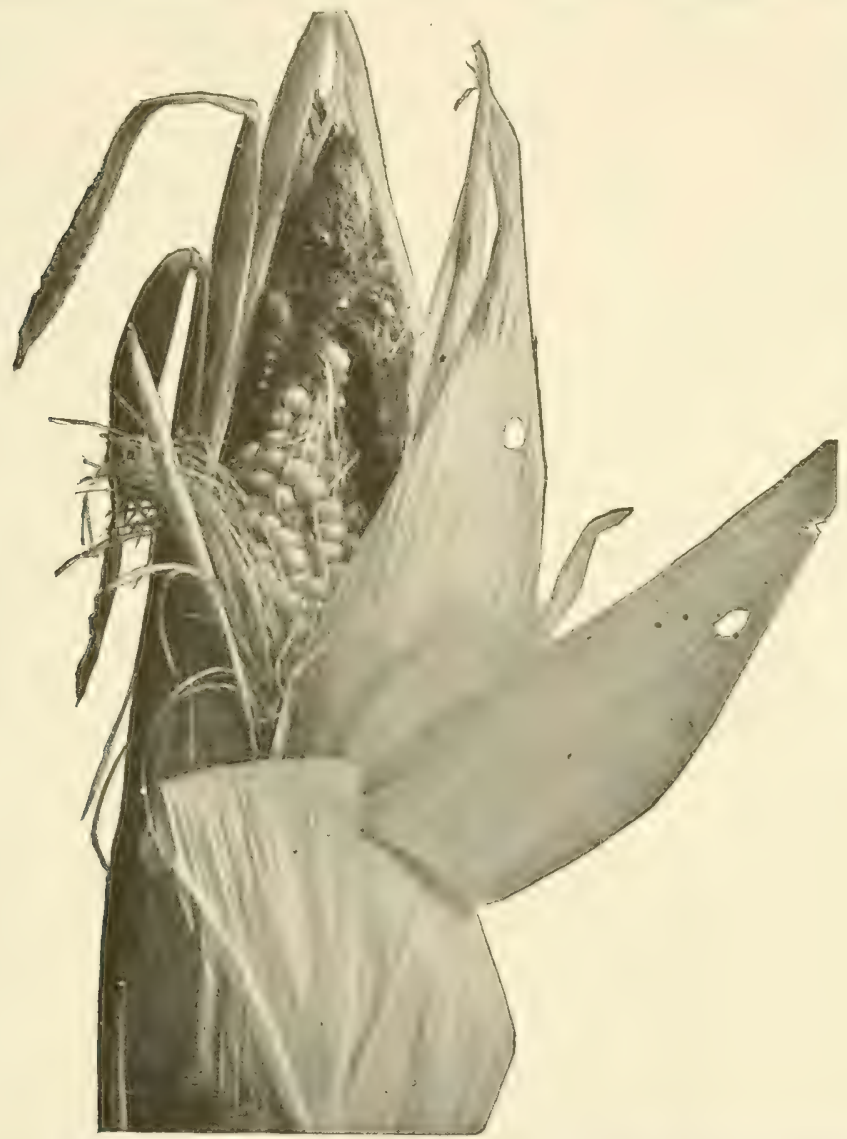

FIG. 147.-Corn ear-worm. Husk of ear of sugar-corn torn open, showing worms at work on tip and hole through which a full grown worm has left.

do further injury. From 2 to 5 per eent of the corn crop of the country, with a cash value of $\$ 60,000,000$ to $\$ 150,000,000$, is thus destroyed by the ear-worm annually.

The third generation of moths appears the last of August in Delaware and Kansas and gives rise to the third brood of 
caterpillars, which is there the most destructive brood on fieldcorn and sugar-corn, frequently causing a loss of from 10 to 50

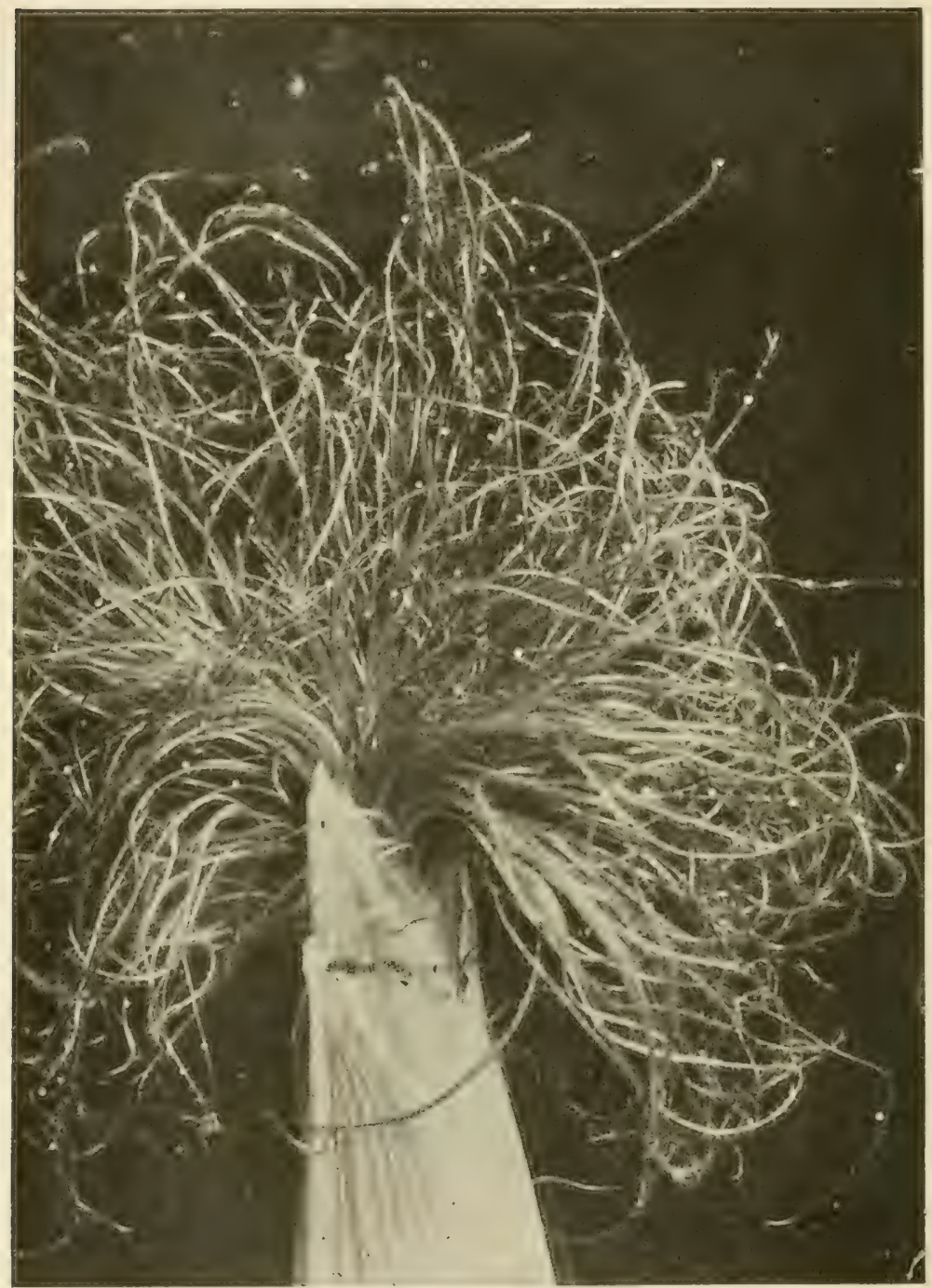

Fig. 148.-Tip of ear of corn showing eggs of corn ear-worm on silks. (After Quaintance and Brues, U. S. Dept. Agr.)

per cent of the latter crop. The caterpillars become full grown during the latter part of September and change to pupæ, which hibernate over winter as already described. 
In the Gulf States there are four full broods and along the Gulf Coast there may be five or six, while in the Northern States there are but two generations, with possibly but one in Ontario.

Control.-As the pupa pass the winter in the soil, by all means the most satisfactory and practical means of control is to plow infested land in late fall or during the winter, plowing deeply and harrowing. This will break up the pupal cells, crush some of the pupæ, and expose others to the rigors of winter to which most of them will succumb.

The early planting of field-corn prevents the moths from laying their eggs upon it, as it will have passed the silking stage and other fields which are in silk will be preferred; it being possible thus to reduce the injury by at least a third by early planting.

Silks and foliage of sweet corn are sometimes poisoned with arsenate of lead applied in the form of a dust, three to five applications being used, and much benefit has been recorded from the treatment but it has not yet proven practical for field corn on account of the expense.

\section{The European Corn Borer*}

Concerning this insect, a recent importation from Europe, we can do no better than to quote from Mr. Caffrey who, in his introduction to Farmer's' bulletin 1046 of the U. S. Department of Agriculture, summarizes the situation as follows:

"The European Corn Borer probably is the most injurious plant pest that has yet been introduced into this country. It is now known to be present in an area of about 320 square miles near Boston, Mass. Unless repressed and restricted it may spread throughout the country and cause serious and widespread losses to the corn crop.

The larvæ, or borers, tunnel through all parts of the corn plant and destroy or severely injure the ears and stalks. The pest also attacks celery, Swiss chard, beans, beets, spinach, oats, potatoes, tomatoes, turnips, dahlias, chrysanthemums, gladiolus, geraniums, timothy, and certain weeds and grasses.

* Pyrausta nubialis Hüebner. Family Pyralidido.

See Vinal and Caffrey, Bulletin 189, Massachusetts Expt. Station and Farmers' Bulletin 1046, Ù. S. Dept. of Agr. 


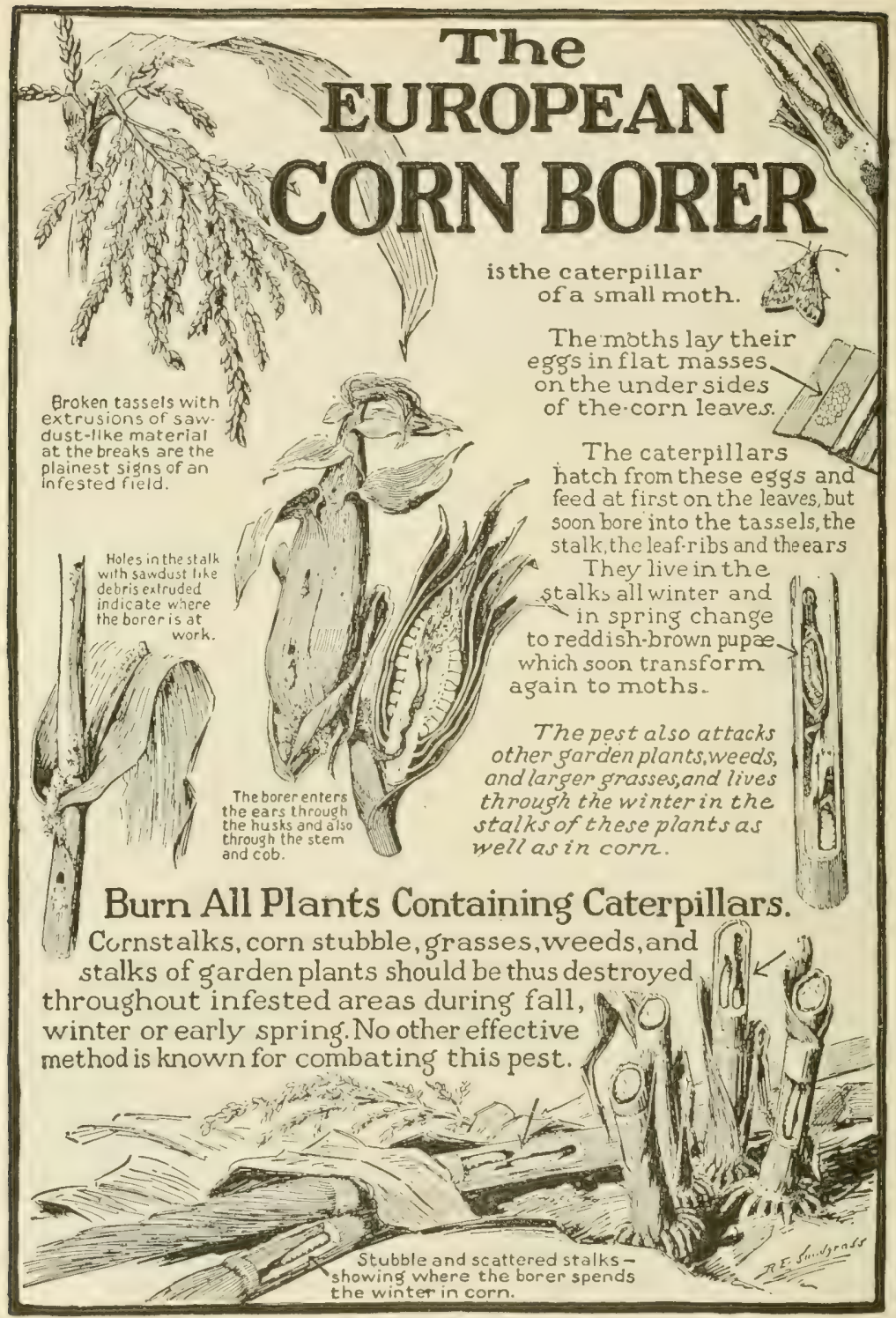

FIG. 149.-Department of Agriculture warning against the European corn borer. (After Caffrey, Farmers' Bulletin 1046.) 
There are two generations each year, so that multiplication and spread are rapid, especially as very few of the borers are destroyed by natural enemies. The winter is passed in the larva or borer stage within infested plants.

To suppress this pest burn or otherwise destroy during the fall, winter, or spring all cornstalks, corn stubble, crop remnants, and stalks of garden plants, weeds, or wild grasses within the infested areas likely to harbor the overwintering borers. Work of this kind is now being conducted by the Federal, State, and local authorities, and the hearty cooperation of all property owners, tenants, or other interested persons is earnestly solicited. This work must be done very thoroughly. The borers in a few overlooked plants may increase by the end of the season to as many as were present before the clean-up.

To prevent the spread of the insect, quarantine measures, both Federal and State, must be strictly enforced to prevent shipment of infested plants or plant products out of the area now infested.

Since the date of this bulletin (April, 1919) the borer has been found in New York State, an area of 400 square miles near Schenectady having been found to be infested.

Since little work has been done on the insect in this country except through the U. S. Bureau of Entomology we give here also a copy of the posters summarizing the apperance of the injury, just as they were sent out by the bureau. It is impossible to predict how rapidly the insect will spread or how well it will adapt itself to our conditions. It can be said, however, that it is potentially the most serious pest which has ever threatened the corn of the country. 


\section{CHAPTER X}

\section{INSECTS INJURIOUS TO STORED GRAINS *}

THE farmer who stores his grain, awaiting a higher price, is sometimes sadly disappointed to find that it has been so riddled by "weevil" that it brings no more than had it been sold previously.

The term "weevil" is rather a comprehensive one, being commonly applied to almost every insect infesting stored foodproducts. Only a few species are commonly injurious in the farm granary.

\section{Grain-weevils}

Of these the Cranary-weevil $\dagger$ and the Rice-weevil 150), are the most common and widely distributed. Both of

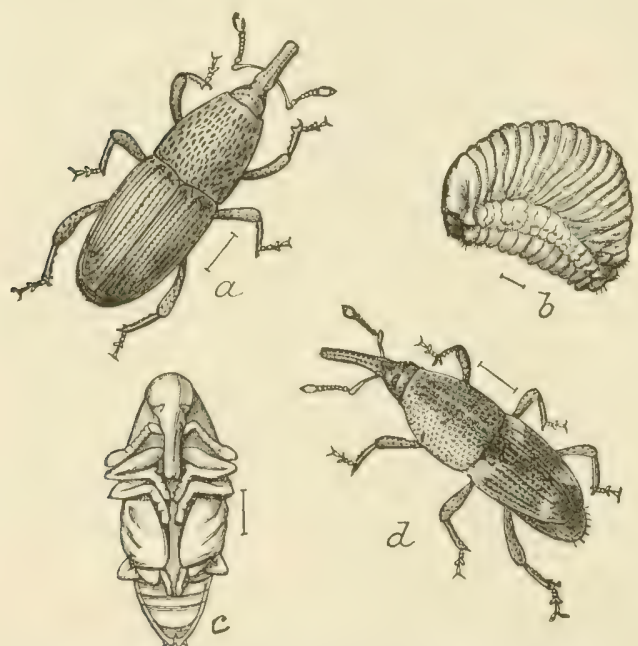

Frg. 150.-The grain weevil (Calandra granaria): $a$, beetle; $b$, larva; $c$, pupa; $d$, the rice weevil (C. oryza: beetle-all enlarged. (After Chittenden; U. S. Dept. Agr.) these insects have infested grain from the most ancient times, so long, in fact, that the granary-weevil has lost the use of its wings and remains entirely indoors. They are small, brown beetles, from one-eighth to one-sixth of an inch in length, with long snouts which are of great service in boring into the kernels of grain. By means of them the females puncture the grain and then insert an egg in the cavity. The larva

* See Farmers' Bulletin 1029, U. S. Dept. Agr., and G. A. Dean, Bulletin 189, Kansas Agr. Exp. Station.

+ Calandra granaria Linn.

† Calandra oryza Linn. Family Calandrida. 
hatching from this is without legs, somewhat shorter than the adult, white in color, and of a very robust build, being almost as broad as long. It soon devours the soft interior of the kernel and then changes to a pupa, from which the adult beetle emerges in about six weeks from the time the egg was laid.

Only a single larva inhabits a kernel of wheat, but several will often be found in that of corn. Not only do the larva injure the grain, but the beetlesfeed upon it, and then hollow out a shelter for themselves within the hull. The beetles are quite long-lived, and thus do considerable damage. The egg-laying period is equally long, and as there are three or four broods in the North and six or more in the south, it has been estimated that the progeny of one pair would amount to 6000 insects in a single season.

\section{Grain-beetles}

Another beetle very common in the granary, but of quite different appearance, is the Saw-toothed Grain-beetle* (Fig. 151).
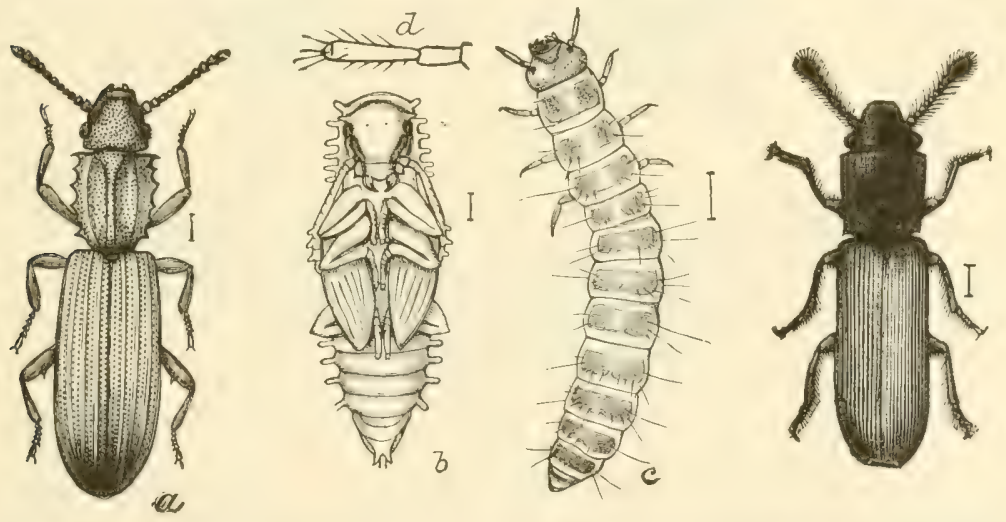

Fig. 151.-The saw-toothed grain beetle (Silvanus surinamensis): a, adult beetle; $b$, pupa; $c$, larva-all enlarged; $d$, antenna of larva-still more enlarged; $d$, the red or square-necked grain beetle (Cathartus gemellatus Duv.) (After Chittenden, U. S. Dept. Agr.)

It is a cosmopolitan pest and is also nearly omnivorous. The beetle is only about one-tenth of an inch long, very much flattened, of a dark-brown color, and may be easily recognized by the six sawlike teeth on each side of the thorax. The larva is of a dirtywhite color, and quite dissimilar to that of the granary weevil.

* Silvanus surinamensis Linn. Family Cucujida. 
Having six legs to carry it about, it is not satisfied with a single seed, but runs about here and there, nibbling at several. When full grown the larva glues together several grains or fragments intoa little case, and inside of this transforms to the pupa and then to the beetle. In early spring this life cycle requires fromsix to ten weeks, but in summer it is reduced to about twenty-five days. Thus there are
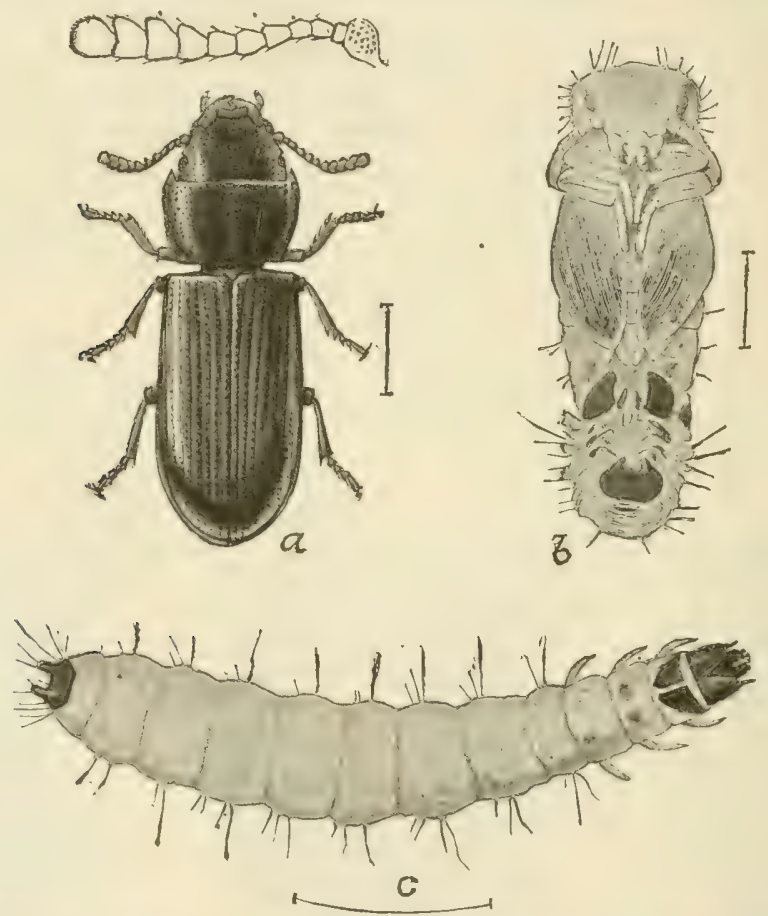

FIG. 152.-The Cadelle (Tenehroides mauritanicus): $a$, adult beetle with greatly enlarged antemna above; $b$, pupa; $c$, larva-all enlarged. (After Chittenden, U. S. Dept. Agr.)

from three to six or more generations during a season, according to the latitude.

The Red or Square-necked Crain-beetle* is about the same size as the last species, but is of a reddish-brown color, and the thorax is almost square, nearly as broad as the abdomen, and not notehed on the sides. It breeds in corn in the field and in the granary, first destroying the germ, so that it is especially

* Cathartus gemellatus Duv. Family Tenebrionidae. 
injurious to seed-corn. It feeds mostly out of doors, though sometimes infesting the granary.

The Foreign Grain-beetle* is of much the same general appearance, but smaller and of a more robust appearance. It feeds upon a great varicty of stored products as well as grain, but rarely becomes troublesome.

The Cadellet also has the bad habit of first attacking the embryo or germ of the kernel, and going from one kernel to another, thus destroys a large number for seed purposes. It possesses, however, the good trait of feeding on other injurious graininsects. The beetle is oblong, flat, nearly black, and about one-third of an inch long. The larva is of a whitish color, with a brown head, the thoracic segments are marked with brown, and
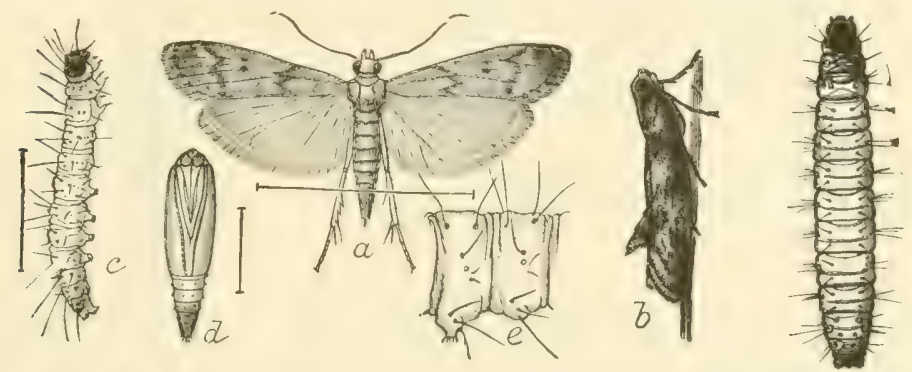

FIG. 153.-The Mediterranean flour-moth (Ephestia linehniella): a, moth; $b$, same from side, resting; c, larvat; $d$, pupa-enlarged; $e$, abdominal joint of larva-more enlarged; $f$, larva, dorsal view. (After Chittenden, U. S. Dept. Agr.)

the abdomen terminates in two dark horny processes. It is a fleshy grub, nearly three-fourths of an inch long' when full grown.

\section{Flour- and Meal-moths}

The larvæ of several small moths sometimes infest grain in store, but rarely do it serious damage, preferring the softer flour, meal and food-products.

The most destructive of these is the Mediterranean Flour moth $\ddagger$ (Fig. 153). This insect was practically unknown until

* Cathartus advena Waltl.

† Tenebroides mauritanicus Linn. Family Trogositida.

¥Ephestia liuehniella Zell. Family Pyrrilididar. See Wr. G. Johnson, Appendix 19th Report State Entomologist of Illinois, and F. L. Washburn, Special Report of the State Entomologist of Minnesota on the Mediterranean flour-moth. 
1877, but during recent years it has occasioned the loss of many thousands of dollars to mill-owners. It occurs throughout Europe, and is found in Mexico and Chili. It was first recognized in America in 1889, and has since done an increasing amount of damage in California, in New York and Pennsylvania, North Carolina, Alabama, New Mexico, and Colorado, and has become quite generally distributed. "The caterpillars form cylindrical silken tubes in which they feed, and it is in great part their habit of web-spinning that renders them so injurious where they obtain a foothold. Upon attaining full growth the caterpillar leaves its original silken domicile and forms a new web, which becomes
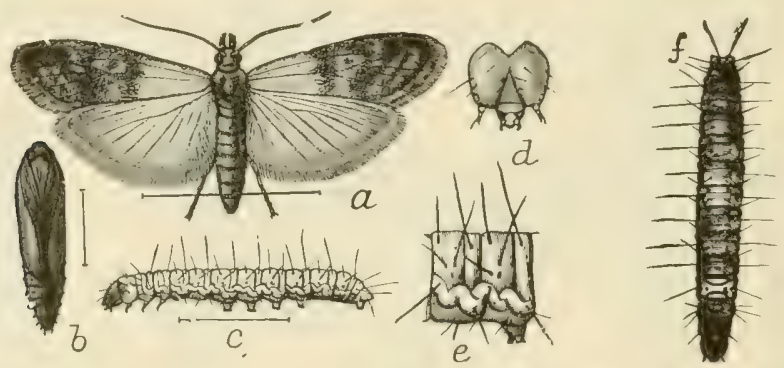

Fra. 154.-The Indian meal-moth (Plodia interpunctella): $a$, moth; $b$, pupa; $c$, caterpillar; $f$, same-dorsal view, somewhat enlarged; $d$, head, and $e$, first abdominal segment of caterpillar-more enlarged. (After Chittenden, U. S. Dept. Agr.)

a cocoon in which to undergo its transformations to pupa and imago. It is while searching for a suitable place for transformation that the insect is most troublesome. The infested flour becomes felted together and lumpy, the machinery becomes clogged, necessitating frequent and prolonged stoppage, and resulting in a short time in the loss of thousands of dollars in large establishments."

The life cycle of this insect requires ordinarily about two months, but may be completed in thirty-eight days under the most favorable conditions. The adult moth measures a little less than an inch across the expanded wings. The fore-wings are of a leadgray color, with transverse black markings, while the hindwings are dirty whitish, with a darker border.

The Indian Meal-moth* (Fig. 154) larva resemble those of the grain-beetles in having a special liking for the embryo of

* Plodia interpunctella Hbn. Family Pyralidido. 
wheat-grains. They spin a fine silken web as they go from seed to seed, to which they become attached, and to which is added a large amount of excrement, thus spoiling for food much more grain than is actually injured.

The moth has a wing-expanse of an inch; the inner third of the fore-wings being a whitish-gray, and the outer portion reddish-brown, with a coppery lustre.

The Meal Snout-moth* (Fig. 155) is of a light brown color,

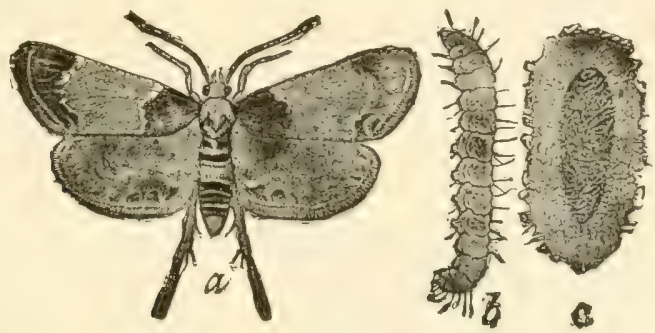

FIg. 155.-The meal snout-moth (Pyralis farinalis): $a$, adult moth; $b$, larva; c, pupa in cocoon-twice natural size. (After Chittenden, U. S. Dept. Agr.)

the thorax, base, and tips of the fore-wings being darker brown. The wings expand nearly an inch and are otherwise marked with whitish lines as shown in the figure. It is very similar to the last-mentioned species in its habits, constructing long tubes with silk and particles of the food in which it is living. The lifehistory is completed in about eight weeks, and four generations may occur in a year. The moisture of "heated" grain is most favorable for the development of this pest, and it need not be feared if grain is kept in a clean, dry place.

The Pink corn-worm $\dagger$ has recently assumed importance in the southern states as an enemy of stored corn. It is a moth similar in shape to the Anguomois grain-moth, but smaller and different in color. Its wing expanse is less than one-half inch and its color is chestnut-brown with whitish-yellow markings. There are long fringes on the margins of both pairs of wings. The eggs are first laid on corn in the field, usually following injury from the earworm or other insect. Later generations attack corn in the crib. The larvæ are small pinkish caterpillars. They feed on grain and even on husks and cobs and spin webs wherever they go.

\section{* Pyralis farinalis Linn. Family Pyralididoe.}

$\dagger$ Batrachedra rileyi Wals. Family Elachistida. 


\section{The Angoumois Grain-moth *}

By far the worst granary pest throughout the South is the "fly-weevil," or Angoumois grain-moth.

History.-This insect is an importation from Europe and receives its name from the fact that in 1760 it "was found to swarm in all the wheat-fields and granaries of Angoumois and of the neighboring provinces [of France], the afflicted inhabitants being thereby deprived of their principal staple, and threatened with famine and pestilence from want of wholesome bread." The insect was first noted in this country in North Carolina in 1730, and in 1796 was so abundant as to extinguish a lighted candle when a granary was entered at night. It is essentially a southern insect,

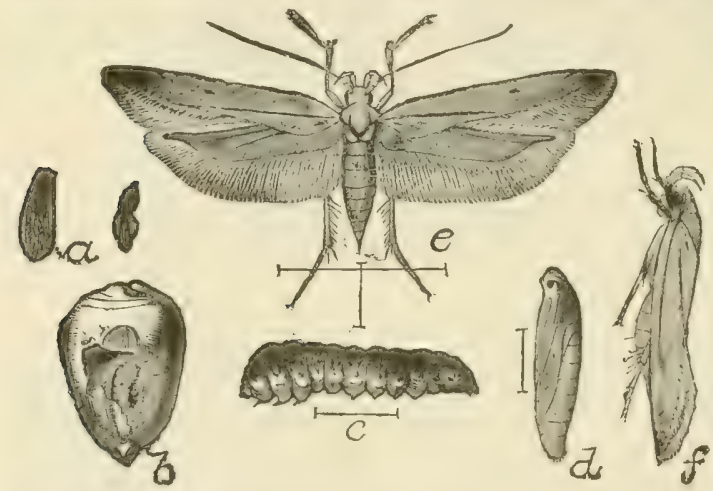

FIG. 156.--The Angoumois grain-moth (Sitotroga cerealella): $a$, eggs; $b$, larva at work; $c$, larva, side view; d, pupa; $e$, moth; $f$, same, side view. (After Chittenden, U. S. Dept. Agr.) being very injurious to stored corn in the Gulf States. Of late years it seems to be moving steadily northward, being reported as injurious in central Pennsylvania and $\mathrm{Ohio.}$ Wheat, corn, oats, rye, barley, sorghum-s eed, and even cow-peas are subject to injury.

Life History.-The injury is not done by the moth, as might be reasonably supposed from the fact that it is the only form of the insect usually seen, but is done by the small caterpillars which feed within the grain, where they may be found during the winter. The caterpillar eats to the surface of the kernel, but not through it, thus leaving a thin lid which the moth can easily push aside when it comes out in the spring, and then covers itself with a fine sillien web. At this time the caterpillar is usually fully grown and is about one-fifth of an inch long, of a white color, with the head yellowish and harder, and having six jointed

* Sitrotoga cerealella Oliv. Family Gelechiida.

See J. L. King, Circular No. 1, Pennsylvania Dept. Agr. 
legs in front, a series of four pairs of fleshy pro-legs along the middle, and another pair of soft legs at the end of the body. With warm spring weather the caterpillar changes to a pupa, and about the time that the wheat comes into head the adult moth emerges. As soon as it emerges, whether outdoors or in a barn, the moth at once flies to the grain-field, where the eggs are deposited. The exact time at which the moths emerge varies, but occurs some time late in May or in June. The moths quite closely resemble the clothes-moth often found flying about houses. The wings are quite narrow, and when expanded measure about one-half an inch from tip to tip, being of a yellowish or buff color, marked with black. The eggs are laid in the longitudinal channel on the side of the grain. Each female lays from sixty to ninety eggs in lots of about twenty each, one lot thus being about enough to infest the kernels of a head. The eggs hatch in from four to seven days. The young caterpillars are at first very active and soon find tender places and bore into the kernels, leaving almost invisible openings. These caterpillars become full grow $\mathrm{n}$ in about three weeks, just about the time the grain is mature. About harvest-time the second brood of moths appears. These lay their eggs during July, depositing them on the ripe heads if the harvest be a little delayed, but on the wheat in stack if harvest is prompt. Usually the caterpillars hatching from these eggs become full grown and remain in the grain over winter, but in warm seasons, especially if warm in September or when the pest is unusually abundant, a third brood of moths appears early in September. These lay another

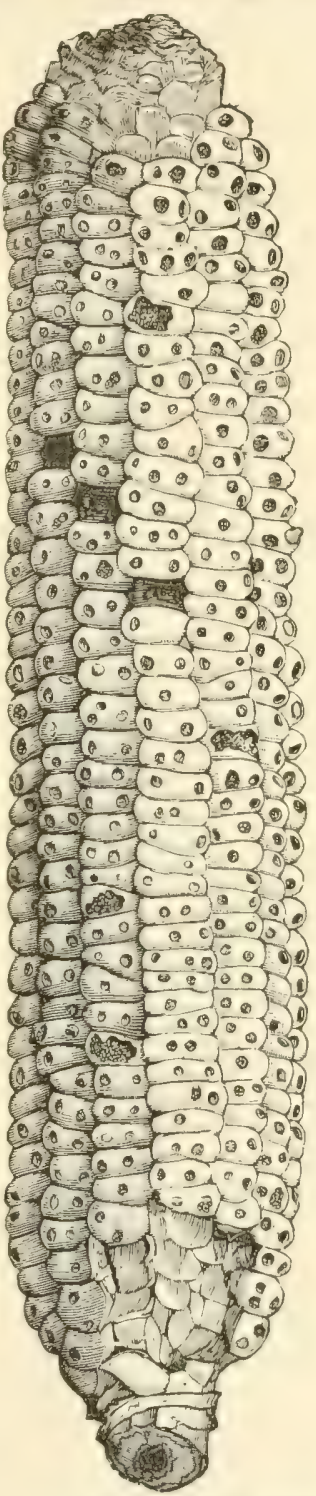

FIG. 157.-Ear of popcorn, showing work of Angoumois grainmoth. (After Riley.) 
batch of eggs about the middle of September, depositing them upon the open ends of grain in stack or mow, which thus becomes more infested than that in the centre. In grain stacked outside, the caterpillars of this brood become full grown slowly and remain in the grain over winter, but if in the barn they grow faster and a fourth brood of moths appears about the middle of October, the moths being noticed in threshing. The insects continue to breed within doors all winter as long as any grain remains, though they become sluggish and cease feeding during cold weather. The number of brools is entirely dependent upon the latitude and weather conditions; in the South, where they can breed continuously, there being as many as eight in a year.

Corn is frequently attacked, but not until it is ripe and husked, and then but rarely when husked in October and November and stored outdoors in slatted cribs. Seed-corn stored in barns, and in the South in almost any situation, is often badly injured.

Aside from the loss in weight, grain when badly infested becomes unfit for milling purposes, and will even be refused by cattle and horses, which should not be urged to eat it, though hogs and fowls will readily consume it.

Remedies.-Dr. J. B. Smith, in an interesting bulletin upon this pest, to which we are indebted for much of the above, advises as follows: "Thresh as soon after harvest as possible, and bulk in tight bins or in good sacks. [By "tight bins" are meant those which will not permit the entrance or exit of the moths.] If the grain is dry when harvested, it may be threshed at once; if not, as soon as it is in good condition. If the sacked grain is infested, there will not be wormy kernels sufficient to heat the grain. The moths cannot make their way out and are stifled. Nothing can come in from outside and the grain remains safe. The threshing itself kills many of the insects and jars and rubs off many of the eggs. If binned, the bins should be tight and the grain should be tested occasionally for any appreciable heating. If it heats perceptibly, it indicates considerable infestation, and it should be treated with carbon bisulfide at once, used at the rate of one drachm per cubic foot, or 1 pound for 250 cubic feet bin-space." Recent investigations have shown that more bisulfide will often be necessary.

Those having wheat unthreshed, whether in stack or mow, should thresh at once, and treat as above directed, except that if 
much of it is noticed to be wormy, it should be treated with carbon bisulfide at once, as soon as threshed, which if done thoroughly will prevent any further infestation that year.

Barns and storehouses should be cleaned up and freed from all loose and scattered grain-chickens will help in this-before April 1st, so that no moths will be allowed to develop and infest the grain in the field. Places where grain has been in stock the previous season should be cleaned up by the aid of chickens. Thus if there is any probability of grain being infested, it should be kept tightly covered in the spring so as not to permit the spread of the moths to the fields.

\section{Prevention of "Weevil"}

Undoubterlly grain-insects can usually be more successfully combated by a proper housing of the grain. No matter how often the insects are destroyed in a granary, if the remainder of the barn is full of dust, sweepings, and refuse, as it generally is, on which the beetles can feed and in which they will breed, and if the granary is not absolutely tight, as soon as the gas passes off the insects from the barn will again enter the granary, and soon it will be as badly infested as ever.

Cleanliness._- "Cleanliness will accomplish much toward the prevention of injury from these pests, the cause of a great proportion of injuries in granaries, mills, elevators, and other structures where grain and feed are stored being directly traceable to a disregard of neatness. Dust, dirt, rubbish, and refuse material containing sweepings of grain, flour, and meal are too frequently permitted to accumulate and serve as breeding-places for a multitude of injurious insects.

"The floors or corners and walls of the barn or storehouse should be frequently swept, and all material that has no commercial value burned."

The Granary.- "The ideal farmer's granary, from the standpoint of insect ravages, should be built at some distance from other buildings, and the rooms constructed of matched floorings so as to be as near vermin-proof as possible. The doors should fit tightly, closing upon a rabbet, which may be covered with felt or packing, and the windows covered with frames of wire gauze to prevent the passage of insects. The floor, walls, and ceilings should be smooth, so as not to afford any lurking-places for the insects, 
and it would be well to have them oiled, painted, or whitewashed for further security. A coating of coal tar has been strongly recommended for the latter purpose."

"The value of a cool place as a repository of grain has been known of old, and a building in which any artificial heat is employed is undesirable for grain storage. The 'heating' and fermentation of grain, as is well known, is productive of 'weevil, 'and this should be prevented by avoiding moisture and by ventilation.

The storage of grain in large bulk is to be commended, as the surface layers only are exposed to infestation. This practice is particularly valuable against the moths, which do not penetrate far beneath the surface. Frequent agitation of the grain is also destructive to the moths, as they are unable to extricate themselves from a large mass, and perish in the attempt. The true granary-weevils (small dark-brown beetles with long curved snouts, similar to the pea-weevil), however, penetrate more deeply, and although bulking is of value against them, it is not advisable to stir the grain, as it merely distributes them more thoroughly through the mass."-Chittenden

Recent observations and experiments* have shown that in the southern states, at least, injury to corn from the forms of weevil which infest the ears in the field, as well as some corn earworm injury, may be largely prevented by planting varieties of corn which produce ears covered with husks which extend beyond the tip of the ears and form a close sheath for the ear, leaving no opening for the entrance of the weevil. Since there is more likelihood of infestation from several species of weevils on corn in the field in the South, the use of such varieties would seem to be good practice for that region.

\section{Destruction of "Weevil"}

†Carbon Bisulfide.- "The simplest, most effective, and most inexpensive remedy for all insects that affect stored grain and other stored products is the bisulficle of carbon, a colorless liquid, with a strong disagreeable odor, which, however, soon passes away." At ordinary temperatures it vaporizes rapidly, forming a heavy gas, which is highly inflammable and a powerful poison.

* E. A. Back, Farmers' Bulletin 1029, U. S. Dept. of Agr.

† See W. E. Hinds, Farmers' Bulletin 799, U. S. Dept. Agr. 
Apptication.-It may be applied directly to the infested grain or seed without injury to its edibleness or viability by spraying with an ordinary watering-ean having a fine rose nozzle. In moderately tight bins it is more effective, however, as it evaporates more slowly and diffuses more evenly, if placed in shallow dishes or pans, or on bits of eloth or cotton waste distributed about on the surface of the grain or infested material. The licquid volatilizes rapidly, and, being heavier than air, reseends and permeates the mass of grain, killing all insects and other rermin present. The bin should then be covered with boarks, canvas, or blankets, and allowed to remain at least twenty-four hours. If to be used for seed, it should not be left for over thirty-six hours; but if not, leave it forty-eight hours, which will do it no injury for food After treating keep the grain corered to prevent reinfestation.

Amount to Use.- It was formerly recommended that the bisulfide be applied at the rate of 1 to 3 pounds to 100 bushels of grain or 1000 cubic feet of open space. Recent experiments, however, have shown the total inadequacy of this dosage. Experiments made by Hinds and Hunter* show that the effectiveness of the gas is in direct proportion to the temperature. Below $60^{\circ} \mathrm{F}$. the fumigation is ineffective and inadvisable. A dosage which will kill practieally all the weevil at $67^{\circ}$ to $70^{\circ}$ will kill but 60 to 70 per cent at $60^{\circ}$ to $65^{\circ}$. They recommend the use of 5 pounds per 1000 cubic feet where the room or hin is quite tight and the temperature is $70^{\circ}$ or above. For open rooms and lower temperatures, the dosage must be largely increased and may not be profitable. The above estimates are based upon the grain being in a eubical shape; if it is spread out shallow, more bisulfide will be necessary.

Caution.- "Certain precautions should always be observed. The vapor of carbon bisulfide is deadly to all forms of animal life if inhaled in sufficient quantity, but there is no dinger in inhaling a small amount. The vapor is highly inflammable, but with proper care that no fire of any kind, as, for example, a lighted cigar, lantern, or light of any lind, be brought into the vicinity until the fumes have entirely passed away, no trouble will be experienced."

Hydrocyanic Acid Gas.-Mills and storchouses which needed

* Hinds and Hunter, Journal of Ticonomic Entomology, Vol. III, p. 47: R. I. Smith, Bulletin 203, N. C. Agr. Exp. Sta. 
treatment were formerly fumigated with carbon bisulfide, which is still cmployed to a considerable extent, but this has been largely replaced by fumigation with hydrocyanic acid gas, which obviates the risk from fire. Directions for the use of this gas should be obtained from the entomologist of the State Experiment Station or from the Bureau of Entomology of the U.S. Department of Agriculture.

Sulfur Fumes.-Professor R. I. Smith (1. c.) has made experiments with sulfur dioxid, produced by burning sulfur slightly wet with alcohol, and finds that it will effectively kill grain insects but injures the germinating power of the grain. "It was found that the fumes produced by burning $2 \frac{1}{2}$ pounds of sulfur either in a moist or dry atmosphere of 1000 cubic feet space, for twenty hours, would kill all exposed arlult insects and practically all the young stages in the grain, but that this also destroyed its germinating power. . While this treatment cannot be recommended for general fumigation, there is no doubt of its being the easiest and cheapest method of fumigating corn cribs, granaries and similar places whenever they are being cleaned out and freed of insects in preparation for the reception of more grain."

Heat.-The heating of grain was one of the earliest means known of combating grain insects, but has been little used in this country. Recently, however, Prof. Geo. A. Dean of the Kansas Agricultural Experiment Station, * has shown that by superheating mills they may be rid of insect pests much more quickly and cheaply than by fumigation, and with no risk from fire, or from cyanide poisoning. His experiments show that if the temperature surrounding an insect be maintained above $120^{\circ} \mathrm{F}$., with a normal amount of moisture, that in a very few minutes it will be killed. This has become one of the most popular methods of cleaning mills and may be used for small quantities of grain where there are facilities for heating it or placing it in a superheated room, but probably carbon bisulfide fumigation will be found more practicable for small amounts.

* Geo. A. Dean, Journal of Economic Entomology, Vol. IV, p. 142 and Bulletin 189, Kansas Agr. Expt. Station. 


\section{CHAPTER XI}

\section{INSECTS INJURIOUS TO CLOVER AND ALFALFA.*}

\section{The Clover Root-borer $\dagger$}

THE Clover Root-borer is practically the only insect pest which seriously injures clover roots. It has long been known as a clover pest in Europe, but was first noticed in this country in western New York in 1876, whence it has spread southward to West Virginia and westward to Illinois and southern Michigan, and has also been injurious in Oregon.

Life History.-During the winter the beetles may be found hibernating in their burrows in infested clover roots. They are not readily distinguishable, for they are scarcely one-eighth

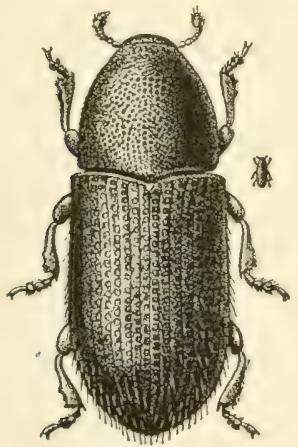

$a$

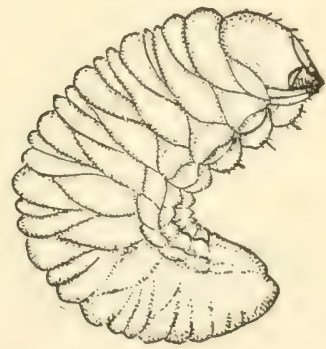

$b$

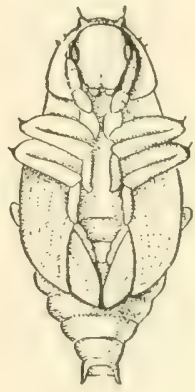

$c$

FIa. 158,--The clover root-borer (Hylastinus obscurus): $a$, adult, natural size at right; $b$, larva or grub; $c$, pupa-much enlarged. (After Webster, U. S. Dept. Agr.)

inch long, and are of a reddish-brown color much like that of the burrow. With the warmer weather of spring they commence

* See The Insect Pests of Clover and Alfalfa, J. W. Folsom, 25th Report of the State Entomologist of Illinois, pp. 41-124, and Bulletin 134, Illinois Agr. Expt. Station.

$\dagger$ Hylastinus obscurus Marsham. Family Scolytidoe. 
burrowing and feeding in the roots, and during late May and early June the females deposit their eggs along the sides of the tunnels. "The female gouges out a shallow cavity, more often in the crown of the plant, sometimes at the sides of the root even

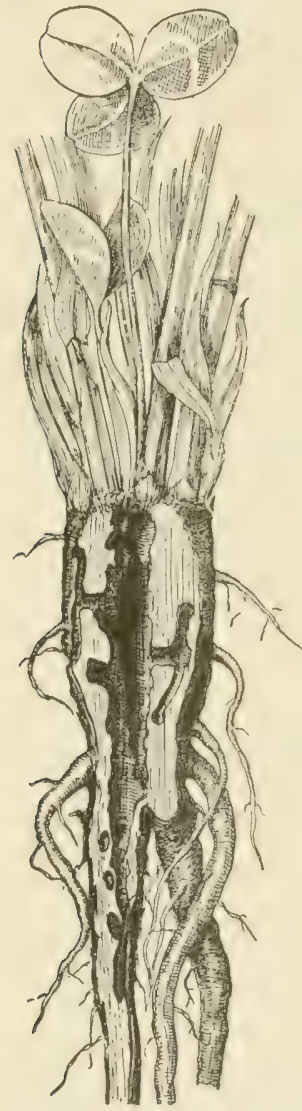

Fir. 159.-Clover root showing work of clover root-borer. Slightly enlarged. (After Webster,) U. S. Dept. Agr.
2 or 3 inches below the crown, and in this places singly, but not far separated, about a half dozen pale whitish, elliptical, very minute eggs. These hatch in about a week, and the larvæ for a time feed in the excavation made by the mother, jut soon burrow downward into the root, and before the 1st of August, the majority of them have become full-grown, and passed into the pupal stage. By October nearly all have become fully developed beetles, but they make no attempt to leave the plant until the following spring." The spread of the insect occurs very largely in the spring when the beetles fly from field to field, seeking uninfested plants in which to perpetuate their kind.

It has been observed that alsike clover is not so badly injured as the mammoth and common red clover, on account of the fibrous roots and the tendency of its taproot to divide. In Europe alfalfa is injured, but little injury has yet been reported to that crop in this country, as yet.

"While an infested clover plant sooner or later succumbs to an attack by this insect, life may be lengthened or shortened by meteorological conditions. Thus, if the spring or early summer is very dry, the plants begin to dry in patches late in June, as soon as the hay crop is removed; but if there is much rain during this period, the weakened plants may continue to live until winter, dying out before spring. In either case the farmer is likely to be misled and attribute the loss to the weather." Clover is practically exempt from attack the 
first year as the roots are not large enough to accommodate the insects, and it is not until the second year that the plants are destroyed.

Control.-The only effective means of control suggested is summer fallowing as soon as the hay crop has been removed.

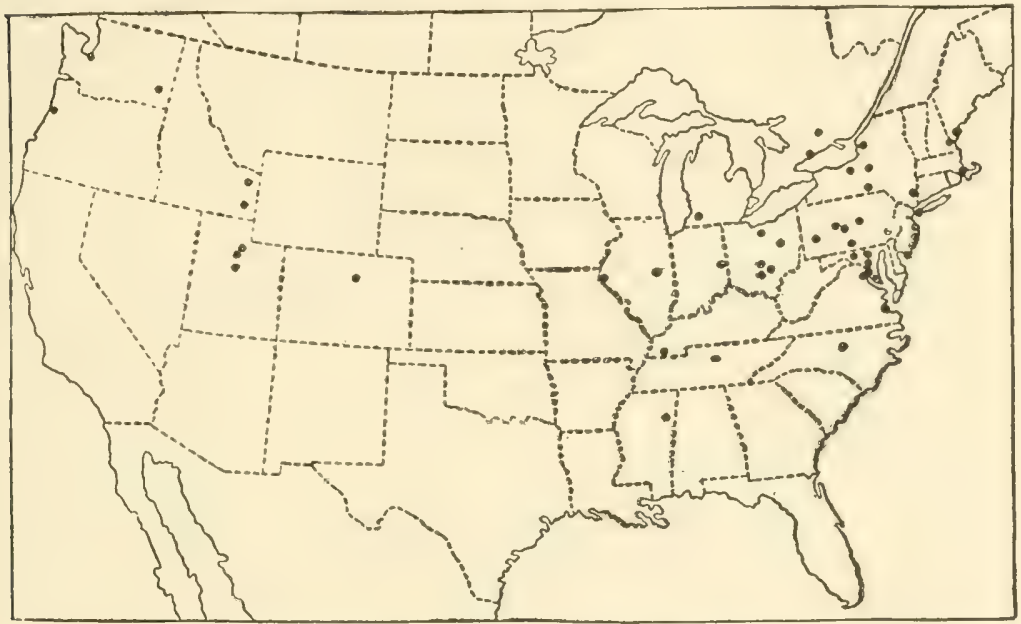

FIG. 160.-Present known distribution in the United States of the clover-root curculio. (After F. M. Webster, L. C.)

The field should then be plowed up at once, before the larvæ have transformed to pupæ, so that the hot sun, and dry winds,
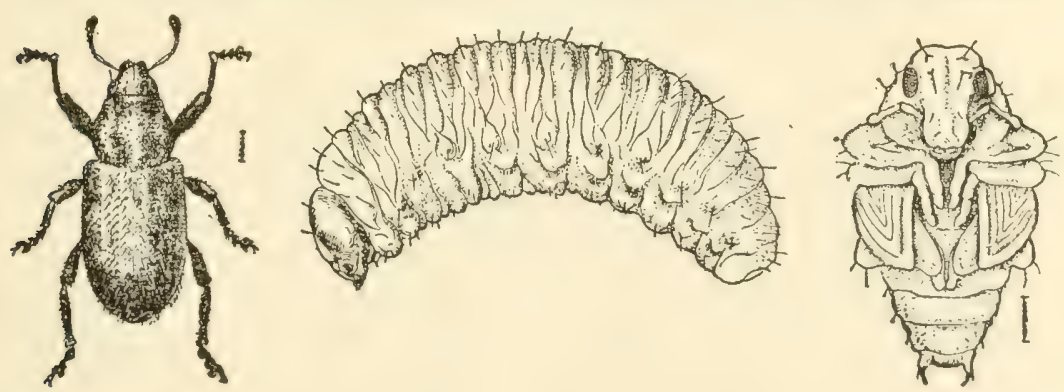

FIG. 161.-Stages of the clover-root curculio. (After Webster, L. C., from Wildermuth): $a$, adult; $b$, larva; $c$, pupa.

will dry out the roots of the clover and thus starve the larvæ, thereby preventing their developing and migrating to other fields. Clover fields should not be allowed to stand over two 
years in infested localities. No injury seems to be done in pastures. A system of rotation in which the crop is mowed for hay and seed the first year, and pastured and then broken up the second year, should keep the pest under control.

An insect very similar in life-history and nature of injury is the Clover-root Curculio.* This insect is also a snout beetle but belongs to a different family. In spite of this, the adults and larva will both probably be confused by the ordinary observer. The curculio has been observed working on alfalfa. $\dagger$

\section{The Clover Leaf-weevil I}

The clover leaf-rveevil is a stout, oval beetle, about one-third inch long, with a long, thick snout. It is of a brownish color, with several narrow gray lines above and broad gray stripes on each side, and with twenty rows of small, deep punctures on the wing-cover's. It also is a native of Europe and made its first appearance in the same section of western New York as the last species, about 1881. Since then it has spread eastward to Rhode Island and Vermont, southward to North Carolina and West Virginia and westward to Wisconsin and Illinois. Every few years the weevils and their larvæ destroy much of the foliage in restricted localities, but rarely are they very injurious the next season. Red clover, alfalfa, and white clover are preferred in the order named; in Illinois the mammoth and alsike are also eaten.

Life Hitsory.-In early fall the female beetles lay their eggs in crevices among the stems near the base of the plant, which hatch in from three to six weeks. The young larva which hatch from them are without legs, but manage to climb by means of the prominent tubercles on the lower surface of the body. They are light yellowish-green, becoming deeper green as they grow older, the head is brown, and down the middle of the back is a white or pale yellow stripe bordered with reddish. The larvæ become partially grown before winter sets in, when they hibernate in rubbish or just under the soil until spring, when they continue to feed upon the foliage and become full-grown in May and early June. They feed mostly at night and are hardly

* Sitones hispidulis Fabricius. Family Curculionida.

† See F. M. Webster, Farmers' Bulletin 649, U. S. Dept. of Agr.

$\ddagger$ Phytonomus punctatus Fab. Family Curculionidae. 
noticeable in the day, when they lie protected around the base of the plant, lying curled up head to tail. The injury to the foliage is quite characteristic, the edges of the leaves being eaten in a regular manner as shown in Fig. 162. When full grown the larva buries itself just under the surface of the soil and makes an oval cell, in which it spins a delicate cocoon consisting of a coarse network of pale yellow threads, which later turn brown,

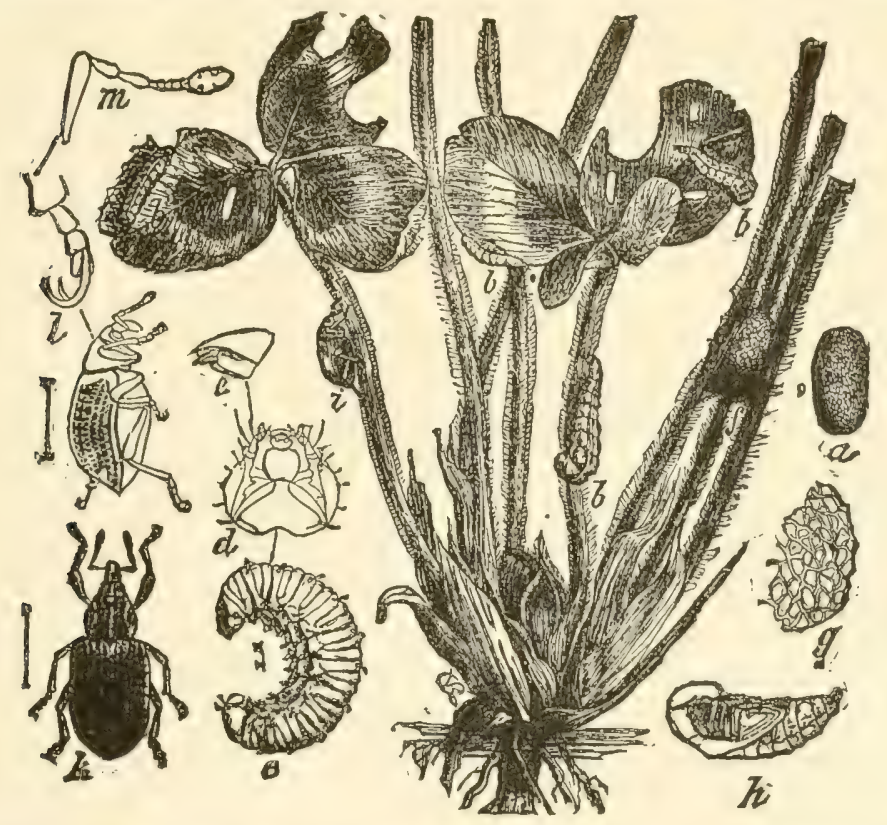

Frg. 162.-Clover leaf-weevil (Phytonomus punctatus Fabr.): a, egg magnified and natural size; $b b b b$, larvie; $c$, recently hatched larva; $d$, head of larva; $e$, jaws of the same; $f$, cocoon; $g$, same magnified to show the meshes; $h$, pupa; $i$, weevil, natural size; $j$, the same magnified; $k$, top view of the beetle; $l$, tarsus and claws of the beetle; $m$, antenna of the beetle. (After Riley.)

as shown in Fig. 162. Occasionally the cocoon is made on the surface or among the bases of the stems. In this the pupal stage is passed, lasting two or three weeks; the beetles being most common in July and August. The damage which the beetles do to the second crop of clover is fully equal that done by the larva to the first, and is more apparent because the soil is then dry and the plant grows more slowly. 
That this insect has not become a more serious pest is due to the fact that as often as it becomes excessively abundant the larvæ are almost completely destroyed by a fungous disease.* When affected by this disease the larva climb to the top of a blade of grass, curl tightly around the tip, and soon die, first becoming covered with a white mold and then turning to a jellylike mass. The spores of the fungus become scattered to healthy individuals, which soon succumb, so that before long nearly all are destroyed, and rarely do enough survive to cause trouble the next year.

Frequent reports are received of poisoning of cattle which have fed on clover having numbers of the larvæ which have died from this fungus. Accounts vary, some reporting serious sickness and even death as the result and others, probably more authentic, reporting merely temporary sickness. In any case, it will be well to keep cattle from the infested plants.

Control.-On account of this disease repeated injury has been so rare that no means of artificial control has been necessary. "The necessity for the employment of any remedy does not appear until the clover is well on in its second year's growth," says Dr. Folsom (l.c.). "If damage is anticipated, however, it would seem advisable to pasture the clover lightly or to clip back in the spring; this does not hurt the clover, is highly desirable as a means of forestalling the attacks of some other clover pests (see page 201), and might check the larvæ of the leaf-weevil somewhat, though it is possible that they would subsist on the cut stems until the new growth started; and in cold weather they can live a long time without any food. After the second season red clover should be plowed under to get rid of this pest, as well as for other agricultural reasons."

\section{The Alfalfa Weevil $\dagger$}

In recent years a first cousin of the last species has been introduced into Utah, where it has become firmly established and promises to become the most serious obstacle to alfalfa culture. The alfalfa weevil is a native of Europe, western Asia, and northern

* Empusa sphacroperma Fres.

† Phytonomus posticus Gyll. Family Curculionida. See E. G. Titus, Bulletin 110 and Circular 10, Utah Agr. Exp. Sta., and F. M. Webster, Circular 137, Bureau of Entomology, U. S. Dept. Agr. 
Africa, where it is common but never very seriously injurious. It was first noticed in America near Salt Lake City, Utah, in 1904, and has been increasing and spreading until it now occupies an area of fully 100 square miles around Salt Lake City. The beetles are from one-eighth to three-sixteenth inch long, dark brown, marked with black and gray hairs which gires them a mottled appearance as shown in Fig. 165. These hairs or scales are gradually rubbed

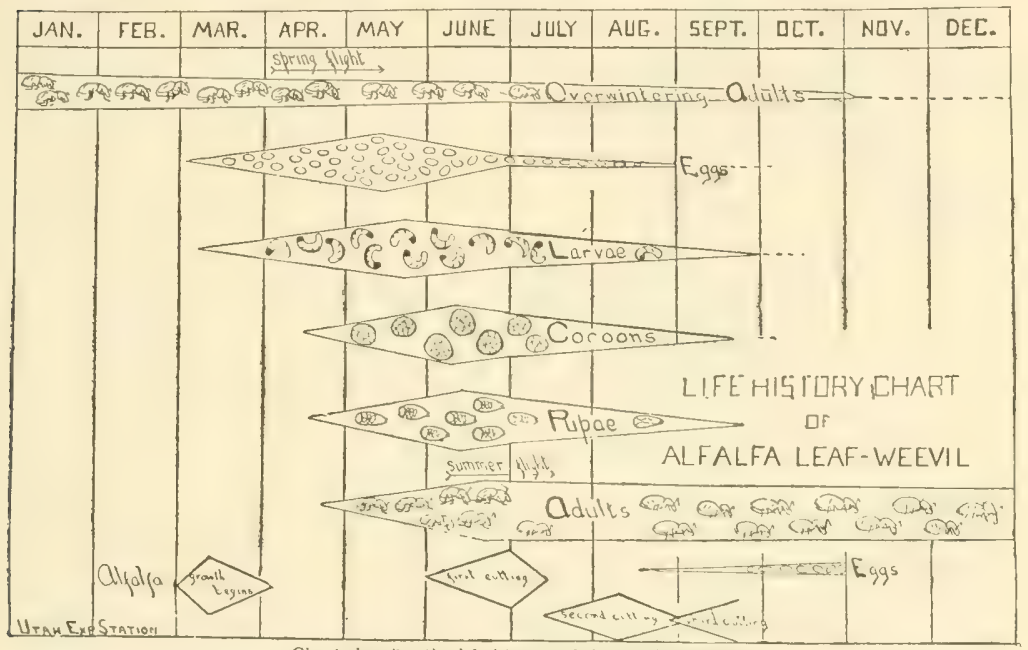

Chart showing the life hlatiory of the Alfalfa Weevil.

FIG. 163.-Chart showing the life history of the Alfalfa Weevil. (From H. R. Hagan, Utah Agr. Expt. Sta. Circular 31.

off, so that in spring many individuals are entirely black with small grayish spots.

Life History. - The beetles seck shelter for hibernation before frost in the autumn, either in the crowns of the alfalfa plants, or under thick grass, weeds, rubbish, leaves, or in hay or straw stacks. Often they winter in barns where the hay is stored, the floors of which are often found covered with the beetles in winter and spring. It is estimated that fully 80 per cent of the weevils survive the winter in Utah. In the spring the beetles emerge and attack the young alfalfa plants as soon as there is sufficient food for them, usually late in March. The females commence laying eggs in early April and continue oviposition until early July. In early spring while the plants are small the 
females often push their eggs down between the leaves, but the usual method is to insert them in punctures made in the stem.

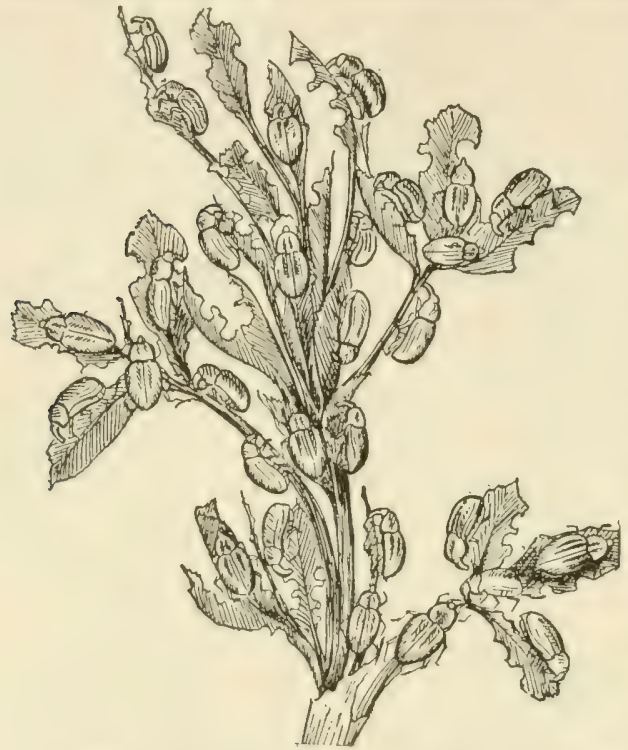

FIG. 164.-The alfalfa weevil, adults, clustering on and attacking sprig of alfalfa-natural size. (After Webster, U. S. Dept. Agr.)
This puncturing of the young stems often results in considerable damage in early spring. A single alfalfa plant which had escaped from cultivation was found to contain 127 of these punctures, and as each puncture contains ten or fifteen eggs, this plant probably bore some 1200 eggs, although it was exceptional.

The eggs hatch in about ten days and the small white larvæ make their way to the leaves in which they eat small holes. They soon turn a decidedly green color, and when full grown are about one-half inch long with a white stripe down the middle of the back
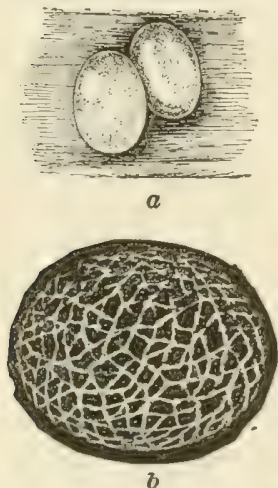
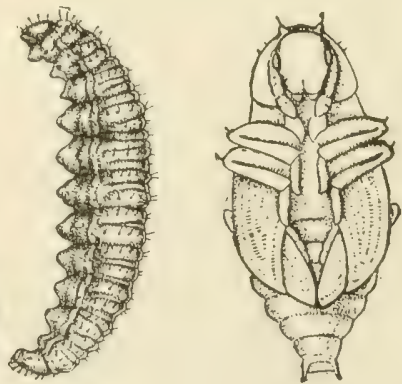

Frg. 165.-The alfalfa weevil (Phytonomus posticus): $a$, eggs; $b$, cocoon; $c$, larva; $d$, pupa; $e$, adult-all much enlarged. (After Webster, U. S. Dept. Agr.) 
and somewhat curved as shown in Fig. 165. They attack the young leaves and crown so that a badly infested field will not get over six inches high; too short to mow. The larva are most abundant in May and decrease through June. When full grown the larvæ crawl or drop to the ground and spin their cocoons in the dead leaves or rubbish. The cocoon is globular and composed of a network of rather coarse white threads, Fig. 165. In it the larva transforms to a pupa, which stage lasts from one to two weeks, when the adult beetle emerges.

From early to midsummer the beetles become more and more abundant, and not only feed on the fresh growth, but attack the bark of the stems so that where excessively abundant they totally destroy the second crop.

"The entire life of the insect, from the deposition of the egg to the emergence of the adult, may be anywhere from forty to seventy days, while the beetle itself may live, including the winter, from ten to fourteen months." - Webster.

Inasmuch as literally millions of the beetles have been gathered by machines from a single acre, and as the beetles have been found in considerable numbers on freight and passenger trains, it is highly probable that the pest will be spread by the several trunk-lines of railroad which pass through the infested region, as in many places alfalfa has escaped from fields and grows as a weed along the railway tracks. It is, therefore, highly important that alfalfa growers be on their guard against this pest and take prompt measures for its destruction wherever it may gain a foothold. The weevils also spread rapidly by flying in spring and summer, which migration is aided by the winds. They may also be spread in articles shipped from an infested region and on wagons or automobiles.

Control.-The methods of control have not, as yet, been satisfactorily determined, though the entomologist of the Utah Agricultural Experiment Station, E. G. Titus, from whose report the following summary is taken, has made extensive experiments with various methods.

Old alfalfa fields are always worst injured, and fields should not be left down in alfalfa over about seven years. Thorough disking in the early spring has proved to be one of the essential factors in securing a good crop, as it increases the stand and 
stimulates a quick growth which enables the plants better to withstand the weevil injury. The use of a brush drag with which a spike-tooth harrow is combined has been found an excellent means of killing the larvæ, as they are knocked to the ground and large numbers killed by the fine dust. If the field is very hard it is advisable to disk it before using the drag. After the use of the drag, the fields should be watered where there is irrigation. In summarizing the methods of control, Professor Titus recommends: "That alfalfa be disked in early spring to

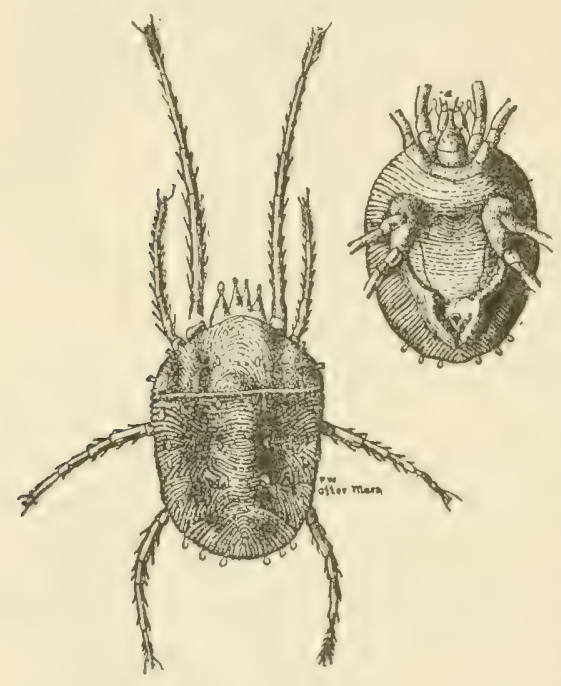

FIG. 166.-The Clover-mite (Bryobia pratensis).

Quarantine measures to prevent the spread are matters of local and state jurisdiction lut are of the highest importance to the alfalfa growers of the country.

\section{The Clover-mite *}

The Clover-mite is nearly related to the common red spider of greenhouses, with which it is often confused, belonging to the same family of vegetable-feeding mites. It is, however, about twice the size of the red spider, being four one-hundredths inch

* Bryobia pratensis Garman. Family Tetranychida. See C. L. Marlatt, Circular 19, 2 d Ser., Division of Entomology, U. S. Dept. Agr. 
long. Though known as the clover mite, on account of its feeding upon that plant, yet this insect was first known as, and is still, an important enemy of fruit-trees, more especially on the Pacific coast, but also in other sections of the country. The most injury seems to have been done to clover in the Central States as far south as Tennessee, though it has suffered somewhat even in the East.

When attacked by the mite the leaves of clover or fruittrees become yellow and have a sickly appearance, as if affected with a fungous disease. Especially upon the upper sides of the tender leaves of clover the juices are extracted over irregular areas, looking more or less like the burrows of some leaf-mining larvæ. Owing to the small size of the mites they may be doing considerable damage to the foliage and yet remain unnoticed; but in the egg stage the pest is much more readily detected and attacked. In the more northern States the eggs are laid in the fall, and do not hatch until the next spring. Farther south, however, the adult mites hibernate over winter. The eggs are of a reddish color, laid upon the bark of trees, especially in the crotches, and in the West are sometimes so thickly placed as to cover considerable areas two or three layers deep.

When the adult mites leave the clover-fields in the fall to find hibernating quarters upon fruit-trees for the winter, they often become quite a nuisance by invading dwelling-houses which are in their path. This is more particularly the case throughout the Mississippi Valley.

Remedies.-The only practical way of protecting clover from the mite is by destroying the eggs and hibernating mites upon the fruit-trees in winter. This may be done by burning all the prunings and thoroughly spraying the trees with kerosene emulsion diluted with five parts of water, or with miscible oils or lime-sulfur mixture. Such a spraying will also protect the fruittrees from the mite, and will destroy numerous other insects, such as the pear-leaf blister-mite, which hibernates upon the trees. Such small insects, so minute as usually to escape notice, are often responsible for a poor growth, and should be properly checked whenever known to be injurious. 


\section{The Clover-seed Midge *}

The Clover-seed Midge seems to occur wherever red and white clover is grown in this country, and is a pest which must be taken into consideration in raising seed, for frequently it is not recognized as the cause of the failure of the seed crop. Alsike clover, and probably mammoth clover, is practically uninjured, as it flowers enough later to escape attack, nor is alfalfa infested.

Life History. - The parent of all this trouble is a small midge, one-twelfth inch long, with black head and thorax and reddish
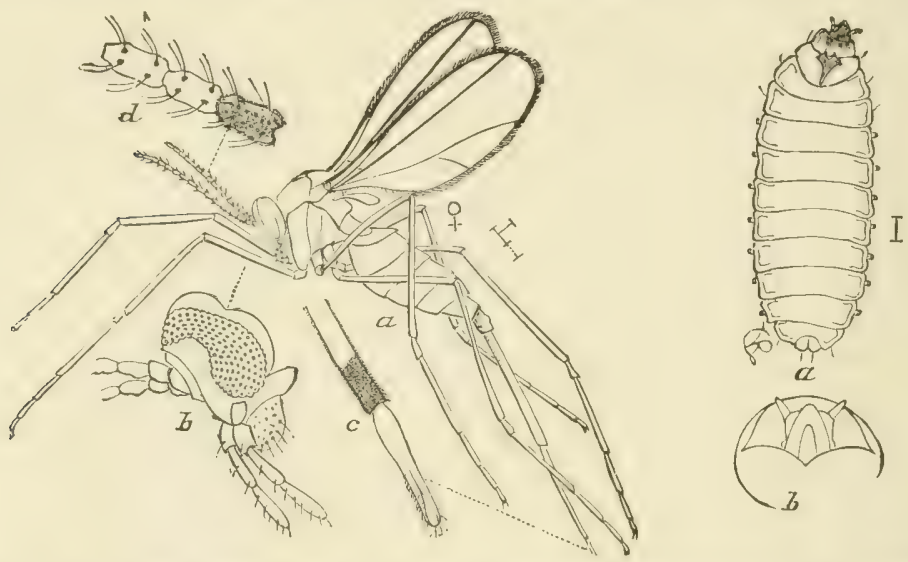

FIg. 167.- The clover-flower midge (Dasyneura leguminicola): $a$, enlarged side view of female, with seales denuded, to show more clearly the structure; $b$, head, more highly magnified, to show structure of the eye, palpi, and basal joints of antennx; $c$, tip of ovipositor, highly magnified and showing at end of next to last joint the manner in which it is clothed with minute hairs; $d$, highly magnified antennal joints, their minute hairy clothing shown on the lower one; 2, $a$, larva enlarged, ventral view; $b$, head retracted, highly magnified. (After Riley.)

abdomen, so small, indeed, that it will rarely be noticed. The antennx have sixteen or seventeen segments, and the wings have but few veins, as shown in Fig. 167. The female bears a slender retractile ovipositor which, when extended from the tip of the abdomen, is fully as long as the body, while the tip of the abdomen of the male is furnished with clasping organs. The midges appear in late spring just as the clover commences to head. The eggs are laid among the hairy spines of the cloverhead or beneath the bracts around it, are yellowish to orange

* Dasyneura leguminicola Lintner. Family Cecidomyiirlex. Also called the Clover-flower Midge. See Farmers' Bulletin 971, U. S. Dept. Agr. 
in color, of an oval shape, and about one one-hundredth inch long. Upon hatching the maggot works its way into the open end of a floret, where it sucks the forming seed, and prevents the petals of the floret from expanding, so that although some of the flowers in the head will bloom, the ficld as a whole does not blossom as usual. The maggot is footless, white to orangered in color, and about one-tenth inch long when full grown. Upon becoming grown in late June and the first week of July the maggots enter the soil and just below the surface make tough, oval, silken cocoons, in which they pupate. The pupal stage lasts about three weeks or more, and the flies of the second generation appear in Central Illinois in late July and early August, being abundant as the second crop of clover heads appear. The eggs are laid in the clover heads and hatch in about three days, and the second generation of maggots do the worst damage to the seed in late August and early September; in the same manner as did the first generation. They become full grown by frost and either hibernate as full-grown larvæ, in which case they pupate early the next spring, or pupate before frost and pass the winter as pupr in the soil.

Control.-Fortunately this pest may be very readily controlled by adapting the methods of harvesting so as to destroy the developing maggots. If clover is grown alone it should be cut early before the maggots have become mature This results in drying, up the food plant and thus destroying the larvæ and hastens the development of the second crop of clover heads, so that the midges of the second generation have but few green heads in which to lay their eggs. Cutting need not be done until the field is fairly fresh with bloom, but should not be delayed until the flowers commence to wither. Where timothy and clover are grown together they should be pastured lightly or clipped back in May, which will result in bringing both the first and second blooming after the greatest abundance of the midges. As the midges do not travel far, it would seem advisable to "prevent the sporadic heading of first-year clover by mowing it back a few weeks after small grains have been harvested, at a time when growth is vigorous, but yet sufficiently early to permit considerable growth before frost sets in. Volunteer clover should always be cut, as it affords a rich nursery for all kinds of clover insects."-Folsom. 


\section{The Clover-seed Chalcid *}

Evidence accumulates that the shortage of the clover-seed crop may frequently be due to the larva of a little chalcis-fly

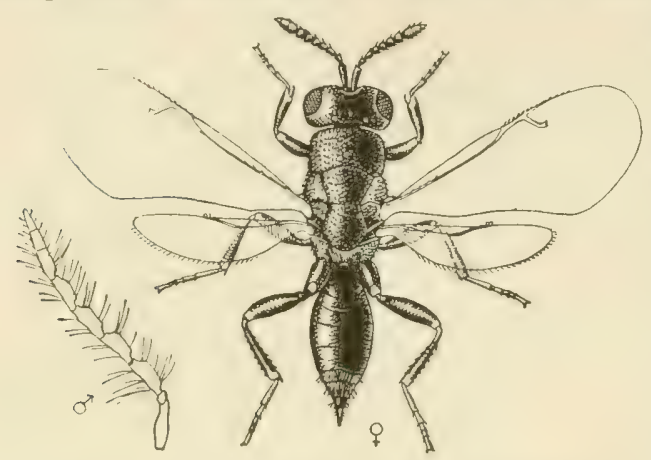

Fig. 168. - The clover-seed chalcis (Bruchophagus funebris): adult female, much enlarged; antenna of male at left, more enlarged. (After Webster, U. S. Dept. Agr.) which hollows out the ripening seed, leaving it brown, brittle and hollow, so that the affected hulls are blown away with the chaff in threshing. As there is no evidence of the pest in the appearance of the heads, and as the worst affected seed is th $\mathrm{u}$ s overlooked in threshing, its work will often evade detection.

If the seed crop is short it will be well to examine seed for the larvæ; many of the seed will he found shriveled and misshapen, and frequently considerable numbers of the adults will issue from the seed soon after threshing.

The adult is a small, wasp-like fly one-twelfth to one-sixteenth inch long, black in color, and with four wings, the hind-wings very small and the fore-wings with but a single vein. It belongs to a family almost all of which are parasitic on other insects, and for many years it was thought to be a parasite of the clover-seed midge, until its true role was discovered. In recent years examinations of ripening heads from all parts of the country show it is probably distributed wherever clover is grown and that from

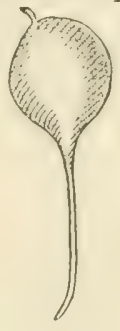

$a$
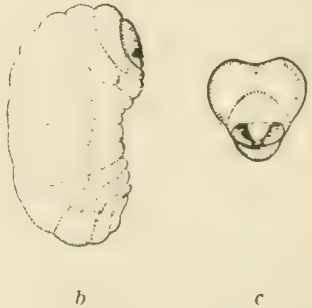

Fig. 169.-The clover-seed chalcis: $a$, egg-highly magnified; $b$, larva an, head more enlarged; $c$, pupa-much enlarged. (After Webster, U. S. Dept. Agr.)

* Bruchophagus funebris Howard. Family Chalcidido. 
20 to 80 per cent of the seed is often destroyed. Both red and crimson clovers are attacked, and a recent bulletin * from the Department of Agriculture states that the insect is actually threatening to destroy the alfalfa seed industry in certain sections which formerly produced it in quantity.

Life History.- The winter is passed by the fully grown larvæ in seed on the ground. The adults emerge in the spring, the maximum appearing about June 10th in central Illinois, according to Dr. Folsom, to whom we are indebted for the most careful study of the pest. The females deposit their eggs in the soft seed, just as the floret is withering, being unable to penetrate the seed after it has hardened. 'The egg is whitish, about .01 inch long, and with a peculiar tail-like appendage (Fig. 169). The maggot-like larva feeds upon the seed, gradually hollowing it out, and when full grown is about one-twelfth inch long, stout and footless, with a small head. The pupal stage is passed within the seed and a second generation of arlults emerges about the middle of August. These lay their eggs in the second growth, and some of the adults from these appear the same season and the rest not until the following year. There seem to be at least three generations a year in central Illinois, but the life history is complicated by the irregularity in the time of development, though the greatest numbers of adults appear about June 10th and August 10th, just as the clover-seed is green.

Control.-Mr. T. D. Urbahns, in the bulletin mentioned, recommends cutting the seed crop promptly and stacking it as soon as possible, using well cleaned seed, destroying burr-clover and cleaning up of waste land as well as destruction of screenings from the thresher and winter cultivation as being practices likely to reduce the damage from the chalcis. He particularly recommends that infested crops be harvested, even if they are of no value for seed, since, if they are left standing and pastured they will infest a whole locality.

\section{The Clover-seed Caterpillar $\dagger$}

"In its ability to diminish the seed crop, this pest ranks with the seed-midge and the seed-chalcid. Attacking a clover head that is green or partly in bloom, the little caterpillar eats out a

* Farmers' Bulletin 636, U.IS. Dept. Agr.

† Enarmonia interstinctana Clem. Family Grapholithidec. 
cavity in the head, destroying many of the unopened buds and some of the tender green seeds, and spoiling the head as a whole. When no young clover heads are at hand, the caterpillar feeds on tender green leaves at the crown of the plant."-Folsom. Red clover is the principal food plant, but white, alsike, and probably mammoth clovers are also affected. The published records show that it occurs in the Northeastern States southwest to Missouri, but it doubtless occurs elsewhere where clover is grown, as it might readily be carried in hay.

Life History.- The adult is a pretty little biown moth, with a wing expanse of two-fifths inch, with silvery markings as shown

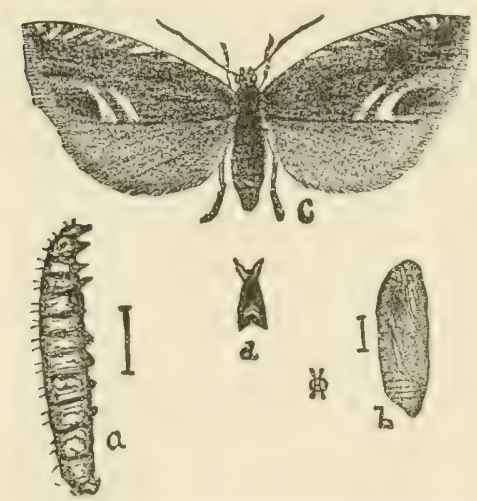

FIg. 170-Clover-seed caterpillar (Enarmonia interstinctana): $a$, caterpillar: $b$, pupa; $c$, moth, all much enlarged: $d$, moth natural size. (After Osborn.) in Fig. 170, the most conspicuous marks forming a double crescent when the wings are closed on the back. The moths appear about the end of May in central Illinois, or just as the clover is coming into bloom, being active in early evening, when the females lay their eggs in the heads. The egg is circular in shape, about .01 inch in diameter, yellowish-white in color, and hatches in five or six days. In first-year clover that has not headed and in second-year clover recently cut, the eggs are laid on young stems and leaflets at the base of the plant, where the larvæ stay.

"Hatching usually at the base of a green clover-head; the larva eats into the head, destroying the green florets as it goes. A small green head is often destroyed entirely, before it is many days old; a larger head is injured only locally at first, remaining green on one sicle, while the other and unaffected side may come into full bloom." Judging from the appearance of the head the work might be that of the seed-midge, but whereas it is hidden away in a single floret, this caterpillar makes a large dirty excavation involving many florets, and is reaclily found by tearing open the head. The caterpillar attacks the bases of the florets, including the semifluid ovules, but does not attack seeds which have 
hardened. "Even when the direct injury is confined to a portion of the clover-head, the entire head is ruined, for it at length dries up and loses the rest of the florets, leaving only the dead and brown receptacle. Less conspicuous, though not inconsiderable, is the injury at the crown of the plant, done chiefly in September and October, by caterpillars of the same species feeding upon the leaves."-Folsom. The total injury varies greatly, but not infrequently 20 per cent of the heads are infested, and in Iowa infestation has sometimes been exceedingly severe. In any event, every head destroyed means the loss of more than one hundred seeds.

The larva become full grown in four to five weeks. The full grown caterpillar is about one-third inch long and varies in color from dirty-white tinged with green to orange, according to the food. The larva spins an oval white silken cocoon, two-fifths inch long, either in the head or at the surface of the ground, which is more or less covered with bits of excrement and floral tissue. The pupa is one-fifth inch long, brown, with the thorax and wing-cases darker, and with two transverse rows of teeth on the back of the abdominal segments except the last, which bears six stout blackish hooks at the tip. The pupal stage lasts two to three weeks and a second generation of moths emerges about the third week of July (in central Illinois). The life cycle is repeated in the same manner and a third generation of moths appears about September 1st. The larve of the last brood feed either in immature clover-heads or at the crown of the plant. Most of them become full grown and transform into pupx, in which stage they hibernate over winter, while others become full grown, but fail to pupate and hibernate under rubbish.

Control.-Cutting and storing the hay crop early in June as advised for the clover-seed midge will kill the larva while still in the heads. "The hay should be hindled lightly and stacked or stored as soon as possible. Osborn and Gossard * have attested the value of this method, and have given these further recommendations: (1) Cut volunteer clover in early June and dispose of the heads speedily; (2) do not allow clover to run for more than two years; (3) sow seed on land remote from old fields; (4) pasture clover in the fall of the first year; (5) plow

* Osborn and Gossard, Insect Life, Vol. IV, p. 254; Bulletins 14 and 15, Iowa Agr. Exp. Sta.; '2d Report Entomological Society of Ontariu, p. 74. Gossard, H. A., Bulletin 19, Iowa Agr. Exp. Sta. 
an old clover-field under in October or November or in early spring, then harrow and roll. These practices operate at the same time against several other clover pests."-Folsom.

\section{The Clover-hay Worm*}

The Clover-hay Worm attacks stacked or stored clover, particularly where it is held over a year or where placed on old hay, eating much of the lower layers and rendering it unfit for food.

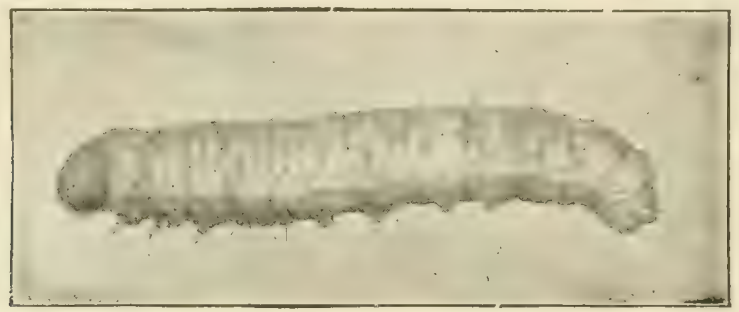

FrG. 171.-Clover-hay worm, greatly enlarged. (After Folsom.)

It has been known to be injurious from Kansas eastwaid, but occurs throughout most of North America, as well as parts of Europe, Asia, and Africa.
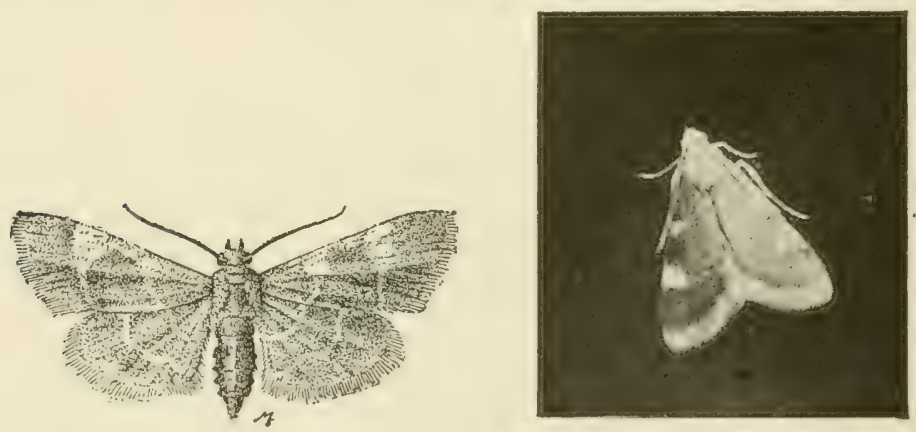

FIG. 172.-The elover-hay worm moth, wings expanded (after Folsom) and at rest (after Pettit) - enlarged.

"The larva attack the bottom of a clover stack to a height of 2 feet or more from the ground; similarly, in the barn, they occur next the floor. They interweave the hay with white silken webs, intermixed with black grains of excrement. . . ; they reduce much of the hay to chaff, and their webs give the hay

* Hypsopygia costalis Fab. Family Pyralidida. 
the appearance of being mouldy; in fact, such hay actually becomes mouldy if it has been lying near the ground. This hay is refused by horses and cattle and is fit only to be burnt. When the hay is removed, swarms of wriggling brown caterpillars are left." The work of the caterpillars is usually noticed in late winter and spring.

Life History.-The moths appear from the middle of June until early July in the Northern States and most of the first generation have disappeared by the end of July. The moths have a wing expanse just under an inch, with silky, wings tinged with purplish above, margined with orange and fringed with golden-yellow. On each side of the fore-wings are two large, golden spots which divide the anterior margin into thirds and continue backward as narrow lilac lines (Fig 172). The hindwings are marked by two transverse, wavy, straw-colored lines.

As soon as some clover-hay is found the female deposits her eggs and the caterpillars feed upon it. When full grown they are about three-quarters inch long, of a dull-brown color. The segments are divided by a transverse groove, and each bears several shining areas, with a fine white hair in each. White silken cocoons, one-half inch long, covered with bits of hay and excrement, are made by the larve in the hay or in cracks and crevices of the barn, in which they transform to pupæ, which are of a honey-yellow color, with the parts clearly defined by the darker color of the sutures. The moths of the second brood emerge from the middle of August until September 1st, but may be found flying until late October. Caterpillars of all sizes may be found in barns throughout the winter and pupate in the spring.

Control.-Usually no serious injury is done except where clover-hay is kept over the second year or longer. When it is fed out each spring, before the next crop is harvested, there is no food for the young caterpillars, and they perish before the new crop comes in. Consequently mows should be cleaned out each spring. New clover-hay should never be placed on top of old hay, and stacks should be placed at some little distance from the old stacks if possible. Burn up the refuse from old stacks, or what remains in the bottom of the mow. Stacks should be raised above the ground on a foundation of logs or rails, so as to keep the bottom as dry and cool as possible, as 
the caterpillars love warmth and moisture. It has been found that salting the hay for 2 or 3 feet at the bottom will prevent injury, and many farmers salt their clover-hay, using about two quarts of salt to the ton.

\section{The Clover Leafhopper*}

The Clover Leafhopper is an insect which may be found in clover and alfalfa fields over a wide range. It is a very small insect, like most common leafhoppers, and its injury is widely distributed, so that it often attracts no notice, but is none the less real. The insects are slender forms, one-eighth inch in length and of a grayish color with darker markings. They hop actively when disturbed and may, at times, be noticed in clouds when one walks through a clover field.

Injury.-The injury is caused in two ways. First, they suck the sap from the stems and foliage of the plant and, later, they

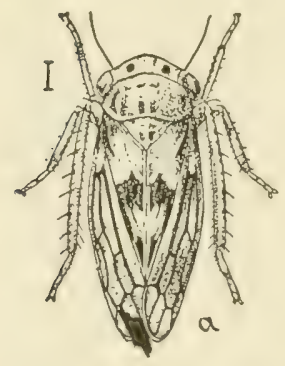

S.sunguinolenla.
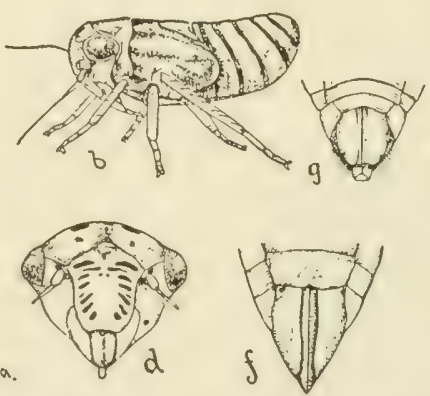

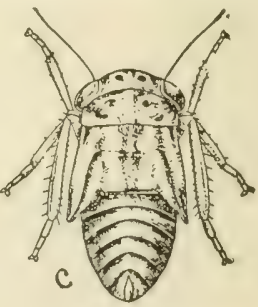

FIG. 173.-The clover leafhopper (Agallia sanguinolenta): $a$, adult; $b$, nymph, side view; $c$, nymph, dorsal view; $d$, fitce; $e$, elytron; $f$, female genitalia; $g$, male genitalia. All enlarged. (After Osborn and Ball, from Gibson, 1. c.)

puncture the tissues and deposit their eggs within them, the result being irregular swellings which interfere with the growth.

Life History.-There are at least three generations but they are more or less indistinguishable on account of over-lapping. They hibernate as adults. The young or nymphs resemble the adults in a general way but are greener in color and less active.

Control.-Clean culture, burning of rubbish in the fall and early cutting of the clover and alfalfa as well as close pasturing

* Agallia sanguinolenta Prov. Family Jassida. 
of grass lands while the adults are numerous are the Bureau of Entomology recommendations for control.*

When leafhoppers are unusually numerous and destructive they may be captured in enormous numbers by the use of a hopperdozer or hopperette, constructed along the same lines as those used for grasshoppers.

\section{Miscellaneous Insects of Clover and Alfalfa}

In addition to the insects already discussed there are many others which attack these crops, either occasionally or regularly. Among these should be mentioned the grasshoppers, a complete discussion of which will be found in Chapter VII, the pea-louse,

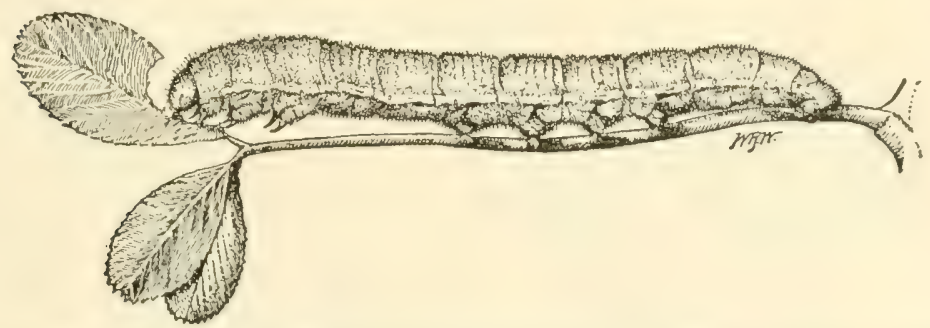

FIG. 174.-The alfalfa caterpillar: full-grown larva. Enlarged about three diameters. (After Wildermuth, lo c.)

which is fully discussed in Chapter $\mathrm{XV}$, and the blister beetles, also discussed in Chapter XV and the one following and in Chapter VII. Besides these there are several species of caterpillars found in greater or less abundance in clover and alfalfa at all times. These include the following:

The Alfalfa Caterpillar $\dagger$ which is the larva of one of our most common yellow butterflies always associated with elover fields and so familiar to all as to need no description. The larva is green in color and similar to the common cabbage worm, differing in the possession of a light stripe on each side through which runs a bright red line. The insects seem to hibernate in all stages and there are two or more broods.

Damage to the crops is usually not severe in any one place but evenly distributed and aggregates more than would be sup-

* See Farmers' Bulletin 737, U. S. Dept. Agr.

t Eurymus eurytheme Boisd. Family Pieridae. See V. L. Wildermuth, U. S. Dept. Agr. Bulletin 124. 
posed. In some localities damage is severe and control measures must be employed. When this is necessary the following prac-

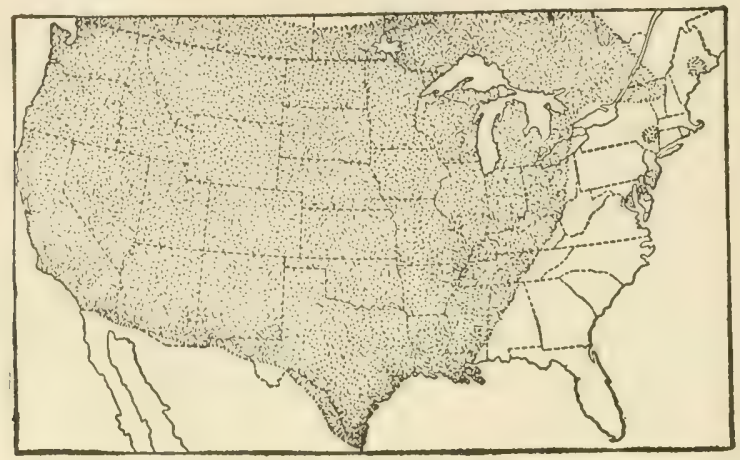

FIG. 175.-Map showing distribution of the alfalfa caterpillar. (After Wildermuth, l. c.)

tices are advisable: Cut the crop early and close to the ground; pasture closely where possible; disk badly infested fields and

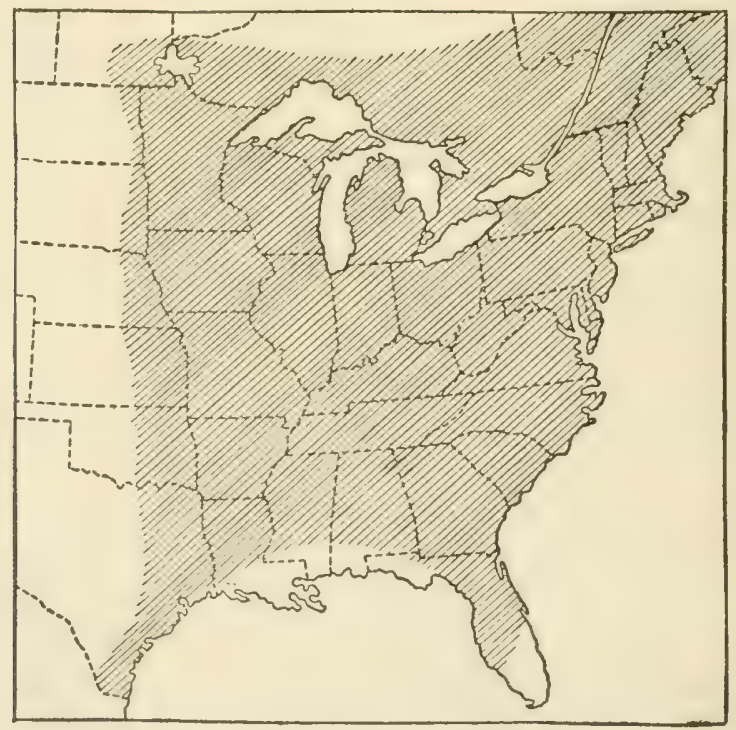

Fig. 176.-Map showing distribution of the green clover worm in the United States. After Hill.)

then run over them a roller or a brush drag; keep cultural conditions in a high state of perfection at all times. 
The Green Clover-worm * is another caterpillar which is frequently abundant in fields of clover, alfalfa, soy beans and related crops. It is a green caterpillar with darker stripes, an inch or more in length and the larva of one of the common dullcolored moths of the cutworm type. It is best controlled by harvesting the crop when the worms are present in the greatest abundance but are not quite grown, whether the crop is quite ready to cut or not. In this way many are starved and others perish from exposure to the sun after the crop has been removed. Supplement this with the brush drag if the worms are especially numerous.

The Alfalfa Looper $\dagger$ is one of the serious occasional pests of alfalfa in the Northwest. It is abundant mainly in irrigated regions. Control measures recommended are similar to those for the green clover-worm and alfalfa caterpillar and are at times supplemented by the use of poisons.

The Garden Webworm

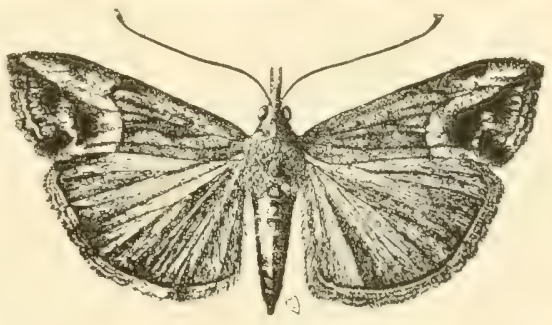

FIG. 177.-The green clover worm; adult or moth. Much enlarged. (After IIill).

(See Chapter XIX) sometimes defoliates alfalfa and related plants and leaves over the injured stalks the webs which serve to identify it. Control measures applicable to it are almost exactly similar to those for the other caterpillars listed.

- * Plathypeña scabrä Fabr. Family 'Voctuidae. See Farmers' Bulletin No. 982, U. S. Dept. Agr.

$\dagger$ A utographa californica Speyer. Family Voctuidae. See J. R. Parker Jour. Econ. Ent., Vol. 8, No. 2, 1915. 


\section{CHAPTER XII}

\section{INSECTS INJURIOUS TO TOBACCO *}

\section{The Tobacco Flea-beetle $\dagger$}

THE Tobace Flea-beetle is one of the important pests of that plant throughout the Middle States, being particularly injurious
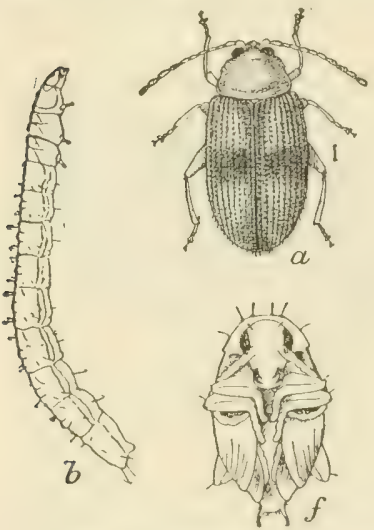
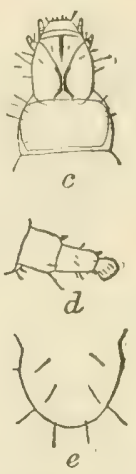
to young plants. The beetles damage the leaves by eating small holes in the upper or under surfaces, or clear through them, so that when badly eaten the leaves look as if they had been peppered with shot. The little beetles which do this damage are hardly more than one-twentieth inch long light brown in color, with a dark band across the wingcovers. A few of them could

FIG 178.-Tobaceo flea-beetle (Epitrix par- do but little damage, but they vula): $a$, adult beetle; $b$, larva lateral view; $c$, head of larva; $d$, posterior leg soon increase in numbers, so of same; $e$, anal segment, dorsal view; that they swarm over the $f$, pupa - $a, b, f$, enlarged about fifteen times; $c, d$, $c$, more enlarged. (After leaves and injure them badly. Chittenden, U. S. Dept. Agr.) Similar injury is done to potato, egg-plant, and tomato, and the beetles also feed on horsenettle, nightshade, and Jamestown weed.

Life History-The eggs are laid in the soil and the larvæ feed upon the roots of common weeds, such as the nightshade and Jamestown weed. The larva is delicate, thread-like and white,

* See L. O. IIoward, Farmers' Bulletin 120, U. S. Dept. Agr., The Principal Insects Affecting the Tobaceo Plant. A. C. Morgan, Circular 123, Bureau of Entomology, IT. S. Dept. Agr.; Yearbook, U. S. Dept, Agr., 1910, pp. 281-296; and Z. P. Metcalf, N. C. Dept. of Agr. Bulletin, Oct., 1909.

$\dagger$ Epetrux parvula Fab. Family Chrysomclidae. 
except the yellowish head, and alout one-eighth inch long. It pupates in the soil. When the beetles become very numerous the larvie sometimes develop on the roots of tobacco, but rarely do serious damage. The life history has not been determined exactly, but the full life cycle seems to occupy about a month, so that there are probably several generations in a year.

Control.-Inasmuch as the larvæ develop on the roots of the weeds mentioned, it is evident that they should be kept down by thorough cultivation. Where the beetles appear, the plants should be sprayed or dusted with Paris green, or probably better, arsenate of lead, the same as for the horn-worm. Dipping the plants in arsenate of lead, 1 pound to 10 gallons of water, just as they are set, has been found to afford very satisfactory protection in Connecticut.

\section{The Tobacco Stalk-worm*}

Professor W. G. Johnson found this species, also known as the Corn-root Webworm, to be a serious pest to growing tobacco-plants in southern Maryland, where it seems to have been a tobacco pest for a good many years, and it has also been noted in Delaware.

The Injury.-The injury to tobacco is described by Professor Johnson as follows: "The uninjured tobacco had

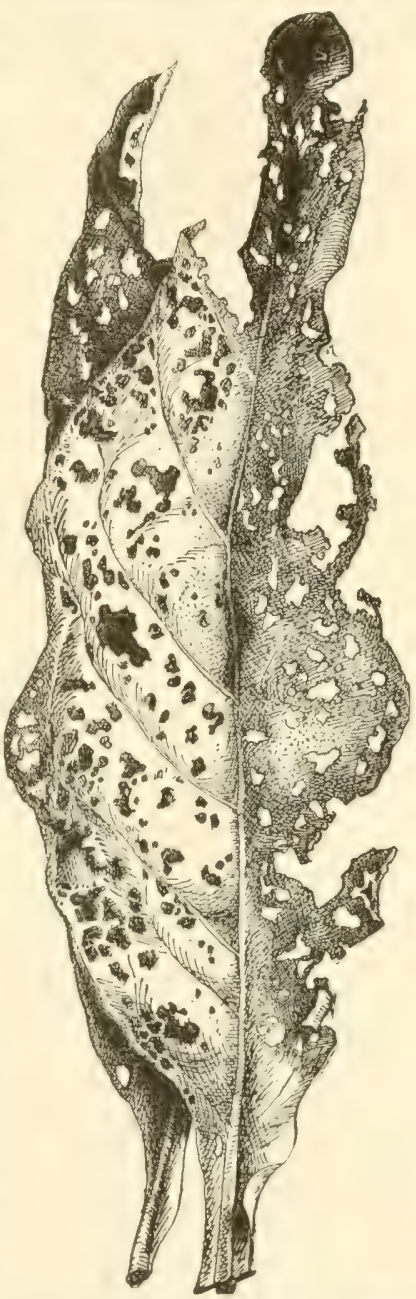

FIG. 179.-T o b a c c o leaves damaged by Epitrix parvul. (After Howard, U. S. Dept. Agr.)

a leaf spread of from ten to twelve inches. A few rods beyond, where the soil was not so gravelly and better, we found the larvæe

* Crambus caloginosellus Clem. Family Crambida. See p. 161 and Bulletin 20, n. s., Div. Ent., U. S. Dept. Agr., pp. 99-101, 1899. 
had literally destroyed the first and second plantings and were at work upon the third, damaging it severely, although the ground had been replanted before the last planting. Here and there was a young plant just beginning to wilt, and invariably we found the larva at work either in the stalk or at the base of the plant just below the surface of the ground. So far as I could ascertain, the attack is always at the surface or just below. In many instances the larvæ had hollowed out the stalks from the base of the roots to the branches of the first leaves. Many plants were gnawed irregularly around the stalk below the surface, and some, in fact, were completely cut off at the surface, the insect always working from below. In the great majority of cases the larva were found in a small mass of web near the plant, and sometimes within it. In one plant, less than six inches high, we found four larvæ within the stalk, but as a rule only a single one was present."

Professor Johnson concluded "(1) that it is most likely to occur over local areas in tobacco following timothy or grass; (2) that the character of the soil has little or nothing to do with its ravages; (3) that the attack upon corn is also a frequent occurrence in the same section; especially when following grass or timothy."

Remedies.-He recommended "(1) that growers of tobacco avoid planting upon grass or timothy sod; (2) that where grass land is plowed down it would be well to put it in wheat, following with clover, before tobacco. If desirable, corn could follow the grass and the land could be seeded in crimson clover at the last working. This would serve a twofold object by revealing the exact location of larvw in the area under cultivation by their attack upon corn, when they could be destroyed largely by frequent harrowing and rolling, and by affording a most excellent soil crop to turn down the following spring, which would be a decided advantage to the tobacco; that if it is found necessary to have tobacco following grass, it should be broken in the spring as early as possible, and frequently rolled and harrowed, at the same time delaying the setting of the plants as long as possible in order to destroy and starve the larvæ within the ground." 


\section{The Spined Tobacco-bug *}

Professor H. Garman has found a small bug, which he has termed the Spined Tobacco-bug, doing more or less injury to plants in Kentucky, and as this insect is widely distributed throughout the country, it probably does more or less damage elsewhere, though never a serious pest. Concerning its work, he says: "Occasional plants in tobacco-fields are at times observed to have become suddenly wilted, the leaves hanging limp, much as if the stalk had been severed. After a time they recover again, and, beyond a temporary check on their growth, appear to have suffered but little injury. If such plants are searched carefully while still wilted, a flat, brown bug with each side of the body produced into an angle, or sharp spine, will be found upon the stalk along the base of the leaves. It is very shy and keeps out of sight, hence any
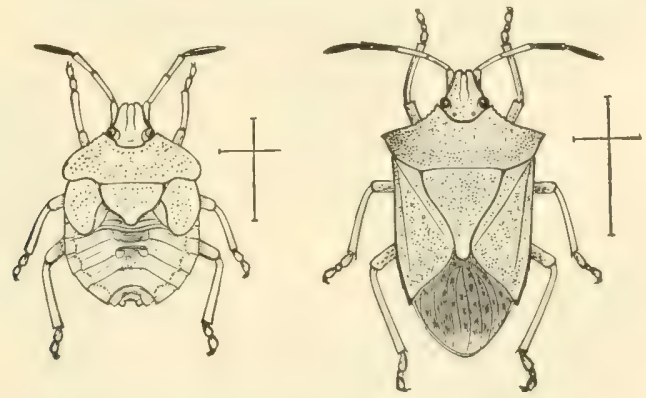

FIG. 180.-The spined tobacco-bug (Euschistus variolarius), nymph at left; adult at right-enlarged. (After Howard, U. S. Dept. Agr.)

brisk movement on the injured plants is likely to cause it to drop to the ground and conceal itself." These insects are true bugs, sucking their food through a beak, which is bent under the body between the legs when not in use. They are about half an inch long, of a drab color above and greenish or yellowish below. Usually only one bug is found on a plant, so that the best way to prevent the injury is to pick them from the plants, and keep down such weeds as thistles and mulleins, upon which such insects feed, in the adjoining fields.

* Eutschistus punctipes Say (variolarius Pal. Beauv.). Family Pentatomida. See Bulletin No. 66, Ky. Agr. Exp. Sta., p. 33. 


\section{The Hornworms or Tobacco-worms *}

Of all the insects feeding upon tobacco, the Hornworms are the most widely injurious and therefore best known. The caterpillars of two species of moths are commonly included under this popular name, both species occurring throughout the tobaccogrowing States, the northern tobacco-worm being more common in the North and the southern tobacco-worm more common in the

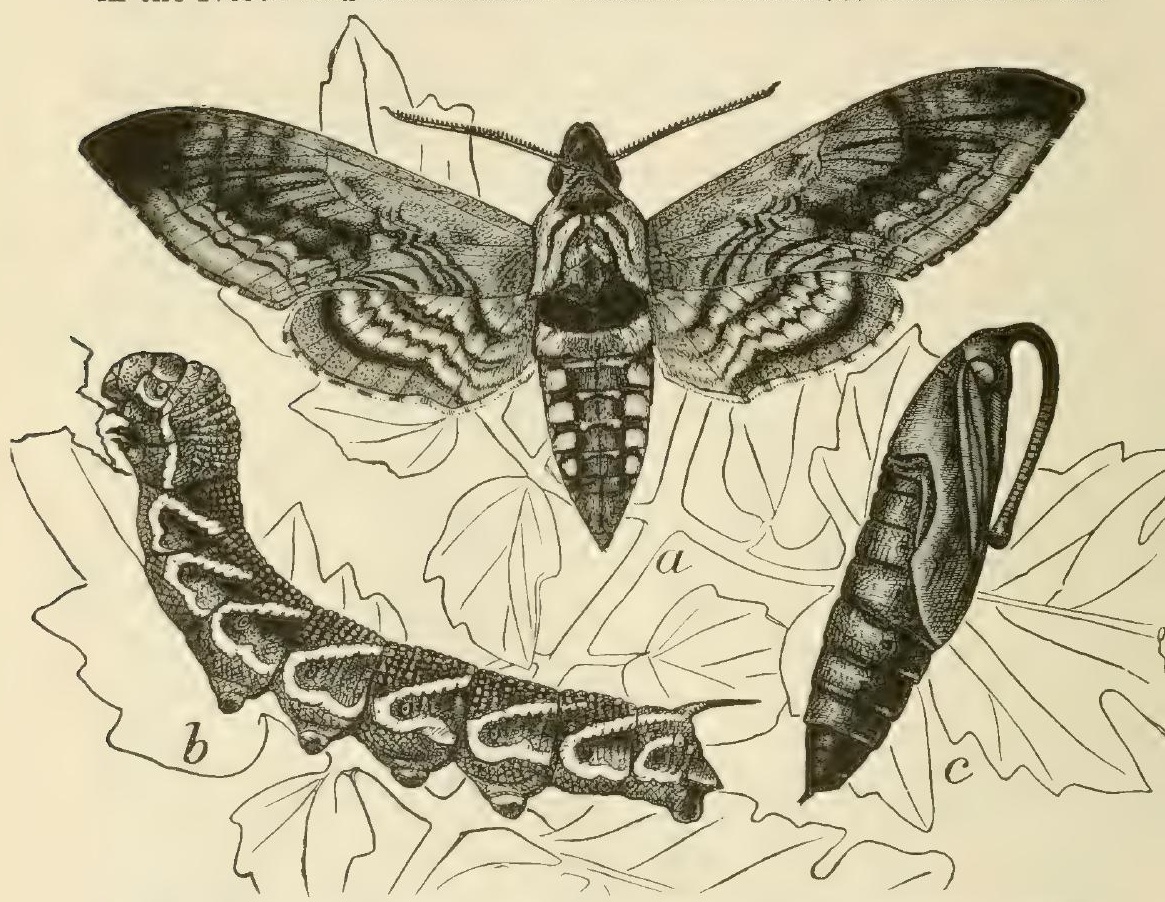

FIG. 181.-Northern tobacco-worm, or "hornworm" (Phlegethontius quinquemaculata): $a$, adult moth; $h$, full-grown larva: $c$, pupa-natural size. (After Howard, U. S. Dept. Agr.)

South. The differences in the adult moths may be readily apprecaited from Figs. 181 and 182, the southern form being darker and with brighter orange spots on the abdomen, and the white lines on the hind-rvings being less distinct. The larvæ of both species commonly attack tomato vines and are commonly called tomato worms where tobacco is not grown.

* Phlegethontius quinquemaculata Haworth (Northern), and P. sexta Johanssen (Southern). Family Sphingido. 
Life History. - The pupæ pass the winter several inches below the surface of the soil and from them the moths emerge in May and June, according to the latitude and season. The females deposit their eggs singly, upon the lower surfaces of the leaves, from which the little caterpillars hatch in from four to eight days. The characteristic work of the larve is too well known to every tobacco grower to necessitate description. The caterpillars become full grown in about three weeks, during which time thev moult some

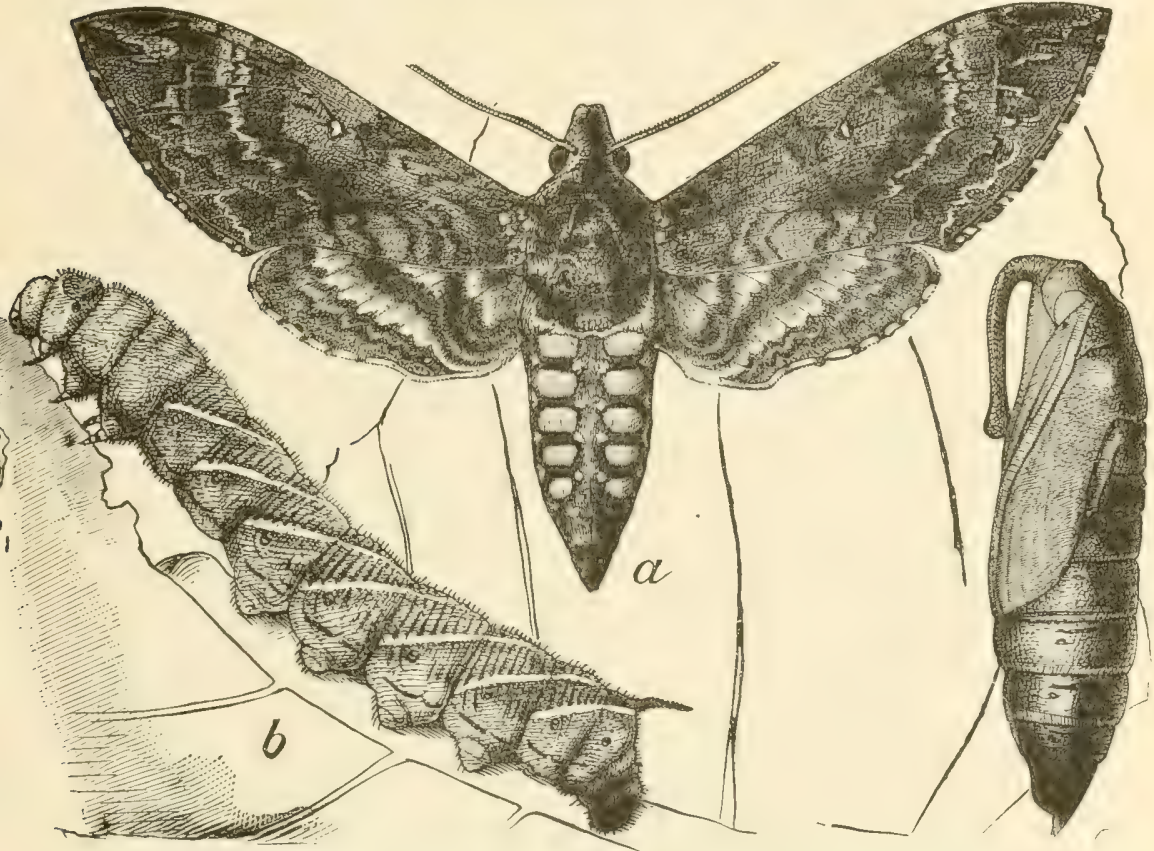

Fig. 182.- Southern tobacco-worm (Phlegethontius sexta): $a$, adult moth; $b$, full-grown larva; $c$, pupa-natural size. (After Howard, U. S. Dept. Agr.)

five times. The full grown larvæ are three to four inches long, of a dark green color with white stripes on the side of the body, those of the northern species having a V-shape, while those of the southern species being simple oblique hands. At the tip of the abdomen is a stout horn, from which is derived the name of hornworm, which in the northern species is black and in the southern is red. The pupæ are formed in the soil, are dark brown, about two inches long, and have a peculiar handle-like process, the sheath of the 
proboscis, which somewhat resembles a horn and which may account for the name of "hornblowers," commonly given them in Marylard and Virginia. The pupal stage lasts about three weeks, when the adults emerge, the whole life cycle requiring from six to eight weeks. Usually two generations occur in a season throughout most of the tobacco belt, but in the North there seems to be but one generation, and in the Gulf States there may be three generations. Occasionally the worms are overlooked in cutting the tobacco and are carried into the barn, where they may do considerable injury even after the tobacco is partially dry.

Control.-The most common method of control is hand-picking, usually termed "worming." In seasons when the worms are not overabundant this may be the most practical method of control, but it is both tiresome and expensive, and the planter has no means of predicting whether the worms will be more or less abundant. Large flocks of turkeys driven through the fields will aid most efficiently in this work.

In many sections the worms are now controlled by spraying or dusting with Paris green or arsenate of lead. More or less popular prejudice against the use of arsenicals has existed, as it was thought the tobacco might be poisonous to the consumer. Careful chemical examinations have shown, however, that the amount left on the foliage after three sprayings would be far too small to have any deleterious effect. The same prejudice formerly existed against the use of arsenicals on potatoes, cabbage and other crops but experience has shown it to be unwarranted. A real ebjection to the use of Paris green is that it sometimes slightly burns the foliage, so that arsenate of lead will doubtless be found preferable.

Morgan* recommends dusting rather than spraying and condemns the use of Paris green. His summary of recommendations is as follows:

"Paris green, although an effective insecticide, frequently burns tobacco very severely and may reduce the value of the crop by as much as 50 per cent in exceptional cases.

Arsenate of lead never seriously injures tobacco even under the most unfavorable conditions.

A dosage of Paris green large enough to be effective against hornworms can not be applied without grave danger of burning tobacco.

* Morgan, A. C. Farmer's Bulletin 867, U. S. Dept. of Agr. 
Paris green, which is applied in dust form without a carrier, is used at the rate of from 1 to 2 pounds per acre.
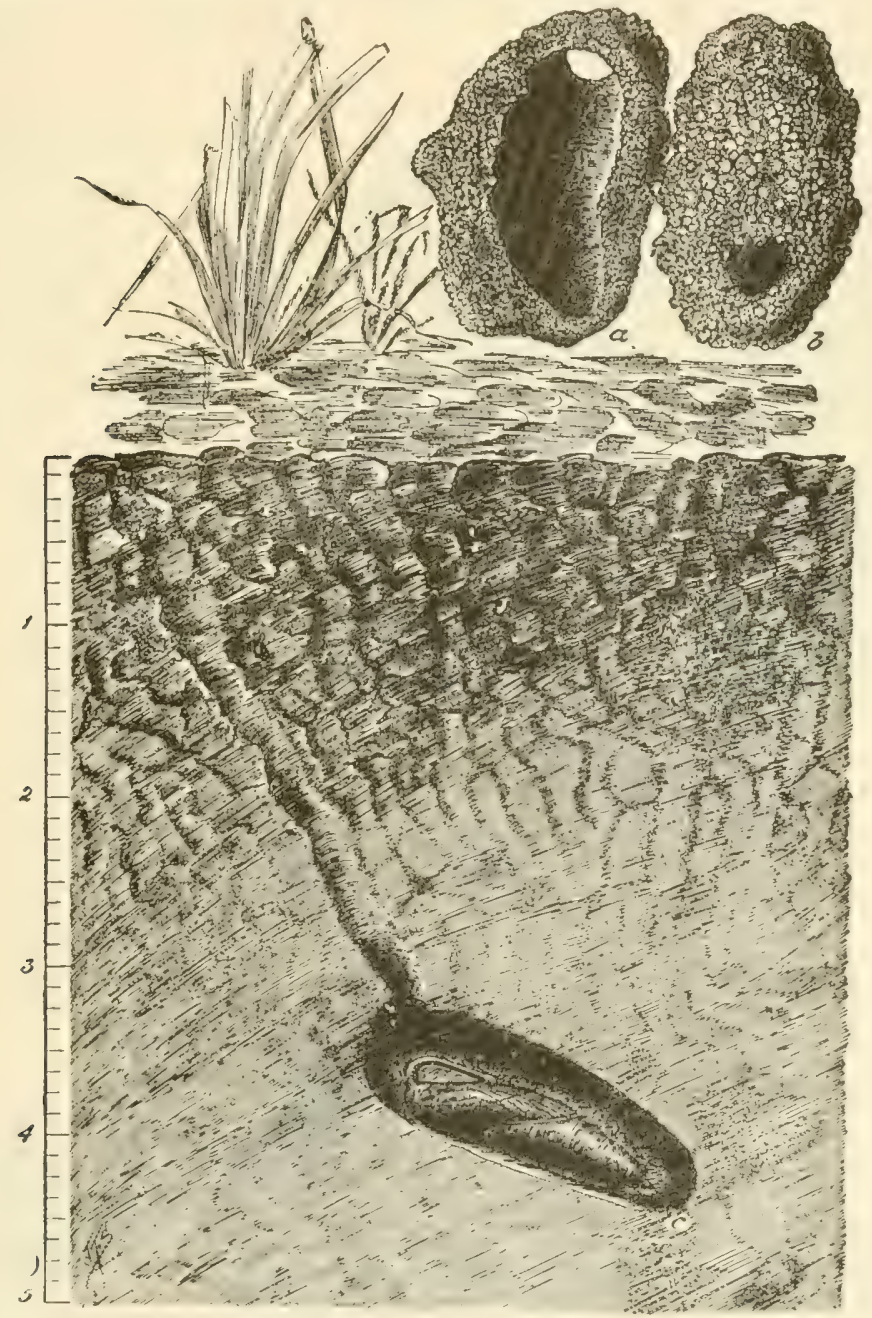

Fig. 183. Hibernation of southern tobacco-worm; $c$, pupa in hibernating cell in soil, at the depth of which pupation usulilly takes plice in the stiffer soils; $a$, eross-section of pupal cell viewed from leelow; b, pupal cell showing entrance hole of larva-two-third natural size; (After A. C. Morgan, U.S. Dept. Agr.)

Arsenate of lead is safe and rffective during rainy weather, whereas Paris green is dangerous and ineffective. 
It is recommended that arsenate of lead be used against the tobacco hornworms and that it be applied as a dust or powder.

The dosage of arsenate of lead in powdered form varies from $3 \frac{1}{2}$ pounds to 5 pounds per acre. If applied as a spray, use from 3 to 4 pounds in 100 gallons of water.

To apply arsenate of lead in powdered form, without a carrier,

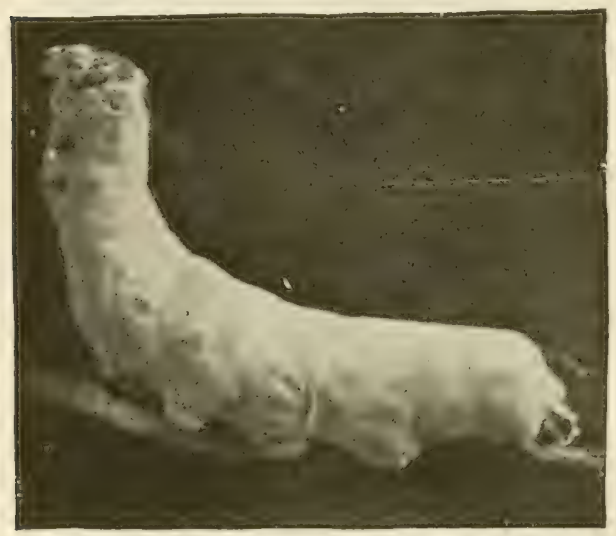

Fig. 184.--Southern tobacco-worm killed by fungus. (After Garman.) use a dust gun having a fan diameter of at least 10 inches and a special device for preventing clogging of the delivery pipe. If a gun with such a device is not used, it will be necessary to $\operatorname{mix}$ the arsenate of lead thoroughly with equal parts of $d r y$ wood ashes.

Apply arsenate of lead when there is no breeze and when dew is on the plants.

Use only such brands' of arsenate of lead as are guaranteed to contain at least 30 per cent of arsenic oxid, of which not more than 1 per cent is free, or water-soluble."

Natural Enemies.-Very frequently worms are found covered with what seem to be small, white eggs. These are not eggs, however, but are the small silken cocoons of a little wasp-like parasite (A panteles congregatus) whose larvæ feed internally upon the juices of the worm and thus ultimately kill it before it transforms to a pupa. Such parasitized worms should never be Fig. 185.--Southern tobacco-worm destroyed, as the parasites are of more value than the damage the

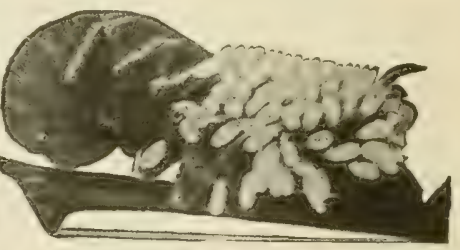
with cocoons of parasite. (After Garman.) worm might do. Very frequently the caterpillars are attacked by a bacterial disease which causes them to turn dark and become shrunken and flaccid. 


\section{The Budworms *}

Two caterpillars of the same genus commonly attack the bud of tobacco and have been distinguished by Dr. L. O. Howard as the true budworm and false budworm, the latter being the same as the well-known cotton bollworm or corn ear-worm. $\dagger$

"The true budworm (Chloridea virescens) ${ }^{\circ}$ occurs in the more southern portions of the tobacco-growing regions," says Dr. Howard, $\ddagger$ " but has not been noted in tobacco-fields north of
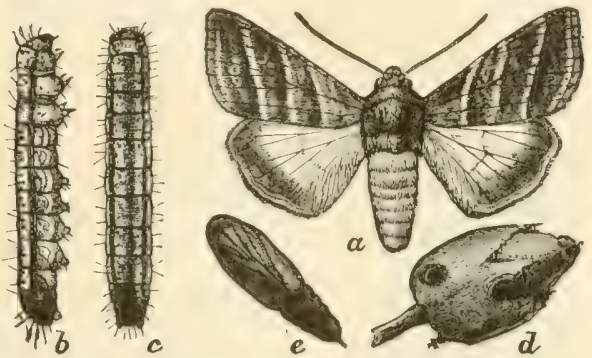

FIG. 186.-The true budworm (Chloridea virescens): $a$, adult moth; $b$, full-grown larva, from side; $c$, same, from above; $d$, seed-pod bored into by larva; $e$, pupa-natural size. (After Howard, U. S. Dept. Agr.)

Maryland. The adult insect is a small greenish moth, well illustrated in Fig. 186. The larva or caterpillar of this moth, also illustrated, is nearly always found in the bud of the tobacco-plant about the time the plant is ready to top. In some seasons they occur in large numbers and damage the tobacco considerably. In the early part of the season, as a general thing, but few of them are found, and in ordinary seasons they are not especially noticed during the early "worming" of the tobacco. In August they begin to be more abundant, and generally leave the plant about the end of the month, entering the ground, transforming to pupr and issuing as moths toward the end of September. These dates are for Virginia, but hold reasonably well as far south as Mississippi. The greatest damage done by this insect is by the August brood, when it enters the rolled-up leaves or bud of the plant. In September and October the next generation of caterpillars is found boring into the seedpod and occasionally into the florver-stem.

The caterpillars of the last fall generation enter the ground and hibernate as pupæ. The insect has several other food-plants aside from cotton, but its most abundant food in the South is the weed

* Chloridea virescens Fab., and C. obsoleta Fab. Family Noctuida.

† See corn ear-worms for full description and illustrations.

\Farmers' Bulletin 120, U. S. Dept. Agr. The principal Insects Affecting the Tobacco Plant. 
known as ground cherry (Physalis viscosa)." The life history of this species is very similar, therefore, to the false budworm or bollworm.

The corn ear-worm (which see) is usually found attacking tobacco in Virginia and Kentucky only late in the season after corn has commenced to harden. It then bores into the buds, seedpods, and flower-stalks, in the same manner as the last species. In

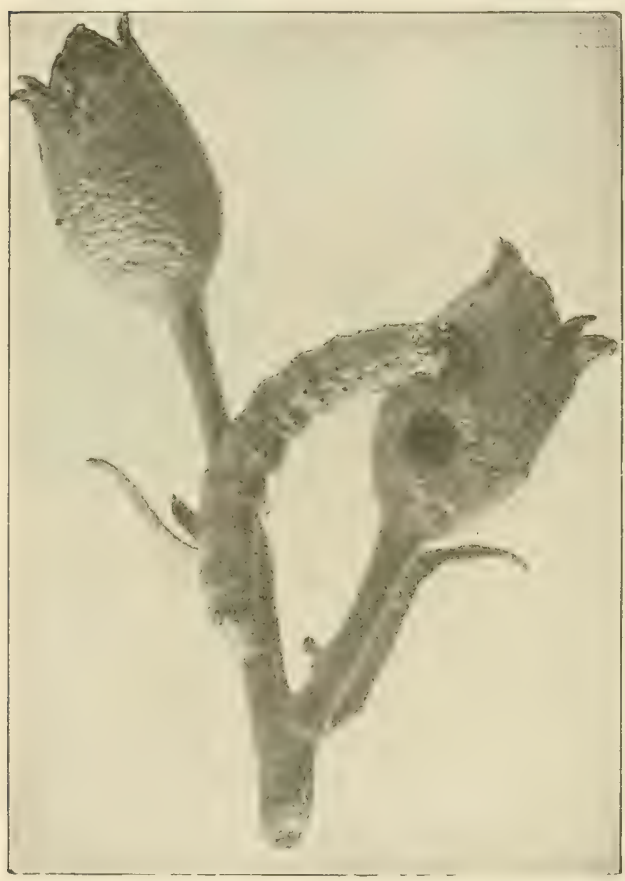

Fig. 187.-Larva of false budworm (Chloriden obsoletr), showing work on seed capsules of tobacco plant. (.Ifter (Quaintance.)
Florida, however, Professor A. L. Quaintance states that its worst injury is done early in the season before corn or cotton are available, the eggs being laid in the bud and theyoung larvæ feeding on the unfolded leaves, doing very serious injury. In Florida the corn ear-worm or false budworm is more common than the former species.

Control.-P o is o n ed corn-meal has been found to be a satisfactory remedy for both species when they bore into the bud. Mixa teaspoonful of arsenate of lead into a quart of finely ground cornmeal and sprinkle into the buds from a can perforated like a pepper can. This should be applied frecuently, especially after heavy rains. Large buds should be opened and a pinch of the poison placed within. When spraying or dusting with an arsenical is practiced against the hornworms it will aid in the control of the budworms, and may be advisable for them alone where injury is serious. When the injury by the false budworm occurs only 
late in the season, it would seem that the moths might be attracted to a trap crop of late corn in the same manner as cotton is protected from it.

\section{The Tobacco Leaf-miner *}

The larva of a small moth has become quite injurious in part, of North Carolina and Florida by mining the inside of the leafs and is thus known as the Tobacco Leaf-miner. This insect occurs in other parts of the country, but has become injurious only in the states named and in recent years. The injury is done by the larvæ eating out irregular patches of the tissue in the leaves, leaving only the upper and lower surfaces, the low er leaves being infested the worst. The leaves are rendered $u n f i t$ for wrappers, splitting and tearing very easily on account of these blotches. A larva does not confine its work to one place, but makes several mines, and a

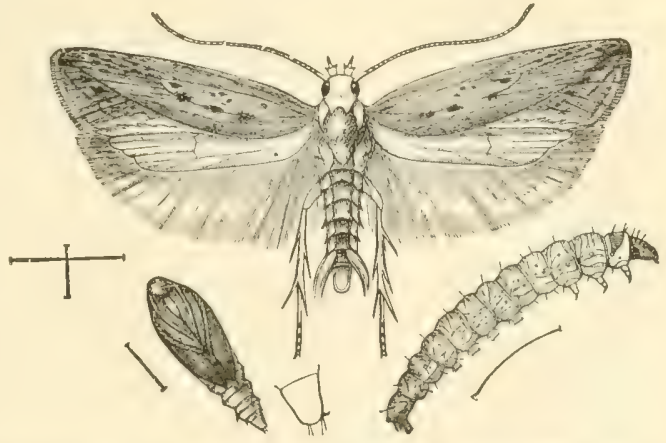

Fig. 188.-Tobaceo leaf-miner or split-worm: adult moth above; larva below at right; pupa below at left, with side view of enlarged anal segmentall enlarged (After Howard, U. S. Dept. Agr.) single larva may thus destroy the value of a leaf for wrapping purposes. This migratory habit is of considerable importance, as in leaving the old and in making new mines the larvæ must necessarily eat a certain amount of the surface of the leaf, and can thus be killed by an arsenical spray. The life history of the insect is not completely known, but as only about twenty days are required for all its transformations, several broods probably occur during a season. The original food-plant of this pest has been found to be the common horse or bull-nettle (Solanum carolinense), which fact further emphasizes the caution already given, to keep all weeds carefully cut down around the tobaccofield, especially those nearly related to tobacco botanically. Many planters destroy the larva by simply crushing them with the hand, and this can be clone quite rapidly, and if done before the mines become numerous should be sufficient to check the injury.

* Phthorimoa operculella Zell. Family Tineido. 
Where spraying or dusting is practised against the hornworm it should be sufficient to destroy most of the miners, as, if the leaf is thoroughly coated with poison, they would get a fatal dose in starting a new mine.

\section{The Cigarette-beetle *}

The most serious pest of dried tobacco is the little brown Cigarette-beetle, which also attacks various drugs and stored

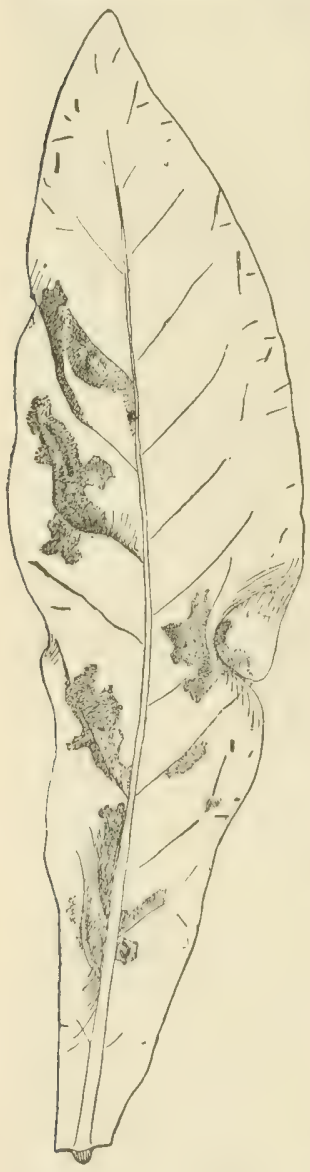

Fig. 189. - Work of split-tworm reduced. (After Howard, U.S. Dept. Agr.) food products. The beetle is but onesixteenth inch long, of a brownish color, and with the pro-thorax bent down so that the head is obscured as if under a hood.

"Working as it does in all kinds of cured tobacco and living in this substance during all the stages of its existence," says Dr. L. O. Howard, "it damages cigarettes and cigars principally by boring out of them, making round holes in the wrappers so that they will not draw. Leaf tobacco is injured for wrapping purposes by being punctured with holes made both by the larvæ and beetles, and fillers and finecut a re injured by the reduction of their substance by the actual amount consumed by the larvæ." "The cigarette-beetle is practically cosmopolitan, and probably occurs in most tobacco factories in the Southern States, as well as in most wholesale drug stores. In the far South this insect multiplies rapidly throughout the greater part of the year, and its development is practically continuous in artificially warmed factories farther north."

Life History. - In heated factories the insect may be found in all stages throughout the year. Otherwise it seems to pass the winter months in the larval state. The larva is slightly larger than the beetle and covered with hair as shown in Fig. 190. When full grown it spins a compact silky 
cocoon covered with bits of whaterer it is breeding in and in it transforms to the pupa. In a warm room the ent ire life eycle has been passed in forty-seven days, and it seems probable that in the District of Columbia, there are two generations a year. The life is undoubtedly intimately related to the moisture and temperature conditions under which it lives.

Control.-When a factory or storehouse has become badly infested a thorough cleaning is the first step in the control of the pest, as tobacco fragments and dust are usually present every-

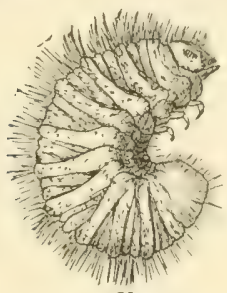

$\alpha$

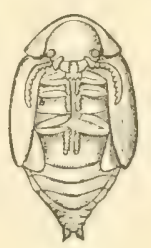

$b$

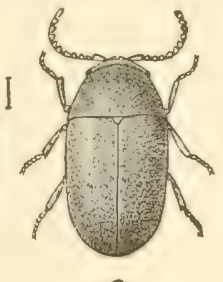

c

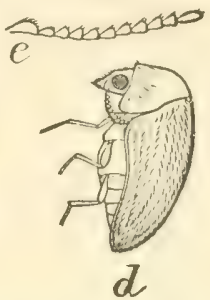

d

FIG. 190.-The cigarette beetle: $a$, larva; $b$, pupa; $c$, adult; $d$, side viw of adult; $e$, antenna-all greatly enlarged; $e$, still more enlarged. (After Chittenden, U. S. Dept. Agr.)

where and ideal conditions for the multiplication of the pest are afforded.

Infested tobacco should be opened up, if packed tightly, placed in tight boxes or in a tight room and exposed to the fumes of carbon bisulfide, using it the same as for grain insects.

The quantity used will depend upon the tightness of the enclosure, the way in which the tobaceo is packed, and the temperature. One pound to every 200 cubic feet will usually be ample. In factories where the beetle is abundant the tobacco should be steamed before use, which will kill all stages of the insect. Loose tobacco, cigars, and cigarettes, should not be left exposed to the beetles, but should be covered up or placed in tight receptacles to prevent their access. Badly infested factories and storehouses may be fumigated with hydrocyanic acid gas. Heating would be effective where practical.

Several other insects are more or less serious pests of tobacco in certain parts of the country or under local conditions. The Tobacco Thrips* has caused considerable loss to growers of wrapper tobacco in Florida where it is grown under shade.

* Euthrips nicotania Hinds. Order Thysanoptera. See W. A. Hooker, Bulletin 65, and Circular 6s, Bureau of Entomology, U. S. Dept. Agr. 


\section{CHAPTER XIII}

\section{INSECTS INJURIOUS TO COTTON *}

\section{Plant-lice $\dagger$}

With the formation of the first true leaves of cotton, winged aphids or plant-lice appear in large numbers on the under side and on the terminals, the "buds" of the plants often being black with them. Almost all of them are the common greenish Melonaphis $\ddagger$ (see page 344 ), which infests melons later in the season. It is evident, therefore, that the practice of planting cotton between rows of melons is undesirable. The aphids migrate to the cotton while it is young from various common weeds upon which they have passed the winter.

Another species, known as the Bur-clover Aphis $\S$ occurs on cotton at about the same time and is not readily distinguishable from the previous species, but is darker and has a shining reddish or brownish-black color.

In cold weather these plant-lice often cause considerable injury to the young plants, and greatly retard their development, since they multiply very rapidly and feed mostly on the growing terminals. If there be a few warm days, however, hordes of small Hymenopterous parasites appear and in a few days often completely rid the plants of the pest.

Control.-Although these aphids may be destroyed by spraying with kerosene emulsion, whale-oil soap, or tobacco water, as a rule the use of these on any considerable scale will hardly be profitable. Keeping the fields clear of weeds by fall and winter plowing will undoubtedly have a beneficial effect in reducing

* See Hunter and Hinds, The Mexican Cotton Boll Weevil, Bulletin 51, Bureau of Entomology, U. S. Dept. Agr.; (uaintance and Brues, The Cotton Bollworm, Bulletin 50, Bureau of Entomology, U. S. Dept. A igr.; Sanderson, Miscellaneous Cotton Insects of Texas, Bulletin 57, Bureau of Entomology, Farmers' Bulletin 223, U. S. Dept. Agr.

$\dagger$ Family A phidido.

+ Aphis gossypii Glov.

$\$$ Aphis medicaginis Koch. 


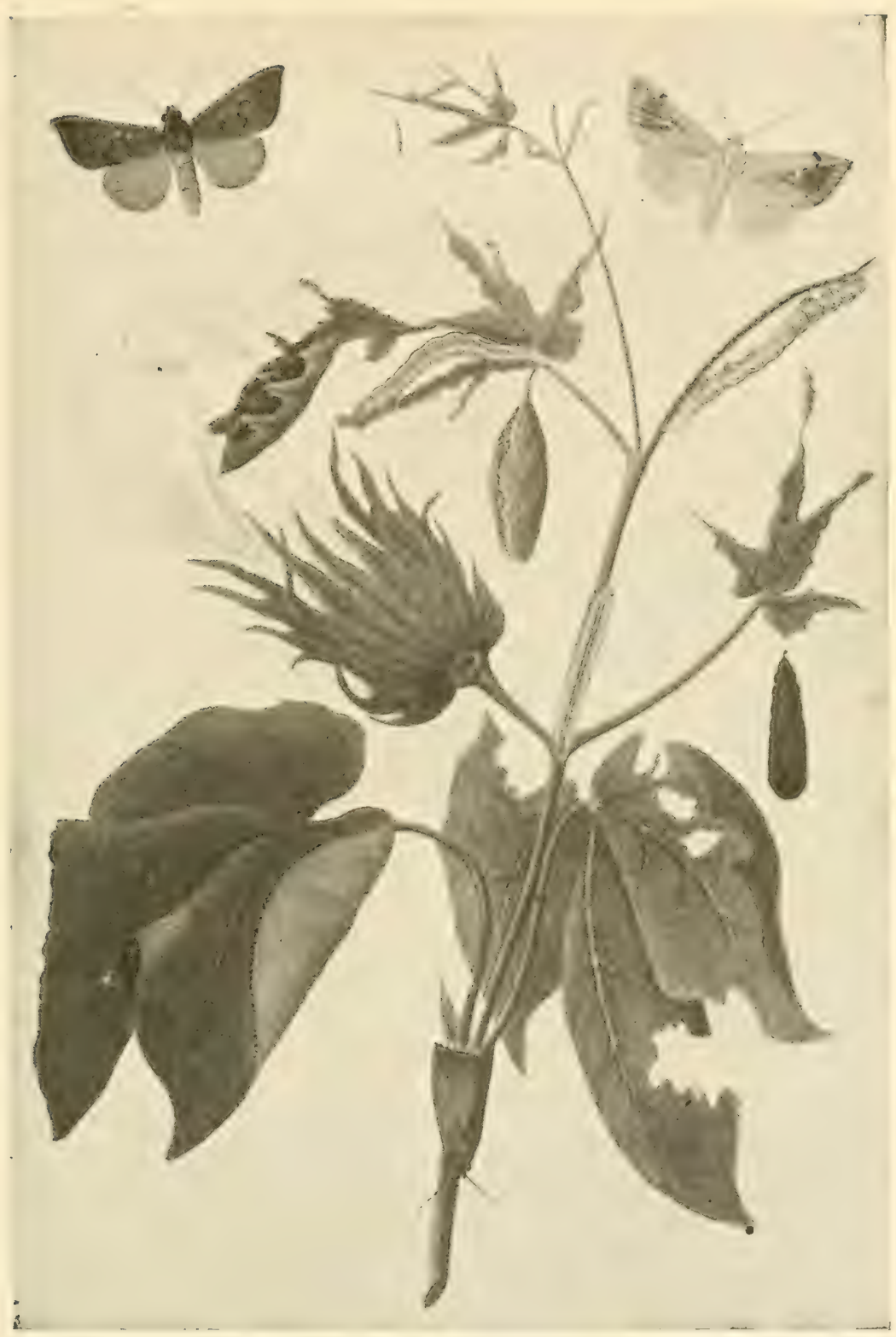

FIG. 191.-The cotton worm (Alabama argillacea): young and full-grown larve or worms, pupa, cocoons in folded leaves, and moths, at rest, and with wings expanded-three-fourths natural size. (After Comstock.) 
the numbers of aphids and in most cases will be the only treatment necessary.

The corn root-aphis is also recognized as a pest of cotton, especially the young plants. When it appears it may be controlled to some extent by frequent shallow cultivation of the young plants until they are well established. Infestation may be avoided by a system of rotation where cotton does not follow either cotton or corn in infested fields.*

\section{The Cotton Worm $\dagger$}

Until the advent of the boll weevil, the cotton worm was much the most serious insect pest of cotton. Since then, however,

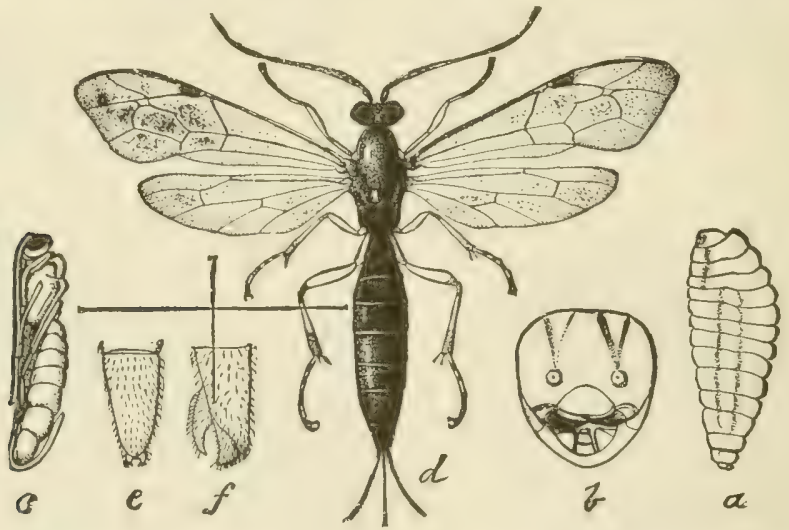

FIa. 192.--Pimpla conquisitor, one of the principal parasites of the cottoncaterpillar: $a$, larve enlarged; $b$, head of same still more enlarged; $c$, pupa; $d$, adult female enlarged; $e, f$, end of abdomen of adult male, still more enlarged. (From Fourth Rept. U. S. Entom. Comm.)!

its importance has been rather overshadowed in the mind of the planter by the onslaught of the invading Mexican pest and where the boll weevil is abundant the stripping of the late foliage by the cotton worm really aids in the control of the weevil, as will be explained later.

Life History.-During the winter months the adult moth hibernates in the most southern portion of the cotton-belt, in the rank wire-grass occurring in the more thickly timbered regions.

* See W. A. Thomas, S. C. Expt. Sta. Bulletin 175.

$\dagger$ Alabama argillacea IIulm. Family Noctuida. See W. E. Hinds, Bulletin 164, Alabama Agr. Expt. Station. 
Only a few of these survive, but they are very capable ancestors. In early March they lay eggs upon volunteer cotton when it is only an inch or two high. The eggs are laid singly, usually upon the under surface of the leaves near the top of the plant, and about 500 are laid by each female. The egg is of a flattened convex shape, bluish-green in color, and with prominent ridges converging to the apex. In midsummer the eggs hatch in three or four days, but in spring and autumn a much longer time is required. The young larvæ are a pale yellow color, but soon assume a greenish tinge, and are marked with dark spots which become more distinct after the first moult, when they become marked like the fullgrown caterpillars, being more or less striped with black. During the early season the greenish caterpillars predominate, but later the black stripes become heavier and the darker forms prevail. The appetites of these caterpillars are only too well known to the cottongrower. At first they are content with eating only the under surfaces of the leaves, occasionally piercing through. Then the leaves commence to look ragged, and when they

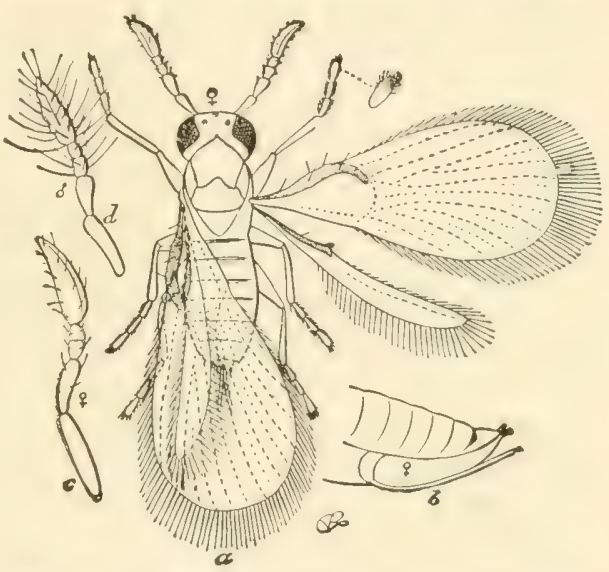

FIG. 193.-Cotton-worm egg parasite (Pentarthron minutem): $a$, adult female, greatly enlarged; $b$, ovipositor; $c$, female antenna; d, male antenna. (From Fourth Rept. U.S. Entom. Comm.)

become scarce the tender twigs and buds are attacked. When they are excessively abundant the larvæ develop cannibalistic tendencies, like the boll worms, and often feed upon the weaker caterpillars. The larvæ become full grown in from one to three weeks, during which time they moult some five times.

When mature the caterpillar crawls into a folded leaf, which is often so eaten away that the pupa hangs exposed, and there spins around it a thin silken cocoon and transforms to the pupa, in which state the insect remains dormant for from one to four weeks, when it emerges as an adult moth. 
The moth is a dull olive-gray color with a wing expanse of about $1 \frac{1}{3}$ inches, which sometimes have a purplish lustre, and which are marked with darker lines as shown in Fig. 191. Like most of the owlet moths it flies only after sunset, but unlike them, it is not confined to the nectar of flowers for food, as its mouth is peculiarly adapted to piercing the skin of ripe fruit and feeding upon its juices. Injury by the cotton worm moth to ripened peaches is frequently noticed in the peach orchards of West Virginia and regions farther north. The moths are strong fliers, those of the later broods being frequently found as far north as Canada.

The first two generations develop rapidly and in the extreme South the moths emerge by early April and are carried northward by the prevailing winds. Eggs deposited by them give rise to a brood of moths which in turn fly farther northward, and thus the worms are gradually found throughout the whole cotton belt, though with a considerable confusion between the various generations. At least seven generations occur on the Gulf Coast, and three at the northern limit of the species. Considering the number of eggs laid by each female and this number of generations, it may be readily perceived how such immense numbers of the caterpillars may arise by the latter part of the season, in a region where practically none remain over winter. If none was killed, the progeny of a single moth after four generations would amount to over $300,000,000,000$ individuals, or if placed end to end, the third generation would be enough to encircle the earth at the equator over four times.

Enemies.-It is thus very fortunate that there are many deadly enemies of the cotton worms, which commence their warfare upon them with their first appearance in spring and continue it with increasing ardor throughout the season. One of the most effective of these is a minute little insect, Trichogramma pretiosa, which develops within the eggs. Mr. H. G. Hubbard once observed that in Florida from 75 to 90 per cent of the fourth brood of eggs were destroyed by this parasite, while only three or four eggs in a hundred esciuped in the sixth brood. Another of the most useful parasites, Pimpla conquisitor, was noticed as early as 1847 to destroy nearly all of the pupie of the last brood. The eggs of the Pimpla are laid upon the caterpillar, and the 
maggots enter the worm and feed upon its juices. It changes to a pupa as usual, but the pupa soon dies, and large numbers are thus killed. Several similar parasites prey upon the cotton worm, and it is to be regretted that we know of no way of encouraging their valuable work. The common insectivorous birds eat large numbers of the worms, especially when they are scarce in early spring, and they should be protected by enacting and ,enforcing most stringent laws against their wanton destruction.

Control.-The most commonly used and effective remedy is to dust the plants with arsenate of lead. Dusting machines drawn by a team which will cover four rows at once are in common use. The dust may be applied with any of the powder guns, but it is most commonly applied to two rows at once by means of bags fastened at the ends of a pole and carried by a man on horseback, who can thus dust 15 to 20 acres per day. These sacks are about 10 inches long by 4 inches in diameter, open the whole length on one side and firmly sewed at the ends. Eight-ounce Osnaburg is the best cloth for the purpose. A strip of oak or strong wood about $1 / 2 \times 2$ inches, and 5 feet long, has a 1 -inch hole bored through it 5 inches from each end, and to this the sack is tacked, fastening one of the edges of the opening to each of the narrow sides of the pole. The sacks are filled through the holes in the pole. When freshly filled a slight jarring will shake out a sufficient amount of the poison, but when nearly empty the pole should be frequently and sharply struck with a short stick or spaces will be missed. The poison has been found most effective without the admixture of flour, but if it is used, lighter cloth should be used for the sacks.

Besides the general use of poisons there have been several important factors which have aided in the control of the cotton worm, so that it is by no means as much of an enemy of the cotton crop as formerly. Among the most important of these, both from an entomological and general agricultural standpoint, is the diversification and rotation of crops, now coming to be more and more practiced by the progressive agriculturists of the South, This alone largely prevents the rapid spread of the pest. Since the seed has become such a valuable product of cotton, smaller varieties with many seeds and a short fibre are being grown. in contrast to the rank-growing, long-fibre sorts formerly pre- 
ferred. Thus the rows are more open, the work of the worms is more readily detected and the poison more easily applied.

\section{Other Caterpillars Injuring the Foliage}

Several of our common caterpillars which ordinarily feed upon various weeds frequently attack cotton foliage in restricted localities and do more or less serious damage. They may be readily controlled by keeping down the weeds upon which they normally feed and multiply and by dusting the foliage as for the cotton worm as soon as they are noticed upon the cotton in any numbers.

Among the more common of these leaf-eating caterpillars is the Garden IVebworm* (see page 363), which may be recognized by the fine silken web which it spins over the young plants. Another is the White-lined Sphinx Caterpillar, $\dagger$ a yellowishgreen caterpillar with black eye-spots and faint stripes, varying to blackish with yellow spots, and distinguishable from most other cotton caterpillars by the horn, characteristic of sphingid caterpillars, at the tip of the abdomen. The Salt-marsh Caterpillart which is one of our best-known "woolly bear" caterpillars, covered with black and red hairs, has frequently stripped cotton of foliage in Texas, as does the Fall Army Worm (see page 114), when it becomes locally overabundant. Nany other species might be mentioned which do more or less local injury.

\section{The Cotton Square-borer $\S$}

Just as the cotton squares commence to form they are often bored into by a small green caterpillar which many planters consider a stage of the bollworm and which otliers have called the "sharpshooter." This injury is often quite serious on a small area, as we have seen 10 per cent of the stalks entirely denuded of squares in sinall fields in Texas where this insect was abundant. The little caterpillars hollow out the squares in the same manner as does the bollworm, often destroying all of those on a plant knee-high and even boring into the tender stalk. The caterpillars are bright green, oval, decidedly flattened, covered with short hairs which give them a velvety appearance, and with

\footnotetext{
* Loxostege similalis Guen. Family Pyralide.

† Deilephila lineata Fab. Family Sphingidoe.

$\ddagger$ Estigmene acræa Drury. Family Arctiide.

§ Uranotes melinus Hbn. Family Lyconidre.
} 
the head retracted under the front of the body, thus being quite unlike any stage of the bollworm. They are the larvæ of a dainty little butterfly (Fig. 194), of a bluish-black color, with dark reddish lustre, and with bright red spots on the posterior border of the hind wings, common around cotton-fields. The small yellowish, transparent eggs are laid on the leaves and stems of cotton, cow-peas, goatweed, and various weeds, and the larvæ have also

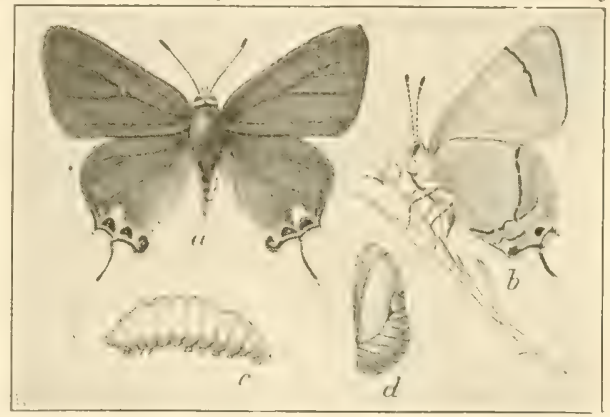

Fig. 194.-The cotton square-borer (Uranotes melimus Hbn.): $a$, adult ; $b$, underwing of same; $c$, larva; d, pupa-natural size. (After Howard, U. S. Dept. Agr.) been found on hops, beans and cow-peas, seeming to prefer the latter to cotton. The eggs hatch in from two to five days, the larvæ become grown in a little over two weeks, and the pupal
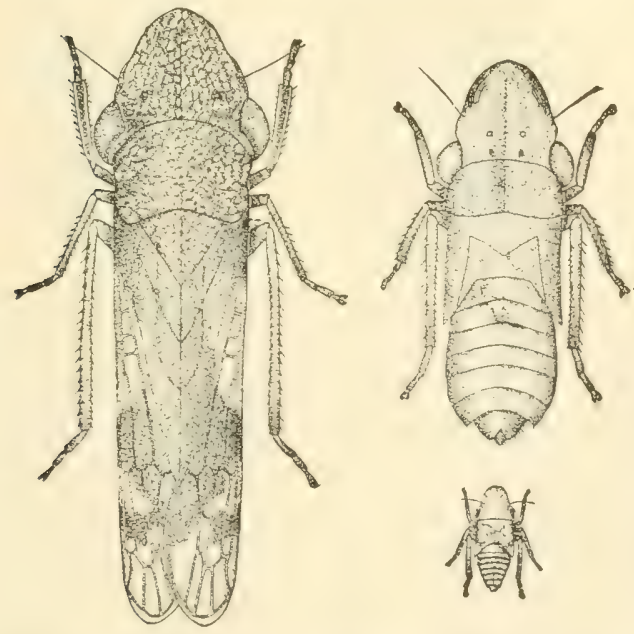

FIG. 195.-The glassy-winged sharpshooter (IIomalodisa triquetra Fab.): adult at left, last stage of nymph at right, young nymph below -all enlarged. (Author's illustration, $U$, S. Dept. Agr.) stage averages about ten days, so that the whole life cycle requires about a month in Central Texas, where there are three or four generations in a season.

Fortunately for the planter the large majority of the caterpillars are parasitized, over 90 per cent of the June generation having been thus destroyed.

Usually, therefore, it is hardly worth while to attempt to combat this insect, as it is not 
often seriously injurious year after year. Should remedial treatment be necessary, thorough dusting with Paris green or arsenate of lead would probably destroy most of them, as the young caterpillars, like the bollworms, feed to some extent upon the foliage before entering the squares.

\section{"Sharpshooters" or Leafhoppers *}

In late summer reports are frequent that cotton is being injured by "sharpshooters," especially on low land. These insects are reported to puncture the squares and bolls, causing them to

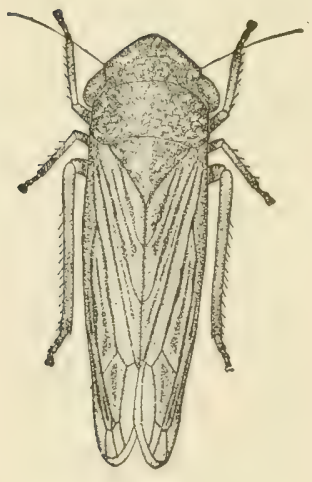

a

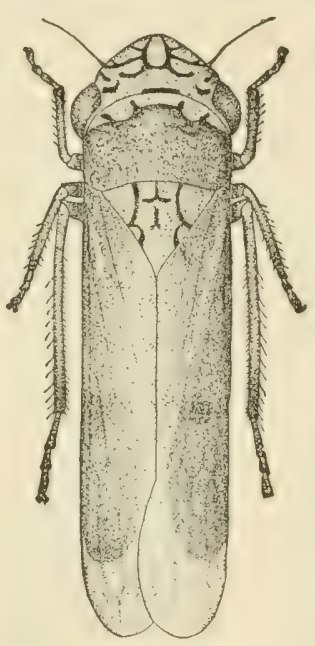

$b$

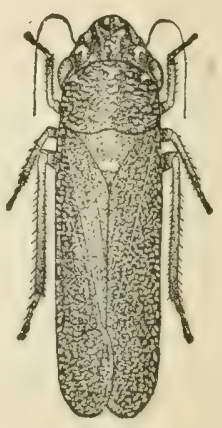

Fig. 196.-.Three cotton leafhoppers commonly called sharpshooters: a, Aulacizes irrorata; b, Oncometopia undata; $c$, Oncometopia lateralismuch enlarged. (Author's illustration, U. S. Dept. Agr.)

drop 'prematurely, a small black speck showing the spot where punctured. The insect which has been most commonly credited with this work is the Classy-winged Sharpshooter, $\dagger$ but with it are usually associated several near relatives with similar habits. $\ddagger$ Few planters are able to identify the cause of the supposed injury, but many know these insects as "dodgers," from their habit of quickly dodging to the opposite side of the stem when disturbed. Extensive observations and repeated experiments during two seasons

* Family Jassidae.

† Homalodisca triquetra Fab.

† Oncometopia undata Fab., O. lateralis Fab., and Aulacizes irrorata Fab. 
failed to show the slightest evidence that these insects are ever injurious to cotton, though they are common upon it, the supposed injury being undoubtedly due to the physiological condition of the plant which causes a shedding of the fruit at the season when the supposed injury occurs.

The adult insects hibernate in rubbish on the ground near the food-plants and appear in early spring on the elm, hackberry, redbud, cottonwood, willow, and the tender shoots of other trees, especially on bottom-land near streams. Here they suck the juices of the tender leaves and deposit their eggs in them. The eggs are laid in rows of ten to fifteen, side by side, just under the

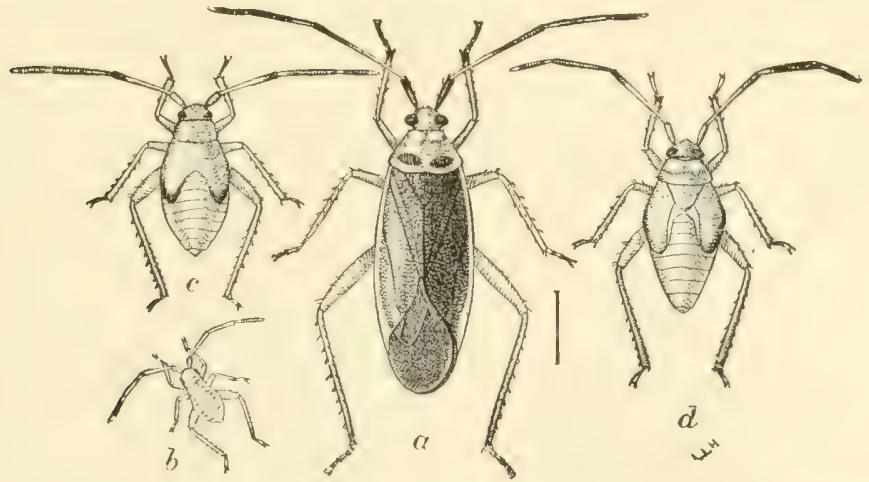

FIG. 197.-The cotton leaf-bug (Calocoris rapidus): $a$, adult; $b, c, d$, stages in growth of nymph; and cotton boll, showing spots injured by cotton leafbug all enlarged. (Author's illustration, U. S. Dept. Agr.)

surface of the leaf, forming a blister-like mark. They hatch in a few days and the young bugs, or nymphs, are grayish or yellowish in color and resemble the adults except in the lack of wings. Two or three generations occur annually in Texas, and the insects are not common on cotton until midsummer. They are exceedingly fond of banana trees, sorghum and sunflowers, sometimes doing considerable injury to the latter, but there is no evidence for considering them pests of cotton.

\section{The Cotton Leaf-bug *}

This insect was the cause of considerable damage in Northern Texas in the latter part of the season of 1904 , and had been pre-

* Calocoris rapidus Say. Family Capsido. 
viously reported as a pest of cotton, though its injury had never been general. It punctures the squares and bolls, either causing them to drop or making the bolls shrivel or decay when punctured. The feeding punctures in the bolls are indicated by small black spots, resembling diseased places, which gradually become larger and sunken, evidently due to some poisonous substance introduced by the beak of the insect as it sucks the juices of the boll. The bugs may be readily recognized from Fig. 197, and by the bright red spots just beyond the middle of the wing. The young are light green marked with red. Several generations of the insect occur annually, but its life history and habits are still unknown, and no means of combating it have been devised.

\section{Other Plant-bugs *}

Several other species of plant-bugs do considerable injury by sucking the bolls and causing them to shrink or decay.
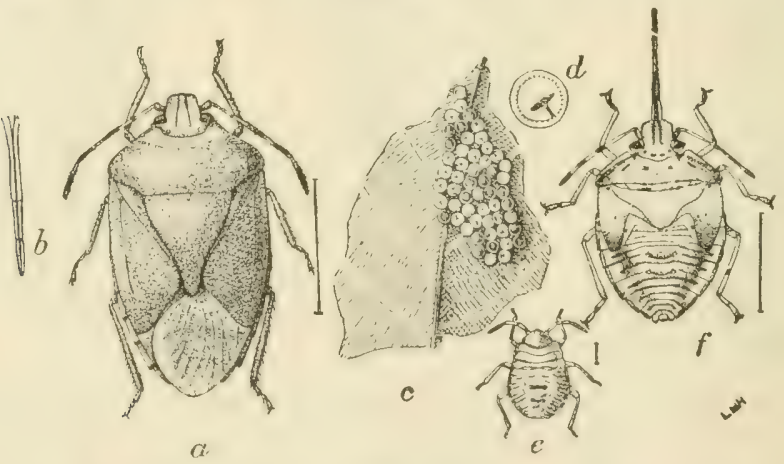

FIG. 198.-The green soldier-bug (Nezara hilaris): $a$, adult; $b$, beak; $c$, eggs. $d$, end of egr more enlarged; $e$, young nymph; $f$, last stage of nymph. (After Chittenden, U. S. Dept. Agr.)

Among these are the so-called "pumpkin-bugs" or "stink-bugs," of which a large green species $\nmid$ is the most commonly injurious, while the blackish, leaf-footed plant-bugs, $\ddagger$ which are more abundant on cucurbs, do similar injury.

* See A. W. Morrill, Plant-bugs Injurious to Cotton Bolls. Bulletin 86, Bureau of Entomology, U. S. Dept. Agr.

† Nezura hilaris Say. Family Pentatomida.

$\ddagger$ Leptoglossus oppositus Say. Family Coreido. 


\section{"Cotton-stainer" *}

The cotton-stainer or red-bug is stated by Hunter to be the most important cotton pest in Florida. It occurs in small numbers in Georgia, South Carolina and Alabama, but does practically no injury there. The principal damage is due to the bugs puncturing the bolis in feeding and staining the lint a brownish color. This stain seems to arise from the injured seed, at least it is most noticeable around the seed. The cocklebur seems to be the most important of the native food-plants, though the bugs feed on the night-shade and Hibiscus and sometimes attack oranges.

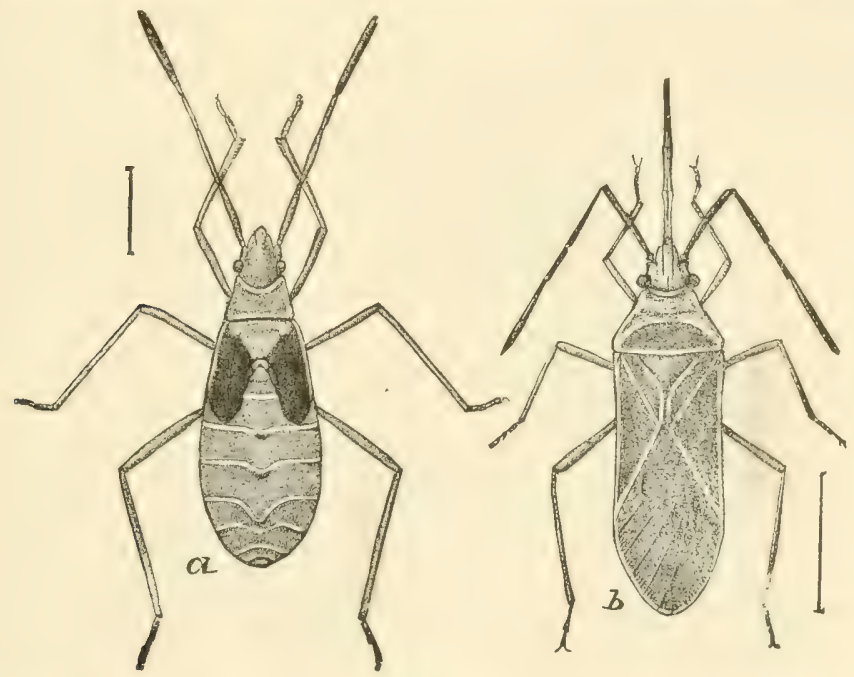

Fig. 199.-The red bug, or cotton-stainer (Dysdercus suturellus) enlarged. $a$, nymph; $b$, adult. (From "Insect Life.")

Prevention of the growth of these weeds is therefore of importance. As the bugs usually assemble in colonies, their red color may be easily observed and they may be jarred from the foliage into buckets containing water covered with a film of kerosene. In the fall and winter these insects assemble in numbers on piles of cotton seed, which may thus be used as traps and the bugs killed with kerosene or hot water.

* Dysdercus suturellus H. Schf. Family Pyrrhocorida. See W. D. Hunter, Circular 149, Bureau of Entomology, U. S. Department of Agrieulture. 


\section{The Cotton Bollworm *}

One of the most destruetive and widespread pests of eotton is the bollworm, the same insect as the carworm of corn already described, which should be consulted for the life history and description. Throughout the cotton belt the moths of the third generation appear about August 1st. At that time the ears

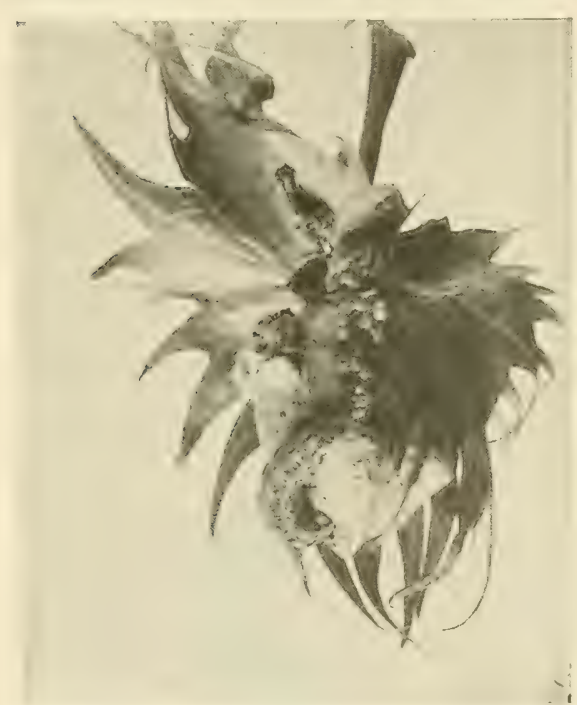

Fig, 200.-Bollworm at work on cotton bolls, boring into grown boll-slightly reduced. (AfterQuaintance and Brues, U.S. Dept.Agr.) of corn have become too hard to furnish suitable food for the larvæ and the moths therefore lay their eggs on the cotton leaves, though if any late corn is in silk it is decidedly preferred. Thus during the month of August the cotton is often seriously injured by the caterpillars boring into the bolls, this injury being most serious in recent years west of the Mississippi and particularly in north Texas and Louisiana. The total damage to cotton is estimated at upward of $\$ 10,000,000$ per annum. Though more or less damage is done by the fourth generation of worms, injury is rarely serious, as the numbers are greatly reduced by parasites and unfavorable weather conditions.

About two-thirds of the eggs on corn are parasitized by a tiny little insect hardly visible to the naked eye, $\uparrow$ which becomes so abundant late in the season as effectively to check the increase of the pest.

Wasps are effective enemies of the bollworms, provisioning their nests with them. Several species of tachina-flies parasitize

* Chloridea obsoleta Fab. Family Noctuider. See Farmers' Bulletin No. 290, U. S. Dept. Agr., by F. C. Bishop and C. R. Jones and Bulletin 50, Bureau of Entomology, U. S. Dept. Agr., by A. L. Quaintance and C. T. Brues.

† T'richogramma pretiosa Riley. 
the caterpillars, while not a few are killed by a bacterial disease. One of the most important natural factors in reducing their numbers, however, is their own tendeney to camnibalism, the larger caterpillars attacking and destroying the weaker with a consequent marked reduction in numbers.

Control.-As in protecting corn from this pest, the most effective means is the plowing of the land containing the pupx in winter or late fall.

Early planting of early fruiting varieties of cotton, with a . liberal use of fertilizers, and frequent cultivation, so as to hasten the maturity of the crop, will result in a good crop being made bef ore the worst injury by the bollworm occurs. These cultural measures ensure the best crops even where there are no insects to be avoided, and as an early crop is less in jured by almost all cotton

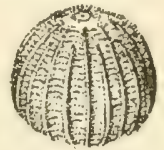

FiG. 201.-Egg of bollworm; side and top views. Highly magnified (From Quaintance and Brues, U.S. Dept. Agr.) insects, the planter should adjust his methods to secure earliness.

As the eggs are laid mostly on the cotton leaves and the little

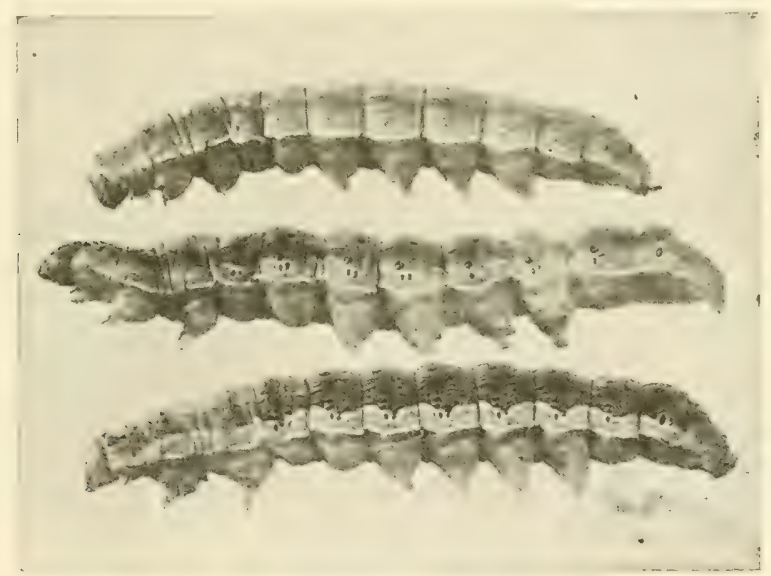

FIG. 202.-Bollworms showing variation in color, upper larva green, middle rose, and lower, dark brown-twice natural size. (After Quaintance and Brues, U. S. Dept. Agr.)

caterpillars nibble the surface before boring into the bolls, the poisoning of the foliage when the eggs are hatching will result in a very material reduction of the subsequent injury. Paris green 
has been most generally used, but recently powdered arsenate of lead has been found superior to it. Arsenate of lead is used at the rate of 2 to 5 pounds per acre, applied either pure or diluted with lime or flour, using either a bag and pole, hand powder-gun or geared dusting machine. The dusting should be done while the plants are wet with dew. When not followed immediately by rain, two applications should be sufficient, the first when the eggs commence

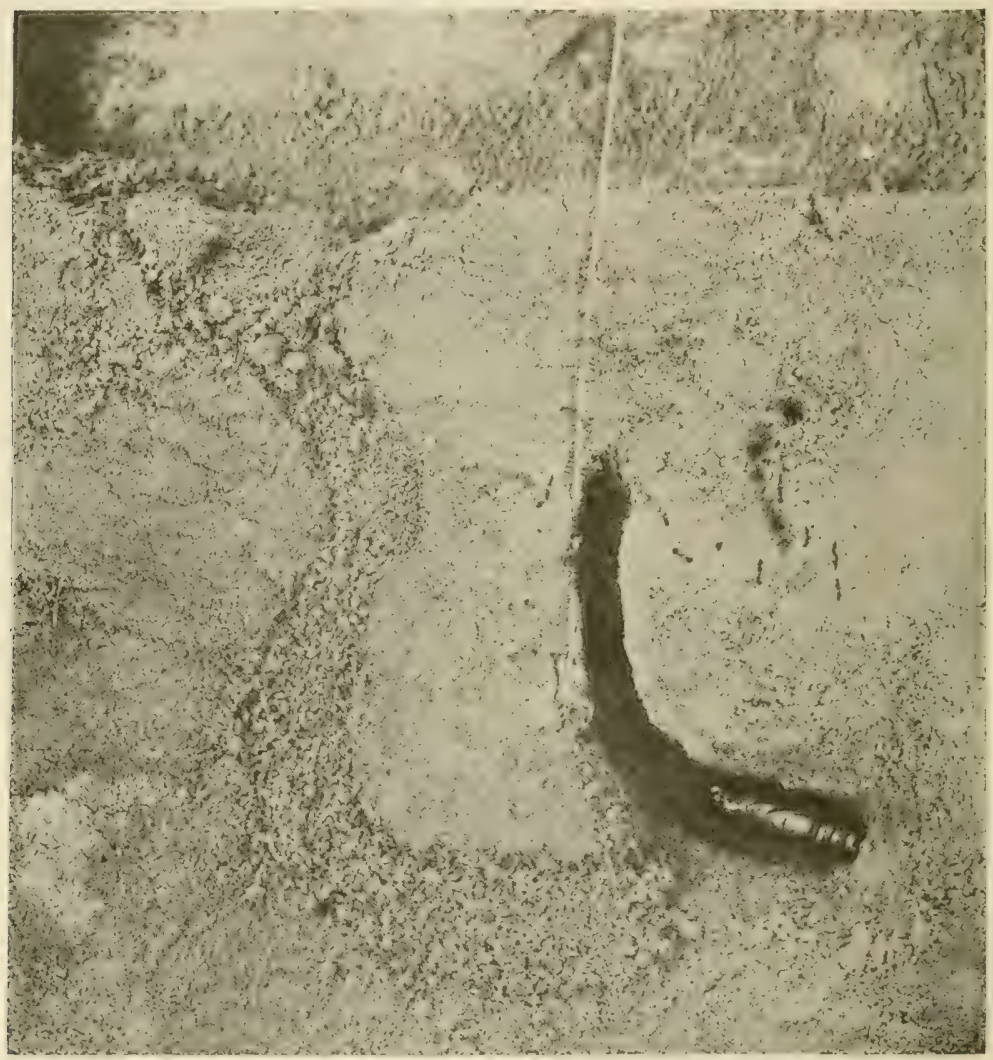

FIG. 203.-Pupa of the bollworm in its burrow in the soil, showing burrow made by the larva and filled in, and the exit burrow for the moth also made by the Jarvi-natural size. (After Quaintance and Brues, U. S. Dept. Agr.)

to hatch in numbers, usually between July 25th and August 5th, and the second about a week later. If rains follow, the applications should be at once repeated. 
Inasmuch as the moths prefer to lay their eggs on corn-silk, cotton may be very effectively protected by the use of strips of late corn and cow-peas, planted through the cotton so as to act as a trap crop. Leave vacant strips four or five rods wide across the fields when planting cotton. About June 1st plant these with alternate rows of Mexican June corn and cow-peas. This will bring the corn into silk about the first of August and will attract the moths to lay their eggs upon it instead of the cotton, while the cow-peas will furnish both food and shelter to the moths. Corn should never be planted with cotton when cotton is planted, for instead of acting as a trap crop it merely furnishes food upon which the worms multiply during the early season and forces those of the third generation to the cotton. The strips of corn and peas should be cut as soon as the worms on them become fairly grown and the land plowed

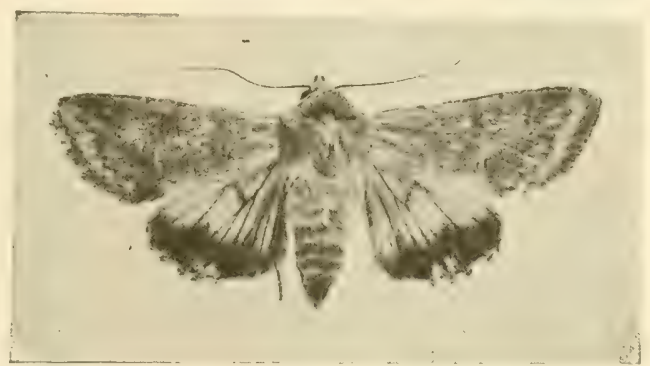

Fig. 204. - The moth of the bollworm or corn earworm-enlarged one-fourth. (After Quaintance and Brues, U. S. Dept. Agr.) to destroy any which may have pupated. " On large plantations the planting of small areas of corn here and there in the fields is practicable. Such early crops as potatoes, oats, or wheat may be followed by corn and cow-peas with practically the same results."

\section{The Cotton-boll Cutworm *}

The larva of this species is a very common feeder upon the foliage of cotton and late in the season bores into the bolls in much the same manner as the bollworm. Cotton is but one of a long list of food-plants, however, as it is a common pest of sugar-beets, corn, wheat, cabbage, potato, asparagus, salsify, peach, raspberry, violet, cucumber, tomato, turnips, pea, rape, pigweed, cottonwood, and grasses according to Chittenden. It occurs commonly throughout the states east of the Rocky Mountains.

* Prodenia ornithogalli Guen. Family Noctuida. See Sanderson, I.c., and F. H. Chittenden, Bulletin 27, n. s., Div. Ent., U. S. Dept. Agr., p. 64. 
The moth has a wing expanse of about $1 \frac{1}{2}$ inches, the forewings being a dark, rich, velvety brown, marked with black, yellow and ochreous as shown in the illustration, while the hindwings are a light gray. The grown caterpillar is $1 \frac{1}{2}$ to $1 \frac{3}{4}$ inches long, and is quite variable in coloration, some being much darker than others, as shown in the illustration. The three whitish lines and the double row of triangular brown spots along the back of the lighter forms will easily distinguish this caterpillar from the bollworm.*
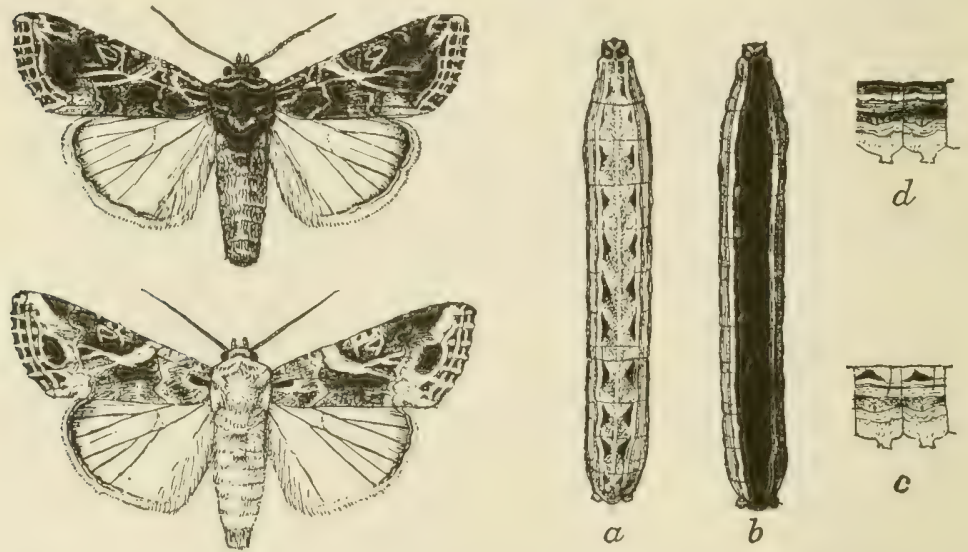

FIG. 205.-The cotton-boll cutworm (Prodenia ornithogalli Guen.): dark form of male moth above; pale form, female moth below; $a$, pale form of larva; $b$, dark form of larva; $c$, lateral view of abdominal segments of jale form; $d$, same of dark form. (After Chittenden, U. S. Dept. Agr.)

Life History.-The life history has not been carefully observed in the North, but from observations made by the writer in Texas the life history in the Gulf States seems to be as follows:

The winter is usually passer in the pupal stage in the soil, though possibly a few moths, emerging late, hibernate. The first brood of moths appears from the middle of May until the middle of June, mostly carly in June. A second brood appears during the latter half of July, and a third late in August and during September. A few of the fourth brood may emerge in December, but most of them do not do so until the very early spring, when they lay eggs upon various weeds on which the larvæ feed

* see Chittenden, 1.c., 1), 36, for distinguishing characters of related species of Prodenia. 
until cotton appears. The length of time occupied in the different stages is seen to be quite variable, but is approximately six days for the egg, twenty days for the larva, and thirteen days (usually ten to fifteen days) for the pupa-making a total of about forty days for the complete life cycle. Dr. Chittenden believes that there are two generations in the North and probably three in the latitude of the District of Colımbia.

Control.-This species has not been sufficiently injurious on cotton to warrant extensive experiments in its control. Where it attacks young plants of cotton or other crops, it may be combated with the means suggested for other cutworms. Where it becomes injurious to the bolls, it might be controlled by thorough dusting or spraying with arsenicals, which would destroy the young larvæ while they are still feeding on the foliage.

\section{The Mexican Cotton Boll Weevil *}

Not since the invasion of the Mississippi Valley by the Rocky Mountain locusts in the 70's has any insect caused such ruin

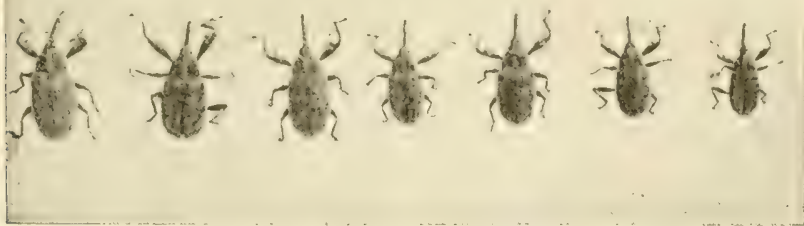

Fig. 206.-The cotton boll weevil, natural size, showing variation in size and color.

to any staple crop as has the boll weevil in the territory affected during the past twenty years, and it is one of the factors in the recent high prices of cotton.

Like several of the worst insect pests of the South it is a native of Central America and came to us from Mexico, crossing the Rio Grande at Brownsville, Texas, about 1890. As early as 1862 the weevil caused the growers at Monclova, Mexico, to abandon cotton culture and when they again planted it in 1893, the beetle promptly appeared and destroyed the entire crop. It multiplied

* Anthonomus grandis Boh. Family Curculionilas. See W. D. Hunter. "The Boll Weevil Problem," Farmers' Bulletin 848, U. S. Dept. Agr.; and Hunter and Hinds, Bulletin 51, Bureau of Entomology, U. S. Dept. Agr. 
rapidly in south Texas, ruining the crops, and by 1895 had spread northward to a line extending eastward from San Antonio. Since then it has spiead northward and eastward, about sixty miles a year, until in 1905 it had covered all of Texas and western Louisiana and is now found almost throughout the cotton area where weather conditions permit.

In 1904, after an exhaustive study of all available data, the writer estimated the loss in Texas alone at $\$ 25,000,000$, and

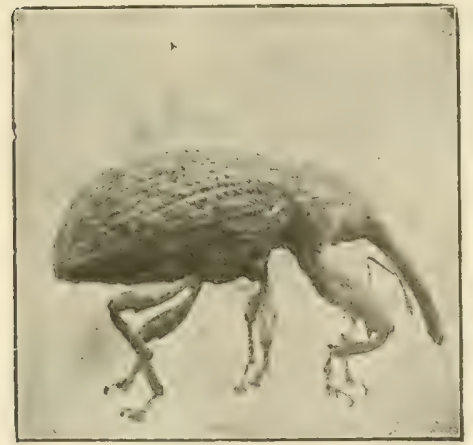

Frg. 207.-The cotton boll weevil- ritory affected enlarged. that the pest had then cost the Ståte $\$ 100,000,000$. Owing to decrease in acreage and the general use of methods for preventing or avoiding injury, the injury has not increased proportionately to the spread of the pest, but the total annual loss is at least as much as in 1904, though no accurate estimates have been recently made for the whole terLife History. - The parent insect is a small brownish beetle about one-quarter inch long, varying from one-eighth to one-third, including the snout, which is about half as long as the body. Recently emerged weevils are light yellowish in color, but they soon become grayishbrown and later almost blackish. There are many nearly related weevils which very closely resemble the boll weevil, and only an entomoligist can identify the species with eertainty, but the two teeth at the tip of the femora of the fore-legs (Fig. 207), are the most characteristic structure by which it may be distinguished. The boll weevil feeds only upon cotton, and weevils found feeding on other plants are certainly of other species.

However, there has recently been discovered in Arizona an insect which very closely resembles the boll weevil and which has been classed by authorities as merely a geographical variety of the true boll weevil and named Anthonomus grandis thurberiae; the Arizona wild cotton weevil, which feeds on a wild cotton (Thurberia thespesivides) found growing in that region. This 
would make it seem probable that the true boll weevil might feed on the wild cotton plant as well as on the true cotton.

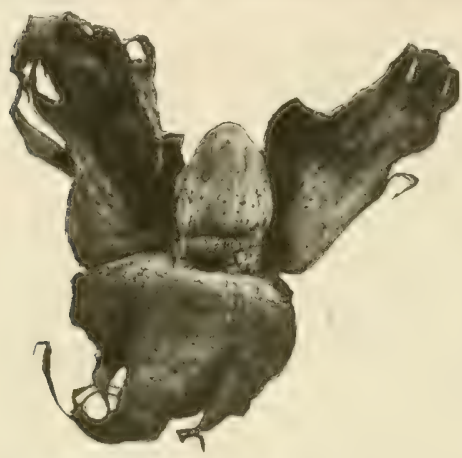
FIG. 209.-Cotton square with bracts
opened to show weevil at work on the bud, which shows a feeding puncture.

The weevils commence to emerge from hibernation soon after cotton is up and continue to emerge until the cotton commences to square freely. During the spring the beetles feed on the foliage, particularly in the tender terminals, and as soon as squares are formed the females commence to lay their eggs in them. Each female lays an average of about 140 eggs, laying four or five a day. The female drills a small cavity in the square and in it deposits a small oval white egg, which hatches in about three days. The grub feeds upon the embryo flower, which usually fails to develop, and the
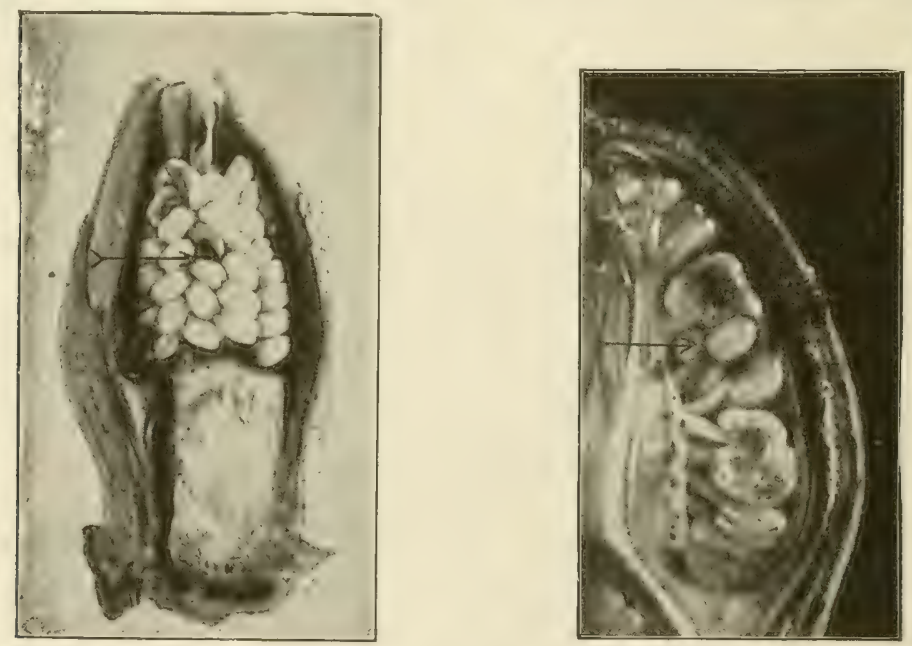

FIG. 210.-The cotton boll weevil; eggs among the anthers at points indieated by arrows, the cross-sestion at the right showing opening through which egg was deposited-greatly enlarged.

infested square generally falls to the ground. In from seven to twelve days the larva is full grown and changes to the pupa, 
which stage lasts from three to five days. Thus from egg to adult requires from two to three weeks, though climatic conditions cause considerable variation in the length of time. The larva is a footless, white grub, with brown head, which lies curled up in the square as shown in Fig. 211, where the soft white pupa is also found. The adult weevils feed entirely during the day. Their length of life depends upon various conditions, but in the summer season the majority do not live over sixty days, while during the cooler

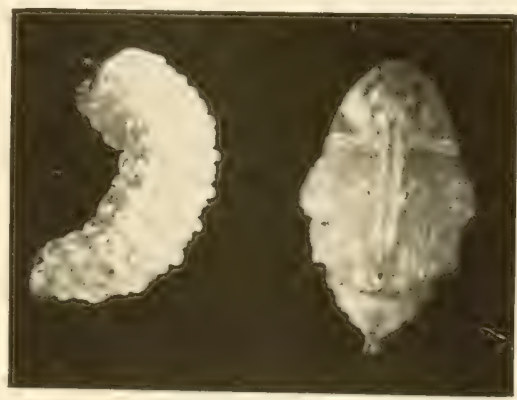

Fra. 211.-The cotton boll weevil, larva and pupa-enlarged. part of the year those which hibernate live five or six months. Many squares are destroyed by the feeding punctures of the weevils. "The males feed upon the squares and bolls without
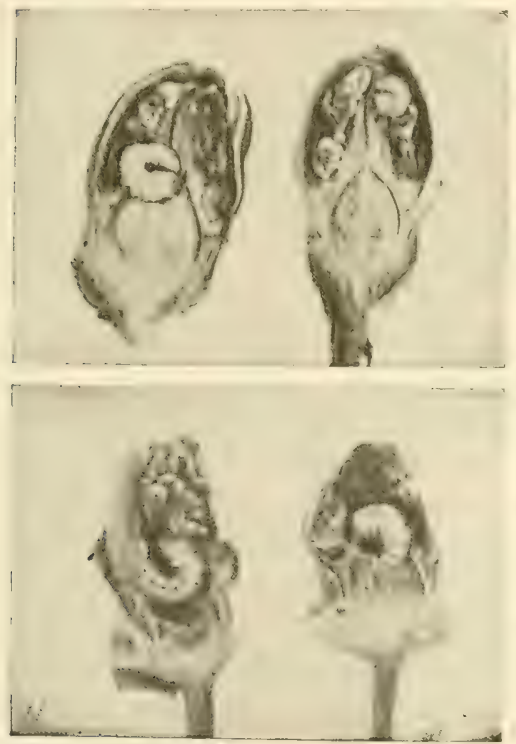

FIG. 212.-Cotton squares broken open, showing the boll weevil larva within enlarged. moving until the food begins to deteriorate. The females refrain from ovipositing in squares visited by other females. This applies throughout most of the season, but late in the fall, when all the fruit has become infested, several eggs may be placed in a single square or boll. As many as fifteen larvæ $\mathrm{h}$ ave been found in a boll. The squares are greatly preferred as food and as pla ces for depositing eggs. As long as a supply of squares is present the bolls are not damaged to any serious extent. The bolls, therefore, have a fair chance to (levelop as long as squares are being formed. When- 
ever frost or other unfavorable weather causes the plants to cease putting on squares, the weevils attack the bolls. A conservative estimate of the possible progeny of a single pair of weevils during a season beginning on June 20, and extending to November 4, is $12,755,100 . "-H u n t e r$. Although the weevil may develop from egg to adult in two or three weeks, it requires an average of about forty-three days for a complete generation and there are probably not over four or five generations in a season

With the first killing frosts, most of the immature stages developing are killed, though in south Texas they often develop

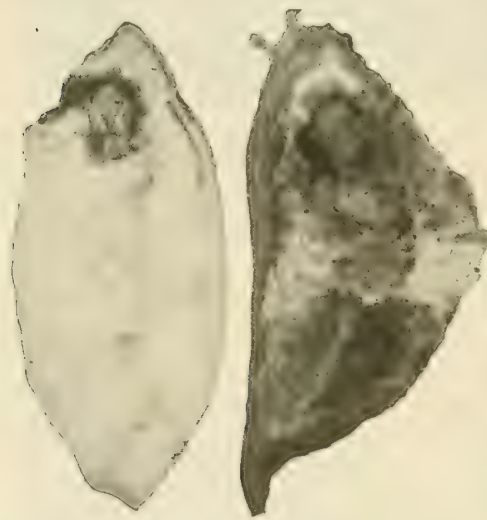

FIG. 213.-Cotton boll weevils hibernating in locks of cotton removed from old bolls left on stalks over winter. during the winter, and the adult weevils soon go into hibernation. When seeking places for hibernation the weevils migrate from field to field, and it is at this season that the principal migration of the pest takes place. The weevils may hibernate in hedges, woods, corn-fields, haystacks, or farm buildings, particularly about seed-houses or similar situations. Experiments have shown that Spanish moss forms an exceedingly favorable place for hibernation, and that many weevils pass the winter in it on trees some distance above the ground. Others may hibernate in the cotton-field, crawling into cracks, under grass, weeds, and trash, and in the empty cotton burrs, while in the more southern sections many hibernate in injured bolls. The weevils which hibernate most successfully do so outside of the cotton fields. The number which survive the winter has been accurately determined under various conditions for several seasons, and depends upon the minimum temperature, the amount of moisture, and the kind of shelter. Thus in central Texas but 2 or 3 per cent survive in many normal winters, while in the open winter of 1906-07 11.5 per cent survived; in South Texas 15 per cent may survive, and in experiments made in Central Louisiana in 1908-09 with rather favorable conditions 20 per cent survived. The 
importance of reducing the number which survive the winter is evident.

Natural Control.-If infested squares fall to the ground and lie on the unshaded, hot soil the larve or pupx within them are soon killed. As many as 40 per cent of the immature stages have thus been found dead in many fields. The importance of wide rows and varieties which produce little shade is therefore apparent, and it is evident that injury will be much less on dry upland soil, and much more severe in bottoms where the cotton grows rank and thick.

Over a score of parasites* prey upon the immature stages within the squares or bolls, and they seem to be increasing in numbers and effectiveness as they become adapted to living upon the weevil, as they are all native insects which prey upon nearly

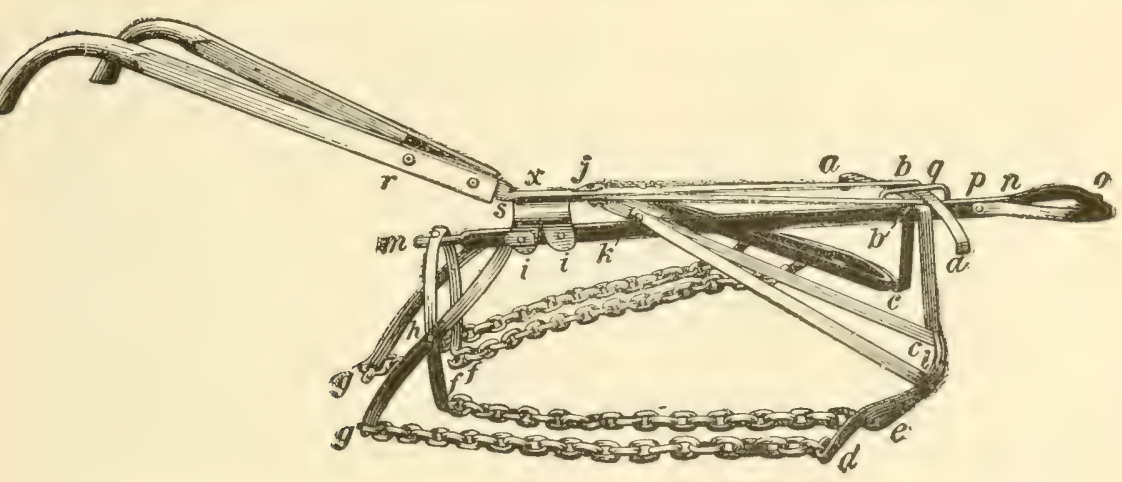

FIG. 214.-Chain cultivator for use in drawing weevil infested squares to center of row. (After Hunter, U.S. Dept. Agr.)

related species of weevils and other insects. As many as two-thirds of the immature stages have been destroyed by them in certain fields, though ordinarily not ever 5 per cent of the total are parasitized. Several species of ants also feed on the immature stages, 20 to 30 per cent of those in fallen squares and bolls often being destroyed by them. The ants destroy many more in the fallen squares than in those hanging on the plants, so that the dropping of the squares aids their good work as well as exposes the squares to the heat of the sun.

* Sce W. D Pierce, Studies of Parasites on the Cotton Boll Weevil, Bulletin 73, Bureau of Entomology, U. S. Dept Agr. 
Usually about 70 per cent of the infested squares drop, and in these 70 to 80 per cent of the immature stages are destroyed by natural causes.*

Control.-By far the most important measure in the control of the boll weevil is the destruction of the plants in the fall as

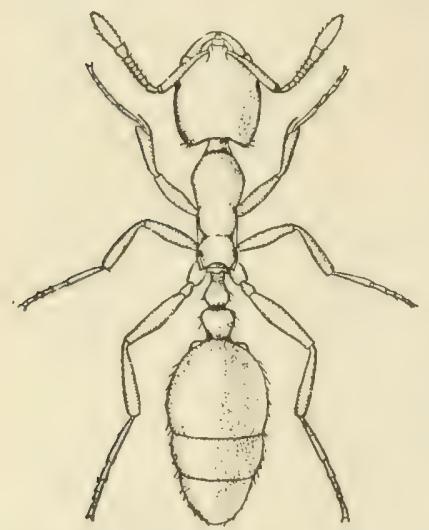

FIG. 215.-Solenopsis geminata soon as the cotton can be picked. This both detroys the weevils and prevents their increase. The stalks should be plowed out and burned as soon as possible. It is well to plow out all but a row here and there upon which the weevils will concentrate, then as soon as the piles are dry enough to burn, cut the remaining rows and burn at once. In this way the great bulk of the adult weevils and all of the immature stages in the squares and bolls are destroyed. The few escaping weevils will Fab., a native ant which is a be starved out before the weather valuable enemy of the boll becomes cold enough for them to weevil - much enlarged.

(After IIunter and Hinds, U. hibernate, or will be so weakened as S. Dept. Agr.)

to die in hibernation. Thus it has been shown by Professor Wilmon Newell, in Louisiana, that where the weevils were forced into hibernation on October 15th only 3 per cent survived the winter, but that when the destruction of the stalks was put off until after December 15 th, 43 per cent survived, with proportional numbers at intervening dates. Furthermore, the development of the late broods which furnish the majority of the weevils which hibernate is effectively prevented. The removal of the plants also facilitates winter plowing, which aids in producing an early crop the next year. Many experiments and the experience of practical planters have shown that the destruction of the stalks in the fall is of primary importance in the control of the weevil, particularly upon bottom lands. Experiments made in Calhoun County, Texas, where the stalks were destroyed on 410

* See W. E. Hinds, Some Factors in the Natural Control of the Mexican Cotton Boll Weevil, Bulletin 74, Bureau of Entomology, U. S. Dept. Agr. 
acres, showed an increase the next season of over one-quarter bale per acre as compared with ficlds where the stalks had been left standing, the benefit being worth $\$ 14.56$ per acre, or over twenty-nine times the cost of the work. It is better to plow out the stalks than to cut them, particularly in the far South, as the stalks will frequently sprout out in the late fall and thus furnish food for the late weevils, or will sprout in early spring and furnish food for those first emerging from hibernation. For the same reasons all volunteer cotton should be destroyed.

It is evident that the thorough defoliation of the plants by the cotton leafworm will secure much the same result as the destruction of the stalks, by removing the food supply of the weevil. Planters should not poison the leaf worms, therefore, when they appear during the latter part of the season in fields injured by the weevil, for though formerly much dreaded they are now a great aid in preventing the increase of the weevil in fall.

It has been demonstrated that injury by the weevil is never so severe where cotton

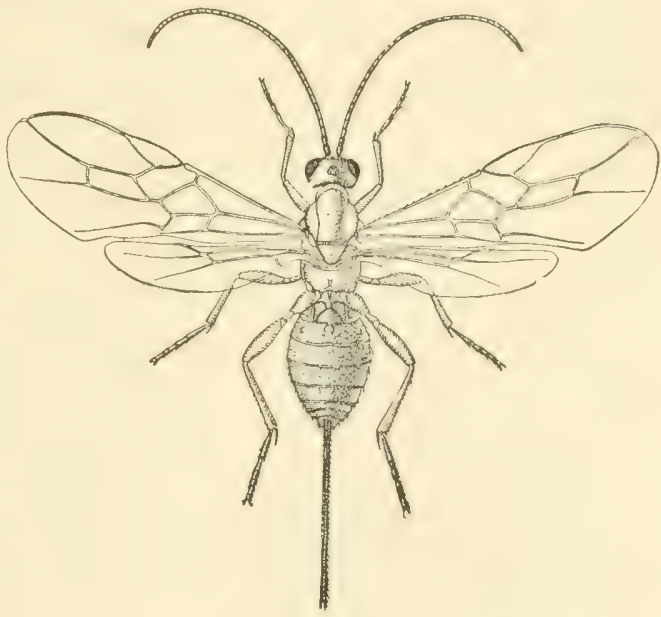

FIG. 216.-Bracon mellitor Say, one of the most important parasites of the boll weevil larva-much enlarged. (After Hunter and Hinds, U.S. Dept. Agr.)

is planted after some other crop, this being due to the fact that the weevils do not fly far from their hibernating quarters in the spring.

By hastening the maturity of the crop, injury by the weevils may be avoided by making the crop before they have become most abundant. Everything possible should therefore be done toward hastening maturity, and this will be of importance in relation to the early destruction of the stalks in the fall. Land should be plowed in the winter and a good seed bed prepared. Cotton 
should be planted as early as possible with safety. A liberal use of commercial fertilizers will hasten the growth of the crop even on fairly fertile soils, and on poor soils their use will return a handsome profit. Early varieties of cotton should be planted, among the most satisfactory being, Rowden, Triumph, Cleveland Big Boll, Cook's Improved, King, Hawkins' Early Prolific, and Simkins. Seed should be secured from the originators of the varieties as far as possible. Chop out the plants as soon as possible. Frequent light cultivation will be found of the greatest importance in hastening the crop. Deep cultivation and cultivating close to the plants should be avoided as causing the squares to shed, and the old practice of "laying by" by ruming a broad sweep down the middles should be avoided. The lightest possible cultivation to keep the surface soil stirred is the best. All of these methods which aid in hastening the maturity of the crop are commonly called "cultural methods" of preventing loss from the weevil. They are not directed againts the weevil itself, but are merely the best agricultural methods for securing an early crop, and on light upland soils attention to these methods will alone be sufficient to secure a good crop.

It has already been shown that the immature stages in squares falling on the hot soil will be killed by the heat. To aid in this the rows should be planted fairly wide apart, and varieties producing a minimum of shade are preferable as are those which readily shed their squares when injured. As most of the squares drop beneath the plants where they are shaded, any means of scraping them into the centers of the rows will aid in their destruction. For this purpose a chain cultivator as described by Hunter (1.c.) (Fig. 215) has proven very efficient for this purpose. The chains may be attached to ordinary cultivators by special attachments.

During 1909 Professor Wilmon Newell and his assistants demonstrated at several places in Louisiana that the weevil may be successfully poisoned by the use of dry or powdered arsenate of lead, though previous experiments with dry Paris green and arsenate of lead as a liquid spray had not proven of practical value for various reasons. An increase of 71 per cent of the crop was secured on considerable areas and the results were duplicated by practical planters. Professor Newell recommends that the 
poison be applied first when the first squares appear and that five applications be given at weekly intervals. The poison must be applied by hand with a powder-gun so that it is blown into the squares. The first application requires about $2 \frac{1}{2}$ pounds per acre and the last 5 to 7 pounds. Since that time there has been a very considerable amount of experimental work on boll weevil poisoning and opinions as to the value of the treatment have been variable. All authorities seem now to agree that poisoning with arsenate of lead or of calcium, applied in the form of a dust, is a valuable means of protection from the weevil, somewhat more favorable results having been secured from the arsenate of lead than from the calcium arsenate. The number of treatments and the amount of material used will vary somewhat with the infestation and local conditions but eight pounds per acre has been used with profit. Professor Newell puts special-emphasis on applying the material so that it will cover the squares, bolls and terminal buds rather than the foliage.*

\section{The Pink Bollworm †}

An insect which might become of the greatest importance to the cotton industry is the pink bollworm, now present in this country in only small areas in Texas and Louisiana and being eradicated in that area by vigorous measures prosecuted by the Bureau of Entomology of the United States Department of Agriculture, which also maintains a strict quarantine to prevent the spread, even prohibiting the growing of cotton in certain counties in order to form a barrier to progress by creating a belt where no

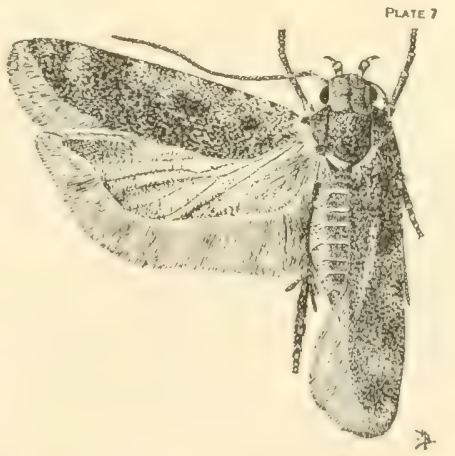
food can be secured by the insect. Fig. 217.-The pink bollworm ( $P$ 'c-

The pink bollworm is probably a native of southern $\mathrm{Asia}$ and tinophore gossypiella): adult; much enlarged. (After Busck, Jour. Agr. Revearch, Vol. IX, No. 10.1

* See Newell and smith, Circular 33, La. Crop Pest Comm., ad Newell and Bynum, Jour. Ec. Ent., Vol. 13, No. 1, 1920; also B. R. Coad, U. S. Dept. Agr., Bulletin 731.

$\dagger$ Pectinophora gossypiclla Saunders. Family Gelechiide. See W. D. Hunter, Bulletin 723, U. S. Dept. of Agr. 
is found in various parts of Asia and Africa and in Hawaii, Brazil and Mexico, having been introduced from the latter country into Texas.

The adult is a small moth of brownish color and with narrow, fringed wings. The wing expanse is never as great as one inch.

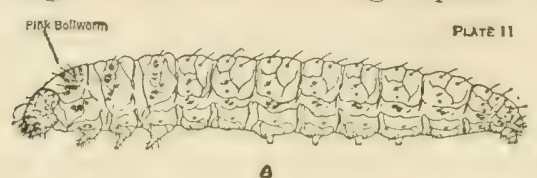

FIG. 218-The pink bollworm: outline drawing of larva, showing structure; much enlarged. (After Busck, Jour. Agr. Research, Vol. IX, No. 10.)
The larva is a small, smooth, pinkish caterpillar with eight pairs of legs and prolegs, b e ing in this respect very unlike the boll weevil larva which is footless. It feeds entirely within the bolls and even in the seeds of cotton and it is in the seeds that it is most likely to be carried from place to place.

Since it is in the process of extermination it is not necessary to do more here than to call attention to the seriousness of the insect and to repeat the warnings to cotton growers to report promptly to the Federal or State authorities the presence of any insect which might possibly be the pink bollworm.

\section{The Red Spider*}

The so-called red spider is a very minute reddish mite which attacks a great variety of cultivated plants and is frequently injurious, often being mistaken for a fungous disease and called a rust. They pass the winter mainly as adults and they breed continuously throughout the growing season of plants, migrating from plant to plant in search of food. They are found over most of the eastern part of the comtry and on the Pacific coast but are much more abundant in the cotton growing regions than elsewhere.

Leaves of badly infested plants turn yellow, wilt, droop and finally fall off.

Control measures recommended as summarized by McGregor and MeDonough, 1. c., are:

"To prevent injury to cotton by red spiders the following steps should be taken: (1) Destruction of all weeds around the

* Tetranychus tclarius Linn. IFamily Tetranychidae. Order Acarina. See MeGiregor and MeDonough, Bulletin 416, U. S. Dept. of Agr. 
farm during the winter and early spring; (2) spraying of cultivated plants around the dwellings with a contact insecticide; (3) maintaining a finely pulverized surface soil; (4) destruction of early infested plants on large areas of heavy infestation by plowing up and burning; and finally, if the infestation is more
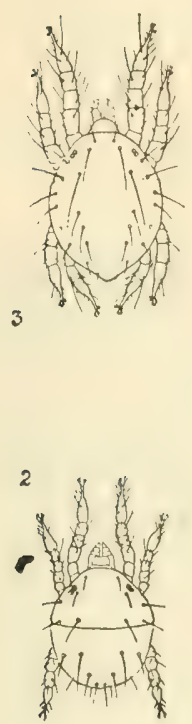
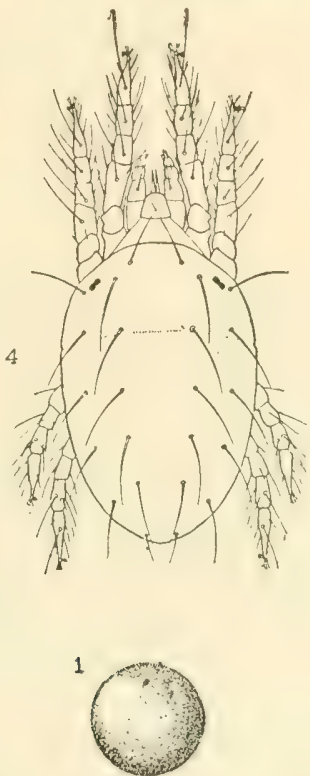

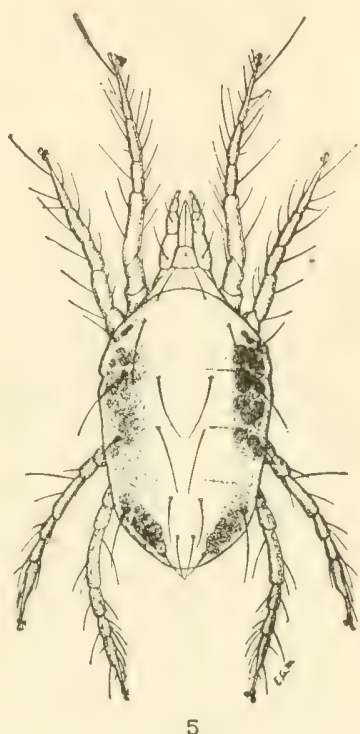

5

FIG. 219.-The common red spider (Tetranychus telarius): 1 , the egg; 2 , the newly hatched larva; $S$, the recently molted protonymph; 4 , the mature deutonymph just prior to the final molt; 5 , the adult female. Highly magnified. (After McGregor and McDonough, Bull. 416, U. S. Dept. of Agr.)

or less general, (5) spraying the cotton plants with one of the following contact insecticides: Potassium sulphide, lime-sulfur, kerosene emulsion, or a flour-paste solution." 


\section{CHAPTER XIV}

\section{INSECTS INJURIOUS TO POTATOES AND TOMATOES}

\section{The Potato Stalk-borer *}

IN some sections this insect has rivaled the famous Colorado potato-bug in the damage it has inflicted upon potato-vines. It

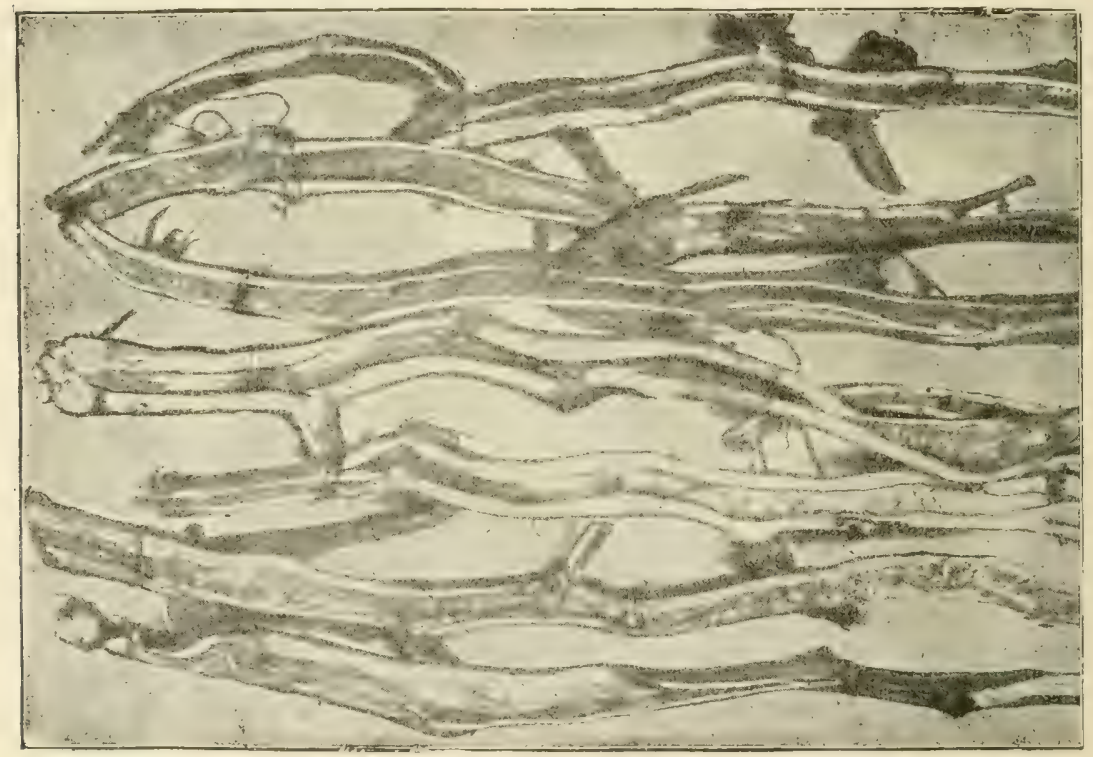

FIg. 220.-IVork of potato stalk-borer in potato-vines. (After J. B. Smith.)

was recorded as badly damaging the crop in Iowa in 1890 , and was found by Dr. Riley in Missouri as early as 1869. The beetles were first noted in New Jersey in 1895, and have been injurious in Maryland and most of the Middle States.

Life History.-The grubs, which bore into the stalks of the vines, are the larve of some small ashen-gray beetles which appear early

* Trichobaris trinotata Say. Family Curculionida. 
in spring and into June. These bectles are about one-fourth of an inch long, with a long, black beak or snout, and are marked at the base of the wing-covers by three blark spots which give the insect its specific name, trinotata. Each bectle punctures a small hole in the base of a stem by means of its beak, hollows out a small cavity, and there lays a single small, oval, whitish egg. From these eggs some small, white grubs with brown heads hatch in a few days and commence to bore into the stalk. These grubs keep eating, either in the main stalk or branches, from August 1st to September 1st, when they have become full grown. At this time the grubs are about one-half an inch long, of a dirty white or yellowish color,
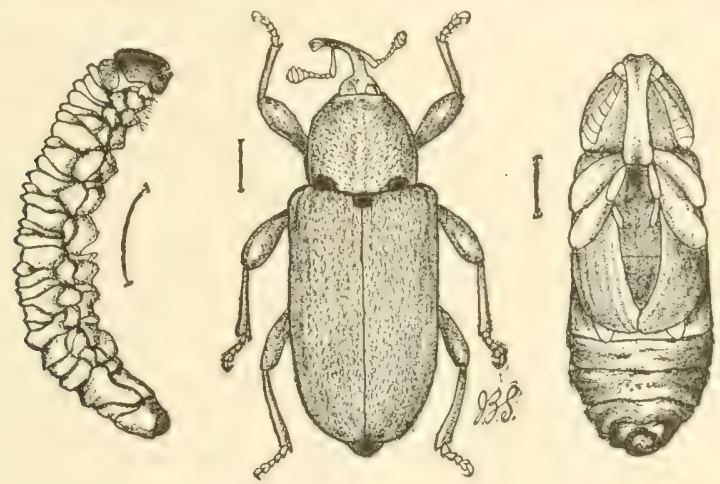

FIG. 221.-Potato stalk-borer (Trichobaris trinotata). Larva, pupa and adult. (After J. B. Smith.)

with a yellowish-brown, horny head, and without legs. About the middle of August, as a general rule, the grubs construct small, oval cocoons of chips and fibres in the stalk of the vine near the surface of the soil, and there transform to the pupæ. During late August and September the mature beetles shed the pupal skins, in which they have remained dormant for the last few weeks, but remain in the vines during the winter, and do not come forth till the following spring.

Remedies.-On account of its internal feeding habits no poison can be successfully used against this pest, and the only remedy, but a good one, is to rake up the vines and burn them as soon as the potatoes have been dug. As this insect also feeds upon the Jamestown weed, horse-nettle, and other weeds of the Nightshade family, or Solanacece, these should be eut down very closely. 
When the grubs are noticed in the plants, a good allowance of fertilizer will do much to quicken growth and thus enable them to mature a crop.

\section{The Potato Tuber-worm *}

The most serious pest of the potato in California is the Tuberworm, which in tobacco regions of the Southern States is known as the "split worm" or leaf-miner (see page 223). Not infrequently 25 per cent of the crop is lost in infested regions in California, injury occurring both in the fields and to the tubers in storage. As the pest is carried in the potatoes and breeds in storage throughout the warm winters of California, and when exported across the Pacific, it is necessary to inspect closely potatoes from infested regions. Although no injury to potatoes has occurred outside of California, and though the insect probably could not exist in the North, it may well be guarded against in the Southern States, where it is a common tobacco pest. $\dagger$

Moths which have developed from larvæ working in stored potatoes are on the wing when young potatoes are up, and lay their eggs at the base of the leaves. The young larvæ bore into the stalks, often causing the plants to wilt and die. On older plants or when the stalks harden, the larvæ leave the stalks and enter the tubers, particularly where they may be exposed. Where potatoes are exposed by being insufficiently covered the moths will lay their eggs directly upon them, as they also do upon potatoes exposed in the field after digging.

Most of the observations upon the life history seem to have been made upon the insect when breeding in stored potatoes. The eggs are about one-fiftieth inch long, oval, white, and laid singly or in pairs, about the eyes of the potatoes, or in similar rough places, where they are seen with difficulty. They hatch in a week or ten days, and the young larvæ are about one-twentyfifth inch long of a transparent white color. The larvæ burrow beneath the skin and bore into the potatoes, filling their burrows with grass and excrement, which soon give rise to various rots which cause the destruction of the tuber, already rendered unfit for food by the burrows. The larvæ become full grown

* Phthorimcea operculella Zell. See W. T. Clarke, Bulletin 135, California Agr. Exp. Sta. Also J. E. Graf Bulletin 427, U. S. Dept. of Agr,

† Recently serious injury by this insect has been reported to potatoes near Hallettsville, Texas. 
in about six or seven weeks. They are then about a half inch long. The head is dark brown; the first segment is an old rose color, with dark brown shield on the back; the second segment is a similar clouded pink; while the third and succeeding segments are a clouded white, often becoming yellowish or greenish, according to the food eaten. The full-grown larva returns to the mouth of the burrow and there makes its cocoon, or leaves it and forms the cocoon in some depression of the potato or in some crack of the storage vessel or in a fold of the bag. The cocoon is constructed quite differently from that of most moths, as described by Mr. Clarke. The larva first makes a mat of silk and then forms an outer layer to the surface of which particles of dirt and rubbish adhere so that the cocoon is well concealed. When this pocket-like cocoon is finished the larva enters it and closes the open end and in it transiorms to the pupa. The pupal stage lasts about two weeks, so that the complete life cycle requires from nine to twelve weeks, there being several generations during the year, according to the emperature.

Control.-As the insect breeds on various common weeds of the Nightshade family (Solanacex), it is important that they be destroyed wherever found. Seed potatoes must be free from the larvæ, or they will soon give rise to moths which will infest a whole field. When young plants are found wilting, the infested stalks should be cut and destroyed as soon as possible to prevent the further development and spread of the pest. Care should be taken in cultivating to hill up the soil, or thoroughly cover the tubers, so that they are not exposed. After digging, the potatoes should not be left exposed in the field any longer than is absolutely necessary and should not be covered with the tops to shade them, as is often done, as this furnishes a shelter for the moths and induces oviposition upon the tuber's. Infested fields should have the stalks and all rubbish and refuse thoroughly raked up and burned as soon as possible, or sheep and hogs may be turned into the fields to destroy the stages which may be left in the vines or in the soil. Where fields have been flooded for two or three weeks after the crop has been dug, they have been entirely freed of the pest. For the treatment of stored potatoes, fumigation with carbon bisulfide in a tight room seems to be the only satisfactory method. This should be done 
as described for grain insects (see page 187). The tubers should be fumigated as soon as stored, and the treatment should be repeated at intervals of two weeks, four or five fumigations being recommended to free the potatoes entirely of all stages. Obviously it will be important to sort over infested tubers and remove all which are materially injured to prevent the increase of rot in others.

\section{Colorado Potato-beetle *}

First and foremost among the enemies of the potato-grower stands the Colorado potato-bectle-the insect which in the early seventies, on account of our ignorance of it, was made an entomo-

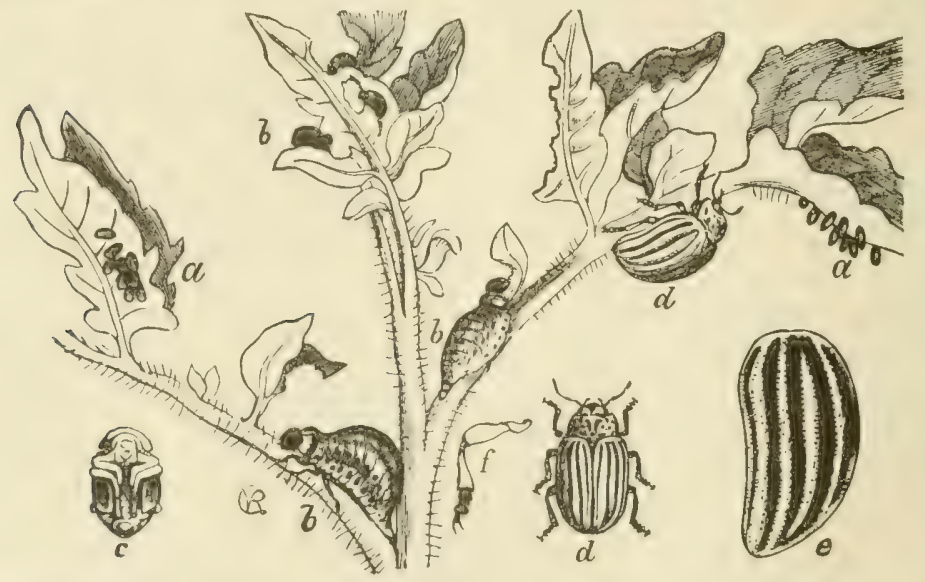

FIg. 222.--The Colorado potato-beetle (Leptinotarsa decemlineata Say.): a, eggs; $b$, larva; $c$, pupa; $d$, beetle; $e$, elytra or wing-cover of beetle; $f$, leg of beetle. (After Riley.)

logical bughear. But "there's no great loss without some small gain," and we may be thankful that the invasion of this beetle also brought about the use of Paris green, an insecticide which has since saved millions upon millions of dollars to the American farmer. Thus, with an effectual remedy which is now used where this pest occurs as regularly as potatoes are planted, "familiarity has bred contempt," and to-day we have but little fear of its attack.

* Leptinotarsa decemlineata Say. Family Chrysomelida. See F. H. Chittenden, Circular 87, Bureau of Entomology, U. S. Agr. Dept. 
History.-As is probably known to most of the older generation who watched its spread eastward, the Colorado potato-beetle, as its name indicates, was a native of the Rocky Mountain region, and until about 18.55 was satisfied with feeding upon various common weeds of the same genus as the potato-plant, principally Solanum datura, and closely allied genera. But with the settlement of this country and the introduction of the Irish potato, these bugs also began to take advantage of the fruits of civilization and transferred their feeding-grounds from the roadside to the potato-patch, and rapidly spread eastward from one to another, as well as being transported in the shipping of the potatoes.

Thus, in 1859 they had reached a point one hundred miles west of Omaha, Neb.; five years later they crossed the Mississippi into Illinois; and they advanced steadily eastward till recorled in the Atlantic States in 1874. Though slow to be introduced into some few sections of the country, it is safe to assert that this pest may to-day be found almost wherever the potato is grown in the United States or southern Canada.

Life History.-During October the beetles enter the earth and there hibernate till the warm sunshine of April or May brings them forth. As soon as the young plants appear, the female beetles deposit their yellow eggs upon the underside of the leaves near the tips, each female laying an average of about five hundred eggs during the course of a month. Meanwhile the beetles have done considerable damage by eating the young and tender plants. In about a week there hatch a horde of very small but very hungry larvæ, which fairly gorge themselves with potato-foliage and increase in size with astonishing rapidity. In two and a half to three weeks, after having eaten an amount of food out of all proportion to their size, the larve become full grown, and enter the earth, where they form smooth, oval cells, and transform to pupx. In a week or two the adult beetles

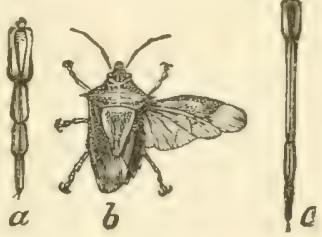

FIG. 223.- $a$, beak of predaceous bug; $b$, Podisus spinosus Dall.; c, beak of plant-feeding bug. - (After Riley.) emerge from the pupal skins and after feeding for a couple of weeks, deposit eggs for a second generation, which develops in the same way, and the beetles from which hibernate as already described. Throughout the territory where the beetles are most in- 
jurious there are two generations a year, but further south there is evidence of at least a partial, if not complete, third generation, and in the northern range of the species there is but one generation a year.

Natural Enemies.-One of the chief agencies to prevent the excessive multiplication of this pest is the weather. Thus, Professor Otto Lugger records that in Minnesota, late in the fall of 1894, the beetles were lured from their winter quarters by a few warm days, and most of them subsequently perished from hunger or frost. In addition to this during the late summer of 1894 there was an excessive drouth, so that but few of the second brood matured. Thus in 1895 there were very few of the insects to be seen.

Among the birds, the common crow, the red-breasted grosbeak, and turkeys often feed upon this pest to a considerable extent.

Probably the most destructive insect-parasite of the larvæ is a Tachinid-fly known to science as Lydella doryphoræ Riley, which

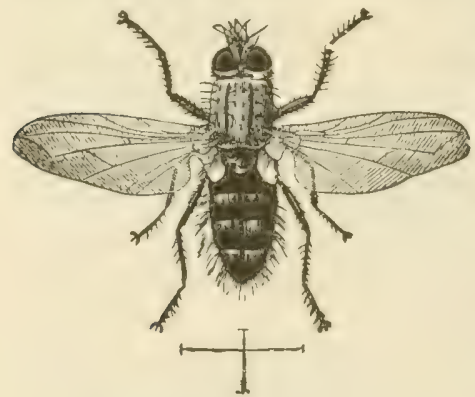

Frg. 224.-Tachinid parasite of Colorado potato-beetle (Lydella doryphore Ril.). (After Riley.) rather closely resembles the common house fly, both in size and color. A single egg is laid on a potato bug and from it hatches a small, footless maggot which burrows inside the bug. When the larva enters the earth, the effect of the maggot's work becomes apparent, and instead of transforming to a pupa and beetle, it shrivels up and dies; but the maggot itself contracts into a hard, brown pupa, from which the fly eventually emerges. Thus in 1868, when first noted by Dr. C. V. Riley, he asserted that in Missouri fully 10 per cent of the second brood and one-half of the third were destroyed by this parasite.

Many of our common lady-bird beetles and their larvæ check the pest by feeding upon the eggs. Several predaceous bugs, particularly the spined soldier-bug (Podisus spinosus Dall.) (Fig. 223) are of value in destroying the larvæ, into which they thrust their short, powerful beaks, and then suck out the juices of the body, 
leaving an emptyskin. One or two of these closely resemble the common squash-bug (Anasa, tristis De G.), but are really very dissimilar, and whereas the beaks of the predaceous forms are short and thick as in Fig. 223, a, those, of plant-feeders, like the squash-bug, are long and slender, as in Fig. 223, $b$.

Several species of ground-bcetles are often found preying upon the larvæ and beetles, but, unlike the bugs, attack them by means
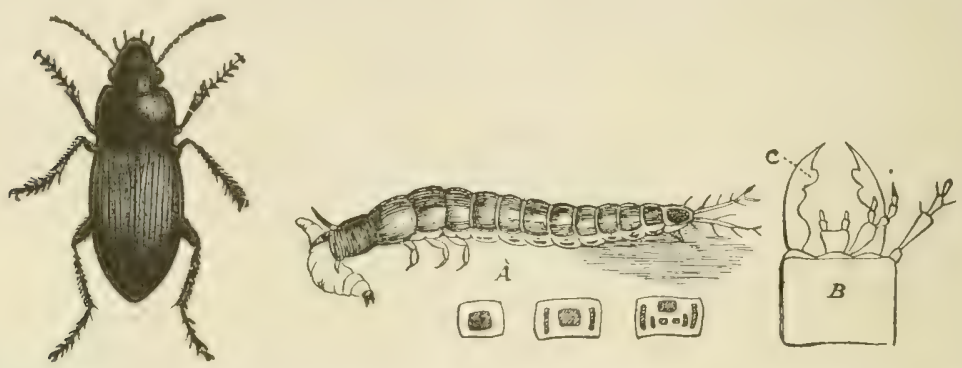

Fig. 226.-Murky ground-beetle (Harpalus caliginosus): $a$, its larva; $b$, head of larva showing mouthparts. (After Riley.)

of their powerful biting jaws. These beetles are also exceedingly beneficial in feeding upon many other injurious insects, and are among the farmers' best insect friends (Fig. 227).

Remedies. - As an artificial remedy for this pest, Paris green has long been proven to be both effectual and practical. For

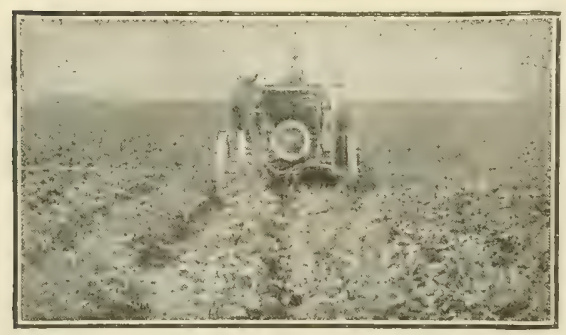

FIG. 227. - Power sprayer adapted for spraying several rows of plants at one means of which $t$ w o rows of time. Courtesy the Bean Spray Pump Co. plants $m$ a y be powdered at once. On larger areas spraying will be found more satisfactory. One pound of Paris green and 1 pound of freshly slaked quicklime to 50 gallons of water will kill all the larvæ, but often 2 to 3 pounds are necessary to destroy the beetles. 


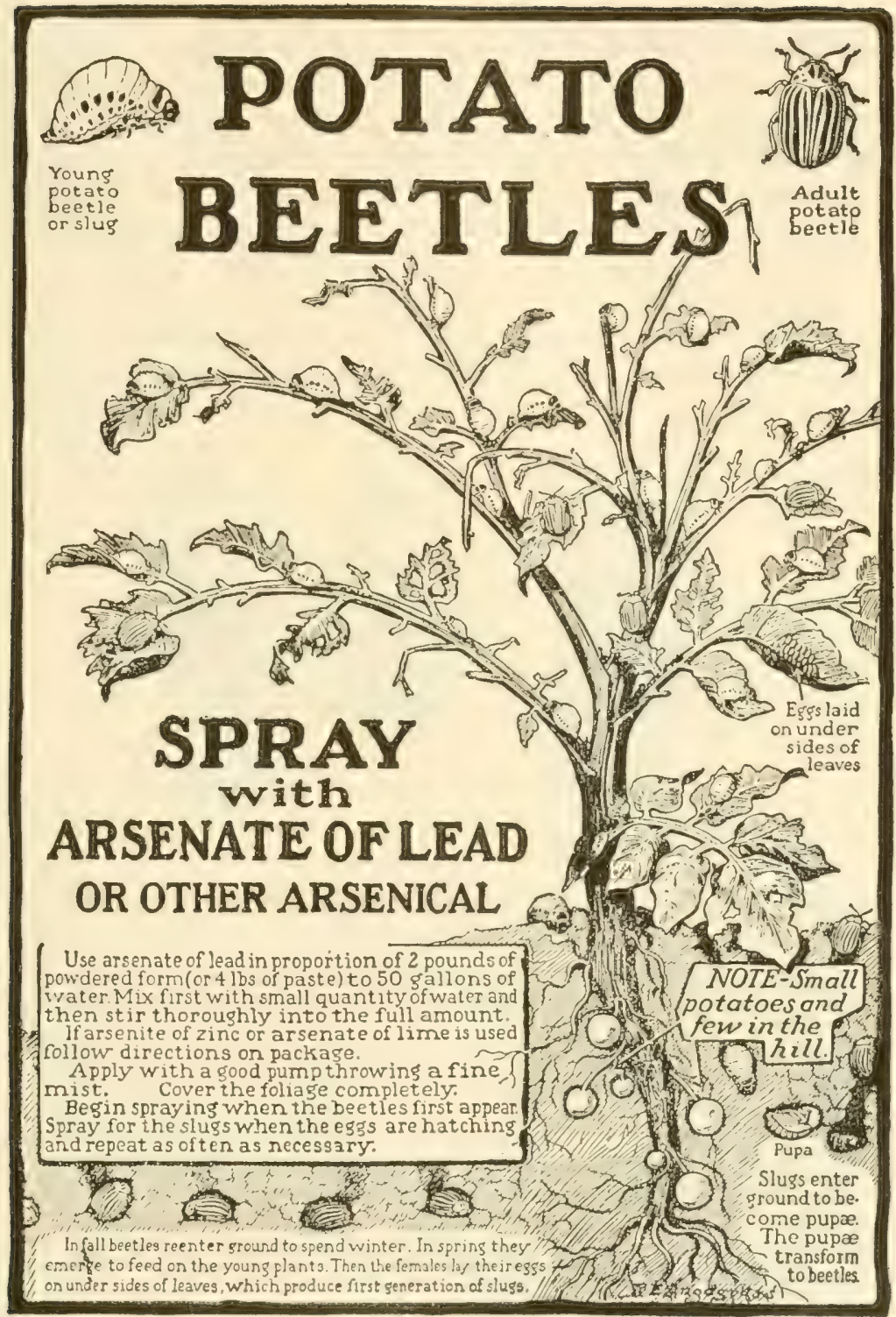

Fig. 228.-Bureau of Entomology, U. s. Department of Agriculture, popular poster on the potato-beetle. 
Many growers now prefer to use arsenate of lead at from 3 to 5 pounds to the barrel, as there is no danger of burning the foliage with it, and it is much more adhesive. Where Bordeaux mixture is not used the arsenate of lead is much preferable on account of its superior adhesiveness. Where Bordeaux mixture is used, arsenite of lime, or arsenite of lime made with soda, may be used, but these homemade arsenicals should not be used alone, on account of their burning the foliage.

The vines should be sprayed first when they are a few inches high, and the spraying repeated once or twice at intervals of ten days or two weeks. The larvæ are so easily killed by arsenicals that potato growers no longer fear their work, but large quantities
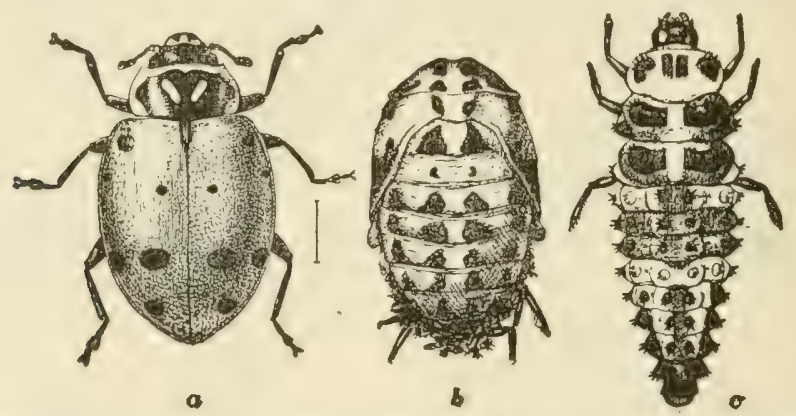

FIG. 229.-The convergent ladybird (Hippodamia convergens): $a$, adult; $b$ pupa; c, larva; enlarged. (After Chittenden, U. S. Dept. Agr.)

of Paris green are wasted by careless application, and by dusting unduly large amounts with poor apparatus, which not infrequently results in burning the foliage. For small areas a bucket or knapsack pump will be found satisfactory, but for over an acre a barrel pump with a row attachment will prove more economical, and for over ten acres a geared machine spraying several rows at once will be needed. Cleaning up the vines and plowing potato land in the fall after the crop has been harvested will aid in reducing the numbers of the hibernating beetles.

\section{Flea-beetles *}

While the potatoes and tomatoes are but a few inches high they are often attacked by myriads of small black beetles, which from

* Family Chrysomelido. 
their power of making long quick jumps are known as flea-beetles. They soon riddle the foliage, often so badly that the plants wilt, and replanting is necessary, particularly with tomatoes.

Several species are known to attack the potato, the two most common being the potato or cucumber flea-beetle (Epitrix cucumeris Harris) and one which Professor H. A. Garman has styled the Southern Potato Flea-beetle (Epitrix fuscula). The Tobacco Fleabeetle (Epitrix parvula) is not uncommonly found on the vines in sections where tobaceo is also grown, and other species do similar injury in other sections. All of these species are, however, essentially the same in habits and life history, and the same remedies apply to all.

The potato flea-bectle* is the most destructive. It is only one-sixteenth inch long, jet black, except the yellowish antennæ

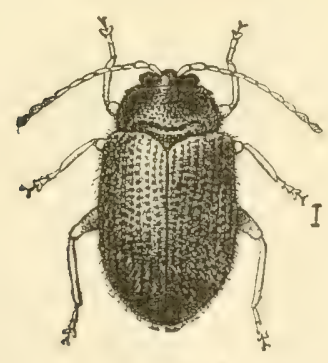

$a$

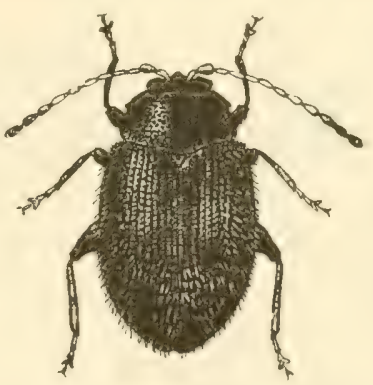

$b$

FIG. 230.-a, potato flea-beetle; $b$, egg-plant flea-beetle, both greatly enlarged. (After Chittenden, U. S. Dept. Agr.)

and legs, and there is a deep groove across the base of the thorax (Fig. 230, a). It seems to occur throughout the United States, but is more commonly injurious in the North. Eggplant and tobacco, as well as numerous garden vegetables are similarly injured. This species has commonly been called the cucumber fleabeetle from its specific name, but it is evidently a misnomer, as it is much more abundant upon the potato and related plants.

During the winter the beetles hibernate under leaves, rubbish, etc. and in the spring come forth and lay their eggs upon the roots of some of our common weeds of the Nightshade family, such as the horse-nettle, Janestown-weed, Desmodium, etc.,

* Epitrix cucumeris Harris. Sce O. A. Johannsen, Bulletin 211, Maine Agr. Expt. Sta. 
in May and June. The larvæ mine in the roots of these plants and transform to pupæ in small earthen cells among the roots, from which the beetles come forth in the spring to attack the foliage of the plants mentioned. According to Johannsen, (l. c.) the larvæ feed mainly on the roots, root-stalks and tubers of the potato. When they feed on the tubers they are responsible for the condition described by growers as "pimply potatoes." There is but one generation per year in Maine and probably in the Northern States generally, according to the same authority.

Injury is usually due to the feeding of the adult beetles which have come out of hibernation in the spring. These riddle the leaves by their feeding, with small holes which look like they might have been made by a charge of fine birdshot. Occasionally the larva injure seed tubers in the spring, but this is rare.

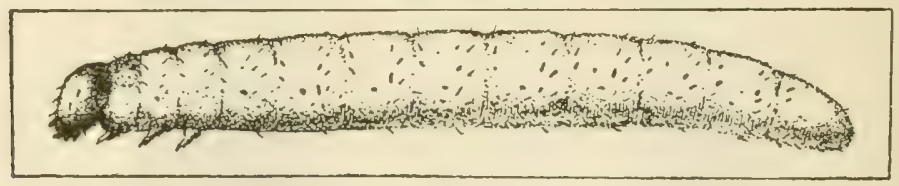

FIG. 231.-Larva of potato flea-beetle. (After Johannsen, 1. c.)

The Eggplant Flea-beetle* so nearly resembles the previous species that it will not be distinguished from it but by the entomologist. It is slightly larger, however, with the wing-covers more hairy, and the groove at the base of the thorax is not so distinct. It has much the same food-plants, but is particularly abundant on eggplant, and is more commonly injurious in the South, below the Ohio and Potomac rivers.

The Tobaceo Flea-beetle $\dagger$ has been previously discussed (page 212) but should be mentioned, as it is commonly injurious to potato, tomato, and eggplant throughout the South, as well as to tobacco, and occasionally to corn and other plants.

Control.-It has been found that Bordeaux mixture acts as an excellent repellant against these little beetles, and that plants well covered with it are not seriously injured. Inasmuch as it is always advisable to spray potatoes as soon as they are a few inches high for fungous diseases and for the Colorado potato beetle, by applying the spray as soon as possible after the plants

* Epitrix fuscula $\mathrm{Cr}$.

† Epitrix parvula Fab. 
are up they will be protected. Both potatoes and tomatoes should be sprayed with Bordeaux mixture and arsenate of lead or Paris green as soon as they are a few inches high. The spray should be applied liberally so as to give the plants a distinct coating of the mixture. Tomatoes are particularly susceptible to injury and might be dipped in arsenate of lead when planting, using 1 pound to 10 gallons of water. The destruction of the weeds upon which the larva commonly develop is obviously important in preventing their multiplication.

Where injury by the larvæ is done to the tubers, it is recommended that they be dug as soon as possible, and be left exposed to the sun for a few hours after digging so as to harden the skin, before being stored. If damage continues in storage, the tubers may be fumigated with carbon bisulfide, as recommended for grain insects.

\section{Potato-scab and Insects}

That certain forms of what is commonly termed "potatoscab" are due to the work of insects has frequently been shown. In 1895 Professor A. D. Hopkins, * of the West Virginia Agricultural Experiment Station, reported some very careful original investigations upon two species of gnats, Epidapus scabies Hopk. and Sciara sp., the larva of which had been conclusively shown to cause a "scab" upon the tubers by boring into them. The larvæ or maggots of the Potato-scab Gnat are about one-sixth of an inch long, and are the young of a wingless gnat shown, very greatly enlarged, in Fig. 232. The females deposit their eggs on the potatoes in storage from autumn to spring, and the maggots hatching from them enter old scab spots or injured places. Under favorable conditions a generation may be developed in twenty to twenty-five days. Later in the spring the eggs are deposited in manure or other decomposing material, on seed potatoes or on growing tubers to which they may be carried on seed potatoes. When they become well established in a potato, it is soon destroyed if they are not overcome by their natural enemies, or unless the soil becomes dry, when they soon disappear. Infested places look very much like the ordinary seab produced by the scab fungus and may be readily mistaken for it. Such * A. D. Hoplins, Special Bulletin 2 (Vol. IV, No. 3), W. Va. Agr. Exp. Sta., p. 97. 
injury was quite general and serious in West Virginia in 1891 and 1892. Dr. Hopkins found that "they breed in and areespecially common in barnyard-manure," that "excessive moisture in the soil has been observed to be the most favorable condition for their development," and that "soaking the seed-potatoes in a solution of corrosive sublimate previous to planting" will kill all the eggs and young larvæ, as it will also destroy the spores of the potato-scab fungus.

Professor H. Garman* has also recorded the injuries of several species of millipedes, or "thousand-legged worms," Cambala annulata and Parajulus impressus, as causing a scab by gnawing into the surface of the tubers. Though both of these observations are unquestionably true, such injury has not occurred in other

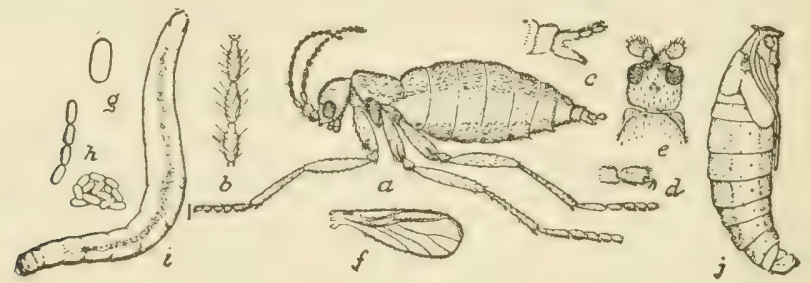

FIG. 232.-Potato scab-gnat (E pirlapus scubei Hopk.); $a$, fly; $i$ larva; $g$, egg; $h$, egg mass-much enlarged. (After Hopkins.)

parts of the country, and it is inprobable that any large portion of potato-scab is due to these insects. Potato-scab is a fungous disease, which, as already noted, may be destroyed by soaking the seed-potatoes in a solution of corrosive sublimate.

\section{Blister-beetles †}

Long before we had made the acquaintance of the Colorado potato-beetle, several species of blister-beetles frequently brought themselves into notice by their injuries, and, therefore, are now known as the "old-fashioned potato-bugs." The name of "blister-beetles" has been bestowed upon them because of the blistering effect which they have upon the skin, they being nearly related to the Spanish fly, used for that purpose.

One of the most common of these is the Striped Blister-beetle, which has three yellow stripes upon its wing-covers, while

* H. Garman, Bulletin 61, Ky. Agr. Exp. Sta., p. 18.

† Family Meloida. 
two other common forms are of a slate-black color. Very often when these' beetles congregate in numbers they are a great nuisance, not only in the potato-patch, but upon many other plants of the garden or truck-farm.

Unfortunately, they present to the farmer a very peculiar problem, for while the beetles are often exceedingly injurious, the larvæ are beneficial, eating large quantities of grasshoppers' eggs

Life His'ory.-The life of these insects is unique. The female lays a large number of eggs in a small cavity in the earth, and from these hatch some small, long-legged larvæ, which run about searching for the pod-like masses of grasshoppers' eggs, upon which they feed. As soon as the appetite of one of these little egg-hunters is appeased, he sheds his skin, and now being surrounded by food and no longer needing his long legs for running, in the next stage of his existence his legs become very short and rudimentary, and he remains almost immobile while feeding upon the rest of the eggs

Control.-Spraying with Paris green or arsenate of lead, as advised for the Colorado potato-beetle will kill the beetles, and where the vines have been regularly sprayed but little trouble will be had with them Where they suddenly appear in large swarms in gardens or on truck land, they are often destroyed by a line of men and children slowly driving them with branches, as the beetles move but slowly If a ditch is available it may be oiled, and the beetles destroyed like grasshoppers, or they may be driven into a windrow of straw, hay, or any inflammable rubbish and burned in it.

\section{Three-lined Leaf-beetle *}

Closely related to the Colorado potato-beetle, and very similar to it in habits, is the Three-lined Leaf-beetle. The eggs may be distinguished by the fact that they are usually laid in rows along the midrib on the under side of the leaf, while those of the potato-beetle are laid indiscriminately in bunches. The larvæ, however, may be readily distinguished from all other insects attacking the potato by being covered with a disgusting mass of their own excrement.

* Lema trilineata Oliv. Family Chrysomelido. 
There are two broods during the season, the larvæ of the first appearing in June, and those of the second in August; but the beetles of the second brood do not emerge until the following spring. In other respects the life history is practically the same as that of the Colorado potato-beetle. The beetle is of a pale
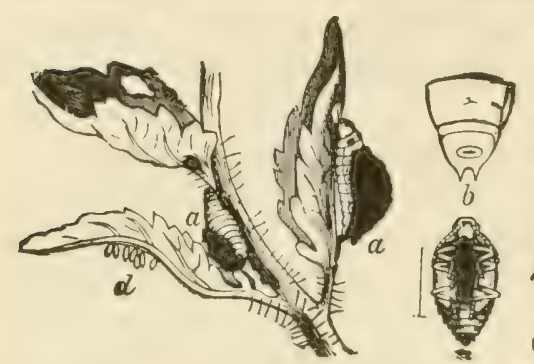

FIG. 233. - Three-lined leaf-beetle (Lema trilineata Oliv.); $a$, larva; $b$, pupa; $d$, eggs; beetle at right. (After Riley.) yellow color, with three black stripes on its back, and in a general way resembles the common striped cucumber - be e t l e (Diabrotica vittata Fab.), though it is somewhat larger and the thorax is decidedly constricted.

In case it becomes necessary to destroy the blister-beetles, both they and the three-lined leaf-beetle may be readily disposed of by applying arsenicals as advised for the Colorado potato-beetle.

\section{The Potato Aphids*}

The potato aphid, also called the pink and green aphid of the potato because it occurs in both these colors, is a widely distributed pest which occasionally does a considerable amount of injury to the potato. It attacks, beside the potato, the pepper vine and several other unrelated plants.

The insect is large for an aphid, and may be either pink or green, and lacks the dark markings characteristic of many species of aphids.

The aphids are found in the spring and early summer feeding on rose bushes and possibly other plants and from these they migrate about mid-summer to potato and other food plants. Both winged and wingless forms migrate, an unusual occurrence as ordinarily only winged individuals take part in the migration. In late summer and early fall the reverse migration takes place.

Not a great part of the season is spent on the potato but in the time the aphids are present they are able to do a great amount

* Macrosiphum solanifolii Ashmead. See Dr. Edith M. Patch, Bulletin 242, Maine Agr. Expt. Sta. 
of damage when they are at all numerous. In addition to the direct injury the aphids do they create conditions favorable for fungus attack, the wounds made by their beaks serving as points of infection and the weakened condition of the plants making them less resistant.

This species has been reported from Maine and California and in many intermediate localities.

Control.-Dr. Patch, (1. c), states that since the insect winters

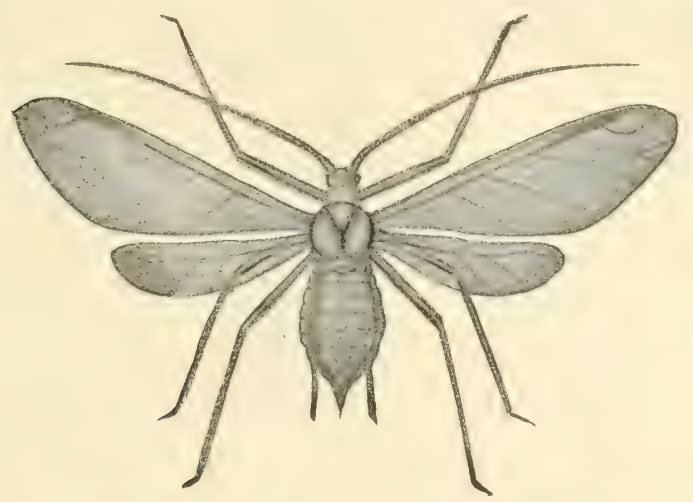

FIG. 234.-The potato aphid. Winged summer form. (After Webster, Iowa Agr. Expt. Sta.)

in the egg stage on many plants near potato fields, clean culture and destruction of weeds in the fall should be a valuable means of control. She recommends, also, spraying rose bushes showing infestation in the spring with tobacco extract and later, if necessary spraying the potatoes with the same material.

\section{The Apple Leafhopper *}

The apple leafhopper is so named from the fact that it is found on apples, especially on young trees in the nursery. To these it is quite seriously injurious, being often the most important insect pest found in apple nurseries. It is called also the potato leafhopper because it attacks potatoes and is even more injurious to them than it is to the apple.

* Empoasca mali LeBaron. Family Jassidle. See Bulletins 111 and 155, Iowa Expt. Sta., E. D. Ball, Journal of Econ. Ent., Vol. 12, No. 2, 1919, pp. 149-154. 


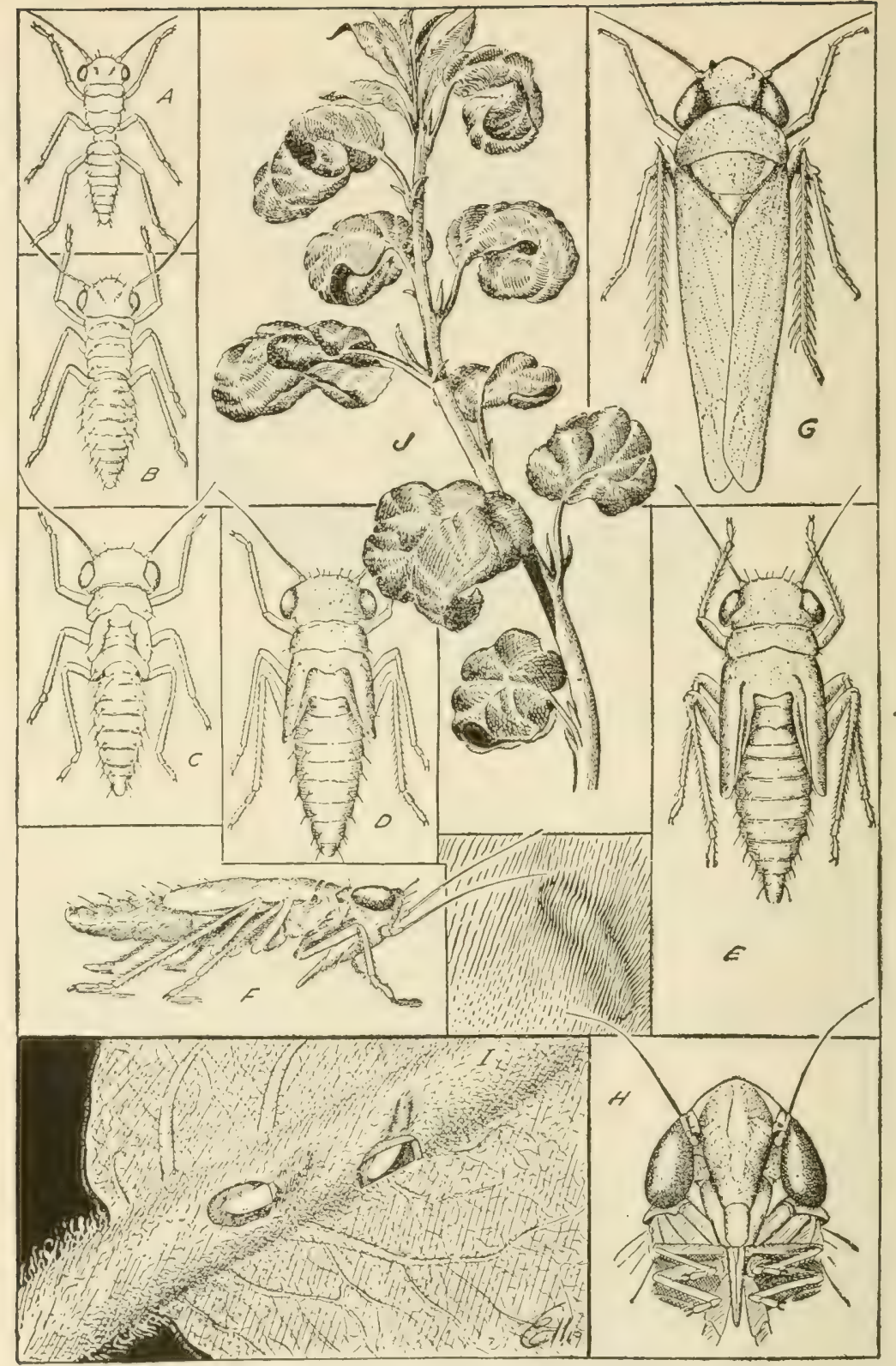

Frg. 235.-The apple leafhopper. (After A. J. Ackerman, Bull. 805, U. S. Dept. of Agr.) A, first nymphal stage; $B$, second stage; $C$, third stage; $D$, fourth stage; $E$, fifth stage; $F$, side view of fifth stage; $G$, adult; $H$, front view of head of adult; $I$, eggs in tissue on underside of apple leaf; $J$, curled condition of terminal leaves due to attack by the apple leafhopper on apple. 
The leafhopper in question is a small insect of slender form, about one-eighth inch in length. The adults have wings and are also provided with hind legs fitted for hopping and are quite active. The young hop to some extent but are much less active than the adults.

They winter usually as adults but are said also to pass the winter in the egg stage, the eggs being laid in the fall on the food plant. There are three or four generations.

Injury to potato is of two kinds; first, the direct injury due to the sucking of sap by the leafhopper and second, the blighting of the leaves said to be caused by the leafhopper. There is some doubt as yet as to just how much the leafhoppers have to do with the transmission of the disease which is called the tip-burn or hopper-burn but Dr. Ball, (1. c.) has presented a very strong case against the hopper. He maintains that the tipburn is the result of a specific poison injected by the hoppers or a specific infection carried by them. The evidence may not be quite conclusive and is still the subject of investigation, but there are at least strong probabilities that the case against the hoppers will be proven. The problem is complicated by the fact that there may be more than one kind of tipburn or tip blight, as a trouble of very similar nature has been observed by the writer in fields where no leafhoppers were to be found. This burn was generally ascribed to weather conditions.

Control.-Control measures against this pest on potato have not been very well worked out, but it is probable that clean culture and spraying with nicotine preparations will be found to give the best results.

\section{Tomato Worms}

The large green horn-worms which attack the foliage of the tomato are the same as those previously described which attack tobacco. Usually they are not so numerous but that they may be readily controlled by handpicking, but if necessary the same remedial measures may be used as advised for them on tobacco.

\section{The Tomato Fruitworm}

The worms which commonly bore into the green and ripening tomatoes are the same as the tobaceo budworm and the cotton 


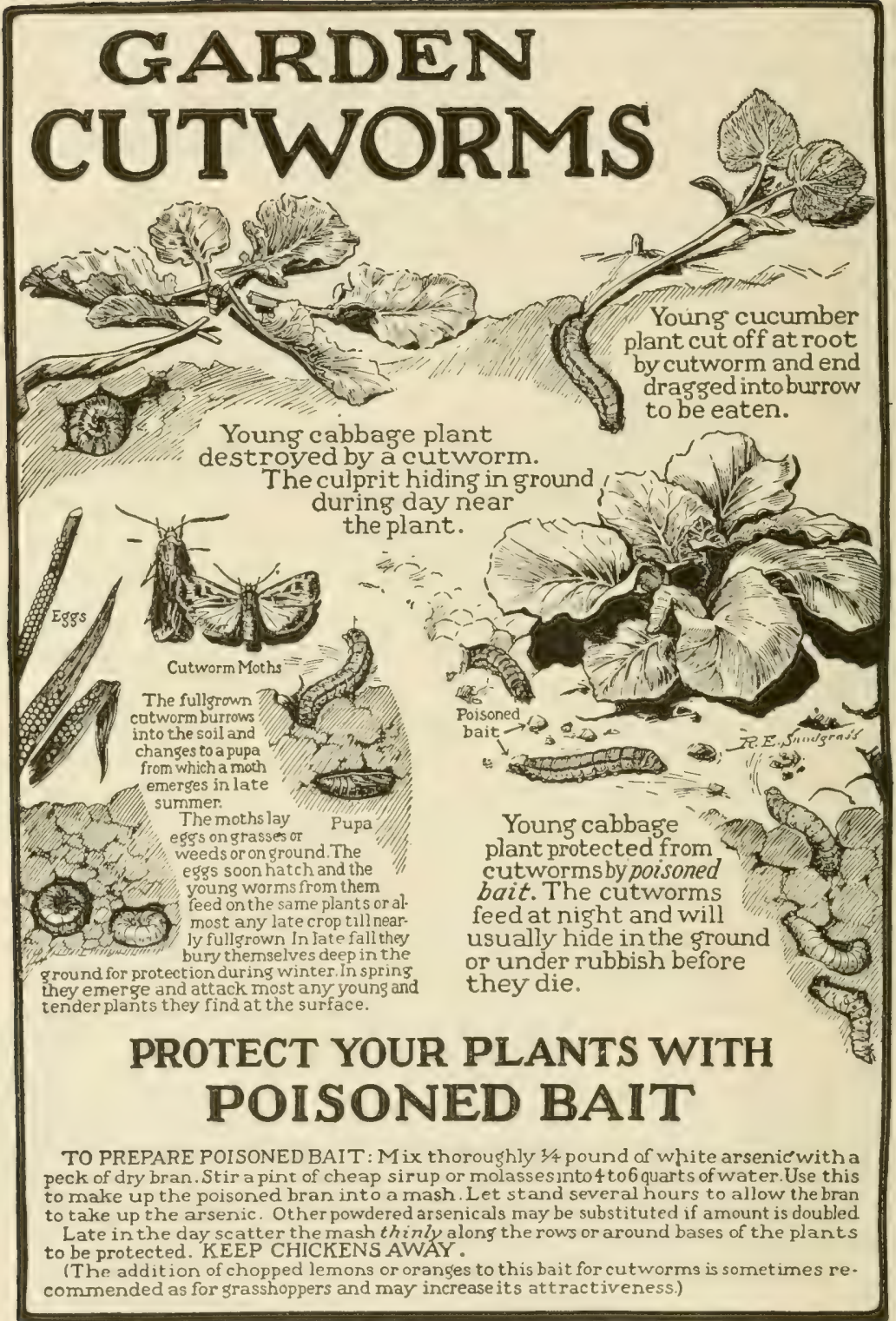

FIG. 306.-Bureau of Entomology Chart, information regarding cutworms 
bollworm (sce pages 168 and 221), under which names their habits and life histories have been fully described.

Obviously tomatoes should not be planted on land which has been in corn or cotton infested by this insect the previous year, unless it has been given thorough winter plowing and harrowing.

It has seemed to the writer that trap rows of sweet corn might be used for protecting tomatoes as they are used with cotton, but no experiments seem to have been conducted which show the prac-

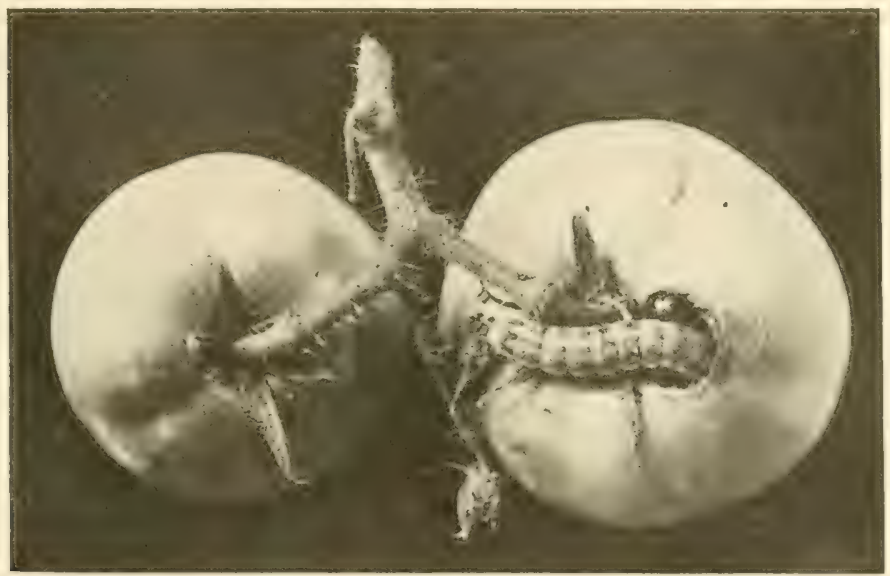

FIg. 237.-Bollworm boring into green tomato. (After Quaintance and Brues, U. S. Dept. Agr.)

ticability of the method. As the young caterpillars feed a little on the foliage before boring into the fruit, a thorough spraying with arsenate of lead, 3 pounds to 50 gallons, will undoubtedly protect the tomatoes if applied as soon as the eggs are laid, and with one or two later applications at intervals of ten days, the exact time depending upon the latitude and season, as indicated by the life history (see page 168). 


\section{CHAPTER XV}

\section{INSECTS INJURIOUS TO BEANS AND PEAS*}

\section{The Pea-weevil $\dagger$}

The common Pea-weevil occurs in almost all parts of the world where peas are grown, and is the usual cause of "buggy" peas. It was the cause of the abandonment, of pea growing in the central Atlantic States as early as the middle of the eighteenth century. It has usually been regarded as a native of North America, having
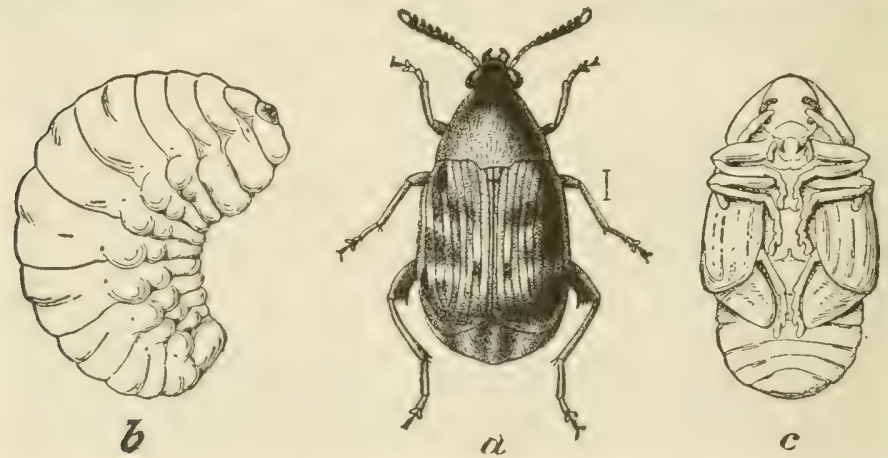

FIG. 238.-The pea-weevil (Bruchus pisorum L.): $a$, adult beetle; $b$, larva; c, pupa-all enlarged. (From Chittenden, U. S. Dept. Agr.)

been introduced into Europe. It does but comparatively little damage in more northern latitudes and for this reason seedsmen secure their seed peas from Canada and northern Michigan and Wisconsin.

The weevil is about one-fifth inch long and about one-half that width, being the largest of the pea- and bean-feeding weevils in this country. "Its ground color is black, but it is thickly covered with brown pubescence, variegated with black and white markings as shown in Fig. 238. The sides of the thorax are notched or toothed, and the abdomen, which projects beyond the wingcovers, is coated with whitish pubescence and marked by two black spots. The hind thighs are thickened and each bears two prominent teeth."

* See F. H. Chittenden, Insects Injurious to Beans and Peas, Yearbook U. S. Dept. Agr. for 1898, p. 233.

† Bruchus pisorum Linn. Family Bruchida. 
Life History.-The winter is passed in the adult stage, the weevils making their appearance in the fields when the peas are in blossom. The eggs are laid singly upon the surface of the pods, attached by a sticky fluid which becomes white when dry. The egg is about one-twentieth of an inch long by one-third that width, of a yellow color, and is shown in Fig. 239.

Upon hatching, the young larva bores through the pod and in to the seed. In this stage the larva has some very small false legs and two plates and six strong spines on the thorax, which aid it in getting through the pod. Upon

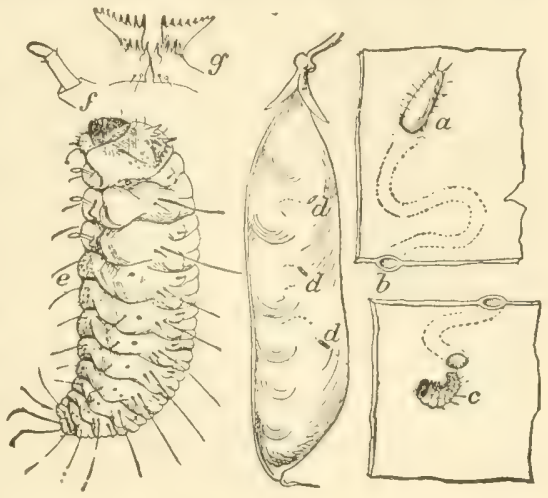
entering the seed the skin is FIG. 239.-The pea-weevil: $a$, egg on pod; shed and these legs, plates and spines are lost. The larva feeds upon the seed, growing rapidly. When full grown it appears as at $b$, $b$, cross section of opening of larval mine; $c$, young larva and opening on inside of pod by which it has entered-enlarged $d, d, d$, eggs on pod, slightly enlarged; $f$, leg of larva; $g$, prothoracic spurious processes-more enlarged. (After Chittenden, U. S. Dept. Agr.)

Fig. 238. It resembles a maggot in general appearance, being white, except the small mouth-parts, which are brown; is fleshy, nearly cylindrical and strongly wrinkled, with three pairs of very short stubby legs. It is about one-fourth an inch long and half as broad. Before its final molt the larva eats a round hole in the pea, leaving but a thin membrane as a covering. It then lines the inside of the pea with a glue-like substance, and within this cell transforms to the pupa.

The pupa is white, showing the notches at the sides of the thorax, but otherwise is not dissimilar from many weevil pupæ. The length of the pupal stage varies from nine to seventeen or more days. In more southern latitudes a large part of the beetles leave the seed in August, but in the North they all remain in the seed over winter, and are planted with the seed. There is but one generation a year and this species does not breed in dry peas.

Injury.-Dr. James Fletcher has stated that this pest is now doing over $\$ 1,000,000$ d:amage in Ontario alone annually, and that 
the growing of peas has been abandoned in considerable areas of that province. In large peas about one-sixth of the food content is destroyed, while in smaller varieties fully one-half. Not only this, but in eating canned green peas one frequently devours several small larvæ in each mouthful, unawares, as but a small dark speck indicates their presence in the green pea. In the dry seed the holes made by the larva can be seen. But 12 to 18 per cent of infested seed will produce plants, which are later in developing and do not yield as well as those unaffected.

Enemies.-The Baltimore oriole has been recorded as feeding on the grubs by splitting open the pods, and the crow blackbird is said to devour many of the beetles in the spring. Practically no parasites or predaceous insects are known to prey upon it, so that it has every opportunity for doing serious injury.

Control.-Holding over Seed.-One of the best means of destroying the weevils where but a few peas are concerned and circumstances will permit, is simply to hold them over for a season, stored in a tight sack or box, before planting. As the weevils will not breed in the dried peas they die in the sack and are thus caught. Peas should always be bagged up and sacks tied immediately after threshing.

Late Planting.-Comparative immunity from injury is claimed by some growers for late-planted peas. Dr. F. H. Chittenden is inclined to the belief that in some localities, such as Washington, D. C., where two crops can be grown in a year, that late planting is all that is necessary to secure sound seed stock.

Treating with Kerosene.-The Canadians have found that kerosene may be used to destroy the weevils. Dr. Fletcher states: "A remedy which has been used by many farmers with satisfaction is to drench the seed with coal oil, using about a half a gallon to the barrel, or five bushels of peas. While applying the coal oil (kerosene) the seed should be placed on the floor, where it can be shoveled over constantly to insure the treatment of all the grain."

Scalding Seed._-" When peas are found to contain live weevils at the time of sowing, these may be destroyed by simply pouring them into a pot of scalding water. The water should be drained off at once or the seed cooled by turning in cold water."-Fletcher.

Heat.-Dr. Chittenden states that it has been found that a temperature of $145^{\circ} \mathrm{F}$. will kill the weevils in the seed without injury to the germinating property of the seed. 
Fumigation.-This is undoubtedly the best means of destroying the weevils, and is now coming into general use. Dr. Fletcher, who has made the most thorough studies of practical methods for controlling this pest, states: "Fumigation with bisulfide of carbon is a sure remedy. When properly done, either in specially constructed buildings known as 'bug-houses' or in any tight bin, every weevil is surely killed if the seed containing them is fumigated for forty-eight hours with this chemical, using 1 pound by weight to every 100 bushels of seed, or, in smaller quantities, 1 ounce to every 100 pounds. For the treatment of small quantities of seed, particularly by farmers, I have found that an ordinary coal-oil barrel is very convenient. This will hold about 5 bushels, or 300 pounds of seed, which may be treated with 3 ounces of bisulfide of carbon. Care must be taken to close up the top tightly. This is best done with a cap made specially for the purpose, but fine sacks laid smoothly on the top, over which boards are placed with a weight on them, will answer. Fumigation with bisulfide of carbon is, I believe, the remedy most to be relied upon in this campaign. It is perfectly effective, is now regularly used by the large seed merchants, and in future will be much more generally used."

\section{The Common Bean-weevil *}

Throughout the United States the common Bean-weevil is the
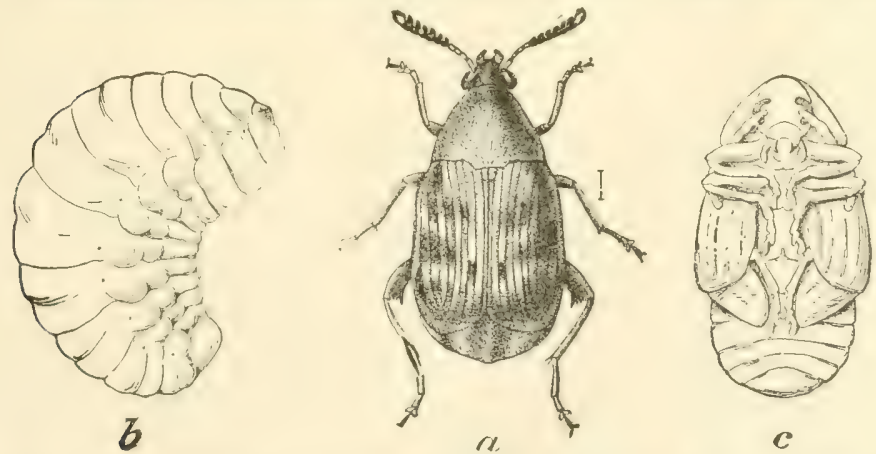

Fig. 240.-The common hean-wveevil (Bruchus obtertus Say): $a$, beetle; $b$, larva; c, pupa-all greatly enlarged. (After Chittenden, U. S. Dept. Agr.)

principal enemy of the bean. The small, white, footless grubs feed within the beans, both in the field and in storage, and trans-

*Bruchus obtectus Say. Family Bruchidx. 
form to the common brown-gray weevils which infest white beans. In the South its attacks are so serious that it is almost impossible to secure a crop uninfested, so that most of the beans both for seed and consumption come from the North. Not until 1870 did injury by this insect attract attention in the United States, but now it occurs throughout our borders and is practically cosmopolitan in its distribution. It is probably a native of Central or South America.

The adult weevil is about one-eighth of an inch long and is cov-
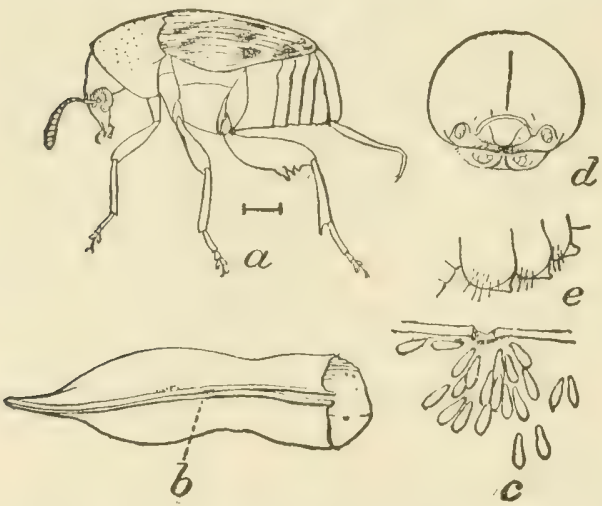

FIG. 241.-The bean-wcevil; $a$, side view of beetle; $b$, section of bean pod showing slit for deposition of egg; $c$, part of inside of pod showing egg-mass inserted through slit-all enlarged. (After Riley and Chittenden, U. S. Dept. Agr.) ered with a fine brown-gray or olive pubescence, giving it that color, while the wing-covers are mottled as shown in Fig. 240 , a. It may be distinguished from the pea-weevil by its longer thorax and by the two small teeth next to the large tooth at the tip of the thighs.

Life History. - In the field the eggs are laid upon or are inserted in the bean-pod through holes made by the female or such openings as are caused by its drying and splitting (Fig. 241, b, c). In shelled beans the eggs are placed loosely among them or in the exit holes of the bectles. The young larva hatching from the egg has long, slender legs, but with the first molt these are lost and when full grown it is a fat grub as shown in Fig. 240, b. The pupal stage is passed in an oval cell made by the larva within the bean. Experiments have shown that the eggs hatch in from five days in the hottest to twenty days in cooler weather; the larval stage requires eleven to forty-two days, and the pupal stage five to eighteen days. Thus the whole life eycle will extend over a period of from twenty-one to eighty days, depending upon the season and 
locality. Probably about six generations occur annually in the District of Columbia, and a less number farther north.

"Unlike the pea-weevil, a large number of individuals will develop in a bean, as many as twenty-eight having been found within a single seed. It will thus be readily seen that the first outdoor generation or any single indoor generation is capable of exhausting seed and completely ruining it for food or planting or any other practical purpose, except perhaps as hog feed."

"The beetles begin to issue from beans in the field in a climate like that of the District of Columbia . . . as early as October, when in the natural course of events the eggs for a new brood would be deposited in such pods as had cracked open, so as to expose the seeds within."

"Weevilly" seed should never be planted, as but a small per cent of it will germinate and the vitality of that germinating is deficient. Professor Popenoe showed in experiments at Manhattan, Kan., that only 50 per cent of the infested seed used germinated, that only 30 per cent could have grown further, and that even these would have produced plants of little vigor or productiveness. (Quotations and facts from Chittenden, l.c.)

Remedies.-No methods are known of preventing injury in the field, and all remedial measures must be applied to the insects in the stored seed. As this species breeds in the stored seed, it is useless to hold it over as for the pea-weevil, and the quicker infested seed is treated the better. Either heat, or better, fumigation, as described for the pea-weevil, should be used. When ready to plant, seed should be thrown lightly into water, when that badly infested will float and can be separated and destroyed.

Professor Geo. A. Dean, of the Kansas Experiment Station, states that beans can be protected from injury and the weevils in them killed, simply by storing them in air-slaked lime. The lime is poured over the beans in the container and shaken down until the beans are entirely covered. We have tested the method and secured perfect results. This is by far the most convenient, method for handling small quantities of beans and peas, especially for those intended for seed. They should be kept in a dry place. 


\section{Other Bean-weevils}

The Cow-pea weevil.*_-This species may be readily recognized by the two large, raised white lobes at the base of the thorax and
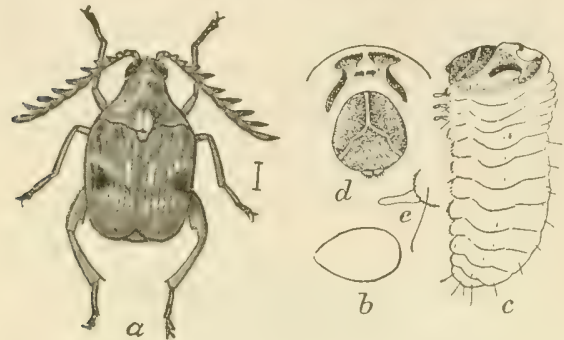

Frg. 242,-The corv-pea weevil (Bruchus chinensis L.): $a$, adult male; $b$, egg; $c$, young larva; $d$, front view of head of same; $e$, thoracic leg of same; $-a$, much enlarged; $b, e$, more enlarged. (After Chittenden, U. S. Dept. Agr.) the strongly pectinate antennæ of the male as shown in Fig. 242, $a$. The cow-pea is the favorite food-plant of this and the following species, but peas and various sorts of beans are also attacked. This species is a southern form, but seems to be spreading, incident to the more widespread growth of the cowpea. Like the common bean-weevil it is practically cosmopolitan in its distribution, but is most injurious in tropical regions. The life history and remedial measures are practically the same as for the common bean-weevil.

The Four-Spotted Bean-weevil.- - The wing covers of this species are covered with gray and white pubescence and four darker spots from which the species is named. It is more slender than the preceding species and the antennæ of the male are not pectinate. The markings are quite variable, but the most com-
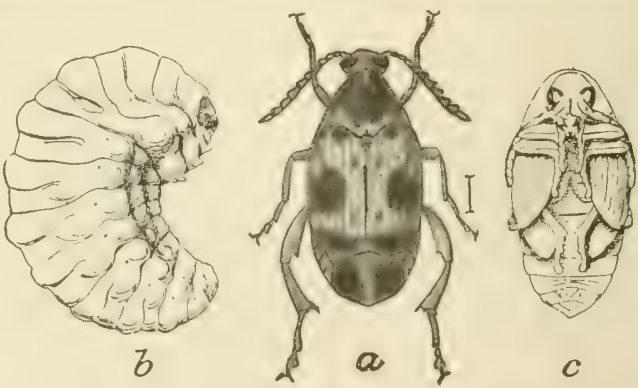

FIG. 243.-The four-spotted bean-weevil: $a$, beetle; $b$, larva; $c$, pupa-all enlarged. (After Chittenden, U. S. Dept. Agr.)

mon form is that shown in Fig. 244. This is an exotic species occurring from Mexico to Brazil and in Mediterranean courtries. In 1885 it was found at the Atlanta Cotton Exposition in blackeyed beans from Texas, and has since become acclimated as far north as Iowa. It seems to breed more readily in fresh and slightly

* Bruchus chinensis Linn.

$\dagger$ Bruchus quadrimaculatus Fab. 
moist seed and, like the preceding species, its work in stored beans seems to cause decomposition and a consequent rise of temperature. The life history and remedial measures are similar to those of the bean-weevil.

The European Beanweevil* was imported into New York and New Jersey in 1870 , at the Columbian Exposition at Chicago in 1893 , and has been observed at College Station, Texas, but does not seem to have become established in this country. It closely resembles the peaweevil in appcarance and life history.

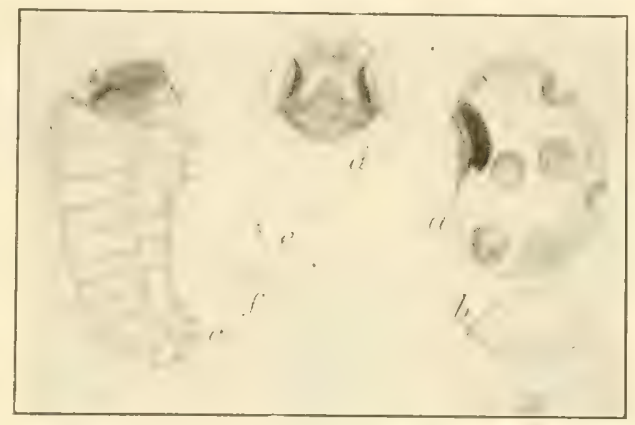

Frg. 244.-The four-spotted bean-weevil: $a$, cowpea, showing holes made by weevils in their escape from seed, also eggs deposited on surface; $b$, egg; $c$, young larva; $d$, head of same; $e$, prothoracic leg; $f$, spine above spiracle of first abdominal segment- $a$, twice natural size; $b, f$, greatly enlarged. (After Chittenden, U. S. Dept. Agr.)

\section{The Bean Leaf-beetle $\dagger$}

Small yellowish or reddish beetles, marked with black, as shown in Fig. 245, and from one-seventh to one-fifth inch long, are often found eating the foliage of beans, and are commonly known as Bean Leaf-beetles. The species occurs throughout the United States east of the Rockies, but has been chiefly injurious in the Middle and Southem States. Besides beans, the beetles feed upon cow-peas and various native plants such as beggarweed or tickseed, tick trefoil (Meibomia), bush-clover (Lespedeza), and hog-peanut (F alcata). They usually become quite numerous before they are observed, for during most of the day they rest or feed on the under sides of the leaves. They are sluggish and seldom fly, and when disturbed often drop to the ground, though they soon crawl back to the plant. Large round holes are eaten in the foliage until finally nothing but the veins and midrib of a

* Bruchus rufimanus Boh.

† Ceratoma trifurcata Forst. Family Chrysomelida. 
leaf is left, the manner of defoliation being quite characteristic of this species. Low-growing and dwarf varieties are worse injured, as pole beans put out new leaves after the injury has stopped,

Life History.-The adult beetles hibernate in or near the bean. fields and emerge from April to June according to the latitude. Minute orange-colored eggs are laid near the stem of the plantjust below the surface of the soil, in clusters of six to ten or more,

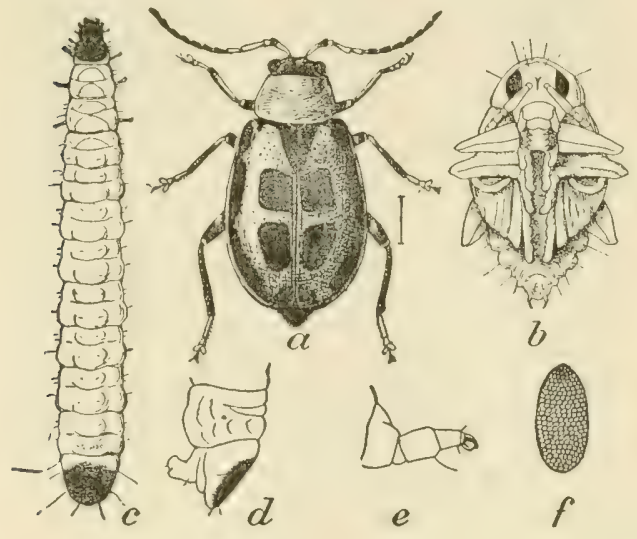
and hatch in from five to eight days. The younglarvæ feed upon the stem and roots, becoming full grown in six or seven weeks. When grown the larva is about three-tenths an inch long, about one-eight as wide, cylindrical, milk-white in color, with dark head and anal segment, as FIG. 245.-The bean leaf-beetle (Ceratoma trifurcata shown enlarged six Forst.): $a$, adult beetle; $b$, pupa; $c$, larva; $d$, side view anal segment of larva; $e$, leg of same; $f$, egg $-a, b, c$, enlarged about six times; $d, e, f$, more times in Fig. 245. The pupa (Fig. 245, b.) is pure white, and from it the beetle emerges in five to eight days. Thus, in the District of Columbia, the whole life cycle requires six to nine weeks, depending upon heat and moisture. In the North there is probably but one generation a year; in Maryland and Virginia one generation develops in July and another in September; while in the Gulf States there are probably three generations, as beetles are numerous in October.

Remedies.-Spraying with arsenical poisons as for the bean ladybird is the most effectual means of controlling the pest when abundant, but they should be applied early to avoid the poison on beans to be eaten green. Owing to the sluggishness of the beetles they may be handpicked in small gardens. Clean culture 
and careful weeding of native foorl-plants such as tick-trefoil and bush-clover, near cultivated crops are most important.

\section{The Bean Ladybird*}

The Bean Ladybird is the most serious enemy of beans in Colorado, New Mexico, Arizona, and Western Kansas, whence it migrated from Mexico. It is an interesting insect in that only two other native species of this family of beetles (Coccinellid $\propto$ ) feed upon vegetation, the normal food of the family being plant-lice, scale insects, and soft-bodied larvæ.

Professor C. P. Gillette† describes it as follows:

"The beetle (Fig. 246, A) is oval in outline, nearly one-third an inch in length by one-fifth an inch in breadth, of a light yellow to a yellowish-brown color and has eight small black spots on each wing-cover. The mature larva is about the same length as the beetle, is of light yellow color and is covered with stout branched spines that are black at their tips, a larva being shown at C, Fig. 246. The larva when fully grown fastens the posterior end of its body to the under side of a leaf and then in a few days sheds its outer skin containing the spines and changes to the pupa state

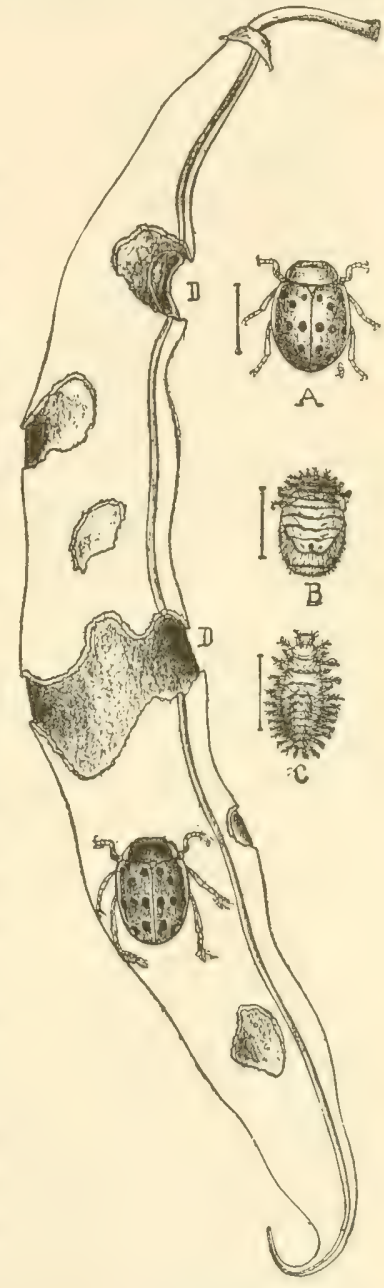
(Fig. 246, B). From these pupæ the Fig. 246.-The bean ladybeetles appear a few days later. They live over winter, and appear about as soon as the beans are up in the garden or field and begin to feed upon the leaves, bird (Epilachna varivestis Muls.): $a$, adult beetle; $b$, pupa; $c$, larva; $d$, bean pod showing injury. (After Gillette, Colo. Agr. Exp. Sta.)

* Epilachna varivestis Muls. Family Coccinellidee.

† Bulletin 19, Colo. Agr. Exp. Sta., p. 25. 
on the under side of which they deposit their yellowish-brown eggs in large clusters after the manner of the 'Colorado potato beetle.' The spiny little larvæ that hatch from these eggs remain on the under side of the leaves, which they skeletonize in feeding. The beetles eat through the veins of the leaves and do not skeletonize them. They also eat into and destroy the green pods as shown in Fig. 246, D. There is also one brood of this insect in a season.

Control.-Paris green dusted upon the plants diluted with 100 parts of air-slaked lime or flour is recommended, or it may be applied with Bordeaux mixture, 1 pound to 200 gallons, but much care must be used not to burn the foliage, which seems to be very susceptible to the arsenic. Arsenate of lead applied as a dust, with or without a carrier, or as a spray at from three to five pounds paste to 100 gallons of water is much more safe and is now more generally used for that reason. In spraying, an unclerspray nozzle must be used to reach under the leaves. Dilute kerosene emulsion will kill the larvæ, but must also be used with caution to avoid injury to the plant. Whaleoil soap might be as effective and less injurious to the plant. Upon small gardens handpicking of the adult beetles as soon as they appear in the spring will probably be the surest means of combating them. Cleaning up the old patch and plowing it under will doubtless aid in preventing successful hibernation.

\section{Blister-beetles}

Several species of elongate, grayish, black or bright green blister-beetles feed in large numbers upon bean foliage. The general life history, habits, and remedies have been already described. (See pages 104, 270.)

The Ash-gray Blister-beetle. *-This is the most common species affecting beans in the East and westward to Kansas and Nebraska. The beetle is a uniform ash-gray color and of the form shown in Fig. 217. The beetles attack this and other legumes in immense swarms, riddling the foliage in a few days if not checked, and appear from the middle of June to the middle of July.

Nuttall's Blister-beetle.†-This species occurs from the Misissippi west to the Rockies, through the region of the Missouri

* Macrobasis unicolor Kby.

$\uparrow$ Cantharis nuttalli Say. 
Valley, and north to the Northwest Territories, where it seems to be particularly destructive to beans, though affecting many garden vegetables. The life history is not known, but is probably similar to that of other species, as the beetles appear about July 1st in years following severe outbreaks of grasshoppers. Owing to the rapidity with which this species works and the large numbers,

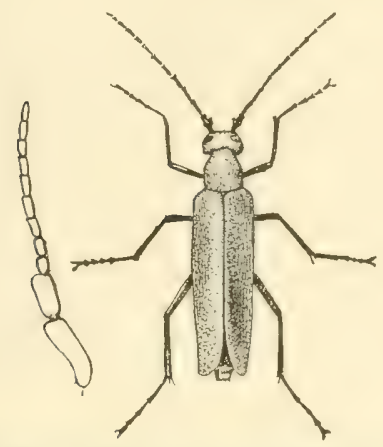

FIg. 247.-The ash-gray blister-beetle (Macrobasis unicolor Kby.): female beetle at right, twice natural size; male antenna at left, greatly enlarged. (After Chittenden, U. S. Dept. Agr.)

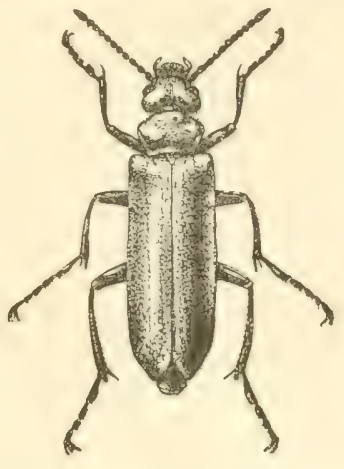

FIG. 248.-Nuttall's blister-beetle (Cantharis muttalli Sily.): female beetle, enlarged one-third. (After Chittenden, U. S. Dept. Agr.)

poisons will be of little avail and mechanical measures must be employed for their destruction.

Control.-See page 271.

\section{The Bean-aphis *}

"Crowded together in clusters upon the top of the stalks and under side of the leaves of the English bean, the poppy, dahlia, and several other plants, may be found a small black plantlouse with pale shanks, and a row of mealy white spots along each side of the back."-Fitch.

This is an old European pest of the bean, where it is known the black dolphin, collier, and black fly, and has sometimes caused the entire destruction of a crop. In the United States : it probably occurs wherever beans are grown, having been reported from New York, Illinois, Iowa, Minnesota and Colorado. The species is probably best known as affecting various species of * Aphis rumicis Linn. Family Aphidido. 
dock, upon the leaves of which it occurs commonly in large numbers. Shepherd's purse, pigweed, the "burning bush "(Euonymus europoeus and atropurpurus), and the snowball bush are also commonly infested.

Life History. - The life history was first described most interestingly by Dr. Fitch in his 13th Report* and has since been confirmed by Osborne and Sirrine. $\dagger$ The eggs are laid in the fall around the buds of the wahoo or "burning bush" (Euonymus atropurpurus), and possibly upon the snowball. The first generation or two multiply upon these plants and then spread to common weeds such as shepherd's purse, pigweed, dock, etc., during the latter part of May and early June, from which they again migrate to beans when that crop is available. During the summer the aphids multiply upon these food-plants viviparously, i. e., by giving birth to live young, all being females, as is the rule with aphids; but about the middle of September, in Iowa, winged males and females migrate back to the wahoo.

Description.-The wingless females are about one-tenth an inch long, pear-shaped, sooty black, frequently marked with pruinose whitish dots along each side of the back. The antennæ are about half the length of the body, yellowish-white, except toward the tips and the two basal segments, which are black. Honey tubes short, scarcely half as long as from their bases to tip of abdomen. Tail half as long as the honey tubes.

The winged females are glossy-black, one-twelfth an inch long to the tip of the abdomen and twice that length to the tip of the closed wings. The abdomen lacks the white spots of the wingless females and pupæ. Legs are black, except shanks, which are whitish with dark tips. Otherwise the winged form resembles quite closely the wingless form. The black color and white spots on the abdomen of the wingless females and pupæ will readily distinguish the species from other aphids on beans.

Control.-Spraying with dilute kerosene emulsion has proven the best means of combating the pest according to Osborn and Sirrine, diluting the stock solution fifteen times, or so the spraying mixture will contain about 5 per cent of kerosene. It seems

* Fitch, 13th Report on the Noxious, Bencficial and other Insects of the State of New York, Trans. N. Y. State Agr. Soc., 1869, p. 495.

$\dagger$ Osborn and Sirrine, Bulletin 23, Iowa Agr. Exp. Sta., p. 901, 1894. 
that the foliage of the bean is quite susceptible to injury from any free kerosene, and probably whaleoil soap 1 pound to 5 or 6 gallons, would prove safer and equally efficient. As it is frequently necessary to spray beans with Bordeaux mixture or other fungicides for fungous diseases, the whaleoil soap might be readily sprayed at the same time.

Of late years tobacco extracts have largely supplanted the oii and soap emulsions and it is probable that they will be more satisfactory in most places as a treatment for this insect.

\section{The Seed-corn Maggot*}

This insect has been termed the Seed-corn Maggot on account of its frequent injuries to early seed-corn, but in recent years it has often seriously injured the seeds of beans and peas, on account of which it has been termed the "bean-fly," while cabbage,

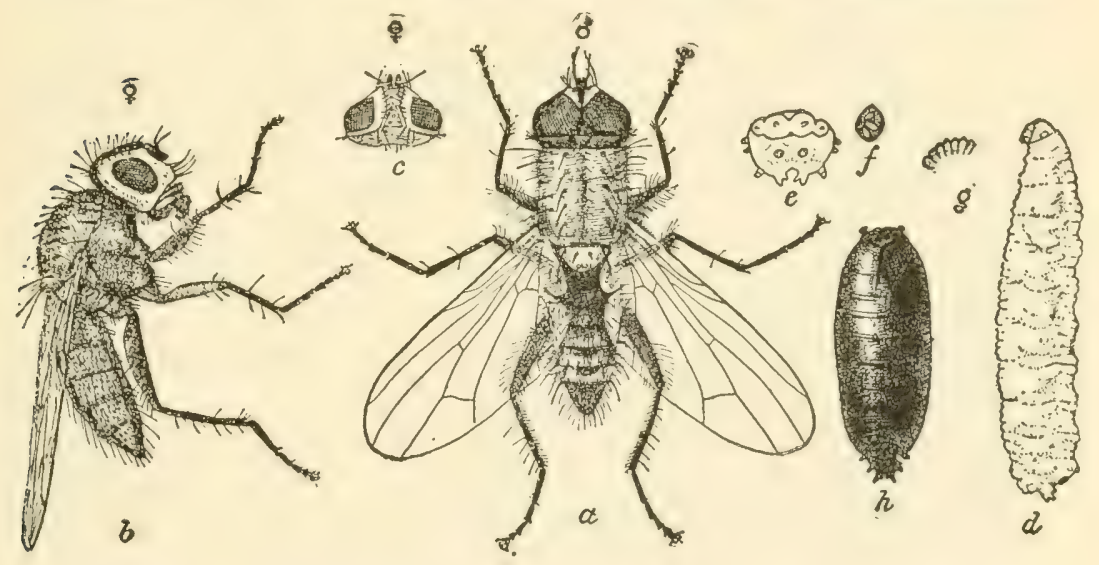

Fig. 249.-Seed-corn maggot (Pegomyia fusciceps): $a$, male fly, dorsal view; $b$, female, lateral view; $c$, head of female from above; $d$, larva, from side; $e$, anal segment of larva; $f$, anal spiracles; $g$, cephalic spiracles; $h$, puparium-all much enlarged. (After Chittenden, U. S. Dept. Agr.)

turnip, radish, onions, beets and seed potatoes are among its other food-plants.

The species is of European origin, and was first noted in this country by Dr. Asa Fitch, in 1856. Since then it has become distributed throughout the United States from Minnesota to Texas and eastward.

* Pegomyia fusciceps Zett. Family Anthomyiida. 
The arlult flies closely resemble the root-maggots affecting the cabbage and onion and are about one-fifth an inch long. The male may be distinguished from nearly related species by a row of nearly equal, short bristles on the inner side of the hind tibiæ or shanks.

The life history of the species has not been carefully observed, but is probably similar to that of other root-maggots. The flies deposit their eggs either upon the young seedling just as it appears above ground, or probably more often on the seed itself. Injury is called to attention by the seed failing to germinate, which, when examined, is found to contain one or more small white maggots, which have destroyed the germ or the young seedling. Thus in 1895, large areas of beans were destroyed in Minnesota.*

The maggots are about one-fourth an inch long, slightly smaller than the onion-maggot, from which they may be distinguished by the tubercles of the anal segment.

Control.-It has been noted that injury often occurs where stable manure has been turned under, and it may be possible that the flies are attracted to it to oviposit or that they are attracted by decaying seed. In preventing attacks of rootmaggots it would seem advisable to apply stable manure the previous fall so that it may become well rotted and incorporated into the soil before seeding. Rolling the seed-bed after planting might also be of value in preventing the access of the flies to the seed.

Applications of commercial fertilizers which will insure a quick growth of the seedling are advisable. The use of carbolic acid emulsion and sand and kerosene upon the surface of the seed-bed after planting and as the seedlings are appearing, as advised for the cabbage root-maggot, will also be of value. Inasmuch as the injury is sporadic and affects the seed before it can be readily detected, reliance must be placed chietly upon general cultural methods as outlined above and others which a better knowledge of the life history of the pest will undoubtedly suggest.

* See Lugger, Bulletin 43, Minn. Agr. Exp. Sta., p. 207 (1st Rept. Minn. State Entomologist). See Circular 63, and Bulletin 33, p. 84, Bureau of Entomology, U. S. Dept. Agr. 


\section{The Pea-aphis *}

Large green plant-lice often become so abundant on the foliage and pods of garden-peas as to kill the plants. Prior to 1899 the pea-aphis had not been a serious pest in this country, but during that and the following season it caused a loss of several million dollars to pea-growers on the Atlantic coast from North Carolina to Nova Scotia and as far west as Wisconsin, especially where peas were extensively grown for eanning. During 1901 injury was by no means as serious, and has materially decreased since then, though sporadic injury occurs almost every year in some section. General injury occurs only periodically for reasons mentioned below. The pest seems to occur throughout the States east of the 100th meridian and possibly farther west. It is an old enemy of peas in England, where it destroyed the crop as long ago as 1810 , and it has long been known in Europe as an enemy of peas, clovers, vetehes and related plants.

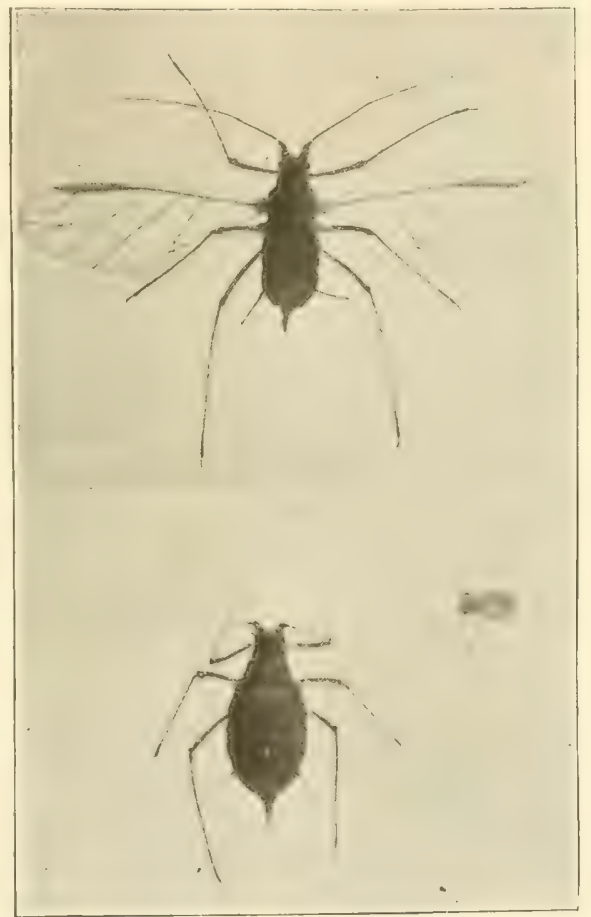

FIG. 250.-The pea-aphis (Macrosiphum pisi Kialt.): winged and wingless viviparous females and young - enlarged.

Both wingless and winged aphids oceur together throughout the season, the latter predominating whenever food becomes scaree. The winged forms are from one-righth to one-seventh of an inch long, with wings expanding two-fifths of an inch. The body is a

* Macrosiphum pisi Kalt. Family A phidider. See Chittenden, Circular 43, Bureau of Ent., U. S. Dept. Agr.; Sanderson, Bulletin 49, Del. Agr. Exp. Sta.; Folsom, Bulletin 134, Ill. Agr. Exp. Sta. 
pea-green color, light brownish between the wings and on the head, the eyes are red, and the legs, antennæ and honey tubes are yellowish, tipped with black. The wingless females are similar in size and color, but are much broader across the abdomen, and the honey tubes are somewhat larger. The mouth-parts of the pea-aphis are of the sucking type, and it secures its food by puncturing and sucking up the juices of the plant. The plant is thus injured by the large number of aphids sucking out its juices and causing it to wilt and die.

Life History. - The aphids pass the winter on clover and vetches, and often increase upon clover so as to do it serious

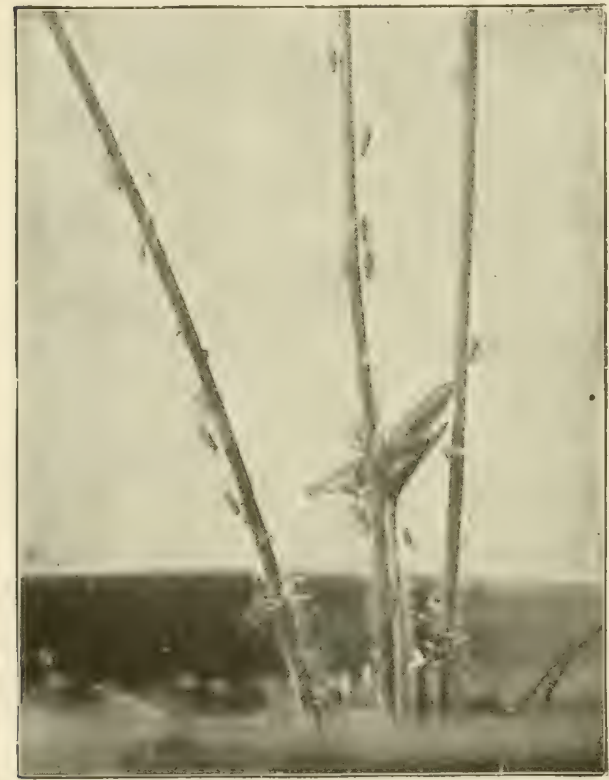

FIG. 251.-The pea-aphids on stems of red clover-natural size. (After Folsom.) injury. Where peas are available the winged females usually migrate to them about the time peas are 6 or 8 inches high, and give birth to live young, which develop into wingless viviparous females. These females, as do those of subsequent broods throughout the summer, give birth to live young, and reproduction goes on at a rapid rate. According to the observations of Mr. R. L. Webster, in central Illinois, an aphid becomes grown about eleven days after it is born, lives about twenty-five days and gives birth to about fifty young, though under favorable conditions over one hundred are frequently born. Sixteen generations have been observed from March 23d to October 4th. Winged aphids develop as often as the foodplant becomes overcrowded and it is necessary to migrate to avoid starvation. 
By midsummer, with the harvesting of the peas, most of the aphids upon them have been destroyed by predaceous and parasitic insects and disease, and they are not observed during late summer unless they have been subsisting on clover throughout the season, when they sometimes destroy the crop in August, as has been observed in Illinois. In early fall they often become common again on late garden peas, and late in October they migrate to clover. Fewer young are born as the weather gets colder in the fall, and the aphids never become numerous enough to do any injury at that season. Late in October and early November - in the Middle States-as the aphids are migrating to clover, winged males appear, and some of the wingless females developing on clover produce eggs. The winged males are similar in size and color to the migratory females, though slightly darker, and have three or four dark spots along the sides of the abdomen and a deep brown dash on either side of the back of each abdominal seginent. The oval eggs are about one-fiftieth inch long, jet black, and are deposited on the lower leaves or stems of clover, and hatch as it commences to grow in the spring. In central Illinois they were observed to hatch March 23d, and the young became full grown and commenced reproduction on April 5th, living until May 12th. In southern Maryland and farther south many of the viviparous females live over winter on the clover and commence to reproduce again in the spring, no eggs having been observed in that latitude, but in central Illinois and northward, the females are probably entirely destroyed by the cold and only the eggs survive.

Natural Enemies. - From 5 to 10 per cent of the aphids are normally destroyed by little wasp-like flies of the genus A phidius whose larvæ live within the aphids. A number of the more common ladybird-beetles, ${ }^{*}$ syrphus-flies, $\dagger$ and lace-winged flies, $\ddagger$ which commonly prey upon aphids, destroy large numbers of the pests, but their work comes so late in the season that the peas are seriously injured long before the aphids are checked by them, though they might prevent a reappearance the next year.

The most important enemy of the pea-aphis is a fungous disease (Empusa aphidis) which is undoubtedly the principal factor in its natural control. The most probable explanation of the

\section{* Family Coccinellida.}

† Family Syrphida.

I Family Chrysopida. Concerning these predaceous insects, see Chap. I. 
remarkable outbreak of the pea-aphis in 1899 and 1900 seems to be that, due to two exceptionally dry springs, the fungus was unable to develop, as it propagates best in damp weather, and the aphids increased unchecked. Though occasional individual aphids were found killed by the fungus carly in the season, not until June 11, 1900, were riseased aphids found in any quantity, but after that so swiftly did the disease destroy them that a weck later but few aphids were to be found and almost all were diseased. Probably this fungus usually destroys the aphids on clover before they have become excessively numerous or have migrated to peas.

Control.-Inasmuch as the aphids spread from peas to clover, the latter crop should not be planted near peas when avoidable. In the spring the aphids should be carefully observed on the clover and if they become excessively abundant, the only way to prevent their migration to peas is to plow under the clover deeply and roll the field.

Highly fertilized land in which the moisture is retained by frequent cultivation very often enables a crop to mature in spite of moderate injury. Peas sown broadcast or planted in 8-inch drills have been much more seriously injured than those planted in rows 18 to 30 inches apart and cultivated, and those planted close together afford no opportunity for brushing or cultivating as described below.

Early varieties of peas have practically escaped injury where late varieties have been wholly destroyed, so that it is obvious that only the earliest varieties should be grown where injury is anticipated.

Early in 1900 Professor W. G. Johmson found that when peas were planted in rows that the aphids could be readily knocked from the vines by means of brushing with a branch, and that by following the brushes with cultivators, the aphicls would be covered with earth and destroyed, either by suffocation or by the heat of the soil. Where the air temperature is $95^{\circ} \mathrm{F}$. the soil will be nearly $120^{\circ}$, and aphids brushed onto it will be actually roasted to death in a few minutes. The cultrvation should not be repeated for about three days, as it requires about that time for the destruction of the insects covered with earth, if it is not hot enough to kill them at once. By this method large areas of peas have been saved from destruction. 
Though the above methods will destroy quantities of the aphids and thus prevent the destruction of the crop, they do not dislodge the young aphids in the terminals, and therefore cannot be relied upon to prevent all injury. Practical field tests have shown that this may be done by spraying with whale-oil soap, 1 pound to 6 gallons of water. In small gardens this may be applied by means of bucket or knapsack pumps, and on small acreages with a barrel sprayer with a row-spraying attachment having nozzles arranged so that the vines will be thoroughly covered from each side. The spray must be applied with considerable pressure so as to foree it into the terminals. Here again nicotine compounds have largely displaced the soap and oil sprays, although soaps are largely used in connection with the nicotine. Mr. L. M. Smith recommends the use of the following formula

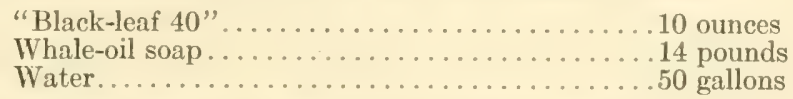

He also recommends that the spraying be done on a bright clear day so as to avoid injury to the vines from the spray material.*

\section{The Pea-moth $\dagger$}

The Pea-moth is an old pest in Europe, whence it was imported into Canada, where it has frequently done considerable mischief. It is known to occur in the large pea-growing sections of New Brunswick, Nova Scotia and Ontario, where it first attracted attention near Toronto in 1893, and was found in the pea growing section of Michigan in 1908. The wings of the adult moth expand about one-half an inch, the fore-wings being "dark, fuscous or dusky, tinged with darker brown and mottled with white," the hind-wings
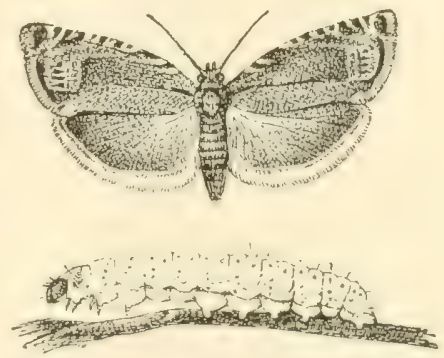

Fig. 252.-The pea-moth (Semasia nigricana Steph.): moth above, larva below-about three tines natural size. (After Chittenden, U. S. Dept. Agr.)

being a uniform fuscous with a rather long inner fringe of hairs, as shown in Fig. 252.

The females may be found flying around pea-blossoms soon

* L. M. Smith, Virginia Truck Expt. Sta., Bulletin for October, 1914.

† Semasia nigricana Steph. Family Tortricida. 
after sunset, and deposit one to three eggs on young pods. The caterpillar hatches in about fourteen days, according to European observations, and attacks the forming seed. Affected pods usually ripen early. The larva is whitish-yellow with a pale brown head and thoracic plate, and about one-half an inch long when full grown. With the opening of the pod the larva crawls out and enters the earth where it spins a very thin silken cocoon. The length of the pupal stage and the method of hibernation do not seem to be well established. Very early and very late varieties are but little injured.

Remedies.-This suggests one of the best means of handling this pest to be the growing of early varieties, such as Alaska, American Wonder, Gregory's Surprise, Nott's Excelsior, and McLean's Little Gem. If the crop is known to be infested, clean up the vines and burn them as soon as it is picked. Spraying with arsenate of lead will doubtless aid in the control where infestation is serious. 


\section{CHAPTER XVI}

\section{INSECTS INJURIOUS TO BEETS AND SPINACH*}

\section{The Beet-aphis $\dagger$}

Trus species was first described by Mr. W. R. Doane in 1900 and seems thus far to have been found only in Washington and Oregon. "Attention was first called to this pest," he says, f " in 1896, when it was found that a field of two or three acres of beets was generally infested, a strip of twenty-five to a hundred yards being so badly injured that the beets were nearly all soft and spongy, and the plants much smaller than the average.

"It has been even more destructive in Oregon than in Washington, at least a thousand tons of beets having been destroyed by it in one year in a single valley devoted largely to beet-culture. Like very many other beet-insects, this species infests also several wild or useless plants.

"The smaller rootlets of the beet are first attacked by this aphis, and if it occurs in considerable numbers these are soon all destroyed, and the leaves thereupon soon wither, and the whole beet shrivels and becomes spongy. This wilting of the leaves will

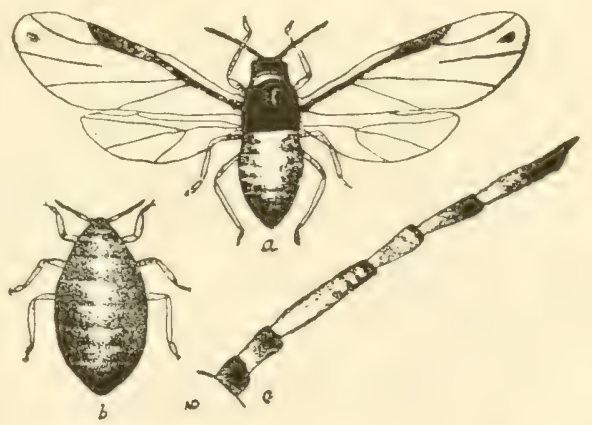

FIG. 253.-The beet-aphis (Pemphigus betor Doane): $a$, winger female; $b$, wingless female; $c$, antenna of winged female. (After Doane.) frequently, in fact, be the first thing to attract the attention of the beet-grower. The actual injury to the crop will, of course, depend

* See Forbes and Hart, Bulletin 60, Ill. Agr. Exp. Sta., and F. H. Chittenden, Bulletin 43, n. s., Div. Ent., U. S. Dept. Agr.

$\dagger$ Pemphigus bete Doane. Family A phidide.

\pm Bulletin No. 42, Wash. Agr. Exp. Sta. 
largely upon the time when the attack of the aphis is made. If the plants are small they may be readily destroyed, while if they are practically full grown the loss of the small rootlets will not materially affect them.

"No sexual generation of this aphis has as yet been discovered and no eggs have been seen, viviparous reproduction continuing throughout the year except when the cold of the winter temporarily suspends the physiological activities of the species. The winged females, appearing from time to time during the summer and fall, serve to distribute the species generally, new colonies being started wherever these females find lodgment and food. In districts liable to injury by this insect it seems inadvisable that beets should he the first crop on new land, or that ground should
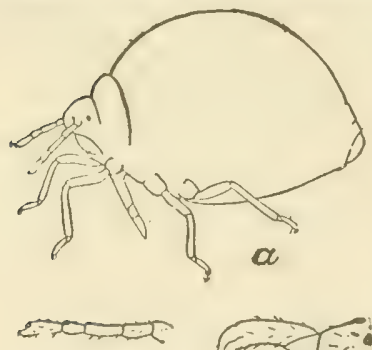

6

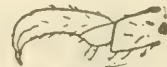

c

Fig. 254.-Beet root-aphis

(Tychee brericornis Hart): $a$, aphis; $b$, antenna; $c$, tarsus-all greatly enlarged. (After Garman.)

beets was also seriously damaged.

No practical means for controlling these pests seems to have been recorded, so that in case of injury the entomologist of the State should be consulted.

\section{White Grubs, Wireworms, and Cutworms}

Fortunately for the sugar-beet farmer the woist insect enemies of that plant feed upon the tops, and very rarely do we hear of serious damage being done the roots. In the East most of the damage to the roots is done by those familiar old farm-thieves, the white grub, the cutworm and the wireworm, As a general rule

* Tychea brevicornis Hart. 
they will be found to be worse on lands previously in sod, which should therefore be avoided when known to be bally infested with either of these insects, as both are difficult to fight after they have once commenced doing noticeable injury.

The life histories and means of control for these pests will be found discussed in Chapter VII.

\section{The Sugar-beet Webworm *}

The sugar-beet webworm is very similar to the garlen webworm, and is so named because it has developed as a serious
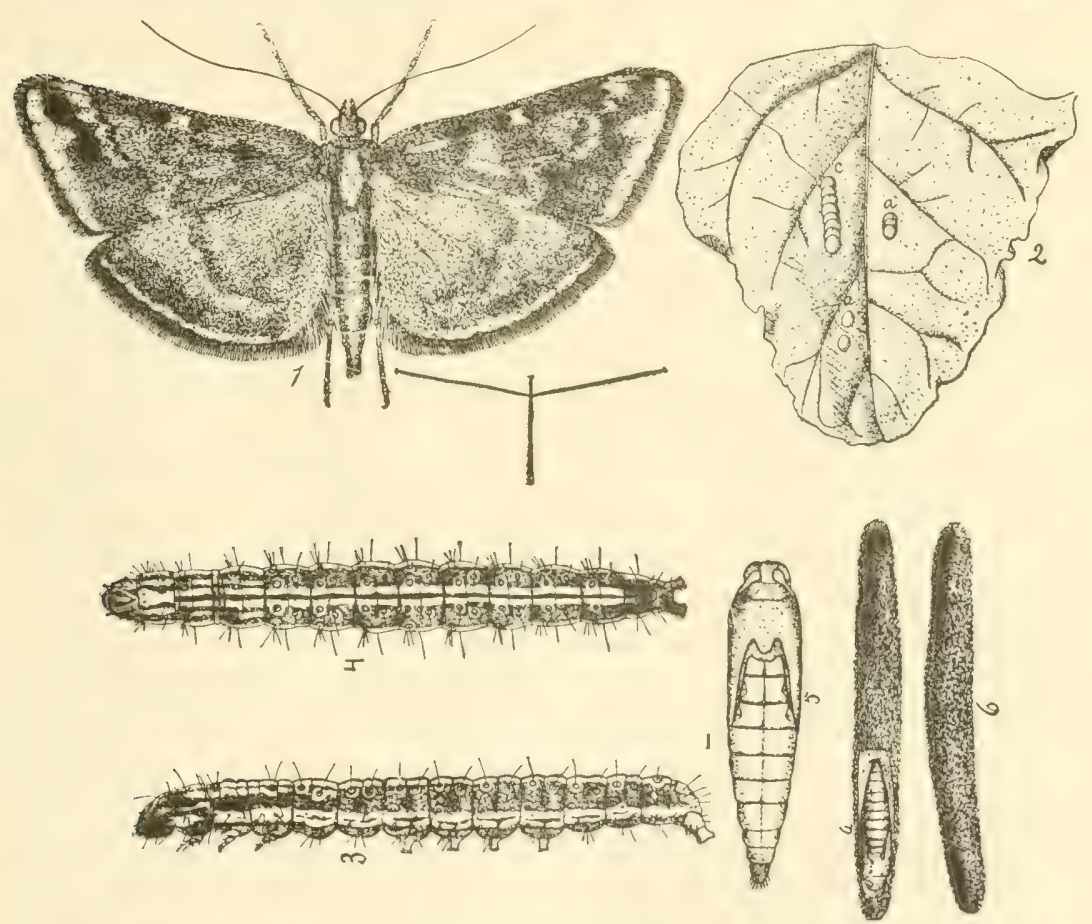

FIG. 255.-The sugar-beet webworm (Lorostege sticticalis Linn.): 1, moth; 2, eggs; 3,4 , larva; 5, pup: ; 6, winter tube of larva, opened at a to show pupa-1, 3, 4, 5, enlarged. (After Gillette, Colo. Agr. Exp. Sta.) pest of the sugar-beet in Kansas, Nebraska, and Colorado. It has been noted as injuring tansy in Michigan, and feeds on

* Loxostege sticticalis Linn. Family Pyraustida. See C. P. Gillette, Bulletin 98, Colo. Agr. Exp. Sta., and references there given. 
cabbage, onions, and alfalfa, as well as pigweed (Chenopodium album) and careless weed (Amaranthus) and will probably feed on many other crops. It is a native of western and central Europe, and northern Asia, and was evidently introduced on the Pacific Coast, as it was noted in Utah in 1869.

The moth is larger than the garden webworm, having a wing expanse of an inch, and is a purplish-brown color with darker and paler bands as shown in Fig. 255. The full-grown larva is about an inch long, of a dark color with a white stripe down the back and one along either side, and marked with numerous black and white tubercles as illustrated.

Life History.-The larvie hibernate over winter an inch or two below the surface of the soil in long silken tubes. In spring they pupate in these tubes and the moths emerge about the middle of May. The eggs are laid on the foliage either singly or in clusters of from three to ten, one overlapping another. The egg is broadly oval, one twenty-fifth inch long, and of a pale green color. The first generation of caterpillars feed on pigweed and alfalfa in Colorado during June. A second generation of larvæ occurs about the middle of July and sometimes injures beets, but the third generation about the middle of August is the one most injurious in Colorado. Most of these larvæ hibernate over winter, but there is a partial fourth generation in Colorado. The larvæ defoliate the plants, and cover them with a web the same as the native garden webworm, with which the life history seems to be practically identical.

Control.- The same means of control as for the garden webworm are advised.

\section{The Beet Army Worm*}

"This caterpillar, which replaces the fall army worm ( $L$. frugiperda-see Chapter VII) in the Western States, differs from it by its more decidedly mottled ground-color, by a row of white dots at the lower margin of the lateral dark band, and by the yellower color of the light stripes. It is an interesting fact that while the preceding species was doing serious, unusual, and widely extended injury in the Eastern and Southern States $(1899$, the present one was similarly abundant in Colorado, where,

* Laphygma exigua Hubn. Family Noctuida. 
besides destroying many kinds of weeds and grasses, it completely defoliated thousands of acres of sugar beets. In some cases where the foliage of the beet did not furnish it sufficient food, the root was attacked and the upper surface was completely gnawed away. L a te plantings, of course, suffered most severely, especially when surrounded by newly broken ground. The weeds most generally eaten were pigweed, saltweed, wild sunflower, and Cleome. Potato, pea, and apple leaves were also devoured. These injuries occurred about the middle of August, at which time the larvæ and pupæ were abun-
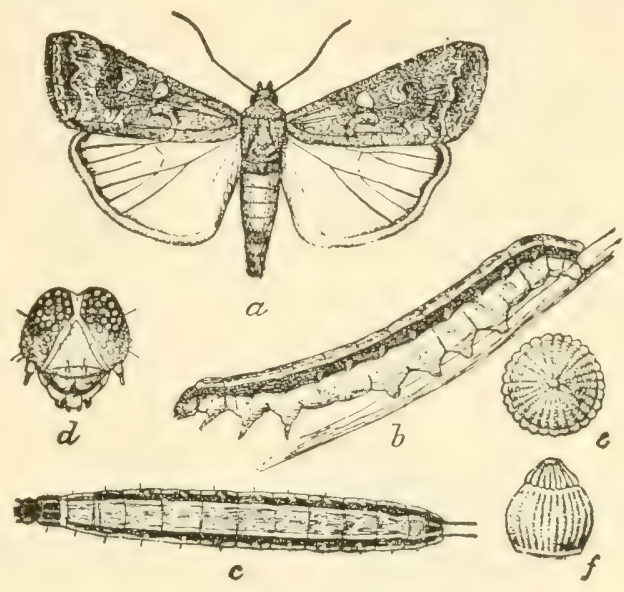

FIg. 256.--The beet army worm (Laphygma exigua Hubn.): $a$, moth; $b$, larva, side view; $c$, larva, back view; $d$, head of larva; $e$, egg from above; $f$, egg from side-all enlarged. (After Chittenden, U. S. Dept. Agr.) dant, and a few moths laden with eggs were noticed."

This species evidently hibernates as a moth, and at least two broods of larvæ may be looked for each year, the first about. June and the second in August. The species has been reported thus far from Colorado and California, but it doubtless has a more extended range in the mountain regions of the far West.

"Professor Gillette's ficld-experiments showed that it could be destroyed by dusting or spraying arsenical poisons on the leaves."

\section{Flea-beetles}

Several species of flea-beetles, chiefly Systena toniata, Systena hudsonias, Disonycha triangularis, and Phyllotreta vittata, often do considerable injury by gnawing small holes in the upper and lower surfaces of the leaves of beets, giving them an appearance as if affected by leaf-spot, or puncturing them full of small holes, and thus stunting the growth of the plants. 


\section{The Spinach Flea-beetle *}

Of the many species of flea-beetles injurious to sugar-beets, the spinach flea-beetle is one of the largest and most destructive. The beetle is nearly one-quarter inch long, shining black, with a greenish or bluish lustre. The prothorax and abdomen are red or reddish yellow, and the legs and antennæ are pale yellowish. It occurs from New England to Montana and southward to the Gulf, and is one of the most common pests of beets and spinach, while its native food plants are chickweed and lambsquarter.

Life History.-The beetles hibernate over winter and emerge in the spring during April and May. The buff or orange eggs are
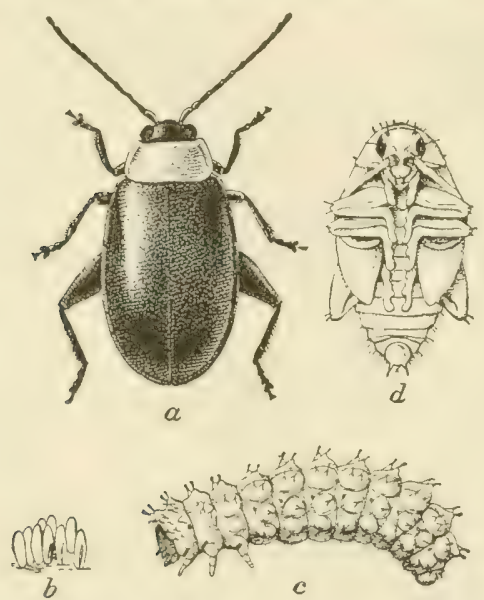

laid on end in small masses, "at the bases of the plants infested, on bits of leaf or earth, or even within the earth" according to Forbes. The eggs hatch from sometime in April to early July, according to locality. The larvæ usually feed on the under side of the leaf, keeping together in families which migrate from

Fig 257. - The spinach flea-beetle (Disonycha leaf to leaf while xanthomelona Dalm.): $a$, beetle; $b$, egg mass; $b b$, sculpture of egg; $c$, larva; $d$, pupa; $e$, young young, and drop to the larva; $f$, abdominal segment of same- $a, c$, $d$, ground - as do the $f$ highly magnified. (After Chittenden, U. S. beetles-when disDept. Agr.)

turbed. While young they merely gnaw the under surface of the leaf, but later they eat through and riddle it with round holes, in which they are aided by the beetles. The full-grown larva is about one-quarter inch long, of a dull gray color, except on red and purple beets, on which it assumes the color of the plant attacked, is of a cylin-

* Disonycha xanthomelerna Dalm. Family Chrysomelidee. See F. H. Chittenden, Bulletin 43, Bureau of Ent., U. S. Dept. Agr., p. 14; S. A. Forbes, 21st Rept. State Ent. of Ill., p. 116. 
drical form, and the segments are strongly marked by rows of raised tubercles, each of which bears a black hair at the tip. The larvæ become grown in late June and early July in Illinois, and enter the earth to pupate, the beetles of the next generation emerging about a month after the eggs were deposited. The beetles of the second generation lay their eggs from July to September and the beetles mature before winter sets in. In the District of Columbia, Chittenden observes that the first generation is more abundant on chick-weed and the second is injurious to beets and spinach.

Control.-Thoroughly dusting or spraying the plants with arsenate of lead will readily destroy the larvæ and probably most of the beetles. As in combating all flea-beetles the destruction of the weeds upon which they multiply is important.

\section{The Larger Beet Leaf-beetle *}

One of the principal pests of the sugar-beet in Colorado and adjacent States is a rather large brownish leaf-beetle which with its larvæ destroy the foliage or so injure it that the plant dies. It is often locally known as the "alkali bug " from the fact the injury is mostly on alkali soil or land near it, and "french bug," probably from the "frenching" of the foliage. The beetle is from one-quarter to one-third inch long, and rather resembles the elm leaf-beetle, varying from pale yellow to black, with the wing-covers striped as shown in Fig. 258. Several wild plants, including blites, Russian thistle, and saltbush $\dagger$ probably furnish the normal food of the insect.

"The beetles are gregarious, 'sometimes occurring in swarms like blister-beetles.' 'Their brownish-gray eggs are deposited in irregular masses, usually on the under sides of the leaves. They hatch in about six days, and their larvæ or young commence feeding at once, continuing for nine or ten days, when they dig their way into the ground, a few days later coming forth as beetles. Although the beetles do much injury, the principal damage is sometimes accomplished by the larvæ, hundreds being found on a single plant, which is either consumed or so injured that it shrivels and dies. The larva, shown in the illustration, measures

* Monoxia pancticollis Say. Family Chrysomelidae.

†Dondia americana and D. depressa, Salsola tragus, and Atriplex argentea. 
when full grown about one-third of an inch in length. The general color is nearly uniform dark olive brown, the conspicuous piliferous tubercles being pale yellow, and the head and portions of the legs black. The eggs are dull brownish gray, and the surface, as seen through a lens, is covered with septagonal and hexagonal areas."*

Control.-Paris green diluted with flour and dusted over the foliage has effectively controlled the pest, and probably any thorough application of any arsenical either wet or dry would be effective. Professor C. P. Gillettet has observed that the beetles accumulate on the "mother" beets early in the spring, so
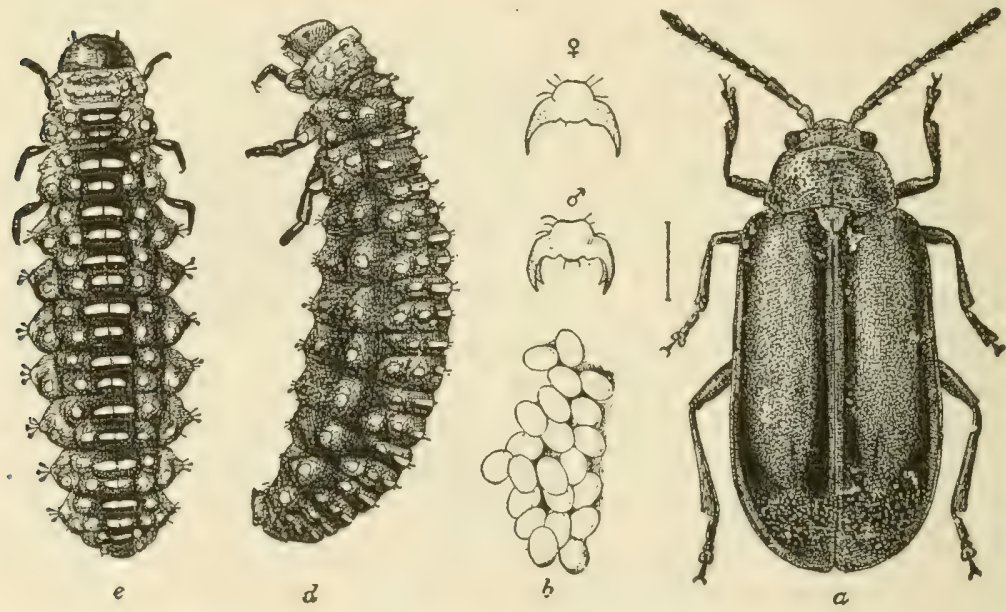

Fig. 258.-The larger beet leaf-beetle (Monoxia puncticollis Say): $a$, female beetle; $b$, eggs; $c, d$, larva from above and side; ${ }^{5}$, claw of male; or, claw of female-all much enlarged. (After Chittenden, U. S. Dept. Agr.)

that if a few beets were left in the ground over winter they might serve as trap plants for the protection of the younger plants in spring. As injury is mostly on or near alkali ground, such soil should be avoided.

* Quoted from F. H. Chittenden, Bulletin 43, Bureau Ent., U. S. Dept. Agr., p. 10.

†C. P. Gillette, 24th Report Colo. Agr. Exp. Sta. (1902), pp. 108-111. 


\section{The Beet Leafhopper*}

Very serious loss to the sugar-beet industry has occurred in Colorado, California and Utah from a condition known as "curly leaf " or " blight." Investigations made by Professor E. D. Ball have shown that the "curly leaf" is undoubtedly caused by the presence of immense numbers of small leafhoppers, from 10 to 100 often being found on a plant in badly infested fields. The curly leaf condition does not seem to result, however, except when the
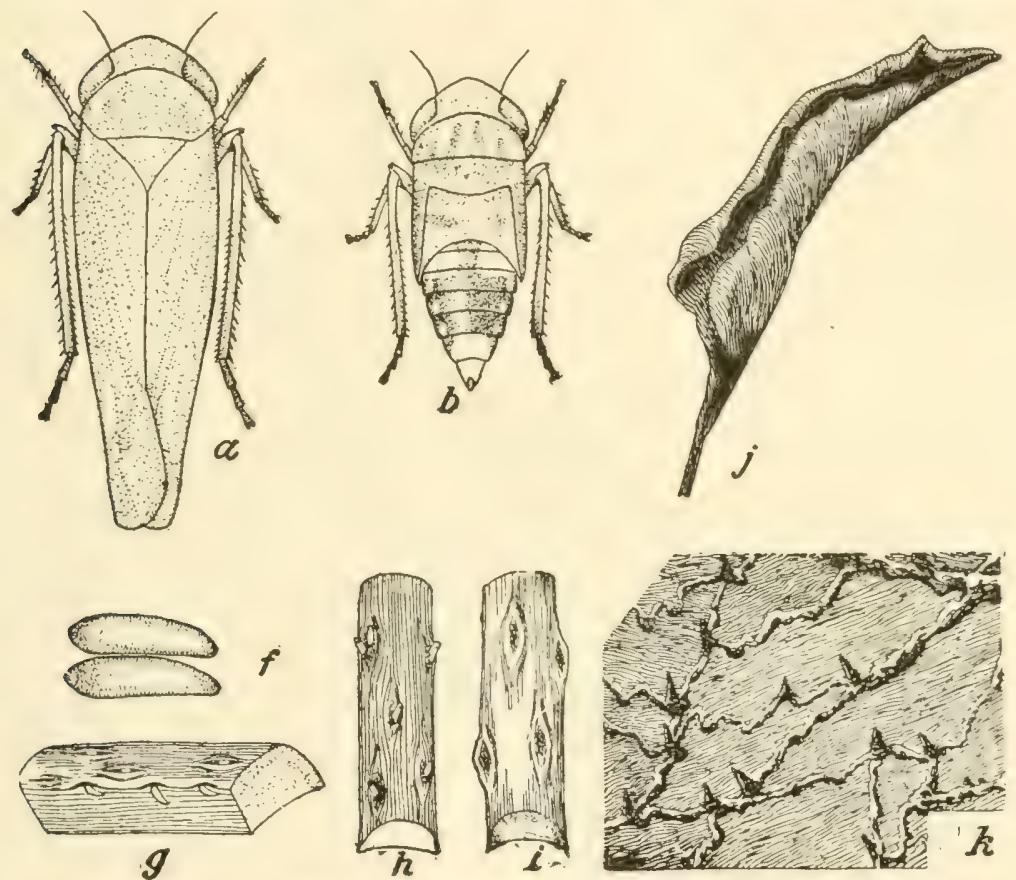

FIG. 259.-The sugarbeet leafhopper (Eutettix tenella Baker): a, adult; $b$, nymph; $f$, eggs-greatly enlarged; $g$, section of beet stem showing fresh eggs in place; $h$, same showing eggs ready to hatch; $i$, old egg scars on beet stems; $j$, small leaf of sugar beet showing characteristic "curly-leaf" condition; $k$, enlarged section of back of an extreme case of curly-leaf showing warty condition of veins. (After Ball, U. S. Dept. Agr.)

soil has become dry and heated, and where plants are shaded or irrigated the damage by the leafhoppers does not seem to produce

* Eutettix tenella Baker. See E. D. Ball, Bulletin 66, Part IV, Bureau of Entomology, U. S. Dept. Agr, and Bulletin 155, Utah Exp. Sta. 
the same trouble. Similar injury has been noted in parts of Oregon, but not of so serious a nature.

The beet-leafhopper is a pale yellowish-green species (Fig. 259), one-eighth to three-sixteenths inch long, and when flying appears almost white, so that it is sometimes locally called the "white fly."

Life History.-The hibernating habits of the adults and their food-plants in the spring have not been well determined. They

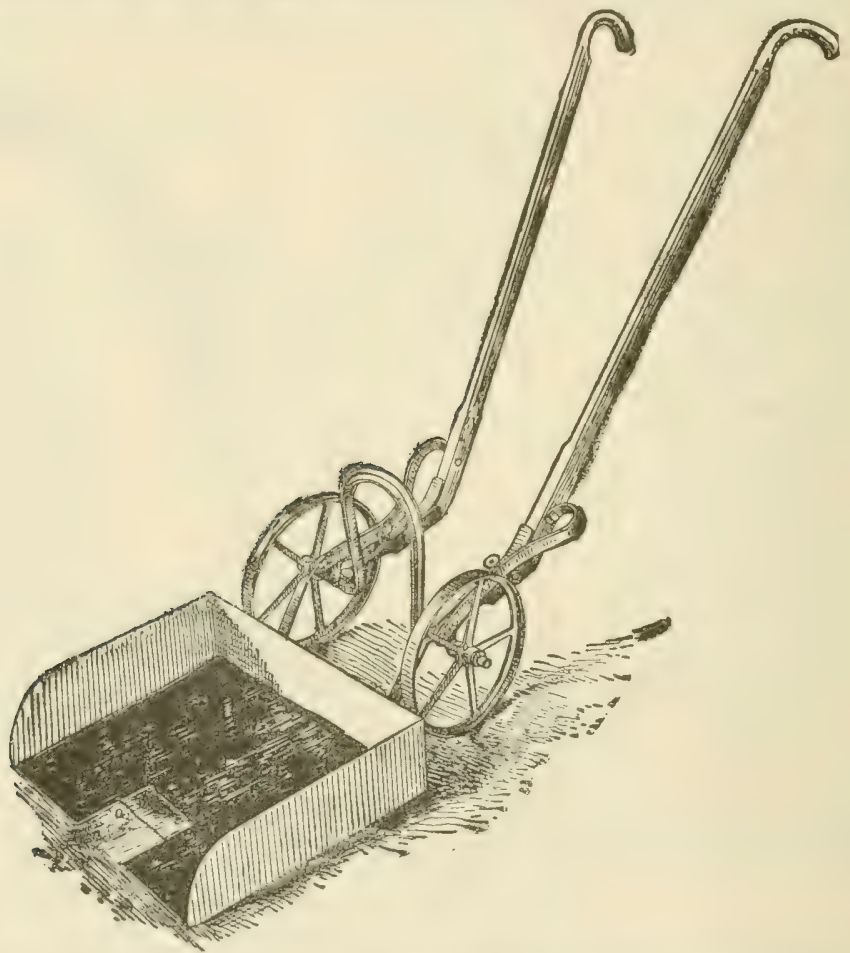

Fig. 260.- "Hopperette" designed for collecting leafhoppers. (After G. C. Davis, Mich. Agr. Exp. Sta.)

appear in the beet-fields late in June and lay their eggs in the leaf-stems, the eggs hatching in about two weeks. The young nymphs appear in July and are very active, being first found in the unfolding leaves at the centre and later spreading to all parts of the plant. The nymphs are variously colored, but the commonest form is a pale creamy color with a brown saddle on the 
middle of the abdomen and various mottlings on the prothorax and wingpads. The nymphs become full grown in from sixteen to twenty-two days and the adults again become abundant in August and September; they evidently hibernate as adults, as no more eggs are laid in the fall as far as observed.

The characteristics of the "curly leaf" are described by Dr. Ball as follows: "The first symptom of 'curly-leaf' or 'blight" of the beetisa thickening of all the smaller veinlets of the leaf, giving it a roughened appearance on the under side. This is followed by a curling of the edge and a final rolling up of the leaf, the upper surface always being rolled in. As this progresses the smaller veinlets grow still larger and more irregular, knotlike swellings appear at frequent intervals, and in extreme cases little nipple-like swellings appear, extending to a height of nearly one-fourth of an inch. This will be noticed first on a mediumsized leaf, gradually spreading to the younger ones, while at the same time the beet almost stops growing and a large number of fibrous roots are sent out. . . . The beet of ten continues in this way throughout the season; in bad cases it shrivels and dies, while in a few instances there is a partial recovery and a new set of leaves, though the sugar content remains very low."

Control.-Practical measures of control do not seem to have been very thoroughly tested. With a better knowledge of the hibernating habits of the species, it may be possible to reduce its numbers at that time. After the hoppers have appeared in numbers they must be dealt with promptly. "A thorough spraying with kerosene emulsion at a strength of 1 part of the stock solution to 5 parts of water, would destroy most of the insects that it hit, and by using a drag in front of the nozzles to turn the leaves over and cause the insects to jump, most of them would be reached." This would probably need to be repeated in about ten days. Hopperdozers have often been successfully used for collecting various forms of leafhoppers. A modification of the form used against grasshoppers with a couple of wings extending out on either side of the row and covered with a sticky substance such as "tanglefoot" or that described on page 458 would undoubtedly prove effective in collecting the adults, particularly before the females have laid their eggs, when they are more readily caught. A "hopperette" designed by Professor 
G. C. Davis for use against leafhoppers on celery in Michigan, is shown in Fig. 260, and may be readily attached to the frame of a wheel hoe. The string across the notch at $A$ strikes the plants and causes the hoppers to jump at the right time. By adding high wide wings to either side of this machine it should be well adapted for beets and similar crops.

However, even the capture or killing of large numbers of the leafhoppers by the means suggested will not, according to Dr. Ball, solve the question of preventing the disease they carry, since a single puncture will often kill a leaf. Some means for the destruction of the hoppers before they reach the beet fields will be necessary before the disease can be eliminated. The outlook for certain beet-growing sections is, therefore, still serious.

\section{Blister-beetles *}

Among those insects attacking the young sugar-beets and often doing considerable damage after they have become partly grown, few are more widespread or do more general injury than the blister-beetles. They have been especially destructive in the northern Mississippi Valley, where they are usually worst after a period of unusual abundance of grasshoppers. Coming suddenly in a large swarm, they settle in a field and thoroughly
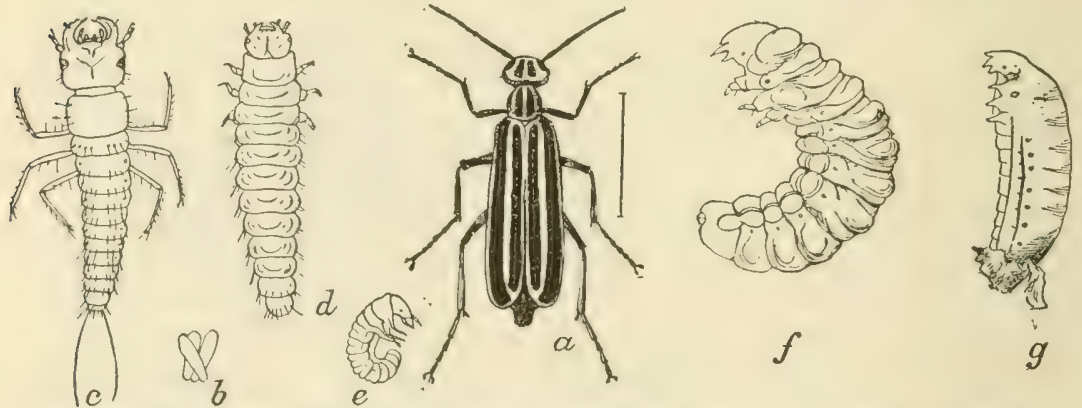

FIG. 261.-The striped blister-beetle (Epicauta vittata): a, female beetle; $b$, eggs; $c$, triungulin larva; $d$, second or caraboid stage; $e$, same as $f$ doubled up as in pod; $f$, scarabeoid stage; $g$, coarctate larva-all except $e$ enlarged. (After Riley and Chittenden, U. S. Dept. Agr.)

riddle the foliage with holes or strip it bare before going to another field.

One of the most common forms is the striped blister-beetle, or "old-fashioned potato-bug" (Epicauta vittata), which is

* Family Meloidæ. 
shown in the illustration, together with the immature stages. The ash-gray blister beetle (Macrobasis unicolor) is also a common form, shown in Fig. 247. Three or four other forms are common throughout the country, but are especially numerous in the West, where grasshoppers are more abundant. The reason for this is discussed, along with an outline of the life-history, in Chapter VII under the heading of natural enemies of the grasshoppers.

Remedies.-However, when they swarm into the beet-fields, potato- or garden-patches, one cannot afford to allow them to consume one crop for the good they may do in saving another from still another insect scourge. So be ready for them on their first appearance; give the plants a thorough spraying with 1 pound of Paris green and 1 pound of lime to 125 gallons of water. It may be well to spray with Bordeaux mixture, which will prevent various fungous diseases, and with which Paris green can be used much stronger without danger of burning the foliage; or it may be applied dry by mixing with from ten to twenty parts of flour or plaster, dusting it on in early morning, while the dew is still on the plants. Arsenate of lead sprayed at the rate of 3 pounds to 50 gallons, or used as a dust, will be equally effective, will adhere to the foliage better, and will be less likely to burn the foliage.

\section{The Beet or Spinach Leaf-miner*}

Frequently beet and spinach leaves will be found with tortuous mines or large blotches which have been mined out by small white maggots beneath the surface epidermis. This injury is most commonly due to the maggot of a small fly shown in Fig. 262. "The ground color is gray with the front of the head silver white. The body, including the legs, is somewhat sparsely covered with rather long stiff black hairs. When in action the body is usually carried in a somervhat curved position, but when extended measures nearly a quarter of an inch. The maggot $(f)$ is white, and so nearly transparent that the contents of the abdomen ean be seen through the posterior portion."

Life History. - "The flies, by close observation, may be seen in flight just above the ground or hovering about their different food plants. The eggs are placed on the lower surface of the

* Pegomyia vicina Lintn. See Chittenden, 1.c., from which the quotations are taken. 
leaves and arranged in masses of from two to five. When the young hatch they bury themselves within the leaf tissue, constructing a thread-like mine which they afterwards extend in a curve or semicircle. Transformation to pupæ takes place in most cases in loose soil, which the maggots enter to only a short distance, or under fallen leaves. Occasionally maggots transform within a leaf if the latter happens to rest on the ground. Dr. Howard states that the eggs hatch in from three to four

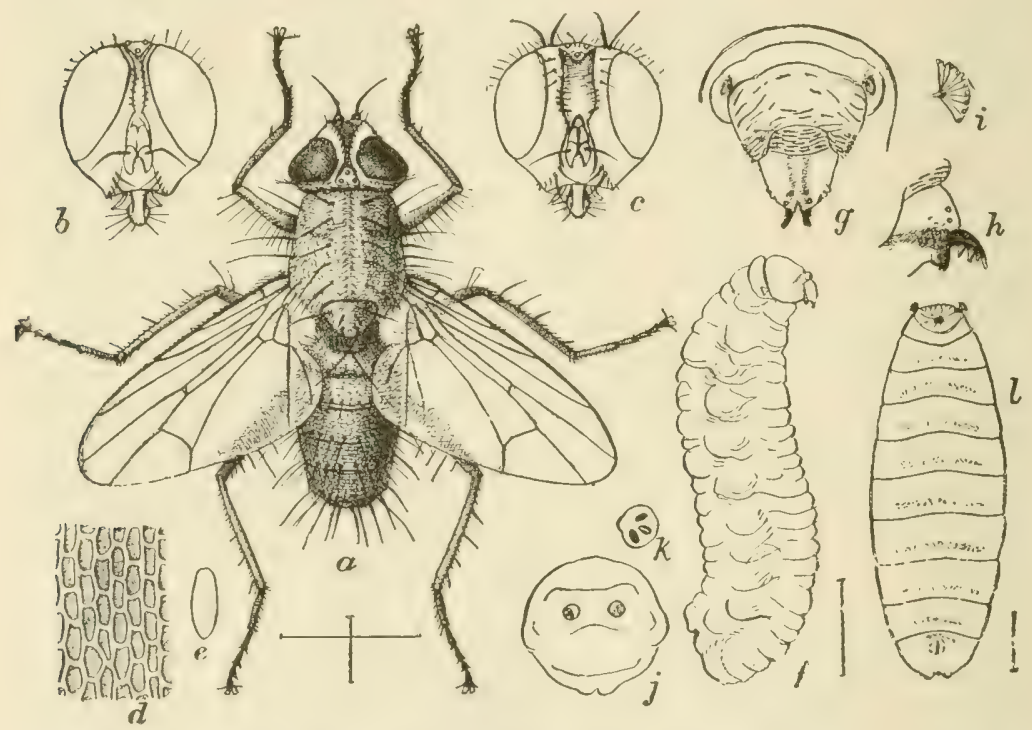

FIG. 262.-. The beet leaf-miner (Pegomyia vicina Lintn.): $a$, fly; $b$, head of male fly; $c$, head of female; $d$, surface of egg highly magnified; $e$, egg; $f$, maggot; $g$, head of same; $j$, anal segment; $k$, anal spiracles-all enlarged. (After Howard, U. S. Dept. Agr.)

days, and the larval stage is passed in seven or eight days, the puparium or resting stage requiring from ten to twenty days. "Injury appears to be most frequent in late fall, but even in larger fields such a practice might prevent its increase may be due to earlier generations in midsummer. "In many cases infestation can be traced directly to the insect having bred in lambsquarters and similar weeds, which if not destroyed by ordinary methods of cultivation mature and die during October." 
Control. -Where this pest occurs in small gardens it may be controlled by picking and destroying the infested leaves, and even in larger fields such a practice might prevent its increase and consequent injury. Those insecticides which have been tried as remedies seem to have had no effect. Deep plowing and thorough harrowing of infested fields as soon as the crop can be removed should greatly lessen injury the next year. As this species seems to prefer spinach to beet, Dr. Chittenden has suggested that spinach might be used as a trap crop in large fields of sugar beets where the injury warranted such a measure. 


\section{CHAPTER XVII}

\section{INSECTS INJURIOUS TO CABBAGE AND RELATED CROPS*}

\section{The Cabbage Maggot $\dagger$}

Throughout the Middle and Northern States the cabbage maggot is one of the most destructive and most difficult to combat of

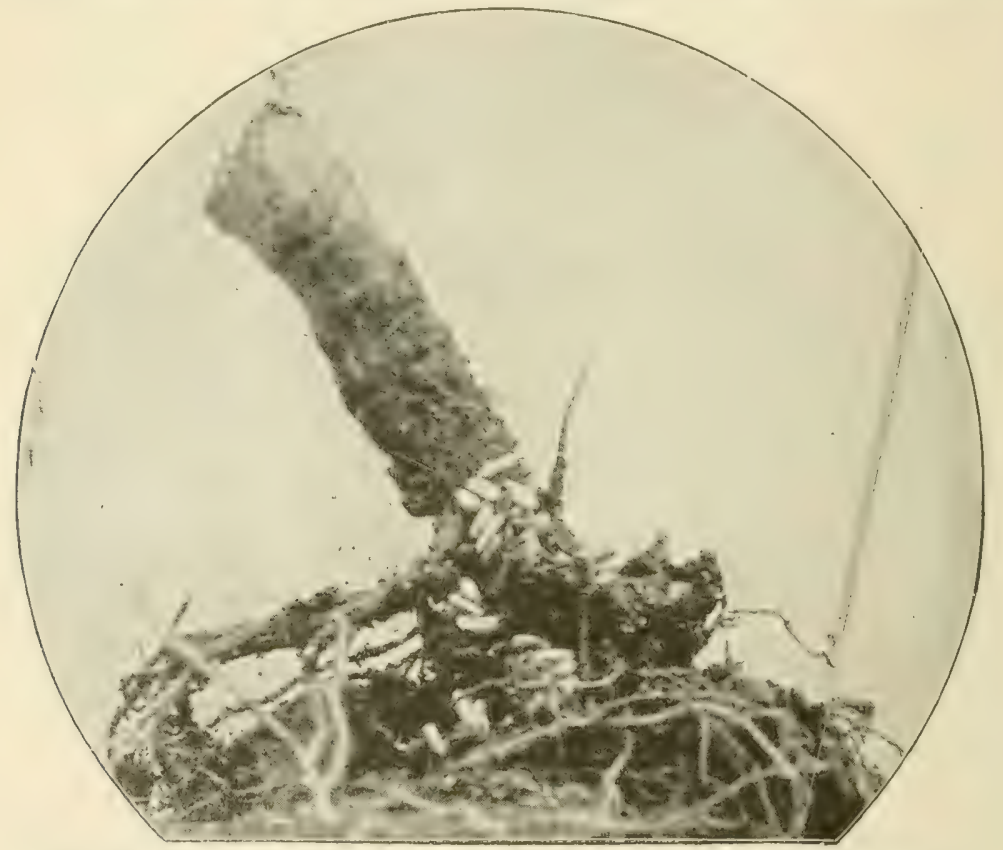

Fig. 263.-Cabbage root infested with maggots. (After Slingerland.)

all the insects affecting cabbage, cauliflower and radishes. Just as the plants are commencing to make a good growth they sud-

* See Garman, "Insects Injurious to Cabbage," Bulletin 114, Ky. Agr. Exp. Sta.

† Phorbia brassice Bouché. Family Anthomyizder. See W. J. Schoene, Bulletins 382 and 419, N. Y. Agr. Exp. Sta., Journal of Economic Entomology, Vol. IV, p. 210. 
denly appear sick, many are found wilting, and soon die. Examination of the roots shows that they have been riddled by small, white maggots as shown in Fig. 263. Early-planted cabbage, cauliflower and radishes are particularly affected, and later in the season the maggots will be found on turnips and wild mustard.

These maggots are the larvæ of a small fly, resembling the house-fly, but distinctly smaller, being only one-fourth inch long, with a narrower body and proportionately larger wings. It is a grayish color with three dark stripes on the thorax and one

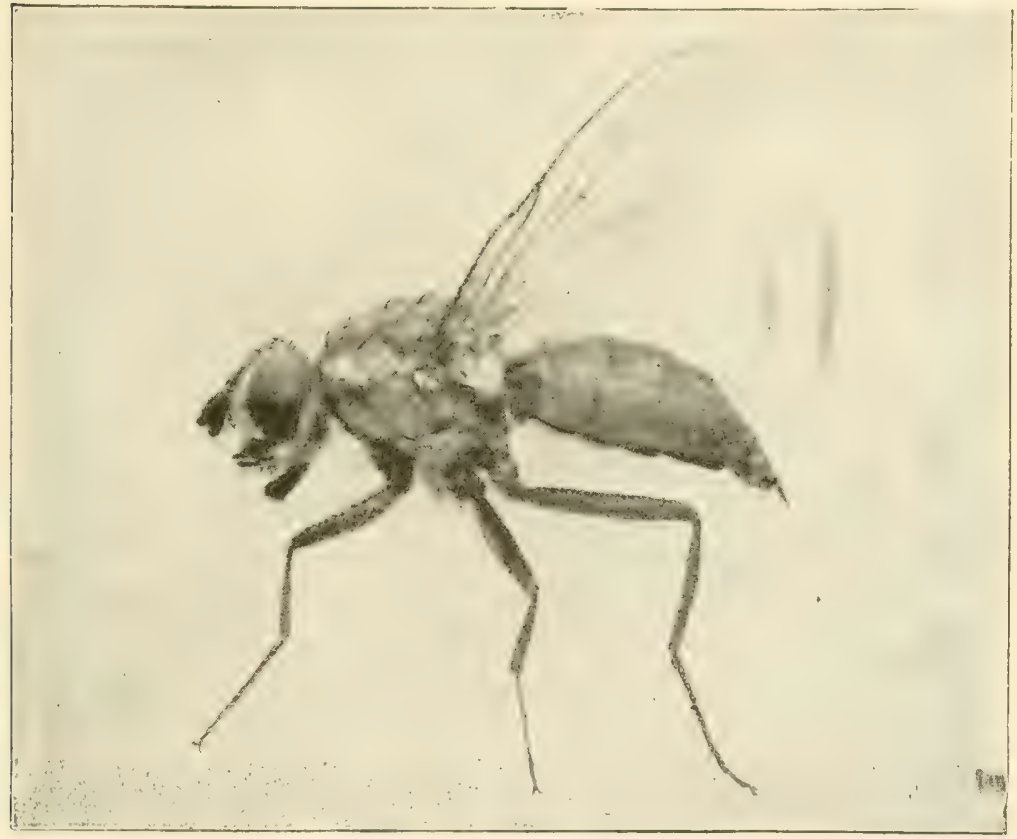

Fig. 264.-The cabbage maggot fly (Pegomyin hrassica Bouche), female, greatly enlarged. (After Slingerland.)

along the middle of the abdomen, and the body bears numerous stiff hairs or bristles. The flies appear just as early cabbage is set out, in late April and early May in New Jersey, and in late May in southern Minnesota. They do not fly far and seem to avoid fields which are swept by the wind.

Life History.-The females deposit their eggs on the stem of the plant or in the soil near the stem, at or just beneath the surface of the soil, each female laying some fifty eggs. The eggs are most 
abundant in late May and early June in central New York. Usually a female lays but one or two eggs on a plant and prefers to lay them in a crevice of the stem or very near it, for if the young maggots have to travel far to reach their food, many will die before finding it, and if laid on hard soil the maggots will be unable to penetrate it to the soft tissue of the root, as they are unable to feed on the hard stem above ground. The eggs are about one twentyfifth inch long, of a pure white color, which renders them easily seen against the soil by one familiar with them, and are of the shape shown in Fig. 265, having a curious ridge along one side. The eggs hatch in from three to ten days, averaging five to seven. The little maggots at once commence rasping the surface of the tender roots, gradually mine into them, and in three or four weeks have become full grown. The grown maggot is one-third inch long, white or yellowish in color, tapering toward the head and

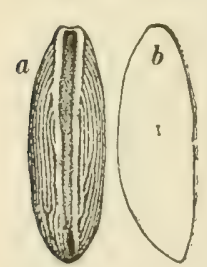

Fig. 265.-Egg of cabbage $\mathrm{mag} \mathrm{g}$ ot, greatly enlarged; hair line at center of $b$ shows natural size; $b$, outline of side view.(After Slingerland.) obliquely truncate at the tip of the abdomen. From the head a pair of strong, black, hook-like, rasping jaws project downward, and just back of the head on either side is a minute, light brown, fanlike projection (Fig. 267b), or spiracle, which leads into the breathing system. The oblique posterior end is surrounded by twelve rounded tubercles and in the centre are two brownish spiracles (Fig. 267a). When done feeding the larva burrows one-half to one inch under the surface of the soil, and the outer skin gradually hardens until it forms a firm brown shell, called a puparium, within which the larva transforms to a true pupa. Frequently the puparia are found in the galleries made by the maggot or in crevices of the roots. During the summer this stage lasts about two weeks, but in the fall most of the insects remain in this condition over winter. Thus the whole life cycle from egg to adult requires about six to ten or twelve weeks, according to the temperature and moisture, and the second generation of flies appear in June in New Jersey or by mid-July in southern Minnesota. The maggots of the second generation seem to do but little damage. The life history of the insect during late summer has not been satisfactorily determined, but there is undoubtedly a third generation and in the South, possibly a fourth, the work of the last gen- 
eration being sometimes noticed in late cabbage in early fall. On Long Island, N. Y., the larvæ have been observed as abundant upon cabbage stumps in September and October, working above ground, and the adults and eggs have been common around the adventitious buds. Rough estimates indicate 300 to 1500 maggots per acre on these stumps. The puparia, of the last, and in the North possibly some of those of the second generation remain in the soil over winter, though there is some evidence that the flies may also hibernate in the Middle States.

Control.-The most effective measures of control consists in cultural methods and preventives, but little practical success having attended the use of remedies to kill the maggots.

Cultural Methods.-Inasmuch as the puparia remain in the soil or in the old roots or stumps over winter, it is important for this as well as other $\mathrm{cabbage}$ pests to gather and destroy all the refuse of the crop as soon as possible and then plow infested land thoroughly in the fall. Mr. Schoene has shown that by plowing badly infested seed-beds six or seven inches deep that only one-fourth as many flies emerged as where the soil was undisturbed. A rotation of the crop will be of value where cabbages are not grown on large acreages. Cabbage and other cruciferous crops should not be planted after each other, as all

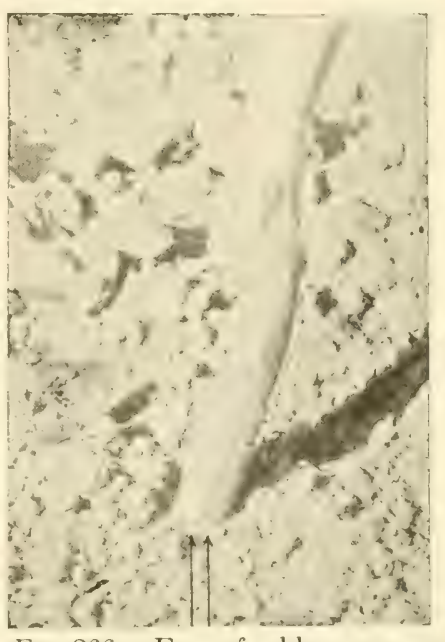

FIG. 266.-Eggs of cabbage maggot at hase of stalk. (Photo by Headlee.) are affected by the same pests. It is evident that if the crop is planted at some distance from that of the previous year, and as the flies are known to avoid wind-swept fields, that many of them will not succeed in finding the new planting.

As the maggots infest wild mustard and various similar weeds, these should be destroyed as far as possible and crops affected by the maggots should not be planted on or near land badly infested with such weeds if avoidable. Wild mustard may be readily killed 
by spraying it while young with iron sulfate, 2 pounds to 1 gallon of water.

Late-planted cabbage is but slightly affected as compared with that planted earlier. The earliest radishes are often quite free from the pest, those planted later and maturing just as the flies are abundant are badly injured, and the later plantings are free from injury.

It is evident, therefore, that where planting of the main crop can be delayed until after most of the flies have oviposited, that it will escape serious injury. Furthermore, either cabbage or radishes may be used as a trap crop, by planting a few rows early and as soon as the flies have laid their eggs on them, plowing

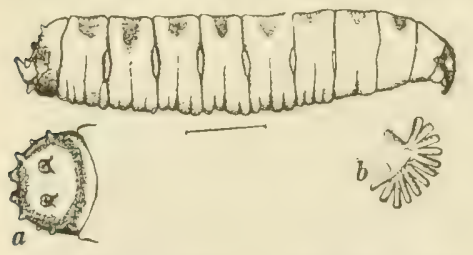

FIG. 267.-Cabbage maggot, side view, enlarged, hair line represents natural size; $a$, view of caudal segment; $b$, outline of spiracle back of head-greatly enlarged. (After Slingerland.) them under deeply and then setting the main crop. All of these methods involve a familiarity with the fly and its eggs which any observant grower may soon acquire.

High fertilization with a quickly available fertilizer will enable the plants to make a rapid growth and will be profitable even if maggots do not occur.

Thorough and frequent cultivation while the eggs are being laid destroys many of them. Indeed, one of the best means of control, which is extensively practiced by many growers, is to hill up the earth around the young plants when set, and as soon as eggs are laid, pull the soil containing the eggs away from the plant into the middle of the row, where they or the maggots hatching from them will be killed by the heat. This involves considerable hand work, but where carefully and intelligently followed is one of the surest means of control.

Preventives. - Where late cabbage is grown the plants often become infested in the seed-bed. To avoid this the seed-beds should be covered with cheesecloth. The sides of the frame are made of 12-inch boards, across which wires are stretched to prevent sagging of the cloth, as the whole must be fly-tight. The cover should be removed a week or ten days before transplanting, so that the plants may harden. If eggs are observed in the seed-bed during this time, transplant at once. 
The most successful preventive yet used consists of a tarred felt card placed around each plant so as to form a collar, lying upon the surface of the soil and thus preventing the fly from depositing her eggs. These cards were originally devised by Professor W. H. Goff, of Wisconsin, and have been extensively used by large growers in that State for many years, as well as in New York, and experiments in New Jersey and Minnesota have proven them very satisfactory. The cards should be made of one-ply tarred felt, as ordinary tarred paper or building paper curls up and is not as effective. The cards are made in a hexagonal shape, with a slit extending from one corner to the centre, which is slit with a star-shaped cut to accommodate the stem. The cards are cut with a tool shown in Fig. 269, which may be made by any blacksmith, and are cut out in rows as illustrated, one cut of the tool making a card. The cards should be placed around the plants when

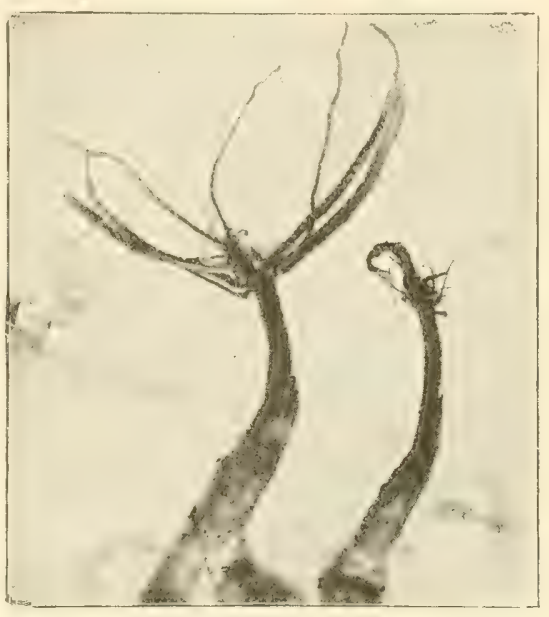
they are set. The earth Fig. 26s.-Calhage ronts destroyed by the should be smoothed down cabbage miggrot. (After Slingerlanil.) and well firmed by the hand, the card then applied to the plant, and pressed down tight to the ground, so that it fits snugly around the stem and the edges of the slit meet. With a little experience the cards may be applied rapidly, and though involving considerable handwork, the testimony of those who have used them for many years shows that the method is entirely practical and is to be preferred to doubtful remedies.

A mixture of lime and carbolic acid has recently been used by applying it to the surface of the soil around the plants, so as to form a slight crust, the carbolic acid acting possibly as a repellant. The lime is slaked to a thin cream, and diluted to 3 pints to a gallon of water to which is added a tablespoonful of crude carbolic acid. It is applied liberally to the 
soil immediately around the plants with a sprinkling can. This has proven quite effective for cabbage in New Jersey, but in Minnesota cabbage so treated showed but little benefit, though radishes were somewhat protected. Kerosene and sand, gas tar and sand, tobacco dust and many other substances have been used to place around the plant and act as repellants or preventives, but all have some objection or have not been sufficiently tested to show their effectiveness and practicability. Dr. J. B. Smith reports, however, that cauliflower-growers at Richfield, N. J., have been using gas tar, 1 part to 25 parts of sand, for
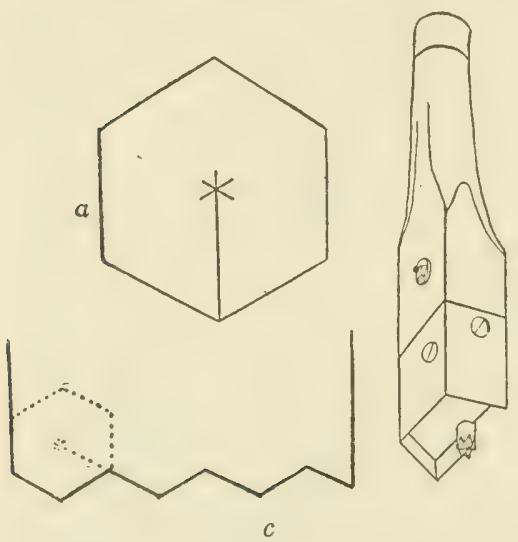

Fig. 269.- $-a$, tarred felt card in outline one-third size; $b$, tool for cutting cards, about one-sixth size; $c$, showing how tool is used, dotted line indicating position of edge of tool. (After Goff.) several years with good results. The gas tar costs $\$ 1.25$ a gallon and will treat 1000 plants. A greater proportion of gas tar has proven injurious.

Remedies.-For the destruction of the maggots, both carbolic acid emulsion and hellebore decoction have been extensively used with varying results, but from the evidence so far submitted, the grower would hardly seem warranted in placing much dependence $\mathrm{upon}$ them, though where preventive measures have been neg-

lected, they may aid in reducing the number of maggots and prevent a total loss.

The surest method of destroying the maggots on the roots is by the use of carbon bisulfide. This is entirely practicable on a few plants, but has not come into general use on a large scale, as no satisfactory tool for its injection into the soil is available. A small hole should be made with a dibble 4 to 6 inches from the infested stem, and a teaspoonful of carbon bisulfide injected and the hole tightly closed with earth. If made too close to the plant the roots will be injured. The fumes kill the maggots by permeating the soil. Where plants are badly infested injection on two sides may be necessary. 


\section{The Imported Cabbage Worm *}

Probably the worst pest of the cabbage and one of the bestknown garden insects is the common cabbage worm, whose parent

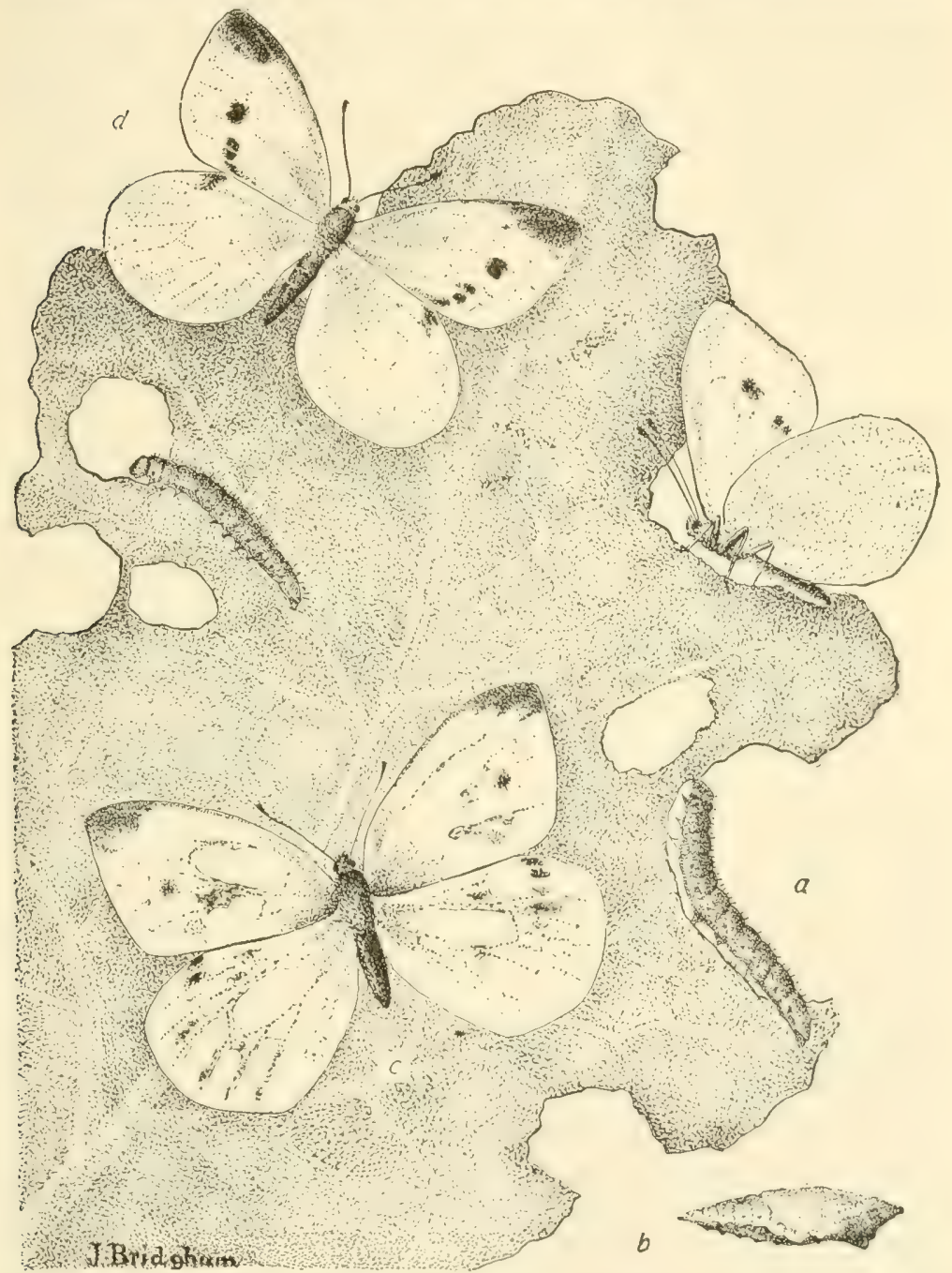

FIG. 270.-The cabbage butterfly (Pontia rape Linn.): $a$, larva; $b$, chrysalis; $c$, male butterfly; $d$, female butterfly. (After C. M. Weed.)

is the common white butterfly. It is an old European pest and was imported near Quebec, Canada, about 1860, whence it spread

* Pontia rape Linn. Family Pieride. See F. H. Chittenden, Bulletin 766, U. S. Dept. Agr. 
to New England, reached New York in 1868, Cleveland, Ohio, by 1875, and the Gulf States by 1880, and has since spread to all parts of the country.

The butterflies are among the first to emerge in early spring. They are white, marked with black near the tip of the fore-wings, which expand nearly 2 inches. The female bears two black spots on each fore-wing, while the male has only one, and both sexes have a black spot on the anterior margin of the hind-wings.

Life History. - The butterflies soon commence to lay their eggs on whatever food-plant is available. The larvæ feed on all of the common cultivated crucifers as well as many wild sorts, so that the species is never without food. The small yellowish, oval eggs are
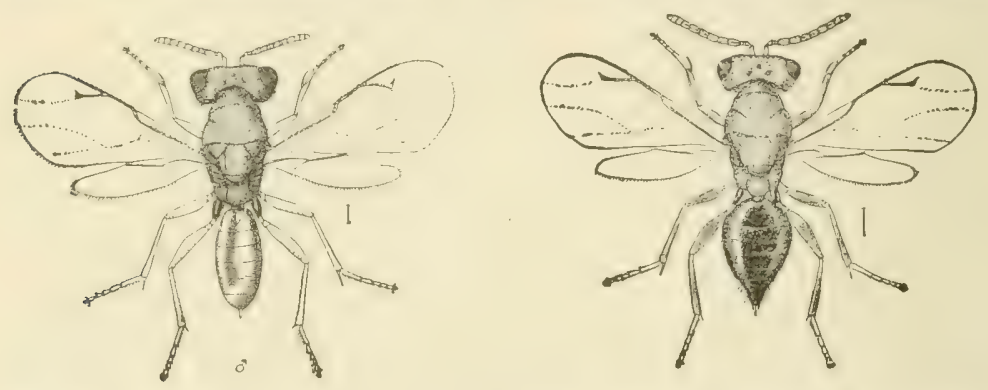

FIG. 271.-Pteromalus puparum, a chalcis-fly which parasitizes the cabbage worm and many other injurious insects, male and female greatly enlarged -hair line shows natural size. (After Chittenden, U. S. Dept. Agr.)

laid on end on the foliage, and are marked with prominent longitudinal ridges. They hatch in from four to eight days. The larvæ grow very rapidly, gorging themselves on the foliage, which they skeletonize in their well-known manner, and become full grown in from ten days to two weeks. The mature cabbage worm is about $1_{4}^{1}$ inches long, of a velvety green color, very similar to the foliage, with a faint yellow stripe down the middle of the back and a row of yellow spots on each side. The surface, when seen under a lens, is finely roughened and dotted with small black specks. The chrysalis is attached to the foliage by a strand of silk around the thorax and is first greenish and later light brown in color. The butterflies emerge in from one to two weeks in the summer, but the chrysalides of the last generation in fall hibernate over winter among the old stallss and rubish on the fields. Thus the whole life cycle in summer requires from three to five weeks. In New 
England there are three generations a season and there are probably five or six in the extreme south, as the butterflies there remain on the wing all winter.

Enemies.-Fortunately, the parasites of the cabbage worm are becoming very effective in checking its multiplication, and in many sections of New England where it has existed the longest, it rarely becomes very injurious, so well do the parasites control it. Most of these are importations from Europe, one of the most important being a small wasp-like Braconid fly (Apanteles glomeratus Linn.) which was purposely imported from England in 1883. During the autumn of 1904 Dr. Chittenden states that
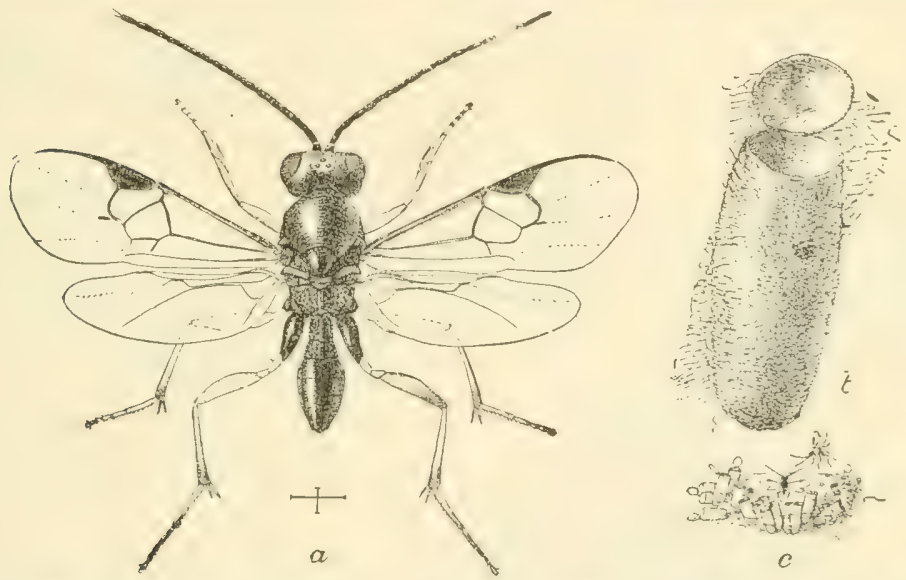

Fig. 272.-Apunteles glomeratus, a parnsite of the cabbage worm: a, adult fly; $b$, cocoon; $c$, flies escaping from cocoons-natural size, $a$, $b$, highly magnified. (After Chittenden, U. S. Dept. Agr.)

it killed practically every worm at Washington, D. C. The maggots of these little parasites live within the worms and when full grown come forth and spin masses of small white cocoons on the foliage, often attached to the dead or dying worm (Fig. 272). Another very important parasite is a minute Chalcis-fly (Pteromalus puparum Linn.), about one-sixteenth of an inch long, which was probably imported with its host. These often emerge in immense numbers, hundreds of them often being secured from a single worm. Wasps frequently prey on the caterpillars, using them for provisioning their nests. Various predaceous bugs also attack the worms as well as numerous other internal parasites. 


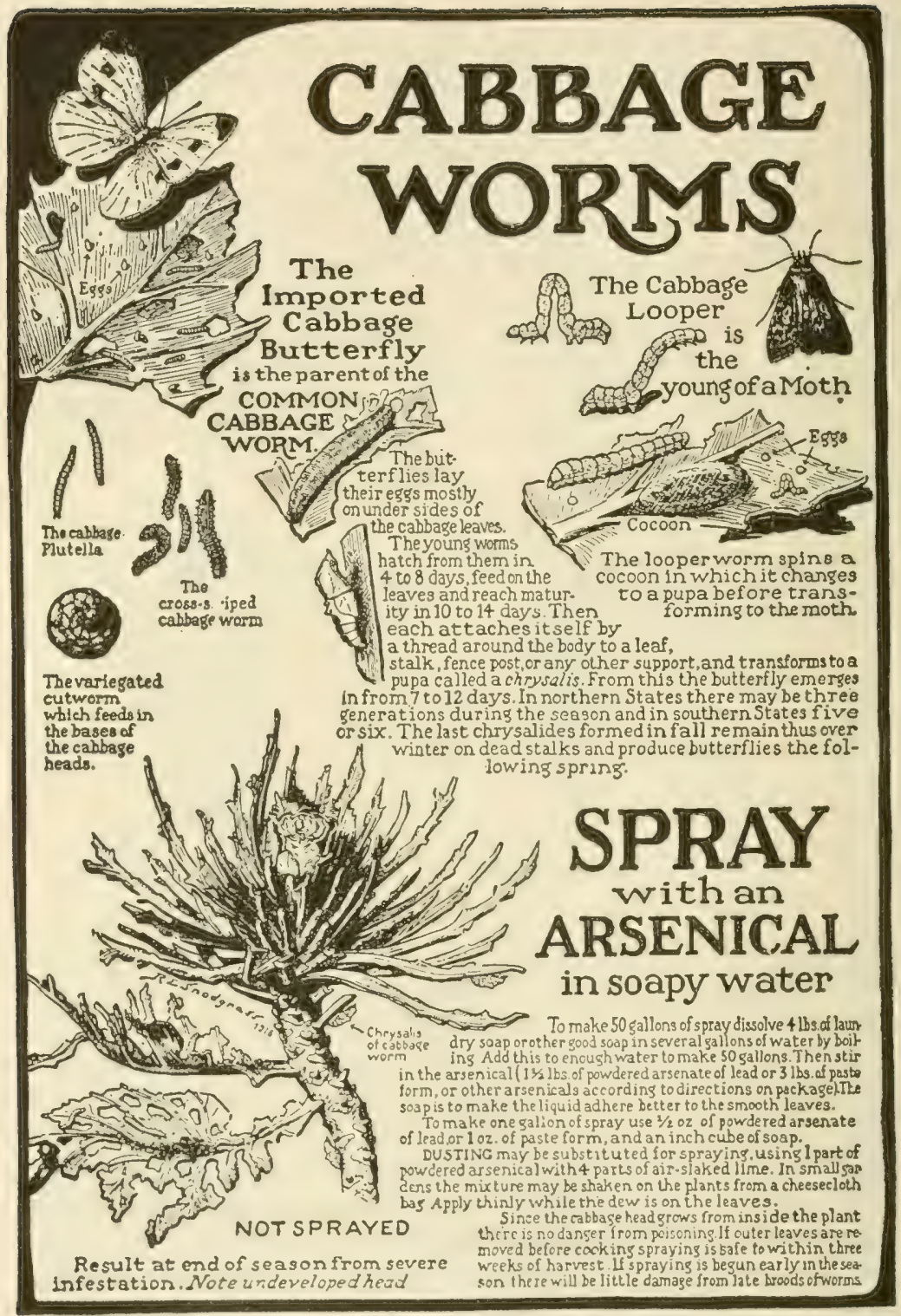

FIG. 273.-Bureau of Entomology (U. S. Dept. of Agr.) chart showing cabbage worms. 
Control.-As the chrysalids pass the winter on the old stumps, foliage, and rubbish on the field, it is evident that they should be destroyed and the field plowed as soon after the crop is removed as possible. A few stalks may well be left standing here and there and be kept well poisoned, so as to act as traps to destroy worms from eggs laid by late female

The most effective means of control is spraying or dusting with Paris green or arsenate of lead. The former is used $\frac{1}{3}$ pound to the barrel and the latter 2 to 3 pounds per barrel of water. As the foliage of cabbage is extremely smooth it will be advisable to add 2 or 3 pounds of resin soap or "sticker" to render the material more adhesive. The arsenicals should be applied as soon as the plants are set, and they should be kept well covered until the heads are half formed. If this is done, the young larvæ
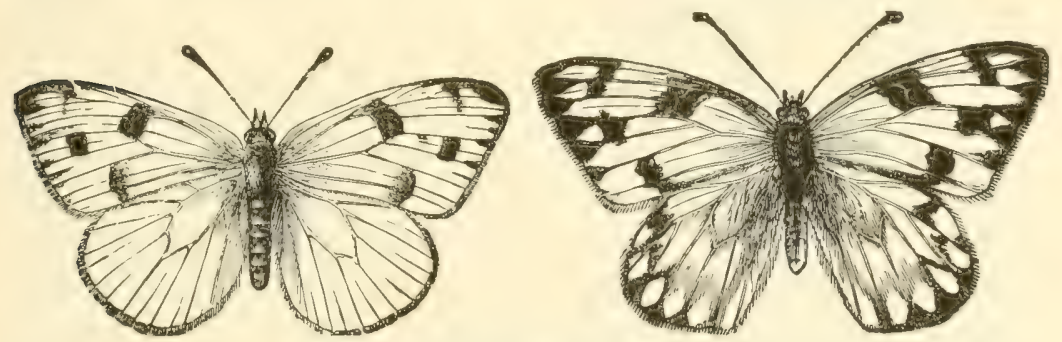

Fig. 274. - The southern cabbage butterfy; $a$, male; $b$, female. (After Riley.)

will be destroyed before they burrow into the heads, and there will be but little damage after the spraying is stopped. Although there is some prejudice against poisoning cabbage, it is entirely unfounded, for it has been shown that a person would need to eat twenty-eight cabbages at once, if dusted in the ordinary manner, to secure poisonous effects. It is obvious that plants should not have large quantities of dust placed on them after they commence to head, and such applications are entirely unnecessary.

Various contact insecticides may be used against the worms on a few plants, but are not practicable for large acreages. Thus water heated to $150^{\circ} \mathrm{F}$., will kill all the worms which it hits. Kerosene emulsion will kill the larvæ, but must hit them, and may leave an odor on the plant. Pyrethrum or buhach has been used effectively, applying it either dry or diluted with flour, or sprayed as a decoction at the rate of 1 ounce to a gallon of water. Dilute tobacco extract has also proven effective, but 
all of these substances have the disadvantage that they must be brought into actual contact with the worms to kill them.

\section{The Southern Cabbage Butterfly *}

Before the invasion of the imported cabbage worm this species was the cause of considerable injury from the Middle States

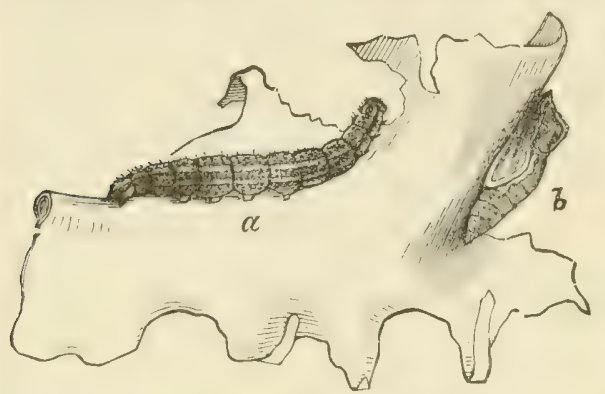

FIG. 275.-The southern cabbage butterfly: $a$, larva; $b$, pupa. (After Riley.) southward, but it has now been largely replaced and overshadowed in importance by the imported species. The male butterfly is very similar in marking to the female of $P$. rapo, and would not be distinguished on the wing. The female is more heavily marked with black, as shown in the figure. The caterpillar is a greenish-blue color with four longitudinal, yellow stripes, and covered with black dots. The habits are very similar to those of the imported cabbage worm, and the same methods of control should be used.

\section{The Potherb Butterfly $\dagger$}

This species is more common in the North and East and is distinguished from its near relatives by the wings being uniform white without spots. The larvæ are very similar to those of the imported species and the habits are very similar. Like the southern species, though formerly very common and often injurious, this species is now rarely common

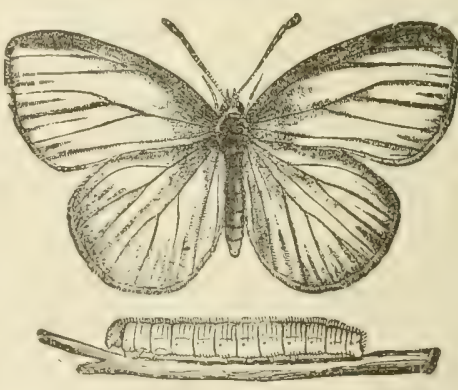
enough to do $\mathrm{much}$ injury and Fis. 276.- The potherb butterfly feeds mostly on wild plants. The and caterpillar. (After Harris.) same remedies as for the imported species should be used.

* Pontia protodice Boisd. Family Pierida.

+ Pontia napi Linn. Family Pierido. 


\section{The Cabbage Looper*}

Next to the imported cabbage worm the looper is probably the most serious pest of cabbage and closely resembles it in the way it strips the foliage.t The name "looper" is derived from its "looping" habit of walking like a measuring worm, due to the absence of legs on the third and fourth abdominal segments. The larvæ are pale to dark green in color, marked with several longitudinal white lines, as shown in Fig. 277, which become obscure as they become full grown, so that they might be easily mistaken for the common cabbage worms were it not for the looping gait. $\mathrm{The}$ species occurs throughout the territory east of $t$ h e Rockies, but is much more commonly injurious in the Middle and Southern States. Although cabbage and cauliflower are the favorite food plants, it attacks all of the cruciferous crops, is frequently injurious to lettuce, peas, celery and beets, and has been found upon quite a list of cultivated crops and various weeds.

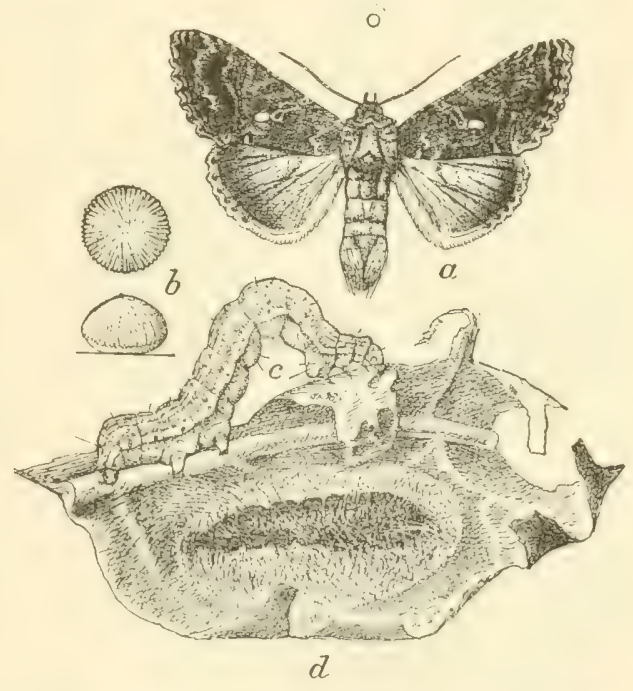

Fig. 277 -The cabbage looper (Aufographa bra:sica Riley): $a$, male moth; $b$, egg from above and from side; $c$, full grown larva in natural position feeding; $d$, pupa in coconn- $a, c, d$, one-third larger than natural size, $b$, more cularged. (After Howard and Chittenden, U. S. Dept. Agr.)

Life History. - The life history has not been carefully observed, but it seems prebable that the winter is passed in the pupa stage in the old leaves, stumps and rubbish of the cabbage field. Sirrine

* Autographa brassice Riley. Family Noctuidu. See F. H. Chittenden, Bulletin 33, n. s., Div. Ent., U. S Dept. Agr.; F. A Sirrine Bulletin 144, N. Y. Agr. Exp. Sta.

$\dagger$ See also page 324 
states that the life history is similar to that of the imported cabbage worm, and it seems probable that there are three generations a year in the Middle States, and possibly more farther South. Injury to cabbage seems to be worse in late summer. When full grown the larva spins a very thin, transparent, white cocoon, attached to the leaf upon which it has been feeding and in it transforms to the light-brown pupa. The pupal stage varies from a week in midsummer to three weeks in October, and the pupæ of the last brood hibernate over winter.

The moth has a wing expanse of about $1 \frac{1}{4}$ inches, and the fore-

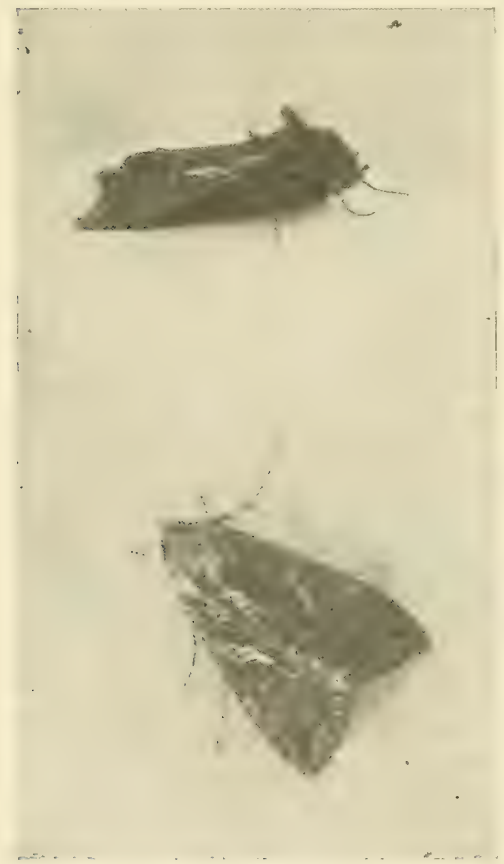

Fig. 278. - The cabbage looper moth at rest from side and from abovenatural size.

cabbage but will be improved by wings are grayish-brown mottled with gray, whitish, and blackish, as shown in Figs 277, 278. Just inside of the centre of the fore-wings is a characteristic white spot. The hind-wings are paler brown, with the outer border darker, and the margins of both wings are strongly scalloped.

Control.-The same general methods as advised for the imported cabbage worm will effect the control of this species. Sirrine states that dusting the plants with Paris green has not proved satisfactory, but found the use of Paris green with the resin soap sticker to be very effective. Arsenate of lead is more adhesive and is therefore superior for the addition of the "sticker."

\section{The Diamond-back Moth *}

The larvæ of the imported diamond-back moth or cabbage plutella are commonly found on cabbage wherever it is grown

*Plutella maculipennis Curtis. Family Tineidoe. 
and as a rule do but little injury, though occasionally they become troublesome.

"The larvæ when full grown measures three-tenths inch in length, tapers a little to the extremities, and is of a pale green color. It is active and irritable, in this respect being very different from any of the larger larvæ described." The wings of the parent moth " are kept folded against the sides of the body, are a little turned up at the tips, and are provided with a long fringe. The color above on the head, thorax, and upper part of the closed wings is a light clay-yellow. That part of the wings that is lowest when they are folded is bronze brown, this color terminating abruptly where it meets the clay-yellow of the back by a well-defined sinuous margin. The length from the front of the head to the tip of the folded wings is about onefourth inch." *

"The eggs are whitish, very minute, and are attached to the leaves, though sometimes when very abundant they are, it is said, placed on the sides of crates holding cabbage." The full-grown larvæ pupate in small

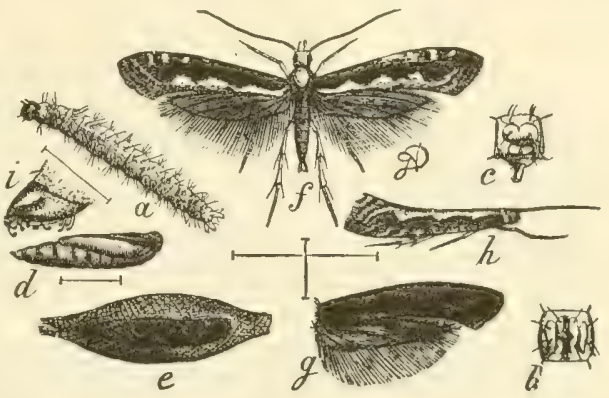

FIg. 279.-The cabbage plutella or diamondback moth (I'lutella maculipennis Curtis): $a$, larva; $b$, segment of same greatly enlarged; $d$, pupa; e, pupa in cocoon; $f$, adult moth; $g$, wings of dark variety; $h$, moth with wings folded. (After Riley, U.S. Dept. Agr.) cocoons composed of a delicate lace-work of silken threads through which the whitish, often brown-striped, pupa may be seen. In winter the cocoons containing pupæe are found on old cabbage stalks in the field or on stored cabbage. Two or three generations a year occur in the more northern states and four or five generations farther south, while in the extreme South it may be found active practically throughout the year. The species has a world-wide distribution.

"During very dry weather these little insects become exceedingly common, and riddle the cabbage leaves with small holes. Wet weather, on the other hand, has long been known to be

* H. Garman, Bulletin 114, Ky. Agr. Exp. Sta., p. 29. 
unfavorable to them," and drenching the plants with water has been recommended as one of the best means of control. The same remedies applied for the other cabbage worms will readily control this little pest.

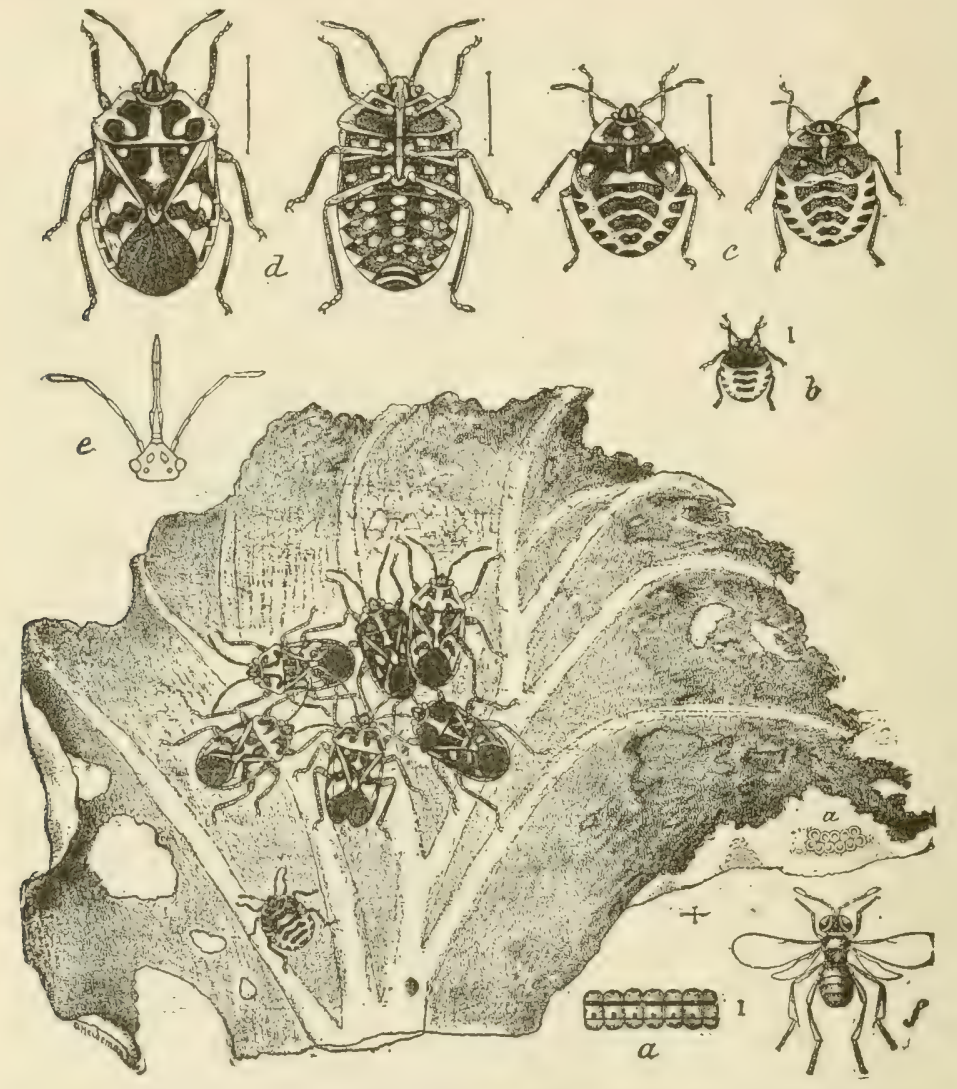

Frg. 280.-The harleculuin cabbage hug (1Iurgantia histrionica Hahn.): a, eggs-enlarged; $b$, nymphs, more enlarged; $d$, adults seen from above and below-enlareed; $e$, head and heak of same; $f$, parasite of eggsenlarged; bugs and eggs $(a)$ on leaf, natural size. (After W. G. Johnson.)

\section{The Harlequin Cabbage-bug *}

Southern truckers have been familiar with the harlequin cabbage-bug, "calico-back," "terrapin-bug," or " fire-bug," as

* Murgantia histrionica Hahn. Family Pentatomida. See F. H. Chittenden, Farmers' Bulletin 1061, U. S. Dept. Agr.; R. I. Smith, Journal Economic Entomology, Vol. II, p. 108, and F. B. Paddock, Bulletin 179, Texas Agr. Expt. Station. 
it is variously called, for the past generation. A native of Mexico and Central America, it migrated into Texas about 1864 and then spread eastward along the Gulf Coast, and northward until it reached Maryland and Virginia, about 1880, New Jersey in the early 90's, and up the Mississippi Valley to southern Ohio and Indiana by 1890. On the Pacific Coast it is found in southern California and Nevada. Although it spread to Long Island, N. Y., southern Pennsylvania, and northern Ohio, and Indiana, its advance was checked by the cold winters of the late

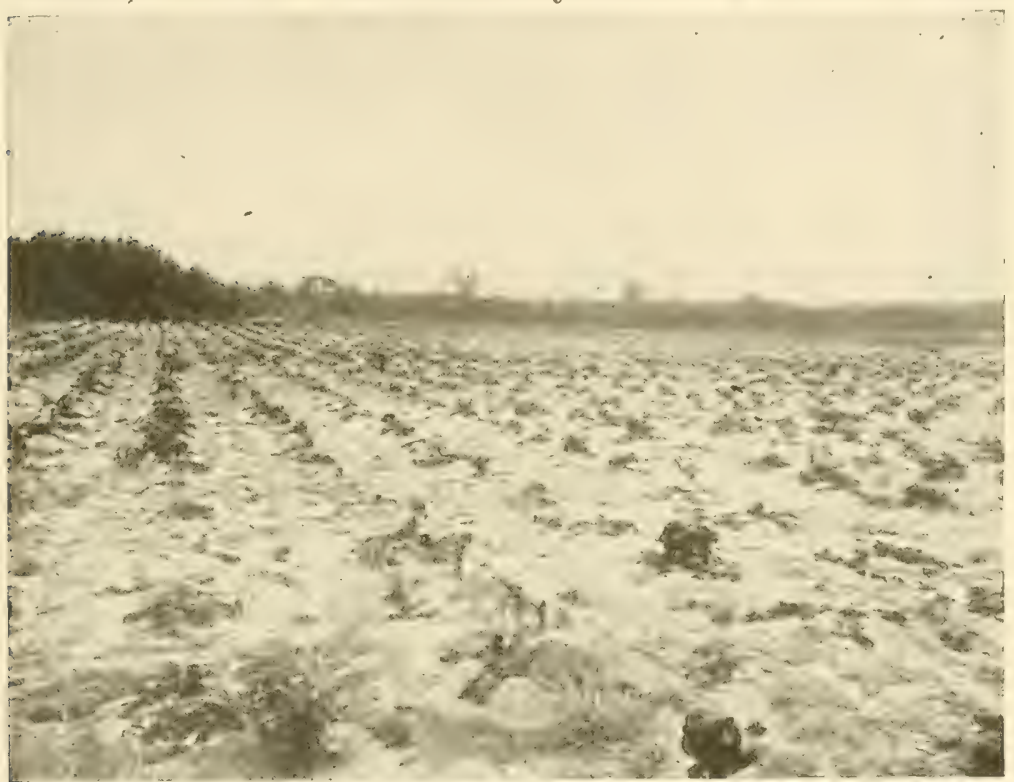

Fig. 281.-Field of cabbage in Delaware ruined by the harlequin bug.

90 's and it will probably never become very injurious north of the Potomac and Ohio rivers.

The appearance of the gayly colored bugs, shining black or deep blue, marked with brilliant red or orange, as shown in Fig. 280, is so distinctive that they are readily recognized, and gives them the name of harlequin-bug or calico-back. They are about one-half inch long, flattened, and the general shape and markings have given them the local name of "terrapin bug." The bugs suck the sap from the leaves of cabbage and other crucifers, the plants wilting and dying, and turning black as if 
they had been swept by fire; hence the name "fire-bug." A half-dozen of the adult bugs will destroy a small plant in a day or two, and as they frequently appear in enormous numbers and as they multiply rapidly, unless they are fought vigorously they will soon destroy a large patch of cabbage.

Life History. - The adults hibernate over winter in old cabbage stumps and under the leaves and other rubbish left on the field, and emerge early the next spring. In South Texas they may be found at work nearly all winter, being common in February and March; in North Carolina they appear about April 1st, and in Maryland about May 1st. The eggs of the first generation are deposited mostly on kale, wild mustard or other wild cruciferæ, each female laying about 100. They are placed in a double row of about a dozen and are white, marked with two black bands and a small spot, which makes them look like small white barrels with black hoops. The eggs of the spring generation hatch in about ten days, and the nymphs feed upon the cabbage for from six to nine weeks before becoming full grown in North Carolina and the District of Columbia, while in the Gulf States the eggs hatch in four to eight days and the nymphs become full grown in three or four weeks, the development of these stages being determined by the temperature. The nymphs are much like the adults in coloration, though differently marked and lacking wings. They molt five times, some of the different stages being shown in the figure. From North Carolina northward there seem to be but three generations of the insect. The summer generation develops more rapidly, the eggs hatching in four or five days, but the fall generation requires about the same time as in spring. In midsummer the whole life cycle may be passed in about two weeks in the Gulf States, according to various authorities, so that there may be a half dozen generations, though the exact life history does not seem to have been observed there.

Control.-This is an exceedingly difficult pest to combat after it has become numerous in the cabbage patch, so that every effort should be made to prevent its appearance. As it hibernates under old stalks and leaves it is obvious that they should be cleaned up and the field plowed as soon as the crop is harvested. By leaving a few piles of stalks, leaves and rubbish, the bugs might be concentrated and then destroyed. 
The most successful method of control yet devised is the use of a trap-crop, to which the bugs are lured as they emerge from hibernation and on which they may be destroyed before they attack the cabbage. Kale planted in the fall or mustard planted early in the spring serves well for a catch crop, and should be planted in rows through the intended cabbage-field. The bugs seem to prefer the kale to the young cabbage, and while concentrated upon it they should be killed by spraying them with pure kerosene. The trap-crop may well be planted at different dates, so that after one row has been destroyed by spraying, another will invite the remaining bugs. The nymphs may be destroyed by spraying them with 15 per cent kerosene emulsion or whale-oil soap, one-half pound per gallon. Whale-oil soap used at the rate of 1 to 2 pounds to the gallon will kill most of the adult bugs hit by it without injury to the cabbage, but dependence should not be placed upon control by spraying, as its practicability on a large scale is yet to be demonstrated.

\section{The Cabbage-aphis *}

Wherever cabbage is grown the common "cabbage-louse" occasionally becomes abundant enough to do serious damage, often destroying young plants, which become covered with the disgusting masses of grayish aphids. They are found commonly in almost every cabbage-patch, but usually their natural enemies are so effective as to prevent their increase; otherwise they would be one of the most serious pests of cruciferous crops. They may be found on all of the cultivated and wild cruciferæ, but cabbages and turnips are injured worst, serious damage often being done to turnips in the South.

"The wingless viviparous female has a rather long oval body, covered with a whitish mealy coat. When this coat has been removed . . . the body is seen to be a grayish-green color, with eight black spots down either side of the back, increasing in size toward the posterior end. The antennæ are green with black tips, and are shorter than the body, and the eyes, legs and tail are

* Aphis brassicce Linn. Family Aphididœ. See C. V. Riley, Report of U. S. Commissioner of Agriculture, 1884, p. 317. C. MI. Weed, "Insect Life," Vol. III, p. 289. G. W. Herrick, Bulletin 300, Cornell Univ. Expt. Station. F. H. Chittenden and C. H. Popenoe, Bulletin 2, Va. Truck Exp. Sta., p. 22. 
black. The young when first hatched are oval, shining, bright yellow in color, and lack the mealy coat. The winged viviparous female is yellowish-green, with the eyes, neck and thoracic lobes black, and the antennæ and nectaries dark brown. The legs are dusky brown and hairy; the tail is dark green or brown and also hairy; the wings are rather short, with stout coarse veins and dark stigma." (Riley).

Life History.--Though the cabbage-aphis is an old European species and was observed in this country as early as the latter part of the eighteenth century, its life history has only recently been carefully worked out by Professor G. W. Herrick and Mr. J. W. Hungate of Cornell University (1.c.), from whose account the following is taken:

The oviparous females appear in the fall and are fertilized by

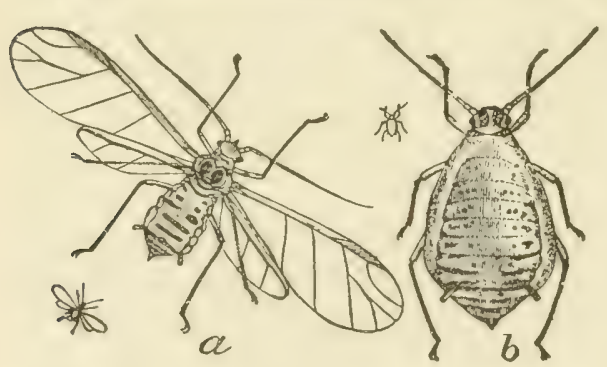

FIg. 282.-The eabbage-aphis (1phis brassico Linn.): $a$, winged form; $b$, wingless viviparous female-greatly enlarged. (After Curtis.) the males, and deposit their eggs in large numbers on the leaves of the cabbage, during October and the first days of November, in central New York. The eggs are laid on rape, turnip, brussels sprouts and kohl-rabi but are most abundant on cabbage, particularly in the crevices and depressions of the under surfaces of the leaves. On leaves taken at random from a badly infested patch, from 177 to 293 eggs were found on a leaf. Two to three eggs are laid by each oviparous female. When first laid the eggs are a yellowish-green, but soon turn a shining black. From eggs taken at random and left under normal outdoor conditions, 76 per cent hatched the next spring, while all eggs hatched which were laid by females known to have been fertilized. Eggs hatched about April 1, 1910, in central New York, the season being an early one. From the stem mothers which hatched from these eggs, twentyone generations of wingless females were reared up to December 3 , 1910, the average length of a generation being about twelve days. During the summer generations of winged females are produced, especially on crowded plants, and these serve to spread the pest to 
unafrected plants. The wingless females become full grown in about thirteen days during the summer and live for about forty-six days, during which time they will give birth to an average of fortyone young, producing as high as six young in a day. The winged forms are much shorter lived, living only about ten days and giving birth to but from seven to thirteen young.

There is no question that in the Southern States the viviparous females may continue to reproduce all winter, and it is quite probable that some of them survive in pits and cellars in the North, where eggs also probably occur. Thus Sirrine* states that it " is certain that this aphid can survive the winter on cabbage stored in cellars or pits, also that cabbage stored in pits for seed purposes furnishes the supply of aphids for infesting the seed stalks in early spring." This being the case it should be an easy matter to destroy the aphids by fumigation before removing them from the pits.

Control.-From the habits outlined it is evident that, as for other cabbage pests, the refuse of the crop should be cleared up and destroyed in the fall. Any of the standard contact insecticides, such as kerosene emulsion, 1 part stock solution to 15 parts of water, whale-oil soap, 1 pound to 6 gallons, or " Black-leaf 40 ," 1 part to 800 of water, will destroy the aphids, but the spraying must be thorough, as the waxy coating serves to protect them. According to Professor Franklin Sherman, any good laundry soap used at the rate of 1 pound dissolved in 3 gallons of water, will destroy the aphids. Where water under pressure is available in a small garden, the aphids may be held in check by washing them from the plants with a strong stream from a garden hose. Plants infested in the seed-bed may be freed from the aphis by dipping in whale-oil soap solution, 1 part to 8 of water.

Fortunately for the grower, the calbage-aphis is usually held in check by numerous parasitic enemies, principally little wasplike flies of the family Braconida, and by several species of ladybird-beetles and syrphus-fly larvæ, which will often destroy a colony within a few days.

\section{The Spinach-aphis or Green Peach-aphis †}

Another species of aphis often becomes destructive to cabbage. spinach, celery and lettuce, as well as various greenhouse crops.

*F. A. Sirrine, Bulletin 83, N. Y. Agr. Exp. Sta., p. 675.

† Myzus persice Sulz. 
In the fall it migrates to peach, and is also known as the green peach-aphis, as which it is discussed on page 587

\section{The Turnip Louse *}

The turnip louse, also called the false cabbage aphis has recently been recognized as a separate pest of crops of this group. It is rather southern in its damage but extends over a large part of

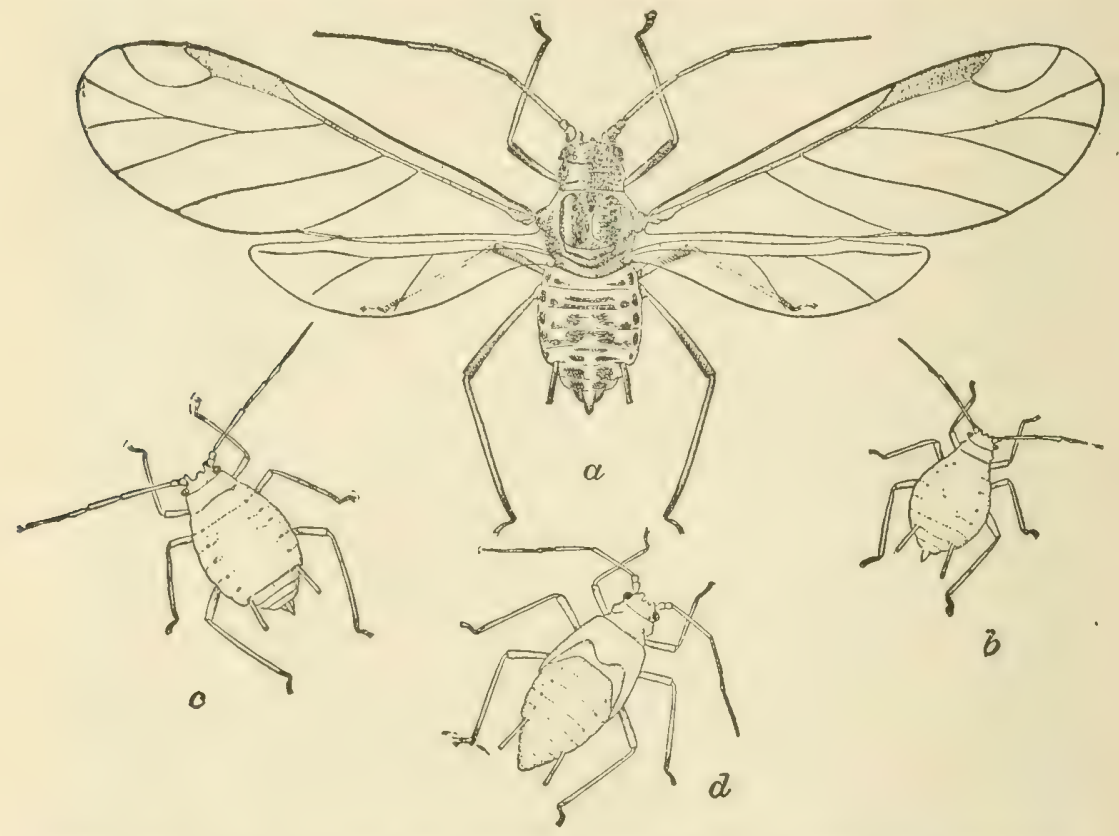

Fig. 283.-The spinach-aphis (Myzus persicœ Sulz.): which often becomes a cabbage pest: $a$, winged adult; $b$, young nymph; $c$, older nymph; $d$, last stage of nymph-all greatly enlarged. (After Chittenden, U. S. Dept. Agr.)

the country. Mr. Paddock's excellent summary of the insect according to his observations in Texas, is given here verbatim:

"A new species of plant louse, commonly called the turnip louse, and not the cabbage louse, as was formerly supposed, does the damage to the fall turnips and winter truck. This damage is general over the entire State of Texas. Not only do the truck

* A phis pseudobrassica Davis. See J. J. Davis, Bulletin 185, Purdue Univ. Expt. Station; and F. B Paddock, Bulletin 180, Texas Agr. Expt. Station. 
regions suffer, but every home garden is damaged by the turnip louse.

The food plants of the turnip louse are turnips, cabbage, mustard, cauliflower, kale, rutabaga and rape.

The normal form of reproduction of the turnip louse in Texas is asexual throughout the year. Observations have been made upon this louse in Texas from Brownsville, on the 26th parallel, to Wichita Falls, on the 34th parallel. True hibernation does not take place in Texas, even at the northernmost point of occurrence the lice reproduce some during the winter. The summer is the critical period in the life history of the turnip louse, as it is forced to sheltered locations and none of the cultivated, host plants are grown at that time of the year. Thirty-five generations of the lice were reared in pot cages in one year.

Two other species of plant life are often found closely associated with the turnip louse. These are the "garden aphis" and the cabbage louse.

The natural factors, of control of the turnip louse are widespread over the State. Two species of parasites, Diaeretus rapae Curt, and Lysiphlebus testaceipes Cress., have been commonly

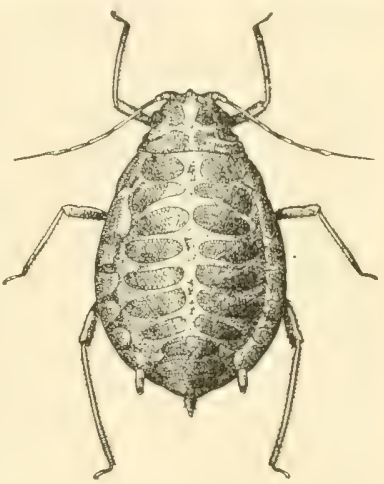

FIG. 284.-The Turnip Louse, wingless viviparous female. (After Paddock.) found, the former at College Station and the latter in other sections. Three species of lady beetles have been observed to feed freely on the turnip louse. These are Hippodamia convergens Guer., Megilla maculata DeG., and Coccincila munda Say. Syrphid flies and lace-wing flies are usually found in limited numbers where the turnip lice are abundant. A fungous disease was very destructive to the turnip louse during the season of 1914 at College Station.

For the artificial control of the turnip louse, spraying is the most satisfactory method. Of the materials which can be used for spraying, laundry soap solution gives as satisfactory results as any and is easily obtainable. The secret of success in the control of the turnip louse is the use of the $45^{\circ}$ elbow and an " angle " type spray nozzle. 
By the use of these it is possible to direct the spray on the under sides of the leaves, where the lice feed.

The preventive measures against the turnip louse are rotation, proper planting time, trap crops, clean culture, and the destruction of the first colonies."

\section{Flea-beetles *}

A considerable number of small flea-beetles attack cabbage and other cruciferous crops, and although as a rule only troublesome, they appear periodically in enormous numbers and do serious injury. They are mostly small species (there being seven species of the genus Phyllotreta alone) not over an eighth of an inch long. One of the most common throughout the country is the striped turnip flea-beetle. $\dagger$ It is polished black with each wing-cover marked with a broad, wavy band of pale yellow. The microscopic white eggs are laid in a little excavation of the root near the crown of the plant. The larvæ mine into the roots and have been reported to do considerable injury to them, but it seems probable that most of them live upon the roots of cruciferous weeds. The full grown larva (Fig. 285a), is about three-eighths inch long, quite slender and tapering, yellowish white, with brown head and anal plate, and with marks on the thorax and transverse rows of minute hair-bearing tubercles as shown in the figure. The Western cabbage flea-beetle $\neq$ is the more common from the Dakotas southward to Mexico and westward to southern California. It is a uniform deep olive-green, with the surface irregularly punctate, and 7-100 inch long. Another species almost indistinguishable from the first species above, is the wavy-striped flea-beetle, $\S$ whose larvæ mine in the leaves of wild pepper grass (Lepidium virginicum), and is most abundant in the Middle and Southern States. The life history has been fully described by Dr. Riley (l.c.).

Control.- Where the plants are sprayed for the cabbage worms with Paris green or arsenate of lead, there will probably be little trouble with flea-beetles. Otherwise, spray with arsenate of lead, 3 to 5 pounds per barrel, or Paris green one-third to one-half pound, adding the resin soap or "sticker," so as to give the

* Family Chrysomelider. Refer to pages 266, 303, for other flea-beetles. See C. V. Riley, Report U. S. Commissioner Agr., for 1884, pp. 301-308.

$\dagger$ Phyllotreta vittata Fab.

$\ddagger$ Phyllotreta pusilla Horn.

\$ Phyllotreta sinuata Steph. (zimmermani Crotch.) 
foliage a good thick coating, for the spray probably acts fully as much as a repellant as a remedy. Where injury is anticipated it will be well to dip the plants in arsenate of lead 1 pound to 10 gallons of water when planting them. By thoroughly dusting the plants with lime, land plaster, strong tobacco dust, dilute pyrethrum, or any of the dusts commonly used for such insects,
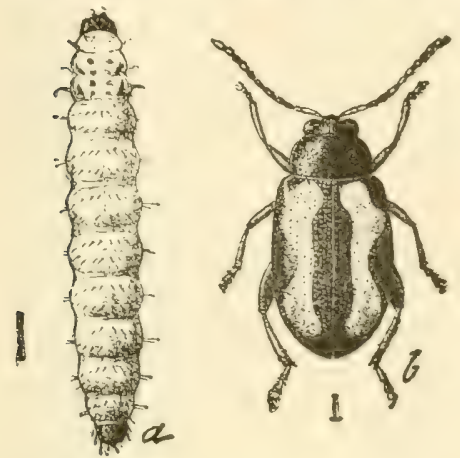

Fig. 285.-The striped turnip fleabeetle (Phyllotreta vittata Fab.): $a$, larva; $b$, adult-greatly enlarged. (After Riley, U. S. Dept. Agr.)

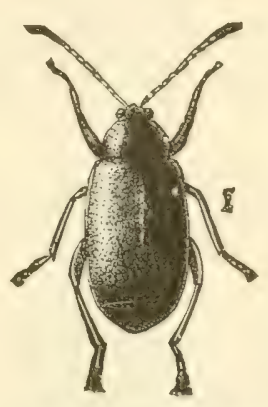

Fig. 286. - The western cabbage fleabeetle-much enlarged. (After Riley, U. S. Dept. Agr.)

applying the dust in the early morning while the dew is on the plants, they may be protected from attack as long as they are kept thoroughly covered. It is evident that the weeds upon which these pests develop in the larval stage should be destroyed. Where plants are attacked in the seed-bed, screening as advised for the root-maggot will prevent injury. Cloth with from 20 to 30 threads to the inch has proven most satisfactory for the screens, which should be applied early and be made perfectly tight. 


\section{CHAPTER XVIII}

INSECTS INJURIOUS TO MELONS, CUCUMBERS, SQUASH, ETC.*

\section{The Stripid Cucumber-beetle †}

JusT as the little cucumber and melon plants appear above the soil they are attacked by hordes of hungry black-and-yellow-striped
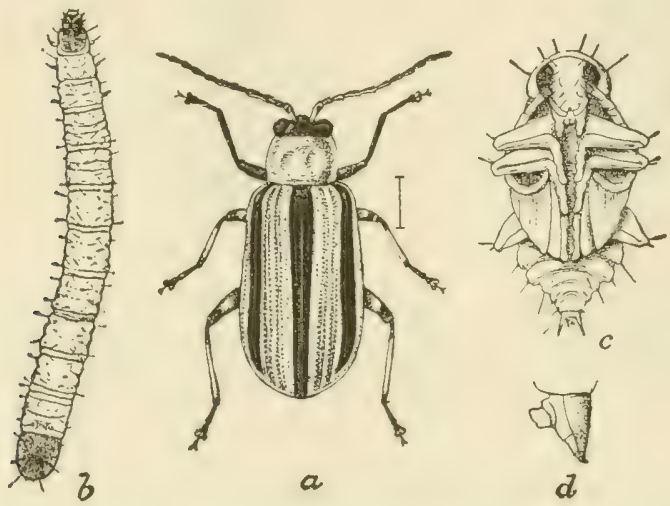
beetles, which feed ravenously up on the succulent seedleaves, often killing thementirelysothat reseeding is necessary. This little striped beetle, often known as the "striped-bug " or "melon-bug," is well known to all growers of cucurbs

FIG. 287.-The striped cucumber-bectle (Diabrotica east of the Rocky vittata Fab.): $a$, beetle; $b$, larva; $c$, pupa; $d$, egg; $e$, Mountains, and
sculpture of egg $-a, b, c$, much enlarged. $d$, more sculpture of egg- $a, b, c$, much enlarged, more
enlarged; e, highly magnified. (After Chittenden, als o occurs in S. Dept. Agr.)

Washington.

The beetle is about two-fifths inch long and half as wide, of a bright yellow color with a black head and three black stripes on the wing-covers.

Life History.-The beetles hibernate over winter in the ground where they have been feeding the previous fall, or along the edge of woodlands, or wherever suitable shelter is obtained, and emerge in the spring two or three weeks before cucurbs are planted. At

* See A. L. Quaintance, Bulletin 45, Geo. Agr. Exp. Sta.; J. B. Smith, Bulletin 94, N. J. Agr. Exp. Sta.; R. I. Smith, Bulletins 205 and 214, No. Car. Agr. Exp. Sta.

† Diabrotica vittata Fab. Family Chrysomelidx. See F. H. Chittenden, Farmers' Bulletin, 1038, U.S. Dept. Agr.; T. J. Headlee, 20th Report N. H. Agr. Exp. Sta., p. 499. 
this season they seem to feed on almost anything, as they have been observed feeding on a long list of food-plants, frequenting flowers whose petals are eaten. As soon as squash, melons, or cucumbers break through the soil, they gather upon them and refuse all other food. If the foliage is covered with any offensive substance they will seek out spots which have not been reached and feed upon them, which fact is of importance in considering remedies. After feeding upon cucurbs for a few days the beetles pair and the females commence to deposit eggs. The eggs are deposited singly and are merely dropped in crevices of the soil or in the opening around the stem of the plant. The egg is oval, about one-fortieth inch long, bright yellow, and sculptured with microscopic hexagonal pits. A female lays about one hundred eggs during a period of a month, and they hatch in about eight days at a mean temperature of $74^{\circ} \mathrm{F}$. The larva is a slender, white, worm-like grub, about three-tenths inch long, with

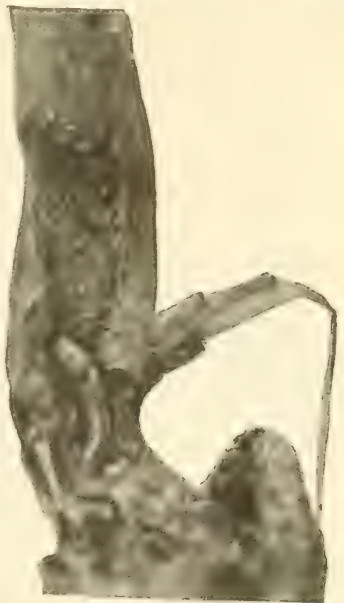

Fig. 25s.- Larva of striped cucumber beetle at work in cucumber stem. (Photo by Headlee.) dark-brown head and anal-plate, and lighter brown thorax. The larvæ bore into the roots, of ten tunneling into the base of the stem, and sometimes mine into melons lying on damp soil. Rarely does injury by the larvæ become noticeable, though we have observed whole patches of cucumber and melon vines killed by them, which seems remarkable, considering the immense numbers of the beetles which must give rise to many times more larve. The larva becomes full grown in about a month and then forms a delicate earthen cell just below the surface of the soil and in it transforms to the whitish pupa, from which the beetle emerges in from one to two weeks, according to the temperature. In southern New Hampshire the beetles emerge from the last of August to the first of October, the complete life cycle requiring from seven to nine weeks, there being but one generation a year, and this seems to be true in New York. In Kentucky the complete cycle requires but thirty-nine days, and in the District of Columbia newly emerged 
beetles are found by mid-July, so that there are undoubtedly two gencrations in that latitude, as the beetles have been found pairing and with well-developed eggs in Delaware, August 1st. In the liatter part of the season the beetles feed on the blossoms and pollen, particularly of squash, rarely touching the foliage. With the first frosty nights they seek shelier under the fallen leaves and enter hibernation with the first killing frosts.

Control.-For a few plants or where the beetles are unusually abundant, coverings of netting have long been used to protect the plants. A barrel hoop cut in two, crossed, and the ends

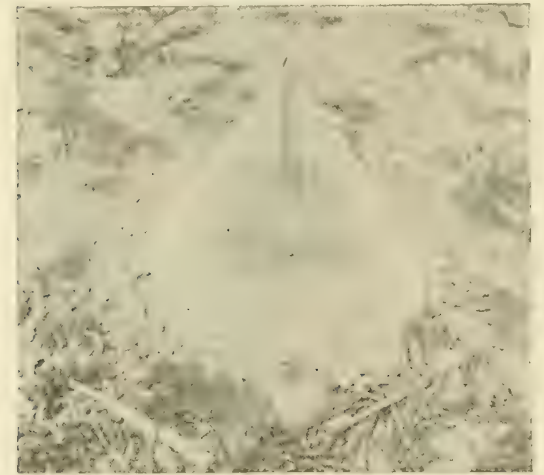

Fig. 289.--Wire screen cover for young cucurbs. (After Headlee.) fastened to another hoop, and the whole then covered with netting, makes an admirable cover, often sold hy dealers. Two stout wires bent into arches and crossed, may also be covered with netting, the lower edge of which is held by earth packed over the edges. Or cone-shaped covers may be fashioned out of wire screening and kept from year to year. (See Headlee, l.c.)

Many growers obviate loss of plants and the necessity of replanting by sowing the seed in rows rather thickly and then thinning out to the desired distance after the worst injury by the beetle is passed. Others make several plantings in each hill at intervals of a week, but the former plan will ensure earlier growth.

The growing of rows of early beans to act as a trap-crop has been suggested, as the beetles will gather on them, it is said, and having an abundance of food will not injure the cucurbits. Squash may be effectively used in this way as the beetles are peculiarly fond of the quick-growing squash seedlings. A week or ten days before the regular crop, plant rows of squash seed around and through the prospective field, and plant more rows when the regular crop is planted. If the main crop be kept well dusted or sprayed as advised below, the beetles will concentrate on the trap- 
squash and might be destroyed upon it by spraying with pure kerosene.

Liberal fertilization with quick-acting fertilizers will aid the young plants to make a quick growth and thus out grow the injury.

Growers have long known that if the plants are kept thoroughly covered with some sort of dust that the beetles will not molest them, and various sprays have been used in the same way. To be effective, the plants must be dusted in early morning while the dew is on and all parts of the plant, above and below, must be thoroughly covered. This must be repeated as often as the dust is washed or blown off, or the plant outgrows it. Air-slaked lime mixed with sulfur, tobacco dust, and bug-death have been the most effective, though similar powders will be found beneficial. Bordeaux mixture has been recommended for this purpose, but seems to have a stunting effect on the young plants. The most valuable repellant seems to be a spray of arsenate of lead 3 to 5 pounds per barrel. This not only repels the beetles better than any other substance tested by Dr. Headlee but also kills many which are forced to feed upon it. Arsenite of lime and zinc arsenite are both recommended by Dr. Chittenden, (l.c.) to be used as is the lead arsenate, either with or without Bordeaux mixture. Most evidence now available indicates that these poisons will protect the vines to a rather limited extent and too much reliance must not be placed upon them. They are of value when used in connection with the cultural methods outlined. The problem of cucumber beetle control is one which needs more investigation, in spite of the fact that the insect has long been known.

Various repellants, such as kerosene, turpentine, naphthalene or moth balls, and other similar odoriferous substances, have been strongly recommended, but careful tests have not demonstrated their efficiency.

It is evident that the eleaning up of vines as soon as the crop can be gathered and the destruction of all refuse will deprive the beetles of food in the fall and force them to seek other hibernating places, thus increasing the mortality.

The spotted cucumber-beetle, Diabrotica 12-punctata Oliv., is found almost always with the striped beetle and injures the plants in the same way. A full account of it will be found in the chapter dealing with insects affecting the corn plant. 


\section{The Melon-aphis *}

Just as the vines commence to run, a plant will be found here and there with the foliage curled up and wilting and within will be found masses of the greenish " melon lice," which have caused the injury by their many beaks sucking out the sap of the plant. If allowed to multiply unchecked and their natural enemies do not prevent their increase, they will sometimes become so abundant

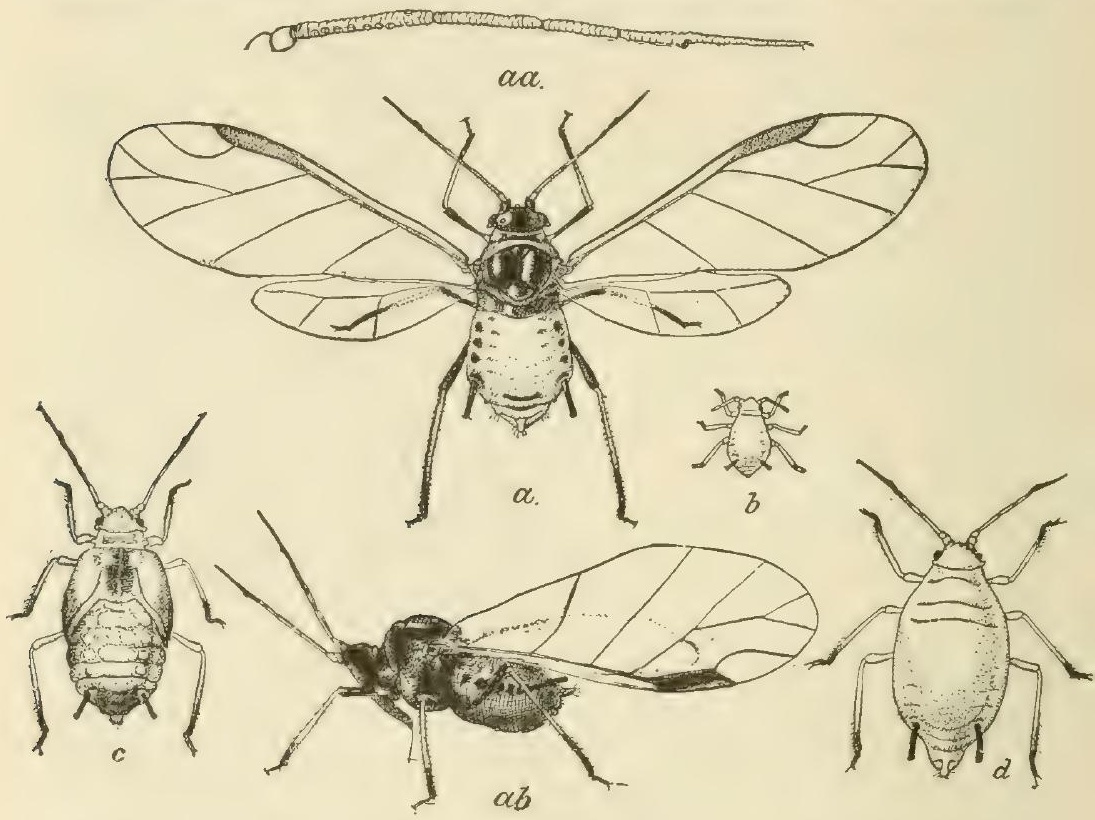

FIg 290.-The melon aphis (4phis gossypii Glov.): $a$, winged female; $a a$, , enlarged antenna of same; $a b$, dark female, side view, sucking juice from leaf; $b$, young nymph; $c$, last stage of nymph of winged form; $d$, wingless female-greatly enlarged. (After Chittenden, U.S. Dept, Agr.)

as to completely ruin a whole crop just as the melons are commencing to ripen. It is one of the worst pests of cucurbs and one which requires constant vigilance on the part of the grower.

The aphids are to be found on various weeds in early spring and appear on cucurbs soon after they start growth. Both winged and wingless females occur throughout the year. The wingless

* Aphis gossypii Glover. Family Aphidida. See F. H. Chittenden, Farmers' Bulletin 914, U. S. Dept. Agr. ; also C E. Sanborn, Bulletin 98, Oklahoma Agr. Exp. Sta., and C. E. Dursh, Bulletin 174, Illinois Agr. Exp. Sta. 
form is about one-fifteenth inch long and varies from light yellow or $\tan$ colored to deep olive-green or deep green which appears almost blackish, the abdomen being always more or less mottled. The rather long, tapering honey-tubes are jet-black, and the legs and antennæ pale whitish-yellow. The young nymphs always show a distinct yellowish-brown or pale salmon-colored area just in front of the honey-tubes and a dark transverse band between them. The nymphs of the last stage, in which the wing pads are visible, are marked on the back with little flecks of silvery white, waxy bloom. The winged female is about the same length and the wings expand one-fifth to one-quarter inch. The color varies as in the wingless form, but there are black spots along the sides of the abdomen, and the head and thorax are dark as shown in the above figure.

The melon-aphis is found throughout the country southward through Central America, and though it often doesserious damage in the North it is worse in the South. It has a long list of food plants, among the crops injured by it being all the cucurbs, cotton, okra, orange, and its occasional food-plants include many others, as it is found on a long list of weeds, most a bundantly on shepherd's purse and pepper-grass, upon which it multiplies in early spring and probably passes the winter.

Life History.- - The life history is much the same as that of most of our common aphids, though of some phases we are still in ignorance in spite of the most careful study. The females give birth to from four to ten aphids a day, depending upon the temperature and food supply, and these become full grown in from six to eight days. As the affected leaf becomes non-succulent the aphids migrate to another leaf and often cluster on the terminal which is checked and stunted. As they become more numerous, winged forms migrate to other plants and within two weeks a colony of fifty or more will form the progeny of every one born by the immigrating female. Reproduction seems to go on this way throughout the year, being stopped only by the cold of winter, as far as has been observed. No true sexual forms or eggs, as are known to occur with other nearly related species, have been observed, and the viviparous forms have been found throughout the winter in Colorado and Texas. 
Enemies.-Fortunately the melon-aphis is subject to the unremitting attack of many insect enemies, the list including some thirty-five species. Among the more important are the common

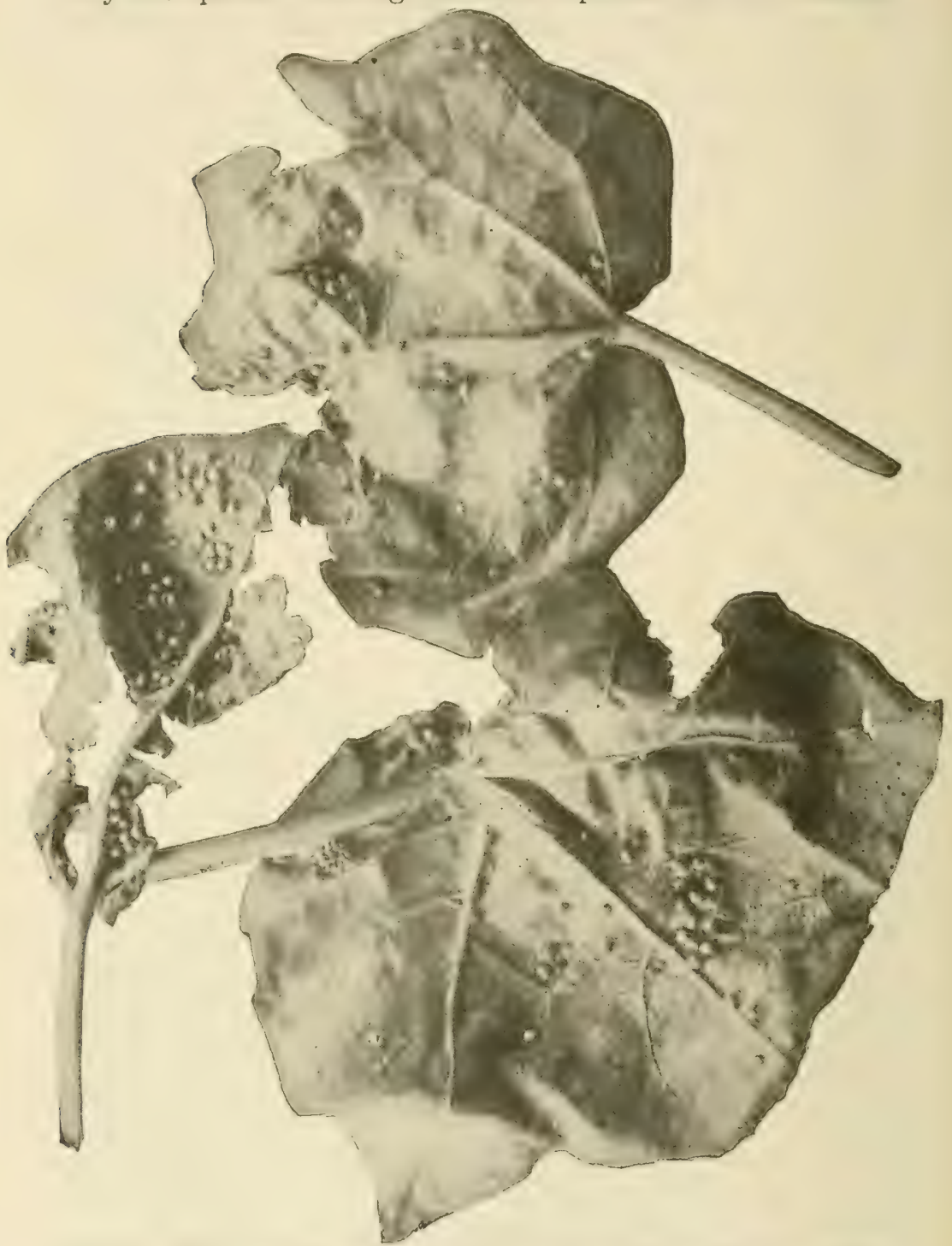

FIG. 291.-Melon aphids on cotton leaf which have been killed by parasites. 
ladybird-beetles and their larve, of which the convergent ladybird,* the nine-spotted ladybird, $\dagger$ and the spotted ladybird, $\ddagger$ shown in Figs 1-5, are among the most effective, and the maggots of various common syrphus-flies, and the aphis-lions. $\$$ Even nore beneficial are the little parasitic fies whose larvæ live within the maggots and destroy myriads of them with incredible swiftness. The most common of these 1 are the same as the most common parasite of the green bug (Fig 120), and they often destroy the aphids over a whole field in a few days. They are most effective in bright, warm weather, when they reproduce most rapidly, but in cool, moist weather they reproduce but slowly, and if such a summer follows similar weather conditions during the spring, the aphids multiply rapidly without a corresponding increase of their enemies and serious damage results. Inasmuch as these same enemies attack the cabbage-aphis, Professor C. E. Sanborn* has suggested that the cabbage-aphis might be encouraged to multiply on crops planted near melons or cucumbers, so that an abundance of parasites and insect enemies might be in readiness to attack the melon-aphis when it appears. This might be done by planting kale, rape, or wild mustard in the fall, upon which the cabbageaphids will pass the winter and will multiply in early spring. This trap crop should be planted in rows around the prospective melon-field, and if the latter be large, rows should be planted through it. If the kale does not soon become infested with the cabbage-aphis, transport some from the nearest cabbage-patch. The ladybirds and parasites multiply rapidly with plenty of the cabbage-aphids for food, and as soon as the food supply becomes scarce they are forced to migrate and will search out any colonies of melon-aphids. This method has not come into general use.

Control.-The most important factor in the control of this, as well as many other aphids, is constant watchfulness, inspecting the plants frequently and destroying badly infested individual plants and treating small areas before the pest becomes spread throughout the crop.

* Hippodamia convergens Guer.

+ Coccinella 9-notata Herbst.

¥ Megilla maculata DeG. Family Coccinellidae.

\$amily Chrysopida.

ๆ Lysiphlebus testaceipes Cress. Family Braconida.

* See Bulletin 89, Texas Agr. Exp. Sta., p. 44. 
Where a few young plants are affected or before the leaves have become badly curled, the aphids may be destroyed by spraying with kerosene emulsion, containing 5 to 8 per cent kerosene, whale-oil soap, 1 pound to 5 gallons of water, or tobacco extracts, the latter having given best results in recent tests. Emulsion must be carefully made or burning will result. The aphids must be hit to destroy them, and it is necessary to use an underspray nozzle (page 73), or to turn the vines over and then return them, so that all the insects may be covered. After the foliage is well curled it is practically impossible to reach the aphids by spraying.

Fumigation with carbon bisulphide and tobacco preparations has been extensively tested and recommended. It has not been found practical on a large scale and there has been some tendency to injure the plants in the process, both by the action of the fumes and by the handling necessary to get the larger vines under the fumigating frames. For this reason it is now considered of doubtful value under any circumstances and is not recommended.

If the vines are watched carefully and sprayed with "Blackleaf $40 "$ at the first appearance of the plant-lice, the matter of control will be found to be relatively simple, and this, along with the cultural methods suggested, is the only treatment that will be found practical for the growers generally. Other spray solutions, or mixtures such as kerosene emulsion or whale-oil soap, may, of course, be substituted for the tobacco with about the same results.

\section{The Squash-bug *}

About the time the vines begin to run a wilted leaf is found here and there which examination shows to be due to the common brownish-black squash-bug. If search be made in early morning, the bugs will usually be found sccreted under clods of earth, or whatever rubbish may be near the vines. They are about threequarters inch long, and too well-known to need other description.

Life History. - For the next month or six weeks the females deposit their eggs, mostly on the under sides of the leaves. They are oval, about one-sixteenth inch long, laid in irregularly shaped clusters. When newly laid they are pale yellow-brown,

* Anasa tristis DeG. Family Coreide. See Weed and Conradi, Bulletin S9, N. H. Agr. Exp. Sta.; F. H. Chittenden, Circular 39, Div. Ent., U. S. Dept. Agr. 


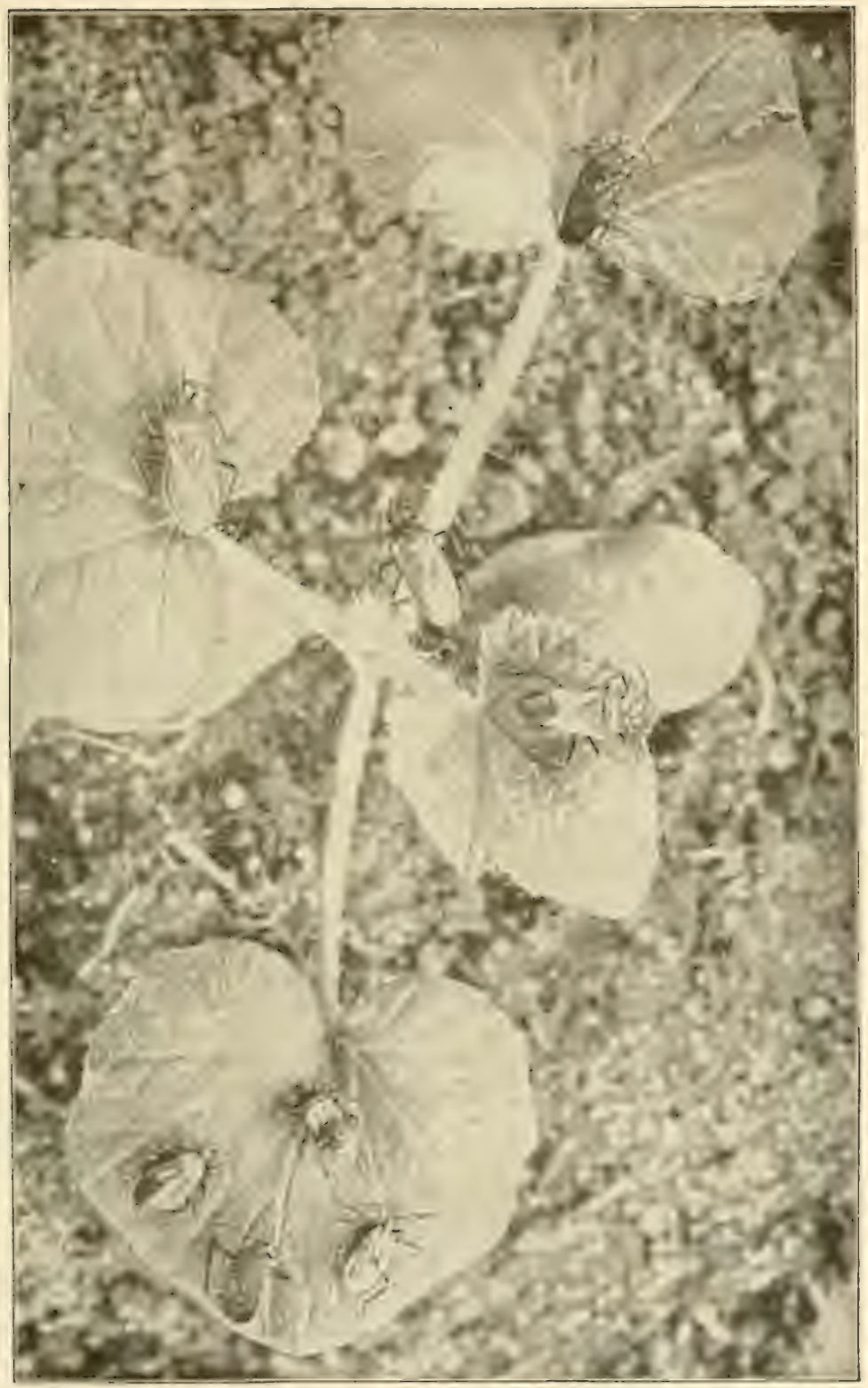

Frg. 292.-Squash-bugs and nymphs at work on young plant-natural size. 
but this soon grows darker, so that the stage of their development may be told by the color. In from six to fifteen days, depending

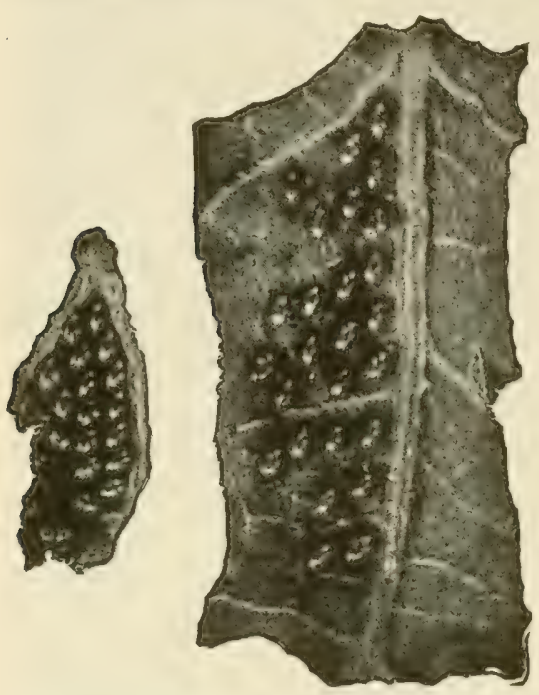

FIg. 293.-Eggs of the squash-bug-enlarged. (Photo by R. I. Smith.)

upon the temperature, the eggs hatch. The young nymphs are brilliantly colored, the antennæ and legs being bright crimson, the head and anterior thorax a lighter crimson, and the posterior thorax and abdomen a bright green, but in a little while the crimson changes to a jet black. The young bugs remain near each other, sucking the juices from the foliage and soon causing the leaves to wither. During their growth, which requires four to five weeks, they moult some five times. The adult bugs appear in August, but in the North they neither mate nor lay eggs that season, but feed until frosts blacken the leaves, when they disappear into winter
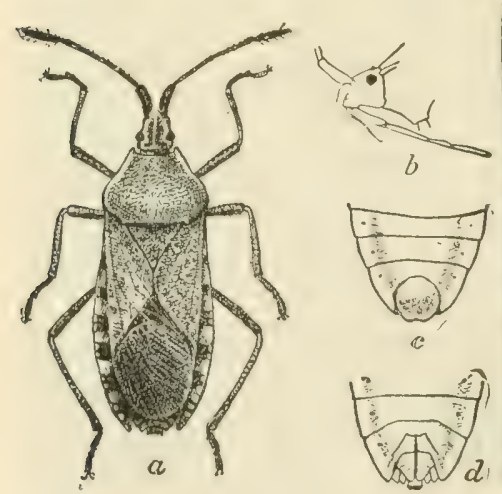

Fig. 294.-The squash-bug; $a$, mature female; $b$, side view of head showing beak; $c$, abdominal segments of male; $d$, same of iemale; $a$, twice natural size; $b, c, d$, more enlarged. (After Chittenden, U.S. Dept. Agr.)

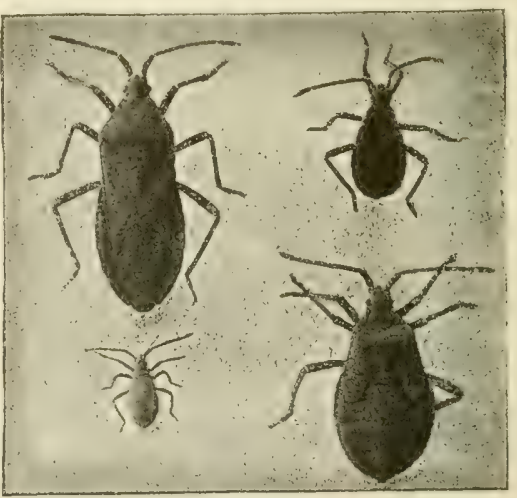

FIG. 295.-The squash-bug: adult at left, and different stages of nymphs -about $1 \frac{1}{2}$ times natural size. (Photo by Quaintance.) 
quarters, hibernating along the edge of woodlands, beneath leaves, under logs, boards or whatever shelter may be available. In the South there are probably two or three broods a year according to the latitude.

Control.-The eggs are easily seen and should be picked off and destroyed. The adults cannot be killed by insecticides, but the nymphs may be destroyed by spraying with kerosene emulsion, or a mixture of "Black-leaf 40 ," one to 400 with soap. The adult bugs may be readily trapped by placing small pieces of board or similar shelter near the vines, under which they will hide at night and from which they may be gathered in the early morning. Cucumbers and melons may be protected by planting early squash among them, as the bugs prefer the squash, from which they may be collected. Cleaning up the vines in the fall is evidently of importance in reducing the number which will hibernate

\section{The Squash Ladybird*}

Although almost all of the ladybird beetles are exceedingly beneficial, this species, with its near relative the bean-ladybird
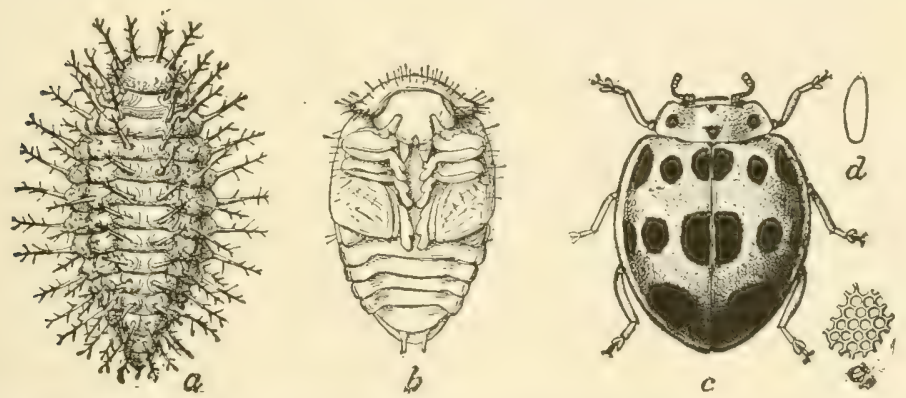

Fic.'296.-The squash ladybird (Epilachna borealis Fab.): $a$, larva; $b$, pupa; $c$, adult beetle-three times natural size; $d$, egg-four times natural size; $e$, surface of egg highly magnified. (After Chittenden, U. S. Dept. Agr.)

are the exceptions which prove the rule, being the only injurious forms with which we have to contend. Both the beetles and larvæ feed on the foliage of various cucurbs, but prefer that of the squash. It is an Eastern species, not being injurious west of the Mississippi

* Epilachna borealis Fab. Family Coccinellida. See F. H. Chittenden, Bulletin 19, n. s., Div. Ent., U. S. Dept. Agr.; J. B. Smith, Bulletin 94, N. J. Agr. Exp. Sta. 
and being most troublesome in the Middle Atlantic States. The beetle is nearly hemispherical in shape, slightly oval, about onethird inch long, yellowish or reddish-brown, marked with seven black spots on each wing-cover and four smaller ones on the thorax as shown in Fig. 296.

Life History.-The life history, as given by Dr. Chittenden for the District of Columbia and northward, is as follows; "The insect hibernates in the adult condition under bark or other convenient shelter and appears abroad sometime in May or June. Egg deposition has been observed in the latter part of

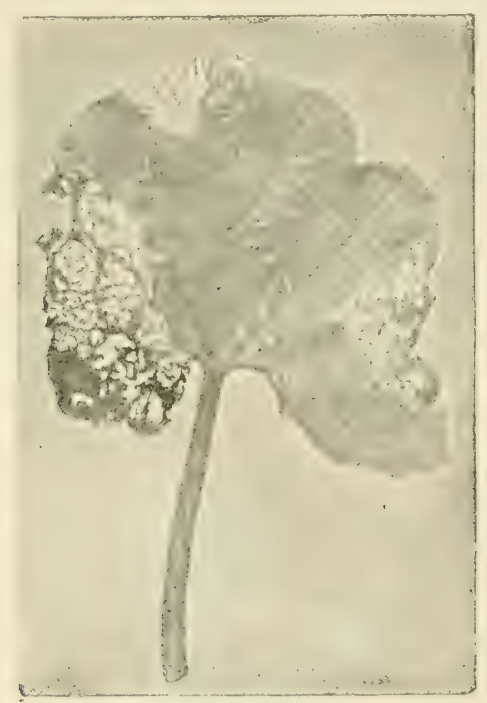

Fig. 297.-Work of the squash ladybird - greatly reduced. (After W. E. Britton.) June, and there is evidence that the eggs are deposited also much later." The eggs are about threetenths inch long, elongate oval of a yellow color, and laid in irregular clusters of from 12 to 50 . "They hatch in from six to nine days, and the larvæ begin to feed at once on the leaves, causing them to wither and die." The larva is yellow, with six rows of black branching spines, and is about one-half inch long when grown. "The larva attains full development in from two to four weeks, ceases feeding, and attaches itself by its anal extremity to a leaf, and next day sheds its larval skin, which is pushed down toward the end of the borly, when the pupa stage is assumed. The larva matures anytime from the middle of July to near the middle of September. In the pupa state the insect remains from six to nine days, when the skin separates down the back and the perfect beetle emerges, the new brood appearing as early as the last of July. After feeding for some time the beetles disappear for hibernation, . . . beginning about the middle of September." The adults have the habit of marking out a circular area of the leaf, which seems to cause the tissue to wilt, and then feeding within 
this area. The larva are to be found feeding on the under surface of the foliage in July and August.

Control.-Usually hand picking the beetles and eggs will control the pest, but if abundant it may be readily destroyed by spraying or dusting with arsenicals.

\section{The Squash-vine Borer*}

In many localities the most serious pest of squash is the Squash-vine Borer, and although other cucurbs are sometimes injured, they are relatively free from attack if squash or pumpkins

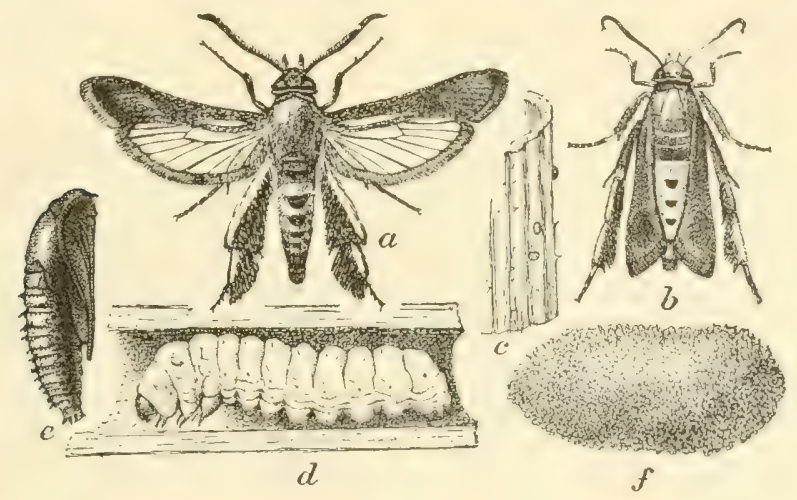

FIG. 298.-The squash-vine borer (Mclittia satyriniformis Hhn.): a, male moth; $b$, female with wings folded at rest; $c$, eggs shown on bit of stem; $d$, full-grown larva in vine; $e$, pupa; $f$, pupal cell-all one-third larger than natural size. (After Chittenden, U. S. Dept. Agr.)

are present. The larvæ bore in the stems, causing them to rot where affected, so that they break off and the plant wilts and dies. The presence of the borer is indicated by the coarse yellowish excrement which it forces from its burrow and which is found on the ground beneath, and by the sudden wilting of the leaves. Injury is most severe at the base of the vine, which gradually decays, so that it is severed and the whole plant dies. A halfdozen or more larva are often found in a single stem, and as many as forty have been taken from one vine, the larvæ attacking all parts of the vine and even the petioles and large ribs of the leaves when abundant. Injury is worst on Hubbard, marrow, cymlings and late varieties of squash.

* Melittia satyriniformis Hbn. Family Sesiida. Farmers' Bulletin 668, U. S. Dept. Agr. 
The adult is one of the clear-winged moths with a wing expanse of about $1 \frac{1}{4}$ inches, the fore-wings being opaque, dark olive green in color, with a metallic lustre and a fringe of brownish black. The hind-wings are transparent, with a bluish reflection, and the veins and marginal fringe black. The abdomen is marked with orange, or red, black and bronze, and the legs are bright orange, with tarsi black with white bands. The species occurs throughout the states east of the Rockies and southward into Central and South America.

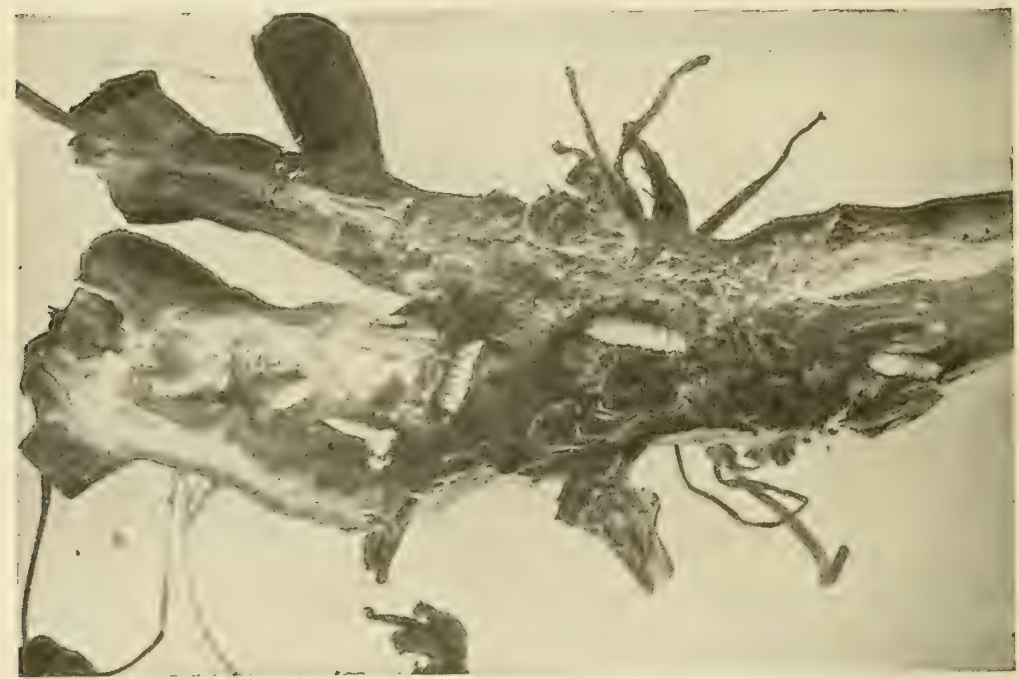

Fig. 299.-A squash stem cut open showing borers within. (Photo by Quaintance.)

Life History.-The moths appear soon after their food-plants start growth, from mid-April along the Gulf Coast to June 1st, in New Jersey, and late June or early July in Connecticut. They fly only in the daytime, and their clear wings and brightly marked bodies give them a close resemblance to large wasps. The eggs are laid on all parts of the plant, but chiefly on the stems, particularly near the base. The oval egg is of a dull red color and about one-twenty-fifth inch long. The moth deposits her eggs singly, and one individual has been observed to lay as many as 212. They hatch in one or two weeks. The young larva enters the main stem and tunnels through it, and often enters the leaf- 
petioles branching from it. It is a soft, stout, whitish caterpillar, with a small black head, and about one inch long when full grown. The larvæ reach maturity in about four weeks and then enter the earth, where they make tough silken cocoons, coated with particles of earth, an inch or two below the surface. In the South the larvæ transform to pupæ from which a second generation of moths emerges in late July, but in the North the larvæ hibernate in the cocoons over winter, and transform the next spring. The pupa is about five-eighths inch long, dark brown, and with a horn-like process on the head between the eyes. By the aid of this the pupa cuts open one end of the cocoon and with the hook-like spines on the abdomen wriggles to the surface of the earth before transforming to the moth. As indicated, there is but one generation in the North, a partial second brood in the latitude of New Jersey and the District of Columbia, and two full generations in the South.

Control.-As the larvæ work within the vines, insecticide treatment is useless, and the pest must be controlled by methods of culture.

Obviously the vines should be raked up and destroyed as soon as the crop is gathered, so as to destroy all of the borers within them. As the larvæ or pupæ hibernate over winter in the soil, it has been found that frequent light harrowing in the fall will bring them to the surface, and that deep plowing in the early spring will then bury any surviving so that the moths cannot emerge. Rotation of the crop will evidently decrease the number of moths. Where the pest is abundant late squash may be protected by planting rows of early summer squashes as soon as possible. These will attract the moths so that there will be relatively few eggs deposited on the main crop planted later. As soon as the early crop is gathered, or as soon as it becomes well infested, if it is used only for a trap, the vines should be raked up and burned so as to destroy all eggs and larvæ. It is well to cover the vines with earth one or two feet from the base so as to induce the growth of secondary roots, which will support the plant in case the vine is severed lower down. The oldfashioned method of slitting the vines with a knife and thus killing the borers is about the only means of destroying them after they have become established. The position of a borer may 
be detected by the excrement extruded from its burrow, and if the wound be covered with moist earth it will assist the healing. Destroy the parent moths whenever they are seen.
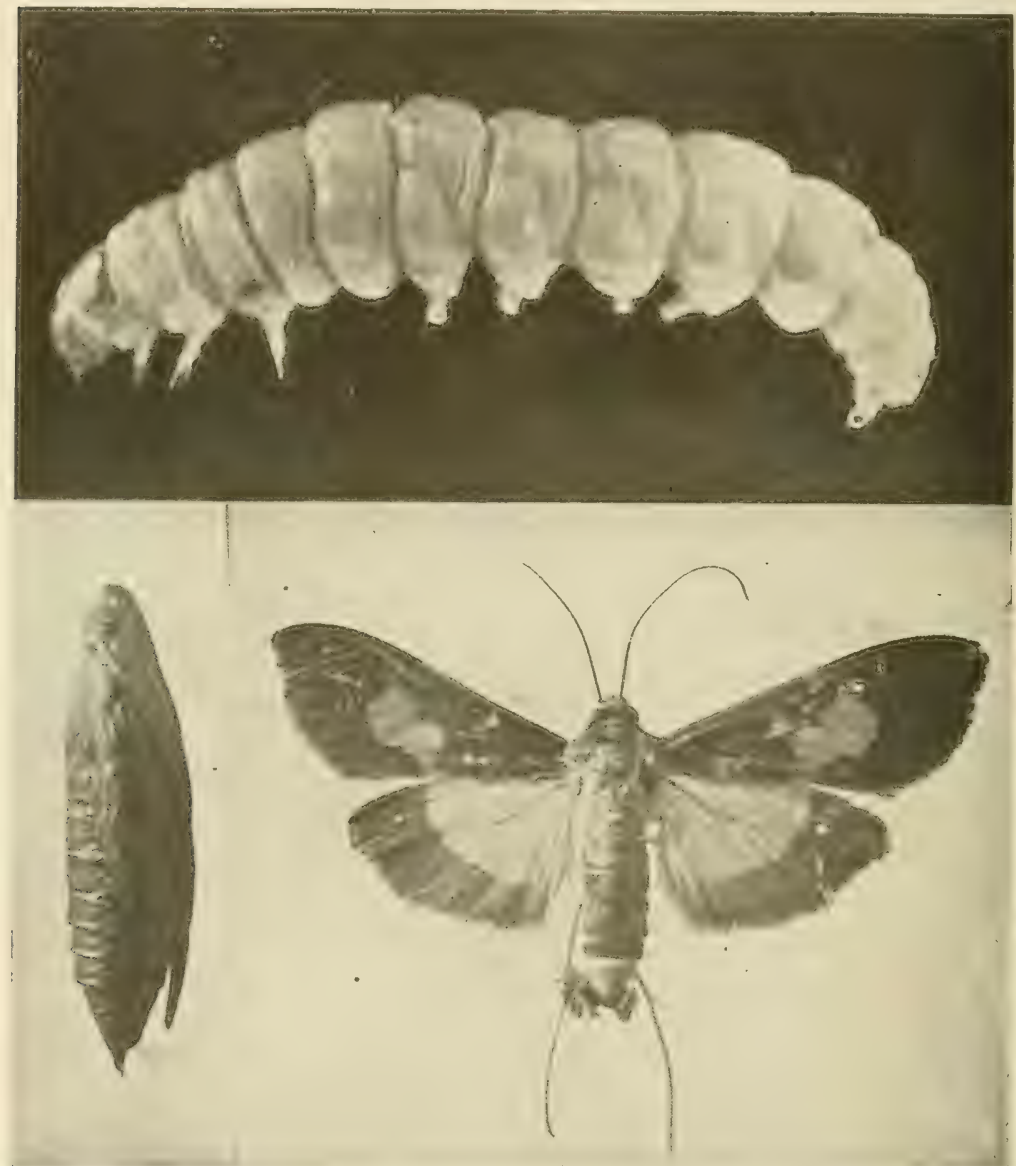

Fig. 300.-The pickle worm (Diaphania nitidalis Cramer): larva, pupa, and adult-all enlarged. (Photos by Quaintance.)

\section{The Pickle Worm*}

The pickle worm is so called because it was first noted as injuring cucumbers grown for pickling, but in the Gulf States, where it is most injurious it is more commonly a pest of melons,

* Diaphania nitidalis Cramer. Family Pyraustider. See A. L. Quaintance, Bulletin 54, Gri. Agr. Exp. Sta., R. I. Smith, Bulletin 214, N. C. Agr. Exp. Sta. 
and, with the following species, with which it is often confused, is often known as the "melon worm." Injury in the Middle States occurs only periodically, though it has been noted in Illinois and southern Michigan, but in the Gulf States it is always a serious pest of all the cucurbs, destroying the blossoms, mining the stems, and boring into the ripening fruit.

The moth has a wing expanse of about $1 \frac{1}{4}$ inches, is yellowishbrown with a purplish iridescence, and is readily recognized by an irregular yellowish transparent spot on the middle of the fore-wings, and the basal half of the hind-wings of the same color. The abdomen terminates in a conspicuous brush of large blackish scales.

Life History. - The moths emerge in late spring and deposit the eggs either singly or in clusters of 3 to 8 on the flowers, buds, or tender terminals. The yellowish-white egg is about onethirtieth inch long, and rather elliptical. The first larvæ are to be found in Georgia by the middle of June. The young larvæ which hatch from eggs laid on the terminals bore into stems and leaves and later often tunnel out the vines like the squash-vine borer. Those from eggs laid on the blossoms usually feed in the blossoms, and a half-dozen may often be found feeding in single squash blossoms, for which they seem to have a decided preference. As they grow older the larvæ warder from one plant to another; often boring into several fruits. The older larvæ bore into the fruit, the excrement being pushed out from the orifice and later accumulating in the cavity within. A single larva boring into the rind will do sufficient injury to start decay and ruin the fruit, and often a halfdozen or more will be found in a single melon. Until half grown the larvæ are marked with transverse rows of black spots. The full-grown larva is about three-quarters inch long, greenish or yellowish-green, with head and prothoracic shield brown. The larva reaches maturity in about two weeks, when a thin silken cocoon is made in the fold of a leaf in which the pupal stage is assumed, which occupies about a week. The pupa is one-half to one inch long, brown, with wing and leg sheaths lighter, and the tip of the abdomen bears a group of short curved spines which hold the pupa more securely in the cocoon. During 
July and August the complete life cycle requires about four weeks in Georgia, and at least three definite generations have been recognized, the injury by the larvæ being most severe in July and August, evidently by the second generation. The winter is passed in the pupal stage in the foliage or trash remaining on the field.

Control.-As injury is worst in late summer, early plantings and early-maturing varieties are but little injured. The thorough de-

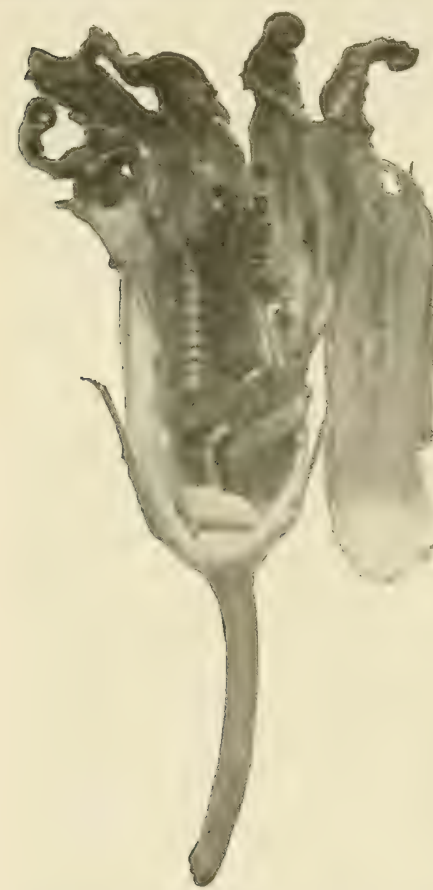

Fig. 301.-Siquash flower infested with pickle worms. (Photo by Quaintance.) struction of the vines, foliage, and trash on the field after the crop is secured is of the utmost importance in controlling this as well as other pests of cucurbs, and may probably be accomplished with this species by deeply plowing under the refuse. Professor A. L. Quaintance, to whom we are indebted for our knowledge of this pest, has found that the moths greatly prefer to oviposit on squash and that it may be successfully used as a trap crop for the protection of other cucurbs. Rows of summer squash should be planted through the cucumber or melon fields as early as possible, the rows being planted every two weeks so there will be flowers through July. The squash bloom, with the contained larvæ, must be collected and destroyed at frequent intervals. Otherwise the squash will merely augment the injury, as the larvæ will migrate to the crop. Careful tests of this method showed almost complete protection to muskmelons. The use of arsenicals has been of little value against this pest as far as tested, but as they should be applied to control the next species, may be of some incidental value. 
INSECTS INJURIOUS TO MELONS, CUCUMBERS, ETc. 359

\section{The Melon Caterpillar*}

This species is very similar to the last in life history and habits and is very commonly confused with it. It seems to be commonly

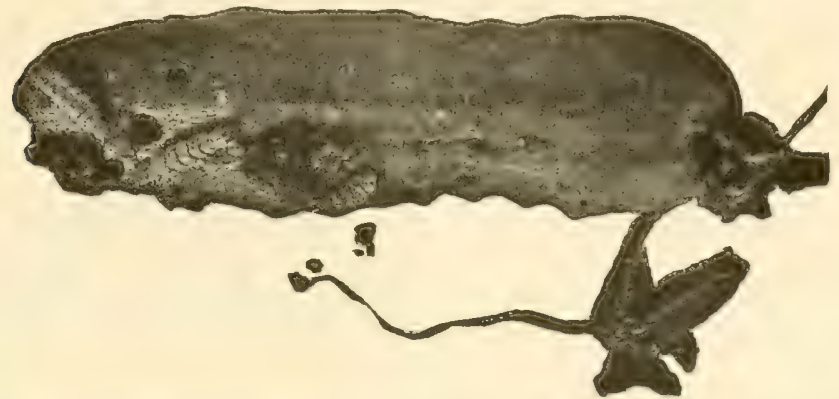

FIG. 302.-Pickle worms at work on a cucumber. (Photo by Quaintance.) injurious only in the Gulf States, though the moths have been taken from Canada to Central America and injury has been seen in Kansas. The moth is a beautiful insect with wings of a pearly iridescent whiteness, bordered with brownish-black and expanding about an inch. The anterior half of the thorax and head is the same color as the wing border, while the abdomen is white, tinged with brownish toward the tip, which is surmounted by a brush of long dark scales. The larvæ are very similar to those of the pickle worm, and the life history so far as ascertained seems to be prac-

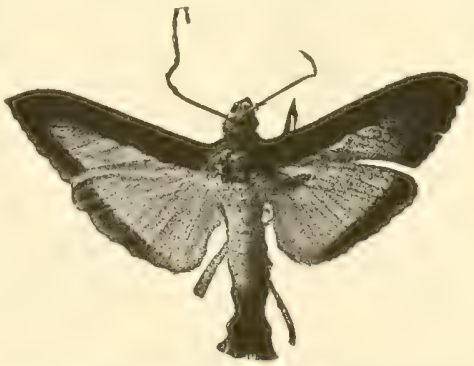

FIG. 303. - The melon-worm moth (Diaphania hyalinita Linn.) - enlarged. (Photo by Quaintance.) tically the same. The essential difference in the habits of this species is that the young larvæ very commonly feed on the foliage. Later on they mine into the stems and fruit and are readily confused with those of the last species.

Control.-The fact that the young larvæ feed on the foliage makes it possible to destroy them with arsenicals, and by

* Diaphania hyalinata Linn. Family Pyraustidce. See A. L. Quaintance, Bulletin 45, Geo. Agr. Exp. Sta., p. 42; R. I. Smith, Bulletin 214, N. C. Agr. Exp. Sta. 
spraying the young foliage with arsenate of lead 3 pounds to the barrel, as advised for the striped cucumber-beetle, they should

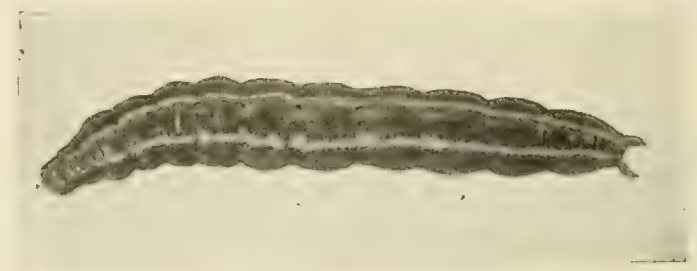

FIG. 304.-The melon-worm-enlargəd. (Photo by R. I. Smith.) be readily controlled. The cultural methods advised for the control of the last cpecies will of course be equally applicable for this. 


\section{CHAPTER XIX \\ MISCELLANEOUS GARDEN INSECTS \\ The Pale-striped Flea-beetle *}

Enorious numbers of the Pale-striped Flea-beetles often appear in late June or early July and nearly ruin the young crops they may attack before being brought under control. Such outbreaks oceur only periodically, so that usually the grower is
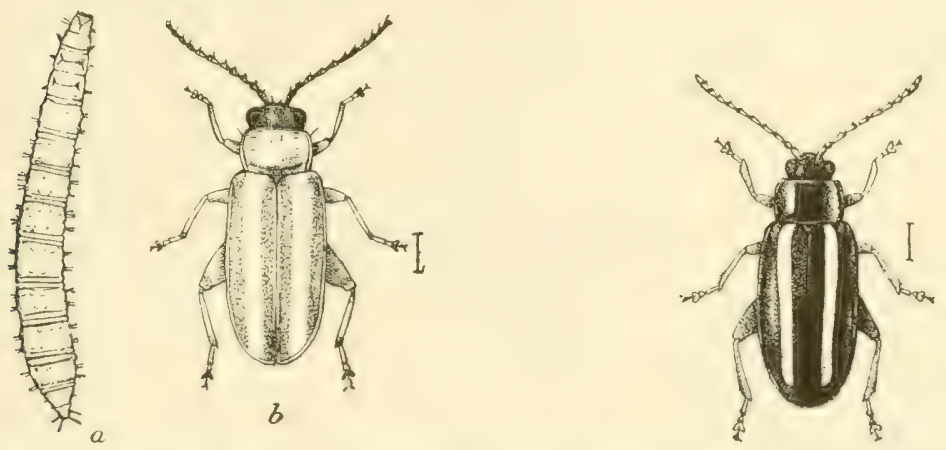

FIG. 305.-The pale-striped flea-beetle (Systena blanda Mels.): a, larva; $b$, beetle; $c$. eggs; $d$, sculpture of egg; $e$, anal segment of larva from side; $f$, same from above; $a, d$, six times natural size; $e, f$, more enlaiged; $g$, the banded flea-beetle (Systent terniata Say)-six times natural size. (After Chittenden, U. S. Dept. Agr.)

unprepared to cope with them, which is true of the appearance of many of our worst insect pests. These flea-beetles are almost omnivorous as regards food, for although particularly injurious to corn and tomatoes, they have also injured beans, beets, potatoes, egg-plant, carrots, melons and other cucurbs, turnips and other crucifers, strawberry, cotton, oats, peanuts, pear foliage, ete.,

* Systena bianaia Mels. Family Chrysomelida. See F. H. Chittenden, Bulletin, 25, n. s., Div. Ent., U. S. Dept. Agr., p. 22; S. A. Forbes, 1sth Report State Ent, Ill., p. 21. 


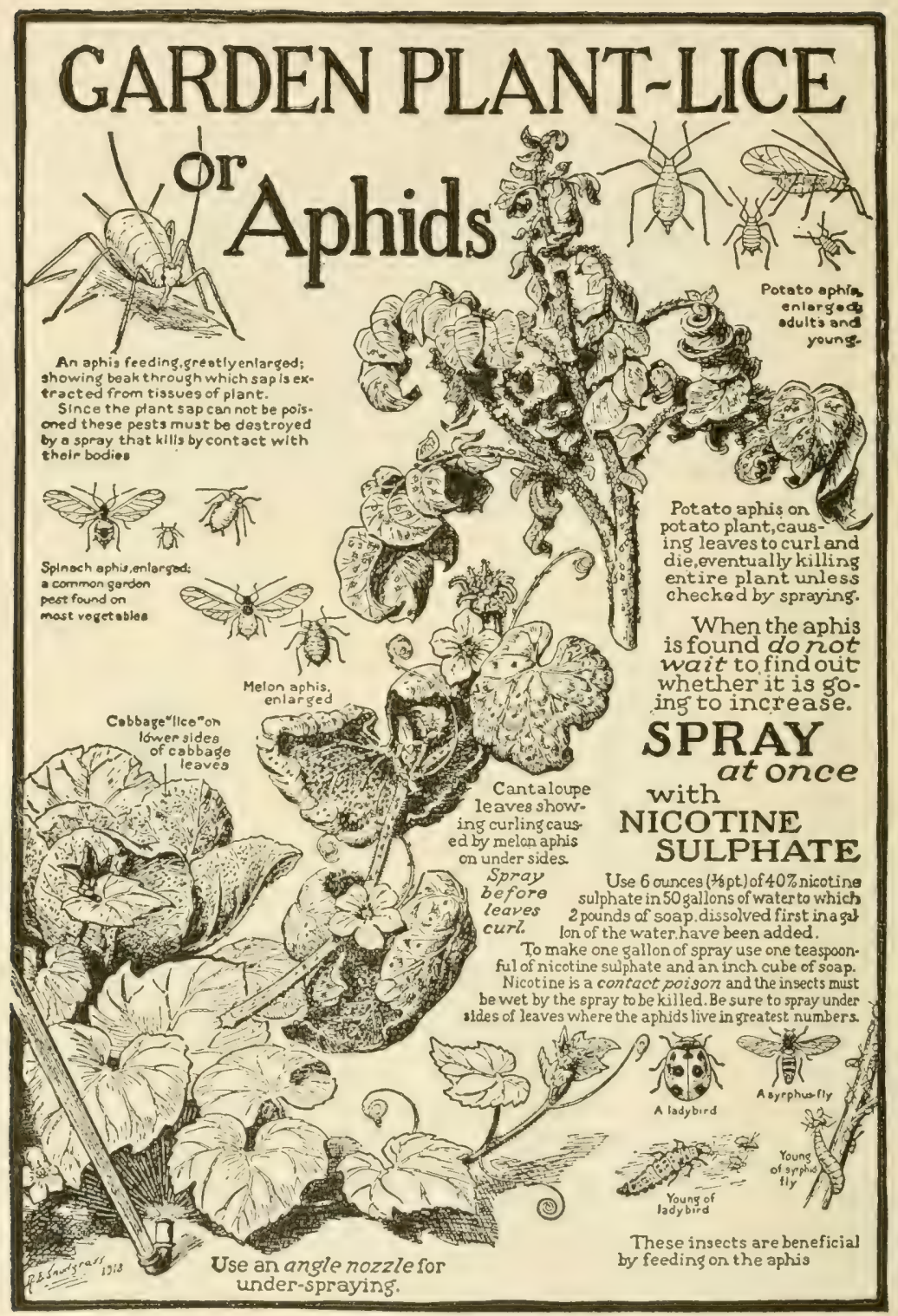

FIG. 306,-General recenmendations and information concerning plant-lice of the garden, as issued by the Bureau of Entomology, U. S. Dept. Agr 
and many common weeds, so that it may be safely said that when abundant they will attack almost any crop at hand. The species seems to occur practically throughout the United States, but injury has been most common in the Middle States east of the plains.

The beetle is about one-eighth inch long, cream-colored, with the wing-covers marked with three stripes of dull light-brown, and the eyes and abdomen are black. A nearly related species, the banded flea-beetle, ${ }^{*}$ is very similar in appearance, the dark stripes being expanded until it is a polished black with two white stripes (Fig. 305b), and the two species have until recently been commonly considered as identical. They are similar in life history and habits so far as known, and may be considered as the same for practical purposes.

Life History..-Very little is known of the life history. The beetles usually appear in late June and early July, coming out in enormous numbers, gnawing small holes in the foliage of the plants attacked, so that when abundant they completely defoliate the plant in two or three days and often necessitate replanting.

Control.-The destruction of the weeds on which the larvæ develop is of obvious importance, and it would be well to plow under deeply any fields grown up in weeds during late summer. Bordeaux mixture is possibly the best repellant for these beetles, though they will be driven off by covering the plants with any dust which thoroughly coats the foliage. Usually the best method will be to spray the plants thoroughly with Bordeaux mixture containing 3 pounds of arsenate of lead or one-third pound Paris green per barrel. All parts of the foliage must be thoroughly coated. Good success has also attended dusting the plants with Paris green and flour and by spraying the beetles with kerosene emulsion. Powdered arsenate of lead dusted over the foliage while the dew is on would probably prove effective, or it might be sprayed at the rate of 3 to 5 pounds to the barrel.

\section{The Garden Webworm †}

The term garden webworm is possibly a misnomer, for although these little caterpillars frequently do more or less injury to various

* Systena toniata Say.

$\dagger$ Loxostege similalis Gn. Family Pyraustider. See C. V. Riley, Report U. S. Comm. Agr. for 1885, p. 265; Sanderson, Bulletin 57, Bureau of Entomology, U. S. Dept. Agr., p. 11, 
garden crops when they become overabundant and migrate to them from the weeds on which they normally feed, and occasionally do some damage to sugar beets, they are best known as a pest of corn and cotton. Though the species occurs throughout the United States and south to South America, it has been most injurious from Nebraska southward and east to Mississippi and Illinois. The larvæ feed normally on the pigweed or careless weed (Amaranthus spp.) from which they sometimes receive the local name of "careless worm," and only when they become overabundant on these weeds do they usually increase sufficiently to migrate from them and attack crops.

The moth is a yellowish, buff or grayish-brown color, marked as shown in Fig. 307, and with a wing expanse of about threequarters of an inch. The larva also varies in color from pale and greenish-yellow to dark yellow, and is marked with numerous black tubercles as shown in Fig. 307, b, c.

Life History. - The hibernating habits are not known, but from analogy with the beet webworm, and the appearance of the

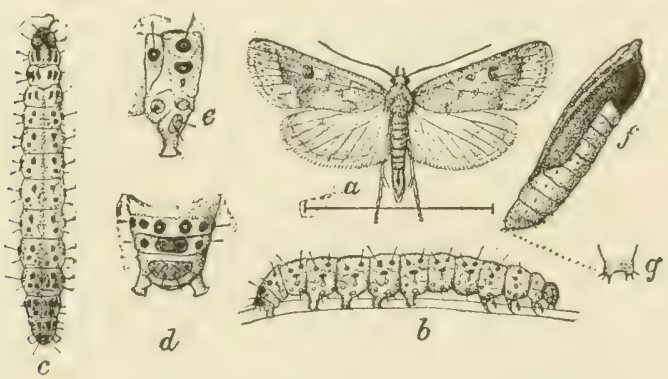

FIG. 307.-The garden webworm (Loxostege similalis Gn.): $a$, male moth; $b, c$ larvie; $d$, anal segment of same; $c$, abdominal segment of same from side; $f$, pupa; $g$, tip of abdomen of same; $a, b, c, f$, somewhat enlarged; $d, e, g$, more enlarged. (After Riley and Chittenden, U. S. Dept. Agr.) moths, it seems probable that the winter is passed by the larvæ or pupæ in the soil. The moths appear in Texas by mid-April and in central Illinois in late May and early $\mathrm{J}$ u n e. The yellowish eggs are laid on the foliage in small patches of from 8 to 20 and in Texas hatch in three or four days. The larva of the first generations feed on weeds or alfalfa, where it is grown, and then migrate to corn and cotton or garden truck, the former crops being attacked when six or eight inches high. In feeding the caterpillars spin a fine web, which gradually envelopes the plant, of which nothing is left but the skeletons of the leaves when the 
larvæ are abundant. The larvæe become full grown in about three weeks in summer, when they descend to the soil and pupate in small silken cells on or just below the surface. The moths emerge about eight days later, so that in midsummer the complete life cycle-occupies about a month. In Texas there are probably five generations a year, and in Nebraska and Illinois three or four generations.

Control.-The plowing of infested land in late fall or winter, or thorough disking of alfalfa will be found largely to control the pest. Where it appears on cultivated crops it may be readily destroyed by at once spraying or dusting with arsenate of lead. The destruction of the weeds upon which it feeds is obviously important in preventing the undue multiplication of the pest.

\section{The Rhubarb Curculio *}

Rhubarb is but little troubled with insect pests, but oceasionally the stalks are found with numerous punctures from
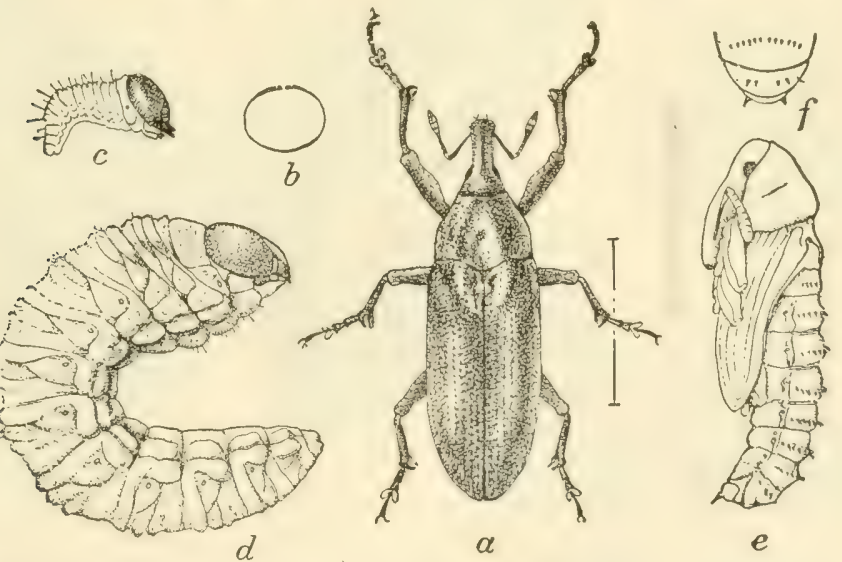

Fig. 308.-The rhubarb curculio (Lixus concarus Say): $a$, beetle; $b$, egg; $c$, newly hatched larva; $d$, full grown larva; $e$, pupa; $f$, back view of last abdominal segment of pupa-all about twice natural size. (After Chittenden, U. S. Dept. Agr.)

which the juice exudes. This has been caused by the feeding and oviposition of a large rusty-brown snout-beetle, which is usually found on the affected plants. It is about three-quarters

* Lixus concarus Say. Family Curculionida. See F. H. Chittenden, Bulletin 23, n. s., Division of Entomology, p. 61. 
inch long, and will be readily recognized from Fig. 308 The beetles hibernate over winter and feed on dock, in the stalks of which the eggs are laid in May. Although eggs are laid in rhubarb, they fail to hatch or the young larvæ die. The grubs become full grown by midsummer and the beetles emerge in late summer and feed a little before entering hibernation.

Control.-As the beetles are sluggish and readily found, they may be easily destroyed by handpicking. Dock plants near the rhubarb patch should be pulled and destroyed in early summer after the beetles have finished laying their eggs.

\section{The Celery Caterpillar*}

Everyone who grows celery, parsley or carrots is familiar with the large, black-striped, green caterpillar which feeds on

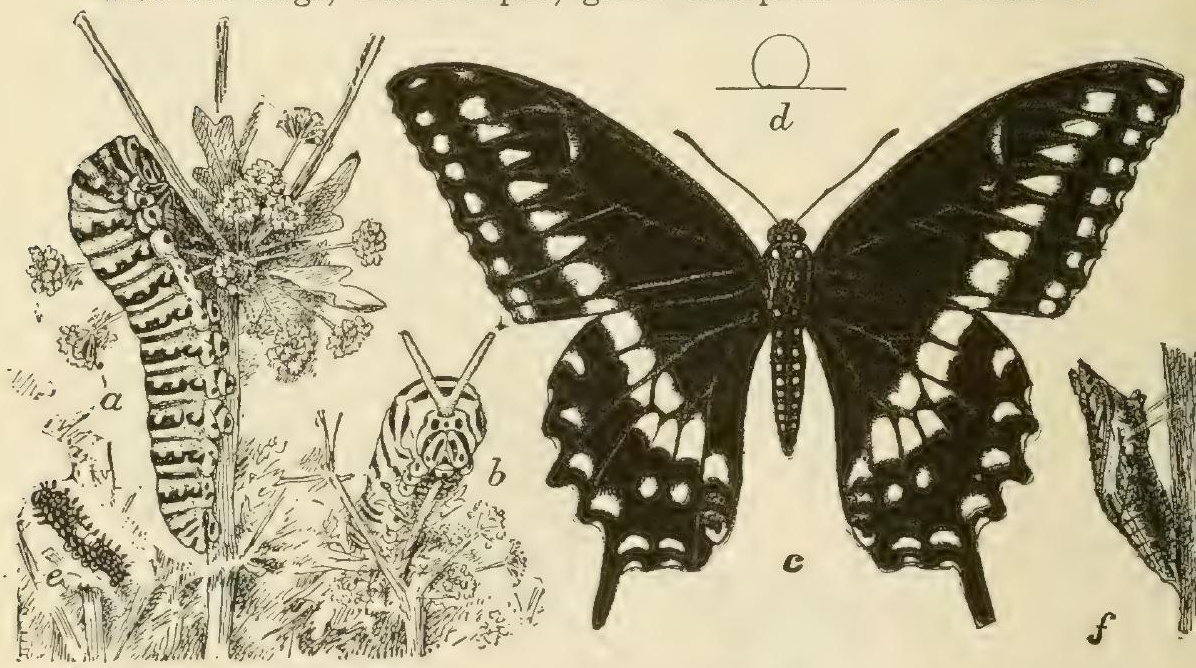

Fig. 309.-The celery caterpillar (Papitio polyxenes Fah.): $a$, full grown larva, side view; $b$, front view of head showing extended osmateria; $c$, male butterfly; $d$, egg; $e$, young larva; $f$, suspended chrysalis-about natural size except d. (After Chittenden, U. S. Dept. Agr.)

their foliage, as it is probably the most common pest of those plants in all parts of the country, ragging the foliage and attacking the blossoms and undeveloped seeds. It is the larva of our most common black swallowtail butterfly, shown natural size in Fig. 309. The wings of the male are velvety black with bands

* Papilio polyxenes Fab. Family Papilionidx. 
of yellow spots. On the inner angle of the hind-wing is a wellmarked eyespot, and the hind-wing terminates in a distinct "tail." The female is somewhat larger, the inner row of yellow spots is wanting, and the hind-wings are covered with pale-blue scales on the posterior half. There is considerable variation, however, in the color of both sexes.

Life History. - In the North the winter is passed in the chrysalis stage and the butterflies appear in May in New England, while in the far South the butterflies hibernate over winter and appear in March or April. The eggs are laid on the foliage and are of a globular form, about one-twenty-fifth inch in diameter, at first pale honey-yellow, but later reddish-brown. The eggs hatch in from four to nine days. The young larva are quite dissimilar from the older stages, being nearly black with a white band around the middle of the body (Fig. 309e). The larvæ feed exclusively on umbelliferous plants, including besides those mentioned, caraway, fennel, parsnip, dill, wild carrot, wild parsnip, and other weeds of this family. The full-grown larva is shown, natural size, in Fig. 309, $a$. It is bright green, sometimes yellowish, and marked with rings and spots of velvety black as illustrated. Just back of the prothorax is a pair of membranous yellow horns called osmateria, which give off a peculiar pungent odor, which is quite disagreeable and evidently aids in frightening away enemies. These osmateria are soft, retractile organs, which are drawn back between the segments and are extruded only when the larva is disturbed.

In the far South the larva will become grown in ten days, but in the North it requires three to four weeks. The caterpillar then attaches itself to some part of the plant by the anal prolegs, and fastens a strong loop of silk around the thorax, and sheds its skin, leaving the chrysalis or pupa firmly attached to the leaf or stem as shown in Fig. 309, $f$. The chrysalis is a dull gray color marked with black and brown and about $1 \frac{1}{4}$ inches long. In from ten days to two weeks the butterfly emerges from the chrysalis. Thus the complete life cycle may be passed in twenty-two days in the South to eight weeks in the North. In the North there are but two generations a year, while in the South there are probably three or four.

Control.-The caterpillars are so readily seen, and if not seen they soon reveal their presence by the peculiar odor when dis- 
turbed, that they may usually be picked off and crushed, and so rarely become sufficiently numerous to warrant other treatment. They may be readily controlled by spraying or dusting with arsenicals.

\section{The Celery Looper*}

This species is very closely related to the cabbage looper and occurs throughout the Northern States east of the Rocky Mountains. According to Forbes and Hart it is more common than the cabbage looper in Illinois, where it is a serious pest of celery and has been reared on sugar-beet, but elsewhere it is not as common.

The moth has a wing expanse of about two inches, the forewings being purplish brown with darker shades of velvety brown
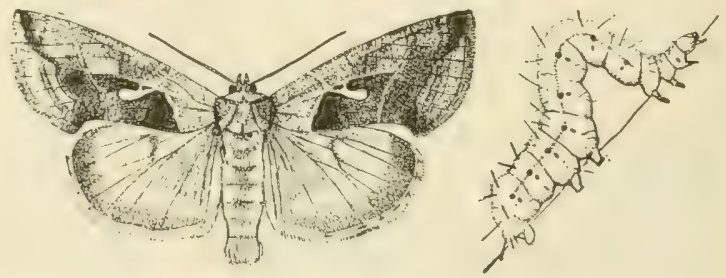

FIG. 310.-The celery looper (Antogragha simplex Guen.): male moth and larva- somewhat enlarged. (After Chittenden, U. S. Dept. Agr )

and with a prominent silvery white discal spot, while the hindwings are yellowish, strongly banded with dark fuscous. The caterpillar or larva is similar to that of the cabbage looper, but the spiracles are surrounded with black rings, while in the cabbage looper these rings are indistinct or wanting.

Forbes and Hart believe that there are three broods in a year. "The caterpillars of the first generation of the year hatch late in May and get their growth late in June or early in July. The life of the second generation extends from the first part of July to the middle of September, and the third begins to issue from the egg early in October. This brood hibernates about half grown, attaining full size during the latter part of April."

Control.-No accounts of experiments in control are on record, but doubtless the same measures as used against the cabbage looper will be found applicable.

* Antographa simplex Guen. Family Noctuido. See Chittenden, Bulletin 33, Division of Entomology, U. S. Dept. Agr., p. 73. 


\section{The Carrot-beetle *}

The Carrot-beetle is a native species which has been particularly injurious to carrots along the Atlantic Coast from Long Island through the Gulf States. The species occurs, however, very generally throughout the country as far north as central Indiana, and on the Pacific coast. It has a considerable number of food-plants; in Louisiana and Mississippi it has injured the corn crop, the beetles cutting the corn just above the roots; in Illinois the beetles injured sunflowers and sweet potatoes; in Indiana they attacked carrots, celery and and parsnips; in Texas they have injured potatoes and shrubs and vegetables of various kinds; and in Nebraska they have damaged sugar-beets.

The damage is done entirely by the adult beetles, which are among the smaller of the Maybeetles or June-bugs, measure one-half to five-eighths of an inch long, and are from reddishbrown to nearly black in color.

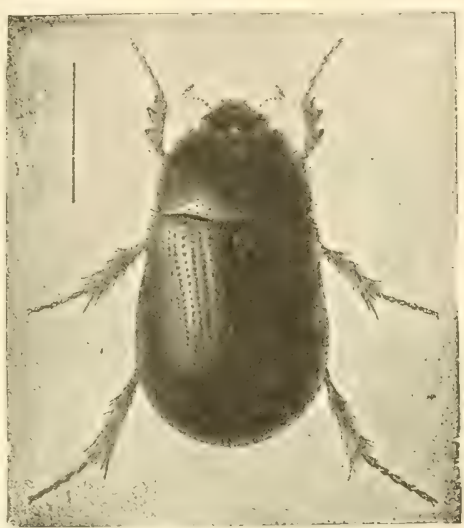

FIG. 311.-The carrot-beetle (Ligyrus giblosus DeG.) - much enlarged. (After Forbes.)

The bectles gouge into the roots or stems just below the surface of the soil, often ruining the root for market without injuring the top. The injury may occur by hibernated beetles in the spring from April to June or by newly transformed individuals in late summer or autumn.

The life history has not been studied, but is probably very similar to that of Lachnosterna.

Control.-No very satisfactory means of control have been tried in a practical way. It is stated that lime seattered over infester fields has driven the beetles away. It is evident that after the crop is gathered infested fields should be pastured with hogs, if possible, or plowed deeply, and plowed again in the spring. Evidently further study of the habits of the pest is necessary before satisfactory means of control may be devised.

* Ligyrus gibbosus DeG. Family Scaraboido. See F. H. Chittenden, Bulletin 33, n. S., Div. Ent., U. S. Dept. Agr., p. 32, and W. P. Hayes, Journal Ec. Ent. Vol. 10, pp. 253-261, 1919. 


\section{The Carrot Rust-fly *}

The Carrot Rust-fly is a European species, being a serious pest of carrots in England and Germany, which has been known in Canada since 1885 and appeared in New York in 1901 and since then in New Hampshire. The larva or maggot which does the injury very much resembles the cheese maggot or skipper in general appearance, is a rather dark brown, and a little less than one-third inch long. The parent fly is about one-sixth inch long with a wing expanse of three-tenths inch, and is a dark

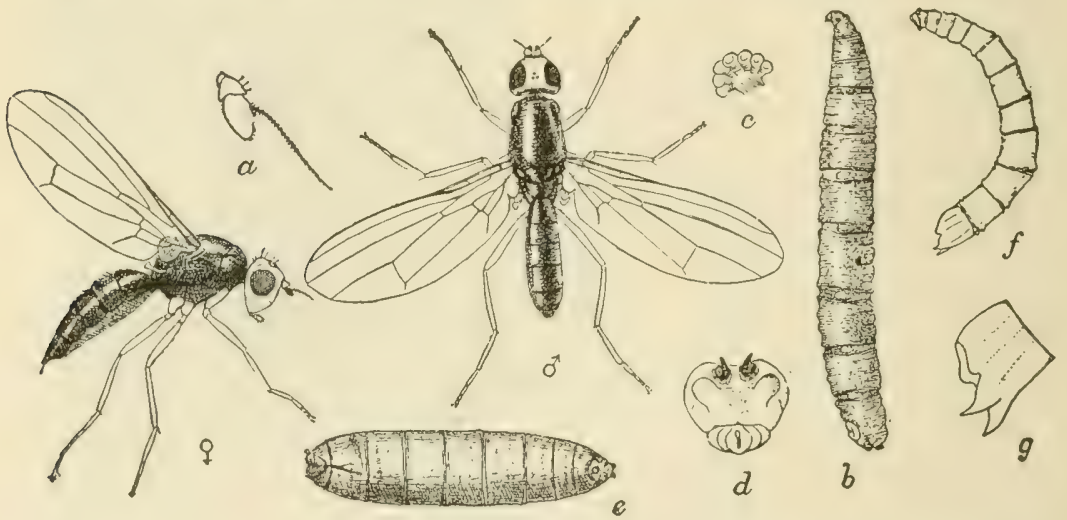

FIG. 312.-The carrot rust-fly (P sila rose Fab.): 50 , male fly; or, female flys, side view; $a$, antenna of male; $b$, full-grown larva from side; $c$, spiracle of same; $a$, anal extremity from the end; $e$, puparium; $f$, young larva; $g$, anal segment from the side--eight times natural size except $a, c, d, g$, more enlarged. (After Chittenden, U. S. Dept. Agr.)

blackish-green color, sparsely clothed with yellow hairs, and with pale yellow head and legs, except the eyes, which are black.

"Attack on carrots is not difficult of recognition. The leaves of the young plants early in the spring turn reddish, and the roots are found to be blotched with rusty patches, particularly toward their tips. The roots when stored for winter, although not always manifesting any degree of injury on the outer surface, may at times be perforated in all directions by dirty brownish burrows, from which the whitish or yellowish larvæ may be found sometimes projecting." Celery is also attacked, the larvæ

*Psila rosx Fab. Family Psilita. See Chittenden, Bulletin 33, n. s. Division of Entomology, U. S. Dept. Agr., p. 26. 
eating the thick part of the root when it is half grown, stunting the plant so as to make it worthless for market. The life history of the species does not seem to have been carefully observed, but from analogy is probably somewhat similar to that of the cabbage root-maggot, except that the maggots of the carrot rust-fly develop and transform on carrots in storage if the temperature be sufficient.

Control.-Control measures as recommended for this insect have not proven of any great benefit so we must wait for additional information before making definite suggestions.

\section{The Parsnip Webworm*}

The Parsnip Webworm is quite a common pest of the forming
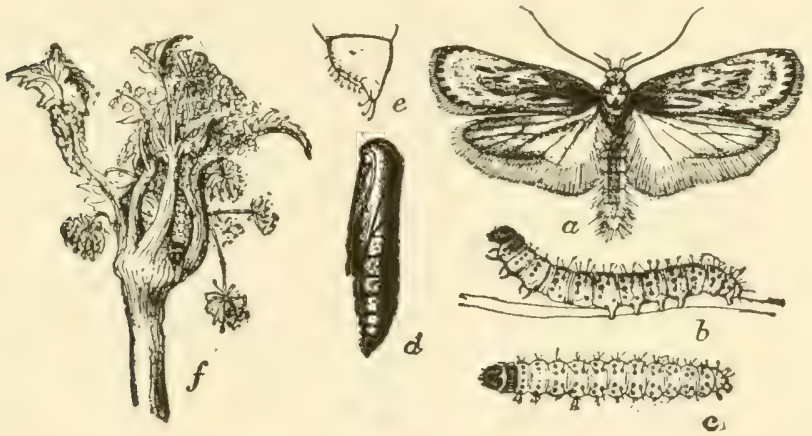

FIg. 313.-The parsnip webworm (Depressaria heracliana De G.): $a$, moth, $b$, $c$, larva; $d$, pupa; $e$, anal extremity of pupa; $f$, umbel of parsrip webbed together by the larvæ-natural size. (After Riley.)

seed of the parsnip, but fortunately it seems to prefer wild carrot as a breeding plant. It is an imported species, occurring in northern Europe, which was first observed in this country in 1873 and since then has become generally distributed over the Northern States and Canada westward to the Mississippi.

The moth is a grayish-buff or pale ochreous color, marked with fuscous, the wings expanding about three-quarters of an inch. The larva is a pale yellowish, greenish or bluish-gray, with conspicuous black tubercles, the head and prothoracic shield black,

* Depressaria heracliana DeG. Family Ecophorida. See C. V. Riley, "Insect Life," Vol. I, p. 94. 
and is about half an inch long when grown. The larvæ web the flower-heads together until they are contracted into masses of web and excrement as shown in the illustration. "After the larvæ have consumed the flowers and unripe seeds and become nearly full grown, they enter the hollow stems of the plant by burrowing their way inside, generally at the axils of the leaves, and then feed upon the soft, white lining of the interior. Here, inside the hollow stem, they change to the pupa state. The larvæ are moderately gregarious. They will sometimes eat newly sown parsnips after the older plants originally attacked have been destroyed, in such cases eating the tender green leaves, while of the older plants they eat only the flower-heads and interior lining of the stems." The moths appear in late July and early August.

Control.-Thorough spraying or clusting with arsenicals will destroy the caterpillars, according to Chittenden. If the flowers are destroyed before they are noticed, cut off and burn all infested stems before the moths emerge from the pupæ. Obviously it will be important to avoid planting parsnips in or near waste places which have grown up in wild carrot.

\section{The Onion Thrips *}

The small yellowish "thrips" which chafe the epidermis from the green leaves, causing them to dry out, whiten and die, have become well known to onion growers in practically all parts of the United States where onions are raised extensively. It is a European insect, occurring in Germany and Russia, and has also been imported into the Bermudas.

The adult thrips is about one-twenty-fifth of an inch long, of a pale yellow color, tinged with blackish. The general appearance, much enlarged, is shown in Fig. 314. The slender, elongate body bears two pairs of narrow, bristle-like wings which are of no value for flight. The fore-wing contains two-wing-veins, and the hind-wing but one, the posterior margin of both bearing a

* Thrips tabaci Lind. Order Thysanoptera. See Quaintance, A. L., Bulletin 46, Fla. Agr. Exp. Sta., "The Strawberry Thrips and the Onion Thrips." Full aceount and Bibliography; Pergande, Th., "Insect Life," Vol. VII, pp. 292-295; Osborne-Mally, Bulletin 27, Iowa Agr. Exp. Sta., pp. 137-142; Sirrine, Bulletin 83, N. Y. Agr. Exp. Sta., pp. 680-683, Farmers' Bulletin 1007, U. S. D. A. 
fringe of long hairs. When at rest the wings lie together along the back.

The thrips belong to a quite distinct order of insects, the Thysanoptera (or Physopoda), species of which are commonly found in the flowers of the rose and clover. The mouth-parts are quite different from those of any other order of insects, being intermediate between those of biting and sucking insects, the mandibles being reduced to bristle-like structures. Their manner of feeding does not seem to be clearly understood, though

Fig. 314.-The onion thrips (Thrips tahaci Lind.) - very greatly enlarged. (Photo by Quaintance.)

Professor Quaintance states that the onion thrips frequently rasps off and swallows pieces of leaf tissue. However, they are able to destroy the surface tissue of the leaf so that it wilts, and fields badly affected become blighted and white. .

This species has quite a list of food-plants, cabbage and cauliflower often being considerably injured. Among others may be mentioned turnip, kale, sweet clover, squash, cucumber, melon, parsley, tomato, and several common garden flowers and weeds.

Life History.--The eggs are slightly less than .01 of an inch long-too small to be visible to the unaided eye-elongate, and curved somewhat kidney-shaped. They are laid singly just beneath the surface of the leaf and hatch in about four days. 
The young nymphs resemble the adults in shape, but are at first almost transparent in color and then a greenish-yellow. They are frequently found feeding in small groups. Both the young and adults have a pair of sharp spines at the tip of the abdomen which they use to drive away enemies by striking them quickly right and left. Two or three days after birth the skin is shed and another molt occurs five or six days later. With the third stage the wing-pads appear. This stage lasts four days, and during it the insects take no food and remain almost quiet, moving with difficulty. On onions the nymphs have been found mostly on the bulbs in the loose soil. With the next molt, the insect becomes mature and winged. Thus, the total life cycle as observed by Professor Quaintance in Florida is about sixteen days. In Russia Dr. Lindeman found that a generation required forty-seven days. "In Florida there are probably no distinct broods, as all stages may be found at the same time. Allowing for the life cycle at sixteen days, a large number of broods could occur during the year, but unfavorable conditions keep them reduced, except daring the spring and perhaps early summer (the worst injury occurring in May and June), so that it will probably not happen that they will develop throughout a year according to their capabilities."

Control.- The best methods of control, according to Dr. Chittenden, include clean farming and crop rotation as preventive measures and spraying with nicotine sulphate as a direct method of killing the thrips. High pressure should be used in spraying and the spray should be directed downward so that it will be forced into the crevices between the leaves or stems, in which the thrips conceal themselves.

\section{The Imported Onion-maggot *}

The common white maggot which bores into the roots and bulbs, causing them to wilt and decay, is probably the most important insect pest of the onion. The present species is by far the most commonly injurious and is termed "imported" because it was early known as a pest in Europe and was imported into this country probably in colonial times.

* Pegomyia ceparum Bouché. Family Anthomyiidce. See same references as for cabbage-maggot. 

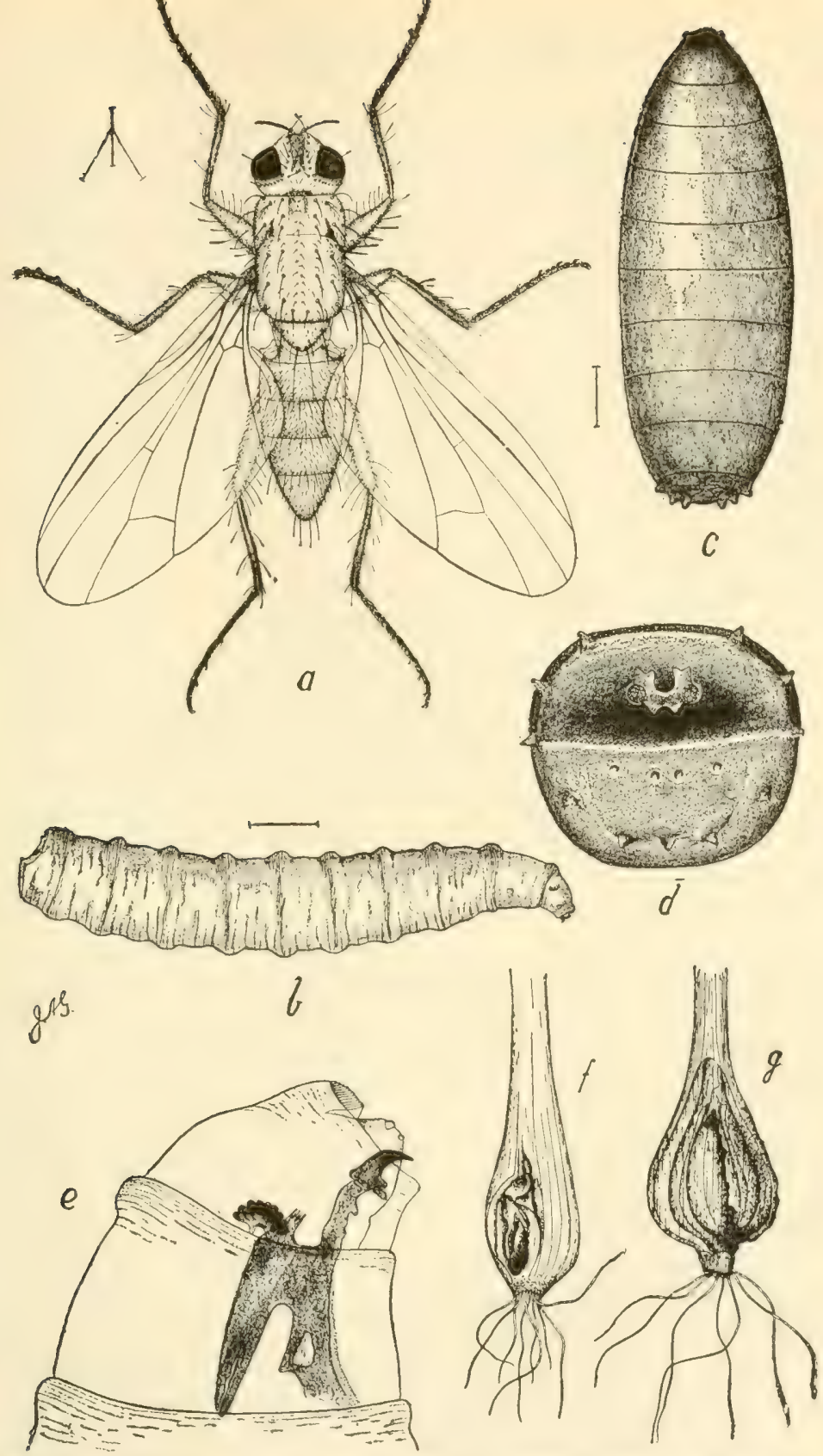

Fig. 315.-The imported onion-maggot (Pegomyia ceparum Bouché): a, adult; $b$, maggot; $c$, puparium; $d$, anal segment of maggot showing spiracles; $e$, head with mouth-parts-all very much enlarged; $f$ and $g$ show injury to young onions. (After J. B. Smith.) 
These maggots are the offspring of small flies, somewhat resembling small houseflies and very similar to those of the cabbage root-maggot.* The wings expand about three-eighths of an inch and the body is half that long. The male is gray with black bristles and hairs, the face is white with black hairs, there are three black lines between the wings, and the abdomen bears a row of black spots along the middle. The female is a little larger, inclined to dark yellowish, and with a yellowish face.

Life History.-The flies appear in the spring by the time young onions are up and the eggs are deposited in the sheath and in the axils of the leaves, from two to six being placed upon a plant. The eggs are just perceptible to the eye, white, oval, and about one-twenty-fifth of an inch long. The young maggot works its way down from the sheath to the root, upon which it feeds until it is consumed, only the outer skin remaining, and often cuts off the plant completely. Another plant is then attacked and often several young plants are consumed before the maggot is full grown. Later in the season the maggots bore into the bulbs, a number of maggots usually being found in a single bulb and their presence being indicated by a slimy mass of soil at the entrace of the cavity. If such bulbs are not killed outright, they usually rot in storage. The first presence of the pest is indicated by the wilting of the young plants, and by the central leaves of the older plants yellowing and dying.

The maggots become full grown about two weeks after hatching and are then about three-eighths of an inch long. They are dull white, with the jaws appearing beneath the skin as a short black stripe at the pointed end of the body. The posterior end of the body is obtuse and is cut off obliquely, the margin of the last segment bearing a number of tubercles by which this species may be distinguished from the cabbage-root maggot. (See Slingerland, l.c.)

The outer skin of the maggot now becomes hardened and within it the insect transforms to the pupa, which remains in the soil at the base of the plant for about two weeks, when the adult fly emerges. Two or three generations probably occur in the Northern States. Professor R. H. Pettit states that some of the

* See Slingerland, Bullet in 78, Cornell Agr. Exp. Sta., p. 495, for characters distinguishing these two species. 
flies hibernate while many of the pupæ remain in the soil over winter and the flies issue from them in the spring. This complicates remedial measures.

Control.-Liberal applications of commercial fertilizers such as nitrate of soda, which will assist to rapid growth, are of great value in overcoming injury by all root-feeding pests. Thorough culture is of value. Rotation of the onion plot to a point far distant from that of the previous year, the cleaning up of old beds, and plowing them deeply in the fall, will aid in the control. Pull up and destroy the young plants affected as soon as noticed, being careful to dig up the maggots with the roots. The appli-

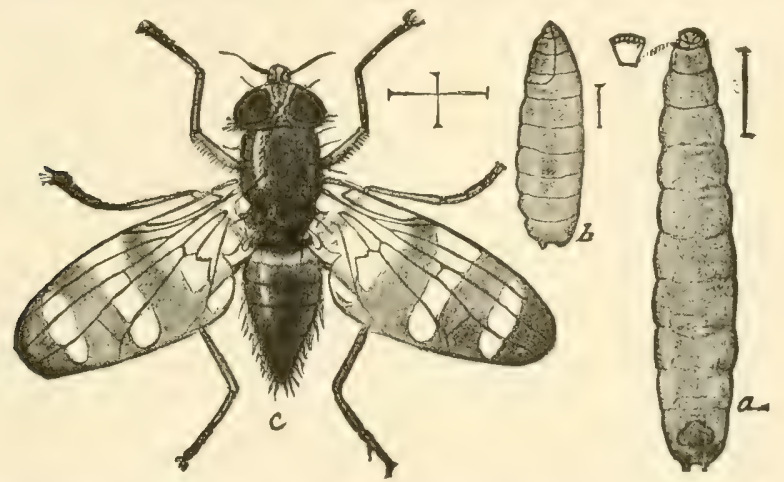

Frg. 316.-The barred-winged onion-maggot (Chatopsis anea Wied.): a, larva, with spiracular opening highly magnified at left; $b$, puparium; c, adult fly-all enlarged. (After Riley and Howard, U. S. Dept. Agr.)

cation of carbolic emulsion as for the cabbage-root maggot has been advocated and will doubtless lessen the injury by repelling the adult flies.

A more recent method of control is based on the fact that the flies are on the wing and feeding for several days before they lay their eggs and that they may be attracted to sweet substances. A poisoned syrup, sprinkled about the field and on weeds nearby, will attract the flies and kill large numbers before they lay their eggs. The syrup is poisoned as follows:

One pint of syrup is mixed with a gallon of water and to this is added one-fifth ounce of sodium arsenite dissolved in a small quantity of hot water. This is sprinkled where it will do the most good at intervals of about a week.*

* See Severin and Severin, Journal Econ. Ent., Vol. 8, pp. 342-350, 1915, and Howard, ibid. Vol. II, pp. 82-85, 1918. 


\section{The Barred-winged Onion-maggot *}

The adult flies of this species may frequently be found upon corn and are readily recognized by the banded wings. They are similar in size to the last species, but the back is metallic bluegreen except the head, which is mostly hoary, with brownishblack eyes. The maggots have been recorded as injurious to corn and sugarcane and have been recently noted in Michigan associated with the common onion-maggot, destroying onions. $\dagger$ The maggots are similar to the onion-maggot but the posterior end is more rounded and may be distinguished from the illustrations. The winter is passed in the puparium as far as observed.

Remedies. - In addition to the measures advocated for the last species, the destruction of the affected onions and the thorough plowing of affected land in the fall is of prime importance. Stored onions which prove infested may be fumigated with carbon bisulfide to destroy the maggots and puparia and prevent the emergence of the adults.

\section{The Asparagus-beetle $\ddagger$}

This is a well-known pest of asparagus in Europe and was first observed in Queens County, New York, in 1862, where it threatened to destroy the asparagus, one of the most valued crops of the Long Island truckers. Since then it has gradually spread northward to southern New Hampshire, south to North Carolina, and west to Illinois and Wisconsin, and has been found at two points in California. There seems no reason why it should not spread to wherever asparagus is grown, at least in the Northern States.

The beetle is a handsome little creature about one-quarter inch long, blue-black in color, with red thorax, and dark blue wing-covers, marked with lemon-yellow and with reddish borders. The markings of the wing-covers are quite variable, the light color sometimes forming submarginal spots, while in other specimens it becomes so diffused as to form the principal color of the wing-covers.

* Chatopsis aenea Wied. Family Anthomyida.

† See Pettit, Bulletin 200, Mich. Agr. Exp. Sta., p. 206.

$\ddagger$ Crioceris asparagi Linn. Family Chrysomelida. See F. H. Chittenden, Yearbook, U. S. Dept. Ayr., 1896, p. 341; Bulletin 66, Bureau of Ent., pp. 6, 93, and Farmers' Bulletin 837. 
Both adults and larve feed upon the tender asparagus shoots in the spring and later attack the fruiting plants. Their attacks render the shoots unfit for market and in many eases their injury has been so severe as to make it extremely difficult to estahblish new beds.

Life History.- The beetles hibernate over winter under whatever rubbish or shelter may be available near the asparagus patch. About the season that cutting asparagus for market commences they appear and lay the eggs for the first new brood

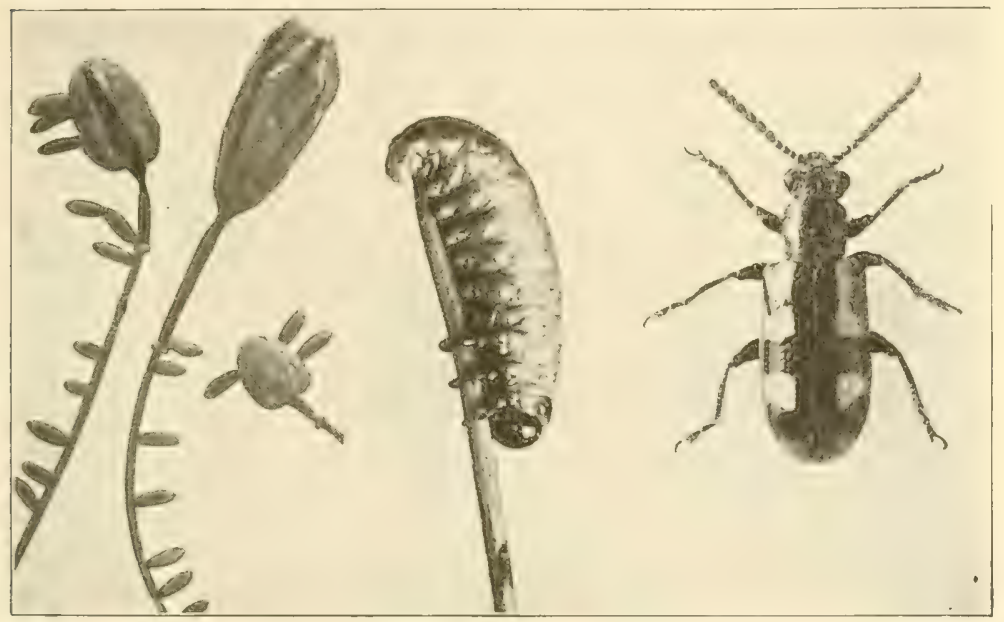

Fig. 317.-The asparagus-beetle (Crioceris asparagi Linn.): eggs, larva, and beetle - all much enlarged. (Photos by W. E. Britton.)

The egg is dark brown, oval, nearly one-sixteenth of an inch long and is laid on end. The eggs are deposited upon the stems or foliage, usually two to seven or more in a row. They hatch in from three to eight days. The young larva at once commence to attack the tender shoots, and later in the season feed upon the foliage. They become full grown in from ten days to two weeks. The full grown larra, as shown in the illustration, is about one-third of an inch long, soft and fleshy, much wrinkled, and of a dark gray or olive color, with black head and legs. The mature larva drops to the ground and just beneath the surface forms a little rounded earth-covered cocoon within which it changes to the pupa, from which the beetle 
emerges in about a week. Thus the complete life cycle may be passed in a minimum of three weeks at Washington, D. C., where there are possibly four generations in a year, while farther north, six or seven weeks may be required for the life cycle, and there are probably only two generations.

The asparagus-beetles are held in check by several natural agencies. Several species of ladybird-beetles feed upon the eggs, while numerous soldier-bugs attack the larvæ which they impale on their stout beaks. The adult beetles are often killed by low temperature in the winter, which doubtless limits their northern spread, while the eggs and larvæ are sometimes killed by the intense heat of summer, which will also probably limit the southern spread of the species.

Control.-One of the best means of control is to keep all shoots cut down in the spring so as to force the beetles to lay their eggs on the young shoots, which are cut for market every few days before the eggs have hatched, and hence no larvæ are allowed to hatch.

Another method which has proven effective is to cut down all the seed stems but a few rows here and there, so that the beetles will concentrate upon them, and then poison these thoroughly with arsenicals, or they may be cut down and burned and other rows allowed to grow as traps.

Air-slaked lime dusted on the plants in the morning while the dew is on will destroy the soft-bodied larvæ very effectively. Another way to destroy the larvæ in hot weather is simply to brush them from the plants so that they will drop on the hot soil. As they crawl but slowly few will regain the plants, particularly if the brushing be followed with a cultivator.

Probably the most effective means of controlling this pest, which was formerly a very difficult one to combat, is spraying with arsenate of lead. Use 3 pounds to 50 gallons, to which 3 pounds of resin soap should be added to render it more adhesive, although good results have been secured without the sticker. Such spraying should be given as soon as cutting is over and should be repeated once or twice at intervals of ten days. Where the young shoots are kept closely cut and the bed is then sprayed, there should be no trouble to control the pest, and young beds should be kept thoroughly sprayed with arsenate of lead from the time the beetles appear until danger from injury is over. 


\section{The Twelve-spotted Asparagus-beetle *}

The Twelve-spotted Asparagus Beetle is also of European origin, having been first introduced into this country near Baltimore, Md., in 1881. Since then it has become almost as widely distributed as the previous species.

The beetles may be distinguished from the last species by the broader wing-covers, each of which is orange-red, marked with six black spots. The chief injury by this species is by the beetles which emerge from hibernation feeding on the young shoots. Later generations attack the foliage, but the larva seem to prefer to feed upon the ripening berries. The larva is of the same general appearance as that of the preceding species, but may be distinguished by its orange color. The eggs are laid singly, and are attached on the sides instead of on end. They are deposited mostly on old plants toward the ends of the shoots which bear ripening berries

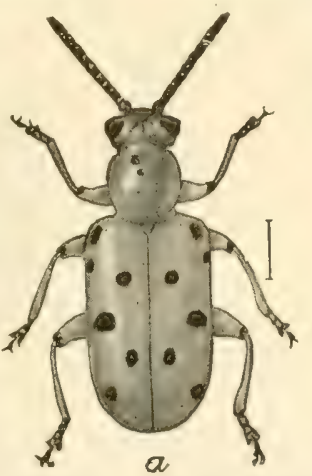

a
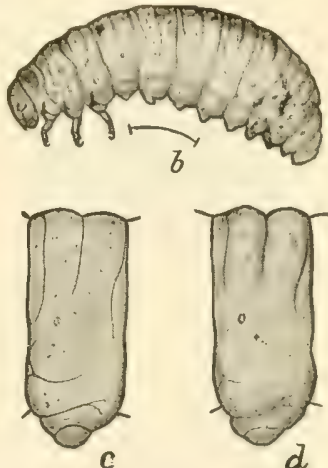

c

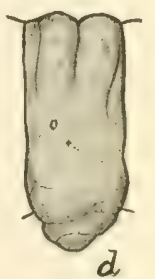

FIG. 318. - The twelve-spotted asparagus-beetle (Crioceris 12-punctata Linn.): $a$, beetle; $b$, larva; $c$, second abdominal segment of larva; $d$, same of $c$, asparagi- $a, b$, enlarged; $c, d$, more enlarged. (After Chittenden, U. S. Dept. Agr.)

lower down. Soon after a larva hatches it finds its way to a berry and feeds upon its ripening pulp, from which it migrates to another, feeding upon several, perhaps, before full growth is obtained, when it drops to the ground and pupates like the last species. The life cycle is essentially the same and there are probably the same number of generations.

Control.-The remedies advocated for the previous species will be found satisfactory except those which are directed against the larvæ, as the habit of the larva of concealing itself in the berry would make the application of insecticides to the seedstalks of little use.

* Crioceris 12-punctata Linn. See F. H. Chittenden, l.c., and D. E. Fink, Cornell Univ. Expt. Sta., Bulletin 331. 


\section{The Asparagus Miner*}

Occasionally injury by the small white maggots of a fly have been observed in the asparagus beds of Long Island, California, Pennsylvania, Massachusetts and District of Columbia, but the damage seems rarely to be very serious. The adult is a small black fly about one-sixth of an inch long and is usually found on the flowers of the asparagus, and occurs from New England to Tennessee. These flies emerge early in June. The exact manner of egg-laying has not been observed, but the young maggots are
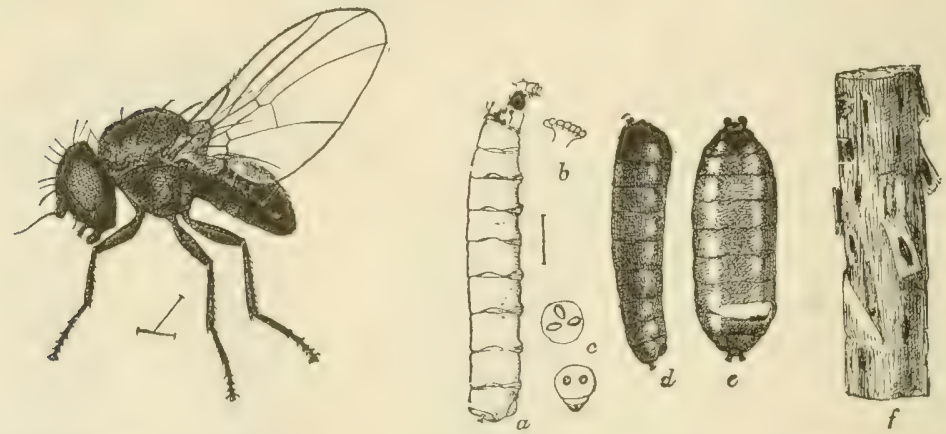

FIg. 319.-The asparagus miner (Agromyza simplex Loew): at left, side view of fly; $a$, larva; $b$, thoracic spiracles; $c$, anal spiracles; $d$, puparium from side; $e$, same from above; $f$, section of asparagus stalk showing injury and location of puparia on detached section- $a, e$, much enlarged; $f$, slightly reduced. (After Chittenden, U. S. Dept. Agr.)

found mining just beneath the surface of the stalks, especially young stalks. The maggots are about one-fifth of an inch long, pure white, except the black rasping hooks which project from the head. When full grown the maggots change to puparia beneath the epidermis. The next brood of adult flies emerge early in August. A second brood of maggots seems to occur and the puparia of the second brood pass the winter, and from them come the flies early the next summer.

Injury from the mining of the maggots has been most serious on seedling and newly set beds, though it may occur on cutting

* Agromyza simplex Loew. Family Agromyzida. See Sirrine, Bulletin 189, N. Y. Agr. Exp. Sta.; Chittenden, Bulletin 66, Part I, Bureau of Entomology, pp. 1 and 5, Fig. 2, and D. E. Fink, Bulletin 331. Cornell Univ. Agr. Exp. Station. 
beds, being apparent by the plants turning yellow and dying much earlier than they naturally do.

Pulling the old stalks and burning them in late summer seems to be the best means for controlling the pest, from our present knowledge of it, which, however, is still rather meager. Dr. Chittenden has suggested that letting a few stalks grow as a trap-crop to which the flies might be lured, and then destroying these stalks, might protect the cutting beds.

D. E. Fink (1.c.) recommends the addition of syrup to the arsenical applied for the beetles so that it will act as a poisoned bait for the flies. In addition to this he suggests pulling the infested stalks in late fall and early spring and destroying them.

\section{The Sweet-potato Flea-beetle *}

As soon as the sweet-potato plants are set out they are often attacked by hordes of hungry little brownish flea-beetles. Small channels are eaten out of both surfaces of the leaf in a very characteristic manner, quite different from the work of other fleabeetles (Fig. 320), and often the whole surface is seared but never punctured. As a result many of the leaves of the seedling are killed outright, turn brown, and decay, while new leaves put out from below, thus checking the growth. These attacks have been found to be worst on low land and that previously in sweet potatoes, and are always first noticed near fence rows or woodland where the beetles have hibernated. The beetle is bronzed or brassy-brown about one-sixteenth inch long, thick set, and the wing-covers when seen under a lens are deeply striated.
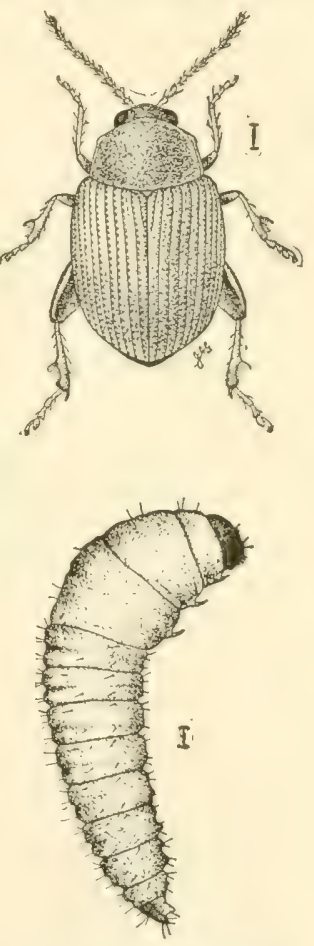

FIG. 320.-The sweetpot a to flea-beetle (Chrotocnema confinis Lec.) : adult and lirva - much en I a r ged. (After J. B. Smith.)

* Chatocnema confinis Lee. Family Chrysomelida. See Sanderson, Bulletin 59, Md. Agr. Exp. Sta.; J. B. Sinith, Bulletin 229, N. J. Agr. Exp. Sta. 
Life History. - The beetles hibernate over winter in rubbish, under logs, leaves or other vegetation, and emerge early in May. They mate as soon as they have fed a little, and disappear by the middle of June in New Jersey. But little is known of the early stages of the insect and they have never been found on sweet-potato plants. The larvæ have been found, however, feeding on the roots of bindweed. The larva (Fig. 320) is a slender, white grub, about one-eighth inch long, and feeds externally upon the smaller roots. The beetles appear again in August, but do not as a rule feed on sweet potatoes, preferring bindweeds and wild morning-glories, from which they disappear in late September.

Control.-By dipping the plants in arsenate of lead, 1 pound to 10 gallons of water, as they are being set, they will be protected and any beetles feeding on them will be killed. The plants should be allowed to dry slightly before being set. Dipping the plants is much better than spraying them later, as it is practically impossible to completely cover the plant by spraying, as may be done in dipping, which is much quicker and less expensive. Late-planted sweet potatoes are much less seriously injured, as the beetles will seek out their wild food-plants and become established upon them, so that late planting may be resorted to when necessary or more convenient. Well grown, stocky plants will better withstand injury, and liberal fertilization will enable them to make a quick growth even if slightly checked.

\section{Tortoise-beetles or Gold-bugs *}

Of all the insects affecting the sweet potato, the brilliant little golden beetles which form one tribe (Casside) of the large family of leaf-beetles, are the most common and are quite peculiar to it. They are beautiful insects, some of the species appearing like drops of molten gold, which has given them the name of "gold-bugs," while the broad expansion of the thorax and wingcovers gives them a fancied resemblance to a tortoise; hence the name "tortoise-beetles." The species affecting the sweet potato are classed in three different genera, but are sufficiently alike in their general habits and life history to be treated together.

* Family Chrysomelidae. 
Life History.-The beetles hibernate over winter and in the spring before the sweet-potato plants are set they feed on their native food-plant, the morning glory. As soon as the plants are set out, the beetles commence to eat large round holes in the leaves, and so riddle them that many often must be replanted. The worst damage, however, is done to the set on which the eggs are laid. Rarely are the new shoots seriously eaten or are eggs laid upon them. The larvæ hatch during the first half of June in Maryland, and require slightly over two weeks to become
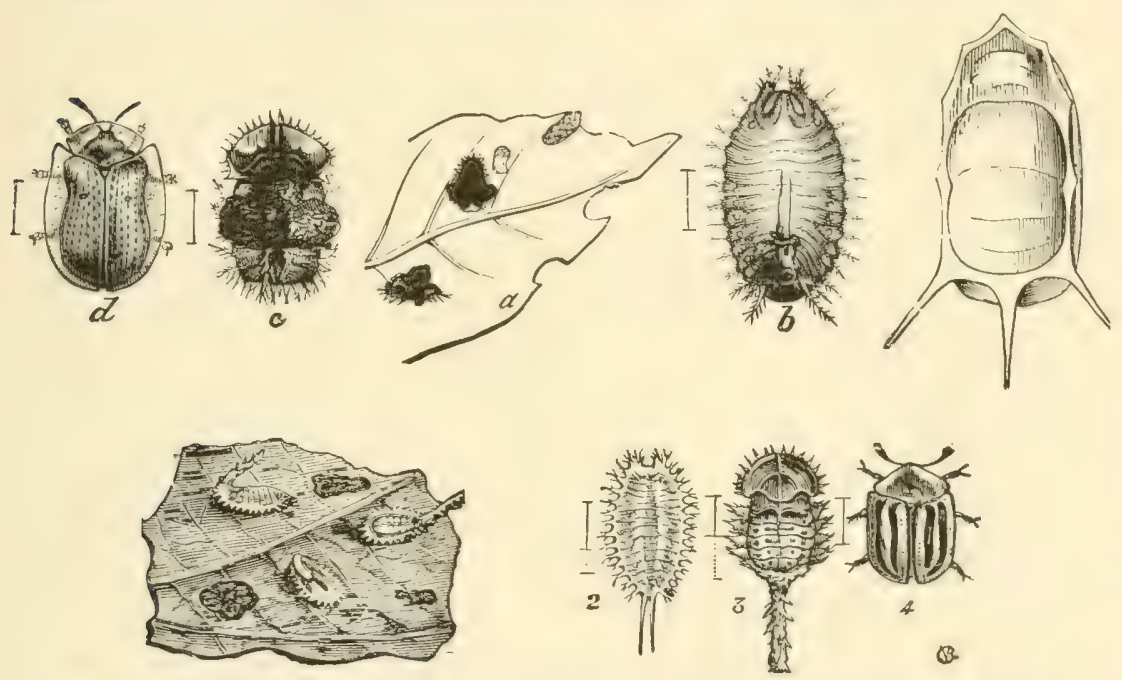

FIg. 321.-Above-The golden tortoise-beetle (Coptocycla bicolor Fab.): $a, b$, larvæ; $c$, pupa; d, beetle; egg at right-all enlarged. (After Riley.)-Below The two-striped sweet-potato beetle (Cassida bivittata Say): 1, larva on leaf; 2, larva; 3, pupa; 4, beetle-all enlarged. (After Riley.)

full grown. Though the larva do considerable damage by eating the foliage, it is not nearly as serious as that done by the beetles. The larva are almost as disagreeable as the adult beetles are attractive, but are nevertheless very interesting creatures. Each of them is provided with a tail-like fork at the end of the body which is almost as long as the body, and in those species in which it is depressed, entirely conceals the insect. Upon this fork is heaped the excrement and cast skins of the larva, and when covered by this "umbrella" it is with great difficulty that the larva is distinguished from a bit of mud or a bird-dropping. The manner in which this fork increases with the size of the 
larva is rather interesting. At each molt, the fæci-fork of the last stage is held upon the new faeci-fork, and in this way those of the different stages are telescoped, the one inside the other, and the stage of growth of the larva may be readily determined by the number of cast skins held on the fork. From the likeness of this burden to a pack, the larvæ are often known as "peddlers." In order more firmly to bind the excrement and cast skins to the fork, the larvæ fasten them together by a fine network of silken threads, which are attached to the spines at the sides of the body. When fully grown the larva fastens itself to a leaf, its skin splits open along the back, and from it comes the pupa, which is held to the leaf by its caudal fork, which is securely encased in the fæci-fork of the larval skin. About a week later the adult beetle emerges, eats for a few days and then disappears from the sweet-potato patch until the following spring, doubtless feeding on morning glory until it enter's hibernation.

Control.-From the similarity of their life history and habits all of these species may be treated at once. As the beetles do the most injury just after the plants are set, they should be dipped in arsenate of lead when setting, as advised for the flea-beetle. If this has not been done or if the beetles are injurious in the forcing bed, the plants should be thoroughly sprayed with arsenate of lead, 3 pounds per barrel or Paris green, $\frac{1}{3}$ pound per barrel with $\frac{1}{2}$ pound of freshly slaked lime.

\section{The Sweet-potato Root-borer*}

Since 1890 sweet potatoes have been seriously injured in parts of Texas and Louisiana by a small white grub which bores into the stems and tubers both in the field and in storage, but strangely it has not spread elsewhere in this country. In Texas the worst injury has been in Calhoun and neighboring counties along the Gulf Coast where extensive growing of sweet potatoes has been abandoned on account of the pest. During recent years it has spread to central Texas and there seems to be no reason why it should not spread over the Gulf States. It is a cosmopolitan insect being reported from China, India, Madagascar, Australia and Cuba. It was first noticed in the vicinity of New Orleans

* Cylas formicarius Oliv. Family Curculionide. See Farmers' Bulletin 1020, U. S. Dept. Agr. 
in 1875 and has since spread northward along the Mississippi.* In 1879 it was reported from Florida and was studied by Professor J. H. Comstock. $\dagger$

The adult beetle is a rather slender insect, about one-quarter inch long, of a bluish-black color, with a reddish-brown prothorax, and has received its specific name, formicarius, from its fancied resemblance to an ant.

Life History.-The yellowish-white, oval eggs are deposited in small cavities eaten out by the mother beetle either at the base of the vine or at the stem end of the tuberous root, or in the

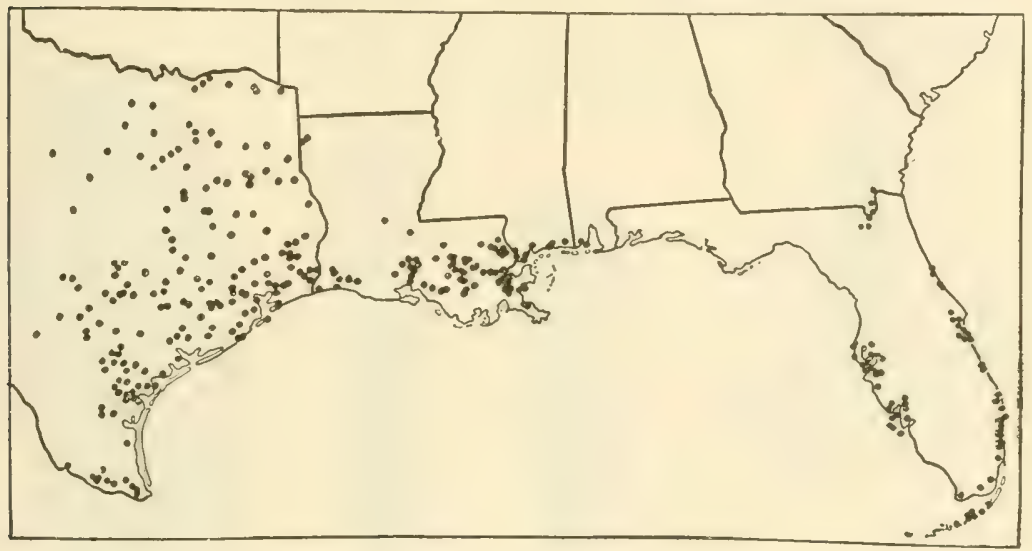

FIG. 322.-Present known distribution of the sweet-potato weevil in the southern United States. (Farmers' Bulletin 1020).

tubers in storage. The small grubs commence to burrow in the vine, sometimes maturing in the vine before any tubers have developed, but usually they descend to the tubers, which in the course of the season, and with the aid of the beetles, they thoroughly riddle. The full-grown larva is about one-quarter inch long, whitish with light brown head, the segments are strongly constricted, and the legs are wanting, being represented by mere tubercles. The grub forms a small cavity at the end of the burrow and transforms to the pupa. In this stage it remains from one to two weeks, when the adult beetle emerges and after a few days commences to lay eggs for another generation. The whole life cycle requires from thirty to forty days, so that there may be several generations in a year, Professor Comstock having

* Bulletin 28, La. Agr. Exp. Sta., p. 999.

† See Report U. S. Comm. Agr., for 1879, p. 249. 
observed three generations. In central Texas the beetles hibernate over winter, but in south Texas they continue to breed in the bins during the winter.

Control.-Dr. F. H. Chittenden (l.c.) recommends the following methods for control in addition to the quarantine measures which have been established by various states to prevent the spread of the beetle in shipments of infested potatoes. Rotation of crops, especially valuable since the weevil does not breed in crops other than the sweet potato and does not breed in any other plants except a few closely related weeds, is the first recom-
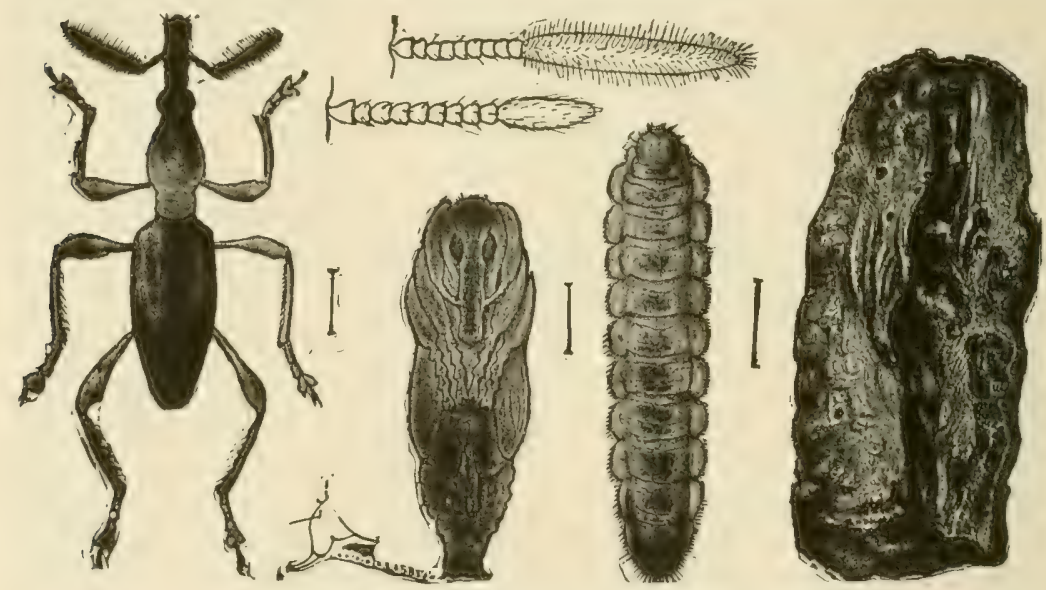

Fig. 323.-The sweet-potato root-borer (Cylas formicarius): extreme left hand figure, adult beetle, with enlarged antennæ at right; figure at left center, pupa; at right center, larva; at extreme right, portion of sweetpotato tuber channeled by borer - all figures except the last considerably enlarged; natural sizes indicated by hair lines. (After Farmers' Bulletin, No. 26, U. S. Dept. Agr.)

mendation. Clean culture, including the destruction of all refuse from infested fields, and the burning or feeding to hogs of all damaged potatoes. Removal of the seed beds as far as possible from the field where the potatoes are to be grown has also proven of great value in reducing the amount of damage. Dipping the plants, before setting, in a solution of lead arsenate and later, spraying with an arsenical, zinc arsenite being suggested as having given success, to kill the early appearing beetles, are also recommended. Prompt harvesting, as soon as the potatoes are ready, and the separation of damaged potatoes is necessary. Keep down volunteer plants upon which the weevils can breed. 


\section{CHAPTER XX}

\section{INSECTS INJURIOUS TO THE STRAWBERRY *}

\section{The Strawberry Root-louse $\dagger$}

IF bare spots are found in the strawberry bed and the neighboring plants are unhealthy, the presence of the root-louse may be suspected, especially if ants are abundant around the plants. If present, the small dark green or blackish aphids will be found clustered on the roots and stems, causing the plants to wither and die. The individual aphid is only about onetwentieth inch long, and deep bluish or greenish-black when mature, the younger stages being lighter, and somewhat pear-shaped as shown in Fig. 324.

Injury by this pest was first noted in southern Illinois in 1884 and a few years later it became troublesome in Ohio. In

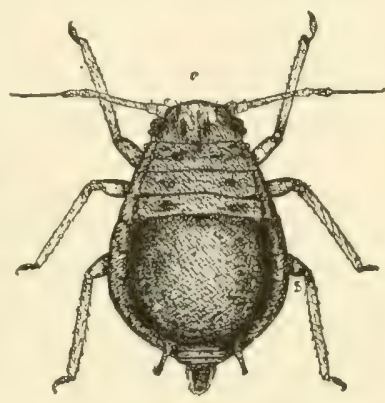
the late '90s it ruined many beds on the Fig. 324.-The strawberry Maryland-Delaware peninsula and became established in New Jersey. Since then it has become distributed on plants root-louse (A phis forbesi Weed); wingless viviparous female of late summergreatly enlarged.

throughout most of the states east of the Rockies, injury having been noted in New Hampshire, Michigan, Minnesota, Kansas, Texas, and Kentucky. Injury is most severe on light, sandy soils and the pest rarely becomes very troublesome on heavier soils. Injury is also more or less periodic, the aphids almost disappearing after doing serious injury for two or three years. Fortunately the strawberry is the only food plant and the rootlice found on other crops are entirely different species.

* See L. Bruner, Report Nebraska Horticultural Society, pp. 49-100; J. B. Smith, Bulletin 225, N. J. Agr. Exp. Sta.; A. L. Quaintance, Bulletin 42, Fla. Agr. Exp. Sta.; S. A. Forbes, 13th Report State Ent. of Ill., pp. 60-180.

† A phis forbesi Weed. Family Aphidido. See Sanderson, Bulletin 49, 12th, 13th and 14th Reports, Del. Agr. Exp. Sta. 
Life History.-The winter is passed in the egg stage, the eggs being black and shining and located on the stems and on the midribs of the leaves. The eggs hatch early in the spring and the young aphids feed on the young leaves in the crown. This generation is composed of wingless females which give birth to

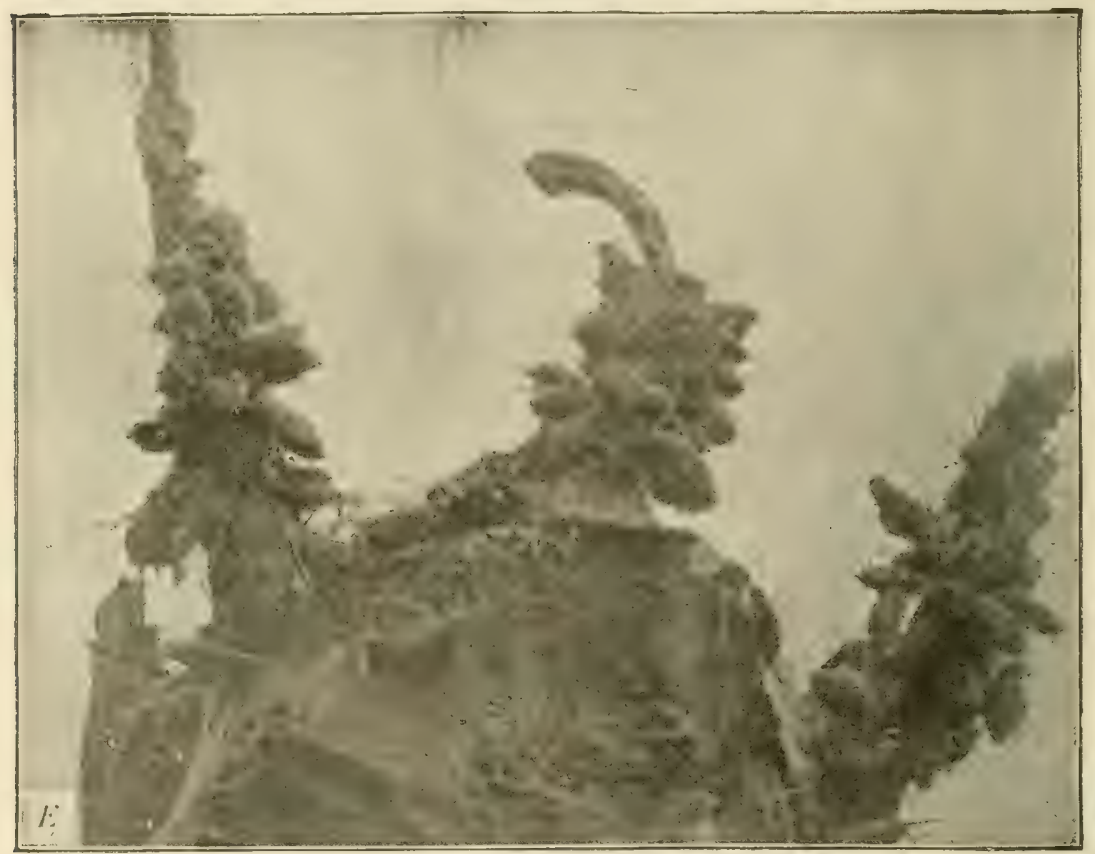

FIg. 325.-Strawberry root-lice clustered on small rootlets from crown of plant—greatly enlarged.

living young and this method of reproduction continues until fall when males appear and the eggs are again produced. Shortly after the aphids have become active the ants appear and carry many of the young aphids down and place them on the roots of the plants. This ant is the same as the one which harbors the corn-root aphis. (See page 152.) On the roots of the plant the aphids cause the most of the damage, weakening and even killing the plants. They are transferred from plant to plant by the ants in the underground stage while above ground winged forms which fly to fresh food plants appear from time to time.

Control.-The aphid is largely kept in check by parasitic encmies similar to those described as attacking the "green-bug" 
and so rarely becomes a serious pest or remains so for a period of years.

The best method of avoiding loss is to set out uninfested plants on land as far removed from infested beds as possible. Plants can be freed from the lice by dipping them, after the

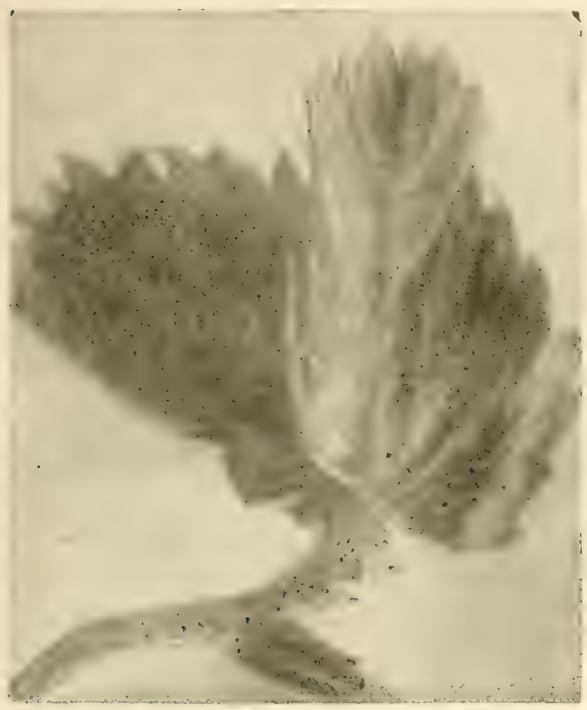

FIG. 326.-Eggs of strawberry root-louse on $\mathrm{F}$

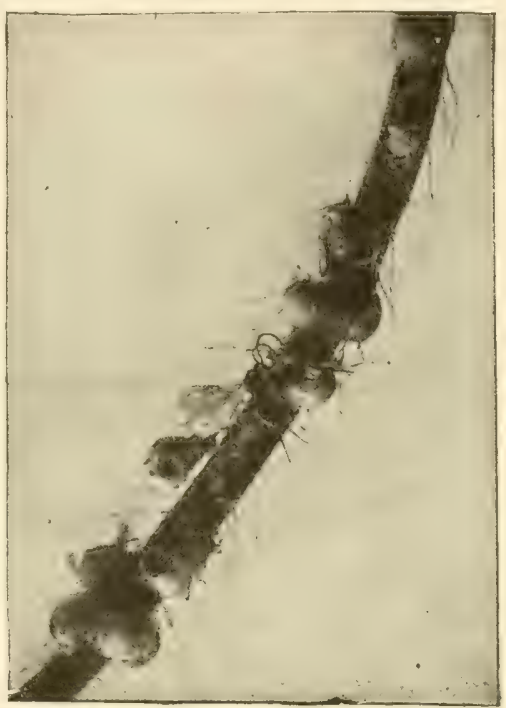

327.-Strawberry root-lice which have been killed by parasites, with one of the little parasitic flies which has just emerged.

eggs have all hatched, in a solution of tobacco. Plants may also be freed from aphids by fumigation with hydrocyanic acid gas (see Delaware bulletin by the senior author). The aphids in an infested bed may be largely destroyed in the spring by scattering straw over the bed and burning before growth has started. There is little danger of injury to the plants if this is properly done.

\section{The Strawberry Crown-borer *}

Strawberry plants are often dwarfed or killed by a small white larva which mines out the interior of the crown, hallowing it out from the bases of the leaves to the larger roots. Usually but one grub is found in a plant, and it looks very much like a small

* Tyloderma fragrarie Riley. Family Curculionida. See S. A. Forbes, 12th Report Ill. State Ent., p. 64; 13th Report, p. 142; H. Garman, Bulletin 80, Ky. Agr. Exp. Sta.. n. 261. 
white grub as it lies curled in its burrow. It is only about onequarter inch long, and legless, the body being white and the head yellowish brown. The adult beetle is a small snout-beetle about

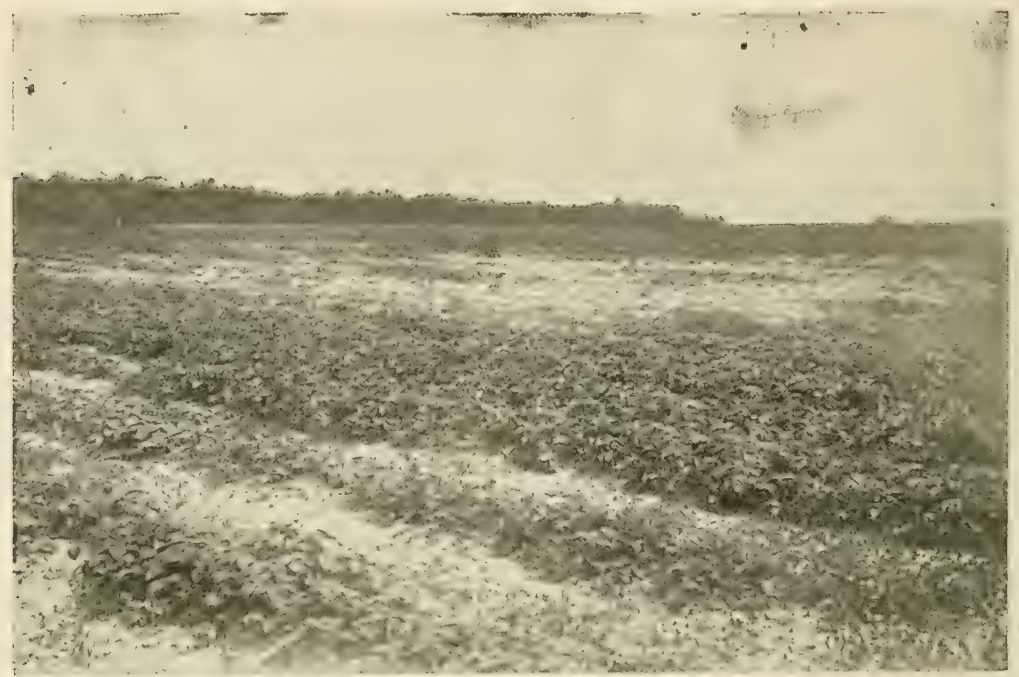

FIG. 32S.-A Delaware strawberry bed in summer of 1900 , showing injury by the strawberry root-louse.

one-fifth inch long, of a dark color, with head and thorax nearly black, and on each wing-cover are three black spots, the middle
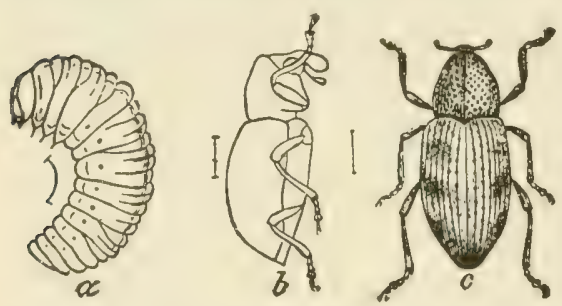
one being the largest and separated from the others by pale lines. According to Professor Garman the wings are too small to be used for flight and this doubtless accounts for the slow spread of the pest. Injury has been

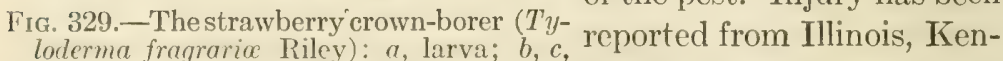
beetle-enlarged. (After Riley.) tucky, Missouri, and Nebraska, but as the larvæ might be readily shipped in plants, it is quite probable that it has become generally distributed but has not done sufficient injury to attract attention.

Life History.-The beetles appear during the latter part of summer and fall and hibernate over winter in the soil, emerging early the next spring. The eggs have not been observed, but are 
undoubtedly laid on the crown between the bases of the leaves in late spring. The larvæ develon in the crowns and become full grown by midsummer or August when they pupate in the cavities formed and the adult beetles emerge in late summer and fall. There seems to be but one generation a year. Old plants are worst injured, and runners formed late in the season are usually free from the pest, as eggs are probably not laid after June.

Control.-Frequent rotation, plowing up the bed after one or two crops, will largely prevent the pest becoming established. Where the insect is well-established in old beds, it will be well to secure plants from beds known to be free from the pest and to plant new beds at some distance from the old ones. Infested beds should have the plants plowed out and raked up and burned as soon as possible after the fruit is harvested and before August. Owing to the fortunate fact that the beetle cannot fly from field to field, if the above measures are consistently carried out there should be no trouble in controlling the injury.

\section{Strawberry Rootworms *}

The larvæ of three species of common leaf-beetles often feed upon the roots of the strawberry and are easily mistaken for the crown-borer or for small white grubs. They may be distinguished from the former by having three pairs of small thoracic legs just back of the head, and from the latter by their being much thicker. These rootworms are from one-eighth to one-sixth inch long, whitish, with brownish heads, and usually feed on the roots externally, though sometimes boring into them or the crown. Dr. Forbes* has indicated the structural differences by which they may be separated and shows that their life histories are quite dissimilar. "The larva of Colaspis appears early in the season, and does its mischief chiefly in the months of April and May, the beetles beginning to emerge in June. That the eggs are laid in the preceding year is highly probable, in which case the species hibernates in the egg. Typophorus, on the other hand, certainly passes the winter as an adult, doubtless laying its eggs in spring, and making its principal attacks upon the plants in June and July, the beetles emerging in the latter part of

* Typophorus cancllus Fab., Colaspis brumnea Fab., Graphops pubescens Mels. Family Chrysomelido." See Forbes, l.c., p. 150. 
July and early in August. Graphops hibernates in the larval condition, pupates in the spring, and emerges in May and June. The
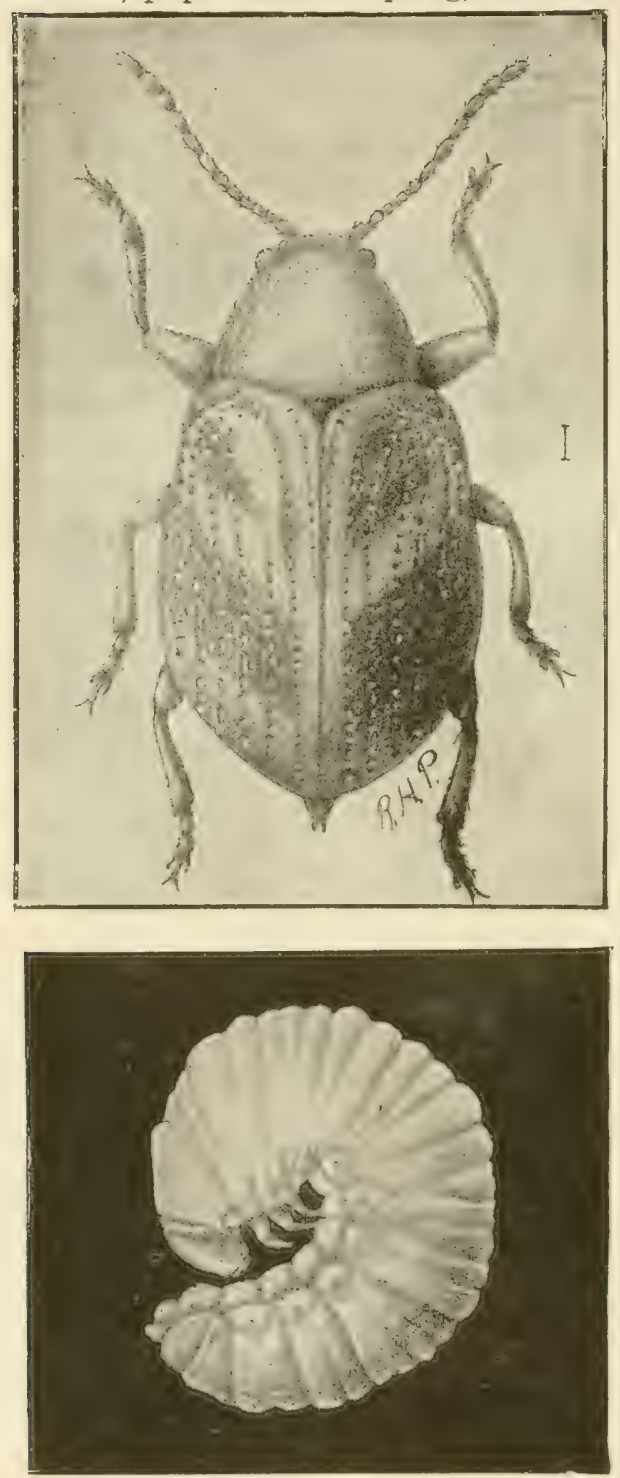

Fig. 330. - The strawberry root-borer (Typophorus cancllus Fab.) : adult and larva-very greatly enlarged, hair line at right of beetle shows natural size. (After Pettit.) eggs are probably laid in July, and the larvæ make their attack upon $t \mathrm{he}$ plant in August and September. . ." Forbes. Thus the larvæ of the three species may be found throughout the season where all occur. The beetles are about one-eighth inch long and may be distinguished as follows, according to Bruner: "Colapsis brunnea is usually of a yellowish clay color, but ranges to ye llow is hbrown. The body is smooth but not shining. Typophorus canellus is usually shiny, b la c k above, varying to brown, with four black blotehes on the wing-covers. The legs and antennæ are always pale. Graphops pubescens is either green or purple with a bronze metallic sheen, and has the entire body more or less covered with a gray pubescence." The pupæ are all found in earthen cells among the roots of the plants. The beetles of all threespeciesfeed on the foliage and when numerous will attract attention. 
Control.-Whenever the plants are not in fruit, the beetles may be destroyed by spraying with 3 pounds of arsenate of lead per barrel, preferably applied with Bordeaux mixture. Where the plants are customarily sprayed with Bordeaux mixture for leaf diseases arsenicals may be added and will probably control this and other strawherry pests. Badly infested fields should be plowed under deeply as soon as the crop is secured and new beds should be planted at some distance from them.

\section{The Strawberry Saw-fly *}

Occasionally the strawbery leaves are skeletonized by yellowish or greenish "worms" one-half to three-quarters of an inch long when full grown. The head is yellow with two brown spots on the side and one or two on top, and there are eight pairs of yellowish abdominal prolegs, in addition to the true thoracic legs, which at once distinguish the saw-fly larvæ trom true caterpillars. The adult saw-flies are about one-quarter inch long, with two pairs of blackish, well-veined wings which are folded over the abdomen when

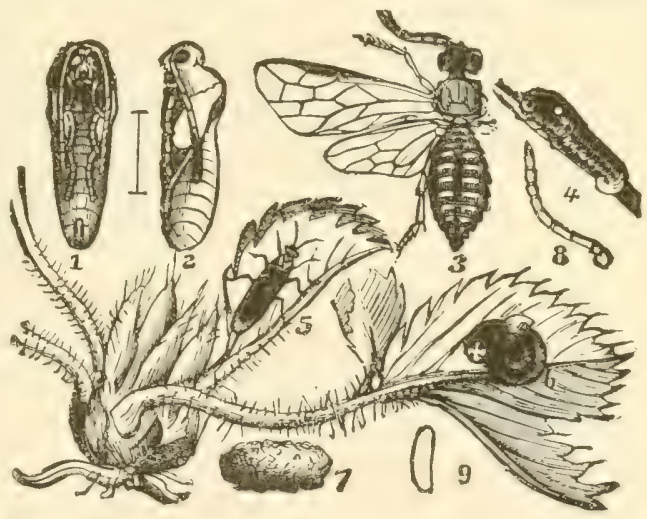

FIG. 331.-The strawherry saw-fly (IIarpiphorus maculatus. Norton): 1, 2, pupa; 3 , 5, adult flies; 4, 6, larrip; 7, cocoon; 9, egg-all enlarged. (After Riley.)

at rest. The body is black, with a row of lighter spots on either side of the abdomen. The flies emerge in late April in Missouri or about a fortnight before the plants flower freely. The eggs are inserted just beneath the epidermis of the leaves and hatch in about two weeks, just as the plants begin to bloom. The larvet eat holes in the leaves and "where numerous, they will defoliate the plants to such an extent as to injure greatly or completely destroy the crop of fruit, and may even kill the plants them* Harpiphorus maculatus Norton. Family Tenthredinido. See J. M. Stedman, Bulletin 54, Mo. Agr. Exp. Sta. 
selves." When at rest or disturbed the larvæ coil themselves up in a spiral on the under side of the leaf as shown in Fig. 331, but if suddenly disturbed they will often drop to the ground. By the last of May the larvæ are full grown and enter the soil, where they make small cells, lined with a gummy substance, and in them hibernate until the next spring, when they pupate and the adult flies emerge.

Injury by the saw-fly has been reported from the Northern and Central States from Missouri and Nebraska to Maine.

A nearly related species * with almost identical habits has done similar injury in Iowa, Illinois and Indiana. The larvæ are a deep green, much wrinkled, with a blackish stripe along the back and an obscure blackish stripe on each side, and the head brown.

Control.--Inasmuch as the larva commence to hatch just as blooming commences Professor Stedman has shown by experiments that spraying the foliage at this time with arsenicals will entirely protect it from the larva. If they commence work before their presence is noticed, the foliage may be sprayed until the first berries are about one-third grown without any danger of poisoning them. Hellebore, 1 pound to 3 gallons of water was also effective, as was dusting with pyrethrum. Although there may be some prejudice against the use of arsenicals, where properly applied at the right time there is no reason why they should not be used.

\section{The Strawberry Leaf-roller $\dagger$}

Where leaves are found folded together, many of them being dry and brown, the small green caterpillars found feeding within the folds are probably those of the Strawberry Leaf-roller. It is a European insect, though it is not injurious there, and the first record of injury in this country was made by Dr. C. V. Riley in 1869, who stated that in one place in Missouri it destroyed ten acres so completely as not to leave enough plants to set a half acre. "Since that time," says Dr. J. B. Smith, "the insect has been frequently mentioned as injurious in many parts of the

* Monostegia ignota Norton. See F. IV. Mally, "Insect. Life," Vol. II, p. 137.

$\dagger$ Ancylis comptana Fröhl. Family Tortricida. See J. B. Smith, Bulletins 149 and 225, N. J. Agr. Exp. Sta. 
country, but rarely is it troublesome for more than a year or two in succession. It is always inclined to be local and its ravages do not often extend over wide areas."

Life History. - The moths appear in the strawberry fields during early May in New Jersey and commence to lay eggs, the moths being found in the fields for about a month. The eggs are laid on the under surface of the half-grown leaves. They are broadly oval or round, much flattened, of a pale green color and about one-fiftieth inch in diameter. They are laid in the fine netting of the leaf, in which they are seen with great difficulty. The larvæ hatch in from five to seven days. The young caterpillar feeds on the upper surface of the leaf for a day or two,

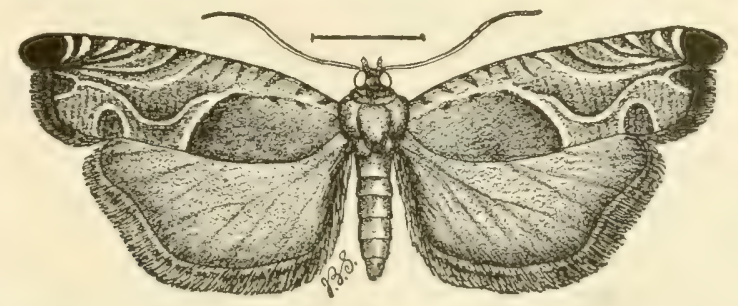

Fig. 332.-The strawberry leaf-roller moth (Ancylis comptana Fröhl.) enlarged. (After J. B. Smith.)

eating into and along the midrib to weaken it. The young larva is at first a light green color with a large head and long hair, which becomes less noticeable as it grows.

It soon commences to draw the edges of the leaf together, folding the upper surface on the midrib, holding it together by numerous strands of fine silk. The insect then spins a partial tube or lining inside, in which it remains until the moth develops. Unless disturbed the larva does not leave this folded leaf, and all the feeding is done out of the reach of sprays. The larva becomes full grown in about four weeks, when it is about half an inch long and of a dark-green color, until just before pupation, when it becomes more yellowish. The head and thoracic shield are shining brown, and the small body tubercles are slightly lighter. The larvæ are slender and very active, wriggling violently when disturbed or taken from their webs.

"Pupation occurs in the tube made by the larva. The pupa itself is brownish-yellow, without obvious processes or protuber- 
ances, and a little more than one-fourth an inch long." The pupal stage lasts about ten days, thus giving about forty-two to fifty days for the complete life cycle from egg to adult.

The moths of the second brood appear late in Jume and during July. This brood is much more abundant on blackberry and raspberry than on strawberry plants. The moths of the third

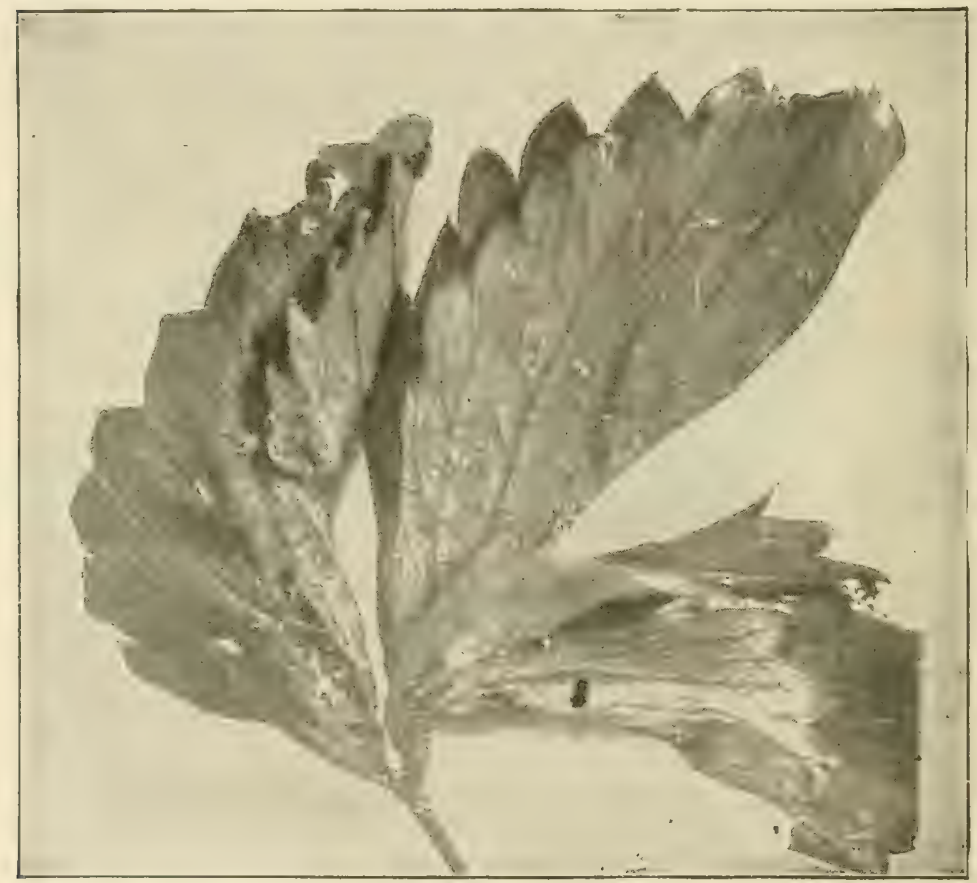

Fig. 333.-Strawberry leaf folded by the leaf-roller. (After J. B. Smith.)

brood appear in August. They are comparatively few in number and also seem to prefer blackberry and raspherry. Young larvæ are, however, to be found on strawherries in September. "According to the account given by Riley, the larva change to pupæ late in September and remain during the winter in that state." Dr. Smith states that he has not observed this personally. In Delaware we have found full-grown larva in folded leaves in midwinter, so that possibly some of them at least do not pupate until spring.

"The adult moth is small, measuring with expanded wings about two-fifths of an inch. In general color it is somewhat 
reddish-brown, the fore-wings streaked and spotted with black and white as shown in the illustration. When the wings are folded, the dark area at the base forms a somewhat conspicuous deeper brown patch in the middle of the back. The hind-wings are of a soft, dark smoky gray, and both wings have long fringes. The insects fly readily during the middle of the day, and run rapidily on the leaves, diving to the under side or into a fold so quickly that it requires close watching to follow their movements. From the fact that newly set fields are often infested, it is probable that they fly for some distance to seek their food plant." - Smith.

"A badly infested strawberry-patch begins to look scorched early in June, and before the middle of that month appears as if a fire had been over it. The fruit, deprived of the food prepared by the foliage, stops growth, ripens undersized or prematurely, or shrivels up altogether, even before it colors." "Often every lobe on a leaf will be folded, and occasionally, when infested leaves cover or touch, an irregular mass of foliage is bundled up in which as many as six or eight larvæ may be found.

"On blackberry not so large a part of the leaf is involved, and frequently only the tip of one of the leaflets is webbed up. Furthermore, the injury is more local, and only that part that is actually eaten is harmed. The total amount of food really devoured is very small, and were it not for the manner of feeding, which interferes with the nutrition of the leaf, the strawberry could easily spare tissue for all these caterpillars that ever infest it. On the raspberry the habit is yet different. Here the larva gets into a partly opened tip and webs it together so securely as to check growth. The actual eating shows a rusty space on the upper side of the leaf, and not much more harm is done."

Control-As stated above, the young caterpillar, just after it is hatched, goes to the upper surface of the leaf and feeds there exposed for a day or two before folding the leaf. "It must be the object of the grower to poison the foliage so early in the season that when the young caterpillar starts feeding, it can find no foliage it can safely eat. Therefore, as soon as moths are found flying in fair numbers, spray with arsenate of lead. Experiments in New Jersey have shown that complete control may be secured with one application if this is thorough and applied at the right time. 
"If for any reason no timely applications were made and the fields become badly infested, nothing practical can be done until the crop is off. Then mow the beds, rake off all the foliage, and burn it. You will burn with it all the larvæ and pupæ that are then unchanged. This lessens the number of moths that come to maturity and so helps somewhat for the following year."

\section{The Strawberry Weevil *}

If the buds appear to be "stung" so that they wither, and if many of the stems are cut so that the buds drop to the ground,
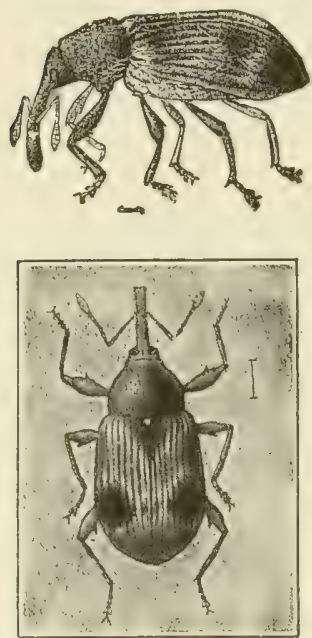

Fig. 334.-The straw-

berry weevil (Anthonomus signatus Say.) enlarged. (After Riley and Chittenden, U. S. Dept. Agr.) the strawberry weevil is the probable cause of the damage. This little weevil is only about one-tenth inch long and so is often unnoticed, and the loss is attributed to other causes. The weevil varies from nearly black to dull red, with a dark spot just back of the centre of each wing-cover. The head is prolonged into a slender curved snout, about half as long as the body. The species is found in most of the States east of the Rockies, but injury has been mosts evere in the Middle and Northern States.

Life History. - The weevils hibernate over winter and appear in spring a few days before the earliest staminate varieties commence to bloom. Other's emerge during the next month, but the most injury is done within the next two weeks. The injury is done by the females, which eat small holes through the outer husk or corolla of nearly matured buds, and in these little cavities deposit their eggs. The stem of the bud is then cut so that it hangs by a mere thread and soon falls to the ground. By severing the stem the development of the bud is arrested, thus preventing the outer covering from unfolding and holding the eggs and larva in the pollen, on which they feed, and by falling to the ground the bud remains moist and will not dry up as it would on the stem. The eggs hatch in from six

* Anthonomus signatus Say. Family Curculionida. See F. H. Chittenden, Circular 21, Div. Ent., U. S. Dept. Agr.; J. B. Smith, Bulletin 225, N. J. Agr. Exp. Sta. 
to seven days and the small whitish larvæ feed on the pollen and later on the harder parts of the buds. Three or four weeks are required for a larva to become full grown. It then forms a little cell in the bud, in which the pupal stage is passed in from five to eight days, when the adult beetle emerges and cuts its way out. Thus the complete life cycle occupies about a month and in the District of Columbia the new generation of beetles appears during June. They are frequently found in large numbers on strawberry flowers and on those of the horse mint (Monarda fistulosa), but the beetles soon seek hibernating quarters, there being but one generation a year.

Control.-As the larvæ feed upon the pollen of the buds of staminate varieties, the staminate varieties are most injured, and injury may be avoided by growing as few rows of staminate

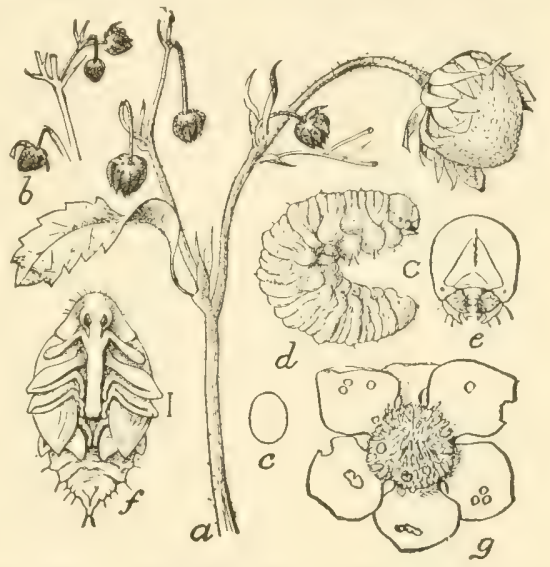

FIG. 335.-The strawberry weevil: $a, b$, spray showing work in bud and stem-natural size; $c$, outline of egg; $d$, larva; $e$, head of same; $f$, pupa; $g$, bud opened to show egg on left and punctures made by snout of beetle through petals. (After Chittenden, U. S. Dept. Agr.) varieties as are necessary for fertilizing the rest of the bed. Indeed the very early staminate varieties might be used as a trap crop for attracting the weevils, which might be destroyed by covering the rows with straw and burning, or possibly by spraying with arsenicals. By planting rows of early varieties, which flower freely and produce an abundance of pollen near woods and fence-rows where the beetles have hibernated and appear first, they might be effectively trapped, and then destroyed. Although the larva cannot be reached with any insecticide, the beetles feed more or less on the buds and foliage, and further experiments should be made in spraying for them with arsenicals. Dr. T. J. Headlee (Circulars 56 and 65, New Jersey Agr. Exp. Station) recommends dusting the plants with arsenate of lead powder one pound mixed with five pounds sulphur dust. On a large 
scale this should be applied with power dusters as the hand dusters have not proven so successful. Begin applications as soon as the weevils appear, not later than the first of May.

Lead arsenate applied as a spray has seemed to give good control in some smaller tests and should be at least as effective as the dust.

The destruction of all trash and rubbish in and around the fields during the winter will destroy some of the hibernating weevils, and it will be well to avoid mulching the beds where the beetle is troublesome, if the mulch is not absolutely necessary, as it furnishes them the best hibernating quarters. 


\section{CHAPTER XXI}

INSECTS INJURIOUS TO RASPBERRY AND BLACKBERRY *

\section{The Raspberry Root-borer $\dagger$}

The larva of the Raspberry Root-borer make tumnels in the roots and lower stems of rasplerry and blackberry, sometimes completely girdling the stem at the crown, so that the name of blackberry crown-borer has also been used. The full-grown larva is from 1 to $\mathbf{1} \frac{1}{2}$ inches long, yellowish-white, with brownish head, and the tips of the small thoracic legs also brownish. The parent insect is one of the clear-winged moths, which fly by day and closely resemble wasps, and is nearly related to the peachand squash-borers. The female is much the larger and is shown natural size in Fig. 336. The body is black with yellow rings, and the legs are yellowish. The wings are transparent except a bronzebrown margin and a narrow band across the fore-wings about one-third from the tip.

Life History.-The moths appear in
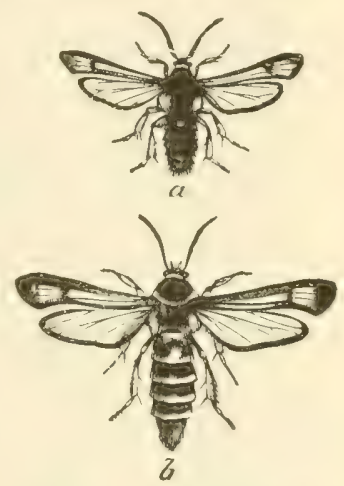

Fic. 336.-The raspherry root-borer (Bembecia marginala Harr.): $a$, male moth; $b$, female moth - natural size. (After Riley.)

late August and September and the females deposit their eggs upon the lower edge of the leaves. The egg is oval, about onesixteenth inch long, deep brownish-red in color. A female lays about $140 \mathrm{eggs}$, which are deposited singly. They hatch in september and the young larvæ crawl down the stems and bore under the bark. Here they may either make a small blister-

* See F. M. Webster, Bulletin 45, Ohio Agr. Exp. Sta.; J. 13. Smith, 12th Report N. J. Agr. Exp. Sta.

$\dagger$ Bembecia maerginata IIarr. Family Sesiido. See J. B. Smith, Bulletin N., N. J. Agr. Exp. Sta., p. 9; W. H. Lawrence, Bulletin 63, Wash. Agr. Exp. Sta. 
like cavity and hibernate over winter, or if hatched earlier they may feed on the sap wood or occasionally bore into the stem and become one-quarter inch or more long before winter. The next season the larva bore in the lower stem and roots, but the

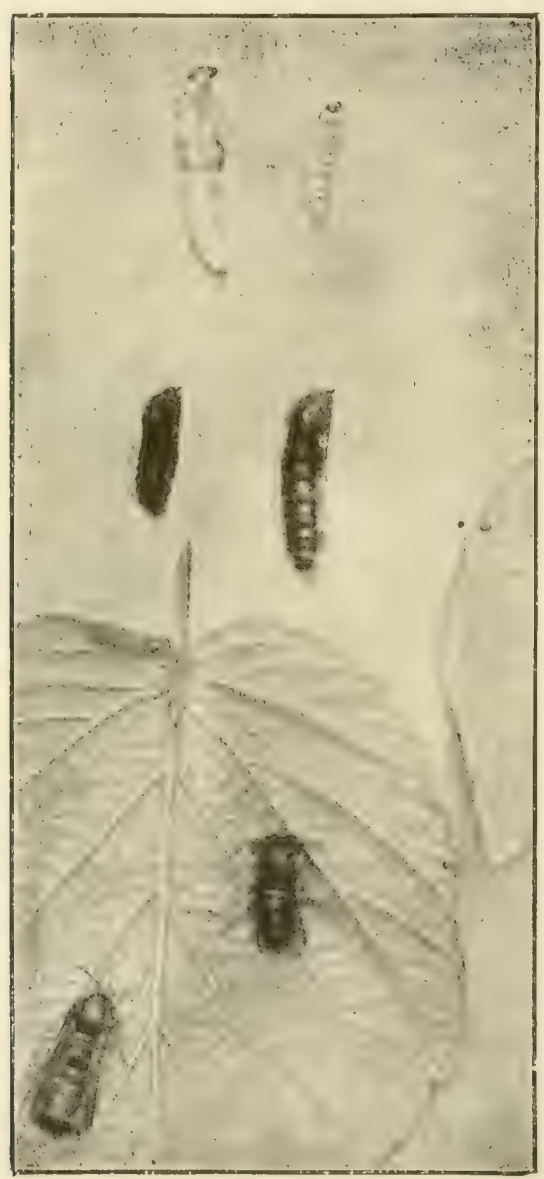

FIG. 337.-Raspherry root-horer (Bembecia marginate Harr.): $a$, female and male larva, full grown; $b$, male and female pupæ; $c$, female, and $d$, male moths resting on leaf; $e, e$, eggs-slightly reduced. (After Lawrence.) nature of the injury differs as observed in different places. In New Jersey, Dr. J. B. Smith states that the larvæ girdle the stem at the crown, causing the plants to die. In spring they abandon the old wood and attack new shoots, but he observed none entering the stem. In Washington, the infested plants seld o m show any signs of the presence of the borers other than a poor growth, though occasionally a few hills will die where the roots have been badly riddled by the larvæ, the injury being mostly in the roots. "The borer," according to Lawrence, "first enters the roots and tunnels through them promiscuously until the second spring, and then directs its course upward, entering and eating the pith of the cane for a distance of one to five inches." At the end of the first summer the larva is one-half to threequarters inch long. By the middle of the second summer the larva is full-grown and bores an exit hole through the wood and bark just above the crown, leaving the hole covered by 
the epidermis only The larva then descends into the tumnel and pupates.

The pupa is about three-quarters inch long, redclish-brown the head bears a sharp-pointed process, and each abdominal segment bears two transverse rows of sharp teeth. By means of these the pupa wriggles itself out of the burrow until it projects from the aperture, and the adult moth emerges. This insect occurs throughout the Middle and Northern States east of the

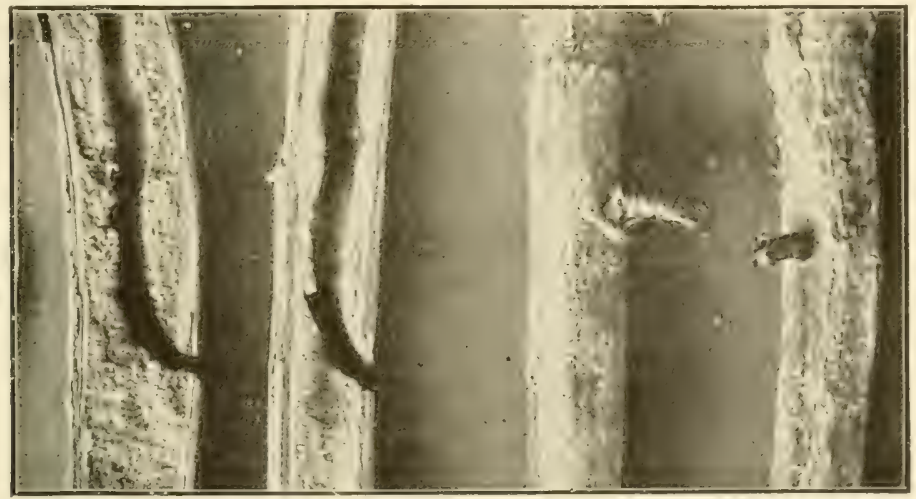

Fig. 33S.-Work of the raspherry root-horer: $a$, two canes with empty pupa cases projecting from burrows; b, canes showing opening of tunnel through which pupæ have wriggled out. (After Lawrence.)

Rockies, is injurious in Washington and around Vancouver, B. C., and has been observed in Colorado and New Mexico.

Control.- The only method of control is to pull up the infested canes, root and branch, and destroy them by burning. As this is the only means of controlling several pests of cane fruits, the canes should always be gone over in spring and those showing any injury removed.

\section{The Raspberry Cane-borer *}

If the tips of the young shoots of raspberry and blackberry are found withered and dying they have probably been girdled by the cane-borer. The adult beetle is about one-half inch long, with a slender, cylindrical body and long antennæ, and of a deep black color except the prothorax, which is yellow with two or three black spots, though these are sometimes lacking.

* Oberea bimaculata Oliv. Family Cerambycida. See Comstock and Slingerland, Bulletin 23, Cornell ['niv. Agr. Exp. Sta., p. 122. 
Life History.-The beetles appear in early summer and the females girdle the young tips by cutting two rings around the shoot about an inch apart, causing the tip to wither and droop. Between these rings will be found a small dark spot where the female has inserted an egg in the cane. A rather large, elliptical, yellow egg is placed in the pith of the cane and in a few days hatches into a small white grub. The larvæ burrow downward through the pith of the stems, the burrows winding from side to side and frequently penetrating the side of the stem, where openings are made every few inches, through which long strings

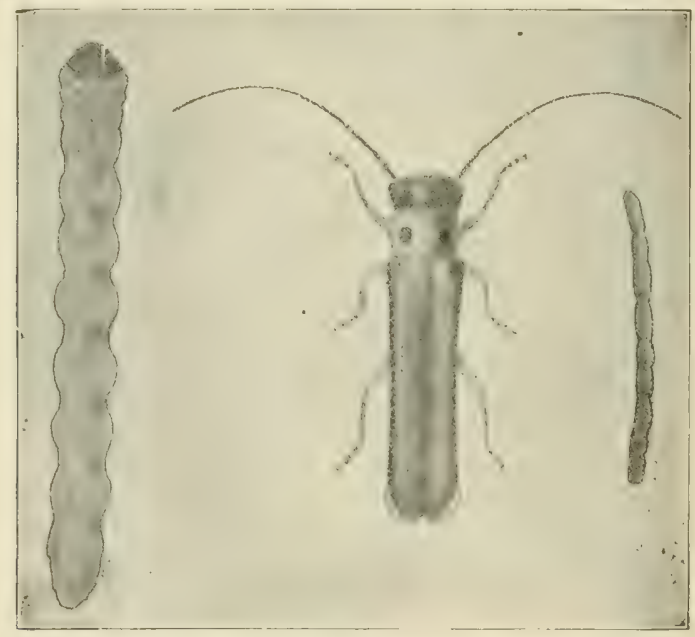

Fra. 339.-The raspherry cane-borer (Oberea bimaculata Oliv.): adult, larva, and larval castings-all enlarged. (After Lugger.)

of excrement are cast out. By fall they are bored to the base of the cane, in which they hibcrnate over winter. The fullgrown larva is about one inch long, of a dull yellow color, with a small dark-brown head. The body is quite cylindrical and the segments constricted as shown in Fig. 339. The pupal stage is passed in the burrow during the spring. Although it has been generally assumed that the life cycle is passed in a single year, there is some reason for believing that two years may be required. The eggs are usually laid only in the young tips, but Comstock and Slingerland found larvæ somewhat over half grown which had made burrows only two inches long in old canes in late July, and Professor Webster has secured larva over half grown in early 
Jume. Possibly, therefore, two years may be required for maturing a generation, and the fact that the pest does not increase may be due to the cutting back of the injured tips of the young canes.

Control.-As soon as the tips are seen to droop they should be cut off below the point girdled and burned. When the entire canes die from the effect of being tumneled, they should be cut in late summer before the larvæ have gone to the base to hiber-

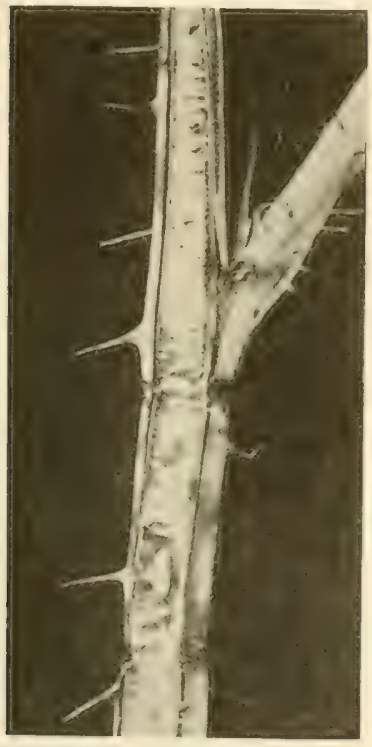

FIG. 340.-Egg of the raspberry cane-borer, showing girdling of cane. (Photo by Headlee.)

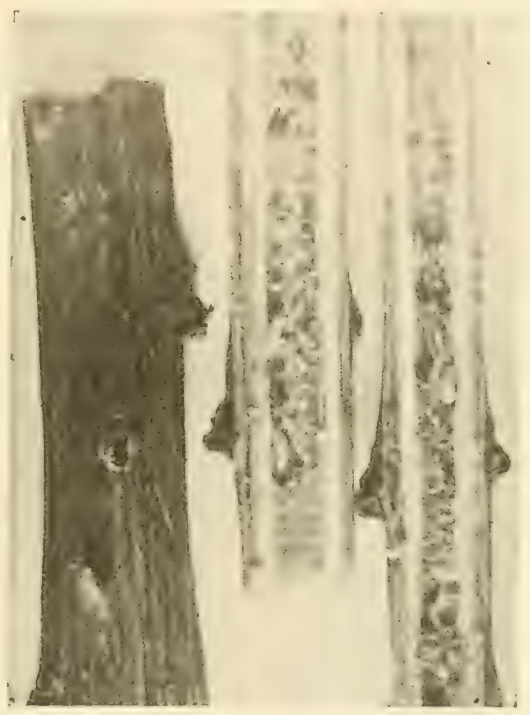

FIG. 341.-Young grubs and exit hole of the raspberry cane-borer. (Photo by Headlee.)

nate. Where such measures are practised the pest may be effectively controlled.

\section{The Striped Tree-Cricket*}

Professor Parrott has recently shown in an interesting bulletin from the New York station that the tree-cricket which most frequently attacks the raspberry is not, as had been supposed, the snowy tree-cricket (Oecanthus niveus DeG.) but a different species, the one named above. The snowy cricket confines its attentions more to apple and other tree fruits.

* Decanthus nigricornis Walker. Family Gryllida. See Parrott and Fulton, Bulletin 388, N. Y. (Geneva) Agr. Exp. Sta. 
When the canes fail to put out leaves in the spring and are

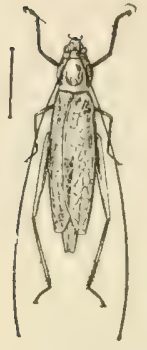

$a$

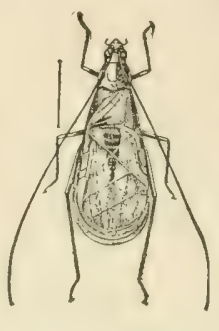

$b$
Fig. 342.-The snowy treecricket (Oecanthus nigricornis Walker): $a$, female; $b$, male. (After Summers.) found to be dead, this often proves to be due to a long ragged wound like that shown in Fig. 343a. "If the rough surface of the wound be cut away with a knife, the injury will be found to consist of a longitudinal series of punctures placed close together. By splitting the cane the nature of the injury can be seen even better. Such a section is shown at $b$ in the figure. The punctures extend through the woody part of the cane into the pith, and here there is in each

an oblong, cylindrical egg. One of these eggs is represented enlarged at $c$. The insect which thus seriously injures the raspberry canes in preparing a safe receptacle for its eggs is a delicate greenish-white cricket. Fig. 342 represents the male. Its wing-covers are crossed by oblique thickenings or ribs, which form part of the musical apparatus of the insect. The female, Fig. $342 a$, differs somewhat in appearance from the fact that the wing-covers are wrapped closely about the body, making the insect much narrower than her mate." (Comstock and Slingerland.) The cry of these tree-crickets is well known, sounding much like that of the katydid, but is less rasping and more monotonous. They are heard in early evening until well into the night, and in the North their chirp is the most noticeable of all the insect noises at that time. This species is quite widely distributed and frequently oviposits in the tender twigs of fruit trees, which are similarly injured, and in the stalks of cotton and various woody weeds.

Life History.-The eggs are laid in the fall and hatch in the late spring. The nymphs

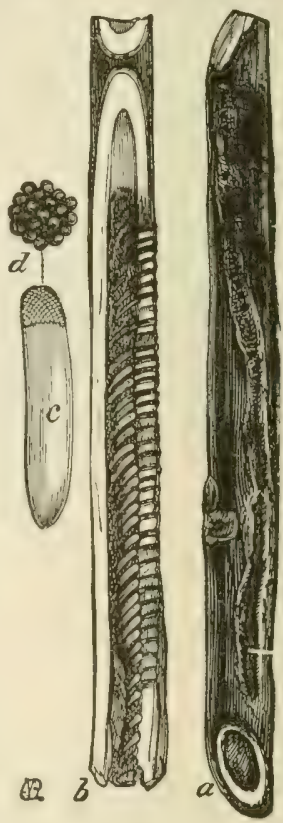

FIG. 343-Raspberry stem injured by the snowy tree-cricket: $a$, wound made by egg - punctures; $b$, longitudinal section through same showing eggs in path; $c$, egg enlarged; $d$, cap of egg, more enlarged. (After Riley.) 
feed mostly on plant-lice and other insects, as do the adults, and though they occasionally nibble foliage, they are seldom injurious, and both nymphs and adults must be regarded as beneficial as far as their feeding habits are concerned. In the North the nymphs become full grown late in July, and there is but one generation a year, but in Texas they become full grown late in June and eggs laid in early July hatch in about two weeks; nymphs are common in late summer, and the adults of the second generation in fall.

Control.-By examining the canes as soon as the foliage starts, those injured may be detected and should be cut out and burned. If not numerous enough to do appreciable damage they may be ignored.

\section{The Red-necked Cane-borer*}

Sometimes the canes of raspberry and blackberry are found with one or more elongate galls, not over one-third larger in diameter than the normal cane, and usually with numerous slits, which have been called the "gouty gall." The infested shoots may throw out leaves, but they rarely ripen fruit and usually die during the season. By opening the gall it will be found that only the bark has been injured by a spiral channel which girdles the stem and causes the gall-like thickening of the bark. Above the swelling evidence will be found of the borer's work in the pith, and from one to six inches above the gall the slender white larve will be found at work.
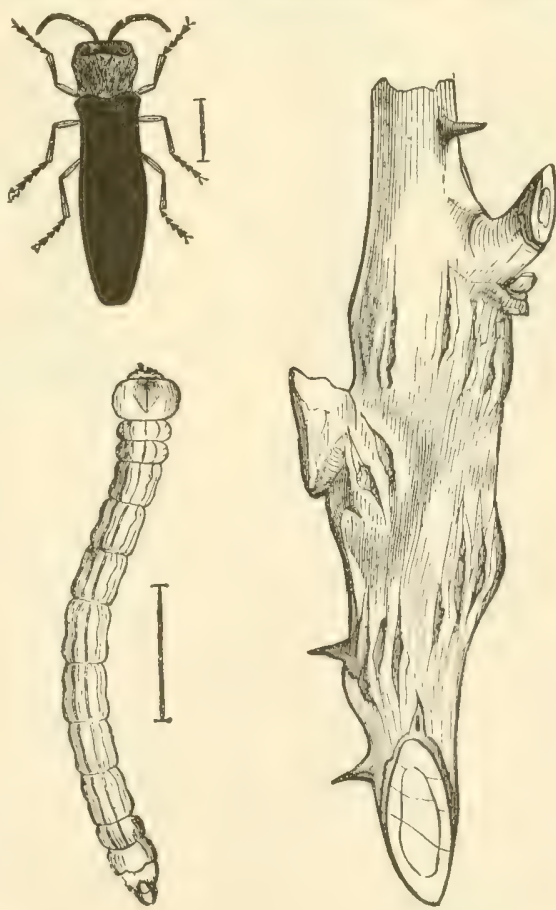

FIG. 344.-The red-necked cane-borer (Agrilus ruficollis Fab.): beetle, larva and gall-all much enlarged. (After Riley.) 
There seems to be considerable difference in the susceptibility of varieties, Dr. Smith observing that the "Wilson" and blackcap raspberries are badly infested, while the "Missouri Mammoth" and others were unharmed.

Life History.-The eggs are laid in June and the young larva enters the bark at the axil of a leaf-stem, and eats around the stem in a long spiral. By early August the galls commence to form where the bark has been girdled, though sometimes no gall results from the injury, and the larvæ mine into the pith. The larva probably become practically full grown in the fall and remain in their burrows over winter, in which they transform to

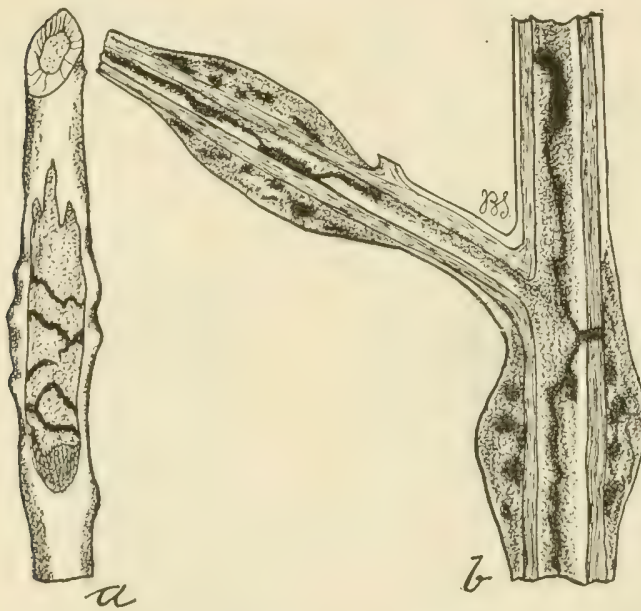

FIG. 345.-Work of the red-necked cane-borer: $a$, tracks of young larve the bark sliced away to show burrows and forming gall ridges; $b$, section through galls on main cane and lateral showing track of larva through bark and pith and pupal cell. (After J. B. Smith.) pupæ in late April, in New Jersey, and the beetles emerge in late May and June. The parent beetle is not over one-third inch long, flattened, with a small wide head, and tapers at the tip of the abdomen. It has brownish-black wing-covers with a bronzy lustre, and the neck and thorax are coppery-red or brassy. The full-grown larva is five-eighths to three-quarters inch long, with a small brown head, a muchexpanded prothorax which looks like the head, and a slender, cylindrical, white body, surmounted by two slender brown horns at the tip of the abdomen.

This cane-borer is a native pest, very common in wild raspberries and blackberries, and occurs generally throughout the country.

Control.-Obviously it may be readily controlled by cutting off the infested canes below the galls and burning them. This should be done any time before May. Where wild canes are infested near those cultivated they should be included in the pruning. 


\section{The Blackberry Gall-maker*}

The so-called "pithy gall" of the blackberry is an elongated, pithy swelling from one to three inches long and nearly an inch in diameter, red or reddish-brown, with the surface divided by deep longitudinal furrows into four or five ridges or parts. The gall is caused by the larvæ of a small black gall-fly, which is about one-twelfth inch long, with red feet and antennæ and four transparent wings, almost lacking wing-veins. The insect passes the winter in the larval stage in the galls, and if one be opened at that season, there will be found about the middle a number of cells about oneeighth inch long, each of which contains a single larva. The larva "is about one-tenth inch long, white, with the mouthparts reddish, and the breathing pores and an oval spot on each side behind the head of the same color."
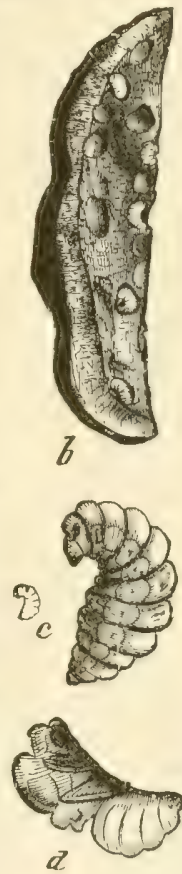

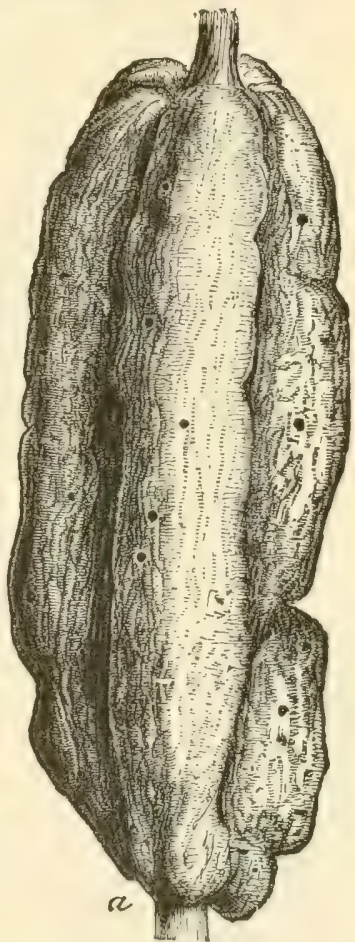
They change to pupæ in spring and the flies appear a little later. Though this gall is also very comFIG. 346.-The pithy-gall of the blackherry: $a$, gall; $b$, section of same showing larvæ in cells; $c$, larva enlarged and natural size; $d$, pupa. (After Riley.)

mon on wild canes it rarely does much injury.

Control.-The affected canes should be cut and burned during the winter.

\section{The Raspberry-cane Maggot $†$}

The tips of young raspberry shoots sometimes droop and wilt in the spring in much the same manner as when affected by the

* Diastrophus turgidus Bass. Family Cynipida.

$\dagger$ Phorbia rubirora Coquillet. Family Anthomyida. See Slingerland, Bulletin 126, Cornell Univ. Agr. Exp. Sta., p. 54; II. H. Lawrence, Bulletin 62, Wash. Agr. Exp. Sta. 
cane-borer later in the season, and though blackberry shoots are similarly affected they ustually recover, but hear small gall-like swellings like those shown in Fig. 348. This is the work of a

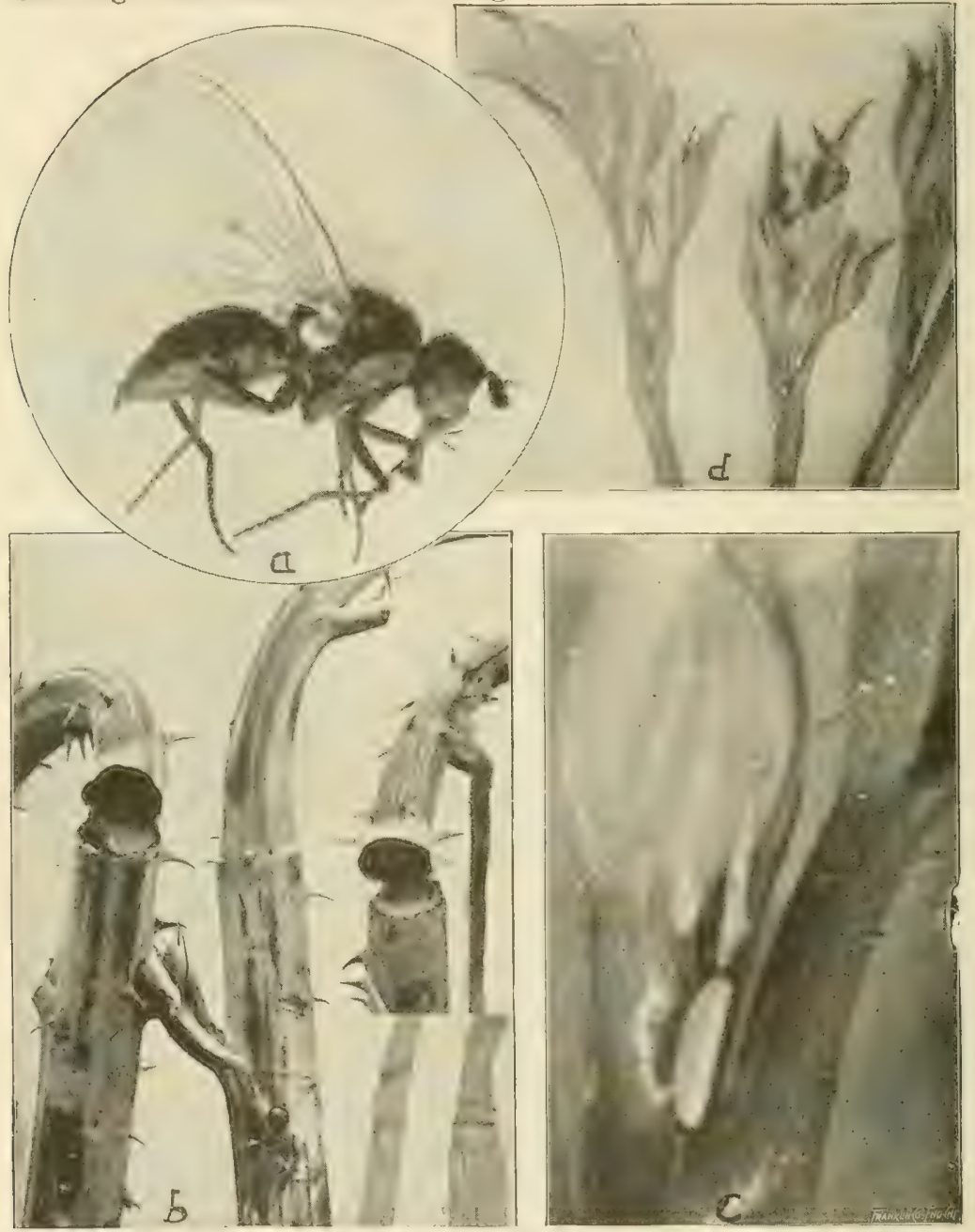

FIg. 347.-The raspherry cane-maggot (Phorbia mulivora Coquillet): $a$, adult female fly; much enlarged; b, raspherry shoots girdled by the maggot, natural size; $c$, egg much enlarged; $d$, tips of shoots each bearing an egg in natural position in the leaf axils, natural size. (After Slingerland.)

small white maggot, nearly related to and looking much the same as the cabbage-maggot which girdles the inner bark of the stem. 
Injury has been observed in New York, Canada, Nichigan, Pennsylvania, and recently it has become a serious pest in Washington, so that it is undoubtedly much more widely distributed than the records indicate. The parent fly, whown in Fig. 347 , is grayish-black, much resembling the house-fly, but slightly smaller.

Life History.-The flies appear in April and deposit their eggs as soon as the shoots are well above ground, continuing until early June. The white egg (Fig. $347, c)$ is elongate, about onefifteenth inch long, and is laid in the axil of a young leaf at the tip of a shoot (Fig. 347, d). The egg hatches in a few days, and the little maggot burrows into the pith of the shoot, leaving a conspicuous entrance hole, which becomes blackish. It tunnels downward, making a small tortuous channel, and after boring for a few days about half way down the shoot, it works its way out to just

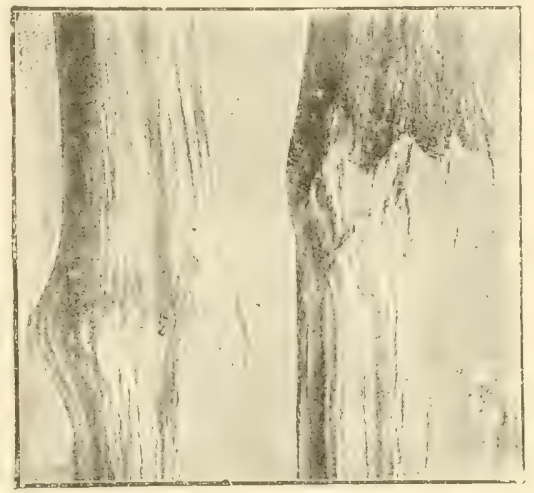

FIG. 348.-Gall-like swelling one living blackberry canes caused by the raspberry cane-maggot. (After Lawrence.) beneath the bark and tumnels around the shoot, often in a spiral, so as to girdle it completely, and usually eats a small hole through the bark at this point. The maggot continues to feed on the pith at this point so as nearly to sever the shoot, the tip of which soon wilts and droops, tuming a deep blue color. On blackiberry shoots, however, the bark is so thick that although the tip droops for a few days, it usually revives and the girdling forms a circular, gall-like swelling, though even blackberries are often killed. Affected shoots usually branch from below the girdled point, making a bushy growth. Lawrence states that later in the season lateral shoots are also attacked. He also observes that maggots never develop in living canes. The maggot continues to burrow downward in the pith and becomes full grown in June, when it pupates at the lower end of the burrow. The puparia are to be found in the lower part of the affected stalk in June and July, but the adult flies do not emerge until the next spring. Control.-As soon as the young tips are seen to droop they: 
should be cut off several inches below the girdled point and burned. This may be done best late in May or in June after all the eggs are laid.

\section{The Raspberry Saw-fly *}

Occasionally raspberry leaves, as well as those of blackberry and dewberry, are skeletonized in May by small green, spiny saw-fly larvæ, which sometimes quite defoliate the plant. Such injury has been commonly noted in the Eastern and Central States. The adult female is a typical saw-fly about one-quarter inch long and with a wing expanse of one-half inch. The body and wings are black except the second and sixth abdominal segments, which are yellowish-white, and the under side is rusty. The male is somewhat smaller and is entirely black except the shoulders, which are yellowish-white.

Life History. - The adults appear about the middle of May in central New York, and the females deposit their eggs late in that month. The eggs are inserted just under the cuticle of the under surface of the leaf, and the tissue around them turns yellowish, so that infested leaves soon become spotted on the upper surface. The egg is nearly pear-shaped, yellowish-white, about one-twenticth inch long, and hatches in seven to ten days. As many as twenty-four eggs have been observed in a single leaf, and frequently the leaves are so spotted as to be readily recognized. The young larva is about one-twelfth inch long, yellowish-white or pale yellowish-green and well covered with spiny tubercles, the spines being first white and later dark brown. The young larvæ feed on the soft parts of the leaf, but as they grow older all but the midrib and larger veins are devoured. The mature larva is about threequarters inch long, from light yellowish-green to darkgreen, closely simulating the color of the foliage, and the body is covered with transverse rows of tubercles, bearing a varying number of strong, barbed spines, which are dark brown on the back and pale green or white along the sides. The larva feeds for about ten days and then enters the soil for from two to three inches and there constructs a small oval cocoon about one third inch long, which looks like a pellet of earth, being formed of a brown mucilaginous sub-

* Monophadmus rubi Harris. Family Tenthredinida. See V. H. Lowe, Bulletin 150, N. Y. Agr. Exp. Sta. 
stance, interwoven with coarse strands of silk, to which particles of earth adhere. The larva then hibernates until the next spring, when it transforms to the pupa and in a few days the adult appears, usually early in May.

Control.-By suddenly jarring or shaking the bushes the larvæ will be shaken to the soil. On light soils this habit may

8
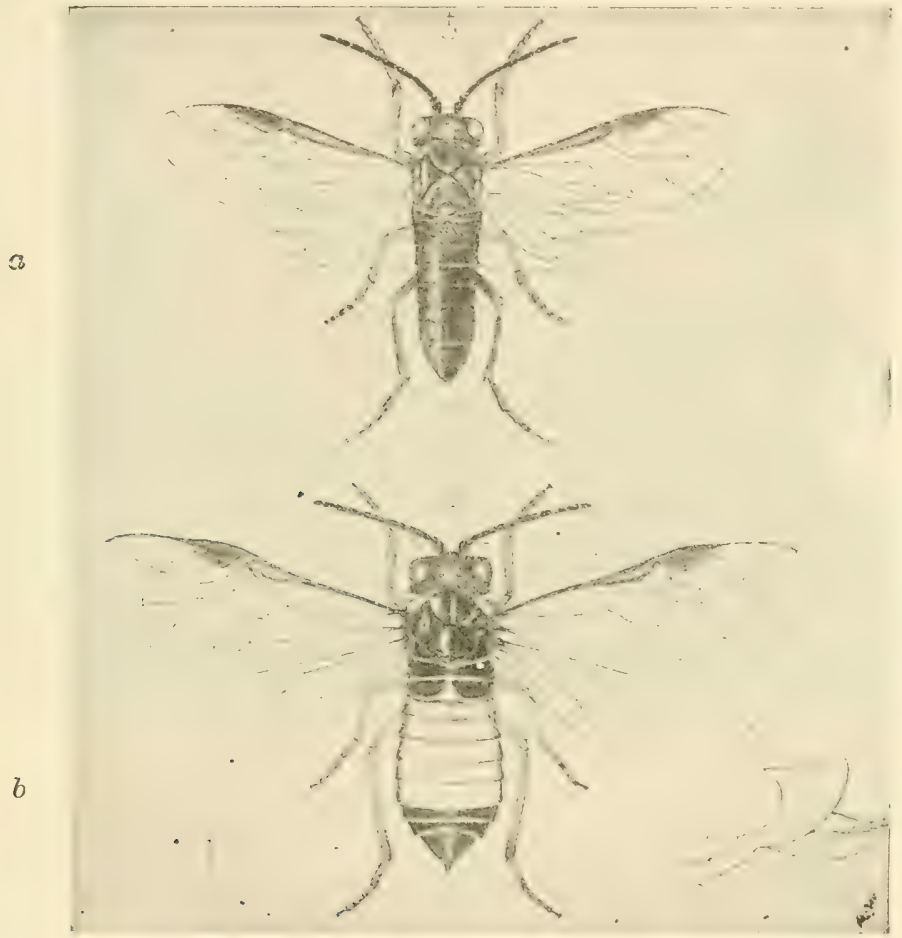

Fig. 349.-The raspberry saw-fly (Monophadnus rubi Harr.): a, male; l, female; $c$, egg blisters on leaf; $d$, larva; $c$, cocoons-all much enlarged. (After Lowe.)

be utilized for their destruction by jarring them to the ground and following with cultivators so as to bury the larvæ in the loose soil. This will be particularly applicable in hot weather, if the soil is hot and dusty, when most of the larvæ will be killed before regaining the plants. By frequent cultivation in late summer or fall the cocoons might be brought to the surface and some of the larvæ might be thus killed during the winter, though 
this needs testing, as they are fairly well protected. The larvæ may be readily killed with arsenical sprays, and if arsenate of lead were applied at the rate of 3 pounds per barrel just as the plants commence to flower, it would undoubtedly control the pest with no possibility of spotting the fruit, or Paris green with Bordeaux mixture might be used in the same way. If careful watch is kept for the pest it can probably be detected in time to apply the arsenicals, which will be much the easiest and most effective to use, but if not observed until the canes are fruiting they should be sprayed with hellebore, 1 ounce to 1 gallon of water. Hellebore may be dusted on the plants mixed with twice its weight of flour, but the spraying may be done more thoroughly.

\section{The Raspberry Byturus *}

The Raspberry Byturus is a small brown beetle belonging to the same family as the larder and carpet beetles, most of which feed on animal matter. It is about one-seventh inch long, red-

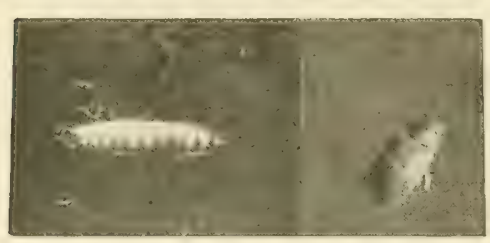

Fig. 350.-Larva and adult of the raspherry byturus - enlarged. (After Goodwin.) dish-yellow or reddish-brown, and covered with a thick coat of pale, tawny hairs. The beetles appear about the midde of May in northern Ohio. They feed on the tender foliage and eat into the flower buds, and sometimes emerge in such numbers that the young foliage is skeletonized and many of the flower buds do not develop. Though the eggs are laid in June, they have not been observed. The larva appear in late June and July and feed in the fleshy head on which the berry is born, causing the affected berries to ripen earlier, making them small and unfit for market. Furthermore the little larvæ not infrequently remain in the cup of the berry, which necessitates picking the berries over and injures their sale. The larva is about onequarter inch long, rather plump and cylindrical, and tapering at each end. The body is white, but each segment is marked across the back with a broad, tawny yellow band, and numerous

* Byturus unicolor Say. Family Dermestides. See W. H. Goodwin, Bulletin 202, Ohio Agr. Exp. Sta. 
short white hairs. When full grown the larva drops to the ground and forms an earthen cell just beneath the surface, in which it transforms to a yellowish pupa, from which the beetle emerges the next spring. Only red raspberries seem to be affected, and some varieties are particularly injured. The insect has been

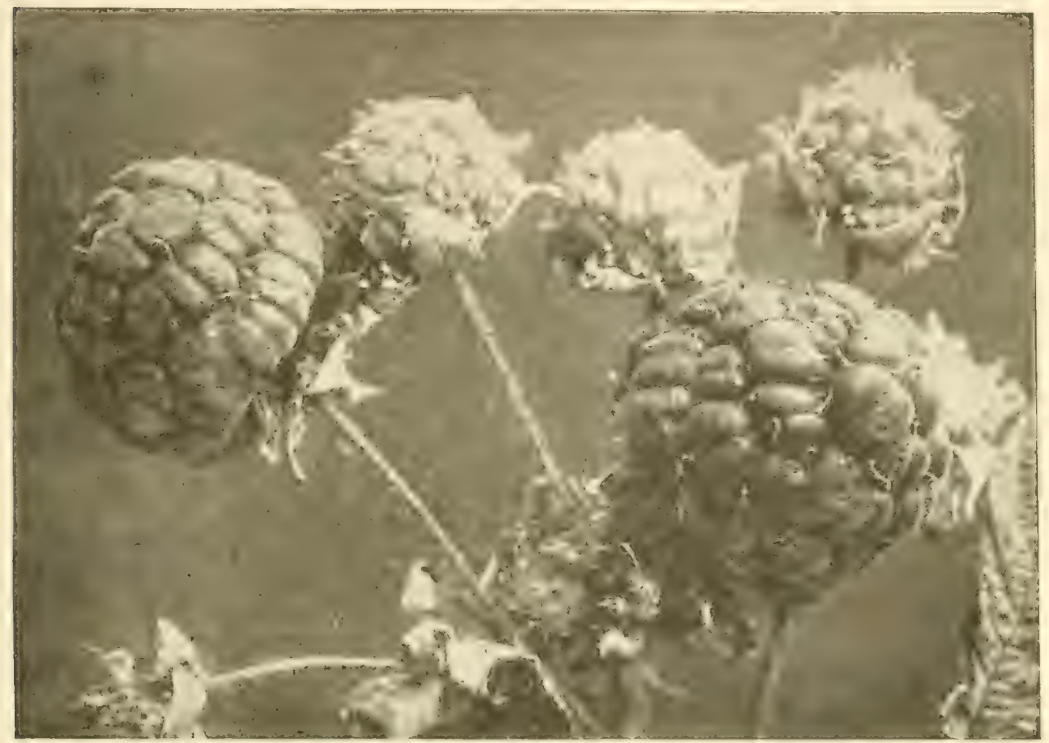

FIG. 351.-Early ripening berries, the smaller ones infested with Byturus larvæ. (After Goodwin.)

reported as injurious from Minnesota to Massachusetts and in Ontario.

Control-Inasmuch as the beetles feed freely on the foliage before ovipositing they may be destroyed by spraying the leaves with arsenate of lead. Mr. Goodwin has shown that where foliage was sprayed with 4 pounds per barrel, that three-fourths of the subsequent injury to the berries by the larvæ was prevented by the destruction of the bectles, and the injury to the flower buds was also lessened. Thorough cultivation in the fall close around the bushes will probably destroy many of the pupæ by exposing them to winter weather. 


\section{CHAPTER XXII}

INSECTS INJURIOUS TO THE CURRANT AND GOOSEBERRY.

\section{The Imported Currant-borer *}

ONE of the worst pests of the currant and gooseberry is the borer, which tunnels out the canes and where abundant frequently kills the plants. It is a European insect which has spread to

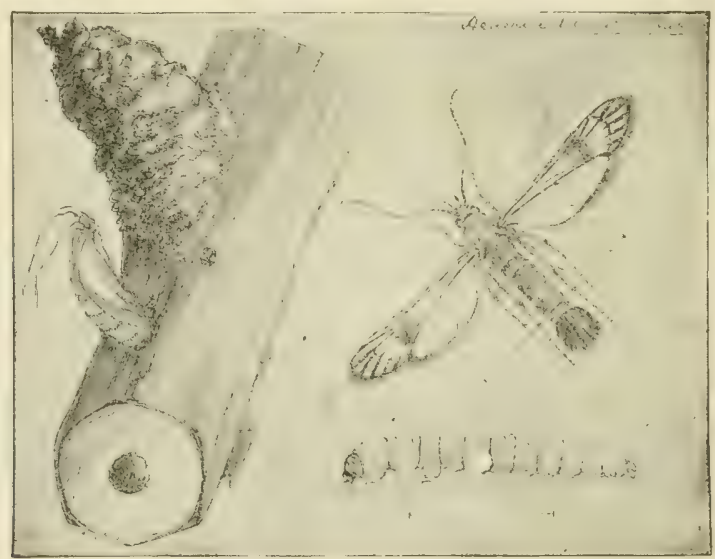

FIG. 352.-The imported currant-borer (Sesia tipuliformis Clerck): moth, larva, and empty pupal skin left protruding from burrow. (After Lugger.)

all parts of this country where these fruits are grown. The adult is one of the clear-winged moths and with the larva is very similar in appearance and habits to the raspberry root-borer The moth is about one-half inch long with a wing-expanse of three-quarters inch. The body is black with a steel-blue lustre, with a bright yellow band around the neck and three yellow bands across the abdomen, which bears a large tuft of long scales at the tip. The wings are clear except for a margin of blackish scales and a band across the fore-wings about one-third from the tip.

* Scsia tipuliformis Clerck. Family Sesiida. See Lugger, 1st ReportMinn. State Entomologist, p. 184. 
Life History.-The moths appear in June and deposit their small globular, brown eggs in the axils of the leaves next the canes, or under scales or in cracks of the canes. The young caterpillars bore into the pith of the canes, which they tunnel out, and are about half grown by winter, when they descend to the bottom of the burrows and hibernate. In the spring they continue their work and become full grown by May. The fullgrown larva is slightly over one-half inch long, of a yellowish color, with brown head, and with numerous small tubercles over the body. It cuts a hole through the side of the burrow, which it closes with small chippings, and then transforms to the pupa. When the moth is ready to emerge the pupa wriggles itself partly out of the burrow by means of the strong spines on the abdomen, and the moth comes forth. Affected canes can be recognized by the dwarfed and yellow foliage and the general unhealthy appearance of the plant, and if not removed will usually die during the season.

Control.-The only method of control is to keep all the old wood removed and to cut out and burn all affected canes in fall or early spring, whenever the injury may best be detected.

\section{The Currant-stem Girdler *}

In late spring, after the young currant-shoots have reached a growth of several inches, two or three inches of the tips sometimes wilt, and fall over and hang suspended or drop to the ground. If examination shows that the tip has been girdled by several sharp cuts, it is probably the work of the Currant-stem Girdler. It is a native insect which was first described from Massachusetts, and has also been found injurious in Rhode Island, Canada, Ohio and Michigan, but has been most troublesome in New York. It has also been noted as a pest of willow and poplar in Maryland, and of basket willow in Kentucky, Indiana, and Ohio, so that it is doubtless quite generally distributed. The adult insect is a slender saw-fly with shining black body and light brownish legs, shown natural size in Fig. 353a. The male is smaller and has a brownish-yellow abdomen, while in the female the first

* Janus integer Norton. Family Tenthredinidre. See Slingerland, Bulletin 126, Cornell Univ. Agr. Exp. Sta.; F. H. Chiłtenden, Bulletin No. 46, Bureau of Forestry, pp. 68-70. 

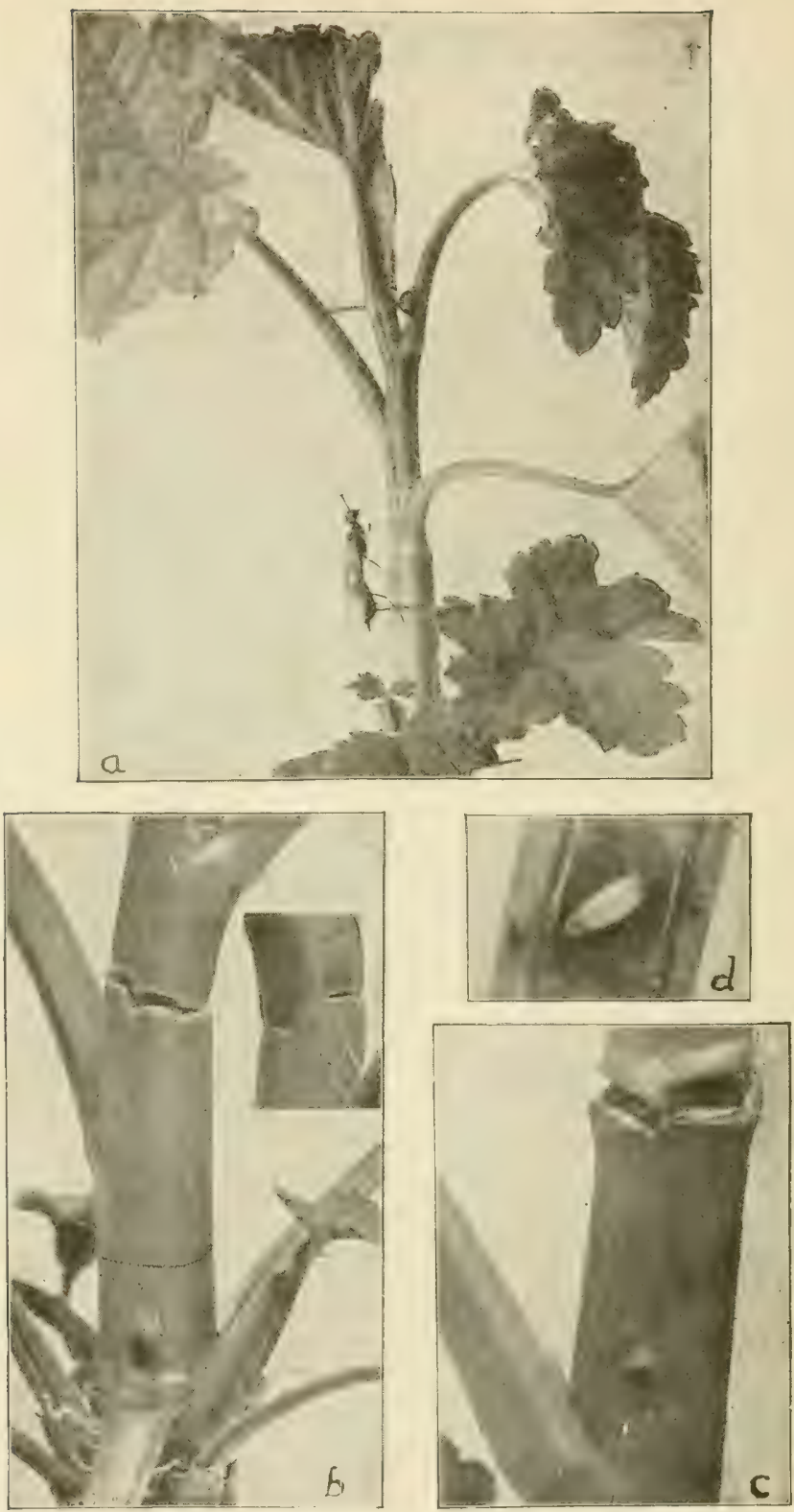

FIG. 353.-The currant stem-girdler (Janus integer Norton): $a$, female at work girdling a currant stem -natural size; $b$, girdled portion of stem much enlarged to show character of girdle; $c$, stem cut open to show egg; $d$, egg - much enlarged. (After Slingerland.) 
half of the abdomen is reddish-orange and the rest is black. The adults are abroad in May, but are very shy and are seldom seen. They are saw-flies in the truest sense of that term, for the female makes most effective use of her saw-like ovipositor, as has been very interestingly described and illustrated hy Professor Slingerland. The ovipositor is thrust into the eane for its whole length, and through it the egg is deposited in the pith. The egg is an elongate-oval shape, yellowish-white, and about one-twenty-fifth inch long (Fig. 353d). Immediately the female moves an inch or two higher and girdles the stalk by numerous thrusts of her ovipositor, which is thrust in and then given a twist to one side so that it comes out at one side of where it was forced in, and makes a horizontal cut. The eggs are laid in late May and early June and hatch in about eleven days. The young larvæ bore into the pith, but the tunnel rarely extends over six inches below the point girdled. The fullgrown larva is hardly one-

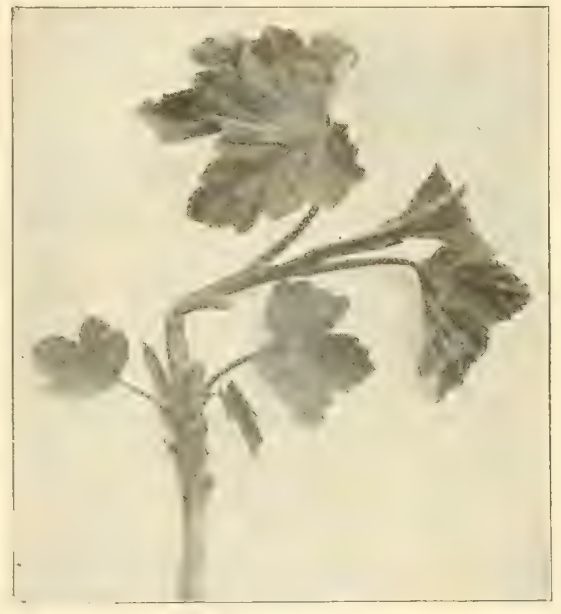

Fig. 35t.-Currant stem girdled by the stem-girdler. (After Slingerland.) half inch long, of a glistening straw-yellow color, with darker head. The thoracic segments are wider than the others and bear rudimentary feet, and from the tip of the stout, cylindrical abdomen projects a horny, brown bifid spine. In the fall the borer cleans out its burrow at the lower end and eats a hole through the woody wall of the stem to the outer bark, which sinks in at this point. The grub then spins a thin silken cocoon about itself, in which it hibernates over winter, transforming to a whitish pupa in April, from which the adult emerges carly in May. The girdling of the stalks is the principal injury, and those which harbor the pest may be recognized, even in winter, by the characteristic dead stubs, cut off squarely at the upper end. 
Control.-The drooping of the tips in May is soon noticed and during June they should be cut off about three inches lower down and burned, or if the pruning is left until winter the infested stubs should be cut off about eight inches below the point girdled, as the larvæ rarely tunnel deeper.

\section{The Four-lined Leaf-bug *}

This is one of our most common leaf-bugs, which has a long list of food plants, but is particularly injurious to the young foliage of currant and gooseberry. The adult bug is easily recognized, as the upper surface is a dark green with four stripes and the tips of the wing-covers black, as shown
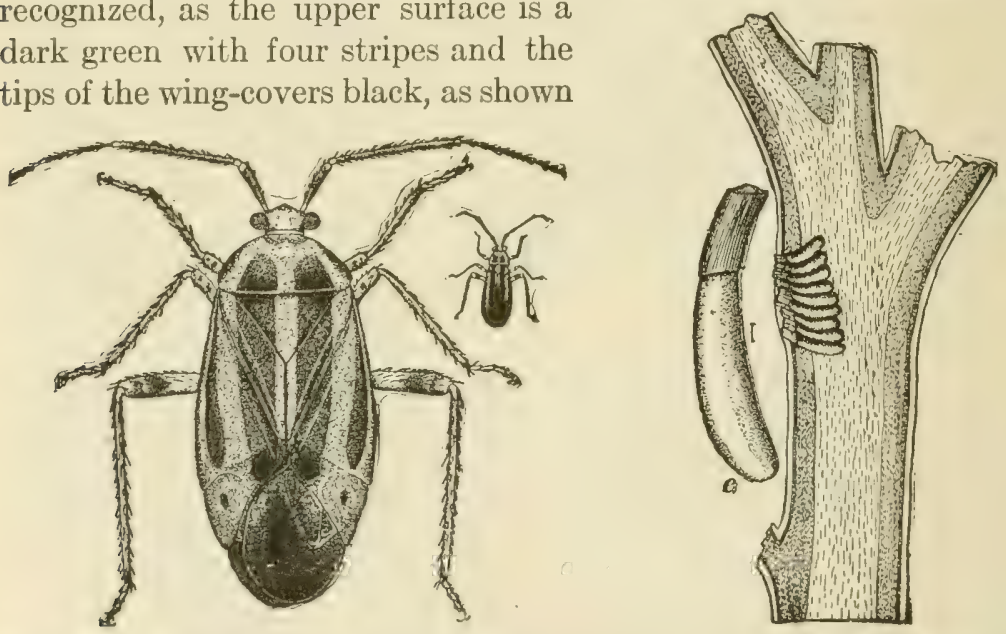

FIg. 355.-The four-lined leaf-bug (Pacilocapsus lineatus Fab.): $a$, adult; $b$, cross-section of stem showing eggs in position and a single egg greatly enlarged. (After Slingerland.)

in Fig. 355. The green changes to yellow after death and the body is bright orange-yellow, and the legs green. The "presence of the pest is indicated by the appearance of the peculiar brown depressed spots on the tender terminal leaves" in early summer. "As the attack continues, whole leaves turn brown, curl up, become brittle, and are torn or broken by the wind. The young shoot is checked and frequently droops and dies. The buds of dahlias and roses are often blasted." Slingerland gives a list of some fifty-seven foodplants, including all sorts of crops, ornamental plants and weeds.

* Pacilocapsus lineatus Fab. Family Capsida. See Slingerland, Buletin 58, Cornell Univ. Agr. Exp. Sta. 
Parsnip, mint, sage, rose, deutzia, dahlia, and others are often badly injured. The species has been observed from Canada to Georgia and westward to the Dakotas, so that it is probably generally distributed east of the Rockies.

Life History. - The nymphs hatch from the overwintering eggs in late May and early June and are very largely responsible for the injury to the foliage. The newly hatched nymph is only about one-twentieth inch long, but is easily recognized by the shining vermilion-red color of the body, marked with large blackish spots on the thorax and with greenish-black antennæ and legs. The nymphs grow rapidly, becoming full grown in seventeen to twenty days after hatching, during which time they have molted five times. The full-grown nymph is about one-fifth inch long, bright orange yellow, and the black wing-pads extend half

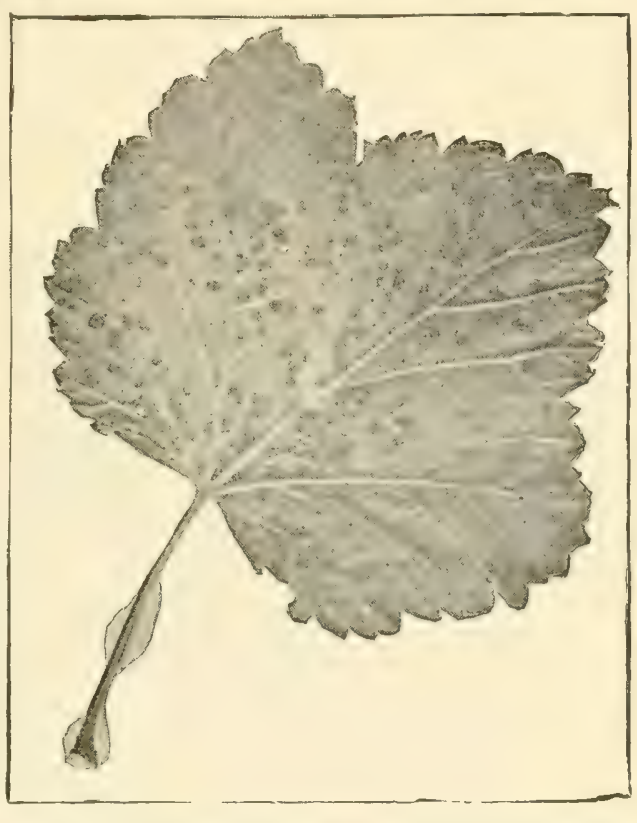
way to the end of the Fig. 356.-Currant leaf spotted by the nymphs abdomen and bear a of the four-lined leaf-bug. (After Slingerland.) yellowish green stripe near the outer margin. The nymphs feed on the tenderest young leaves, sucking out the juices and soft tissue through their tiny beaks, and thus causing the spots mentioned. "As the nymphs increase in size the spots are a little larger and more numerous, until not only hundreds occur on a single leaf, but often nearly all the parenchyma is taken from the leaf." The nymphs are very active and dart from one side of the leaf to the other when disturbed. The adult bugs appear about the middle of June and are active for a month or more, when they disappear. They mate and the females commence to lay 
eggs about a week after they first appear. The female is furnished with a strong ovipositor with which she inserts the eggs in slits cut lengthwise into the stems of the plants extending nearly half way through the pith. A half-dozen or more eggs are packed together in the small slit, which may be one-eighth inch long. The individual egg is about one-sixteen th inch long, light yellow, and shaped as in Fig. 355e, with the upper third capped by a white, finely striated portion. "With the growth of the surrounding tissue of the stem, the eggs are usually forced out of the slit somewhat, so that about one-half . . of the white portion of the egg projects from the slit." Most of the slits are made two or three inches, rarely orer six inches, below the tender tips.

Control-Experiments indicate that the nymphs may ise.

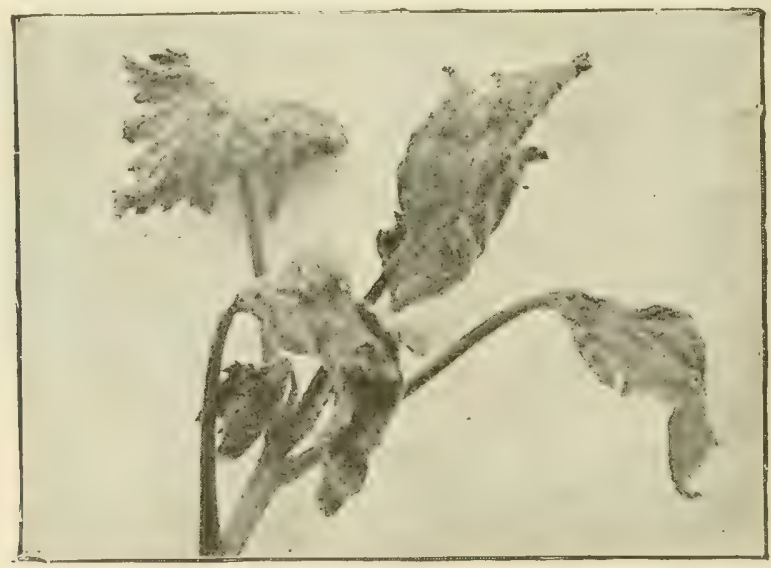

Fig. 357.-Currant leaves killed by the four-lined leaf-bug. (After Slinger-land.)

killed by spraying them with kerosene emulsion containing 10 per cent kerosene. Tobacco extracts should also be tried. The aclults are not susceptible to this treatment, however. Both nymphs and adults will drop from the foliage when disturbed, and Professor Slingerland has suggested that they might be jarred into a pan of kerosenc. By drawing pans, such as constructed for combating the pea-aphis, between the rows and jarring the bugs into them, many might be destroyed. As the eggs are readily recognized, the tips containing them should be cut off and destroyed during the winter. 


\section{The Currant-aphis*}

The young foliage of currants, and sometimes of gooseberries, is often found curled up in late spring with many bladder-like galls on the leaves, inside of which are found the numerous yellowish-green plant-lice which have caused them. The wingless females are about one-twelfth inch long, yellowish-green or green, mottled with darker shades, and with bright red eyes. The winged female is slightly longer, with wings expanding onethird inch. It is bright greenish-yellow, with pale olive head, thoracic lobes brown, and the abdomen is marked by several dark

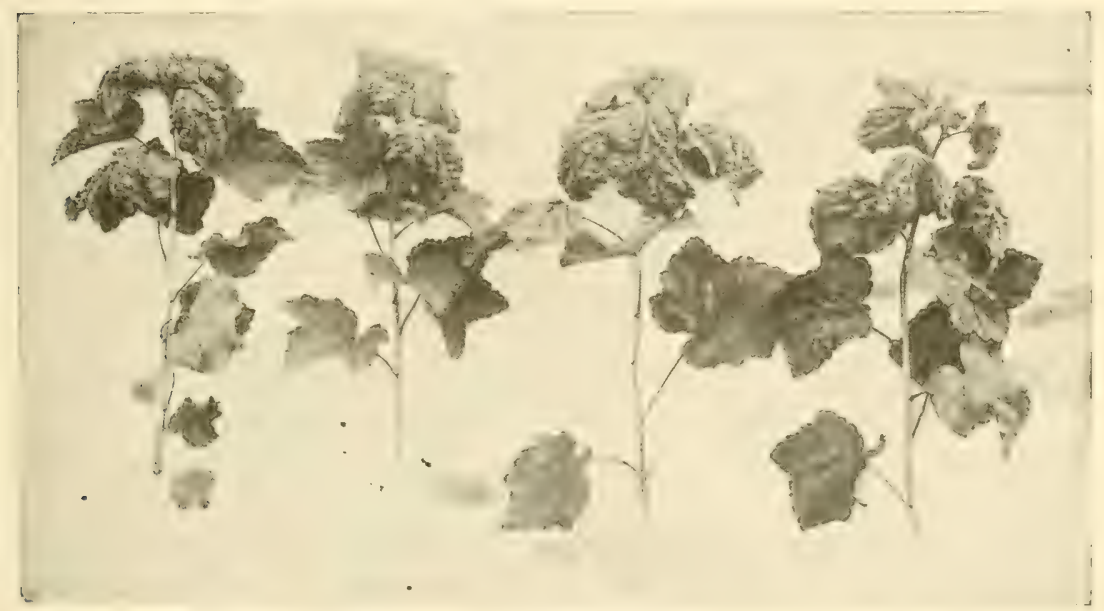

FIG. 358.-Currant foliage curled by aphids. (After Lowe.)

transverse bands and lateral spots. It is an old European species and is probably found throughout the United States where currants are grown.

Life History.-The life history is practically the same as that of several other aphids previously deseribed and need not be rehearsed in detall. The small black eggs are found on the stalks in winter and hatch just as the foliage appears. The aphids multiply on the follage, eausing it to curl as described, until midsummer, when they either migrate to some other food-plant or become greatily reduced in numbers through the attacks of parasites and predaceous insects, which are very effective in the

* Myzus ribis Linn. Family A phidider. See V. H. Lowe, Bulletin 139, N Y. Agr Exp. Sta, p. 660 Another spec1es, Rhopalosiphum ribis Linn., is also common on eurrant and is described and figured by Mr. Lowe. 
control of this species. Mr. Lowe states that a few females may be found on the foliage throughout the summer. In late October winged males appear and mate with the true females, which then lay the eggs.

Control.-The aphids may be readily killed by spraying with kerosene emulsion, whale-oil soap, 1 pound to 6 gallons of water, or tobacco extracts, but the spraying must be done before the

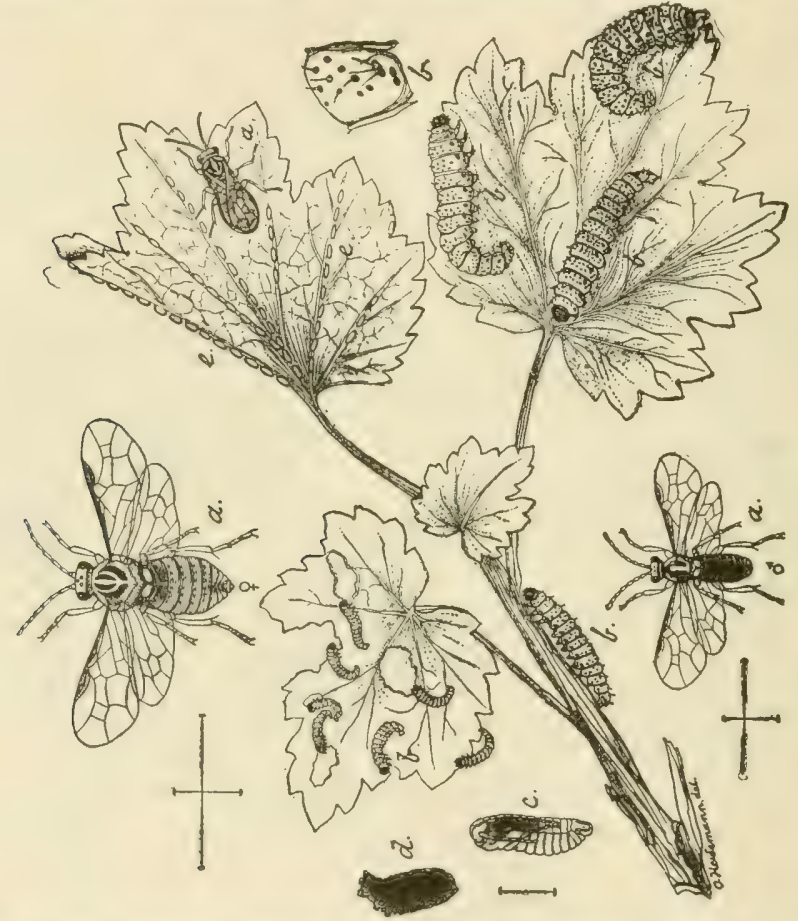

FIG. 359.-The imported currant-worm (Pteronus ribesii Scop.): $a$, male and female sar-flies; $b$, larvie; $c$, pupa; $d$, cocoon; $e$, eggs-all enlarged. (After Lugger.)

foliage becomes badly curled. Ordinarily they may be held in check by picking off the curled leaves by hand.

\section{The Imported Currant-worm *}

"The most destructive insect that attacks the currant," says Profesior Lugger, " is the above-named saw-fly, which feeds

* Pteronus ribecii Scpp. Family Tenthredinida. See Lugger, Bulletin 43 Minn. Exp. Agr. Sta., 179; C. L Marlatt, Bulletin 3, T ch. Series, Div Ent., p. 61. 
indiscriminately on all kinds of currants and gooseberries. The imported species is supposed to have been accidentally introduced into this country about the year 1857, and has since spread over the greater part of the United States and Canada. The eggs are glued to the main-ribs of the leaf as shown in Fig 359, and not inserted into pockets, as is usually the case with saw-flies. . . . In from four to ten days the egg hatches into a very small whitish caterpillar with a white head and ornamented with black spots on each side. This color, however, changes to green as soon as the caterpillars begin to feed, and after their first skin is shed, the head becomes black and many black spots appear on the body. This coloration persists until the last molt when the insect becomes grass-green. The head, however, retains the black spots on each side. The length of the worm is now about three-fourths of an inch. While growing they at first skeletonize the leaves; later they eat the entire leaf, with the exception of the ribs, and at last they devour immense quantities of them, often completely stripping the bushes of their foliage. If this is repeated year after year, the plants produce less and less fruit and eventually die. The larvæ now descend to the ground, in which they spin a small, oval cocoon of brownish silk, either just below the surface of the ground or among the leaves and rubbish that collect below the plants. Inside these cocoons they change to pupx and later to adults, which are ready to issue as winged saw-flies during the last of June or in July (in Minnesota), sometimes not until the first of August. They now pair and produce a new generation of injurious worms. . , the adults of which do not, however, issue until the following spring. As the two broods overlap, we can find larve of all stages during the greater part of the summer." The adult saw-flies are well illustrated in Fig. 359. The female is about one-third inch long, of a light yellowish color marked with blackish as shown in the figure, while the male is smaller and rather darker.

Control-See next insect.

\section{The Native Currant-worm *}

The native currant-worm is not usually so destructive as the European species, but occasionally, becomes injurious and is

* Gymnonychus appendiculatus Hartig. Family Tenthredinida. 
widely distributed, occurring from New England to Minnesota and Colorado, in British Columbia, and probably in the Pacific States. The larva is about two-thirds the size of the imported species, but is uniformly pale-green except the head which is black until the last molt, after which it becomes partly green. One generation of larvæ appears in late June and another in August. The cocoons are usually attached to the twigs or leaves of the bushes. The female saw-fly is dull black with dull yellow head, and honey-yellow legs.

Control.-While fruiting the foliage should be dusted or sprayed with hellebore, which is the time-honored remedy for currantworms. However, before the fruit has set and after it is picked, spraying with arsenicals will be much cheaper and more effective, and as it is often desirable to spray gooseberries for diseases with Bordeaux mixture, by adding arsenate of lead or Paris green to it, the worms may be easily controlled.

\section{The Currant Span-worm *}

The Currant Span-worm is readily distinguished from the other currant "worms," by being one of the measuring-worms or inch-worms which loop along as shown in Fig. 360. It is not frequently very destructive, but occasionally becomes a pest, more particularly of black currants and gooseberries, throughout the eastern half of the country. The caterpillar is slightly over an inch long when full grown, and of a whitish color with a wide yellow stripe down the back, another along each side, and several black spots on each segment. The under side is white with a slight pinkish tinge, with a broad yellow median stripe, and is also spotted with black. The moth has a wing expanse of about $1 \frac{1}{4}$ inches, is a pale yellowish color, with several brownish spots, varying in size and sometimes forming one or two irregular bands across the wings.

Life History.-The eggs (Fig. 360a) are laid in midsummer on the twigs of the infested plants and hatch as the bushes come into full leaf the next spring. The caterpillars become full grown in three or four weeks, when they pupate just beneath the surface of the soil, and two or three weeks later the moths emerge.

* Cymatophora ribearia Fitch. Family Geometridce. 
Control.-Hellebore is not as effective as against the saw-fly larva and as the larva usually appear before the fruit is setting, they may be better controlled by spraying with arsenicals. When the caterpillars are disturhed they drop from the foliage, letting themselves down by a silken thread and remaining suspended in
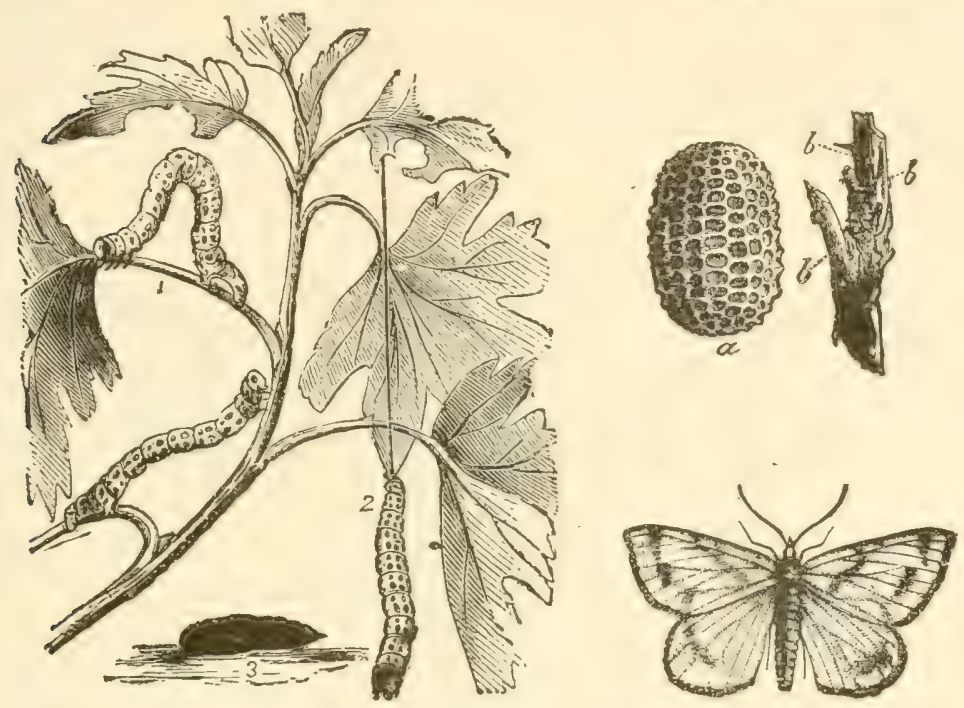

FIg. 360.-The currant span-worm (Cymatomorpha riberia Fitch): 1, 2, larva, 3 , pupa; $a$, egr; $b$, egges on twig; $c$, moth-a, much (nlarged, others nat ural size. (After Saunders.)

mid-air until danger is over, when they reascend the thread. This habit may be utilized for their destruction by jarring the bush so that they will drop, and then passing a forked stick around it so that all the threads may be caught and the caterpillars may be drawn out in groups and crushed with the foot.

\section{The Currant-fly *}

Currants and gooseberries sometimes turn red and drop prematurely, due to the injury by small maggots which may be found within them. The insect has been troublesome in Maine and is sometimes a serious pest in Colorado. It is a native insect and is probably generally distributed throughout the northern United States and southern Canada. The adult fly is about the size of

* Epochra canadensis Loew. Family Trypetida. See F. L. Harvey, Bulletin 35, Maine Agr. Exp. Sta. 
a house-fly, a pale yellowish or yellowish-brown color, with dark bands across the wings, and a tapering abdomen, as shown in Fig. 361 .

Life History. - The flies appear in late spring and the females deposit their eggs in the older berries. A female will lay about 200 eggs during the period of a month, placing but one in a berry, so that a single fly may do considerable damage. The white egg is about one-twenty-fifth inch long and laid just under the skin, where it is easily seen. The egg hatches in a few days into a

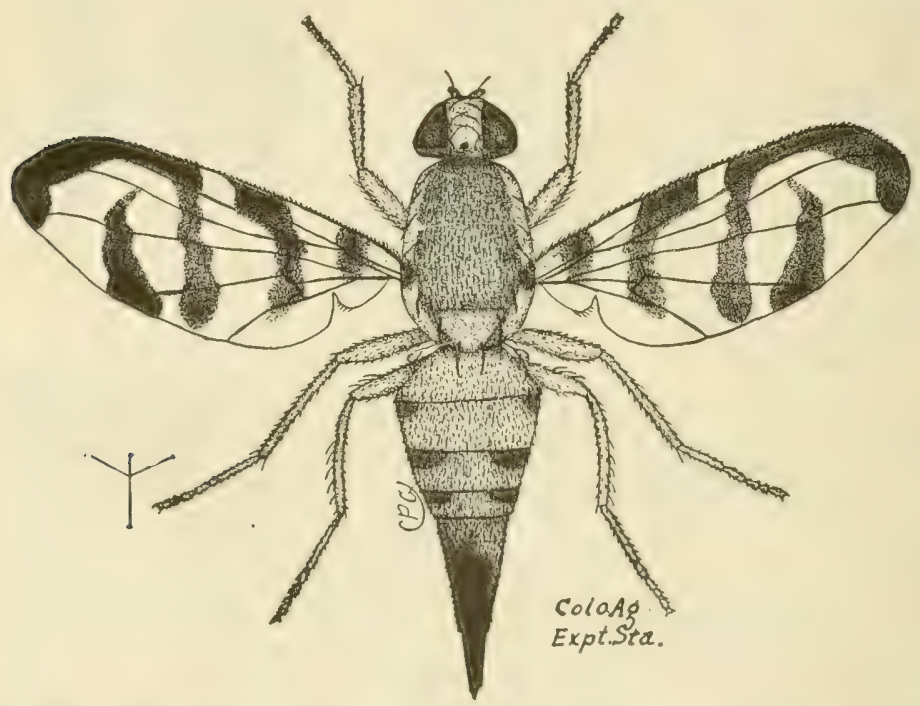

FIG. 361.-The currant-fly (Epochra canarlensis Loew.)-much enlarged; (After Gillette.)

small white maggot, which burrows around the berry and then feeds upon the seeds. The location of the larva may be seen, as the infested currant soon shows a clouded appearance and finally turns red and a black spot appears. The maggot becomes full grown in about three weeks and then eats its way out of the berry, which has usually fallen to the ground. The mature maggot enters the soil for about an inch and there changes to the pupa, from which the fly emerges the next spring.

Control-As the maggots usually remain in the berries a few days after they drop, all fallen berries should be frequently 
picked up and destroyed. Poultry running among the bushes will do this very effectually. Other methods will suggest themselves from the above life history, but none seems to have been carefully tested. 


\section{CHAPTER XXIII}

\section{INSECTS INJURIOUS TO THE GRAPE.*}

\section{The Grapevine Phylloxera $†$}

THus insect is native east of the Rocky Mountains, where it has always lived upon wild vines and did not attract attention until it was imported into France about 1859, as it does practically no damage to the native American grapes. It soon spread through the principal wine districts of southern Europe, where it

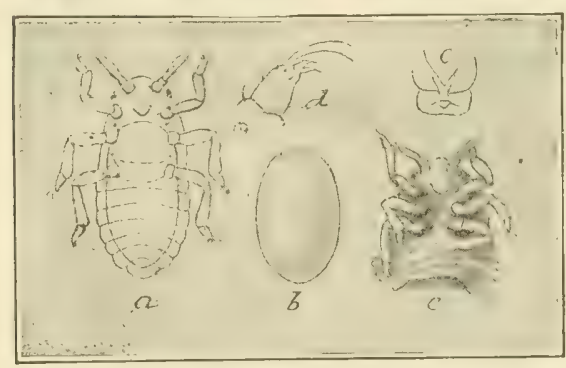

Fig. 362.-The granevine phylloxera (Phylloxera vastatrix Planchon): $a$, true sexual female, the dark colored area indicating the single egg; $b$, egg ; $c$, shrivelled female after oviposition; $\bar{d}$, foot of same; $e$, rudimentary and functionless mouth-parts. (After Niarlatt, U. S. Dept. Agr.)

caused immense losses and the temporary abandonment of vineyards, due to the fact that the European varieties are very susceptible and readily succumb to injury by it. It has spread to southern Russia and the adjoining countries of Asia, and Algeria, and has been carried to New Zealand a nd South Africa. In this country it is injurious only in California, where it was imported on French vines about 1874. It was first noticed in Sonoma County and since then has spread to all the principal grape-growing regions north of Tehachapi and has probably destroyed 50,000 acres.

This aphid exists in several forms, which injure both foliage and roots. On the leares irregular spherical galls are produced, and the root-inhabiting form produces galls on the roots. The

* See A. L. Quaintance, Farmers' Bulletin 2s4, U. S. Dept. Agr. H. J. Quayle, Bulletin 192, Cal. Agr. Exp. Sta.; F. Z. Hartzell, Bulletin 331, N. Y. Agr. Exp. Sta.

$\dagger$ Phylloxera rastatrix Planchon. Family A phidida. See C. L. Marlatt, Farmers' Bulletin 70, U. S. Dept. Agr., and Quayle, 1. c. 
leaf-galls are very common on American grapes, but are no indication of the presence of the root form, as the roots are rarely injured where the foliage is covered with leaf-galls. On the other hand the European varieties rarely exhibit any leaf-galls, but are very susceptible to the root phylloxera, which multiplies without any external indication of its presence until the vine is seriously injured. The injury to the vine is not due so much to the sap taken from the vine by the myriads of aphids which may inhalit the roots, as to their poisonous effect on the root tissue and its subsequent decay. Wherever the phylloxera attack the roots, small swellings are produced, composed of soft tissue which soon decays. When such a gall is formed at the end of a young root, its growth is stopped, and on larger roots a decay sets in which finally girdles the root and all below the injured point dies. As all the roots become affected the vine stops growing, the leaves be-

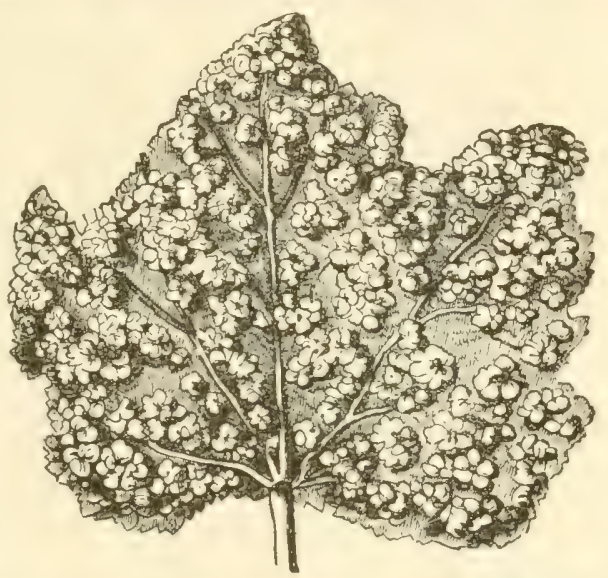
come sickly and yellow- FIG. 363.-Under side of grape leaf showing ish, and the vine dies, and galls caused by Phylloxera. (After Riley.) the phylloxera disappears from the rotting roots, so that the cause of the injury would be obscure were the nature of the injury not known.

Life History.-The life listory of the phylloxera is a complicated one, involving four different forms of aphicls; the leafgall form, the root or destructive form, the winged or colonizing form, and the sexual form. The winter eggs are deposited on the rough bark of the old wood in the fall and hatch the following spring. The young aphids settle on the leaves, where the irritation caused by their mouth-parts soon causes a depression around each which forms a gall projecting on the lower side of the leaf. "In about fifteen days the louse becomes a plump orange-yellow, full-grown, wingless female, and fills its gall with small yellow 
eggs, dying soon after. The eggs hatch in about eight days into young females again, like the parent, and migrate to all parts of the vine to form new galls. Six or seven generations of these wingless females follow one another throughout the summer, frequently completely studding the leaves with galls." In California the young hatching from the winter eggs go directly to the roots where they give rise to new colonies, there being no gall forms, according to Quayle. Where the leaf-gall females

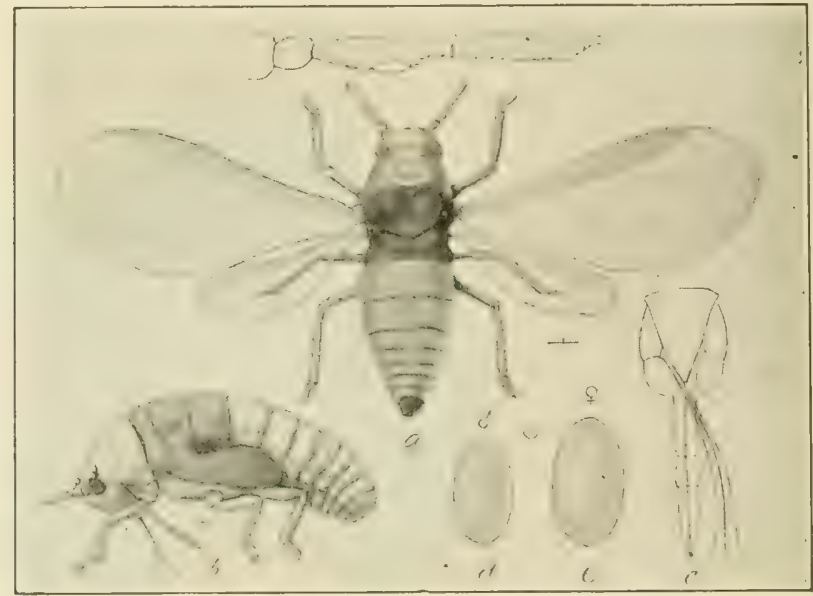

Frg. 364.--The grapevine phylloxera: $a$, winged migrating female; $b$, last stage of nymph of same; $c$, mouth-parts with thread-like sucking setre removed from sheath; $d$, and $\epsilon$, eggs of male and female, shorving sculpturing-all enlarged. (After Marlatt, U. S. Dept. Agr.)

occur many of them probably migrate to the roots during the summer, and all do so with the approach of cold weather. In the spring the roots are attacked and a series of generations of wingless females multiply on them. As there are five to seven generations in a season and each female lays from 30 (Quayle) to 100 (Marlatt) eggs, it is evident that they will soon be numerous enough to destroy the vine. The root-inhabiting females are very similar to those in the leaf-galls, and are about one-twenty-fifth inch long when mature and half as long when young and active. They are light greenish-yellow in summer and darker in winter, and when numerous the infested roots look as if dusted in spots with pow- 
dered mustard, according to Quayle. He states that "the newly hatched insect is fairly active, and at first moves from place to place on the roots, but finally, when it reaches the egg-laying stage, inserts its sucking-tube into the root and remains fixed." During the late summer and early fall some of the root-lice develop into winged females which escape through cracks in the soil and fly to neighboring vines. They lay from two to four eggs beneath the loose bark on the old wood and soon die. "The eggs are of two sizes, the smaller a $\mathrm{nd}$ fewer in number yielding males in nine or ten days, and the larger the females of the only sexed generation in the whole life round of the insect. In this last and sexed stage the mouth-parts of both sexes are rudimentary, and no food at all is taken. The insect is very minute and resembles the

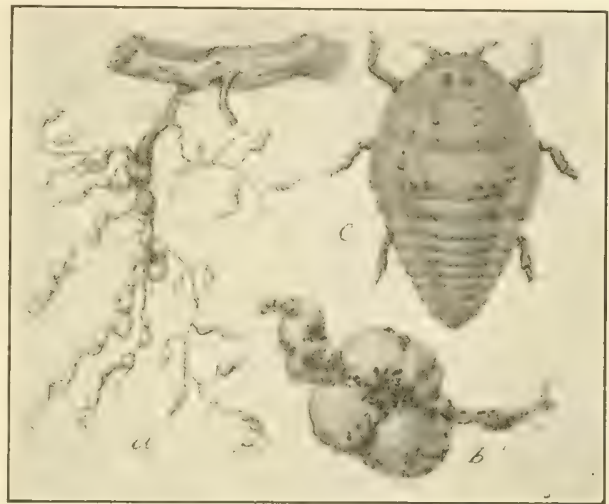

FIG. 365.-Grapevine phylloxera: $a$, root galls; $b$, enlargement of same showing disposition of lice; $c$, root-gall louse-much enlarged. (After Marlatt, U. S. Dept. Agr.) newly hatched louse of either the gall or root form. After fertilization the single egg of the larva-like female rapidly increases in size until it fills the entire borly of the mother and is laid within three or four days, bringing us back to the starting point." * The phylloxera has been distributed over the world by infested rooted plants or cuttings bearing winter eggs, and it spreads locally by means of the winged females, by the escape of the young root-lice through cracks of the soil and their migration to neighboring plants, or by bits of infested roots being spread in cultivation, and by the leaf-gall lice being spread to other plants by the wind or by being carried by birds or insects.

Control.-The principal means of control lies in the use of resistant vines. These may be varieties which have proven successful in the eastern United States, where the insect is native, or more commonly the stocks of grapes from the Eastern States

${ }^{*}$ Quotations from Marlatt, 1. c. 
are grafted with the desired varieties. There is a marked variation in the resistance of different species and varieties and not all of them can be successfully used as stocks for the desired scions, so that the successful use of the method, which is fully outlined by Quayle, 1.c., requires a considerable knowledge of viticulture.

Carbon bisulfide has been used very extensively for destroying the root-lice, but is expensive and is only applicable on rich, deep, loose. soils. It cannot be used successfully on soils containing much clay, or on dry rocky hillsides, or when the soil is saturated with moisture, and is most effective on sandy soils where the insect is least injurious. It is now seldom used and is considered impractical by growers.

One of the best methods of destroying the root-lice where water is available is by submersion. In California the best results are secured by flooding with at least six inches of water for a week or ten days as soon as the vines have ceased active growth in November. A little later two to three weeks' submersion will be necessary and in winter thirty-five to forty days. Flooding for a couple of days in midsummer seems to destroy some of the insects, but its main value is in stimulating a vigorous growth of new rootlets. Longer flooding in summer, when the aphids might be most easily destroyed, injures the vines.

On very sandy soils vines are uninjured by the phylloxera. All sandy soils are unfavorable to the pest and vines on them die more slowly, but to secure complete immunity there must be at least 60 per cent of silicious sand. Sands containing clay or which form lumps offer less resistance.

\section{The Grapevine Root-borer *}

The larva of the Grapevine Root-borer feed in the old roots at some little distance from the base of the vine, and as there are no indications of the pest, its presence may easily pass unnoticed. Although not generally recognized as a serious one it has been known as a pest of the grape for fifty years, and has been observed to do considerable damage in Kentucky and West Virginia. Although the vines are not killed, they are so enfeebled that they make but little growth and the crop is much curtailed. All

* Memythrus polistiformis Harris. Family Sesizdoc. See Fred E. Brooks, Bulletin 110, W. Va. Agr. Exp. Sta., and Bulletin 730, U. S. Dept. Agr. 
varieties are affected in West Virginia, including the wild fox grape, Vitis labrusca. It is stated that in the South the Scuppernong, or southern wild fox grape, is immune from attack. The species has been observed from Minnesota and Kansas eastward through Ohio and Kentucky to West Virginia and North Carolina. The parents of the borers are clear-winged moths nearly

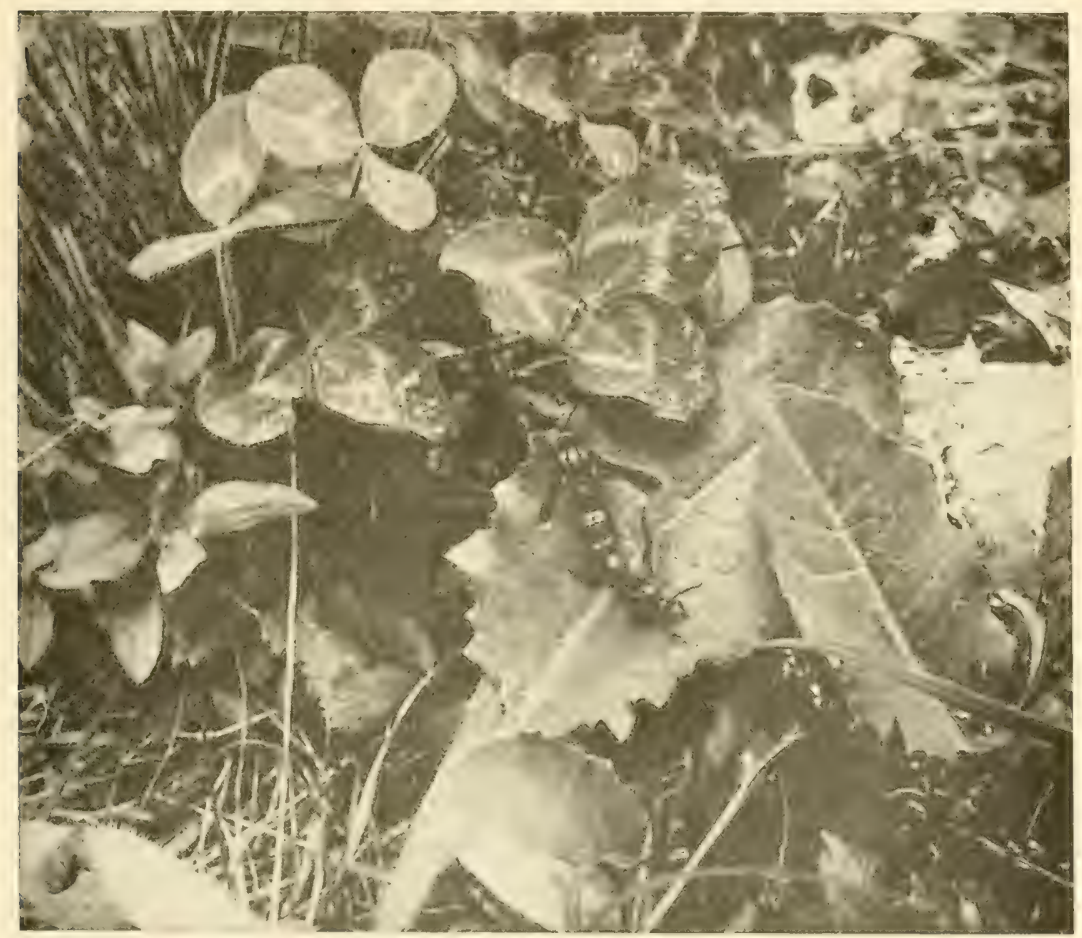

FIG. 366.-The grapevine root-borer (Memythrus polistiformis Harris): male and female moths on wild lettuce leaf under grapevine-natural size. (From Brooks.)

related to the peach-tree borer, currant-borer, and raspberryborer. The females are seven-eighths inch long with wings expanding $1 \frac{1}{2}$ inches. They are a dark lustrous brown color, the forewings being brown and the hind-wings transparent and bordered with brown. The posterior margins of the second and fourth abdominal segments are orange or lemon-yellow, and there are spots of the same color at the bases of the wings. The males 
are considerably smaller than the females. The moths fly during the day and are readily mistaken for wasps of the genus Polistes. The males fly in a quick. wasp-like mammer, and when they rest on a leaf will occasionally flutter the wings like an angry wasp, which is accompanied by a low buzzing sound, which makes the mimicry very effective.

- Life History.-The eggs are laid singly on weeds, grasses or other vegetation in the vineyard or on the bark or leaves of the

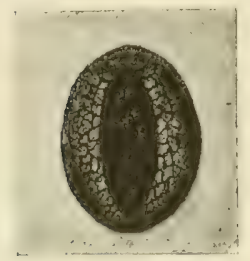

FIG. 367.-Egg of grapevine rootb o r e r - v e r y greatly enlarged. (After Brooks.) vines, a single female laying some 400 eggs. The egg is oval, one-twenty-fifth inch long, of chocolate-brown color, and finely pitted and sculptured. They are very readily washed off by the rain and drop to the soil, where they hatch in about three weeks. The little larvæ bore directly into the soil, wherever they may be, in search of grape roots, and may survive for several days without any food. Upon reaching a root the larva bores through the outer bark and then makes an irregular burrow in the softer parts of the bark, which may encircle the root several times. As the burrows grow larger they run with the grain of the wood, and as they are enlarged with the growth of the larva, only the outer bark is left on roots one-half inch or less in diameter, the interior being tunnelled out and filled with the castings of the larva. Most of the larvæ feed a foot or so from the base of the vine, though one was found on a root nine feet from the base. The larvæ bore in the roots until the second fall, when they are about full grown and make cells or hibernacula, thinly lined with silk, in which they hibernate in the root. The larva becomes full grown the next spring and is then $1 \frac{1}{2}$ to $1 \frac{3}{4}$ inches long, of the general shape shown in Fig. 368, yellowish-white, with a small brown head, three pairs of brown thoracic legs, and five pairs of abdominal prolegs. When ready to pupate the larva comes near the surface of the soil and there makes a tough cocoon an inch or so long, composed of earth and excrement and lined with silk, and in it transforms to a brown pupa with yellow bands around the abdomen. In about four or five weeks the pupa wriggles half way out of the cocoon and the moth emerges, leaving the empty pupal skin 
projecting above the surface of the ground. The moths emerge in late July and early August in West Virginia and the egge are laid in a few days. Thus the life cycle requires two full years and larvæ of two sizes may be found in the roots at any time, except during the pupal period, when all will be about half to two-thirds grown.

Control.-On account of their subterranean habits it is manifestly impossible to dig out the borers, as is done with similar species except for a few valuable vines. If the Scuppernong is as immune as has been reported, it might be used as a stock throughout the South, where it will thrive. $\mathrm{By}$ recognizing the parent moths, they

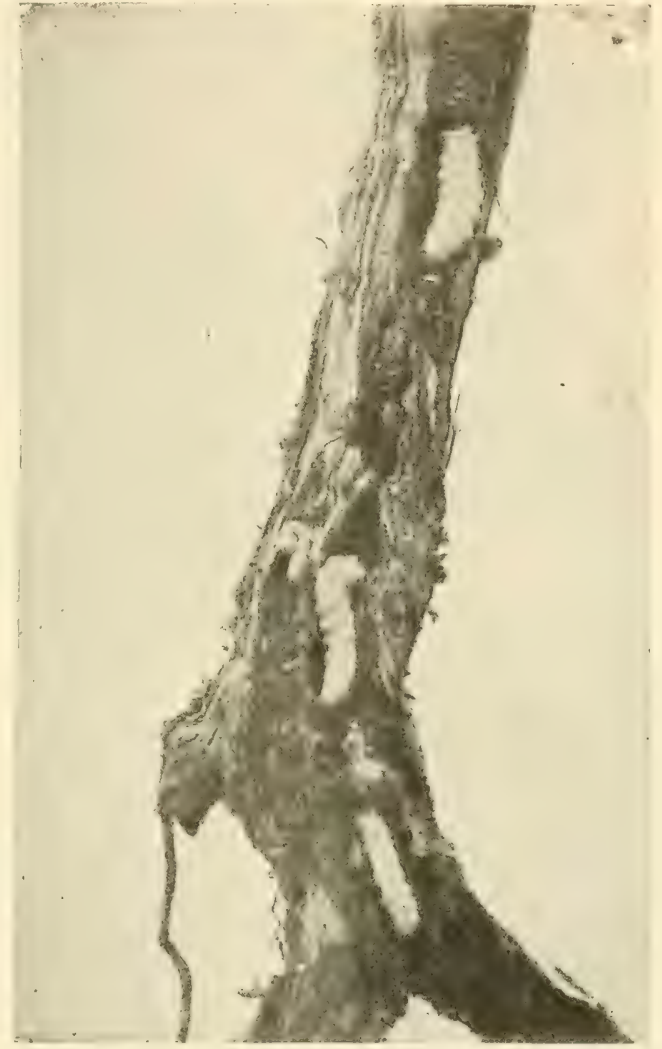

Fir. 368.-Crapevine root-borers at work. Five borers were feeling in this section when taken from the gromel -two-thirds natural size. (Photo by W. E. Rumsey.)

may be destroyed by approaching them quictly when at rest and striking them quickly with a paddle or board and many might thus be killed during the time they are most abundant.

By thorough cultivation in June and July many of the cocoons will be thrown to the surface or buried so decply that many of the pupæ will be destroyed, or the adults will be unable to reach the surface. With liberal fertilization, cultivation will stimulate the vine to withstand the injury. Brooks has shown that in West Virginia the crested flycatcher (Myiarchus crinitus) 

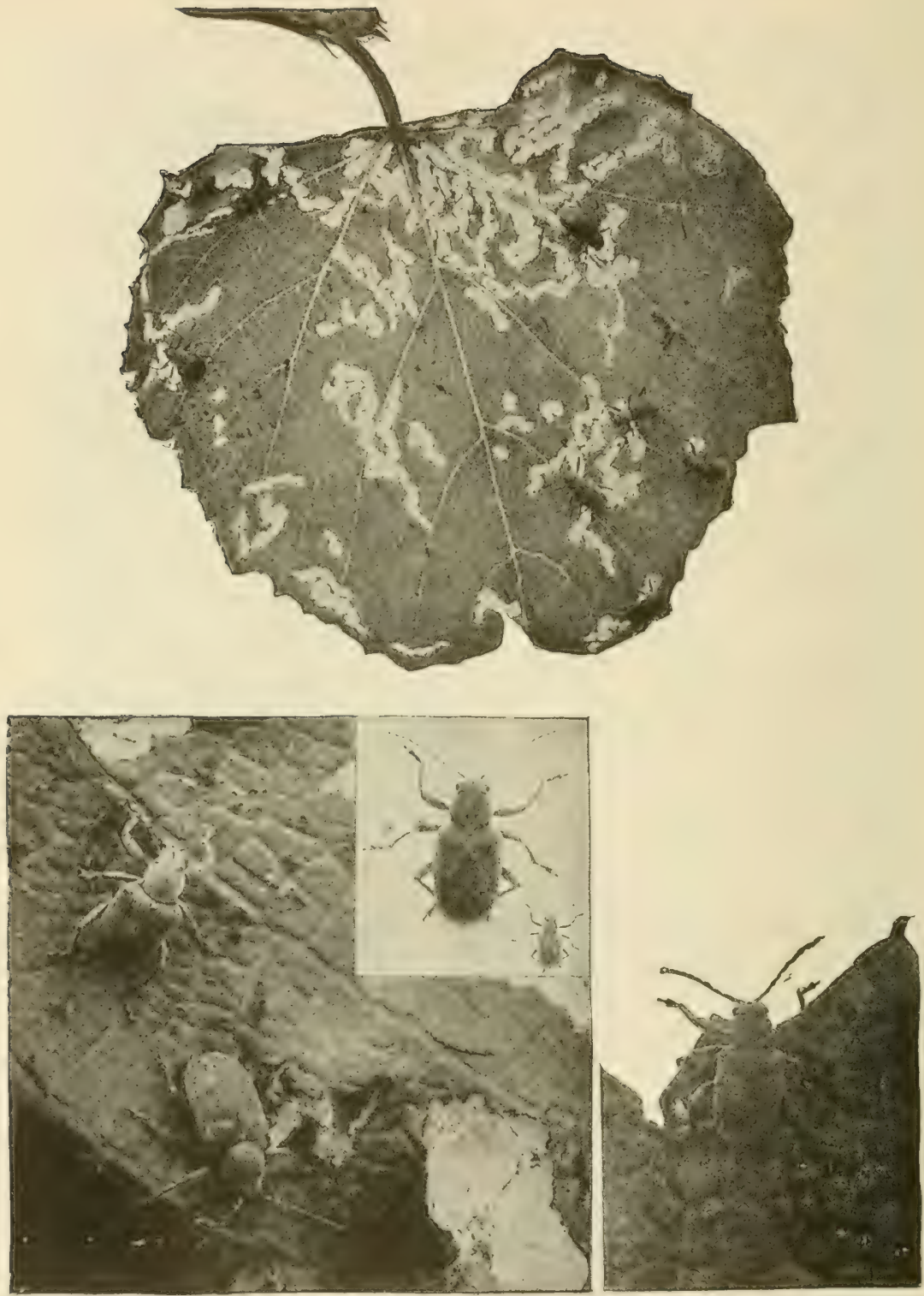

Fia. 369.-Grape root-wworm (Fidia viticida Walsh): beetles feeding on foliage-natural sizc, and enlarged. (After Slingerland.) 
feeds upon the moths and may be a factor in the control of the pest

\section{The Grape Root-worm *}

The Grape Root-worm is the larva of a small, hairy, chestnutbrown beetle which feeds on the upper surfaces of the leaves

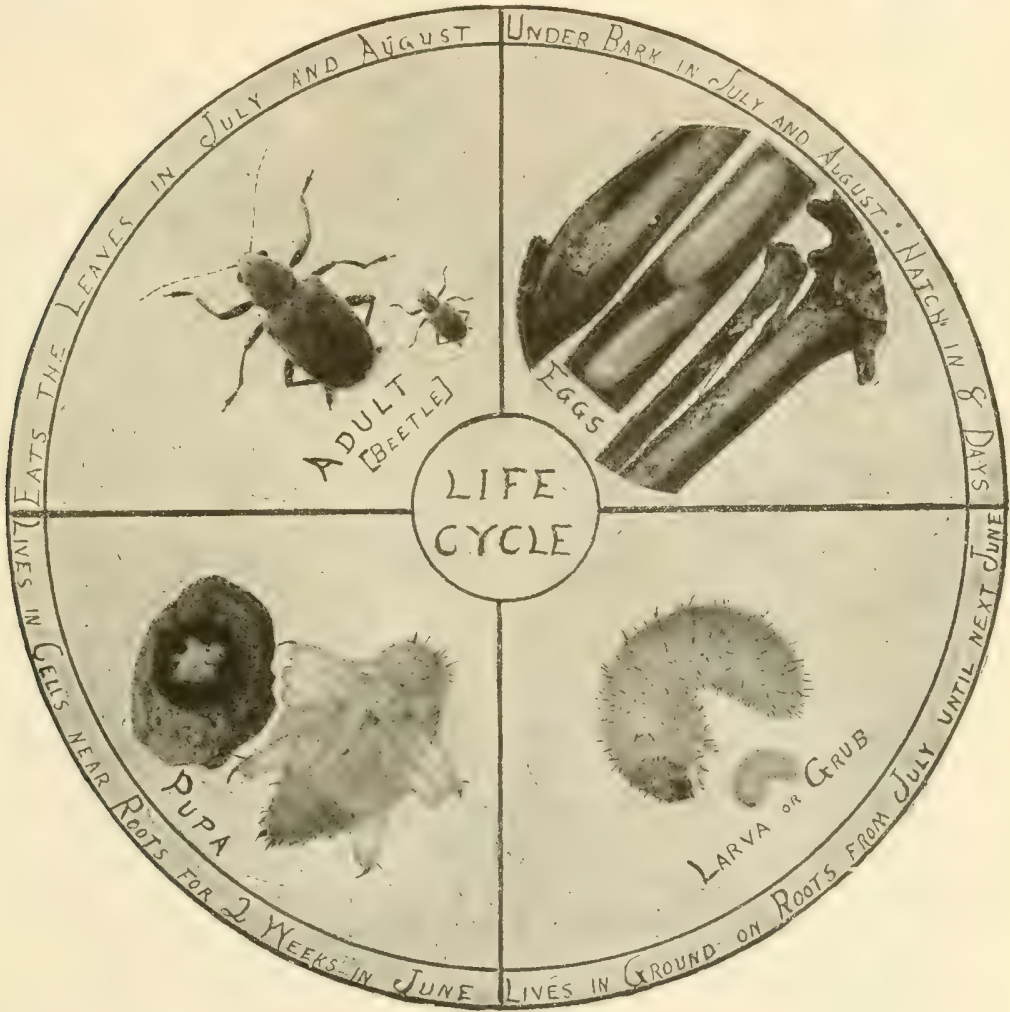

Fig. 370.-The life cycle of the grape root-worm-enlarged and natural size. (After Slingerland.)

eating out series of patches or holes in characteristic chain-like feeding marks which afford an easily recognizable indication of the

* Fidia vitiricia Walsh. Family Chrysomelidee. See Quaintance, l.c.; Hartzell, l.c., and Bulletin 453, N. Y. Agr. Exp. Sta.; M. V. Slingerland, Bulletins 184, 208, 224, and 235, Cornell Univ. Agr. Exp. Sta.; E. P. Felt, Bulletin 19, Office State Ent. of N. Y.; Fred Johnson, Bulletin 68, Part VI, Bureau Entomology, U. S. Dept. Agr.; Johnson and Hammar, Bulletin 89, ibid. 
presence of the pest in the vineyard. The larvie devour the smaller roots and eat out pits and burrows in the larger roots, and where abundant may kill the plants in a year or two, but more commonly they cause an enfeebled growth and a consequent failure to produce profitable crops. Injury has been most severe in the grape belt of western New York, Pennsylvania, and northern Ohio, but the species occurs generally throughout the Mississippi Valley and
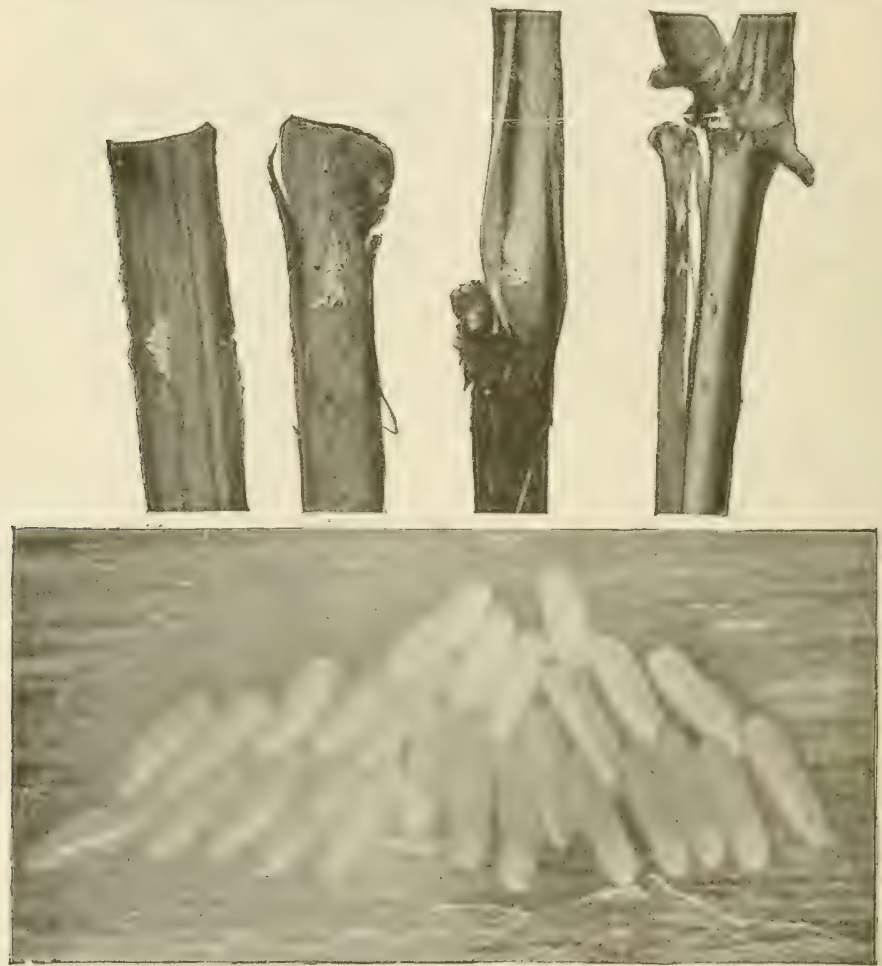

Fia. 371.-Egrgs of the grape ront-worm, natural size as seen on grapr canes above - enlarged below. (After Slingerland.)

the Eastern States, and has been reported from California. "The insect thrives best in vineyards which are neglected, and in the absence of cultivation and timely spraying it is likely to become a serious pest in any vineyard throughout its range of distribution. This is especially the case in light, sandy soils and in regions where grape growing is a considerable industry." A nearly related species, * has been known to injure the foliage seriously

* Fidia cana. 
in Texas, but it is not known whether it affects the roots. In California, the imported grape ront-worm * is sometimes destructive, has practically identical hathits, and is controllerl by the same methods.

The adult beetle is about one-quarter inch long, brownish in color, and covered with grayish-white hairs, with a stout body and long legs, as shown in Fig. 369. The full-grown larva is about five-cighths inch long, whitish in color, and usually rests in a curved position as shown in Fig. 370. The head is slightly

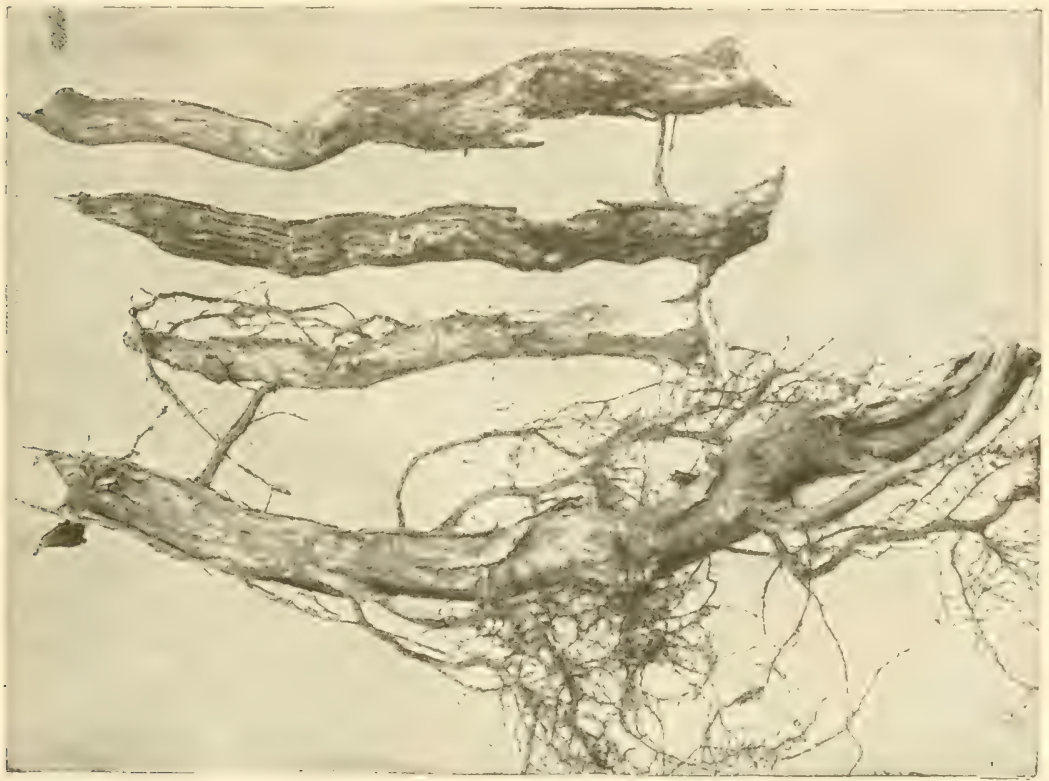

Fig. 372.-Portions of three grane ronts denuded of their hark and fibrous roots by grape root-worms, and part of a similar root taken from a thrifty vine, showing its normal bark and rootlets. Reduced in size. (After Slingerland.)

narrower than the body and yellowish-brown, as are the wellmarked spiracles on the side of each segment.

Life History. - The adult beetles appear about the close of the blooming period, or in late June and early July in the latitude of New York, and live for a month or more. They emerge earlier on warm, light sandy soils, and later on heavier soils. In a few

* Adoxus vitis Fourcroy. A small, shining, brown or black beetle, onefifth inch long. See Quayle, l.c. 
days their feeding commences to be noticed on the leaves and the females may be found laying their eggs. A female will lay from 150 to 900 eggs, averaging about 175, most of which are laid during the first two or three weeks. The eggs are laid in masses of 25 to 40 beneath the old bark or generally over the canes. The individual egg is one-twenty-fifth inch long, at first whitish, but soon turns yellow, and tapers at each end. The eggs hatch in from nine to twelve days, when the young larvæ drop to the ground and seek the roots. The young larvæ are only oneseventeenth inch long, so that they are able to penetrate the soil. When established on the roots they feed freely and grow rapidly,

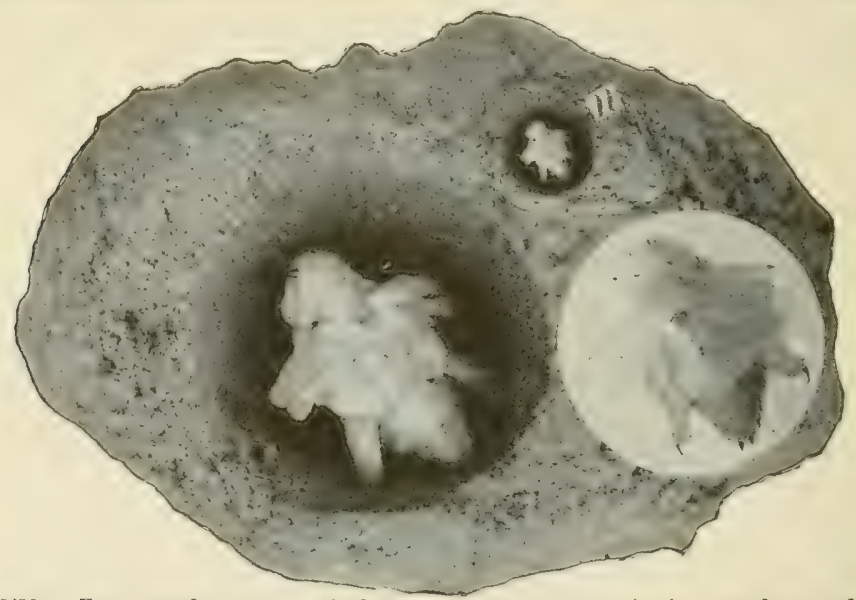

FIG. 373.-The tender pupa of the grape root-worm in its earthen cell, enlarged-natural size at $n$. (After Slingerland.)

becoming nearly full grown by fall. In the fall they descend several inches into the soil and make small earthen cells, in which they hibernate. In the spring they return to the roots nearer the surface, and those not already full grown feed until growth is completed. They then make small earthen cells 2 or 3 inches below the surface of the ground in which they transform to pupæ. These cells are easily broken open and the pupse are thus crushed or killed by stirring the soil in cultivation. The pupa, shown in Fig. 373e, is one-quarter to one-third inch long, whitish, with the head, thorax and tip of the abdomen pinkish, and with spines on the head, appendages, and abdomen as illustrated. The pupæ are most abundant in New York during June, the pupal stage lasting about two weeks. 
Control.-Extensive experiments made by several investigators have shown that the beetles may be very largely destroyed by thorough spraying with arsenate of lead just as they appear. By applying the poison when they are first noticed feeding they may be killed off before many of the eggs are laid, and sprayed vineyards have shown a reduction of over 90 per cent of the eggs found on untreated vines. Arsenate of learl should be applied at the rate of 3 pounds to the barrel as soon as feeding marks are found on the foliage, and again a week or ten days later, and should be added to the Bordeaux mixture used for the diseases of the vine. The spraying must be done with the greatest thoroughness, as the beetles dislike the sprayed foliage and will seek out that which has been missed. The nozzles on traction outfits should therefore be arranged so as to hit all parts of the vines (see Fig. 374) and the pump should maintain at least 100 pounds pressure. With the machines in common use not over 7 or 8 acres a day may be covered thoroughly, and about 125 gallons will be required per acre. If the work is hurried

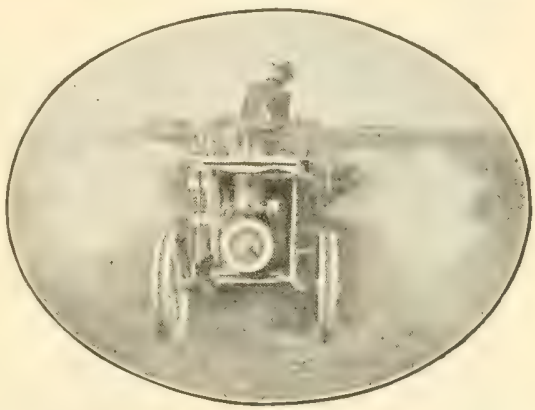

Fig. 374. - A power sprayer with nozzles arranged for grape spraying (The Bean Spray Pump Co.) to cover greater acreage, the treatment will usulally be less effective. When the infestation is unusually severe cheap molasses may be added to the arsenate spray to make it attractive to the beetles.

The beetle is noticeably less destructive in well-cultivated vineyards, and it has been shown that thorough eultivation in early summer breaks up the pupal cells and destroys large numbers of the pupx. Most of the pupae are within 2 or 3 inches of the surface and within $1 \frac{1}{2}$ or 2 feet from the base of the vine. In the fall the earth should be thrown toward the vines to form a ridge along the row, so that the larva will mostly pupate near the surface of this ridge. The next spring, when most of the larvæ have entered the pupal stage, this ridge should be thrown away from the vines, thus exposing the pupse. A "horse-hoe" 
commonly used in vineyards is useful in this work, but a handhoe will need to be used to throw the earth away from the immediate base of the vine. The soil should then be kept well stirred by cultivation at frequent intervals, all of which is merely part of good practice, independent of the control of the root-worm.

\section{The Grapecane Gall-maker *}

The Grapecane Gall-maker is a small reddish-brown snoutbeetle about one-eighth inch long, which lays its eggs in the

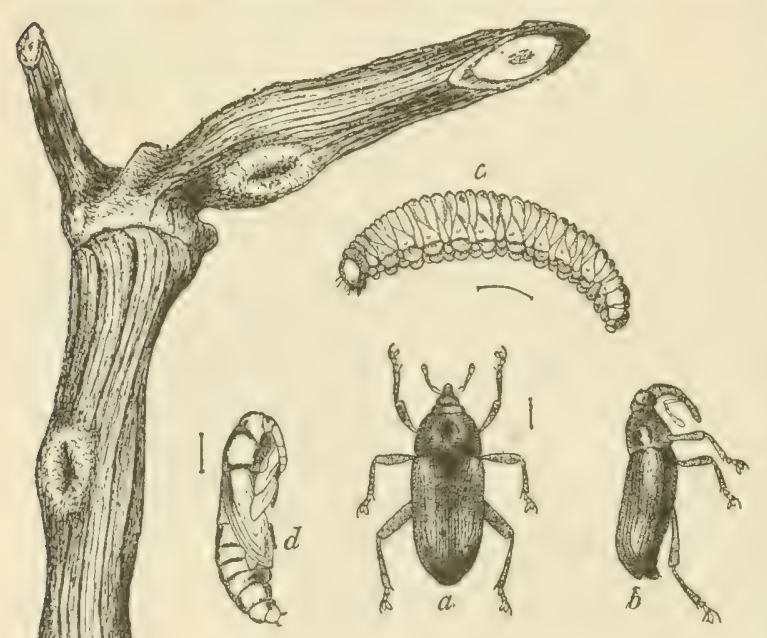
canes, giving rise to $\mathrm{galls}$ about twice the diameter of the cane and 1 or $1 \frac{1}{2}$ inches long; with a deep scar in one side. It has been noted as injurious in Ohio and West Virginia, and from therecords seems to be generally distributed over the Eastern States, but is by no means a serious pest.

Life History.-The adult beetles appear in May and are gone by early July. They feed sparingly on the vine, making little pits in the tendrils, in the buds or bark of new canes or in the midribs on the under side of the leaves. The females soon lay their eggs and make the egg scars. These cause the galls

FIG. 375.-The grilueceme gall-naler ( 1 mpeloglypter sesostris Lec.): a, adult from above; $b$, same, side view; $c$, larva, side view; $d$, pupa; $e$, section of vine showing galls-all enlarged. (After F. M. Webster.) Natural size. (After Brooks.)

* Ampelonlupter sesostris Lee. Family Curculionider. See Fred E. Brooks, Bulletin 119, WV. Va. Agr. Exp. Sta..; F. M Webster, Bulletin 116, Ohio Agr. Exp. Sta. 
and constitute practically the only injury to the vine. The eggs are laid just above a joint and beyond the outermost fruit, so that the injury does not interfere with the crop. A female eats out a small hole with her snout, in it lays a small yellowish-white egg, and fills up the hole with fibers scraped off from the surface of the cane. She then makes another hole immediately above this, but merely places a drop of liquid in it and then fills it up with fibers in the same manner. Eight to a dozen holes are thus made in a row and filled. Very soon this wound causes a swelling of the vine, but the gall does not reach full size for six or eight weeks. On vines producing dark-colored fruit, the wood about the wound takes on a purplish color. The galls seem to have but little effect on the growth and vigor of the vine, except that the canes are more readily broken by the wind or in pruning. The larva is a little yellowish-white, footless grub about two-fifths inch long, which feeds about the egg-chamber and then burrows in the pith. It becomes full grown in eight to ten weeks, when it pupates within the burrow; the bectle emerges in late August, and hibernates over winter.

As the scar in the side of the gall where the eggs were deposited remains open, a very large proportion of the larvæ are subsequently parasitized by various chalcis, and tachina-flies, which will probably prevent the insect ever becoming much of a pest.

Control.-The galls may be cut out and burned during July or August without any injury to the crop, as they occur beyond the fruit, and at that time will contain the larva or pupæ. As the beetles feed on the foliage and new growth it is probable that but little damage will result in vineyards well sprayed with arsenicals for other pests.

\section{The Grapecane Girdler*}

This beetle is very similar to the last except that it is black in color. Its native food-plant is the Virginia creeper, which it has deserted in West Tirginia, and occasionally elsewhere, to attack grape. The species seems to oceur generally through the Central and Eastern States.

* Ampeloglypter ater Lece Family Curculionide. See Fred E. Brooks, Bulletin 119, W. Va. Agr. Exp. Sta. 
Life History.-The life history is almost identical with that of the preceding species, the habit of the species differing only in the manner of oviposition. The eggs are laid in late May and early June. In laying the egg, the female deposits it in the same manner as does the previous species, and then instead of placing a series of holes in a row she makes them in a ring around the cane, only the first one containing an egg. She then goes to the next joint above and makes a series of holes around it, completely severing it, so that it hangs by a shred and soon drops. The little larva feeds in the pith of the joints on either side of the egg puncture, and these two joints die and drop to the ground. The larva becomes full grown in about a month and changes to
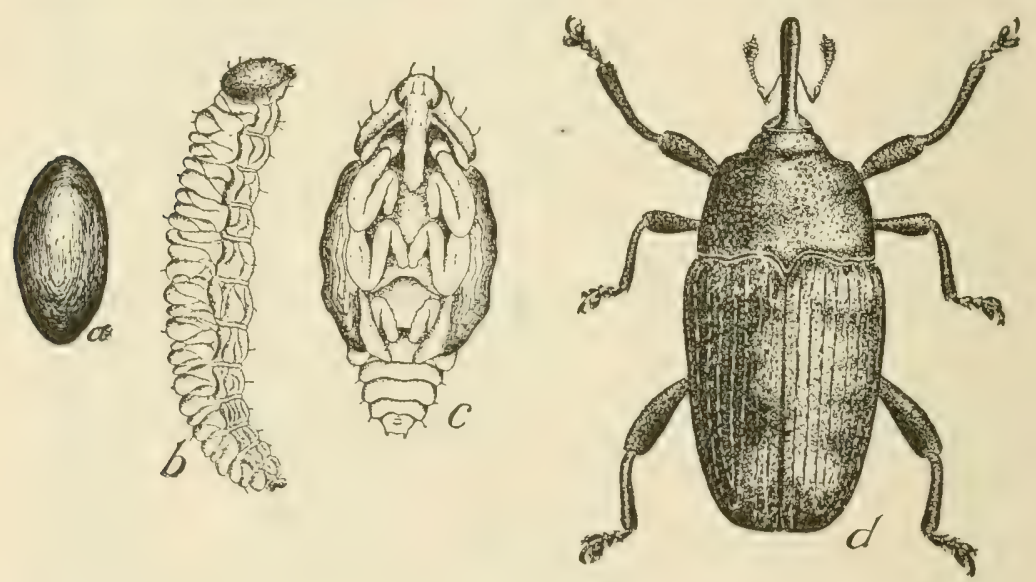

FIG. 376.-The grapecane girdler (Ampeloglypter ater Lec.): $a$, egg; $b$, larva; $c$, pupa; $d$, beetle-all enlarged. (After Brooks.)

a pupa in its burrows soon after the dead section drops, first filling the burrow with little pellets of fibres. Two weeks later the adult beetle emerges, appearing during late summer. The whole life cycle thus requires sixty-five to seventy days. The beetles hibernate over winter.

Control.-The injured canes are quite conspicuous in early summer and by cutting them off a few inches below the egg sears the eggs and larvæ may be removed and destroyed. Brooks is of the opinion that the beetles will be largely destroyed in vineyards thoroughly sprayed with arsenicals for other grape insects. 


\section{The Grape Cane-borer *}

During the spring young grape shoots sometimes suddenly
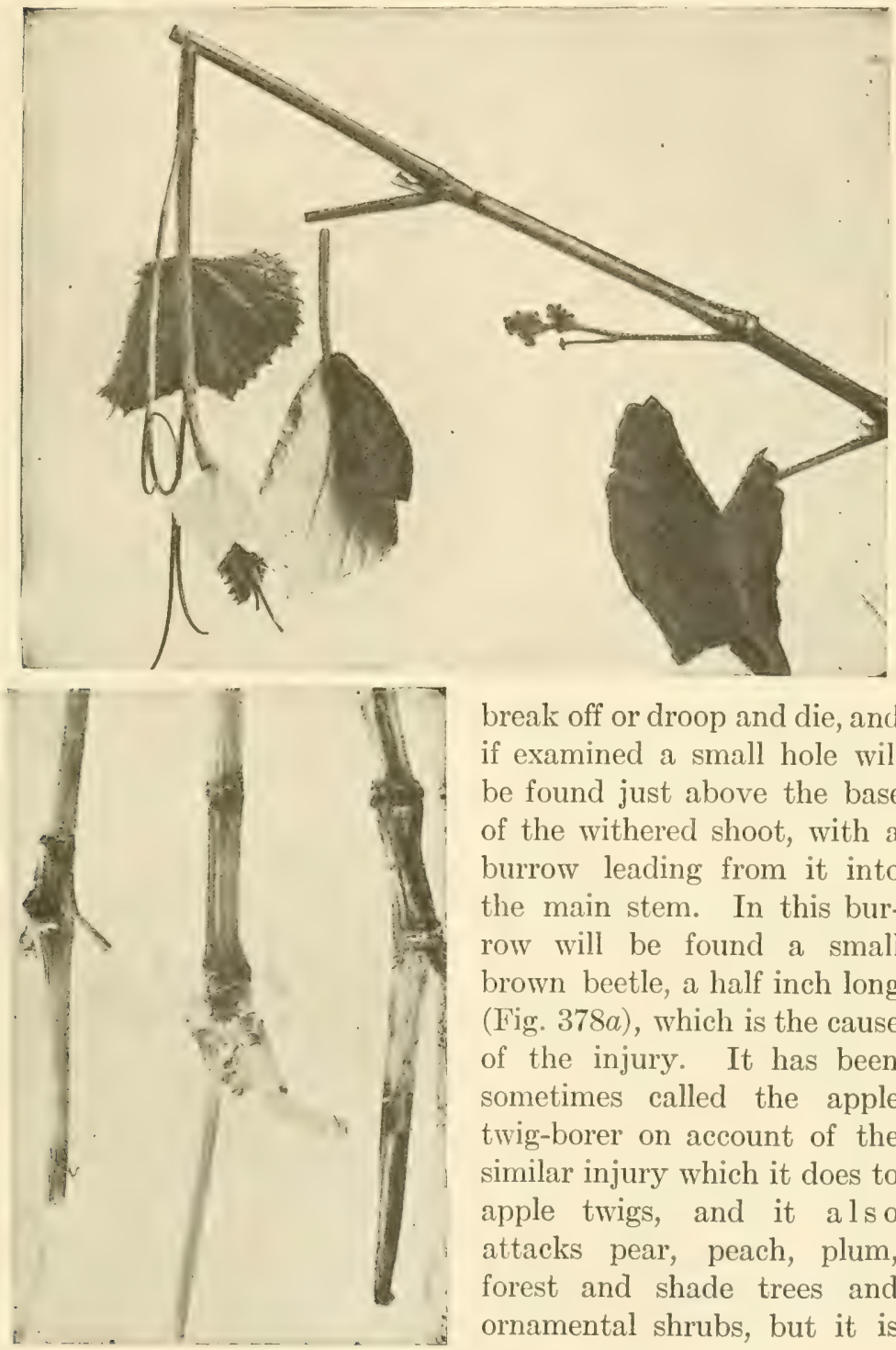

break off or droop and die, and if examined a small hole will be found just above the base of the withered shoot, with a burrow leading from it into the main stem. In this burrow will be found a small brown beetle, a half inch long (Fig. 378a), which is the cause of the injury. It has been sometimes called the apple twig-borer on account of the similar injury which it does to apple twigs, and it also attacks pear, peach, plum, forest and shade trees and ornamental shrubs, but it is

Fic. 377.-Work of the grapecane girdler. (After Brooks.)

* Amphicerus bicaudatus Say. Family Ptinide. See C. L. Marlatt, Farmers' Bulletin 70, U. S. Dept. Agr. 
particularly destructive to the grape. Its injury is most noticed in winter and early spring, and frequently results in lilling all the new growth and sometimes the entire vine. Injury has been most severe in the states bordering the Mississippi from Iowa southward, where it is one of the most scrious insect pests of the vine, and though the beetle occur's eastward to the coast it rarely does much damage farther east.

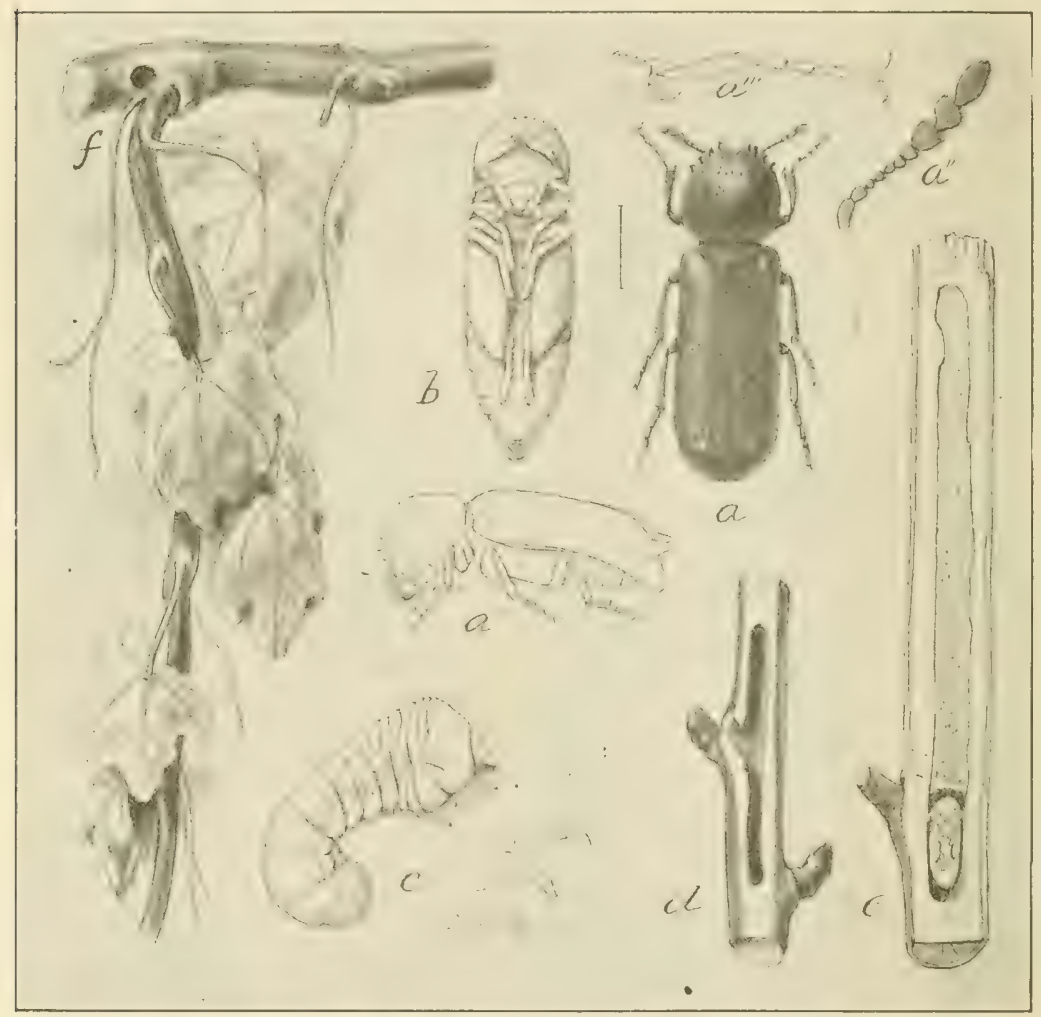

Frg. 378.-The arape "ane-borer (Amphicerus bicautatus Say): $a$, beetle, back and side views; $b$, pupa; $c$, larva, with feet enlarged; $d$, burrow in apple twig made by adult; e, larval gallery in tamarisk, with pupa in cell at end; $f$, injury to young shoots and eane showing entrance of beetle near $f$, and the characteristic wilting and new growth-all much enlarged except $d, e, f$. (After Marlatt, U. S. Dept. Agr.)

"It breeds in dying wood, such as large prunings, diseased canes, and also in dying or drying wood of most shade and fruit trees. It has also been found by the writer [Marlatt] breeding 
very abundantly in roots of uprooted maples and in diseased tamarisk stems. In old, dry wood it will not brecel, so far as known, nor in vigorous live growth, but seems to need the dying and partially drying conditions mentioned. The insect has but one brood yearly. The bectles mature for the most part in the fall, and generally remain in their larval burrows until the following spring. A few may leave the burrows in the fall and construct others in the twigs of apple or other plants in which to hibernate. In the spring, however, they begin their destructive work early, burrowing into the axils of the grape and occasionally also into other plants. This is undoubtedly partly for food, but seems largely malicious, for it certainly has nothing to do with egg-laying. . . . The eggs are laid chicfly in May or April in its southern range, and the larva develop during summer, transforming to beetles and pupe in the fall. On the Pacific coast a closely allied, but somewhat larger species (Amphicerus punctipennis Lec.) . . probably has similar ... habits . .."

Control-All diseased wood and prunings should be removed in late spring, thus destroying the material in which the larvæ develop. If this is neglected and the beetles appear in the vineyard, the only means of stopping their depredations is to cut out by hand the affected parts and destroy the beetles. On warm days the beetles may sometimes be collected while running over the vines.

\section{The Grapevine Flea-beetle *}

When the grape buds are swollen in the spring they are often attacked by numbers of little blue or greenish beetles which eat out or entirely consume them. When abundant these little beetles may destroy all the buds on a vine, thus greatly retarding the leafing out or even occasionally killing the plant. The beetle is about one-fifth inch long, of robust shape, and possesses the thick thighs characteristic of flea-beetles, which enable it to jump a considerable distance when disturbed. It is common throughout the States east of the 100th meridian and nearly related species do similar damage on the Pacific Coast. (See Quayle, 1.c.) The wild grape is undoubtedly the natural food-plant of

* Haltica chalybea Ill. Fanily Chrysomelida. See Quaintance, 1.c.; Ifartzell, l.e.; and M. V. Slingerland, Bulletin 157, Cornell Ĺniv. Agr. Exp. Sta. 
the species, though it is occasionally found on plum, apple, pear, quince, blue beech and elm.

Life History.-After feeding a few days the female beetles commence to lay their eggs in cracks of the bark at the base of the buds, or in any crevice or in the cavity eaten out of the bud by the beetle, or sometimes on the foliage. The eggs are a long oval shape, one-fortieth inch long, and of a dark straw-yellow color. The eggs hatch just as the young leaves are expanding,

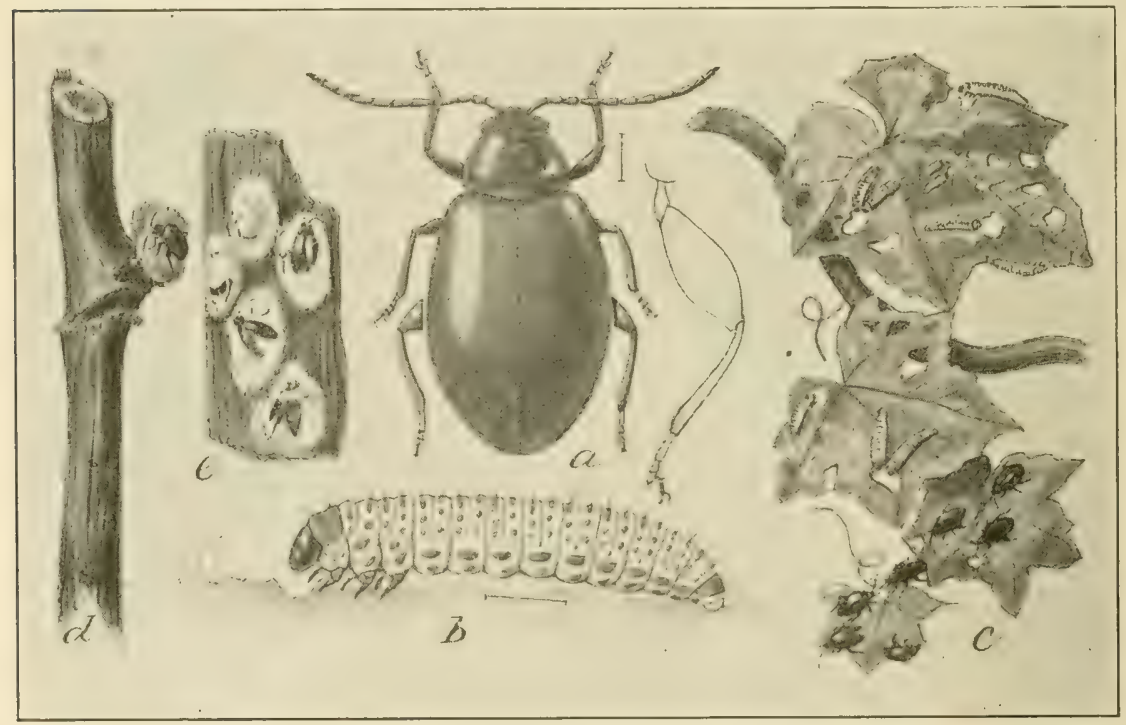

FIG. 379.-The grapevine flea-beetle (IIaltica chalylica Ill.): $a$, adult with hind leg at right further enlarged; $b$, larva, much enlarged; $c$, beetles and larve on foliage-natural size; $d$, heetle feeding on bud; $e$, diseased beetles. (After Marlatt, U. S. Dept. Agr.)

and upon them the young larva feed greedily. The larvæ feed on the upper surface of the leaf, eating out irregular holes through the skin and into the soft tissue, and become full grown in three or four weeks. The young larvæ are a very dark brown, but when grown they are one-third inch long and a dark yellowishbrown, marked by regular rows of blackish tubercles each of which bears a small hair. The head, anal and prothoracic plates and legs are black. The full-grown larva drops to the ground and an inch or two beneath the surface makes a small cell in which 
it transforms to a -white pupa, from which the adult beetle emerges in one or two weeks. In New York there is but a single generation, but more than one generation may occur in the South. Upon emerging the beetles feed on the grape and other plants, doing no particular damage, and enter hibernation in the fall.

Control.-Where vineyards are regularly sprayed with arsenicals there will be but little trouble with the flea-beetles, as the grubs are very easily destroyed on the foliage. In neglected vineyards the beetles often become very abundant and may be

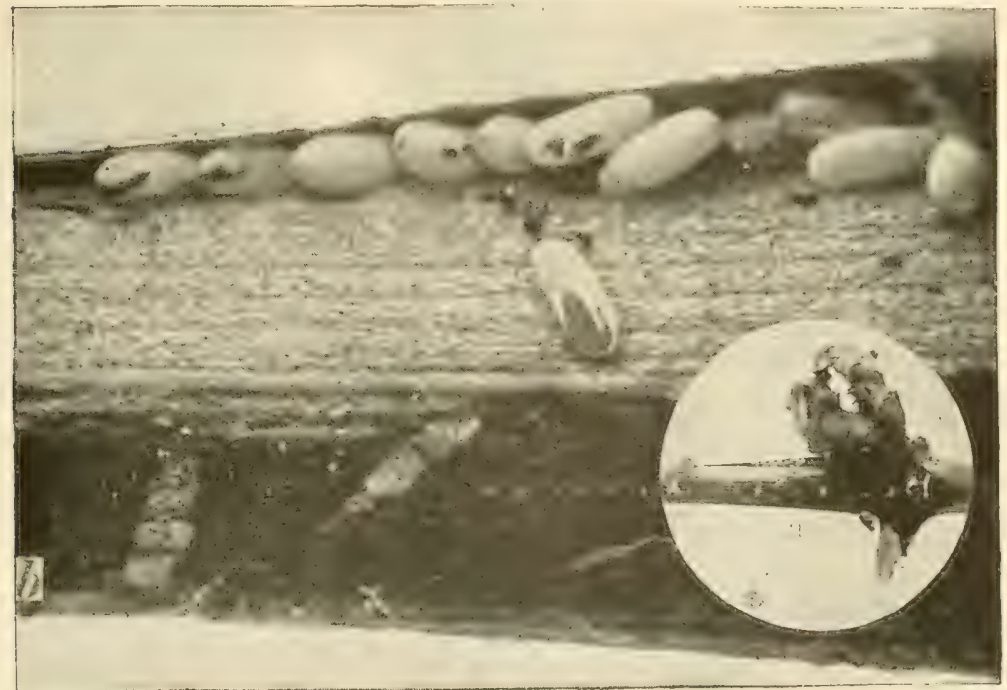

FIg. 380.-Eggs of the grapevine flea-beetle, natural size at $a$, and enlarged at $b$. (After Slingerland.)

quite destructive in such localities. Where it is necessary to combat the beetles to prevent injury to the buds, close watch should be kept for them and the buds should be thoroughly sprayed at once, using 4 pounds of arsenate of lead per barrel. Usually this will need to be applied just as the buds are becoming well swollen, and must be applied promptly and thoroughly, as the beetles work quickly and a day's delay may mean the destruction of the buds. In a small vineyard or on a few vines the beetles may be collected by hand in the early morning when they are sluggish, or may be jarred to canvas-covered frames kept saturated with kerosene placed beneath the vines. 


\section{The Rose-chafer *}

About the time the grape is in bloom, immense swarms of the common Rose-chafers or Rose-bugs often appear, covering the plants, feeding on the blossoms, later attacking the young fruit and foliage, and sometimes eating the leaves quite bare except the larger veins. The chief damage, however, is done by destroying the blossoms or newly set fruit, or by so injuring the young berries that they are misshapen and worthless The beetle is

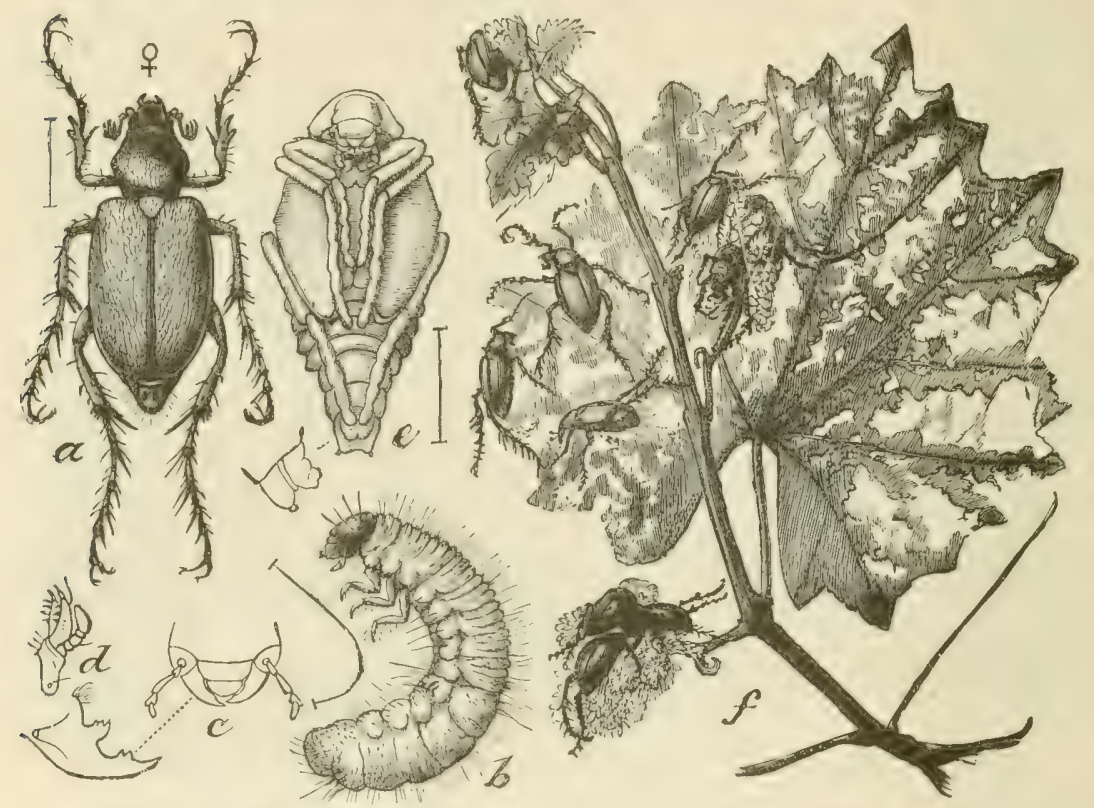

Fra. 381.-The rose chafer (Macrodactylus subspinosus Fab.): $a$, beetle; $b$, larva; $c, d$, mouth-parts of same; $e$, pupa-all much enlarged; $f$, heetles at work on foliage-natural size. (After Marlat.t, U. S. Dept. Agr.)

about one-third inch long, of a light-brownish color, covered with numerous lighter hairs, and has very long spiny legs, which always seem to be in its way and make it most awkward and clumsy. It is a very general feeder, being common on roses, from which the common name is received, and also on such orna-

* Macrodactylus subspinosus Fab. Fanily Scarabridr. See Quaintance, 1.c.; Hartzell, 1.c.; J. B. Smith, Bulletin \$2, N. J. Agr. Exp. Sta.; Fred Johnson, Bulletin 97, Part III, Bureau of Entomology, U. S. Dept. Agr.; and F. H Chittenden, Farmers' Bulletin 721, U S. Dept. Agr. 
mentals as Spiraca and Deutzia, while it frequently injures the blossoms of apple, plums, cherries and peaches, and when very abundant will attack various vegetables, grasses, and grains. The species occurs commonly from Canada to Virginia and Tennessee and westward to Colorado, and in Texas and Oklahoma, but seems to do but little damage west of the Mississippi, being most injurious in the Middle States. It is particularly destructive where there are areas of light sandy soil grown up in grasses and weeds, upon the roots of which the larva feed.

Life History.-After feeding three or four weeks the beetles suddenly disappear. During the middle of June, in New Jersey, the females lay from 12 to 20 eggs, depositing them in the soil singly. These hatch in two to three weeks and the larvæ feed on the roots of various grasses and possibly weeds and other vegetation. They become nearly full grown by fall, when they go below the frost line and hibernate over winter. The larva looks very much like a small white grub, which it closely resembles in every way, and is about three-quarters inch long when full grown (Fig. 381, b). In the spring the grubs come near the surface of the soil and enter the pupa stage, which lasts from ten to thirty days according to the temperature. There is but one generation a year, and the injury is done by the beetles during the three or four weeks they are abroad.

Control.-When the beetles are very abundant the only satisfactory method of control is to pick them by hand or jar them from the vines onto frames from which they may be collected. In jarring, an umbrella-shaped frame covered with canvas or, preferably, oilcloth, which slopes to a can of kerosene at the bottom, is often used, being somewhat similar to that used for the plum curculio. This is held under the vines and they are sharply jarred or shaken, when the beetles will drop to the frame particularly in early morning. Handpicking into a can of kerosene and water is probably the most common method, however. Where the beetles are not excessively abundant they have been controlled in some cases by thorough spraying with arsenate of lead, 5 to 10 pounds per barrel, preferably applied with Bordeaux mixture, and recent experiments of the N. Y. Agricultural Experiment Station with 5 pounds of arsenate of lead and 12 pounds of glucose per barrel gave excellent results. The num- 
bers of the pest may also be much reduced by keeping down the grass and weeds in the vineyard, and particularly on light sandy soils adjoining lands should be broken up and cultivated in annual crops as far as possible, thus reducing the breeding grounds of the pest. By bagging the grapes as soon as the fruit is set the clusters may be protected from this as well as other pests and diseases wherever such treatment is practicable.

All recent work seems to indicate that the treatment with arsenate of lead and molasses is the best means of control. The spray should be applied before the beetles appear in large numbers and it may be necessary to repeat it once or twice.

Self-boiled lime-sulphur has been said (Headlee) to act as a repellant, but there is need for more experimental work before this can be generally established.

\section{The Grape Leaf-hopper *}

Wherever the grape is grown in the United States and Canada, the foliage will be found more or less infested with the small Leaf-hoppers, often locally called "thrips," which feed and breed on the under surface of the leaves during the season. By late summer the vines may be covered with the hoppers, which will fly off in clouds when disturbed, and every year there is serious injury in various localities. The injury is done by the little hoppers sucking out the juices of the leaves through their tubelike mouth-parts. A small white spot first appears around the feeding puncture, due to the loss of chlorophyll in the leaf, and when the punctures have become numerous the leaf has a varicgated appearance. As the injury increases the leaf yellows and finally dries up and falls to the ground. Where it becomes general, this injury reduces both the quantity and quality of the fruit. The pest is an insidious one, as it is not usually noticed until it becomes very abundant in late summer, by which time most of the injury has been done and it is too late to prevent it. For this reason its control has been very generally neglected by grape growers with a consequent loss the cause of which is often unsuspected.

* Typhlocyba comes Say. Family Jassida. See Quaintance, I.c.; Hartzell, 1.c., and Bulletin 359, N. Y. Agr. Expt. Sta.; Quayle, l.c.; and M. V. Slingerland, Bulletin 215, Cornell Uriv. Agr. Exp. Sta., and Fred Johnson, Bulletin 19, U. S. Dept. Agr. 
The adult hoppers are about one-eighth inch long and the wings are prettily marked with yellow and red as shown in Fig. 382. "In summer the young and adult insects are light yellowish in color, but before going into hibernation, the eyes of the adults darken and the peculiar yellow spots on the wings change to an orange red, thus giving the hibernating adults a general reddish appearance. These darker markings on the adults vary so much that nine different varieties are now recognized, two of which are represented at $b$ and $c$, in Fig. 382. Often several

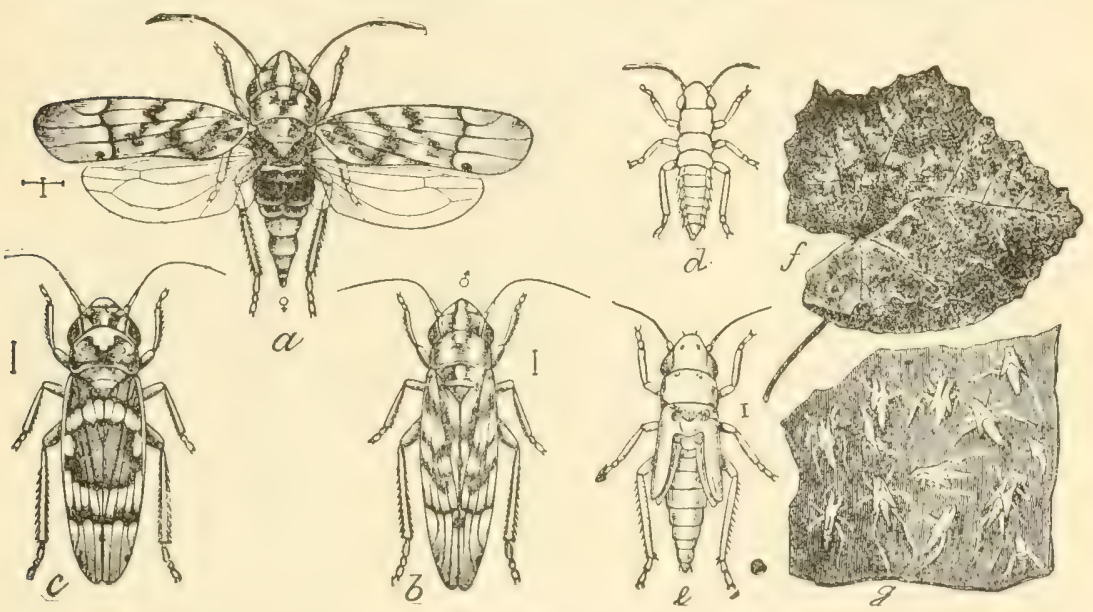

Fig. 382.-Grape leaf-hopper (Typhlocyba comes): a, adult female; $b$, adult male; $c$, another form of the species, showing variation in markings; $d$, newly-hatched nymph; $\epsilon$, last stage nymph; $f$, appearance of injured leaf; $g$, cast pupa skins- $a, \epsilon$, much enlarged; $g$, less enlarged; $f$, reduced. (From Marlatt, U. S. Dept. Agr )

of the varieties may be found together on the same vines, but usually one color form largely predominates." The nymphs are a light yellowish-green color with lemon-yellow stripes on each side of the body. They pass through five molts before becoming adults, the wing-pads gradually getting larger in the later stages. No very similar insects are common on the grape, so that the pest is readily recognized.

Life History.-The adult hoppers hibernate over winter under leaves, grass, or trash in or near the vineyard, in neighboring woods, along ditches or fenees, ete. They emerge about May 1 in New York and at first feerl on whatever suceulent foliage may be available. By the time tie grape foliage appears they have 
mostly emerged and infest the vineyards. These hibernating hoppers feed and breed on the lower leaves, disappearing about the time the first young become adult. After a few weeks the females commence egg-laying, which continues for about two months. The eggs are laid just beneath the surface of the leaf in groups of from six to nine, or singly, and as they are but onethirty-fifth inch long and almost transparent, they are scarcely visible save for the eyes of the embryonic nymphs. The eggs hatch in nine to fourteen days. The young nymphs feed like the adults, at first on the lower leaves, but soor spread to all parts of the plant. In New York they hecome grown in thirty to thirty-five days, and there is but one full generation a year, with a partial second generation, most of the individuals of which probably do not mature before frost. Feeding continues until cool weather, when the adults enter hibernation. In Colorado, New Mexico and California and probably throughout the South, there are two full generations a year. In California, according to Quayle, the nymphs from eggs laid by the hibernating hoppers appear by the middle of May and the following generation of nymphs about the middle of July.

Control.-Cleaning up all fallen leaves and trash in the vineyard during the winter, or plowing it under in the early spring, will reduce the number of hibernating hoppers, and it has been observed that they are much less numerous in vineyards where clean culture is practiced. The burning over of adjacent meadows, wood lots and fence rows will also be advisable where practicable.

In California, where the vines are not trellised, a hopper-cage, which has been fully described by Quayle, l.c., is successfully used for cutching the hopper's before they commence to oviposit in the spring. In the East this could not be used, but Professor Slingerland has shown that the hibernated hoppers may be eaught on sticky shields before they oviposit.

However, it has been found that such methods of capturing and destroying the adults are expensive and give at best only partial relief from the trouble. It has been found a much better practice to kill the nymphs. This is done very efficiently by spraying them with "Black-leaf 40 " at the rate of 1 to 1500 , applying the spray at the time the nymphs are present in the 
greatest numbers on the under side of the grape leaves. If this is properly done, one application will give control. The time for spraying, in the Northern States, will generally be during the latter half of July.

\section{The Grape Leaf-folder *}

Very frequently grape leaves are found folded or rolled together, with the interior surface more or less skeletonized,

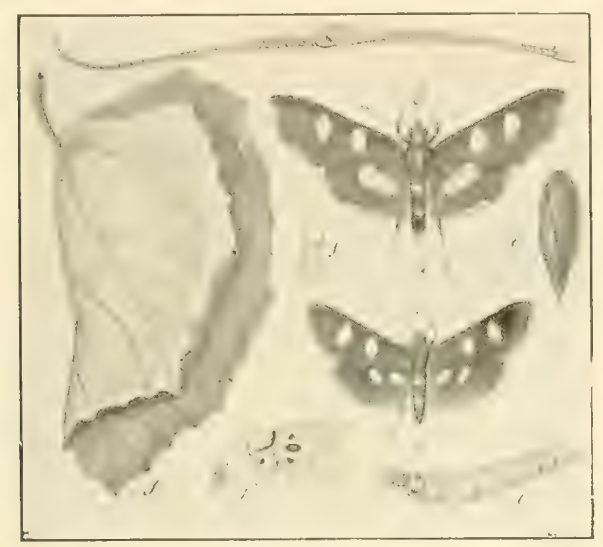

FIG. 383.-The grape leaf-folder (Desmia fun cralis Hübn. $): a$, male moth and enlarged antenna of same; $b$, female moth; $c$, larva; $d$, head and thoracic segments of same enlarged; $c$, pupa; $f$, tip of pupa-enlarged; $g$, grape leaf folded by larva. (After Marlatt, U.S. Dept $\Lambda \mathrm{gr}$.)

from which a slender larva will wriggle out and fall or hang suspended on a silken thread. The Grape Leaf-folder occurs throughout the United States, and though usually not injurious, sometimes becomes abundant enough to do serious damage. The moth is black with white spots on the wings, and bands across the abdomen, as shown in Fig. 383. The larva is about an inch long, of

a greenish-white color, with head and prothoracic shield light brown, and with brown spots on the sides of the first two thoracic segments.

Life History. - "There are two broods each year in the more Northern States and three or possibly more in the South. The insect winters in the pupal stage in the folded and fallen leaves, the moths appearing in the spring shortly after the foliage puts out, and the eggs are placed in small patches here and there on the vine. Upon hatching, the young larva attack the foliage, folding the leaves as stated. Mr. Johnson has observed that the larva of the first brood may attack bunches of grape blossoms and young fruit in a way similar to the grape-berry moth In

* Desmia funeralis Hübner. Family Pyralidar. See Quaintance, and Quayle, l. c., also J. F. Strauss, Bulletin 419, U. S. Dept. Agr. 
three or four weeks the larvæ are full grown and transform to pupæ within the folded leaves, moths emerging eight or ten days later. By midsummer and fall the insects become quite abundant, and in badly infested vineyards the folded leaves are everywhere in evidence and are quite conspicuous from the color of the lower surface. In the fall the larvæ pupate in the folded leaves and pass the winter in these on the ground."-Quaintance.

Control.- Where but a few larvæ occur they may be crushed

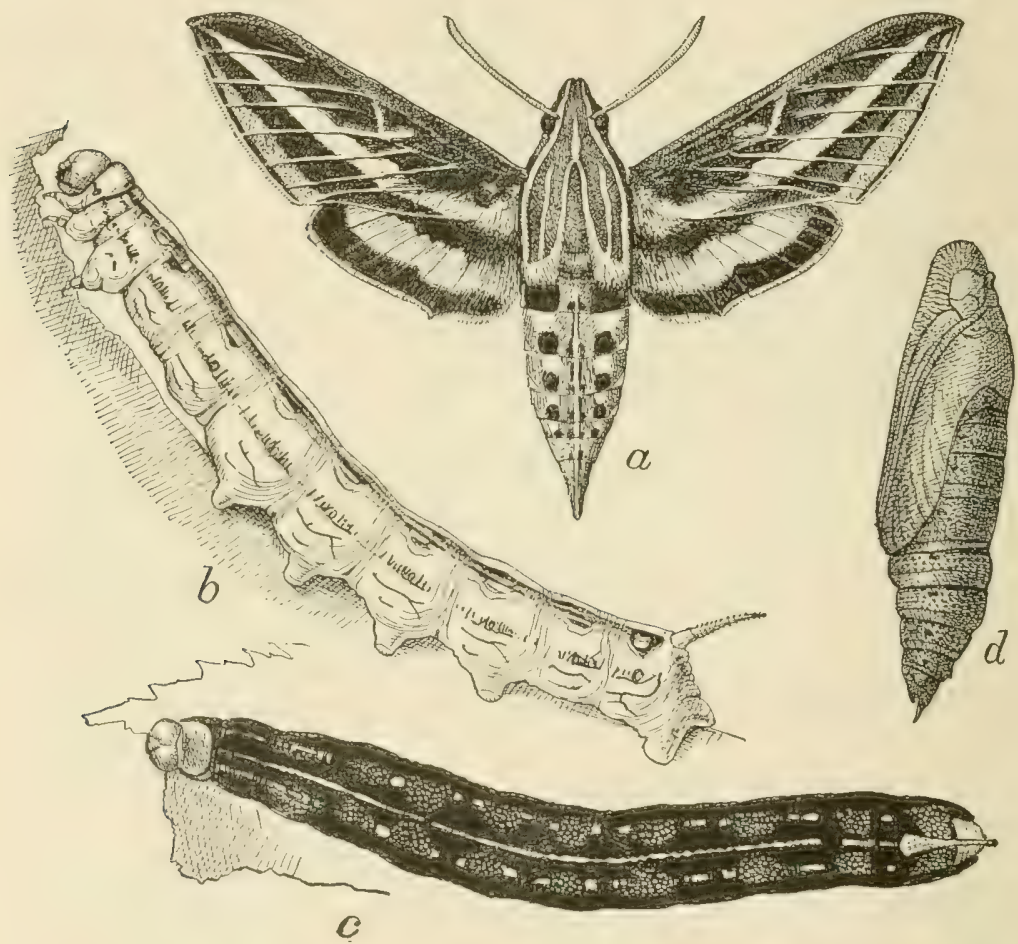

Nig 384.-The white-lined sphix Deilephila lnicata Fab.): $a$, moth $b$, pale larva; $c$, dark form of larva; $d$ pupa-all natural size. (After Chittenden, U.S. Dept. Agr.)

by hand, and if this is done with the first brood it will greatly reduce the numbers later in the season. Vineyards sprayed with arsenicals will be protected, as the young larvæ will be killed before they fold the leaves. By collecting and burning the fallen leaves or plowing them under deeply, many of the hibernating pupæ may be destroyed. 


\section{Hawk-moth Larvæ*}

Several species of Hawk-moth or Sphinx-moth larvæ are commonly found on the vine. Most of them are widely distributed throughout the country and feed on wild grape and Virginia creeper. Usually they are not numerous enough to do serious

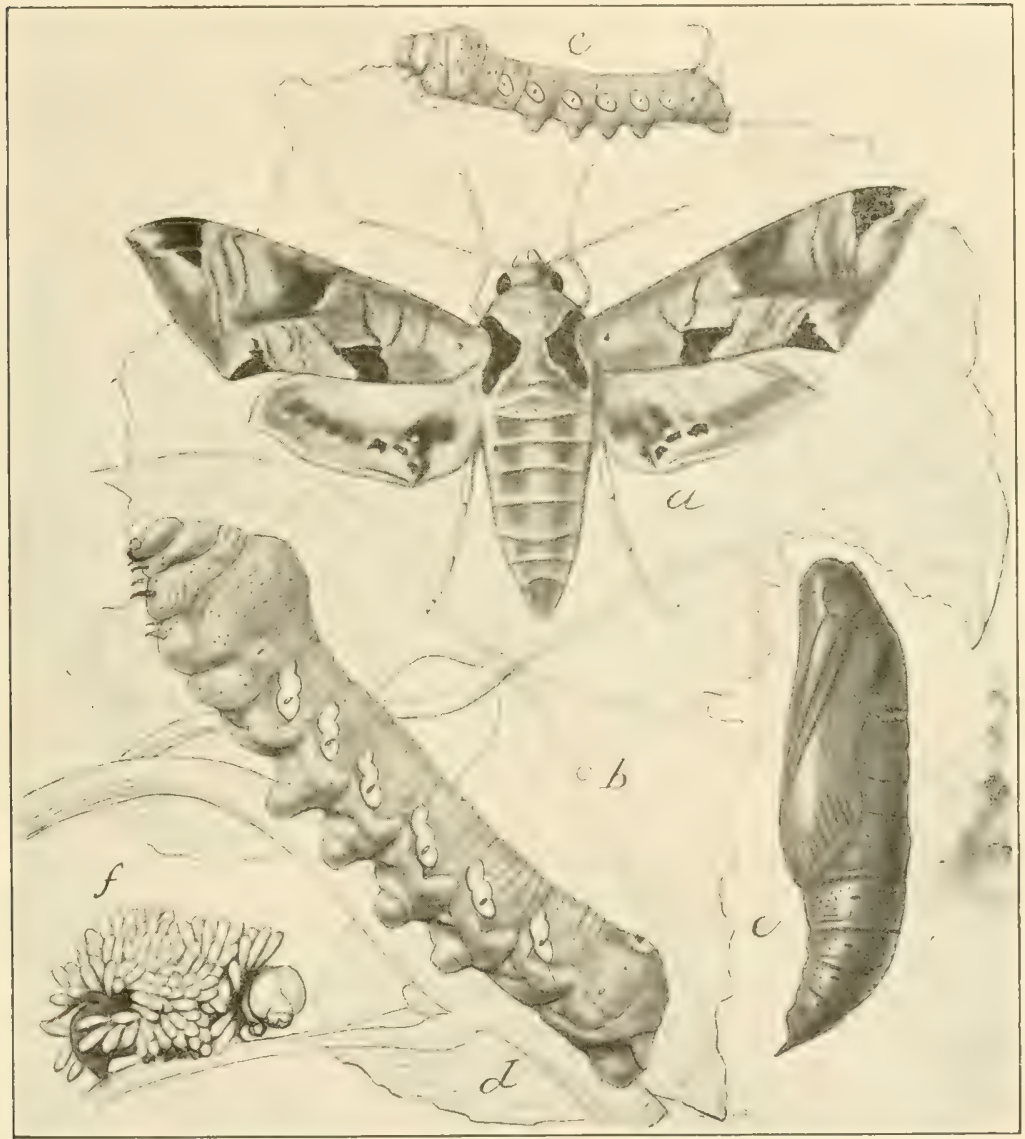

Fig. 385. - The achemon sphinx (Pholus achemon Dru.): $a$, moth; $b$, egg; $c$, young larva; $d$, mature larva; $e$, pupa; $f$, parasitized larva-all natural size. (After Marlatt, U. S. Dept. Agr.)

damage, and as they strip a branch at a time, they are readily seen and may be destroyed before much injury is done. Occasionally,

* Family Sphingider. See O. Lugger, 4th Report State Ent. Minn.; Iad M. Eliot and Caroline MI. Soule, "Caterpillitrs and their Moths." (N. Y., 1902). 
however, one or two larvæ may entirely strip a young vine, and exceptionally the larva appear in considerable numbers on old vines, stripping them bare of foliage. They are large, smoothbodied larvæ, 2 to 3 inches long, and may be distinguished from those of other families of moths by the strong horn on the next to the last segment, which has given them the common name of horn-worms. In many species, this horn is present only in the first one or two stages of the larva, disappearing with the next molt and being replaced by a bright eye-spot, as shown in Fig. 385, $c, d$. The life history of the various species is much the same, except that some have only one, while others have two generations a year in the North, though most all probably have two generations in the South. They hibernate as large dark-brown pupæ, 3 or 4 inches below the surface of the ground, and the moths emerge in spring. The moths are particularly attracted to petunias, and may often be caught hovering over them at night. The eggs are laid on the foliage, usually singly, and the larva hatch in a few days. They eat ravenously, and will consume an enormous number of leaves within a few days. Usually the coloration of the larvæ changes more or less as they grow, so that when full grown they are different from the younger stages. When there are two generations, the second generation of larvæ will appear in late July, but whether one or two generations occur, the larve maturing in late summer transform to pupx which hibernate.

Control.-Usually the work of the larvæ is so conspicuous and they are so easily found that they may be controlled by handpicking. Where the vineyards are sprayed regularly for other pests there will be but little trouble with these larvæ, as they will be killed while young.

\section{The Grape-berry Moth *}

The larvæ of the Grape-berry Moth are the most common cause of wormy grapes. 'The first generation of larva web together the grape clusters before the blossoms open or soon after the grapes are set, and feed upon the clusters. Later the larvæ bore into the green and ripening fruit, producing purplish spots

* Polychrosis viteana Clem. Family Tortricidce. See Quaintance, 1.c.; Hartzell, l.c.,; M. V. Slingerland, Bulletin 223, Cornell Univ. Agr. Exp. Sta.; Gossard and Houser, Circular 63, Ohio Agr. Exp. Sta. Dwight Isely, Bulletin 550, U. S. Dept. Agr. and W. H. Goodwin, Bulletin 293, Ohio Agr. Expt. Sta. 
resembling the appearance of injury by the black rot. The berries decay from the work of the litrve and from the entrance of fungous discases. The insect orems throughout the United States, but has been particularly injurious in the Chantauqua, N. Y., Erie, Pa., and Northern Ohio grape belts. So far as known the grape is the only food-plint and the species is a native one. though its habits are very similar to a nearly related European species.

The adult is a little purplishbrown moth, with wings expanding not quite one-half inch, and
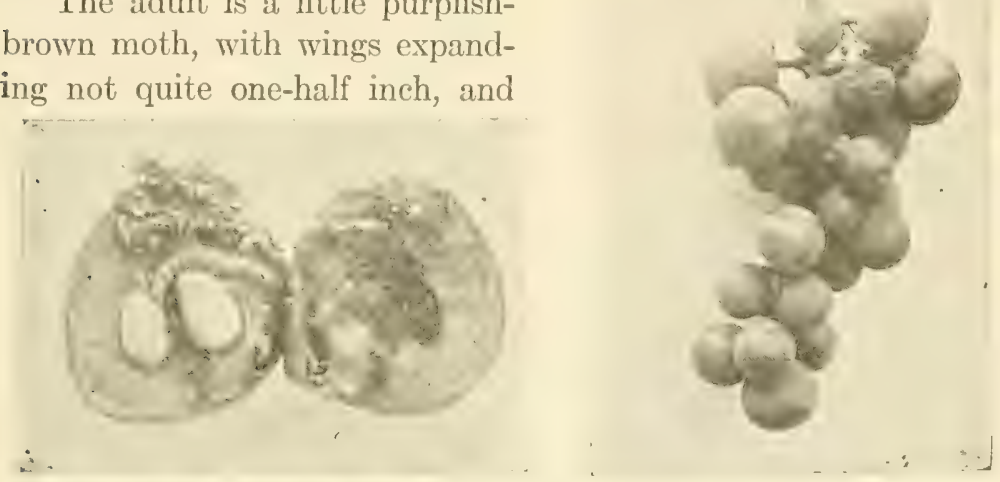

Fig. 356.-The work of the grape-berry moth; infested cluster and single berry opened to show larva at work-enlarged. (After slingerland.)

shaded with brownish markings as shown in Fig. 387. The ground color is lilaceous or leaden-blue and the spots are dark brown.

Life History.-The moths appear in the spring as the shoots of the grape are pushing out, and continue to emerge for some weeks. The earlier ones lay their eggs on the blossom clusters, while the later ones deposit them on the young grapes. The minute flat, scale-like eggs are stuck to the surface of the stems or berries, and look like small glistening, whitish spots. The little larvæ hatching from them feed on the blossoms and small berries, webloing the clusters together, and might do much more damage than the later generations were it not that they are much fewer in number, there being a great mortality of the insects over winter. The larve become full grown in about three weeks. The mature larra is about three-eighths inch long, varying in color from dark greenish to dark purplish, with a light-brown 


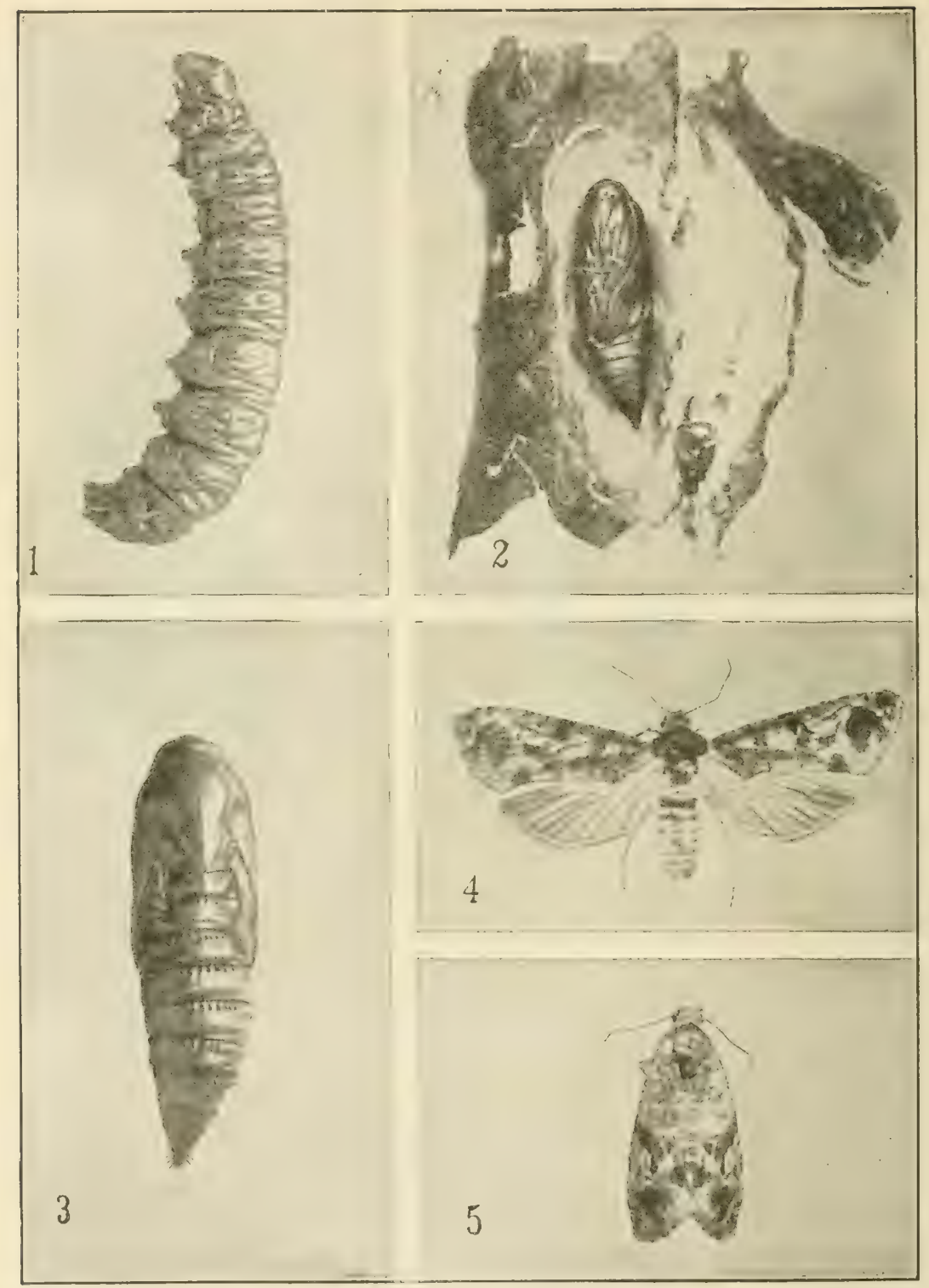

Fig. 387.-Grape-Berry Moth: 1, Larva; 2, Pupa (ventral aspect) in cocoon; 3, Pupa (dorsal aspect.); 4, 5, Adult. All greatly enlarged. (After Isely, l.c.) 
head and black thoracic shield. The body is covered with numerous faintly outlined darker spots, from which arise whitish hairs. The larva cuts out a picee of a leaf on three sides, folds it over and fastens the free edge to the leaf with silk. The fold is then lined with a thin layer of silk, making a thin cocoon in which it transforms to a light greenish-brown pupa, from which the moth emerges twelve to fourtecn days later. The moths of the second and later generations place their eggs on the berries and the larva bore into them and feed on the pulp and seeds. In New York the moths of the second generation appear in early

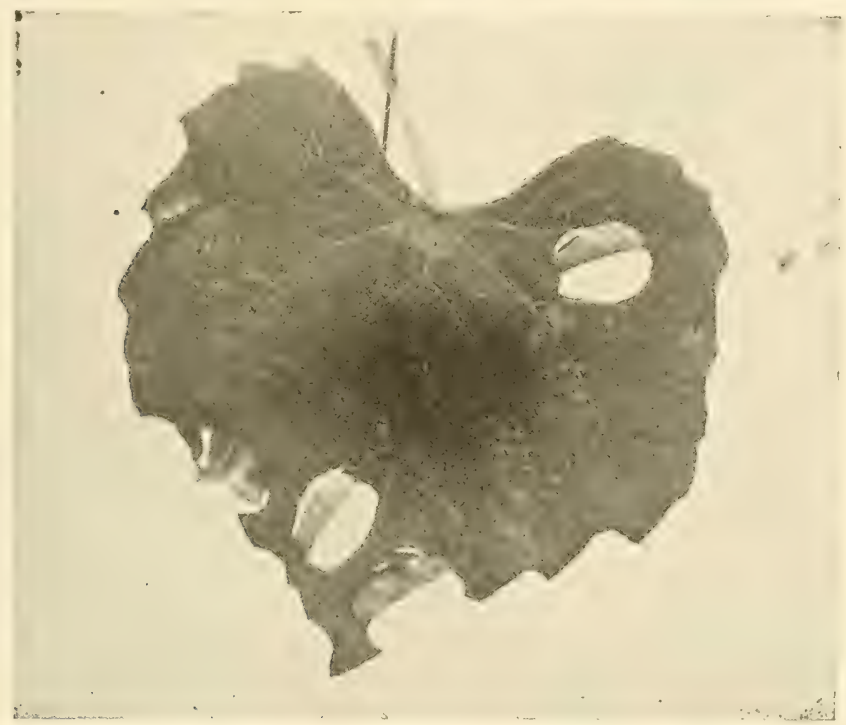

FIG. 38S. - Grape leaf showing cocoons in the making and finished by grapeberry moth caterpillars-natural size. (After Slingerland.)

July and the second generation of larve occurs during July and August. In New York those larve of the second generation which mature before mid-August pupate and give rise to a third generation, while those maturing later transform to pupæ, but hibernate. Often there is nearly a complete third brood in that latitude, and farther south there are undoubtedly at least three generations. The winter is passed in the pupal stage in the cocoons, which break off from the fallen leaves.

Control.-Infested berries should be picked off both to destroy the larvæ and to prevent the spreading of fungous diseases. 
Plowing under the fallen leaves either in fall or early spring should result in burying many of the pupæ so as to prevent the escape of the moths, and is good practice for other grape pests. The principal reliance should be placed upon spraying with arsenate of lead, 3 pounds per barrel, applied with Bordeaux mixture, to which a soap "sticker" should be added to make the mixture more adhesive to the berries. The first spraying should be made before the blossoms open, to catch the early larvæ; the second should be made as the grapes finish blooming; and the third, early in July. The addition of the "sticker" is most important in the last spraying, when the berries are partly grown. The spray must be applied with sufficient number of nozzles and pressure to penetrate the foliage and cover the clusters thoroughly.

Isely (1.c.) shows conclusively that it is much more satisfactory to apply the spray by hand with short leads of hose and short spray rods, called trailers, than it is to depend upon any fixed arrangement of the nozzles which does away with the hand work. Difference in efficiency between the two methods favored the trailers by from 15 to 20 per cent and more than repaid the extra cost.

To preserve some clusters in extra fine condition or to protect grapes on a small number of vines, paper bags are sometimes tied over the clusters as soon as the berries have set.

\section{The Grape Curculio *}

The larva of the Grape Curculio feed on the pulp and seeds of the berries, causing wormy grapes, much as do those of the berry-moth. The larva may be readily distinguished, for those of the curculio are white, footless grubs, while those of the berrymoth are greenish. with well-developed legs, and are quite agile, wriggling away quickly when disturbed. The adult curculio is a small, brown, robust, snout-beetle about one-tenth inch long, and nearly as hroad. It is very difficult to see, looking like a bit of dirt or the excreta of some of the larger caterpillars common on the vine. It is common from Arkansas to Minnesota castward to New York and North Carolina. It has been particularly injurious in West Virginia, and seems to be most harmful in that latitude.

* Craponius incruatis Say. Family Curcutionider. See Quaintance, 1.c., and Fred E. Brooks, Bulletin 100, W. Va. Agr. Exp. Sta. 
Life History. - The beetles hibernate over winter in or near the vineyards, especially along the edge of woodlands. They appear in the spring about the time the grapes blossom and feed upon the foliage for three or four weeks until the berries are
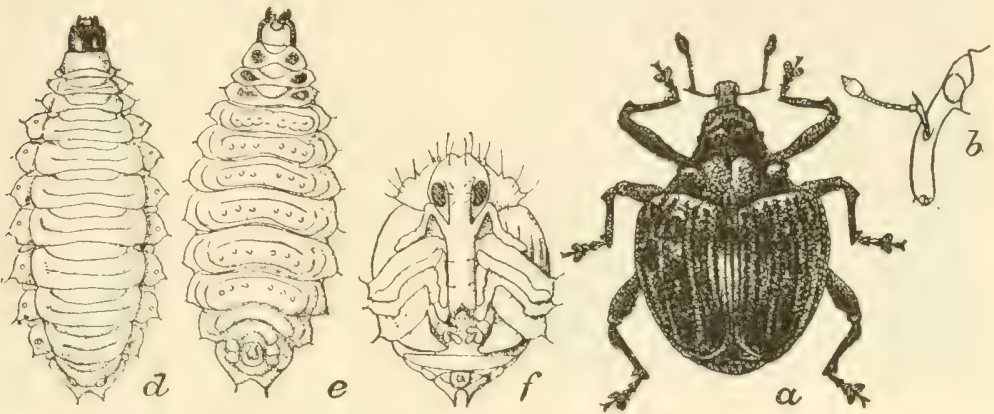

Frg. 389.-The grape curculio (Craponius inuqualis Say): $a$, beetle; $b$, head of same from side; $d$, larva from above; $e$, sime from below; $f$, pupaall much enlarged. (After Quaintance, U. S. Dept. Agr.)

about one-fourth grown. The beetles cut small characteristic holes in the leaves, and this habit of feeding on the foliage so

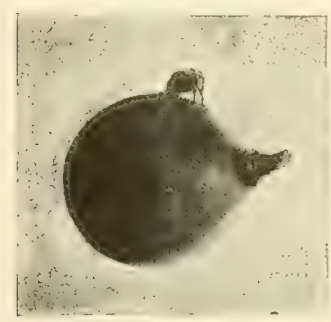

Fig. 390.-The grape cureulio in act of egg-lay ing-natural size; $e$, showing position of $\mathrm{egg}$ in grape-enlarged. (After Brooks.) long makes it possible to kill them with arsenicals before oviposition is commenced. In West Virginia the females begin egglaying late in June, most of the eggs being laid in early July, but egg-laying may continue for eighty-one days, during which time a female will lay an average of 257 eggs. The female excavates a small cavity in the berry in which the egg is placed and hatches in four to six days. Infested berries often show a purplish spot around the eggpuncture. The larva bores in the pulp and in three or four days reaches the seed, which is then devoured. The larva becomes full grown in twelve to fifteen days, when it eats its way out of the berry and drops to the.ground in search of a suitable place to pupate. The mature larva is white, about one-third inch long, tapering from the middle of the body toward either end, without legs, and clothed with fine short hairs. The larvæ make small earthen cells under stones, 
lumps of earth or just below the surface of the soil, and in them transform to pupæ, from which the beetles emerge in eighteen

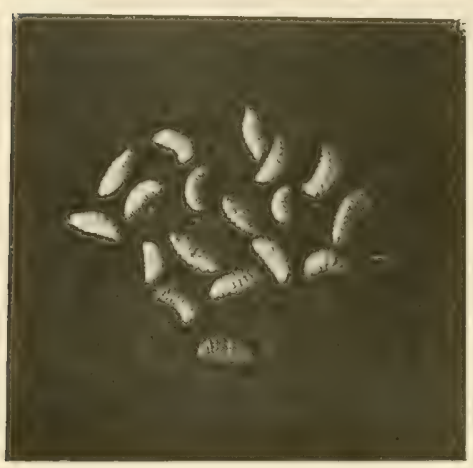

FIG. 391.-Grape curculio larvænatural size. (After Brooks.) to nineteen days. Thus the complete life cycle from egg to adult requires thirty-five days. The hibernating beetlesare still abroad when the new beetles appear, and Brooks states that the average life of a beetle is one year and nineteen days. Although the beetles of the new brood lay some eggs, but few of them develop, and in West Virginia there is practically but one generation, although farther south a second generation may occur. The beetles feed until fall, when they enter hibernation. Control.-As the beetles feed so long on the foliage in early

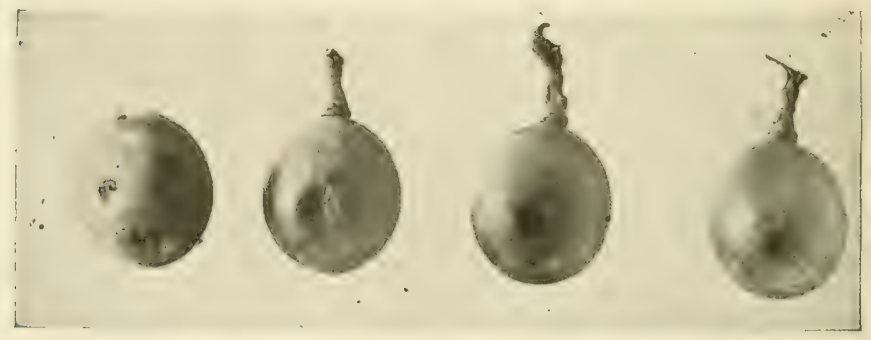

FIG. 392.-Grapes showing egg-punctures of grape curculios. (After Brooks.) summer they may be readily killed by spraying with arsenicals as advised for the berry-moth and grape-root-worm beetle.
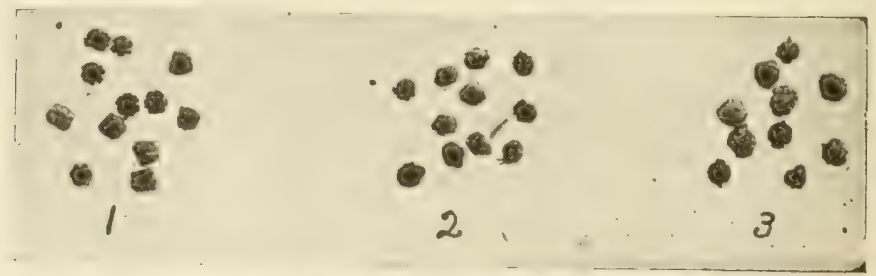

Frr. 393.-Showing the resemblance of the grape curculios at 2 to excrement of sphinx caterpillars at 1, and mummied grapes at 3. (After Brooks.) 
Thorough cultivation in midsummer would doubtless destroy some of the pupæ in the same manner as in the case of the rootworm. Infested fruit may be collected and destroyed as for the berry-moth with equally good results. Where spraying is regularly practiced there probably wili be little need of resort to other methods. 


\section{CHAPTER XXIV}

\section{SOME INSECTS INJURIOUS TO ORCHARD FRUITS*}

\section{The San Jose Scale $\dagger$}

Probably the most serious of all the insect pests of the orchard is the San José Scale, for it will kill young trees in two or three years, and old trees must be sprayed annually to keep it under control. So insidious is the attack of the pest to those unfamiliar with it that it has killed many thousands of trees before the owners suspected its presence. It may be most readily detected on the fruit, which becomes spotted with small red circles which form around the scales, but usually the fruit is not attacked until the tree is badly infested. On the young twigs and along the veins of the leaves a similar reddish discoloration appears around the scales. The trunk and branches covered with scales have a rough grayish appearance, as if they had been coated with dark ashes. By scraping the surface the soft, juicy, yellowish insects will be revealed beneath the covering scales. If a single female insect be examined it will be found that it is covered by a small, circular scale, varying from grayish to blackish in color, formed of concentric circles, the centre of which is quite convex and forms a "nipple," which is yellowish and shining when the surface is rubbed off. If this scale be raised with a pin, beneath it may be seen a small, soft, oval, orange-colored object, which is the true female insect. She is an almost shapeless mass of protoplasm, lacking head, legs and eyes, only the thread-like mouth parts and anal plate being distinct. The scale itself is merely a waxy covering secreted by the insect beneath. The scale of the male is smaller and somewhat elongated, the nipple being at the larger end.

* See Quaintance and Seigler, Farmers' Bulletin 908, U. S. Dept. Agr.

$\dagger$ Aspidiotus perniciosus Comstock. Family Coccide. See C. L. Marlatt, Bulletin 62, Bureau of Entomology, U. S. Dept. Agr., and the numerous publications of many of the experiment stations, listed in his bibliography. 
Injury by this species was first noticed near San José, Cal., about 1880 where the seale was most destruetive and was investigated hy Profeswol' J. II. Comstock, who first described it. About 1887 it was brought east on Japanese plum trees secured by Eastern nurseries and was distributed by them on young

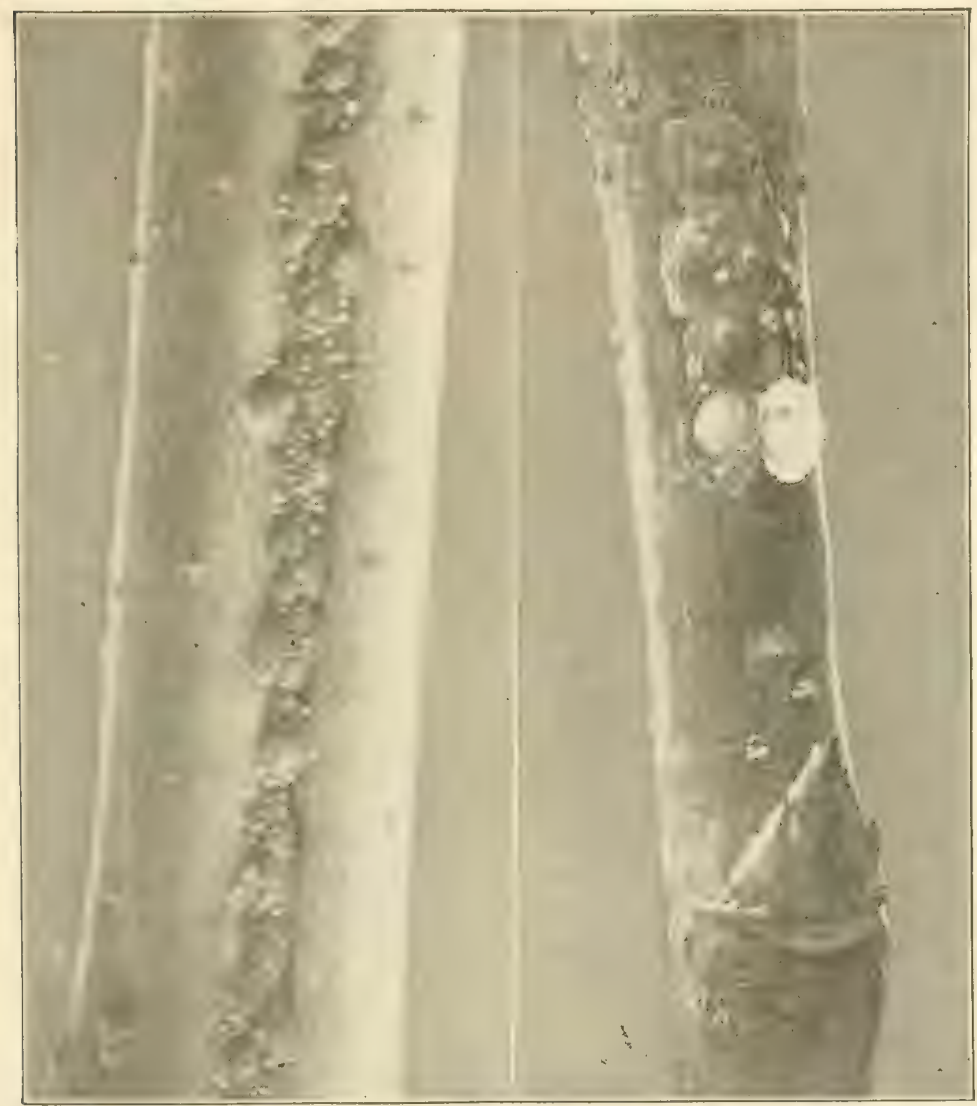

FIg. 394.-Peach twigs infested with the sinn Jose scale. On the twig at the right a seale has been turned back showing the fenale insectenlarged. (After W. E. Britton.)

trees, so that in 1893 it was discovered in orchards in Maryland and Virginia. Since then it has been spread on nursery trees to practically every State. Investigations made by C. L. Marlatt in 1901 showed that the insect is undoubtedly a native of east- 
central China, and was probably brought to this country on flowering-peach or some ornamental plant.

Life History.-The winter is passed by partly grown insects under the scales, which begin to feed with the bursting of the buds in spring. In the latter part of April the insects have become full grown in the District of Columbia, and the males emerge and fertilize the females. The male is a small, yellowish, twowinged fly. The males emerge at night and are so small they are seldom seen unless reared. About a month later the females commence to give birth to live young and continue to do so for some six weeks. This species differ's from most scales in having no egg

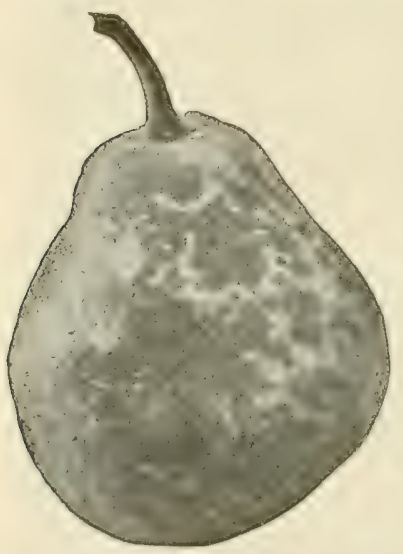

FIg. 395.-Pear injured by the San José scale showing the discolored spots. stage, the eggs hatching in the body of the female. The young insects are very small, yellowish in color, and resemble small mites. They have six legs, a pair of antennæ, and a long thread-like beak through which the food is sucked, as shown in Fig. 398. The young insect moves about freely for from twelve to thirty-six hours, then thrusts its beak into the bark or fruit, and if a female does not move again. White, waxy filaments soon exude from over the body, and in a couple of days the insect is entirely covered by them, and as they mat down a scale is formed which conceals it. This young scale is whitish with a prominent nipple in the center. After the first molt, the females lose eyes, legs, and antennæ, for which they have no further use. Nourished by the sap of the plant the insect develops rapidly and is full grown in about a month. In the District of Columbia there are four or five generations a year, in the South there are probably more generations, while at the northern limit of the species there are two or possibly three generations, as breeding continues until after killing frost. As with other small insects, it is the remarkable power of reproduction to which the destructiveness of the pest is clue. Thus it has been estimated that at Washington, D. C., the progeny of a single female would number $3,216,080,400$ by fall, if all were to survive. It is not surprising, 
therefore, that a tree with but a few scales on it in spring will be covered by them and the fruit unfit for market in the fall,

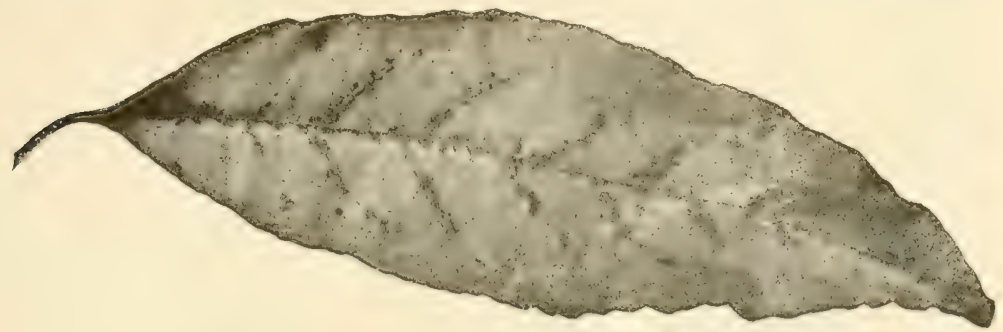

Fig. 396.-Peach leaf bearing San José scales along veins.

and that with these millions of little beaks pumping out the sap and poisoning the tissues a tree soon succumbs.

The pest has been spread mostly by being transported on nursery trees. Trees infested from the nursery will usually have

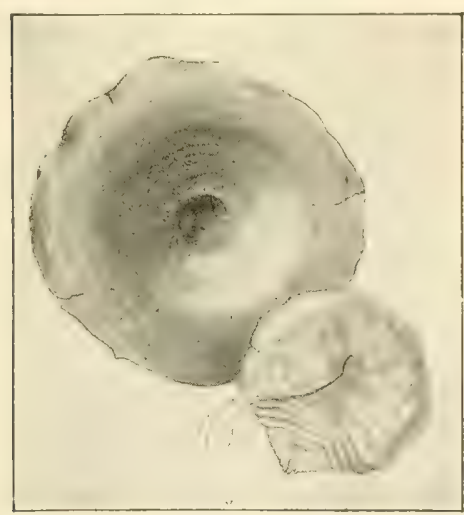

Frg. 397.-Adult female San José scale, with scale removed to expose the insect. (After Alwood.) more scales on the lower trunk, from which they will spread to the limbs, while those infested from neighboring trees will have more scales on the young wood. Where the pest is abundant the young insects are undoubtedly blown from tree to tree by the wind, or they may be carried on the feet of birds or insects, or brushed off and earried by persons or teams working in the orchard. The insect has been found on a long list of plants, but on many of them it is largely accidental. Injury is practically confined to plants of the Rosace $c$, which family includes all our common deciduous fruits. Of the orchard trees peach, pear, Japanese plum, apple and quince are most injured in the order named, while cherry and European plum are less injured.

Control.-As yet no spray has been found for use in summer which will more than check the increase of the pest without injury to the tree, and summer spraying is resorted to only when 
winter treatment has been neglected or has proven inefficient. 10 or 15 per cent kerosene emulsion, dilute miscible oils, dilute lime-sulfur mixture, or whale-oil soap, 1 pound to 4 or 5 gallons, may be used for summer spraying.

On the Pacific Coast trees are very generally fumigated with hydrocyanic acid gas * for this and other scale insects, but the

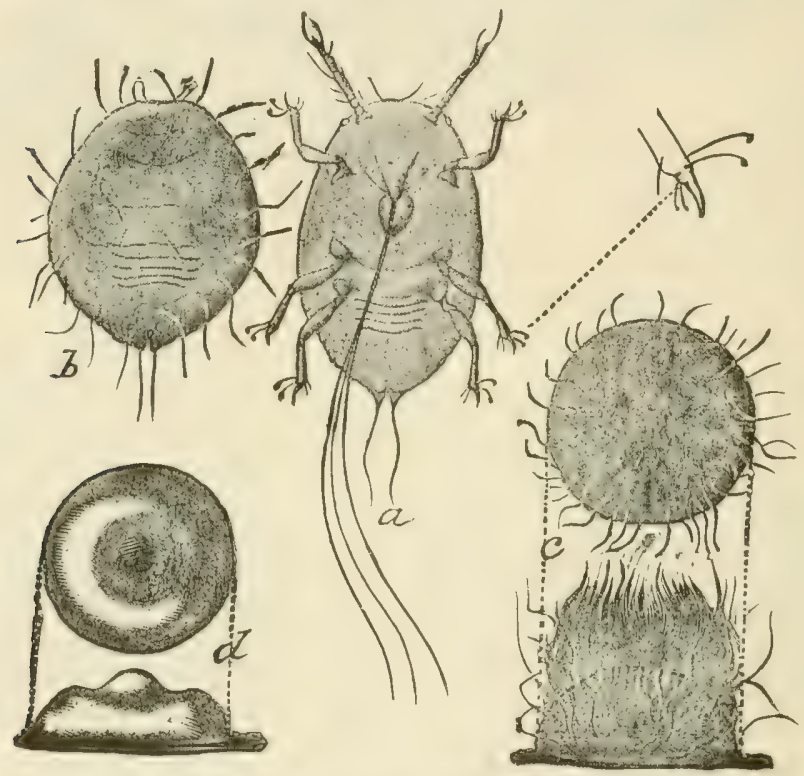

Fig. 398.-Young larva and developing San José scale (Aspidiotus perniciosus Comst ): $a$, ventral view of larva, showing sucking beak and setæ separated, with enlarged tarsal claw at right; $b$, dorsal view of same, still more contracted and with the first waxy filaments appearing; $c$, dorsal and lateral views of same, somewhat contracted, illustrating further development of wax secretion; $d$, later stage of the same dorsal and lateral views, showing matting of wax secretions and first form of young scaleall greatly enlarged. (After Howard and Marlatt, U. S. Dept. Agr.)

treatment has never come into favor in the East, principally, perhaps, because of the larger trees and the more scattered nature of the fruit industry.

Practically the only methods now used in the East consist in spraying the dormant trees with washes which penetrate the scales and destroy the insects. This may be done more effec-

* Sce C. W. Woodworth, Bulletins 122 and 152, Cal. Agr. Exp. Sta.; R. S. Woglum, Bulletins 79 and 90, Bureau of Entomology, U. S. Dept. Agr. 
tively if the trees are pruned and headed in so as to reduce the wood to be covered. Rough bark should be seraped off so that the scales bencath may be reached. Bully infested trees should be sprayed in the early winter as soon as they have hardened up and again in the spring just as the buds commence to swell. The spring spraying will suffice for trees slightly infested. Every bit of bark on the tree must be thoroughly wet, so none will escape. Lime-sulfur mixture seems to be the favorite wash for winter spraying at present, as it not only kills the scale, but aids in the control of many fungous diseases. Miscible oils are also extensively used and have a certain advantage on hairy apple shoots and on badly infested trees, as they are more penetrating and spread better. Kerosene or crude oil emulsion containing 20 to 25 per cent of oil was the first remedy to be used and is still extensively employed. Whale-oil soap, at the rate of 2 pounds to the gallon, applied hot, is effective, but is too expensive for large users.

\section{The Fruit-tree Bark-beetle *}

If the outer bark is punctured by numerous small "wormholes" so that it looks as if it had been struck with a charge of bird-shot, it indicates the presence of the fruit-tree bark-beetle or some nearly related species (sce p. 477). Usually more or less gum exudes from the holes, particularly on stone fruits. Diseased or weak-growing trees are most subject to attack, but occasionally serious damage is done to perfectly healthy trees, especially when young. Injury is largely due to allowing dead and dying trees to stand in the orchard, thus encouraging the breeding of the pest in them and its spread to healthy trees. "Another form of injury is the destruction at the beginning of spring of small twigs, together with the leaves which they bear. The beetles are also reported to destroy leaves by boring into the base of the buds at their axils." The holes in the bark are caused by the exit of the small parent beetles and by their subsequent entrance to deposit eggs. The adult beetle is about one-tenth inch long, by a third as wide, and of a uniform black color, except the tips of the wing-covers and parts of the legs, which are red.

* Ecoptogaster rugulosus Ratz. Family Scolytida. See F. H. Chittenden Circular 29, Division of Entomology, U. S. Dept. Agr., and F. E. Brooks, Farmers' Bulletin 763, ibid., H. A. Gossard, Bulletin 264, Ohro Agr. Exp. Station. 
Life History. - The beetles emerge from the trees in April and May in the Middle States. The female burrows through the bark, and partly in it and partly in the satp-wood she eats out a vertical gallery or brood chamber, along the sides of which at short intervals she gnaws out little pockets in which she places her eggs. The larva hatching from these eggs excavate little side galleries, which branch out and widen as the larvæ increase

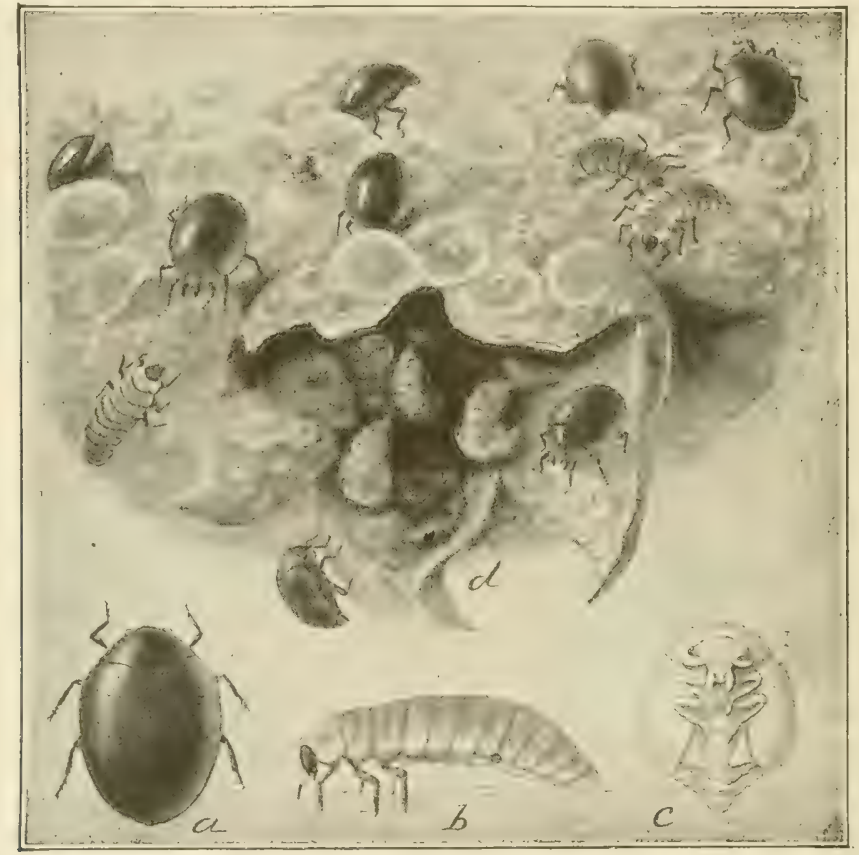

FIg. 399.-One of the most important native enemies of the San José scale, a little black ladybird-beetle (.Hicroucisea misella): $a$, beetle; $b$, larva; $c$, pupa; $d$, beetles, larvæ, and pupx, among scales-all greatly enlarged. (After Marlatt, U. S. Dept. Agr.)

in size (Fig. 401). The larve become mature in about three weeks, when they form cells at the ends of their burrows and transform to pupx, from which the adult bectles emerge about a week later. There are probably three generations a year in the Middle States according to Dr. Chittenden.

Were it not for the effective work of parasitic and predaceous insects which prey upon it, this insect would be a most serious pest. One of the most valuable of these is a little chalcis-fly * of which Dr. Chittenden bred 92 specimens from 72 of the develop- 
ing beetles, and we have frequently had twigs in which practically all of the developing beetles were parasitized.
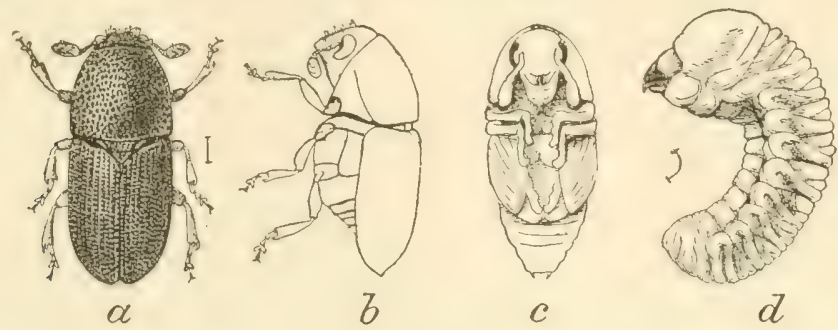

Fig. 400.-The fruit-tree bark-beetle (Scolytus meyulosus): $a, b$, beetle; $c$, pupa; d, larva-enlarged. (After Chittenden, U. S. Dept. Agr.)

Control.-The most important point in the control of this and

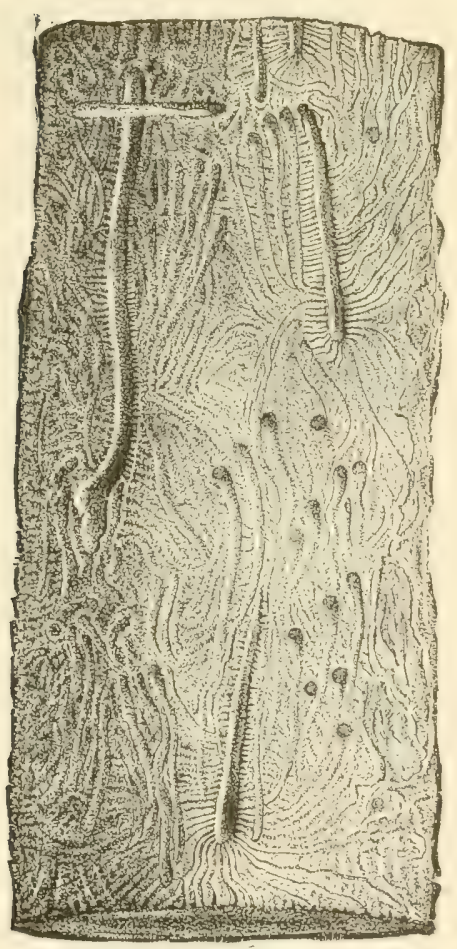

FIG. 401.-W ork ' of' the fruit-tree bark-beetle showing the main galleries, the side or larval galleries, and the pupal cells-slightly enlarged. (After Ratzeburg.) similar pests is to cut out and destroy all dead and diseased wood. Burn all prunings and trimmings. Affected trees should be liberally fertilized in the spring so that they may make a quick growth and better withstand the injury. Repellant washes have been advised for deterring the beetles from ovipositing. A thick soap wash containing a pint of crude carbolic acid to 10 gallons may be used. Professor Gossard advises whitewashing the trees in early spring, again in mid-summer and lastly about October 1st, adding one-quarter pound of table salt or some Portland cement to make it more adhesive. He also reports killing the beetles in their burrows with an emulsion of carbolineum. "Emulsify by dissolving 3 pounds of naphtha soap in 3 gallons of water by boiling. While hot, add 1 gallon of carbolineum (avenarius) and agitate as for 
kerosene emulsion with a force pump. Add four gallons of water for use and apply with a spray pump. Keep face and hands protected from this spray." The carbolineum is rather expensive, however, and does not seem to be much more effective than the whitewash.

Control measures, aside from pruning, are rarely necessary.

\section{The Buffalo Tree-hopper *}

The work of the Buffalo Tree-hopper consists of a series of cuts or incisions in the limbs of fruit or shade trees, made by the female in the process of egg-laying, which result in very character-
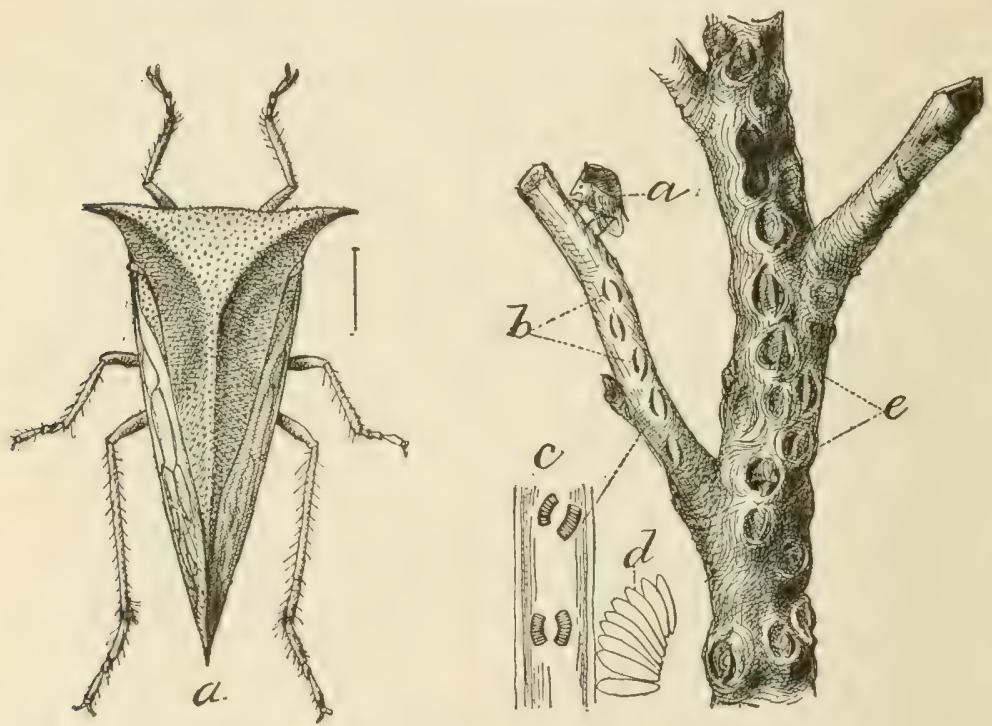

FIg. 402.-The buffalo tree-hopper (Ceresa bubalus Fab.): $a$, $a$, adult, enlarged and natural size; twig of apple showing recent egg-punctures at $b ; c$, bark reversed with eggs in position; $d$, single row of eggs-enlarged; $e$, wounds of two or three years standing on older limbs. (After Marlatt, U. S. Dept. Agr.)

istic wounds. This injury is somewhat like that done by the periodical cicada or by tree crickets, but the scars are larger and are placed irregularly. When badly attacked the limbs of small trees sometimes become so searred that they are badly stunted or may be killed. The cause of this mischief is a curious

* Ceresa bubalus Fab. Family Mcmbracide. See C. L. Marlatt, Circular 23, Div. Ent., U. S. Dept. Agr., and H. E. Hodgkiss, Tech. Bulletin 17, N. Y. Agr. Exp. Sta., p. 92. 
little grass-green insect, about three-eighths inch long, whose pronotum is broadly expanded into two sharp horns, which are fancied to be like those of the buffalo, as indicated by the common name of the insect. They are very common, frequenting all sorts of rank-growing vegetation, appearing in midsummer, and being most numerous in August and September.

Life History.-Egg-laying is commenced in August and is continued until killing frosts. The eggs are laid in two curved slits, with from six to twelve in each, as shown in Fig. 402, $c$, d. In making these slits the female cuts the bark between them entirely loose, so that the intervening wood soon dies, possibly to prevent

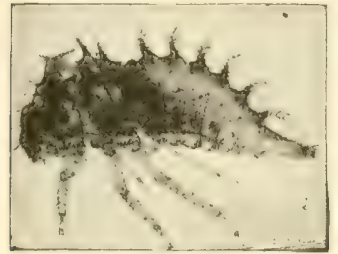

Fig. 403.- Nymph of

buffalo tree-hopper enlarged. (A f t e r Hodgkiss.) the growth of the wood crushing the eggs. A large scar is thus formed which enlarges with each season's growth, and finally becomes an oval shape by the center dropping out. After a few years badly infested limbs become very rough, are easily broken by the wind and furnish vantage points for the attack of borers. The eggs hatch the next May or June. Like the adults, the young nymphs feed on all sorts of succulent vegetation, seeming to prefer the juicy annual plants even to the tender terminals of trees, the orchards suffering most being those grown up in weeds.

Control-By keeping young orchards well cultivated and free from weeds, the nymphs will have no food in early summer and will starve or leave for better feeding grounds. Patches of weeds near young orchards should also be destroyed. When trees are badly wounded by the egg punctures they should be well pruned and the prunings burned to destroy the eggs.

\section{The Periodical Cicada*}

"There is probably no insect that has attracted more general interest and attention in this country than the Periodical Cicada, or the so-called Seventeen-year Locust. The earliest settlers

* Cicada septendecim Linn. Family Cicadide. See C. L. Marlatt, Bulletin 71, Bureau of Entomology, U. S. Dept. Agr.; A. D. Hopkins, Bulletin 68, W. Va. Agr. Exp. Sta. 
doubtless associated its vast noisy swarms with the devastating invasions of the Migratory Locust of the East. Hence the popular name locust, which has been used so long that it is doubtful if it will ever be discarded for the proper name-Periodical Cicada." They are quite different from the true locusts, or grasshoppers, however, for the latter have biting mouth-parts while the cicadas suck the juices of the plant through a tube-like beak. Some twenty-seven distinct broods of the cicada have been distinguished, seventeen of which appear at seventeen-year intervals and ten of them appear at thirteen-year intervals, the former being mostly
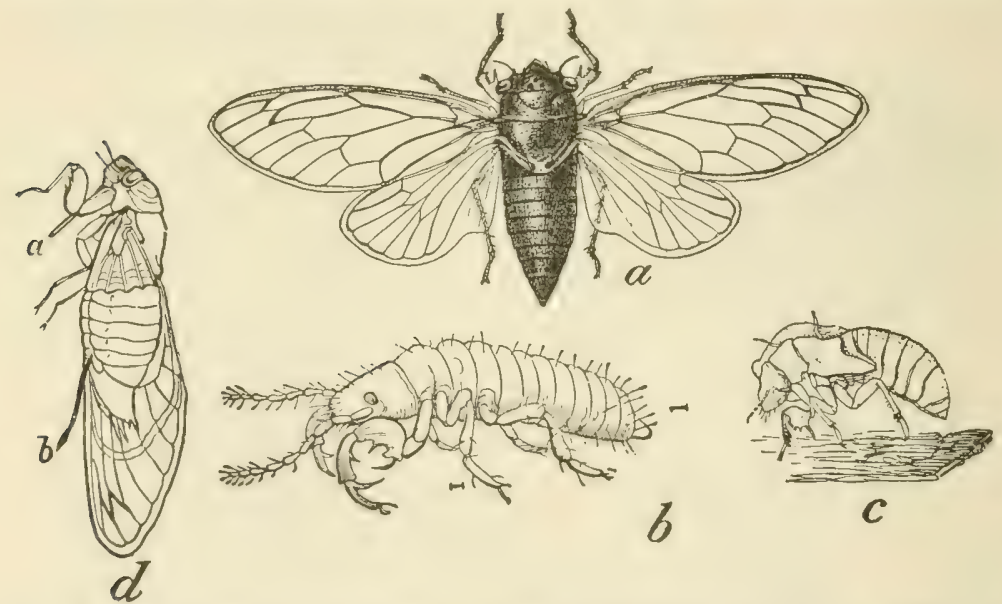

FIG. 404.-The periodical cicada (Cicada septendecim Linn.): $a$, adult; $b$, young nymph-enlarged; $c$, cast skin of full grown nymph; $d$, adult females showing ovipositor at $b$, and beak at $a$-natural size. (After Marlatt and Riley, U. S. Dept. Agr.)

in the North and the latter mostly in the South. Some one or more of these broods appears in every State east of the Rockies except Maine, New Hampshire and Vermont. Every year there is a brood emerging in some part of the country, and the different broods have been carefully mapped so that their emergence may be anticipated.

Life H istory. - The adults appear in immense swarms in late May or early June. "About four or five days after their first appearance," says Dr. Hopkins, "the males begin to sing," filling the air with their shrill calls, which are produced by two drum-like membranes on the under surface of the first abdominal 
segment. "About eight or ten days later the sexes begin to mate, and in about four or five days more the females commence
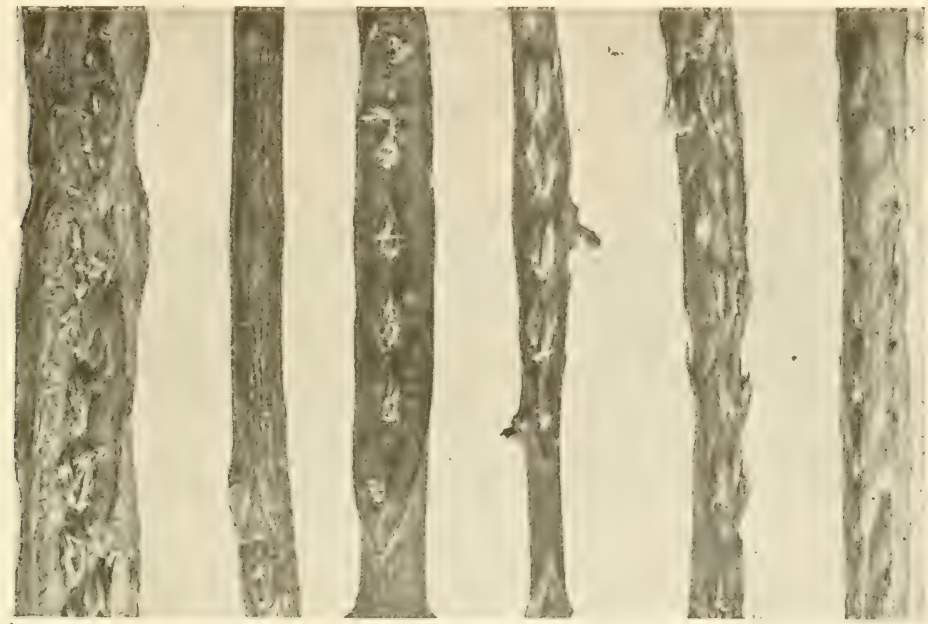

FrG. 405.-Typical cicada injury. Photo by W. E. Rumsey

to deposit eggs. Each female is said to deposit from three to five hundred eggs in numerous ragged punctures made by her

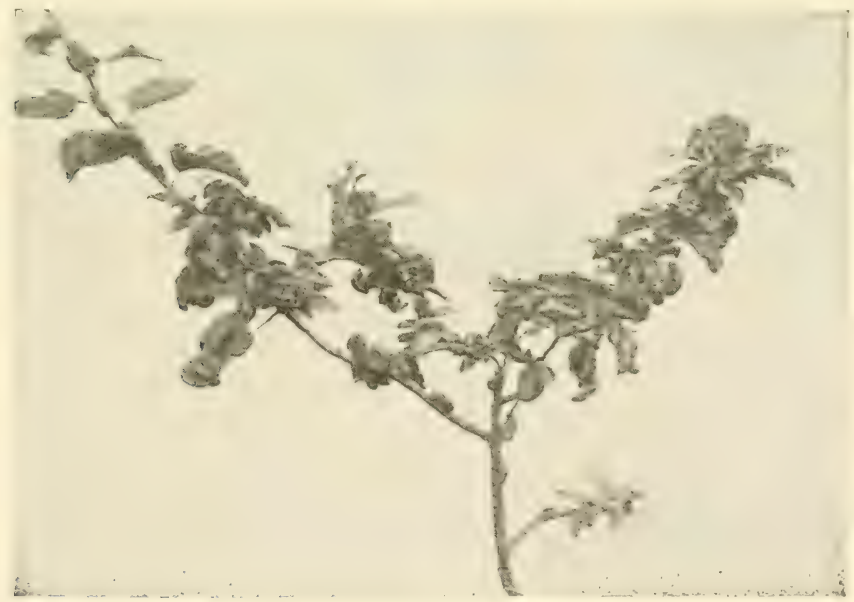

Fig. 406.--Emergence of cicada.

powerful ovipositor in the twigs of shrubs and trees, and sometimes in the stems of herbacens plants. These hatch in about 
six or eight weeks from the time they are deposited and the young cicada larva emerge and fall to the ground. They then burrow beneath the surface and enter upon their long menial existence in the ground, feeding on the liquids of roots and possibly subsisting on such nutriment as may be obtained from the soil itself. They change their position from time to time, and may rarely enter the earth for a distance of eight to ten feet or more," though usually within two feet of the surface. "By the twelfth or thir-

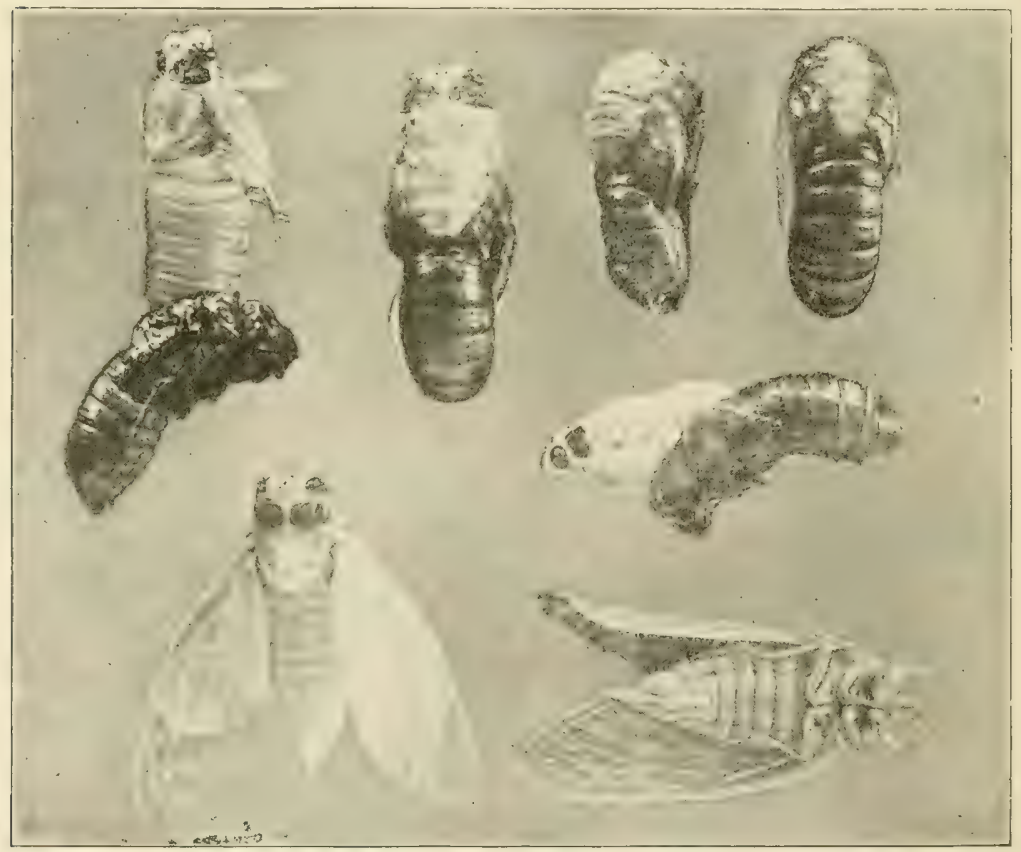

FIG. 407.-The full-grown nymphs of the periodical cicada in different stages of molting and the newly emerged adults with body and wings still soft and white.

teenth year the larva attains its full growth and in time changes to the intermediate or pupa stage.* During the spring of the fifteenth and sixteenth years great numbers of the pupæ may be

* Dr. Hopkins and other writers commonly use the terms larva and pupa in describing the immature stages of the cicada, but there seems no reason for discarding the term mymph used for other Hemiptera, and which is certainly useful in distinguishing the immature stages of insects with incomplete metamorphosis from those with complete metamorphosis which have a true pupa. 
found near the surface, and a few individuals may cmerge during May and June of the sixteenth year. Early in April of the seventeenth year the pupe commence to make preparations to emerge from the ground by excavating burrows or exit gallerics to the surface. These exits are completed by the last of April. Ordinarily they extend only to the surface, and are kept open from a depth of a few inches to a foot or more. In some soils these exit holes are extended four or five inches above the surface by means of clay carried up from the subsoil, and are called cicada chimneys. The pupæ come from the ground in the evening and at night, usually between sundown and ten o'clock, and proceed to the nearest upright object, which may be a tree, the side of a building, fence, or weed stem-anything, in fact, upon which they can climb and expose their bodies to the action of the open air. In about an hour after emerging the skin on the back splits open and the adult insect works its way out (Fig. 406). The wings, which are short and soft at first, rapidly develop; the body, wings and legs harden, and by the following day the adult is ready to take flight and enter upon its short aerial life, limited to about thirty days. During this short period they feed but little, if at all, the males devoting their time during the day to flying about and making a noise, while the voiceless females busy themselves depositing eggs. "If the young nymphs do any injury to the roots of trees or plants,

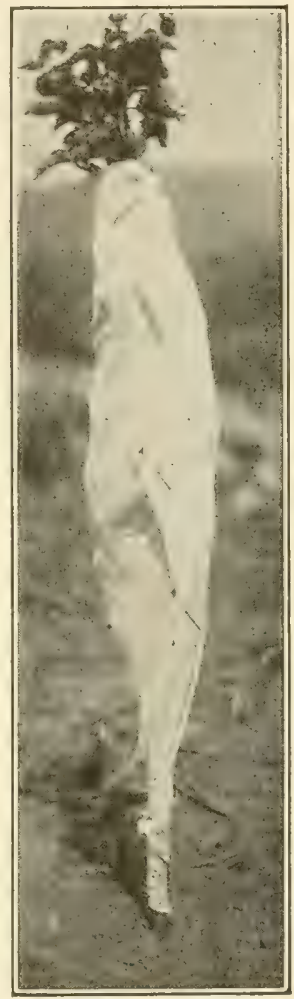

FIG. 408.- Young tree shrouded with cheese cloth to prevent cicada injury. Photo by W.E. Rumsey. it is very rarely perceptible. The adult females, however, are capable of causing serious injury to young fruit trees in orchards and nurseries by the numerous punctures in the twigs, limbs and main stems made by them in the act of ovipositing The egg puncture makes an ugly wound, beyond which the twig dies, and the foliage of large trees on which hundreds of cicadas have 

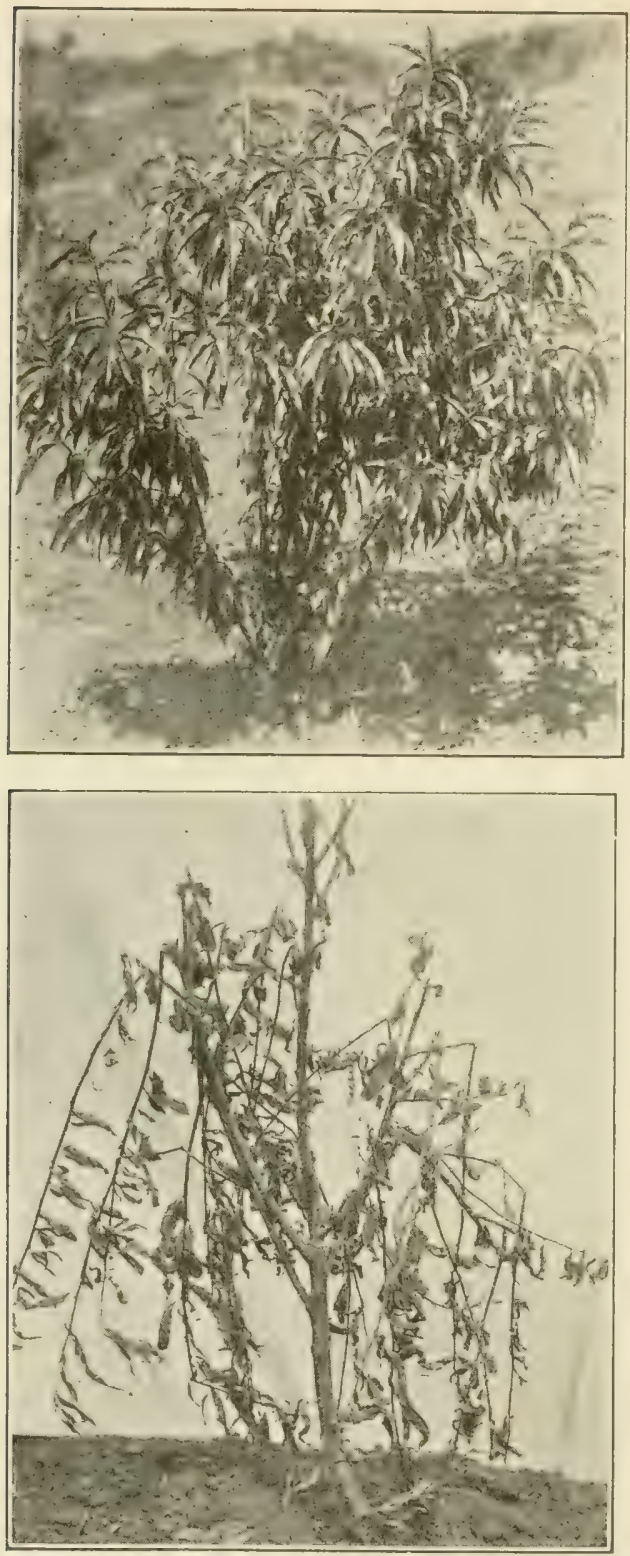

FIG. 409.-Result of protecting trees with cheesecloth. Above, protected trees at end of the season; below, unprotected tree at the same time. Photos by W. E. Rumsey. oviposited turns, brownasif the tree had been scorched by fire. On young trees this results in destroying the growth of a year or two and misshaping the tree, and the scars which remain late $r$ furnish points of attack for borers and the w o olly apple-aphis.

Just before the cicadas leave the ground they are attacked by hogs and also by disease. Upon leaving the ground they are at once assailed by a host of predaceous insects and various animals. One of the most valuable insect enemies is a large wasp (Sphecius speciosus Dru.), which may often be seen bearing the adults to its burrow, where they furnish food for her young. The English sparrow is remarkably fond of the adults and is the most valuable factor in exterminating them in cities and towns. It has been noticed that cicadas are much more likely to emerge from newly 
cleared land, and with the removal of the forests and cultivation of the land they are undoubtedly becoming more scarce.

Control.-There is no means of destroying the adults, but many of the pupæ may be destroyed by allowing hogs to run on land known to be infested during April and May of the year they emerge, where it is feasible to do so. Injury to young orchards may be avoided by not planting during the year or two previous to the emergence of a brood in the particular locality. Budding and grafting should also be avoided during the previous spring. Orchards should not be pruned the year before a cicadayear, so that there may be plenty of young wood in which they may oviposit and which may then be removed without injury to the tree. Evidently a knowledge of the time of appearance of each brood in different sections is of great importance and may be secured from the maps published (see MIarlatt, l.c.). After all the eggs are laid the affected twigs should be pruned off in July and burned before the eggs have hatched.

Newly planted trees may be protected to a large extent by wrapping them in cheesecloth during the presence of the adult cicadas. The method has been tried in West Tirginia and in Virginia and the benefits have been sufficient to warrant the necessary expenditure.

\section{The Fall Webworm *}

The common Fall Webworm is so called because in the North, where there is but a single generation, its webs are abundant in August and September, in contrast to those of the tent caterpillar, with which they are often confused, which are found in the spring. The wings of the adult moths expand from one to $1 \frac{1}{4}$ inches, and are either a pure milk-white, or more or less spotted with black, the number of spots being exceedingly variable. The full grown caterpillars are about an inch long, covered with long black and white hair's which project, from numerous black tubereles. They are also quite variable in color, some being uniformly yellowish with black and yellow tubercles, while others have a dark stripe down the back and are almost black.

Life History.-In the North the moths emerge late in June and in July, and lay the egges late in July. The eggs are deposited on the leaves in pale yellowish-green patches of 400 to 500 , often

*Hyphantria cunea Dru. Family Arctiido. 
covered with whitish down from the body of the female, and hatch in about ten days. The young larva are pale yellowish with brown markings and appear to be almost all head and hair. They at once spin a web over the foliage on which they are feeding, those from one egg mass feeding together and enlarging the

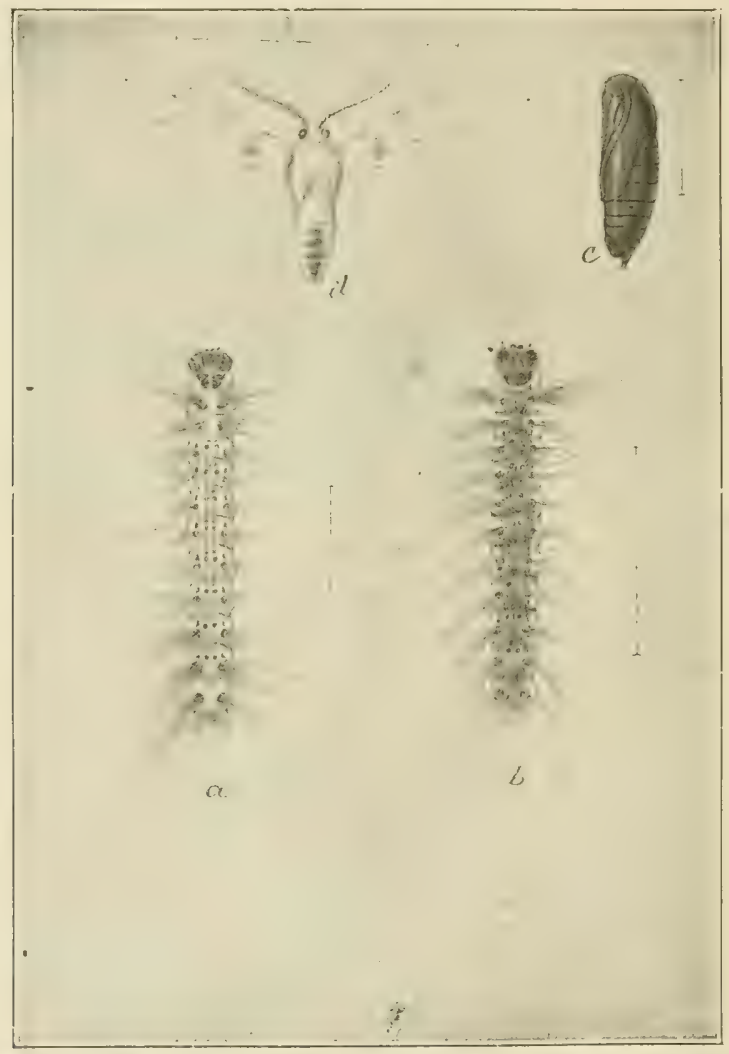

Fig. 410.-The fall webworm (Hyphantria cunea Dru.): $a$, light form of full-grown larva; $b$, dark form of same; $c$, pupa; $d$, spotted form of moth-all slightly enlarged. (After Howard, U. S. Dept. Agr.)

web as necessary. In the North the webs are usually noticed in early August and are started at the tips of the limbs. Within them the surfaces of the leaves are eaten off until they are left dry and brown. When all the foliage on a limb has been consumed, the caterpillars leave the web, enclosing the dead leaves, and form a new web on a fresh branch, and thus the tree soon becomes covered 
with unsightly webs, which are often mingled so that the whole tree is webbed over. The web is easily distinguished from that

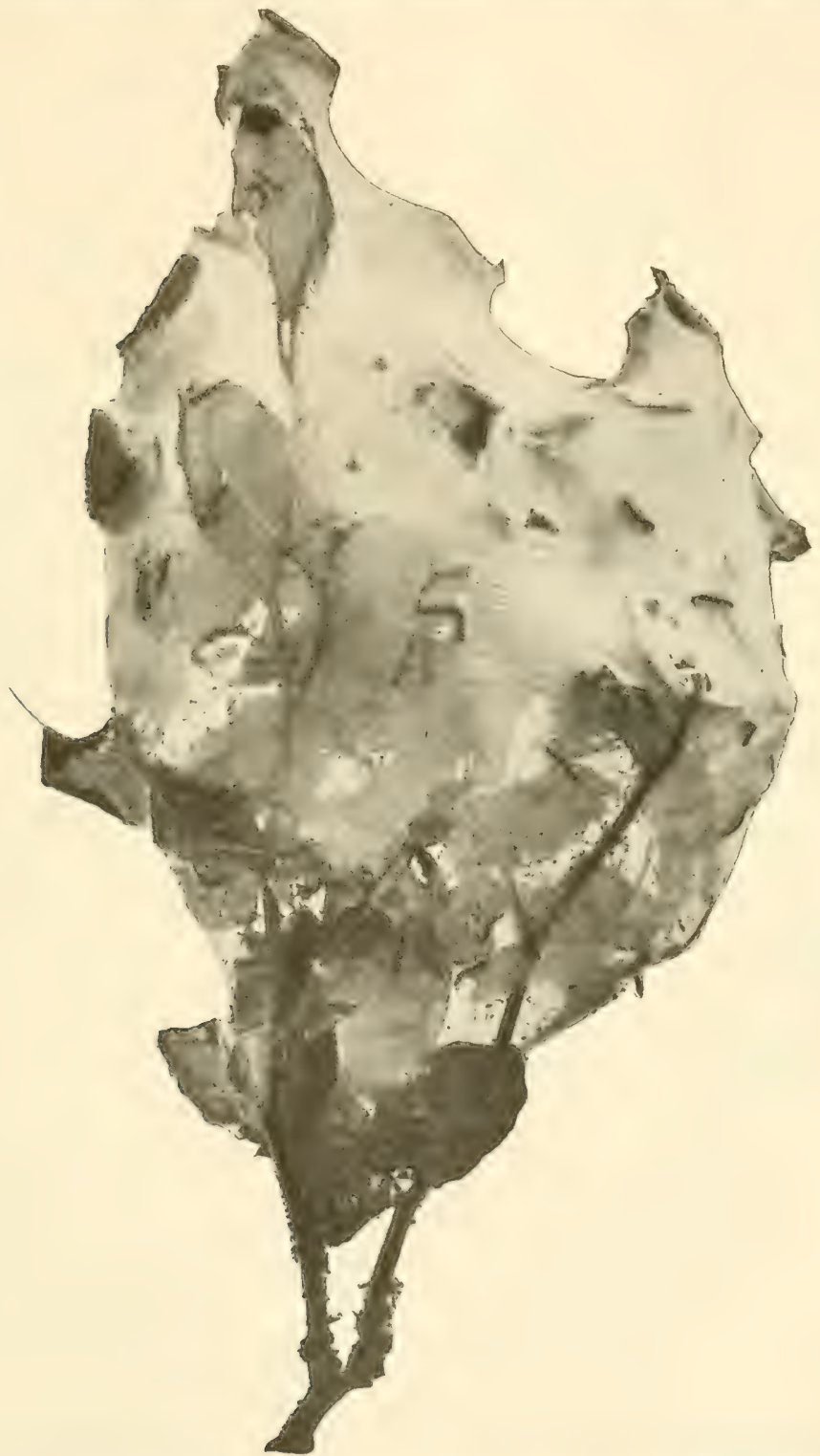

FIG. 411.-Web of the fall webworm on apple, showing enclosed foliage and larvæ feeding within. 
of the tent caterpillar, as it is found later, and the tent caterpillar makes a relatively small web in the fork of a limb and never encloses foliage in it. The caterpillars become full grown in a month to six weeks, and then find secluded places under the bark or in a hollow of the tree, in the rubbish at its base, or in a fence corner, or sometimes just under the surface soil, and there spin flimsy silken cocoons with which they mingle their own hairs. They then transform to small brown pupæ about one-half inch long, in which stage the winter is passed. In the Middle States

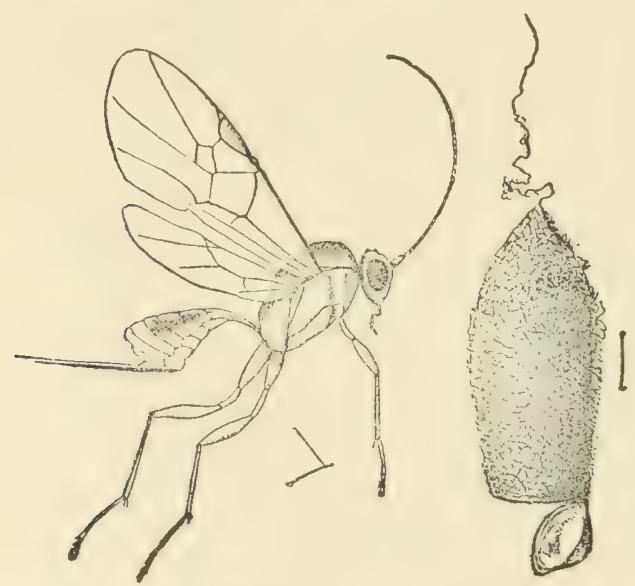

FIG. 412.-Metcones hyphantrix, a common parasite of the fall webworm; $a$, adult female; $b$, empty cocoon showing cap and suspending thread -enlarged. (After Riley, U. '.'. Dept. Agr.) and farther south there are two generations, the moths appearing in April and May and laying eggs in late May and early June, the caterpillars from which becomefull grown by mid-July. The second generation of caterpillars appears in late August and September at about the same season as farther north, and their pupx hibernate. Were it not for their parasitic enemies these caterpillars would be much more of a pest, and it is when the parasites become scarce that injury results. One of their most common and effective enemies is a little Braconid fly, ${ }^{*}$ whose small brown cocoon (Fig. 412) is often found suspended from a twig or leaf. Many caterpillars are also killed by various predaceous bugs, and frequently they are killed off by fungous disease

The fall webworm is a common pest of all orchard trees, and frequently extends its injuries to shade trees. The larva are not uncommon on cabbage, beets and a long list of garden crops. According to Dr. H. G. Dyar this species is confined to the South

* Meteorus hyphantric Riley. 
Atlantic States, but it has been confused with another species (Hyphantria textor Harris) by practically everyone, and it is still a question as to whether the two species are really distinct and if so how they are to be distinguished. If the latter form be a distinct species, it occurs throughout the United States and has the same habits.

Control. - The insect is readily controlled by spraying with any of the arsenicals when the work of the young larvar is first noticed. Where orchards are sprayed for the codling moth there will be little trouble with the first generation, and fruit-growers will do well to make it a practice to spricy in August where they are troubled with this and other leaf-eating caterpillars.

Mechanical destruction of the nests is good practice when spraying is not done.

\section{The Brown-tail Moth.*}

The Brown-tail Moth has become injurious only in Massachusetts, New Hampshire and Maine although it has several times been brought into other states in the winter nests on seedling trees imported from France and Belgium. With the present efficient quarantine service it is rather unlikely that it will become established elsewhere. On the contrary, it seems that its range may gradually be reduced although actual extermination can not be looked for in the immediate future. It has long been a serious pest in parts of central and western Europe, whence it was

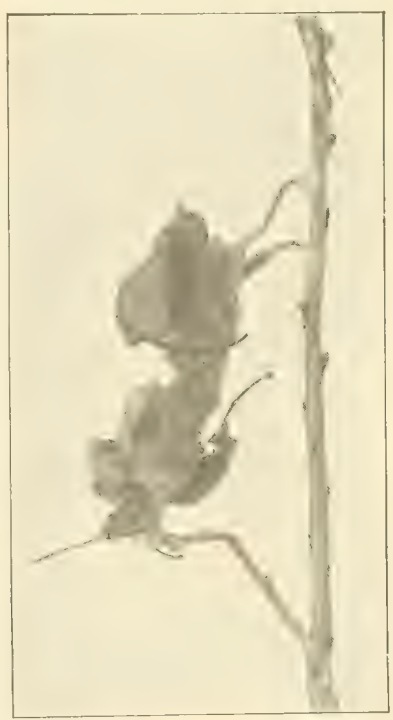

FIG. 413.-Winter web of the brown-tail moth-one-half natural size. introduced into Massachusetts about 1890 , but did not attract attention until 1897. The female moth is pure white except the tip of the abdomen, which is golden brown and forms a large

* Euproctis chrysorrhora Linn. Family Liparider. Sce L. O. Howard. Farmers' Bulletin 264, U. S. Dept. Agr.; F. D. Sanderson, Bulletin 136, N. I. Agr. Exp. Sta.; A. F. Burgess, Farmers' Bulletin 845, U. 's. Dept. Agr. 
tuft or brush, which gives the insect its name. The wings of the female expand $1 \frac{1}{2}$ inches, the males being slightly smaller, and bear one or two streaks of brown on the under sides. The full-grown caterpillar is $1 \frac{1}{4}$ inches long, dark brown, marked with a white dash on the side of each segment. The body is dark brown or blackish, well marked with patches of orange and covered with numerous tubercles bearing long barbed hairs. On the centre of the fifth and sixth abdominal segments are small retractile red tubercles. The tubercles along the back and sides are thickly

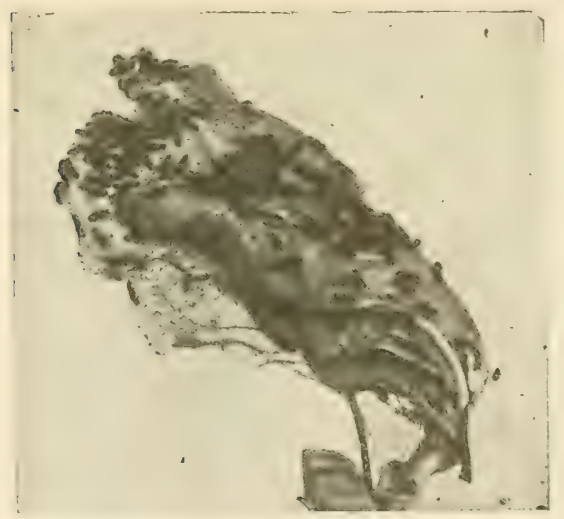

FIG. 414.- Winter web of the brown-tail moth bearing young larvæ which have emerged before the foliage has appeared and are feeding on the dead leaves of the nest-two-thirds natural size. covered with short brown hairs which give them a velvety appearance. These microscopic hairs are barbed and are the nettling hairs which, when they alight on the skin, produce a dermatitis much like that caused by poison ivy. As the cast skins are carried here and there by the wind and the young caterpillars drop from the trees, people are frequently badly poisoned where the pest becomes abundant, so that it is a serious public nuisance as well as as defoliator of fruit and shade trees. The caterpillars prefer fruit trees, pear, wild cherry, and apple being most relished, but become abundant on almost all the common shade trees, except the evergreens, and particularly on oak.

Life History. - The moths emerge in midsummer. They are strong fliers and are readily carried by the wind for many miles. They are attracted to lights in great numbers, so that they are more abundant in cities and villages. Late in July the eggs are laid on the terminal leaves, 300 or 400 being laid in an elongate mass and covered with brown hairs from the tip of the female's abdomen. They hatch in about three weeks and the young larvæ feed on the surface of the leaves, leaving only the brown skeletons, so that badly infested trees turn brown in early fall. The cater- 
pillars hatching from an egg mass feed together on adjoining leaves, which they soon commence to draw together with silken threads, and by the first frosts they have spun them into a tough web. This is attached to the twig by the old leaf stems, which are bound to it by silk. The web looks like a couple of dead leaves from a distance, but the leaves are merely the outer covering, and if the silk web be torn

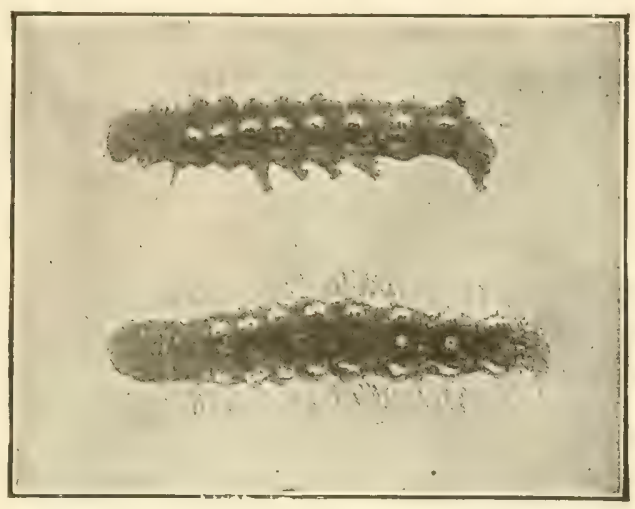

FIG. 415.-Full-grown larvæ of the brown-tail moth-natural size. open, there will be found numerous small pellets of silk each enclosing from three to twelve of the little partly grown catcrpillars. The

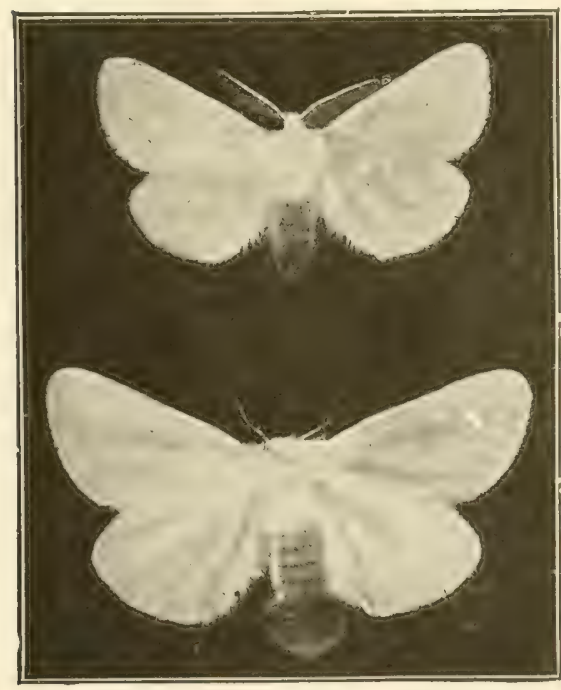

Fig. 416:-The brown-tail moth (Euproctis chrysorrhoea Linn.): male above, female below-natural size.

In Europe there are sereral parasites which prey on all stages of the insect and which the State of Massachusetts with the the buds burst in the spring and feed on the expanding foliage. Where abundant they soon strip a tree, for each of the nests harbors 400 or 500 little caterpillars. In five or six weeks they have become full grown and spin thin cocoons of white silk among the leaves, in which they transform to dark-brown pupæ. About three weeks later the moths emerge.

Several native parasites and predaceous bugs prey upon the caterpillars, but do not seem materially to reduce their numbers. caterpillars emerge just as 
cooperation of the U. S. Bureau of Entomology is introducing in hope that they may ultimately be as effective in this country

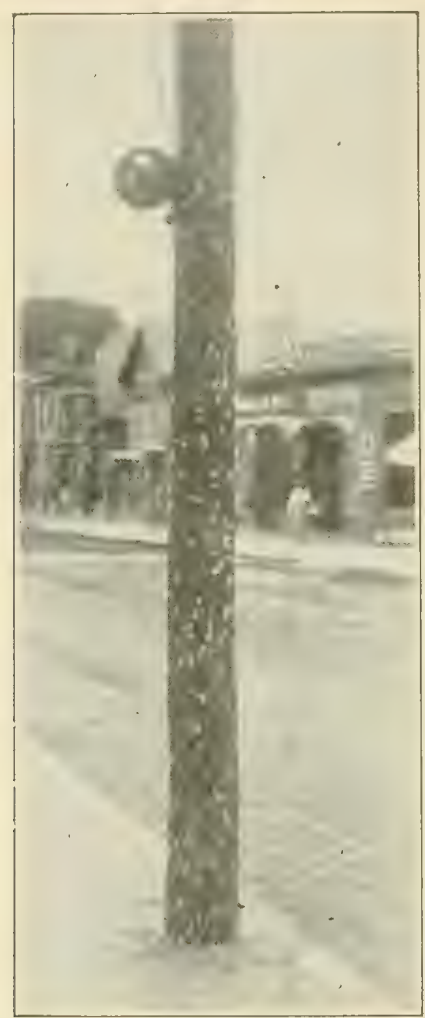

FIg. 417.-Brown-tail moths assembled on electric light pole, Mialden, Miass., July 12, 1905. (After Iirkland.) against both the brown-tail and gipsy moths. The most effective natural check of the brown-tail caterpillar is a fungous disease which often completely destroys large colonies, both in the spring and fall.

Control.-On fruit and shade trees the winter nests may be pruned off and burned in winter, thus preventing any injury the next spring, but this is impracticable on forest trees, which as a rule are not seriously injured. The repeated pruning often injures the trees, as it is difficult to cut all the nests without removing more of the new growth than is desirable. It is better, therefore, to spray the trees with arsenate of lead, 4 pounds to the barrel, as soon as the eggs hatch in late summer, and thus destroy the young larvæ before they have spun their winter webs.

\section{The Gipsy Moth *}

History.-The Gipsy Moth has been known as a serious insect pest in Europe from the time of the earliest naturalists, the first authentic recorel heing in 1662. It extends throughout the continent of Furope, over much of Asia and into Northern Africa, but is chiefly injurious in Central and Eastern Europe. It fre-

* Porthctria dispar Linn. Family Liparila. Siee Forbush and Fernald, "The (iipsy MIoth," Milss. State Board of Igr. (1S92); L. O. Howard, Farmers' Bulletin 275, [. S. Dept. Agr.; Anmual Reports of the Mass. Superintendent for the siuppression of the Gypsy and Brown-tail Moths; E. D. Sanderson, Bulletin 136, N. H. Agr. Exp. Sta.; Rogers and Burgess, Bulletin 87, Bureau of Entomology, U. S. Dept. Agr., containing bibliography, and A. F. Burgess, Bulletin 204, U. S, Dept. Agr. 
quently does serious injury there by defoliating large areas of forest and more ferquently fruit and shade trees, but its ravages cease in two or three seasons, not to oceur again for several years, like those of many of our native insects, such as the forest tent caterpillar and tussock moth. In 1868 the insect was brought to this country by Professor Leopold Trouvelot at Medford, Mass., in his experiments in silk producing. Escaping from him into the neighboring woodland, the insect increased gradually for several years before being noticed, but in 1890 had become such a serious

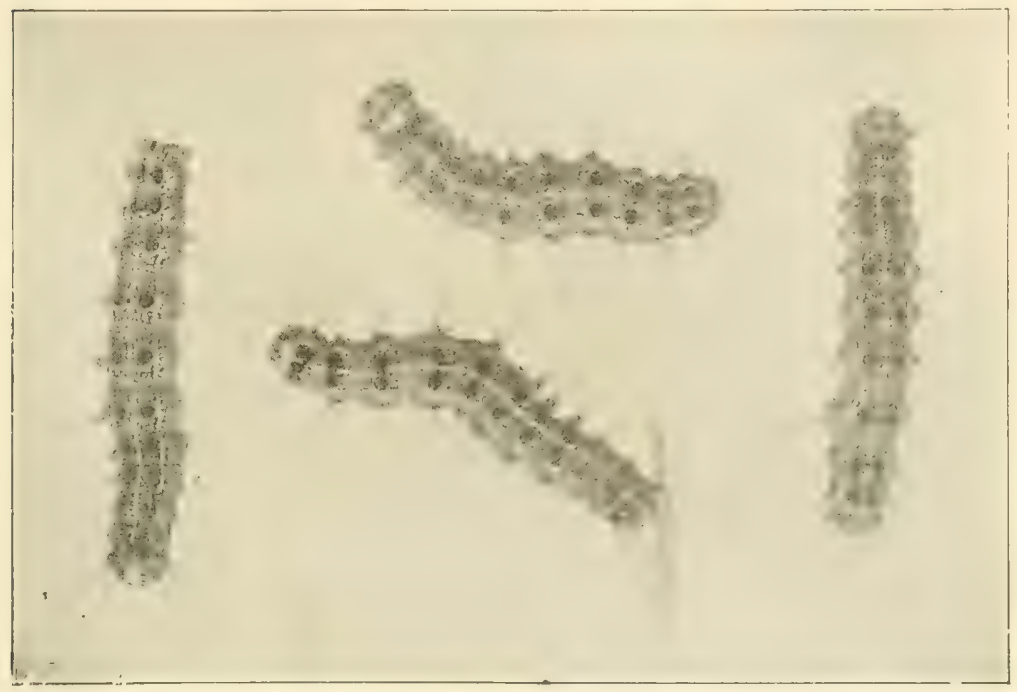

FIG. 418.-Gipsy moth eaterpillars-natural size. (After W. E. Britton.) pest throughout this and neighboring towns that the State of Massachusetts commenced the arduous task of its extermination. At this time the insect oceurred in some twenty towns. For the next ten years it was successfully combated by the Massachusetts authorities, and in 1898 it had spread to but three towns not infested in 1890 and in many places it had apparently been exterminated. So slight was the injury that legislative appropriations were discontinued for four years, during which time the moth spread over four times the area previously occupied and became so abundant that State action was again necessary. From 1905 to 1910 it spread throughout eastern Massachusetts and southern New Hampshire and Maine, and was found in two or three local. 
ities in Connecticut.* Appropriations for its control have been increased until now the State of Massachusetts and the Federal Government are each appropriating \$300,000 per annum and the total cost of combating it in New England must be considerably over a million dollars per year. As it is gradually spreading, there seems every reason to fear that it may ultimately invade other States.

Life History and Description.-The eggs are laid in July and
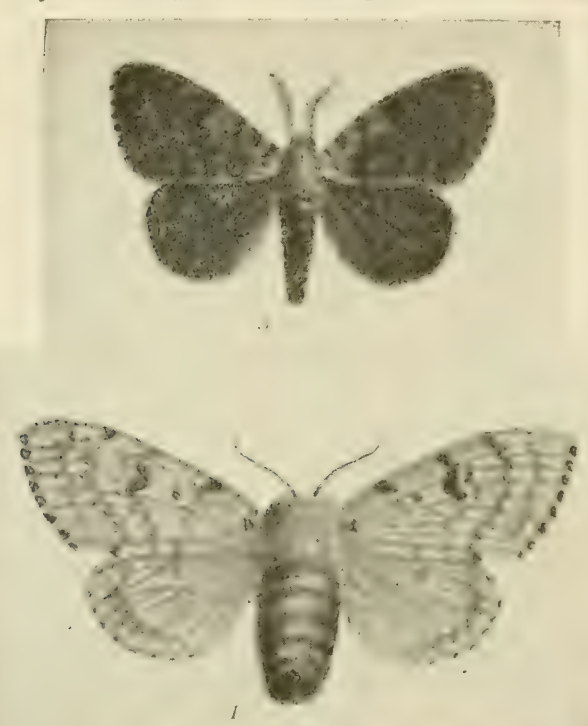

FIG. 419.-The gipsy moth (Porthetria dispar

Linn.): male above; female below-naturil size. (After Forbush and Fernald.)
August, in a mass of 400 to 500 , covered with yellowish hairs from the body of the female. The mass is an irregular ovalshape $1 \frac{1}{2}$ by $\frac{3}{4}$ inches, and is deposited on the bark of trees, but where abundant, on fences, stones, buildings, etc. The eggs hatch about May 1, and each mass yields a swarm of young caterpillars, the bulk of which becoine full grown by midsummer. The mature caterpillar has a dusky or sootycolored body. Along the back is a double row of five pairs of blue spots, followed by a row of "six pairs of red spots, which readily distinguish this from any other common caterpillar. The full-grown caterpillar is about 3 inches long. Sometime in July or early August it spins a few threads of silk as a support, sheds its slin and changes into a pupa, sometimes enclosed in a thin cocoon, but often hanging pendant from its attach-

* Connecticut State authorities, in co-operation with the Federal authorities, have exterminated the insect within that State. 
ment. Characteristic light redelish hairs are scattered over the pupa. The pupal stage lasts from tem days to two weeks, when the adult emerges. The moths emerge from the middle of July to late August. The male is brownish-yellow, viarying to greenish-brown in color, the wings being marked with darker stripes, has a slender body and the wings expand about $1 \frac{1}{2}$ inches. It flies by day with a peeuliar zig-zag flight. The female moth is nearly white with numerous small black markings, is heavybodied and sluggish. The wings expand about 2 inches, but fortunately the female is unable to use them for flight. Were it not for this the spread of the pest would have been much more rapid. After mating the moths live but a short time and do no damage.

The pest is spread mostly in the caterpillar stage The young caterpillars drop down on fine silken threads and may alight on vehicles which transport them to non-infested areas. When just hatched, the caterpillars have very long hairs, slightly expanded at the base, and these, with the silk which they spin out, serve to buoy them up in the air so that they may be carried for a considerable distance by a strong wind Where they occur in myriads on high trees, the little caterpillars may be carried by the wind for considerable distances, and this is one of the chief means of spread.* The egg masses may also be transported on merchandise or boxing, and the pest has undoubtedly become established in several localities in this way. A few cases of importation on nursery stock have been known

The caterpillars will attack any of the fruit, shade or woodland trees, and where they become excessively abundant will destroy all green vegetation of almost any kind. It is essentially a pest of forest trees, but where it oceurs it defoliates all of the common fruit trees. Coniferous trees are killed after being once stripped of their foliage, and deciduous trees usually die after four or five defoliations. Recent experiments show that the young caterpillars when they hatch from the eggs are unable to feed on conifers, so that growths of soft wood may be protected by keeping all hard-wood trees cut out

* See C. W Collins, Bulletin 273, U, S Dept. Agr. 
Control.-In the orchard the gypsy moth is readily controlled by painting the egg masses with creosote in winter and by spraying

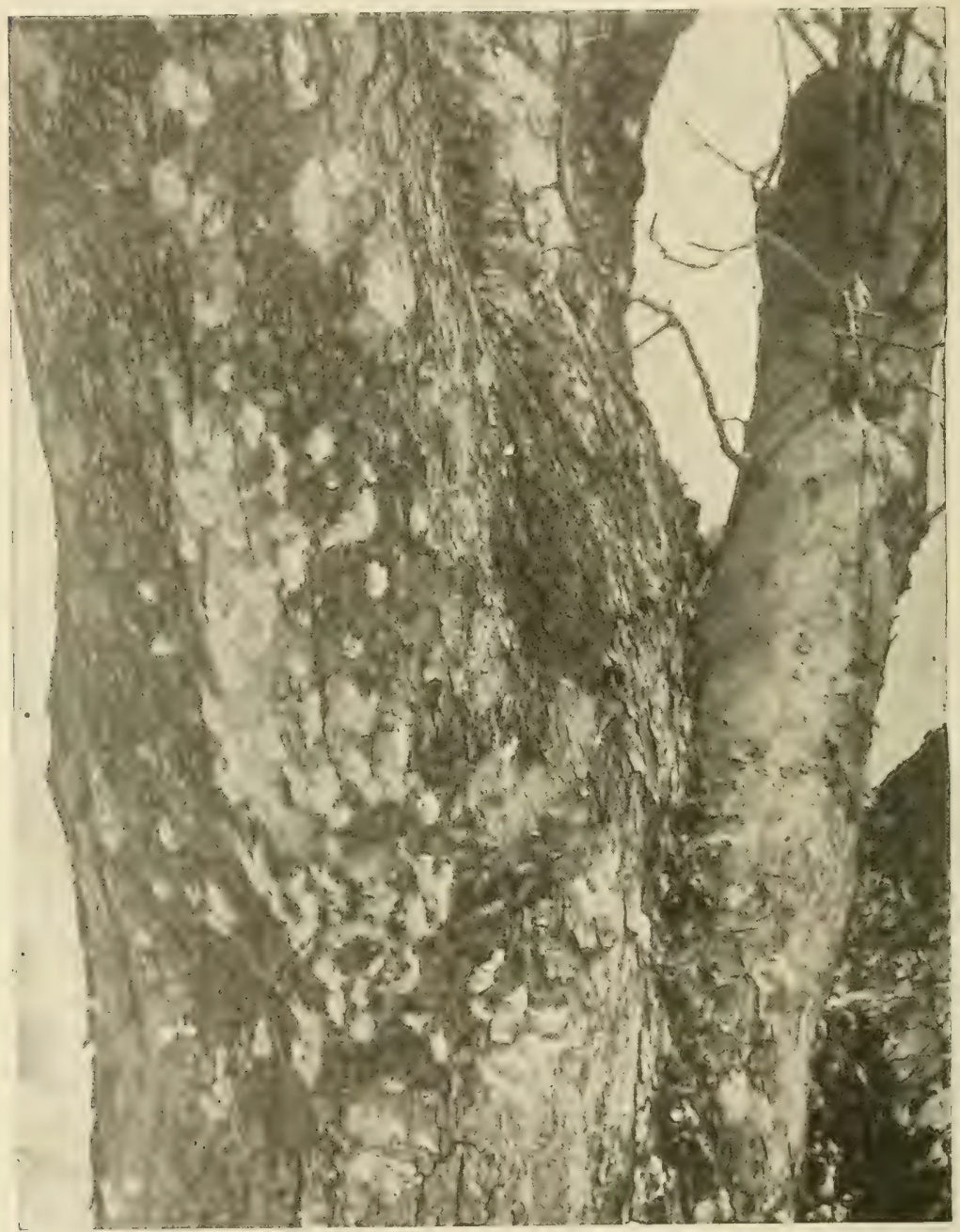

Fia. 420.-Egg masses of the gypsy moth on the trunk of an apple tree.

the trees with arsenate of lead, 5 pounds per barrel, just as the eggs are hatching in the spring. Where this is practiced there is very little trouble in controlling it in orchards. Upon shade and forest trees the problem is much more difficult and the reader 
should consult the authors cited (footnote, p. 492) as to the best means and apparatus. Although the pest is still confined to New England, it is such a serious one and there is so much danger of its spread elsewhere, that fruit-growers should be on their guard against it and should submit suspected specimens to the nearest entomologist. Should it be found in any other States, no expense should be spared to exterminate it absolutely before it may become established.

The Federal authorities, in adclition to maintaining a rigid quarantine within the areas infested by the gipsy-moth and the brown-tail moth, have made very intensive biological studies of the insects, both in this country and in its native home in Europe and have imported from Europe many of its natural enemies, including diseases, hymenopterous parasites and predaceous insects which attack it. Most important among the latter and possibly the most important of the insect enemies, is the ground beetle Calosoma sycophanta L., which is shown in the accompanying illustration.

It is hoped that the importation of a large number of different kinds of natural enemies will, in time, reduce these insects to the status of native pests which are occasionally somewhat injurious but which are, over a period of years, held in check by the natural means of control, and the progress of the work during the past few years makes it seem likely that this will be accomplished.

\section{Canker Worms *}

Since the early colonial days Canker Worms have been among the best-known insect pests of the apple orchard, but they are general feeders and attack several orchard and shade trees. According to Dr. W. E. Britton they "seem to have a preference for the foliage of apple, elm, chestnut, pear, oak, hickory, box-elder, and maple, in about the order named," and cherry and plum are recorded by others. The canker worms are among the most common of the "loopers" or "measuring worms," and are the larve of two nearly related species of moths, very similar in both appearance and habits. The larvæ defoliate the

* Family Geometridae. See D. IV. Corpuillet, Circular 9, Div. Ent., U. S. Dept. Agr.; W. E. Britton, Biemnial Report Conn. Agr. Exp. Sta., 19070S, p. 777; 1. L. Quaintance, Bulletin 68, Part II, Bureau of Entomology, U. S. Dept. Agr. 
trees in early spring, particularly in old sod orchards which have not been cultivated or sprayed.

\section{The Spring Canker Worm*}

This species is so called from the fact that its eggs are laid in the early spring instead of in the fall, as are those of the other species. It occurs from Maine to Iowa and southward to Texas, and in Colorado and California, but has not been reported on the Atlantic Coast south of New Jersey according to Coquillet. It seems to be particularly injurious in the Mississippi Valley. The full-grown caterpillar is from threequarters to one inch long, slender, and cylindrical, and has no prolegs on the middle of the abdomen. The color varies from ash-gray to green or yellow, but the predominating color is dark greenish-olive or blackish, marked with narrow pale lines down the back and a whitish stripe along each side. The wings of the male moths expand an inch, and are semi-transparent, brownish-gray, with three rather indistinct dark lines across the fore-wings. The females are wingless and at the first glance look much more like spiders than moths. They are about one-third inch long, of a dull brown or grayish color with a dark brown stripe down the middle of the back.

Life History.--The moths emerge from the pupx in the ground in March and April and the females climb up the trunks of the trees, where they place their eggs in irregular masses of about fifty, under loose scales of bark, in cracks in the bark, in crotches of limbs, etc. The individual eggs are yellowish-green, turning quite

Fig. 422.-Canker worms dropping from foliage in characteristic attitudes. (After Bailey.)

dark just before the larve hateh, of an oval shape, and about one-thirty-fifth inch long. The eggs hatch in about a month and the young caterpillars commence to feed on the leaves just as they

* Paleacrita vernata Peck. Family Geometridoe. 
are expanding, at first eating small holes through them, but later
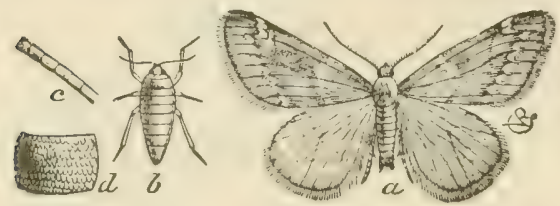

FIG. 423.-The spring canker worm (Paleacrita vernata): $a$, male moth; $b$, female moth-both natural size; $c$, joints of female antenna; $d$, joint of female abdomen; $c$, ovipusitor-enlarged. (After Riley.)

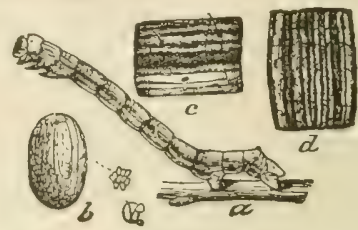

Fig. 424.- The spring canker worm (Paleacrita-vernata): $a$, larva-natural size; $b$, eggs-natural size and enlarged; $c$, side view of segment of larva; $d$, dorsal view of same-both enlarged. (From Riley.

devouring all but the midribs. The young caterpillars have a habit of dropping from the trees and hanging suspended on strands
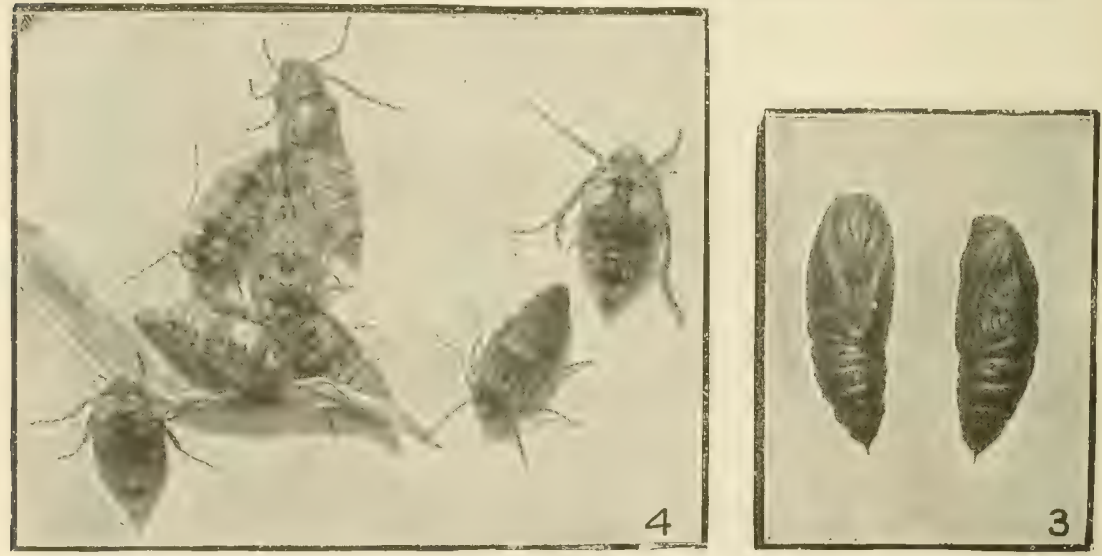

Fic. 42.5.-The female moths of the spring canker worm-twice natural size, and pupæ-three times natural size. (After Quaintance, U. s.' Dept. Agr.)

of silk. In four or five weeks they have hecome full grown and enter the soil to a depth of 2 to 5 inches, where they hollow out earthen cells, which they line with a little silk and in them change to pupæ, in which stage the summer and winter is passed. The pupæ is

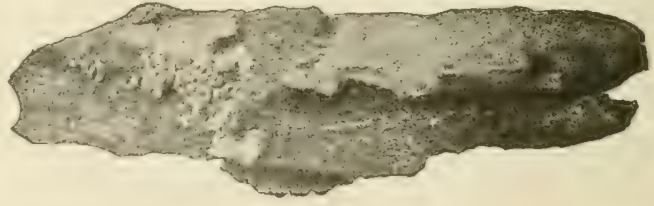

Fig. 426.-Egg's of spring 'canker worm-twice natural size. (After W. E. Britton.) 
nearly one-third inch long, light brown in color, somewhat pitted, and the male pupa bears a simple spine at the tip of the abdomen.

\section{The Fall Canker Worm *}

The Fall Canker Worm seems to be the more common form in New England according to Dr. Britton and is a more northern species according to Coquillet, occurring through the NorthCentral States and in Colorado and northern California. As its name indicates, it differs in life history in that the moths emerge in November and December, "often occurring in great numbers on foggy days during a thaw after the ground has been frozen." They are most numerous about the middle of November in Connecticut, although Dr. Britton states that when the ground freezes in early fall and does not thaw, many of the adults do not emerge until March, when the life history would be identical with the last species. The eggs are laid in clusters of about 100 , arranged in rows, each egg fastened on end, a nd are laid on the bark of the smaller branches or on the trunk. The egg is brownish-gray, rather darker than that of the spring
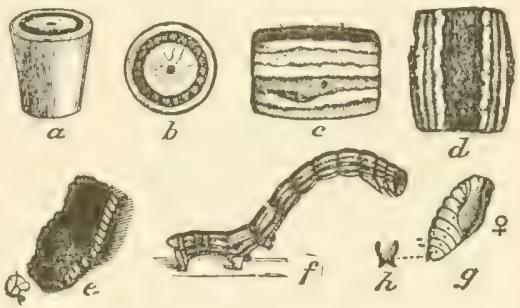

Fig. 427.-The fill canker worm (Alsophila pometrina): $a, b$, agg; $c$, $d$, side and dorsal views of larval sogmentenlarged; $e$, egg mass; $f$, larva; $g$, female pupa-natural size; $h$, anal tubercle-enlarged. (From Riley.)

species, and is shaped like a flower-pot, the outer end being marked with a dark spot in the centre and a dark ring neur the margin. The eggs hatch in late April and early May in Connecticut. The larvæ are very similar in general appearance to those of the spring canker worm, but may be easily distinguished by having two pairs of prolegs on the middle of the abdomen. The pupa is similar to that of the other species, but is somerhat stouter and the spine at the tip of the abdomen of the male pupa is always forked. The cocoon is much tougher, contains more silk, and is therefore less easily crushed. The male moth is slightly larger than that of the other species, with longer antennæ, and the wings are firmer, less transparent and darker in color. The fore-wings are crossed by two whitish bands, the outer one being indented on the front

* Alsophila pometaria Harris. Family Geometridce. 
margin so that it forms a distinct spot, and this outer band is seen on the hind-wings, though it is less distinct. The females are a uniform, ash-gray without markings, and with longer antennæ than those of the other species, the segments of which are about as broad as long, and are bare of hairs.

Control.-In old sod orchards where the pest is always worst. thorough cultivation will largely destroy the pupæ during the sum-

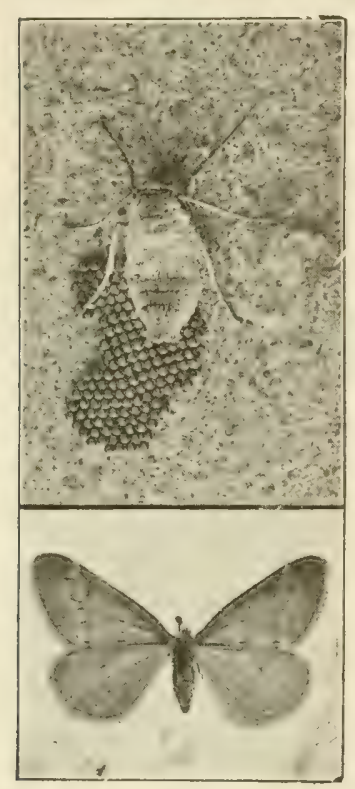

FIg. 428.-Wingless female moth and egg mass, and winged male moth of the fall canker worm - twice natural size. ( A f t e r W. E. Britton.) mer. The caterpillars may be quickly destroyed by spraying with arsenate of lead, 3 pounds per barrel. The first spraying should be applied as soon as the foliage is fairly expanded and before the trees bloom, and the second should be given as soon as the blossoms drop. The first is the more important and one thorough spraying will usually suffice, as the young caterpillars are much more easily killed. Where for any reason sprayIng is not feasible, the females may be prevented from ascending the trees by encircling the trunks with bands of tanglefoot or someother sticky substance which they cannot cross. These bands should be applied in early October and late March, according to the species prevalent. The tanglefoot may be applied directly to the bark of the tree, making a band two inches wide by one-quarter inch thick. Printer's ink, bodlime, and caterpillar-lime are often used, but should not be placed on the bark. A narrow band of cotton batting should be run around the tree and covered with a strip of building paper 4 to 6 inches wide, on the center of which the sticky band should be placed, thus preventing any injury to the bark by the material. Where spraying and cultivation are customary canker worms rarely become troublesome, but they are likely to be the worst insect pest of street-trees and wood-lots in the Middle-west. 


\section{The Evergreen Bagworm *}

The Bagworm is more frepuently eonsidered as a shade-tree pest than as an orchard encmy. At the sinne time its possibilities for injury in the orchard are of great importance. We have seen apple orchards with many trees killed in a period of two years and in one instance in Kiansas a ninety-acre orchard

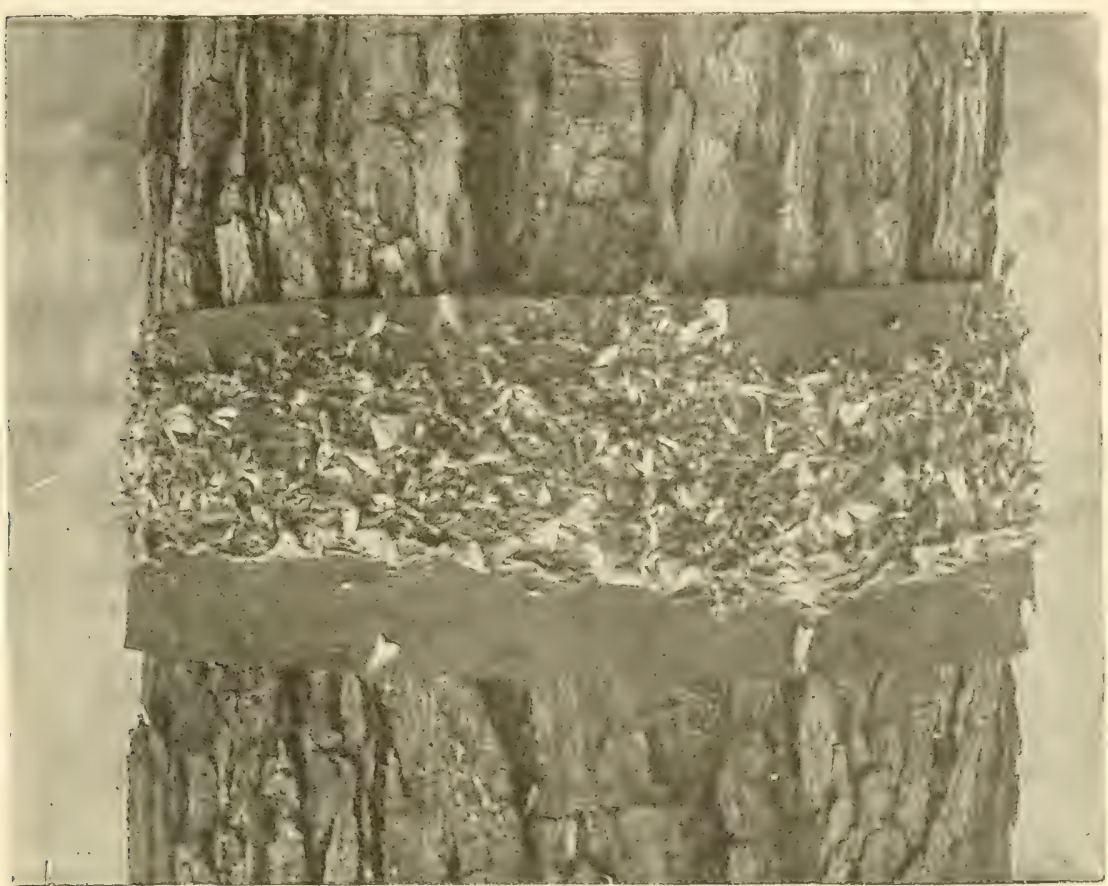

FIc. 429.-Cinker worm moths and egg masses caught on sticky band. (After W. E. Britton.)

was abandoned because the insect had injured most of the trees beyond recovery. The bagworm feeds on evergreens such as juniper or red-cedar and arborvitie as well as on fruit and shade trees. It attacks locust, maple, poplar, apple, plum and many other trees, showing a preference for the evergreens and the locust.

* Thyridopteryx ephemeroformis Haw. Family Psychide. See Howard and Chittenden, Farmers' Bulletin 701, U.S. Dept. of Agr., and L. IIaseman, Bulletin 104, Missouri Agr. Expt. Station. 
It is a native insect and is found generally over the country east of the Rockies and south of the northern tier of States, but injury is most serious in the Central States.

Injury is usually sporadic, occurring for a year or two and then disappearing. This is due to the subjection of the insect by its many parasites which keep it from being at all times a first-class pest.

The male moth is a small, black form with short, rounded, clear wings and is rarely seen. The female is wingless and does

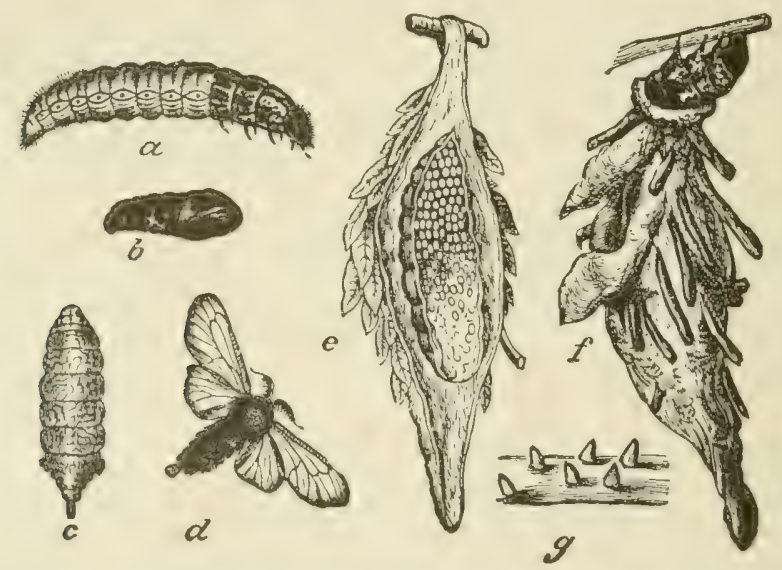

FIG. 430.-Bagworm, Thyritopteryx cphemeroformis: $a$, larva; $b$ and $c$, pupa, side and back views; $d$, adult; $e$, case containing the eggs; $f$, larva in case; $g$, eggs. Natural size. (After Forbes.)

not leave the bag or cocoon. In this cocoon, in the fall, she lays her eggs and in this state the winter is passed. In early spring the eggs hatch and the young larvæ feed on foliage, forming almost inmediately their bags or cocoons which they enlarge as they grow. The cocoons are first the shape of tiny cones which project from the upper surface of the leaves upon which the insects are feeding and conceal all but the head and feet of the worm. When the insect is nearly grown it begins to taper the lower end of the cocoon and by the time growth is completed the cocoon tapers about equally toward each end, being spindle-shaped. It is attached firmly by a band of silk to a small twig and the larva pupates. Males emerge in a few weeks but the females remain in the bags and produce their eggs. 
Control is accomplished by spraying with arsenate of lead, applied at the time of the first appearance of the foliage as for the curculio and canker-worms.

\section{The Plum Curculio*}

Throughout the States east of the Rocky Mountains, the Plum Curculio is one of the worst pests of the common stone and pome fruits. Its larva is the common white "worm" found in peaches, plums, and cherries, while apples and pears are scarred and gnarled by the feeding and egg punctures made by the adults. It is a native insect which breeds on wild plums, wild crab-apples and hawthorns. The adult is a thick-set snout-beetle about one-quarter inch long, brownish in color, marked with gray and black, and with four black ridged tubercles on the wing-covers. The larva is a footless, cylindrical, whitish grub, about one-third inch long, with a small brown head,

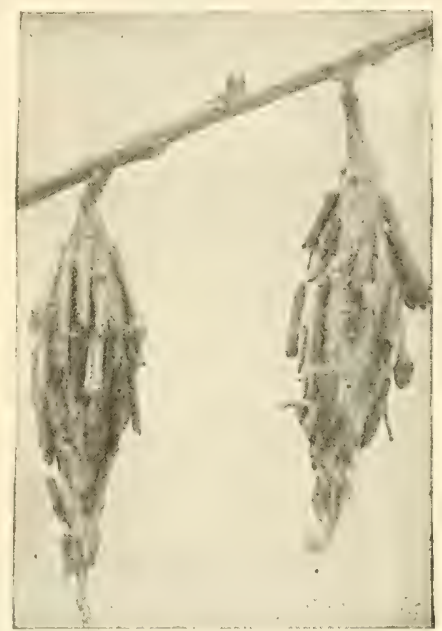

FIG. 431. - Bagworm cocoons or "Bags." and usually lies in a curved position as in Fig. 432.

Life History..- The beetles hibernate under grass, leaves, and other trash on the ground in or near the orchard, or in neighboring woodlands, and conmence to emerge just before the fruit trees bloom in the spring. They feed somewhat on the buds, unfolding leaves and blossoms, but mostly on the young fruit as soon as it is set; indeed, in New England the beetles do not emerge until a week or two after the apple blossoms fall. The females commence to lay eggs in the young fruits as soon as formed. The egg puncture of the plum curculio is shaped like a crescent and

* Conotrachelus nenuphar Herbst. Family Curculionida. See C. S. Crandall, Bulletin 98, Ill. Agr. Exp. Sta.; S. A. Forbes, Bulletin 108, ibid.; J. M. Stedman, Bulletin 64, Mo. Agr. Exp. Sta.; E. P. Taylor, Bulletin 21, Mo. State Fruit Exp. Sta.; A. L. Quaintance, Tearbook U. S. Dept. Agr., 1905, p. 325; Circular 120, Bureau of Entomology, U. S. Dept. Agr., and Bulletin 103, ibid. 
has given it the very apt name of "little Turk." The female first eats out a small hole with her stout snout, and deposits a small, oval, white egg in the cavity. She then cuts a small

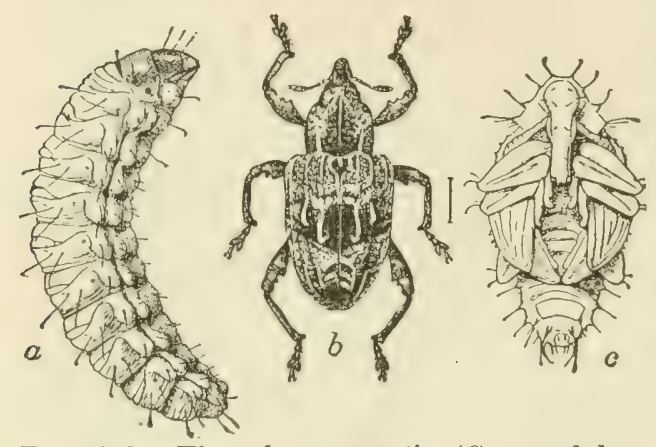

FIG. 432.-The plum curculio (Conotrachelus nenuphar Herbst.): $a$, larva; b, beetle; $c$, pupa-all much enlarged. (After Chittenden, U. S. Dept. Agr.) segment of the skin and flesh around it so that the growth of the fruit will not crush the egg, the whole operation taking from fifteen to thirty minutes. The life of the female averages about two months, during which time she will lay 100 to 300 eggs and probably make as many more feeding punctures. The punctures made by the adults of both sexes in feeding are simple round holes like those in which the eggs are laid, but without
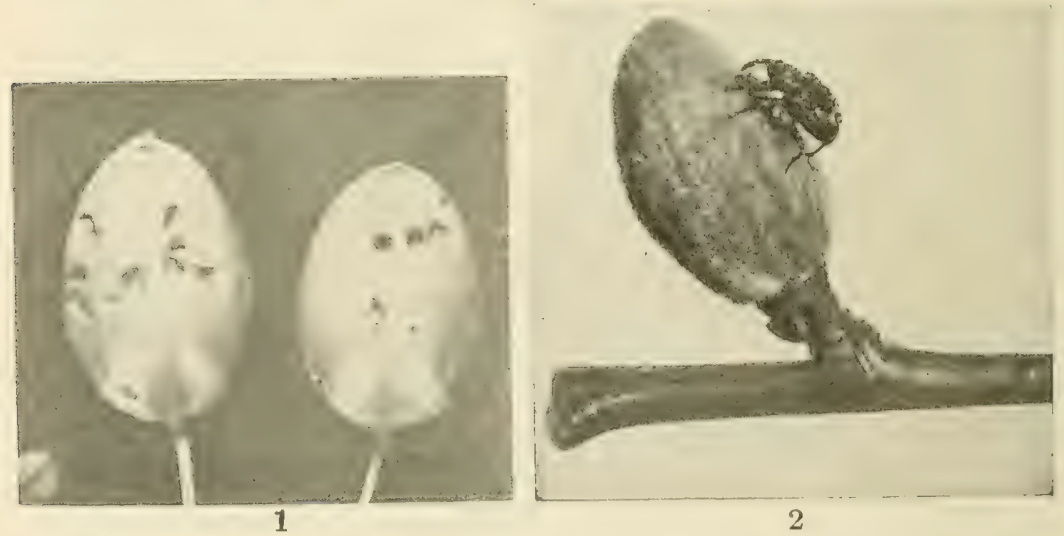

Fig. 433.-1, young plums showing crescent-shaped egg punctures of the plum curculio; 2 , adult curculio on young peach-four times natural size. (After Quaintance, U. S. Dept. Agr.)

the crescent marks. Frequently gum exudes from punctures on the stone fruits.

The egg hatches in from three to five days and the young larva bores into the fruit until grown, usually feeding around the 
pit in stone fruits. The larva becomes grown in from twelve to eighteen days (in peaches) acoording to (quaintance, but in cen-

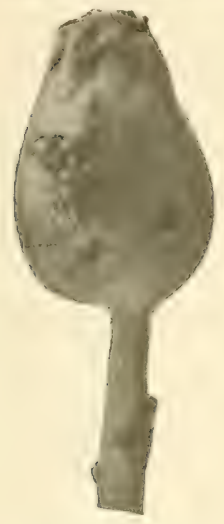

FIG. 434.-Plum curculio on young apple and egg punctures - enlarged.

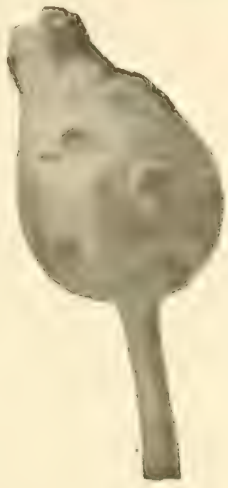

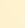

tral Illinois in fallen apples it requires from twenty to twenty-six days according to Crandall. When full grown the larva leaves

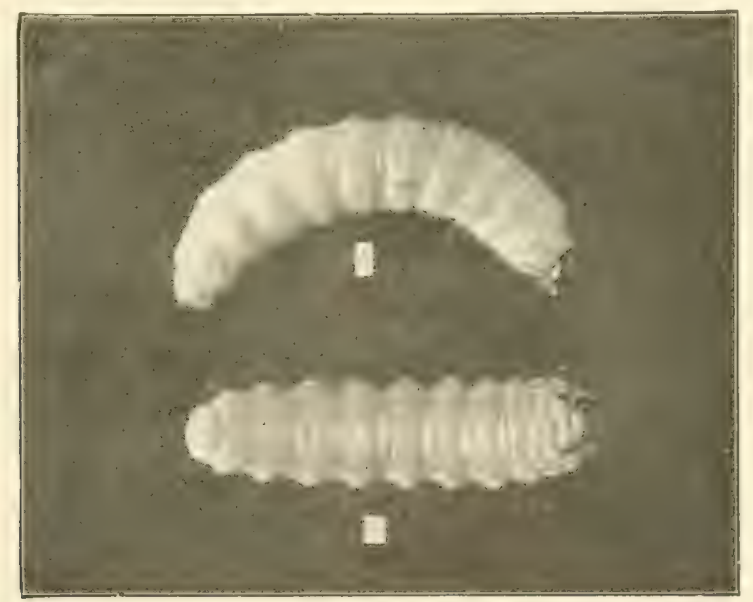

Fig. 436.-Larve of the plum curculin-cnlarged five times. (After Stedman.)

the fruit and enters the soil, where it forms a small cell an inch or two below the surface, in which it transforms to a white pupa. Three or four weeks elapse hefore the emergence of the adult 
beetles; the first emerge about ten weeks after the apples blossom, the majority appear two or three weeks later, and the rest continue to emerge until October. If the weather is dry

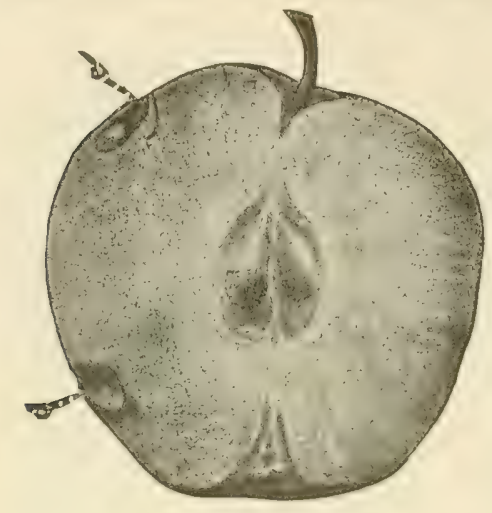
the beetles may remain in the cells much longer than normally, while a shower will bring out numbers of them. Upon emerging the beetles feed upon the ripening fruit. In many sections the injury to apples by the feeding punctures then made is worse than the spring injury, as the surface of the fruit is injured and entrance places for rot are furnished. The beetles average about one puncture a day for six weeks after emergence in central

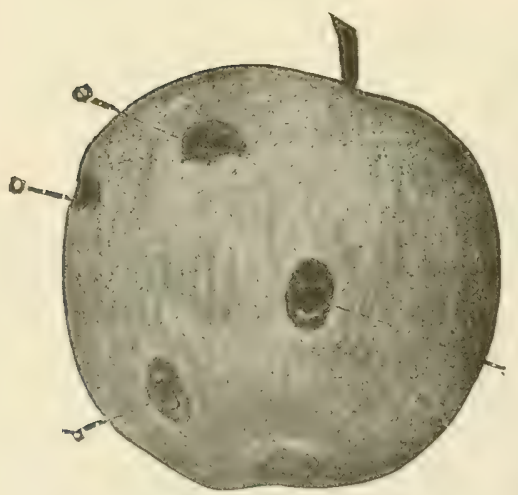

FIg. 437.-IVork of the plum curculio on apple: $d$, feeding punctures from surface and in section; $e$, egg puncture from surface; $e_{.}$, same in section-all enlarged." (After C. S. Crandall.) Illinois and commence to enter hibernation with the first frosts. In New Hampshire we have seen no evidence of injury by the beetles in late summer or fall.

Injury,-Injured plums and peaches usually drop to the ground, or if they remain on the tree, ripen prematurely, and rot more quickly. Cherries stick to the tree, but the fruit is often small and gnarled from the egg-scars, or eaten o ut by the larva. In apples the larvæ only develop in those which drop to the ground, the rapid growth of the apples probably crushing the eggs. The egg-scars and feeding-punctures cause apples to become gnarly, this being particularly true of summer varieties, which are often rendered worthless, and even winter sorts are blemished by the scars which also furnish points of attack for rots. 
Control.-Frequent cultivation while the pupae are in the soil in midsummer will throw them to the surface and crush many of them, and has been found to aid materially in the control of the pest. As the larv often develop in the fallen fruit, it is well to gather it every few days and destroy it before the larva have left it to pupate, which will also aid in the control of other fruit pests. The beetles have a habit of "sulling," "playing possum," or feigning death, when suddenly disturbed, and will drop to the ground if a limb is jarred. This has given rise to the common practice of jarring peach, plum, and cherry trees and collecting the beetles on frames beneath them. This may be done with simple frames covered with eanvas, a frame being placed on either side the tree and a flap extending from one over the edge of the other, from which the beetles are picked up, or a regular curculiocatcher such as has been commonly used in New York may be more convenient. This is used as shown in Fig. 438, the frame being covered with oil-cloth and slanting to a can containing kerosene for the destruction of the beetles which slide into it. The jarring should be done in the morning, as the beetles do not drop as readily in midday.

The jarring method of curculio control has, at the best. merely a historical interest now as it is impractical in commercial orchards and of doubtful value elsewhere.

Modern methods for curculio control are based on the feeding habits of the adults. Since these feed on the young foliage in the spring before and during the egg-laying period they may there be poisoned. Arsenate of lead is the material most largely used, the applications on apple as recommended for the codling moth giving fair control. If curculio injury is more serious, there should be a spray applied to the apples before the blossoms open. This is known as the "cluster-bud" spray and is often necessary for canker-worm control as well as advisable for certain diseases. On peach, plum and cherry, the time of application is varied to some extent, but if one bears in mind that it is well to keep the foliage covered with poison from the time it appears in the spring for a period of about six weeks and arranges the 
spray schedule so as to accomplish this as nearly as possible, he will secure satisfactory control of the curculio.

Arsenate of lead must be applied with care to the peach as the foliage is tender. It is frequently applied with selfboiled lime-sulphur and if this is not used lime should be substituted

\section{The Oriental Peach Moth or Fruit Moth**}

Another recent importation from the Orient which deserves mention on account of its almost unlimited possibilities for evil

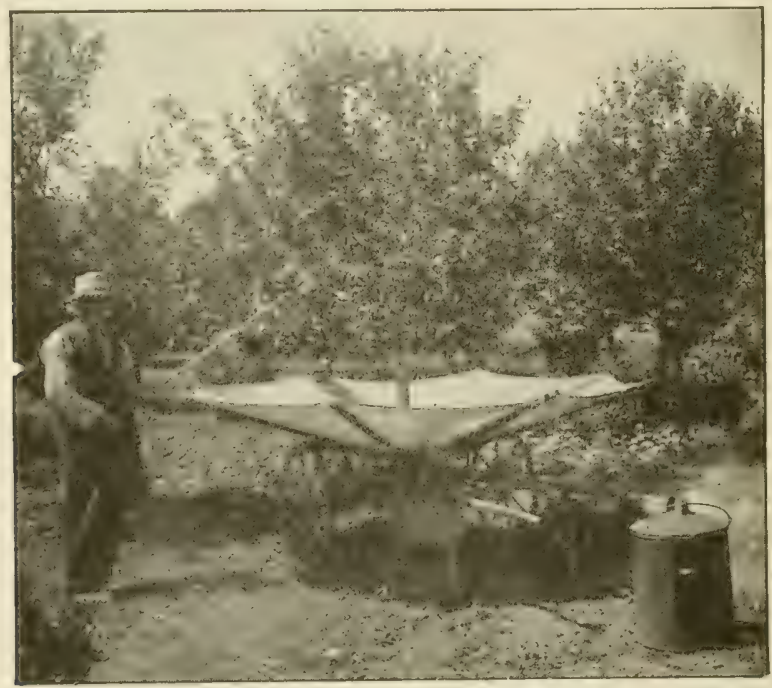

Frg. 438.-Jarring trees over a curculio catcher. (After Slingerland.)

is the so-called Oriental Fruit-moth or Peach-moth. It is closely related to the colling-moth but is more difficult to control as it has four to six broods each year and it feeds on foliage, in fruit and in the twigs, its feeding habits being such that effective control by means of spraying would be impossible.

This insect has been noticed in the District of Columbia and has since been found in Maryland, Virginia, West Virginia,

* Laspeyresia moelsta Busk. Family Tortricida. See Philip Garman, Bulletins 209 and 223, Md. Agr. Expt. Station, and Quaintance and Wood, Jour. Agr. Research, Vol. VII, No. 8, and Wood and Selkregg, ibid, Vol. XIII, No. 1. 


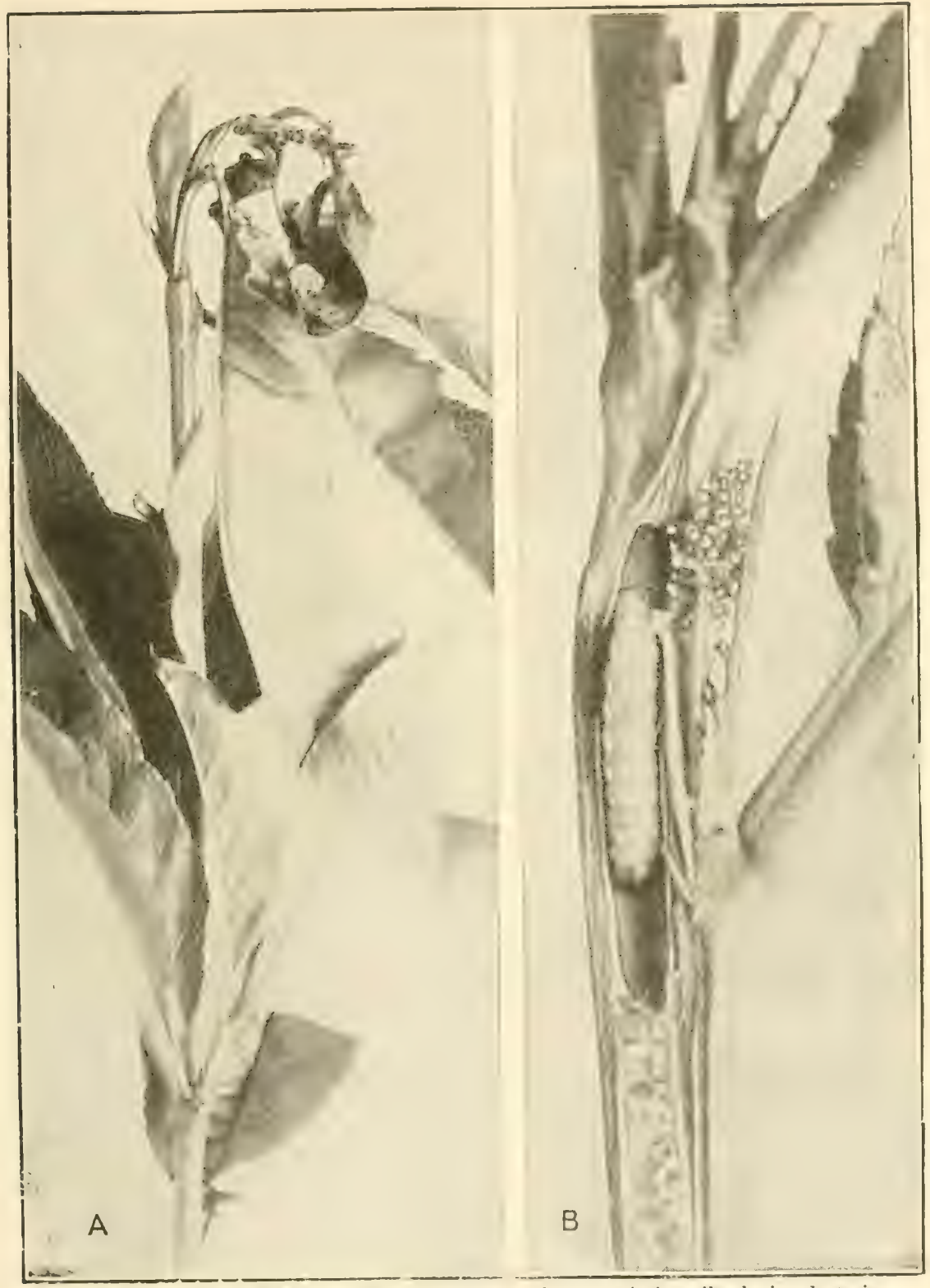

FH, 439. Work of Oriental fruit moth: a, chatracteristic wilted tip; $h$, twig cut open showing larva in burrow. (After Wood and Selkregg, l. c.) 
and neighboring states. It has not developed in abundance

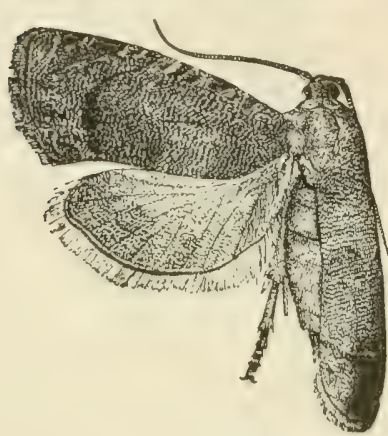

Fig. 440.-Adult Oriental fruit moth. After Wood and Selkregg, $1 \mathrm{c}$. except in and near the District of Columbia as yet and it is possible that it will find some conditions here which will tend to discourage its wide spread.

The larvæ are similar to the cod-

ling moth but may be distinguished by food habits which have been mentioned The moth is the size of the codling moth but a duller and more uniform gray in color.

Control measures have not yet been determined. 


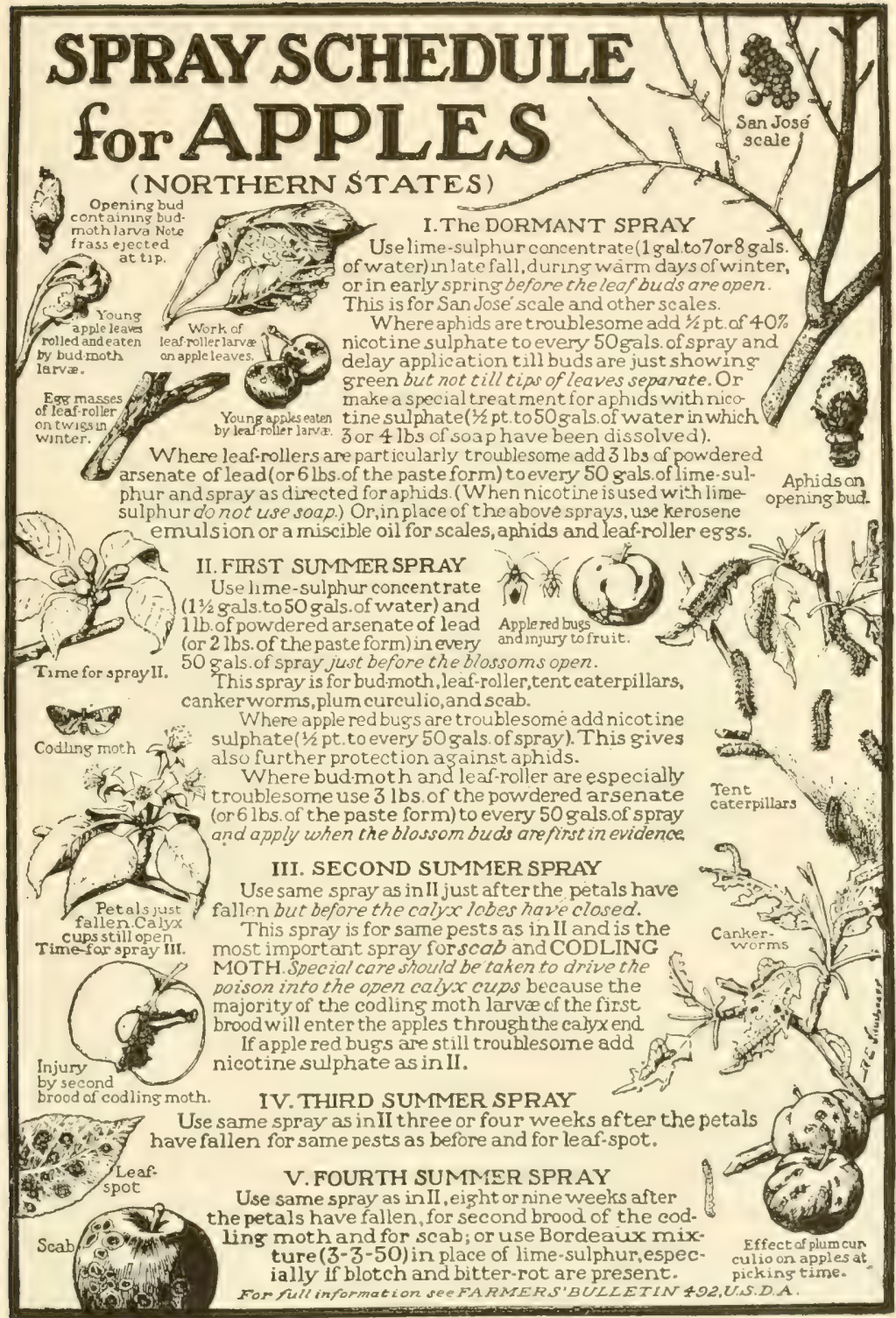

Fig. 442.-Apple spraying chart. Bureau of Entomology, U. S. Dept. Agr. 


\section{CHAPTER XXV}

\section{INSECTS INJURIOUS TO THE APPLE AND PEAR}

\section{The Woolly Apple-aphis *}

The Woolly Aphis is one of the most destructive pests of young apple orchards, and as it works mostly upon the roots it often escapes detection until the tree is badly injured or killed.

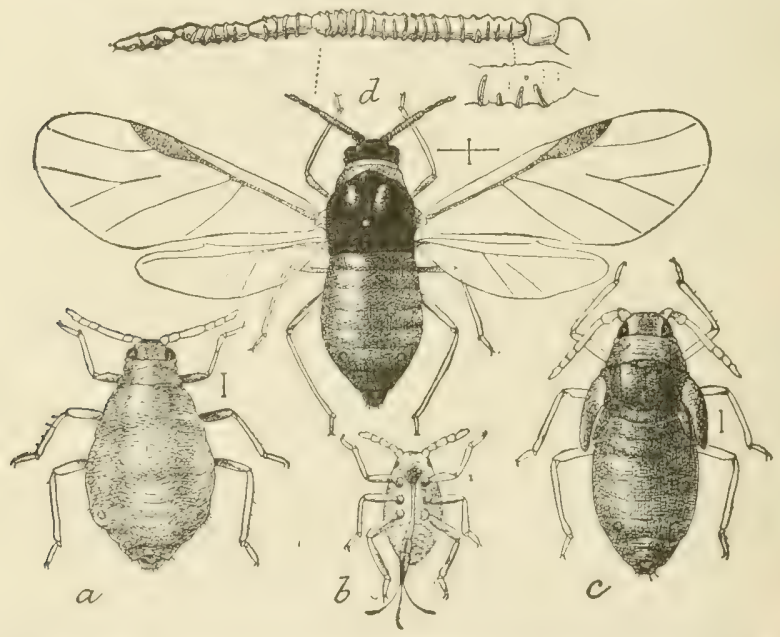

FIG. 443.-The woolly apple-aphis (Eriosoma lanigera Hausm.): a, agamic female; $b$, young nymph; $c$, last stage of nymph of winged aphis; $d$, winged agamic female with enlarged antenna above-all greatly enlarged and waxy exeretion removed. (After Marlatt, U. S. Dept. Agr.)

The aphids will be found clustered in bluish-white, cottony masses, looking like patches of mold, on the smaller twigs, particularly water-sprouts, and around wounds or scars on the trunk

* Eriosoma lanigera Hausmann. Family Aphidido. See C. L. Marlatt, Circular 20, Div. Ent., U. S. Dept. Agr.; R. I. Smith, Bulletin 23, Ga. State Board of Ent.; Gillette and Taylor, Bulletin 134, Colo. Agr. Exp. Sta., p. 4: C. P. Gillette, Journal of Economic Entomology, Vol. I, p. 306; A. C.' Baker, Report 101, U. S. Dept. Agr., and B. R. Leach, Bulletin 730, U. S. Dept. Agr. 
or limbs. Their presenee in these places is always an indication that others are feeding upon the roots, where they cause gall-like swellings, so that the roots soon herome a mass of knots and die in a year or two if the injury continues. When badly attacked a tree becomes sickly, the foliage turns yellow, and if not killed outright by the aphids, it fallis an easy prey to borers and other pests. Injury seems to be worse on light soils and not so severe on heary soils. Whether the insect is a native or a European species is a matter of dispute. In Europe it is called the "American blight," and was described from Germany in 1801. It has now become distributed all orer the world on nursery stock, which forms the principal means of its dissemination.

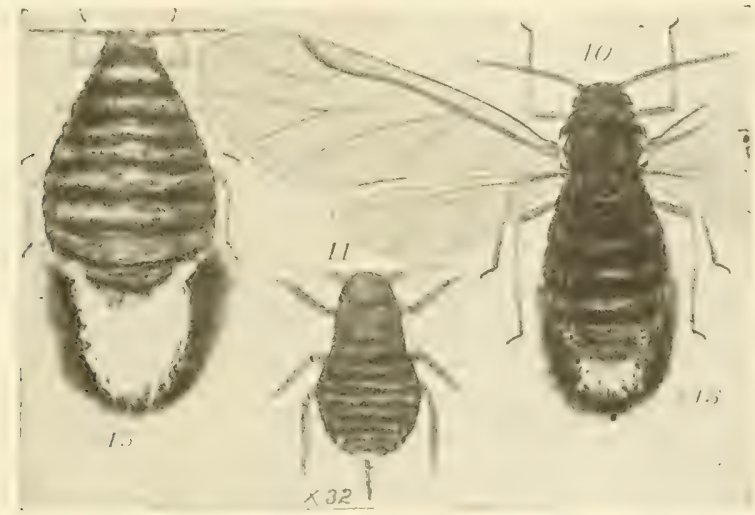

FIG. 444. - The woolly apple-aphis: at left, apterous viviparous female; 10 , fall migrant; 11, over-winter young. (After Gillette and Taylor.)

Life History.-On infested trees aphids will be found in all stages of growth on the roots in early spring. On the trunk, under bits of bark or under the dead bodies of those killed the previous fall, will be found numerous small aphids which have hibernated there, though in the North these may be killed out during severe winters. As the buds begin to open, the aphids on the trunk locate on tender new bark and commence to feed, and many migrate from the roots to the top at about the same time They are not usually letected until they have multiplied sufficiently to make small white patches, on the bark or leaves, which look like mold. During the spring and summer all are wingless females, not over one-tenth inch long, of a reddish-brown 
color and covered with a white, waxy secretion, given off in threads from the abdomen so as to form a cottony mass over the colony.

These females produce from 2 to 20 young per day, which become full grown in from eight to twenty days according to Alwood, 100 or more probably being produced in two weeks.
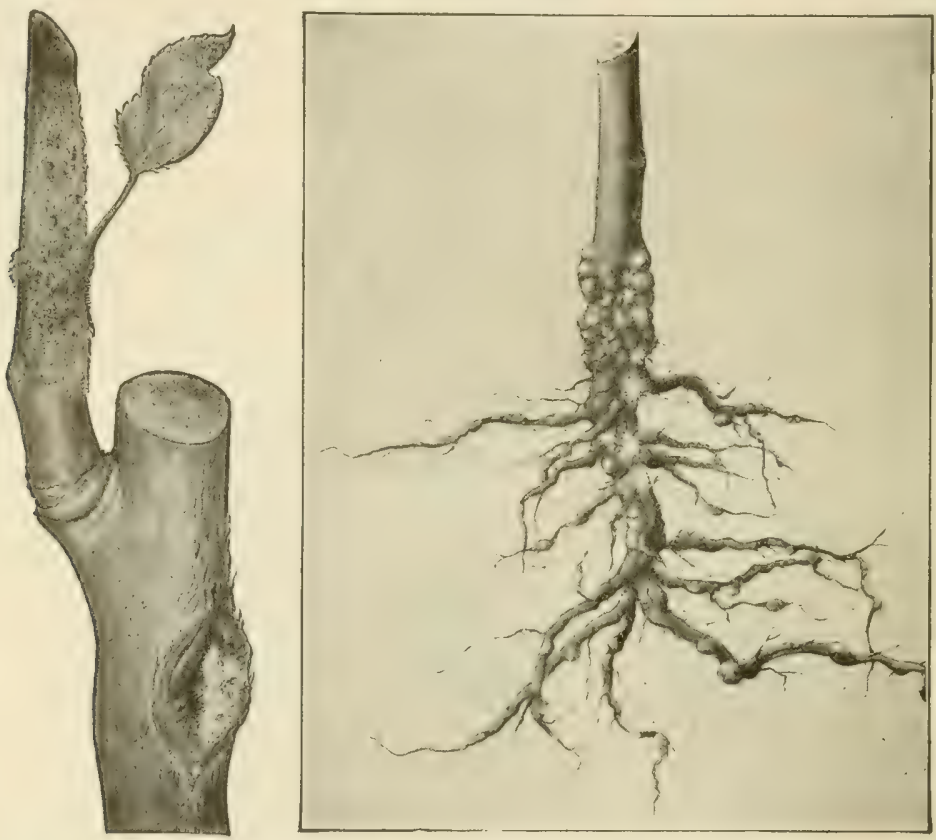

Fig. 445.-The woolly apple-aphis: at left, colonies on twig and in scar on an apple limb; at right, crown and root of young apple tree, showing characteristic swellings produced by the root aphids. (After Alwood.)

Reproduction continues on both tops and roots except as checked by the cold of winter, the aphids becoming most abundant in midsummer. Early in the fall a generation of winged aphids appears, which migrates to other trees. They are about onetwelfth inch long and have a wing expanse of one-quarter inch. They appear to be black, but the abdomen is really a dark yellowish or rusty brown color when closely examined, and bears more or less of the waxy secretion on the tip. Each of these winged females gives birth to from four to six wingless males and

* Bulletin 45, Va. Crop Pest Commission, p. 12, Special Bulletin, Va. Agr. Exp. Sta. 


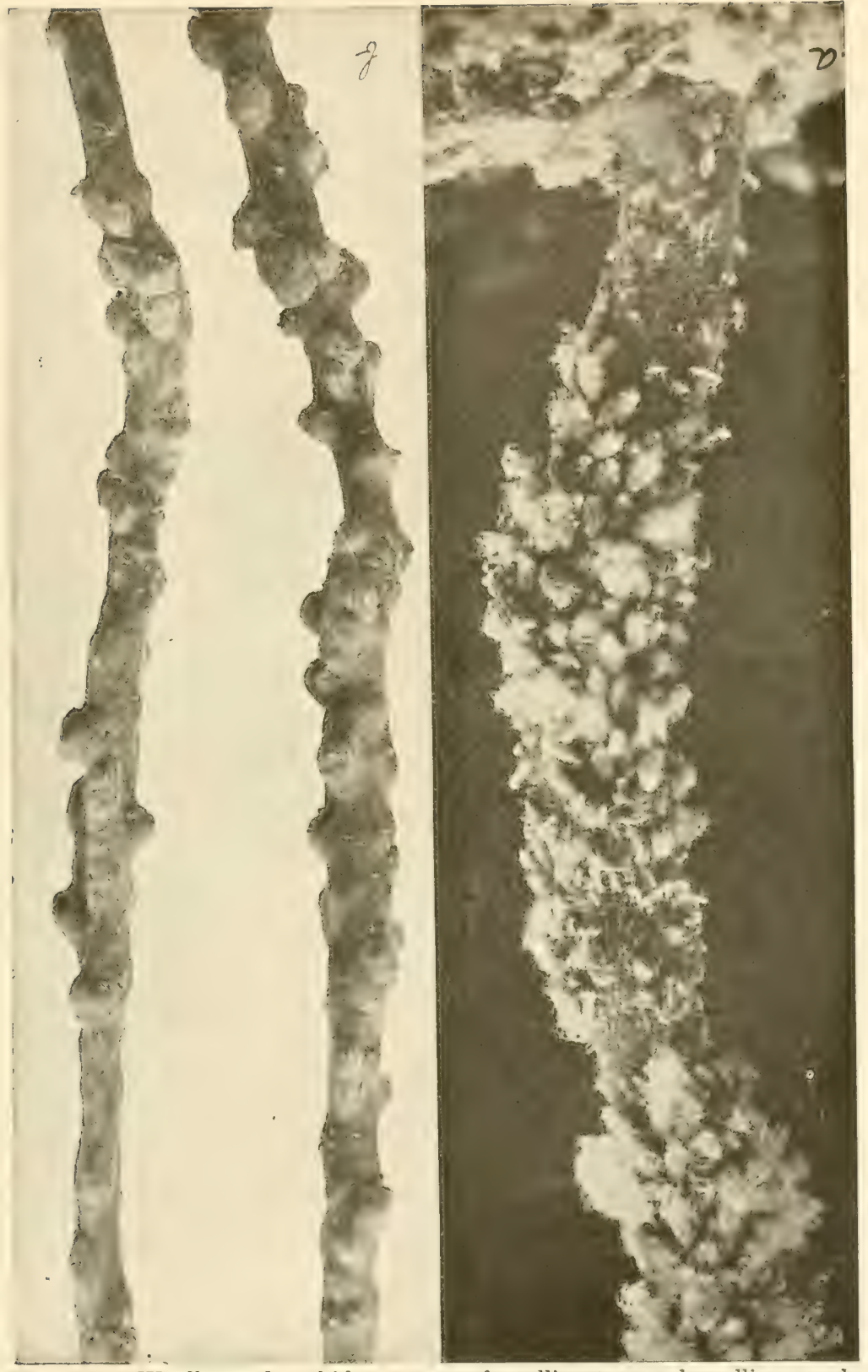

Fig. 446. - Woolly apple-aphids on stem of seedling tree and swellings made on roots slightly enlarged. (After Rumsey and Brooks.) 
females, which are deposited on the trunk of the tree. The sexes are wingless, much smaller than the summer forms, and are without beaks, so that they take no food. The female is a brown-ochre color, and the male dark green or greenishbrown and smaller, as shown in Fig. 448. They become full grown in about eight days, when they mate and the female then
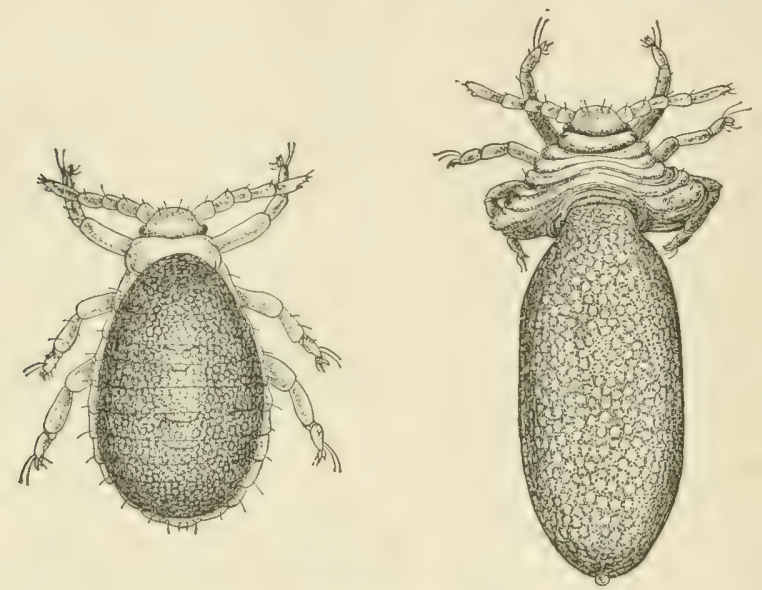

FrG. 447.-Sexual female of the woolly apple-aphis, showing egg before and after extrusion-greatly enlarged. (After Alwood.)

lays a single large black egg, which is deposited in the crevices of the bark on the lower part of the trunk. These eggs hatch in the spring and give rise to new colonies.

As they multiply large galls are produced on the roots, the tissue probably being poisoned by the mouth-parts of the insects. As a result the roots soon die and the aphids then migrate to the growing roots, so that their absence on the worst knotted roots does not indicate that they have forsaken the tree but that they are on younger roots,

Control.-Nurserymen commonly apply a liberal amount of tobacco dust in trenches along the rows, which kills the aphids and acts as a repellant, as well as being worth half its cost as a fertilizer. This is probably the best practice in the nursery unless the aphids become abundant when more vigorous treatment should be used, but tobaceo has not always proven a satisfactory treatment for orchard trees though used with apparent success 
in some instances. The aphids may be destroyed on the foliage by spraying with 7 per cent kerosene emulsion, miscible oils diluted 30 to 40 times, whale-oil soap, 1 pound to 6 gallons, or tobacco extracts, "black leaf -40 " being used 1 part in 700 of water. Whatever insecticide is used must be applied in a strong spray so as to wet thoroughly and penetrate the waxy covering of the aphids. A winter spray of lime-sulphur wash destroys the hibernating aphids on the trunk, and doubtless kerosene emulsion or miscible oils applied in early spring, as for the San José scale, would be as effective, though the lime-sulphur would probably also destroy some of the eggs. The trunks of trees known

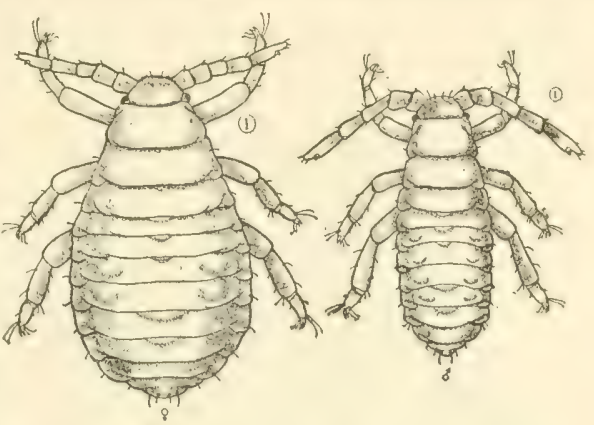
to be infested may be Fig. 448.-Sexual female and male of the banded with tanglefoot or similar sticky materwoolly apple-aphis - greatly enlarged. (After Alwood.)

ials as described for canker worms (p. 502) to prevent the aphids from migrating from the roots to the top. Where the aphids are abundant on the roots, the earth should be removed for 6 or 8 inches deep over the affected roots and lime-sulphur solution, diluted about one to eight, applied in quantities sufficient to wet the soil thoroughly about the roots. Other solutions tried for soil treatment have given less success than this.

Some success has been reported by Leach from the use of carbon disulphide in water solution, one ounce to four gallons, applied about the roots with a power sprayer. Sodium cyanide solution, applied in the same way also gave fairly good results. With any of these methods there is the disadvantage that they require large quantities of water to be transported to the orchard and all are somewhat expensive.

Liberal fertilization, to enable the tree to do well in spite of the presence of the aphids is probably more practical for most growing conditions. 


\section{The Round-headed Apple-tree Borer *}

The young apple orchard must be given frequent inspection to detect the work of the round-headed borers, for if they become established in the young trees it is difficult to kill them and they soon girdle the trunks. They are most injurious to apple and quince, less so to pear, and also infest wild thornapple trees and mountain ash. The species occurs generally east of the Rocky Mountains, but is not commonly injurious in the Gulf States. The presence of the borers may be detected by the retarded growth

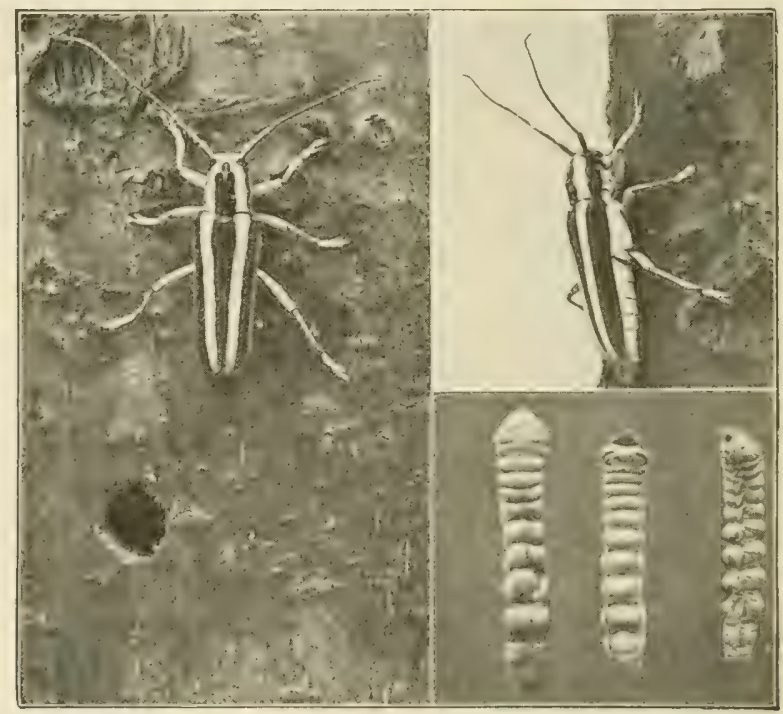

FIG. 449.-The round-headed apple-tree borer (Saperda candida Feb.) larvæ, adults, and exit holes-natural size. (After Rumsey and Brooks.)

of the trees, with a yellowing of the foliage, and the sawdust like castings which the larvæ throw out from the entrances of their burrows, accompanied by a discoloration of the bark over the new burrows, and in early spring there is often a slight exudation of sap. Injury is most severe in neglected orchards, where grass and weeds are allowed to grow about the bases of the trees, as the beetle, which flies at night, seeks the concealment of the rank vegetation during the day. The parent beetle is a handsome

* Saperda candida Fab. Family Cerambycido. See E. P. Felt, Bulletin 74 , N. Y. State Museum, p. 23, which gives full bibliography to 1902, and F. E. Brooks, Farmers' Bulletin 675, U. S. Dept. Agr. 
insect about three-quarters inch long. The antenna and legs are gray, the head and under surface of the body silvery white and the upper surface is light brown with two longitudinal white stripes.

Life History. - The beetles emerge from late Way to the middle of July and the females soon commence to deposit their eggs. The female eats out a little slit in the bark, in which the egg is inserted and often pushed under the bark and then covered with a gummy substance. It is a pale rust-brown color, ahout one-third inch long, of a broad oval shape, and usually concealed on young trees. The egg hatches in two or three weeks. The young larvæ tunnel just under the bark on the sap-wood, usually working down
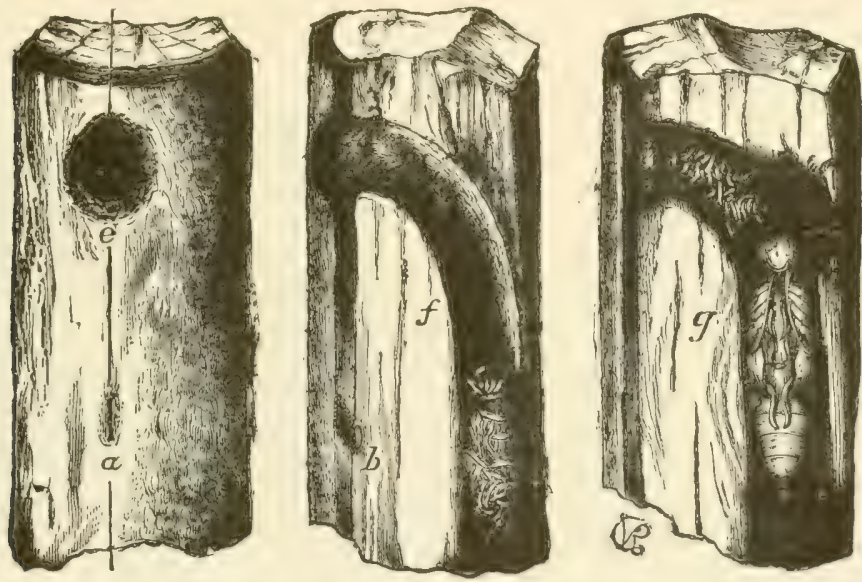

FIG. 450.-Work of the round-headed apple-tree borer: $a$, puncture in which egg is laid; $b$, same in section; $e$, hole from which beetle has emerged; $f$, same in section; $g$, pupa in its cell. (After Riley.-)

toward the base of the tree, the bark over these burrows often cracking the next spring, and the fine castings and borings sifting out. At the heginning of the second year the larva is about five-eighths inch long. The larva continues in the sap-wood during the second season, and it is at this time the most serious damage is done, for where several occur in a tree they almost girdle it. The next season they penetrate into the heart-wood, and several of them will fairly riddle a small tree with their cylindrical burrows. The full-grown larva continues this burrow out into the bark, often cutting clear across a tree. The upper part of the burrows are stuffed with fine borings and the lower 
part with long wood fibres. The full-grown larva is a light yellowish, cylindrical grub, about three-quarters inch long. The head is small, legs are lacking, and the body tapers gradually from the thorax backward, the segments being quite constricted. The third spring the larvæ transform to pupæ and about three weeks later the adult beetles emerge through large round holes. This habit is varied, according to Brooks, in some localities the majority of the beetles emerge in two years from the time

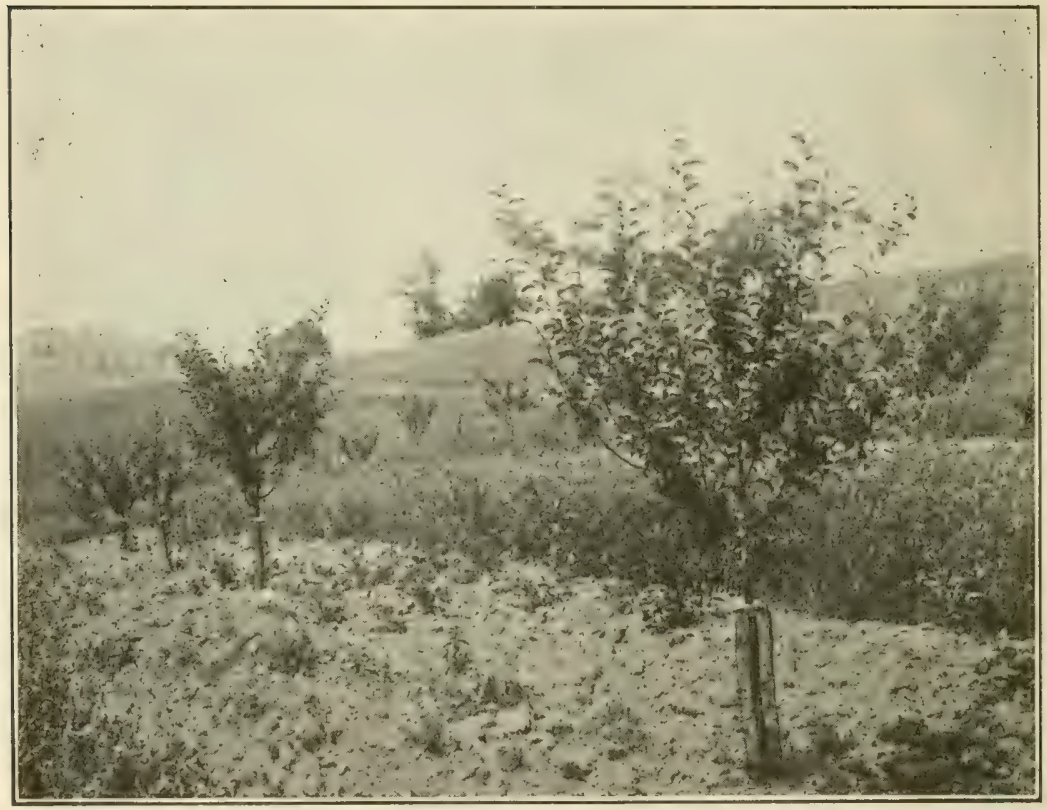

FIG. 451.-Young apple tree protected from borers by a wire screen protector. Photo by W. E. Rumsey.

of hatching in place of in three, as is generally the case in the northern range of the insect.

Control.-The females may be prevented from laying their eggs by wrapping the trunks with wire netting, building paper, or wood veneer. If non-rusting wire netting is used it may be left on and will also protect the trees from mice and rabbits. The paper or wood wrappings should be applied about May 1st, and removed in late summer. They should be tied to the tree tightly just below the crotch and should extend an inch or two into the soil below. The wire netting should be held out from the 
trunk of the tree by a layer of cotton batting under it at the upper end. Various washes have been used to repel the beetles. Thick whale-oil or caustic soft-soap to which a pint of crude carbolic acid is added to every 10 gallons is often used and should be painted over the trunk so as to form a thick coating. Others recommend a thick coating of whitewash to which a little Portland cement is added to make it more adhesive. These should be applied by the middle of May and as often as need be to keep the trunk covered until late summer. Asphaltum, melted and painted onto the trunks, gives better results than any of the other materials of this nature, according to results secured in West Virginia, but none of the treatments seems to be entirely satisfactory.

If the trees are gone over every fall and spring, the egg scars and burrows of the young larvæ may be detected and these may be cut out while still in the sap-wood, without much injury to the tree. When the borers get into the heart-wood it is almost impossible to dig them out without doing more injury to the tree, but they may sometimes be destroyed by injecting carbon bisulfide into the burrows and plugging the aperture with putty or clay. Where a tree has been nearly or quite girdled, it may sometimes be saved by bridgegrafting. Orchards kept free of grass and weeds and trees with smooth healthy bark are much less affected. Brooks reports; also, that the beetles

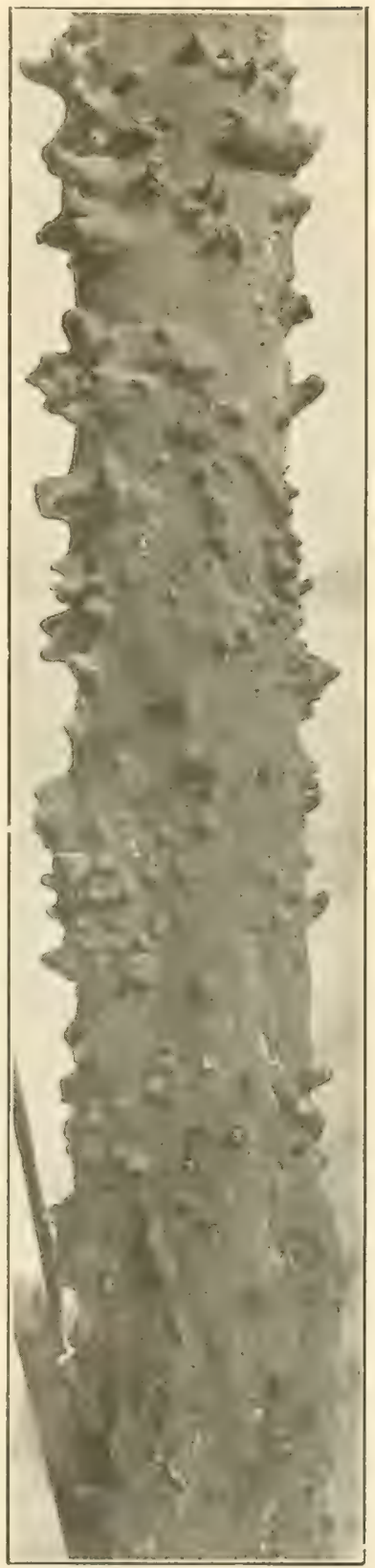

Fig. 452. - Young tree painted with asphaltum to keep out borers. Photo by W. E. Rumsey. 
may be poisoned by arsenicals; if so, the codling moth spray probably is responsible for smaller numbers of borers being found in sprayed orchards than in neglected ones.

\section{The Flat-headed Apple-tree Borer *}

This species is more abundant than the preceding, but does less damage. It prefers trees which have been weakened or are

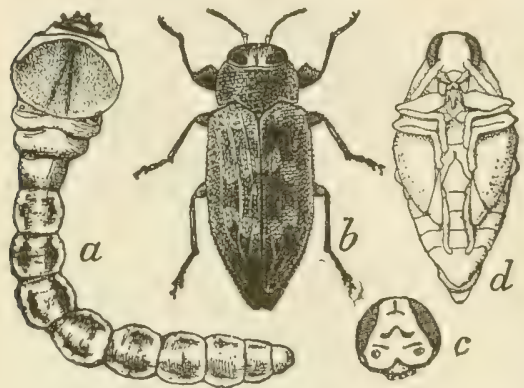

FIG. 453.-The flat-headed apple-tree borer (Chrysobothris femorata Fab.): $a$, larva; $b$, beetle; $c$, head of male; $d$, pupa-twice natural size. (After Chittenden, U. S. Dept. Agr.) diseased, and attacks almost all of the common orchard trees as well as numerous shade and forest trees, so that it is everywhere common. The species is found from southern Canada to Mexico. The larvæ live just beneath the bark, where they hollow out broad flat channels which extend slightly into the sap-wood. The infestation may be detected by the discoloration of the bark. Where abundant they will often completely girdle young trees, thus causing their death, and they are frequently found abundant under the loosening bark of the dying limbs of large trees, as they infest not only the trunks, but the lower limbs. The adult beetle is about one-half inch long, dull metallic brown above, and the wing-covers taper sharply at the tip, somewhat like a click beetle. The wing-covers are ornamented as shown in the figure, and beneath them, as seen when in flight, the body is a bright metallic greenish-blue. The male is smaller and the head is green. The beetles are active during the heat of the lay and may often be found on logs or injured trees.

Life H istory.-- The beetles emerge from the middle of May until mid-summer. The eggs are deposited in crevices of the bark, several often being laid together. The eggs are yellowish, irregularly ribbed and about one-fiftieth inch long. The species receives its name from the shape of the larva, the thorax of which is very broadly expanded, so that it looks like the head, which is very small and almost concealed by it. The abdomen is much smaller and the whole body is flattened. The larva is about

* Chrysobothris femorata Fab. Family Buprestido. See F. E. Brooks, Farmers' Bulletin 1065, U.S. Dept. Agr. 
one inch long, and usually rests in the curved position shown in Fig. 453. The larva becomes full grom in a single year and in the South may pupate in November, but in the North does not pupate until the next spring, when it remains as a pupa about three weeks. The beetle emerges through an elliptical exit hole, in contrast to the round hole of the round-headed borer.

Control.-As this beetle is everywhere present, injury may always be expected if trees are not lept in a healthy condition, but if the orchard is well cared for it seldom suffers much damage. The same measures for preventing oriposition as suggested for the previous species are advised, but the repellant washes must be applied higher on the trunks and should extend to the lower branches as high as can be reached.

\section{The Oyster-shell Scale *}

Not infrequently young apple and pear trees are encrusted and killed by the Oyster-shell Scale, as are young poplars and maples. It is probably our most common scale insect, being almost always found on apple trees, on which it works on the bark or the twigs and trunk, reproducing even on old trunks, where the scales will be found under the loose bark and are undoubtedly a factor in causing the bark to slough off. All of the common orchard trees are occasionally infested but rarely injured, as are also maple, poplar, horse-chestnut, willow and lilac. Quaintance and Sasscer give a list of over 100 trees, shrubs, and plants upon which the scales have been found. The species is a cosmopolitan one, having been

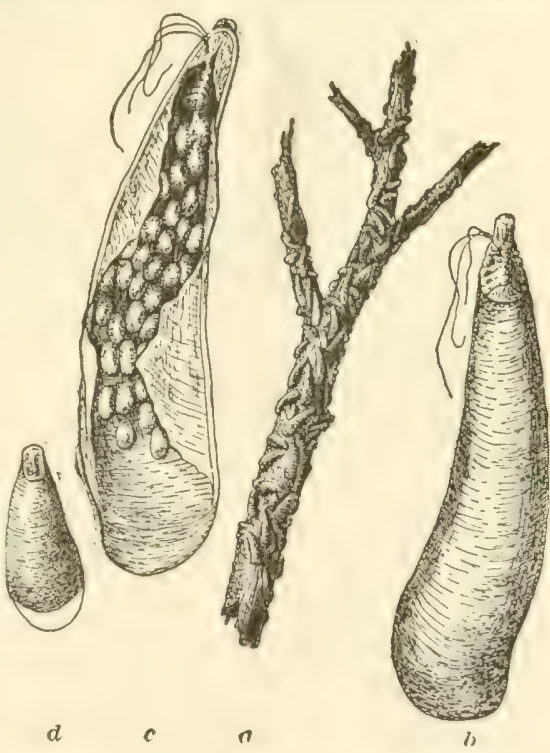

Iitu. 4.4. - The oyster-shell seale (Lepidosrephes ulmi Linn.): $a$, female seales on twig; $b$, female scales from above; $c$, same from below showing eggs; $d$, male scale-enlarged. (After Howard.)

* Leprdosaphes ulmi Linn. Family Coccider. See Quaintance and Sasscer, Farmers' Bulletin 723, U S. Dept. I I gr., and references there given. 
introduced into this country at an early date and now being found in every State, and occurs throughout the world, where the foodplants exist.

The mature female scale is about one-eighth inch long, of a dark-brown color, sometimes almost blackish, and shaped somewhat like an oyster-shell, as shown in Fig. 454. The male scale is much smaller, and with but one cast skin at the anterior end, as shown in the same figure.

Life History.-If one of the female scales be turned over during the winter, numerous oval, white eggs will be found under it, with the shriveled body of the female insect tucked away

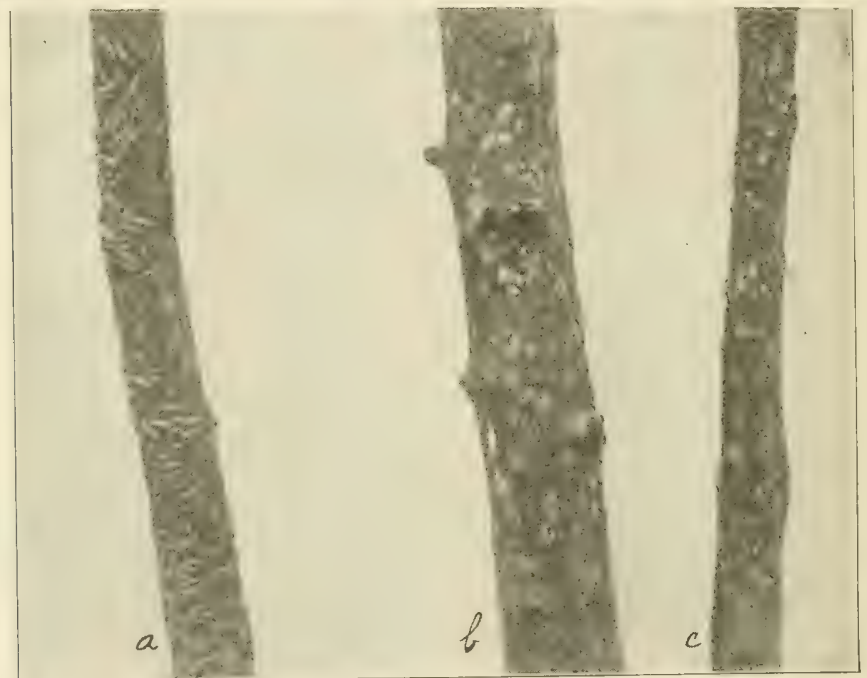

FIG. 455.-Three common scale insects; $a$, oyster-shell scale; $b$, scurfy scale; $c$, San José scale. All natural size. (Photo by Rumsey.)

at the anterior end. These eggs hatch a week or two after the apples blossom, producing small yellowish insects, which look like mites as they crawl over the bark, which they often give a yellowish tinge where very abundant. The young insect is of microscopic size. It settles down after a few hours' wandering and begins sucking the sap from the bark. In a day or two long, white waxy filaments exude from over the body, which soon mat down and form the protecting scale, to which the cast skins are added when the insect molts. The female loses her 
legs, antennx, and eyes, after the first molt, and when full grown is an elongate, yellowish, jelly-like mass, being simply a "reproductive sack, with her sucking mouth parts, through which the food is taken, inserted in the tissues of the plant." The females become full grown in about eight to ten weeks, when they lay from 40 to $100 \mathrm{eggs}$ and then die. In the North there is but one generation a year, but from the District of Columbia southward there is a partial or complete second generation. When the male insects are full grown they emerge from the scales as two-winged flies, fertilize the females and die at once.

Control.-See below

\section{The Scurfy Scale *}

"The Scurfy Scale, while infesting a considerable number of plants (some 35 in number), is a less general feeder than the preceding species. It occurs principally upon rosaceous plants, such as the apple, peach, pear, plum, cherry, etc., and als o on currant and gooseberry among cultivated plants, but seldom becomes so abundant as to cause particular injury or require specific treatment." It is especially common on apple and

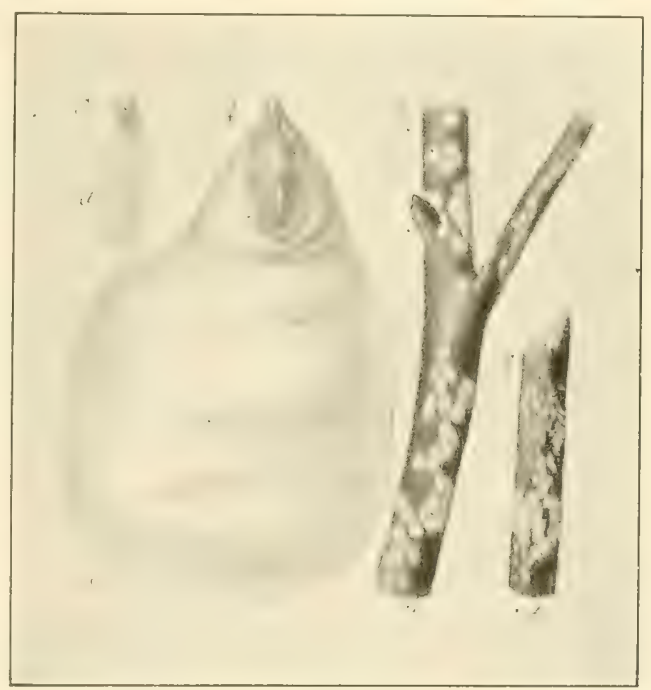

Fig. 456.-The scurfy scale (Chionaspis furfura Fitch): $a, c$, females, $b, d$, males- $a, b$, natural size, $c, d$, enlarged. (After Howard, U. S. Dept, Agr.) pear and less so on cherry and peach, though it has been observed as quite destructive to peach in the South, greatly stunting the trees, though none were actually killed. The female scale is a

* Chionaspis furfura Fitch. Family Coccida. See Quaintance and Sasscer, 1.c. 
dirty-gray color, irregularly shaped as shown in Fig. 456, c The male scale is much smaller, elongate, snowy white, and with three distinct ridges, Fig. 456, d. It is an American insect, being common from Southern Canada to the Gulf States. The life history, as far as known, is practically identical with that of the last species.

Control.-As the last two species are practically identical in habits, they may be controlled by the same methods. Where the trees are sprayed with lime-sulfur wash for the San José scale, there will be but little trouble with these scales, and where specific treatment is required for them experiments indicate that a thorough coating with the lime-sulfur wash while the trees are dormant, preferably in the spring just before the buds open, is one of the most effective remedies. The wash does not seem to kill the eggs, but to kill the young soon after hatching, and has been used successfully on both fruit and shade trees, but if there be frequent rains in late spring, so that it is washed off, or if the scales are very thick, it is not always entirely effective, but yearly treatments will always prevent serious damage.

\section{Apple Plant-lice *}

Several species of aphids or plant-lice commonly infest the foliage of the apple, and less commonly that of the pear, and though they differ somewhat in appearance and habits they are sufficiently alike to be discussed together, as the same methods of control apply to all.

\section{The Apple-aphis $†$}

This is the common Apple-aphis of Europe, and was first noticed in this country late in the last century, when it spread to all parts of the country within a few years, probably being

* See Sanderson, 13th Report, Del. Agr. Exp. Sta.; A. L. Quaintance, Circular 81, Bureau of Entomology, U. S. Dept. Agr.; Gillette and Taylor, Bulletin 133, Colo. Agr. Exp. Sta., Parrott, Hodgkiss and Lathrop, Bulletins 402, 415 and 431, N. Y. Agr. Expt. Station, Quaintance and Baker, Farmers' Bulletin 804, U. S. Dept. Agr., and Robert Matheson, Memoir 24, Cornell Agr. Expt. Station.

$\dagger$ Aphis pomi DeG. Family A phidida. See above references, and J. B. Smith, Bulletin 143, N. J. Agr. Exp. Sta.; C. P. Gillette, Journal of Economic Entomology, Vol. I, p. 303, and H. E. Hodgkiss, Bulletin 461, N. Y. Agr. Expt. Station. 
distributed on nursery trees. Only young trees are usually much injured by this and the following species of aphids, old trees rarely being injured, except that where the aphids are excessively abundant they sometimes injure the young fruit, causing it to become stunted and misshapen. The foliage of young trees soon becomes covered with the vermin, which feed on the under surfaces of the leaves, causing them to curl up and then drop. This curling of the foliage is more commonly caused by this species than any other, though the rosy apple-aphis has a similar effect. The aphids secret the
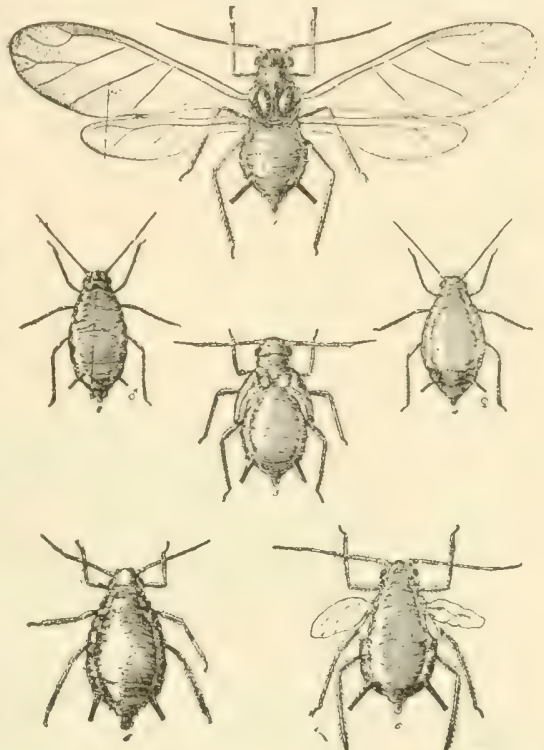
sweet honey-dew very pro- Fi(i. 457. - Stages of the apple-aphis, $A$ this fusely and so attract large pomi. After Baker, U. S. Dept. of Agr. numbers of ants, which feed upon it. The ants are always found associated with them, and the presence of numerous ants on a tree

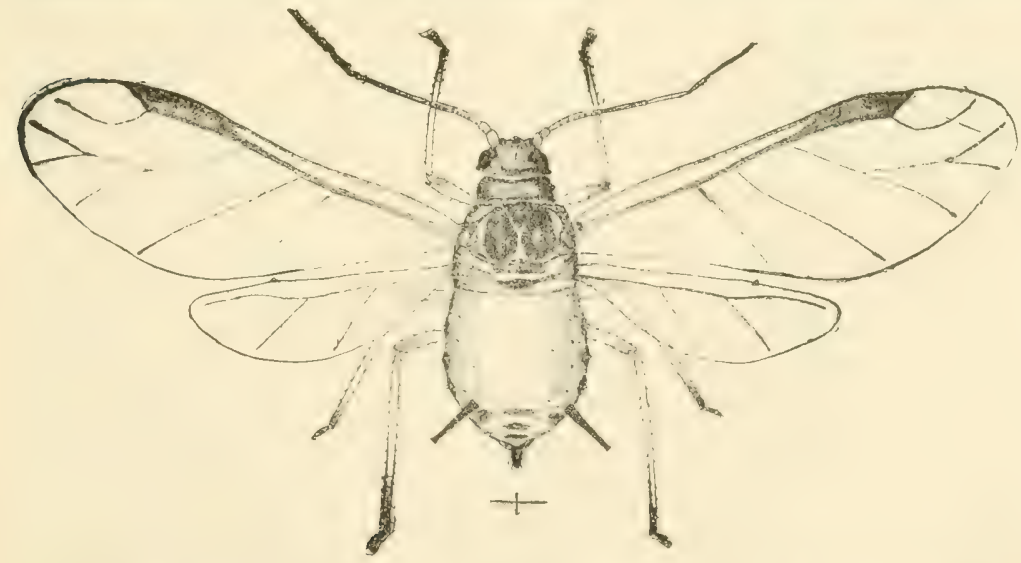

FIG. 458.-The apple-aphis, winged viviparous female-greatly enlarged. is a good indication of aphids. The honey-dew soon covers badly 
infested foliage and upon it there grows a blackish fungus which gives the leaves a sooty appearance, often visible on the twigs after they drop, and a good indication of injury by this species. The full-grown wingless females are about one-twelfth inch long, and shaped as shown in Fig. 457. They are of a bright green color, though occasionally yellowish, and the tips of the antennæ, honey-tubes, and tail are black. The winged female is slightly longer and the wings expand about one-quarter inch, the head is deep olive brown; the thorax is blackish, and there are three black spots on the lateral margin of the abdomen, but otherwise it is colored like the wingless female.

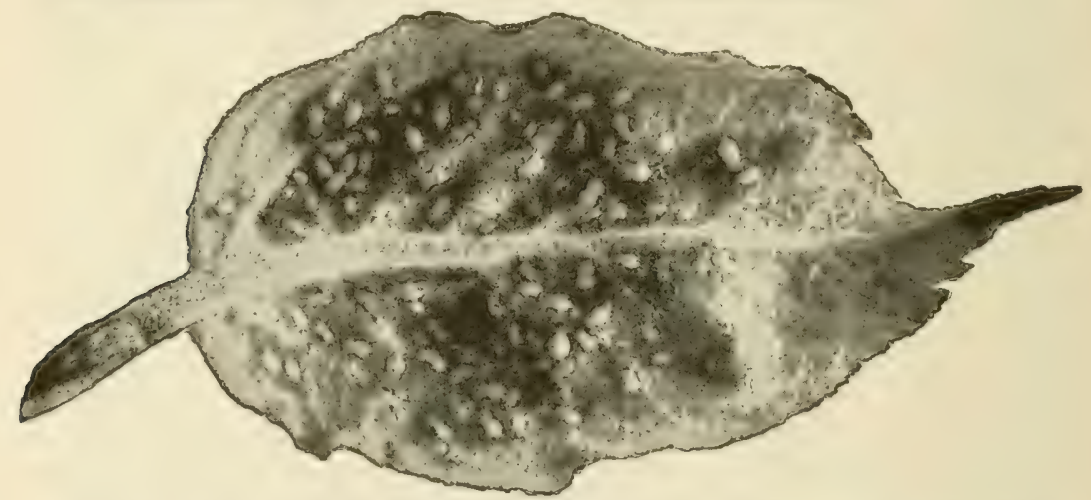

Fig. 459.-Nymphs of the apple-aphis, clustered on a leaf, showing developing wing-pads.

Life History.--The minute, oval, shining black eggs are to be found on the twigs cluring the winter, especially at the crotches and around buds and scars. They hatch just before the leaf buds open and the young aphids become full grown in two or three weeks, all of them being wingless. During the next two or three weeks each of these females will give birth to from 50 to 100 young, a few of which develop wings. All of the aphids of this second generation are also females, which give birth to live young without the intervention of males, which do not appear until fall. Their young develop in a week or ten days and most of them become winged and migrate to other trees. The development and reproduction continues in this fashion throughout the summer, both winged and wingless females being found in most colonies, though the size and coloration differ in the various 
generations. Those which are to become winged may be distinguished after the third molt by the blackish wing-pads at the sides of the body. With the first frost of fall the young develop into true males and females. Both are wingless, the male being much the smaller, has long antenne, is yellowish or rusty-brown, and is very active, while the female is larger, moves more slowly and is lighter in color, but later becomes a very

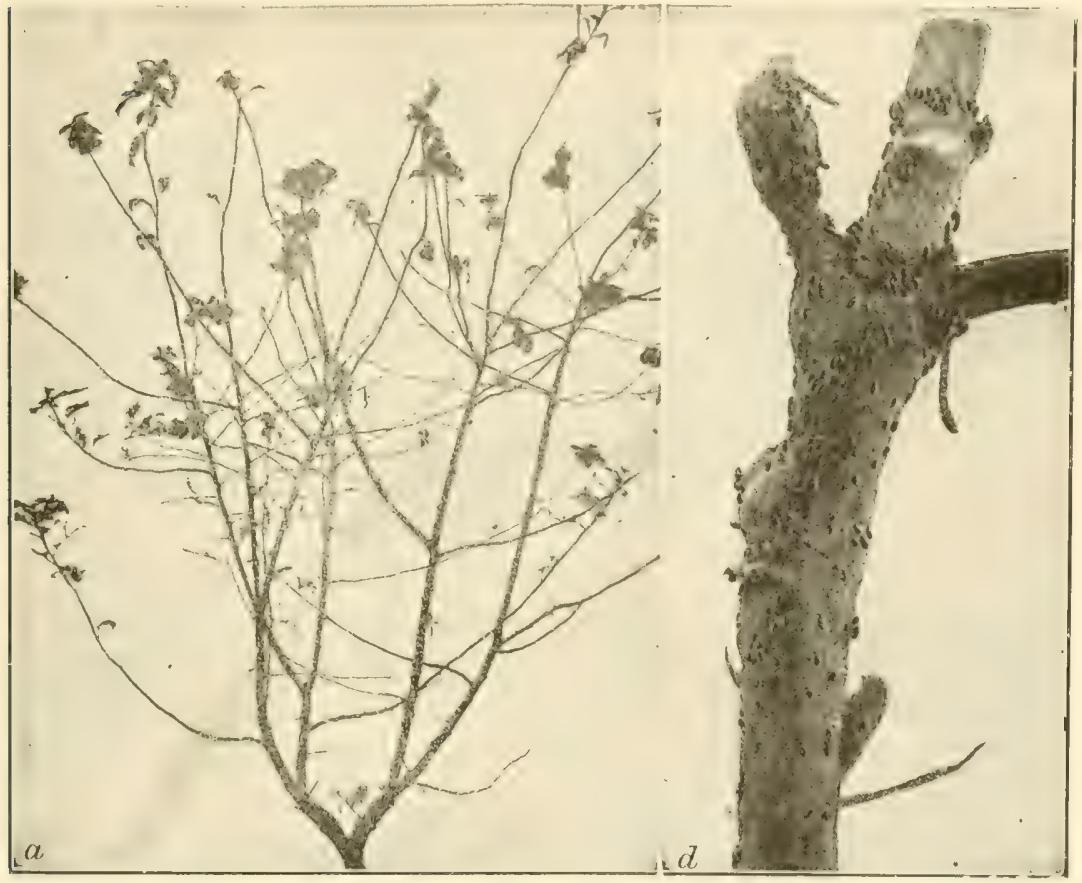

FIG. 460.-The apple-aphis; $a$, young tree partially defoliated by the aphis; $d$, winter eggs on twig.

dark green. The sexes mate and the females lay 1 to 3 eggs in the places mentioned. All of the aphids die by late fall and the eggs remain to give rise to new colonies in the spring.

With the rapid multiplication above deseribed it is not surprising that the foliage is soon eovered with thousands of aphids, and that with so many sucking the sap the leaves soon curl up and drop. This is often a serious drain upon the vitality of young trees, stunting their growth, and so weakening them that they 
are more liable to be attacked by other insects and diseases, while the premature dropping of the foliage prevents the full growth of the tree and the proper hardening of the wood before winter. This species shows marked preference for certain varieties of apples and rarely injures others. Apple, pear and quince are the only fruit trees infested by this species, which lives upon them throughout the year.

These lice may also attack the fruit as it begins to set, causing some dropping and a considerable amount of distortion to the

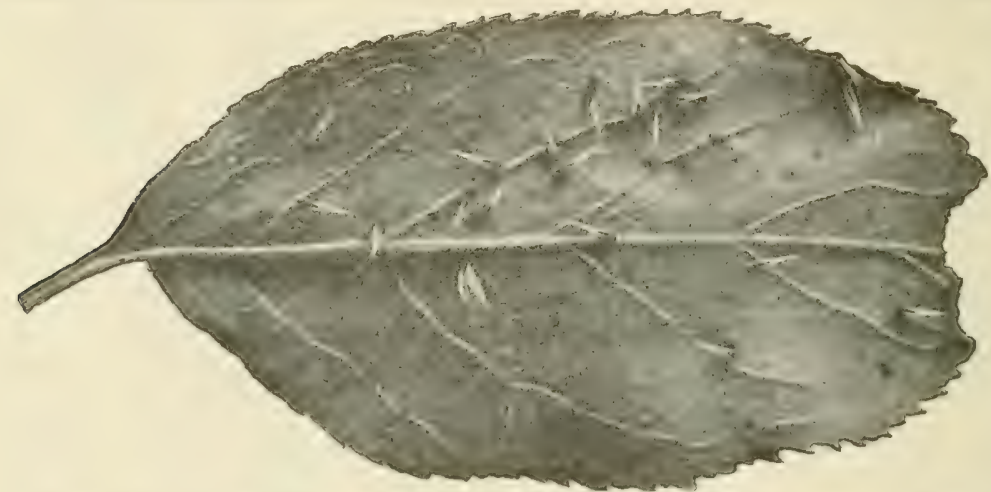

Fra. 461.-The apple-aphis, winged fall migrants on leaf-natural size.

fruit. Such fruits rarely attain full size and may easily be recognized at picking time. The rosy-aphis causes somewhat similar injury which may be even more severe. In normal years the injury to the fruit amounts to as much as the injury to the foliage.

\section{The Rosy Apple-aphis *}

This species is larger than the preceding. with a rounder body, and is commonly of a rosy color, though the wingless females vary from a salmon or tan color to slaty gray, purplish or black. It has been injurious only to apple in this country, where it has become widely distributed, but in Europe its native food-plants are various wild species of Sorbus and Cratogus. The wingless female is about one-tenth inch long, the head, thorax and margin

* A phis sorbi Kaltenbach. Family A phidida. See Sanderson, and Gillette and Taylor (Aphis pyri Boyer), cited above; and W. E. Britton, 9th Report, State Entomologist of Connecticut, p. 343, also other citations below "Apple Plant-lice," and A. C. Baker and W. F. Turners, Jour. Agr. Research, Vol. VII, No. 7. 
of the abdomen being dark reddish-brown, and covered with a powdery substance which gives it a deep blue color, the middle of the abdomen being lighter yellowish. The antenna and legs are whitish, marked with dusky. The honey-tubes are pale yellow, tipped with black, and are long and tapering. Between the eyes are two small tubercles, and on the middle of the two segments in front of the tail are a pair of similar small tubercles, which are quite characteristic of this species. When fully developed the female becomes much darker and distended with young, which may be seen through the abdomen. The winged female is about

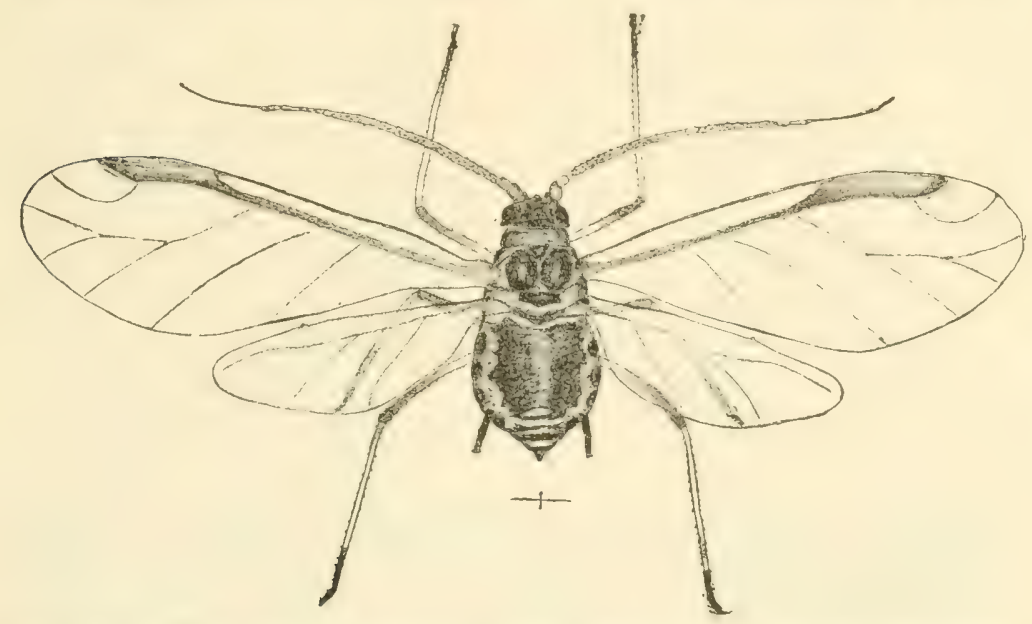

FIG. 462.-The rosy apple-aphis (Aphis sorbi Kait.): winged viviparous female greatly enlarged.

the same length, the head, thorax and honey-tubes being black, and the abdomen yellowish-red. The winged females in the fall differ from those of the spring in lacking the small tubercles between the eyes, but both spring and fall winged females have the two pairs of small tubercles in front of the tail. They also differ in having a large black splotch on the centre of the abdomen, bands across the terminal abdominal segments, and spots along the sides, also black. The male is winged and similar to the winged viviparous females which migrate back to the apple in fall. The egg-laying females are wingless, very much smaller than the summer forms, and light lemon-yellow in color. 
Life History - The eggs occur on the twigs, as do those of the last species, hatch about the same time; and the first

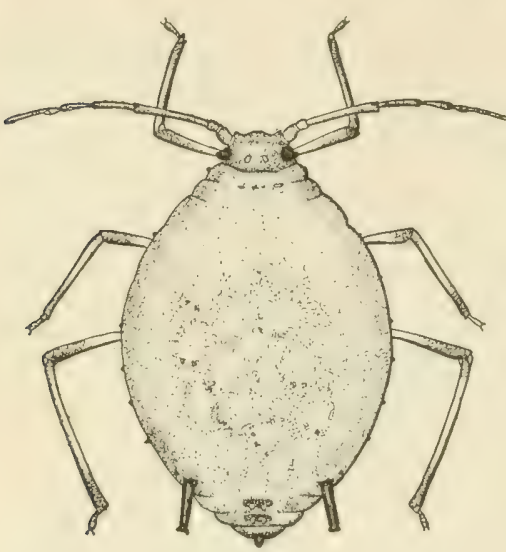

Fig. 463.-The rosy apple-aphis, wingless viviparious female-greatly enlarged.

two or three generations develop on the apple in the same manner. Like the last species, the third generation is mostly winged females which migrate from the apple to some unknown food-plant, on which they pass the summer. The winged females return to the apple foliage in thefall and then give birth to young, which develop into the true males and females, which may be found laying their eggs in company with the last and other species.

This species curls the leaves to a greater extent than does the apple aphis, and is likewise accompanied by ants. Dr. Britton states that "the rosy apple aphis . . . seems especially prone to attack the fruit spur's and inner portions of the tree-top rather

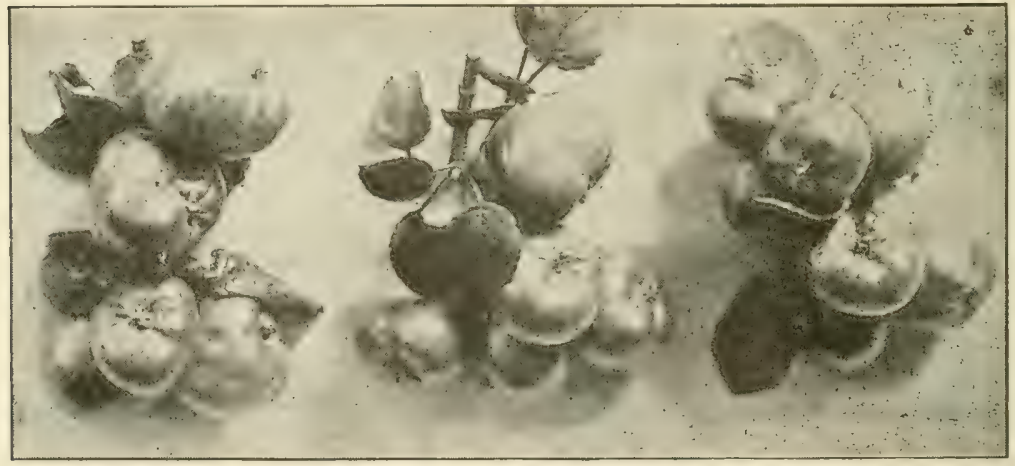

Fig. 464.-Apples showing typical aphis injury. (Aphis sorbi.)

than the terminal twigs and exterior part," and that it "affects seriously the growth of the fruit," preventing its growth and development, and causing it to be gnarled and irregular in shape, similar to the damage by the last species sometimes observed. (See accompanying figure). 


\section{The European Grain-aphis *}

This species is found on the apple, pear, quince and plum in the spring and fall and on the small grains and various grasses during the summer. - Until recently it has been the more common form on apple in the East, but is not now so numerous as the appleaphis. It is an old European species and was evidently imported to this country at an early date, as it is widely distributed through out the United States. The wingless females are distinctly smaller than the previous species, and are of a light green color, marked with transverse diamond-shaped bands of darker green,
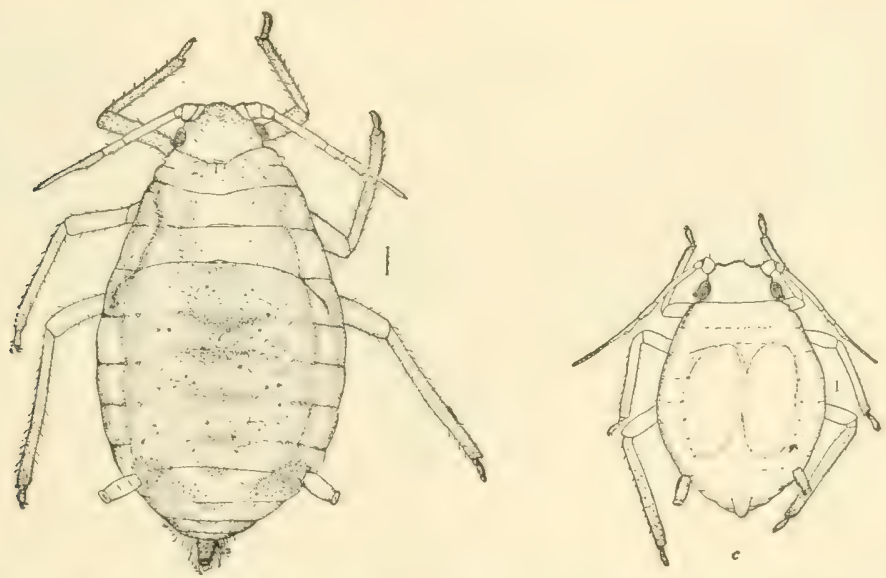

FIg. 465.-The European grain-aphis (A phis arence Fab.): wingless viviparous female, and egg-laying or oviparous female-greatly enlarged.

across the abdominal segments. The honey-tubes are shorter, distinctly enlarged at the middle and flared at the tip, which

*A phis avena Fab. Family Aphidida. See Th. Pergande, Bulletin 44, n. s., Div. Ent., U. S. Dept. Agr., p. 5 and authors cited above. The author described this species as Aphis fitchii in 1902, and although there seems to be no question that it feeds on gratins and grasses during the summer, there are several reasons for believing that there are either two species or that the life history has not been sufficiently observed. Thus in some sections it is exceedingly common on grain but rare on apple, and in others just the opposite condition is found. Matheson, l.c., uses for this insect the name A phis arenor Fab., but Baker and Turner, Journal Agr. Research, Vol. XVIII, No. 6, call the species on apple the apple-grain aphis and ascribe to it the name Rhopalosiphum prunifolia Fitch. They maintain that the name A phis arena is a synonym for $R$. padi $\mathrm{L}$. It is to be hoped that the systematists in this group will soon come to an agreement for the sake of uniformity. It should be mentioned that the latter authorities, 1.c., under Rosy Apple-aphis, consider that species as A phis malifolix Fitch rather than as A. sorbi Kaltenbach. 
distinguish the species of this genus. The winged female has the head and thorax blackish, and the abdomen yellowish-green or brownish, usually lacking the greenish bands of the wingless form, and the honey-tubes are brown with rusty spots around the base. The species may be distinguished by the very short second fork of the median vein at the tip of the fore-wings.

Life History.-The eggs are found on the apple and pear, and the first two generations in the spring develop as do those of the preceding species. All of the second, or sometimes the third, generation become winged and migrate to small grains and

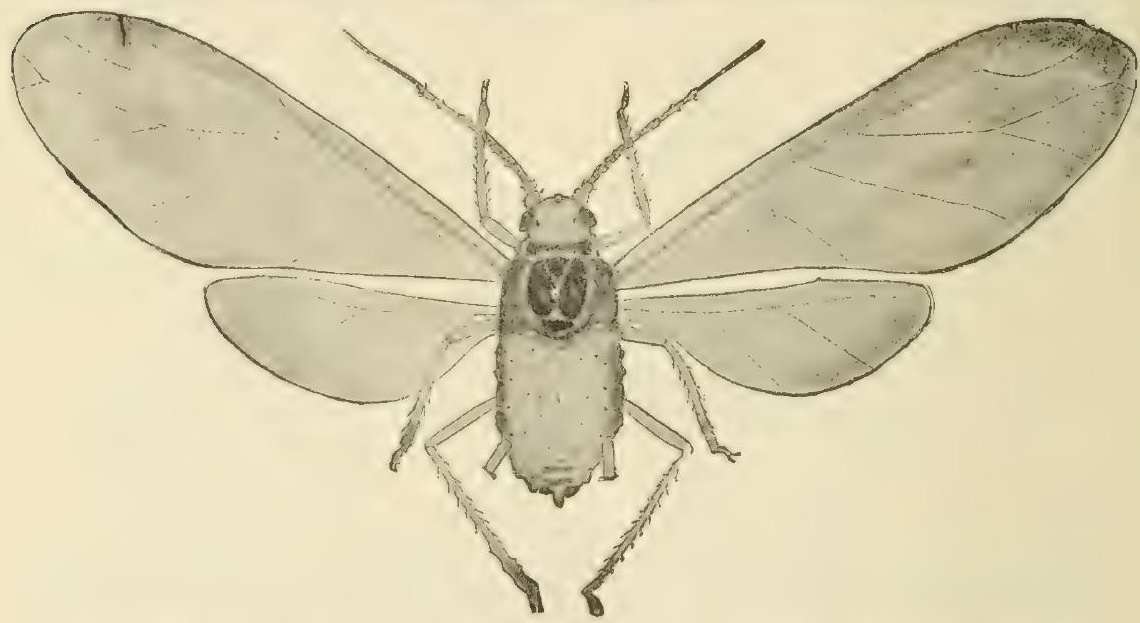

FIG. 466.-The European grain-aphis, migrating winged viviparous female of the second generation-greatly enlarged.

grasses, on which they feed during the summer. In the fall winged females return to the fruit trees and give birth to young, which develop into wingless females and winged males, which mate and produce the winter eggs. Pergande states that "the species is biennial and that the progeny of the spring migrants from the apple subsist almost exclusively upon various grains and grasses until the fall of the second year, when a generation of return migrants makes its appearance." This is certainly true in the South, where the aphids may be observed on grains throughout the winter, but it may be questioned whether they usually survive the winter on grains or grasses in the North. 
Professor F. M. Webster* has observed this species on wheat in Ohio, and states that in mild winters it remains on the wheat, going down on the stems to just below the surface of the soil or to the upper roots, as we have observed it in Texas. "Here they go on reproducing when the temperature is favorable," he says, "the adults being apterous so far as observed by me, until spring, when they ascend to the foliage, the adults after this being both winged and wingless. On the stems and roots below the surface of the ground they are of a greenish color, tinged with reddishbrown, especially posteriorly, the full-grown individuals often being wholly of a dark brown. It is during autumn that they do their greatest injury to the wheat by sucking the juices from the young plants, often, if on poor land and if in dry weather, checking their growth and causing the foliage to turn yellow." This species is seldom much in evidence on grains or grasses in midsummer and rarely becomes very injurious to them. On the apple it is abundant on the young foliage and particularly on the flower buds and blossoms, where it is much more common than the other species. It does not, however, curl the foliage nearly as severely as the other species, due to its earlier migration.

$\therefore$ Control.-It has been found in many places that by delaying the lime-sulfur spray as applied for scale until the buds are beginning to open in the spring the grower may effectively control the aphis, the spray killing at this time the orer-wintering eggs. It must be admitted, however, that there are times when this treatment is not effective. Just why is not known. When this spray is omitted or fails to kill the aphids, they may be controlled by spraying with Blackleaf 40 at the rate of 1 to 1000 , four pounds of soap being added to the mixture if it is applied without bordeaux or the arsenicals. Hodgkiss recommends a spray called the nicotine-lime spray, made by adding two to four pounds copper sulphate and six pounds lime to the 1 to 1000 solution of nicotine sulphate (Blackleaf 40). The above amount for each 100 gallons of the spray. This acts to some extent as a deterrent as well as an insecticide. Any spraying done must be done before the leaves curl, since the insects must be hit with the spray to be killed and when they are protected by curled leaves it is impossible to hit any great number of them.

*See Bulletin 51, Ohio Agr. Expt. Station, p. 111. 


\section{The Tent Caterpillar *}

From the earliest times the webs of the tent caterpillar have adorned the neglecter, wayside apple and cherry trees in all parts of the country east of the Rocky Mountains. On the Pacific coast a nearly related species has very similar habits. The adult moths are common in July in the North or in May in the Gulf States. They are stout-bodied, of a reddish-brown color, with two nearly parallel white bands extending obliquely across the fore-wings. The females have a wing expanse of about $1 \frac{1}{2}$ inches, while the males are smaller and may be distinguished by their feathery antennæ. The sexes soon mate and the females deposit their eggs about five or six weeks after apples blossom. The egg-mass is from one-half to three-quarters inch long and forms a grayish-brown, knot-like band around the twig on which it is laid, closely resembling the bark in color. Each mass contains about 200 eggs, placed on end, packed closely together and covered with a light brown, frothy glue, which gives a tough, smooth, glistening surface to the whole mass. The little caterpillars hatch just as the leaf buds are expanding in the spring. Ofttimes they emerge before the leaf-buds have expanded sufficiently to furnish any food, in which case they satisfy their hunger with the glutinous covering of the egg-mass, spinning a thin web over it. Soon they are able to bore into the buds and a web is commenced at the nearest crotch. Wild cherry and apple are the favorite foorl-plants and are often stripped of their foliage year after year, but all of the common fruit trees are more or less frequented, and when very abundant the common shade trees are attacked and occasionally one is defoliated. The little caterpillars from one egg-mass cooperate in spinning the tent which furnishes them shelter at night and during cold or wet weather. This is gradually enlarged with new layers of silk, the caterpillars living beneath the outer layers. The caterpillars are grown in five or six weeks, when they become exceedingly restless and wander away from the nest in search of suitable places for spinning their cocoons. The full-grown caterpillar is about two inches long, deep black in color, sparsely covered with yellowish hairs, with a white stripe down the middle of

* Malacasoma americana Fab. Family Lasiocompida. See A. L. Quaintance, Farmers' Bulletin 662, U. S. Dept. Agr.; V. H. Lowe, Bulletin 152, N. Y. Agr. Exp. Sta.; E. P. Felt, 14th Report State Ent. N. Y., pp. 177-190. 


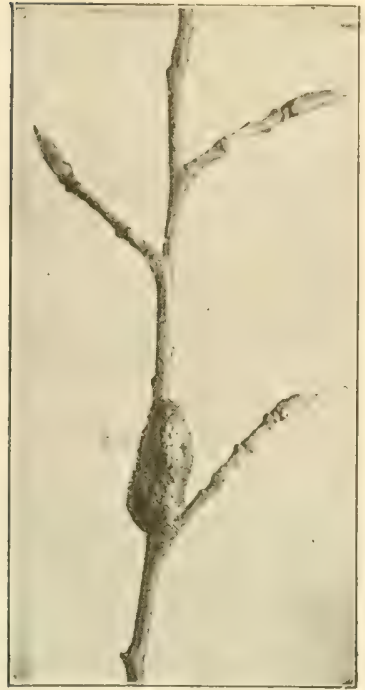

Fig. 467.-Egg mass on twig-natural size.

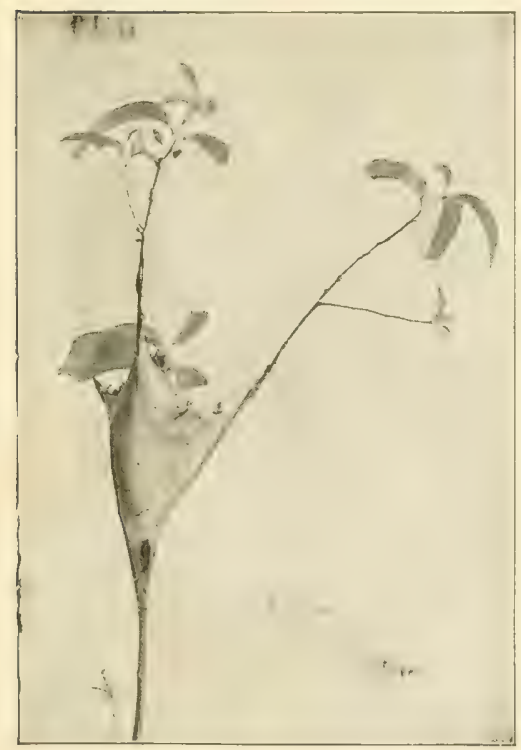

FiG. 469.-Weiwly-formed web.

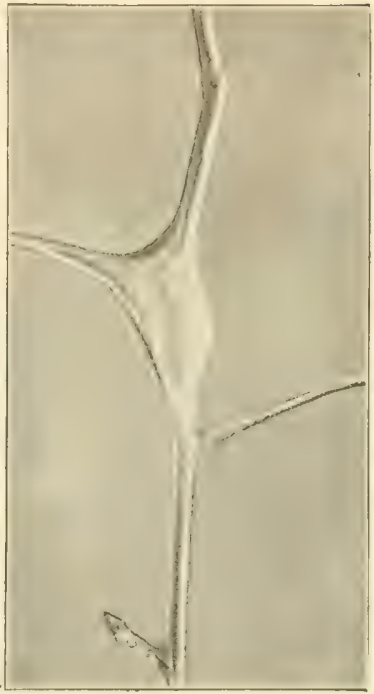

FIG. 468.-Egg mass covered with web of newly hatched caterpillars.

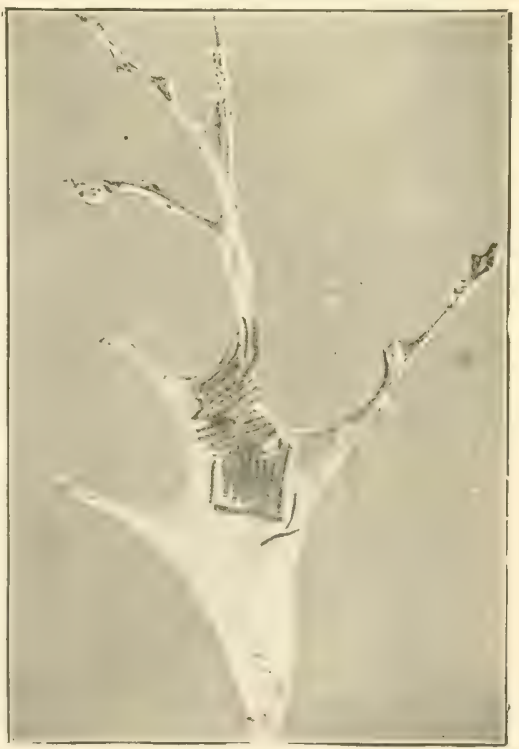

Fig. 470.- Web bearing half-grown caterpillars-reduced in size. 
the back. On the side of each segment is an oval pale blue

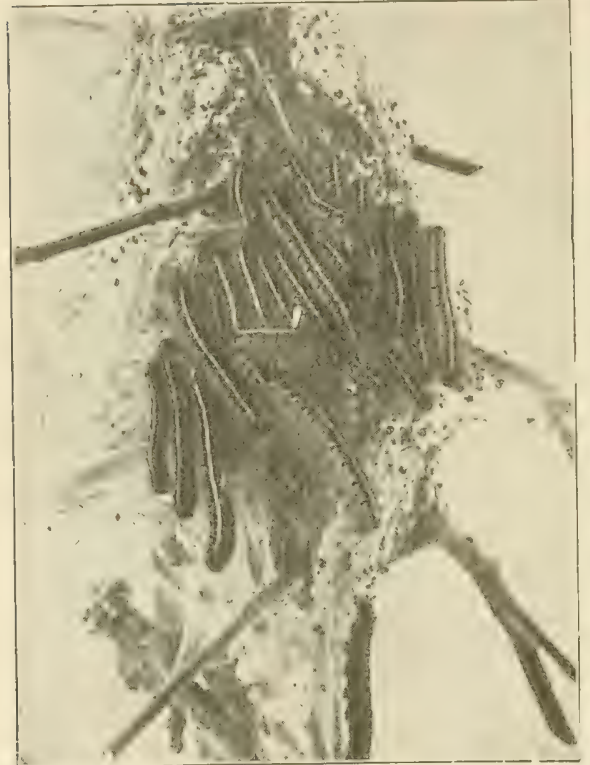

Fig. 471.-Tent caterpillars on web-one- being but one generation half natural size. (Photo by Weed.) spot with a broader velvety black spot adjoining it in front, giving somewhat the effect of an eye-spot. Having found a suitable place under loose bark, in a fence, in the grass or rubbish beneath the tree, or in the shelter of some neighboring building, the caterpillar settles down and proceeds to encase itself in a thin cocoon of tough whitesilk, in which it transforms to the pupa. About three weeks later the adult moth emerges from the pupa to continue the life cycle, there a year.

The caterpillars are held in check by numerous parasitic

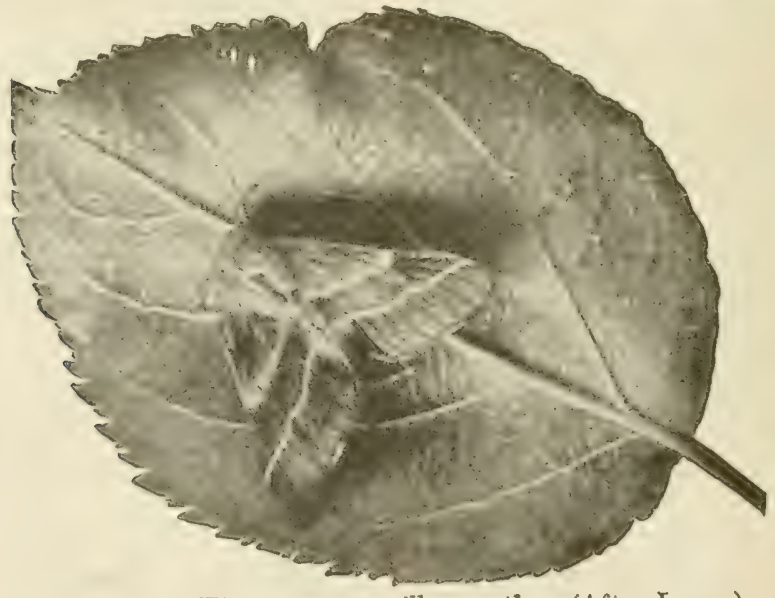

FIG. 472.-The tent caterpillar moth. (After Lowe.)

insects, some 24 species having been found preying upon them by Mr. W. F. Fislie in Now Hampshire, ${ }^{*}$ as well as by preda- 
ceous soldier bugs (Podisus spp).) and many of our common birds. Large numbers of the caterpillars are also carried off by a bacterial disease.

Several species of little chalcis-flies are parasitic in the eggs and destroy a large proportion of them. Were it not for these natural enemies the tent caterpillar woukl become a much more serious pest.

Control.- The egg-masses may easily be detected and pruned off during the winter, and it would be well to leave them in a box

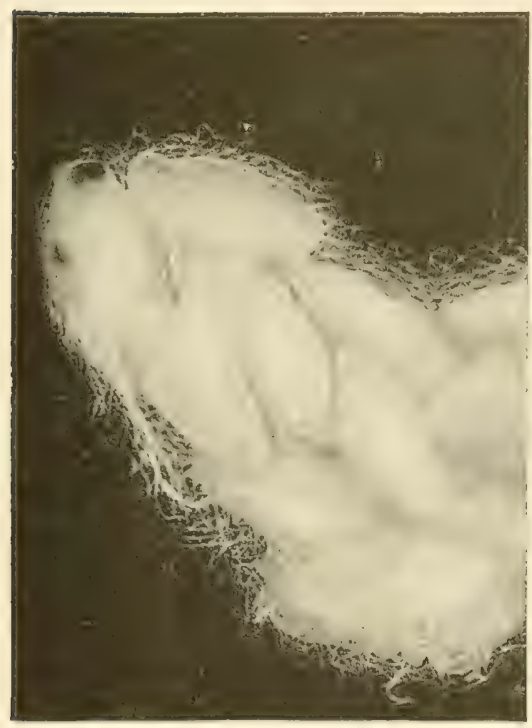

Frg. 473.-Coenons of the tent caterpillar, natural size. (After Lowe.)

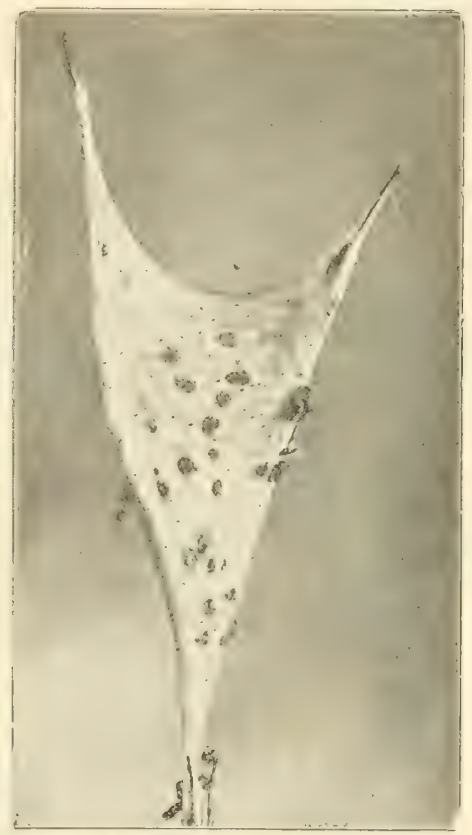

Fig. 474.-W(1) of the tent caterpillar riddled by birds. (Photo by Weed.)

eovered with netting so that the parasites may escape. Neglected apple and wild-cherry trees should be destroyed, as they harbor this and other pests and are usually valueless. The caterpillars may be quickly destroyed by spraying with Paris green or arsenate of lead just after the foliage comes out, before the trees blossom. If there are hut a few nests the caterpillars may be

* See W. F. Fiske, Tech. Bulletin 6, N. H. Agr. Exp. Sta. 
destroyed in them by spraying the nest on a cloudy or cool day with pure kerosene. Apply the spray with an extension rod and fine nozzle so that the nest will be thoroughly soaked, without spraying the surrounding foliage. Or the caterpillars may be destroyed by burning the nests with a torch while they are in them, or while young they may be swabbed out with a broom or brush and crushed.

No injury need be feared in an orchard sprayed for codlingmoth and other insects.

\section{The Yellow-necked Apple Caterpillar *}

During late summer the tips of apple limbs are often found defoliated for a foot or two and if examined a mass of caterpillars

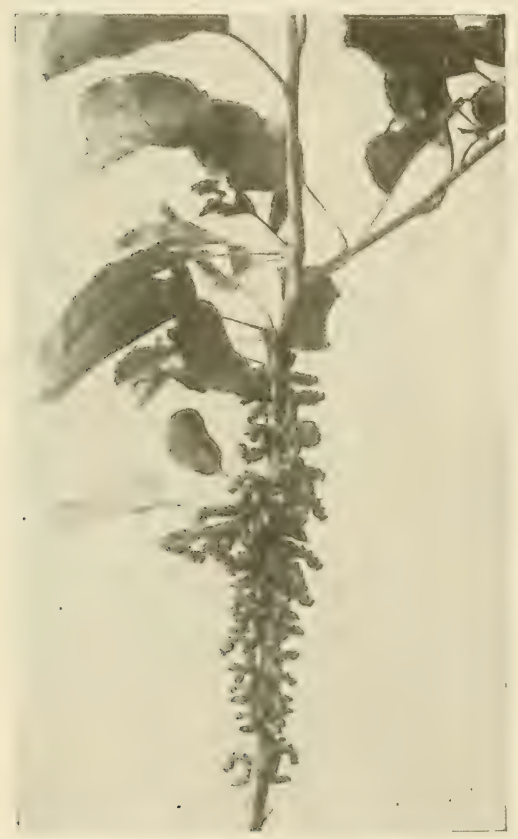

FIG. 475.-Yellow-necked apple caterpillars assembled on twig in natural position-from life, much recluced. will be found huddled together as if confessedly guilty. Usually these will prove to belong to this or the following species. The full-grown yellow-necked apple caterpillar is about two inches long, with a jet black head and the next segment, often called the neck, a bright orange-yellow, from which the insect is named. Down the middle of the back runs a black stripe, and on cither side of the body are three stripes of black alternating with four of yellow and the body is thinly clothed with long, soft white hairs. While young the caterpillars feed only on the under surfaces of the leaves, but as they become larger the whole leaf except the stem, is devoured. They feed together in colonies, usually starting at the tip of a limb, where the eggs were laid, and strip-

*Datana ministra Drury. Family Notodontide. See A. S. Packard, Memoirs National Academy of Sciences, Vol. VII, p. 106; E. D. Sanderson, Bulletin 139, N. H. Agr. Exp. Sta., p. 213. 
ping the foliage toward the base, and are often found clustered together in a solid mass. If the limb is jarred or a caterpillar touched, it at once assumes a position characteristic of this genus, throwing the head and tail in the air with a jerk and clinging to the limb by the abdominal prolegs, as shown in Fig. 475. The wings of the adult moth expand about two inches and are a reddish-brown color, while the head and thorax are chestnut-brown. The fore-wings have three to five transverse lines, one or two spots, and the outer margin of a dark color, and the hind-wings are pale yellowish without markings.

Life History. - The winter is passed in the pupal stage in the soil, from which the moths emerge from May to July. The round, white eggs are laid on the leaves in masses of 75 to 100 , and hatch d u ring mid-summer. The caterpillars feed during the late summer and become full grown in four or five weeks, when they enter the earth for from 2 to 4 inches and there transform to naked
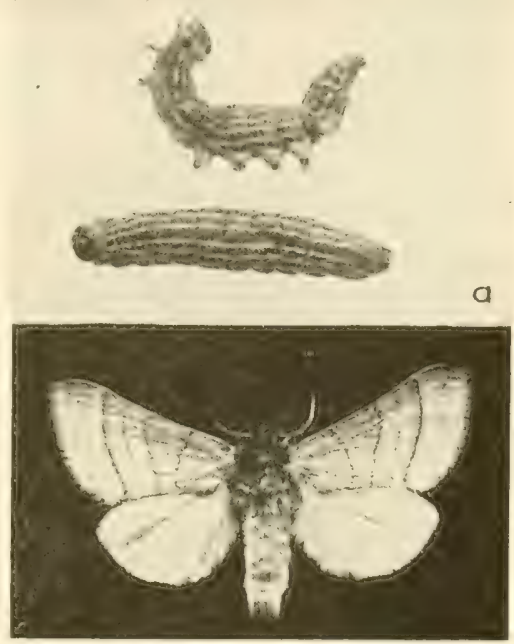

FIG. 476.-The yellow-necked apple caterpillar (Dalana ministra Dru.): mature larvæand moth-natural size. brown pupæ, without making any cocoons. There is but one generation in the Northern and Middle States.

The species occurs throughout the Northern and Middle States east of the Rocky Mountains, and in the far South there seem to be no records of the species. Though most common on apple, it also feeds on pear, cherry, quince, and plum, and on hickory, oak, walnut, chestnut and other shade and forest trees, sometimes defoliating them, as do other nearly related species.

Control.-As the work of these caterpillars is soon noticed, and as they habitually feed in colonies, it is an easy matter to hand pick and destroy them, or swab them off the limbs with a rag or waste saturated with kerosene, or where a colony is clus- 
tered at the tip of a limb, it may be cut off and crushed. If this and other caterpillars are abundant on the foliage in late summer, it will be well to spray with arsenate of lead, 3 pounds to the barrel, while the caterpillars are small, which will be about six to eight weeks after the apple blossoms fall

\section{The Red-humped Apple Caterpillar *}

This species is often associated with the preceding in very similar injury, and has practically the same habits. The name

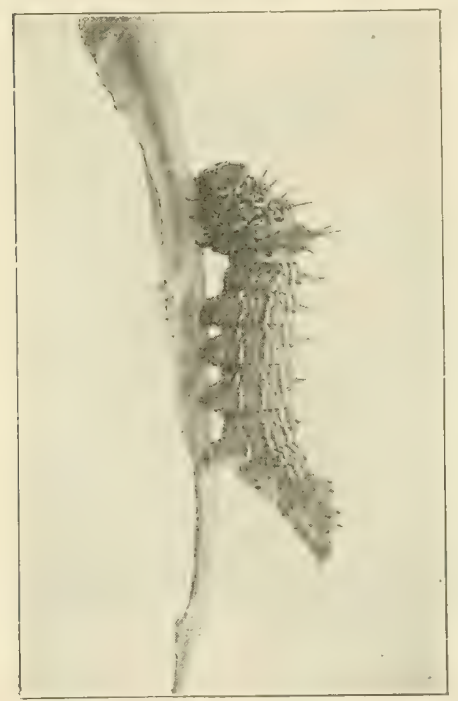

Fig. 477.-The red-humped apple caterpillar (sichizura concinna S. \& A.) - slightly enlarged. is given on account of the prominent hump on the fourth segment of the larva which, with the head, is a bright coral red. The mature caterpillar is striped with yellowish-white, alternating with dark brown or blackish lines, and a double row of black spines extends along the back. The fore-wings of the moth expand about $1 \frac{1}{4}$ inches, are dark brown on the inner and grayish on the outer margin; they have a dark-brown dot near the middle, a spot near each angle, and several longitudinal streaks of the same color along the posterior margin. The hind-wings of the male are brownish and of the female dusky brown, the body is light brown with the thorax of a darker shade.

This species occurs throughout the United States and feeds on apple, plum, rose, thorn, cherry, blackberry, willow, oak, hickory, and other trees and shrubs. The caterpillars become full grown in late summer or early fall and then spin loose silken cocoons to which are attached bits of earth and rubbish, so that

* Schizura concinma Smith and Abbott. Family Notodontida. See A.S. Packard, Memoirs National Academy of Sciences, Vol. VII, p. 212; E. D. Sanderson, Bulletin 139, N. H. Agr. Exp. Sta., p. 216. 
they closely resemble their surroundings as they lie on the ground beneath rubbish, or just under the surface of the soil. After some time the larva transform to pupse, in which stage the winter is passed. Otherwise the life history is practically the same as the preceding species, except that there is some evidence of there being two generations in the South. The larvæ of $\mathrm{th}$ is species are very frequently parasitized by little ichneumon-flies * which destroy whole colonies of them while still young, the inflated skins being found on the under side of a leaf, often perforated by the round exit holes of the parasite.

Control.-Same as for the preceding species.

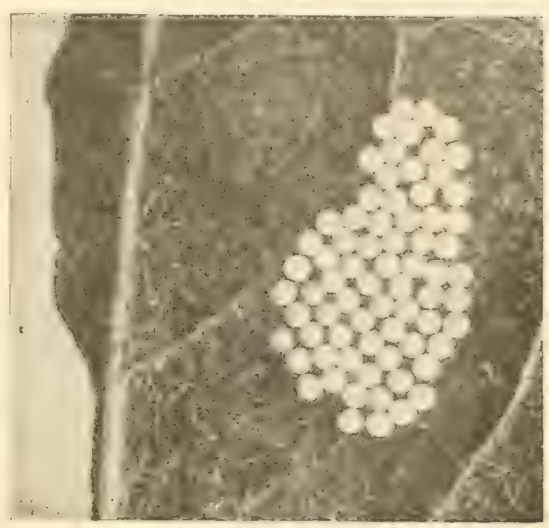

FIG. 478.-Eggs of the red-numped apple caterpill ar-enlarged.

\section{The Apple Leaf-miner $\dagger$}

This is the most common leaf-miner of the apple and makes small brown trumpet-shaped blotches under the upper surfaces of the leaves. It has not been regarded as a serious pest until recently, but during the last few years it has become so abundant as to do serious injury to apple foliage in New England and the Middle Atlantic States, in some instances largely defoliating the trees. It is a native insect which is generally distributed east of the Rocky Mountains

The adult is a little moth whose wings expand about one-third inch and are broadly fringed as shown in the figure. Clemens describes it as follows: "Head and antennx shining dark brown, face ochreous. Fore-wings uniform, shining dark brown with a purplish tinge, slightly dusted with pale ochreous; cilia of the

*Limneria fugitiva Say, and L. ademasia Ashm. Family Ichneumonide † Tischeria malifoliclla Clemens. Family Tincida. See A. L. Quaintance, Bulletin 68, Part III, Bureau of Entomology, U. S. Dept. Agr.; C. D. Jarvis, Bulletin 45, Storrs (Conn.) Agr. Exp. Sta.; C. O. Houghton, Bulletin 87, Del. Agr. Exp. Sta. 
general hue. Hind-wings dark gray; cilia with a rufous tinge." The full-grown larva is one-third inch long, somewhat flattened, and tapers from the broad thorax to the last segment. It is light green except the back of the prothorax and the anal segment, which are brown.

Life History. - The moths emerge in late April in Delaware and in May in Connecticut. The small greenish-yellow, blister-like

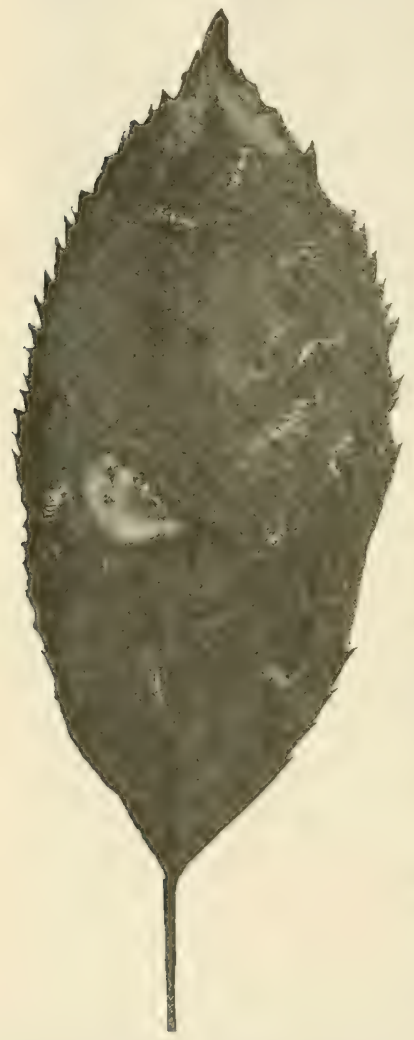

FIG. 479. - Trumpet-shaped mine of the apple leaf-miner (Tischeria malifoliella Clem.) (Photo by Quaintance, U. S. Dept. Agr.) eggs are elliptical in outline, about onefiftieth inch long, and are attached closely to the surface of the leaf. They hatch in from eight to t en days and the young larvæ mine directly into the leaf from the under side of the eggs. The larvæ become full grown in about three weeks and pupate in their mines, the pupal stage lasting eight to ten days. Thus the whole life cycle requires but about thirty-three days in the District of Columbia, where there are four generations a year, and about six weeks in Connecticut, where there are but two generations. The larvæ of the last generation line their mines with silk and in them pass the winter in the fallen leaves, transforming to pupæ the next spring.

Control.-As the larvæ pass the winter in the fallen leaves, the insect may be entirely controlled by plowing under the leaves in late fall or early spring or by raking them up and burning them. When the larvæ become so abundant as to threaten serious injury in summer they may be killed in their mines by spraying the foliage with 10 to 15 per cent kerosene emulsion, but this is not satisfactory in the early fall. 


\section{The Pistol Case-bearer* and the Cigar Case-bearer $\dagger$}

These interesting little case-hearers have long bern known as apple insects, but only in comparatively recent years have they done sufficient injury to attract attention. Both species have

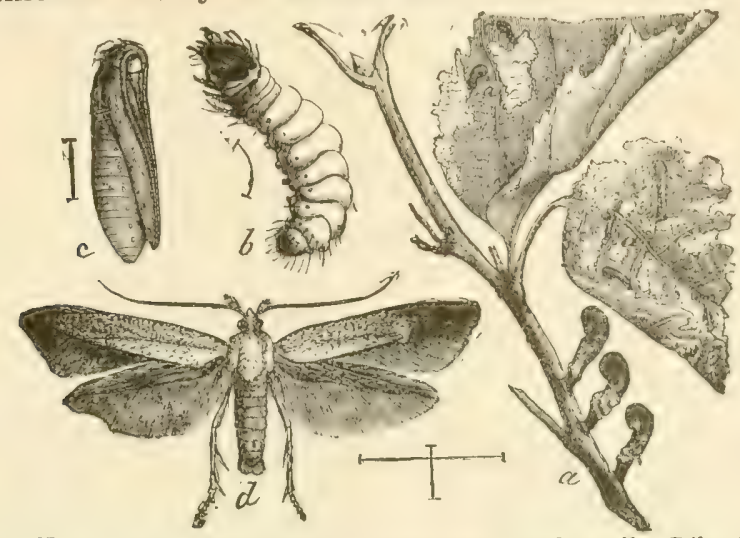

F1G. 480 -The pistol case-hearer (Coleophora malirorella Riley). a, apple twig showing larval cases and work on leaves; $b$, larva; $c$, pupa; $d$, moth, $b, c, d$, enlarged. (After Riley.)

done serious damage in New York by boring into the young buds and blossoms, and eating off the surface of the leaves, so that in some cases orchards have been practically defoliated The pistol
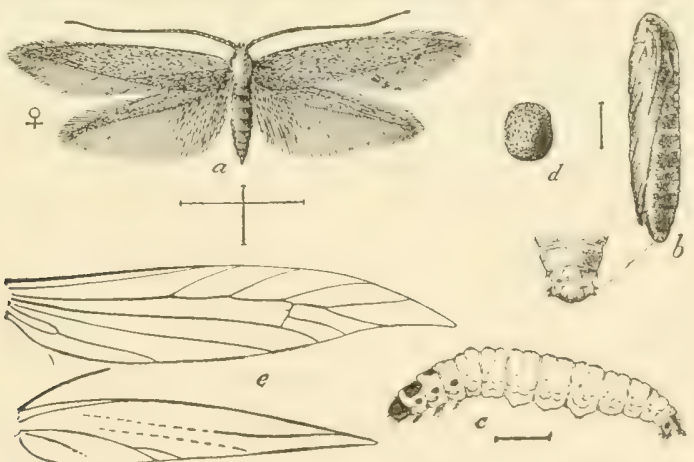

FIG. 481.-The cigar ease-hearer (Coleophora fetcherella Fernald): a, adult female; $b$, side view of pupa and upper view of cremaster of same; $c$, larva: d. egg; e, venation of wings-much enlarged. (After Hammar, U. S. Dept. Agr.)

* Coleophora malivorella Riley. Family Elachistida. See V. H. Lowe. Bulletin 122, N. Y. Agr. Exp. Sta.

† Coleophora fletcherella Fernald. Family Elachistids. See M. V. Slingerland, Bulletin 93, Cornell Univ. Agr. Sta.: A. Ci Hammar, Bulletın So, P'art I1, Buseau of Entomology, U S. Dept. Agr. 
case-bearer seems to be generally distributed over the eastern United States and southern Canada, while the cigar case-bearer is known to occur in Canada from Nova Scotia to British Columbia, in New York, Michigan, Kansas and New Mexico. As both insects are readily carried on nursery stock they are doubtless much more widely distributed than the records indicate.

Life History.-The life histories of the species are very similar and have been most interestingly described in detail by the authors cited. The young caterpillars hibernate in their little cases, which are at tached to the twigs usually near or upon the buds.

Those of the pistol case-bearer are about one-eighth inch long and resemble the bark in color. A short time before the leafbuds burst in the spring, the larvæ become active and attack the growing buds, gnawing through the outer cover to feed on
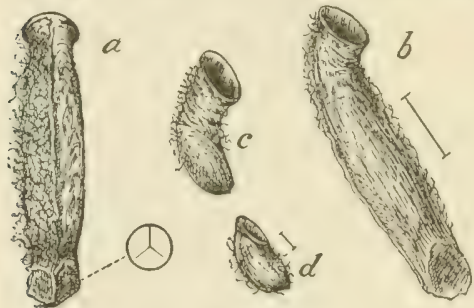

Fig. 482,-The cases of the cigar case-bearer: $a$, upper view of the cigar-shaped case; showing the smooth and the hairy sides and the three-lobed hind opening; $b$, side view of same; $c$, the case as it appears in the spring with the tube-like addition; $d$, the fall and winter casemuch enlarged. (After Hammar, U. S. Dept. Agr.)

the tender tissues beneath. Later they feed on the young leaves, making small holes through the surface and feeding on the soft tissue within in much the same manner as a true leaf-miner In feeding they do not leave the case, but reach out as far as possible from it. As they grow they enlarge their cases, which finally assume the shape characteristic of the species.

Those of the cigar case-bearer are straight and resemble a miniature cigar, being of a brown color and composed of bits of leaf bound together with silk. The cases of the pistol casebearer resemble an old-fashioned pistol in shape, the butt being at the upper end, and are blackish, being composed of excrement and silk. As the caterillars become larger they devour the entire leaf, except the midrib and large veins, and also attack the flower buds, flowers and fruit. The larvx of the cigar case-bearer become full grown about the middle of June in New York, when they migrate to the twigs, where they attach their cases firmly to the bark and, turning around so that their heads are outward, 
transform to pupx. The pupal stage lists ten or twolve days, most of the moths emerging in early July. The pistol case-bearers become full grown and transform about a month earlicr. The adults of both species are little grayish moths with wings expanding about one-half inch, and broadly fringed with long hairs. The eggs of both species are laid singly on the under sides of the leaves and hatch in ten days to two weels. The young caterpillars which hatch from them feed within the leaf for a short time as leaf-miners, before they make their little cases and migrate to the twigs, where they remain until spring.

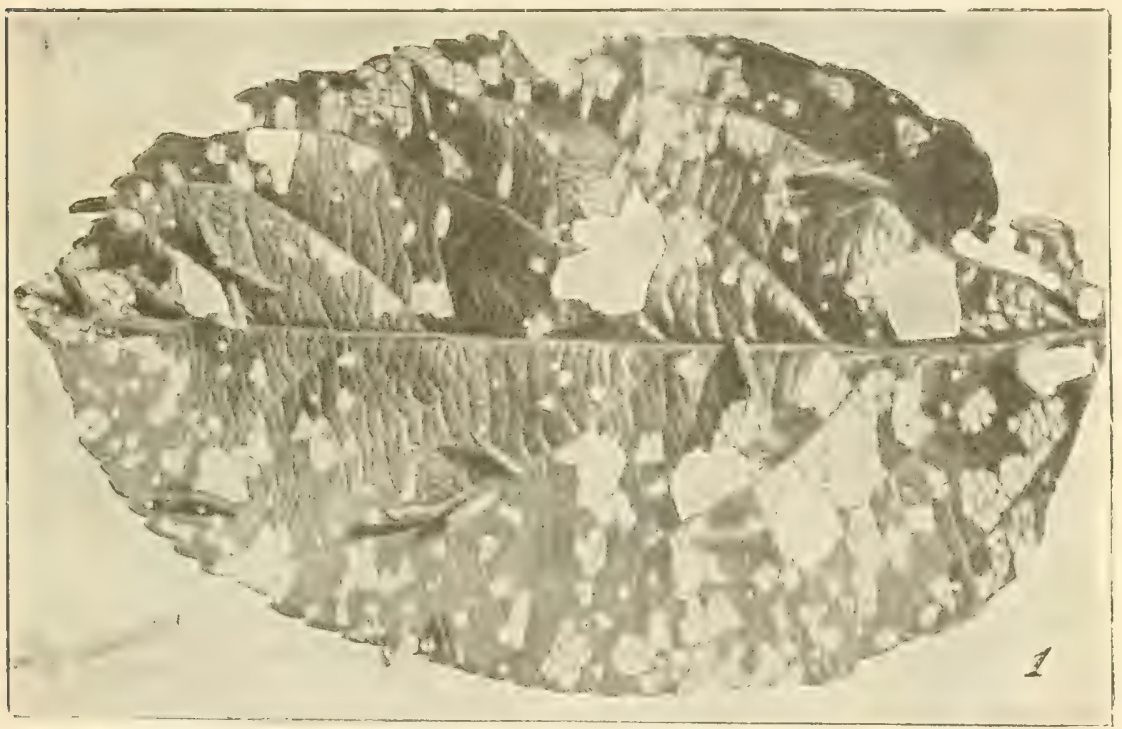

FIg. 483.-Apple leaf with eigar case-bearers at work-natural size. (After Hammar, U. S. Dept. Agr.)

Control.- Spraying with Paris green or arsenate of lead just before the leaf buds open and again ats sorn as the foliage is out, will destroy the little caterpillars.

\section{The Bud Moth*}

This is a European species which was first noted in this country in 1841, and has since spread throughout the Northern and Middle

* Tmetocera ocellana Schiff. Family Tortricida. See M. V. Slingerland, Bulletin 107, Cornell Tniv. Agr. Hxp. Wta.; W. E. Britton, 9th Report, State Entomologist of Connecticut, p. 353. 
States east of the Rocky Mountains and to Oregon and Idaho. The larvæ feed on all of the common deciduous fruit trees, and blackberry, but are most commonly injurious to apple. The adult moth is a dark ash gray with broad yellowish bands across the fore-wings, which expand about five-eighths inch. The full-grown caterpillar is one-half inch long, of a light chestnutbrown color, with the head, legs and thoracic shield dark brown or black, smooth and shiny.

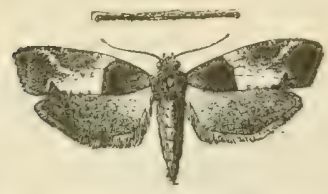

Fig. 4S4.-The bud moth

(Tmetocera o c e ll a $n$ a Schiff.)-twice natural size. (After W. E. Britton.)

Life History.-The larvæ hibernate in small, oval, silken cases attached to the bark of a twig. About the time the buds begin to swell in the spring, the caterpillars bore into them, thus early protecting themselves from insecticides. As the young leaves and flowers unfold, the caterpillars form nests for themselves by tying the leaves together, and destroy the young foliage and flower buds, but do not leave the nests in feeding. In New York, they become full grown during June, a n d transform to pupæ in the silk-lined. nests. About ten days later the moths emerge and lay the eggs singly or in small clusters on the under surface of the leaves. The egg is disk-like, much flattened, usually oval in shape, and transparent, resembling a minute $\mathrm{drop}$ of water. The eggs

soon hatch and the Fig. 485.- Y Young apple leaves in fested by the young caterpillars

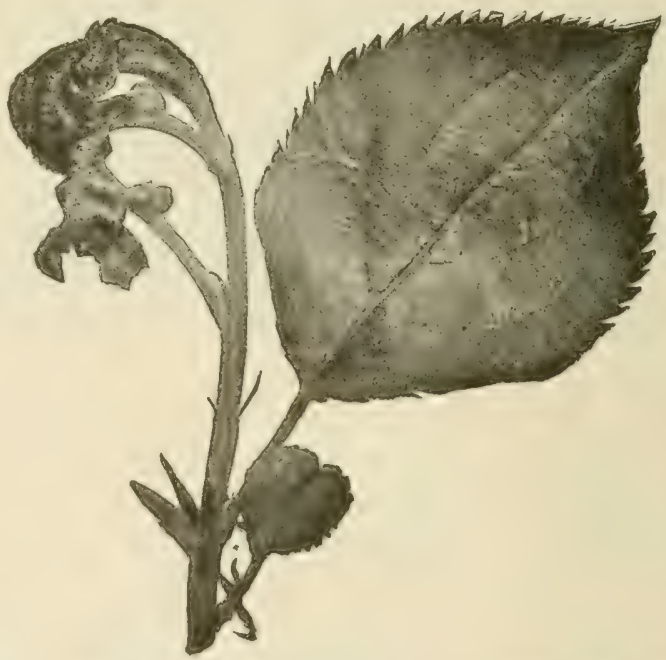
bud moth larva. (After W. E. Britton.) feed on the under sides of the leaves, protecting themselves by a 
thin silken web. In the fall they migrate to the twigs and form the small silken cases in which they pass the winter.

Control-Dr. Britton reports that the caterpillars may be

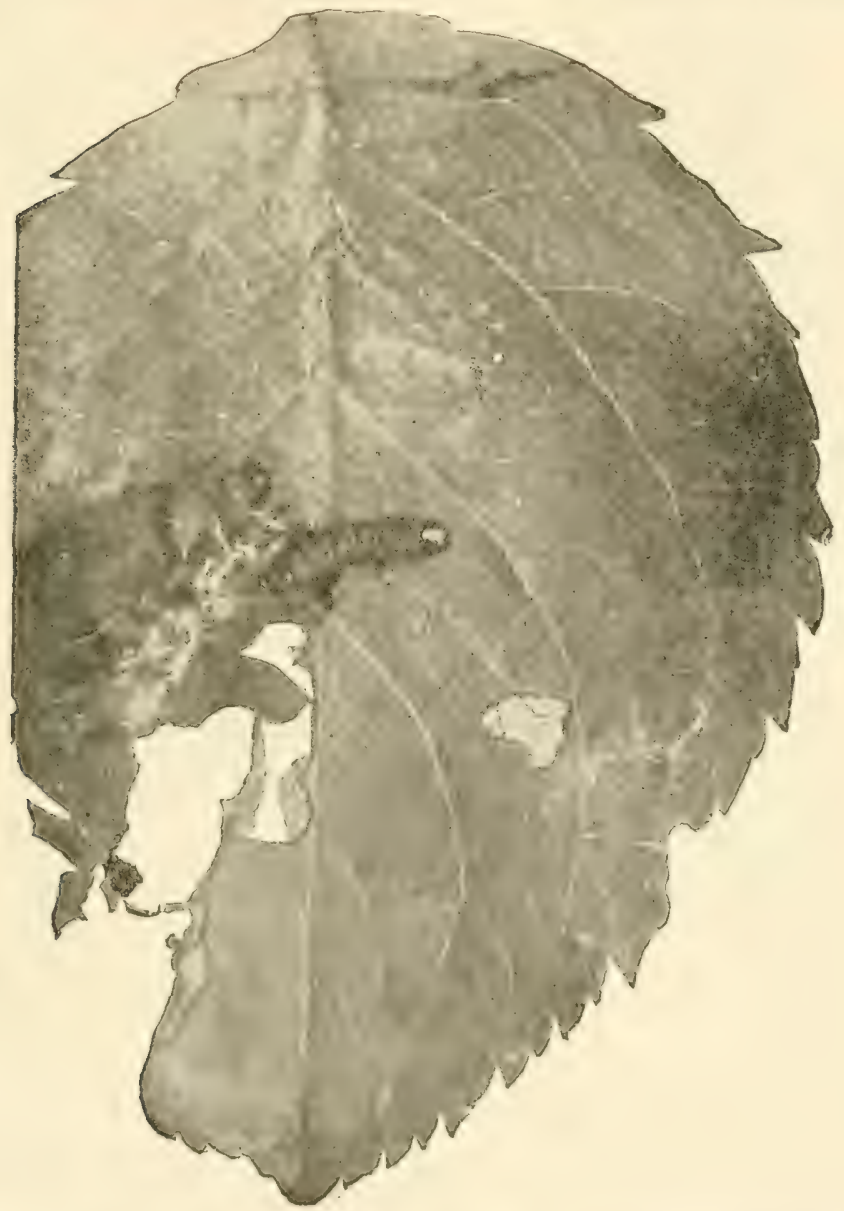

Frc. 486.-Apr.le leaf injured by the bud moth caterpillar-natural size. (After W. E. Britton.)

effectivcly restroyed by spraying with arsenate of lead 1 pound tc 10 gallens, which should be applied just as the buds are bursting and again before the trees blossom. 


\section{The Codling Moth*}

The common apple worm, the larva of the codling moth, is probably the best known and most generally destructive of all the apple insects. It is an old European insect and has been

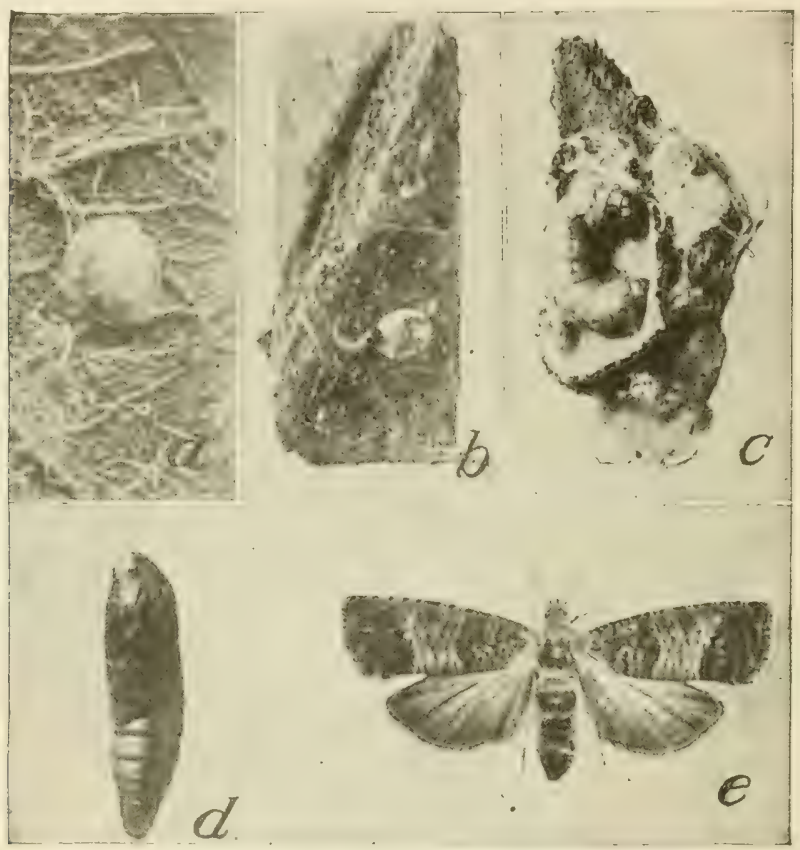

FIG. 487.-The codling moth (Cydia pomonella Linn.): a, egg-greatly enlarged; $b$, young larva hatching from egg; $c$, larva in winter cocoon on inside of a bit of bark; $d$, pupa-original; $e$, moth-after slingerland-all much enlarged.

distributed to almost all parts of the world where apples are grown. The "wormy" apple is so well known that the work of the larva needs no description, but the aggregate loss which it occasions is not always appreciated, as most of the injured fruit drops and no account is kept of the windfalls, and if the picked

* Cydia pomonella Linn. Family Tortricida. See A. L. Quaintance. Yearbook U. S. Dept. Agr, 1907, p. 435; E. L Jenne, Bulletin 80, Part I, Bureau of Entomology, U. S. Dept. Agr.; C. B. Simpson, Bulletin 41, n. s., Div. Ent., U. S. Dept. Agr, E. D. Sanderson, Bulletin 143, N. H. Agr. Exp. Sta ; and bulletins of the State Agricultural Experiment Stations. Laspeyresia is now said to be the correct generic name, both it and Carpocapsa taking precedence over Cydia. However, as things now stand any one of the three names may be used. 
fruit is not seriously infested the grower does not notice that he has lost a large part of the crop, though where the pest is abundant so much of the fruit is injured that but little remains to be picked on unsprayed trees. In 1907 Professor Quaintance estimated the annual loss due to this insect in the United States at about $\$ 12,000,000$, and this estimate must now be about doubled.

The moths fly at dusk and are rarely seen, as during the day they rest on the bark which they closely resemble in color. The wings expand about three-quarters inch and have somewhat the appearance of grayish-brown watered silk, but when more closely examined are seen to be crossed by numerous lines of gray and brown scales. Near the hind angle of each front wing is a large dark brown spot marked with streaks of brown or gold. The hindwings are of a lighter grayishbrown color, darker toward the outer margin.

Life History. - The winter is passed by the full-grown larva in their small white cocoons

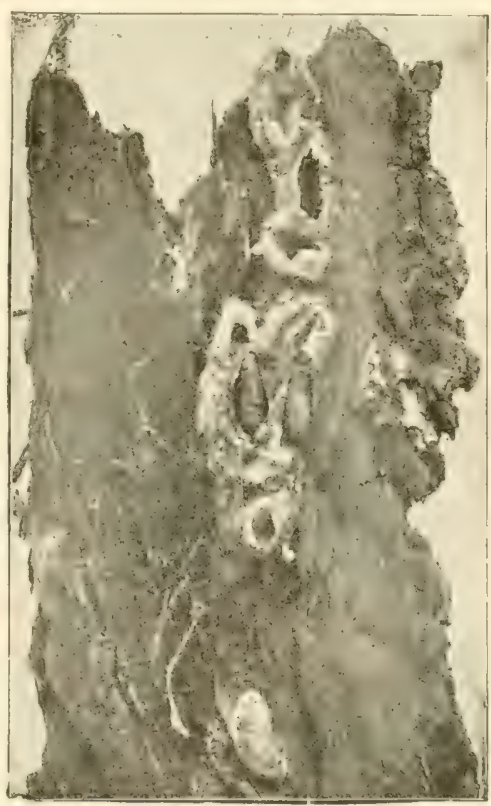

FIG. 488.-Cocoons of codling moth as found attached to a piece of loose bark-natural size. (After Slingerland.)

beneath, or in erevices of, the bark. About the time the apples blossom the larvæ transform to small brown pupæ, from which the moths emerge in two to three weeks. If the evenings be warm the females commence to deposit their eggs within a few days, laying most of them on the foliage. A female lays from 60 to 75 eggs and though most of them are placed on leares near the young fruit, ofttimes they are deposited on limbs or trees with no fruit. The individual egg looks much like a small white blister about the size of a pinhead. It is at first quite transparent, but later a brownish or blackish streak is seen, showing 
the little caterpillar forming within. The eggs hatch in from five to ten days, depending upon the season and temperature, most of them hatching about three or four weeks after the blossoms fall.

The young apple worm is at first only about one-sixteenth inch long, of a whitish color, with a shining black head, and with distinct blackish tubercles over the body, which become quite indistinct in later life. Upon hatching the young larva usually feeds a little on the tender parts of the leaves before it crawls to the nearest apple, which is probably 8 or 10 inches

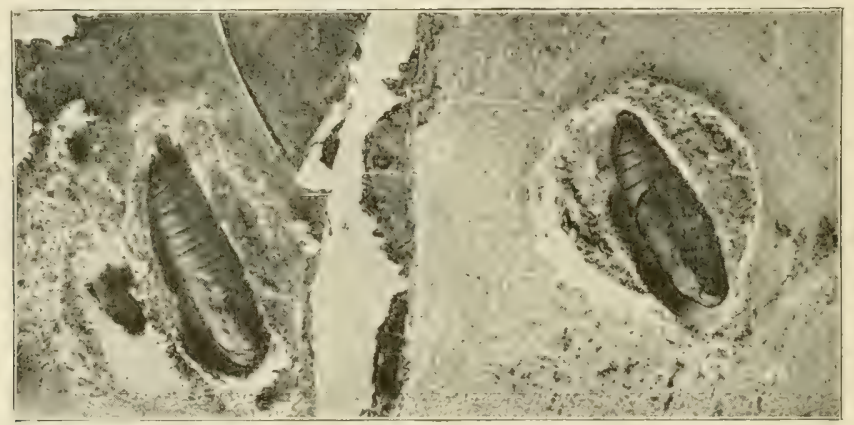

FIg. 489.-Pupæ of codling moth in cocoons-enlarged. (After Slingerland.)

distant. Over 90 per cent of the larvæ enter the apples through the blossom end and feed a little within the calyx before they bore inward to the core. The others enter at the stem end or at the side, where a leaf may touch the apple. The seeds of the apple seem to be most relished, for the larva soon hollows out each of them as well as the surrounding core, its work being indicated by the well-known excreta thrown out from the calyx, showing the "worminess" of the apple. The larva becomes full grown in from three to four weeks and eats it way out through the side of the apple, leaving a round exit hole, and seeks a place to form its cocoon. The full-grown caterpillar is about three-quarters inch long, whitish or pinkish in color, with a brown head and faint tubercles over the body, and with three pairs of thoracic legs and five pairs of abdominal prolegs. The cocoons are found mostly on the trunks of the trees, as in winter. The pupal stage of the first summer generation lasts ten to twelve days, and the moths emerge about eight weeks after the eggs were laid. 
In northern New England but 2 or 3 per cent of the larvæ pupate, the majority hibernating over winter, so that there is but a small second generation. Farther south a large number transform and in the Middle States there are two full generations. In the far South, as in Georgia, Arkansas and New Mexico, there are three generations. In any event the larvæ leave the apples in the fall and hibernate in their cocoons, those but partly grown usually dying before spring. The life cycle of the second and third generations are essentially the same as that of the first, except that

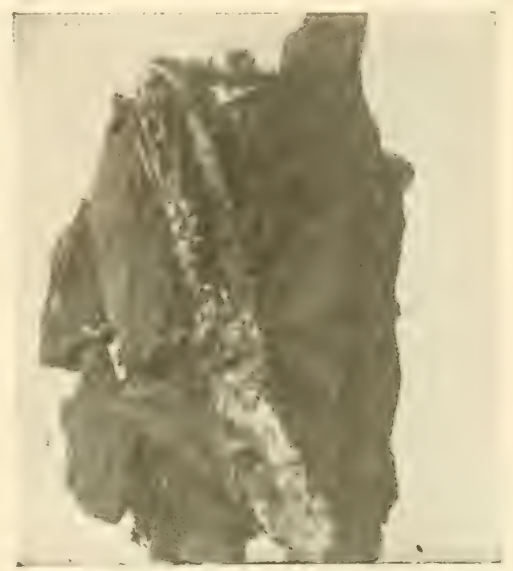

FIG. 490.-Pupa skin of codling moth remaining attached to cocoon-enlarged. a large proportion of the eggs are laid on the fruit and more of the larva enter the apples through the sides or stem end. The work of the larva of the later broods is also somewhat

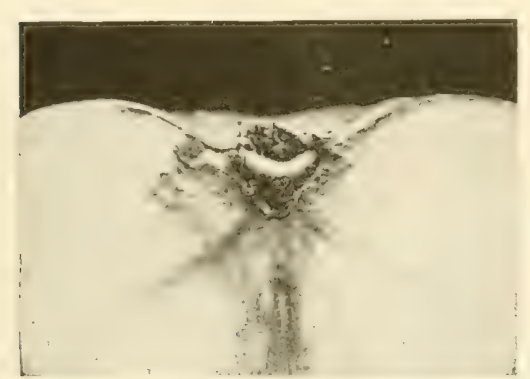

FIG. 491.-Younglarvin of codling moth in calyx cavity of apple-enlarged. different, as much of it consists of eating around the blossom end or on the face of the apple, eating out small holes or tunneling under the skin, as shown in Fig. 496. When two or three generations occur, the injury by them often becomes very serere if the first generation has not been largely destroyed by thorough spraying. Tery similar injury is done by the larva of the lesser apple worm, ${ }^{*}$ which is very difficult to distinguish, but fortunatcly the same treatment will eontrol both pests.

Control.- Seraping the loose bark from the trees and keeping the bark smooth removes the favorable conditions for the hibernation

* Enarmonia prunirora Walsh. Family Tortricida. See A. L. Quaintance, Bulletin 68, Part V, Bureau of Entomology, L'S. Dept. Agr.; Foster and Jônes, Bulletin 80, Part III, ibid. 
of the larvæ. A large proportion of the hibernating larvæ are destroyed by woodpeckers and nut-hatches during the winter and

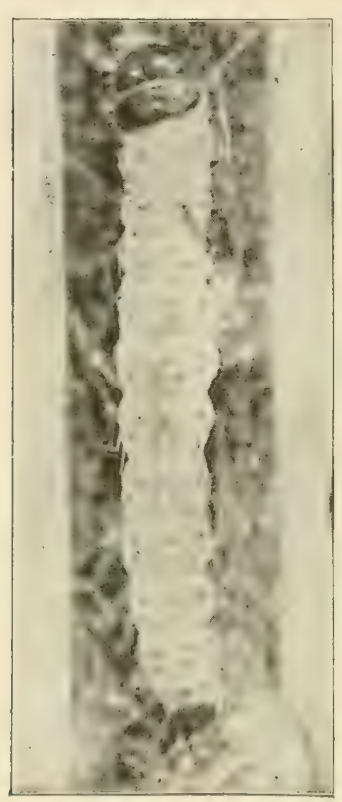

FIG. 492.-Larva of the codling moth only a few days old, showing tubercles-much enlarged. (After Slingerland.)

sprayed for fungous diseases at the same time Paris green may be applied with it and the Bordeaux will cause it to adhere as well as arsenate of lead and there will be little danger of burning with a good quality of Paris green. One-third pound per barrel of Paris green, 2 or 3 pounds of arsenate of lead, or 1 quart of stock solution of arsenite of lime are the proper strengths for general use. The first spraying for the codling moth should they should be attracted to the orchards by hanging up bones and suet. Picking up the fallen apples and destroying them before the larvæ have left them to form their cocoons will do much to lessen the numbers and will aid in the control of other insects. Cellars and storage houses where apples are kept over winter should be screened to prevent the exit of the moths in the spring. The principal method of control, however, is in spraying with arsenicals, which, when properly done, will destroy practically all of the larvæ. Although Paris green and arsenite of lime have long been used for this purpose, arsenate of lead is now preferred on account of its superior adhesive qualities and because there is less danger of burning the foliage with it. Where Bordeaux mixture is

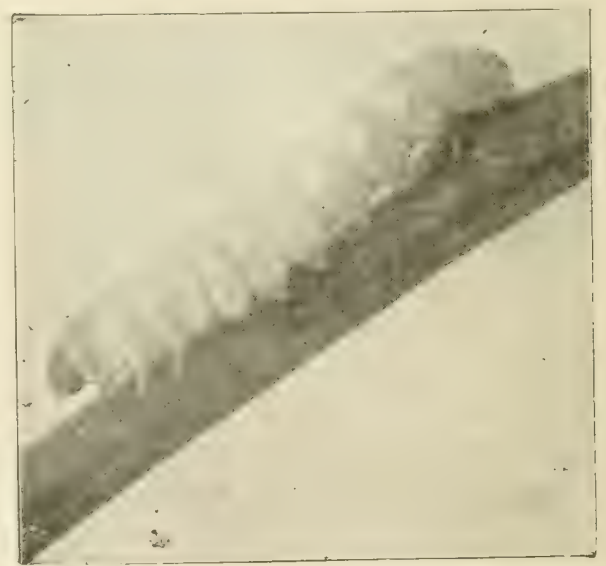

FIg. 493.-Full grown larva of the codling moth - enlarged about three times. (After Slingland.) 
be given just after the hlossoms have fallen and before the sepals of the calyx close, the object heing to plater the poison in the calyx cavity so that the little larva will be poisoned when it

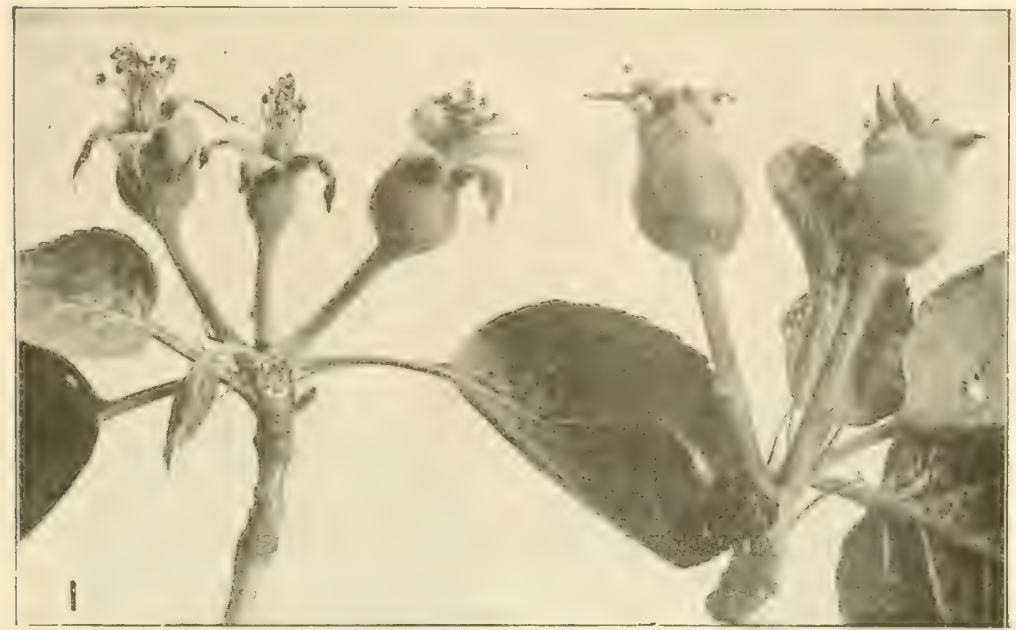

Fic. 491.-Young apples in right condition to spray for the colling moth and with callyx sepats closed too far for effective spraying. (Iffer (Uuaintance, U. S. Dept. Agr.)

enters and feeds in the calyx a few weeks later. In general this spraying should be given within a week or ten days after two-
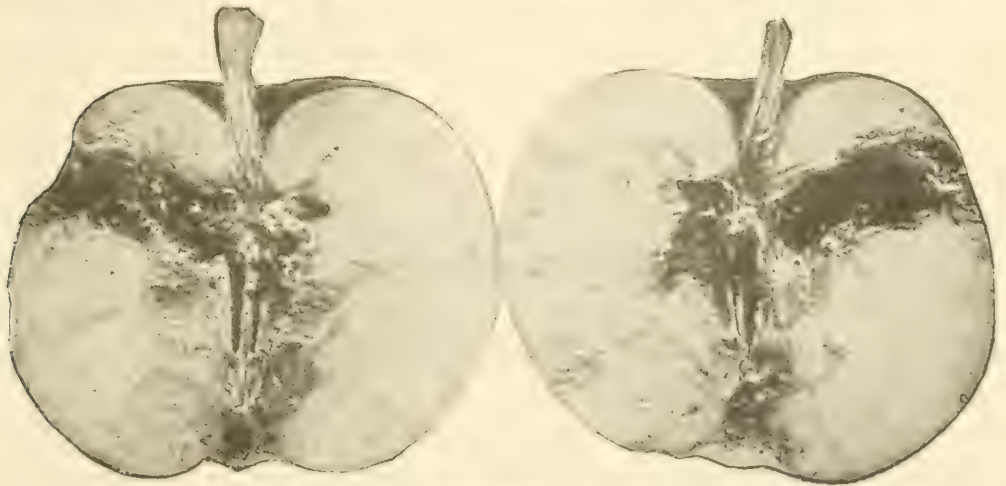

Fig. 495.-Work of the first generation of codling moth larva.

thirds of the petals have dropped, but the time will depend upon the variety and the season.

In the West great emphasis has recently been placer upon 
using a coarse spray with a high pressure, 100 to 250 pounds, which will drive the spray through the bases of the stamens into the lower calyx cavity, and though excellent results are undoubtedly secured in this way, experiments in the East indicate that a mist spray is equally effective if thoroughly applied, whether the lower calyx cavity is reached or not. There is no question, however, of the importance of maintaining a good pressure, of at least 100 pounds, so that the spray may be forced through the foliage; for the blossoms point in all directions, and the spray must be forced through the tree to reach those pointing inward on the opposite side. An angle on the end of
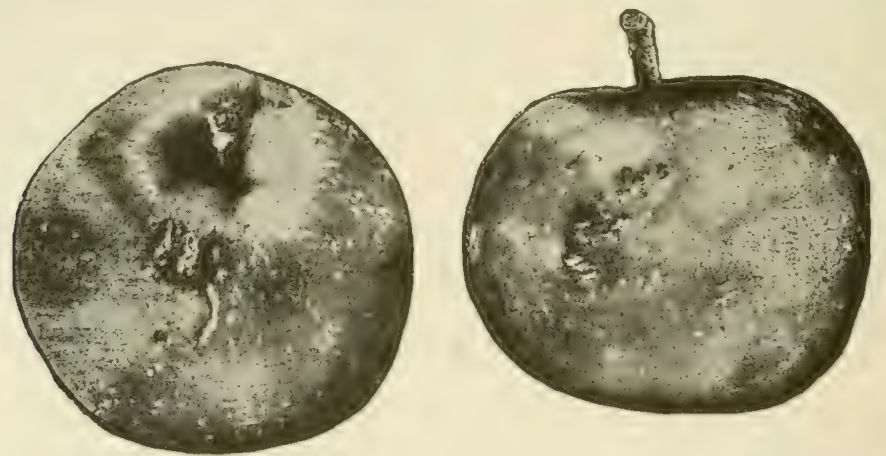

FIG. 496.-Work of the second generation of codling moth larvæ.

the spray-rod which will turn the nozzle at 35 or 45 degrees will greatly aid in reaching all parts of the tree.

The second spraying should be applied three or four weeks after the blossoms fall, just as the eggs are hatching. At this time the object should be to cover the foliage thoroughly, so that the young larve may be killed while they feed on the foliage. Consequently both the upper and under surfaces of the leaves should be coated. If the first spraying has been well done, the second will often be unnecessary where there is but a partial second brood or where the pest is well under control, but as it is often necessary to spray for the fungous diseases at this time it is well to add the arsenical, which but slightly increases the cost. Where there is a full second generation, as in most of the Middle and Pacific States, a third application as the second generation of larvæ are hatching, will be found advisable about 
nine or ten weeks after the petals fall, and a fourth two or three weeks later may be necessary. With thorough spraying not over 1 or 2 per cent of the picked fruit should be wormy, as most of the wormy fruit will drop early in the scason.

Recent experiments have shown that quite as effective codling moth control can be secured by dusting with powdered arsenate of lead with sulphur as the carrier. Some of the advantages of dusting are discussed under the description of the dusting practice in an early chapter.

\section{The Apple-maggot or " Railroad Worm " *}

The apple-maggot has long been known as the worst pest of summer and fall apples in the New England States, and has extended its injuries to eastern New York and southeastern Canada. It has been recorded from Michigan, Wisconsin, Illinois, Minnesota, New Jersey, and Pennsylvania, but seems to be only occasionally injurious there, though it has been reared from haws in Illinois and Wisconsin, which would indicate that the insect is native in those States. Evidently it is widely distributed throughout the northeastern United States, but for some reason is most injurious in New England. The fruit is injured by the small white maggots, which burrow through the flesh, leaving discolored streaks through it, often becoming so numerous as entirely to honeycomb the pulp which breaks down into a yellowish mass merely held together by the skin. An apple quite fair exteriorly will often be found to be almost completely "railroaded" by the maggots, although brown, slightly sunken streaks in the skin usually indicate their presence. Sweet and subacid varieties of summer and early fall apples are worst injured, but where the pest develops unchecked, winter sorts, such as the Baldwin and particularly the Northern Spy, are often seriously injured.

The parent of the maggot is a little fly slightly smaller than the house-fly, of a blackish color, with yellowish head and legs,

* Rhagoletis pomonclla Walsh. Family Trypetida. See A. L. Quaintance Circular 101, Bureau of Entomology, U. S. Dept. Agr.; F. L. Harvey, Report Maine Agr. Exp. Sta., 1889, p. 190; W. C. O'Kane, Journal of Economic Entomology, IV, 173, and Bulletin N. H. Expt. Sta. No. 171, also H. H. P. Severin, Bulletin 251, Maine Agr. Expt. Sta. 
greenish eyes, and three or four white bands across the abdomen. The wings are marked by four black bands, as shown in Fig. 497, which distinguish it from similar flies found on apples.

Life History.-The flies emerge during July in New England and live for several weeks. The females at once commence depositing their eggs in the early varieties of apples. The eggs are laid just under the skin in a vertical position, on the cheek of the apple. The egg is elliptical, about one-thirtieth inch long, and yellowish in color. A female will lay 300 to $400 \mathrm{eggs}, 12$ or 15 often being placed in a single apple. The eggs hatch in four or five days and the little maggots at once burrow into the pulp. By means of a vertical motion of the head they rasp the pulp with the small, black hook-like mouth parts, and in less than

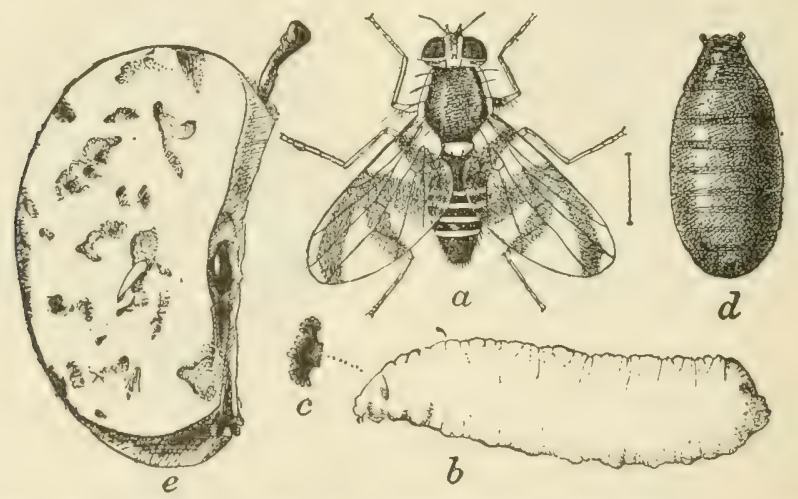

FIG. 497.-The apple-maggot (Rhagoletis pomonella Walsh): $a$, adult; $b$, larva or maggot; $c$, funnel of spiracle on head; $d$, puparium; $e$, portion of apple showing injury by maggots; $a, b, d$-enlarged; $e$-reduced. (After Quaintance, U. S. Dept. Agr.)

a minute can tunnel their own length. They become full grown in four to six weeks during the summer, but if only partly grown when winter sets in, many of them seem to hibernate until spring. The mature maggot is about one-third inch long, yellowish-white, footless, much like similar maggots, and distinguishable by the microscopic characters of the spiracles of the first and last segments. The mature maggot goes just beneath the surface of the ground, where its skin hardens to a puparium in which the pupa is formed, in which stage the winter is passed. In barrels or storage places the maggots pupate beneath the apples, and 
occasionally a puparium is found in the burrow of the maggot within an apple. Most of the puparia are within 1 or 2 inches of the surface. There is but one generation a year. Some of the pupx do not emerge the next spring but remain dormant for an entire year in addition to the usual hibernating period, so if all the active individuals were killed one year there would still be emerging adults the following spring.

Control.-As most of the affected fruit drops to the ground, during summer it should be picked up twice a week and destroyed before the maggots have left it to pupate. Where this is carefully done injury by the pest is greatly reduced. Particular attention should be given to the destruction of infested summer apples. Hogs pastured in the orchard will do this work admirably, and where there are but a few trees on bare or cultivated ground chickens will destroy the larva. Plowing the orchard deeply as early as feasible in spring and keeping it well cultivated in early summer will bury the puparia so as greatly to lessen injury, which is always worse in uncultivated sod orchards. Poisoned syrups, sprayed onto the trees to attract the flies, have given good protection from the maggot but have scorched foliage on account of the use in them of a soluble form of arsenic. This method of treatment must be considered as still in the experimental stage.

\section{The Apple Curculio *}

The apple curculio has been commonly confused with the plum
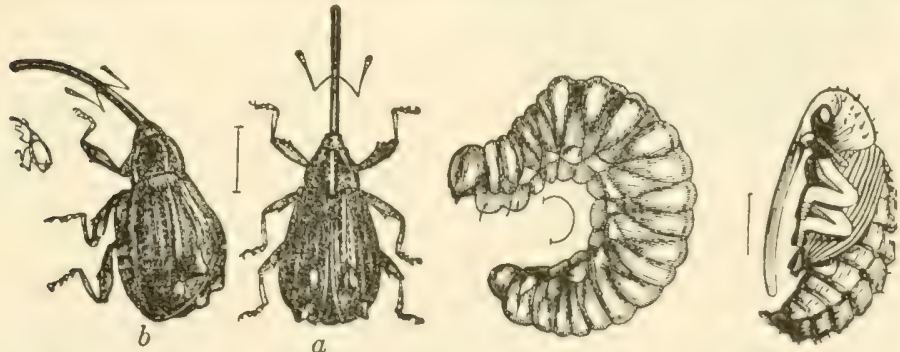

FIG. 498.-The apple curculio (Anthonomus quadrigibbus Say): $a$, $b$, adult beetles; $c$, larva; $d$, pupa-all enlarged. (After Riley.)

curculio, but is by no means as eommon or injurious, and is quite distinct in both appearance and habits. The adult beetle

*Anthonomus quadrigiblus Say. Family Curculionida. See C. S. Crandall, Bulletin 98, Ill. Agr. Exp. Sta., p. 514; F. E. Brooks, Bulletin 126, W. Va. Agr. Exp. Sta., p. 113. 
is about the same size as the plum curculio, but more reddishbrown in color, the abdomen is more robust, and the wing-covers bear four prominent humps, the anterior being much larger than those on the plum curculio. The snout of the apple curculio is
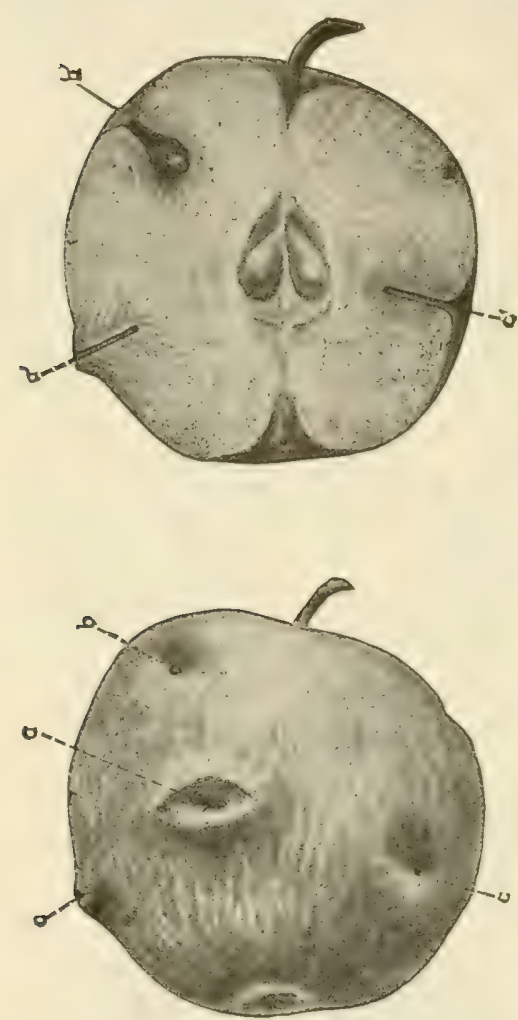

FIG. 499.-Work of the apple curculio; $a, a^{\prime}, c, c^{\prime}$, feeding punctures from the surface and in section; $b, b^{\prime}$, egg punetures from the surface and in section. (After C. S. Crandall.) as long as the rest of the body and is held straight forward from the head, instead of hanging down as does the snout of the plum curculio. The work of the apple curculio is also different in that after laying the egg in a small cavity in the fruit, on crescent-shaped mark is made around it. The apple curculio is a native species which breeds in wild haw, wild crab, and wild cherry, and has been reared in $\mathrm{plum}$, quince and pear. "It has been reported from Connecticut and Ontario south to North Carolina and westward as far as New Mexico. It seems to have been more troublesome in Missouri, Illinois and other mid-western States than elsewhere," but has never done anything like the injury due to the plum curculio and can hardly be regarded as a serious pest.

Life History.-The beetles commence laying eggs in the fruit soon after the blossoms drop and continue for a period of sixty days, an individual female laying about 65 eggs. The eggs hatch in about five days and the larva feed on the flesh of the apple for about twenty days, when they transform to pupæ within the fruit. A week later the beetles emerge, but feed very little during the late summer before they enter hibernation for the winter: most of them leaving the trees by the latter part of August. 
The larva is a footless, whitish grub a half inch long when full grown with a hump-backed appearance due to the enlargement of the anterior abdominal segments, which prevents the larva from straightening out. The beetles injure the fruit by puncturing it for feeding and for the deposition of eggs, causing it to become dimpled and gnarled as does the plum curculio, and the larve feed within the fruit, mining the flesh, in which they undergo their complete development.

Control.-Thickets of wild cral, or hawthorn trees should be destroyed wherever near an orchard, for the beetles will breed in their fruit and then migrate to the orchard. Jarring as for the plum curculio may be practiced on young trees, and spraying as for that species will doubtless largely reduce the injury. Usually this insect is not sufficiently injurious to warrant special treatment where its native food-plants are not overabundant near the orchard.

\section{The Pear Leaf Blister-mite*}

The pear leaf blister-mite has long been known as a pest of pear foliage wherever the pear is grown, and has similarly affected apple foliage in Europe, but only in recent years has it become a serious pest of apple foliage in New York, New England, Ontario and Pennsylvania. Just why it should suddenly become an apple pest after having oceurred in this country for years without noticeably injuring it is a mystery, though dry seasons may possibly be accountable for it.

The work of the mites is recognized by reddish blisters forming on the young foliage, which later turn blackish and have a corky texture. Badly affected leaves drop, so that a tree is often largely defoliated, and where the mites are abundant they attack the young fruit.

The mites are not true insects, as they belong to the same class as the spiders, scorpions, and ticks. One of the more common larger mites is the red spider of greenhouses, which affects flowering plants, vegetable crops, and fruits of all sorts. These little blister-mites are of microscopic size, only $1-100$ to $1-200$ inch in length, so that they can be seen only with a lens, and must be

* Eriophyes pyri Pgst. Class Arachnida. Order Acarina. Family Eriophyido, with which are associated several nearly related species with similar habits. See Parrott, Hodgkiss and Schoene, Bulletins 283 and 306, N. Y. Agr. Exp. Sta. 
examined with a compound microscope to distinguish the species. One is shown much magnified in Fig. 500. They are elongate, with two pairs of legs, and slender abdomens, composed of 50 to 80 small rings, frequently marked with rows of small tubercles and ornamented with a few hairs and bristles.

Life History.-The mites spend the winter in the buds, and as warm weather approaches in the spring they become active and move toward the base of the growing bud scales and feed there. As the young leaves unfold the mites migrate to them. They burrow through the surface of the leaf and feed upon the succulent tissue within, setting up an irritation which soon results in reddish spots on the surface. Within these mines the eggs are laid, as many as 14 having been found in a single blister. The young hatch in about a week and burrow around in all

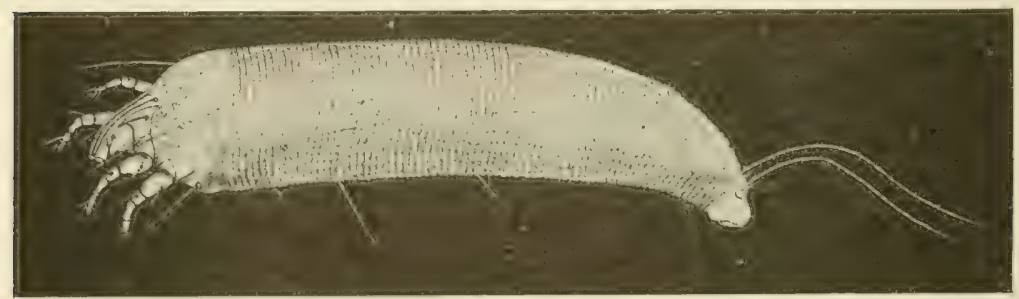

FIG. 500.-The pear leaf blister-mite (Eriophyes pyri Pgst.): highly magnified. (After Parrott.)

directions, feeding on the tissues and juices. When full grown they leave the gall through snall openings in the under surface and start new colonies which produce similar galls. They continue to reproduce and migrate throughout the summer, and under favorable conditions become numerous enough to completely infest the new leaves as they appear. In the fall they leave the leaves to hibernate in the buds as already described.

On pear the blisters are at first greenish pimples, which become reddish and later brilliant red blisters, and finally they become brown or black and the tissue corky. When numerous the galls coalesce, forming dark brown patches over the leaf, which often break open, particularly along the edges of the leaves. On the blossom ends of the fruit and on the stems they produce light-colored pimples, which do not seen to injure the fruit. On apple the blisters are less brilliantly colored than on pear, 
and become a light brown or dark green color on the upper leaf surface and uniformly brown beneath, looking something like the work of the apple rust. The young fruit is sometimes at alcked, on which small green pimples, which litter make blister-like spots or pock marks, are made toward the blosison ends, but which do not seem to cause much damage.

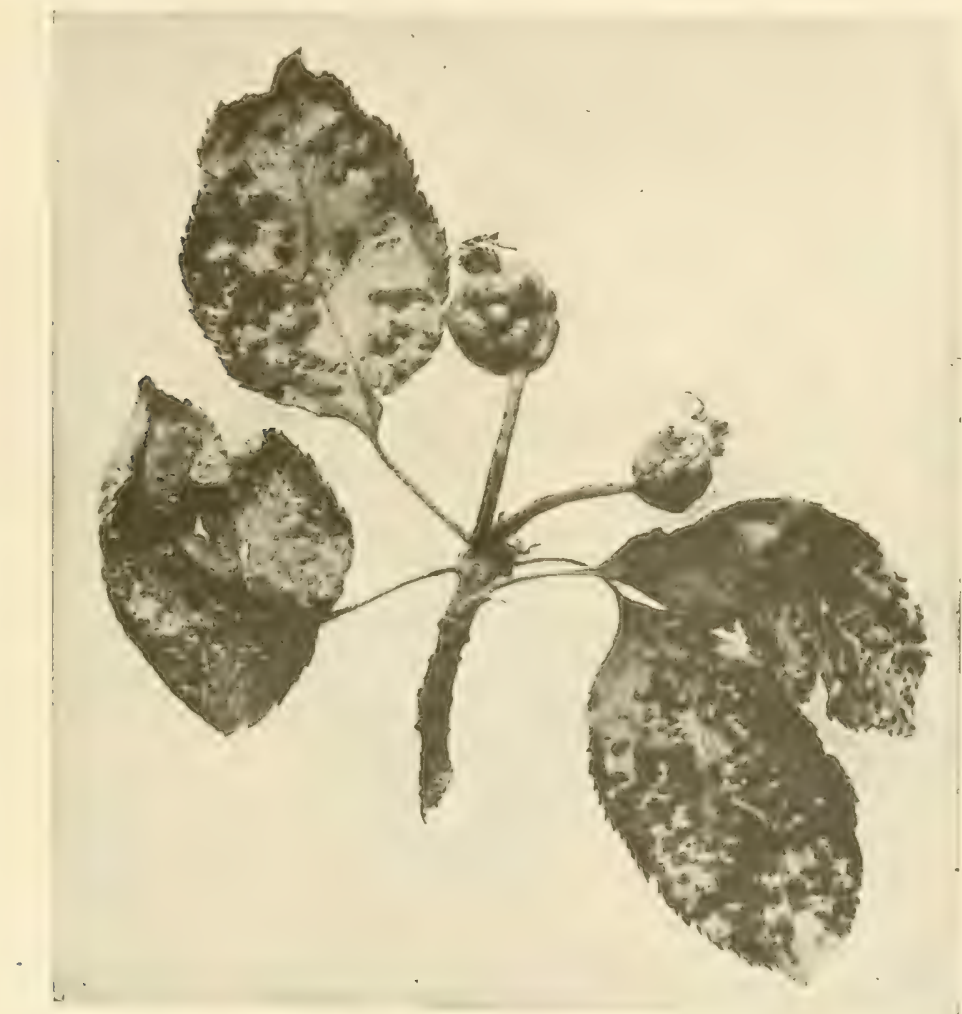

Frs. 501. -()h lewf cluster with galls of pear leaf hister-mite on apple fruit and leaves. (After Parrott, Hodgkiss and Schoene.)

control.-The mites may be controlled by spraying with 10 per e'ent kerosene emulsion, miscible oils, or lime-sulfur wash used the same as for the San José scale. Spraying should be done in Oetober or November as soon as possible after a majority of the leaves have fallen, as many of the mites are still in the pubescence of the young wood, where they are more easily de- 
stroyed than when under the bud scales. In spring spray just as the buds begin to break and show the tips of the young leaves; spraying later than this will injure the foliage, and earlier spraying is not as effective. By using lime-sulfur in the spring, the usual treatment with Bordeaux mixture for diseases at that time is rendered unnecessary. Where infestation is serious both fall and spring sprayings should be given; otherwise the fall spraying is the better. The buds and new growth should be thoroughly drenched, while the rough bark of the trunk and old limbs may be neglected as far as the mites are concerned. Where pear trees are but slightly infested, the spread of the pest may often be prevented by simply pruning out and burning the infested twigs upon the first appearance of injury.

\section{The Pear Psylla*}

Where the pear psylla is abundant, pear growers have come to fear it next to the San José scale, and until recently owners
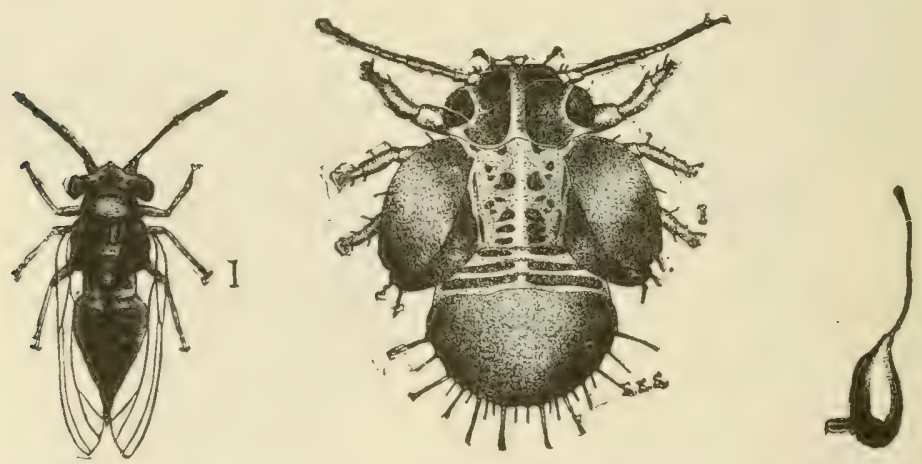

Frg. 502,-The pear psylla (Psylla pyricola Foerst): adult, full-grown nymph and egg-all greatly enlarged in different proportions. (After Slingerland.)

in eastern New York became so discouraged in their attempt to control it that orchards were cut down. It is an old European pest and was first noted in Connecticut in 1832, since when it has spread southward to Maryland and Virginia and westward to Michigan and Illinois, in which States it has done considerable injury. The psyllas are nearly related to the plant-lice and are

* Psylla pyricola Foerst. Family Psyllida. See M. V. Slingerland, Bulletins 44 and 108, Cornell Univ. Agr. Exp. Sta.; C. L. Marlatt, Circular 7, Div. Ent., U. S. Dept. Agr. 
sometimes called jumping plant-lice, on aceount of the habit of the adults of giving a quick jump and flying from the foliage when disturbed. Like the plant-lice they reproduce very rapidly and suck the juices from the foliage and fruit. Usually the first indication of the pest is the prescence of large quantities of honeydew, secreted by the nymphs, with which the foliage becomes covered, and which attracts numerous ants. When the psyllas are numerous the leaves and fruit become coated with this sticky substance and it even drops from them like rain and runs down the trunk. A blackish fungus grows on the honey-dew and is always a good indication of the presence of the psylla.

Badly infested trees are so injured by loss of sap that they shed their leaves in midsummer, the lower ones being the first to turn yellow and drop. The young fruit also drops from badly infested trees, which make but little growth, as the young shoots are often attacked and wither early in the season.

The adult psylla is about one-tenth inch long, of a reddishcrimson color with brownish-black markings, bronzy eyes and dark wing-veins, looking very much like a miniature cicada or dog-day harvest-fly.

Life History.-The adults hibernate over winter in crevices of the bark and there lay their eggs late in April or early May on the twigs or around the buds. The egg is about one-cighteenth inch long, hardly perceptible without a lens, and orange-yellow in color. It is pear-shaped with the small end drawn out into a long thread, and the larger end is attached to the bark by a short stalk (Fig. 502). The later generations deposit the eggs on the leaves often in rows or bunches. The eggs hatch in two to three weeks and the young nymphs feed on the leaf petioles in the axils of the leaves and later on the leaves, young fruit and tender shoots, from which they suck the sap. The nymph is a peculiar-looking little bug, broadly oval, flattened, of a yellowish color, with crimson eyes, but later becomes reddish with black markings and conspicuous black wing-pads, as shown in Fig. 502 . They move very slowly and are frequently quite covered by their own honey-dew. After molting some four or five times, they finally transform to adults in about a month. According to Slingerland there are four generations in New York and probably five in Maryland. 
Control.-As the adults hibernate over winter in the bark the treatment advised for the pear leaf blister-mite furnishes the best means of control for the psylla, and winter treatment is absolutely essential for its successful control. Otherwise, the best time to spray is in the spring just after the eggs have hatched and before the nymphs have secreted much honey-dew. If winter or spring spraying has been neglected, the trees should be thoroughly sprayed with "Black-leaf 40 " one to 1000 with soap added. Spraying should be done after a shower, which will wash

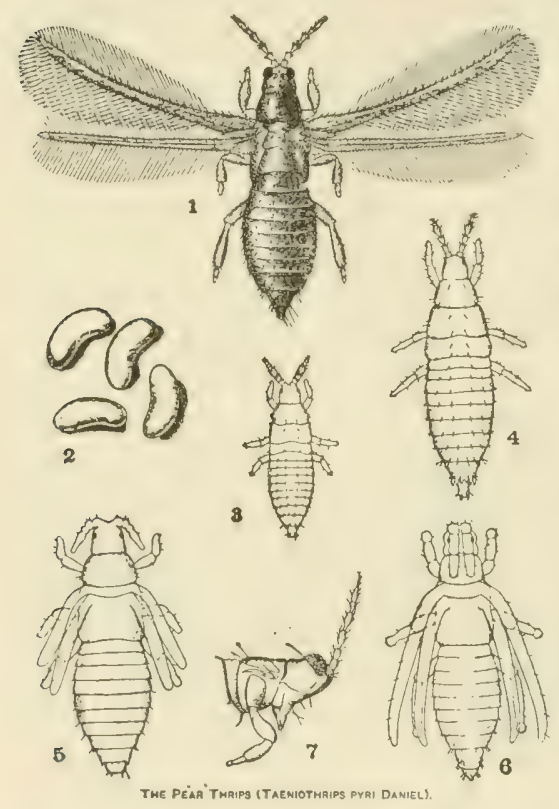

Fig. 503. The Pear Thrips (Taniothrips Pyri Daniel).-1.-Adult. 2.-Eggs. 3.-First-stage larva. 4.-Full-grown larva. 5.-Pupa, first stage. 6.-Pupa, last stage. 7.-Side view of head showing mouth parts. All greatly enlarged. (After Foster and Jones, l.c.) much of the honey-dew off, as the chief difficulty in summer spraying is to reach the nymphs through the thick coating of honey-dew with which they are covered. Obviously the spray should be applied with considerable pressure in a coarse spray.

\section{The Pear Thrips*}

The pear thrips has been known as an enemy of pears, plums, prunes, cherries and other plants in California since 1904 and within the last decade has been reported from New York, Pennsylvania, New Jersey and Maryland. It feeds on fruits, buds, flowers and leaves and causes injury aggregating at least a million dollars annually in California. The insect is not markedly different, to the casual observer, from the several other species of thrips discussed elsewhere in this volume. Adults appear on the fruit buds early in the spring and lay their eggs on fruit and leaf

* Taniothrips pyri Daniel. Family Thripida. See Foster and Jones, Bulletin 173, U. S. Dept. of Agriculture. 
stems and young fruit, feeding at the same time on growing parts of the plant. Injury by the adults is generally to the fruit buds before blossoming. The young forms feed on foliage and fruit and cause the defacement of fruit called fruit scab which greatly reduces the quality, especially of prunes which are the greatest sufferers. They remain inactive as fully grown nymphs from early summer until the following spring when the adults again appear.

Control.- Since the insect spends a large part of the year in the soil in immature stages thorough cultivation throughout the summer may be expected to destroy large numbers. Spraying has not given entire satisfaction, but distillate oil emulsions are largely used in California. These are made by mixing 30 pounds fish oil soap, twenty gallons distillate oil and twelve gallons of hot water, by pumping them together under high pressure through a spray outfit into the tank. This is stock solution and should be diluted at the rate of one to twenty. To this should be aclded Black-leaf 40, about one-half pint to 100 gallons of the spray. This is applied at the time the buds are bursting and may be repeated after the petals fall. Spraying with thick whitewash gives some control but the first solution is preferred. Any spraying treatment should be supplemented by liberal fertilization.

\section{The Pear Slug *}

Not infrequently the foliage of pear and cherry, and occasionally of plum trees turns brown in midsummer, which is found to be due to small, slimy, slug-like larva which have eaten off the surfaces of the leaves. The Pear Slug is a common pest throughout the country, having been known here for over a century. It is an old European pest and has become distributed to many of the British colonies in various parts of the world. The parent insect is a small saw-fly, about one-fifth inch long, glossy black, with four wings which are iridescent, with a smoky band across the middle, and which are folded over the back when at rest.

Life History.--The flies are ahroad by the time the foliage is well out, by the middle of April in Maryland and late May or early June in New England. Like most of the saw-flies the female is

* Caliron cerasi Linnaeus. Family Tenthredinide. See C. L. Marlatt, Cireular 26, Div. Ent., U. S. Dept. Agr., and R. L. Webster, Bulletin 130, Iowa Agr. Expt. Station. 
furnished with a strong ovipositor with saw-like teeth at the tip, with which she cuts a little blister-like cell beneath the upper surface of the leaf, in which the egg is deposited, as shown in Fig. 505. The egg hatches in about two weeks and the little larva makes its way out of the cell through a crescent-shaped cut.

The young larva is at first nearly white, except the yellowishbrown head, but very soon a slimy or gluey olive-colored liquid

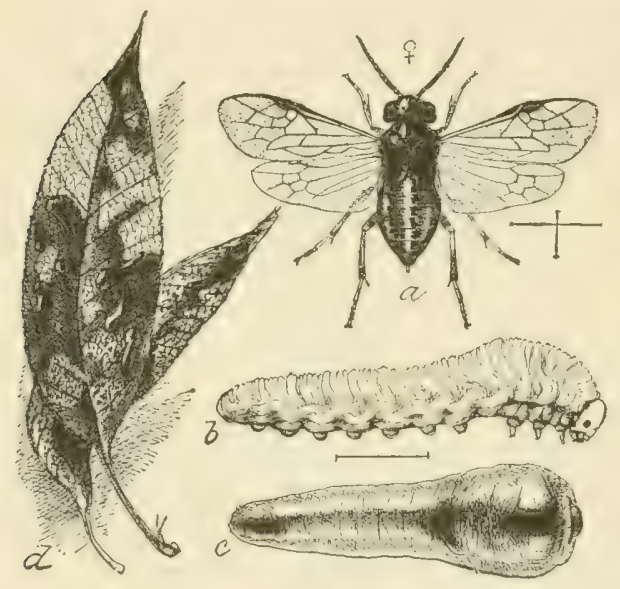

FIg. 504.-The pear slug (Caliroa corasi Linnaeus.): $a$, adult female saw-fly; $b$, larva with slime removed; $c$, same in norma state; $d$, leaves withlarva natural size; $a, b, c$, much enlarged. (After Marlatt, U. S. Dept. Agr.)exudes from over the entire body, giving it the appearance of a minute slug, from which it gets its name. The head is now dark brown, appearing almost black under the slime, and the body is also darker. The anterior segments are much swollen, concealing the head and the thoracic legs. The abdomen is furnished with seven pairs of prolegs, the usual pair on the last segment being wanting so that the tip of the abdomen is slightly elevated. The little slugs commence eating out small bits of the upper surface of the leaf, which they gradually enlarge until nearly the whole upper surface is denuded, leaving merely a net work of veins, held together by the brown epidermis of the lower surface, which is nearly intact. Leaves thus injured turn brown, die and drop, so that a tree will sometimes be nearly defoliated, except for the new growth which starts out. The larvæ grow rapidly, becoming full grown in about twenty-five days, when they are about one-half inch long. When full grown the larva molts for the fifth time and loses its olive-green slimy appearance, becoming a light orange-yellow color, clean and dry, with a lightcolored head marked by only the small circular black eye-spots on the sides. 
The larva now enters the ground for an inch or two, where it forms a small cell, which is moistened with saliva so that the walls become somewhat impervinst to water. In six or eight days it transforms to the pupat and in about two weeks after the larva entered the ground the adult fly digs its way out of the soil. Some of the larvie of each generation, and all of those of the last generation remain in the soil over winter and transform to pupæ the next spring. At Washington, D. C., the first generation of larvæ disappear by the end of June and the second generation, which is probably followed by a third generation, is most abundant in early July, when the principal injury is done. Farther north there are but two generations, the second appearing in August.

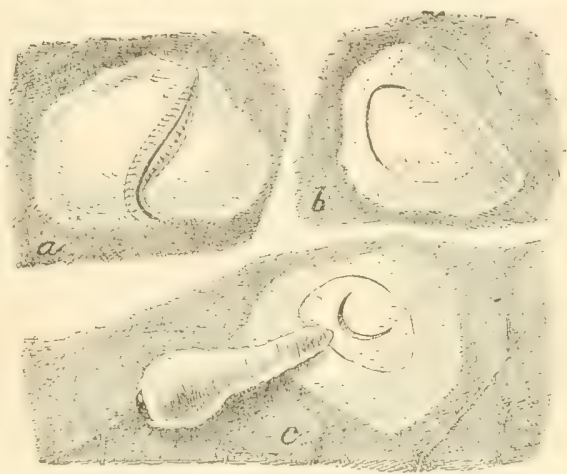

FIt. 50:).-Illustrating method of oviposition and emergence of the pear slug: $a$, cutting of cell beneathepiclermis, showing the tip of the ovipositor; $b$, the cell after the egg has been deposited; $c$, same after escape of the larva -all much enlarged. (After Marlatt, U. S. Dept. Agr.)

Control.-By spraying with any of the arsenicals when the work of the slugs is first noticed on the foliage they may be quickly destroyed. Whale-oil soap, or other soap, 1 pound to 4 gallons, will also destroy the larva as a contact insecticide. Hellebore, air-slaked lime, or almost any finely divided dust, thoroughly dusted over the trees will also destroy most of the larve, which are very readily killed. In gardens where water under pressure is available, the slugs may be washed off by a jet from a hose, as they are frequently washed off by heary rains, and are much less injurious in wet seasons.

\section{The Tarnished Plant-bug *}

The tarnished plant-bug is one of the most common and troublesome plant-lugss throughout the country from Canada to

* Lygus pratensis Linn. Family Capsidr. Sce Stedman, Bulletin 47, Missouri Agr. Exp). Sta., Croshy and Leonard, IBulletin 34t, Cornell Univ. Agr. Expt. Station, and Leonard Hascman, Research Bulletin 29, Missouri Agr. Expt. Station. 
Mexico. Seemingly it is nearly omnivorous, as it attacks almost all of the common garden crops, small fruits, tender shoots of fruit trees and young nursery trees, many flowering plants, and most of our common weeds. It is rather more important as an enemy of pears than on any other crop, causing deformation of the fruit to some extent every year in some of the important pear growing regions. At the same time it is quite as common as a garden pest, attacking a great variety of garden crops. Injury on pears
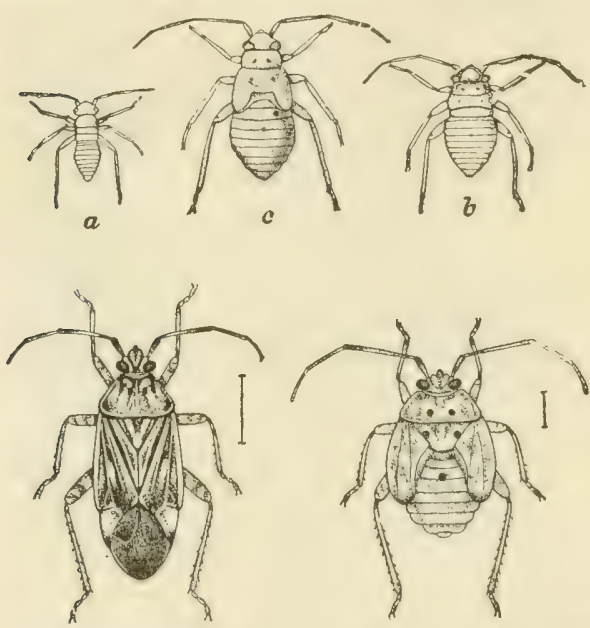

by a bug of very similar appearance is reported in New York. The bug most prevalent there is called the False Tarnisheld Plant bug (Lyyus invitus Say). Injury by the tarnished plant-bugs to peach has been blamed for a disease known as peach stopback. Both nymphs and adults injure the plants by sucking out the juices, and on many plants a Fig. 506.-The tarnished plant-bug (Lygus small black spot appears pratensis Linn.) $a, b, c, d$, four stages of where the insect has been nymphs; $e$, adult bug-all about four times natural size. (After Forbes and Chittenden, U. S. Dept. Agr.) feeding, which causes a deformation of the stem or leaf, as in the "buttoning" of strawberries, or tends to "blight" the terminal as in the case of dahlias, potatoes, and similar crops.

The adult is nearly one-quarter inch long, of a brassy-brown color, marked with black and yellow, and the thorax with red. The color and markings are quite variable. The nymphs feed upon the same plants as the adults and pass through four stages, shown in Fig. 506. The first stage is only one-twentieth inch long and yellowish or yellowish-green. The second stage is about twice as large, and similarly colored, except that there are two pairs of dark spots on the thorax and one on the middle of the third abdominal segment, which grow more distinct in the last two 
stages. With the third stage the small wing pads become visible and in the fourth stage they extend halfway down the abdomen.

Life History.-The adults hibernate over winter under any shelter available, such as the trash on affected fields, under leaves, boards, stones, etc., and emerge in early spring. The eggs are laid in Missouri in April. But little is known of the places of oviposition, except that Taylor * has shown that sometimes apples are severely dimpled by the egg punctures. It is evident, therefore, that the eggs are inserted in the stems or leaves of the food-plants. The pale yellow egg is about onethirtieth inch long, oval, elongate, and flared at the outer end, so as to be somewhat bottle-shaped. The first generation becomes full grown in about a month, after which all stages may be found feeding together until September or October. In southern Missouri Professor Stedman states that there are three generations while in northern Missouri only two, but the exact number has not been carefully determined.

Control.-This is is an exceedingly difficult insect to control, owing to the large number of food-plants and the fact that the adult takes wing and flies off quickly upon the least disturbance. As it sucks its food, arsenical insecticides are of course useless, and some contact insecticide must be used with which the insect may be hit. The nymphs may be sprayed at any time, but to hit the adult bugs they must be sprayed in early morning, while still sluggish. Spraying will be profitable where the nymphs are abundant, but it is doubtful whether it will be found a satisfactory means of combating the adults. Ten per cent kerosene emulsion and tobacco extracts have been used successfully. Where they are abundant the adults may be collected in considerable numbers by sweeping the foliage in early morning with a strong inseet net and then dropping them into kerosene. Clean culture, including the destruction of all weeds, and such vegetation or trash as may furnish hibernating quarters, is important, as it is observed that injury is always worse where weeds have been allowed to multiply and the ground has been covered with weeds and trash.

* See E. P. Taylor, Journal of Economic Entomology, Vol. I, p. 370. 
Haseman (1. c.) states that insecticides have been of little value in the control of the insect in nurseries and recommends that injury be prevented by destruction of the weeds which harbor it, particularly members of the Composita of which the "Mare's tail" (Erigeron canadensis) is said to be the most important. 


\section{CHAPTER XXVI.}

\section{INSECTS INJURIOUS TO THE PEACH, PLUM AND CHERRY *}

\section{The Peach-tree Borer $\dagger$}

Wherever peaches are grown they are subject to the attacks of the ever-present borers, and if neglected will soon succumb to their injury. East of the Rocky Mountains the common peachtree borer has been kriown since the earliest settlements, and it also occurs in Colorado and Oregon. It is a native insect which probably lived on wild cherry and wild plum, and is known to attack plum, prune, apricot and nectarine, though chicfly a peach pest. On the Pacific Coast a nearly related species, the California peach-tree borer, $\ddagger$ does similar injury and has very similar habits. The lesser peach-tree borer $\S$ is commonly associated with the more common borer and has done considerable injury in western New York, Maryland, Virginia and Georgia. It occurs throughout the country and is doubtless commonly confused with the larger and more common species. Although it is quite different in its life history and habits, the injury is very similar, and as it must be controlled by the same methods it need not be separately considered.

The presence of the borers may be detected by the mass of gummy, gelatinous material, more or less mixed with soil, which exudes from the crowns of trees injured by them. The injury is done by the larva feeding on the soft inner bark of the crown of the root, the adjacent roots and the base of the trunk. Often the larvæ will completely girdle a tree and where a tree is infested

* See J. B. Smith, Bulletin 235, N. J. Agr. Exp. Sta.

† Sanninoidea exitiosa Say. Family ścside. See Quaintance, Yearbook U. S. Dept. Agr., 1905, p. 330; M. V. Slingerland, Bulletin 176, Cornell Univ. Agr. Exp. Sta.; H. N. Starnes, Bulletin 73, (ieo. Agr. Exp. Sta.

† Sanninoidea opaleseens Hy. Ed. See C. W. Woodworth, Bulletin 143, Cal. Agr. Exp. Sta.

\$Synanthedon pictipes (. \& R. See A. A. Girault, Bulletin 68, Part IV, Buresu of Entomology, U. S. Dept. Agr., and J. L. King, Bulletin 307, Ohio Agr. Expt. Station. 
by several borers, the foliage turns yellow and if not treated will soon die. Such a tree is much more susceptible to the attacks of bark beetles and diseases. Probably as many peach trees are lost from the work of borers as from any other one pest, with the possible exception of the San José scale.

The adults are clear-winged moths which fly during the day and might be readily mistaken for wasps. The females are a deep steel-blue with a broad orange band across the abdomen. The fore-wings are opaque, covered by the bluish scales, and

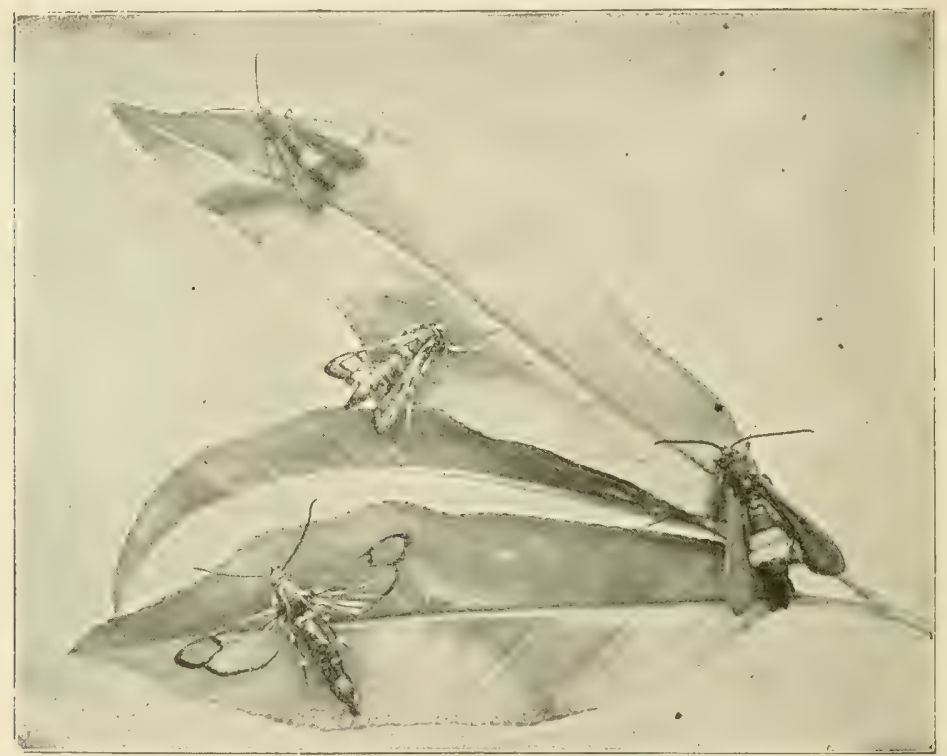

FIg. 507.-Peach borer moths (Sanninoidea exitiosa Say)-natural size. The upper one and the one at right are females, the other two males. (After Slingerland.)

expand about 1,1, inches, while the hind-wings are transparent except the dark margin. The males are smaller, with the wings clear except the margins and a line across the fore-wings, and the abdomen is marked with three or four narrow yellow stripes.

Life History.- The moths emerge in New York and New Jersey from the middle of July to the latter part of August, at Washington, D. C., from the middle of June until mid-September, the majority emerging in late July, while in Georgia the majority emerge in late August and early September. As there is but one 
generation a year, the time of emergence in these different latitudes is decidedly anomalous when compared with the life histories of other insects. The femal's soon lay their eggs, preferring to place them on the base of the trunk, but of ten placing them higher, or even on weeds or trash, or on the soil. A single female may lay from 200 to 800 eggs. The eggs are about one-fifticth inch long, and slightly over half as wide, truncate at one end, and a light chestnut-brown or reddich-brown in color, not easily seen on the bark of the tree. They hatch in about ten days and the young larvæ at once seek out small cracks in the bark through which they cnter the soft bark of the tree. Their presence may be easily detected by the powdery, brownish rass which they throw out of their burrows. The young larvæ grow rapidly and continue feeding until forced into hibernation by cold weather, and in the South doubtless feed during warm days in the winter. Feeding is resumed in the spring, the larvæ boring through the lower layers of the bark and causing masses of gum to exude as already described. Larvæ of almost all sizes may usually be found in late spring, and the resulting moths appear irregularly

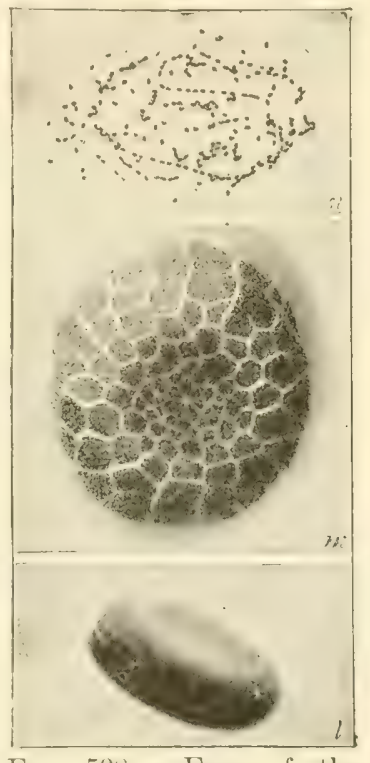

Fici. 50.5. - Eggs of the peach borer: natural size at $u$; an egg greatly enlarged at $l$; and end of egg greatly magnified, showing micropyle at $m$. (After Slingerland.) over a period of two to three months. The full-grown borer is a light yellowish larva about 1 inch long, with a brown head and thoracic legs, and five pairs of prolegs on the abdomen. The body is sparsely elothed with brownish hairs which arise from small, smooth tubercles. The grown larva constructs a cocoon at or near the surface of the ground, usually on the trunk near the burrow, but often on the soil, which is composed of particles of excrement and bark, bound together with gum and a thin lining of silk. In this it transforms to a brown pupa from which the moth emerges in about three weeks. 
Control.-One of the best means of preventing injury and making the removal of the borers easier is to mound the soil around the trunk as high as possible, just before the moths emerge in the summer. This forces them to lay their eggs high up on the trunk, where the little borers may later be readily found. In some way this mounding seems to prevent the establishment of the young larvæ, as several experimenters have found that from half to three-fourths of the borers are kept out of the trees in this way. In the early fall the earth should be leveled down to facilitate finding the little larvæ. Oviposition on the lower trunk may also be prevented by wrapping the trunk with building paper, or any heavy paper, which should extend well into the soil below and be tied tightly just below the crotch at the top.

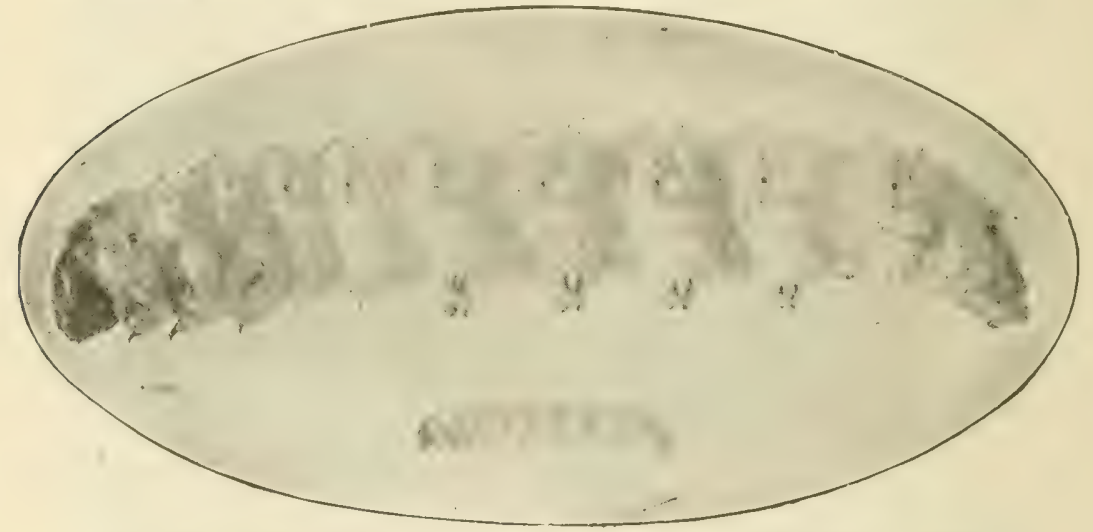

Frg. 509.-The peach borer larva, natural size and enlarged. (After Slingerland.)

Such wrapping may be used to advantage with the mounding up of the earth and thus largely prevent oviposition. The wrappers should be applied before the moths appear and be removed in the early fall. Various washes composed of soaps, lime, glue, cement, carbolic acid, and various other ingredients have been commonly recommended and widely used for preventing the laying of the eggs and the entrance of the young larvæ, but careful tests have failed to show their value. Doubtless this is due to the roughness of the bark of the peach, over which it is difficult to make a complete coating, and the little larva will enter through the smallest 
crevice. Some wash which would penetrate the burrows of the young linrs and destroy them, as does the arenarius arbolinemm with the bark beetles, would seem to be the most promising line of treatment, and some of the washes which have been extensively used by practical growers should be critically tested on a commercial scale.

Preliminary experiments in West Virginia have given excellent results in the control of the horers by the anpliation of soluble oils of the commercial brands, at dilutions of from one to twelve to one to nine. The soil is scraped away from the base of the tree, the crown and lower part of the trunk thoroughly drenched with the oil, applied with a sprayer, and the soil drawn back into place about the tree.

Mechanical protectors have generally proven to be of little value and in common orchard practice the growers still depend very largely on the old fashioned method of "worming," that is, removing the borers from the trees by hand. This may be done in the spring or in the fall. Professor Starnes recommends that, in Georgia, the work be done in the fall since many of the small borers are then in the surface bark and in masses of

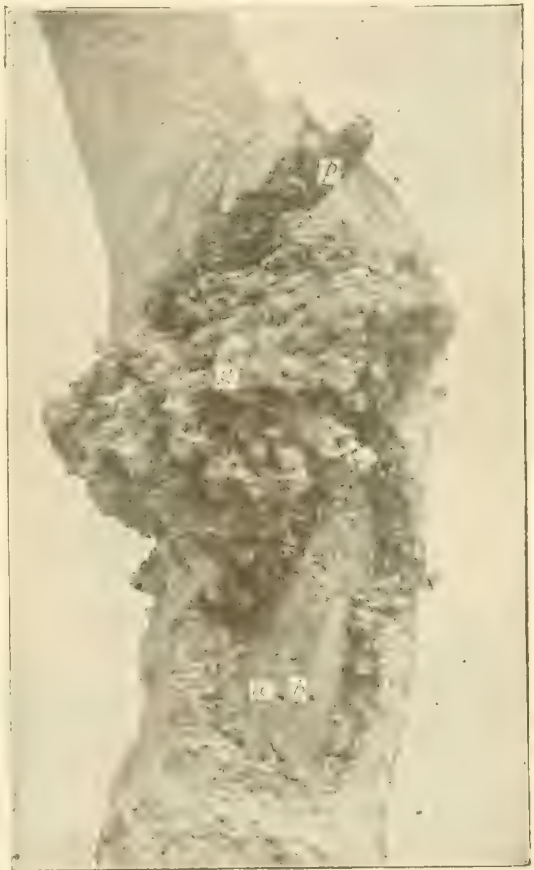

FIG. 510. - Work of a single peach inorer, naturat size: $w$, b, burrow of borer; /, enmmom masi; p, pupat projecting from eoeoon. (Ifter slingerland.) exuded gum and may he easily destroyed while in the spring they are found in better protected situations maler the bark. In the North fall worming seems to be less satisfactrory. Tonls for worming consist of a stout knife and a piece of steel wire, sharpened at one and. Special knives with eurved blades are sometimes preferred. Some use the ordinary pruning knife and some prefer a blade similar to that of the blackinith's hook-knife. 


\section{The Peach Twig-borer *}

On the Pacific Coast the Peach Twig-borer, often known there as the peach worm, is one of the most serious pests of the peach. In the Eastern States it has been injurious in Delaware, Virginia and Maryland, but only occasionally. Probably the insect occurs throughout the country wherever the peach is grown, as it is an old European insect which was first noticed in the United States in 1860. On the Pacific Coast the over-wintering larvæ bore into the tender shoots in early spring and during the summer

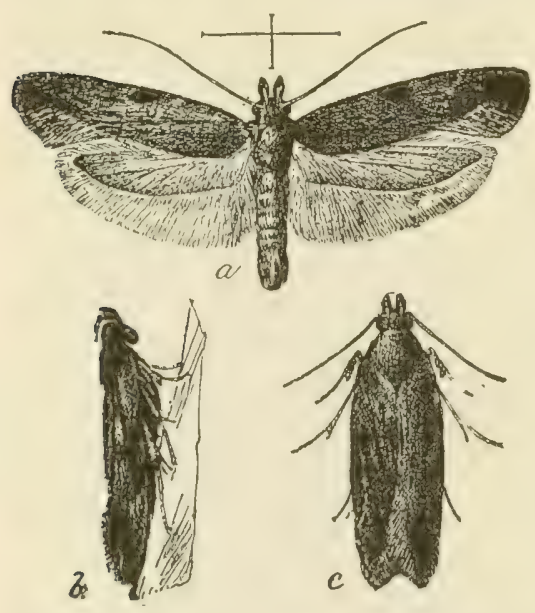

Fig. 511. - The peach twig-borer (Anarsia lincatclla): adult moth with wings spread and folded - much enlarged. (After Marlatt, U. S. Dept. Agr.) bore into the fruit, particularly the later varieties. Prune, nectarine, apricot, almond, and pear are also injured.

The adult moth is a darkgray color, with fore-wings expanding about one-half inch and marked with darker spots. The full grown larva is about one-half inch long, of a dull reddish-brown color with dark brown or blackish head.

Life History.- "The insect passes the winter as a very small larva in silken-lined cells or burrows in the spongy tissue of the bark at the crotehes of the limbs. Their presence is indicated by small mounds of comminuted bark, as shown in Fig. 512, at $a$ and $b$. Early in the spring, as the foliage is putting out, the larvæ begin to leave their burrows and attack the tender shoots, boring into and down the pith, the galleries ranging from about one-third inch to $1 \frac{1}{2}$ inches in length. The shoot thus injured soon wilts and dies, as shown in Fig. 513, at a. Many shoots may be attacked by a single larva, which is thus capable of doing considerable harm. There are two or three generations of larvæ during the summer in

* Anarsia lineatella Zell. Family Gelechiiida. See W. T. Clarke, Bulletin 144, Cal. Agr. Exp. Sta.; C. L. Marlatt, Bulletin 10, n. s., Div. Ent., U. S. Dept. Agr.; A. L. Quaintance, Yearbook U. S. Dept. Agr., 1905, p. 344. 
the West, those of the second and third attacking the fruit, the later varieties being the worst injured. Aceording to Professor C. V. Piper, the larva enter's the peach at the stem end, usually boring into the pit, the seed of which it seems to prefer, usually causing the stone to split as the fruit ripens; or simply the flesh may be tunnelled, depending on whether or not the stone is hard when the fruit is attacked. In California, according to Clarke, the larva usually enters the fruit along the suture at the stem end, and excavates a chamber beneath the skin, which blackens and shrivels somewhat, affording entrance to organisms of decay. In the ripe fruit the

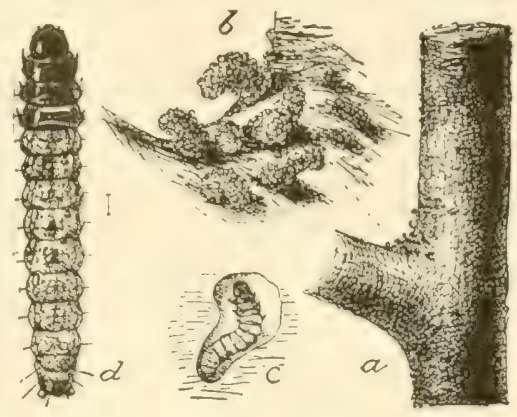

FIG. 512.-Peach twig-borer in winter quarters: $a$, twig, showing in crotch minute masses of chewed bark above larval chamber; $b$, same, much enlarged; $c$, larval cell enlarged; and $d$, larva very greatly enlarged. (After Marlatt, U. S. Dept. Agr.) larvæ frequently make their way to : and around the stone, which, if split, may be entered and the seed feed upon. . . . Early in the

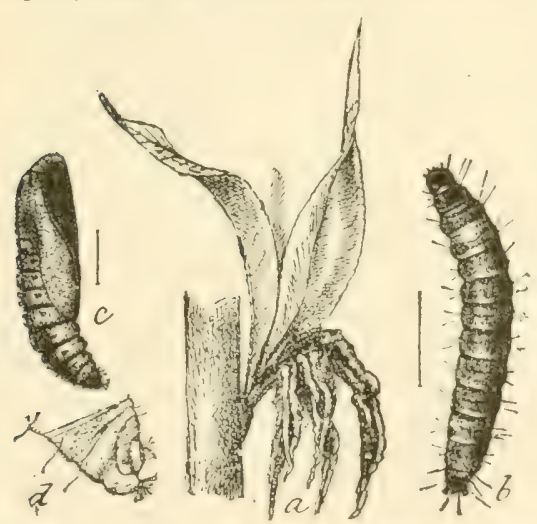

Frg 513.-The peach twig-borer: $a$, new shoot of peach withering from attack: of larvæ; b, larva enlarged; $c$, pupa, enlarged. (After Marlatt, U.S. Dept. Agr.)

fall, about September 1, in California, the very young larvæ from eggs of the last generation of moths construct their hibernation cells in the soft tissue of the crotches of limbs, where they remain until the following spring, thus spending some six months in this condition." - Quaintance.

Control.-By spraying during the winter, or preferably after the buds have swollen in the spring with kerosene or distillate-oil emulsion, the oil is absorbed by the castings at the mouth of the burrows of the hibernating larven, and thus penetrates the burrows and kills the larva. Lime-sulfur wash, 
applied from the time the buds commence to swell until the first blossoms, has also been widely and successfully used. The wash should be applied as late as possible before blossoming. Recently Mr. E. P. Taylor has shown * that in western Colorado the larva are very readily lilled by arsenate of lead, 3 to 5 pounds per barrel, applied just as the buds are beginning to open. The arsenate of lead must contain no soluble arsenic, or it may burn the foliage. This treatment is given at the same season as the limesulfur wash and is much easier to prepare and apply.

\section{The Peach-tree Bark-beetle $\dagger$}

The peach-tree bark-beetle is very similar in both appearance and habits to the fruit-tree bark-beetle, and may be readily confused with it. It is a native insect which attacks only peach, cherry and wild cherry, and so far has been injurious only in western New York, northern Ohio, and the Niagara district of Ontario, though it occurs from New Hampshire to North Carolina and west to Michigan.

"When the heetles are present in large numbers their injury to the tree is quickly brought to the attention of the orchardist by the large amount of sap exuding from the trees through the many small horings made hoth in the trunk and limbs of the tree. . . The adults or beetles produce the primary injury to healthy trees, the work of the larva being secondary. The healthy trees, by repeated attacks of the adults, are reduced to a condition favorable to the formation of egg-burrows. When the beetles are ready to hibernate in the fall they fly to the healthy trees and form their hibernation cells. These latter are injurious to the trees, for through each cell there will be a tiny flow of sap during the following scason." When the beetles emerge in the spring they bore into the bark of healthy trees and later leave them to form egg burrows in sickly trees. From these numerous burrows the sap issues in large quantities and in many cases forms large gummy masses around the trees. After three or four years of such injury the tree is so reakened that the beetles form their egg burrows beneath the bark and the larva soon finish its

* E. P. Taylor, Bulletin 119, Colo. Agr. Exp. Sta., p. 8.

$\dagger$ Phlcotribus liminaris Harris. Family Scolytider. See H. F. Wilson, Bulletin 68, Part IX, Bureau of Entomology, U. S. Dept. Agr. 
destruction. There are two generations a year, the summer brood appearing in the latter half of August and the other hibernating over winter.

Control.-The same methods are advised as for the fruit-tree bark-beetle, which see.

\section{The Peach Lecanium*}

The presence of the "terrapin scale," as this species is often called, is usually indicated by the sooty appearance of the branches and foliage of affected trees. This is due to the fact that the scales excrete considerable honey-dew, which covers the bark and

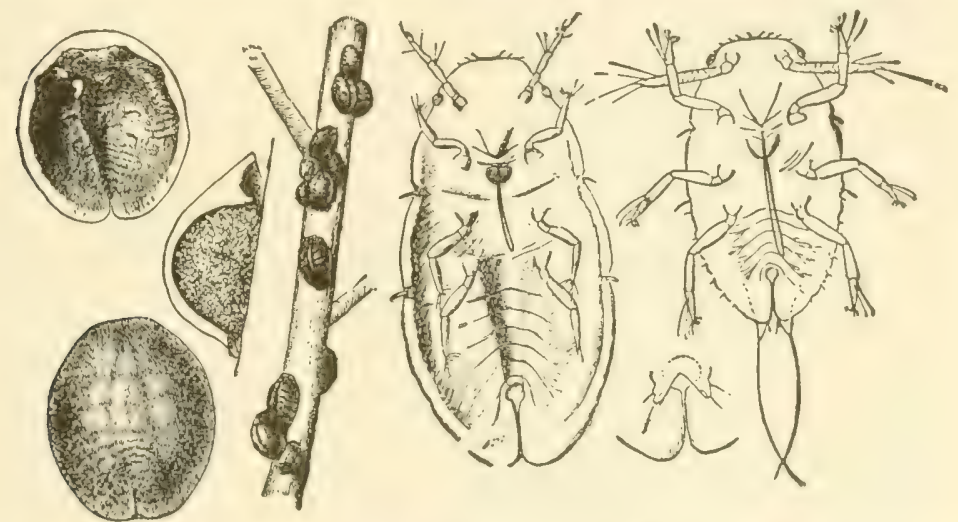

FIG. 514.-The peach lecanium or terrapin scale (Eulecanium nigrofasciatum Pergande): adults at left, natural size and much enlarged; young at right, and unfertilized female at center-much enlarged. (After Howard, U. S. Dept. Agr.)

leaves, and on which a sooty fungus propagates. It is a common species throughout the eastern United States and also attacks the apple, maple, sycamore, linden and birch, but is most injurious to peach and plum. The hibernating, partly grown, female scale found on the bark in winter, is about one-twelfth inch long, hemispherical, and of a reddish color mottled with radiating streaks of black, particularly about the margin. Sometimes

* Euclecanium nigrofasciatum Pergande. Family Coccida. See J. G. Sanders, Circular 88, Bureau of Entomology, U. S. Dept. Agr.; A. L. Quaintance, Yearbook U. S. Dept. Agr., 1905, p. 340; T. B. Symons and E. N. Cory, Bulletin 149, Md. Agr. Exp. Sta., and F. L. Simanton, Bulletin 351, U.S. Dept. Agr. 
these streaks coalesce and form a dark band around the center, while other individuals are occasionally entirely red or black.

Frequently trees become badly encrusted with these scales, but rarely are they killed by them. The fruit on badly infested

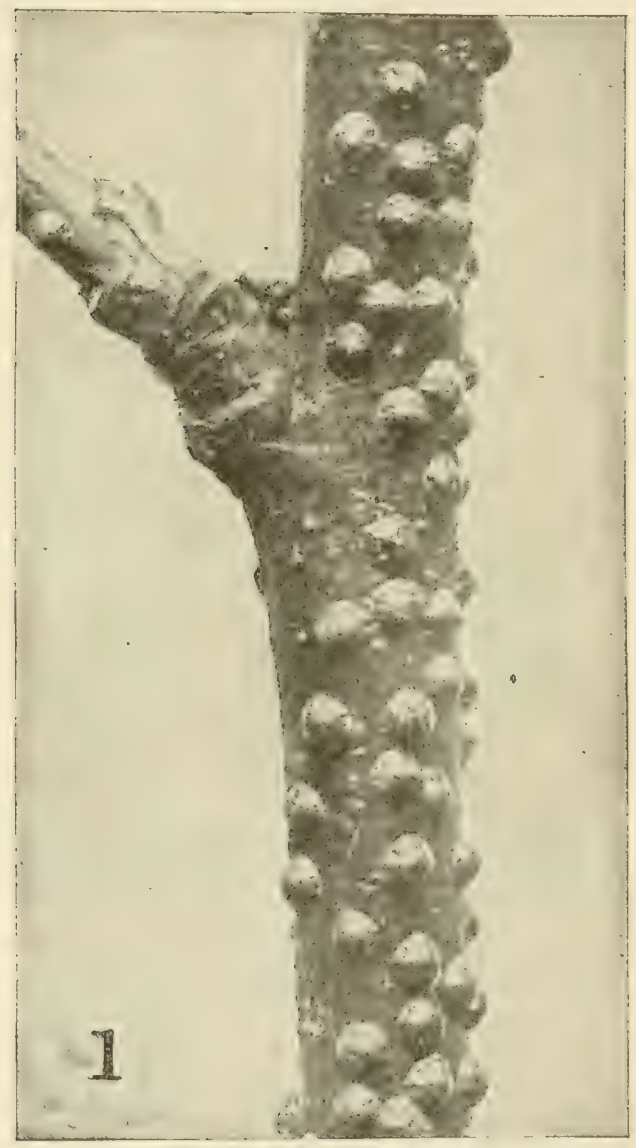

Fig. 515.-The Peach Lecanium-cnlarged. (After Simanton.) trees is, however, poorly developed, insipid, and covered with the sooty fungus so as to be almost unsaleable, and the trees are stunted and rendered more liable to the attack of other insects.

Life $H i$ story.There is but one generation a year. In the winter they are mostly nearly grown female scales. These mature early in the spring and deposit their eggs in a mass beneath the body, which forms the hard scale above them. In Missouri the eggs hatch about June 10th, and continue to hatch for a month. The male scales are much smaller than the females, elongate, slightly convex, and greenish-white in color. Late in July the winged males appear and live about a week. The young female scales continue growth during the summer and hibernate when about two-thirds grown.

Control.-Lime sulphur seems to be ineffectiva against this insect but orchards which are sprayed year after year with it 
suffer less than unsprayed ones. The best treatment for general use is miscible oil spraying. The oils to be used at about one to 16 or 18 and applied in the spring after the buds swell but before they open. Two treatments in successive years must be given to

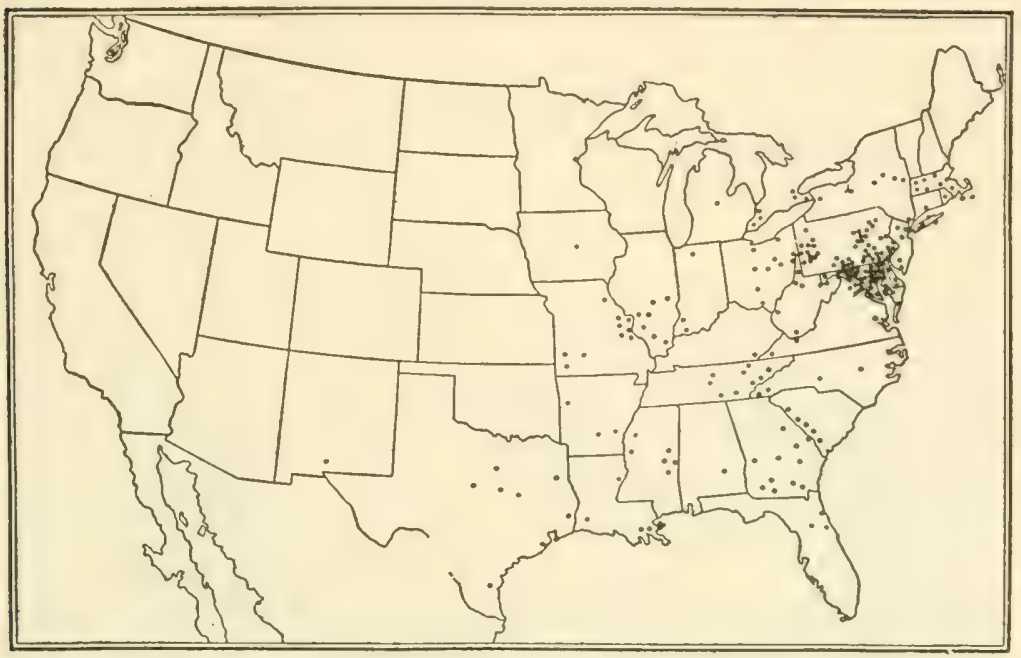

FIG. 516.-Distribution in the United States of the terrapin scale (Eulccanium nigrofasciatum). (After Simanton, 1.c.)

get the full benefit and it is better, in infested regions, to make it an annual treatment.

\section{The Black Peach-aphis *}

The black peach-aphis is a native species which has been most injurous in the Middle Atlantic States, but has become widely distributed on nursery trees. It attacks the roots, tender shoots and foliage of the peach. When occurring on the roots, trees are often seriously injured before its presence is suspected. Young trees are particularly affected, the injured trees having a yellowish sickly foliage. Usually, however, the presence of the aphids on the young shoots and leaves will he an indication of its inhabiting the roots also. In the spring and early summer the aphids cluster on the tender shoots at the croteh of the tree and low down on the limbs and soon form a disgusting black mass over the young leaves, which are tightly curled up from the injury. 
On young trees in the nursery and on young orchard trees, this injury to the foliage is sometimes so severe as to kill or severely check the growth.

Both winged and wingless aphids are found on the foliage, but only the wingless forms occur on the roots. Both forms are about onc-twelfth inch long and shining deep brown or black in color when mature. The partly grown aphids, which form the larger part of most colonies, are reddish-yellow or amber colored.

Life History. - The wingless aphids feed and reproduce upon the roots throughout the year, all being females and giving birth

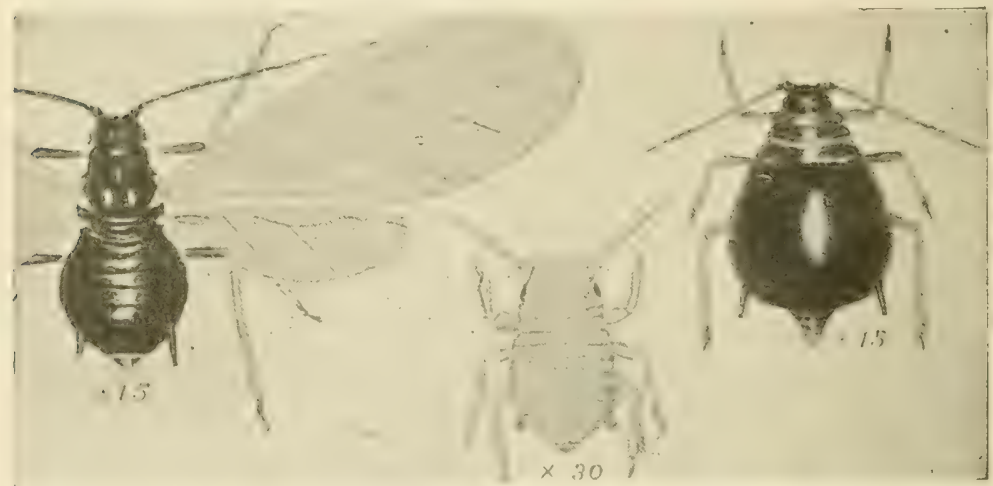

FIG. 517.-The black peach-aphis (Aphis persica-niger Er. Sm.): winged viviparous female; young female, first instar; apterous viviparous femalemuch enlarged. (After Gillette and Taylor.)

to live young after the manner of the aphids. In the spring some of them migrate to the young foliage, often appearing on the tender twigs before the buds open. They multiply rapidly, and as a result of the hundreds of little beaks sucking out the juices the shoot soon withers, which causes the young to develop into winged aphids which migrate to other trees. Honey-dew is excreted very freely by the aphids, which are therefore attended by numerous ants which doubtless aid in their transportation from tree to tree and from the roots to the leaves and back. "During summer the aphids for the most part are to be found

* A phis persica-niger Er. Sm. Family Aphidida. See C. P. Gillette, Bulletin 133, Colo. Agr. Exp. Sta., p. 37; A. L. Quaintance, Journal of Economic Entomology, Vol. I, p. 308, Yearbook U. S. Dept. Agr., 1905, p. 342. 
on the roots, though a few may be found on the foliage and the shoots in badly infested orchards at almost any time during the growing season . . L Light sandy soils are worst infested, though they have been found in abundance on stiff clay soils." (Quaintance, 1.c.).

Control.-The roots of young trees suspected of being affected should be carefully examined and if aphids are found they should be dipped in strong tobaceo water. Nurserymen prevent injury by making liberal applications of tobaceo dust in the trench and along the rows. Tobacco dust may also be used against the aphids on the roots of orchard trees by removing the surface soil and applying a liberal dressing of the dust, which will be leached down on to the roots by the rains. It should be applied over the smaller roots. The treatment for the root forms has not been sufficiently studied to warrant any conclusions as to satisfactory methods, but the same as advised for the woolly appleaphis (p. 518) are suggested. When the aphids appear on the young shoots in the spring they may be readily controlled if the trees are observed for their appearance, for they are very gregarious, clustering on one shoot until it is well covered before spreading to the rest of a tree, and becoming abundant on it before spreading to others. Often the small infested shoots may simply be broken off and destroyed. The aphids may be killed by spraying them with tobacco extract.

\section{The Green Peach-aphis *}

This aphid is a European species which has long been known as a pest of peach foliage in this country, where it has become widely distributed. Considerable interest attaches to the species, as it furnishes a striking example of the summer migration of aphids to different food-plants, and a consequent difference in appearance in form and color. During the summer this species feeds upon various vegetables and succulent plants, and is so different in color and form that it has been well known not only as a separate species, but as bolonging to a distinct genus. ('oncerning its injury to the peach, E. P. Taylor states: "The peach-growers of IVestern Colorado have suffered loss from it, from its heavy infestation of the leaves of the trees in the spring, 
causing them to curl and drop prematurely to the ground, and from the withering and subsequent dropping of the buds and forming peaches also infested by the aphids at this time." Similar injury has been reported from Missouri, and doubtless occurs occasionally in other sections.

Life History. - The winter is usually passed in the egg stage on the peach, plum, apricot, nectarine, cherry or other trees, though the wingless females sometimes persist on the summer food-plants where there is sufficient protection to enable them to endure the cold of winter, as in cabbage pits, or in the South. The small, oval, shining black eggs are deposited in the axils of the buds or in crevices of the bark. "The eggs hatch very early in the spring so that the young stem-mothers from them are often almost fully grown before the earliest peach or plum blossoms open. About the time the buds begin to open on these trees, the stem-mothers are all of a deep pink color and begin to give birth to living young. These young instead of being pink like their mothers are pale yellowish-green throughout their lives, and usually there is a median and two lateral dark green stripes passing over the abdomen. Very few of this brood attain wings. The third generation become very largely winged and begin leaving the trees upon which they were born about the mid. dle of May in the peach-growing sections of the State (Colorado). By the middle of June these lice have almost completely left the trees and may be found establishing their colonies upon various succulent vegetables." The winged females which migrate from the peach are about one-twelfth inch long, with a wing expanse of one-third inch. They are a yellowish-green color with head, antennæ, thoracic lobes, honey-tubes, a large spot on the centre of the abdomen, and small lateral spots in front of the honey-tubes are blackish. The wingless females during the summer are pale yellowish and lack the longitudinal green stripes on the abdomen. According to Taylor's observations the spring generations on peach become full grown in about two weeks and an individual aphid lives about a month. In the fall

* Myzus persicre Sulz. Family Aphidida. (Syn.-Rhopalosiphum dianthi Schr.). See Gillette and Taylor, Bulletin 133, Colo. Agr. Exp. Sta., p. 32; C. P. Gillette, Journal of Economic Entomology, Vol. I, p. 359; E. P. Taylor, ibid., p. 83; F. H. Chittenden, Bulletin 2, Va. Truck Exp. Sta., p. 30. 
winged females return to the peach and winter host-plants, and give birth to young which develop into wingless females which lay the winter eggs. The true males are winged and migrate from the summer food-plants.

Control.-The trees affected should be sprayed about a week

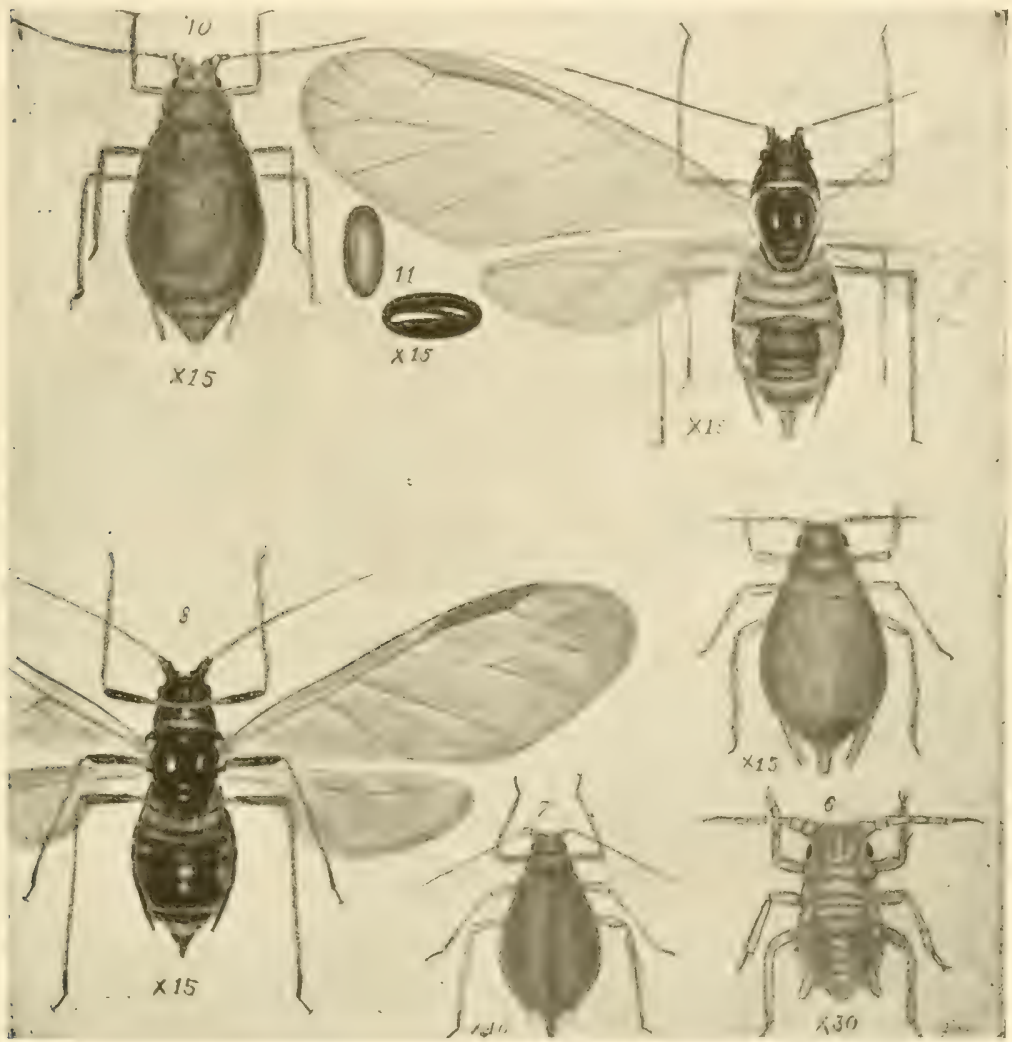

FIG. 51S.-The green peach Aphis (1 yzus persice Sulz.): 5, adult stem mother; 6 , young of stem mother; 7 , apterous viviparous female of second generation; 8, spring migrant; 9, fall migrant; 10, egg-laying female; 11, eggsall much enlarged. (After Gillette and Taylor.)

before the buds open with tobaceo extract. If the trees are sprayed with lime-sulfur for the twig-borer just before blossoming, it should kill most of the aphids. Tobacco extract may be used on the foliage of affected plants as necessary. 


\section{The Green Soldier Bug *}

The Green Soldier Bug has done serious injury to peaches in Ohio and West Virginia as well as other localities in recent years and is known as an important enemy of garden crops, particularly Lima beans. It "stings" the developing pods of the beans, sucks the sap from them and no beans develop.

Its injury to peaches is done by sucking sap from the developing fruits from the time they are half-grown until they ripen.

The adult is one of our larger green stink-bugs of the commonstink-bug form and will be easily recognized from its name. The nymphs are darker in color, ranging from blackish to yellowishgreen with black markings, depending upon the stage. The nymphs are more likely to be observed doing the damage than are the adults.

This species is very similar to another southern form called the southern green plant-bugt, which injures fruits but is more important as a pest on truck crops.

Control.-It is fortunate that this insect is held in check by climate and natural enemies since there are no artificial control measures availahle as yet. Hand picking, or jarring into cans of kerosene, might pay on a small scale in gardens. It appears that the insect may be expected to occur in injurious numbers only after mild winters and it is attacked by several parasites so its occurrence as a pest is only occasional.

\section{The Plum Gouger $\ddagger$}

This is a mative beetle which breeds upon wild plums and is most injurious to native varieties. It is common throughout the Mississippi Valley, but seems to be most injurious westward and occurs in Colorado. The work of the beetles might be easily mistaken for thit of the curculio (p. 505). The adult beetle is readily distinguished from the curculio, however, by lacking the humps on the wing-covers.

* Nezara hilaris Say. See R. D. Whitmarsh, Bulletin 310, Ohio Expt. Station, and p. 236, Chapter XIII.

$\dagger$ Nezare viridula L. See T. H. Jones, Bulletin 6\$9, U. S. Dept. Agr., and J. R. Watson, Bulletin 134, Florida Expt. Sta., also page 630, Chapter XXVII. $\ddagger$ Coccotorus scutellaris Lee. Family Curculionido. 
It is about one-quarter inch long, with a snout half as long, the wing-covers are a leaden-gray color, finely spotted with black and brown, while the thorax and head are marked with ochreous yellow.

Life History.-Like the curculio, the beetles hibernate over winter and appear in the spring as the trees blossom. At first they puncture the calyx and feed on the ovary of the flower, completely destroying it for fruit production, and then puncture the growing plums, both for food and for egg-laying. In feeding on the plums the adults gouge out small round holes, from which gum

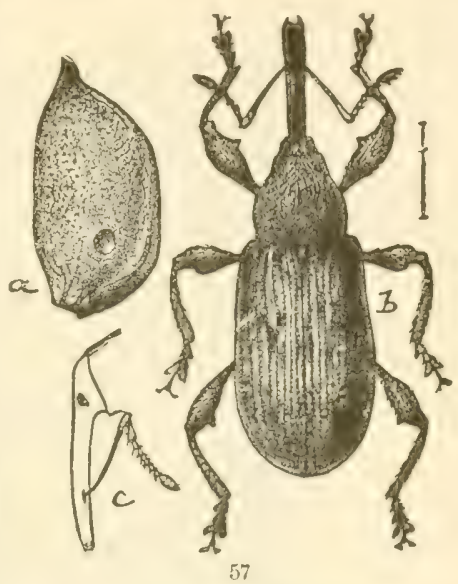

Fis. 519.-The plum gouger (Coecotorus scutellaris Lec.): a, plum stone showing exit hole of larva; $b$, adult; $c$, side view of head of beetle-enlarged. (.Ifter Riley and Howard, L. s.. Dept. Agr.) disturbed. The eggs are laid while the pit of the plum is still soft. The female beetle drills a small hole which is larger helow, in the plum, and in it deposits a small yellowish-white cge, whose outer end lies flush with the surface of the plum. As soon as the larva hatches it eats its way into the pit, feeding upos the meat of the seed until full grown. It then eats a hole through the outside of the pit so that the adult beetle may escape, and then transforms to a pupa. The larva is very similar to that of the curculio, but is a milky white rather than a glosicy white and lacks the reddish tinge on the lower surface. Affected plums do not drop as when injured by the curceulio. The pupal stage is passed in the pit of the plum and the adult beetle emerges through the hole cut for it by the larva. The beetles emerge a little before the plums ripen and often practically destroy them, as fruit hadly punctured becomes gnarly and worthless. The beetles feed on the plums a short time and then seek hibernating quarters for the winter.

Control.-Control measures have not been thoroughly tested, but where the beetles are abundant it would be well to try spraying with arsenate of lead as advised for the curculio. 


\section{Plum Aphids}

Three species of aphids are common on the plum foliage in spring and fall, and often do serious damage by curling up the foliage in the spring and causing it to drop prematurely, thus checking the growth of the tree and preventing proper fruiting. The life histories of the three species are very similar in that the eggs are laid upon the plum in the fall, upon which two or three generations develop in the spring, but in early summer they migrate to other food-plants, from which they return to the plum in the fall. The life history is much the same as that of the apple-aphis, and green peach-aphis, and need not be rehearsed in detail.

\section{The Mealy Plum-louse *}

This is a light-green species which is covered by a bluish-white mealy powder. It has a long narrow body, one-tenth inch long,

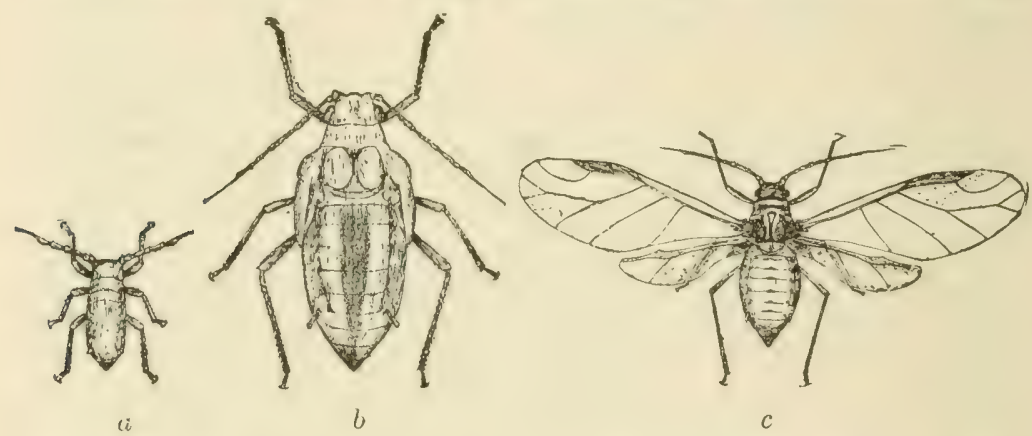

Fig. 520.-The mealy plum louse (Hyalopterus arundinis Fab.): a, young nymph; $b$, last stage of nymph of winged form; $c$, winged viviparous female-all much enlarged. (After Lowe.)

marked with three longitudinal stripes of a darker green. The honey-tubes are short, thick, and slightly constricted at the base. The winged female is similar in coloration except that the abdomen bears several transverse triangular marks of darker green. In June the winged females migrate to certain grasses upon which the aphids reproduce during the summer, though small colonies

* Hyalopterus arundinis Fab. Family Aphidide. W. D. Hunter in Bulletin 60, Iowa Agr. Exp. Sta., p. 92, states that Aphis prunifolice Fitch is probably the same species. Certainly $H$. arundinis and pruni, Aphis pruni and prunifolio, seem to have been applied to the same species in the economic literature in America. See Lowe, V. L., Bulletin 139, N. Y. Agr. Exp. Sta., F. 657, and W. M. Davidson, Bulletin 774, U. S. Dept. Agr. 
are to be found on the plum throughout the summer. In the fall they return to the plum, where the winter eggs are laid. This species is known to occur in Germany, England, Australia, and

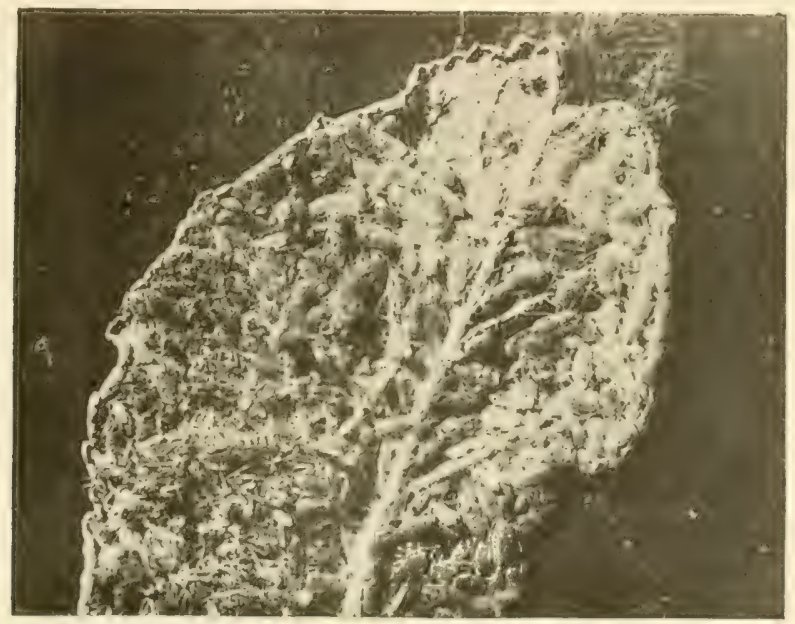

Frg. 521.-Mealy plum aphides clustered on leaf. (After Lowe.)

New Zealand, and seems to be widely distributed over the United States. It occurs here on plum and prune and in Europe is said to infest grape, peach, apricot, and nectarine, according to Lowe.

\section{The Hop Plant-louse *}

This species is best known as a pest of hops during the summer and rarely does very serious damage to the plum, though often quite abundant on it. The wingless aphids are light green or yellowish green without any noticeable markings. The winged forms have the same body color, with the head, thoracic lobes, and a few dashes on the abdomen, black. The species may be readily distinguished by the prominent tubercle which projects from the head on the inside of the base of each antenna, and a less prominent tubercle on the basal segment of each antenna. According to the studies of Dr. C. V. Riley and his assistants, the third generation in the spring migrates from the plum to hops in late spring and in fall winged viviparous females give birth to a few young which develop into egg-laying females which

* Phorodon humuli Schrank. Family 4 phidider. See C. V. Riley, Report U. S. Dept. Agr., 1888, p. 93; W. T. Clarke, Bulletin 160, Cal. Agr. Exp. Sta. 
mate with winged males which have developed on hops, the winter eggs being laid on the plum and other species of Prunus. In California, Clarke has been unable to find any evidence of the species on plum or other vegetation outside of the hop yards, where he finds the true sexes occuring in the fall, but no evidence of eggs. Hops are often seriously damaged by being reduced in size and weight and from the loss in aroma due to the presence of the aphids in them. The species is of European origin, where it is a well-known enemy of hops, and has become widely distributed in the United States and Canada.

Control.-Where it oviposits on plum it may be best controlled by spraying as for the other plum aphids in the spring. After it becomes established on hops it may be controlled by spraying with "Black-leaf 40."

\section{The Rusty-brown Plum-louse *}

This species is readily distinguished from others common on plum and prune by the dark rusty-brown color, with the base of the antennæ, tibiæ, and tail a contrasting white. This species has become a very serious pest to plum foliage in the South and Southwest, and we have observed serious injury in New Hampshire, so that it is evidently widely distributed. The aphids collect on the tender young twigs, which they stunt or kill, assemble on the under sides of the leaves, which hecome corrugated and curled from their attack, and when abundant they attack the blossoms and their stems and thus prevent the setting of fruit. In early summer the winged females migrate to various common grasses, such as fox-tail, red top, barnyard grass, crab grass, and others, upon which they breed during the summer, and from which the winged forms return to plum in the fall. They become darker in color late in the season and the wingless, egg-laying female is almost black, as is also the small winged male.

Control.-The treatment advised for the apple-aphis (p. 537) will be effective for the three species above, while on the plum, and the spraying should be done early in the season before the aphids have become numerous and curled the foliage.

* Aphis scteriar Thos. Family Aphidide. See Gillette and Taylor, Bulletin 133, Colo. Agr. Exp. Sta., p. 41; C. E. Sanborn, Bulletin 88, Oklahoma Agr. Exp. Sta. 


\section{The Black Cherry-louse *}

This species has long been known ats a cherry pest in Europe and during the last fifty years has become generally distributed over the eastern United States, and oceurs in Colorado. So far as known the eherry is the only food-plant. Dr. Weed was of the opinion that the aphids left the cherry during late July and migrated to some summer food-plant which he was unable to find, but observations by Gillette and Taylor in Colorado would indicate that they may remain on the cherry, but berome so reduced in numbers by their natural enemies that only a few survive during midsummer, and these give rise to larger colonies in late summer and early fall. Both the winged and wngless forms are deep shining black, the body is rather broad and flat,

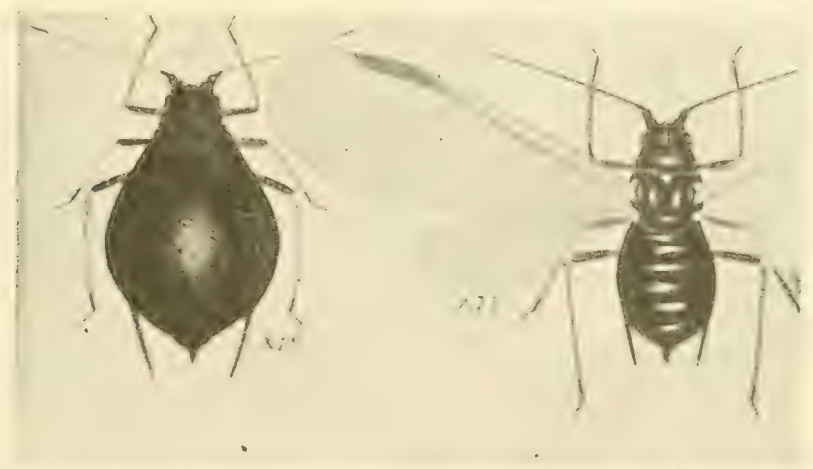

Fic. 522.-The black cherry-aphis (1 Iyzus cerasi Fab): 1, apterous viviparous female; '2, winged viviparous female-cnlarged. (. Ifter (iillette and Taylor.)

and the honey-tubes are unusually long and are cylindrical. small winged males and wingless females oecur on the foliage in the fall and the latter lay their egges on the twigs about the buds. Like the black peach-aphis, this species has the habit of acemulating in large numbers on the smaller sprouts or limbs near the ground before spreading to the rest of the tree or other trees, so that prompt treatment when first observed will prevent general infestation.

Control.-Spraying as for the apple-aphis (p. 537), will eontrol the pest.

* Myzus cerasi Fab. Family Aphididr. See C. Mr. Meed, Bulletin Ohio Agr. Lxp. Sta., Tech. Ser., Vol. I, No. 2, p. 111; C. P. Gillette, Journal of Economic Entomology, Vol. I, p. 362. 


\section{The Cherry Fruit-fly $\dagger$}

The cherry fruit-fly is a native insect whose maggot lives in the flesh of the cherries, causing them to rot. It is very nearly related to the apple maggot (p. 559) which it very closely resembles in both appearance and life history. Injury by it has been recorded in Massachusetts, New York, Ontario, Pennsylvania, District of Columbia, Michigan and Iowa, so that it is probably generally distributed over the northeastern States. Although its native food-plant is unknown it is probable that it lives on some wild sour cherry. As cherries are always more or less injured
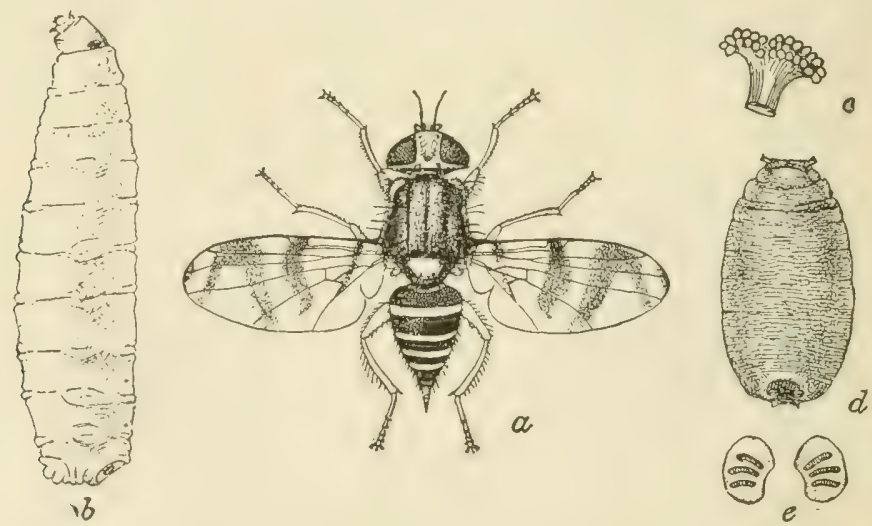

Fig. 523.-The cherry fruit-fly (Rhagoletis cingulata Loew.): $a$, fly; $b$, maggot; $c$, anterior spiracles of same; $d$, puparium; $e$, posterior spiracular plates of pupa-all enlarged. (After Chittenden, U. S. Dept. Agr.)

by the plum curculio, it is quite proballe that injury by this maggot may have been attributed to the curculio and its identity passed unnoticed. Sour and subacid varieties, such as the Morello and Montmorency, are worst injured, but black cherries and indeed all varieties are more or less damaged.

The fly is slightly smaller than that of the apple-maggot, being about one-sixth inch long with a wing expanse of three-erghths inch. The body is blackish, the head and legs are pale yellowishbrown, the sides of the thorax are marked with a longitudinal

$\dagger$ Rhagoletis cingulata Loew. Family Trypetide. See M. V. Slingerland, Bulletin 172, Cornell Univ. Agr. Exp. Sta.; F. H. Chittenden, Bulletin 44, Bureau of Entomology, U. S. Dept. Agr., p. 70, and J. F. Illingworth, Bulletin 325, Cornell Agr. Expt. Station. 
yellow band, the abdominal segments are marked with whitish or pale brownish transverse bands, and the wings are rrossed by four blackish bands. The maggot is about one-quarter inch long and is indistinguishable from the apple-maggot.

Life History. - The eggs are deposited just under the skin of the cherry from June until August, or probably during the whole season of the fruit. The eggs hatch in a few days and the little maggots penetrate to the pits, feeding on the flesh and forming a rotting cavity very similar to that made by the grub of the curculio. But few of the affected cherries fall from the trees, and as they frequently show but little effect of the damage, the infested fruit may be marketed and the pest thus spread. When full grown the maggots leave the cherries and form puparia just beneath the surface of the ground, or in the bottoms of baskets or in rubbish, wherever the affected fruit may be. Fig. 524. - Section of a cherry, enlarged to The flies commence to emerge from these puparia by the middle of June in

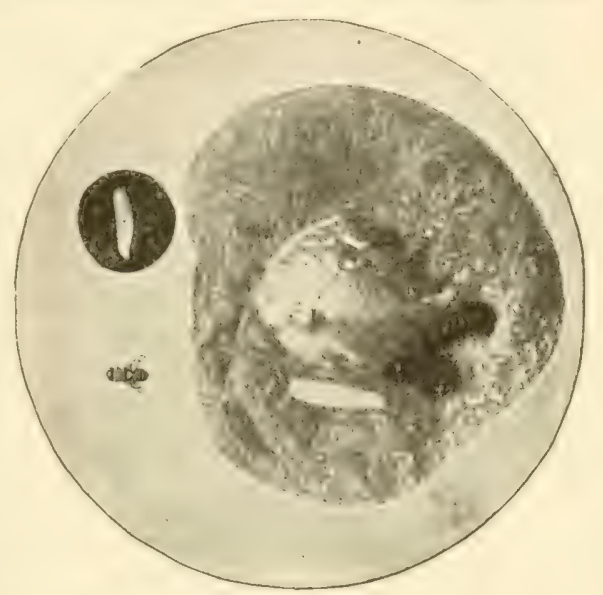
show the maggot of the cherry fruit-fly and nature of its work. The small figures ahove show the maggot and parent fly natural size. (After Slingerland.)

New York and are found during the summer months.

Control.-There is but little evidence as to practicut means of control. Deep plowing in spring should result in hurying the puparia so deeply as to prevent the emergence of the flies. Cultivation is evidently of little value, as the pest occurs in wellcultivated orchards, so that shallow cultivation does not seem to affect the puparia. Chickens have been observed to destroy the puparia, and will doubtless prove as effective as against the apple-maggot where they can be confined beneath affected trees on cultivated soil. The destruetion of all fruit, whether windfall 
or remaining on the tree will, of course, aid in control. Recently a nearly related fruit-fly has been successfully controlled in South Africa by spraying the foliage with arsenate of lead sweetened with treacle or brown sugar, thus attracting the flies which are poisoned by the arsenate, and this method is worthy of trial both for the cherry is uit-fly and apple-maggot. 


\section{CHAPTER XXVII.}

\section{SOME INSECTS INJURIOUS TO CITRUS FRUITS*}

\section{Scale Insects $\dagger$}

Trere are many scale insects injurious to citrus fruit. Possibly taken collectively they are the most important pests of this clitss of fruit. Their importance is due in part to difficultiess encountered in control which do not operate in the control of scale insects on deciduous trees. Dormant sprays, the main dependence for scale control on the latter group of plants, are not available for use against citrus seales. It will not be feasible to discuss all the important scales in detail here but the two natural groups, the armored scales and the unarmored scales, will be discussed separately.

\section{Armored Scales $\ddagger$}

There are several armored scales which are important pests of citrus trees. Of these the most destructive is probably the Purple Scale § present in Florida and the other Gulf States and in C'alifornia.

This scale resembles the common oyster-shell scale of the Southern States. It is found for the most part on citrus fruits and is of world-wide distribution. It attacks leares, twigs and fruit. and is often seen on fruit in northern markets.

The California Red Scale or Orange Scale is more important in

* See H. J. Quayle, Bulletin 214, Califomia Fxp. Sta.; J. R. Watson, Bulletin 148, Florida Exp. Sta.; W. W. Yothers, Farmers' Bulletin 933, U. S. Dept. Agr.; C. E. Wilson, Quarterly Bulletin, State Plint Board of Florida, Vol. II, No. 1, and various bulletins from the Florida Aer. Exp. Sta., The State Plant Board of Florida, The Californial Agr. Exp. Sta., The California State Commission of Horticulture and the I. S. Dept. of Agr.

$\dagger$ Family Coceider. See list of publieutions given above and special bulletins mentioned in connection with the different scales.

$\ddagger$ See previous reference.

\$Lepidosaphes beckii Newman, See H. J. Quayle, Bulletin 226 Callifornia Agr. Exp. Sta.

- Chrysomphalus aurantii Mask. See H. J. Quayle, Bullet in 2222, California Agr. Exp. Sta. 
California than in Florida, but is present in Florida. It is said to be second only to the black-scale as a pest in California. Adults of this scale are circular, of reddish color and about the size of an ordinary pin-head. There are several generations in the course of the year but these overlay so that young may be found through all the season. The young, like those of the San José scale are pro-

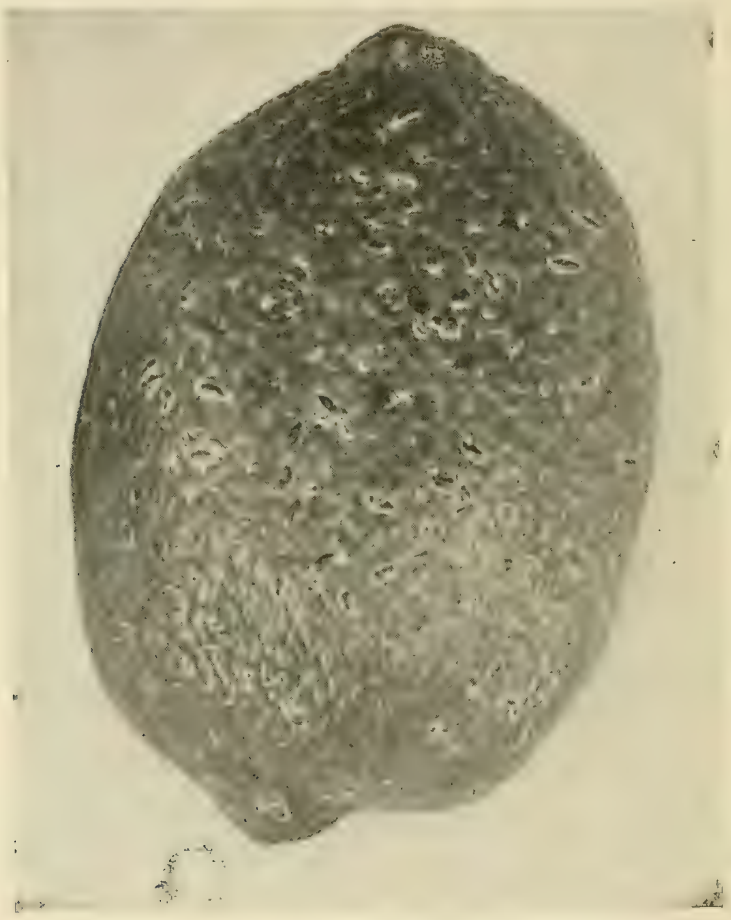

Fig. 525.-Purple Scale on lemon.

duced alive and not hatched from eggs as is usually the case with scales.

This scale attacks trunk, hranches, foliage and fruit and in. jures the tree by sucking the juices from it. It also injures the appearance of the fruit upon which it may sometimes be seen in the market.

The Yellow Scale * is a variety of the California Red Scale and differs from it in its lighter color and slightly different distribution.

${ }^{*}$ C. aurantii var, citrinus Coq. 
The Long Scale * is one of some importance in Florida, but is not reported from California as a pest. It is similar in habits and distribution on the plant to the Purple Scale, being often found on the fruit with that scale, but it may be distinguished by its narrower

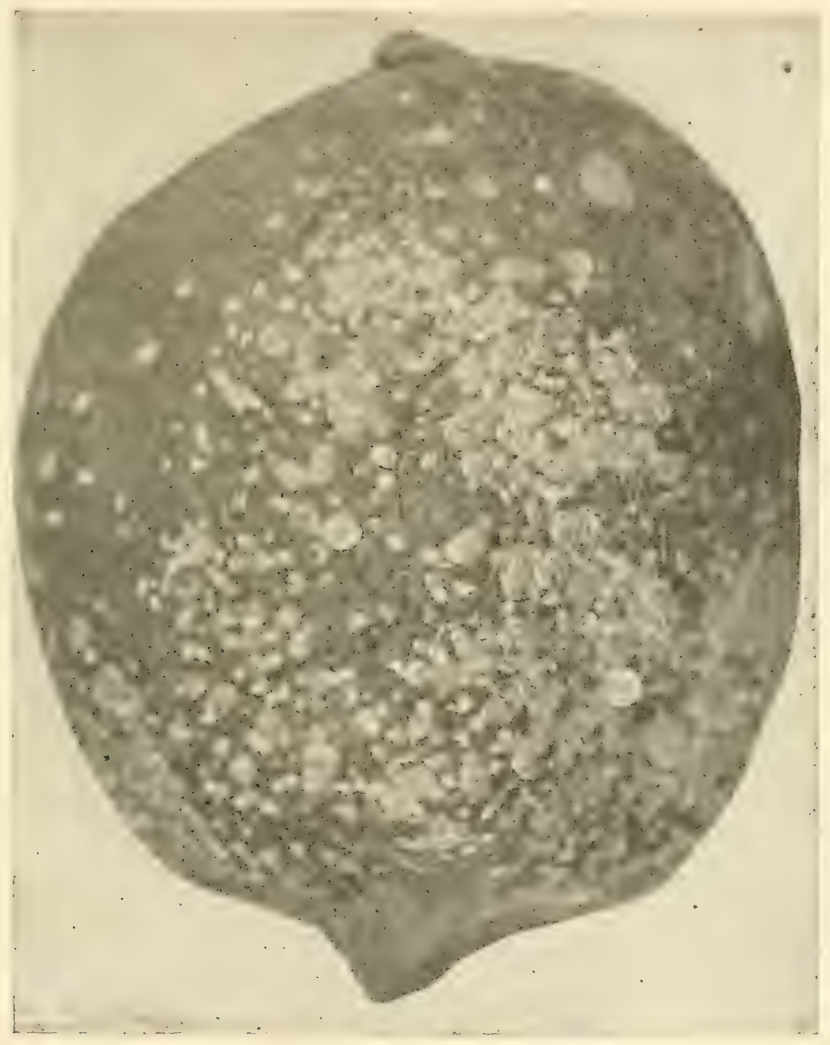

FIG. 526.-The Chaff Scale on lemon.

shape. Being about the same length as the purple scale it is much narrower. They are not always distinguished by the growers.

A scale often associated with the red and yellow scales and similar to them except in color, which is more of a light gray, is the Greedy Scale $\uparrow$. Its main injury is in disfiguring the frut for market as it rarely interferes seriously with the growth of the tree

* Lepidosaphes gloverii Pack. See Watson, 1.c

$\dagger$ Aspidiotus camelliae Sign (or rapax Comstock). 
Similar to it is the Oleander Scale * which, on account of its frequent occurrence on lemons is sometimes called the lemon-peel scale. The two latter forms are common in California, but not known to infest citrus in Florida. The San José scale (see page 470 ) is a pest in both localities, but does not do as much damage to the citrus fruits as it does to the deciduous kinds, being largely over-shadowed by the other scales mentioned.

In Florida the most destructive scale is the Florida Red Scale or Round Scale $\dagger$. It lacks importance from the fact that it is not so widely distributed as some of the others and does not seem to spread so rapidly or to be as generally present in an infested planting. This scale is reddish brown in color with a lighter brown center and is nearly circular. It infests the leaves and fruit and will easily defoliate a tree when it is abundant.

The Chaff Scale $\ddagger$, a thin gray form, sometimes completely covers the bark of trees in Florida, especially the bark of the smaller branches. The Snow Scale, $\S$ so called on account of the white color of the males, is closely related to the scurfy scale of the apple. Neither the Chaff Scale nor the Snow Scale is seriously injurious.

\section{The Unarmored Scales}

Members of this group lack the separable scale found in the previous group of scales, the protection to the body being provided by a thickened and sometimes hardened body-wall rather than by a secretion from the body wall. They are generally larger than the armored scales and are much thicker bodied, their shape suggesting that of the common terrapin, on which account several species receive local names of terrapin-scale or tortoise-scale.

The Black Scale $q$ is the most important of the scale insects in California, being, according to Quayle, the most destructive of the insects attacking citrus fruits in that state. It occurs in Florida but rarely attacks citrus plants there, being more common on oleander and other trees. Its injury is due not so much to its feeding habits as to the secretion by the scales of a substance resembling

* A. hederae Comstock.

$\dagger$ Chrysomphalus aonidum L.

$\$$ Parlatoria pergandii Comstock.

\$Chionaspis citri Comstock.

If Saissetia olex Bern. See H. J. Quayle, Bulletin 223 California Agr. Exp. Sta. 
the honey-dew of plant lice which promotes the growth of a black fungus, known as the sooty-mold fungus, on the leaves and fruit, and makes it necessary to wash the fruit. Washing the fruit involves great loss due in part to the eost of the washing, but more to the infection of the fruit with molds through abrasions in the skin made in the process. The sooty-mold fungus on the leaves, although it lives from the honey-dew and not the leaf, interferes with the growth of the leaf by forming a dense coating over it. This is injurious to the leaf and to the tree.

The Black Scale is large, from oneeight inch to one-fourth inch long, more or less hemispherical in shape, and somewhat wrinkled or ridged on the surface. The life cycle requires several months but eggs are produced o ver long periods and in great numbers, as many as 3000 from one female, so there appears to be one more or less continuous generation.

The S of t Brown Scale, ${ }^{*}$ sometimes called the Turtle Back Scale is similar to the one just discussed but smaller, of a brown color and lacking the darker markings of the Black Scale. It is occasionally Fic. 527.-Black Scale (Saissetia . locally injurious in the citrus fruit

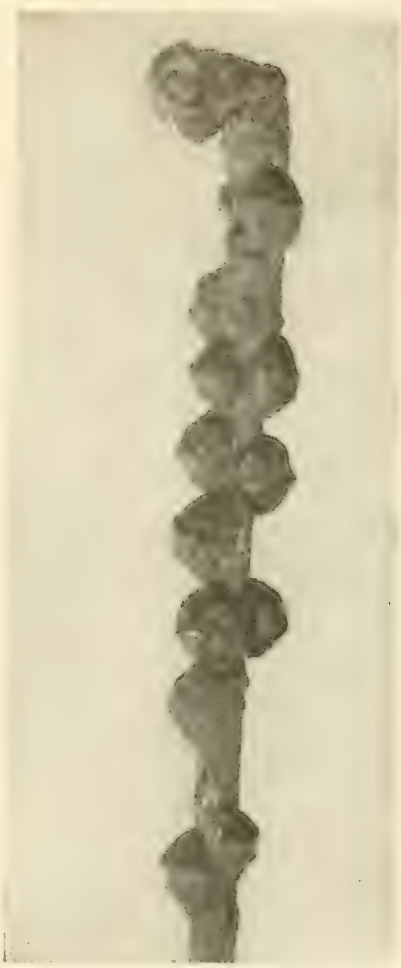
region and is present over a large part of the country, attacking a variety of plants. Its injury in citrus groves is due to the honeydew and consequent growth of sooty-mold fungus. The adult scales are somewhat more than one-eighth inch long and the shape is less nearly hemispherical. The young are produced alive, eggs being hatched within the body of the insect, and the young attack, by preference, the young growth. There are three or four broods.

${ }^{*}$ Coccus hesperidum $\mathrm{L}$. 
The Hemispherical Scale * is essentially a greenhouse pest, being found on ornamental plants of many sorts in greenhouses. It has some importance as a pest in citrus plantings as it thrives outdoors in climates suitable for orange growth. It is of a rather uniform brown color, fairly large size and is rather smooth and polished on the surface.

Other scales of this type are found on orange, lemon and other trees of this type but none of them is as important as the ones

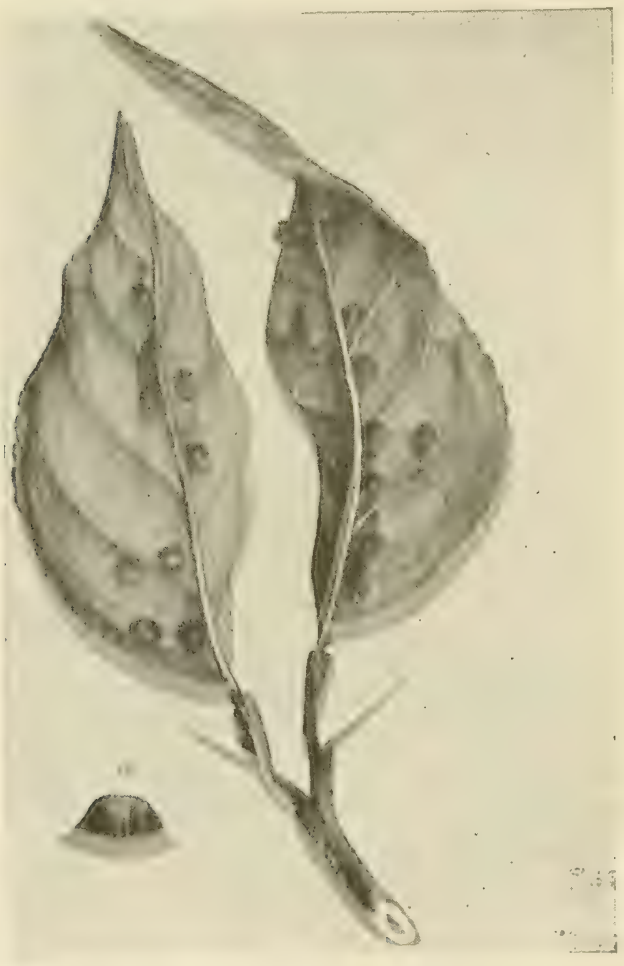

FIG. 528.-IIemispherical seale, Saissetia hemisphaerica. mentioned. In Florida, the Wax Scale (Ceroplastes floridensis Comstock)characterized by a thick covering of white wax, and two other species of the same genus, are frequently to be seen but rarely do serious damage.

The Cottony Cushion Scale or Fluted Scale $\dagger$ is possibly the most famous of the scales attacking the citrus plants. While not so injurious now as formerly, it threatened, for some years after its introduction into California in 1868 , the very existence of the citrus industry. Other efforts to control it having

failed, a search wasmade by agents of the Department of Agriculture at Washington, for its native home, in the hope of finding there some insect which fed habitually upon it and was capable of keeping it in check. In this search they were more successful than other

* Saissetia hemispherica Targ.

$\dagger$ Icerya purchasi Mask. 
agents have been in recent years in the search for similar enemies to other introduced insects for they found, in Australia, which appeared to be its original home, a lady-bug beetle which fed on this scale. Some of these beetles * were sent to California where they were reared and distributed to the infested groves and in a few years had reduced the scale to the status of an occasional pest and it is no longer feared, doing less damage normally now than several other species and being always easily reduced in numbers by the distribution of the ladybugs.

The Cottony Cushion Scale is more nearly related to the mealy bugs than to the soft-scales, with which it is usually classed. It is brown in color and has some resemblance to the soft or unarmored scales. It takes its common name from the appearance of the females at egg-laying time when they produce underneath the posterior portion of the body a mass of cottony wax which is fluted or furrowed on the upper side and forms a dense cushion. In this cushion the eggs are laid. At this stage the scale is not unlike the common cottony-maple scale of the east (Pulvinaria innumerabilis).

Recognition of this species is easy on account of the appearance of the females. Adults are found on the bark, but young are more likely to be

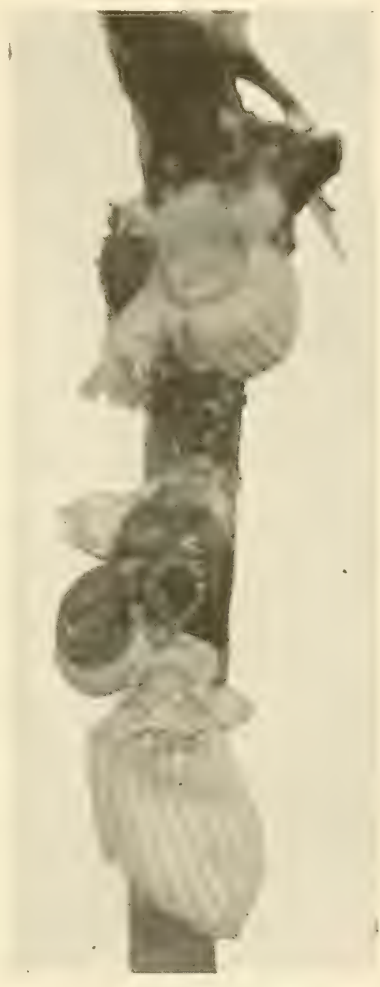

FIG. 529.-Cottony Cushion Scale. on the foliage. There are three or four annual generations.

The scale is generally distributed in California, and is present, in many localities in Florida. While the lady-bugs will control it, it is necessary to keep watch and see that they are present in infested groves.

* Novius (Vedalia) cardinalis Muls. 
In Florida the State Plant Board collects, rears and distributes these lady-bugs, to the growers, a nominal charge being made for the service. The beetle is commonly called the Vedalia or the Australian lady-beetle.

There is present in California another effective parasite of the Cottony Cushion Scale, a true fly, of the family Agromyzide (Gryptochaetum monophlcebi). This was introduced from Australia the same time as the Vedalia beetle.

\section{Control of Scales in Citrus Groves}

Since the control measures employed for scale insects are essentially the same as those for the whitefly and the mealy-bugs discussion of them will be deferred and will follow the discussion of those insects.

\section{Mealy Bugs *}

Several species of mealy-bugs occur in citrus plantings as well as on truck and other crops in the South and on greenhouse plants

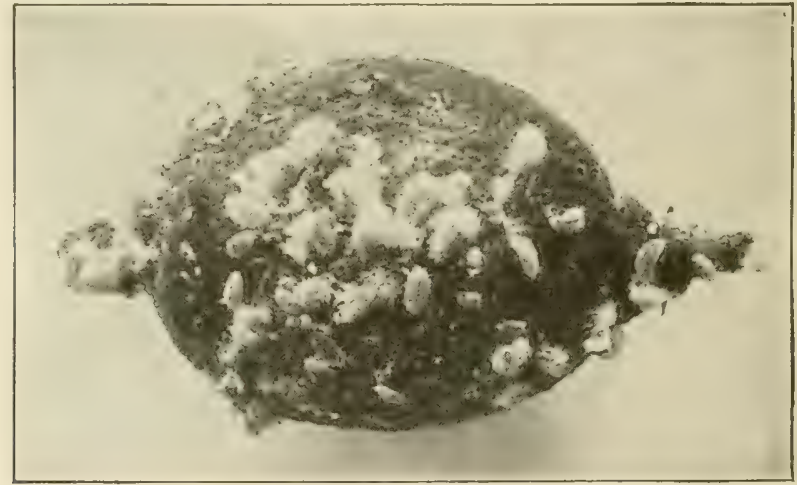

FIG. 530,-Lemon infested with the common mealy-bug. After Woglum and Neuls. U. S. Dept. of Agr.

and some outdoor ornamentals farther north. The most important of these is the Citrus Mealy-bug $\dagger$ and since they all have much the same habits and appearance they will all be treated

* Family Coccida, Sub-family Dactylopiina.

$\dagger$ Pseudococcus citri Risso. 
under this head. The mealy-bug is common in all citrus growing regions and is at times a serious pest.

It attacks many plants, but prefers the citrus fruits. It is found on all the growing parts of the plants, but prefers sheltered situations as between the leaf-stem and the stem. It also gets into crevices in the bark and sometimes clusters on the stem end of the fruits and between fruits which are hanging against each other.

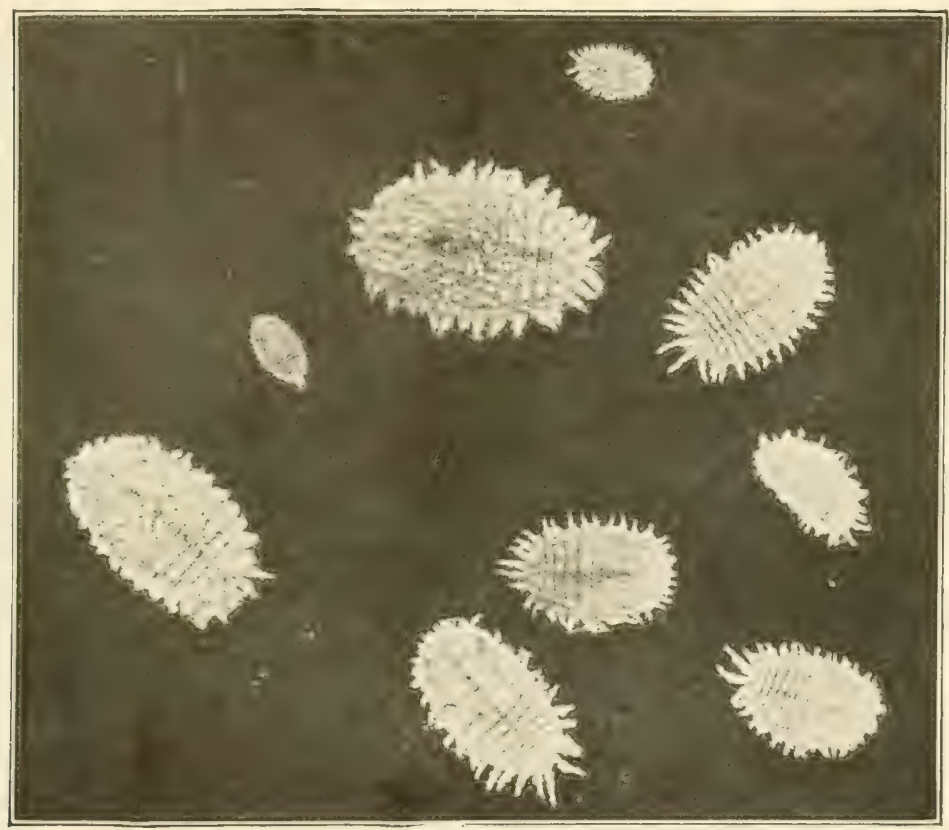

FIG. 531.-A group of common mealy-bugs. Enlarged about 9 times. After Woglum and Neuls, U. S. Dept. of Agr.

Mealy-bugs secrete a form of honey dew in which grows a black sooty-mold of fungus which disfigures the fruit and renders washing, with its objectionable features, necessary. If not washed off the fruit they will remain on it after picking and continue to breed causing loss in transit or storage.

The eggs are laid in a mass of cottony wax secreted by the females and the young are fairly active. The adults are never permanently attached to their food-plant as are the scales. They breed more or less continuously but there are several generations. 
They are likely to be more abundant in dry weather, spring and fall in Florida.

The insect is resistant to sprays, being protected by its waxy covering and the young are also resistant to fumigation so that the insect is hard to control. It will however, yield to persistent treatment under the methods to be described.

Mealy-bugs, like most of the other important citrus insects, are subject to the attacks of many kinds of parasitic and predaceous enemies which may, under favorable conditions, entirely eliminate the necessity for artificial control measures. It has been observed in California that the work of these enemies is interfered with by the Argentine ant* which drives away the parasites or destroys them in some stages. It is therefore frequently of advantage to protect the infested trees from these ants, either by banding with some sulsstance which will keep them out of the trees, as sticky tree-tanglefoot, or by poisoning the ants. This is done quite successfully by the use of the following poison as recommended by Woglum and Neuls $†$ from whom the following directions are quoted:

"To free trees of ants the ideal procedure would be to eradicate these insects from the area affected. The writers have not carried on any such tests, but the published results of work carried on by the Department of Agriculture against the Argentine ant $\ddagger$ would indicate the feasibility of freeing orchards of this pest.

The procedure followed with noteworthy success in municipal control work was the distribution throughout the affected area of a poisoned sirup in a suitable container. A paraffined paper bag, with perforations for the passing of ants, containing about a gill of sirup, was used as a container for nailing to trees."

"The sirup is made as follows:

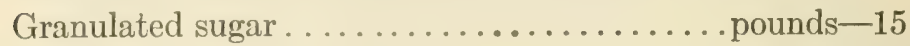

Water...................................... 7

Tartaric acid (crystallized) . . . . . . . . . ounce- $1 / 4$

Boil for 30 minutes. Allow to cool.

Dissolve sodium arsenite (C. P.) . ........... ounce- $3 / 4$

* Iridomyrmex humilis Mayr.

† Woglum and Neuls, Farmers' Bulletin 862, U. S. Dept. of Agr.

\pm Barber, E. R. The Argentine Ant: Distribution and Control in the United States, U. S. Dept. of Agr., Bul. 377, 23 p., 4 fig. 1916. Newell, Wilmon, and Barber, T. C. The Argentine Ant. U. S. Dept. of Agr., Bul, Ent. Bul. 122. 
In hot water .......................

Cool. Add poison solution to sirup and stir well. Add to the poisoned sirup:

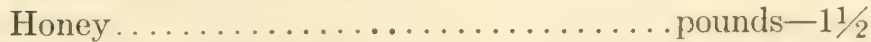

Mix thoroughly.

"A number of experiments with banding in orchards infested with the Argentine ant have proved the practicability of this method of keeping trees free of ants during their activeseason, and this method of control is recommended as the most effective one tried. Before the band is applied the tree should be pruned so that the lowest branch is fully a foot above the ground, and all rubbish should be removed from beneath the tree and the soil cultivated to destroy all grass and weeds. The only banding material which has given satisfaction is a mixture * made up as follows:

Finely powdered flowers of sulphur ... part by weight-1 Commercial tree-banding sticky material.....

\section{parts by weight-6}

"The two ingredients are mixed together thoroughly with a wooden paddle until of a uniform color and consistency. That possible injury may be avoided, this is not applied directly to the bark, although direct application of the commercial sticky treebanding material alone has never been noted in California to affect citrus trees seriously. First coat the trunk with a thin layer of paraffin and apply the mixture of sulphur and sticky tree-banding material over this. Paraffin that has a high melting point is preferable, and it is applied with a brush while melted. It hardens almost immediately, after which the mixture just referred to can be applied in a band about 5 inches wide and almost one-fourth inch thick. A single application of this material has kept trees free of ants for several months during warm weather.

"Ants that are on trees at the time of banding usually drop off within a day or two unless nests are in the trunk or branches. If nests are present, however, they should be destroyed by applying pyrethrum or some other ant powder, or with a fine spray of gasoline from a plumber's torch, or with cresolated emulsion applied with a

${ }^{*}$ Compounded by Mr. J. R. Horton of the Bureau of Entomology, U. S. Department of Agriculture. (See Horton, J. R. Some weatherproof bands for use against ants. In Mo. Bul. Cal. State Com. Hort,, v. 5, no. 11, p. 419-421. 1916.) 
3-gallon compressed-air sprayer. This should be done early in the morning, while the ants are least active.

"Inspection should be made sveekly for the discovery of rein-

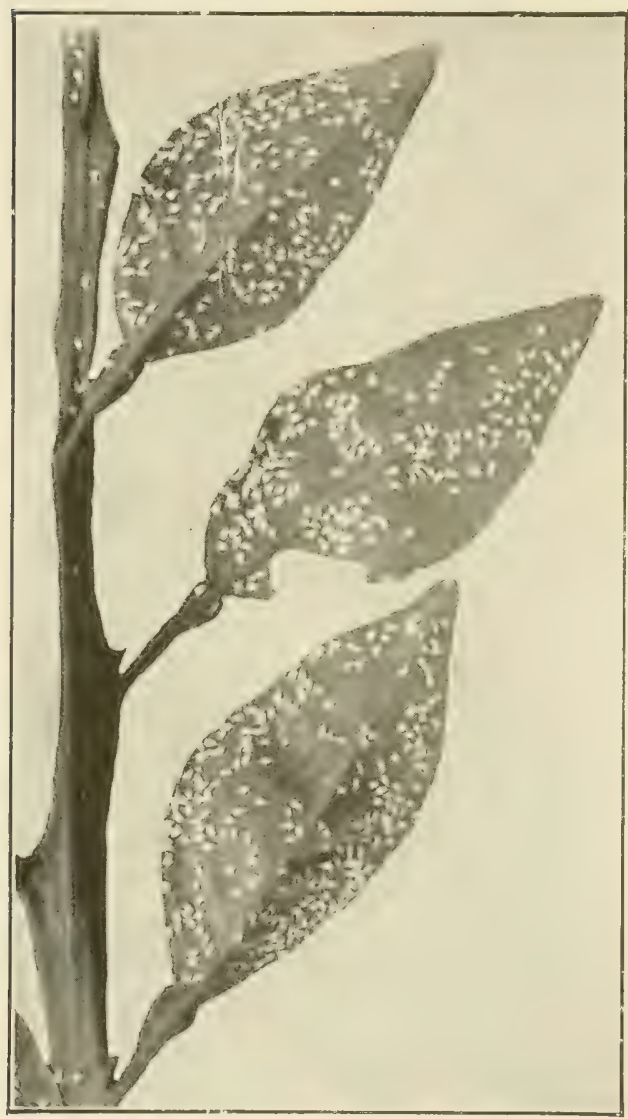
fested trees, thebands being renewed where necessary and the branches of the trees kept from coming in contact with weeds or the ground."

\section{Whiteflies*}

The whiteflies are the most important of the insects attacking citrus fruits under the conditions existing in Florida but are not so serious in California, as they are, as yet, present in that state in only one or two restricted localities. Indications are that, once they are established, they will be as important there as in Florida.

According to Watson (1. c.) there are eight species of

Fig. 532-Adults of the common white fly crowding the under surface of new orange leaves. (Morrill and Back.) U. S. Dept. of Agr.

whiteflies attacking citrus fruits in Florida. Two of these, the Common Whitefly $\dagger$ and the Cloudy-Winged Whitefly are pests of the first importance while a third is occasionally

* Family Aleurodidae.

† Dialeurodes citri R. \& H.

$\ddagger D$. citrifolii, Morgan. 
important (the Woolly Whitefly*). The last named species is almost perfectly controlled by a Hymenopterus parasite,

The life history of all these is essentially the same, as are their habits, and one discussion will fit all reasonably well.

The eggs are minute objects laid on the under side of the leaves. The young crawl about and begin to suck sap, staying away from the light as much as possible. They soon become stationary, like scales, and remain so until the growth is completed, when they transform to adults which are minute fly-like insects about onesixteenth inch long. The wings are white and covered with a fine waxy powder.

Injury from whiteflies is the result of their feeding habits which drain the tree of its sap and also of the production by them of quantities of honey-dew, the effect of which is exactly the same in this case as in the case of the scale insects having the same habit, that is, the growth of sooty-mold on all parts covered with the honey-dew and the consequent interference with the function of the leaf and the necessity which arises for washing affected fruits with the attendant loss from the process. Blackening of the trees from the sooty-mold is the most prominent sign of the presence of the whiteflies in number.

\section{Control of Whiteflies $\dagger$}

Whiteflies may be controlled by spraying and by fumigation. The practice of these control methods as applied to whiteflies does not differ materially from the same methods as used for scales and mealy-bugs. They are therefore all discussed under the general head dealing with control measures for these insects. Another means of controlling the whitefly, and applicable only to it, is the control by the use of parasites or fungus diseases which attack these insects.

There are four of these diseases which are most important in the control of whiteflies, with but one exception they infect the young insects only. Of these the most important is the Brown Fungus (Egerita webberi), which appears as brown spots on the under side of the leaves. A young whitefly attacked by one of these spores produces a growth of the fungus from which minute

* Aleurothrixus howardii, Quaintance.

† See P. H. Rolfe and II. S. Fawcett, Bulletin 119, Florida Exp. Sta. 
threads or hyphae extend out in every direction and carry the disease to other young on the same leaf without the production of more spores. The hyphce grow around the edge of the leaf to the upper surface and there produce the spores. When the spores are produced they are carried by the wind and other natural agencies and are quite likely to infect all the flies on a tree or even in a grove.

This fungus appears mainly in the late summer and in the autumn and grows best in wet weather. It attacks both the Common Whitefly and the Cloudy-Winged Whitefly.

The Red Fungus or Red Aschersonia (Aschersonia aleyrodis), is next in importance. It develops in and on the young fly and does not send out the hyphae as does the brown fungus. It can therefore be carried only in the spore form. The spores are formed in small pits on the fungus growth, such growths being called fungus pustules. This species thrives earlier in the season than does the brown fungus and it also is effective against both the common species.

The Yellow Fungus, or Yellow Aschersonia (Aschersonia flavocitrina) is interesting as well as important. In appearance and growth it is almost exactly like the red fungus, but bright lemon yellow. It affects only the Cloudy-winged Whitefly, of which it is an important parasite.

The fourth species of importance is called Microcera (Fusarium) and is particularily destructive to the Cloudy-winged Whitefly. It attacks several of the scale insects as well as the whitefly and is of importance in their control. It grows more quickly than the other fungi, requiring less than a week for the formation of spores where the other species require nearly a month. It infests young larvae to the greatest extent, but attacks both eggs and adults as well. It thrives better during cooler weather than do the others, but it needs plenty of moisture.

All fungi do best under rainy weather conditions, and it is said that if the rainy season persisted throughout the year there would be no need for artificial measures of control for the whitefly and possibly also for some of the scales.

Preservation and distribution of fungi-These fungi may be preserved until needed by placing leaves with the fungus and spores present on them in cold storage or by drying the leaves and storing them. From such material, cultures may be introduced 
early in the season before fresh fungus is available. Special directions for this should be obtained from the State Plant Board or the State Experiment Station,* (of Florida).

The fungus is introduced into groves or trees infested with whitefly but free from fungus, either by placing infered leaves in and about the trees or by making a viater infusion from the leaves, thus forming an infusion of the spores and spraying or sprinkling this on the under side of the leaves. When material is scarce the infusion may be placed in a large pan or bucket and the ends of a few branches of each tree dipped into this, dependence for further spread being placed on the natural methods of dissemination.

The recommendation for the use of fungi states that they may not always be depended upon for complete control, but that, in the best practice, use should be made of them in connection with the use of the contact insecticides described.

Pure Cultures of Fungi.-Of the several fungus parasites of whiteflies known in Florida, two, namely, the Red Aschersonia and the Yeilow Aschersonia, can be readily grown in the laboratory in pure cultures on sterilized sweet potato. The brown fungus has also been tried, but while a vegetative growth can readily be obtained it has so far refused to produce spores. The methods for growing these fungi in pure cultures were perfected some years ago by the Florida Experiment Station.

When in 1915 the State Plant Board of Florida was organized, the growing of pure cultures of the Red and Yellow Aschersonias became one of the projects of the Entomological Department. Since that time a few hundred to as many as severai thousand cultures have been annually produced. A culture consists of the amount of fungus and fungus spores that can be grown in a pint widernouth bottle and is sufficient for starting fungus in an acre grove. More or less may be used but the amount indieated has been found to be quite sufficient. Sterilized pluas of sweet potato were originally the medium upon which these fungi were grown, but it was soon discovered that the ardition of a small

* See E. W. Berger, Bulletins 97 and 103, and J. R.Watson, Bulletin 12:3, and Annual Reports for 1907 of the Entomologist and Pathologist, Fla. Agr. Exp. Sta.

t See H. S. Faweett, "Fungi Parasitic upor: Aleyrodes citri," Special studies No. 1, Univ. of the State of Fla., June 1908. See also, E. W. Berger, p. 12, Bulletin 103, Florida Exp. Sta., 1910. 
amount of agar improved the consistency of the cultures so that they can be shipped without contents of the bottle becoming mixed up, or disarranged. The presence of the agar, furthermore, permitted allowing the contents of the bottles to cool and harden in a sloping position, resulting in what has been called a "Sweet potato-agar-slant" which has certain advantages for manipulation in the laboratory

\section{Control of Scale Insects, Mealy-bugs and Whitefly.}

Three general methods for the control of the above insects are used. They are, spraying, practiced in California and in Florida with equal success; fumigating, practiced in California, but not so successful under Florida conditions on account of the large amount of rainfall; and control by the encouragement and distribution of fungi parasitic on the insects, this method being adapted to Florida conditions rather than to those which obtain in California, since these fungi usually are favored by excessive amounts of moisture.

Spraying.-Spraying for the insects in question is rather increasing in favor as new methods and materials are being perfected. Formerly it was considered impossible to do successful spraying for these insects because of the close heads and dense foliage of the citrus trees and their lack of a dormant period which would permit the use of insecticides stronger than the foliage could stand and would also permit more thorough treatment of the trunk and branches than is possible where the tree retains its foliage for the entire year.

However, sprays have been developed which will kill the insects without injury to the foliage and there are spraying machines with which these sprays can be applied thoroughly with careful labor. Lack of success is likely to be due to faults in the application of the sprays rather than to the inefficiency of the method.

In spraying for all the insects in this list several things must be considered. First is the fact that these are all sucking insects which must be hit by the spray to be killed; second is the fact that there are several stages, some of which are more easily killed by spray materials than are others so it is necessary to have a reasonable knowledge of these stages in order to apply the sprays when they will do the most good; and third, the fact that they 
breed and increase with great rapidity so that a few individuals escaping the first treatment may in a few weeks make additional treatments necessary, even with the most efficient spraying.

Spray materials most widely used are the oil emulsions and miscible oils. In Florida there are two kinds of emulsions used, called the boiled emulsion and the cold-stirred emulsion. Directions for making these are given by Mr. W. W. Yothers in Farmers' Bulletin 933, U. S. Department of Agriculture, and are quoted here as the best available:

"Experiments covering a 10 -year period have shown that the best insecticides for controlling white flies and scale insects are those having a base of cheap lubricating oil or what may be called 'paraffin oil.' 'These oils are made into emulsions according to the formulas following.

"Fish-oil soap at the rate of from 5 to 8 pounds to 50 gallons of water in May, or from 12 to 16 pounds to 50 gallons of water during the winter season, is an effective spray that has been used for many years without injury to the foliage or fruit.

"While both the fish-oil soap and the oil emulsions are effective in killing the whiteflies and scale insects, experience indicates that the latter are far superior to the former under Florida conditions. This superiority is due to the physical properties of the oils. The high boiling point and great viscosity possessed by these oils make them operative over a longer period of time after application, and, too, they are only slowly affected by average temperatures and showers. Foliage sprayed with miscible oils remains slightly oily in appearance and to the touch for several weeks after apraying. Fish-oil soap leaves no such evidence that the trees have been sprayed. The oil spray is much less affected by showers than is the fish-oil-soap spray. Summer showers falling after the oil spray has once had an opportunity to dry on the foliage have little effect in lessening the efficiency of the spray. Such showers, however, have a very evident effect upon the number of insects killed by the soap spray. The effectiveness of the weaker strengths of fish-oil soap is much more reduced by showers than is the effectiveness of the weaker strengths of oil sprays.

"In experimental work on a large scale for the control of the citrus white fly the miscible-oil sprays have given better results 
than have the soap sprays. This greater efficiency seems to be due, not to a higher percentages of larvae and pupae killed when the spray is applied, but to the effect that oil sprays exert upon unhatched eggs or upon the young larvae hatching from them within 10 to 14 days after spraying. The oil forms a film over the eggs which prevents a large percentage from hatching, and the young larvae from those which do hatch are killed either in the act of emerging from the shell or in crawling over the oil-coated leaf. Those who are in touch with the white-fly problem appreciate the fact that no matter how efficacious an insecticide may be in killing larvae and pupae on the leaves at the time the spray is applied, if it does not either kill these unhatched eggs or remain operative long enough to kill the larvae that subsequently hatch, much of the benefit of spraying is counterbalanced by reinfestation.

"There are two ways of making miscible-oil emulsions: (1) Without heat; (2) with heat. The first is called the 'coldstirred emulsion' the second, the 'boiled' emulsion. Both kinds of emulsion are efficient, reliable, and easily made.

\section{Cold-Stirred Emulsion.}

Fish-oil soap:

Formuta.

By weight

8 pounds

By measure................. 1 gallon

Paraffin oil, 24 or 28 Baume......... 2 gallons

Water..................... 1 gallon

"Directions for preparation.-In preparing the stock mixture," the soap should be put into a receptacle of about five gallons capacity and the oil added while the mixture is being vigorously stirred. It is important that the oil be added in small quantities at first, and that the stirring be sufficient to keep the oil and soap in the form of an emulsion after cach addition of oil. Thus, at first about a pint of oil should be added to the soap and the mixture stirred until no free oil appears. As the amount of oil is increased it should always be stirred or mixed thoroughly before the next addition is made. After the required amount of oil 
has been added and after free oil has ceased to appear on top of the soap, the water is slowly poured in, about 1 quart at a time As previously stated, the only apparatus required to make this formula in a small way is an ordinary galvanized iron pail and a paddle.

"The foregoing formula may be modified under certain conditions, as the quantity of soap will depend largely upon the time consumed in adding the oil and the amount of stirring; the amount of soap being lessened if the stirring be uniform and ample time be taken in the careful preparation.

If it be desired to make this formula on a large scale, a 300gallon cylindrical tank may be fitted with paddles, which are attached to a shaft in a vertical position, occupying the center of the tank. The shaft is fitted with a beveled gear on the upper end. A horizontal shaft is then connected with the vertical shaft by means of another beveled gear, while the other end has a pulley to connect with the engine. A series of brakes should be fitted to the sides of the tank to prevent the entire mass from turning around with the paddles. An entire barrel of fish-oil soap may be placed in this tank and the stirring begun at once. Two barrels of oil may then be run into the soap through an inch or $1 \frac{1}{2}$-inch hole in the end of the barrel, or the oil may be run out of the bung-hole. After the oil has been added, either one-half or two-thirds of one barrel of water can be added to complete the preparation of the stock solution. In the final spray this should be so diluted as to contain about 1 per cent of oil by adding 1 gallon of the stock solution to 50 gallons of water.

"It is also highly practicable to fit up a 50-gallon barrel in the same way as described above for the 300 -gallon tank. By attaching a crank to the horizontal shaft the mixer can be run by hand instead of by an engine. Such a mixer, designed and used by Mr. J. A. Stevens, De Land, Fla., has been found practicable. The writer has used an ice-cream freezer for making an emulsion, by removing the can and adding a false bottom of 1 -inch board to hold up the stirring gears. In fact, many different types of mixers can be constructed, depending on the material available and the scope of the work involved. 


\section{Boiled Emulsion.}

Formula.

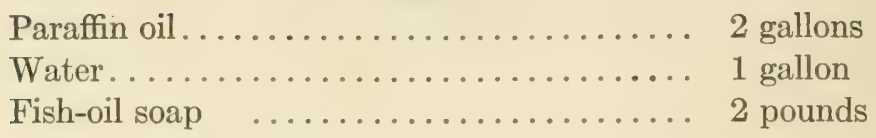

\section{or \\ Hard soap \\ 2 pounds}

"Directions.-Put oil, water, and soap into a kettle or other vessel that will stand fire, and heat to the boiling point. While still very hot, pump the material into another vessel and then back again. Emulsion can not be made by this formula without a pump; stirring is not sufficient.

"Dilute to make 200 gallons of spray material.

"For making the above formula the writer has used 9 and 15gallon kettles, wash boilers, and 100-gallon oil tanks with uniform success.

"If it is desirable to make this formula on a somewhat larger scale, the materials can be heated in a large kettle or other vessel and then dipped into a barrel pump outfit and the mixture emulsified by pumping it back upon itself. For safety it is best to have all the material pass through the pump twice, but it must not be pumped after it has become cool. Excessive pumping will break up a good emulsion. It can also be heated in a large galvanized oil tank having a capacity of 4 barrels and emulsified by means of the spraying machine. In this ease the suction hose should be put into the tank of hot material and the discharge hose into the spray tank. For the second pumping, put the suction hose into the spray tank and the discharge hose into the storage barrels. When the spraying machine is used for this purpose, an old suction hose should be used, as well as a discarded piece of hose for the discharge end. This should be not more than 10 feet in length. The material should be run through an ordinary nozzle with the disk left off. The overflow will not emulsify this material.

"Owing to the high temperature of the mixture, pumps used for emulsifying should have metal valves. If made of other material their period of usefulness is very short. It should always be remembered that a pressure pump must be used for emulsifying. The writer has never sueceeded in making an emulsion with a rotary pump. 
"Difficulties that may arise in making the boiled formula are: (1) A lack of sufficient heat; (2) improper pumping; (3) an improper emulsifier. In many tests the water and soap only were heated, and failure to produce a perfect emulsion resulted in every instance. On the other hand, when all the materials were heated together a perfect emulsion was secured. The materials should be heated until a slight foam or a few bubbles appear, but it is not necessary to boil for any length of time.

"Some growers have failed because they attempted to stir the materials together with a stick, and others because they used a rotary pump. Neither of these is satisfactory.

"The emulsifying agent is very important. There is no doubt that potash fish-oil soap is the most satisfactory of all soaps for the making of any of these emulsions. When this material is used the oil very scldom separates and the resulting emulsions never become too thick to be poured or handled conveniently. On the other hand, when hard soaps are used which are made from caustic soda and fats containing large proportions of stearin and small quantities of resin, the emulsions separate on cooling, and will cause much trouble in mixing on the day after they are made. If the emulsion made from any hard soap found on the market is used on the same day that it is made no trouble will be experienced. The 'cold-stirred' formula is difficult to make with hard soaps. The writer has found it impossible to make emulsions by using any of the soap powders, even if flour is used as a stabilizer.

"Before any spray material is applied to a tree it should be tested to determine if it is a perfect emulsion. To do this, add a small amount to some soft water; if no oil floats or no thick, greasy scum forms, it is satisfactory. If free oil appears the emulsion is imperfect and should not be used. Creat care should be used to stir the contents of the barrel thoroughly before any test is made.

"Just at present the boiled-emulsion formula is the one which will appeal to the average citrus grower in Flopida. It is, beyond all question, the cheapest efferetire insecticide for white flies and scale insects.

"The oils used in the making of these formulas usually test. from $24^{\circ}$ to $32^{\circ}$ Baume and have a viscosity not less than 200 . 
The best oils for spraying purposes have a viscosity of about 300 to 400 and they may be purchased from any of the oil companies operating in the citrus-growing belt. Petroleum fuel oil and distillate or gas oil may also be used and when applied should be used at twice the strength indicated for the lubricating oils. The soaps may be purchased from any grocery or fertilizer company.

\section{Proprietary Miscible Oils.}

"There are several proprietary miscible oils on the market which the writer has found to give highly satisfactory results. These should be diluted so that the spray material will contain somewhere between $3 / 4$ per cent and 1 per cent of oil. The writer would advise the use of oil emulsions when diluted to about 1 per cent. Experience indicates that such substances as rosin oll and sulphuric acid should not be used in proprietary insecticides."

Use of Fungus Diseases. - A method for the control of some citrus insects, particularly the whiteflies, in Florida, is the artificial dissemination of fungus spores causing certain fungus diseases to which these insects are susceptible. The discussion of the fungi and methods used is included with the discussion of the whiteflies as this method is not so extensively used for other insects.

There are, however, four* principal fungus parasites or diseases, of scales that are at times very effective in the natural control of citrus scales in Florida and the Gulf Coast. These are the Red-headed Scale-fungus (Sphaerostible coccophila Tul) the White-headed Scale fungus (Ophionectra coccicola E. \& E..), the Black Scale fungus (Myriangium duriaei Mont), and the Pink Seale fungus (Microcera fujikuroi Miyabe \& Sawada).

The first of these infects and kills the purple scale, long scale and chaff scale and several scales infesting deciduous trees, including the San José; the second infects the purple scale and long scale; the third the purple scale, chaff scale, Iong scale and San José Scale; the fourth the Florida red scale and purple scale.

* See P. H. Rolfs and H. S. Fawcett, Bulletin 119 (Revision of 94). Fla. Exp. Sta. for the first three fungi named herewith. See J. R. Watson, Report of Entomologist, Annual Report 191, Fla. Exp. Sta. for the 4th or pink scale fungus. 
These fungi are generally introduced or distributed in scaleinfested trees by tying small pieces of fungus material ( 2 or 3 inches long) to twigs or branches having the most scale. The fungus material may also be rubbed up in water and the resulting infusion of spores and water sprayed into the trees or mixed with the infusion of spores used for distributing the whitefly-fungi

\section{Fumigation.*}

By all means the most popular and efficient means of control for citrus fruit insects in (alifornia is funigation with hydrocyanic acid gas. General discussion of the nature of this gas and its

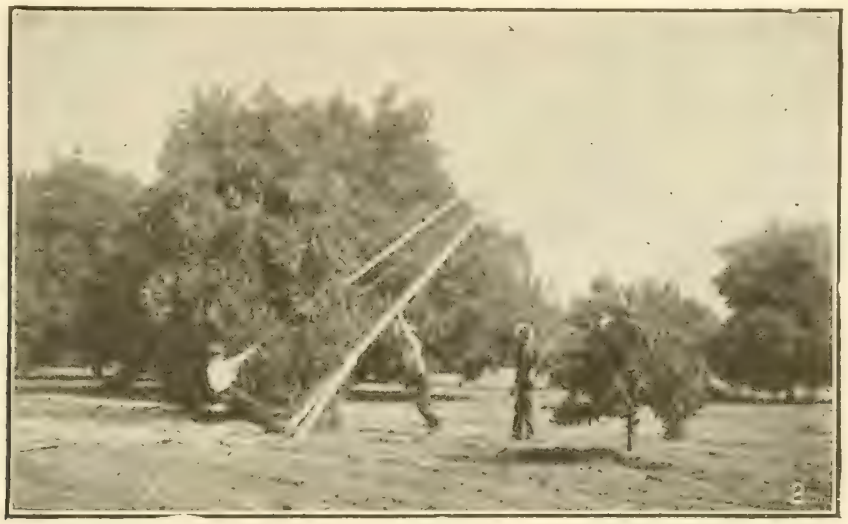

Fig. 533.-Fumigation of citrus trees. Some steps in preparation. After Woglum, U. S. Dept. of Agr.

preparation will be found in the chapter on insecticides in this volume. The application of the process to outdoor conditions for use to kill insects on trees is, in itself, a matter of special study. The work in California is usually done by contract by concerns which make that work their business, but the grower should have an idea of the nature of the process in order to be able to tell whether the work is being done properly.

The fumigating season extends from August to January and the work should be done when the temperature is not either unusually high or unusually low. It is usually done during the night.

* See R. S. Woglum, Farmers' Bulletin 823, U. S. Dept. of Agr. and bulletins of the California Agr. Expt. Station. 
The method consists, essentially, of the enclosure of the trees to be treated, in individual tents made of material as nearly imprevious to the gas as possible and of generating in the tents gas according to a variable table, based on the cubic content, the amount of leakage, which latter is less in proportion for large trees than for small, and upon other factors. Very accurate dosage tables have been worked out and are available wherever fumigation is a common practice. Time of exposure to the action of the gas is from 45 minutes to one hour, the same as for deciduous trees being fumigated in houses for San José Scale.

Special machinery for the generation of the gas is used by the large fumigating concerns. With these the gas is generated outside the tents and piped into them and the necessity for separate generating outfits for each tent is lone away with.

Fumigation has been tried rather extensively in Florida, but not so well adapted for Florida conditions as for those in California and so is not recommended for use in Florida.

As mentioned before in connection with fumigation, it should not be undertaken except under the direction and advice of experts as otherwise there is danger to the trees and to the operator.

\section{The Citrus Thrips.*}

The Citrus Thrips is one of the smallest members of a group in which the largest species are considered as minute insects. It has been known to be injurious to citrus fruits for a quarter of a century but the injury was not generally recognized until about ten years ago, on account of the small size of the insect. So far as is now known it is confined almost entirely to California and is not found in the gulf states. In Florida a different species, the Florida Flower Thrips $\dagger$ is similarly injurious.

The thrips sucks the juices from foliage and fruit and kills the cells surrounding its puncture. These dry up and form characteristic scabs and much of the injury is due to their thus scabbing the fruit, especially around the stem end where they cause a condition described as "stem-end ring." They also cause curling of the leaves and a grayish discoloration and interfere in this way with

* Scirtothrips citri Moulton. See J. R. Horton, Bulletin 616, U. S. Dept. of Agr.

†Frankliniella bispinosus Watson. 
the growth of the plant. Injury to young fruits often results in a large amount of dropping. Splitting and other deformation of the fruit is another evil effect of thrips injury.

The California thrips is transported from place to place for the most part on young trees where it is present in the egg stage. Local spread is the result of the flight of the adults. It is not confined to the citrus plants, but feeds on several others such as grape, pomegranate and apricot and these may serve as sources of infestation. The life cycle

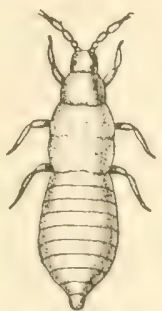

a

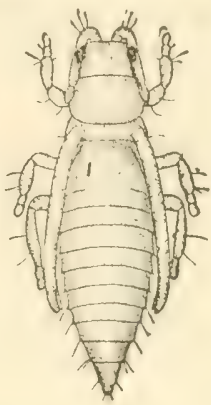

b

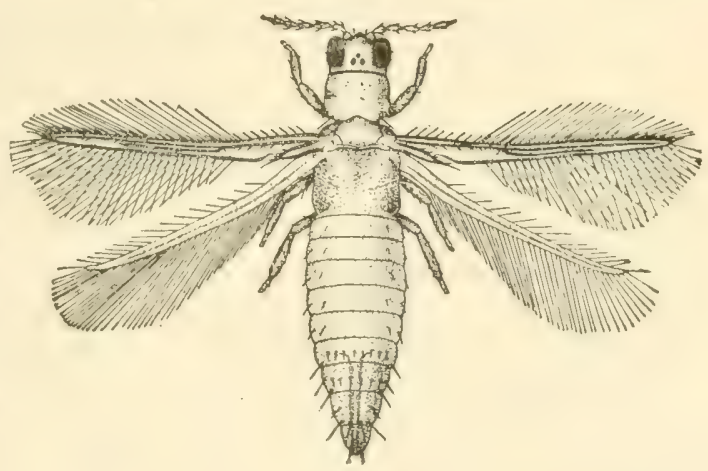
requires about a month and there FIg.534.-Citrus Thrip: a, Young nymph; b, Full grown are from six to eight nymph; c. Adult. After Horton, U. S. Dept. of Agr. generations which overlap so that they are practically indistinguishable. The winter months are passed in the egg stage. The Florida flower thrips is present everywhere and infests the blossoms of many plants.

Control.-Natural enemies are an important factor in thrips control. They include larvae of the lace-wing flies (Chrysopa californica Ceq.), lady-bug larvae, some of the assassin-bugs (Reduviido) several species of spiders and a fungus disease. In some years these enemies will render artificial control measures unnecessary.

Spraying is resorted to for control where any artificial measures 
are necessary. Horton l. c., summarizes the spraying recommendations based on spraying tests made in California as follows:

"In the tests the following insecticides and combinations gave the best results. Any of these mixtures may be relied upon to give satisfactory control when properly applied.

1. Lime-sulphur solution.-If the lime-sulphur is of a density of $36^{\circ}$ Baume, dilute 1 gallon with 56 gallons of water; if of a density of $33^{\circ}$ Baume, dilute 1 gallon with 50 gallons of water.

2. Sulphur-soda solution.-Two gallons of the stock solution, prepared as described diluted with 25 gallons of water. *

3. Lime-sulphur and tobacco extract (40 per cent nicotine sulphate).-Dilute 1 part of the lime-sulphur, if 34 to $36^{\circ}$ Baume,

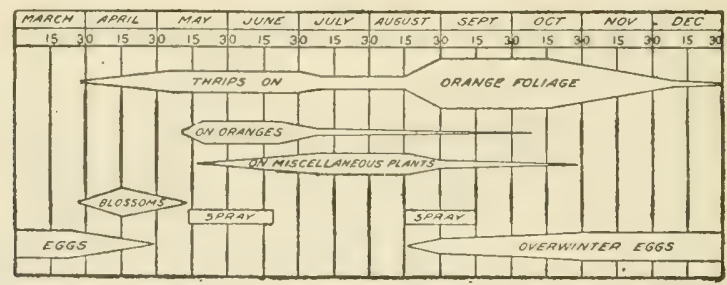

FIa. 535.-Graphic illustration of the seasonal activities of the citrus thrips as related to blossoming and later growth periods of the orange and indicating also the spray periods. After Iorton, U. S. Dept. of Agr.

with 86 parts of water; if 30 to $33^{\circ}$ Baume, with 75 parts of water. Then add 1 part of the tobacco extract to 1,000 parts of the limesulphur as diluted above.

4. Tobacco extract (40 per cent nicotine sulphate).-Dilute 1 part with 800 parts of water.

Lime-sulphur and soda-sulphur solutions are more effective against the citrus thrips than any other mixture thus far tested, and particularly the lime-sulphur at the strength stated above.

* The sulphur-soda solution was prepared as follows:

Powdered sulphur...................... 30 pounds

Powdered caustic soda (98 per cent) ........... 15 pounds

Water to make........................ 30 gallons

The sulphur was made into a paste with water and the soda added, while the mixture was constantly stirred, in sufficient quantity to cause boiling, a little water being added occasionally to retard the cooking. When all the sulphur was dissolved, enough cold water was added to make a stock solution of 30 gallons. A clear, amber liquid, much resembling good limesulphur, was the result. 
A large percentage of the thrips can be killed by spraying with this solution, and there is a further effectiveness due to its decumposition for a long period after deposition on the leaves. In orchards sprayed with good lime-sulphur the sulphurous odor is often strong for two months or more after the applications. The decomposition products repel the thrips, which are slower to reinfest orchards so sprayed than those sprayed with solutions that soon evaporate and leave no trace.

"Tobacco extracts when used at the proper strengths are also very effective. Both tobacco extract and lime-sulphur, when mixed together, are effective in weaker solutions than when diluted with water alone. Contrary to expectation, the addition of soaps to tobacco extract did not give increased value to the tobacco in these tests. Soap solutions used alone appear to be worthless at the dilutions tested.

"Resin wash at any strength practicable for use on the orange trees in this section is worthless. At the greatest strength used in these experiments it failed to reduce thrips injury to an extent worthy of attention. It is, furthermore, very injurious to fruit and foliage.

"Plain water spraying was utterly ineffective, demonstrating that merely striking the thrips with a liquid at high pressure to wash them from the trees has no appreciable effect in diminishing their numbers. A few hours after spraying with water there remained on the trees as many living, active thrips as before spraying."

\section{The Florida Flower Thrips *}

The Florida Thrips is larger than the true citrus thrips, being about one twenty-fifth of an inch long while the other is frequently less than one-half that size. It is of a yellowish or yellowish-red color and may be observed most easily in or about the blossoms of the orange. It injures the fruits and plants in much the same way as does the citrus thrips but is more likely to destroy the blossoms or the fruit just as it is setting by making its way down into the flower to the ovary which it attacks. Its injury is more

*Frankliniella bispinosus Watson. 
noticeable where there is a light amount of bloom, where the bloom is heavy the injury serves in a way as a natural thinning

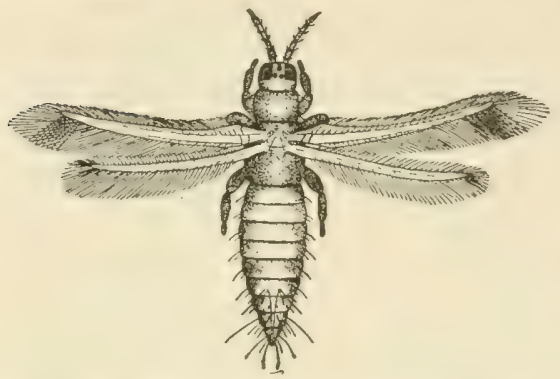

Fia. 536.-Florida Flower Thrips. From

Watson after Dozier. Enlarged (Florida Agr. Exp. Sta.). and may be beneficial. Disfiguring of the fruit is a source of some loss from this insect. The life history resembles that of the citrus thrips but there are probably more generations.

They may be controlled, where control measures are essential, by the methods outlined for the citrus thrips.

\section{The Rust-mite or Silver-mite *}

According to Watson, the rust-mite is, in Florida, out-ranked as a pest only by the white fly and the purple scale. In California it is less important being restricted in its distribution, and called the "Silver-mite" on account of its silvering effect on lemons. It was imported into California from Florida.

The rust-mite is just visible to the unaided eye, is rather elongate and broader at the anterior end, tapering to a rather long point toward the posterior end.

The eggs are few in number but $\mathrm{hatch}$ in a short time and the life cycle may take a period as short as two weeks. In consequence the multiplication, during favorable seasons is very rapid. The broods are inseparable.

Mites injure the foliage by sucking oils from the cells and in this way injures the trees. Their chief injury is, however, to the fruit which they attack in the same way. Here they cause

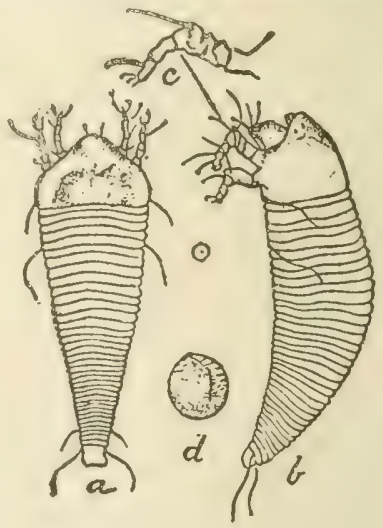

FIG. 537.-Orange rust-mite: $a$, dorsal view; $b$, lateral view, enlarged, the dot in circle indicating natural size; $c$, leg; $d$, egg with embryo just about ready to hatch more enlarged. (After Hubbard) U. S. Dept. of Agr.

* Eriophyes oleivorus Ashmead. See H. J. Quayle, Bulletin 234, Cal. Exp. Sta. Class Arachnida, order Acarina, Family Eriophyida. 
a russeting of the fruit which reduces its quality mainly by detracting from its appearance but also by reducing the size. Oranges and grapefruit are the greatest sufferers in Florida. Russeted fruits may frequently, even now, be seen on the market.

Control of the Rust Mite.-Weather conditions are a factor in the check of the mites, cold and wet weather being unfavorable to their development. These can not be relied upon to prevent damage and spraying is practiced wherever the mites are abundant.

Sulphur is the best insecticide for these pests. It may he applied in the form of a dust, mixed with hydrated lime which is used as a carrier, at the rate of one part lime to three parts sulphur. The dusting outfits discussed in the chapter devoted to spraying apparatus are suitable for use in applying this material, but care must be used to see that the dust carries through the dense foliage of the trees.

Free sulphur mixed with water or with water and soap is a good spray for the mite. Four or five pounds of sulphur, four pounds of soap and fifty gallons water, are about the proper proportions.

Commercial lime-sulphur testing $32^{\circ}$, Baume scale, should be diluted with seventy-five parts of water and will make a very good treatment for the mites.

Soda-sulphur spray, made as described for the control of the thrips and diluted at the rate of one to forty, is another effective spray.

Thoroughness is as important as for the treatment of other citrus pests.

\section{Red Spiders *}

These pests are, like the mites, members of the class Arachnida and the order Acarina, being, in fact, true mites themselves. They are larger than the rust mites and one species is quite red in color, being called the Florida red-spider, while the other is

* Tetranychus mytilaspitis Riley (or T. citri McGregor.) and T. sexmaculatus Riley. See H. J. Quayle (1. c.). 
more greyish and has six dark spots which suggest the specific name and the common name of the six-spotted mite.

Red-spiders are common in the spring or during dry weather.
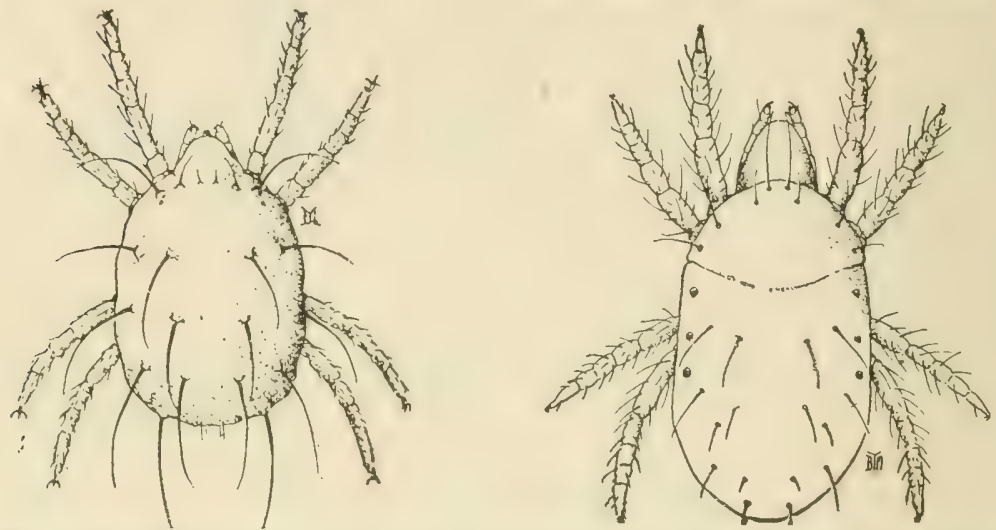

FIG. 538.-Red-spiders: The Citrus Red-spider, on the left; The Six-spotted mite on the right. After Quayle, California Agr. Expt. Sta.

They feed on the juices of leaves and fruits and cause russeting and mottling of the fruit. Often they remain upon lemons in storage and cause injury during the curing process.
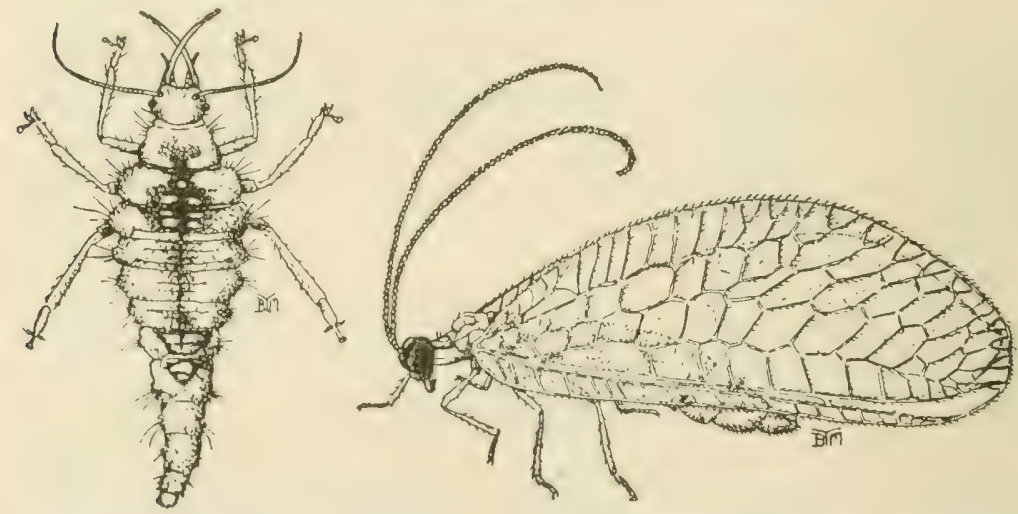

F1G. 539.-The green lace-wing, Chrysopa californica Coq., an important enemy of red-spiders. After Quayle.

Control is the same as for the rust-mite, the compounds of sulphur and sulphur in the free state having been found to be the best treatment for all forms of mites. 


\section{Diabrotica soror *}

The most common of the leaf-beetles on citrus fruits on the Pacific coast are the members of this species which is almost identical with the twelve-spotted cucumber beetle or Southern corn-root worm. It attacks the tender foliage of the orange but rarely damages the lemon. The larva, like that of the cucumber beetles, feeds on the roots of plants where it is little noticed.

Control.-On small trees the beetles may be jarred off into tar or oil on screens while they are sluggish in the early morning. On larger trees they must be poisoned. Lead arsenate paste at the rate of two pounds to fifty gallons water is

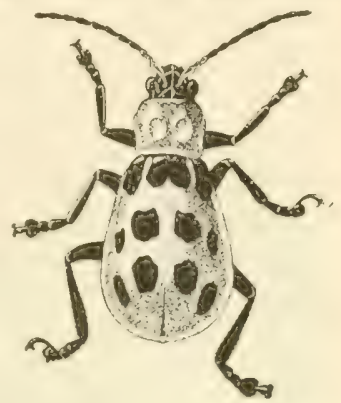

FIa. 540.-Diabrotica soror. After Quayle, Cal. Agr. Exp. Sta. effective. The powdered form, applied as a dust with sulphur, might kill these beetles and the mites at the same time.

\section{The Melon Aphis †}

The Melon-aphis is occasionally injurious to the young shoots of citrus trees in the spring. They are of no special importance to the citrus trees, but as these serve as an alternate host they should be destroyed when present in considerable numbers, for the protection of the other host plants, such as melons, cotton and other plants.

Black-leaf 40, 1 to 1000 , with soap as a spreader, is effective here as elsewhere.

\section{The Orange Dog $\ddagger$}

This conspicuous caterpillar is the larva of an equally conspicuous large, swallow-tail butterfly, black, with broad, yellow hands running diagonally across the forewings and just inside the margins of both wings.

The larva feeds on foliage but may easily be destroyed by handpicking or by the use of any arsenical. This is a Florida species.

* Family Chrysomelidos.

$\dagger$ A phis gossypii Glover. See same, Chapter XVIII.

$\ddagger$ Papilio cresphontes Cramer. Family Papilionida. 
The illustration gives a good idea of the appearance of the larva.

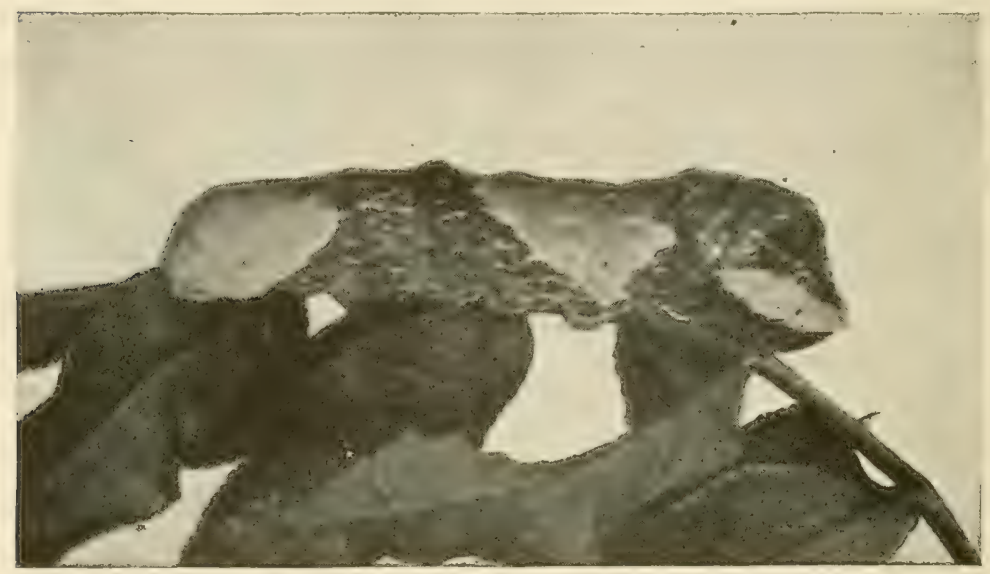

Fig. 541.-The orange dog caterpillar on Xanthoxylon. Slightly enlarged.

\section{The Southern Green Soldier-Bug.*}

This insect, also called the pumpkin-bug, along with some

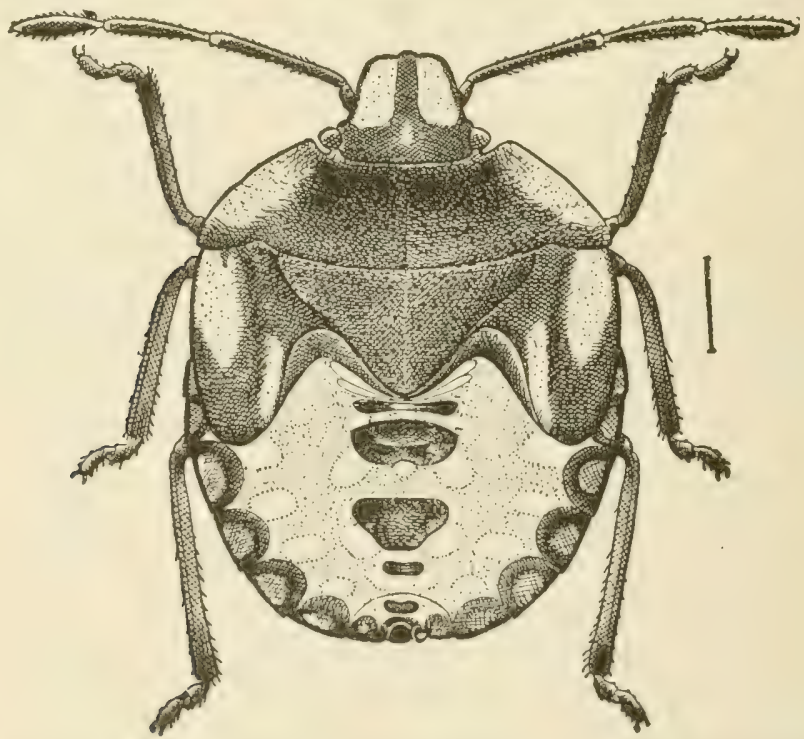

Fra. 542.-Pumpkin bug (Nezarr virdula): Young. Six times natural size. (From U. S. Bur. of Ent.)

* Nezara virdula Linn. Family Pentatomida. 
other bugs is common on truck crops, clovers and other plants and in the fall when these die and dry up they sometimes go to citrus where it attacks fruit and tender growth, ausing the former to drop.

It is similar in description and habits to the Green Soldier-bug described as a peach pest. The cotton stainer (Dysdercus suturellus) is often nearly as injurious.

The adults go into partial hibernation during the winter months. There are several over-lapping generations.

Control.-No spray has been developed to kill these bugs in the adult stage. Young will be killed by oil, soap and tobacco sprays. Adults may be collected by being jarred into large nets held under the trees. Bugs so collected are killed with kerosene.

\section{Argentine Ant.*}

The Argentine ant is a houschold pest of first importance in certain regions and has even greater importance in the citrus groves. It is primarily of importance in Louisiana but occurs in California as well. It has been known as a household pest in New Orleans for many years, but was imported about 1891, presumably from the Argentine, where it was originally deseribed, on coffee ships rumning from points in Brazil to New Orleans.

Its chief importance in citriculture is its interference with the various species of natural enemies of mealy-bugs and scale insects. It is also said to foster some kinds of seales and plant lice directly and to feed on buds, flowers and fruits of plants. It is important in the sugar-plantings of Louisiana where it fosters a mealy-bug (Pseudococous calceolaric Mask.) which is one of the most important enemies to sugar-cane production. It is saicl also to interfere with the natural enemies of the boll weevil. This makes a heary indictment for one minute insect but probably only faintly echoes the truth.

The Argentine ant is a very small species of a general brownish color. They live in nests, usually in or on the ground but occasionally in trees. 'Their destruction is usually a matter of destruction of the nests, primarily, although it may be possible to destroy colonies by persistent poisoning of the adults away from the nests.

*Irilomyrmex humilis Mayr. See J. R. Horton Farmers' Bulletin, 928 U. S. D. A. and Bulletins 647, ibid., also Wilmon Newell, Jour. Ec. Ent., Vol. II, Nos. 2 and 5. 1909. 
The poison used to protect trees from these ants in the California orange groves has been described in the discussion of the mealy-bugs. An interesting account of methods of trapping and of poisoning to rid orange groves in Louisiana of the ants will be found in the publication by Mr. Horton to which reference has been made.

There seems to be little doubt that, serious as this insect is, it can be controlled in orange groves and in dwellings, but that it is almost necessarily a problem for community action, if permanent
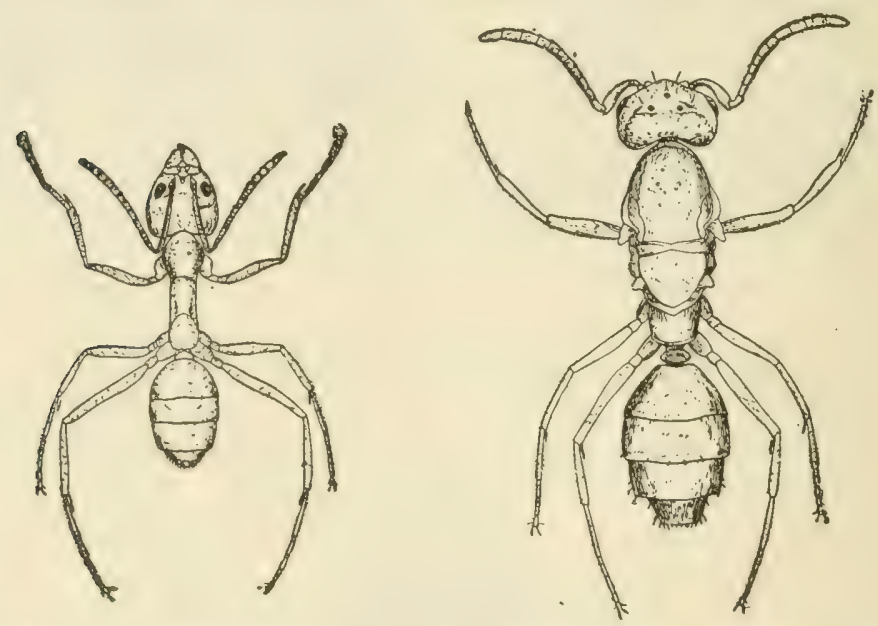

Fia. 543.-The Argentine Ant. Left, worker; Right, wingless queen. After Newell. Jour. Ec. Ent.

results are to be secured. Space here will not permit further discussion of the very interesting problems arising from the study of the control of this ant.

\section{Other Citrus Insects.}

Some of the most important citrus-fruit insects do not yet occur in this country and large sums of money are spent annually to keep them out by maintaining rigid quarantines. They are, therefore, a source of expense to the industry, even though they are not actually present.

Among these there should be mentioned the Mexican Orange Maggot (Trypeta ludens Loew.) and the Mediterranean Fruit 
Fly (Ceratitis capitata Wied.) and the Spring Citrus Whitefly or the Black Fly (Aleurocanthus woglumi Ashby).

The Black Fly, as the latter insect is now generally called, at-

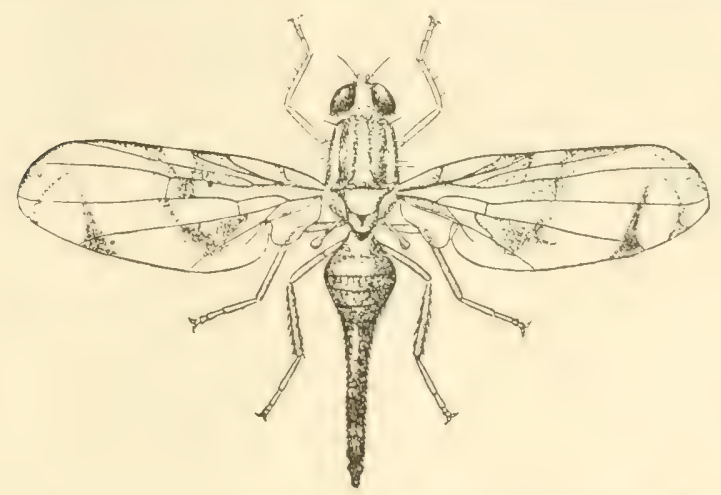

FIG. 544.-Fly of orange maggot (Trypeta ludens.) After Riley.

tacks citrus, mango and avocado. It came originally from India. It is a serious pest in the Bahamas, Cuba and Jamaica, but is not known in Florida. The State Plant Board of Florida is main-

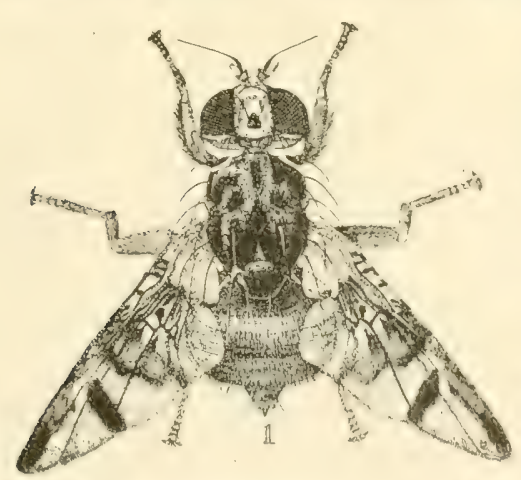

Fig. 545.-Mediterranean fruit-fly. After Froggatt. taining a rigid quarantine to prevent the addition of this very dangerous pest to the list of enemies of the citrus grower in Florida.

The orange maggot occurs in Mexico where it attacks oranges in much the same way that the apple-maggot injures apples, many maggots being found in the pulp of the infested fruit. The Mediterranean fruit fly attacks oranges and also peaches and other fruits. It occurs in Bermuda and Hawaii and also in all the continents but the mainland of North America. The nature of its injury is like that of the orange maggot. The adults of both species resemble the adults of the cherry-fruit fly, the currant fly and the apple-maggot. 
Since citrus fruits are, as yet, in this country, free from insects which work within the fruit, no price can be too high to pay for the exclusion of these forms.

The complete list of the citrus insects from the gulf states and California is a long one, but the reader who is interested will do well to consult the publications cited at the beginning of the chapter, as well as the bibliography, for more detailed accounts of the insects here treated and for the ones not mentioned. 


\section{CHAPTER XXVIII}

INSECTS INJURIOUS TO MAN AND TO THE HOUSEHOLD.

MANY insects attack man, directly. Many others injure him indirectly by destroying his property within his dwellings or by annoying him by their presence even when they are not actually destructive. Such insects represent many groups of the most diverse habits. The study of some of the more serious of these pests has, in oomparatively recent years, been crystallized into the science known as medical entomology and through much of the widely advertised work pertaining to certain forms the public has come to realize, as never before, the importance of recognizing and controlling insects which were formerly tolerated.

\section{The Housefly*}

It is certainly safe to say that no insect is so well known as the housefly. It is present in every part of the world inhabited by civilized man and in most parts of the world which are capable of sustaining life at all. While it has always received recognition as a nuisance and a more or less filthy and repulsive object it is only recently that it has been recognized as an actual menace to the health of any community. The feeding habits of the adult render it particularly dangerous in the carrying of disease germs. It feeds alike on foods prepared for the table of man and on the vilest forms of animal waste, excrement, sputum, pus and any sort of decaying material. Most of these food materials of the fly are particularly adapted for the propagation of bacteria and many of such bacteria are disease-causing forms which may be infective when takien with the food. It is for this reason that the fly is particularly liable to be the agent for the transmission of typhoid fever and other diseases which affect the digestive tract. It is also quite capable of transmitting tuberculosis and

* Musca domestica Linn. Family Muscide. See bulletins from the U.S. Dept. of Agr., and the State Experiment Stations. Titles too numerous to be listed. 
is an object of suspicion in connection with any infectious disease. The structure of the adult fly and its habits make it more adaptable to the transmission of germ infections than any other insect. It has hairs and bristles on mouth-parts and feet which pick up filth or other matter. Secretions from the mouth parts aid in the infection.

Possibly the greatest danger of infection from flies is through the milk supply, even though they frequent most other foods. Milk is an attractive food for

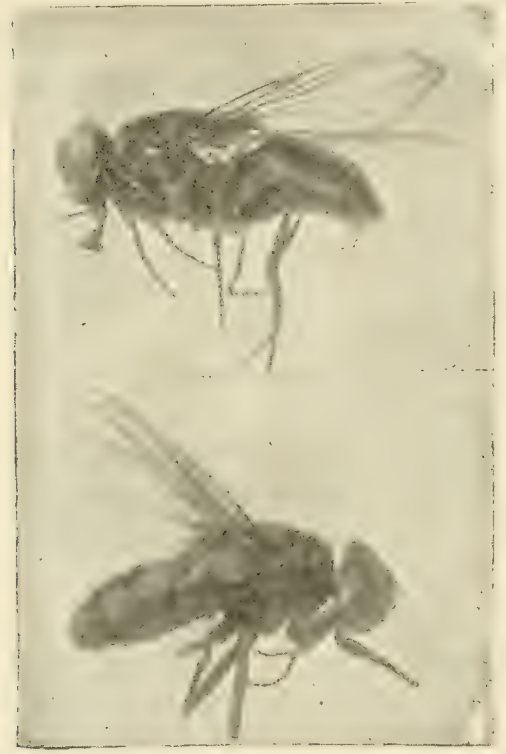

Fig. 546.-Housefly above, the stablefly below, showing difference in mouth parts.

probably also in the adult stage. flies and is also a very good culture medium for bacteria so that infection in milk is likely to develop more rapidly than in other foods. And flies, when they are permitted to be, are always more numerous about dairies and meat-markets than elsewhere. However, it is not necessary here to build up a case against the fly. The foregoing remarks will serve merely as a reminder of what is already well-known.

The fly breeds by preference in horse manure but will also breed in other kinds of manure, in many kinds of filth and garbage and even in human excrement. It winters in the larval and pupa stages and There are many overlapping generations in the year, those late in the season being much larger than the early ones because of the heavy mortality during the winter months. The adults need no description. They are similar to the stable-fly but differences in their mouth-parts illustrated in the accompanying figure will readily, separate them.

It will be seen that the mouth-parts of the housefly are such that it is unable to bite or puncture the skin. At times the house- 
flies seem to be biting. This is due to the fact, that under some weather conditions the stable flies scek shelter in the houses and they, with their piercing mouth-parts, do the biting generally attributed to the housefly.

Larvae of houseflies are white maggots of the ordinary form. They are, when grown about threeeighths inch in length and may be found in the breeding places mentioned. When ready to pupate they frequently leave the breeding material and travel some distance in search of suitable places in which to pass the pupal stage. This habit has been utilized in control measures as at that time they can be trapped.*

The pupae are found in the soil or under rubbish. They are brown, regular-oval objects, one-fourth FIG. 547.-Larvae of the housefly. inch in length and will not be readily distinguished from those of several other species.

Control.-Housefly control is accomplished in several ways. The principal ones are abolition of breeding places and trapping of adults and larvae. Abolition of breeding places is done by protecting all material in which they may breed by screening or otherwise
Fig. 548.-Pupae of the

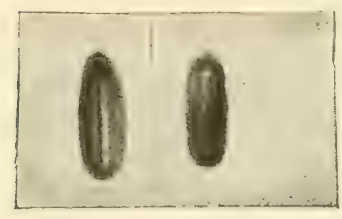
housefly.

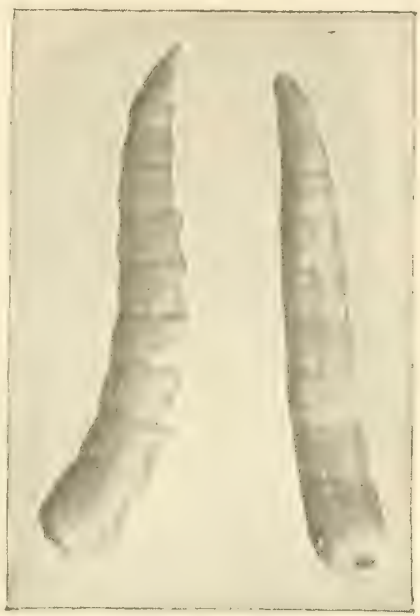

covering it until it may be destroyed. Fly-tight manure and garbage receptacles are widely used for this purpose. Garbages destroyed as promptly as possible and manure is distributed over the fields so that it will dry out and be no longer a suitable breeding material. If the screened receptacles of this type be further provided with flytraps, so that they will serve to attract and capture the adult flies which would otherwise have deposited their eggs in them or fed there, they will serve a double purpose.

* See E. N. Cory, Bulletin 213, Mil. Agr. Exp. Sta. and R. H. Hutchinson, Bulletin 200, U. S. Dept. of Agr. 
Adult flies are trapped in a great number of different kinds of traps. The principles of construction and operation are so familar
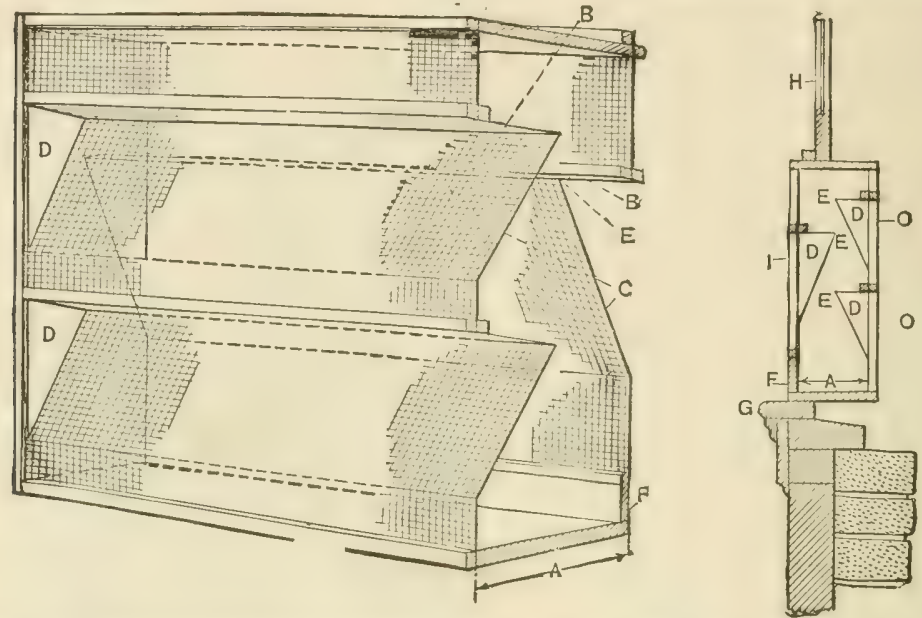

Fig. 549.-Hodge type window trap). At left trap with end removed to show construction. At right, cross section of trap placed in window. $A$. End of trap; $B$, upper side of folds in sereen; $C$, lower side of folds in screen; $D$, portion of end of trap sawed out and returned after attaching screen; $E$, holes along apex of folds; $F$, door for removing dead flies; $G$, window sill; $H$, upper window sash; $I$, inside entrance for flies; $O$, outside entrance for flies. (After Bishopp, U. S. Dept. of Agr.)

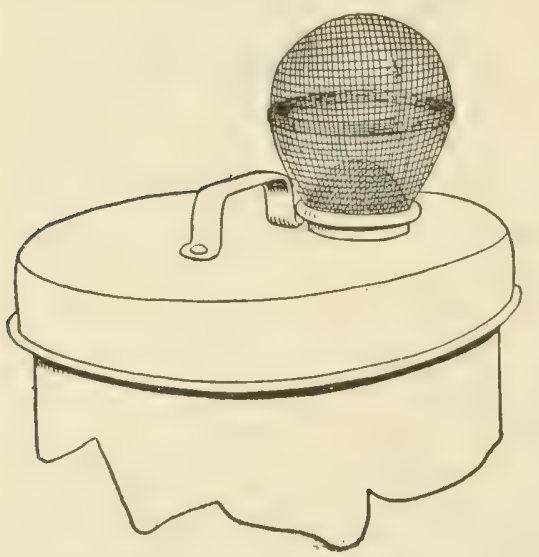

Fig. 550.-Top of garbage can with Hodge trap attached. (After Bishopp, U.S. Dept. of Agr.)

stroyed. The construction is simp!e. lined with cement so that it will hold as not to need description. One is pictured below for use in windows of dwellings and stables, and others for different situations.

Trapping of maggots is based upon the habit of $\mathrm{mi}$ grating from the feeding place just before pupating. Practical traps are designed rather to capture the larvae breeding in manure than elsewhere since manure is the only breeding material that can not, and should not, be immediately deA shallow pit is dug and water. Over this, about a 
foot from the bottom, a slatted platform is constructed, the platform being a little smaller in area than the pit. On this platform the manure is stored. The manure should be kept wet. This may be accomplished by pumping or sprinkling water over the surface daily. This process also keeps water in the pit. When the larvae migrate they fall into the pit and are drowned. Experiments have shown that from 95 to 99 per-cent of all the larvae can be destroyed in this way. After about ten days the manure is no longer suitable as a breeding place

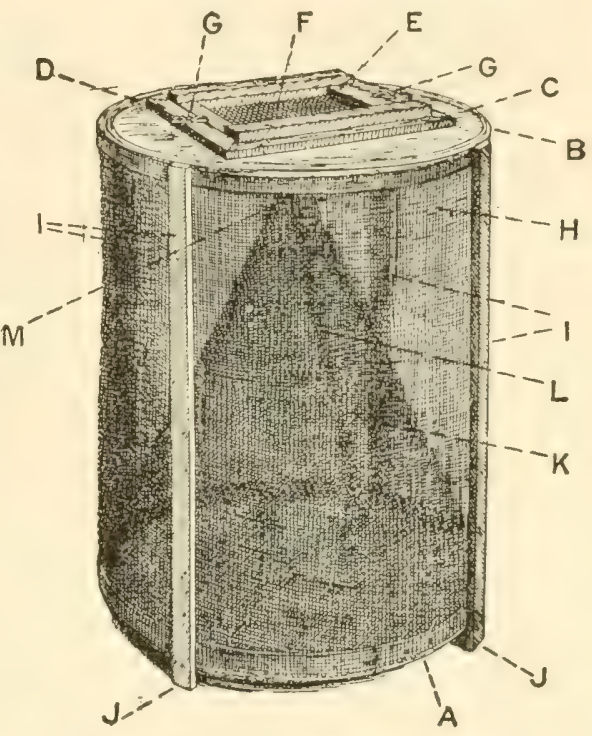
and it may he removed to make room for more.

Fra. 551.-Conical hoop fly trap. (After Bishopp, U. S. Dept. of Agr.)

Details may be secured Irom the publications cited.

Larvae are sometimes poisoned in their breeding places by treating the manure with powdered borax or hellebore, dry or in

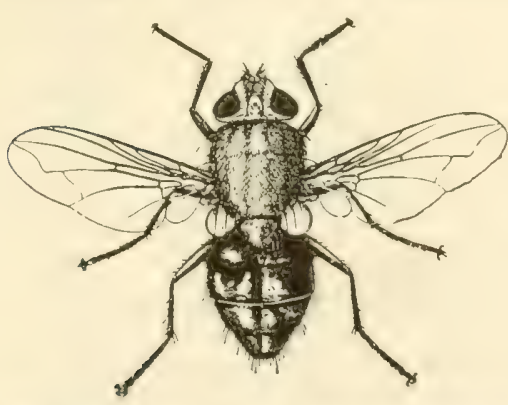

Fic. 552.-One of the green-bottle flies (Lucitia caesar). Mi u h enlarged. Howard, U. S. Dept. of Agr. water. About one pound of borax to 16 cubic feet is the strength required, whileslightly less hellebore will give good results. Careless handling of the borax, resulting in the uneven distribution or the use of too much may result in injury to plants fertilized with the manure.

In addition to the above methods we have the time honored fly-papers, fly-killers, window-sereens and poisons for the adult flies. These can, at best, give only partial relief. 
Cleanliness about the house and premises generally will result in much benefit as flies are attracted to dirty places by the sense of smell.

Other flies are found about the house. Among these, the

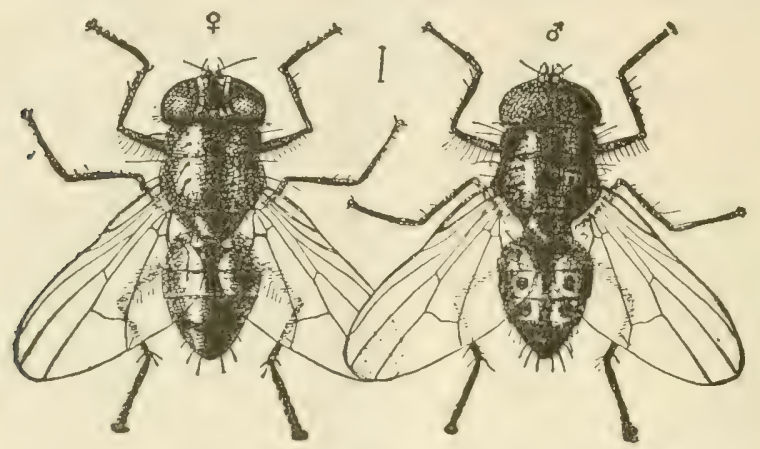

FIG. 553.-A "little house fly" (Fannia brevis): Female at left, male at right Much enlarged. After Howard, U. S. Dept. of Agr.

stable-fly has been mentioned. The blue and green bottle flies are well known and are the usual source of maggots in meat. Some of the flesh-flies also produce maggots in meat when they

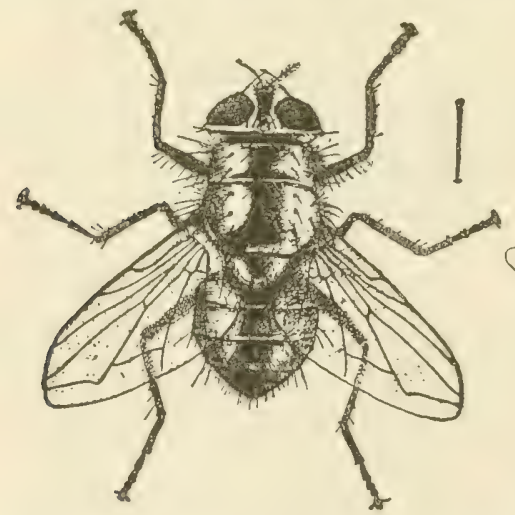

Fig. 554.-The cluster-fly, Pollenia rudis Fab. After Ḧoward.
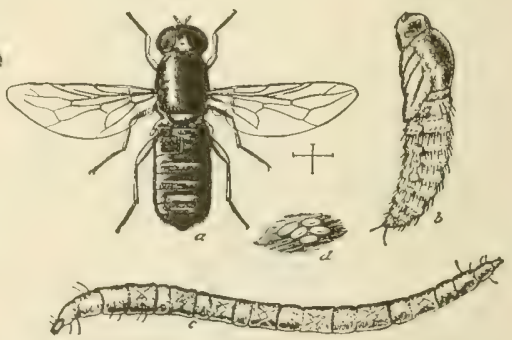

have opportunity. Some flies of other species frequent houses but are harmless. A few of these are illustrated. 


\section{Mosquitoes *}

Mosquitoes, like house flies, have long been known as nuisances, almost intolerable in certain locations, but it is only within the last quarter of a century that their disease-carrying possibilities became known. It has been determined in that time that they are the sole means of the transmission of malarial fever and of yellow fever from man to man, that they transmit also certain tropical diseases, and that there are strong probabilities of their being implicated in the transmission of other diseases.

Malarial fever is transmitted

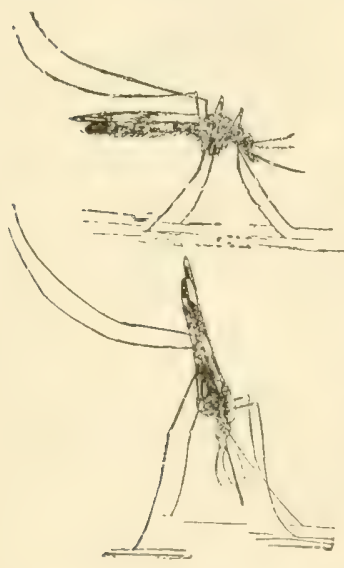

FIG. 557.-Distinction between malirial and other mosquitoes. Resting position of Culex above and Anopheles below. After Howard, U. S. Dept. of Agr.

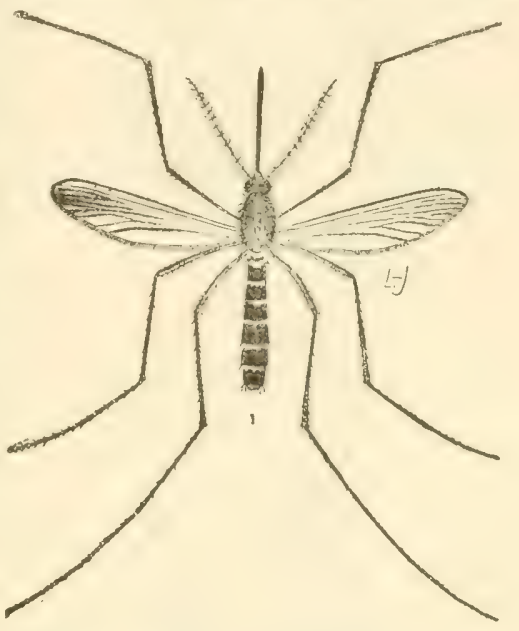

Fig. 556.-The house mosquito; Culex pipiens. After J. B. Smith, New Jersey Agr. Expt. Sta.

by mosquitoes belonging to the genus Anopheles, of which there are several different species. It is caused by a minute one-celled animal of the lowest type, which resembles in many ways the bacteria, but is entirely distinct from them. This organism spends a part of its cycle of development in the body of the mosquito and a part in the blood of man. Taken from man in the blood sucked up by the mosquito, it develops within the body of the mosquito, then makes its way to the salivary glands of the mosquito and is injected into the blood of the victims of the mosquito when it bites.

* Family Culiculae. See numerous publications, those of Dr. J. B. Smith, from the New Jersey Exp. Sta., and of Dr. L. O. Howard of the Bureau of Entomology, U. S. Dept. of Agr., being most extensive. 
The organism causing yellow fever is not known, but it is known by absolutely conclusive experimental evidence which has been demonstrated on a large scale, that a mosquito, (A edes calopus) is the sole means of the transmission of the disease from a yellow fever patient to a healthy person. Soon after this was proven it was demonstrater. The city of Havana and the Panama Canal Zone, long centers of infection for the fever, were, by a vigorous campaign, freed from mosquitoes. Yellow fever, never known to

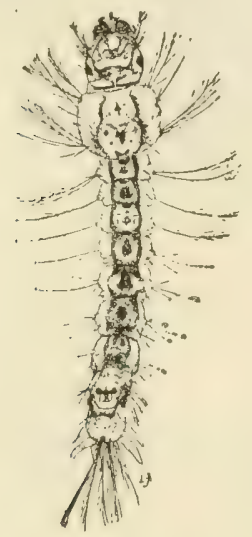

Fig. 558.-Dorsal view of the larva of a malarial mosquito, Anopheles. After Smith, New Jersey Agr. Expt. Sta.

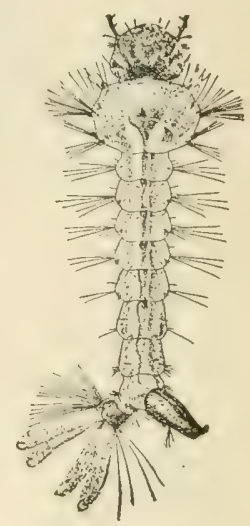

Fig. 559. - The yellow-fever mosquito; larva. Much enlarged. After Howard, U.S. Dept. of Agr.

be absent in those regions, was thereafter almost unknown. Other cities have since followed these examples and the control of the once dreaded disease is merely a matter of thoroughness in ridding the localities of mosquitoes. Similar measures result in the lessening or disappearance of malaria.

Mosquitoes breed in water, usually stagnant. The larvae are the common wrigglers which used to be summer residents of every rain-barrel. The pupae are sufficiently illustrated in the illustrations, so they need no description.

Many species of mosquitoes are not known to carry diseases but are of extreme importance since, on account of their biting habits and tremendous numbers, they render large tracts of country 
almost uninhabitable and in other distriots, ereatly resluce the
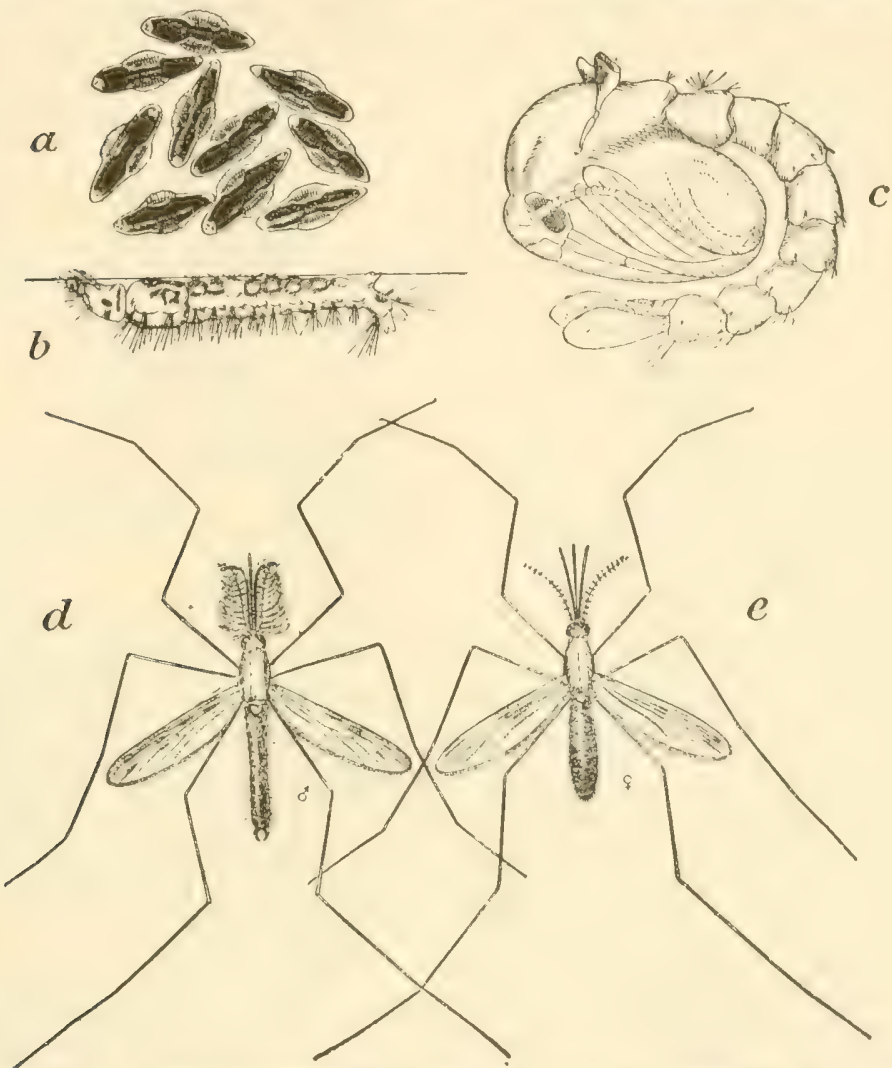

Frg. 560.-A malaria mosquito: $a$, eggs; $b$, larva; $c$, pupa; $d$, male adult; $e$, female adult. After Howard, U. S. Dept. of Agr.

vitality of the people. Real estate values in such districts are, of course, far below the normal. Two important species,

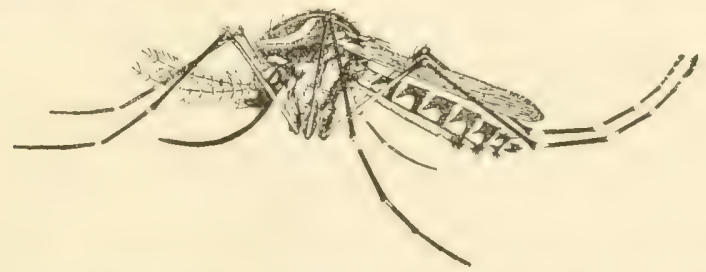

Fig. 561.-The yellow-fever mosquito; adult female, side view. Much enlarged. After Howard, U. S. Dept. of Agr. 
both of which we illustrate, are the House Mosquito (Culex pipiens), and the Salt-Marsh Mosquito (Culex sollicitans).

Mosquito control is based upon the breeding habits. Eggs,

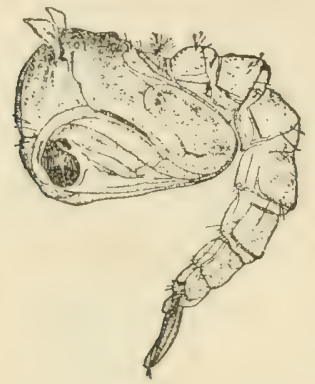

Fig. 562.-The yellow-fever mosquito: pupa. Much enlarged. After Howard, U. S. Dept. of Agr.

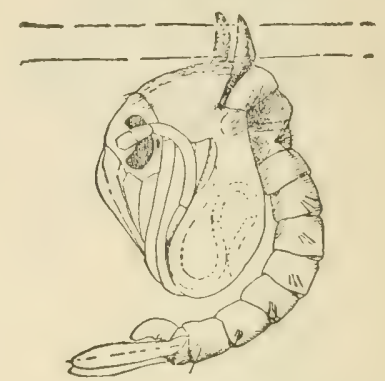

Fig. 563.-Culex pupa. After L. O. Howard, U. S. Dept. of Agr.

larvae and pupae are found in the water. If stagnant water is removed from a locality the mosquitoes will go. If it is removed in part, the mosquito plague will be lessened. If it is rendered unfit for the mosquito in any way the effect will be the same. Control measures, therefore, include drainage of swamps, ponds, pools and other standing water where possible; the oiling of standing water that can not be drained away, since a film of oil on the surface of the water destroys all stages of the mosquitoes in the water and effectively prevents breeding so long as it remains; treating water with chemicals to destroy young of the mosquito;

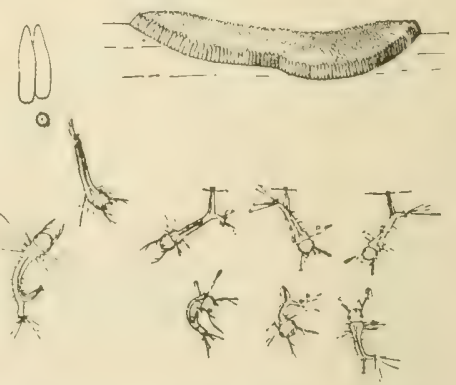

FIg. 564.-A mosquito egg-boat and larvae just hatched (Culex). From Howard, U. S. Dept. of Agr stocking sluggish streams and artificial lakes with species of fish which feed on mosquito larvae and pupae. Of these the most effective method is cirainage. To be thoroughly effective it must take into account not only large bodies of water but also the water which may stand in sewers, old cans in a back yard, stopped-up 
drain-pipes on houses and, in fact, any standing water which

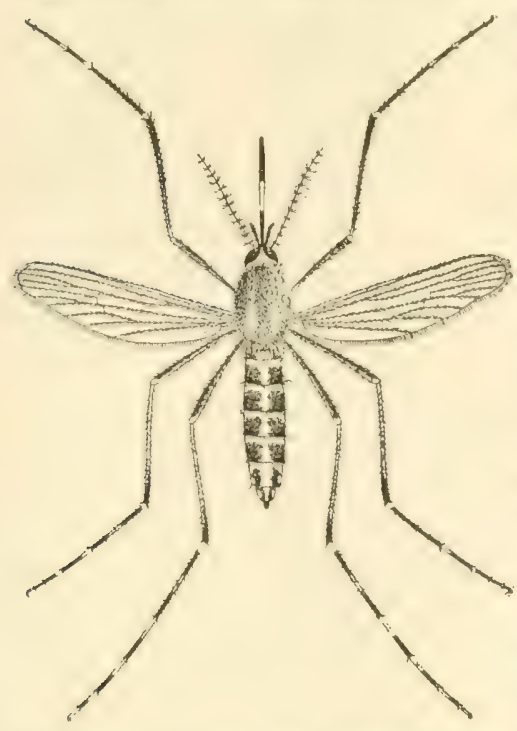

Fic. 565.-Culex sollicitans. (After Sinith, Report on MIoscquitoes of New Jersey). will remain for as much as a week. It is usually necessary to supplement drainage with oiling.

In several states expensive drainage operations have reclaimed thousands of acres of land which was useless. These operations are usually under state direction and at state expense, at least in part.

The use of chemicals in the water is still in the experimental stage.

Mosquitoes, in the north, usually winter as adults. There are several generations in a season, a generation requiring in warm weather less than two weeks and in cooler weather somewhat longer.

The accompanying illustrations will take the place of descriptions.

\section{Fleas*}

The flea is a third insect which has, within the very recent past been transferred from the list of innocuous pests and placed with the dangerous insect enemies of man. While it is true that some common species have not yet been proven to be specific bearers of disease it is now known that one, the rat-flea (Xenopsylla cheopsis) has been pretty definitely proven to be the usual, if not the only, mosns of transmission of the plague or bubonic ferer. This fact puts all fleas under suspicion and makes them even less tolerable under eivilized conditions than before.

Fleas that affect man, in the more enlightened portions of the world, are more or less accidental visitors from domestic animals, usually cats and dogs. There are several species, the more important being the human flea (Pulex irritans), and the cat and

\footnotetext{
* Order Siphonaptera.
} 
dog-flea, (Ctenocephalus canis). These breed in accumulations of organic matter in protected places where there is some moisture. This may be in cracks and crevices in the floor of a dwelling, in dirt floors of basement rooms, or in the soil under buildings where the animals are allowed to go. The larvae are like slender maggots and are rather inactive. The length of the life cycle is quite variable, ranging from less than three weeks to several months. Adult fleas attack animals of many kinds, including man. Some
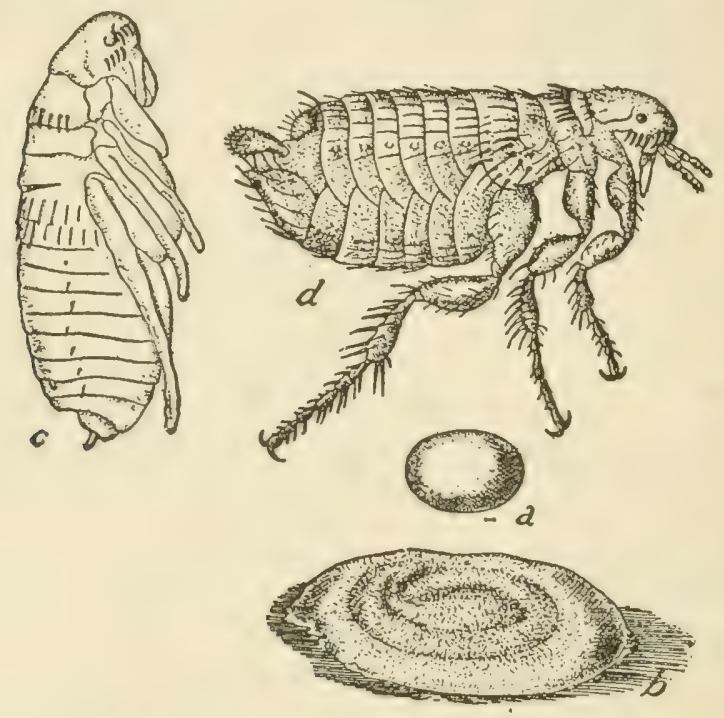

FIG, 566.-The dog flen: $a$, egg; $b$, larva in cocoon; $c$, pupa; $d$, adult; $b, c, d$, much enlarged; $a$, more enlarged. U. S. Dept. of Agr.

forms attack poultry and one of the most important members of the group is the chicken sticktight flea, diseussed later.

Domestic fleas are controlled by lilling the adults and by eliminating breeding places. They may be killed on animals by the use of some of the insecticide soaps, of which there are many on the market, or by the use of some stock-dip composed of the coal-tar derivatives such as creolin, in water. All the fleas must be thoroughly wet with the mixture. Kerosene emulsion at a strength of about one to fifteen may be substituter, care being taken to have the oil all emulsified. Napthalene powder 
dusted into the hair will cause the fleas to drop off. If the animal be held over white paper the stupefied fleas falling on the paper can easily be caught and killed.

Fleas in breeding places may be killed by treating with gasoline or kerosene, if where such substances can be used safely. Under permanent carpets the only remedy is to remove and thoroughly clean the carpets and to treat the floors with strong soapsuds or gasoline. Movable rugs are much better from the standpoint of flea control than carpets. It is probable that where a vacuum cleaner is used frequently little trouble $w$ ill be experienced with fleas. When fleas are breeding out of doors all the rubbish should be cleaned off the ground and the soil soaked with salt water.

Control of the rat flea involves destruction of rats and

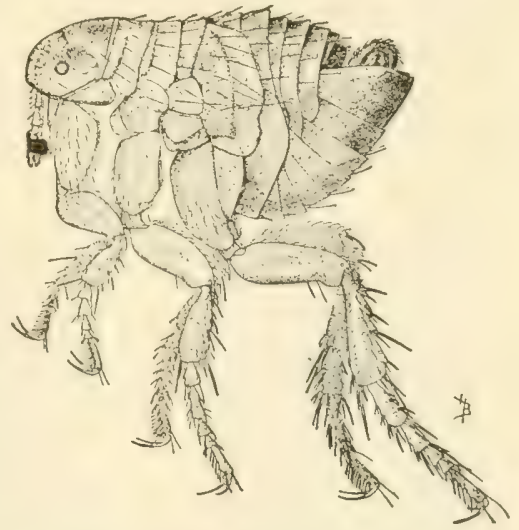

Fig. 567.-The human flea: adult male. Greatly enlarged. After Bishopp U. S. Dept. of Agr.

this is done in cities as a community proposition. In seaports such as San Francisco and New Orleans, where bubonic plague sometimes appears this is more important than elsewhere. At the same time modern civilization has proscribed the rat and it should be destroyed for other reasons.

Further details in the treatment of fleas may be obtained from Farmers' Bulletin 897, U. S. Department of Agriculture, "Fleas and Their Control," by F. C. Bishopp.

\section{Bedbugs *}

The bedbug has not yet been proven guilty of transmitting any definite disease of importance in this country. It is under suspicion because its habits give it the opportunity to carry many different kinds of disease. This it undoubtedly does, in the role of a simple carrier, if not as a direct inoculator.

The bedbug is a small, flattened, brownish insect which may

*Cimex lectularius, Linn. Family Cimicida (Acanthiido). 
reach the length of one fourth inch. It lives in the habitations of man, especially in old or poorly kept houses where it has plenty of cracks and crevices in which to hicle or where it is little disturbed by the housckeeping process. The eggs are deposited in secluded places and the young resemble the adults. They feed to some extent on mice and on domestic animals and in addition can exist for long periods without food as they are often found in houses which have been vacant for months.

Control is a matter of eliminating all hiding places possible and treating the others with benzine, kerosene, carbolic acid or

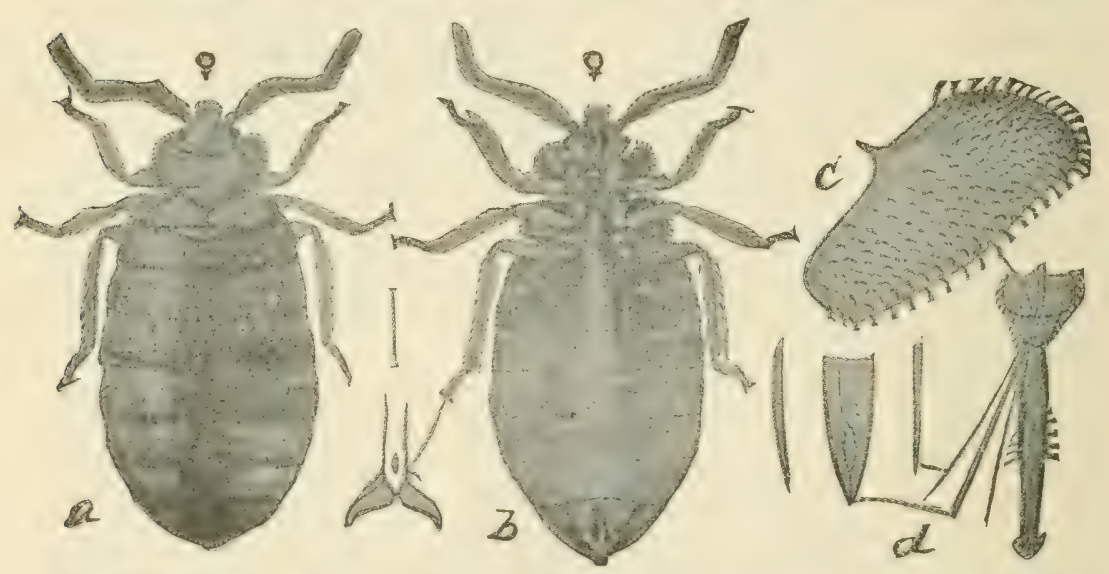

Fig. 568.-Bedlbug: $a$, and $b$, adult females from above and below, gorged blood; $c$, and d, struetural details. (After Marlatt, U. S. Dept. of Agr., Ent. Bul. 4, n. s. 1896.)

other substances and repeating the treatment until all signs of the bugs disappear. Fumigation and heating, to $120^{\circ}$ or higher are effective when practical.

\section{Lice *}

Lice are the most disgusting of the human parasites and are no longer common among enlightened peoples except in situations where the ordinary sanitary precautions can not be observed The louse, or "cootie" of the armies in the war is an example of extraordinary development of a species under unusual con-

*Pediculida. Order Siphunculata. 
ditions. Lice are more commonly found in camps and among children in poor surroundings.

There are three common species: The head-louse (Pediculis capitis), the body-louse (Pediculus restmenti), and the pubic louse (Phthirius inguinalis)

The body louse is the "cootie" of the "A. F. F." or the "grayback" of the lumber camps. It attaches itself to clothing, concealing itself in seams where the eggs are laid. From there it makes its way to the body only to feed. The head louse spends its entire life in the hair on the head, attaching its eggs or "nits" to the hairs.

Head lice may be killed by the use of hair-oils or other oil which will not injure the hair or skin. Clipping the hair is the best remedy for children. Body lice require treatment of the body and of the clothing. Clothing should be steamed or fumigated and underclothing boiled. Oils or sulphur ointment or "blue ointment" will kill the lice on the body. Oils were very largely used in the "de-lousing stations" among the allied armies in France. A very effective remedy is to sponge the entire body with a solution of bi-chloride of mercury, 1 to 1000, washing the body a few minutes later. This will kill all stages in one thorough application. It is applicable for all species but is not so desirable for use on the head louse.

\section{Chiggers *}

These pests will need little description for those readers who live in the South and the Central States, at least the effect of them will be familiar to all in those regions where they are the bane of the barefoot youngsters on the farm and are at times troublesome to adults. They are minute mites, probably of different species, which live normally on certain weeds and are especially abundant in berry plantings or among wild berry vines. When they are jarrei off onto the skin they immediately hurrow and later become engorged with blood, causing intense itching and local swellings. This feeding habit is not normal for them and the mites die, but only after the damage is done.

* Order Acarina, Class Arachnida. 
Susceptible persons should avoid places where the mites or chiggers are known to be numerous or, if compelled to visit such places may prevent ill effects by bathing in strong soapy water to which some salt has been added. If this is done within a few hours, no inconvenience will be noticed. After the injury has appeared, the irritation may be allayed by use of ammonia or soda. Sulphur dusted into the clothes will prevent attack by the mites.

The season for the mites is mid-summer to early autumn.

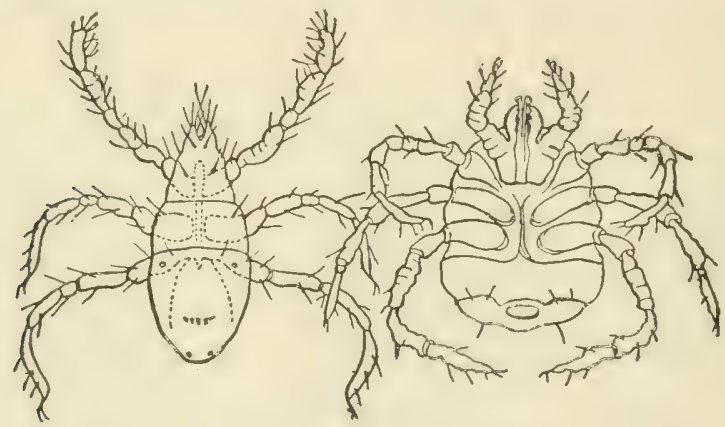

Fig. 569.-Common "Chiggers". Leptus americanus at left ; Leptus irritans at right. Highly magnified, dots under anal extremity indicating nat ural size. (After Riley), U. S. Dept. of Agr.

\section{Roaches *}

The roaches which infest the house are of several kinds, but all are alike in their habits and similar in their mode of derelopment. They injure food not so much by feeding upon it, although they will eat almost anything, as by running over it and making it unfit for human consumption.

Roaches hide during the daytime in cracks and crevices, under floors, behind baseboards, around water pipes and wherever they can escape observation. In these places they lay their eggs, which are produced in relatively large, bean-shaped capsules which are carried for some time projecting from the abdomen of the females. The young develop slowly, months being sometimes required and often the eggs do not hatch for long periods.

* Family Blattida. 
For this reason control measures must be kept up persistently so as to kill newly hatched young as they appear from time to time

Roaches may be killed with poisons or by fumigating or they may be trapped. A trap deseribed by Mr. C. I. Marlatt, of the Bureau of Entomology, is the acme of simplicity. It consists

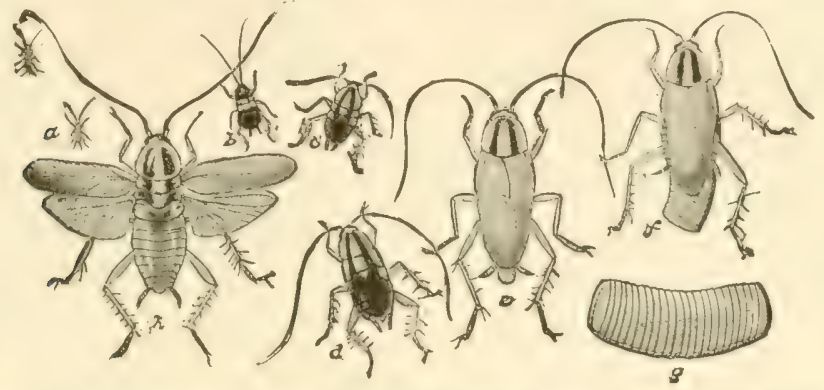

Fig. 570.-The Germin roich (Blattella germanica): $a$, first stage; $b$, second stage; e, third stage; d, fourth stage; e, arlult; f, adult female with egg case; $g$, egg case, enlarged; $h$, adult with wings spread. All natural size except $g$. (From Riley, U. S. Dept. of Agr.)

of an ordinary breadpan with the sides greased with rancid butter. The butter acts as a bait and the roaches fall into the pan and are unable to climb up the greased sides and escape.

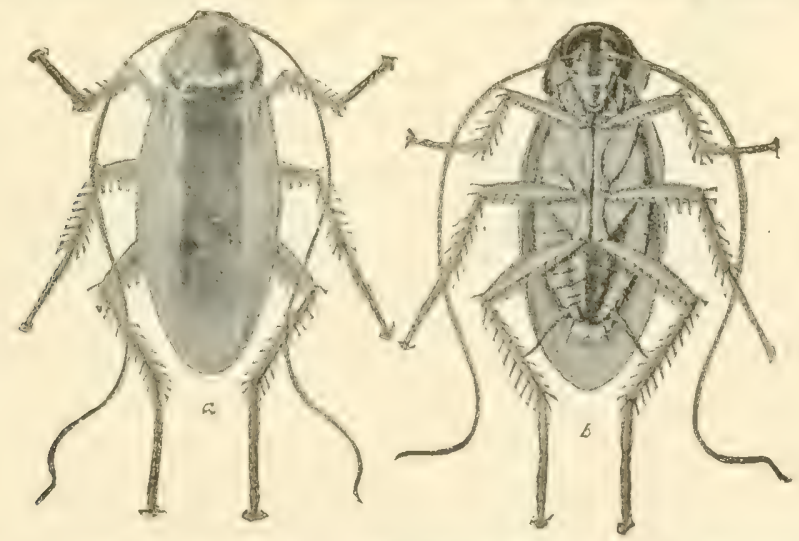

Fta. 571.-The American roich (Periplancta americana): $a$, view from above; $b$, from beneath. Both enlarged one-third. After Marlatt, U. S. Dept. of Agr.

Roaches may be poisoned with chocolate mixed with borax, ahout equal parts being used. Plaster of paris mixed with flour or with chocolite has also been recommended. Sodium fluoride 
is the best standard poison and repellant. If this be dusted in all craclis and hiding places every few days and the treatment be kept up for several weeks, the roaches will be entirely killed or driven away. All control measures available should be put into use at the very first sign of roaches on the premises. If this is done no heavy infestation can occur.

The common roaches belong to four spccies. The Oriental Cockroach (Blatta orientalis L.) is of European or Asiatic origin. The German Roach (Blatella germanica L.), was also introduced from Europe while the Australian Roach (Periplaneta australasia Fabr.), comes to us from Australia. The fourth species is the American Roach (Periplaneta americana L.), the largest species and a native one. No essential cifference in their habits is to be noted.

\section{House Ants *}

Ants of several species have been troublesome pests of man as far back as history gives any records. They destroy food and

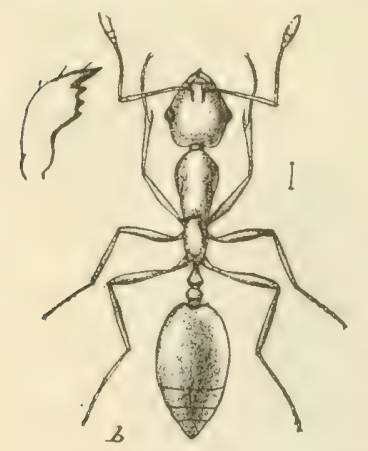
render it unfit for use and at times actually attack man. There are several species.

The Little Red Ant, (Monomorium pharaonis Linn.,) is the smallest species and perhaps the worst. It makes its nests under houses or in the ground nearby and is often difficult to get at.

The Little Black Ant, (Monomorium minimum Buckley,) is larger and darker in color, being about three-sixteenths of Fig. 572.-The Little Red an inch in length while the previous Ant. From Riley.

The black form generally makes its nests outsicle the house where they are more readily accessible.

The Argentine Ant (see page 631), has already been discussed. It is the most serious pest among the ants where it oceurs.

The Black Pavement Ant, (Tetramorium caspitum Linn.,) is much larger than the others, some inclividuals being nearly onehalf inch long. It is frequently found in houses but is never as numerous as the smaller species.

* Family Formicidae. 
Ants may be controlled by exposing poisoned syrup, made according to the directions given on bage bos, where they can hare easy aceess to it. The writer has tried this many times for different ants and they have invariably disappeared in a short time. This has been so satisfactory that it seems unnecessary to suggest anything else.

\section{The Carpet Beetle*}

The Carpet Beetle, the larra of which is commonly called the "Buffalo-Noth," injures carpets and other animal products or fabries. The adult is a small beetle one-eighth inch in length, of oval shape and dark or black color with lighter markings giving it a

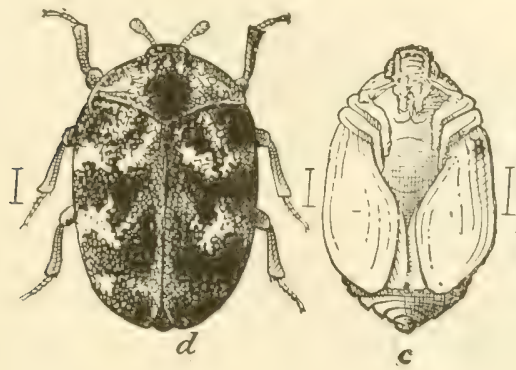

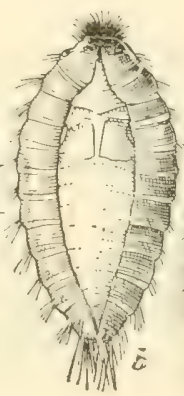

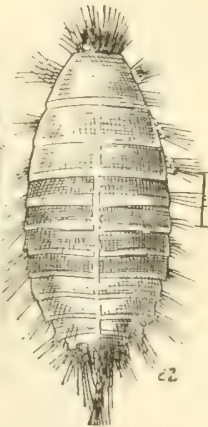

Fig. 573.-The Carpet Beetle. From Riley.

mottled effect. The larvae are thick, soft-bodied, hairy grubs found in and about the food matrials. Eggis are laid on the food and eggs, larvae and pupac will be found in or near the food while the adults leave the houses and fly to flowers at times.

A similar species, darker in color and without the light markings, is the Black Carpet Beetle (Attagenus piceus Oliv.).

Control measures consist in taking up earpets and rugs and beating and airing them. Thorough swepping of the floors followed by treatment of the cracks with asoline will kill the young which may be present. Fumigation or heating will be found to be effective. The substitution of rugs for earpets is advised. Where this is not desirable protection for the carpets can be secured hy placing building paper under them and dusting

* Anthrenus scrophularice L., Family Dermestide. 
or sprinkling the paper with alum, powdered or in solution. If the paper is not used the same protection will be secured by dusting powdered alum under the carpets. A vacuum cleaner is very effective in keeping out these insects.

\section{The Clothes Moths*}

The clothes moths are among the most annoying of household pests and the injury they do is considerable. They feed on woolens, feathers and fur and more rarely on other fabrics. There are three species, the Case-Making Moth (Tinea pelionella L.), being the most common while the Webling Clothes-Moth (Tinea biselliella Hummel), is common in some more southern localities

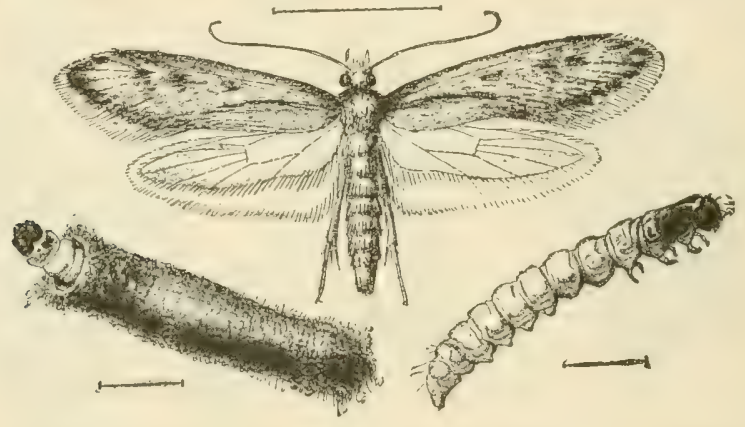

Frg. 574.-A clothes moth (Tinea pellionella). From Riley.

and a third, the Tapestry Moth (Tricophaga tapetzella L.), is rather rare and much larger and more striking in color than the commoner species. The common forms are minute yellowishwhite moths with faint darker markings. One species makes for itself small tube-like cases of the material upon which it is feerling and silk spun by itself. The other spins webs throughout its galleries but does not make eases. The larvae are very small whitish caterpillars. The casc-making moth has but one generation appearing in the spring while the other common species has a fall generation as well.

Small quantities of clothing may easily be protected by fumigating them in a trunk with carbon bisulphicle, observing the usual precautions. They may also be fumigated in a good tight clothes-closet, preferably in an unused room. Moth proof

*Famly Tincide. 
bags for the storage of woolen articles are of value. Cold storage is one of the safest forms of protection through the summer months. Any box which can be made practically air-tight will afford protection if the articles are uninfested when the boxes are closed.

We have found that storing in rooms where the temperature is unifurmly high, above 90 at all times, will afford as complete protection as the cold storage.

\section{Miscellaneous Household Insects}

The Silverfish or Fish-NIoth (Lepisma saccharalis or domestica) is an insect which sometimes defaces papers or gets into food materials but is not usually serious. The general belief is that they feed on starchy materials by preference but will feed on animal matter.

The House Centipede (Scutigera forceps), not an insect at all but a centipede, is a slender-bodied animal with many very long legs frequently seen running on walls and ceilings. It is not injurious, except to delicate nerves, as it feeds upon flies and other insects.

Book-lice (Corrodentia), are minute louse-like insects, almost colorless and just large enough to be seen, which run over old books and papers and sometimes may deface them slightly. They, however, do little damage and need not be feared.

White ants or Termites (Leucotermes flavipes), are ant-like insects which

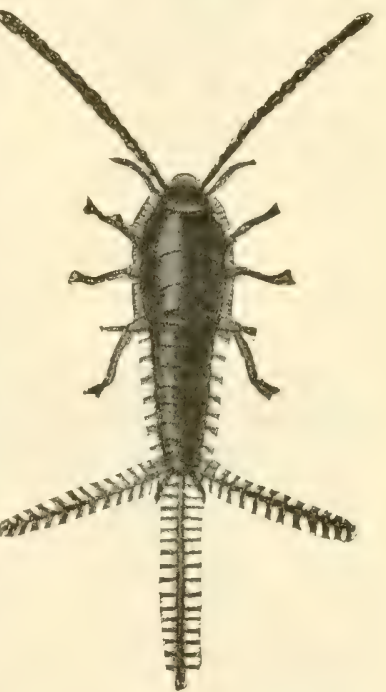

Fig. 575.-Adult silverfish, about two and one-fourth times natural size (Marlatt, U. S. Dept. of Agr.) sometimes do considerable injury by mining into the foundation timbers, floors and even walls of houses. They have been known to cause the collapse of large buildings and often necessitate replacing foundations and floors in the southern states. They injure plants also, injury having been noted on the orange, on plum and particularly on apple-seedlings in the middle-west. 
They live, like true ants, in colonies and have different kinds of individuals or castes.

Except for the black, winged males and females which may be seen emerging and flying from the nests for a few days in the

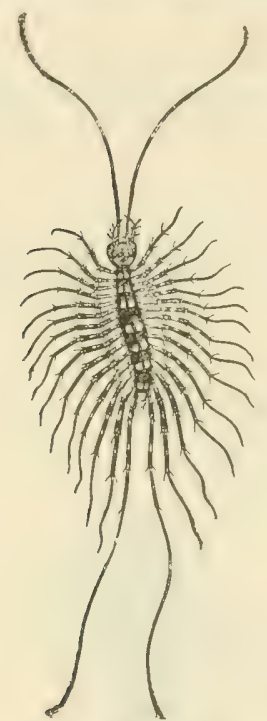

Fig. 576.-The house centipede (Scutigera forceps): Adult. Natural size. (After Marlatt, U.S.Dept. of Agr.)

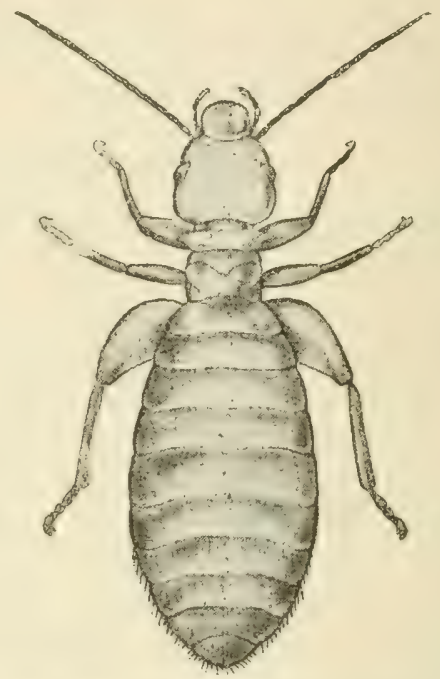

Fig. 577.-Adult book-louse, about fifty times natural size (After Back, U. S. Dept. of Agr.)

spring, they are soft-bodied, yellowish-white, wingless insects about one-fourth inch long. They normally live in decaying wood out of doors.

Control consists largely of prevention. Where they are prevalent it is well to use concrete for foundations or to treat timber to be used with creosote preparations of some kind.

The insects injurious to stored grains infest also many stored food products. For a complete discussion of these the reader is referred to Chapter $\mathrm{X}$. 


\section{CHAPTER XXIX.}

\section{INSECTS INJURIOUS TO DOMESTIC ANIMALS AND POULTRY}

Several of the insects listed as pests of man are also annoying or injurious to domestic animals. Among these the most important are the mosquitoes. House flies, although present in large number where there are animals, do not cause injury of a direct nature and do not annoy the animals particularly since they are unable to bite.

\section{The Stable Fly*}

The stable fly resembles very closely the house fly, the most easily noticeable difference being in the mouth parts, as shown in Fig. 546.

The habits of the stable fly are quite similar to those of the house fly also. The eggs are laid on straw or other material and the larvae develop on decaying vegetation of many kinds, usually in manure which contains a large amount of straw or in scattered or wet and decaying straw from the bottoms of stacks.

The adults bite, attacking many domestic animals, and are frequently the most annoying and numerous of the flies to be found on animals, usually being so in stables.

Stable fly control is secured in the same way as house fly control, by eliminating, so far as possible, the breeding places and by trapping the adult flies. The same means to accomplish

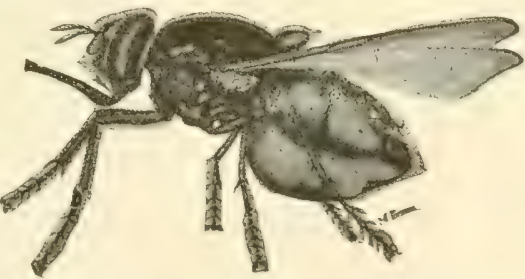

Fig. 578.-The stable fly: Adult female, side view, ('ngorged with blood. Greatly enlarged. (After Bishopp, U.S. Dept. of Agr.)

these ends are used as in case of the house fly, taking into account the slight differences in the breeding places. A fly cradication campaign should make no difference in the species but destroy all flies possible. Control measures may be supplemented by protection of animals. This may be done by screening windows of stables

* Stomoxys calcitrans L. Family Muscider. See F. C. Bishopp, Farmers' Bulletin 540. 
or by darkening the stables. It is accomplished to some extent by the use of fly nets, most of which are of little use, or other covers for the animals. It is also accomplished by the use of repellant substances sprayed on the animals, but this process usually affords only temporary relief and is troublesome and expensive. Proper care of straw to prevent its becoming scattered, wet and rotten, will prevent breeding to a large extent. On the whole, the best control will be secured by the use of fly-traps in the stable windows and the disposal of such wastes as may furnish breeding places as promptly as conditions permit.

\section{The Horn Fly *}

In appearance the horn fly is very much like a small house fly but its mouth parts are similar to those of the stable fly and are
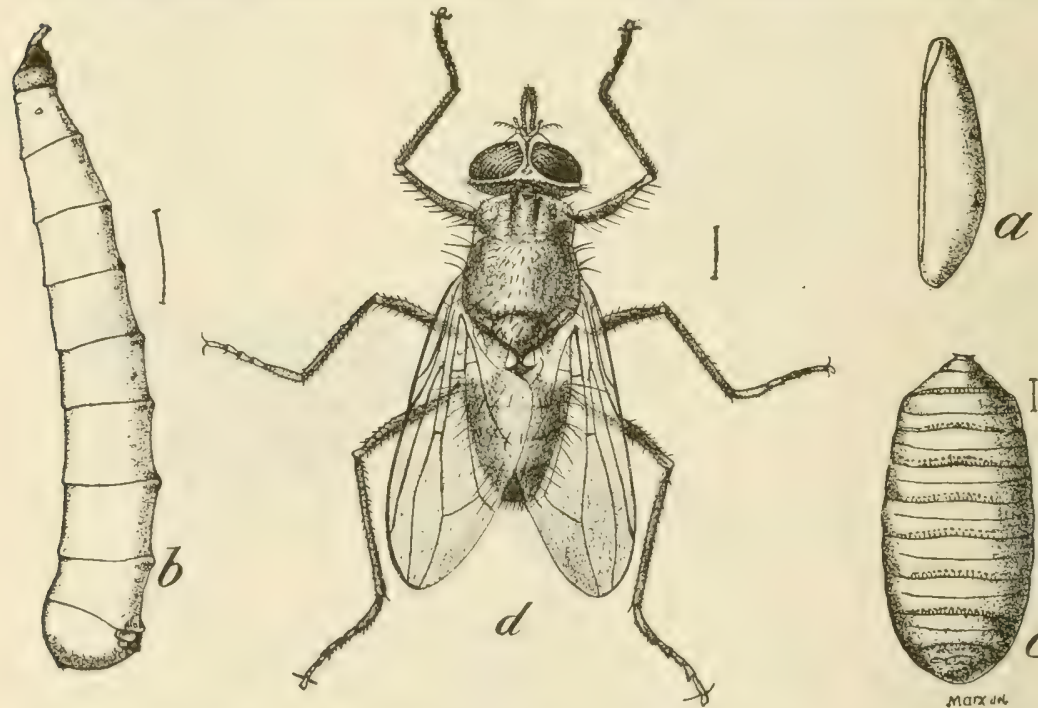

FIG. 579.-The Horn fly: $a$, egg; $b$, larva; $c$, pupa; $d$, adult. (After Marlatt, U. S. Dept. of Agr.)

used to good effect to the same purpose. It attacks cattle for the most part and is found clustered in large numbers about the horns, on the shoulders and flanks of cattle in pasture all through the summer. It is possibly the most annoying of the flies, attacking cattle, and is certainly responsible for loss of weight and reduction in the milk flow so noticealle in the fly season.

*Haematobia serrata R.-D. Family Muscida. 
The hom fly was brought from Europe some fifty years ago and has spread over the greater part of this country. It is more difficult to suggest control measures for it than for the other species since it breeds in the droppings from animals in the pastures. If these can be spread out so that they will dry quickly, no flies can develop, but it is seldom that conditions will permit this. Sheltering cattle during the heat of the day and providing plenty of shade and water in the pastures will alleviate the discomfort of the animals. Provide brush patches through which the cattle may pass to brush off flies that they can remove in no other way. Repellents, as for the stable fly, while they may be somewhat effective will rarely be practical.

\section{Horse Flies*}

Several kinds of flies, ranging in size from that of the house fly
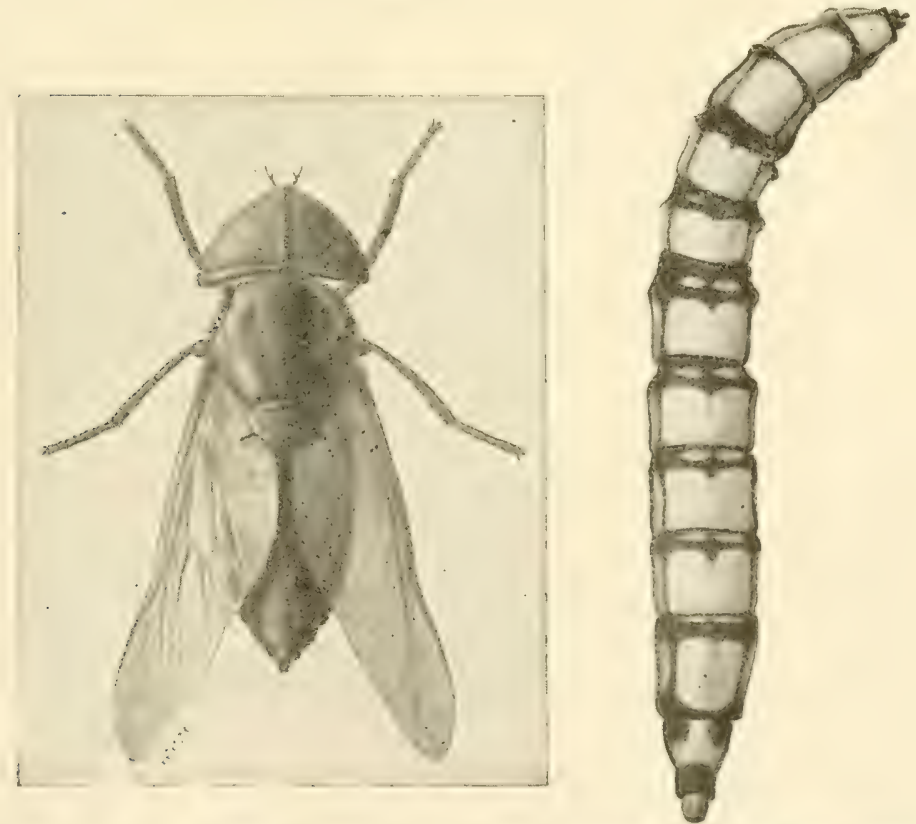

Fig. 580.-The Black Horse Fly. (After Garman, Ky. Agr. Exp. Sta.)

to more than an inch in length are common pests of horses and cattle and, upon occasion, attack man. The more familiar kinds

* Family Tabanida. 
are the large Black Horse Fly (Tabanus atratus Fab.), which is the largest form commonly seen and particularly abundant in wooded sections where its vicious biting and bullet-like flight make it quite conspicuous; a slightly smaller grayish-brown somewhat striped species is nearly as large and is found on cattle more frequently than is the preceding; and the several smaller kinds with green eyes, suggesting the common name Greenheads, (Tabanus lineola Fab. is one), which attack by preference the ears of horses and do not hesitate to attack man.

Larvae of horse flies are cylindrical maggots, pointed at both ends, which live in ponds and marshes.

Little can be done to eliminate the horse flies, or gad-flies as they are sometimes called. Fly-nets, with ear-nets attached are much more useful for these than for the smaller flies which attack animals.

\section{The Screw Worm Fly *}

In the southwest an important insect pest of livestock, par. ticularly range animals, is a maggot or screw-worm, the larva of a fly intermediate in size and appearance between the common house and stable flies and the green-bottle flies. The distribution of the insect includes the territory from the lakes to the gulf, but it is a serious problem only in the South and Southwest.

The injury is the result of the work of the larvae in the flesh of the infested animals. Eggs are deposited by the adults in wounds or often even on exposed mucous membranes. The larvae upon hatching burrow in the flesh and cause inflammation and mechanical injury followed by infection and the sores refuse to heal without treatment. Wire-cut animals, saddle-galled horses, and range cattle at the time of calving, offer conditions suitable to attract these flies. Injury to man is not uncommon, the eggs being usually deposited in the nostrils during sleep and the larvae working their way up into the nasal passages. Children are the most frequent sufferers.

The extent of the injury in the infested regions is hard to estimate but it is certainly great. The flies breed in decaying animal matter as a rule, the infestation of living animals being only an occasional habit for the species.

- Chrysomyia macellaria Fabr. Family Muscida. See Bishopp, Mitchell and Parman, Farmers' Bulletin 857, U. S. Dept. of Agr. 
Control is difficult, but partial control at least is not impossible. Since the great majority of the flies mature in carcasses of dead animals the proper disposal of these is of greatest importance. Burning is the approved method. If this can not be done they should be buried. If they can be covered with lime before the soil is thrown on them it will give better results. Elimination of points of infestation by prevention of wounds, destruction of ticks, since the tick wounds are points of entrance into the animals, and the arrangement of the calving season so that the calves will be produced when the flies are not present, will lessen the losses.

Treatment of wounds already infested involves the use of chloroform to kill the maggots and the use of a good repellent substance on the wounds to keep away flies. Pine tar is recommended as a satisfactory repellent.

Maggots from several other species of flies sometimes are found in wounds but they exhibit a preference for wounds showing infection and having some morbid flesh in them. Most any of the meat-infesting maggots may be found in such wounds. A species of particular importance is the Black Blowfly (Phormia regina Meig.), which oviposits in soiled wool of sheep. The larvae feed in the soiled wool and later, after the skin becomes irritated and sore, enter the flesh. Sanitary measures and the control measures advocated for the screw-worm will be effective for this fly.

\section{The Horse Bots*}

Horse bots are of three kinds, one of which is of rather restricted range. The common horse bot (Gastrophilus intestinalis DeGeer) is most abundant over the entire country. The Chin fly or throatbot (G. nasalis), is also rather common and widely distributed. The third species, the nose-fly (G. hamorrhoidatis), is found only in the North Central states and those to the west of that group).

Bot flies vary a little in size and general appearance, but all resemble bees to some extent. The common bot-fly is seen in late summer laying its eggs on the horses. It looks like a bee with a long slender abdomen which is doubled forward beneath the rest of the body and between the fore legs. The throat-bot is smaller and more hairy but otherwise similar.

* Family Oestrider. See W. E. Dove, Bulletin 597, U. S. Dept. of Agr. 
Eggs of the common bot fly are small, oval, yellow objects commonly called nits, and attached to hairs on the fore-quarters of the horse. The horse licks them off and they hatch in the mouth, making their way into the stomach. Here they live some months, passing out with the excrement in the spring or early summer and pupating in the soil. Injury is due to malnutrition and to the irritation of the tissues of the stomach.

The throat-bot differs in its habits in some details from the common bot-fly. It generally lays its eggs just under the chin or

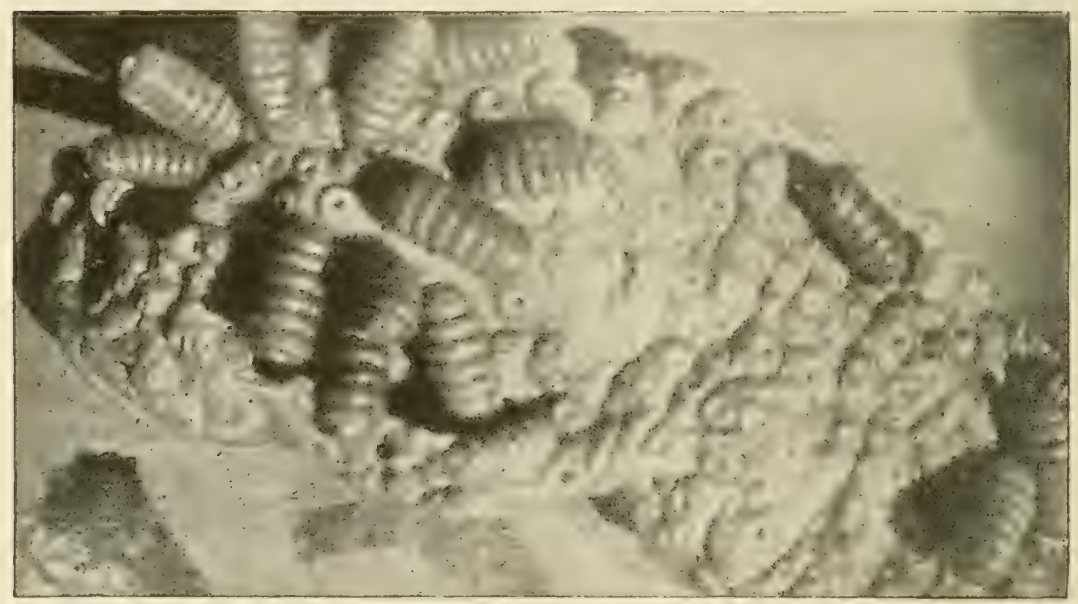

Fig. 581.-Bots attached to the wall of the stomach of a horse. (After Osborn, U. S. Dept. of Agr.)

jaws. The larvae of this species sometimes attach themselves in the pharynx where they may seriously interfere with taking food or even with the breathing. They attach also in the stomach but are most frequently found in the dundenum where they may be so numerous as to interfere with the passage of the excreta, in which case serious consequences ensue.

The nose-fly attaches its eggs usually on hairs on the lips and it causes much more excitement to the animal in the process than do the other species. Apparently the egg-laying in this situation is attended by some pain to the animal. The larvae attach in the stomach or duodenum and later, when nearly or quite grown reattach themselves in the rectum or anus, causing acute discomfort to the animal and interfering with the passage of the excreta. 
Full grown larvae of all species drop to the ground and pupate in the soil.

Work horses and horses kept in stables and given daily care can . be protected from bot flies by treating the eggs every few days with benzine, kerosene or carbolic preparations or by clipping the hair. Horses in pastures or on the range, especially colts which are most frequent sufferers, can not be so easily protected. Mechanical

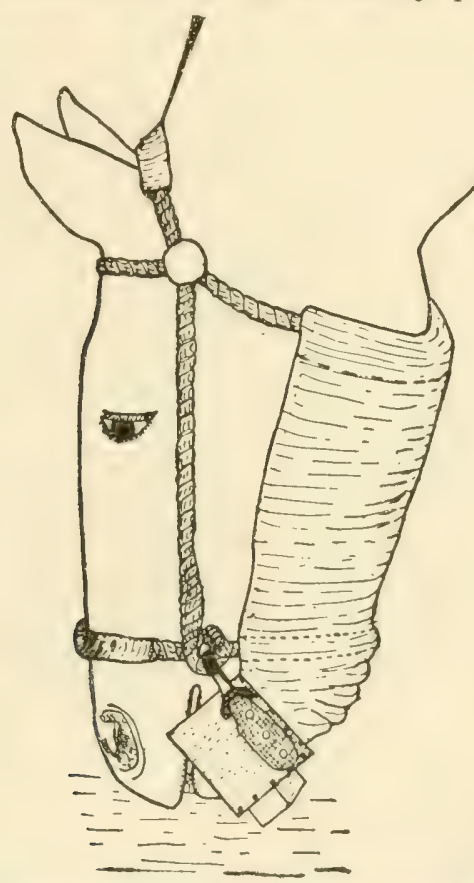

Fig. 582.-Horse protected fromattack of bot-flies. After Dove, U. S. Dept. of Agr.

devices have been suggested to protect the animals, especially from the nose fly. A muzzle which has given some protection is copied from W. E. Dove, l. c. (See Fig. 582).

If animals be furnished shelter which is somewhat darkened for the daylight hours and be encouraged to graze at night, considerable protection will result since the bots are active only during the daytime.

Internal treatments to rid the infested animals of bots have been tried. The one recommended by the Department of Agriculture is quoted below from Dove. 
"The day preceding the treatment a small amount of hay and a moderate amount of oats is given in the morning; in the evening food is withheld and a purgative given-Barbadoes aloes 1 ounce, or raw linseed oil 1 pint. The day of the treatment, at 6 o'clock in the morning, give 3 drams of carbon disulphid in a gelatin capsule; at 7 o'clock repeat the dose in the same manner; and at 8 o'clock give the third and last dose, making in all 9 drams of carbon disulphid in three gelatin capsules.

"The above treatment is for the adult horse. For a yearling colt half the quantity of carbon disulphid used for a mature horse will give the desired results. If properly administered the gelatin capsule reaches the stomach intact, but soon dissolves and the carbon disulphid rapidly evaporates, suffocating all bot larvae and other parasites with which it comes in contact, but not injuring the horse. Worms are quite often expelled as well."

\section{The Ox-warble *}

The $\mathrm{Ox}$ Warble is most prominent in the spring when it makes itself apparent in the swellings or warbles on the backs of cattle.

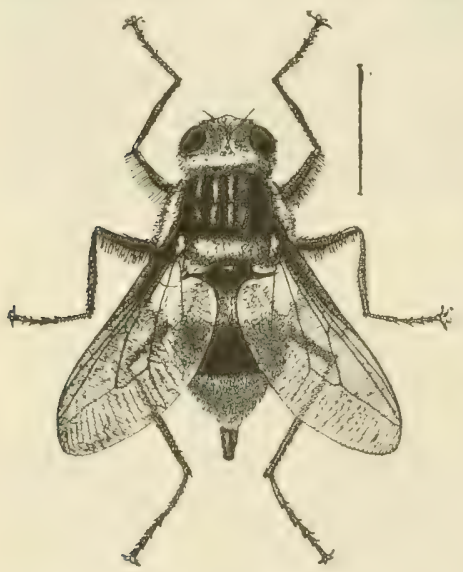

Fig. 583.-The Ox Warble, female. From "Insect Life."

It is the larva of a fly somewhat like the horse-bot fly but more like a drone bee.

The flies lay their eggs on the legs and feet and the lower part of the body of the animal. Here they hatch and fall to the ground attaching themselves to stems of grasses with which they are taken into the mouth of the animal, pass into the œesophagus and burrow their way into the thick walls of the asophagus where they may be found in animals killed in early fall. From this location they make their way between the muscles until they finally lodge just beneath the skin of the back where they complete their development, cause the characteristic swellings and finally emerge through small holes

\section{* Hypoderma lineata Villers, Family Oestridae.}


A different species (Hypoderma bovis) is common in Europe and has been found in Canada and several localities in the United States.

There is, after years of study and observation of the ox-warbles, still some difference of opinion as to how they get to their final location under the skin of the back. Some claim that they bore through the skin of the lower parts of the body and crawl beneath the skin to the back. Some observations to confirm this have been recorded. The other common belief is that the eggs are taken into the mouth, where they hatch and work through the walls of the osophagus.

\section{The Sheep Grub*}

The third important example from the bot-fly family is the sheep grub. The adult of this species is smaller than that of the preceding but, like it, has some resemblance to a honey-bee. Adults are present throughout the summer and lay their maggots

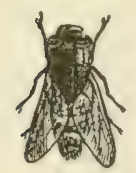

1
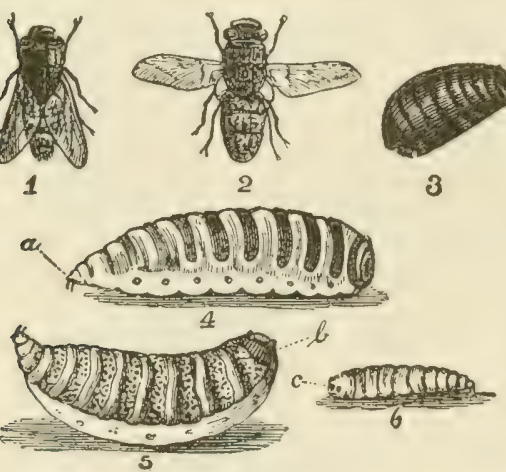

2

es with larvece and Fig. 585.- Sheep bot flies with la
pupa. (After Riley.) (the eggs being hatched in the body of the female) in the nostrils of the sheep. The larvae then work their way up the nasal passages and into the frontal sinuses and sometimes even into the brain. They cause trouble familiar to sheep men under the name of the blind-staggers or gid. Symptoms are giddiness, or inability to control movements naturally, loss of appetite and even death. The larvae remain in the head of the animal for as much as ten months, being sneezed out at maturity. They pupate in the ground and emerge as adults in some four to six weeks.

Remedies are difficult to advise. Prevention of oviposition by providing darkened shelters for the daytime or by smearing the noses of the animals with tar will be of value. Tar may be renewed by the sheep in this way: Place small logs here and there in the pasture. Bore in these several holes with a two-inch

* Estris ovis L. Family CEstrida. 
augur and put salt in the holes. Around each hole smear a quantity of tar. Sheep seeking salt will get the tar on their noses and be protected in a measure as long as it remains.

It is difficult to rid the sheep of the maggots once they have become established. In their early stages they may be reached by injection through the nostrils but later this is not practical. It should be done at any time under the advice of a veterinarian.

\section{Lice of Live Stock*}

There are two general groups of lice which may affect livestock. These are the biting lice, Mallophaga, which feed on hair, scales from the epirdermis and other waste on the animal, but are irritating to the animal and cause poor general condition, and the true lice or sucking lice, Siphunculota which suck blood from the host.

\section{Biting Lice $\dagger$}

There are several species of biting lice to be found on domestic animals. Aside from the ones on poultry the most common are the biting lice of cattle (Trichodectes scalaris). These are small whitish forms about one-sixteenth of an inch in length and of the general form shown in the illustration.

A similar species occurs on the horse. It may be a trifle larger and lighter

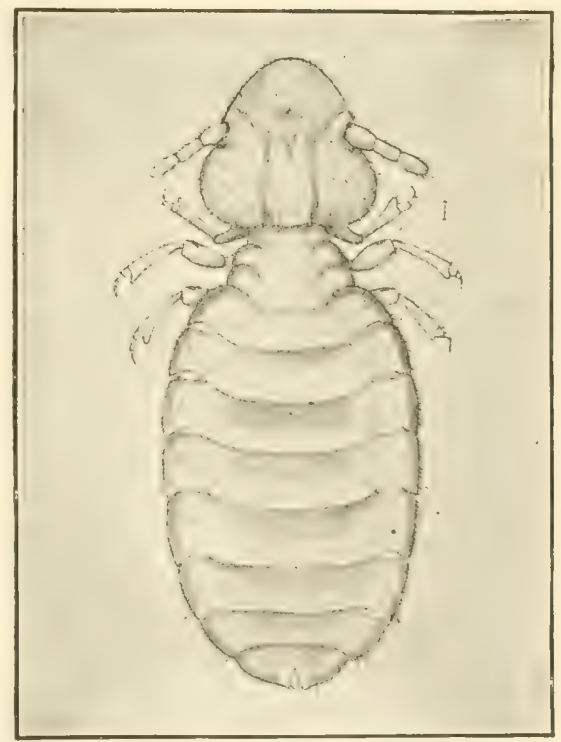

FIG. 586.-The biting louse from cattle. U. S. Dept. of Agr. in color but otherwise will appear just as the cattle louse. Its specific name is $T$. parumpilosus. Biting lice on other live stock are more rare, but may occur.

* See Marion Imes, Farmers' Bulletin 909, U. S. Dept. of Agr.

$\dagger$ Mallophaga. 


\section{Sucking Lice *}

The common sucking louse of cattle is the short-nosed oxlouse (Hcmatopinus eurystermus). It is bluish-gray in color and considerably larger than the biting louse, being about one-

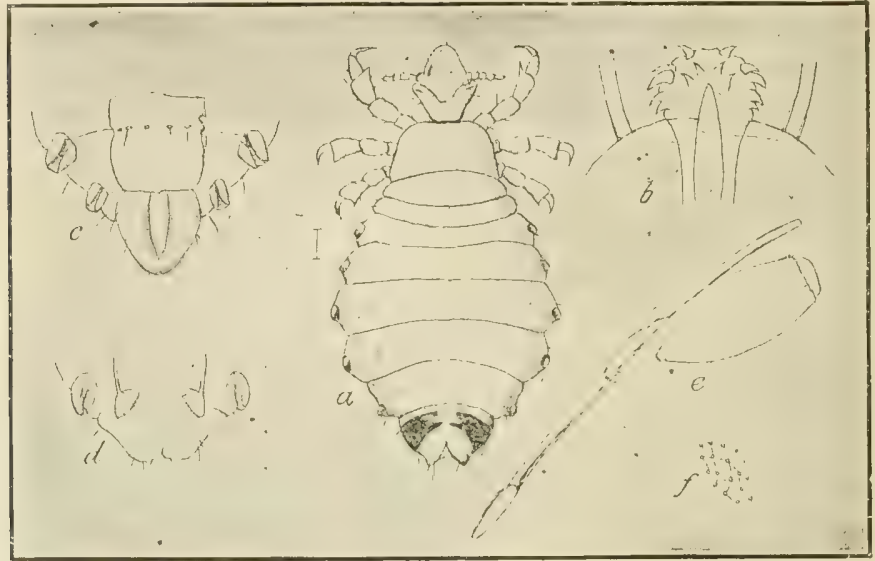

FIG. 587.-The short-nosed ox-louse. U. S. Dept. of Agr.

eighth inch in length. The head of this species, as well as the other species of sucking lice, is rather pointed while the heads of the biting species are more rounded.

The long-nosed ox-louse ( $H$. vituli), is longer and more slender than the shortnosed louse. It is generally less in jurious.

The long-nosed hog-louse (H. suis), is the largest member of th is group which is at all common. It is nearly a quarter of an inch long and is broad across the abdomen. It is found on hogs frequently and is said to be the worst enemy of swine next to the cholera. Lice are easier to eradicate on swine than

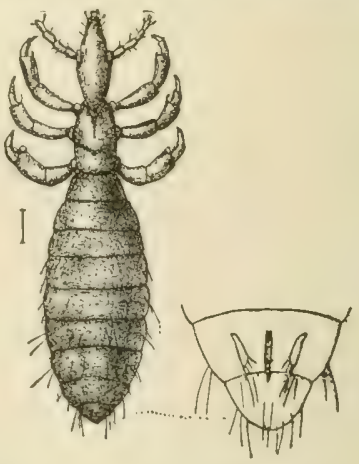

Fig. 588.-Long nosed ox: louse. U. S. Dept. of Agr. on the larger animals, so only neglect need cause loss from them.

A biting louse ( $H$. pedalis), is found on the feet and legs of sheep, below the long wool but it is rare and does little injury. Dogs occasionally become infested with lice, both sucking and biting. 


\section{Control of Lice}

Lice may be killed by the use of dips as recommended for other parasites. Spraying the animals with nicotine or kerosene emulsion will be effective provided all parts are wet with the spray clear to the skin. Some danger of colds to the animals must be considered when they are being dipped or sprayed.

Sulphur or sulphur and lard, thoroughly applied, will kill lice.

Experiments at the West Virginia Station have shown that lice on an animal ean be killed by the use of blu'-ointment. This is applied over a small area, two inches wide and six inches long, on the side of the neck or elsewhere, so it can not be reached by the animal. A small amount of the ointment is thoroughly rubbed into the skin. In a short time the lice disappear. Just what the action is, is not known. Precautions must be taken to keep the animals from licking the parts treated. This is easy in the case of hogs and horses, but more difficult with cattle which often lick each other. It will always be well to cover the treated parts with burlap, fastening it securely so that it can not be rubbed off and replacing it immediately if it becomes loosened.

\section{The Sheep Tick*}

The Sheep Tick is not a tick at all except in general appearance, but a wingless fly. The insect spends the entire life on the sheep, sucking blood from the host for nourishment. Development in this group is unusual, the young being retained in the bodies of the females as larva until ready to pupate and being deposited not as eggs but as pupr, which are glued to the wool of the sheep. The effect of these parasites on the host is to lessen their vitality. This is generally indicated by the condition of the wool, which is rough and scraggly.

Sheep ticks can be controlled by

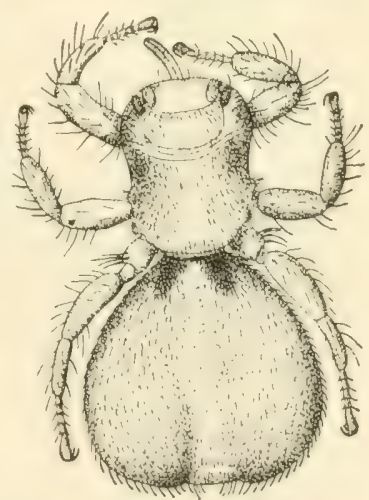

FIG. 589.-The Sheep Tick. Ky. Agr. Exp. Sta. dipping the animals in Blackleaf 40 diluted 1 to 1000 . This is best done at shearing time, as when the wool is long it is almost

* Melophagus orinus L. Family Hippoboscider. Order Diptera. See Marion Imes, Farmers' Bulletin 798, U. S. Dept. of Agr. 
impossible to get the dip to penetrate to all the ticks. Migration from animal to animal is slow and flocks once freed from the ticks may be kept free by keeping out infested animals. Most of of the ticks are removed with shearing and sometimes, if the lambs do not become infested, shearing will eliminate the necessity for special treatment.

Dipping for this and other pests will be discussed more in detail at the end of the chapter.

\section{Scab Mites*}

Scab mites attack cattle and sheep, causing a diseased condition called scabies. Similar mites attack horses, hogs and man, causing the irritation called itch or, in animals, mange. The more important of these are the species affecting cattle and sheep.

\section{Cattle Scab or Scabies *}

The organism causing cattle scab is a minute mite, and like other mites is not an insect but a member of the order Acarina.
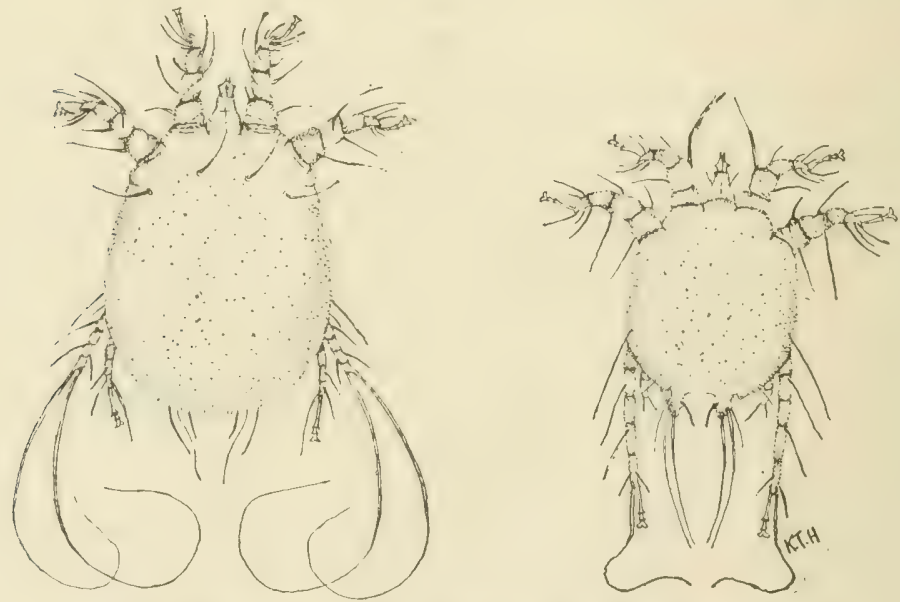

FIG. 590.-Sheep scah-mite. (After Good, Ky. Agr. Exp. Sta.)

The mite is a minute oval object but is visible to the unaided eye. Eight short, tapering legs project from the margin of the body

* Psoroptes communis bovis. See Marion Imes, Farmers' Bulletin 1017, U. S. Dept. of Agr. 
in different directions like the spokes of a wheel. The entire life is spent on the host and the life cycle requires about two weeks. Multiplication is rapid.

Symptoms include a roughened condition of the coat on the infected areas, this gradually spreading all over the body and being followed by shedding of the hair and a seabby appearance of the skin, caused by the burrowing of the mites and the consequent irritated condition.

Control of seabies is secured through the use of dips. Of these the lime-sulphur compounds are recommended, since they kill all the parasites which may be on the animal. Dipping will be discussed separately since it is the treatment recommended for several of the parasites of stock.

\section{Sheep Scab*}

The organism causing the sheep scab is merely a variety of the one causing the scab of cattle, Psoroptes communis oris,

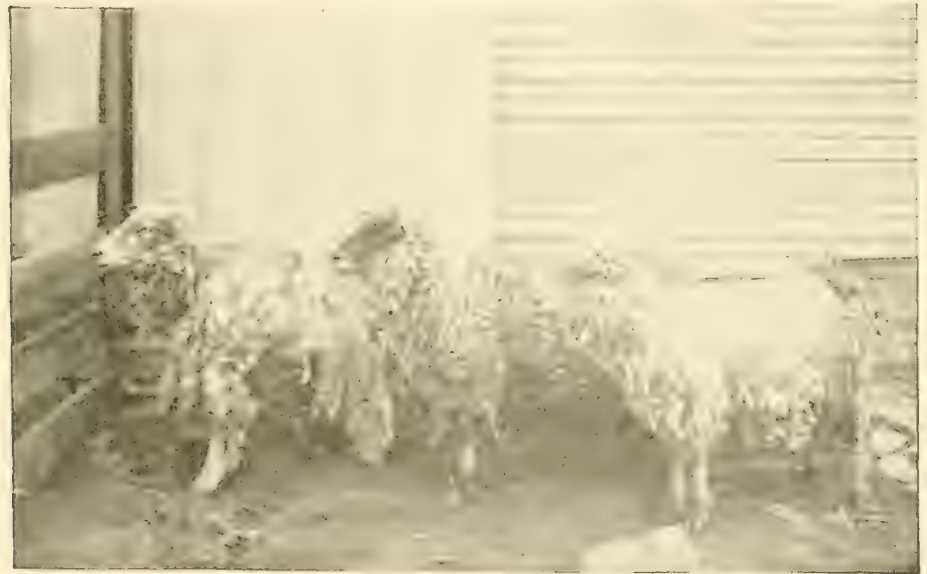

Fia. 591.- Sheep infected with scabies. Early and late stages. Ky. Agr Exp. Sta.

being the name for the sheep seab organism and $P$. communis boris, being responsible for the eattle scab. A third variety $P$. communis equi, causes the scab of horses.

The life" history of the sheep scab mite is the same as for

* See Marion Imes, Farmers' Bulletin 713, U. S. Dept. of Agr. 
the cattle scab and the symptoms are similar. Shedding of the wool in patches is an advanced symptom in sheep while a ragged condition of the wool shows earlier.

Control of sheep scab, as of cattle scab, is accomplished by dipping, the same dips being available for both.

\section{Mange and Scabies of Horses*}

Scabies of horses is a disease similar to the scabies in cattle. Mange is caused by a mite of a different genus, (Sarcoptes scabei). The species involved has several rarieties, named to indicate the host. Thus the one on horses is equi, on dogs it is called canis, on hog suis, while the same mite is hominis on man. The mites may he transferred from one host to another but generally do not live long except on the original host. The disease caused by the mange or itch mites does not differ materially from the ordinary scabies. Earliest indications of infection are a tendency to rub affected parts, the hair being entirely rubbed off in spots.

Treatment of mange or scabies in horses, consists of rubbing some solution such as is used in dips into the skin of the affected parts, being sure that the entire infected area is treated and repeating the process three or four times at intervals of about four days. Limesulphur solution, as recommended for dipping, is as convenient and satisfactory as anything. Nicotine preparations will also be found to be effective.

\section{Swine Mange}

Swine mange manifests itself usually on the upper parts of the body from head to tail. A general roughened and unhealthy appearance of the skin will suggest the existence of the disease. This may be confirmed by the finding of the mites. This is done by scraping off the skin until some of the deeper layers are reached and examining with a microscope.

Treatment consists of dipping or local application of some of the dips sold for the purpose or of home made lime-sulphur solution. If the animals are dipped the dip should be kept at about body temperature.

\section{Ticks Attacking Cattle*}

Several species of ticks attack cattle and others are occasional parasites of other animals and may be found on man. Perhaps

* Order Acarina. 
the most serious of the ones attacking man is the tick which has received the name of the Rocky Mountain Fever Tick (Domacentor vemustus, Banks), because it has been shown to be an agent in the transmission of the ferer of that name, which is a highly fatal disease occurring in many of the Rocky Mountain States but most prevalent and virulent in the Bitter Root Valley of Montana. This tick spends a part of its life on the smaller wild mammals anda part on the large mammals, wild and domestic. Upon occasion it

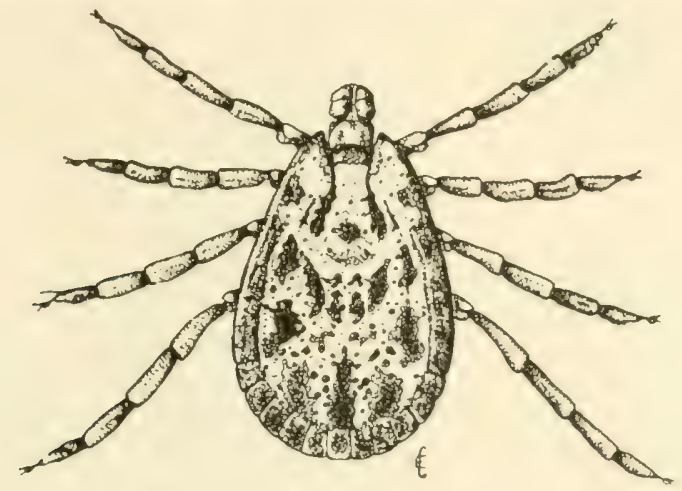

Fia. 592.-The Rocky Mountain spotted fever tick. (After R. A. Cooley, Montana Agr. Exp. Sta.)

bites man, and in so doing may infect him with the fever if it has previously received the virus from another infected person or animal.

\section{The Cattle Tick*}

The most important of the cattle ticks, and one of the most important of the arthropods affecting the cattle industry, is the Texas Fever Tick or North American Fever Tick, a common pest of cattle in the South and the sole means for the transmission of the disease known as Texas Fever. This disease and so the tick, has been the greatest obstacle to the establishment of the livestock industry in regions of the South which are otherwise well adapted to cattle raising.

The fully grown adult ticks may be as much as a half inch long and are thick bodied and oval in shape. The head is much smaller than that of other ticks found on cattle and is reddish brown in color. Body color is yellowish or a dull brown with mottling of

* Margaropus annulatus. See Farmers' Bulletin 1057 and numerous other U. S. Dept. of Agr. publications. 
yellow or brown of different shades. The adult female becomes engorged with blood and eggs and drops from the animal to the ground where she lays from 1500 to 3000 eggs. From these eggs the young or seed ticks hatch in from two to six weeks, depending on the temperature. The young seed ticks crawl onto grass or
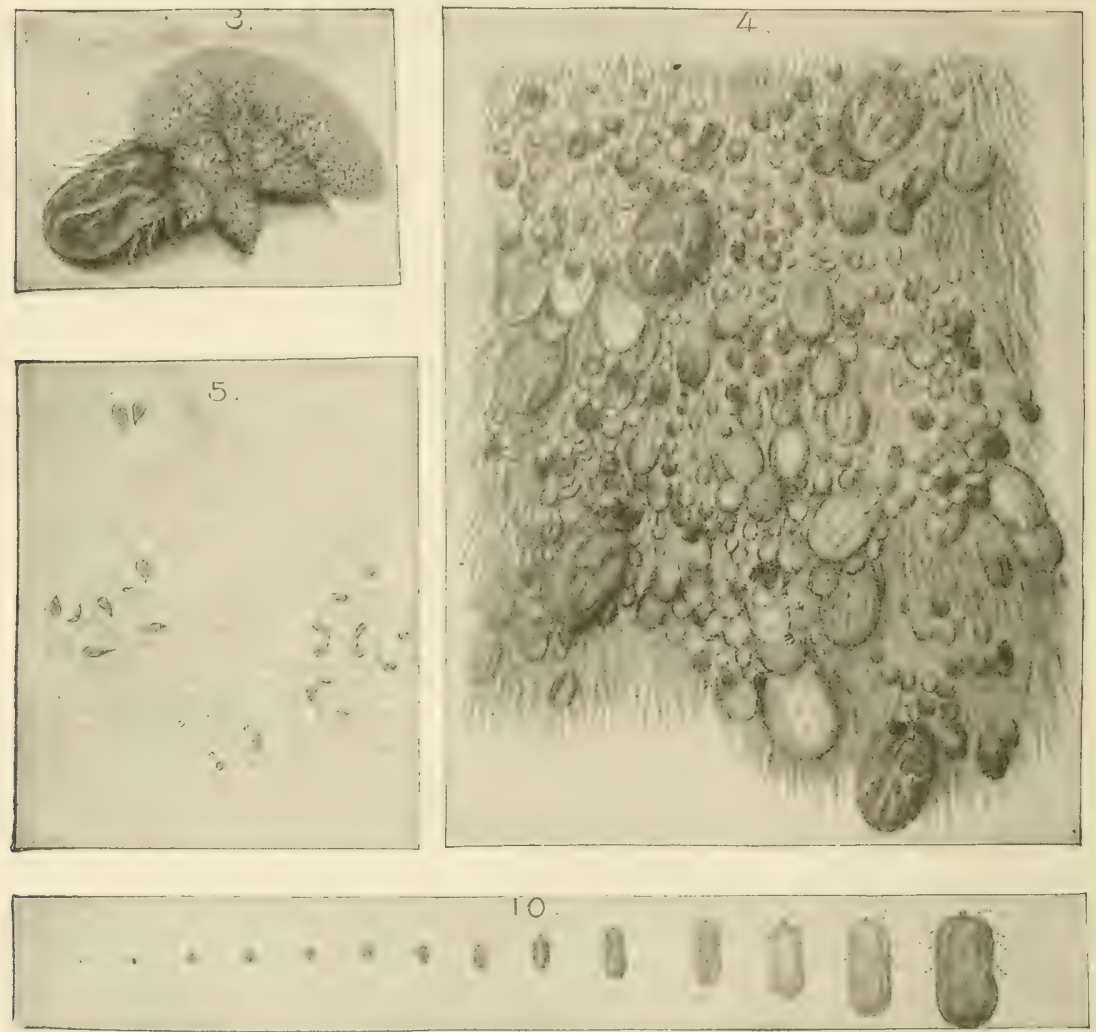

FIG. 593.-The cattle tick (U. S. Dept. of $A$ gr.): 3 , mature female with eggs; 4, ticks attached to the hide; 5, blood cells containing Babesia organisms; 10 , various stages of ticks. Natural size except 5, which is enlarged 1,000 times.

weeds and transfer themselves to cattle at the first opportunity. If they fail to do this they die, but not 'ecessarily for three or four months. On cattle they attach themselves to the tender and protected parts and suck blood, maturing in warm weather in some six weeks. If the parent of these ticks was from an infected animal, 
they may infect the new host with the Texas fever at this stage, even though they are so small as to be scarcely visible.

Texas fever is caused by a minute protozoan animal of the same general group as the parasite causing malaria (Babesia bigemina.)

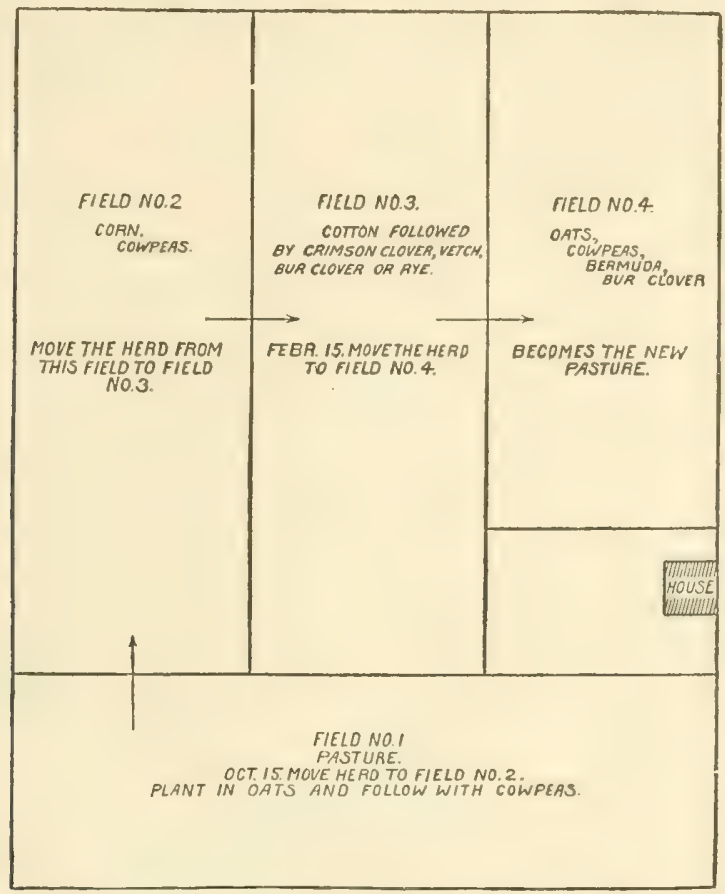

Fif. 594.-Plan for freeing cattle and pastures from ticks by rotation, requiring eight months, U.S. Dept. of Agr.

It passes from the body of the infected female, no one knows just how, into the eggs so that all her progeny are infective. Apparently healthy cattle from permanently infected districts are usually carriers of the disease but have developed immunity to the effects. They are as dangerous as sources of infection for the ticks as are the cattle sick with the disease.

It has been definitely shown that the disease can not be transmitted in nature in any way except by the bites of the infected ticks. That being the case, the obvious way to eliminate the disease is to destroy the ticks. The U. S. Department of Agri- 
culture and the authorities in several of the southern states have worked out a plan whereby it is possible to eradicate the tick from the entire Texas fever area. This makes use of the habits of the ticks and the fact that they have no alternate host. The general scheme is a system of rotation of pastures. Cattle are removed from infested pastures, dipped to free them from ticks remaining on them or not, depending upon the number of pastures available.

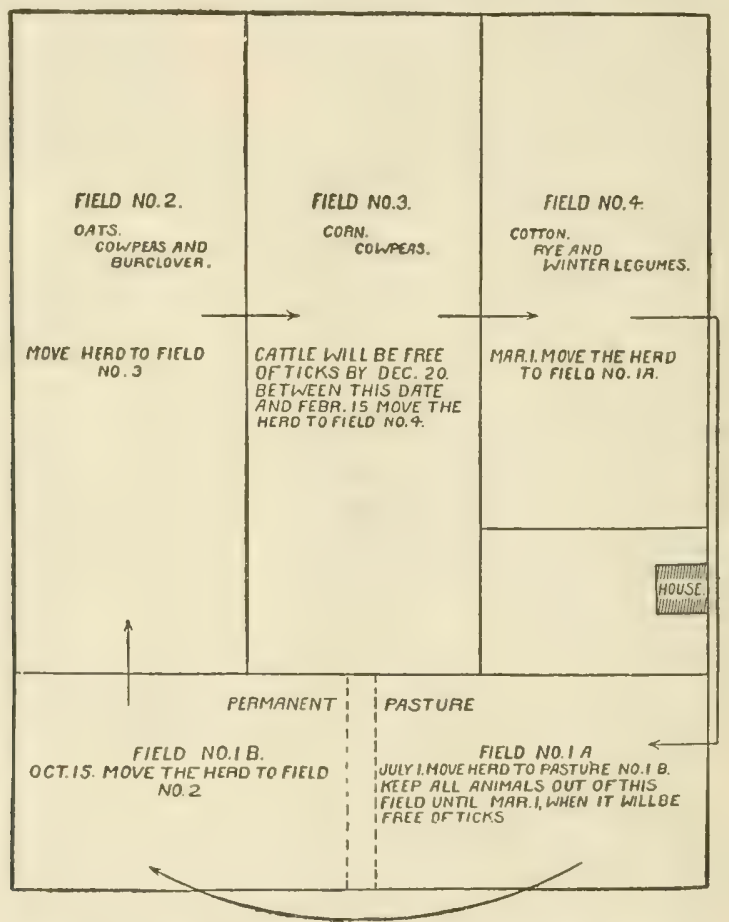

FIG. 595.-Plan for freeing cattle and pastures from ticks by rotation, requiring four months, with new pasture, U. S. Dept. of Agr.

The infested pasture is then plowed up or allowed to remain idle for some four months by the end of which time all ticks in it will have died. If there are tick free pastures available, the cattle from the first pasture may be dipped to kill the ticks upon them and then placed in the tick-free pasture, care being taken not to introduce, at any time, tick-carrying cattle into this pasture 


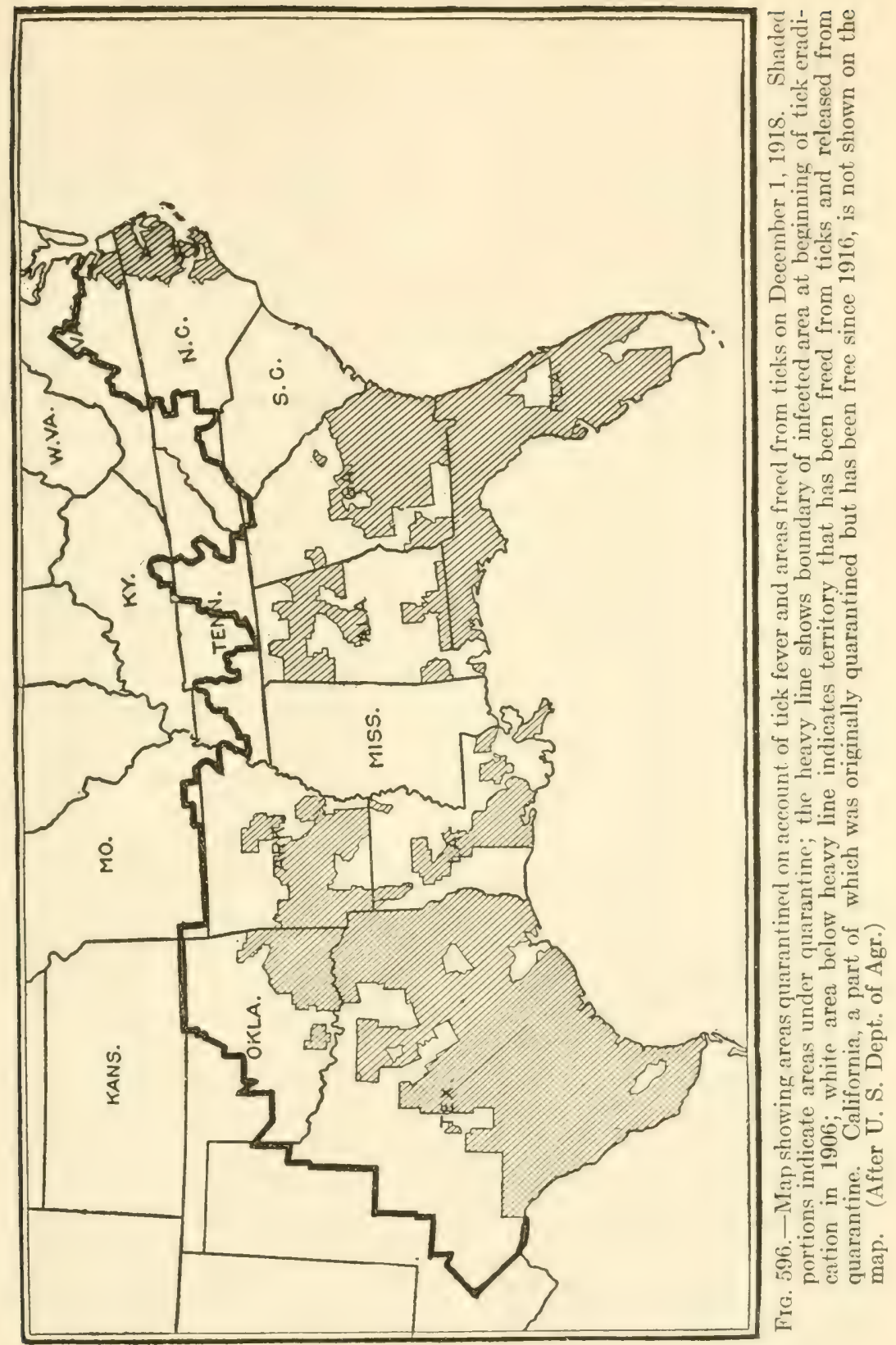


After four months they may be removed back to the original pasture. If, however, no tick-free pasture is available, a different scheme is used. The cattle are moved after as many of the adult ticks have dropped to the ground as are likely to drop off soon. They are then taken to another pasture, still infested at this time. Here they remain not more than twenty days when they are removed to asthird field where they remain another twenty days, and then to a fourth field where they remain until they are free of ticks, but from which they are removed hefore any seed ticks appear in the fifth ficld. This field is by this time tick-free and the cattle may remain there until the original field has had time to become free, which is usually shortly after this time. The time required depends upon the season of the year in which it is started. The accompanying diagram shows the general scheme of rotation in practice.

The whole tick-infested area was placed under quarantine in 1906 by the Federal authorities and movements of cattle from the quarantined area were permitted only under supervision. Since that time large parts of the quarantined area have been freed from ticks and the quarantine removed. The map shows the wonderful progress of this work. It is surely only a matter of a few years until the Texas fever tick, and with it the fever, will have disappeared from the United States.

\section{Dipping Live Stock for Parasites}

Many of the external parasites are best treated by dipping them or immersing them in some solution of an insecticidal nature. Lice, sheep ticks, ticks on cattle and the mites causing mange and scabies all may be killed in this manner.

Numerous dipping solutions or dips have been tried out and recommended. Only those which are applicable to the majority of the pests in question will be mentioned here.

Nicotine is a standard dipping material. It should be used at a strength containing approximately five one-hundredths of one per cent of nicotine. This strength corresponds to Black-leaf 40 diluted one to 800 . Other dips should be used in the same proportionate strength, dilution, for commercial products being usually indicated on the package. 
Lime-sulphur solutions have long been used for dipping cattle, having been manufactured for that purpose before they were used for spraying. They do not differ in composition from the same materials used as sprays. Strengths of commercial materials will be indicated on the packige. Home-made materials should contain 8 pounds unslaked lime and 24 pounds sulphur to the hundred gallons. The process of cooking is the same as for the spray of the same materials.

Sulphur and nicotine in combination have been used for dipping. In this dip flowers of sulphur is mixed with the nicotine, the amount necessary to make a 1 to 800 solution of nicotine containing two per cent of sulphur being used. These are then added to the water.

Widely used dips for various purposes are the arsenical dips. Arsenical dips may be made by using caustic soda, 4 pounds, white arsenic 10 pounds and sal-soda crystals 10 pounds. Dissolve the caustic soda in about a gallon of hot water and add the arsenic as fast as it can be dissolved in the hot water without boiling, then dilute to about four gallons and add the sal-soda, then dilute the whole to exactly five gallons. This forms one of the two necessary stock solutions. The other is made as follows: Dissolve 3/4-pound caustic soda in a quart of water, then add a gallon of pine tar, stirring until a smooth even mixture is secured. Both the above stock solutions should be kept in closed containers. The diluted dipping solution for use should contain four-fifths of a gallon of the arsenic stock and one-third gallon of the tar stock.

Other dips are marle from coal-tar preparations, but are usually sold as proprietary dips, and should be used as directed.

Dipping vats are of many styles. For large stock ranches they may be made permanent and arranged so as to handle large numbers of animals. Smaller farms may well have permanent rats which need not be so elaborate. For small animals, sheep for instance, vats are not necessary but are desirable for convenience in handling the animals. Sheep may be dipped in large barrels. A eanvas hag for dipping sheep has been used with satisfaction in small operations.

Anyone contemplating the use of dips or the construction of dipping vats and apparatus should consult the Bureau of Animal 
Industry, U. S. Dept. of Agriculture, or the State Experiment Station, which will give free advice and often will be able to send experts to assist in the preparation for such work. Farmers' Bulletins Nos. 1057, 713, 909, 798, and 603 deal with pests for which dips are used and with the preparation of dips and dipping vats, and should be consulted before beginning such work. They like all Farmers' Bulletins, are free upon application to the U. S. Department of Agriculture, Washington, D. C.

\section{Poultry Lice*}

Only the biting lice attack poultry or birds of any kind, the sucking lice being found exclusively on mammals. Three species

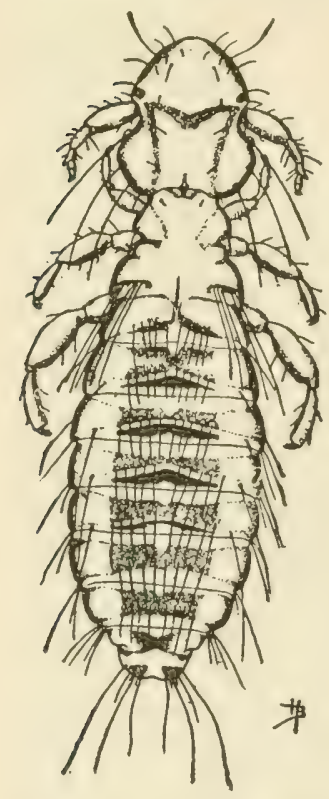

FIG. 597. - Head louse: male, top view. Greatly enlarged. After Bishopp, U.S. Dept. of Agr.

are common on chickens and others are occasionally found. Different species attack ducks, turkeys and other fowls.

\section{The Head Louse of Chickens $\dagger$}

This louse is most frequently found on the head but may occur on the neck and other parts. It is dark grayish in color and may be as long as one-tenth inch. Eggs are deposited on the down or feathers about the head and the lice feed on the skin and feathers close to the skin. The life cycle requires about three weeks. Young resemble the adults except in size and in their lighter color. It is this species that causes most trouble with young chicks to which it passes readily from the mother hen. As the chickens get older these lice become less numerous and troublesome. Since poultrymen insist that profits from poultry raising depend very largely upon the vigor of young chicks it will be seen that the control of these lice is important. This may be accomplished as described later for all poultry lice.

*Order Mallophaga. See F. C. Bishopp and H. P. Wood, Farmers' Bulletin 801, U. S. Dept. of Agr.

$\dagger$ Lipeurus heretographus Nitzsch. 


\section{The Body Louse of Chickens*}

Possibly the most common of the chicken lice is this species. It is found on the skin of the fowl rather than on the feathers, but may occur on the neck and head as well as on the body. It is found most frequently just below the vent but may occur in numbers on other regions of the body and on the thighs. Eggs are laid in clusters near the base of the feathers, being most numerous in the regions where the lice are found in greatest numbers. The complete life cycle requires about a month, but there is little difference between the young and the adults except in size. The color is yellowish and the size of the grown forms is about one-twelfth of an inch in length. This species does

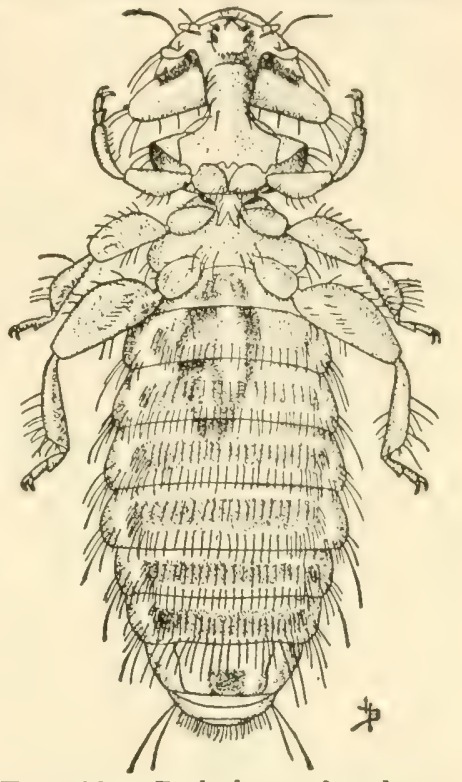

Fig. 598 - Body louse: female underside. Greatly enlarged. After Bishopp, U. S. Dept. of Agr.

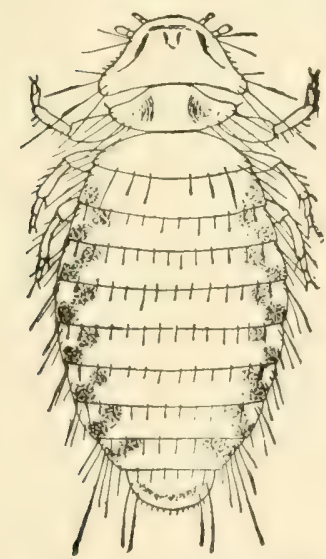

Fig. 599. - The Shaft Louse. U. S. Dept. of Agr. the most

\section{The Shaft Louse $\dagger$}

This species is smaller than the body louse and is sometimes called the small body louse although it is found on the feathers rather than on the body. It is found on the shaft of the feathers where it feeds on the barbs, for this reason being less injurious than the other species mentioned, both of which feed on the skin to a great extent.

\section{Control of Chicken Lice *}

Control of these forms, as is the case with so many other pests, is best accomplished by prevention. If the premises and fowls

* Menopon biseriatum Piaget. $\dagger$ Menopon pallidum Nitzsch. 
can once be entirely freed from lice, they may be kept so by keeping away all stray fowls and by thorough treatment of new stock may be brought in from the outside. To rid a flock of lice, the best time to do the work is late summer or fall, preferably before the moulting period, and when there are as few fowls in the flock as will likely be kept at any time.

Experiments by Bishopp and Wood have shown that the best material for treatment is sodium fluoride, which is obtained in the form of a dry powder. One application of this material, properly used, is said to free the premises entirely from lice.

The material is applied either as a dust or in water as a dip, the action as a dust being slower than when applied as a dip.

Applied as a dust it should be placed in small quantities, about what can be picked up between the thumb and the forefinger, to at least a dozen different places on the body of the fowl, these places to be distributed as evenly as possible. Or the material may be sifted into the feathers while they are ruffled and spread out, but this method is not as convenient as the so-called pinch method.

Sodium fluoride for dipping should be used at the rate of threefourths ounce to the gallon of lukewarm water and dipping should be done toward noon on a warm sunny day. The water should be placed in a tub and the fowls dipped directly into the water, the feathers being ruffled while the bird is submerged to allow the water to penetrate. The head is immersed once or twice after the rest of the body has been dipped. This method is quicker than the pinch method but should not be used in cold weather unless one has heated poultry houses to work in.

In West Virginia it has been found that a pinch of blueointment rubbed into the skin just below the vent and another on the head and under the wings, will rid the fowls of lice but that this method must not be used for young chicks or for hens brooding young chicks.

Other remedies for lice have been tried, but in view of the excellent results from the sodium fluoride treatment it would seem inadvisable to recommend any other treatment. 


\section{Mites on Poultry*}

The Common Chicken Mite (Dermanyssus gallinae DeGeer,) is the most important of the chicken mites. It is of universal occurrence in this country where there are chickens. The mite itself is a minute whitish gray object, just large enough to be seen in good light with the unaided eyre. The mites feed on blood from the chickens, and when numerous result in a condition of depleted vitality indicated by an unthrifty appearance. The mites feed on the poultry at night hiding in crevices in the houses, about the roosts and on the floors during the day. The life cycle

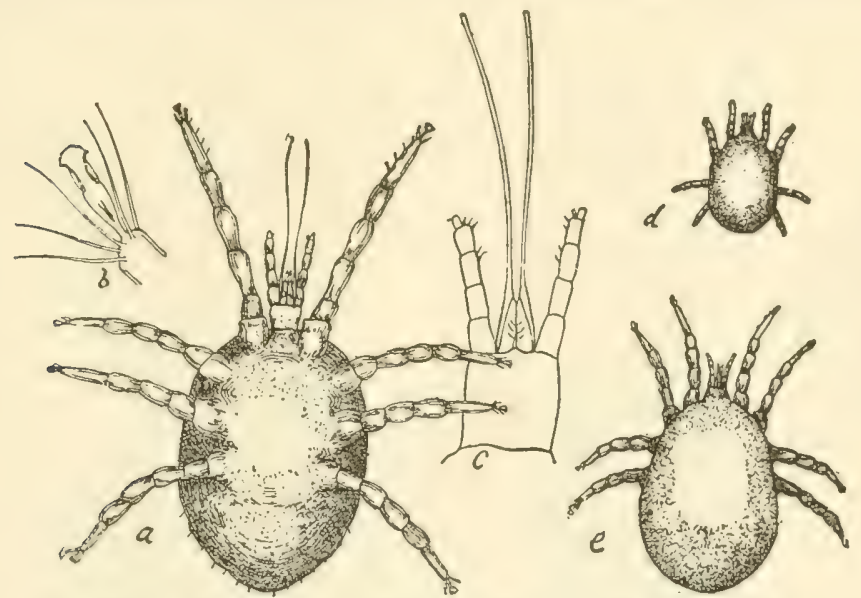

Fig. 600.-The Common Chicken Mite, U. S. Dept. of Agr.

in warm weather requires only a week so the increase in numbers may be extremely rapid.

Control is based on this habit of leaving the fowls in the day and remaining in the houses. Application of many different kinds of insecticides will kill the mites if thoroughly done. In old badly infested houses all the roosts and nests should be removed, all the litter burned or buried deeply and the nest boxes and roosts themselves burned if they can easily be replaced as is often the case. The house should then be sprayed with a good spray from a pump which will give plenty of pressure. A good harrel outfit will be satisfactory. Good results ean be secured with more work, in small houses by the use of some small atomizer but the larger outfit is to be preferred. The spray should be directed at different 
angles toward all parts of the house. The floor should be soaked and even the roof or ceiling should be sprayed. Spraying the outside will help to give complete control as such spray will penetrate cracks which have not been reached from the inside.

Roosts and nests should be made as simple as possible and as easily removable, for the sake of subsequent treatments, as can be arranged.

Satisfactory sprays are crude petroleum, thinned with onefourth its volume of kerosene, which will destroy all the mites at one application; kerosene or kerosene emulsion, which requires several treatments; lime-sulphur, which also should be applied three for four times at intervals of a week; whitewash, to which has been added five per cent of crude carbolic acid or cresol. Nicotine preparations have given good results but require two or three applications and must be used stronger than in spraying plants.

The periodical use of a strong whitewash with carbolic acid added is a good sanitary measure, entirely aside from its effect
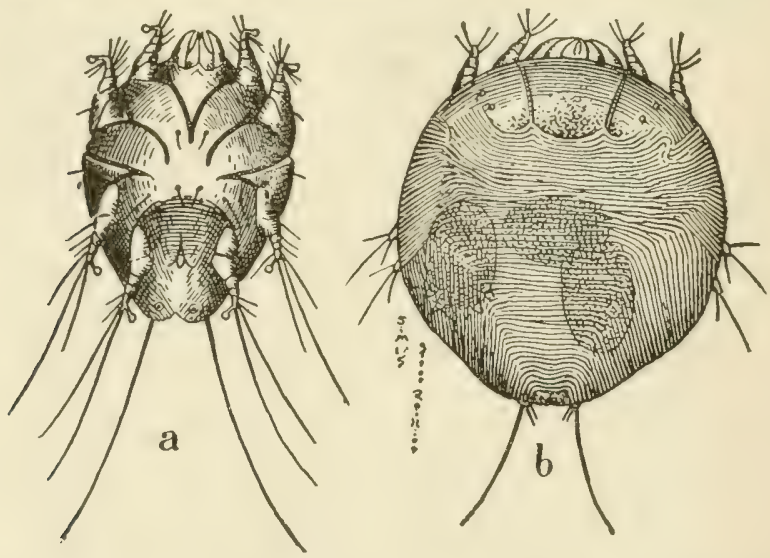

FIG. 601.-Depluming scabies (C. lacvis var. gallinae); (a) adult male (x 114); (b) adult female (x 108). (From Mote, after Sim, O. Agr. Exp. Sta)

on the mites and is to be recommended. If this is done, say once every two or three months, the mites will probably never become numerous.

Other poultry mites include the Depluming Mite (Cnemidocoptes gallinae Railliet), which burrows into the skin of the fowl 
near the base of the feathers. The intense itching caused by the mites induces the fowls to pick out feathers in their efforts to allay the irritation.

The treatment recommended by Bishopp is the repeated use of sulphur ointment, well rubbed into the skin. H. P. Wood

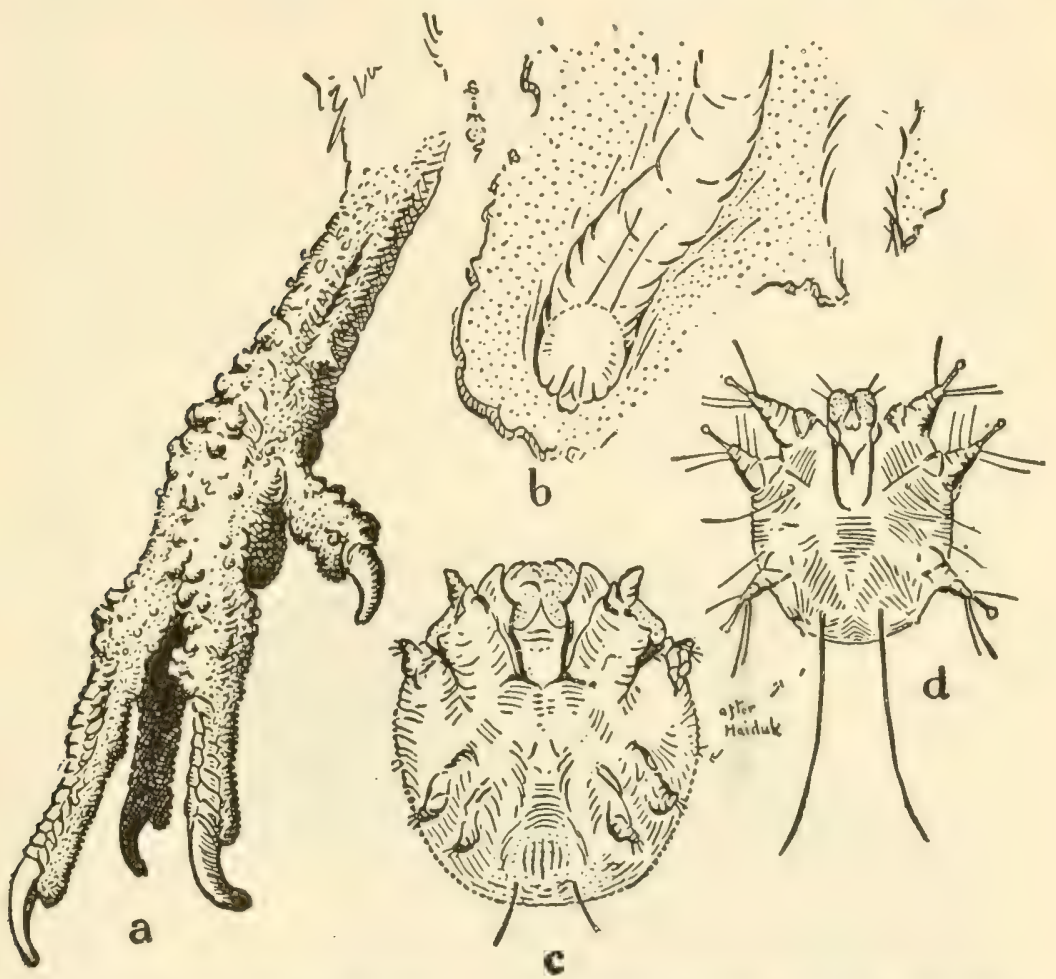

FIg. 602.--Scaly leg (C. mutans): (a) leg of chicken infested by mites (reduced):

(b) mite in burrow in skin (x 60); (c) adult female (x 82); (d) adult male (x 130). (From Mote, after Sim, O. Agr Exp: Sta.)

reports ${ }^{*}$ complete success in the control of this mite as well as lice by dipping the fowls in a solution of ehemically pure sodium fluoride, two-thirds ounce, sulphur 2 ounces, laundry soap onethird ounce in about one gallon of water. Only one application was found necessary.

The Scaly-leg Mite, the cause of the chicken disease called *Journal of Econ: Entomology, Vol. 12, No. 5. 
scaly-leg, burrows into the skin and beneath the scales of the feet and occasionally gets on the comb and the neck. The legs become encrusted with the scaly tissue resulting from the work of the mite and the feet sometimes get to be so tender that the fowl can scarcely walk.

The treatment recommended is to soak the legs in warm water so as to soften the scales and then to dip the legs into crude petroleum. The same material applied to the roosts may prevent the spread which is from fowl to fowl on the roosts.

Chiggers, the same as those found attacking man, are sometimes troublesome to chickens which are allowed to roam in pasture fields grown up in brush as is common on farms. Dusting with sulphur dust and keeping chickens, especially the young ones, out of infested pastures, will aid in the control of the chiggers.

\section{Other Poultry Pests}

Beside the mites and lice named, there are other species which

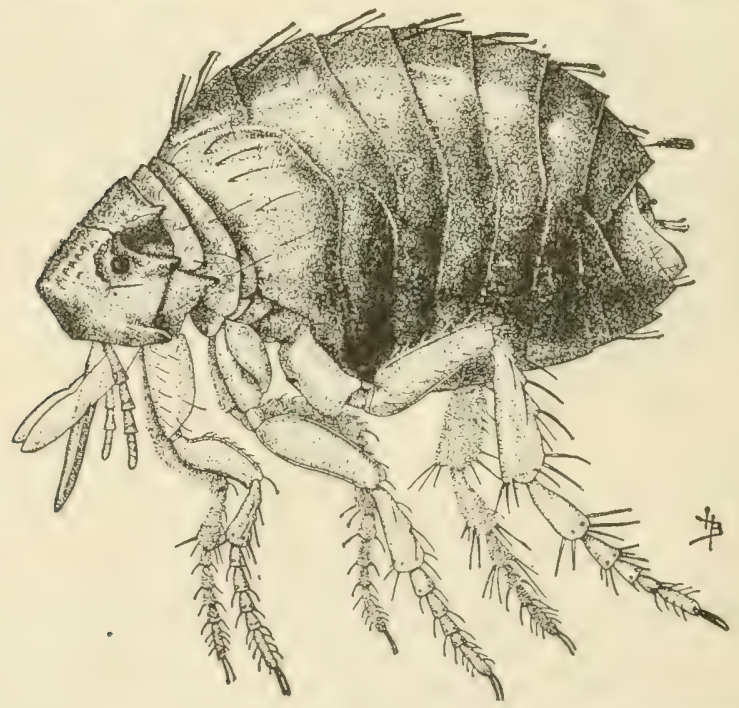

Fir. 603.-The sticktight flea: adult female. Much enlarged. (After Bishopp, U. S. Dept. of Agr.)

attack chickens and each other kind of domestic fowl has its own species of these insects. These differ little from those found on chickens and will respond to the same treatment. 
Chickens suffer in some regions from the attacks of a flea, the Chicken Sticktight Flea (Echidnophaya yallinacea Westwood). This flea is oceasionally found on dogs and cats, and on other animals, but is known for the most part as a pest of chickens. It occurs in the southern and southwestern states more abundantly than elsewhere. This flea is dark in color, almost black, and differs from other fleas in its feeding habits. When once it starts to feed it is difficult to dislodge while other fleas are correspondingly difficult to get to stay in one place. Bishopp reports that as high as 85 per cent of the young chicks have been killed by this flea and injury to older fowls is considerable. They infest first the heads and necks and later the bodies of the hosts, being present throughout the year.

In control of the flea it is necessary, first to keep poultry away from other animals which may act as carriers; then clean out the chicken houses as for control of the mites, soak the floors, if of earth, with salt water and spray the house as for mites, but preferably with crude petroleum or with a solution of creolin, Treat all possible breeding places with the same substances and shut the chickens out from those which it is impossible to treat.

The fleas themselves on the poultry may be killed by treating the infested portions with carbolated vaseline or with kerosene and lard. Destroy rats as these sometimes harbor the fleas.

Other fleas which sometimes infest poultry may be controlled in the same manner as the one above.

A rather new poultry pest, found in the Southwest only, is the Fowl-tick (Argas miniatus Kock). Chickens may be killed by this pest and certainly no infested chicken can thrive. The appearance of the tick is not different from other
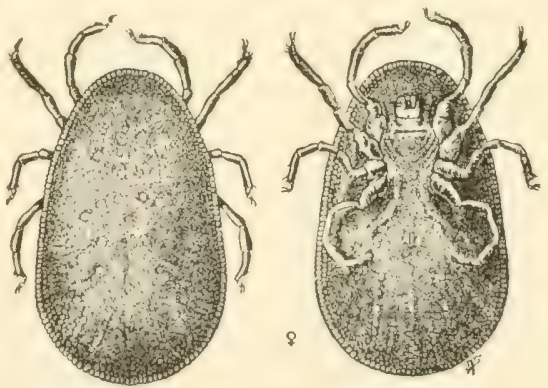

Fig. 601.-The fowl tick: adult female, upper and lower sides. Greatly enlarged. (From Bishopp, U. S. Dept. of Agr.)

ticks and large mites. Young remain attached to the hosts for several days but the older ticks feed at night only, hiding in cracks during the day as do the mites. Treating the house with crude 
petroleum as for mites, is said to be more effective and satisfactory as a means of control than destruction of the pests once they are established. Proper sanitary and local quarantine measures should be devised for this purpose, the object in general being to start business in uninfested quarters and by rigid inspection and quarantine, to keep out all infested fowls. 


\section{BIBLIOGRAPHY}

An extended bibliography, to do so much as approximate completeness, would occupy much more space than can be devoted to it here. We therefore list only a few titles and indicate the general sources of information.

1. Publications of the United States Department of Agriculture:

a. Farmers' Bulletins. Sent free upon application. Over 1100 titles have been issued and a great proportion of these deal with entomology in its economic aspect.

b. Department Bulletins. Nearly a thousand of these have been issued in the last seven years. They deal with problems in a somewhat more scientific and detailed manner than do the Farmers' Bulletins. A goodly number of them are upon entomological subjects.

c. Bulletins of the Bureau of Entomology. About 130 of these were issued. They deal with a wide range of subjects in the field of economic entomology.

d. Circulars from the Bureau of Entomology. About 175 of these were issued. They contain brief popular accounts of many of the common insects.

e. The Journal of Agricultural Research. In this journal are published the results of original investigations. Much excellent work on insects has been published in this journal. The individual papers are usually obtainable as separates.

Many of these publications are to be obtained free from the Department of Agriculture. Others may be purchased 
at small cost from The Superintendent of Documents, Washington, D.C. Some titles are out of print, but such papers are usually obtainable in revised form in later publications. A very excellent library of entomology might be formed entirely of publications in the several series listed above.

2. Publications of the various state agricultural experiment stations.

Each one of the several states maintains one or more experiment stations. These issue bulletins from time to time and much of the best information available on injurious insects is contained in these bulletins. Subjects of local interest are likely to be more fully treated in the state bulletins.

These bulletins may always be obtained free upon applicacation so long as the supply lasts.

3. State publications issued by agencies other than the State Agricultural Experiment Stations. This will include the State Departments of Agriculture which issue reports from the state entomologists. Much valuable information will be found in these reports which is not available elsewhere. Especially extensive reports of this nature are issued by the State Entomologists of New York, Illinois, Minnesota, Missouri and Indiana.

Other state agencies issuing publications which include entomological subjects are State Horticultural Boards or Commissions, as in Florida and California, State Entomological Commissions and State Educational Departments.

State publications can usually be secured free upon application.

4. The Journal of Economic Entomology.

Much of the newest work in economic entomology is reported first in this journal and many articles are available there only. It issues six numbers annually and the subscription price is low. It may be obtained through Mr. A. F. Burgess, Melrose Highlands, Mass.

5 General texts.

Fundamental information on entomology is obtained best from some one of the standard texts, of which there are sev- 
eral, adapted more or less to the varying needs of students. Some titles follow:

Manual for the Study of Insects, Comstock. J. H. \& A. B. Comstock Publishing Co., Ithaca, N. Y.

American Insects, Kellogg, Y. L. Doubleday, Page and Co. School Entomology, Sanderson, E. D., and Peairs, L. M. John Wiley and Sons, Inc., N. Y.

Agricultural Entomology, Osborn, H. F. Lippineott.

Economic Entomology, Smith, J. B. Lippincott.

Injurious Insects, O'Kane, W. C. Macmillan.

Elementary Entomology, Sanderson, E. D., and Jackson, C. F. Ginn and Co.

Manual of Vegetable Garden Insects, Crosby, C. R., and Leonard, M. D. Macmillan.

Manual of Fruit Insects, Slingerland, M. V., and Crosby, C. R. Macmillan.

Medical and Veterinary Entomology, Herms, W. B. Macmillan.

Handbook of Medical Entomology, Riley, W. A., and Johannsen, O. A. Comstock Publishing Co.

Fumigation Methods, Johnson, W. G. The Orange-Judd Co.

The above is a partial list. There are hundreds of other publications which will be of help to the student when they chance to be available. 



\section{IN D EX}

Acanthiidæ, 647

Acarina, 254, 563, 626, 649, 670, 683

Achemon sphinx, 461

Acrididæ, 95

Adalia bipunctata, 9

Adhesives, 58

Adoxus vitis, 443

Aedes calopus, 642

Agerita webberi, 611

Agallia sanguinolenta, 268

Agrilus ruficollis, 409

Agriotes mancus, 81

Agromyza simplex, 382

Agromyzidæ, 382, 606

Agrotis annexa, 88

$$
\begin{aligned}
& \text { messoria, } 85 \\
& \text { ypsilon, } 85
\end{aligned}
$$

Air-slaked lime, 283

Alabama argillacea, 228

Aleurocanthus woglumi, 633

Aleurodidæ, 610

Aleurothrixus howardi, 611

Alfalfa caterpillar, 209

looper, 211

weevil, 195

Alsophila pometaria, 501

American acridium, 100

frit fly, 132

roach, 652

syrphus-fly, 12

Ampeloglypter ater, 447

Amphicerus bicaudatus, 449

punctipennis, 451

Anarsia lineatella, 580

Anasa tristis, 348

Ancylis comptana, 396

Angoumois grain moth, 182

Anopheles, 640
Ant, Argentine, 608, 652

corn-field, 152

little black, 652

little red, 652

pavement, 652

Ant syrup, 608

Ants, house, 652

Ants, white, 655

Anthomyia egg parasite, 103

Anthomyiid $x, 291,311,314,374,411$

Anthonomus grandis, 243

grandis thurberix, 244

quadrigibbus, 561

signatus, 400

Anthrenus scrophularix, 653

Apanteles congregatus, 220

glomeratus, 323

Aphididæ, 135, 149, 226, 289, 299, $333,344,389,423,432$, 514, 528,

586,592

Aphidius, 136, 295

avenaphis, 136

Aphis avenæ, 535

brassicæ, 333

fitchii, 535

forbesi, 389

gossypii, $226,344,629$

maidi-radicis, 149

maidis, 155

medicaginis, 226

persicæ-niger, 586

pomi, 12,528

pseudo-brassicæ, 336

pyri, 532

rumicis, 289

setariæ, 594

sorbi, 532 
Aphis, apple, 528

black peach, 585

cabbage, 333

corn-root, 149

currant, 425

English grain, 135

European grain, 535

green peach, 587

melon, 344

pea, 293

rosy apple, 532

spinach, 335

spring grain, 137

woolly, 514

Aphis lions, 347

Apple aphis, 528

rosy, 532

woolly, 514

caterpillar, red-humped, 544

yellow-necked, 542

curculio, 561

leafhopper, 273

leaf miner, 545

maggot, 559

plant lice, 528

Apple-tree borer, flat headed, 524

round headed, 520

tent caterpiliar, 16,538

worm, 552

worm, lesser, 553

Apple twig borer, 449

Application of insecticides, 56

Arctiidæ, 232, 485

Argas miniatus, 687

Argentine ant, 608

Arizona wild cotton weevil, 244

Armored scales, 599

Army worm, 110

$$
\begin{aligned}
& \text { beet, } 302 \\
& \text { fall, } 114
\end{aligned}
$$

Arsenate of calcium, 42

lead, powdered, 40,41

Ársenic, white, 43

Arsenical dips, 679
Arsenite of lead, 41

lime, 41

sodium, 43

zinc, 43

Aschersonia aleyrodes, 612

flavocitrinis, 612

Ash-gray blister beetle, 311

Asparagus beetle, 378

twelve spotted, 381

miner, 382

Asphalt paint, 53

Asphaltum, 53, 523

Aspidiotus camelliæ, 601

hederae, 602

perniciosus, 470

rapax, 601

Assassin bugs, 623

Atomizers, 59

Attagenus piceus, 653

Aulacizes irrorata, 234

Australian roach, 652

Autographa brassicæ, 327 californica, 211 simplex, 368

Babesia bigemina, 675

Bagworm, 503

Banded flea-beetle, 363

Banding material, 609

Bark-beetle, fruit tree, 475 peach tree, 582

Barred winged onion maggot, 378

Barrel pumps, 62

Batrachedra rileya, 181

Bean aphis, 289

ladybird, 287

leaf-beetle, 285

Weevil, 281

European, 285

four-spotted, 284

Bedbugs, 647

Bee-flies, 104

Beet aphis, 299

army worm, 302

leaf beetle, 305

leafhopper 307 
Beet leaf miner, 311

root aphis, 300

Bembecia marginata, 403

Bibliography, 689

Bill bugs, 160

Biting lice, 667

$$
\text { maize, } 162
$$

Black carpet beetle, 653 cherry louse, 595

Black-fly, 633

"Black Leaf 40", 51

Black peach aphis, 585 scale, 602 scale fungus, 620

Blackberry gall maker, 411

Blatta orientalis, 652

Blatella germanica, 652

Blattidæ, 650

Blissus leucopterus, 90

Blister beetle, ash gray, 288, 311

Nuttall's, 288

striped, 310

Blister beetles, 104, 270, 288, 310

Blister mite, 363

Body louse, 649

Book lice, 655

$$
\text { of chickens, } 681
$$

Boll weevil, 243 worm, 168

Bordeaux mixture, 53 nozzle, 70

Borer, cotton square, 232

flat headed, 524

grapecane, 449

peach tree, 575

peach twig, 580

round headed, 520

Botflies, 661

Bottle flies, 640

Brachymena 4-pustulata, 23

Bracon mellitor, 251

Braconidae, 16, 137

Bran mash, 57

Brown fungus, 67

-tail moth, 489

Bruchidx, 278

Brucophagus funebris, 202
Bruchus chinensis, 284

obtectus, 281

quadrimaculatus, 284

pisorum, 278

rufimanus, 285

Bryobia pratensis, 198

Bucket pumps, 59

Bud moth, 549

Bud worms, 221

Buffalo moth, 652

Buffalo tree-hopper, 478

Buhach, 50

Buprestidæ, 409, 524

Byturus unicolor, 416

Cabbage aphis, 333

bug, Harlequin, 330

butterfly, 321

Southern, 326

looper, 327

maggot, 314

plutella, 328

worm, imported, 321

Cadelle, 179

Calandra granaria, 176 oryzæ, 176

Calandridæ, 160, 176

Calico-back, 330

California peach-borer, 575 red scale, 599

Caliroa cerasi, 569

Calocoris rapidus, 235

Calosoma calidum, 14 scrutator, 14 sycophanta, 498

Cambala annulata, 270

Camnula pellucida, 99

Canker worm, fall, 501 spring, 499

Canker worms, 498

Cantharis nuttalli, 288

Capsidæe, 235, 422, 571

Carbolic acid emulsion, 52

Carbolineum, 477

Carbon bisulphide, 53, 186, 320

Carpocapsa pomonella, 552 
Carrot beetle, 369 rust fly, 370

Case-bearers, 547

Case-making moth, 654

Cassida bivittata, 385

Cassidx, 384

Cat and dog flea, 646

Cathartus advenæ, 179 gemellatus, 178

Cattle scab, 670 ticks, 672

Carpet beetles, 653

Ceratitis capitata, 633

Ceroplastes floridensis, 604

Cecidomyiidæ, 117, 133, 200

Celery caterpillar, 366 looper, 368

Cephidæ, 128

Cephus occidentalis, 128

pygmæus, 129

Cerambycidæ, 405, 520

Ceratoma trifurcata, 285

Ceresa bubalis, 478

Chætocnema confinis, 383

Chætopsis ænea, 378

Chaff scale, 602

Chalcididx, 122, 202

Chalcis flies, 17

Cherry fruit fly, 596 louse, black, 595

Chicken lice, 681 mites, 683

Chiggers, 649

Chilocorus bivulnerus, 11

Chin-fly, 661

Chinch bug, 90

Chionaspis citri, 602 furfura, 527

Chiropachis colon, 476

Chloridea obsoleta, 168, 221, 238 virescens, 221

Chrysobothris femorata, 524

Chrysomelidæe, 143, 212, 260, 266, $271,285,304,338,361,378,383$, $393,441,629$
Chrysomphalus aonidum, 602 aurantii, 599

citrinus, 600

Chrysomyia macellaria, 660

Chrysopidæ, 137, 295, 347, 623

Cicada, 26, 479

Cicadidæ, 479 septendecem, 479

Cigar case-bearer, 547

Cigarette beetle, 224

Cimicidæ, 647

Cimex lectularius, 647

Cirphus unipuncta, 110

Citrus insects, 599 mealy bug, 606 thrips, 622

Clayton gas, 55

Clothes moths, 654

Cloudy-winged whitefly, 610

Clover insects, 189

hay-worm, 206

leafhopper, 208

leaf weevil, 192

mite, 198

root-borer, 189

root curculio, 192

seed caterpillar, 203

seed chaleid, 202

seed midge, 200

Cluster-fly, 640

Cnemidocoptes Iævis gallinæ, 684 mutans, 685

Coccidæ, 470, 525, 583, 599

Coccinella novem-notata, 8,347

Coccinellidæ, 8, 137, 287, 295, 351

Coccotorus scutellaris, 590

Coccus hesperidum, 603

Codling moth, 552

Collinus meromyzæ, 133

Colaspis brunnea, 393

Cold storage, 655

Coleophora fletcherella, 547 malivorella, 547

Colorado potato beetle, 260

Compressed air spayers, 61

Conotrachelus nenuphar, 505

Contact insecticides, 39,44 
Convergent lady-bug, 10, 266 Cooties, 649

Coptocycla bicolor, 385

Coreidæ, 236, 348

Corn-borer, European, 173

Corn earworm, 21, 168

Corn leaf aphis, 155

root aphis, 149

webworm, 146

worm, southern, 144 western, 143

stalk borer, larger, 16 lesser, 167

wireworm, 81

Cornfield ant, 152

Corrodentia, 655

Cotton boll cutworm, 241

weevil, 243

bollworm, 238

caterpillars, 232

dusting, 231

leaf-bug, 235

stainer, 237, 631

worm, 228

egg-parasite, 230

square borer, 232

Cottony-cushion scale, 604

Cottony maple scale, 605

Cow-pea weevil, 284

Crambidæ, 146, 158, 213

Crambus caliginosellus, 146, 213

Craponius inaequalis, 466

Criddle mixture, 110

Cricoceris asparagi, 378

12-punctata, 381

Crop rotation, 30

Crude petroleum, 45

Ctenocephalus canis, 646

Cucujdæ, 177

Cucumber beetle, spotted, 343 striped, 340

Culex, 640

flea-beetle, 267

Culex pipiens, 640

sollicitans, 644

Culicidø, 641
Curculio, apple, 561

clover root, 192

grape, 466

plum, 505

Curculionidæ, 192, 195, 243, 256,365,

$391,400,447,466,505,561,590$

Curly-leaf, beet, 307

Currant aphis, 425

borer, imported, 418

fly, 429

span-worm, 428

stem girdler, 419

worm, imported, 426

worm, native, 427

Cut-offs, 74

Cutworm, bronzed, 86

cotton boll, 241

dark-sided, 85

dingy, 87

glassy, 88

granulated, 88

greasy, 88

well-marked, 88

Cutworms, 86, 300

Cydia pomonella, 552

Cylas formicarius, 386

Cymatophora ribearia, 428

Cynipidæ, 411

Dactylopiinæ, 606

Dasyneura leguminicola, 200

Datana ministra, 542

Deilephila lineata, 232, 460

Depluming mite, 684

Dermacentor venustus, 673

Dermanyssus gallinæ, 683

Dermestidæ, 416, 652

Desmia funeralis, 459

Destruction of weevil, 186

Development of insects, 20

Diabrotica 12-punctata, 144, 343

longicornis, 143

soror, 629

vittata, 272,340

Dialeurodes citri, 610

citrifolii, 610 
Diamond-back moth, 328

Diaphania hyalinata, 359 nitidalis, 356

Diastrophus turgidus, 411

Diatræa zeacolella, 158

Dictyophorus reticulatus, 101

Diplosis tritici, 133

Dipping live stock, 678

Diptera, 15, 669

Disc nozzles, 68

Disonycha triangularis, 303 xanthomelæna, 304

Dolerus arvensis, 129 collaris, 129

Drasterius elegans, 81

Drepressaria heraclina, 371

Drone-fly, 11

Dusting apparatus, 75 mixtures, 77

Dysdercus suturellus, 237, 631

Earworm, 168

Echidnophaga gallinacea, 687

Egg-plant flea-beetle, 267

Elachistidæ, 181, 547

Elasmopalpus lignosellus, 167

Elateridæ, 80

Empoasca mali, 273

Empusa aphidis, 295

sphæroperma, 194

Enarmonia interstictiana, 203 prunivora, 553

English grain-louse, 135

Ephestia kuehniella, 179

Epicauta vittata, 105, 310

Epidaphus scabei, 269

Epilachna borealis, 351 varivestris, 287

Epitrix cucumeris, 267 fuscula, 267 parvula, 212, 267

Epochra canadensis, 429

Eriophyes oleiverus, 626

$$
\text { pyri, } 563
$$

Eriophyidæ, 563, 627

Eriosoma lanigera, 514

Eristalis tenax, 11
Estigmene acræa, 232

Eulecanium nigrofasciatum, 583

Euproctis chrysorrhœe, 489

European bean-weevil, 285 corn-borer, 173

grain-aphis, 535

Eurymus eurytheme, 209

Euschistus punctipes, 215

Eutettix tenella, 307

Euthrips nicotaniæ, 225

Evergreen bagworm, 16, 503

Exorista flavicauda, 104

leucanix, 104

Fall army-worm, 114

Fall canker worm, 501

Fall webworm, 485

Fannia brevis, 640

Farm methods, 29

Feltia subgothica, 87

Fidia cana, 442

viticida, 441

Fiery ground beetle, 13

Fire-bug, 330

Fishmoth, 655

Flea, cat and dog, 646

chicken sticktight, 687

human, 645

Fleabeetle, banded, 363

cucumber, 267

egg-plant, 267

grapevine, 451

pale striped, 361

potato, 267

spinach, 304

sweet potato, 383

tobacco, 212, 267

Fleabeetles, 266, 303, 338

Fleas, 645,687

Flesh-fly, 104

Florida flower thrips, 620,625 red scale, 602

Flour moths, 179

Fly-free datas, 120

Fly nets, 660

Fly-traps, 638

Formicidæ, 652 
Four-lined leaf-bug, 422

Four-spotted bean weevil, 284

Fowl-tick, 687

Frankiniella bispinosus, 622, 625

Fruitfly, cherry, 596 Mediterranean, 632

Fruit moth, 510

Fruit-tree bark-beetle, 475

Furnigation, 54, 281, 621

Fusarium, 612

Garden webworm, 211, 232, 363

Gas tar, 82

Gases, 39, 53

Gastrophius hemorrhoidalis, 661 intestinalis, 661 nasalis, 661

Gelechiidæ, 182, 253, 580

Geometridæ, 428, 498

German grain-aphis, 135 roach, 652

Girdler, grapecane, 447

Glassy cutworm, 88

Glassy-winged sharpshooter, 234

Gold-bugs, 384

Grain-beetle, foreign, 177 red-necked, 177 saw-toothed, 177

Grain weevils, 176

Granary weevil, 176

Grape-berry moth, 462 cane borer, 449

cane girdler, 447

curculio, 466

leaf-hopper, 458,459

root-worm, 441

Grapevine flea-beetle, 451

phylloxera, 432

root-borer, 436

Grapholithidæ, 203

Graphops pubescens, 393

Grass saw-fly, 129

worm, 114

Grasshoppers, 95

Graybacks, 649

Greedy scale, 601
Green-bug, 137

Green clover-Ivorm, 211

peach-aphis, 335,587

soldier-bug, 236, 590

Ground beetles, 13

Ground beetle, fiery, 13 murky, 13

Gryllidæ, 407

Gryptochxtum monophiahi, 606

Gymnonychus appendiculatus, 427

Gypsy moth, 492

Hadena devastatrix, 88

Hæmatobia serrata, 658

Hæmatopinus eurysternus, 668

pedalis, 668

suis, 668

vituli, 668

Haltica chalybea, 451

Harlequin cabbage-bug, 330

Harmolita grandis, 124

tritici, 122

Harpalus caliginosus, 15, 264

Harpiphorus maculatus, 395

Hawk-moths, 461

Head louse, 649

$$
\text { chicken, } 680
$$

Heat, 188

Hellebore, 43

Hemispherical scale, 604

Hessian-fly, 117 .

Hippoboscid:s, 669

IIippodamia convergens, 10, 266, 357

Hog-louse, 668

Homalodisa triquetra, 234

Hop plant-louse, 593

Hopperdozers, 107

Hopperette, 308

Horizontal pumps, 66

Horn-fly, 658

Hornworms, 216

Horse bots, 661

Horse flies, 659

Horse scab, 672

House ants, 652

centipede, 655

mosquito, 644 
Housefly, 635

Household insects, 635

Human flea, 645

Hyalopterus arundinis, 592

Hyalastinus obscurus, 189

Hydrocyanic acid gas, 54, 187, 622

Hydrometers, 49

Hymenoptera, 15

Hymenopterous parasites, 15

Hyphantria cunea, 485

textor, 489

Hypoderma bovis, 666 lineata, 664

Hypsopygia costalis, 206

Icerya purchasi, 604

Ichneumon flies, 15

Ichneumonidæ, 545

Imported cabbage worm, 321

currant borer, 418

worm, 426

grape root-worm, 443

onion maggot, 374

Iudian-meal moth, 180

Injury by insects, 1

Insect parasites, 15

Insecticides, 39

application of, 56
contact, 39

Internal anatomy of insects. 28

Iridomyrmex humilis, 608, 631

Janus integer, 419

Jassidæ, 208, 234, 273, 307, 456

Joint-worm, 121

Kainit, 149

Kedzie formula, 43

Kerosene, 45

$$
\text { emulsion, } 44
$$

Knapsack pumps, 60

Lace-wing flies, 295, 623

Lachnosterna, genus, 78

$$
\text { arcuata, } 79
$$

Lady-bird, bean, 287

Lady-bird, convergent, 347

nine-spotted, 347

spotted, 347

squash, 351
Lady-bugs, 8

vedalia, 605

Laphygma exigua, 302 frugiperda, 114

Larger corn-stalk borer, 158

Lasiocampidæ, 538

Lasioderma serricorne, 224

Lasius niger, 152

Lasius niger, americanus, 152

Laspeyresia molesta, 510

Leaf-bug, four-lined, 402

Leaf-folder, grape, 459

Leaf-footed bugs, 236

Leaf-hopper, apple, 273 grape, 456

Leaf-miner, apple, 545 beet, 311 spinach, 311

Lebia grandis, 14

Lema trilineata, 271

Lepidosaphes beckii, 599 gloveri, 601 ulmi, 525

Lepisma domestica, 655 saccharalis, 655

Leptinotarsa decemlineata, 260

Leptoglossus oppositus, 236

Leptus americanus irritans, 650

Lesser apple worm, 555

corn-stalk borer, 167

peach-tree borer, 575

Leucopermes flavipes, 655

Lice, 648

on live stock, 667

poultry, 680

Light traps, 37

Ligyrus gibbosus, 369

Lime-sulphur wash, 46

dilution table, 48
Geneva formula,
47
self-boiled, 49

Limneria ædemesia, 545 fugitiva, 545

Liparidæ, 489

Lipeurus heterographicus, 680 
Little black ant, 652

house-fly, 640

red ant, 652

Lixus concavus, 365

Locust, California devastating, 99 differential, 101

lesser migratory, 98

pellucid, 99

red-legged, 99

Rocky Mt., 95

two-striped, 100

London purple, 40

Long-nosed hog louse, 668

Long-nosed ox louse, 668

Long scale, 601

Loxostege similalis, 232, 363 sticticalis, 301

Lubber grasshopper, 101

Lycænidæ, 232

Lydella doryphoræ, 262

Lygæidæ, 90

Lygus pratensis, 571

Lysiphlebus testaceipes, 140, 347

Macrobasis unicolor, 288, 311

Macrodactylus subspinosus, 454

Macrosiphum cerealis, 135

$$
\begin{aligned}
& \text { granaria, } 135 \\
& \text { pisi, } 293 \\
& \text { solanifolii, } 272
\end{aligned}
$$

Maize bill-rug, 163

Malacosoma americana, 16, 538

Malaria, 641

Mallophaga, 667, 680

Mange, horse, 672 swine, 672

Margaropus annulatus, 673

Mayetiola destructor, 117

Meal moths, 179

$$
\text { snout-moth, } 181
$$

Mealy bugs, 606

$$
\text { plum-louse, } 592
$$

Mediterranean flour moth, 179

$$
\text { fruit-fly, } 632
$$

Megilla maculata, 10, 347

Melanoplus atlantis, 99

$$
\text { bivittatus, } 100
$$

Melanoplus devastator, 99

differentialis, 101

femur-rubrum, 99 spretus, 95

Melanotus cribulosus, 81

Melittia satyriniformis, 353

Mełoidæ, 270, 310

Melon aphis, 344, 629 caterpillar, 359

Melophagus ovinus, 669

Membracidæ, 478

Memythrus polistiformis, 436

Menopon biseriatum, 681 pallidum, 681

Meromyzæ americana, 129

Metamorphosis of insects, 20

Meteorus hypantrix, 488

Mexican cotton boll-weevil, 243 orange maggot, 632

Microcera, 612

fujikuroi, 620

Microgaster, 16

Microweisea misella, 476

Millipedes, 270

Miscible oils, 46, 620

Mite, clover, 198

depluming, 684

poultry, 683

rust, 626

scab, 676

silver, 626

Monomorium minimum, 652 pharaonis, 652

Monophadnis rubi, 413

Monoxia puncticollis, 305

Mosquitoes, 641

Mouth-parts, 25

Murgantia histrionica, 330

Murky ground beetle, 14, 264

Musca domestica, 635

Muscardine fungus, 95

Muscidæ, 635, 657, 660

Myriangium durixi, 620

Myzus cerasi, 595

persicæ, 335,587

ribis, 425 
Nephelodes minians, 86

Nezara hilaris, 236, 590 viridula, 590, 630

Nico-fume, 51

Nicotine-lime spray, 537

Nine-spotted lady-bird, 8

Noctua clandestina, 87

Noctuidx, 82, 86, 110, 114, 168, 211, $221,228,238,241,302,327,368$

Nose-fly, 661

Notodontidæ, 542

Nozzles, 68

Novius cardinalis, 665

Oberea bimaculata, 405

Ecanthus nigricornis, 407 niveus, 407

Ecophoridae, 371

Estridae, 661

(Estris ovis, 660

Oil emulsions, 615

Oncemetopia lateralis, 234 undata, 234

Onion maggot, barred winged, 378 imported, 374

thrips, 372

Ophion macrurum, 16

Orange dog, 629 maggot, 632 scale, 599

Orchard dusting, 75

Oriental peach moth, 510 roach, 652

Oscinus variabilis, 132

Ox-louse, long nosed, 668 short nosed, 668

Ox-warble, 664

Oyster-shell scale, 525

Pachynematus extensicornis, 129

Paleacrita vernata, 499

Pale-striped flea-beetle, 361

Papaipema nitella, 82

Papilio cresphontes, 629

polyxenes, 366

Papilionidæ, 366, 629

Parajulus impressus, 270
Paris green, 39

Parlatoria pergandii, 602

Parsnip webworm, 371

Pavement ant, 652

Pea aphis, 293

moth, 297

weevil, 278

Peach lecanium, 583 tree bark betle, 582 borer, 575 twig borer, 580

Pear leaf blister-mite, 563 psylla, 566 slug, 569 thrips, 568

Pectinophora gossypiella, 253

Pediculidæ, 648, 668

Pediculus capitis, 649 vestmenti, 649

Pegomyia ceparum, 374 fusciceps, 291 vicina, 311

Pemphigus betæ, 299

Pentarthron minutem, 228

Pentatomidæ, 215, 236, 330, 630

Peridroma saucia, 85

Periodical cicada, 479

Periplaneta americana, 652 australasiæ, 552

Persian insect powder, 50

Petroleum, 45

Phlegethontius quinquemaculatus, 216 sexta, 216

Phorhia brassicæ, 314

Phorodon humuli, 593

Phløethribus liminaris, 582

Pholus achemon, 461

Phorbia rubivora, 411

Phthirius inguinalis, 649

Phthorimæa operculella, 223, 258

Phyllotreta pusilla, 338 sinuata, 338 vittata, 303, 338

Phylloxera, grapevine, 432

Phylloxera vastatrix, 432 
Phytonomus posticus, 195 punctatus, 192

Pickle worm, 358

Pieridæ, 209, 321

Pimpla conquisitor, 230 inquisitor, 15

Pink bollworm, 253 corn-worm, 181 scale fungus, 620

Pipiza radicans, 12

Pistol case-bearer, 547

Pithy gall, 411

Plant bug, southern green, 590 tarnished, 571

Plant-bugs, 236

Plant lice, apple, 528 cotton, 226 louse, hop, 593

Plathypena scabra, 211

Plodia interpunctella, 180

Plum aphids, 592 curculio, 505 gouger, 590 louse, mealy, 592 rusty-brown, 594

Plutella maculipennis, 328

Podisus spinosus, 261

Pociliocapsus lineatus, 422

Poisioned baits, 57

Pollenia rudis, 640

Polychrosis viteana, 462

Pontia napi, 326

protodice, 326

rapæ, 321

Porthetria dispar, 492

Potato aphids, 272 beetle, Colorado, 260 three-lined, 271

flea-beetle, 267

scab and insects, 269

stalk-borer, 256

tuber-worm, 258

Potherb butterfly, 326

Poultry lice, 680 mites, 683

Potver sprayers, 67

Proctotrypidæ, 17
Prodenia ornithogallis, 241

Pseudococcus calceolariæ, 631

$$
\text { citri, } 606
$$

Psila rosæ, 370

Psilidx, 370

Psoroptes communis bovis, 670 equi, 671

Psychidæ, 503 ovis, 671

Psylla pyri, 566

Psyllidæ, 566

Pteromalus puparum, 322

Pteronus ribesii, 426

Ptinidæ, 224, 449

Pubic louse, 649

Pulex irritans, 545

Pulvinaria innumerabilis, 605

Pumpkin bugs, 236, 630

Purple scale, 599

Pyralididæ, 167, 173, 180, 206, 232, 459

Pyralis farinalis, 181

Pyrausta nubialis, 173

Pyraustidæ, 173, 301, 356, 363

Pyrethrum 50

Pyrrochoridæ, 237

Railroad worm, 559

Raspberry bytutus, 416 cane-borer, 405 cane maggot, 411 root borer, 403 sawfly, 413

Rat flea, 645

Red-bugs, 237

Red fungus, 612 -headed scale fungus 620 -humped apple caterpillar, 544

-necked cane borer, 409 spider, 254, 627

-tailed tachina-fly, 113 -weevil, 133

Repellants, 39. 52

Rhagoletis cingulata, 596

Rhagoletis pomonella, 559

Rhopalosiphum dianthi, 588 padi, 535 
Rhopalosiphum prunifoliæ, 535

$$
\text { ribis, } 425
$$

Rhubarb curculio, 365

Rice weevil, 176

Roaches, 650

Roach-traps, 651

Rocky Mt. locust, 95 spotted-fever tick, 673

Rods, extension, 73

Root-borer, grapevine, 436

Root-louse syrphus-fly, 12

Root worm, grape, 441

Rose chafer, 454

Round-headed apple tree borer, 520

Round scale, 602

Rosy apple aphis, 532

Rust mite, 626

Rusty-brown plum louse, 594

Saissetia hemispherica, 604 oleæ, 602

Salt-marsh caterpillar, 232 mosquito, 644

San Jose scale, 470, 602

Sanninoidea exitiosa, 575 opalescens, 575

Saperda candida, 520

Sarcophaga carnaria, 104

Sarcoptes scabei, 672

Sawfly, raspberry, 413

strawberry, 395

wheat, 128

Saw-toothed grain beetle, 177

Scabs, 670

Scab-mites, 670

Scale insects, citrus, 599

Scale, black, 602

California red, 599

chaff, 602

cottony-cushion, 604

Florida red, 602

greedy, 601

hemispherical, 604

long, 601

orange, 599

oyster-shell, 525

purple, 599
Scale, round, 602

San Jose, 470, 602

scurfy, 527

snow, 602

soft-brown, 603

terrapin, 583

turtle-back, 583

yellow, 600

wax, 604

Scales, armored, 599

unarmored, 602

Scarabæidæ, 78, 369, 454

Scenopinus fenestralis, 640

Schistocerca americana, 100

Schizura concinna, 544

Sciara, 269

Scirtothrips, 622

Scolytidx, 189, 475, 582

Scolytus rugulosus, 475

Screw-worm fly, 660

Scurfy scale, 521

Scutigera forceps, 655

Searcher, 14

Seed corn maggot, 291

Semasia nigricana, 297

Sesia tipuliformis, 418

Sesiidæ, 353, 403, 418, 436, 575

Seventeen-year locust, 479

Shaft louse, 681

Sharpshooters, 234

Sheep grub, 666

tick, 669

Short-nosed ox-louse, 668

Shot-hole borer, 475

Silvanus surinamensis, 177

Silverfish, 655

Silver-mite, 626

Siphonaptera, 645, 687

Siphunculata, 648, 667, 680

Sitones hispidulus, 192

Sitotroga cerealella, 182

Snow scale, 602

Soaps, 46,51

Sodium arsenite, 43

fluoride, 682

Soft-brown scale, 603 
Soldier-bug, Southern green, 630 spined, 261

Solenopsis geminata, 250

Solid stream nozzle, 70

South African fungus, 109

Southern green plant-bug, 590 soldier-bug, 630

Sphærostible coceophila, 620

Sphecius spheciosus, 484

Sphenophorus cariosus, 162 maidis, 163 obscurus, 160 ochreus, 160 parvulus, 160 pertinax, 162 placidus, 162 robustus, 163 scoparius, 162 sculptilis, 162

Spinach aphis, 335

flea-beetle, 304 leaf-miner, 311

Spined soldier-bug, 262 tobacco-bug, 215

Sphingidx, 232, 461

Sphinx-moths, 461

Sporotrichum globuliferum, 95

Spotted cucumber beetle, 343 lady-bird, 10

Spray-guns, 71

Spray hose, 73 connections, 74

Spraying apparatus, 59

Spring eanker-worm, 499 citrus whitefly, 633 grain-aphis, 137

Squash bug, 348

ladybird, 351 vine borer, 353

Stable-fly, 640, 657

Stalk-borer, 82

Stickers, 58

Sticktight flea, chicken, 689

Stomoxys calcitrans, 640, 657 Strainers, 74

Strawberry crown-borer, 391

leaf-roller, 396
Strawberry root-louse, 389 rootworms, 393 sawfly, 395 weevil, 400

Striped blister beetle, 270, 310 cucumber beetle, 340 tree-cricket, 407 turnip flea-beetle, 338

Structure of insects, 20

Sucking lice, $648,667,680$

Sugar-beet webworm, 301

Sulphur, 50, 188

dioxide, 55

fumes, 55

-soda spray, 624

Sweet-potato beetle, two-striped, 385 flea-beetle, 383 root-borer, 386 weevil, 386

Swine mange, 672

Synanthedon pictipes, 575

Syrphidæ, 11, 295, 347

Syrphus flies, 11, 347

Syrphus americanus, 12 ribesii, 11

Syrup, poisoned, 608

Systæchus oreas, 104

Systena blanda, 361 hudsonias, 303 tæniata, 303, 363

Tabanidæ, 659

Tabanus atratus, 660 lineola, 660

Tachina-flies, 104

Tæniothrips pyri, 568

Tapestry moth, 654

Tarnished plant bug, 571

Tarred paper cards, 320

Tenebrioides mauritanicus, 179

Tenebrionidæ, 179

Tent-caterpillar, 538

Tenthredinidæ, 128, 395, 413, 419, 426,569

Termites, 655

Terrapin bug, 330 scale, 583 
Tetramorium cæspitum, 652

Tetranychidæ, 198, 254

Tetranychus citri, 626 mytilaspidis, 626 sex-maculatus, 626 telarius, 254

Texas-fever tick, 673

Three-lined leaf-beetle, 271

Thripidæ, 568 potato-beetle, 271

Thrips, citrus, 620 florida flower, 620,625 onion, 372 pear, 568 tobacco, 225 tabaci, 372

Throat bot, 661

Thyridopteryx ephemeræformis, 16, 503

Thysanoptera, 225, 372, 568, 620

Ticks, 672 fowl, 687

Tinea biselliella, 654 pelionella, 654

Tineidæ, 223, 258, 545, 654

Tischeria malifoliella, 545

Tmetocera ocellana, 549

Tobacco, 51

budworms, 221

fleabeetle, 212, 267

leaf-miner, 223

split worm, 223

stalk-worm, 213

thrips, 225

worms, 216

Tomato fruitworm, 275

hornworms, 275

Tortoise beetles, 385

Tortricidæ, 297, 396, 462, 510, 549 552

Towers, sprayer, 74

Toxoptera graminum, 137

Traction sprayers, 67

Trap-crops, 36

Tree crickets, 407

Tree-hopper, buffalo, 478

Tree-tanglefoot, 52
Trichobaris trinotata, 256

Trichodectes parumpilosus, 667 scalaris, 667

Tricophaga tapetzella, 654

Trogositidæ, 179

Trombidium locustarum, 103

Trypeta ludens, 632

Trypetidx, 429, 559, 596

Turnip louse, 336

Turtle-back scale, 603

Twice-stabbed ladybird, 11

Two-spotted ladybird, 9

Tychœa brevicornis, 300

Tyloderma fragariæ, 391

Typhlocyba comes, 456

Typophorus canellus, 393

Uranotes melinus, 232

Vedalia ladybug, 605

Warbles, ox, 664

Wax scale, 604

Webbing clothes moth, 654

Webworm, fall, 485

garden, 363

parsnip, 371 sugar-beet, 301

Western cabbage flea-beetle, 338 grass-stem sawfly, 128

Whale-oil soap, 46

Wheat bulb worm, 131 joint-worm, 121 maggots, 129 midge, 133 saw-flies, 127 saw-fly borer, 129 stem maggot, 129 straw worm, 124 wireworm, 81

White arsenic, 43

White ants, 655

White grubs, 78, 300 White-lined sphinx, 232

Whitefly, cloudy-winged, 610 common, 610 spring-citrus, 633 woolly, 611 
Whiteflies, 610

White-headed scale fungus, 620

Window fly, 640

Winthemia 4-pustulata, 113

Wireworms, 80, 300

Woolly aphis, 514

Woolly whitefly, 611
Xenopsylla chæopsis, 645

Yellow aschersonia fungus, 612

Yellow fever, 642

Yellow scale, 600

Yellow-necked apple caterpillar, $5 \mathbf{4} 2$ 



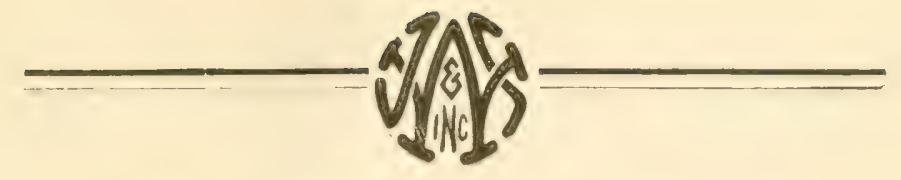

\section{Wiley Special Subject Catalogues}

For convenience a list of the Wiley Special Subject Catalogues, envelope size, has been printed. These are arranged in groups - each catalogue having a key symbol. (See special Subject List Below). To obtain any of these catalogues, send a postal using the key symbols of the Catalogues desired.

1-Agriculture. Animal Ifusbandry. Dairying. Industrial Canning and Preserving.

2-Architecture. Building. Concrete and Masonry.

3-Business Administration and Management. Law.

Industrial Processes: Canning and Preserving; Oil and Gas Production; Paint; Printing; Sugar Manufacture; Textile.

\section{CHEMISTRY}

4a General; Analytical, ()ualitative and Quantitative; Inorganic; Organic.

4b Electro- and Physical; Food and IVater; Industrial; Medical and Pharmaceutical; Sugar.

\section{CIVIL ENGINEERING}

5a Unclassified and Structural Engineering.

5b Materials and Mechanics of Construction, including; Cement and Concrete; Excavation and Earthwork; Foundations; Masonry.

5c Railroads; Surveying.

5d Dams; Hydraulic Engineering; Pumping and Hydraulics; Irrigation Engineering; River and Harbor Engineering; Water Supply, 
CIVIL ENGINEERING-Continued

5e Highways; Municipal Engineering; Sanitary Engineering; Water Supply. Forestry. Horticulture, Botany and Landscape Gardening.

6-Design. Decoration. Drawing: General; Descriptive Geometry; Kinematics; Mechanical.

\section{ELECTRICAL ENGINEERING-PHYSICS}

7-General and Unclassified; Batteries; Central Station Practice; Distribution and Transmission; Dynamo-Electro Machinery; Electro-Chemistry and Metallurgy; Measuring Instruments and Miscellaneous Apparatus.

8-Astronomy. Meteorology. Explosives. Marine and Naval Engineering. Military. Miscellaneous Books.

\section{MATHEMATICS}

9-General; Algebra; Analytic and Plane Geometry; Calculus; Trigonometry; Vector Analysis.

\section{MECHANICAL ENGINEERING}

10a General and Unclassified; Foundry Practice; Shop Practice.

10b Gas Power and Internal Combustion Engines; Heating and Ventilation; Refrigeration.

10c Machine Design and Mechanism; Power Transmission; Steam Power and Power Plants; Thermodynamics and Heat Power.

11-Mechanics.

12-Medicine. Pharmacy. Medical and Pharmaceutical Chemistry. Sanitary Science and Engineering. Bacteriology and Biology.

\section{MINING ENGINEERING}

13-General; Assaying; Excavation, Earthwork, Tunneling, Etc.; Explosives; Geology; Metallurgy; Mineralogy; Prospecting; Ventilation.

14-Food and Water. Sanitation. Landscape Gardening. Design and Decoration. Ilousing, House Painting. 







\section{LIBRARY OF CONGRESS

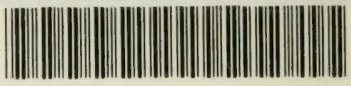

00008880839 